Millennium-Studien

\title{
Millennium Studies
}

KARL UBL

\section{Inzestverbot und Gesetzgebung}

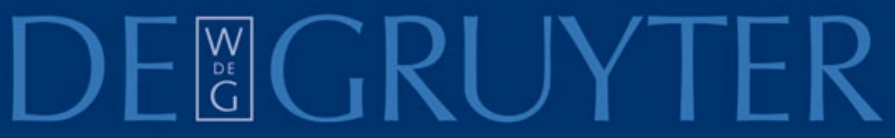


Inzestverbot und Gesetzgebung

$\mathrm{W}_{\mathrm{DE}}^{\mathrm{G}}$




\title{
Millennium-Studien
}

zu Kultur und Geschichte des ersten Jahrtausends n. Chr.

\section{Millennium Studies}

in the culture and history of the first millennium C.E.

\author{
Herausgegeben von / Edited by \\ Wolfram Brandes, Alexander Demandt, Helmut Krasser, \\ Hartmut Leppin, Peter von Möllendorff
}

Band 20

Walter de Gruyter · Berlin · New York 


\section{Inzestverbot und Gesetzgebung}

Die Konstruktion eines Verbrechens

$(300-1100)$

von

Karl Ubl

Walter de Gruyter · Berlin · New York 
Gedruckt mit Unterstützung des Förderungs- und Beihilfefonds Wissenschaft der VG Wort.

Diese Publikation wurde im Rahmen des Fördervorhabens 16TOA021 - Reihentransformation für die Altertumswissenschaften („Millennium-Studien“) mit Mitteln des Bundesministeriums für Bildung und Forschung im Open Access bereitgestellt. Das Fördervorhaben wird in Kooperation mit dem DFG-geförderten Fachinformationsdienst Altertumswissenschaften - Propylaeum an der Bayerischen Staatsbibliothek durchgeführt.

\section{(cc) BY-NC-ND}

Dieses Werk ist lizenziert unter der Creative Commons Attribution-NonCommercial-NoDerivatives 4.0 International Lizenz. Weitere Informationen finden Sie unter http://creativecommons.org/licenses/by-nc-nd/4.0/.

Die Bedingungen der Creative-Commons-Lizenz gelten nur für Originalmaterial. Die Wiederverwenung von Material aus anderen Quellen (gekennzeichnet mit Quellenangabe) wie z.B. Schaubilder, Abbildungen, Fotos und

Textauszüge erfordert ggf. weitere Nutzungsgenehmigungen durch den jeweiligen Rechteinhaber.

@ Gedruckt auf säurefreiem Papier, das die US-ANSI-Norm über Haltbarkeit erfüllt.

ISBN 978-3-11-020296-0

ISSN 1862-1139

Bibliografische Information der Deutschen Nationalbibliothek

Die Deutsche Nationalbibliothek verzeichnet diese Publikation in der Deutschen Nationalbibliografie; detaillierte bibliografische Daten sind im Internet über http://dnb.d-nb.de abrufbar.

(C) Copyright 2008 by Walter de Gruyter GmbH \& Co. KG, 10785 Berlin

Dieses Werk einschließlich aller seiner Teile ist urheberrechtlich geschützt. Jede Verwertung außerhalb der engen Grenzen des Urheberrechtsgesetzes ist ohne Zustimmung des Verlages unzulässig und strafbar. Das gilt insbesondere für Vervielfältigungen, Übersetzungen, Mikroverfilmungen und die Einspeicherung und Verarbeitung in elektronischen Systemen.

Printed in Germany

Umschlaggestaltung: Christopher Schneider, Berlin 


\section{Vorwort}

Diese Arbeit ist in der anregenden Atmosphäre des Historischen Seminars der Universität Tübingen entstanden und wurde von der Fakultät für Philosophie und Geschichte im Sommersemester 2007 als Habilitationsschrift angenommen. Wilfried Hartmann hat mir während meiner Zeit als wissenschaftlicher Assistent so wenig lästige Arbeiten anvertraut wie möglich (nämlich gar keine). So hatte ich in den vergangenen sechs Jahren keinen Grund, mich nicht mit dem Thema meiner Habilitation zu beschäftigen. Dass dieses Thema einige unvorhergesehene Wandlungen durchmachte, hat er mit Fassung getragen und mit Ratschlägen begleitet. Für sein Vertrauen wie auch für seine Kritik möchte ich ihm herzlich danken. Einen besonderen Dank möchte ich zudem an Ludger Körntgen aussprechen. Bei regelmäßigen Gesprächen zur Mittagszeit hat er mich als Cicerone in die Welt des frühen Mittelalters eingeführt. Die wissenschaftlichen Kontroversen wären mir ohne seine prononcierte Parteinahme nicht so schnell vertraut geworden. Für Hinweise und Korrekturen danke ich meinem Bruder Ralph Ubl sowie Wolfram Brandes, Mischa Meier, Steffen Patzold, Ellen Widder und Klaus Zechiel-Eckes. Widmen möchte ich dieses Buch meiner geliebten Frau. Sie lernte die quälenden Details einer Qualifikationsschrift näher kennen, als sie wollte; und sie durchschaute meine wissenschaftliche Neugierde mehr, als ich wollte. Ich bin ihr nicht nur für ihre Mitarbeit an der Fertigstellung des Buches zu Dank verpflichtet, sondern auch dafür, dass ich die Last des Unternehmens an glücklichen Tagen abstreifen und einfach vergessen konnte. 



\section{Inhalt}

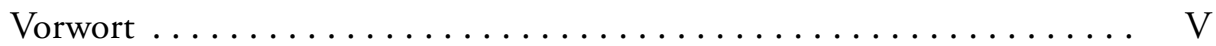

1. Einleitung $\ldots \ldots \ldots \ldots \ldots \ldots \ldots \ldots \ldots \ldots \ldots \ldots \ldots \ldots \ldots \ldots \ldots \ldots \ldots$

1.1 Erklärungen für einen Sonderweg $\ldots \ldots \ldots \ldots \ldots \ldots \ldots \ldots$

1.2 Die Zählungen der Verwandtschaft ................ 14

1.3 Entdifferenzierung des Rechts $\ldots \ldots \ldots \ldots \ldots \ldots \ldots \ldots .27$

2. Die Aneignung einer Tradition im 4. Jahrhundert .......... 35

2.1 Römische Inzestverbote $\ldots \ldots \ldots \ldots \ldots \ldots \ldots \ldots \ldots \ldots \ldots \ldots \ldots$

2.2 Die Gesetzgebung der christlichen Kaiser .............. 46

2.3 Christianisierung ohne Bibel $\ldots \ldots \ldots \ldots \ldots \ldots \ldots \ldots \ldots \ldots \ldots$

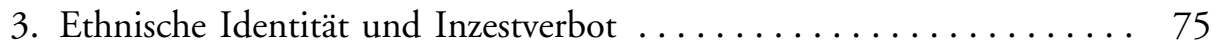

3.1 Endogamie der Germanen? . . . . . . . . . . . . . . . . . 77

3.2 Das Dossier der Rechtsfälle ......................... 84

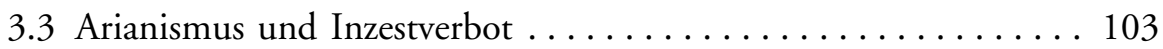

3.4 Literarische Stilisierung von Ethnizität $\ldots \ldots \ldots \ldots \ldots \ldots \ldots 112$

4. Der Ordnungswille der Bischöfe und das christliche Königtum . . . 115

4.1 Avitus von Vienne und die burgundischen Könige .......... 118

4.2 Obsession im merowingischen Kirchenrecht ............ 137

4.3 Die Implementierung im weltlichen Recht des Frankenreichs ... 175

4.4 Königtum und Kirche im Reich der Westgoten ........... 191

4.5 Irritation und Stabilisierung .................... 211

5. Das Inzestverbot und die Begründung des karolingischen Königtums . 217

5.1 Bonifatius und der Zusammenstoß der Kulturen ........... 219

5.2 Die Etablierung einer Dynastie durch das Eherecht ......... 251

5.3 Das Inzestverbot auf der Bühne der Politik ........... 287

6. Theorie und Praxis des Inzestverbots im Karolingerreich ....... 291

6.1 Einheit und Vielfalt: Eine Reise durch das Frankenreich . . . . . 294

6.2 Der Standpunkt des Theologen: Hrabanus Maurus .......... 308

6.3 Der Standpunkt der Fälscher: Pseudoisidor und Benedictus Levita 323

6.4 Der Standpunkt des Kirchenpolitikers: Hinkmar von Reims .... 340 
6.5 Der Standpunkt des Sammlers: Regino von Prüm ... . . . . . . 359

6.6 Gelebte Praxis oder klerikales Wunschdenken? ............. 373

7. Die Radikalisierung des Inzestverbots im 11. Jahrhundert ........ 384

7.1 Der Eklat um König Robert II. von Frankreich . . . . . . . . . 387

7.2 Die Inzestkampagne Heinrichs II. . . . . . . . . . . . . . 402

7.3 Die Formierung der päpstlichen Doktrin ............ 440

7.4 Ausdehnung als Zufall und Chance ................ 473

8. Die abendländische Inzestgesetzgebung im Kontext . . . . . . 477

Quellen- und Literaturverzeichnis .................... 499

Register ................................ 567 


\section{Einleitung}

Der 14. August 1193 war ein denkwürdiger Tag im Leben König Philipps II. von Frankreich. Philipp traf in Amiens zum ersten Mal mit seiner Verlobten Ingeborg von Dänemark zusammen und nahm sie noch am selben Tag zur Frau. In der Hochzeitsnacht muss Schlimmes passiert sein. Denn am nächsten Tag, als geistliche und weltliche Fürsten mit großem Gefolge der Krönung des königlichen Paares in der Kathedrale von Amiens beiwohnten, konnte sich der König in seiner Mimik nicht beherrschen. Er wurde blass, zitterte, schauderte am ganzen Körper und konnte das Ende der Feierlichkeit kaum erwarten. Die Zuschauer der Krönung sahen, wie der König den Blick von seiner neuen Ehefrau voller Hass abwandte und ihr gegenüber einen auffälligen Ekel empfand ${ }^{1}$. Das Verhalten des Königs war so ungewöhnlich, dass sogleich wilde Spekulationen über seine Motive im Umlauf waren. Die einen schrieben den Hass des Königs dem übelriechenden Atem der Dänin zu, andere machten irgendeine verborgene Hässlichkeit des Körpers verantwortlich oder zweifelten an der Jungfräulichkeit der Braut. Papst Innocenz III. suchte die Schuld beim Bräutigam, der ihr gegenüber beim Geschlechtsverkehr vielleicht „etwas Außergewöhnliches" ausgeführt habe. Auch die gängigen Mutmaßungen über Werke des Teufels oder über schwarze Magie fehlten nicht. Der König äußerte wenig später den Wunsch nach Scheidung und brach einen Streit vom Zaun, der zu einem dauernden Zerwürfnis mit dem Papst führen sollte. Sieben Jahre lang weigerte er sich, seiner angetrauten Braut erneut von Angesicht zu Angesicht gegenüberzutreten. Die Abneigung des Königs musste tief in seiner Persönlichkeit verwurzelt gewesen sein. Seine innere Motivation, so Robert Davidsohn, „birgt ein Schleier, welchen die Forschung nicht völlig zu durchdringen vermag“".

König Philipp II. war entschlossen, die Scheidung mit allen verfügbaren Mitteln juristisch zum Erfolg zu bringen. Er schlug den Weg ein, den bereits sein Vater Ludwig VII., Friedrich I. Barbarossa und eine große Anzahl von

1 Gesta Innocentii III c. 48 (69 f.).

2 Davidsohn, Philipp II. 1888, 35. Davidsohns Darstellung von 1888 ist bislang nicht ersetzt. Einen Überblick verschaffen BaLdwin, Government 1986, 82-87; MALECZEK, Stammbäume 1988, 135-140; Foreville, Innocent III 1992, 295-303; D’Avray, Marriage 2005, 102-104. 
Fürsten gewählt hatten ${ }^{3}$ : er plädierte auf unerlaubte Verwandtschaft zwischen ihm und seiner Braut. Dies war im 12. Jahrhundert der Königsweg, um das allseits anerkannte Prinzip der Unauflösbarkeit der Ehe zu durchbrechen und die Erlaubnis für eine weitere Ehe zu Lebzeiten der ersten Ehefrau zu erlangen. Am Hof des französischen Königs war man zuversichtlich, eine unerlaubte Verwandtschaft aufzufinden, da das Inzestverbot bis zum 12. Jahrhundert eine enorme Ausdehnung erfahren hatte. Die Hofgeistlichen mussten nur die maßgebliche Sammlung des Kirchenrechts, das Decretum des Magister Gratian von Bologna (ca. 1140), zur Hand nehmen, um über die Fülle an Inzestvorschriften Kenntnis zu erhalten. In diesem Handbuch, das als Privatarbeit entstanden war und zum gültigen Rechtsbuch der gesamten Kirche aufstieg, war eine verwirrende Vielfalt von Eheverboten versammelt. Die Ehe unter Blutsverwandten untersagten gleich mehrere päpstliche Gesetze im Decretum bis in den siebten Grad kanonischer Zählung ${ }^{4}$. Dies besagt, dass keine Nachkommen derselben Urururururgroßeltern eine Ehe eingehen durften. Um alle Vorfahren bis in den siebten Grad zu überprüfen, musste man insgesamt 128 Personen ausfindig machen, die vor etwa 200-300 Jahren gelebt hatten. Wenn man voraussetzt, dass diese Ahnen und ihre Nachfahren jeweils im Durchschnitt zwei Nachkommen in die Welt gesetzt haben, beträgt die Zahl der Cousins in der gleichen Generation 8192 Personen $^{5}$. Rechnet man den Ahnenverlust ${ }^{6}$ ein sowie die Tatsache, dass nur die Hälfte davon dem weiblichen Geschlecht angehört, bleiben immer noch einige tausend Personen übrig. Wenn Ingeborg nicht unter diesen zahlreichen hochadeligen Blutsverwandten des Königs gefunden werden konnte, waren die Möglichkeiten jedoch nicht erschöpft. Denn das Kirchenrecht betrachtete nicht nur die Blutsverwandtschaft als Ehehindernis, sondern auch die Schwiegerverwandtschaft - und diese gleich auf drei verschiedene Arten. Zu den Schwiegerverwandten zählte Gratian die Ehefrau eines Blutsverwandten bzw. die Blutsverwandten der Ehefrau bis in den siebten Grad (also

3 Vgl. Bouchard, Divorce 2003 (Ludwig VII.); Hlawitschka, Auflösung 2005 (Friedrich I.); MaYer, Kreuzzüge 2000, 109 (König Amalrich I.); Weller, Heiratspolitik 2004, 86-90 (Friedrich I.), 262 f. (Heinrich der Löwe), 678 (Otakar I. von Böhmen).

4 Decretum Gratiani C. 35 q. 1 c. 1 -22 (1263-1270). Zur Entstehung vgl. Winroth, Making 2000. Die Stammbäume bei Gratian behandelt SснаDт, Arbores 1982, $141-$ 189.

5 Mit dieser Zahl (ohne Ahnenverlust) rechnet zu Recht Ficker, Untersuchungen 1 1891, 485. Scherer, Handbuch 2 1898, 295, zählt 16129 Verwandte, weil er auch die Verstorbenen mitzählt. Ihm folgt Landau, Ehetrennung 1995, 163. Flandrin, Familien 1978, 36, und Mitterauer, Christentum 1990, 54, gehen von 2713 Cousinen aus, Siegmund, Frauenraub 1998, 118, von ca. 400 Personen.

6 Unter Ahnenverlust versteht man in der Genealogie den durch Heirat zwischen Verwandten entstehenden Schwund an Vorfahren. Der Ahnenverlust kann in der siebten Generation bis zu $50 \%$ und mehr betragen. 
nochmals einige tausend Personen), die Schwiegerverwandten der Ehefrau bis in den dritten Grad sowie die Ehefrau eines Schwiegerverwandten der Ehefrau bis in den zweiten Grad. Zuletzt trat bei Gratian das Verbot der geistlichen Verwandtschaft hinzu, die durch die Patenschaft bei Taufe oder Firmung hergestellt wurde.

Die Suche der Hofgeistlichen Philipps II. war erfolgreich. Achtzig Tage nach der Hochzeit präsentierte man auf einer eigens einberufenen Synode in Compiègne eine unerlaubte Blutsverwandtschaft zwischen Ingeborg von Dänemark und der ersten Ehefrau Philipps II. im vierten Grad. Bischöfe, Grafen und Ritter, die allesamt dem Lager des französischen Königs angehörten, bestätigten mit Eid die durch eine genealogische Tafel veranschaulichte Verwandtschaft ${ }^{7}$. Dies genügte, um nach dem geltenden Kirchenrecht eine nachträgliche Scheidung wegen Inzest auszusprechen. Ingeborg von Dänemark wurde in ein Kloster abgeschoben, der König von Frankreich nahm sich Agnes von Meran als neue Ehefrau. Ingeborg appellierte ihrerseits an die päpstliche Kurie - zunächst ohne Erfolg. Erst der seit 1198 amtierende Papst Innocenz III. scheute nicht davor zurück, die Frage der Ehe zwischen Philipp und Ingeborg zum Grundsatzkonflikt um die Geltung des christlichen Eherechts zu machen ${ }^{8}$. Aus der Sicht des theologisch gebildeten Papstes sollte die Stabilität der Ehe Vorrang vor der Frage des Inzests genießen. Am Fall Philipps wollte er ein Exempel statuieren, damit das Inzestverbot nicht mehr als Scheidungsgrund missbraucht werden konnte. Nachdem dänische Gesandte den apostolischen Stuhl auf Fehler in der Genealogie der Franzosen aufmerksam gemacht hatten, wähnte der Papst das Recht endgültig auf seiner Seite und verhängte im Jahr 1200 das Interdikt über Frankreich. Erst nach dem Tod der Agnes von Meran (1201) entspannte sich die Lage. Der Papst ermöglichte Philipp die Legitimierung der gemeinsamen Kinder aus der Verbindung mit Agnes und damit die Sicherung der dynastischen Nachfolge, beharrte jedoch weiterhin auf der Gültigkeit der Ehe mit Ingeborg. Philipp akzeptierte im Jahr 1213, als er kurz vor der geplanten Invasion Englands einen dauerhaften Frieden mit der Kirche schließen wollte, Ingeborg als Ehefrau und Königin, ohne ihr jedoch zeit seines Lebens die „eheliche Pflicht“ zu erweisen.

Die Geschichte von Philipp und Ingeborg zeigt die Absurdität des christlichen Eherechts, die durch die Ausdehnung des Inzestverbots erreicht worden ist. Niemand war im 12. Jahrhundert in der Lage, alle für das Eherecht rele-

7 Herausgegeben von Davidsohn, Philipp II. 1888, 297-312, und in Les Registres de Philippe Auguste, 549-553.

8 Tenbrock, Eherecht 1933; Maccarone, Sacramentalità 1978. 
vanten Verwandten zu überblicken'. Es ist durchaus möglich, dass zwischen Philipp und Ingeborg eine weit entfernte Blutsverwandtschaft im siebten Grad bestand, die dem Hof des französischen Königs verborgen geblieben ist, aber von heutigen Genealogen angenommen wird ${ }^{10}$. Prinzipiell war unter den im Decretum Gratiani versammelten Vorschriften jede Ehe inzestuös, weil unmöglich die Unbedenklichkeit positiv nachgewiesen werden konnte. Diese Ausdehnung des Inzestverbots auf potentiell jede Ehe ist interkulturell und historisch einzigartig ${ }^{11}$. Die folgende Untersuchung will Antworten auf die Frage finden, wie es zu dieser radikalen Ausweitung des Inzestverbots gekommen ist. Sie beginnt mit dem Zeitpunkt, als das Thema des Inzestverbots an der Wende vom 3. ins 4. Jahrhundert Objekt der weltlichen und kirchlichen Gesetzgebung geworden ist, und schließt mit der Formierung der päpstlichen Doktrin, wie sie uns im Decretum Gratiani entgegentritt. Seit dem 12. Jahrhundert begannen Juristen und Päpste mit der schwierigen Aufgabe, dieses normative Gerüst schrittweise abzubauen, bis sich die Reformation endgültig von diesem Erbgut der katholischen Kirche verabschiedete. In der Zeit vom 4. bis zum 11. Jahrhundert stand das Inzestverbot dagegen oft an der Spitze der Tagesordnung von gesetzgebenden Versammlungen und kann als Schlüsselthema dieses Zeitalters angesehen werden. Eine Geschichte des Inzestverbots und seiner praktischen Konsequenzen von Diocletian bis Gregor VII. verspricht daher Einblick in die Charakteristik dieser Epoche, in der Verwandtschaft, Ehe und Familie eine herausragende Bedeutung einnahmen.

Wenn im Titel der Arbeit der Konstruktionscharakter des Inzestverbrechens hervorgehoben wird, soll damit nicht zwei Missverständnissen Vorschub geleistet werden. Es geht mir weder darum, das Inzestverbot allein in den Köpfen der Menschen (insbesondere der Kleriker) zu lokalisieren und nicht als Teil der sozialen Wirklichkeit zu betrachten ${ }^{12}$. Noch soll ein ,Baumeister' (wie die Kirche) hinter der historischen Entwicklung identifiziert werden, dem die Ausdehnung des Inzestverbots zur Last gelegt werden könnte. Vielmehr will ich mit der Metapher der Konstruktion einerseits die Maßlosigkeit der Ausdehnung, andererseits die Eigenart des Inzestverbrechens unterstreichen. Im Unterschied zu anderen Verbrechenstypen findet bei Ehen innerhalb der Verwandtschaft keine Schädigung Dritter statt. Nur bei sexuellem Missbrauch innerhalb der Familie ist dies der Fall, doch dieses Verbrechen wurde im frühen Mittelalter nur

9 So deutlich Ficker, Untersuchungen 1 1891, 486-489. Ähnlich SCHERER, Handbuch 2 1898, 295; Esmein, Mariage 1 1891, 355; Baldwin, Masters 1970, 323; Weigand, Ausdehnung 1994, 6; Brooke, Idea 1989, 134.

10 Bruguière, Mariage 1979, $142 \mathrm{f}$.

11 Vgl. die Zusammenstellung bei Lévi-Strauss, Strukturen 1989; Mitterauer, Europa 2003, 70-108.

$12 \mathrm{Zu}$ den konzeptionellen Problemen der Konstruktionsmetapher vgl. Searle, Construction 1995; HaCKING, Construction 1999. 
ausnahmsweise als Inzestdelikt wahrgenommen ${ }^{13}$. Die Klassifizierung von Verwandtenehen als Kapitalverbrechen verdankt sich allein dem moralischen Werturteil der Gesellschaft. Welche Sanktionen für angemessen gehalten, welche Begründungen erdacht und welche Funktionen dem Inzestverbot zugeschrieben wurden, gibt unmittelbar Aufschluss über das normative Selbstverständnis einer Gesellschaft. Systematisch lässt sich das Inzestverbrechen mit Delikten wie Sodomie und Blasphemie vergleichen. Diese Delikte gerieten im Spätmittelalter zunehmend in das Fadenkreuz der weltlichen Strafverfolgung und verdrängten das Verbot von Verwandtenehen aus der öffentlichen Aufmerksamkeit ${ }^{14}$. Das Inzestverbrechen ist aber nicht nur ein ,konstruiertes' Delikt ohne Schadensfolgen, es symbolisiert auch die öffentliche Ordnung als solche. Ehen innerhalb der Verwandtschaft führen zur Segmentierung der Gesellschaft, während das Inzestverbot einen Kreislauf des Frauentausches anregt, der zu einer Integration der Gesellschaft führt ${ }^{15}$. Das Inzestverbot erzwingt Inklusion durch Exklusion. Eine Gesetzgebung, die das Inzestverbot in den Mittelpunkt stellt, reflektiert daher seine eigenen Bedingungen: dass Gesetze dazu eingesetzt werden, die öffentliche Ordnung herzustellen - eine öffentliche Ordnung, die von der Segmentierung durch Inzestehen in ihrer Existenz gefährdet ist. In diesem Sinn befasst sich die folgende Studie mit „Inzestverbot und Gesetzgebung", d. h. mit dem Wandel von Form, Funktion und Inhalt der Gesetzgebung im ersten Jahrtausend und mit den Auswirkungen, die dieser Wandel auf die Ausgestaltung des Inzestverbots hatte.

\subsection{Erklärungen für einen Sonderweg}

Die Diskussion über die Gründe der Ausdehnung des Inzestverbots wird von Jack Goodys Buch „Die Entwicklung von Ehe und Familie in Europa“ (1983) beherrscht ${ }^{16}$. Goody suchte Ursachen für die Zweiteilung der Welt des Mittelmeers in einen südlichen Bereich, in dem die Cousinenehe eine erlaubte und sogar bevorzugte Eheverbindung darstellte, und einen nördlichen Bereich, in dem jede Form der endogamen Heirat zwischen Cousin und Cousine sozial und rechtlich geächtet war. Den Grund für diesen Unterschied erblickte Goody in der christlichen Inzestgesetzgebung des 4. Jahrhunderts. Erst damals sei ein

13 Und zwar im Fall der Königin Theutberga, siehe 345-352. In der anglophonen Wissenschaft wird Inzest und sexueller Missbrauch oft gleichgesetzt. Vgl. das bekannte Buch von Hamer, Incest 2002 sowie zuletzt JaRzebowski, Inzest 2006, 32-41.

14 Jordan, Invention 1997; SChwerhoff, Blasphemie 1997; LoETz, Gotteslästerer 2002; Hoareau-Dodinau, Répression 2002; Puff, Sodomy 2003; Reinle, Sodomiedelikt 2007. Allgemein zur Kriminalitätsgeschichte vgl. Schwerhoff, Einführung 1999.

15 So lautet das zentrale Argument bei Lévi-Strauss, Strukturen 1989. Siehe auch 14.

16 Goody, Development 1983. 
Bruch in der mehr oder weniger einheitlichen endogamen Ehepraxis des Mittelmeerraumes erfolgt. Die Kirche habe sich für die Ausdehnung des Inzestverbots nicht auf die Heilige Schrift berufen können, da im Alten Testament nur bestimmte Eheverbote innerhalb der Hausgemeinschaft ausgesprochen, andere Ehen wie die Cousinenehe jedoch als erlaubte, ja sogar bevorzugte Verbindungen angesehen worden seien. Die Inzestverbote des 4. Jahrhunderts stellt Goody deshalb nicht in den Kontext des Religionswechsels vom Heidentum zum Christentum, sondern in den Kontext der Strategien der Weitergabe von Besitz. Die Kirche habe die Möglichkeiten der Weitergabe von Besitz an potentielle Erben einschränken wollen, um auf diese Weise sich selbst als Adressat von Erbschaften ins Spiel zu bringen. Wie das Verbot der Scheidung, des Konkubinats, der Polygynie und der Adoption sei die Ausdehnung des Inzestverbots mit dem Zweck etabliert worden, die Schaffung von natürlichen und künstlichen Erben zu verhindern und den Einfluss der Kirche in der Gesellschaft zu vergrößern. Diese These leuchtet für das Verbot von Konkubinat, Polygynie, Adoption und Scheidung auf den ersten Blick ein, weil mit diesen Strategien eine potentielle Kinderlosigkeit umgegangen werden konnte. Ihr Verbot durch das Christentum könnte tatsächlich zu einem Anstieg der Vermächtnisse geführt haben, weil die Anzahl der kinderlosen Ehepaare zunahm. Für das Inzestverbot entfaltet Goody eine umständlichere Argumentation ${ }^{17}$. Goody betrachtet die Cousinenehe als Strategie, den Familienbesitz durch die Heirat unter Nachkommen zusammenzuhalten und die familiären Bande zu stärken. Das christliche Verbot der Cousinenehe habe zu einer Zerschlagung des Familienbesitzes und zur Lockerung der Bindung von Familien an ihre Ländereien geführt. Damit sei die Übertragung von Vermächtnissen an die Kirche erleichtert worden. Nicht das Christentum als Religion, sondern der Profit der Kirche, die sich im 4. Jahrhundert als Institution mit eigenem Recht und umfassenden Besitzungen etablierte, habe die „radikale Veränderung der europäischen Familienstruktur " ${ }^{\text {"18 }}$ herbeigeführt.

Goodys Verdienst besteht darin, vor dem Hintergrund der ethnologischen Forschung erstmals die Erklärungsbedürftigkeit der abendländischen Inzestgesetzgebung herausgestellt zu haben. Seine eigene Erklärung für das Phänomen, im Rahmen eines zugespitzten und generalisierenden Essays publiziert, ist dagegen auf fundamentalen und einhelligen Widerspruch gestoßen. Aus althistorischer Sicht wurde die postulierte Einheit der eherechtlichen Praxis im Mittelmeerraum als Fiktion entlarvt ${ }^{19}$. In der frühen römischen Republik galten ähnlich ausgedehnte Inzestverbote wie in der Spätantike. Sie wurden zwar im

17 Goody, Development 1983, 123-125; Ders., Geschichte 2002, 50.

18 Goody, Geschichte 2002, 48.

19 Saller - Shaw, Marriage 1984; Saller, History 1991; Martin, Anthropologie 1993; Moreau, Inceste 2002. 
Recht der Kaiserzeit schrittweise als Zugeständnis an die unterschiedlichen Ehepraktiken der unterworfenen Völker abgebaut, in der Praxis des lateinischen Westens waren sie jedoch weitgehend noch in Geltung. Die Römer verstanden ihre Exogamie geradezu als Unterscheidungsmerkmal gegenüber den anderen Völkern des Orients und schauten mit Verachtung auf die Geschwisterehe in Persien und Ägypten herab. Die Kluft zwischen dem Norden und dem Süden des Mittelmeers lag weiter zurück, als Goody zugestehen will. Auch die Frage, ob solche Institutionen wie Adoption, Wiederverheiratung und Konkubinat in römischer Zeit überhaupt der Sicherung von Erben dienten, ist kontrovers diskutiert und zum überwiegenden Teil verneint worden ${ }^{20}$. Besonders beim Inzestverbot kann die von Goody aufgedeckte Logik der Kirche kaum überzeugen $^{21}$. Warum sollten Familien mit zerstreutem Landbesitz eher geneigt sein, der Kirche Vermächtnisse zu hinterlassen, als Familien, die auf den Zusammenhalt ihrer Güter achteten? Auch die Voraussetzung, dass es im römischen Reich oder bei den barbarischen Germanen einen solchen Zusammenhalt von Familie und Besitz gab, ist nach den neueren Forschungen kaum aufrechtzuerhalten $^{22}$. Schließlich wird der Kirche selbst wohl eine zu große Last aufgebürdet, wenn man ihr eine derart komplexe Strategie zuschreiben will ${ }^{23}$. Weder haben sich kirchliche Autoren in diesem Sinne geäußert, noch trifft es zu, dass eine solche Strategie notwendigerweise zum Erfolg geführt hätte.

Goodys Konzept der Kirche wirft noch weitere grundsätzliche Fragen auf. Joseph Lynch hat zu Recht in Frage gestellt, ob die Kirche überhaupt durch Gesetzgebung ex nibilo eine solch starke Diffamierung des Inzests ins Werk hätte setzen können. „Die frühmittelalterliche Gesetzgebung war in dieser Hinsicht

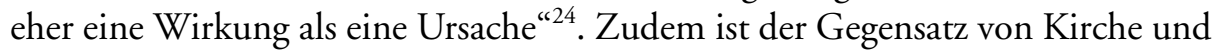
Laien für die Spätantike und das Frühmittelalter kaum geeignet, die gesellschaftliche Wirklichkeit angemessen zu erfassen. Ein solches Geschichtsbild beruht auf der fragwürdigen Annahme, zwischen dem Adel und der Kirche habe „ein permanenter Kalter Krieg ${ }^{\text {“25 }}$ stattgefunden. Gerade die Geschichte der Inzestgesetzgebung ist durch die Mitwirkung christlicher Herrscher an der Ausdehnung des Verbots geprägt. Dies trifft für die römischen Kaiser des 4.

20 Saller - Shaw, Marriage 1984; O’Roark, Marriage 1996; Martin, Anthropologie 1993.

21 Chris Wickham, Rezension von Goody, in: Journal of Peasant Studies 14 (1986) 129_ 134; Herlihy, Sense 1990; Jong, Limits 1989, 46-48; Dies., Riddle 1998, 107; D'Avray, Damian 1992, 74-77.

22 Saller - Shaw, Marriage 1984; Martin, Anthropologie 1993; Murray, Structure 1983.

23 Jong, Riddle 1998, 107; D’Avray, Damian 1992, 78.

24 Lynch, Godparents 1986, 260. Zustimmung bei Jong, Limits 1989, 48; Mitterauer, Christentum 1990, 50.

25 D'Avray, Damian 1992, 78. 
Jahrhunderts ebenso zu wie für den fränkischen König Pippin I., für den ottonischen Kaiser Heinrich II. wie für den byzantinischen Kaiser Leon III. Erst das Reformpapsttum des 11. Jahrhunderts formte die Kirche zu einer von der Laienwelt klar unterschiedenen Institution mit einem ausdifferenzierten Rechtssystem und einer bürokratischen Ämterhierarchie ${ }^{26}$. Vor dieser Zeit teilten die adeligen Bischöfe viele Interessen mit ihren laikalen Standesgenossen, während sich das Leben des niederen Klerus in den Landkirchen nur wenig von dem der bäuerlichen Schichten unterschied ${ }^{27}$. Wie insbesondere die Geschichte des Zölibats lehrt, ist die kirchenrechtliche Entwicklung der Spätantike und des frühen Mittelalters wesentlich durch Vorstellungen und Forderungen der Laien beeinflusst worden ${ }^{28}$. Mayke de Jong wies überzeugend nach, dass sich die Laien durchaus mit der Norm identifizierten, eine christliche Ehe unter Beachtung des Inzestverbots zu führen ${ }^{29}$. Es ist folglich nicht plausibel, der Kirche einen popish plot zu unterstellen, eine groß angelegte Strategie gegen den Rest der Gesellschaft.

Diese Argumente berühren auch einen anderen Vorschlag zur Erklärung des ausgedehnten Inzestverbots des Mittelalters. Eine beliebte, wenn nicht die gängigste Erklärung unterstellt der Kirche das Ziel, mit dem Verbot von Verwandtenehen die Zerschlagung der germanischen Sippenverbände bezweckt zu haben ${ }^{30}$. Am ausführlichsten ist diese These vor wenigen Jahren von dem französischen Historiker Jean-Pierre Poly begründet worden. Im Vergleich mit anderen Beiträgen zu diesem Thema wirkt Polys Buch überaus befremdlich, weil er unter Missachtung der neueren Forschung die Prinzipien der rechtshistorischen Schule des 19. Jahrhunderts reaktiviert. Poly nimmt an, dass ein ausgeklügeltes und differenziertes Recht der germanischen Völker existierte, welches nicht durch die verzerrende Darstellung kirchlicher Quellen des frühen Mittelalters, sondern nur durch die ,reinen' Quellen des skandinavischen Hochmittelalters erforscht werden könne. Das Problem einer solchen rekursiven Erschließung des germanischen Rechts ist längst erkannt worden. Dieser methodische Zugang nivelliert die Unterschiede in der Sozialstruktur und in den Lebensbedingungen der germanischen Völker und vernachlässigt die Tatsache der Romanisierung und Akkulturation der völkerwanderungszeitlichen Gentes. Die Forschung hat deshalb davon Abstand genommen, ein einheitliches ger-

26 Morris, Monarchy 1989, 98-108.

27 Hartmann, Zustand 1982; Godding, Prêtres 2001, 240-260; Krause, Sozialgeschichte 2006.

28 Fuhrmann, Überall 1989, 150-171; Angenendt, Religiosität 1997, 455.

29 Jong, Limits 1989; DIEs., Riddle 1998.

30 Buchner, Wesenszüge 1958, 266; Goody, Development 1983, 59; Rouche, Mariages 1986, 858; Brundage, Law 1988, 193; Chélini, Aube 1991, 184; Mikat, Inzestgesetzgebung 1994, 73; Le Jan, Famille 1995, 310-326; Jong, Riddle 1998, 119; Brown, Rise 2003, 421; Poly, Chemin 2003, $483 \mathrm{f}$. 
manisches Recht vorauszusetzen, das ähnlich wie die Sprache allen germanischen Völkern zugrunde gelegt werden könne ${ }^{31}$. Poly kombiniert die antiquierte rekursive Methode mit einer geradezu grotesken Fehleinschätzung der kirchlichen Quellen ${ }^{32}$. Die These von der verzerrenden Darstellung der Realität durch die Kirche entbindet ihn davon, die kirchlichen Quellen als solche ernst zu nehmen und gewissenhaft $\mathrm{zu}$ interpretieren. Beispielhaft soll hier nur seine Konstruktion eines „eherechtlichen Augustinismus“ erwähnt werden. Demnach hat der Kirchenvater Augustinus die Utopie eines Gottesstaates mit ausschließlich exogamer Ehepraxis entworfen, die dann Schritt für Schritt bis zum Hochmittelalter in die Realität umgesetzt worden $\operatorname{sei}^{33}$. Diese These missachtet zweierlei: Zum einen knüpfte Augustinus in seinen Überlegungen an Gedanken heidnisch-antiker Autoren an und zum anderen vertrat er gerade nicht eine Utopie der Exogamie, sondern forderte zur Bildung von Allianzen auf, sobald die enge Verwandtschaft zwischen Cousins überschritten wurde. Eine Ausdehnung des Inzestverbots auf prinzipiell alle Ehen wie im Hochmittelalter ist mit diesem Gedankengang unvereinbar.

Aus der Fixierung auf die Rolle der Kirche als Institution hat ein gedankenreicher und scharfsinniger Aufsatz Michael Mitterauers herausgeführt ${ }^{34}$. Mitterauer lehnt den von Goody hergestellten Zusammenhang zwischen Inzestverbot und Besitzübertragung ab und lenkt den Blick auf die religionsgeschichtliche Dimension. Besonders fruchtbar ist sein Vergleich des abendländischen Kirchenrechts mit dem Kirchenrecht der orthodoxen und orientalischen Kirchen. Dort fand nämlich in ähnlichem Ausmaß eine Ausweitung des Inzestverbots statt wie im Abendland. Selbst die armenische Kirche und die jüdische Sekte der Karaïten im 9. Jahrhundert seien von der Ausdehnung des Inzestverbots erfasst worden. Den christlichen Kirchen insgesamt eine Gier nach Vermächtnissen und Schenkungen zu unterstellen, scheitere jedoch an der Tatsache, dass die Kirche nur im Westen zu einem der größten Grundbesitzer avanciert sei. Mitterauer hält daher alle Erklärungen, die sich auf die besondere soziale oder politische Situation des Westens beziehen, für nicht überzeugend. Dieses Argument trifft auch auf das oben erwähnte Erklärungsmodell für die Ausdehnung des Inzestverbots zu, nämlich die durch die Kirche beabsichtigte Zerschlagung der germanischen Sippenverbände im Frühmittelalter. In Byzanz galt seit der Gesetzgebung Leons III. (741) derselbe Umfang des Inzestverbots

31 Siehe 77-84, wo ich mich mit Polys Germanen-Thesen ausführlich befasse.

32 Beispielhaft sei hier nur genannt, dass Poly ohne Begründung eine ganze Reihe von Quellen der Fälschung bezichtigt, z. B. Briefe Gregors II. (JE 2174) und Gregors III. (JE 2239) sowie die Synoden von Rom (743) Verberie (756) und Compiègne (757): Poly, Chemin 2003, 281-285. Zur krassen Fehleinschätzung der Position des Hrabanus Maurus siehe 237 Anm. 107.

33 Poly, Chemin 2003, 29. Zu dem Augustinus-Text siehe $61 \mathrm{f}$.

34 Mitterauer, Christentum 1990. Vgl. auch ders., Europa 2003, 70-108. 
wie in der westlichen Kirche, in der Frage der Schwiegerverwandtschaft favorisierte man im Osten sogar eine strengere Auslegung ${ }^{35}$. Bis in die Zeit um 1000 sollte sich an diesem Gleichschritt zwischen den beiden Kirchen nur wenig ändern. Die Existenz germanischer Sippenverbände, wenn dieses Forschungskonstrukt überhaupt noch haltbar ist ${ }^{36}$, kann also für die Ausgestaltung des christlichen Eherechts keine Bedeutung gehabt haben.

Diese parallele Entwicklung in vielen christlichen Kirchen lässt sich aus der Sicht Mitterauers nur in einem religionsgeschichtlichen Vergleich verständlich machen $^{37}$. Das Christentum hält Mitterauer insofern für singulär, als es nicht nur wie andere monotheistische Religionen die Bedeutung der Abstammung neutralisiert, sondern sogar eine ausgesprochen feindliche Haltung gegen die Gruppenbildung durch Verwandtschaft eingenommen habe. Jesus Christus habe mit der durch die Taufe vollzogenen Zugehörigkeit zur Kirche die Verbindlichkeit einer neuen Gemeinschaft und die Trennung von allen verwandtschaftlichen Bindungen eingefordert. Sein Aufruf, im Zeichen der Endzeit um des Himmelreichs willen die eigene Familie zu verlassen (Luc. 18, 29), habe der christlichen Kirche eine prinzipielle Distanz zu Verwandtschaft und Abstammung mit auf den Weg gegeben. Das Mönchtum setzte nach Mitterauer diese Forderung in die Tat um, indem es seine Mitglieder von allen verwandtschaftlichen Bindungen befreit und stattdessen den Gehorsam gegenüber dem Ersatzvater (abbas) verlangt habe. Diese Abstammungsfeindlichkeit des Christentums begreift Mitterauer als Ermöglichungsgrund für eine Ehepraxis, in der die Stärkung verwandtschaftlicher Bindungen durch endogame Ehen keine Rolle spielen sollte. Warum ist es aber dann zur Ausdehnung über die in Lev. 18 genannten Eheverbote gekommen? Mitterauer macht dafür verschiedene Faktoren verantwortlich. Besonders asketisch und rigoros gesinnte Christen hätten dazu geneigt, die Verbote von Levitikus durch Analogie zu erweitern und durch die Anwendung der Lehre von der fleischlichen Einheit der Eheleute (una caro) auf Schwiegerverwandte zu übertragen. Auf diese Weise sei das Verbot der Heirat zwischen Tante und Neffe (Lev. 18, 12-13) durch das analoge Verbot der Heirat zwischen Onkel und Nichte erweitert worden. Gestützt auf die unacaro-Lehre seien auch die Schwiegerverwandten unter dieselben Inzestverbote wie die Blutsverwandten geraten. Da die christliche Religion der Verwandtschaft keine positive Funktion zugeschrieben habe, sei in diesem Feld ungehindert experimentiert worden. Für die Entwicklung im Westen hält Mitterauer die

35 Einen Überblick geben Zhishman, Eherecht 1864, 233-347, und Joyce, Ehe 1934, $484-491$.

36 Vgl. Genzmer, Sippe 1950; Kroeschell, Sippe 1960; Murray, Structure 1983; Hechberger, Adel 2005, 303-306; Wickham, Framing 2005, 551 f.; Lubich, Verwandtsein 2008, 130-146.

37 Mitterauer, Europa 2003, 70-108. 
Kombination dieser asketischen Strömung mit dem altrömischen Exogamiegebot in der Gesetzgebung der christlichen Kaiser für entscheidend: „Die Aufnahme römisch-rechtlicher Verwandtschaftskonzeptionen in das christliche Eherecht war langfristig für die Ausweitung der verbotenen Grade von enormer Bedeutung “38.

Auf wenigen Seiten gelingt es Mitterauer, die bislang überzeugendste Erklärung für die Ausweitung des Inzestverbots zu skizzieren: Auf der Grundlage der Abstammungsfeindlichkeit des Christentums kamen die Übernahme der römischen Verwandtschaftskonzeption, das Prinzip der Analogie und das Prinzip der una-caro-Lehre zur Entfaltung. Die historischen Folgen der abendländischen Exogamie schätzt Mitterauer sehr hoch ein: Die Präferenz von Gatten- über Abstammungsbeziehungen, die bilaterale und nicht patrilineare Struktur der Verwandtschaft, die Bedeutung von genossenschaftlichen Sozialformen sowie der Haus- und Dorfgemeinschaft hängen ihm zufolge sehr eng mit der Ausformung der christlichen Ehelehre zusammen ${ }^{39}$. Auf der Grundlage dieser Voraussetzungen habe sich das typische europäische Heiratsverhalten herausgebildet, das als eines der wichtigsten Strukturmerkmale der abendländischen Geschichte angesehen wird.

So anregend insbesondere die vergleichende Perspektive auf die christlichen Kirchen in ihrer Gesamtheit ist, so werden dadurch auch neue Fragen aufgeworfen. Erstens erscheint es problematisch, im Rahmen einer historischen Erklärung das Christentum auf einen Wesenskern festzulegen. Die feindliche Einstellung zur Abstammung war ein Moment der Parusieerwartung des Wanderpredigers und wich im Lauf des frühen Mittelalters problemlos einer positiven Wertung der Herkunft. Schon in der Spätantike konnten Orosius und Isidor der gentilen Struktur ihrer Welt etwas Positives abgewinnen und legitimierten die Vielheit der Völker durch die Ableitung von den Söhnen Noahs ${ }^{40}$. Eine ausgesprochen positive Bewertung von Abstammung lag den neuen Formen der Frömmigkeit wie der Verehrung dynastischer Heiliger und der durch Familienstiftungen organisierten Totenmemoria zugrunde ${ }^{41}$.

Eine zweite Frage ergibt sich aus der komparativen Sicht auf die Inzestverbote der christlichen Kirchen. Mitterauers Darstellung erweckt den Eindruck, als ob parallel und unabhängig voneinander gleichförmige Entwicklungen abgelaufen seien, die in eine Ausdehnung des Inzestverbots mündeten. Gerade die Parallelität dieser Entwicklungen lässt den Rückgriff auf einen Wesenskern des Christentums plausibel erscheinen. Liefen diese Entwicklungen jedoch wirklich parallel und unabhängig voneinander $\mathrm{ab}$, oder muss nicht

38 Mitterauer, Christentum 1990, 69.

39 Mitterauer, Europa 2003, 70-108; ders., Geschichte 2003.

40 PoнL, Völkerwanderung 2005, 23.

41 Angenendt, Adam 1994, 46-49; Ders., Religiosität 1997, 334-347. 
vielmehr eine wechselseitige Beeinflussung angenommen werden? Zwischen der abendländischen und der byzantinischen Kirche fanden Wechselwirkungen bis in das 8. Jahrhundert hinein statt ${ }^{42}$. Das byzantinische Recht strahlte auf den gesamten Raum des östlichen Mittelmeers aus ${ }^{43}$. Ein für die Geschichte des Inzestverbots so wichtiger Text wie die Ecloga Leons III. (741) fand in slawischer, armenischer und arabischer Sprache Verbreitung ${ }^{44}$. Innerhalb der orientalischen Kirchen bestand ein noch engerer Austausch ${ }^{45}$. Doch die Beziehung zwischen den ,Christenheiten' erschöpfte sich nicht nur im Austausch, das Kirchenrecht beruhte auch auf der gleichen Grundlage: auf dem im 4. Jahrhundert erreichten Diskussionsstand. Ein Blick auf die Rezeption der Schriften des Basilius von Cäsarea macht dies deutlich. Im Westen war der Kirchenvater Ambrosius ein Bewunderer und Leser seiner Schriften ${ }^{46}$, im Osten gingen seine Werke direkt in das Kirchenrecht ein ${ }^{47}$. Auch die armenische, die melkitische und die koptische Kirche erkannten die Kanones des Basilius als Teil des Kirchenrechts an ${ }^{48}$. Dieses Beispiel ist nicht zufällig gewählt. Denn Basilius war der erste Theologe, der die una-caro-Lehre auf das Inzestverbot übertrug und auf diese Weise die Ehe mit der Schwester der Frau als Inzest brandmarkte ${ }^{49}$.

Dieser Einwand gewinnt bei einem Blick auf die unterschiedliche Entwicklung der Ehehindernisse in den christlichen Kirchen an Gewicht. Die Christen in Irland, die von der Rechtsentwicklung des 5. und 6. Jahrhunderts nicht erfasst wurden, blieben den Eheverboten des Alten Testaments treu, wie sie in der Kirche vor der Konstantinischen Wende gegolten hatten ${ }^{50}$. Eine Ausdehnung der Ehehindernisse ist auch bei denjenigen Kirchen zunächst nicht erfolgt, die sich seit dem Konzil von Chalkedon von 451 mit der Orthodoxie über die Frage der göttlich-menschlichen Natur Christi zerstritten hatten. Die koptischen Christen kennen bis heute nur das Verbot der Ehe mit Nichte und Tante, nicht dagegen das Verbot der Cousinenehe ${ }^{51}$. Andere Kirchen wie die syrisch-orthodoxe Religionsgemeinschaft übernahmen erst im Hochmittelalter unter dem Einfluss des Papsttums und des Patriarchen von Konstantinopel die Ausdehnung des Inzestverbots ${ }^{52}$. Eine zügige Rezeption dieser Vorschriften in

42 Siehe 212 und 233-236.

43 Vgl. Wolfram Brandes, Art. „Byzantinisches Recht“, in: HRG 1 (²2006) 800-804.

44 Siehe $481 \mathrm{f}$.

45 Brown, Rise 2003; Hamilton, Welt 2004.

46 Siehe 64 Anm. 143.

47 Zhishman, Eherecht 1864, 34; Fedwick, Translations 1981.

48 HaGE, Empêchements 1954, XXV.

49 Siehe 53.

50 Siehe 225-233.

51 Seligman, Studies 1924, 276 f.; Dauvillier - ClercQ, Mariage 1936, 131.

52 Dauvillier - ClercQ, Mariage 1936, 128-130; Selb, Kirchenrecht 2 1989, 260 262; DERS., Christianisierung 1992, 9-11. 
der Spätantike erfolgte dagegen in der armenischen Kirche ${ }^{53}$. Der Historiker wird daher auf den konkreten Kontext der jeweiligen Epoche verwiesen. Warum und unter welchen Umständen die Errungenschaften der Spätantike von einer Kirche angenommen, von einer anderen Kirche verworfen wurden, lässt sich nur am konkreten Beispiel beantworten. Im Westen ist überdies seit dem 13. Jahrhundert der Stellenwert von Exogamie deutlich gesunken. Eine prinzipielle Ablehnung von Inzestehen durch das Christentum ist somit kaum aufrechtzuerhalten.

Zudem besteht die Gefahr, durch den interkulturellen und interreligiösen Vergleich folgende Tatsache aus dem Blick zu verlieren: Nur im Abendland ist das Inzestverbot in solche Dimensionen vorgedrungen, dass seine Einhaltung aus prinzipiellen Gründen nicht mehr möglich war. Dieser Endpunkt der Entwicklung wird von Mitterauer unterschlagen und kann mit seinem Instrumentarium auch nicht erklärt werden. Dies soll weniger als Kritik verstanden werden, sondern vielmehr als Hinweis auf die Möglichkeit, dass durchaus verschiedene Faktoren für die Ausdehnung des Inzestverbots vom 4. bis ins 11. Jahrhundert maßgeblich gewesen sein könnten. Die Gesellschaft veränderte sich in dieser Zeit ebenso grundlegend wie die Kirche und die Rechtspraxis. Es verspricht keinen Erfolg, nur einen Faktor wie die Religion oder die Besitzgier der Kirche herauszugreifen und das Phänomen auf diese Weise zu isolieren. Ein solches Verfahren scheitert allein schon daran, dass im Lauf der 800 Jahre ganz unterschiedliche Verwandtenehen untersagt wurden: Kaiser Constantius II. bedrohte die Ehe mit der Nichte durch die Todesstrafe, Papst Gregor II. verhängte über die Verbindung zwischen der Mutter und dem Taufpaten ihres Kindes das Anathem, und Heinrich II. regte zur Verfolgung von Ehen zwischen weit entfernten Verwandten an. Warum sollte es für diese sehr verschiedenen Normen nur eine Erklärung geben? Schließlich macht es einen Unterschied, ob die Ehe mit der Mutter, der Schwester, der Cousine, der Stieftochter, dem Adoptivkind oder der Taufpatin verboten wird.

In der ethnologischen Forschung hat sich schon vor 50 Jahren die Einsicht durchgesetzt, dass unter dem abendländischen Begriff „Inzest“ verschiedenartige Phänomene in verschiedenartigen Gesellschaften subsumiert werden ${ }^{54}$. Die beiden gängigen funktionalistischen Erklärungen des Inzestverbots beschränken sich jeweils auf einen bestimmten Aspekt. Bronislaw Malinowski stellte die Ehe innerhalb der Kernfamilie in den Mittelpunkt seiner Untersuchungen und sah die Funktion des Inzestverbots in seinem stabilisierenden Einfluss auf das

53 Dauvillier - ClercQ, Mariage 1936, 131; Redgate, Armenians 1998, 208.

54 Goody, Approach 1956; Margarete MEAD, Art. „Incest“, in: International Encyclopedia of the Social Sciences 7 (1968) 115-121, hier 118. 
Verhältnis zwischen Eltern und Kindern ${ }^{55}$. Das Inzestverbot schützt demnach die Kernfamilie vor dem Eindringen des keiner rationalen Kontrolle unterworfenen sexuellen Begehrens. Claude Lévi-Strauss betonte dagegen nicht die innerfamiliäre, sondern die intrafamiliäre Funktion des Inzestverbots ${ }^{56}$. In seiner vergleichenden Studie zur Cousinenehe in Gesellschaften mit einer „elementaren Struktur der Verwandtschaft" betrachtete er das Inzestverbot als Tauschgebot. Familien seien durch Regeln der Exogamie dazu gezwungen, ihre Frauen mit anderen Familien auszutauschen und auf diese Weise einen Kreislauf des Frauentausches in Gang zu setzen. Dieser Kreislauf sei die ursprüngliche Form des Tausches innerhalb archaischer Gesellschaften, rufe die Akzeptanz der sozialen Regel der Reziprozität hervor und markiere den Übergang zur Kultur menschlicher Zivilisation. Hinter der scheinbaren Willkür von Inzestregeln entdeckte Lévi-Strauss das Streben, Ordnung in das Beziehungsgeflecht zwischen Familien zu bringen und durch die Konstituierung eines Verwandtschaftssystems die gesellschaftliche Integration zu gewährleisten. Malinowski und Lévi-Strauss hatten offensichtlich jeweils verschiedene Phänomene im Blick und entwarfen dafür ein Erklärungsschema. Aus dieser Diskrepanz zog Jack Goody die Folgerung, das Inzestverbot sei nicht wie in der ethnologischen Forschung des frühen 20. Jahrhunderts als universale Norm der Menschheit zu betrachten, weil es auf die Art der untersagten Verwandtschaft ankomme ${ }^{57}$. Ist die konzeptionelle Einheit des Inzestverbots nicht mehr vertretbar, müssen auch unterschiedliche Erklärungsansätze herangezogen werden, um den Weg der christlichen Inzestgesetzgebung nachzuvollziehen.

\subsection{Die Zählungen der Verwandtschaft ${ }^{58}$}

Bei der Frage, wie es zur Ausdehnung des Inzestverbots kam, spielt die Zählweise der Verwandtschaft eine entscheidende Rolle. Schon der Begründer der historischen Schule der Rechtswissenschaft, Karl Friedrich Eichhorn (17811854), vertrat die Meinung, die Ausdehnung sei durch ein Missverständnis der Verwandtschaftszählung erfolgt ${ }^{59}$. Habe um 500 das Inzestverbot die gesamte

55 Malinowski, Mutterschaft 1927. Einen ähnlichen Standpunkt vertreten Seligman, Taboo 1935, und Parsons, Taboo 1954.

56 Lévi-Strauss, Strukturen 1981. Lévi-Strauss beruft sich insbesondere auf Tyler, Method 1889. Vgl. auch Evans-Pritchard, Kinship 1951, 43-48.

57 Goody, Oriental 1990, 320.

58 Bei der Angabe der Verwandtschaft folge ich der Usance der Genealogen und bezeichne das Verhältnis zwischen Onkel und Nichte mit 1/2, dasjenige zwischen Cousins mit 2/2 (usw.), um die Entfernung zum Stammvater zu zählen.

59 Eichhorn, Grundsätze 2 1883, 387 f.; Esmein, Mariage 1 1891, 349; Chélini, Aube $1991,186$. 
Verwandtschaft des römischen Rechts umfasst, sei dies später im Sinne der germanischen Zählung missverstanden worden und somit auf den doppelten Umfang angewachsen. Über den Zeitpunkt, wann der Wechsel von der römischen zur germanischen Zählung stattfand, gibt es unterschiedliche Ansichten. Die meisten Historiker nehmen an, dass im 8. Jahrhundert beide Zählweisen nebeneinander verwendet worden seien und dass entweder in der Mitte des 9. oder spätestens im 11. Jahrhundert die germanische Zählweise den Sieg davon getragen habe ${ }^{60}$. Die Schwierigkeit der Datierung liegt zum einen in der Tatsache begründet, dass die Quellen nur ausnahmsweise die verwendete Zählweise erläutern. Erst in der Zeit der entstehenden Rechtswissenschaft im hohen Mittelalter wurde es üblich, die Komputation der Verwandtschaft mit den Methoden der scholastischen Wissenschaft zu erörtern. Es ist daher nicht in jedem Fall möglich, die Quellen des frühen Mittelalters mit Sicherheit einer bestimmten Zählweise zuzuordnen. Zum anderen sind die unterschiedlichen Ansichten der Historiker auf die disparate Forschungslage zurückzuführen. Für die Geschichtsschreibung der Inzestgesetzgebung war es ausschlaggebend, dass die wichtigen Erkenntnisse von Julius von Ficker nicht wahrgenommen wurden, die er im Rahmen seiner Forschungen zur Erbenfolge im germanischen Recht publizierte $^{61}$. Das Standardbuch von Joseph Freisen, auf das sich die gesamte deutsche Forschung stützt, ist vor den Untersuchungen Fickers erschienen ${ }^{62}$. Das Referenzwerk von Adhémar Esmein über das christliche Eherecht nahm Fickers Ergebnisse ebenso wenig zur Kenntnis wie die anderen Darstellungen französischer Historiker (Jean Fleury, Pierre Daudet, Georges Duby) ${ }^{63}$. Die ,herrschende Lehre' zur Verwandtschaftszählung stützt sich also noch immer auf den Forschungsstand aus der Zeit vor dem Werk Julius von Fickers. Es ist an der Zeit, die herrschende Lehre kritisch in Frage zu stellen.

Einhellig wird in der Geschichtsforschung an der Existenz von drei verschiedenen Zählungen der Verwandtschaft festgehalten: der römischen, der kanonischen und der germanischen Komputation ${ }^{64}$. Die römische Zählung war dem Mittelalter aus den Quellen des römischen Rechts vertraut ${ }^{65}$. Ihr zufolge

60 Nach Freisen, Geschichte 1893, 411-420, Esmein, Mariage 1 1891, 349, GuerreauJalabert, Prohibitions 1994, 302, Weigand, Ausdehnung 1994, 7, Corbet, Burchard 2001, 7, und Jong, Riddle 1998, 110, setzte sich die kanonische Zählung seit ca. 850 durch; nach Fleury, Recherches 1933, 270 f., und Joyce, Ehe 1934, 455, geschah dies nach verhaltenen früheren Vorstößen erst im 11. Jahrhundert.

61 FiCKeR, Erbenfolge 11891.

62 Freisen, Geschichte 1893.

63 Dies trifft für die zweite, 1929 erschienene Auflage zu: Esmein, Mariage 1929; Fleury, Recherches 1933; Daudet, Établissement 1941; Duby, Chevalier 1981.

64 Freisen, Geschichte 1893, 406-439; Esmein, Mariage 1 1891, 341-351; Le Jan, Famille 1995, 164.

65 Inbesondere über das Breviarium Alaricianum. Über dessen Verbreitung vgl. Wretschko, De usu 1905; Wood, Code 1993. 
zählt man jede Zeugung zwischen zwei Verwandten. Onkel und Nichte sind im dritten Grad, Cousins im vierten Grad und Cousins zweiten Grades im sechsten Grad verwandt. Die Grenze der Verwandtschaft wird im römischen Recht meist mit dem sechsten Grad angegeben, einige Quellen zählen jedoch die Kinder des Cousins zweiten Grades (sobrino nati) noch zur Verwandtschaft ${ }^{66}$. In den für das Mittelalter wichtigen Pauli Sententiae begegnet daher der siebte Grad als Grenze der Verwandtschaft ${ }^{67}$. Verwendet wurde diese Zählweise zunächst im Erbrecht, eine Konstitution von Kaiser Honorius (409) übertrug sie auf das Eherecht ${ }^{68}$. Die bildliche Darstellung der Verwandtschaft orientierte sich ursprünglich an dem Bild einer Treppe (scalae) mit einzelnen Stufen (gradus) ${ }^{69}$. In der Spätantike kam jedoch auch das Bild eines Stammbaumes mit verschiedenen Ästen auf ${ }^{70}$. Für diese Bilder sind die Etymologiae des Isidor von Sevilla der wichtigste Überlieferungsträger. Isidor stellt die Verwandtschaft nach römischem Recht dar und fügt dieser schriftlichen Darstellung mehrere figurae hinzu ${ }^{71}$. Das erste Bild bedient sich der Stufenmetapher, das zweite der Baummetapher. Während das erste Bild wie der Text von sechs Graden ausgeht, führt das zweite Bild die Verwandtschaft bis zum siebten Grad. Diese beiden Verwandtschaftsbilder auf der Grundlage der römischen Zählweise herrschten bis ins 12. Jahrhundert vor und wurden nur in Details abgewandelt ${ }^{72}$. Andere bildliche Darstellungen aus römischen Rechtsquellen (Breviar, Institutionen) spielten nur eine untergeordnete Rolle.

Im Kirchenrecht des 12. Jahrhunderts wurde das Verwandtschaftsbild der Stammbäume auf eine andere Zählung umgestellt. Ihr zufolge werden nur die Zeugungen bis zum gemeinsamen Stammvater der verwandten Person gezählt. Geschwister sind im ersten Grad, Geschwisterkinder im zweiten Grad und Geschwisterenkel im dritten Grad verwandt. Da diese Zählung seit einer Dekretale Alexanders II. (ca. 1063) vom Papsttum ausdrücklich befürwortet und somit im Kirchenrecht verankert wurde ${ }^{73}$, wird sie „kanonische Zählweise“ genannt. Manche Historiker bezeichnen sie auch als germanische Zählweise, da sie voraussetzen, die einstufige Zählung bis zum Stammvater sei den Germanen eigen gewesen und erst nachträglich von der Kirche übernommen worden. Dieser These ist bereits Joseph Freisen mit dem Argument entgegengetreten, die

66 Kaser, Privatrecht 1 1971, 58; DERs., Privatrecht 2 1975, 506.

67 Lex Romana Visigothorum, Pauli Sent. 4, 10 (408).

68 Codex Theodosianus 3, 10, 1 (147).

69 Schadt, Arbores 1982, $55 \mathrm{f}$.

70 Erstmals fassbar bei Isidor von Sevilla, Etymologiae 9, 6, 28 als Brauch der advocati. Schadt, Arbores 1982, 56-59, und Klapisch-Zuber, Ombre 2000, 36-42, sprechen sich gegen einen Ursprung in klassischer Zeit aus.

71 Isidor von Sevilla, Etymologiae 9, 6, 28.

72 SChadt, Arbores 1982.

73 Siehe 470. 


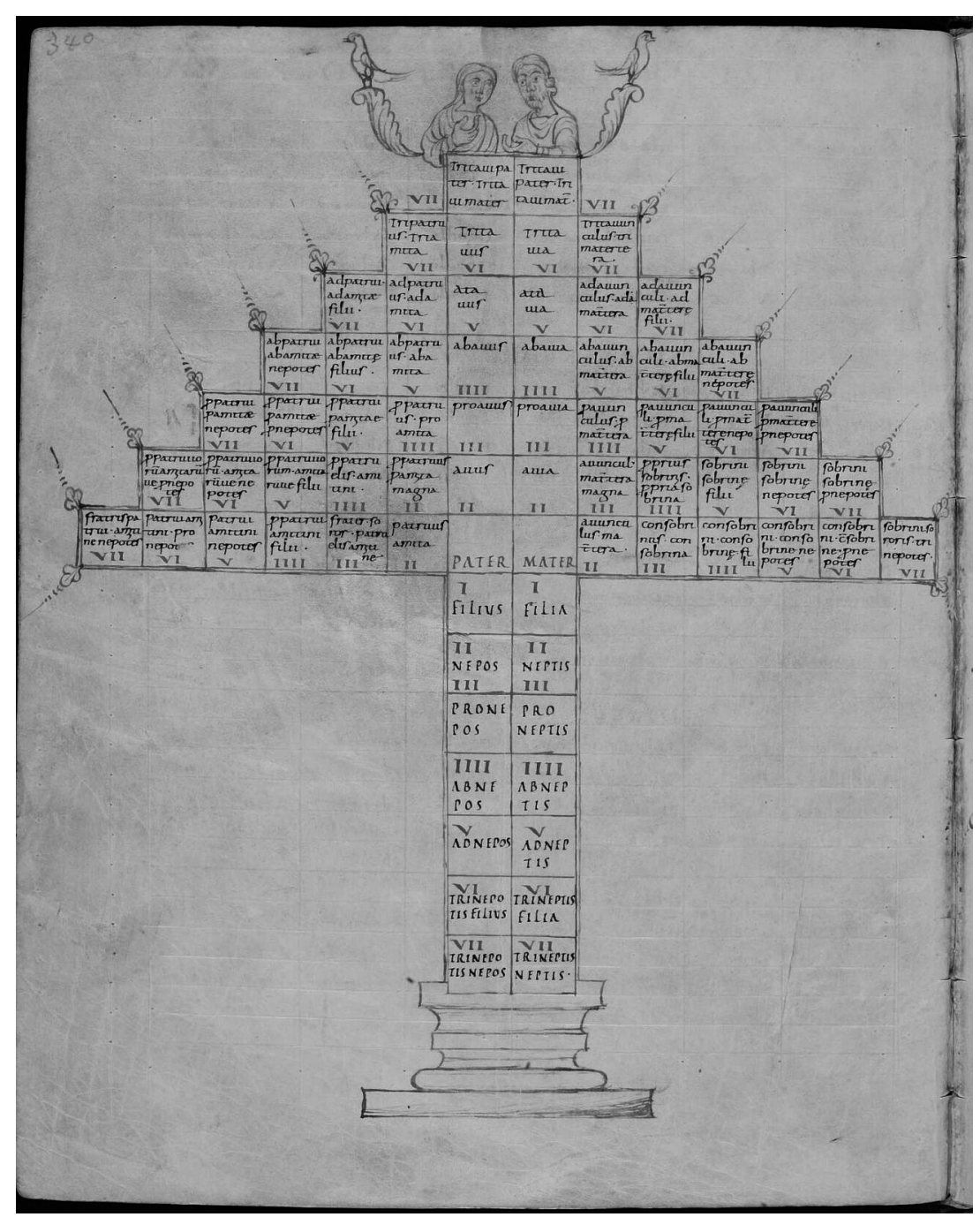

Abb. 1: Stammbaum mit römischer Zählung in einer Handschrift von Isidors Etymologiae (St. Gallen, Stiftsbibliothek, 231, p. 340, ca. 880-890)

Zählung in Generationen sei von den Gelehrten des Kirchenrechts aus der Heiligen Schrift abgeleitet worden ${ }^{74}$. Gregor der Große, der erstmals die kanonische Komputation verwendete, griff ausdrücklich auf biblische Zeugnisse zurück $^{75}$. In seiner Antwort auf Fragen des Erzbischofs Augustinus von Canterbury (Libellus responsionum) erläuterte er eigens die Komputation in Gene-

74 Freisen, Untersuchungen 1886.

75 Ausführlich unten 222. 
rationen bis zum Stammvater und machte damit auf die Neuheit der Zählweise aufmerksam. Durch die weite Verbreitung des Libellus responsionum in der kirchenrechtlichen Literatur des Frühmittelalters fand diese Komputation immer mehr Anhänger und verdrängte allmählich die römische Zählweise.

Die dritte Zählweise wird den Germanen zugeordnet. Manche verstehen darunter die kanonische Zählung in Generationen bis zum Stammvater ${ }^{76}$, andere bezeichnen damit eine erstmals bei Burchard von Worms nachweisbare Abweichung von der kanonischen Zählweise ${ }^{77}$. Burchard war der Ansicht, man zähle die Zeugungen nicht vom Stammvater, sondern von den Stammgeschwistern eines Ehepaares. Geschwister seien nämlich als „Stamm“ aufzufassen und daher nicht durch einen Grad getrennt ${ }^{78}$. Geschwisterkinder sind demnach im ersten Grad, Geschwisterenkel im zweiten Grad, Geschwisterurenkel im dritten Grad verwandt. Der herrschenden Lehre zufolge hätten sich die Germanen zur Bezeichnung der Grade der Wörter geniculum bzw. genu bedient. Dieser Begriff des „Knies“ taucht in verschiedenen Quellen des germanischen Rechts auf, von der Lex Salica und dem Edictus Rothari bis zu den friesischen Rechtsquellen des ausgehenden Mittelalters. Die germanische Zählweise ist deshalb auch als Kniezählung bekannt. Als Bild hätten sich die Germanen am menschlichen Körper orientiert, wie es in den Bilderhandschriften des Sachsenspiegels bezeugt sei. Man habe vom Haupt bis zu den Fingernägeln die sieben Gelenke des Armes gezählt, um auf anschauliche Weise die Verwandtschaft abzuzählen ${ }^{79}$.

Von diesen drei Zählweisen der ,herrschenden Lehre' erweist sich die germanische Komputation als Forschungskonstrukt. Die Vorstellung einer den Germanen eigentümlichen Zählweise der Verwandtschaft beruht auf der Idee eines ursprünglich einheitlichen deutschen Rechts aller germanischen Völker ${ }^{80}$. Diese Idee war die Grundlage der historischen Rechtswissenschaft seit dem frühen 19. Jahrhundert und diente den Juristen zur Schaffung eines deutschen Rechts der Gegenwart. Heinrich Brunners „Deutsche Rechtsgeschichte“, ein Werk vor allem über das Zeitalter der fränkischen Geschichte des Frühmittel-

76 Fleury, Recherches 1933, 10 f.; Joyce, Ehe 1934, 451; Guerreau-Jalabert, Parenté 1989, 75; Chélini, Aube 1990, 185; Mitterauer, Christentum 1990, 54; Jong, Riddle 1998, 107; Siegmund, Frauenraub 1998, 115-117; Bouchard, Families 2001, 41.

77 Grimm, Rechtsalterthümer 1899, 468-470; Wasserschleben, Prinzip 1860, 15; Amira, Erbenfolge 1874, 45 f.; Freisen, Geschichte 1893, 411-420; BrunNer - von SCHWERIN, Rechtsgeschichte 1 1906, 115 f.; Ficker, Erbenfolge 1 1891, 289.

78 Siehe ausführlich 430.

79 STUTz, Verwandtschaftsbild 1890. Mehr Verwirrung als Klarheit bringt die neue Untersuchung von MEUten, Erbfolgeordnung 2000.

80 Wormald, Making 1 1999, $11-24$, hier 11: „This impressive movement still awaits its historian“. Vgl. Sјӧноцм, Rechtsgeschichte 1972; Busch, Germanenbild 2004. 


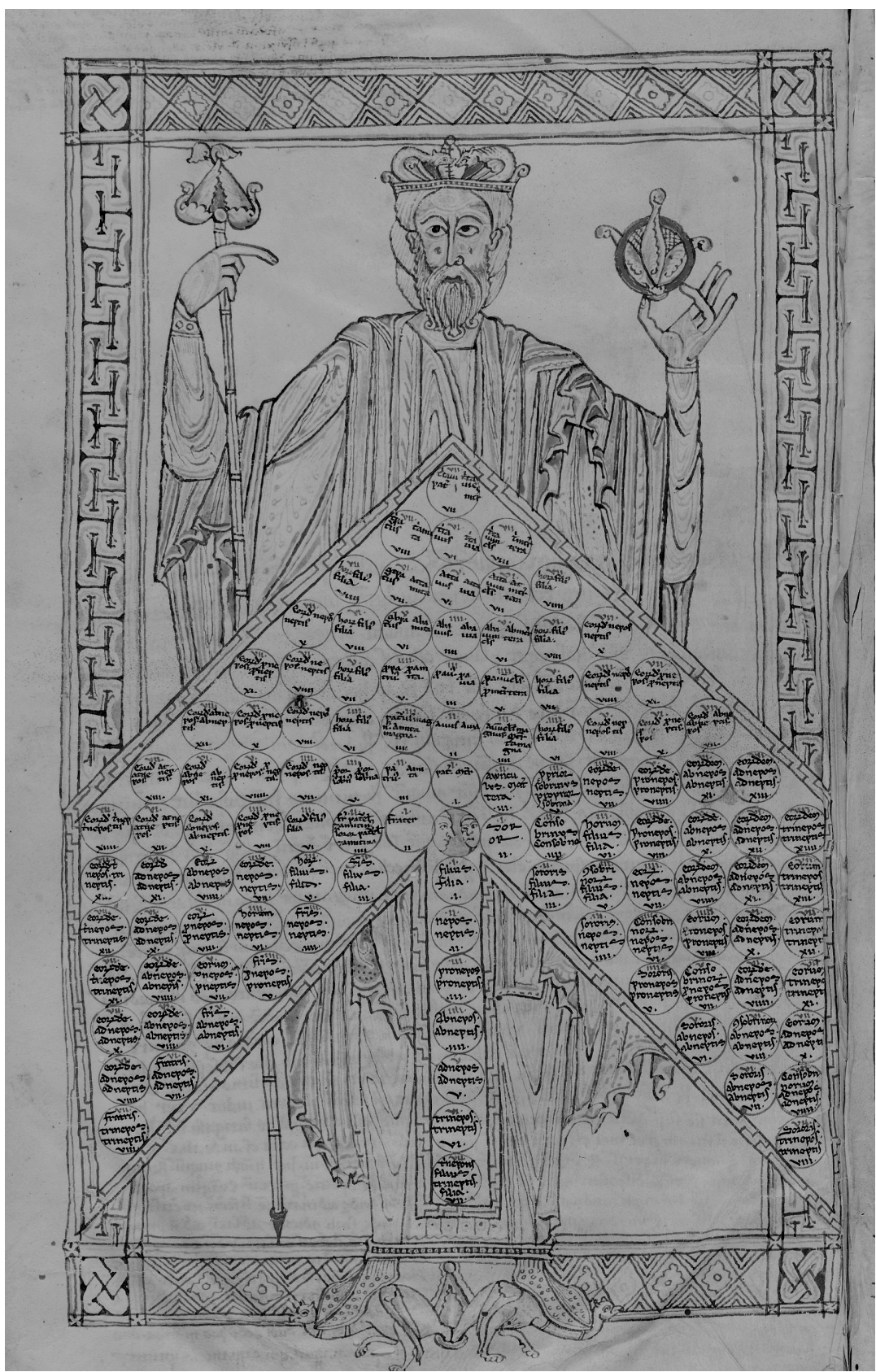

Abb. 2: Stammbaum mit kanonischer Zählung in einer Handschrift des Decretum Gratiani (München, Bayerische Staatsbibliothek, Clm 28175, fol. 321v, 13./14. Jahrhundert) 
alters, ist das Monument dieser rechtshistorischen Schule. Brunner bekannte sich ausdrücklich zu den Grundsätzen, dass die Germanen einen Rechtsstaat hatten und dass ihr Recht systematisch rekonstruiert werden $\mathrm{kann}^{81}$. Die $\mathrm{Zu}-$ schreibung einer eigenen Zählung der Verwandtschaft war nur eine logische Folge aus diesem Ansatz der historischen Rechtsschule. Es ist eine Ironie, dass gerade das fünfbändige Werk über die germanische Erbenfolge von Ficker, der dieser Auffassung uneingeschränkt huldigte ${ }^{82}$, das Material zur Demontage der germanischen Zählung ausbreitet. Ficker stellt in einer erstaunlichen Fülle von Quellenzeugnissen die unterschiedlichen Konzepte der Verwandtschaft vor und kommt zu dem Schluss, es müsse bei den Germanen ganz unterschiedliche Zählungen der Verwandtschaft gegeben haben. Er nennt die „Zählung nach Vetterschaften“, die „Zählung nach Knieen“, die „Zählung nach der längsten Linie“ und die „Zählung nach Geschwisterschaften “83. Obwohl Ficker den Einfluss des gelehrten Rechts auf die ,deutschrechtlichen' Quellen des hohen und späten Mittelalters erheblich unterschätzt, muss an seinem - kaum wahrgenommen - Befund einer Vielzahl von gebräuchlichen Verwandtschaftszählungen festgehalten werden. Das Konstrukt einer einheitlichen germanischen Zählung ist angesichts dieses Befundes nicht aufrechtzuerhalten. Es lohnt sich, die Argumente im Einzelnen zu erläutern.

Zentrales Element des Konzepts der germanischen Zählung ist der Begriff des Knies. Dieser Begriff ist unzweifelhaft Teil der germanischen Rechtssprache. Er begegnet zuerst in den Volksrechten der frühmittelalterlichen Reiche, beim Angelsachsen Bonifatius, in einigen karolingischen Gesetzen und im frühen 11. Jahrhundert in den volkssprachlich verfassten Gesetzen der Angelsachsen ${ }^{84}$. Als „genoil“ geht der Begriff in das Altfranzösische ein ${ }^{85}$. Am häufigsten sind die Belege jedoch in den friesischen Rechtsquellen des Spätmittelalters zu finden ${ }^{86}$. Über das zugrunde liegende Bild der Kniemetapher gibt es unterschiedliche Ansichten. Am plausibelsten ist die Ansicht Fickers, es sei damit in allgemeiner Weise der Knoten in einer Linie gemeint ${ }^{87}$. Die herrschende Lehre hat dagegen die Kniemetapher zum Körperbild des Sachsenspiegels Eikes von Repgow in Beziehung gesetzt ${ }^{88}$. Diese Verknüpfung ist nicht haltbar. Eike benutzte nämlich

81 Brunner - von Schwerin, Rechtsgeschichte 1 1906, 1.

82 FICKER, Erbenfolge 1 1891, 1-21.

83 FiCKer, Erbenfolge 1 1891, $289 \mathrm{f}$.

84 Du Cange, Glossarium 4 1883, 57; Niermeyer u.a., Lexicon 1 2002, 610; Oxford English Dictionary $8\left({ }^{2} 1989\right) 486$.

85 Godefroy, Dictionnaire 4 1885, 260 f.; Tobler u.a., Wörterbuch 4 1960, 254.

86 Holthausen - Hofmann, Wörterbuch 1985, 59; Deutsches Rechtswörterbuch 7 (1983) 1155.

87 Ficker, Erbenfolge 1 1891, 387.

88 Siehe 18 Anm. 77. 
nicht den Begriff des „Knies“, sondern den des „Glieds ${ }^{\text {(89 }}$. Das Knie kommt in den Abbildungen des Sachsenspiegels nicht vor, weil die Zählung an den Gelenken der Arme durchgeführt wird. Überdies hat Hermann Schadt den entscheidenden Nachweis erbracht, dass Eike die Körperanalogie aus dem kanonischen Recht übernommen hat ${ }^{90}$. Der erste, der diese Analogie ausführlich benutzte, war der italienische Eremit und Kardinal Petrus Damiani in der Mitte des 11. Jahrhunderts ${ }^{91}$. Damiani wiederum stützte sich nicht auf das germanische Recht der Langobarden, sondern auf bildliche Darstellungen der Verwandtschaft mit einer Präsentationsfigur, deren Arme die äußersten Verwandten des römischen Stammbaums umfassen. Diese Darstellungsform ist erstmals im Spanien des 10. Jahrhunderts nachweisbar und geht vielleicht auf byzantinische Quellen zurück. Ein germanischer Ursprung der Körperanalogie ist daher ausgeschlossen.

Anders als die Körperanalogie ist der Begriff des „Knies“ dagegen in der Tat der germanischen Rechtssprache ${ }^{92}$ zuzuordnen. Was ist die Bedeutung dieses Begriffs? Julius von Ficker hat mit bestechenden Argumenten gezeigt, dass die frühen Quellen der germanischen Volksrechte mit dem Begriff des Knies unmöglich die kanonische oder germanische Zählweise gemeint haben konnten ${ }^{93}$. Die frühen Quellen zählen nicht einstufig in Generationen, sondern wie das römische Recht zweistufig in Zeugungen. Als Beispiel kann die Regelung der Lex Salica zum Reipus gelten. Als Reipus bezeichnet das fränkische Recht die finanzielle Abgeltung der Verwandten eines verstorbenen Mannes durch die Witwe, die damit die Erlaubnis zur erneuten Heirat erlangen konnte ${ }^{94}$. Wenn bestimmte namentlich genannte nahe Verwandte nicht mehr leben, soll der Reipus (also die Abgeltung) an die Angehörigen „bis zum sechsten Knie“ gezahlt werden. Wenn solche entfernte Verwandte nicht aufzufinden sind, geht die Zahlung an den Fiskus ${ }^{95}$. Ficker stellt klar, dass unmöglich das sechste Knie einstufig aufgefasst werden kann, weil sonst tausende Verwandte ausfindig gemacht werden müssten. Überdies ist es ausgeschlossen, dass in diesem Umfang keine lebenden Verwandten mehr anzutreffen sind. Die Regelung zum Eintritt

89 Eike von Repgow, Sachsenspiegel, Landrecht I 3, 3 (MGH Fontes iuris N.S. 1, 74-76). Vgl. Deutsches Rechtswörterbuch 4 (1951) $639 \mathrm{f}$.

90 SCHADT, Verwandtschaftsbild 1976.

91 Ausführlich unten 454.

92 Vgl. Ruth Schmidt-Wiegand, Art. „Rechtssprache“, in: RGA 24 (²003) 268-276; SeE, Rechtswörter 1964; Fruscione, Frage 2005; dies., Ansätze 2006.

93 FiCKer, Erbenfolge 1 1891, 386-438.

94 Ausführlicher zu diesem Titel der Lex Salica unten 79-84.

95 Et si nec ipse frater fuerit, qui proximior fuerit extra superiores nominatos singillatim dicti secundum parentilla usque ad sextum genuculum, si hereditatem illius mariti defuncti non accipiat, ille reipus illius accipiat. Iam post sexto genuculum, si non fuerint, in fisco reipus ipse vel causa, quae exinde orta fuerit, colligatur. Lex Salica 44, 11 (MGH LL nat. Germ. 4/1, 172). 
des Fiskus wäre dann vollkommen überflüssig. Das sechste Knie meint nach Ficker daher die Verwandten bis zum Cousin zweiten Grades (3/3) und ist römisch gezählt. Dieselbe Überlegung trifft für den Edictus Rothari und die Lex Ribuaria zu, die beide die erbberechtigte Verwandtschaft im 6. bzw. 5. „Knie“ enden und dann den Fiskus eintreten lassen ${ }^{96}$. Fickers Beobachtungen werden durch einen Brief des angelsächsischen Missionars Bonifatius bestätigt. Bonifatius bezeichnet darin den Onkel als ,im dritten Knie“ verwandt und bedient sich daher ebenfalls der zweistufigen Zählweise des römischen Rechts ${ }^{97}$.

Ficker führt die zweistufige Zählung auf einen alten germanischen Brauch der Verwandtschaftszählung zurück, der zufällig mit der römischen Zählung übereingestimmt habe. Diese Annahme erweist sich als überflüssig, da die drei genannten Regelungen der Volksrechte eindeutig auf Vorlagen des römischen Rechts beruhen ${ }^{98}$. In den Volksrechten bediente man sich folglich der römischen Zählweise und ersetzte den römischen Terminus gradus durch den germanischen geniculum. Der Begriff geniculum selbst impliziert keine bestimmte Verwandtschaftszählung. Erst Mitte des 8. Jahrhunderts setzte sich auf den Konzilien König Pippins I. die einstufige Verwendung des Begriffs nach kanonischem Recht durch ${ }^{99}$. Von diesen Überlegungen ausgehend kommt Ficker zu dem richtigen Schluss, dass die Terminologie nichts über die Zählweise aussagt ${ }^{100}$. Die Begriffe gradus, generatio und geniculum stehen nicht für die römische, kanonische und germanische Komputation. Am deutlichsten ist dieser Befund wohl bei Benedictus Levita, dem großen Sammler und Fälscher von Rechtsquellen aus der Mitte des 9. Jahrhunderts. Benedikt benützt alle gängigen Termini (gradus, generatio, progenies, geniculum, propinquitas) und meint dennoch nur eine bestimmte Zählweise, die römische ${ }^{101}$.

96 Omnis parentilla usque in septimum geniculum nomeretur, ut parens parenti per gradum et parentillam heres succedat. Edictus Rothari 153 (MGH LL 4, 35). Et deinceps usque quinto geniculo, qui proximus fuerit, in hereditate succedat. Lex Ribuaria 57, 3 (MGH LL nat. Germ. 3/2, 105).

97 Quia laicus quidam magne persone ad nos veniens dicebat sibi ab apostolicae sedis pontificae sanctae memoriae Gregorio datam fuisse licentiam, ut in matrimonium acciperet viduam avunculi sui. Quae et ipsa fuit etiam uxor consobrini sui et ipsa illo vivente discessit ab eo; et isti viro, qui nunc eam accipere desiderans adfirmat sibi licentiam data, in tertio ienuculo propinqua illius esse dinoscitur et votum vovit Deo castitatis et velata fuit et iterum abiecto velamine maritata. S. Bonifatii et Lulli epistolae 50 (MGH Epp. sel. 1, 83 f.).

98 Zum Reipus in der Lex Salica siehe 77-84; Lex Ribuaria 57, 3 (MGH LL nat. Germ. 3/ 2, 105); zum Edictus vgl. Halban, Recht 2 1901, 113. Die Erwähnung des Fiskus allein ist ein gewichtiges Indiz für römischen Ursprung.

99 In tertio genuclum separantur ... Decretum Vermeriense c. 1 (MGH Capit. 1, 40).

100 Ficker, Erbenfolge 1 1891, 389. Falsch dagegen Goody, Development 1983, 136; Jong, Limits 1989, 40; Jongbloed, Wanburtich 2006, 19.

101 Siehe 331. 
Ein weiteres Element des Konzepts der germanischen Zählung bleibt noch zu klären, nämlich die durch Burchard von Worms angewandte Zählung von den Stammgeschwistern. Burchard benutzte diese Zählung nicht nur in seiner bedeutenden Kirchenrechtssammlung, er wirkte auch an der Festschreibung dieser Methode durch zwei Konzilien mit (Diedenhofen 1003, Seligenstadt $1023)^{102}$. Papst Alexander II. duldete die Zählweise, da sie verbunden mit der Grenze des sechsten Grades dasselbe Inzestverbot ergab wie die kanonische Komputation bis zum siebten $\mathrm{Grad}^{103}$. Fortan zerbrachen sich die Wissenschaftler an den Rechtsschulen den Kopf über diese Zählung und vermittelten sie an Eike von Repgow ${ }^{104}$. Die Frage, warum sich Burchard und die Bischöfe des ottonischen Reichs zu dieser Abänderung der Zählweise veranlasst sahen, wird unter Historikern kontrovers diskutiert. Verbreitet ist die Auffassung, Burchard habe die Nennung des sechsten und des siebten Grades bei Isidor mit dieser Zählung harmonisieren wollen ${ }^{105}$. Isidor schreibt nämlich einerseits, dass der sechste Grad als Grenze der Verwandtschaft in Analogie zu den sechs Weltund Menschenalter stehe. Andererseits enthält sein zweiter Stammbaum den siebten Grad, der sich fortan im karolingischen Kirchenrecht als Inzestgrenze etablieren sollte. Die Harmonie zwischen Verwandtschaftsgrenze und Weltbzw. Menschaltern konnte Burchard nur durch einen Eingriff in den Text von Isidor von Sevilla aufrechterhalten ${ }^{106}$. Die Zählung von den Stammgeschwistern bis zum sechsten Grad ergibt nämlich denselben Umfang wie die (kanonische) Zählung vom Stammvater bis zum siebten Grad. Diese Erklärung hat jedoch die Historiker nicht zufrieden gestellt, weil damit der Erfolg dieses Eingriffs nicht erklärbar scheint. Julius von Ficker identifizierte daher die Zählung bei Burchard mit der auch sonst in ,deutschrechtlichen' Quellen nachweisbaren Zählung nach Vetterschaften ${ }^{107}$. Wie heute auch habe man im Mittelalter von ersten, zweiten und dritten Vettern gesprochen (bzw. von Vettern ersten, zweiten und dritten Grades). Burchard habe mit der Benennung der Vettern als primi diesen Usus zum Ausdruck bringen wollen. Eine andere Erklärung gab Ernest Champeaux in einem Artikel voller verquerer Spekulationen und faktischer Ungereimtheiten ${ }^{108}$. Ihm zufolge weigerte sich Burchard, Geschwister durch

102 Siehe 424 .

103 Siehe 470.

104 SCHADT, Verwandtschaftsbild 1976.

105 Wasserschleben, Prinzip 1860, 11 f.; Lewald, Bonizo 1938, 76 f.; Schadt, Arbores $1982,111 \mathrm{f}$.

106 Eine Gegenüberstellung der Texte bei Corbet, Burchard 2001, $99 \mathrm{f}$.

107 Ficker, Erbenfolge 1 1891, 311. In der Forschung wird diese Zählung auch „Magschaftszählung“ oder „comput fraternel“ genannt.

108 Champeaux, Jus 1933, 244-249. In einem späteren Aufsatz will er zeigen, dass bereits Isidor diese Zählung in seinem ersten Stemma benutzte: Champeaux, Parenté 1937. Da 
einen Grad zu trennen, da sie das identische Blut in sich hätten. Champeaux begreift diese Zählung nicht als germanische Eigenheit, sondern sieht in ihr eine im Volk übliche Methode, die sich im Hochmittelalter gegen die adelige Komputation behauptet habe. Die Belege für diese Ansicht sind erstaunlich dünn. Alle eindeutigen Quellenstellen für eine Anwendung dieser Zählung können nämlich auf die Wirkung Burchards von Worms zurückgeführt werden. Eine dritte Deutung hat unlängst Patrick Corbet vorgeschlagen ${ }^{109}$. Das Überspringen der Geschwister in der Zählung sei ein Trick Burchards gewesen, um gewisse Ehen verfolgen zu können, die bislang nicht unter das Inzestverbot fielen, aber aus Gründen politischer Opportunität verhindert werden sollten. Diese These einer absichtlichen Manipulation mit politischer Zielsetzung lässt sich jedoch, wie noch ausführlich zu zeigen sein wird ${ }^{110}$, an den Quellen nicht erhärten.

Die Erklärungen für Burchards Zählung sind allesamt spekulativ und führen nicht zu einem klaren Bild. So viel wird man jedoch festhalten können: Die Zählung von den Stammgeschwistern an ist ein Phänomen der kirchenrechtlichen Fachliteratur. Sie begegnet erstmals bei Burchard und dann in von ihm abhängigen Quellen der Kanonistik. Von dort übernahmen sie zum Beispiel der Historiker Giselbert von Mons ${ }^{111}$ und der Autor des Sachsenspiegels Eike von Repgow. Alle Ansätze, die diese Zählung auf germanischen Brauch oder volksnahe Sitte zurückführen, sind daher wenig überzeugend. Ein Motiv für Burchard wird tatsächlich in der Harmonisierung von Isidor zu suchen sein. Auch andere Quellen aus dieser Zeit zeigen, dass der Widerspruch bei Isidor als Problem empfunden wurde ${ }^{112}$. Ein anderer Punkt verdient ebenso hervorgehoben zu werden: Bei der Nennung der Vorfahren in Eheprozessen hat man, wie viele Quellen belegen, üblicherweise mit den Stammgeschwistern und nicht mit dem Stammvater begonnen. Dies lässt sich an Quellen des 11. bis 14 . Jahrhunderts nachweisen ${ }^{113}$. Es könnte daher nahe gelegen haben, auch die Zählung mit den Stammgeschwistern zu beginnen. Vorstellungen einer Identität des Blutes bei den Geschwistern, wie sie Ernest Champeaux anhand einer kanonistischen Quelle geltend macht ${ }^{114}$, könnten eine Rolle gespielt haben. Ent-

das Stemma jedoch durchgehend römisch zählt, gelingt ihm dies nur durch die willkürliche Reduzierung auf einen ,authentischen“ Kern.

109 Corbet, Burchard 2001, 101-103.

110 Hierzu siehe 407-410.

111 Giselbert von Mons, Chronicon Hanoniense 122 (135); 136 (201); 154 (239). Für Champeaux, Jus 1933, 252, ist dies ein Beleg für die Verbreitung der Zählung im „Volk“. Angesichts der Bildung Giselberts ist diese Annahme kaum zutreffend. Viele andere Belege Champeaux sind ebenso haltlos.

112 Conrat, Arbor 1909, 15 f.; Schadt, Arbores 1982, 101-103.

113 Dies belegen die Beispiele von Hzawitschka, Konradiner-Genealogie 2003, 125-131. Weitere Belege bei Helmholz, Litigation 1974, 216.

114 Champeaux, Jus 1933, 247, nach Freisen, Geschichte 1893, 399. 
scheidend ist jedenfalls, dass diese Zählung erst seit Burchard Verbreitung gefunden hat und nicht in frühere Quellen hineingelesen werden darf ${ }^{115}$.

Von dem Konstrukt einer germanischen Zählung ist folglich nichts übrig geblieben. Die Körperanalogie, die einstufige Zählung bis zum Stammvater oder bis zu den Stammgeschwistern und die Einteilung in verschiedene „Glieder" können nicht für die germanische Rechtstradition vereinnahmt werden. Nur der Begriff des „Knies“ stammt aus dem germanischen Rechtswortschatz, impliziert jedoch keine bestimmte Verwandtschaftszählung. Vor diesem Hintergrund halte ich die Hypothese für bedenkenswert, dass die numerische Zählung der Verwandtschaft als Errungenschaft des Schriftrechts und der Verwissenschaftlichung des Rechts aufgefasst werden muss. Wilhelm Grönbech stellte bereits fest: „Das Aufzählen von Verwandten nach Graden und Generationen war dem einheimischen Denken fremd" ${ }^{\text {"116. }}$. Die Volksrechte der Germanen beschränken sich in der Regel auf die engere Verwandtschaft ${ }^{117}$, während alle Festlegungen auf einen entfernten, numerischen Grad der Verwandtschaft dem römischen Recht entnommen sind. Schon seit längerem hat sich die Vorstellung der Existenz von großen Sippenverbänden bei den Germanen als Forschungskonstrukt der historischen Rechtsschule erwiesen ${ }^{118}$. Die numerische Zählung der Verwandtschaft war nicht erforderlich und ist erst von außen vom römischen Recht - in das Recht der frühmittelalterlichen Reiche eingedrungen. Wenn man diese Hypothese akzeptiert, wird es auch verständlich, warum es im Frühmittelalter häufig zu Abwandlungen, Missverständnissen und Widersprüchlichkeiten in der Benutzung von Stammbäumen kam. Der am meisten verbreitete Stammbaum aus Isidor enthält eine korrumpierte römische Zählung ${ }^{119}$, Burchard entwarf einen in mehrfacher Hinsicht widersprüchlichen Stammbaum ${ }^{120}$, Petrus Damiani verwickelte sich in der ersten ausführlichen Abhandlung zur Verwandtschaftszählung in verschiedene Widersprüche ${ }^{121}$, und die Gelehrten der Rechtsschule von Pavia erfanden eine eigene Komputation ${ }^{122}$.

115 Nach Freisen, Geschichte 1893, 411, wird seit den germanischen Volksrechten so gezählt. Dagegen bereits FICKER, Erbenfolge 1 1891, 402.

116 GröNBECH, Kultur 1 1978, 372.

117 Dies ist das Ergebnis der Studie von Murray, Structure 1983. Zum selben Urteil kommt Lubich, Verwandtsein 2008, bei der Untersuchung historiographischer Texte des frühen Mittelalters.

118 Siehe die Literatur oben 11 Anm. 36.

119 Vgl. Sснадт, Arbores 1982, 70-77. In der Seitenverwandtschaft zählt der Stammbaum um einen Grad weniger als die römische Zählung. Hinkmar von Reims benutzte diese Zählung, siehe unten 343. Die bislang vorgebrachten Erklärungen sind unbefriedigend: Mejer, Computation 1842; Conrat, Arbor 1909; Meijers, Zählung 1925.

120 Siehe 433 Anm. 253.

121 Siehe 453-455.

122 Nach Liber Papiensis Roth. 153 (MGH LL 4, 317 u. 322 f.) befinden sich Geschwister (wie in der römischen Zählung) im zweiten Grad; Geschwisterkinder jedoch im 3. und 
In einer Zeit, als das Schriftrecht weder durch eine gesetzgeberische Instanz stabil gehalten noch im wissenschaftlichen Unterricht gepflegt wurde ${ }^{123}$, war die numerische Zählung nicht ohne weiteres anwendbar. Sie war im Frühmittelalter mehr eine Angelegenheit der juristischen Theorie als der juristischen Praxis. In der Praxis dominierte dagegen vielmehr ein strategischer Umgang mit Verwandtschaftsbezeichnungen ${ }^{124}$. Diese Feststellung wird durch das Ergebnis der folgenden Untersuchung erhärtet, dass erst im 11. Jahrhundert das Inzestverbot die überschaubare Verwandtschaft überschritten hat. Die Radikalisierung des Inzestverbots im frühen 11. Jahrhundert machte die Anwendung einer numerischen Zählung dringend erforderlich und etablierte diese nun auch fest in der konkreten Rechtssprechung.

Die Entwicklung der Verwandtschaftszählung im Mittelalter stellt sich daher wie folgt dar ${ }^{125}$ : Im frühen Mittelalter wurde die römische Zählung ausdrücklich (wie im westgotischen Recht ${ }^{126}$ ) oder stillschweigend (wie im fränkischen $\operatorname{Recht}^{127}$ ) übernommen. Als Teil des römischen Erbes drang sie nicht in das Gewohnheitsrecht ein, da man ihrer nicht bedurfte. Im Kirchenrecht, dem frühmittelalterlichen Schriftrecht par excellence, war ihr eine längere Existenz beschieden. Die Quellen der irischen und angelsächsischen Kirche bedienten sich der römischen Zählweise. Der Briefwechsel des Bonifatius ist dafür ein untrüglicher Beweis. Das Papsttum fühlte sich ebenfalls der römischen Rechtstradition verpflichtet. Gregor II. und Gregor III. im 8. Jahrhundert, Leo III. an der Wende zum 9. und Nikolaus I. machten von der römischen Zählweise Gebrauch. Auch im Westfrankenreich des 9. Jahrhunderts, wo die Kenntnis des römischen Rechts intensiver als zuvor gepflegt wurde, galt diese Zählweise. Bei Hinkmar von Reims und Pseudoisidor ist dies gewiss, bei Benedictus Levita wahrscheinlich. Die von Gregor I. begründete kanonische Zählweise tauchte dagegen unvermutet auf den Konzilien Pippins I. auf. Während Bonifatius noch römisch gezählt hatte, favorisierte sein Nachfolger als

Geschwisterenkel im 4. Grad. FICKer, Erbenfolge 1 1891, 498-503, hält die Überlieferung für verdorben. Fleury, Recherches 1933, 164-171, ist der Ansicht, die Päpste des 8. hätten sich der Zählung des Liber Papiensis des 11. Jahrhunderts bedient.

123 Das einzige frühmittelalterliche Zeugnis einer Verwendung des Stammbaums vor Gericht ist das Konzil von Douzy (874) unter der Leitung Hinkmars von Reims. Die hohe Gelehrsamkeit des Erzbischofs kann nicht als repräsentativ gelten.

124 Dies zeigt sich an der diffusen Verwendung der lateinischen Begriffe consobrinus, sobrinus, nepos, consanguineus u.a. Vgl. MEJer, Computation 1842, 202; Bur, Formation 1977, 137 ; Le Jan, Famille 1995, 163-167; Jackman, Konrad 2006, 79 f. Siehe auch 126 Anm. 60. Die Begriffe für Verwandtschaft bezeichnen immer nur die engeren Angehörigen: Lubich, Verwandtsein 2008, 126. Zum strategischen Umgang mit Verwandtschaft vgl. die klassische Deutung von Bourdieu, Sinn 1987, 288-351.

125 Ich nehme hier Ergebnisse vorweg, die in den folgenden Kapiteln ausführlich begründet werden.

126 Lex Visigothorum IV, 1, 1-7 (MGH LL nat. Germ. 1, 171-173).

127 Siehe 21. 
Leiter der fränkischen Kirche, Erzbischof Chrodegang von Metz, die kanonische Zählung. Die Synoden von Verberie (756) und Compiègne (757) unter seiner Leitung zählten die Verwandtschaft einstufig, d.h. kanonisch. Warum sich Chrodegang für diese Zählung entschied, kann nicht mehr mit Gewissheit geklärt werden. Der aus einer fränkischen Adelsfamilie des heutigen Belgien stammende Chrodegang war vermutlich mit dem römischen Recht nicht vertraut und griff daher auf die Zählung Gregors des Großen im Libellus responsionum zurück. Im 9. Jahrhundert ist die kanonische Zählung mit Sicherheit bei Bischof Gerbald von Lüttich, in der anonymen Translatio S. Pusinnae aus Sachsen und bei Notker von St. Gallen nachweisbar ${ }^{128}$. Dass auch die meisten anderen Quellen aus dem Ostfrankenreich des 9. Jahrhunderts diese Zählweise gebrauchten, ist eine begründete Vermutung. Erst im frühen 11. Jahrhundert lassen sich wieder sichere Aussagen treffen. In dieser Zeit zählten alle Quellen innerhalb Deutschlands kanonisch oder in der von Burchard geprägten Abwandlung der kanonischen Zählung. In Italien und Frankreich setzte sich dagegen die kanonische Zählung erst durch die Anstrengungen des Reformpapsttums durch.

\subsection{Entdifferenzierung des Rechts}

Aufgrund der vielfältigen Kontinuitäten zwischen dem römischen Kaiserrecht, den Volksrechten der germanischen Könige und dem Kirchenrecht werden in der rechtshistorischen Forschung die Epochen der Spätantike und des Frühmittelalters als Einheit betrachtet ${ }^{129}$. Wie bereits in der Diskussion um die Thesen Jack Goodys angeklungen ist, trifft diese Einschätzung für die Geschichte der Inzestgesetzgebung in besonderer Weise zu. Die folgende Untersuchung beginnt daher mit den Kaisergesetzen des 4. Jahrhunderts und endet mit den päpstlichen Dekretalen des 11. Jahrhunderts. Waren die Kaisergesetze als Ergänzung und Reformulierung eines bereits bestehenden Rechtssystems erlassen worden, gab die päpstliche Gesetzgebung seit Gregor VII. den Anstoß für die Herausbildung eines institutionell verankerten und wissenschaftlich durchdachten Systems des Kirchenrechts. In der Zwischenzeit löste sich das Recht als autonomer Funktionsbereich der Gesellschaft allmählich auf. Im Frühmittelalter fand eine Entwicklung statt, die man in Anlehnung an den Begriff der Ausdifferenzierung als Entdifferenzierung des Rechts bezeichnen

128 Translatio S. Pusinnae c. 3 (MGH SS 2, 682); vgl. Corbet, Burchard 2001, 36. Zu Gerbald und Notker siehe 302 und 370 Anm. 399.

129 Grundsätzlich dazu Mordex, Recht 1987. Beispiele dafür gibt es reichlich: Nehlsen, Sklavenrecht 1970; Oexle, Conjuratio 1985; Ders., Kultur 1995; Hartmann, Bischof 1986; Siems, Handel 1992; Ders., Entwicklung 1991; Reynolds, Marriage 1994; Esders, Rechtstradition 1997; ZedDies, Religio 2003. 
kann ${ }^{130}$. Nach dem Ende römischer Staatlichkeit verlor das Rechtssystem seine in der Antike erreichte Autonomie, da der Einsatz physischer Gewalt zur Durchsetzung rechtlicher Normen nicht mehr garantiert werden konnte. Recht war nicht in einer schulischen oder wissenschaftlichen Ausbildung verankert, sondern wurde in den germanischen Nachfolgereichen weitgehend an außerrechtliche Sozialstrukturen gebunden: an schicht-bedingten Status, an Zusammenhänge der Verwandtschaft, der Freundschaft und des Klientelismus. Am deutlichsten zeichnete sich diese Entwicklung im Verfahrensrecht $a b^{131}$. Der Prozess vor Gericht glich sich mehr und mehr einer politischen Streitschlichtung zwischen unabhängigen Parteien an, ohne dass die öffentliche Gewalt zu letztinstanzlichen Entscheidungen ermächtigt gewesen wäre. Als Beweismittel verlor der Zeugenbeweis gegenüber der Institution der Eidhelfer, eines Indikators für soziale Solidarität, zunehmend an Bedeutung ${ }^{132}$. Mit der Verdrängung wahrheitsfähiger Beweismittel büßte das Gericht seine Eigenständigkeit ein und diente mehr dem sozialen Konsens als der Zuteilung von Recht und Unrecht ${ }^{133}$.

Dieser Prozess der Entdifferenzierung hat das Frankenreich und die anderen Reiche des Frühmittelalters in unterschiedlicher Weise und Intensität erfasst. Die Kirche war lange Zeit ein Refugium des römischen Rechts, bis in der Karolingerzeit die spezifisch fränkischen Beweismittel wie das Gottesurteil und der Reinigungseid auch in das kanonische Prozessrecht Eingang fanden ${ }^{134}$. Im Süden Europas überdauerte die Schriftlichkeit des Gerichtsverfahrens länger und wurde teilweise nie ganz aus der Praxis verdrängt ${ }^{135}$. Dieser ,rechtliche Pluralismus ${ }^{136}$ hatte eine Instabilität des Normengefüges zur Folge, die im gesamten frühen Mittelalter fortdauern sollte. Auch das Inzestverbot war von dieser Pluralisierung erfasst, da der Verwandtschaftsbegriff des römischen Rechts

130 Luhmann, Ausdifferenzierung 1981; DERs., Recht 1993, 239-296. Luhmanns Terminologie ist in der rechtshistorischen Forschung auf große Akzeptanz gestoßen und wird auch in der folgenden Untersuchung herangezogen. DiLCHER, Rechtsgewohnheit 1992, 39, spricht vom Frühmittelalter als einer Zeit „ohne klare Ausdifferenzierung“. Der Begriff der Entdifferenzierung (dedifferentiation) wird in der Soziologie zur Beschreibung fundamentalistischer Bewegungen verwendet. Vgl. Tiryakian, Significance 1985; LECHNER, Fundamentalism 1990.

131 Jürgen Weitzel, Art. „Gerichtsverfahren“, in: RGA 11 (1998) 153-171; DeRs., Versuch 1997.

132 EsDers, Reinigungseid 2007.

133 Davies - Fouracre (Hg.), Settlement 1986; Geary, Means 1995; Althoff, Spielregeln 1997.

134 Leitmaier, Kirche 1953; Nottarp, Gottesurteilstudien 1956, 213-246; Jaсов, Parole 1999; Kerner, Reinigungseid 1977/1978; Schmitz, Memorandum 2004, 7-16.

135 Für Italien vgl. Bougard, Justice 1995; Everett, Literacy 2003. Für Südfrankreich vgl. Kienast, Studien 1968, 151-170; Esders, Rechtstradition 1997, 268-286.

136 Esders, Rechtsdenken 1993, 123; Guillot, Justice 1995, 685. Zum Konzept des Rechtspluralismus vgl. Pospíśst, Anthropology 1971, 97-126; Lampe (Hg.), Rechtspluralismus 1995. 
in unterschiedlicher Weise den Untergang des römischen Reichs überdauerte und erst im 11. Jahrhundert durch die Gesetzgebung der Päpste endgültig überwunden wurde.

Ein Aspekt dieser Entdifferenzierung, der im Rahmen dieser Untersuchung besonders interessiert, ist die Symbiose von Recht und Religion. Nach der Konstantinischen Wende wirkte das Christentum zunächst durch Zumutungen wie das Kirchenasyl irritierend auf das System des römischen Rechts ${ }^{137}$. Im 4. Jahrhundert entstand die Gewohnheit, verdächtigten Personen und sogar verurteilten Verbrechern in der Kirche Schutz vor staatlicher Verfolgung zu gewähren. Diese Gewohnheit führte zu einer empfindlichen Irritation des Rechtssystems, da die Zuteilung von Recht/Unrecht aufgehoben und stattdessen das Vergeben von Schuld eingefordert wurde. Die Kirche behinderte den normalen Verfahrensweg und ersetzte das gerichtliche Urteil durch eine formlose Schlichtung. Eine solche neuartige normative Erwartung konnte das Rechtssystem entweder ignorieren, oder es konnte die eigenen Strukturen daran anpassen. Die erste Option ergriff Kaiser Arcadius, indem er das Kirchenasyl per Gesetz untersagte. Dieser Versuch scheiterte. Wenige Jahre später wurde das Kirchenasyl von Theodosius II. gesetzlich anerkannt und bestimmten Einschränkungen unterworfen. Insbesondere die Eigentumsordnung - das Eintreiben von Schulden und die Ergreifung flüchtiger Sklaven - sollte nicht beeinträchtigt werden. Die Reichweite des Asyls wurde daher auf das Strafrecht beschränkt. In dieser Weise konnte es für den Kaiser eine neue Funktion erfüllen: die Überwachung der Provinzstatthalter durch die kirchliche Hierarchie. Diese Überwachung war gerade vor dem Hintergrund der zunehmenden Brutalität des Strafrechts und der fehlenden Rechtsbindung der Statthalter dringend geboten. In den Begriffen von Luhmanns Evolutionstheorie führte die Irritation also zur Selektion und schließlich zur Restabilisierung des Rechtssystems.

Diese stabilisierende Wirkung des Christentums nahm im Verlauf des Zusammenbruchs des Imperiums im Westen zu. Als Leiter einer hierarchischen Organisation mit weit verstreutem Grundbesitz waren die Bischöfe auf die Kontinuität der Errungenschaften des römischen Rechts angewiesen und konnten sich ohne die Geltung eines rudimentären öffentlichen Rechts nicht behaupten. Fundamental waren die Unterscheidungen zwischen Amt und Person sowie zwischen Eigentum und Besitz. Nur wenn die Kleriker ihr Amt nicht als vererbbar und das Kirchengut nicht als Eigentum ansahen, war die Reproduktion der Bischofskirche gesichert. Die Fortdauer des Rechts konnten jedoch die Bischöfe allein nicht gewährleisten, da ihnen das Mittel physischer Gewalt fehlte bzw. nur in eingeschränktem Ausmaß zur Verfügung stand. Sie waren daher auf die Entwicklung neuer Mechanismen der Stabilisierung des Rechts

137 Vgl. Langenfeld, Christianisierungspolitik 1977; Siems, Entwicklung 1991; Ducloux, Naissance 1994; Dreher, Ursprünge 2006. 
angewiesen. Hierzu zählt an erster Stelle die Exkommunikation. Mit ihrer Hilfe wurde der Umfang der Gemeinschaft definiert und Verstöße jedweder Art generalisierend mit Ausschluss bestraft. Im 7. Jahrhundert breitete sich von Irland die Tarifbuße aus, die den Ausschluss zeitlich begrenzte und damit auch für mindere Vergehen handhabbar machte ${ }^{138}$. Diese Mechanismen wurden durch Karl den Großen verschärft, indem er den Bischöfen den Auftrag erteilte, von sich aus nach Übeltätern zu suchen und Bußen zu verhängen. Daraus entstand die bischöfliche Sendgerichtsbarkeit, die im Ostfrankenreich der Zeit um 900 feste institutionelle Formen annahm ${ }^{139}$. In Frankreich schufen die Bischöfe im 10. Jahrhundert einen neuen Mechanismus, um bestimmte Zeiten, Orte und Personen zu sakralisieren und so den Niedergang öffentlicher Ordnung zu begrenzen: die Gottesfriedensbewegung ${ }^{140}$.

Exkommunikation, Tarifbuße, Sendgericht, Gottesfrieden: Mit diesen Mechanismen versuchten die Bischöfe, in einem eng umgrenzten Bereich öffentliche Ordnung zu garantieren und die Durchsetzung des Rechts zu gewährleisten. Physischen Zwang ersetzten sie durch die Androhung des jenseitigen Strafgerichts.

Die geringe Intensität staatlicher Herrschaft im Frühmittelalter führte nicht nur zu einer Entdifferenzierung des Rechts und zu einer Symbiose von Recht und Religion, sondern auch zu einer gesteigerten Bedeutung von Ehe und Verwandtschaft. Gesellschaftliche Integration wurde in dieser Epoche weniger durch obrigkeitliche Herrschaft als durch die Solidarität der Familie, durch genossenschaftliche Einungen wie Gilden und Bruderschaften und durch die wechselseitige Verpflichtung von Bündnissen und Klientelverbindungen gewährleistet ${ }^{141}$. Eine fundamentale Form des Bündnisses war in dieser Zeit die Eheschließung zwischen adeligen Familien. Sie wurde durch die Inzestverbote einem differenzierten Regelwerk unterworfen. Eine Geschichte der Inzestgesetzgebung darf diese Tatsache nicht außer Acht lassen. Der rein religionsgeschichtliche Ansatz, wie er von Mitterauer befürwortet wird, kann meines Erachtens daher nur einen beschränkten Einblick in die Voraussetzungen der Entwicklung des Inzestverbots gewähren. Der Zusammenhang von Sozialstruktur und "Struktur der Verwandtschaft“ ist ein zentrales Ergebnis des ethnologischen Klassikers von Claude Lévi-Strauss. Dieser Zusammenhang kann zwar in der frühmittelalterlichen Gesellschaft nicht so eng gefasst werden wie in

138 Vgl. Vogel, Pécheur 1982; Frantzen, Literature 1983, 19-60; Jong, Transformations 2000.

139 Siehe 368-373.

140 Vgl. u.a. Hoffmann, Gottesfriede 1964; Head - Landes (Hg.), Peace 1992; Goetz, Gottesfrieden 2002, 37-39.

141 Althoff, Amicitiae 1992; Ders., Verwandte 1990; Oexle, Conjuratio 1985; Ders., Friede 1996; Epp, Amicitia 1999; Sмiтh, Europe 2005, 83-114. 
den von Lévi-Strauss untersuchten „elementaren Strukturen“ archaischer Völker. Das Frühmittelalter kannte nämlich nur Eheverbote und keine Ehegebote und hatte daher in der Terminologie Lévi-Strauss" eine „komplexe Struktur“ der Verwandtschaft. Trotzdem übten die Inzestverbote zweifellos einen maßgeblichen Einfluss auf die Formation von Familie und Verwandtschaft aus. Als wichtige methodische Folgerung möchte ich daher in der folgenden Untersuchung stets auch die Beziehung zur Sozialstruktur im Blick behalten.

Eine weitere methodische Folgerung ist aus der Tatsache der Entdifferenzierung zu ziehen. Es ist nämlich unter diesen gesellschaftlichen Rahmenbedingungen weder sinnvoll, eine Normengeschichte im traditionellen Sinn zu schreiben, noch den rechtssoziologischen Ansatz Niklas Luhmanns zu übertragen, wie es auf eindrucksvolle Weise Marie Theres Fögen für die Zeit der Antike vorgemacht hat ${ }^{142}$. Die Anwendung einer Theorie in der Art von Luhmanns Systemtheorie, die am Beispiel der modernen Gesellschaft erarbeitet wurde, erscheint mir nicht zielführend für eine Zeit, in der es nicht einmal in Ansätzen ein ausdifferenziertes Rechtssystem gab. Eine traditionelle Normengeschichte, wie sie teilweise immer noch gepflegt wird, scheitert an der falschen Annahme, der Sinn einer Vorschrift im Frühmittelalter wäre eo ipso gewesen, eine Norm zu statuieren, Recht zu setzen oder zu verändern und damit auf das Verhalten der Betroffenen einzuwirken. Die einzelne Vorschrift, sei sie weltlicher oder kirchlicher Herkunft, kann nicht unreflektiert in Bezug zu anderen Vorschriften gesetzt werden, sondern muss in erster Linie im Kontext ihrer Entstehung interpretiert werden. Der Sinn einer Norm könnte ebenfalls darin bestanden haben, eine programmatische Absichtserklärung zu verkünden, ein politisches Argument einzubringen oder der Profilierung eines christlichen Herrschers zu dienen ${ }^{143}$. In der heutigen Rechtstheorie bezeichnet man solche Normen als „symbolische Gesetzgebung “144. Sie zielt weniger auf die Veränderung des Verhaltens als vielmehr auf die Identifikation mit der politischen Herrschaft ab. Vorschriften gegen Diskriminierung oder Anti-Terror-Gesetze sind klassische Beispiele für Normen, die in erster Linie Zustimmung und Identifikation bei den Adressaten der Gesetzgebung hervorrufen sollen. Im Rahmen des Kirchenrechts sind Gesetze mit symbolischer Wirkung besonders häufig anzutreffen. Daneben wurden auch solche Vorschriften als Normen akzeptiert, die die Meinung eines Einzelnen zum Ausdruck bringen, z. B. die eines Augustinus, eines Isidor von Sevilla oder eines anonymen fränkischen Bischofs. Jede einzelne

142 Fögen, Rechtsgeschichten 2002; DiEs., Rechtsgeschichte 2002. Zur Diskussion vgl. auch Esders, Rechtsdenken 1993; Thier, Systemtheorie 2000; Arlinghaus, Rituale 2004.

143 Wormald, Lex 1977; Vollrath, Landfrieden 1997, 616.

144 Vgl. Fögen, Gesetz 1987 mit Verweis auf Noll, Gesetzgebung 1981. Zuletzt Voss, Gesetzgebung 1989; SIEHR, Objektivität 2005. 
Vorschrift muss daher zunächst auf die Quellenüberlieferung, auf die literarische Gattung und auf das Motiv des Autors geprüft werden, bevor man sie in den Zusammenhang einer rechtsgeschichtlichen Entwicklung einordnen kann. Daraus ergibt sich, dass die folgende Darstellung historisch-chronologisch voranschreitet und keine systematische Gliederung befolgt. Für das Frühmittelalter ist nur eine kontextualisierte Rechtsgeschichte vor dem Gesamthintergrund der Gesellschaft erfolgversprechend. So kann verhindert werden, dass Rechtsquellen in ihrer Bedeutung überschätzt und in eine konstruierte ,logische Entwicklung eingepasst werden.

Besonderes Augenmerk einer kontextualisierten Rechtsgeschichte muss auf die handschriftliche Überlieferung gelegt werden. Im Rahmen der vorwiegend oralen Rechtskultur des frühen Mittelalters besaßen Normen eine „relative

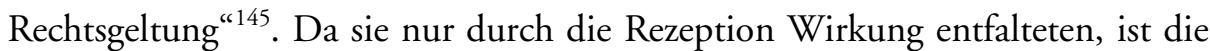
Überlieferung ein wichtiges Indiz für ihre Akzeptanz und Verbreitung. Zwei Beispiele können dies veranschaulichen. Der Libellus responsionum Gregors des Großen und das römische Konzil von 721 sind in über 200 Handschriften ${ }^{146}$ verbreitet und konnten eine ganz andere Wirkung entfalten als das in einer singulären Handschrift bezeugte „programmatische“ Kapitular Karls des Großen aus dem Jahr $802^{147}$. Dagegen ist jedoch zu berücksichtigen, dass Karl die Inzestvorschrift seines Kapitulars auf einer Reichsversammlung zahlreichen weltlichen und geistlichen Amtsträgern verkündete, während der Nachweis der Kenntnis von kirchlich überlieferten Inzestverboten durch Laien erst erbracht werden muss. Das Faktum der Anzahl von Handschriften ist daher nicht allein ausschlaggebend. Das Beispiel der Überlieferung der Lex Salica führt diese Tatsache unter einem anderen Aspekt deutlich vor Augen. Die beeindruckende Vervielfältigung in über 80 Handschriften suggeriert eine breite Akzeptanz des Gesetzbuchs in der Karolingerzeit. Donald Jackman begreift daher die Inzestregelung der Lex Salica als geltendes "Gewohnheitsrecht" des Adels im 9. und 10. Jahrhundert ${ }^{148}$. Die Überlieferung reicht jedoch als Argument für die Effektivität der Lex Salica nicht aus. Zum einen gibt es in den doch recht zahlreichen Diskussionen um das Inzestverbot keinen Hinweis darauf, dass die Bestimmung der Lex Salica als gültig erachtet oder überhaupt jemals mit ihr argumentiert wurde. Zum anderen verdanken wir Hermann Nehlsen den Nachweis, dass einige der über 300 Jahre alten Gesetze in der Überlieferung in

145 Weitzel, Recht 2002.

146 Zum Libellus vgl. Meyvaert, Libellus 1986, 543. Das Konzil von Rom (721) ist in allen wichtigen Kirchenrechtssammlungen vertreten (u.a. Collectio vetus Gallica (Anhang), Collectio Dionysio-Hadriana, Collectio Dacheriana, Pseudoisidor, Regino von Prüm, Burchard von Worms).

147 Mordek, Bibliotheca 1995, 474.

148 JaCKMan, Eherecht 1995, 192; DERs., Konrad 2006, 79. 
einer Weise verstümmelt und durch Kopierfehler verunstaltet wurden, dass ihre Anwendung ausgeschlossen war ${ }^{149}$. Den Grund für das häufige Abschreiben der Lex Salica sieht Nehlsen daher in ihrer symbolischen Bedeutung als identitätsstiftendes Gesetzbuch des fränkischen Volkes. Nicht nur die Anzahl und der Gebrauch der Handschriften, auch das Motiv der Vervielfältigung muss also berücksichtigt werden.

Die Kontextualisierung der Rechtsgeschichte erfordert neben der Beachtung der handschriftlichen Überlieferung auch den Vergleich mit der Praxis der Eheschließung. Gerade im Frühmittelalter stellt diese Anforderung den Historiker jedoch vor beinahe unüberwindbare Schwierigkeiten. Die Verwandtschaft zwischen Personen ist aufgrund der Einnamigkeit nur selten mit Sicherheit nachzuweisen. Oft stehen sich in Einzelfragen die Standpunkte der Genealogen unversöhnlich gegenüber ${ }^{150}$. Allein im Umfeld der Königsdynastien lassen sich gesicherte Aussagen über Verwandtschaftsverhältnisse von Eheleuten treffen. Die Mehrheit der Beispiele aus dem 9.-11. Jahrhundert ist aus der Aufstellung der Nachkommen Karls des Großen und Heinrichs I. gewonnen. Die Herrscher und Fürsten waren jedoch durch das Ideal des christlichen Königtums dem Eherecht der Kirche in einer besonderen Weise verpflichtet. Ein Korrektiv für diesen beschränkten Blick auf die Realität bieten nur die Eheprozesse selbst, sofern darin die Verwandtschaft der Eheleute im Detail festgehalten wurde. Sie könnten einen brauchbaren Leitfaden für die Umsetzung der Inzestverbote in der Praxis bereitstellen, wenn sie zum einen besonders zahlreich überliefert wären und wenn zum anderen ihre Repräsentativität sichergestellt wäre. Beides ist nicht der Fall. Im frühen Mittelalter verfügen wir nur über ein sehr beschränktes Dossier von Inzestfällen. Für die zahlreichen Beispiele des 11 . Jahrhunderts muss die Repräsentativität erst eigens nachgewiesen werden, da einige Historiker sie bestreiten und den Eheprozessen eine politische Manipulation unterstellen. Erst eine dritte Art von Beispielen kann mehr Gewissheit verschaffen: nämlich solche Beispiele, in denen die Normen selbst Gegenstand der Argumentation und des Missbrauchs von Seiten der betroffenen Laien wurden. Ein solcher strategischer Umgang mit den Normen ist nur dann möglich, wenn deren prinzipielle Akzeptanz außer Frage steht. König Philipp II. war nur deshalb in der Lage, das Inzestverbot als Grund zur Scheidung von Ingeborg zu missbrauchen, weil er mit der Wahl einer dänischen Ehefrau hinlänglich sein Bemühen unter Beweis gestellt hatte, die in der Öffentlichkeit

149 Nehlsen, Aktualität 1977. Vgl. auch Wormald, Lex 1977; Ders., Making 1 1999, 33 70. Eine abweichende Meinung vertritt MCКіттеRick, Carolingians 1989, 23-75.

150 Das beste Beispiel hierfür ist die Genealogie der Konradiner, siehe 392 Anm. 37. Eine souveräne Einführung in die Probleme der frühmittelalterlichen Adelsforschung gibt Reuter, Nobility 1997, 184-189. Vgl. auch zuletzt Hechberger, Adel 2005, mit erschöpfender Literaturübersicht. 
bekannte Verwandtschaft des französischen Königshauses bei der Partnersuche zu umgehen. 


\section{Die Aneignung einer Tradition im 4. Jahrhundert}

In Jack Goodys Rekonstruktion der europäischen Familiengeschichte ist die christliche Kirche für die Ausweitung des Inzestverbots verantwortlich ${ }^{1}$. Im 4. Jahrhundert habe die Kirche die Ehe mit der Cousine untersagt und entsprechende Gesetze der römischen Kaiser erwirkt. Damit sei der grundbesitzenden Schicht ein wichtiges Instrument entrissen worden, durch Eheschließungen in der zweiten Generation einer Zersplitterung des Eigentums vorzubeugen. Die althistorische Forschung hat dieser These heftig widersprochen ${ }^{2}$. Die Kritiker wiesen darauf hin, dass bereits in der frühen Republik die Ehe mit der Cousine ersten und zweiten Grades untersagt gewesen sei. Erst später, unter dem Einfluss der Mittelmeerwelt und unter dem Druck der Anpassung an das lokale Gewohnheitsrecht des Orients, sei diese streng exogame Praxis immer weiter aufgeweicht worden. In der Praxis seien aber Ehen zwischen Cousin und Cousine weiterhin kaum geschlossen worden. Die Verschärfung des 4.-6. Jahrhunderts ließe sich demnach eher als Rückkehr zu den alten römischen Sitten interpretieren. Die Römer hätten sich nämlich stets als exogames Volk gesehen. Die Vorstellung eines fundamentalen Unterschieds im Heiratsverhalten habe zu den wesentlichen Bestandteilen des ethnographischen Diskurses der Antike gezählt. Vor allem das Volk der Perser sei als Gegensatz zur exogamen Praxis der Römer angesehen worden. Die Eigenständigkeit des Westens habe daher ihre Wurzeln in der frühen Geschichte Roms und nicht in der Christianisierung des Staates im 4. Jahrhundert.

Diese Debatte zeigt, wie wichtig es ist, sich über die römischen Grundlagen der Inzestgesetzgebung Klarheit zu verschaffen. Nur vor diesem Hintergrund wird es möglich sein, den spezifischen Beitrag des Christentums zu erkennen. Ein grundlegendes Problem dabei ist, dass kaum gesicherte Aussagen über das konkrete Heiratsverhalten in der römischen Gesellschaft möglich sind ${ }^{3}$. Abgesehen von den reichen Quellenbeständen für Ägypten ${ }^{4}$ gibt es kaum aussagekräftige Dokumente zur Ehepraxis. Man muss sich daher weitgehend auf die Rechtsquellen verlassen sowie auf die historiographischen Nachrichten zu Ge-

1 Siehe $5-8$.

2 Saller - Shaw, Marriage 1984; Saller, History 1991; Martin, Anthropologie 1993; Thraede, Blutschande 2002, $66 \mathrm{f}$.

3 Die umfangreichste Materialsammlung bietet Moreau, Inceste 2002. Die Rechtsquellen behandelt Puliatti, Regime 2001.

4 Thierfelder, Geschwisterehe 1960; Hopkins, Marriage 1980; Shaw, Marriage 1991; Hopkins, Mariage 1994. 
setzesänderungen. Wie jedoch zu Recht festgestellt wird, sind Änderungen im Recht nicht mit Änderungen in der Praxis gleichzusetzen 5 . Der Wirkungsgrad insbesondere der spätantiken Kaisergesetzgebung wird in der jüngsten Forschung überaus kontrovers diskutiert ${ }^{6}$. Darüber hinaus wurden viele Gesetze der Spätantike nur für bestimmte Provinzen erlassen und entstanden als Antwort auf konkrete Zustände in diesen Regionen ${ }^{7}$. Erst durch ihre Aufnahme in eine Kodifikation wie den Codex Theodosianus oder den Codex Iustinianus entfalteten sie eine Wirkung im gesamten Reichsgebiet. Da die Gesetze in der Kodifikation Theodosius' II. keiner kritischen Auswahl unterzogen wurden, ist jedoch keineswegs gesichert, dass der Inhalt der Gesetze auf tatsächliche Probleme im gesamten Reich eine Antwort geben wollte und dort auch rezipiert wurde ${ }^{8}$.

Diese ambivalente Natur der Rechtsquellen muss bedacht werden, wenn im Folgenden ein Überblick über die römische Tradition der Inzestgesetzgebung bis zur Spätantike gegeben wird. Als roter Faden dieses Überblicks soll die Frage nach dem christlichen Einfluss dienen. Nachdem die christliche Kirche in den ersten drei Jahrhunderten dem Thema des Inzestverbots keine Aufmerksamkeit geschenkt hatte, etablierte sich im 4. Jahrhundert eine christliche Tradition der Inzestgesetzgebung. Wie ist es zur Aneignung des Inzestthemas durch die christliche Kirche gekommen und welche Konsequenzen hatte dies für die Geschichte der Inzestgesetzgebung? Zur Beantwortung dieser Frage werde ich zuerst ausschließlich die Quellen zur heidnischen Antike und im zweiten Teil die Quellen aus der christlichen Spätantike in Betracht ziehen. Diese Trennung unterscheidet sich von der Herangehensweise Philippe Moreaus, der vor kurzem eine ebenso ausführliche wie niveauvolle Untersuchung der antiken Inzestvorstellungen vorlegte'. Sein Fazit lautet, dass der Wechsel zum Christentum keine deutlichen Spuren in der Geschichte der Inzestvorstellungen hinterlassen hat. Die von mir vollzogene Trennung der Quellen nach dem Glaubensbekenntnis soll nicht das Urteil im Sinne des christlichen Einflusses präjudizieren. Die Ergebnisse Moreaus haben in vielen Punkten zu einer neuen Sicht auf die Wandlungen des Eherechts beigetragen. Trotzdem werde ich an der These festhalten, dass das Christentum einen Wandel bewirkt hat. Dieser Wandel lässt sich nur bei einer Trennung der Quellenbestände deutlich herausarbeiten.

5 SALLER, History 1991, 342; Nathan, Family 2000, 12.

6 Die Ineffektivität betonen MacMullen, Curruption 1988, 87-135; Demandt, Spätantike 2007, 255. Dagegen Corcoran, Empire 1996, 245-253; Honoré, Law 1998, 25; Harries, Law 1999, 77-98.

7 Honoré, Code 1986, 177; Harries, Law 1999, $24 \mathrm{f}$.

8 Matthews, Law 2000.

9 Moreau, Inceste 2002. 


\subsection{Römische Inzestverbote}

Es erscheint wenig angemessen, ein Buch zum Inzestverbot im christlichen Zeitalter mit einer Untersuchung der Quellen zur frühen römischen Republik zu beginnen. Diese Quellen sind jedoch aus einem Grund von entscheidender Bedeutung. In der althistorischen Forschung herrscht nämlich die Auffassung vor, man sei am Ende der Spätantike zur selben Ausdehnung des Inzestverbots gelangt, wie sie bereits in der frühen Republik Geltung besessen habe ${ }^{10}$. Im 6. Jahrhundert n.Chr. war sich die gallische und spanische Kirche darin einig, dass das Inzestverbot alle Verwandten nach römischem Recht betrifft und daher bis zum 6. Grad, d.h. bis zur Cousine zweiten Grades, Geltung beansprucht. Dieselbe Ausdehnung hatte nach einigen Quellen bereits das Verbot von Verwandtenehen in der frühen Republik. Dies legt die Ansicht nahe, das römische Recht habe zunächst eine schrittweise Auflockerung des Inzestverbots erfahren und sei später, im christlichen Zeitalter, wieder zur Strenge der alten republikanischen Sitten zurückgekehrt. Diese Ansicht halte ich aus verschiedenen Gründen für verfehlt, insbesondere ist sie zur Erklärung des Wandels in der Spätantike nicht geeignet.

\section{Ungewisse Ursprünge}

Der Kern der Geschichte des Inzestverbots im Zeitalter der Republik ist unbestritten. Irgendwann in den Jahren zwischen 241 und 219 v. Chr. fand die erste Heirat innerhalb des sechsten Grades statt. Ein Patrizier mit dem Namen Publius Cloelius heiratete eine Frau aus seiner Verwandtschaft und kränkte dadurch den Plebejer Marcus Rutilius, der mit dieser Frau verlobt gewesen war. M. Rutilius denunzierte die Ehe als neuartig und provozierte einen Volksaufstand, „so dass die erschrockenen Patrizier auf das Kapitol flüchteten “11. Wenig später muss auch das Verbot der Cousinenehe gefallen sein. Denn bereits im Jahr 171 v. Chr. berichtete nach Livius der Centurio und Volkstribun Spurius Ligustinus in einer Rede an das Volk von seiner Lebensgeschichte und erwähnt beiläufig die Ehe mit seiner Cousine ${ }^{12}$. Diese Ehe war vor etlichen Jahren geschlossen worden, da der stolze Familienvater seine sechs Söhne und zwei Töchter nicht unerwähnt lässt, die bereits zum Teil selbst verheiratet waren. Um 200 v. Chr. war daher eine Cousinenehe nichts Außergewöhnliches. Bis zum Ende der Republik ist eine Reihe von solchen Eheschließungen in der Führungsschicht dokumentiert. Scipio Aemilianus heiratete seine Cousine Sempronia, Marcus Antonius seine Cousine Antonia, Brutus seine Cousine Porcia

10 Weiss, Endogamie 1908, 340; Evans-Grubbs, Law 1995, 338; Moreau, Inceste 2002, 409; Thraede, Blutschande 2002, 82.

11 Siehe 38 Anm. 17.

12 Livius 42, 34 (97 f.). 
und M. Aemilius Lepidus seine Cousine Servilia ${ }^{13}$. Dass solche Ehen auch unterhalb der hohen römischen Aristokratie geschlossen wurden, zeigt ein von Cicero genanntes Beispiel aus dem Municipium Larinum. Da er der Ehe eine plena dignitas zuschreibt ${ }^{14}$, kann kein Zweifel über die Selbstverständlichkeit solcher Verbindungen bestehen. Einen Schritt weiter ging Kaiser Claudius. Um seine Nichte Agrippina zu heiraten, ließ er im Jahr 49 durch den Senat ein Gesetz verabschieden, das die Ehe mit der Tochter des Bruders vom Inzestverbot ausnahm ${ }^{15}$. Diese Grenze des Inzestverbots blieb bis zur Christianisierung des römischen Staates im 4. Jahrhundert erhalten.

So unbestritten diese Entwicklung einer allmählichen Lockerung des Inzestverbots ist, so angreifbar sind die einzelnen Zeugnisse dafür. Vor allem die Tatsache eines ursprünglichen Verbots der Ehe mit der Cousine zweiten Grades ist nur durch zwei problematische Quellen abgesichert. Erstens beruht die Annahme eines solchen Verbots auf einem Exzerpt aus Livius, das in einer kirchenrechtlichen Sammelhandschrift des 12. Jahrhunderts überliefert ist $^{16}$. Dieses Exzerpt berichtet von der oben genannten Heirat des P. Cloelius und ordnet diese Anekdote dem ansonsten verlorenen 20. Buch des Geschichtswerkes $\mathrm{zu}^{17}$. Der Vorfall müsste sich demnach in der Epoche zwischen 241 und 219 ereignet haben. Dagegen spricht jedoch der anachronistische Konflikt zwischen Patriziern und Plebejern mit der Flucht auf das Kapitol, der bereits die Verwunderung Mommsens ausgelöst hat ${ }^{18}$. Man könnte das Exzerpt durch die Annahme retten, Livius berichte in Buch 20 von einer Episode aus früheren Zeiten, wie es für die Arbeit des Historikers nicht untypisch ist ${ }^{19}$. Andere Zweifel sind jedoch schwieriger zu beseitigen. So müssen auch die Befürworter der Echtheit des Exzerpts anerkennen, dass die Begrifflichkeit in jeder Hinsicht nicht zum Vokabular des römischen Historikers passt, sondern vielmehr auf eine Entstehung im frühen oder hohen Mittelalter hindeutet ${ }^{20}$. Gerade in dieser Zeit ist der im Exzerpt genannte siebte Grad als Inzestgrenze von der Kirche geltend

13 Vgl. die Belege bei Moreau, Inceste 2002, 190.

14 Cicero, Pro Cluentio 12, 1 (57).

15 Tacitus, Annales 12, 7, 2 (239); Sueton, Claudius 26, 7 (210).

16 Entdeckt wurde das Fragment in Paris, Bibliothèque Nationale, Lat. 3858C von Paul Krüger, vgl. Mommsen - Krüger, Anecdoton 1870. Zur Handschrift vgl. Corcoran, Constitution 2000; Fowler-Magerl, Clavis 2005, 108 u. 128.

17 Livius libro vicesimo. P. Celius patricius primus adversus veterem morem intra septimum cognationis gradum duxit uxorem. Ob hoc M. Rutilius plebeius sponsam sibi praeripi novo exemplo nuptiarum dicens sedicionem populi concitavit adeo ut patres territi in Capitolium perfugerent. Mommsen - KRÜGER, Anecdoton 1870, 163. Die Literatur ist umfangreich: Schminck, Livius 1982; Hanard, Inceste 1986; Bettini, Familie 1992, 240 f.; MoREAU, Inceste 2002, 181-186.

18 Mommsen - Krüger, Anecdoton 1870, 167.

19 Bettini, Familie 1992, 165.

20 Argumente bei Schminck, Livius 1982, 152; Moreau, Inceste 2002, $183 \mathrm{f}$. 
gemacht worden. Diese Nennung des siebten Grades ist besonders verdächtig, weil die zweite Quelle den sechsten Grad als Grenze des Inzestverbots nennt. Andreas Schminck hat daher die Vermutung geäußert, ein mittelalterlicher Fälscher habe das Exzerpt aus bekannten Versatzstücken zusammengesetzt, um die Universalität des kirchlichen Inzestverbots zu untermauern ${ }^{21}$. Diese Vermutung muss Spekulation bleiben, da die überliefernde Handschrift bislang keine Reputation als Reservoir von Fälschungen erworben hat. Es genügt jedoch der durchaus angebrachte Verdacht, die Nennung des siebten Grades sei hinzugesetzt worden, um das gesamte Exzerpt für die Erforschung des römischen Inzestverbots unbrauchbar zu machen.

Die zweite Quelle für das ursprüngliche Verbot des sechsten Grades ist eine von Tacitus geschilderte Rede des Lucius Vitellius vor dem Senat. Vitellius rechtfertigt darin die Ehe des Kaisers mit seiner Nichte Agrippina gegen den Vorwurf der Neuheit:

„Aber eine Ehe mit der Tochter eines Bruders widerspricht unseren Sitten! - Nun, bei anderen Völkern ist sie durchaus gewöhnlich und durch kein Gesetz verboten. Ehen zwischen Geschwisterenkeln waren auch lange nicht üblich und haben sich doch im Lauf der Zeit eingebürgert. Die Sitte passt sich dem Bedürfnis an. Auch diese Neuerung wird bald allgemeiner Brauch werden ${ }^{\text {“22 }}$.

Da Vitellius im Geschichtswerk als übler Schmeichler und unheilvoller Ratgeber hinter dem Kaiser diskreditiert wird, ist der Quellenwert dieser Rede umstrit$\operatorname{ten}^{23}$. Es ist nicht ausgeschlossen, dass Tacitus dem Vitellius eine Übertreibung in den Mund legt, um die Ehe mit der Nichte als logische Folgerung aus der allmählichen Lockerung der Eheverbote darzustellen. Der römische Historiker lässt das Vorgehen des Vitellius als besonders dekadent erscheinen, da er zur selben Zeit politische Gegner mit Inzestverleumdungen zum Selbstmord treibt. $\mathrm{Ob}$ man also der Rede des Vitellius trauen kann, ist fragwürdig.

Weitere Quellen für die alt-römische Inzestgrenze des sechsten Grades sind nicht bekannt. Nur indirekt wird eine solche Grenze scheinbar durch den Brauch des Verwandtschaftskusses nahe gelegt. Polybius berichtet, dass der Kuss mit Verwandten bis zur Cousine zweiten Grades, also bis zum sechsten Grad, praktiziert worden ist ${ }^{24}$. Plutarch ergänzt diese Information durch den Hinweis

21 Schminck, Livius 1982, 163. Die These Schmincks ist auf Ablehnung gestoßen bei Hanard, Inceste 1986, und Bettini, Familie 1992, $240 \mathrm{f}$.

22 At enim nova nobis in fratrum filias coniugia: sed aliis gentibus sollemnia, neque lege ulla prohibita; et sobrinarum diu ignorata tempore addito percrebuisse. morem accommodari prout conducat, et fore hoc quoque in iis quae mox usurpentur. Tacitus, Annales 12, 6, 3 (238 f.).

23 Gegen die Glaubwürdigkeit argumentieren Saller - Shaw, Marriage 1984, 434, und Thraede, Blutschande 2002, 57.

24 Polybius, Historiae 6, 11a, 4 (2, 253). 
auf die Verbindung mit dem Inzestverbot ${ }^{25}$. Der Kuss statuiert ihm zufolge die Grenze der Zuneigung zwischen Verwandten, die nicht überschritten werden dürfe. Kombiniert man diese zwei Nachrichten, scheinen sie das Verbot der Ehe bis zum sechsten Grad zu belegen ${ }^{26}$. Skeptisch macht jedoch die Tatsache, dass auch die Verwandtschaft des Mannes einer Ehefrau, also die Schwiegerverwandtschaft, mit diesem Kuss begrüßt werden sollte ${ }^{27}$. Für diese Verwandten bestand jedoch kein Eheverbot. Darüber hinaus erwähnt Polybius das Inzestverbot gar nicht, und Plutarch berichtet nur davon, dass die Ehe mit der Cousine ersten Grades erlaubt worden ist, als ein verarmter Adeliger seine vermögende Cousine heiraten wollte und durch die Intervention des römischen Volks vor Gericht dazu ermächtigt worden ist ${ }^{28}$. Weder Plutarch noch Polybius wussten von einem Inzestverbot bis zur Cousine zweiten Grades. Ein solches Verbot ergibt sich nur scheinbar aus der Kombination der beiden Quellen.

Die Belege für die Inzestgrenze des sechsten Grades sind daher alles andere als eindeutig. Prinzipiell erscheint die Annahme wenig plausibel, im 3. Jahrhundert v.Chr. habe innerhalb einer Generation eine dramatische Lockerung des Inzestverbots stattgefunden, ohne dass sich für einen solchen Umbruch in der Verwandtschaftsstruktur andere Belege anführen lassen. Die herrschende Meinung setzt bis ca. 241 ein Verbot der Ehe zwischen Geschwisterenkeln voraus und nimmt an, bereits um 200 sei die Ehe mit dem Geschwisterkind als Selbstverständlichkeit angesehen worden. Diese Rekonstruktion ist nicht überzeugend. Die historisch klar fassbare Zeit von ca. 200 v. Chr. bis zur Christianisierung im 4. Jahrhundert ist demgegenüber von größter Kontinuität geprägt. Mit Ausnahme der Lockerung durch Kaiser Claudius, die im Übrigen kaum Nachahmung gefunden hat ${ }^{29}$, gibt es keine Rechtsänderung. Wenn man hinzunimmt, dass bereits die legendären Aufzeichnungen über die Anfänge Roms Ehen zwischen Cousin und Cousine erwähnen, zeigt dies erneut die Selbstverständlichkeit solcher Eheschließungen in der römischen Geschichtsschreibung $^{30}$. Eine allmähliche Lockerung des Ehehindernisses der Verwandtschaft wird von den römischen Historikern nicht grundsätzlich angenommen. Man kann meines Erachtens die vorherrschende Meinung als plausible Rekonstruktion nur dann akzeptieren, wenn man eine längere Entwicklung annimmt als das letzte Drittel des 3. Jahrhunderts v. Chr.

25 Plutarch, Aetia Romana 6 (277 f.).

26 Moreau, Inceste 2002, 180-182.

27 Darauf macht Linke, Verwandtschaft 1995, 183, aufmerksam.

28 Plutarch, Aetia Romana 6 (277 f.).

29 Tacitus, Annales 12, 7, 2 (239); Sueton, Claudius 26, 3 (210). Vgl. auch Moreau, Inceste 2002, 198-203.

30 Diskutiert von Franciosi, Clan 1999; Bettrini, Familie 1992, 176 f.; Moreau, Inceste 2002, 172 Anm. 4. 
Ein weiteres Problem ergibt sich daraus, dass das Wissen von der Struktur der Verwandtschaft in der frühen Republik durch diese Inzestgrenze nicht wesentlich bereichert wird. Im Gegenteil, der Laie gewinnt den Eindruck, spezielle Anpassungen seien notwendig, um die Inzestgrenze des sechsten Grades sinnvoll in eine Geschichte der römischen Verwandtschaft einzufügen ${ }^{31}$. Besonders die Vereinbarkeit mit der agnatischen Struktur der Verwandtschaft steht zur Diskussion. Die Stellung des pater familias, das Erbrecht der männlichen Verwandtschaft (ab intestato) und die kultische Funktion der gens sind Belege für die Dominanz der agnatischen Verwandtschaft. Das Inzestverbot des sechsten Grades soll sich dagegen sowohl auf die cognatische als auch auf die agnatische Verwandtschaft erstreckt haben. Einige Historiker versuchen dieser Diskrepanz durch die Leugnung einer festen Struktur von Familie und Verwandtschaft Rechnung zu tragen ${ }^{32}$. Andere unternehmen den Versuch, das Inzestverbot diesen Gegebenheiten anzupassen. Nach Gennaro Franciosi umfasste das Inzestverbot bis zum 6. Grad in frührömischer Zeit nur die agnatischen Verwandten einer gens, die als exogamer Clan aufzufassen sei. Franciosi erschließt diese Hypothese aus der Form der römischen Verwandtschaftsnamen und aus der Gleichsetzung von Terminologie und Sozialstruktur ${ }^{33}$. Bernhard Linke teilt die Hypothese Franciosis und weist das Exogamiegebot der römischen gens dem 10. und 9. Jahrhundert v.Chr. zu. Erst im 3. Jahrhundert sei es zur Ausdehnung des Verbots auf die cognatische Verwandtschaft gekommen, die aber nach dem Zeugnis von Livius bald wieder außer Kraft gesetzt worden $\operatorname{sei}^{34}$. Die Komplexität dieser Rekonstruktion steht in krassem Gegensatz zu den spärlichen Quellenzeugnissen. Sie beruht weitgehend auf etymologischen Spekulationen zur indogermanischen Verwandtschaftsterminologie sowie auf starren ethnologischen Gesetzmäßigkeiten. Beides hilft bei einem Verständnis der historisch fassbaren Entwicklung der römischen Geschichte wenig weiter. Ich enthalte mich daher einer eindeutigen Beurteilung des Umfangs des Inzestverbots in der Zeit der römischen Republik. Festhalten lässt sich nur Folgendes: Das Inzestverbot des sechsten Grades hinterließ keine verwertbaren Spuren in

31 Drummond, Rome 1989, stellt die verschiedenen Modelle unverbunden nebeneinander.

32 Dixon, Family 1992, 11; Moreau, Inceste 2002, 410.

33 Franciosi, Clan 1999, 85. Vgl. auch Thomas, Mariages 1980, 358; Moreau, Prohibition 1978. In seinem neuen Buch distanziert sich Moreau vorsichtig von solchen Spekulationen: Moreau, Inceste 2002, 168. Hanard, Inceste 1986, erschließt dagegen eine ursprüngliche bevorzugte Heirat mit der matrilinearen Kreuzcousine, die dann von der Inzestgrenze des 6 . Grades abgelöst worden sei.

34 Linke, Verwandtschaft 1995, 28-31 und 181-185. Ihm folgt Smith, Clan 2006, 30 32. Franciosi und Linke machen sich den starren juridisme von Benveniste und LéviStrauss zu eigen. Die Kritik von Bourdieu, Stratégies 1972, hat in dieser Diskussion noch keine Wirkung entfaltet. 
späterer Zeit und übte keinen maßgeblichen Einfluss auf die Ausweitung des Inzestverbots in christlicher Zeit aus.

\section{Das Damaskusedikt Kaiser Diocletians}

Von ca. 200 v. Chr. bis ca. 400 n. Chr. war also die Ehe zwischen Cousin und Cousine nichts Ungewöhnliches. Wie oft solche Ehen tatsächlich geschlossen wurden, lässt sich anhand der überlieferten Quellen nur undeutlich erkennen. In der Senatsaristokratie, für die sich allein verlässliche Stammbäume rekonstruieren lassen, wurde durchaus die Möglichkeit der Erneuerung bestehender Allianzen in der zweiten oder dritten Generation genützt $\mathrm{t}^{35}$. Berühmt ist das Beispiel der Familie Kaiser Constantins, in der gleich mehrfach Cousinenehen geschlossen wurden. Dass diese Eheform auch unterhalb der römischen Führungsschicht praktiziert wurde, belegen einige Quellen zum Erbrecht in den Digesten. Dort wird an zwei Stellen mit Beispielen einer durch den Großvater arrangierten Ehe zwischen zwei Enkelkindern argumentiert ${ }^{36}$. Epigraphisches Material kann diesen Befund nicht erhärten, da Verwandtenehen nur dann vermutet werden können, wenn die Eheleute denselben Gentilnamen tragen und über die agnatische Linie verwandt sind. Ehen zwischen Kreuzcousins lassen sich auf diese Weise nicht belegen. Die niedrigen Zahlen von endogamen Ehen in der Studie von Richard Saller und Brent Shaw sind aus diesem Grund nicht aussagekräftig ${ }^{37}$. Man wird deshalb davon ausgehen können, dass die von der Rechtssprechung erlaubten Eheverbindungen unter Verwandten auch tatsächlich praktiziert wurden.

Jack Goody ist also in seiner Meinung, vor der Christianisierung des römischen Staates habe die Cousinenehe im gesamten Mittelmeerraum zu den akzeptierten Eheformen gezählt, Recht zu geben. Für die weitere Geschichte des Inzestverbots ist es jedoch von großer Bedeutung, dass die vom römischen Recht verbotenen Verwandtenehen einer drastischen Diffamierung ausgesetzt waren ${ }^{38}$. Eine grundsätzliche Aufhebung des Inzestverbots stand in Rom nicht zur Debatte, selbst die philosophischen Schriftsteller stellten die Gültigkeit dieses Prinzips nicht in Frage. Verstöße gegen das Inzestverbot wurden mit schweren Verbrechen gegen die göttliche Ordnung wie Vatermord oder Kannibalismus gleichgesetzt und hatten die Todesstrafe durch Sturz vom Tarpeischen Felsen zur

35 Belege bei Moreau, Inceste 2002, 190 f., 227-232 u. 313-317.

36 Dig. 28, 7, 23-24 (433 f.); Dig. 23, 2, 3 (330); Cod. 6, 25, 2 (258). Vgl. Thomas, Mariages 1980, 348 f.; Moreau, Inceste 2002, 191.

37 Saller - Shaw, Marriage 1984. Den Wert der Ergebnisse bestreitet Moreau, Inceste 2002, $313 \mathrm{f}$.

38 Ausführlich demonstriert von Moreau, Inceste 2002, 29-81. 
Folge $^{39}$. Wie der Jurist Gaius beglaubigt, wurden Inzestehen als nefas, als Gottlosigkeit wahrgenommen ${ }^{40}$. Ehen zwischen Geschwistern, wie sie für das ptolemäische und römische Ägypten nachweisbar sind, und Verbindungen zwischen Aszendenten und Deszendenten wie in Persien galten den Römern als verachtenswürdige Praktiken ${ }^{41}$. Verleumdungen wegen Inzest waren daher, wie das oben zitierte Beispiel von Tacitus veranschaulicht, ein beliebtes Instrument der politischen Diffamierung.

Diese Abscheu vor dem Inzest wich im Verlauf der Erweiterung des römischen Bürgerrechts einer zunehmenden Relativierung. Nachdem Caracalla im Jahr 212 den Bürgerstatus auf die gesamte Reichsbevölkerung ausgedehnt hatte, warf dies für die Juristen die Frage der Anwendbarkeit der harten römischen Bestrafung des Inzests auf ${ }^{42}$. Im Osten des römischen Reichs waren Ehen innerhalb der engen Verwandtschaft keine Seltenheit. Eine strikte Durchsetzung der römischen Gesetzgebung wäre in der Praxis auf großen Widerstand gestoßen. Die Juristen führten deshalb die Unterscheidung zwischen universalen und zivilrechtlichen Inzestfällen ein. Nur die auf Grund des ius gentium verbotene Ehe zwischen Aszendenten und Deszendenten sollte die volle Bestrafung des römischen Rechts nach sich ziehen. Alle anderen Inzestverbote des ius civilis sollten dagegen eine zivilrechtliche Bestrafung zur Folge haben.

Eine Abkehr von dieser Relativierung bedeutete das in Damaskus erlassene Edikt Kaiser Diocletians vom 1. Mai 295 $5^{43}$. Darin nimmt der Gesetzgeber keine Rücksicht auf den Unterschied zwischen verschiedenen Inzestfällen und stellt alle Ehen bis zum dritten Grad unter dieselbe Strafe (mit Ausnahme der von Claudius sanktionierten Ehe mit der Tochter des Bruders). Die Strafandrohung ist unbestimmt, kann jedoch sowohl die Todesstrafe als auch die Deportation umfassen: „Wenn aber Vergehen gegen die Würde des römischen Namens und die Heiligkeit der Gesetze nach dem festgesetzten Tag entdeckt werden, sollen sie mit angemessener Härte bestraft werden “ ${ }^{44}$. Für alle Inzestehen vor einem im

39 Moreau, Inceste 2002, 341-343. Zweifel daran äußerte Susan Treggiari in ihrer Besprechung Moreaus: Classical Review 54 (2004) 203-205.

40 Gai institutiones 1, 64 (18).

41 Chadwick, Relativity 1979, 149-151; Lee, Marriage 1988; Moreau, Inceste 2002, 87-96.

42 Weiss, Endogamie 1908, 357-359; Guarino, Studi 1943, 231; Moreau, Inceste 2002, 107-113.

43 Sowohl die exakte Datierung als auch die Urheberschaft sind umstritten. Wegen chronologischer Unstimmigkeiten hat BARNES, Empire 1982, 62, in Galerius den Urheber gesehen. Dass dieser jedoch auf Initiative Diocletians handelte, stellt auch er nicht in Abrede.

44 Si qua autem contra Romani nominis decus sanctitatemque legum post supra dictum diem deprehendentur admissa, digna severitate plectentur. Collatio legum Mosaicarum et Romanarum 6, 4, 8 (159). Zur Deutung vgl. Corcoran, Empire 1996, 250; Ders., Constitution 2000, 13; Puliatti, Regime 2001, 162. 
Gesetz angegebenen Termin tritt dagegen ein Straferlass ein. Wenn Ehen zwischen Verwandten aus Unerfahrenheit der Brautleute oder aus Unkenntnis des Rechts geschlossen worden seien, sollten die Eheleute nicht weiter belangt werden, die Kinder jedoch als unehelich angesehen werden.

Dieser Rechtsinhalt steht zu dem rhetorischen Aufwand des Damaskusedikts in einem deutlichen Missverhältnis ${ }^{45}$. In weitschweifigen Formulierungen und bildhaftem Vokabular wird der Gegensatz zwischen der moralischen Verwerflichkeit des Inzests und der sakrosankten Heiligkeit des römischen Inzestverbots in den Mittelpunkt gestellt. Zur Diffamierung des Inzests werden alle verfügbaren rhetorischen Mittel eingesetzt. Den Gipfel der negativen Charakterisierung erreicht der Gesetzgeber im folgenden Satz:

„Es ist nämlich eine Gottlosigkeit zu glauben, dass die häufigen Vergehen einiger Leute in der Vergangenheit Bestand haben, als sie sich in der promiskuen Weise der häuslichen und wilden Tiere, angetrieben von fluchwürdiger Leidenschaft und ohne jeglichen Respekt für Recht und Gesetz, zu unerlaubten Ehen hinreißen ließen “446.

Als Gegensatz dazu führt Diocletian an insgesamt sieben Stellen die spezifisch römische Tradition und Gesetzgebung ins Feld. Der Kaiser beschwört die Bewahrung der römischen Sitten als Garant für die Gewogenheit der Götter und die Stabilität des Staatswesens ${ }^{47}$.

Die Historiker sind sich einig, dass Diocletian in keinem anderen Edikt ein solch aufwendiges Bekenntnis zur römischen Tradition in Kult und Gesetz verlautbaren ließ ${ }^{48}$. Nach dem berühmten Preisedikt von 301 handelt es sich beim Edikt von Damaskus um den längsten Gesetzestext aus der Kanzlei des Tetrarchen. Die Gründe für ein derart wortreiches und ideologisch gefärbtes Edikt hat erstmals Henry Chadwick zu ergründen versucht ${ }^{49}$. Chadwick sieht darin den Versuch Diocletians, die römischen Werte im Osten des Reichs zur Geltung zu bringen und mit dieser gesteigerten moralischen Autorität seine Feldzüge gegen die Perser zu legitimieren. Als Belege für diese Behauptung zieht er zum einen den Ort der Publikation in Damaskus heran und zum anderen die Nähe dieses Edikts zu dem wenig später erfolgten Gesetz gegen die Manichäer.

45 So besonders Guarino, Studi 1943, 255.

46 Nefas enim credere est ea, quae in praeteritum a conpluribus constat esse commissa, cum pecudum ac ferarum promiscuo ritu ad inlicita conubia instinctu execrandae libidinis sine ullo respectu pudoris ac pietatis inruerint. Collatio legum Mosaicarum et Romanarum 6, 4, 2 (158).

47 Ita enim et ipsos inmortales deos Romano nomini, ut semper fuerunt, faventes atque placatos futuros esse non dubium est, si cunctos sub imperio nostro agentes piam religiosamque et quietam et castam in omnibus mere colere perspeximus vitam. Collatio legum Mosaicarum et Romanarum 6, 4, 1 (157).

48 Chadwick, Relativity 1979; Corcoran, Empire 1996, 70; Ders., Constitution 2000, $8 \mathrm{f}$; Moreau, Inceste 2002, 112.

49 Chadwick, Relativity 1979. 
Darin wird mit derselben Insistenz auf römische Werte die Strafe der Verbrennung über Anhänger des Manichäismus verhängt, den der Gesetzgeber als Häresie der Perser brandmarkt ${ }^{50}$. Genauso wie Diocletian die Römer vor der „Infizierung" durch die manichäische Häresie schützen wollte, habe er nach Chadwick auch der „Verunreinigung" durch die endogame Praxis der Perser vorbeugen wollen ${ }^{51}$. Denn die Perser waren im ethnographischen Diskurs der Römer für Eheschließungen innerhalb der engsten Verwandtschaft bekannt. In der Bezeichnung des Inzests als „barbarisch“52 sieht Chadwick eine Anspielung auf diesen Sachverhalt.

Das heidnische Kaisertum der Antike endete also mit einem Herrscher, der erstmals motu proprio ein Edikt zum Inzestverbot erlässt. Bislang war der Inzest nur beiläufig in der Ehegesetzgebung des Augustus gestreift worden und in einigen Reskripten zum Thema kaiserlicher Verfügungen geworden ${ }^{53}$. Wie die Christenverfolgung und die brutale Strafandrohung gegen die Manichäer diente Diocletian das Damaskusedikt zur Propaganda der römischen Tradition in Kult und Recht. Die Reform der Moral zählte zu seinem umfassenden Programm der Erneuerung des römischen Reichs nach der Krise des 3. Jahrhunderts. Als bedeutendste Schöpfung dieser Erneuerung gilt das tetrarchische Herrschaftssys$t^{5} \mathrm{~m}^{54}$. Kern dieses Systems war die Adoption von zur Herrschaft berufenen Caesares durch die beiden herrschenden Augusti sowie die Verheiratung der Caesares mit Töchtern der Augusti. Jedem Mitglied der so konstruierten Herrscherfamilie wurde der Beiname eines Iovius und Herculius gegeben und dadurch der Sphäre des Göttlichen angenähert. Der Iovius Diocletian nahm somit gegenüber seinem Mitherrscher Galerius die Rolle des Adoptivvaters und Schwiegervaters ein, Constantin war Adoptiv-Sohn und Schwiegersohn von Maximian. Diese Schaffung einer der göttlichen Sphäre angenäherten Herrscherfamilie war nur möglich, indem das Inzestverbot des römischen Rechts, das auch zwischen Adoptivverwandten Gültigkeit beanspruchte, ignoriert wurde ${ }^{55}$.

50 Vgl. Volterra, Costituzione 1966; Fögen, Enteignung 1997, 27-31. Bei der Datierung des Manichäeredikts ist jedoch nach CorCoran, Empire 1996, 135, gegen Chadwick am Jahr 302 festzuhalten. So auch ReEs, Diocletian 2004, 58.

51 Collatio legum Mosaicarum et Romanarum 15, 3, 4 (188) (inficere) und 6, 4, 3 (158) (polluere).

52 Collatio legum Mosaicarum et Romanarum 6, 4, 3 (158).

53 Nach Guarino, Studi 1943, und Mette-Dittmann, Ehegesetze 1991, 42-49, hat Augustus auch Gesetze zum Delikt des incestus erlassen. Moreau, Inceste 2002, $344-$ 348, bestreitet dies mit Bezug auf die ältere Literatur. Vgl. auch Puliatti, Regime 2001, $11-21$.

54 Kolb, Diocletian 1987; Kunoff, Diocletian 2001, 107-135; Demandt, Spätantike 2007, $59 \mathrm{f}$.

55 Kolb, Diocletian 1987, 68, weist auf Vorläufer hin und erwähnt, dass im Prinzipat solche Inzestverbindungen noch gemieden wurden. Zum Konzept der vergöttlichten 
Man wird also unterscheiden müssen zwischen der römischen Tradition und ihrer Instrumentalisierung in der spätantiken Gesetzgebung ${ }^{56}$. Das Damskusedikt betrachtete den Inzest weiterhin als nefas, in der Realität gehörte das Inzestverbot nicht mehr zum Kernbestand der moralischen Wertvorstellungen in der römischen Gesellschaft. Augustin - sicher ein unverdächtiger Zeuge in dieser Sache - ordnete das Inzestverbot nicht der göttlichen Ordnung, sondern der menschlichen Gesetzgebung $\mathrm{zu}^{57}$.

\subsection{Die Gesetzgebung der christlichen Kaiser}

Die im Hochmittelalter kumulierende Ausdehnung des Inzestverbots beginnt im 4. Jahrhundert. Die Kaiser Constantius II. und Theodosius I. untersagten per Gesetz die Ehe mit der Nichte, mit der Schwägerin und mit der Cousine. Die Tatsache, dass diese Gesetze von christlichen Kaisern erlassen wurden, die von einem besonders ausgeprägten Glaubenseifer beseelt waren, bot für die ältere Forschung eine hinreichende Erklärung für die Ausweitung des Inzestverbots. Der Einfluss des Christentums habe, so die Ansicht Biondis in seinem monumentalen Werk zum christlichen Kaiserrecht der Spätantike, zu einer Anpassung der überkommenen Gesetze zu den Verwandtenehen geführt ${ }^{58}$.

Biondis ,Meistererzählung' von der Christianisierung des Rechts ist in den letzten Jahrzehnten zunehmend in die Kritik geraten. Bahnbrechend war ein Aufsatz von Paul Veyne über „Familie und Liebe im hohen Kaiserreich ${ }^{459}$. Veyne stellte die zunehmend restriktivere Einstellung gegenüber Sexualität in den Rahmen eines Mentalitätswandels, der sich unabhängig vom Christentum durch die allmähliche Dominanz eines reaktionären Konservativismus der Unterschichten vollzogen habe. Michel Foucault nahm diesen Ansatz auf und konfrontierte die annähernde Gleichförmigkeit der heidnischen und christlichen Sexualmoral mit einem durch das Christentum erneuerten Verständnis von personaler Identität ${ }^{60}$. Auch in dem Standardwerk zur Geschichte der spätan-

Herrscherfamilie: Clauss, Kaiser 1999, 189-195; Kolb, Herrscherideologie 2001, 35 37.

56 Moreau, Inceste 2002, 35, deutet dagegen die Wertung des Inzests durch die Juristen als Reflex tief verankerter Vorstellungen.

57 Generalem iustitiam non violat quis, nisi libidine transgressus fuerit aut placitum societatis humanae, sicut est furtum, rapina, adulterium, incestum et huiusmodi; aut naturam, sicut est contumelia, caedes, homicidium, concubitus masculorum vel pecorum. Augustinus, De octo quaestionibus ex veteri testamento 1 (CCL 33, 469).

58 Biondi, Diritto 3 1954, 94 f. So auch Fleury, Recherches 1933, 61; Guarino, Studi 1943, 230; Мikat, Inzestgesetzgebung 1994, 28; Giardina, Family 2000, 396.

59 Veyne, Famille 1978.

60 Foucault, Geschichte 1 1977. Die jüdischen Wurzeln christlicher Sexualvorstellungen betont hingegen neuerdings GACA, Making 2003. 
tiken Körperlichkeit betonte Peter Brown die Konvergenz heidnischer und christlicher Moralvorstellungen ${ }^{61}$.

In der Bewertung des spätantiken Eherechts entzündete sich die Diskussion um die Auswirkung der Christianisierung vor allem an den gesetzgeberischen Initiativen Constantins des Großen. Der erste christliche Kaiser hat insgesamt ca. 100 Gesetzestexte zum Eherecht hinterlassen und so seinem Engagement in dieser Hinsicht deutlich Ausdruck verliehen ${ }^{62}$. Ein zeitgenössischer Panegyricus schrieb ihm deshalb die Bewahrung der Keuschheit und die Befestigung der Ehe als Verdienste $\mathrm{zu}^{63}$. In der Diskussion um die Christianisierung des Eherechts spielen vier Gesetze Constantins eine wichtige Rolle ${ }^{64}$. Erstens hob der Kaiser die finanziellen Nachteile für ehe- und kinderlose Personen auf, die Augustus zur Anhebung der Geburtenrate festgesetzt hatte. Zweitens verschärfte er die Strafe für Ehebruch, indem er die Exekution durch das Schwert befahl. Drittens untersagte er das nebeneheliche Konkubinat des Mannes und viertens erlaubte er eine einseitige Scheidung nur bei besonders schweren Kapitalverbrechen wie Zauberei, Kuppelei und Grabschändung. Da diese Gesetze lediglich in abgekürzter Form in späteren Kodifikationen enthalten sind, ist über die Motivierung aus den Texten selbst wenig zu erfahren. Eine christliche Begründung wird nicht ausdrücklich gegeben, sie wäre auch fehl am Platz, weil neben der noch in der Minderheit befindlichen christlichen Bevölkerung auch die heidnische Mehrheit angesprochen werden sollte. Die Charakterisierung der Gesetze kann daher nur durch einen Vergleich mit der älteren Tradition des römischen Rechts sowie mit der zeitgleichen kirchlichen Synodalgesetzgebung erfolgen. Zuletzt hat Judith Evans-Grubbs eine umfassende Untersuchung zu dieser Frage vorgelegt $^{65}$. Ihre Ergebnisse sind auf breite Zustimmung gestoßen ${ }^{66}$. Evans-Grubbs lässt den christlichen Einfluss nur für die Aufhebung der Diskriminierung von ehe- und kinderlosen Personen gelten. Die Einschränkung der einseitigen Scheidung hält sie nur teilweise für christlich motiviert, da dies weder den Forderungen der Christen genügt habe noch dauerhaft in Kraft geblieben sei. Im Übrigen sei die Gesetzgebung Constantins von traditionellen Erwägungen der Bewahrung von Statusunterschieden zwischen Freien und Sklaven sowie von einer in der Bevölkerung verbreiteten restriktiven Moral geprägt gewesen. Die

61 Brown, Keuschheit 1991, 9-46.

62 Evans-Grubbs, Law 1995; Nathan, Family 2000, 57-73.

63 Panegyrici Latini, Nazarius 10, 8, 4 (172).

64 Codex Theodosianus 8, 16, 1 (418 f.); Codex Iustinianus 9, 9, 29 (376); Codex Iustinianus 5, 26, 1 (216); Codex Theodosianus 3, 16, 1 (155 f.).

65 Evans-Grubbs, Law 1995.

66 Arjava, Women 1996, 184; Nathan, Family 2000, 72; Piepenbrink, Konstantin 2002, 104-108. Verhaltene Kritik bei Giardino, Family 2000, 393 f.; Kuefler, Revolution 2007, 362-364. Zur christlichen Gesetzgebung Constantins allgemein vgl. Drake, Constantine 2000, 321-346; Girardet, Wende 2006, 113-152. 
Mentalität Constantins gehe folglich nicht auf das Christentum, sondern auf die alten Werte der bäuerlichen Bevölkerung zurück, die er erstmals in der bürgerlich geprägten Gesetzgebung zur Geltung gebracht habe.

Die minimalistische Sicht auf den Einfluss des Christentums gewinnt besondere Plausibilität, wenn man die weitere Geschichte des Scheidungsrechts in den Blick nimmt ${ }^{67}$. Bis zur Zeit Justinians I. wurde die einvernehmliche Scheidung keiner Regelung unterworfen. Sie blieb weiterhin erlaubt und wurde noch in der Merowingerzeit in juristischen Formen vollzogen. Constantin schränkte nur die einseitige Scheidung ein und verlangte von der scheidungswilligen Seite den Nachweis eines gravierenden Fehlverhaltens des Ehepartners. Diese Regelung wurde vom heidnischen Kaiser Julian zurückgenommen und erst wieder durch Theodosius II. im Jahr 421 in Kraft gesetzt. Derselbe Kaiser hob das Gesetz für den Osten im Jahr 439 wieder auf, während die Regelung Constantins im Westen durch eine Novelle Valentinians III. bestätigt wurde. Diese schwankende Haltung setzte sich in der Gesetzgebung Justinians I. fort. Der spätantike Gesetzgeber nahm also keine dogmatische Haltung gegenüber der Frage der Scheidung ein, wie man sie vor dem Hintergrund der weiteren Entwicklung des christlichen Eherechts erwarten würde.

Philippe Moreau überträgt diese minimalistische Sicht auf die Geschichte der Inzestgesetzgebung ${ }^{68}$. Sein Kronzeuge ist die astrologische Schrift Mathesis des Firmicus Maternus aus dem Jahr 334/337. Firmicus Maternus war Heide sizilianischer Herkunft und stammte vielleicht aus senatorischem Adel ${ }^{69}$. Wenige Jahre nach der Abfassung der Mathesis bekehrte er sich zum Christentum und trat als fanatischer Befürworter der staatlichen Ausrottung des Heidentums in Erscheinung. In seinem zweiten Werk De errore prophanarum religionum beschreibt er detailliert die heidnischen Kulte seiner Zeit und legt den Kaisern Constantius II. und Constans I. eine rücksichtslose Gesetzgebung gegen die Heiden nahe. Wie Moreau erstmals erkannte, drückte Firmicus Maternus in beiden Werken seine ausgeprägte Abscheu vor dem Inzest aus, lieferte aber in der früheren heidnischen Schrift eine deutlich umfassendere Liste von „schändlichen" Verwandtenehen ${ }^{70}$. Unter anderem bezeichnete er die Ehe mit der Nichte, der Schwägerin und der Cousine als Inzest, also alle Eheformen, die im Lauf des 4. Jahrhunderts von den christlichen Kaisern per Gesetz untersagt wurden. Daraus schließt Moreau auf einen umfassenden Mentalitätswandel, der sowohl die heidnische als auch die christliche Bevölkerung erfasst und zu einer restriktiveren Handhabung des Inzestverbots geführt habe. Der Prozess der

67 Reynolds, Marriage 1994, 44-65; Arjava, Women 1996, 177-189.

68 Moreau, Inceste 2002, 310-313. Ähnlich bereits Gaudemet, Condamnations 1996, 396; Thraede, Blutschande 2002, 64.

69 Konrat Ziegler, Art. „Firmicus Maternus“, in: RAC 7 (1969) 946-960.

70 Firmicus Maternus, Mathesis 3, 6, $28-30(1,153)$; 7, 12, 2 (2, 239). 
Ausdehnung des Verbots sei daher weniger als Neuerung zu begreifen, sondern als Rückkehr zu den veteres mores der frühen Republik, die bereits im Damaskusedikt Kaiser Diocletians beschworen worden seien.

Die anregende Studie Moreaus hat die Gewichtung gegenüber der älteren Forschung radikal verschoben. Wurde der Einfluss des Christentums bislang als entscheidender Katalysator der Verschärfung betrachtet, legt er den Schwerpunkt auf die anhaltende Wirkmächtigkeit der römischen Tradition. Da Moreau die Quellen zur synodalen Gesetzgebung jedoch vorschnell beiseite schiebt und auf einseitige Weise möglichst späte Datierungen bevorzugt, kann ich seiner minimalistischen Sicht nicht in jeder Hinsicht zustimmen. Ich halte deshalb eine erneute Untersuchung der Quellen des 4. Jahrhunderts für erforderlich. Mein Ziel besteht nicht darin, das Christentum als entscheidenden Faktor zu rehabilitieren, sondern die Entwicklung in den Kontext der Umgestaltung von Kirche und Reich nach der Konstantinischen Wende zu stellen.

\section{Die Ehepolitik Constantius' II.}

Constantius II. kam nach dem Tod seines Vaters im Jahre 337 gemeinsam mit seinen älteren Brüdern Constans und Constantin II. an die Macht ${ }^{71}$. Er regierte den östlichen Reichsteil und hatte in den ersten Jahren seiner Herrschaft mehrere Feldzüge gegen das persische Sassanidenreich zu bestehen. In diese Zeit fällt eine Konstitution, die der Kaiser am 31. März 342 in Antiochia an die Einwohner der Provinz Phoenicia richtete ${ }^{72}$. Sie lautet: „Wenn jemand auf abscheuliche Weise glaubt, die Tochter seines Bruders oder seiner Schwester zur Ehefrau machen zu können oder zur Umarmung mit ihr - und zwar nicht als Onkel - schreitet, soll er der Kapitalstrafe unterliegen " ${ }^{\text {"73. }}$. Dieses Gesetz verbietet also genau diejenige Eheform, die Kaiser Claudius 300 Jahre zuvor in einem Senatusconsultum für legitim erklärt hatte. Da jedoch Constantius nicht ausdrücklich das ältere Gesetz aufhebt, sind in jüngster Zeit an diesem Zusammenhang Zweifel geäußert worden. Paola Cuneo und Simon Corcoran halten eine Verbindung zu den Perserkriegen für wahrscheinlich, wie sie Chadwick für das Edikt Diocletians vermutet hat ${ }^{74}$. Constantius habe mit dem Verbot von besonders im Osten verbreiteten Ehepraktiken die moralische Autorität Roms festigen wollen. Ausgangspunkt für diese Deutung ist die Tatsache der Veröffentlichung für eine bestimmte Provinz. Dies scheint darauf hinzuweisen, dass das Gesetz nicht als universales Edikt, sondern als Anweisung an die lokalen

71 Barceló, Constantius II. 2004

72 SEECK, Regesten 1919, 190.

73 Si quis filiam fratris sororisve faciendam crediderit abominanter uxorem aut in eius amplexum non ut patruus aut avunculus convolaverit, capitalis sententiae poena teneatur. Codex Theodosianus 3, 12, 1 (150).

74 Cuneo, Legislazione 1997, 93 f.; Corcoran, Constitution 2000, 14. 
Amtsträger gedacht gewesen sei. Erst die Aufnahme unter die edictales generalesque constitutiones des Codex Theodosianus hat nach Cuneo und Corcoran diesem Gesetz reichsweite Gültigkeit verschafft. Diese Deutung hängt jedoch an der durchaus umstrittenen Wertung des Adressaten. Eine reichsweite Gültigkeit hätte auch dann erzielt werden können, wenn die ursprüngliche Anweisung an eine bestimmte Provinz erfolgt ist. Die Gültigkeit von regionalen Gesetzen war ambivalent; wenn sie allgemeine Normen proklamierten, konnten sie durchaus als universal gültiges Edikt anerkannt werden ${ }^{75}$. Die Juristen des Codex Theodosianus sahen diesen Text als entscheidendes Gesetz in dieser Frage an. Noch im Damaskusedikt Diocletians war die von Claudius erwirkte Ausnahmeregelung in Kraft gewesen ${ }^{76}$.

Über die Motivation des Constantius lässt sich keine Aussage treffen, da der Prolog des Gesetzes nicht überliefert ist. Die Ehe zwischen Onkel und Nichte wurde weder vom mosaischen noch vom römischen Recht als Inzest gewertet. Nur bei asketisch gesinnten jüdischen Splittergruppen des 1. Jahrhunderts wurde diese Eheform mit der in Lev. 18, 12 untersagten Ehe zwischen Tante und Neffe gleichgesetzt und unter Verbot gestellt ${ }^{77}$. Im Neuen Testament hinterließ diese Auffassung keine Spur. Michael Mitterauer wies darauf hin, dass die Heirat des Herodes mit seiner Nichte deshalb Anstoß erregte, weil seine Nichte gleichzeitig auch seine Schwägerin war. Der Verstoß gegen das Verbot des Levirats und nicht die Heirat mit einer Nichte rief den Widerstand Johannes' des Täufers hervor, der seine Hinrichtung zur Folge hatte. Drei Jahrhunderte später bedrohte der christliche Kaiser Constantius II. die Nichtenehe mit der Todesstrafe ${ }^{78}$. „Dieser Wandel in der Einstellung zur Nichtenheirat ist besonders eklatant "

Ein weiteres Gesetz zum Inzestverbot erließ Constantius II., nachdem seine beiden Brüder gestorben waren und er die Alleinherrschaft über das Reich erlangt hatte. Am 30. April 355 untersagte er die Ehe mit der Schwägerin: „Obwohl es die Vorfahren als erlaubt ansahen, nach der Auflösung der Ehe des Bruders dessen Ehefrau zu heiraten sowie nach dem Tod der Frau oder nach einer Scheidung von ihr eine Ehe mit deren Schwester einzugehen, sollen sich alle von solchen Ehen fernhalten und nicht glauben, aus einer solchen Ehe rechtmäßige Kinder zeugen zu können; denn unehelich sollen sie sein, die

75 Honoré, Making 1986, 177; Sirks, Code 1986, 286; Matthews, Making 1993, $26-$ 29; DERs., Law 2000, $69 \mathrm{f}$.

76 Collatio legum Mosaicarum et Romanarum 6, 4, 5 (159).

77 Damaskusschrift V 6-11 (75).

78 Cuneo, Legislazione 1997, 94. Guarino, Studi 1943, 259, identifiziert dagegen die Kapitalstrafe mit der deportatio.

79 Mitterauer, Christentum 1990, 45. 
geboren werden ${ }^{\text {“80 }}$. Im Unterschied zum ersten Inzestgesetz betont der Gesetzgeber dieses Mal ausdrücklich die Tatsache einer Rechtsänderung. Da das Gesetz in Rom publiziert wurde und an den Praefectus praetorio Volusianus gerichtet ist, steht der Charakter des Gesetzes als universales Edikt außer Zweifel. Eine Motivation ist durch die Kürze des Textes nicht fassbar.

Bei der Beurteilung des Gesetzes von 355 hilft die kirchliche Gesetzgebung weiter. Zunächst soll das Verbot des Levirats ins Auge gefasst werden. In Lev. 18, 13 wird diese Form der Ehe für das jüdische Volk untersagt. In Deut. 25, 5 wird das Verbot im Fall der Kinderlosigkeit der ersten Ehe außer Kraft gesetzt. Im christlichen Zeitalter war die Gültigkeit der jüdischen Inzestverbote keineswegs selbstverständlich. Das Apostelkonzil von Jerusalem hat beschlossen, dass die alttestamentarischen Vorschriften nur insofern für die Heidenchristen verbindlich sein sollten, als „Götzenopferfleisch, Blut, Ersticktes und Unzucht zu meiden" seien (Act. 15, 29). Ob mit Unzucht (porneia) auch Inzest gemeint war, ist nicht eindeutig zu erweisen ${ }^{81}$. In der späteren Exegese hat man jedenfalls keinen Zusammenhang zwischen Unzucht und Inzest hergestellt. Den einzigen Hinweis auf die weitere Geltung des Inzestverbots konnten spätere Interpreten aus dem Vorgehen des Paulus in Korinth erhalten. In 1. Cor. 5 greift der Apostel ein Mitglied der Gemeinde wegen der Ehe mit seiner Stiefmutter an und fordert ihren Ausschluss aus der Christengemeinde. In den nächsten Jahrhunderten ist den Apologetikern keine Information zur christlichen Bewertung des Inzestverbots zu entnehmen ${ }^{82}$. Erst nach der Duldung des Christentums durch Galerius und Constantin wird auf der Synode von Neocaesarea im Jahr 314/315 das Verbot der Leviratsehe ohne Ausnahme eingeschärft ${ }^{83}$. Seitdem zählte es zum unbestrittenen Kern des christlichen Eherechts.

Das Verbot der Ehe mit der Schwester der Frau (Sororat) hat eine wechselvollere Geschichte. In der Bibel ist nur die gleichzeitige Ehe mit zwei Schwestern untersagt (Lev. 18, 18). Die frühesten Belege für ein grundsätzliches

80 Etsi licitum veteres crediderunt, nubtiis fratris solutis ducere fratris uxorem, licitum etiam post mortem mulieris aut divortium contrahere cum eiusdem sorore coniugium, abstineant huiusmodi nubtiis universi nec aestiment posse legitimos liberos ex hoc consortio procreari: nam spurios esse convenit, qui nascentur. Codex Theodosianus 3, 12, 2 (150 f.).

81 Vgl. Мiкat, Inzestgesetzgebung 1994, 16 f; Thraede, Blutschande 2002, 65 (mit weiterer Literatur).

82 Thema der Apologetik ist der Inzest nur insofern, als die Heiden den Christen Geschlechtsverkehr zwischen Verwandten vorwerfen: Thraede, Inzest 2002; DERs., Blutschande 2002, 67-76.

83 Mulier si duobus fratribus nupserit, abici debere usque ad diem mortis; sed propter humanitatem in extremis suis sacramentis conciliari oportet, ita tamen ut, si forte sanitatem recuperaverit matrimonio soluto ad paenitentiam admittatur. Quod si defuncta fuerit mulier in huiusmodi consortio constituta, difficilis erit paenitentia remanenti; quae sententia tam viros quam mulieres tenere debebit. Konzil von Neocaesarea (ca. 314/315) c. 2 (EOMIA 2, 120). 
Verbot dieser Eheform sind umstritten und werden daher von Moreau nicht herangezogen. Adolf Lumpe sprach sich dafür aus, dass bereits das Konzil von Neocaesarea neben dem Levirat auch das Sororat ins Visier genommen hat ${ }^{84}$. Die Formulierung des Kanons ist jedoch zweideutig. Der Text bezieht sich auf das Levirat, während das Sororat erst in der Rubrik hinzugefügt wurde ${ }^{85}$. Der zweite Beleg stammt aus dem Konzil von Elvira. Die dort versammelten spanischen Bischöfe erlegten den in einer solchen Ehe verbundenen Personen einen fünf Jahre dauernden Ausschluss aus der Gemeinde auf ${ }^{86}$. Die Datierung dieses Konzilskanons hat in den letzten Jahren verschiedene Deutungen erfahren. Philippe Moreau stützt sich auf den Beitrag von Maurice Meigne, der erstmals die Authentizität der Kanonesreihe in Frage stellte ${ }^{87}$. Meigne betrachtet nur die ersten 21 Kanones als Erlass einer Kirchenversammlung, die zwischen dem Ende der Christenverfolgung in Spanien (306) und dem Jahr 314 getagt habe. Der Rest sei erst später hinzugekommen und bestehe aus einer Sammlung des spanischen Kirchenrechts des 4. Jahrhunderts. Den oben erwähnten Inzestkanon schlägt Meigne dem später entstandenen Teil zu. Diese Einschätzung entbehrt jedoch nicht einer gewissen Willkür, da die handschriftliche Überlieferung die einheitliche Entstehung der 81 Kanones bezeugt. Nur aufgrund von wenig überzeugenden Plausibilitäten gelingt es Meigne, diesen Befund in Zweifel zu ziehen. Zum Beispiel bemüht er das Argument, dass die anderen Synoden des frühen 4. Jahrhunderts kaum mehr als 20 Kanones erließen und derselbe Sachverhalt auch für die Synode von Elvira zutreffen müsse. Die inhaltlichen Argumente Meignes bieten ebenfalls keinen festen Anhaltspunkt. Über die dogmatische Entwicklung des frühen 4. Jahrhunderts ist man teilweise so unzureichend informiert, dass die Entstehung aller Kanones in der Zeit um

84 Fischer - Lumpe, Synoden 1997, 495.

85 Johannes Scholasticus, Synagoga L titulorum 44, 3 (137); Konzil von Neocaesarea (ca. 314/415) c. 2 (CCO 1/2, 76). Zur syrischen Übersetzung vgl. Fischer - Lumpe, Synoden, $495 \mathrm{f}$. Die im Mittelalter gängige Rubrik (De his quae duobus fratribus nupserint vel qui duas sorores acceperint), die das Delikt auf die Ehe mit zwei Schwestern erweitert, geht der Edition Turners zufolge auf die Übersetzung durch Dionysius Exiguus zurück.

86 Si quis post obitum uxoris suae, sororem eius duxerit, et ipsa fuerit fidelis, quinquennium a communione placuit abstineri, nisi forte velocius dari pacem necessitas coegerit infirmitatis. Konzil von Elvira (ca. 306) c. 61 (VIves, 12).

87 Meigne, Concile 1975; Moreau, Inceste 2002, 321. Zustimmung zu Meigne auch bei Denzler, Geschichte 1992, 25; Hess, Development 2002, $41 \mathrm{f}$. Philologische Argumente für die sukzessive Entstehung der Kanones werden von BARreda - Vilella, Cánones 2002, vorgebracht. Die Beweisführung ist nicht zwingend. 
310 keineswegs ausgeschlossen werden kann. An der Authentizität der Kanones von Elvira ist also beim heutigen Kenntnisstand festzuhalten ${ }^{88}$.

Wenn demnach bereits die spanische Kirche kurz nach 300 die Ehe mit der Schwester der Ehefrau als Inzest betrachtete, erfährt die christliche Prägung des Gesetzes Constantius' II. eine Bestätigung. In Elvira nahmen 19 Bischöfe und 24 Priester teil. Einer von ihnen war Ossius von Córdoba, der später als einer der wichtigsten kirchlichen Ratgeber Constantins des Großen Karriere machen sollte $^{89}$. Das Konzil kann daher in viel größerem Ausmaß als repräsentative Meinungsäußerung gelten als die singuläre Stellungnahme des Firmicus Maternus, die Philippe Moreau ins Feld führt. Dass der Standpunkt der spanischen Bischöfe von den Wortführern der Kirche geteilt wurde, belegen zwei Quellen aus dem Ende des 4. Jahrhunderts.

Die erste Quelle ist ein Brief des Basilius von Caesarea an seinen Suffragan Diodor von Tarsus aus dem Jahr $374^{90}$. Basilius berichtet darin von einem unter dem Namen Diodors zirkulierenden Schreiben, das die Ehe mit der Schwester der Ehefrau für legitim erklärt. Mit dem vorsichtig vorgetragenen Zweifel an Diodors Autorschaft eröffnet Basilius seinen Kollegen einen eleganten Ausweg, sich von dem Inhalt dieses Schreibens zu distanzieren ${ }^{91}$. Denn der griechische Kirchenvater lässt keinen Zweifel daran, dass er eine solche Ehe als ausreichenden Grund für den Ausschluss aus der christlichen Gemeinschaft ansieht. Diese Ansicht bezeichnet er als „herrschende Sitte, tradiert von heiligen Männern". Trotz dieser scheinbaren Klarheit hält er es für nötig, das Verbot durch eine ausführliche Bibelexegese zu begründen. In dem angeblichen Schreiben Diodors wurde nämlich aus dem Verbot der gleichzeitigen Ehe mit zwei Schwestern in Lev. 18, 18 die Folgerung gezogen, dass eine solche Ehe nach dem Tod der einen Schwester erlaubt sei. Basilius entgegnet dem mit zwei Argumenten: einerseits werde diese Folgerung in der Bibel nicht ausdrücklich sanktioniert und andererseits dürften nicht alle Gebote des Alten Testaments nach der Ankunft des Heilands Gültigkeit beanspruchen. Die Bibel habe nur bestimmte in der damaligen Zeit übliche Eheformen verbieten und nicht eine vollständige Liste aller Inzestverbote geben wollen. Das Neue Testament stelle außer Zweifel, dass Mann und Frau ein Fleisch würden und daher die Schwägerin als Teil der Familie unter das Inzestverbot fallen müsse. Basilius spricht sich also nicht für eine wörtliche Umsetzung der Inzestverbote von Levitikus aus, sondern für eine Anpassung an die Ehelehre des Neuen Testaments. Der Kir-

88 So auch Orlandis - Ramos-Lissón, Konzilien 1981, 3. Unentschieden ist Gaudemet, Sources 1985, 49. Die Studie von Reichert, Canones 1990, bleibt ebenso wie die Untersuchung Meignes an der Oberfläche und trägt nicht zur Frage der Datierung bei.

89 Clercq, Ossius 1954, 85-110.

90 Basilius von Caesarea, Ep. 160 (2, 88-92). Vgl. Fleury, Recherches 1933, 32-36; Мiкат, Inzestgesetzgebung 1994, $21-25$.

91 Vgl. Van Dam, Conversion 2003, 64. 
chenvater schickte diese Ausführungen auch an Bischof Amphilochius von Ikonium und bestimmte in einem weiteren Brief an denselben Adressaten eine siebenjährige Buße für eine solche $\mathrm{Ehe}^{92}$.

Nicht nur in Kappadokien, auch in Gallien herrschte Unsicherheit in der Frage des Verbots der Ehe mit der Schwester der Frau. Die gallischen Bischöfe wandten sich jedoch nicht an einen für seine Bibelkenntnis berühmten Gelehrten wie Basilius, sondern an den als Patriarch des Westens anerkannten Bischof von Rom. Die Datierung dieser Anfrage ist strittig und lässt sich keiner endgültigen Klärung zuführen ${ }^{93}$. Die Form der päpstlichen Antwort spricht für eine Entstehung unter Damasus I. im späten 4. Jahrhundert. Von den päpstlichen Dekretalen, die unter dem Nachfolger des Damasus, Siricius, erstmals fassbar sind, unterscheidet sich die päpstliche Antwort durch die synodale Form. In den Handschriften ist der Text mit den Worten Canones synodi Romanorum ad Gallos episcopos überschrieben ${ }^{94}$. Wie Basilius musste sich der Papst mit den alttestamentarischen Grundlagen des Verbots auseinandersetzen. Bigamie, Ehe, Konkubinat und Inzestehen seien, so der Papst, alles Erscheinungen des Alten Testaments und einem zur Keuschheit verpflichteten Christen nicht mehr erlaubt ${ }^{95}$. Im Hintergrund der Argumentation steht auch hier die Stelle Lev. 18, 18, obwohl sie nicht ausdrücklich zitiert wird. Stattdessen beruft sich der Papst auf das Verbot einer solchen Ehe in Deut. 27, 23: „Verflucht, wer mit der Schwester seiner Frau schläft". Dieser apokryphe Vers ist nur in einigen wenigen Überlieferungen der Septuaginta bezeugt ${ }^{96}$.

92 Basilius von Caesarea, Ep. 199 c. 23 (2, 158); ep. 217 c. 78 (2, 214).

93 Die Zuschreibung an Damasus hat Babut, Décrétale 1904, begründet. Getzeny, Stil 1922, 94-100, sprach sich in Anschluss an Coustant für Siricius aus. Zustimmung bei Caspar, Geschichte 1 1930, 216 u. 262. Die Mehrheit der Forscher blieb jedoch bei der These Babuts, die Pietri, Roma 1976, 764-772, nochmals mit Argumenten stützte. Duval, Décrétale 2005, 1-7 u. 125-128, schließt sich der Zuschreibung an Damasus an und erwägt die Mitarbeit des Hieronymus. Nach der Entdeckung neuer Fragmente sind jedoch die für Damasus sprechenden handschriftlichen Argumente weggefallen. JASPER, Canones 1996, sprach sich daher wieder für eine spätere Entstehung aus, eher im frühen 5. Jahrhundert als im späten 4. Jahrhundert.

94 Die Überlieferung der Collectio Weingartensis und Tuberiensis haben Exempla sinodi Romani ad Gallos episcopos: JASPER, Canones 1996, 322.

95 Sed nunc hoc non patitur fieri testamentum, ubi amplius de integritate tractatur, et castitas Christo docente laudatur cum dicit: Non omnes capiunt verbum Dei, sed quibus datur. Canones synodi Romanorum c. 12 (40).

96 Nam lex dicit: maledictus qui cum uxoris suae sorore dormierit. Canones synodi Romanorum c. 12 (40). Zur Überlieferung dieses zweifellos als Zusatz zu wertenden Halbverses im Codex Vaticanus, Codex Sinaiticus und im Lyoner Heptateuch vgl. Мıкат, Inzestgesetzgebung 1994, 34. 
Neben Basilius und dem Papst teilten auch andere christliche Autoren der Zeit um 400 die Ablehnung der Ehe mit der Schwester der Frau ${ }^{97}$. Die Meinungsführer des Christentums, nicht Heiden wie Firmicus Maternus, liefern ausführliche argumentative Begründungen für ein solches Verbot und fordern auch Strafen wie Buße und die Auflösung der Ehe ein. Moreau ist zwar darin Recht zu geben, dass auch aus heidnischer Sicht eine Verbindung mit der Schwägerin als Gottlosigkeit betrachtet und in die Nähe des Inzests gerückt werden konnte ${ }^{98}$. Eine Ausweitung des Inzestverbots auf die Schwägerin, wie sie in Neocaesarea und Elvira ausgesprochen wurde, konnte dem Heiden Firmicus Maternus durchaus plausibel erscheinen. Doch ist auf folgendem Unterschied zu beharren: Nur die Christen hatten einen überzeugenden Grund, eine solche moralische Forderung in einem weltlichen Gesetz festzuschreiben, denn die Betonung der Einheit von Frau und Mann im Neuen Testament machte die Anpassung der alttestamentarischen Inzestverbote notwendig und glaubhaft.

Eine christliche Motivation der Inzestgesetze Constantius' II. fügt sich zweifelsohne auch besser in die legislative Tätigkeit des Kaisers ein. Constantius II. führte nicht nur in Fragen des Ehebruchs die Initiativen seines Vaters fort, die Privilegierung der Kirche nahm bei ihm ein solches Ausmaß an, dass die Rechtshistorikerin Paola Cuneo von einem capovolgimento in der Gesetzgebung spricht $^{99}$. Seit der Usurpation des den Heiden gewogenen Magnentius verschärfte sich zunehmend die antipagane Politik des Kaisers und mündete schließlich in der Anweisung der Schließung aller Tempel unter der Drohung der Todesstrafe ${ }^{100}$. Ein eindeutig christlicher Hintergrund ist gleichfalls bei der Verhängung der Todesstrafe über passive Homosexualität vorauszusetzen, die der Kaiser gemeinsam mit seinem Bruder Constans im Jahr 342 verfügte ${ }^{101}$. Es

97 Collatio legum Mosaicarum et Romanarum 6, 7, 7 (161), vermutlich entstanden um das Jahr 400 in christlichen Kreisen Roms nach Liebs, Italien 1987, 162-174; Honoré, Law 1998, 8; Harries, Code 1998; Canones apostolorum 19 (CCO 1/2, 17; EOMIA 1, 4), entstanden in Syrien am Ende des 4. Jahrhunderts; Cyprianus Gallus, Heptateuchos Lev. 130 (108), aus dem Gallien des 5. Jahrhunderts. Als Kaiser Honorius aus politischen Gründen Thermantia, die Schwester seiner Frau, heiratete, streute der Hof das Gerücht des fehlenden Vollzugs der ersten Ehe: Zosimus, Historia nova 5, 28, 1-3 (3/1, 41). Anders als Moreau, Inceste 2002, 243, halte ich dieses Gerücht für konstruiert, um einen Verstoß gegen das Inzestverbot zu verschleiern.

98 Moreau, Inceste 2002, 68 u. 241, führt noch vier weitere Quellen aus dem 1. und 2. Jahrhundert an. Sie verurteilen jedoch erstens den Ehebruch mit der Frau der Schwester zu Lebzeiten der Ehefrau; und zweitens sprechen sie überwiegend nicht von Inzest, sondern von nefas. Als Inzest bezeichnen einen solchen Ehebruch nur die Declamationes minores 286, 7 (136) und 291, 2 (144). Auch in Konzil von Ankyra (314) c. 25 (CCO 1/2, 73) wird eher der Ehebruch als der Inzest mit der Schwester der Verlobten inkriminiert.

99 Cuneo, Legislazione 1997, CI. Vgl. auch Barnes, Athanasius 1993, 167-174.

100 Noethlichs, Maßnahmen 1971, $69 \mathrm{f}$.

101 Codex Theodosianus 9, 7, 3 (447). 
wäre zwar übertrieben, der gesamten Gesetzgebung des Kaisers eine christliche Färbung zu unterstellen, da die meisten Erlasse administrative Regelungen zum Inhalt haben und von den Juristen am Kaiserhof formuliert wurden ${ }^{102}$. Die Tatsache jedoch, dass einzelne Gesetze eindeutig einer religiösen Motivation entsprungen sind, macht dieselbe Annahme auch für die Inzestverbote wahrscheinlich. Die Präsenz und das Lobbying christlicher Bischöfe am Hof Constantius' II. sind hinreichend belegt ${ }^{103}$.

\section{Theodosius I. und das Verbot der Cousinenehe}

Das religionspolitische Engagement Theodosius' des Großen äußerte sich schon bald nach seiner Ernennung zum Kaiser am 19. Januar 379 ${ }^{104}$. Noch als er in Thessaloniki mit den Folgen der verheerenden Niederlage von Adrianopel des Jahres 378 zu kämpfen hatte, erließ er im Jahr 380 das berühmte Edikt Cunctos populos, in dem er gemeinsam mit Valentinian II. und Gratian das Glaubensbekenntnis von Nicäa im gesamten Reich für verbindlich erklärte. Als Garanten des rechten Glaubens traten in diesem Edikt der Bischof Damasus von Rom und der Patriarch Petrus von Alexandria auf. Die Initiative dafür ging von Theodosius aus, der das Edikt in Thessaloniki ausgestellt hat. Auch in den folgenden Jahren bemühte er sich um eine Einigung innerhalb der Christenheit und regte auf dem Konzil von Konstantinopel (381) die Formulierung eines verbindlichen Glaubensbekenntnisses an. Gegner dieses Bekenntnisses, die sich vor allem in seinem östlichen Reichsteil konzentrierten, ließ er durch eine brutale und rücksichtslose Häretikergesetzgebung verfolgen ${ }^{105}$. Abweichler von der Rechtgläubigkeit wurden aus der staatlichen Rechtsgemeinschaft ausgeschlossen.

Das Bekenntnis zum Glauben des römischen Bischofs Damasus hat zu Überlegungen über die persönlichen Bindungen des Theodosius Anlass gegeben ${ }^{106}$. Vor der Katastrophe von Adrianopel hatte sich Theodosius in seiner Heimat, dem spanischen Galicien, aufgehalten. Dort war gerade in jener Zeit der Anspruch des Papstes auf das Amt des Patriarchen des Westens zur Anerkennung gelangt. Der Bischof Himerius von Tarragona schickte an Damasus eine Anfrage mit einer Reihe von kirchenrechtlichen Zweifelsfällen und erwartete aus Rom eine rechtsgültige Antwort. Der Papst - es war Siricius, der Nachfolger des Damasus - antwortete mit einem in der Art eines kaiserlichen Reskripts stilisierten Schreiben. Dieses Schreiben bezeichnet man als die erste

102 Cuneo, Legislazione 1997, CXIV.

103 Hunt, Bishops 1989.

104 Ensslin, Religionspolitik 1953; Ernesti, Princeps 1998. Eine Neuinterpretation des Edikts Cunctos populos bei Errington, Accounts 1997, 411-414.

105 Noethlichs, Maßnahmen 1971, 128-165.

106 Matthews, Aristocracies 1975, 107-115. 
päpstliche Dekretale ${ }^{107}$. Spanische Bischöfe standen auch in Kontakt zu Theodosius, dessen Familie sich schon lange zum Konzil von Nicäa bekannt hatte. In den ersten Jahren seiner Herrschaft stiegen Personen spanischer und südgallischer Herkunft zu hohen Ämtern im Ostreich auf und beeinflussten die Grundlinien seiner Politik. Diese Tatsache hat John Matthews bewogen, von einem spanischen Clan am Hof des Kaisers zu sprechen, der sich durch besonders eifrige Frömmigkeit auszeichnete ${ }^{108}$. Als bedeutendste Gestalt ist Maternus Cynegius zu nennen, der die Präfektur im Osten innehatte und an den verschiedene Gesetze religionspolitischen Inhalts adressiert sind. Als hoher Amtsträger ließ er die Zerstörung heidnischer Tempel in Antiochia zu einem Zeitpunkt zu, als Theodosius noch keine Verschärfung der traditionellen Heidengesetzgebung ins Auge gefasst hatte ${ }^{109}$.

An denselben Maternus Cynegius im Amt des Prätorianerpräfekten ist das einzige im Wortlaut erhaltene Inzestgesetz des Theodosius gerichtet ${ }^{110}$. Seine genaue Datierung ist fraglich, da das Gesetz nach den Consularfasten im Jahr 393 entstanden, der Adressat Cynegius jedoch bereits im Jahr 388 verstorben ist. Im Anschluss an Seeck hat sich die Forschung auf das Jahr 387 geeinigt ${ }^{111}$. Der Gesetzesinhalt lautet: „Die Erlaubnis der Ehe mit der Gattin des Bruders oder die Ehe mit zwei Schwestern schaffen wir gänzlich ab, auch wenn die frühere Verbindung auf irgendeine Weise aufgelöst worden ist "112. Theodosius wiederholt also das von Constantius II. erlassene Verbot der Ehe mit der Schwägerin und stellt klar, dass dies nicht nur im Fall des weiteren Bestands der ersten Ehe, sondern auch nach einer Scheidung zu gelten hat. Als Hintergrund für dieses Gesetz ist die von Basilius und von den Canones synodi Romanorum überlieferte Diskussion um die Gültigkeit der Ehe mit zwei Schwestern zu vermuten. Die Bibel sprach das Verbot nämlich nur aus, wenn die erste Ehe weiter Bestand hatte. Diese Ansicht wird im Inzestgesetz des Theodosius unmissverständlich zurückgewiesen. Das Verbot des Sororats soll auch nach der Scheidung von der ersten Frau gültig sein. Ähnlich hatte sich bereits das Edikt von Constantius II. ausgesprochen. Es stellt sich daher die Frage nach dem Grund der Wiederholung. Überwiegend ist man der Ansicht, dieser Regelung sei besonders im Osten, wo die Exogamie nicht im gleichen Ausmaß verwurzelt war wie im Westen, Widerstand entgegengebracht worden ${ }^{113}$. Bis zu Justinian

107 JASPER, Beginning 2001.

108 Matthews, Aristocracies 1975, $144 \mathrm{f}$.

109 PLRE 1 1971, 235 f. Vgl. Leppin, Theodosius 2003, 124; Hahn, Gewalt 2004, 79-81.

110 Codex Iustinianus 5, 5, 5 (199). Codex Iustinianus 5, 5, 4 (199) vom Jahr 387 behandelt indirekt auch Inzestehen; vgl. Moreau, Inceste 2002, 397.

111 Seeck, Regesten 1919, 273. Moreau, Inceste 2002, 252.

112 Fratris uxorem ducendi vel duabus sororibus coniungendi penitus licentiam submovemus, nec dissoluto quocumque modo coniugio. Codex Iustinianus 5, 5, 5 (199).

113 Weiss, Endogamie 1908, 360 f.; Moreau, Inceste 2002, 242 f. 
sollte das Verbot der Ehe mit der Schwägerin im Ostreich noch mehrfach wiederholt werden ${ }^{114}$. Wie noch zu erörtern sein wird, hat auch die gallorömische Bevölkerung des 6. Jahrhunderts das Verbot der Ehe mit zwei Schwestern nicht beachtet ${ }^{115}$.

In dieselbe Zeit wie dieses erhaltene Inzestgesetz fällt auch das Verbot der Cousinenehe durch Theodosius ${ }^{116}$. Da es bald einer Revision unterzogen wurde, ist es nicht in die späteren Kodifikationen aufgenommen worden und daher im Wortlaut nicht bekannt. Als erster berichtet der berühmte Gelehrte und Redner aus Antiochia, Libanios, von einer derartigen Gesetzesänderung. In seiner Rede an Theodosius lobt der Heide Libanios den innovatorischen Geist der kaiserlichen Gesetzgebung, um den Herrscher zur Abschaffung der gewohnheitsmäBigen Fronfuhren der bäuerlichen Bevölkerung zu bewegen ${ }^{117}$. Als Beispiel für diesen innovatorischen Geist nennt er das Verbot der Cousinenehe, das lange bestehende Gewohnheiten der Eheschließung außer Kraft gesetzt habe, aber dennoch als richtige Maßnahme zu befürworten sei. Dass das Verbot der Cousinenehe auch bei anderen Heiden auf Akzeptanz stieß, belegt das Zeugnis der anonymen Epitome de Caesaribus aus der Zeit um 400. Am Ende der persönlichen Würdigung des Kaisers billigt der heidnische Autor das Verbot als Ausdruck seiner keuschen Gesinnung: „Er untersagte per Gesetz, dass anrüchige Dienstleistungen und Prostituierte bei Gelagen angeboten werden, und er verwandte sich so sehr für Keuschheit und Sitte, dass er die Ehe mit Cousinen als eine Ehe mit Schwestern untersagte" ${ }^{\text {"118. }}$.

Die Akzeptanz des Verbots der Cousinenehe von heidnischer Seite ist noch auffälliger, wenn man die „überaus harte Strafe "119 in Betracht zieht, die Theodosius über Gesetzesbrecher verhängte. Nach dem Zeugnis eines späteren Gesetzes sah der Kaiser die Todesstrafe durch Verbrennung sowie die Konfiskation der Güter vor ${ }^{120}$. Wie bereits Constantius II. machte Thedosius einen

114 Codex Theodosianus 3, 12, 3 (151 f.): Arcadius; 3, 12, 4 (152 f.): Theodosius II.; Codex Iustinianus 5, 5, 8 (199): Basiliscus; Codex Iustinianus 5, 5, 9 (199): Zenon. Zur Datierung der zuletzt zitierten Gesetze vgl. Bonini, Considerazioni 1965.

115 Siehe 95.

116 Zur Frage der Geltung des Gesetzes im gesamten Reich trotz des „partage législatif“ vgl. Moreau, Inceste 2002, 193-195.

117 Libanios, Oratio 50 de angariis (3, 476). Norman, Works 1977, 55, datiert die Rede in das Jahr 385. Vgl. Moreau, Inceste 2002, 193.

118 ... prohibueritque lege ministeria lasciva psaltriasque comissationibus adhiberi, tantum pudori tribuens et continentiae, ut consobrinarum nuptias vetuerit tamquam sororum. Epitome de Caesaribus 48, 10 (175). Vgl. Moreau, Inceste 2002, 195.

119 Nam Theodosius imperator etiam patrueles fratres et consobrinos vetuit inter se coniugii convenire nomine et severissimam poenam statuit ... Ambrosius, Ep. 58, 8 (CSEL 82/2, 116).

120 Das folgt aus der Revision durch Arcadius: Si quis incestis posthac consobrinae suae vel sororis aut fratris filiae uxorisve eius postremo, cuius vetitum damnatumque coniugium est, 
deutlichen Unterschied zwischen einer Ehe unter Blutsverwandten und einer Ehe unter verschwägerten Personen. Nur die erste Form der Inzestehe hatte die Kapitalstrafe zur Folge.

Die Ablehnung der Cousinenehe durch den Heiden Firmicus Maternus ist also kein Einzelfall. Auch Libanios und der Autor der Epitome de Caesaribus konnten sich mit einem solchen Verbot anfreunden. Dies hat Philippe Moreau zu der Schlussfolgerung bewogen, man könne das Gesetz des Theodosius nicht auf den Einfluss des Christentums zurückführen ${ }^{121}$. Das Argument des Theodosius bestand, wenn man den indirekten Nachrichten trauen kann, in der Gleichsetzung der Cousine mit einer Schwester. Diese von dem Religionsbekenntnis unabhängige „Logik der Angleichung“ weist für Moreau auf einen Mentalitätswandel hin, der Heiden und Christen gleichermaßen erfasst habe. Der heidnische Autor der Epitome de Caesaribus hebt an Theodosius lobend hervor, dass er seinen Onkel wie einen Vater, seine Nichten und Neffen wie seine eigenen Kinder behandelt habe ${ }^{122}$. Diese Stärkung der Familienbande habe gemeinsam mit einer restriktiven Sexualmoral dazu geführt, dass die Cousine mehr und mehr wie eine Schwester betrachtet worden sei und man sich zu einer Rückkehr zur alten römischen Inzestgrenze verpflichtet gefühlt habe.

Die Deutung Moreaus muss an den christlichen Quellen zum Verbot der Cousinenehe überprüft werden. Ein wichtiges Zeugnis wird von Moreau nicht berücksichtigt: die bereits oben genannten Canones synodi Romanorum ad Gallos episcopos. Der Text von c. 14 der Canones ist nämlich zweideutig, weil in der Rubrik die Ehe mit der Frau des Onkels, im Text des Kanons jedoch die Ehe mit der Tochter des Onkels untersagt wird. Die letzten Herausgeber der Canones haben den ersten Satz emendiert und daher den Text als Verbot der Cousinenehe gedeutet ${ }^{123}$. Moreau lässt diese Emendation nicht gelten und bezieht den gesamten Kanon auf die Ehe mit der Frau des Onkels ${ }^{124}$. Moreaus Entscheidung halte ich jedoch nicht für überzeugend. Das Verbot der Ehe mit der Frau des Onkels ist durch die Bibel beglaubigt (Lev. 18, 14). Der Papst hätte zur Begründung nur auf die entsprechende Bibelstelle verweisen müssen, wie er es

sese nubtiis funestarit, designato quidem lege supplicio, hoc est ignium et proscriptionis, careat proprias etiam, quamdiu vixerit, teneat facultates. Codex Theodosianus 3, 12, 3 (151).

121 Moreau, Inceste 2002, 195 („religieusement neutre“). Die These von Roda, Matrimonio 1979, nach der Theodosius mit diesem Gesetz die endogame heidnische Elite Roms treffen wollte, erscheint mir dadurch hinfällig.

122 Patruum colere tamquam genitorem, fratris mortui sororisque liberos habere pro suis, cognatos affinesque parentis animo complecti. Epitome de Caesaribus 48, 18 (176).

123 Item de eo qui abunculi sui $<$ filiam $>$ uxorem duxerit. Abunculi filiam ducere non licet, quoniam ... Canones synodi Romanorum c. 14 (42). Ebenso BABUT, Décrétale 1904, 82, und Thompson, Correspondence 1990, 363. In der Rubrik der Collectio Weingartensis, von Babut und Thompson nicht herangezogen, fehlt ebenso das Wort filia: Duval, Décrétale 2005, 22.

124 Moreau, Inceste 2002, 322. 
auch sonst in den Canones tat. Stattdessen entwickelte er eine umständliche Argumentation, die wegen des schlechten Zustands der Überlieferung nur mehr schwer rekonstruiert werden kann $^{125}$. Ein Satz lässt sich jedoch nur auf eine Ehe unter Blutsverwandten beziehen ${ }^{126}$. Die Ehe mit der Frau des Onkels kann nicht gemeint sein. Auch wenn der Sinn des Kanons geklärt ist, so erschwert ein anderes Problem die Nutzbarmachung dieser Quelle. Oben wurde bereits angesprochen, dass die Datierung der Canones umstritten ist. Nur wenn die $\mathrm{Zu}$ schreibung an den 384 verstorbenen Papst Damasus tatsächlich zutrifft, würden die Canones zeitliche Priorität vor dem Gesetz des Theodosius genießen. Dann wäre die Vermutung berechtigt, der Papst habe den Kaiser eventuell in dieser Hinsicht beeinflusst oder zumindest bestärkt. Wie bereits festgehalten, drückte Theodosius seine Wertschätzung für den Papst in dem kaiserlichen Edikt Cunctos populos aus, in dem Damasus zum Garanten des rechten Glaubens stilisiert wurde.

Ein päpstlicher Einfluss auf das Verbot der Cousinenehe ist also möglich, muss jedoch wegen der offenen Datierung der Canones synodi Romanorum Spekulation bleiben. Nach dem Tod Damasus' I. war der Bischof Ambrosius von Mailand der wichtigste kirchliche Gegenspieler des Kaisers. Seine Einstellung zur Frage der Cousinenehe gab er in einem Brief an den hohen kaiserlichen Amtsträger Aemilius Florus Paternus ${ }^{127}$ kund. Der Brief ist im letzten Jahrzehnt des 4. Jahrhunderts entstanden, vermutlich noch zu Lebzeiten von Theodosius $^{128}$. Ambrosius antwortet darin auf eine Anfrage des Paternus über die Eheschließung seines Sohnes mit der Tochter seiner Tochter. Es handelte sich also um eine Ehe zwischen Onkel und Nichte. Paternus hatte sich in dieser Frage bereits an seinen zuständigen Ortsbischof, möglicherweise den Papst ${ }^{129}$, ge-

125 Der gesamte Kanon lautet: Abunculi filiam ducere non licet, quoniam, similis causa generando per gradus patris extranei separatur atque purgatur; retro autem redire fas non est. Nam qui thorum patris vel matris violare praesumpserit, non hoc coniugium sed fornicatio nominatur. Quisque tamen contra canones apostolicos facere usurpaverit, privandus est sacerdotio si pertinax fuerit; si vero correxerit, aboleatur quod praesumptum est, ut possit reconciliatus nostrum habere consortium. Canones synodi Romanorum c. 14 (42). Babut und Duval emendieren similis causa generando in si velis causam generatio. Thompson, Correspondence 1990, 363, lehnt diese Emendation ab. Der letzte Satz macht deutlich, dass nur angehende Kleriker wegen einer solchen Ehe belangt werden: Duval, Décrétale 2005, 110.

126 Die Begründung retro autem redire fas non est hat Ähnlichkeit zu einem von Cassiodor vorgebrachten Argument gegen die Cousinenehe: ... ne et se in proximitatem redeundo polluerent et dilatationem providam in genus extraneum non haberent. Cassiodor, Variae VII 46 (CCL 96, 294).

127 Matthews, Aristocracies 1975, 110 f. u. 143 f.; PRLE 1 1971, 671 f.

128 Die Frage der Datierung bespricht Moreau, Inceste 2002, 306.

129 So die keineswegs zwingende Hypothese von Moreau, Inceste 2002, 307, der die Anwesenheit des Paternus in Rom voraussetzt. McLynn, Ambrose 1994, 259, lokalisiert den Bischof in Spanien. 
wandt, war jedoch mit einer negativen Antwort zurückgewiesen worden. Ambrosius befand sich in der schwierigen Lage, dass er weder eine Autorität aus der Bibel noch ein Gesetz aus dem römischen Recht für ein Verbot der Ehe mit der Nichte anführen konnte. In Levitikus ist nur die Ehe zwischen Neffe und Tante genannt, und das Gesetz Constantius' II., adressiert an die Bewohner der Provinz Phoenicia, war ihm offenbar nicht bekannt. Diese unerfreuliche Lage kompensierte er mit der Berufung auf das Verbot der Cousinenehe durch Theodosius. Ambrosius benutzte ein Argument a fortiori: Wenn eine Verbindung im vierten Grad durch das Gesetz untersagt sei, müsse auch eine Ehe im dritten Grad zwischen Onkel und Nichte unter das Inzestverbot fallen ${ }^{130}$.

Die Berufung auf das Gesetz des Theodosius bekräftigte Ambrosius durch weitere Argumente aus der römischen Tradition: Zum einen würden Nahehen zu einer Verwirrung in der Bezeichnung der Verwandtschaftsverhältnisse führen, zum anderen würde das Verhältnis zwischen Onkel und Nichte dem eines Vaters zu seiner Tochter gleichen ${ }^{131}$. Er erschließt deshalb ein naturrechtliches Gebot, das jedem einzelnen in das Herz eingeschrieben sei ${ }^{132}$. Der Bischof von Mailand stützt sich also, wie Moreau sehr klar herausstellt, auf traditionelle römische Argumente gegen Inzestehen. Unabhängig von dem Umfang der biblischen Inzestverbote scheint er an einem Grundsatz festzuhalten, der ihm von der restriktiven Moral seiner Zeit und der römischen Tradition vorgegeben war. Wie in den Canones synodi Romanorum geben nicht spezifisch christliche Argumente den Ausschlag, sondern solche, die im römischen Kulturkreis generell auf $\mathrm{Zu}$ stimmung gestoßen sind. Dasselbe trifft auch für die Ausführungen des Augustinus in seinem Hauptwerk De civitate dei zu. Augustinus will darin das Verbot der Cousinenehe gerade nicht als spezifisch christliches Verbot rechtfertigen, sondern benützt allein naturrechtliche Begründungen. Im Zentrum seiner Überlegungen steht das Konzept der Ausbreitung der caritas durch Exogamie $^{133}$ : Das Inzestverbot wirke als vinculum sociale, da die Verschwägerung zwischen nicht blutsverwandten Familien zur sozialen Integration der

130 Ambrosius, Epistula 58, 14 (CSEL 82/2, 114).

131 Quanta deinde etiam reliquorum confusio vocabulorum! ... Quid tam sollemne quam osculum inter avunculum et neptem, quod iste quasi filia debet, haec quasi parenti? Ambrosius, Epistula 58, 2-7 (CSEL 82/2, 113-115).

132 Interdictum est enim naturae iure, interdictum est lege quae est in cordibus singulorum, interdictum est inviolabili praescriptione pietatis, titulo necessitudinis. Ambrosius, Epistula 58, 5 (CSEL 82/2, 115).

133 Habita est enim ratio rectissima caritatis, ut homines, quibus esset utilis atque honesta concordia, diversarum necessitudinum vinculis necterentur, nec unus in uno multas haberet, sed singulae spargerentur in singulos ac sic ad socialem vitam diligentius conligandam plurimae plurimos obtinerent. Augustinus, De civitate dei XV 16 (CCL 48, 477). Vgl. Moreau, Inceste 2002, 125-127. In Ders., Prohibition 1978, wird auf das gleich lautende Argument in Plutarch, Aetia Romana 108 (333), verwiesen und für eine gemeinsame Abhängigkeit von Varro plädiert. 
Gesellschaft führe. Dieses Argument als spezifisch für einen „eherechtlichen Augustinismus" (Jean-Pierre Poly ${ }^{134}$ ) zu betrachten, ist verfehlt, da es in der römischen Tradition fest verankert ist. Augustinus schreibt, dass sogar die "gottlosen Verehrer vieler und falscher Götter diesen Brauch beobachten“, da die herrschende Sitte bereits vor dem Verbot des Theodosius eine Ehe unter Geschwisterkindern untersagt hätte ${ }^{135}$. Für Ambrosius wie für Augustinus ist die Abscheu vor Inzest in der Natur des Menschen verankert.

Die ganz und gar unchristliche Rechtfertigung des Verbots der Cousinenehe durch die Christen scheint also die Deutung Moreaus zu bestärken. Ambrosius, der Papst der Canones synodi Romanorum und Augustinus bedienen sich aus dem Fundus der römischen Tradition, um die Ausweitung des Inzestverbots zu rechtfertigen. Neben dieser wörtlichen Lektüre darf aber nicht die Tiefenstruktur der Texte ignoriert werden. Die Argumentationstaktik der Christen ist nämlich kaum überraschend, weil die Bibel selbst keine Argumente für ein solches Eheverbot liefert. Irgendwie musste für diese Rechtsänderung geworben werden, und ein Rückgriff auf bekannte Argumentationsmuster war dazu am besten geeignet. Zudem muss man gegen die Ansicht Moreaus festhalten, dass allein christliche Autoren eine Rechtfertigung des Verbots der Cousinenehe in Angriff nahmen. Steht bei Libanios und dem heidnischen Autor der Epitome de Caesaribus das Lob des Gesetzes von Theodosius eindeutig in einem panegyrischen Kontext ${ }^{136}$, war den Wortführern der lateinischen Christenheit die Begründung des Verbots offenbar ein wichtiges Anliegen. Ambrosius hat das Schreiben an Paternus gemeinsam mit einem zweiten Brief an dessen Sohn Cynegius seiner Briefsammlung einverleibt und mit der gezielten Veröffentlichung der Sammlung für dieses Eheverbot geworben ${ }^{137}$. Augustinus schaltet in seiner Nacherzählung der biblischen Geschichte einen Exkurs zur Cousinenehe ein, um seinem Standpunkt offen Ausdruck zu verleihen. Die Heiden indes akzeptierten ein solches Verbot durch Theodosius als Ausdruck seiner keuschen Lebenshaltung, fühlten sich aber nicht zu einer Rechtfertigung veranlasst. Libanios spricht die zutreffende Tatsache aus, die Gesetzesänderung des Theodosius widerspreche den Sitten der Bevölkerung. Augustinus stellt dagegen die Neuerung als Bekräftigung einer schon lange fest verwurzelten Gewohnheit

134 So lautet die Überschrift eines Kapitels von PoLy, Chemin 2003, 256.

135 Quod humano genere crescente et multiplicato etiam inter impios deorum multorum falsorumque cultores sic observari cernimus, ut, etiamsi perversis legibus permittantur fraterna coniugia, melior tamen consuetudo ipsam malit exhorrere licentiam, et cum sorores accipere in matrimonium primis humani generis temporibus omnino licuerit, sic aversetur, quasi numquam licere potuerit. Augustinus, De civitate dei XV 16 (CCL 48, 477 f.).

136 Bei Libanios ist dies offensichtlich: In seiner Autobiographie äußert er keine Vorbehalte gegen die geplante Ehe mit seiner Cousine: Libanios, Oratio 1, 95 (1, 130). Im gleichen Sinn Libanios, Oratio 37, 8 (3, 243).

137 Ambrosius, Epistula 59 (CSEL 82/2, 117 f.). 
$\operatorname{dar}^{138}$. Dass diese Aussage nicht der Wahrheit entspricht, belegt eine Reihe von Verwandtenehen in der Aristokratie und im Kaiserhaus des 4. Jahrhunderts ${ }^{139}$. Noch im 6. Jahrhundert wurden sowohl in Italien als auch in Gallien Ehen mit der Cousine geschlossen ${ }^{140}$. Die unrichtige oder zumindest stark verzerrende Aussage Augustins macht eines deutlich: Bei der Rechtfertigung des Verbots der Cousinenehe handelt es sich um eine Argumentationsstrategie, die den zugrunde liegenden Beweggründen nicht gerecht wird.

Bei der Bewertung des Verbots der Cousinenehe greift die alleinige Betonung einer römischen Kontinuität, wie sie Moreau vertritt, zu kurz. Meiner Ansicht nach müssen zwei von Moreau unterschätzte Faktoren stärker gewichtet werden: die Frage der Bibelinterpretation und die Funktion der kaiserlichen Gesetzgebung. Moreau berücksichtigt nicht, dass Ambrosius das Verbot der Cousinenehe in der Bibel verankert sehen will. Auf die Anfrage des Paternus gibt er zu bedenken: „Lass uns zuerst die Beschlüsse des heiligen Gesetzes befragen. Du gibst nämlich in deinem Brief vor, dass eine solche Ehe [zwischen Onkel und Nichte] durch dieses göttliche Recht als den Kindern erlaubt betrachtet werde, weil es nicht verboten sei. Ich aber behaupte, es sei verboten, weil, da Geringfügigeres wie die Ehe zwischen Cousin und Cousine verboten ist, ich umso mehr das für verboten erkläre, was einer engeren Verwandtschaft zugehörig ist. Wer nämlich Geringfügigeres einschränkt, entbindet nicht von Schwerwiegenderem, sondern unterbindet es " ${ }^{\text {"141 }}$. Noch deutlicher wird er an einer anderen Stelle: „Wie kann man nämlich daran zweifeln, wenn das göttliche Gesetz auch den Geschwisterkindern die eheliche Verbindung verbietet, die sich im vierten Grad vereinigen “142. Auf welcher Grundlage sich Ambrosius zu dieser Aussage berechtigt fühlte, muss ein Rätsel bleiben. Da Paternus selbst die Bibel als Argument heranzog, konnte er nicht mit der Unwissenheit seines Briefpartners gerechnet haben. Die Herausgeberin der Briefsammlung sieht in der Erwähnung der lex divina einen Verweis auf das allgemeine Verbot von Verwandtenehen in Lev. 18, 6. Vielleicht kann man Ambrosius eine ähnliche

138 Experti autem sumus in conubiis consobrinarum etiam nostris temporibus propter gradum propinquitatis fraterno gradui proximum quam raro per mores fiebat, quod fieri per leges licebat, quia id nec divina prohibuit et nondum prohibuerat lex humana. Augustinus, De civitate dei XV 16 (CCL 48, 478).

139 Moreau, Inceste 2002, 313-317 u. 369-375.

140 Siehe $85-88$ und $118-120$.

141 Sed prius sacrae legis scita interrogemus; praetendis enim in tuis litteris quod permissum hoc divino iure conubium huiusmodi pignoribus existimetur, eo quod non sit prohibitum. Ego autem et prohibitum assero, quia cum leviora interdicta sint de patruelibus fratribus, multo magis hoc, quod artioris est plenum necessitudinis, interdictum arbitror. Qui enim leviora adstringit, graviora non solvit sed alligat. Ambrosius, Epistula 58, 4 (CSEL 82/2, 114).

142 Quid enim est quod dubitari queat, cum lex divina etiam patrueles fratres prohibeat convenire in coniugalem copulam, qui sibi quarto sociantur gradu. Ambrosius, Epistula 58, 3 (CSEL 82/2, 115). 
Argumentation unterstellen, wie sie der von ihm hoch geschätzte Kirchenvater Basilius in der Frage der Schwagerehe entwickelte ${ }^{143}$. Dieser vertrat die Position, die namentliche Aufzählung der Verwandten in Levitikus reiche nicht aus und müsse an das neutestamentliche Verständnis der Ehe angepasst werden. Was in der Bibel nicht ausdrücklich verboten sei, solle deshalb nicht als erlaubt angesehen werden ${ }^{144}$. Basilius nahm die biblischen Inzestverbote ernst, nicht aber ihren Umfang.

Der zweite Faktor, der für das Verständnis des Verbots der Cousinenehe in Rechnung gestellt werden muss, ist die Wertung der Gesetzgebung als religiöser Propaganda. Unter Theodosius erreichte die Schärfe der Religionsgesetzgebung nach der Regierung des Constantius II. einen neuen Höhepunkt ${ }^{145}$. Zu Beginn seiner Herrschaft wollte er die Glaubenseinheit erzwingen, indem er allen, die sich nicht zur Glaubensformel von Nicäa bekannten, die staatsbürgerlichen Rechte aberkannte. Als im Westen der Usurpator Eugenius an die Macht kam und sich der heidnischen Aristokratie annäherte, ließ Theodosius „im Ton einer Missionspredigt ${ }^{\text {"146 }}$ auch die private Ausübung des heidnischen Kultes untersagen. Der Weg zur einheitlichen ,Staatskirche` war geebnet. Die Schärfe der Religionsgesetzgebung wirkte sich wie bei Constantius II. auf das Eherecht aus. Theodosius verallgemeinerte das Verbot ehelicher Verbindungen zwischen Juden und Christen, das Constantius ausgesprochen hatte, und drohte Delinquenten mit der Strafe für Ehebrecher, dem Tod durch das Schwert ${ }^{147}$. Auch das Gesetz des Constantius gegen passive Homosexualität wurde verschärft ${ }^{148}$. In diesen Kontext muss man auch die Inzestgesetze stellen. Sie setzten die Politik Constantius' II. fort und waren Äußerungen einer Propaganda des christlichen Kaisertums ${ }^{149}$. Ihr Charakter als symbolische Gesetzgebung lässt sich an der geringen Effektivität erkennen. Untersuchungen zur Effektivität der Religionsgesetzgebung Kaiser Theodosius' haben deutlich die Diskrepanz zwischen der erbarmungslosen Rhetorik und der fehlenden Realisierung herausgearbeitet ${ }^{150}$.

143 Ambrosius zeigte Basilius seine Wahl zum Bischof an, um für Unterstützung gegen den Arianismus zu werben, und war mit dessen Schriften gut vertraut: Dassmann, Ambrosius 2004, 36 u. 206.

144 Basilius von Caesarea, Ep. 160, 3 (2, 89). Das gleiche Argument benützt Ambrosius, Epistula 58, 5 (CSEL 82/2, 115): Numquid ideo liceat, quia non est prohibitum. Minime. ... Quanta huiusmodi invenies non interdicta a lege per Moysen edita ...

145 Noethlichs, Maßnahmen 1971, 129-182; Ernesti, Princeps 1998, 17-88.

146 ENßLin, Religionspolitik 1953, 83.

147 Codex Theodosianus 3, 7, 2 (142) u. 9, 7, 5 (448). SEECK, Regesten 1919, 273. Vgl. Noethlichs, Judentum 1996, 104.

148 Collatio legum Mosaicarum et Romanarum 5, 3 (155).

149 KIng, Theodosius 1961, 93-96. Das Konzept eines christlichen Kaisertums relativieren McLynn, Ambrose 1994, 106-111, und Leppin, Theodosius 2003, 121 u. 232.

150 Hunt, Christianising 1993, 157; Friell - Williams, Theodosius 1994, 56; ErringTON, Accounts 1997; DERs., Church 1997, 21. 
Ähnliches wird für die Inzestgesetze gelten ${ }^{151}$. Nur so ist vorstellbar, dass Theodosius einerseits die Schließung einer Cousinenehe mit der Kapitalstrafe bedrohte und andererseits die Möglichkeit kaiserlicher Dispensierungen eröffnete $^{152}$. Die Inzestgesetze sind daher Ausdruck einer dem christlichen Ideal der Keuschheit verpflichteten Propaganda ${ }^{153}$.

Gegen Moreau möchte ich daher an einem bischöflichen Einfluss auf das Verbot der Cousinenehe festhalten. Diese Einschätzung erfährt durch die Betrachtung der weiteren Geschichte dieses Verbots im Ostreich Bestätigung. Nach dem Tod von Theodosius konnte sich der Prätorianerpräfekt Rufinus, ein Mitglied der spanisch-südgallischen Entourage des Kaisers und Förderer des Mönchtums, nur kurz an der Macht halten ${ }^{154}$. Die Ermordung des Rufinus durch den Goten Gainas löste ein Revirement am Hof von Konstantinopel aus, im Zuge dessen die alte Elite der östlichen Provinzen die Schlüsselpositionen in der Reichsverwaltung besetzte. Das Vorgehen gegen Heiden und Juden wurde konzilianter, und die Beeinträchtigung der weltlichen Gerichtsbarkeit durch die Kirche wurde zurückgedrängt ${ }^{155}$. Herausragender Vertreter dieser Elite war Flavianus Eutychianus ${ }^{156}$. Kaiser Arcadius adressierte zwei Gesetze an ihn, die beide die Cousinenehe zum Gegenstand hatten. Im Jahr 396 schuf der Kaiser die Todesstrafe und die Konfiskation als Strafe ab und erlegte stattdessen den inzestuösen Eheleuten erbrechtliche Nachteile auf ${ }^{157}$. Als Eutychianus zum Prätorianerpräfekt des Ostens aufgestiegen war, schuf Arcadius im Jahr 405 das Verbot der Cousinenehe vollständig $a b^{158}$. Es lässt sich erkennen, dass das Verbot der Cousinenehe von einer klerikalen Elite getragen wurde, der die Wortführer des Westreichs angehörten: Ambrosius, der Papst und Augusti-

151 So lautet auch die Vermutung von Krause, Gefängnisse 1996, 348 Anm. 7.

152 Solche Dispensierungen sind nach der übereinstimmenden Aussage von Ambrosius und Symmachus häufig ergangen: Ambrosius, Epistula 58 (CSEL 82/2, 116); Symmachus, Epistola 9, 133 (MGH Auct. Ant. 6/1, 271). Zur Praxis der Dispensierung vgl. Moreau, Inceste 2002, 366-375. Dass bereits Theodosius Dispensierungen ermöglichte, belegt Codex Theodosianus 3, 10, 1 (147).

153 Die Osteramnestie lässt Theodosius für Inzestuöse mit folgenden Worten nicht gelten: Quis adultero vel incesti reo tempore castitatis ignoscat? Codex Theodosianus 9, 38, 8 (497). Zu diesem Thema vgl. auch Codex Theodosianus 9, 38, 6-7 (497) sowie Constitutiones Sirmondianae 8 (913 f.). Vgl. hierzu Puliatti, Regime 2001, 171.

154 Matthews, Aristocracies 1975, 134-136; Liebeschütz, Barbarians 1990, 89-92.

155 Liebeschüтz, Barbarians 1990, 146-153; Langenfeld, Christianisierungspolitik 1977, 127-165; Ducloux, Naissance 1994, 53-80; LotTER Moser, Religionsgesetzgebung 2001, 42-47.

156 PLRE 1 1971, 319-321.

157 Codex Theodosianus 3, 12, 3 (151 f.) an Eutychianus als Prätorianerpräfekt des Illyricum.

158 Codex Iustinianus 5, 4, 19 (196). 
nus ${ }^{159}$. Unter der Herrschaft Theodosius' I. übten sie und ihr Umfeld Einfluss auf die kaiserliche Gesetzgebung aus. Danach kamen Personen wie Eutychianus an die Macht, die nicht an der Änderung der traditionellen endogamen Praxis des Ostens interessiert waren.

\section{Justinians christliches Eherecht}

Das Recht war für Justinian das maßgebliche Instrument, um sein Projekt der Reform des römischen Reichs zu verwirklichen ${ }^{160}$. Mit der Kodifikation der kaiserlichen Konstitutionen (Codex), der Zusammenstellung der alten Rechtsliteratur (Digesta) und der Abfassung eines vorbildlichen Lehrbuchs (Institutiones) sollten die Unstimmigkeiten und Widersprüchlichkeiten der Tradition beseitigt werden. Justinians Verhältnis zur Tradition war zwiegespalten: Einerseits inszenierte er seine Reform als Überwindung der Nachlässigkeit seiner Vorgänger und als Rückkehr zur authentischen Rechtstradition; andererseits kennzeichnete er sein eigenes Kodifikationswerk als in der Geschichte einzigartiges Unternehmen und forderte die Anpassung des Rechts an die neuen Zeitumstände ${ }^{161}$. Teil dieser Anpassung war die umfassende Christianisierung des Rechts, die in der am 16. November 534 erlassenen zweiten Redaktion des Codex zum Ausdruck kam. Während hundert Jahre zuvor die Kodifikatoren des Codex Theodosianus noch die überkommene Gliederung des Edictum perpetuum Hadrians reproduzierten und das neu entstandene Kirchenrecht an verschiedenen Stellen des Gesetzbuches einfügten, zeigt die Gliederung des Codex Iustinianus eine deutliche christliche Prägung ${ }^{162}$. Das erste Buch beginnt mit einem Titel zum rechten Glauben und zum Dogma der Trinität und versammelt anschließend die wichtigsten Themen des Kirchenrechts ${ }^{163}$.

Die Christianisierung des Rechts erfasste auch die Ehe. Im Codex war diese Rechtsmaterie dem Privatrecht zugeordnet und zog noch nicht die Aufmerk-

159 Belege für eine christliche Verurteilung der Cousinenehe aus dem Ostteil des Reiches sind rar. Einen Vorbehalt dagegen bezeugt ein koptischer Text über Bischof Demetrios von Alexandria: Budge, Martyrdoms 1914, 398, zitiert bei Brown, Keuschheit 1991, 509. Nach WipszycKa, Études 1996, 264, handelt es sich um einen „récit très fantaisiste".

160 Einen Überblick aus historischer Perspektive geben Moorhead, Justinian 1994, 32-38; Noethlichs, Iustinianus 2001, 703-753; Humfress, Law 2004; Evans, Justinian 2005, 21-32.

161 Vgl. Mans, History 1986, 28 f.; Noethlichs, Propaganda 2000, 120-125; Meier, Zeitalter 2003, 137-150.

162 Harries, Code 1998, 69; Detlef Liebs, Art. „Jurisprudenz“, in: RAC 19 (2001) 604638, hier 631-636.

163 Vgl. Alivisatos, Gesetzgebung 1913. 
samkeit des Kaisers auf $\operatorname{sich}^{164}$. Erst in der Novellengesetzgebung, die im Jahr 535 einsetzte, unternahm Justinian immer wieder neue Anläufe, das Eherecht zu regulieren und eine christliche Praxis in der Scheidungsfrage zur Geltung zu bringen. Am umfangreichsten ist die Novelle 22 aus dem Jahr 535, die 48 ausführliche Kapitel umfasst und als „Codex der christlichen Ehe“ bezeichnet wurde $^{165}$. Obwohl Justinian die Mängel der kaiserlichen Gesetzgebung früherer Zeiten im Prolog in deutlichen Worten anprangert, bleibt er in der Novelle 22 im Rahmen der Tradition. Er fasst die Ehe grundsätzlich als auflösbar auf: Geschiedene Ehen sollten rechtsgültig bleiben, ungerechtfertigte Scheidungen jedoch durch Vermögensstrafen geahndet werden. Erst nach der Wende des Jahre 542, als Justinian durch eine Politik der Frömmigkeit auf eine Serie von katastrophalen Ereignissen reagierte ${ }^{166}$, verschärfte er auch die Diskreditierung der Scheidung. In der Novelle 117 von 542 schränkte der Kaiser die Scheidungsgründe weiter ein und untersagte erstmals in der Geschichte des römischen Rechts die einvernehmliche Scheidung ${ }^{167}$. Ausgenommen von dieser Regelung war nur der beiderseitige Eintritt der Eheleute ins Kloster. Im Jahr 556 wiederholte er diese Verbote und drohte Gesetzesbrechern mit Vermögensverlust und mit der zwangsweisen Einweisung ins Kloster ${ }^{168}$. Diesen Strafen sollte man nur durch eine Versöhnung der Eheleute entgehen können. Dieselbe Maßnahme der Klostereinweisung sollte nach dieser Novelle auch Ehebrecherinnen treffen $^{169}$.

Nicht nur die drastische Einschränkung der Möglichkeiten zur Scheidung, auch die Art der Bestrafung war christlich motiviert. Die Einweisung ins Kloster sowie die Übertragung eines Teils des Vermögens an diese Einrichtung sollte erfolgen, „damit nicht durch diese Verachtung sowohl das Urteil Gottes missachtet als auch unsere Gesetz übertreten werden " ${ }^{\text {170 }}$. Die Übeltäter waren zur Buße und zur Wiedergutmachung verurteilt, um dadurch den Zorn Gottes zu besänftigen. Die zugrunde liegende Argumentationsstruktur kommt am deutlichsten in der Nov. 77 zum Ausdruck ${ }^{171}$. Homosexualität, Blasphemie und

164 Mit Ausnahme von Codex Iustinianus 5, 17, 10-11 (213). Vgl. Reynolds, Marriage 1994, 54.

165 Bretone, Geschichte 1992, 257. Ausführlich analysiert von Noonan, Novel 1968.

$166 \mathrm{Zu}$ den vierziger Jahren als Krisenjahre: MoorheAd, Justinian 1994, 89-101; Noethlichs, Propaganda 2000, 120-130. Zur Reaktion Justinians Meier, Zeitalter 2003.

167 Novella 117, 10 (560 f.). Vgl. Reynolds, Marriage 1994, 58.

168 Novella 134, 11 (686).

169 Novella 134, 10 (685).

170 ... ut non propter hunc contemptum et dei iudicium contemnatur et nostra lex transgrediatur. Novella 137, 11, 1 (687).

171 Vgl. Jones, Novellae 1988, 191. Von den Herausgebern wird die Novelle in das Jahr 535 gesetzt. Andere Datierungen in die Jahre zwischen 535 und 539 erwähnt MeIER, Zeitalter 2003, 594 Anm. 123, der selbst eine Entstehung nach 542 befürwortet. Im Un- 
bestimmte Formen des Eides werden darin mit den „äußersten Qualen“ bestraft, damit nicht der gerechte Zorn Gottes durch solche gottlosen Handlungen erregt werde. „Denn wir lernen aus den heiligen Schriften, dass wegen solcher gottloser Taten Städte und ihre Einwohner gleichermaßen zugrunde gehen “172. Diese Berufung auf die Strafgewalt Gottes im Alten Testament war im Rahmen des spätantiken Rechts eine radikale Neuerung. Mischa Meier führt diese epochemachende Argumentationsstruktur auf die persönliche Frömmigkeit Justinians zurück und versteht sie als Reaktion auf eine Serie von Katastrophen wie Erdbeben, Pestepidemien und Hungersnöte ${ }^{173}$. Justinian vollzog damit einen Schritt weg von der traditionellen „pragmatischen “174 Argumentation hin zu einer dogmatisch-biblischen Argumentation der Gesetzgebung, wie sie das frühe Mittelalter prägen sollte. Die Drohung mit dem Zorn Gottes ermöglichte es dem Gesetzgeber, von der Gesellschaft die Einhaltung neuer normativer Erwartungen zu verlangen.

Justinians Gesetze zum Inzestverbot fallen in die Anfangsjahre seiner Regierungszeit und sind noch von der römischen Begründungstradition geprägt. In der Novelle 12 aus dem Jahr 535 drückt er in für ihn typischer Weise seine Empörung über die mangelhaften Gesetze seiner Vorgänger aus ${ }^{175}$. Diese würden inzestuöse Eheleute nur durch Vermögensverlust bestrafen, der vor allem die Kinder aus dieser Ehe und nicht die Eheleute selbst betreffe. Wie das syrischrömische Rechtsbuch belegt, war nämlich vor Justinian die von Arcadius im Jahr 396 getroffene Regelung in Geltung ${ }^{176}$. Danach konnten inzestuöse Eheleute ihr Vermögen behalten, durften es jedoch nicht an ihre Kinder oder an andere Verwandte vererben, die ihrer Ehe zugestimmt hatten. Waren keine Verwandten vorhanden, ging das Vermögen nach dem Tod der Eheleute an den Fiskus. Justinian stellt diese Regelung als ungerecht hin, da die unschuldigen Kinder mehr bestraft würden als die schuldigen Eltern. Er ordnet daher an, dass das Vermögen der Eheleute konfisziert werden soll und die Übeltäter selbst keine Ämter ausüben dürfen sowie ins Exil gehen müssen ${ }^{177}$. Handelt es sich um

terschied zur nach dem Erdbeben von 557 verfassten Novella 141 gibt es in der Novella 77 keine direkten Bezugnahmen auf bestimmte Ereignisse. Eine präzise Datierung erscheint daher schwierig.

172 Docemur enim a divinis scripturis, quia ex huiusmodi impiis actibus et civitates cum hominibus pariter perierunt. Novella 77, 1 (382).

173 Meier, Zeitalter 2003, 591-599.

174 Vgl. Fögen, Gesetzgebung 1987; Reynolds, Marriage 1994, 61-65.

175 Pro incestis dudum scriptas ab imperatoribus leges non perfecte habere iudicamus ... Novella 12 pr. (95). Zu Justinians Kritik an seinen Vorgängern vgl. Meıer, Zeitalter 2003, 146. Zur Inzestgesetzgebung des Kaisers ausführlich Puliatti, Regime 2001, 189-224.

176 Das syrisch-römische Rechtsbuch $₫ 98(2,137-141)$ nach Codex Theodosianus 3, 12, 3 (151 f.).

177 Sitque ei poena non confiscatio solum, sed etiam cinguli privatio et exilium, et si vilis fuerit, etiam corporis verberatio, quatenus discat caste vivere et intra naturam se continere ... 
niedrig gestellte Personen, soll die Prügelstrafe hinzukommen. Für bestehende Inzestehen legt Justinian eine Frist von zwei Jahren fest, innerhalb derer die Ehe aufgelöst werden und nur eine geringe Vermögensstrafe eintreten sollte. Erbberechtigt sind nur Kinder aus früheren rechtmäßigen Ehen. Für Kinder aus Inzestehen schließt Justinian ausdrücklich eine nachträgliche Legitimierung aus ${ }^{178}$.

Die Motive dieser Strafverschärfung sind traditionell. Justinian setzt sich als gerechter Herrscher in Szene, der eine angemessene Bestrafung der Übeltäter im Auge hat. Überdies wird der Inzest mit für die römische Tradition typischen Argumenten diffamiert: Inzestehen seien gottlos, gegen die Natur und führten zu einer Verwirrung der Verwandtschaftsnamen ${ }^{179}$. Selbst die vernunftlosen Tiere würden diese Grenze der Natur nicht überschreiten ${ }^{180}$. Dieser Klassizismus der Form ist zweifelsohne das Werk Tribonians, des Autors eines Großteils der frühen Novellen ${ }^{181}$. Wären diese Gesetze zehn Jahre später erlassen worden, hätte sich Justinian ebenso einer biblischen Legitimation bedienen können, da in Levitikus 18 die Ausmerzung des gesamten Volkes angedroht wird, falls die Inzestgesetze nicht eingehalten würden. Vielleicht war eine solche für die Frömmigkeit Justinians typische Begründung bereits im Hintergrund wirksam, im Frühmittelalter sollte diese Argumentationsstruktur vorherrschend werden.

Neben einer Verschärfung der Strafpraxis ließ Justinian auch den Umfang des Inzestverbots erweitern. Im Jahr 530 beantwortete er eine Anfrage des Prätorianerpräfekten Julian zur Ehe zwischen Pflegevater und Pflegetochter. Der Kaiser erlaubte eine solche Ehe unter der Bedingung, dass der Pflegevater das Kind nicht wie seine Tochter behandelt und er sie zuvor in Freiheit gegeben hatte. Eine andere Form der Ehe ordnet Justinian ausdrücklich dem Inzestverbot zu: die Ehe zwischen Pate und Patenkind. „Es ist jedoch gänzlich verboten, diese Person zu heiraten, die jemand - sei es als Pflegekind oder nicht - von der hochheiligen Taufe aufgenommen hat, da nichts anderes eine väterliche $\mathrm{Zu}$ -

Novella 12, 1 (95 f.). In Novella 154 (730), einem Spezialgesetz für die Provinzen Mesopotamien und Osroene droht Justinian sowohl den Inzestuösen als auch den nachlässigen Amtsträgern mit der Todesstrafe. Amnestie davon erließ im Jahr 566 Kaiser Justin II.: Novellae Justini 3 (5 f.); Dölger, Regesten 1924, 1 (Nr. 5).

178 Novella 74, 6 (377) vom Jahr 539; Novella 89, 15 (444) vom Jahr 539. Noethlichs, Iustinianus 2001, 730, spricht von einer „merkwürdig unbarmherzigen Abscheu gegen inzestuöse Kinder". Diese kommt auch in einem abseitig überlieferten Gesetz Justinians zum Ausdruck, das Corcoran, Constitution 2000, eingehend analysiert und Diocletian zuschreibt. Moreau, Inceste 2002, 365 f., favorisiert dagegen die Autorschaft Justinians, m.E. zu Recht. Überliefert ist das Gesetz zusammen mit dem oben besprochenen Anecdoton Livianum.

179 Novella 12, 1 (95 f.); Novella 154 pr. (730) vom Jahr 535/536. Vgl. Moreau, Inceste 2002, $63 \mathrm{f}$.

180 ... egerit vero quae impia sunt et scelesta, et talia concupierit qualia plurima etiam irrationabilia amovent animalia. Novella 12, 1 (95). Vgl. Moreau, Inceste 2002, 80.

181 Honoré, Tribonian 1978, 137. 
neigung und ein gerechtes Eheverbot nach sich ziehen kann wie eine solche Verbindung, durch die ihre Seelen mit Gottes Hilfe verbunden worden sind“182. Dieses Gesetz wurde Teil des Codex Iustinianus und markierte den Beginn der Anerkennung der geistlichen Verwandtschaft als Ehehindernis. Dass die Maßnahme Justinians auf einem verbreiteten Vorbehalt gegenüber solchen Ehen in der Bevölkerung beruhte, konnte Joseph Lynch aufgrund einer Anekdote aus Prokop wahrscheinlich machen ${ }^{183}$. Prokop benutzte den Ehebruch zwischen der Frau Belisars Antonina und dem Patenkind des Feldherrn, um die moralische Verwerflichkeit Antoninas in grellen Farben auszumalen. Diese Strategie konnte nur funktionieren, wenn solche Verbindungen auch von der Leserschaft als Inzest aufgefasst wurden.

Die Erweiterung des Inzestverbots auf die Patenschaft ist besonders in einer Hinsicht ein wertvolles Zeugnis. Sie macht nämlich deutlich, dass auch Justinian an einer Anpassung des römischen Inzestverbots an das zeitgenössische Verständnis der Verwandtschaft gelegen war. Das Verhältnis der Patenschaft wurde als eine besondere Art der Verwandtschaft stilisiert, in der der Pate in erster Linie die Rolle einer väterlichen Schutzperson und weniger die eines Gewaltinhabers einnahm ${ }^{184}$. Die offensichtliche Parallele zur Adoption musste bewirken, dass auch in diesem Fall eine Ehe untersagt wurde. Justinian befürwortete dies, obwohl er in der Frage der Cousinenehe auf dem Standpunkt des Ostreichs beharrte und diese Form der Ehe für erlaubt erklärte ${ }^{185}$. Den Grund für die Haltung des Kaisers wird man wohl darin sehen müssen: Eine Ehe zwischen Pate und Patenkind war nicht im Sinne der Patenschaft, da durch die Patenschaft eine soziale Bindung neben der Blutsverwandtschaft und der durch Ehe konstituierten Schwägerschaft geschaffen werden sollte. Das Verbot einer solchen Ehe musste auf Akzeptanz stoßen und stellte die Behörden vor kein Problem, da solche Ehen wohl nur selten vorkamen. Die Ehe mit der Cousine war dagegen im östlichen Mittelmeerraum eine wenn nicht verbreitete, so doch unbedenkliche Praxis. Ein Verbot hätte sich gegen den Widerstand der Bevölkerung durchsetzen müssen.

182 Ea videlicet persona omnimodo ad nuptias venire prohibenda, quam aliquis sive alumna sit sive non, a sacrosancto suscepit baptismate, cum nibil aliud sic inducere potest paternam adfectionem et iustam nuptiarum prohibitionem, quam huiusmodi nexus, per quem deo mediante animae eorum copulatae sunt. Codex Iustinianus 5, 4, 26 (197).

183 Lynch, Godparents 1986, 225-229, mit Verweis auf Prokop, Anecdota 1, 1 (7-10).

184 Vgl. Jussen, Patenschaft 1991, $158-164$.

185 Institutiones 1, 12, 4 (4); Codex Iustinianus 6, 25, 2 (258); 5, 4, 19 (196). Bonini, Considerazioni 1965, 512, meint, dass durch den Codex Theodosianus wieder das Verbot der Cousinenehe im Osten eingeführt wurde. Dem widerspricht jedoch das Zeugnis des römisch-syrischen Rechtsbuchs $\$ 98$ (2, 137-141). In diesem Sinn auch MorEaU, Inceste 2002, 197. Zur Frage der Geltung im Westen erlassener Gesetze nach 438 vgl. Sirks, Code 1986, 275 u. 292. 


\subsection{Christianisierung ohne Bibel}

Diocletian, der Initiator der schwersten Christenverfolgung, hat als erster Kaiser ein Edikt zum Inzestverbot erlassen und darin die Strafen für Vergehen drastisch verschärft. Gerechtfertigt hat er dies unter anderem mit der Heiligkeit der Verwandtschaft und der Bewahrung römischer Keuschheit. Als knapp hundert Jahre später der christliche Kaiser Theodosius den Umfang des Inzestverbots erweiterte, griff er auf dieselben Legitimationsformeln zurück. Selbst Justinian bediente sich noch ausschließlich aus dem Fundus der römischen Tradition, um die Strafe gegen das Eingehen verbotener Verwandtenehen zu verschärfen. Diese Kontinuität ist auf den ersten Blick schwer mit der These in Einklang zu bringen, das Christentum habe die Erweiterung und Verschärfung der Inzestgesetzgebung maßgeblich beeinflusst. Ebenso wenig wird diese Annahme durch die Bibel selbst gestützt. Im Alten Testament sind nur jene Eheverbindungen untersagt, die auch im römischen Recht der hohen Kaiserzeit als Verbrechen diskriminiert waren. Philippe Moreau setzt deshalb die Ausdehnung der Eheverbote mit einer restriktiver werdenden Moral und mit einer um sich greifenden „Logik der Assimilation“ in Verbindung. Diese Moral der Keuschheit habe die gesamte Gesellschaft erfasst und in der Spätantike zur Wiederbelebung der altrömischen Inzestgrenze geführt. Im Unterschied zur älteren Forschung negiert Moreau den christlichen Einfluss.

Diese Debatte um den Einfluss des Christentums wirft grundsätzliche Fragen auf. Im Rahmen einer Untersuchung des 4. Jahrhunderts einen essentialistischen Begriff des Christentums zu verwenden, führt aus historischer Perspektive nicht weiter. Was die Essenz des Christentums ausmacht, definierte jede Zeit für sich selbst und war gerade in der Epoche nach der Konstantinischen Wende heftig umstritten. Das Inzestverbot stand nicht im Mittelpunkt dieser Kontroversen, aber es berührte andere umkämpfte Fragen wie die Stellung der Bischöfe zum Staat, die Rolle des Kaisers in der Kirche sowie die Formen sexueller Askese ${ }^{186}$. In diesem Rahmen gewann die Frage nach Umfang und Inhalt der Eheverbote eine neue Bedeutung. Diese Rechtsmaterie in neuen Gesetzen zu regeln, verlangten nicht die Heiden; die Initiative ging von Bischöfen und besonders frommen Kaiser aus.

Zum Verständnis dieser kaiserlichen Inzestgesetzgebung kann ein Vergleich weiterhelfen. Die Führungsrolle Diocletians ist nämlich kein Einzelfall. Diocletian untersagte auch als erster Kaiser die Wissenschaft der Astrologie und erließ erstmals ein Edikt gegen die Manichäer. Marie Theres Fögen hat diese Gesetze untersucht und in den Kontext des sich steigernden „kaiserlichen Wissensmonopols“ im 4. Jahrhundert gestellt. Nach Fögen bewirkte die ver-

186 Vgl. Brown, Keuschheit 1991; Ders., Power 1992; Barnes, Athanasius 1993; Drake, Constantine 2000. 
stärkte Sakralisierung des Kaisertums unter Diocletian die Intoleranz gegenüber Gruppen, die einen vom Kaiser als summus pontifex unabhängigen Zugang zum übernatürlichen Wissen in Anspruch nahmen. Der sakrale Herrscher der Spätantike wollte durch die Gesetzgebung die „Regierbarkeit der Gesinnung “"187 erzwingen. Die nachfolgenden christlichen Kaiser „beschrieben das rechte Verhältnis zwischen Gott und Kaiser nicht wesentlich anders, sondern nur deutlicher und definitiver ${ }^{\text {“188 }}$. Sie wandten den Anspruch auf „Regierbarkeit der Gesinnung" gegen das Heidentum selbst und fanden in den Häretikern neue Opfer für ihren religiösen Eifer. Constantius II. erklärte die altehrwürdige Tradition der Opferschau zum „Wahnsinn“ und diffamierte sämtliche Vertreter der Magie und Wahrsagekunst als „Feinde des Menschengeschlechts“. Unter Theodosius I. kam diese Vorstellung vom Menschengeschlecht und seinen Feinden „beim Aufbau einer neuen christlichen Gesellschaft zum Einsatz. Es sind die Häretiker, Apostaten und Andersgläubigen, die nun als Fremde und Feinde der menschlichen Gesellschaft bezeichnet werden “189.

Bei der Inzestgesetzgebung ist eine ähnlich komplexe Entwicklung vorauszusetzen. Den Inzest als Verstoß gegen die göttliche Ordnung (fas) hat Diocletian erstmals zum Gegenstand eines Edikts erhoben. Als summus pontifex und Mitglied einer vergöttlichten Herrscherfamilie schrieb er sich die Bewahrung der altrömischen Keuschheit auf die Fahne und legitimierte damit sein gesetzgeberisches Vorgehen gegen Verwandtenehen. Diese Sorge um die göttliche Ordnung stellte auch das Motiv für die christlichen Kaiser dar, neue Gesetze zum Inzestverbot zu erlassen. Die Legitimationsgrundlage für die Verschärfung und Ausweitung des Inzestverbots blieb daher im Wesentlichen gleich. Wie bei der „Enteignung der Wahrsager" gingen die wesentlichen Initiativen von Constantius II. und Theodosius I. aus, die sich um eine Anpassung an die Lehre der Bibel bemühten. Doch worin bestand die Lehre der Bibel in der Frage des Inzestverbots? Bis zur Tolerierung des Christentums durch Constantin hatten sich die Bischöfe mit dieser Frage nicht befasst. Erst die Synoden von Elvira und Neocaesarea markieren den Beginn der Formierung einer christlichen Doktrin der Ehehindernisse. Die Bischöfe griffen auf die Normen von Levitikus 18 zurück und konstruierten eine christliche Tradition des Inzestverbots, die es bislang noch nicht gegeben hatte. Abgesehen von den eindeutigen Verboten der Bibel herrschte anfangs keine Einigkeit. Der Briefwechsel zwischen Basilius von Cäsarea und Diodor von Tarsus zeigt dies in aller Deutlichkeit. Die Diskussion drehte sich nicht um die Bewahrung von altrömischen Traditionen, sondern vielmehr um ganz konkrete Fragen: ob das Sororat ebenso wie das Levirat, die Nichtenehe ebenso wie die Neffenehe unter das Inzestverbot fallen sollten. Wie

187 FöGEN, Enteignung 1997, 33.

188 FöGEN, Enteignung 1997, 286.

189 FöGEN, Enteignung 1997, 232. 
in vergleichbaren Fällen ist auch hier anzunehmen, dass die zahlreichen Konflikte und Widerstände, mit denen die Christianisierung des Reichs im 4. Jahrhundert verbunden war, dazu führten, dass sich letztlich die Vertreter der strengen Auffassung durchsetzten ${ }^{190}$. Dieser Befund einer allmählichen Klärung des Standpunkts berechtigt nicht dazu, den Einfluss dieser Debatten innerhalb der Christengemeinde auf die Gesetzgebung seit Constantin insgesamt zu leugnen.

Anders gelagert ist das Verbot der Cousinenehe. Hierfür konnte auch ein gutwilliger Interpret wie der von Hieronymus wegen seiner exegetischen Fähigkeiten gescholtene Ambrosius in der Bibel keinen Anhalt finden. Doch an dieser Tatsache mussten christliche Theologen keinen Anstoß nehmen. Dass die mosaischen Gesetze des Alten Testaments nicht wörtlich zu befolgen, sondern in dem figuralen Schema von Weissagung und Erfüllung zu deuten sind, war ihnen allen wohl bekannt. Das generelle Verbot von Verwandtenehen in Lev. 18, 6 konnte daher durchaus als Ausgangspunkt genutzt werden, um das biblische Inzestverbot an die Verwandtschaftsvorstellung der eigenen Zeit anzupassen. Waren diese Konzepte der Verwandtschaft noch von dem altrömischen Verbot der Ehe mit der Cousine ersten und zweiten Grades beeinflusst? Ich kann mich einer solchen Hypothese nicht anschließen. Die Ehe mit der Cousine war zumindest seit 200 v. Chr. eine Selbstverständlichkeit und unterlag keinerlei Diffamierung. Erst ein kleiner Kreis von Theologen und Kirchenpolitikern Damasus, Ambrosius und Augustinus - sprach sich für das Verbot aus und konnte sich beim Kaiser Gehör verschaffen. Von diesen drei Bischöfen gibt Augustinus eine aufschlussreiche Begründung. Die exogame Ehepraxis führt nach Augustinus zu einer Ausbreitung der christlichen Caritas, da die Menschen auf diese Weise mit vielen Personen in verwandtschaftliche Beziehung treten müssen. Dieses traditionelle römische Argument gewinnt im Rahmen der Ehelehre des Kirchenvaters eine neue Bedeutung. Die Ehe erhält einen positiven Wert als Mittel der Diffusion von Caritas und kann gegen die Anfeindungen der im 4. Jahrhundert dominanten asketischen Bewegung verteidigt werden. Das Verbot der Cousinenehe muss als Teil von Augustins Einsatz für die Aufwertung der Ehe betrachtet werden.

Die Ausweitung des Inzestverbots wie in der älteren Literatur einseitig als Christianisierung aufzufassen, greift also sicher zu kurz. Hierin ist Philippe Moreau rechtzugeben. Sie wäre jedoch nicht ohne den Impuls erfolgt, der durch die Konstantinische Wende in der römischen Gesellschaft zur Wirkung gelangt ist und der zur Schaffung einer neuen christlichen Rechtsordnung geführt hat. Das Christentum, das in der Ausweitung der Eheverbote zum Ausdruck kam, war das Christentum des 4. Jahrhunderts und nicht ein ,authentisches' Christentum der Bibel.

190 Vgl. Brown, Power 1992, 116; Drake, Constantine 2000, 439. 
Eine Folge der Ausweitung des Inzestverbots war die Diskreditierung der Cousinenehe im Westen, wie Jack Goody richtig gesehen hat. Wie weit das Verbot der Cousinenehe in der Praxis durchgesetzt wurde, muss aus Mangel an Quellen allerdings offen bleiben. Da ein Gesetz zur Ermöglichung kaiserlicher Dispensierungen für nötig erachtet wurde, ist das Verbot bei der Elite des Kaiserreichs zumindest nicht unbekannt geblieben. In den Genealogien der Senatorenfamilien des 5. und 6. Jahrhunderts lassen sich keine Ehen innerhalb der engeren Verwandtschaft nachweisen ${ }^{191}$. In der theodosianischen Dynastie wurden im Unterschied zur Dynastie Constantins des Großen keine Cousinenehen geschlossen. Die politisch hochbedeutsame Eheschließung zwischen Valentinian III. und Eudoxia im Jahr 437 fand genau jenseits der neuen Inzestgrenze statt und wurde von der christlichen Historiographie enthusiastisch begrüßt ${ }^{192}$. Eine breite Durchsetzung des Verbots im gesamten Westreich wird man jedoch angesichts des Verfalls staatlicher Strukturen im 5. Jahrhundert kaum annehmen können. Den Bischöfen des frühen Mittelalters stand noch viel Arbeit bevor. Von den aus der Durchsetzung des Verbots entstandenen Konflikten wird das vierte Kapitel berichten. Da diese Konflikte bislang ausschließlich auf den germanischen Widerstand gegen das christliche Inzestverbot zurückgeführt wurden, werde ich mich zuvor dem Thema der ethnischen Identität und der Ehepraxis der ,Germanen' zuwenden.

191 Vgl. Stroheker, Adel 1948, 236-239; Mathisen, Epistolography 1981; Ders., Aristocrats 1993, 11-26.

192 Eudoxia war die Tochter von Valentinians Cousin Theodosius II. Vgl. Socrates, Historia ecclesiastica VII 44, 1 (392); Epiphanius - Cassiodor, Historia ecclesiastica tripartita XII 13 (CSEL 71, 681 f.). Bereits Kaiser Honorius heiratete die Tochter seiner Cousine: Zosimos, Historia nova V 28, $1-3(3 / 1,53)$. 


\section{Ethnische Identität und Inzestverbot}

Im 5. Jahrhundert ist die römische Herrschaft im Westen des Imperiums zugrunde gegangen. An ihre Stelle traten Königreiche unter germanischer Führung mit einer großteils romanischen Bevölkerung. Die Führungsschicht dieser Reiche übernahm im Wesentlichen die bestehenden Verwaltungsstrukturen und eignete sich in einem lang andauernden Prozess der Akkulturation die römische Herrschaftspraxis an. Dazu zählte auch die Nachahmung des spätantiken Kaisertums. Das Profil eines römischen Kaisers war in besonderem Maße durch sein Verhältnis zum Recht geprägt. In der Spätantike war die Kompetenz der Gesetzgebung fest in der Hand des Kaisers und stellte ein wichtiges Mittel kaiserlicher Politik dar ${ }^{1}$. Im 5. Jahrhundert fasste Theodosius II. den Entschluss, die unübersichtlich gewordene Masse an Konstitutionen unter systematischen Gesichtspunkten zu sammeln. Der Codex Theodosianus wurde 438 für den Osten und ein Jahr später für den Westen als verbindliches Gesetzeswerk erlassen ${ }^{2}$. Die Könige der germanischen Reiche mussten sich diesem Anforderungsprofil stellen. Bereits die ersten westgotischen Könige, die sich offen als souveräne Herrscher begriffen, betätigten sich als Gesetzgeber. Unter König Eurich wurde zwischen 466 und 484 die erste Kodifikation eines germanischen Herrschers, der nur fragmentarisch erhaltene Codex Euricianus, erstellt ${ }^{3}$. Ähnlich vollzog sich die Entwicklung bei den Ostgoten, Burgundern und Franken.

Doch die gesetzgeberische Tätigkeit der germanischen Könige verdankte sich nicht ausschließlich der Anpassung an das spätantike Herrscherprofil ${ }^{4}$. Mindestens ebenso wichtig waren die praktischen Probleme bei der Ansiedlung der Germanen. Unabhängig von der Frage, ob die germanischen Siedler zunächst nur anteilig am Steueraufkommen beteiligt oder von Beginn an mit Anteilen an Landbesitz versorgt wurden, ist in der Forschung die allmähliche Inbesitznahme von großen Domänen durch die Germanen unumstritten ${ }^{5}$. Dadurch waren sie mit Problemen konfrontiert, die sie aus der Zeit der Wanderschaft, des Krieges und der Siedlung innerhalb der Germania in dieser Weise nicht kannten. Insbesondere das Recht der Burgunder legt davon ein beredtes

1 Millar, Emperor 1977, 228-259; Harries, Law 1999, 19-26.

2 Matthews, Law 2000.

3 Zum Codex Euricianus ausführlicher unten $192 \mathrm{f}$.

4 Diesen Faktor betonen besonders Nehlsen, Aktualität 1977, und Wormald, Lex 1977.

5 Zur Diskussion vgl. Kaiser, Erbe 2004, 68 f.; Pohl, Völkerwanderung 2005, 35 f. 
Zeugnis $\mathrm{ab}^{6}$. Bestimmungen zur Vererbung, zur Ausstattung der Frau bei Ehe und Witwenschaft sowie zu den Eigentumsverhältnissen nehmen einen großen Teil der Kodifikation in Anspruch. Gleichfalls mit dem Erwerb von Landbesitz verbunden war die Regelung der Sklaverei ${ }^{7}$. Die Landwirtschaft beruhte weitgehend auf Sklaven und Kolonen, der Niedergang der Bevölkerungszahl und die damit verbundene Landflucht bedrohten jedoch die Wirtschaftlichkeit der Domänen. Das Sklavenrecht zählte daher zu den zentralen Materien der Volksrechte. Regelungsbedürfnis bestand jedoch nicht nur aufgrund des Erwerbs von Landbesitz, auch die Mechanismen der Konfliktlösung warfen neue Probleme auf ${ }^{8}$.

Die Volksrechte der frühmittelalterlichen Reiche spiegeln also zum einen das Herrscherprofil der Spätantike, zum andern die neu erwachsenen Probleme der Ansiedlung und Reichsgründung wider. Sie entstanden auf römischem Boden und sind wohl alle durch die Mithilfe römischer Juristen niedergeschrieben worden. Vor diesem Hintergrund überrascht es nicht, dass in der neueren Forschung der germanische Charakter der Volksrechte immer mehr in Abrede gestellt wird. Bereits der Altmeister der Rechtsgeschichte, Heinrich Brunner, erkannte in einigen Bereichen den Einfluss römischer Rechtsinstitute im fränkischen Gesetzbuch'. Systematisch erfasst wurden die Wechselbeziehungen zwischen römischem und germanischem Recht durch die Untersuchungen Ernst Levys zum ,Vulgarrecht ${ }^{6}$ der Spätantike ${ }^{10}$. Im Eigentumsrecht gelang Levy der Nachweis, dass die Volksrechte der Burgunder, Goten und Langobarden in vielerlei Hinsicht Entwicklungen des in der Praxis befolgten Provinzialrechts aufnahmen. In jüngster Zeit stellte Ian Wood die These in den Raum, Rechtsinstitute wie der Reinigungseid mit Eidhelfer und das Gottesurteil, die bislang als Kern germanischen Rechts angesehen worden sind, seien auf das römische Provinzialrecht im Gallien des 5. Jahrhunderts zurückzuführen ${ }^{11}$. Belege dafür sind jedoch rar. Von einem Teil der rechtshistorischen Forschung wird deshalb am Begriff des germanischen Rechts festgehalten, um Rechtsinstitute zu bezeichnen, die nachweislich nicht der römischen Tradition angehören

6 KaIser, Burgunder 2004, 82-87; Wood, Gentes 2003, 260 f. Ausführlich unten 128 130.

7 Nehlsen, Sklavenrecht 1972; Kaiser, Burgunder 2004, 81.

8 Nehlsen, Entstehung 1983; Wood, Disputes 1986; Sснотt, Formen 1995.

9 Brunner, Lex 1894; Brunner, Dos 1894.

10 Vgl. Levy, Law 1951; DERs., Vulgarrecht 1956. Die nachfolgende Diskussion fasst zusammen Martin Schermaier, Art. „Römisches Vulgarrecht“, in: RGA 25 (22003) $175-178$.

11 Wood, Disputes 1986, 17-19. Zustimmend Collins, Law 1998, 9; Halsall, Migrations 2007, 462-466. Vgl. dagegen die differenzierte Darstellung bei EsDERs, Reinigungseid 2007. 
und in verschiedenen germanischen Volksrechten auftreten ${ }^{12}$. Andere Historiker verwerfen den historisch wenig tragfähigen Begriff des „Germanischen" und sprechen von neuen Rechtsbildungen innerhalb der romanisch-germanischen Mischkultur des frühen Mittelalters ${ }^{13}$.

Die Frage nach der ethnischen Zuordnung von Normen ist daher nicht immer sinnvoll und kann selten eindeutig beantwortet werden. Trotzdem halte ich es aus zwei Gründen für notwendig, diese Frage in Hinblick auf das Inzestverbot zu stellen. Einerseits ist es für den Kontakt mit der römischen Rechtstradition von Bedeutung, ob die Germanen eine ähnlich ausgeprägte Abscheu vor dem Inzest kannten wie die Römer. In der Forschung wird dies weitgehend abgelehnt und die Obsession, mit der auf den gallischen Konzilien des 6. Jahrhunderts das Inzestverbot eingeschärft wurde, auf den Widerstand der germanischen Franken zurückgeführt ${ }^{14}$. Andererseits werden in der Forschung gegensätzliche Meinungen darüber geäußert, ob die Germanen endogame oder exogame Heiratsregeln befolgten. Michael Mitterauer schließt aus dem geringen Widerstand, den die Franken den Inzestverboten entgegenhielten, auf das Fehlen von präferentiellen Regeln der Partnerwahl ${ }^{15}$. Jean-Pierre Poly tritt dagegen vehement für die Praxis der Endogamie bei den Germanen ein und zieht daraus weitgehende Folgerungen für die Geschichte des frühen Mittelalters. Um zu einem Ergebnis in dieser Frage zu kommen, werde ich zuerst die direkten Quellen über die Germanen behandeln und dann die tatsächlich im frühen Mittelalter bekannt gewordenen Inzestfälle des 6. und 7. Jahrhunderts ins Auge fassen. Zuletzt soll die Gesetzgebung der arianischen Könige untersucht werden, die nicht im gleichen Ausmaß wie die katholischen dem Druck der Bischöfe ausgesetzt waren und daher zwanglos an der vermeintlichen germanischen Endogamie hätten festhalten können.

\subsection{Endogamie der Germanen?}

In den Handbüchern des frühen 20. Jahrhunderts herrschte Konsens über die Stellung der Germanen zur Verwandtenehe. Schrader, Brunner und Rietschel waren sich darin einig, dass die Germanen weder eine besondere Abscheu vor

12 Kroeschell, Recht 1986; Wormald, Leges 2003, 30 f.; Dilcher, Leges 2006, 37.

13 Hierzu vgl. Pohl, Völkerwanderung 2005, 64; Depreux, Loi 2002, 65; Siems, Weiterwirken 2006, 255.

14 Wallace-Hadrill, Church 1983, 170; Mikat, Inzestgesetzgebung 1994, 67; Gaudemet - Basdevant, Canons 1 1989, 240; Poly, Chemin 2003, 483 f. Für weitere Belege siehe auch 8 Anm. 30.

15 Mitterauer, Geschichte 2003, 227. 
dem Inzest hatten noch strikte endogame Heiratsregeln kannten ${ }^{16}$. Geschwisterehen in der germanischen Mythologie wurden allenfalls als Zeugnis einer längst vergangenen Urzeit gewertet, für die historische Epoche jedoch verworfen. Ehen zwischen Aszendenten und Deszendenten sowie unter Geschwistern seien nicht üblich gewesen. Schrader ging so weit, eine prinzipielle Exogamie aus der Praxis des Brautkaufes zu erschließen ${ }^{17}$. Da es üblich gewesen sei, die Braut durch große Vermögenswerte aus ihrer Verwandtschaft loszukaufen, sei es undenkbar, dass die Braut aus der eigenen Verwandtschaft genommen worden sei. Dieses Argument ist nur zum Teil überzeugend, weil die Praxis des Brautkaufes schwer als Teil des ,germanischen' Rechts nachgewiesen werden kann. Nur im burgundischen und sächsischen Recht wird eindeutig festgehalten, dass die Mitgift zum Teil oder zur Gänze an die Eltern der Braut zu zahlen ist ${ }^{18}$. Bei den anderen germanischen Völkern kann man eine solche Praxis nur hypothetisch voraussetzen, weil in den schriftlichen Quellen bereits die Mitgift eindeutig der Ehefrau zugedacht oder jemand anderem zu ihren Händen anvertraut wird. Tacitus gibt nur undeutlich Auskunft, da er einerseits von einer Gabe an die Ehefrau spricht, andererseits aber die Art der Gaben (Rind, Pferd, Schild, Schwert) eher einen an die Eltern gerichteten Kaufpreis erahnen lassen ${ }^{19}$. Wenn daher das Argument von Schrader nicht durchgehend greift, so kann man dennoch festhalten, dass die Ehe vor allem als ein Anlass für Vermögenstransaktionen und nicht so sehr als ein Partnertausch innerhalb der Verwandtschaft wahrgenommen wurde.

Dieser Ansicht von der untergeordneten Bedeutung der Heiratsregeln sind in den letzten Jahren Michel Rouche ${ }^{20}$ und Jean-Pierre Poly entgegengetreten. Poly hat diesem Thema vor kurzem eine ausführliche Darstellung gewidmet. In seinem Werk über den „Weg der barbarischen Liebe“ unternimmt er den Versuch, die Heiratspraxis der Germanen unabhängig von den christlichen Quellen des Frühmittelalters zu rekonstruieren. Der Kern von Polys Rekonstruktion besteht in der Unterscheidung von drei verschiedenen Heiratspraktiken bei den Germanen $^{21}$. Ausgangspunkt ist der Bericht des Tacitus, die Germanen hätten

16 Schrader, Reallexikon 1901, 910 f.; Siegfried Rietschel, Art. „Verwandtenehe“, in: RGA 4 (1918/1919) 416 f.; BrunNER - SCHWERIN, Rechtsgeschichte 2 1928, 856-858.

17 Schrader, Reallexikon 1901, 910 f. Über die Unvereinbarkeit von Brautpreis und Cousinenehe vgl. auch Seligman, Studies 1924, 266; Lévi-Strauss, Strukturen 1989, $419-425$ und 624 .

18 Ganshof, Statut 1962, 18-29; Hughes, Brideprice 1978, 262-296; Reynolds, Marriage 1994, 82-85.

19 Tacitus, Germania 18 (13).

20 Rouche, Mariages 1986, 858 f.; Ders., Clovis 1996, 334.

21 Nur am Rande soll darauf verwiesen werden, dass Polys essentialistischer Germanenbegriff kaum den Stand der historischen Forschung wiedergibt: PoHL, Germanen 2000; DERs., Germanenbegriff 2004. 
sich in alten Liedern als Nachkommen des Urvaters Mannus verstanden, der drei Stämme hinterlassen habe, die Ingwäonen, Erminonen und Istwäonen ${ }^{22}$. Diesen Stämmen ordnet Poly drei unterschiedliche Kultformen mit spezifischen Heiratsregeln zu. Die Ingwäonen, zu denen er auch die Franken zählt, hätten die Cousine mütterlicherseits bevorzugt geheiratet, die Istwäonen dagegen die Cousine väterlicherseits. Die Erminonen hätten dagegen jede Heirat innerhalb der engeren Verwandtschaft ausgeschlossen. Die exogame Praxis der Erminonen steht laut Poly im Zusammenhang mit der Verehrung Odins und hat sich mit der Vorherrschaft dieses Gottes in der Zeit der Völkerwanderung bei allen germanischen Völkern durchgesetzt. Dieses Theoriegebäude stürzt in sich zusammen, wenn man es mit dem Stand der historischen Wissenschaft zur germanischen Frühgeschichte vergleicht. Es kann als Konsens der Forschung angesehen werden, dass die Verknüpfung der Mannusstämme mit bestimmten Ereignissen in historischer Zeit nicht möglich ist ${ }^{23}$. Die Verbindung dieser schon in sich sehr strittigen Genealogie der Germanen mit unterschiedlichen Heiratsregeln bringt Poly nur über haltlose etymologische Spekulationen zustande ${ }^{24}$. Diese sollen uns hier nicht beschäftigen. Der einzige historische Beleg ist die Heirat des Cheruskerfürsten Arminius mit Thusnelda ${ }^{25}$. Den Quellen ist jedoch nicht eindeutig zu entnehmen, dass Thusnelda die Cousine des Arminius war. Die althistorische Forschung lehnt eine solche Verwandtschaft $a b^{26}$.

\section{Der reipus des fränkischen Rechts}

Der zentrale Beleg Polys für die endogame Praxis der Franken ist der Titel De reipus der Lex Salica ${ }^{27}$. Dieser Titel war von je her ein locus classicus der Rechtsgeschichte, weil darin am ausführlichsten eine Rangfolge innerhalb der Verwandtschaft dargelegt und scheinbar das Prinzip der Matrilinearität befolgt wird. In Kombination mit anderen, weniger eindeutigen Stellen bei Caesar und Tacitus erschlossen viele Historiker des 19. Jahrhunderts eine ursprünglich mutterrechtliche Organisation bei den Germanen. Dieser Interpretation ist von

22 Tacitus, Germania 2 (2 f.).

23 Wenskus, Stammesbildung 1977, 234-246; Timpe, Söhne 1991; Dobesch, Forschungsreferat 1998; Pohl, Germanen 2000, 58 f.; Reinhard Wolters, Art. „Mannusstämme“, in: RGA 19 (²2001) 234-237.

24 Den Namen Arminius zerlegt er z. B. in „AerminEoh“ mit der Bedeutung „Hengst des Aermin“ (Poly, Chemin 2003, 91), obwohl die sprachliche Herkunft dieses Namens in der Forschung umstritten ist, vgl. Timpe, Arminius-Studien 1970, 16-19; Ders., Gedanken 1973. Diese Spekulationen werden selbst von einem wohlwollenden Rezensenten wie Georg Scheibelreiter zurückgewiesen: Francia 33/1 (2006) 210-213.

25 Poly, Chemin 2003, 91.

26 Timpe, Arminius-Studien 1970, 47 f.; Gerhard Dobesch, Art. „Segimer“, RGA 28 (2005) $108-110$.

27 Lex Salica 44 (MGH LL nat. Germ. 4/1, 168-173). 
Heinrich Brunner der Boden entzogen worden, indem er auf den römischrechtlichen Hintergrund aufmerksam machte und die Bestimmung als Neuregelung des fränkischen Königs erkannte ${ }^{28}$. Brunners Interpretation wurde durch die Untersuchung Alexander Murrays weiter gefestigt ${ }^{29}$.

Der Inhalt des Titels ist folgender: Wenn ein Mann eine Witwe heiraten will, muss er den Gerichtsvorsteher um die Einberufung eines Gerichtstages bitten. Dorthin muss er drei Schillinge mitbringen und von drei Männern prüfen lassen. Diese Summe soll er dann als Reipus an die Verwandten des verstorbenen Mannes übergeben, um von ihnen die Erlaubnis zur Heirat der Witwe zu erhalten. Unterzieht er sich nicht diesem Verfahren, ist er zu einem Strafgeld von 63 Schillingen verpflichtet, die an die Reipus-Empfänger zu zahlen sind. Diese Empfänger werden in folgender Reihenfolge genannt: 1. der Sohn der Schwester; 2. der Sohn der Nichte; 3. der Sohn der Cousine; 4. der Bruder der Mutter (Onkel); 5. der Bruder; 6. die Verwandten bis in das sechste Knie; 7. der Fiskus ${ }^{30}$. Es herrscht darüber Einigkeit, dass alle als Verwandte des verstorbenen Mannes aufzufassen sind, wie dies ausdrücklich nur vom Bruder gesagt wird. Bedeutend ist ferner der Zusatz, der Bruder sowie andere Verwandten könnten nur dann den Reipus in Empfang nehmen, wenn sie nicht die Erbschaft des verstorbenen Mannes angetreten hätten. Daraus hat Brunner die Folgerung gezogen, dass in diesem Titel der Antagonismus zwischen Erbberechtigten und Zustimmungsberechtigten zum Ausdruck kommt ${ }^{31}$. Die Verwandten des verstorbenen Mannes sind nämlich einerseits potentielle Interessenten am Erbe derjenigen Vermögensbestandteile, die der Witwe vom Mann übertragen wurden, und andererseits berechtigt, die Zustimmung zu einer weiteren Heirat zu erteilen. Die Lösung des fränkischen Gesetzgebers bestand darin, die beiden Gruppen voneinander zu trennen und die Zustimmungsberechtigung an nicht Erbberechtigte zu übertragen, d.h. an die matrilineare Verwandtschaft. Diese ist nach fränkischem Recht der patrilinearen Verwandt-

28 BRUNNER, Lex 1894.

29 Murray, Structure 1983, 163-175.

30 Si nepus sororis filius fuerit senussimus, ipse eos accipiat. Si neptus non fuerit, neptis filius senior reipus illus accipiat. Si vero neptas filius non fuerit, consobrine filius, qui ex maternae genere venit, illi eos accipiat. Si vero nec consobrine filius fuerit, tunc avunculus frater matris reipus ille accipiat. Si vero nec adhuc avunculus fuerit, tunc frater illius, qui eam mulierem ante habuit, si in hereditatem non est venturus, ipse eos reipus accipiat. Et si nec ipse frater fuerit, qui proximior fuerit extra superiores nominatos singillatim dicti secundum parentilla usque ad sextum genuculum, si hereditatem illius mariti defuncti non accipiat, ille reipus illius accipiat. Iam post sexto genuculum, si non fuerint, in fisco reipus ipse vel causa, quae exinde orta fuerit, colligatur. Lex Salica 44, 4-11 (MGH LL nat. Germ. 4/1, 170-172). Der Herausgeber hat den schwer verständlichen Text zurecht gebogen. Ich folge deshalb Murray, Structure 1983, 164-166, der dem A1 Text (Paris, Bibliothèque Nationale, Lat. 4404) den Vorzug gibt.

31 BrunNer, Lex 1894, $75 \mathrm{f}$. 
schaft im Erbe nachgeordnet. Vorbild für diese Lösung ist nach Brunner ein Gesetz Valentinians I. vom Jahre 371, in dem dieses Problem in ähnlicher Weise behandelt wurde ${ }^{32}$. Der Gesetzgeber der Lex Salica hat diese Bestimmung an das fränkische Erb- und Eherecht angepasst, um eine friedliche Einigung über die Wiederheirat zu ermöglichen. Als Novelle gibt sich der Titel laut Brunner durch die Erwähnung des Fiskus sowie durch die gerichtliche Einigung zu erkennen, da Eheschließungen sonst nicht vor Gericht, sondern privat abgewickelt worden sind. Murray hat diese Deutung durch den Hinweis abgesichert, dass die Empfänger des Reipus nicht zwingendermaßen aus der matrilinearen Verwandtschaft stammen müssen, da dies für die weiter entfernten Personen nicht ausdrücklich festgelegt $\operatorname{se}^{33}$. Es gehe dem Gesetzgeber nicht um ein abstraktes Prinzip, sondern um die Vermeidung des von Brunner rekonstruierten Antagonismus zwischen Erbberechtigten und Zustimmungsberechtigten.

Diese Deutung wäre in sich kohärent, wenn der Text in einem Punkt nicht Schwierigkeiten bereiten würde. Denn in der Rangfolge der Verwandten fehlt offensichtlich der Cousin vor der Erwähnung des Sohnes der Cousine. Karl August Eckhardt hat diese Lücke in seiner kritischen Edition durch die Einfügung eines Nebensatzes geschlossen ${ }^{34}$. Dieser wenig überzeugenden Emendation ist Alexander Murray beigetreten ${ }^{35}$. Jean-Pierre Poly hat diese Glättungsversuche zu Recht verworfen und an diesem Detailproblem seine völlig neue Deutung des Reipus-Titels aufgehängt ${ }^{36}$. Der matrilineare Cousin sei deshalb nicht erwähnt worden, weil die eheliche Verbindung mit der matrilinearen Cousine bei den ingwäonischen Franken üblich gewesen $\operatorname{se}^{37}$. Der Cousin des verstorbenen Mannes wäre deshalb möglicherweise identisch mit dem Bruder der Witwe. Eine Heirat zwischen Bruder und Schwester sei von den Franken jedoch als Inzest angesehen worden, weshalb man das Zustimmungsrecht dieses Verwandten nicht habe abkaufen müssen. Nur ein besonderer Cousin sei an fünfter Stelle erwähnt worden, nämlich der Onkel des Sohnes einer matrilinearen Cousine, die nicht mit der Witwe selbst identisch ist. Poly bezieht den an vierter Stelle stehenden avunculus nämlich im Unterschied zur herrschenden Meinung nicht auf den verstorbenen Mann, sondern auf den davor genannten Sohn einer matrilinearen Cousine. Auf diese komplizierte

32 Codex Theodosianus 3, 7, 1 (141).

33 Murray, Structure 1983, 172-174.

34 Lex Salica 44, 8 (MGH LL nat. Germ. 4/1, 170).

35 Murray, Structure 1983, 165 u. 173.

36 Poly, Cousine 2000; Ders., Chemin 2003, 94-103.

37 Die Bezeichnung der Franken als Ingwäonen beruht auf der Gleichsetzung mit den von Plinius, Historia naturalis 4, 14, 99 (1, 347) den Ingwäonen zugerechneten Chauken. Dass eine solche Gleichsetzung die Komplexität der fränkischen Ethnogenese unterschätzt, sei nur am Rande angemerkt: KAISER, Erbe 2004, 80-84; PoHL, Völkerwanderung 2005, 165-172. 
Weise habe der Gesetzgeber zum Ausdruck bringen wollen, dass ein Cousin als Zustimmungsberechtigter nur dann in Frage kommt, wenn es sich nicht um den Bruder der Witwe handelt ${ }^{38}$. Die Matrilinearität der Verwandten gewinnt für Poly deshalb einen ganz neuen Sinn: Der Reipus soll nicht die Zustimmung zur Ehe abgelten, sondern das Recht der übrigen matrilinearen Verwandten auf die Ehe mit der Witwe. Der Reipus-Titel handelt demnach von der Abgeltung der Heiratsansprüche weiterer Verwandter. Die Witwe konnte im Kreis der Verwandten (mit Ausnahme des Bruders) herumgereicht werden, ein Fremder musste hingegen diese Ansprüche gegen Gebühr ablösen. Daraus erklärt sich für Poly der Widerstand der Franken gegen das Eheverbot der Schwiegerverwandtschaft, wie sie von der Kirche mit der una-caro-Lehre verfochten wurde.

Die Probleme dieser radikalen Umdeutung sind immens. Poly selbst muss den Text der Lex Salica weitgehend nach Gutdünken korrigieren, um die Auflistung der Verwandten in eine scheinbar richtige Reihenfolge zu bringen. Insbesondere die späte Nennung des Bruders des verstorbenen Ehemanns bereitet Poly große Schwierigkeiten. Gerade für die Ehe mit dem Schwager gibt es eine Reihe von Beispielen aus dem Frühmittelalter. Er muss deshalb eine spätere Kontamination des Textes durch die christliche Kirche erschließen, die eine Veränderung der Reihenfolge bewirkt habe ${ }^{39}$. Dies verweist auf ein grundsätzliches methodisches Problem, da Poly sämtliche kirchliche Quellen des Frühmittelalters unter Generalverdacht stellt und deshalb den hochmittelalterlichen Quellen zu den Germanen des Nordens den Vorzug gibt ${ }^{40}$. Dieser Generalverdacht gibt ihm die Lizenz, alle im Frühmittelalter überlieferten Texte nach eigenem Ermessen zu emendieren. Aber nicht nur dieses methodische Problem macht Polys Deutung unhaltbar, auch der Wortlaut des Titels widerspricht ihr deutlich. Denn an zwei Stellen wird eindeutig die Bedingung angesprochen, dass nur diejenigen als Empfänger des Reipus in Frage kommen, die nicht erbberechtigt sind ${ }^{41}$. Der Text selbst verweist auf den Antagonismus von Erbberechtigten und Zustimmungsberechtigten, der dem Gesetz Valentinians zugrunde lag. Die Begrenzung durch den 6. Grad der Verwandtschaft sowie die Erwähnung des Fiskus deuten ebenfalls auf den römisch-rechtlichen Hinter-

38 Nach Poly, Cousine 2000, 32, bezieht sich die Mutter in $\$ 9$ (tunc avunculus, frater matris) auf die Mutter des in $₫ 8$ genannten Sohns der Cousine. In $₫ 8$ ist jedoch keine Mutter erwähnt, und deshalb ist sich die bisherige Forschung darin einig, die Bezugsperson wie in allen anderen Paragraphen in dem verstorbenen Ehemann zu sehen.

39 „Peut-être y-a-t-il là un ajustement fait au VIe, lorsque le christianisme devint plus pregnant ..." Poly, Cousine 2000, 31. Die Ehe mit einer Fremden (d.h. nicht verwandten Person) bezeichnet PoLy, Chemin 2003, 102, als Friedelehe; zu diesem anachronistischen Konzept vgl. die Kritik von Ebel, Konkubinat 1993; Esmyol, Ehefrau 2002; Karras, Myth 2006.

40 Poly, Chemin 2003, $19 \mathrm{f}$.

41 Siehe oben 80 Anm. 30. 
grund der Reipus-Regelung ${ }^{42}$. Die Interpretation Brunners ist also im Text deutlich verankert, während Poly davon ausgehen muss, dass alle wichtigen Grundannahmen zum Verständnis des Textes verschwiegen wurden ${ }^{43}$. Man wird deshalb weiterhin an den Ergebnissen Brunners festhalten müssen.

Trotz der Ablehnung einer Einordnung des Titels in die Inzestproblematik gibt er uns dennoch indirekt Aufschlüsse über die Heiratspraxis der Franken. Denn der Titel setzt voraus, dass die Verwandtschaft der Ehegatten grundsätzlich verschieden ist. Die ungewöhnliche Einschaltung des Gerichts in die ansonsten rein private Eheschließung erfolgt nämlich mit dem Ziel, Interessenskonflikte der Verwandtschaft des verstorbenen Mannes und der Witwe zu schlichten. Anders als bei ihrer ersten Hochzeit ist nicht mehr die eigene Verwandtschaft für die Verheiratung zuständig, sondern diejenige des verstorbenen Mannes $^{44}$. Dies ist ein Unterschied zu den Verhältnissen im römischen Recht, nach dem die Witwe bis zu ihrem 25. Lebensjahr wieder in die Gewalt ihres Vaters oder ihres Vormunds gelangte. Ein solcher Widerspruch zwischen den Interessen ist aber nur dann vorstellbar, wenn sich die Verwandtschaften der Ehepartner grundsätzlich nicht berührten ${ }^{45}$. Auch eine andere Regelung der Lex Salica stützt diese Vermutung. Darin wird demjenigen, der im Beisein seiner eigenen Verwandten sowie der Verwandten seiner Braut die Ehe versprochen hat und sich danach zurückzieht, die Strafe von $62 \frac{1}{2}$ Schillingen angedroht ${ }^{46}$. Hier wird ebenfalls die Trennung der beiden Verwandtschaftskreise vorausgesetzt. Weitere Zeugnisse für diese Tatsache bieten Formelsammlungen aus dem Frankenreich $^{47}$.

Das von Poly in die Diskussion gebrachte Zeugnis für eine endogame Ehepraxis der Franken ist also unzureichend. Die Volksrechte des frühen Mit-

42 Zur Komputation der Verwandtschaft in der Lex Salica siehe 21.

43 Den Grund für dieses Schweigen sieht Poly in der Kluft zwischen der Entstehung der Lex im 4. Jahrhundert und der Kodifizierung unter Chlodwig: Poly, Corde 1993. Die Datierung in das 4. Jahrhundert ist jedoch nicht haltbar, da schon in den ersten Titeln der Lex ein Königtum genannt ist, während Gregor von Tours vergeblich nach Königen der fränkischen Frühzeit fahndete: u. a. Lex Salica 13, 6-7 (MGH LL nat. Germ. 4/1, 60 f.); Gregor von Tours, Decem libri historiarum II 9 (MGH SS rer. Merov. 1/1, 52). $\mathrm{Zu}$ weiteren Problemen einer solchen Frühdatierung siehe 83 Anm. 43.

44 Murray, Structure 1983, 170.

45 Deutlich ausgesprochen ist diese Voraussetzung beim sog. achasius in Lex Salica 100, 1 (MGH LL nat. Germ. 4/1, 256): ... achasium parentibus, qui proximiores sunt marito defuncto, donet ... Der achasius wird von der Frau an die Verwandten ihres verstorbenen Mannes gezahlt, wenn sie eine zweite Ehe eingehen will und ihre vom Mann geschenkte dos behalten will.

46 Si quis filiam alienam ad coniugium quaesierit, praesentibus suis et puellae parentibus, et postea se retraxerit et eam accipere noluerit, mallobergo frifrasigena, solidos LXII et dimidium culpabilis iudicetur. Lex Salica 65a (MGH LL nat. Germ. 4/1, 234).

47 Formulae Salicae Lindenbrogianae 7 (MGH Formulae, 271); Formulae Sangallenses 18 (MGH Formulae, 388); Formulae Augienses B 24 (MGH Formulae, 357). 
telalters enthalten keine positiven Heiratsregeln. Vom Codex Euricianus bis zu den isländischen Grágás $^{48}$ des 12. Jahrhunderts stammen alle Vorschriften zum Inzestverbot aus dem römischen und christlichen Traditionsfundus. Die Ehe, so wie sie uns in den Volksrechten, in den Formelsammlungen und in den historiographischen Zeugnissen begegnet, war in erster Linie eine Transaktion zwischen zwei Familienverbänden, bei der wirtschaftliche Gesichtspunkte im Mittelpunkt standen. Im römischen Reich hat es sich nicht anders verhalten. Bereits dem byzantinischen Historiographen Agathias ist deshalb die Ähnlichkeit zwischen fränkischer und römischer Heiratspraxis aufgefallen ${ }^{49}$.

\subsection{Das Dossier der Rechtsfälle}

Heimito von Doderer zeichnete in seinem Roman über „Die Merowinger“ des 20. Jahrhunderts das Bild einer durch mehrfache Inzestehen gebildeten ,totalen Familie'. Der Held des Romans, Freiherr Childerich III. von Bartenbruch, verfolgt das Ziel, durch Ehen innerhalb der Verwandtschaft in seiner Person die gesamte Familie zu verkörpern. Er wurde sein eigener Vater, Sohn, Enkel etc. Diese Imagination des studierten Historikers Doderer sagt einiges aus über das Bild der Merowinger in der Geschichtsschreibung. Sie gelten als eine Dynastie, die in ihren Eheschließungen keine Rücksicht auf christliche oder ständische Normen nahmen, sondern ihrer Begierde und ihrem Machtstreben freien Lauf ließen. Ian Wood, einer der besten Kenner der merowingischen Geschichte, ist der Meinung, die Frankenkönige hätten sich um das christliche Inzestverbot nicht gekümmert ${ }^{50}$. Inwiefern trifft dieses Bild für die Merowinger des 6 . Jahrhunderts zu und lässt es sich auf die Franken insgesamt übertragen? Die zuvor untersuchten Rechtsquellen geben keine Hinweise darauf, dass die Ehepartner aus derselben Verwandtschaftsgruppe stammten. Dieser Befund ist mit den Beispielen aus den erzählenden Quellen zu konfrontieren. Aus Geschichtsschreibung und Hagiographie ist eine Reihe von Inzestfällen in der Merowingerzeit bekannt, die durch die Anstrengungen der Bischöfe an die Öffentlichkeit gelangt sind. Eine Zusammenstellung dieser Inzestfälle kann einen Eindruck vermitteln, in welchen Bereichen die Kirche auf besonderen Widerstand gestoßen ist. Allerdings ist es nicht möglich, anhand der Namenstradition immer eindeutig die ethnische Identität der betroffenen Personen festzustellen ${ }^{51}$. Ein weiteres Problem betrifft die Frage, ob die herrschenden

48 Vgl. Jochens, Church, 380.

49 Agathias, Historiae I 2, 3 (11); Cameron, Agathias 1968, $113 \mathrm{f}$.

50 Wood, Family 2000, 431.

51 Vgl. Sonderegger, Prinzipien 1997; Goetz, Gentes 2002; Haubrichs, Akkulturationsvorgänge 2004 . 
Familien durch die Herausbildung des erblichen Königtums mit besonderen Zwangslagen konfrontiert waren, die sonst nicht übliche Inzestehen nahe legten. Es wird daher nötig sein, die folgenden Fälle mit der erforderlichen Vorsicht zu interpretieren.

\section{Die Ehe mit der Cousine}

Die in der Geschichtsschreibung gängige Behauptung, die Kirche habe mithilfe des Inzestverbots die germanischen Sippenverbände zerschlagen wollen, findet keine Bestätigung in den Quellen. Ehen zwischen Cousin und Cousine sind selten belegt. Aus der Merowingerzeit lassen sich nur drei Beispiele namhaft machen. Den ersten Fall berichtet Gregor von Tours zum Jahr 581. Damals ermordete ein gewisser Vidastis Avus in Chinon nahe Tours die Brüder Lupus und Ambrosius. Alle Beteiligten waren romanischer Herkunft und stammten aus der Gegend von Tours bzw. Poitiers. Vidastis hatte eine Affäre mit der Frau des Ambrosius, die gleichzeitig seine Cousine war, und wurde von ihr nächtens in die Räumlichkeiten der Brüder eingelassen, wo er sie ermordete. Wenige Tage nach dem Mord heirateten die Ehebrecher, ohne die vom römischen und kirchlichen Recht vorgeschriebene Trauerfrist zu beachten. Einige Jahre später, 584, erfuhr Vidastis die gerechte Strafe, als er bei einem Konflikt mit dem Sachsen Chulderich von einem Speer durchbohrt wurde. Gregor beendet diesen Bericht mit der moralisierenden Bemerkung: „So rächte die göttliche Allmacht das unschuldige Blut, das er mit seiner Hand vergossen hatte. Denn der Elende hatte vielfach Räubereien, Unzucht und Mordtaten begangen, doch will ich lieber davon nichts weiter erzählen “52. Gregor bezeichnet die Verbindung zwischen Vidastis und seiner Cousine nicht ausdrücklich als Inzest und belässt es im Unklaren, ob er den verdienten Tod auch als Folge der inzestuösen Verbindung betrachtete.

Das Beispiel des Galloromanen Vidastis ist von besonderem Interesse, weil die Ehe zwischen Cousin und Cousine im Westen des römischen Reichs seit dem Ende des 4. Jahrhunderts verboten war. Dieses Verbot ist in das westgotische Breviar aufgenommen und von der Kirche im Lauf des 6. Jahrhunderts mehrfach wiederholt worden ${ }^{53}$. Trotzdem hatte diese Form der Verwandtenehe weiter Bestand. Bereits im 4. Jahrhundert, unmittelbar nach dem erstmaligen Verbot, gibt es Zeugnisse für das Bemühen sowohl christlicher als auch heidnischer Aristokraten, eine Dispensierung von diesem Gesetz zu erhalten ${ }^{54}$. Ein Dispensformular dieser Art ist noch aus dem ostgotischen Reich Theoderichs

52 Fuitque ultrix divina maiestas sanguinis innocentis, quem propria effuderat manu. Multa enim furta, adulteria homicidiaque miserrimus saepe conmiserat, quae silere melius poto. Gregor von Tours, Decem libri historiarum VII 3 (MGH SS rer. Merov. 1/1, 328).

53 Siehe $197 \mathrm{f}$.

54 Siehe 65 Anm. 152. 
des Großen überliefert ${ }^{55}$. Philippe Moreau meint, man könne aus diesen Belegen auf eine Verbreitung dieser Ehepraxis innerhalb der Oberschicht schlie$ß^{5}{ }^{56}$. Denn für sie allein war die Möglichkeit gegeben, vom Kaiser eine Ausnahmegenehmigung zu erhalten, und für sie war es attraktiv, durch die Verbindung mit nahen Verwandten ihre umfangreichen Besitzungen auf wenige Hände zu konzentrieren. Die Protagonisten aus Gregors Bericht lassen einen solchen Schluss durchaus zu. Sie stammten zwar nicht aus der Oberschicht, aber sie gehörten als Bürger von Tours bzw. Poitiers der Herrenschicht der jeweiligen Civitas $a^{57}$. Erbschaftliche Erwägungen der Familie spielten allerdings gewiss keine Rolle, da die Cousine zunächst mit Ambrosius verheiratet gewesen war und erst danach, offensichtlich aus eigenem Willen, eine Ehe mit Vidastis eingegangen ist.

Eine andere Stelle aus Gregors Werk liefert hingegen einen klaren Beleg für erbschaftliche Erwägungen beim Abschluss von Cousinenehen. Diese Stelle findet sich in Gregors Buch über die Wunder des heiligen Apostels Andreas, einer Schrift, die schwierige quellenkritische Probleme aufwirft. Denn das Original der apokryphen Andreasakten aus dem späten 2. Jahrhundert ist bis auf wenige griechische und koptische Fragmente verloren. Gregor bekennt im Vorwort des Wunderberichts seine Abhängigkeit von den Andreasakten, die Art dieser Abhängigkeit lässt sich jedoch nur an wenigen Passagen überprüfen. In der jüngsten umfassenden Studie plädiert Jean-Marc Prieur überzeugend für weitgehende redaktionelle Eingriffe durch Gregor von Tours ${ }^{58}$. Manche Episoden wie diejenige über die Cousinenehe schreibt Prieur überhaupt der Phantasie des gallischen Bischofs zu. Ursprünglich hätten die Acta Andreae gemäß ihrer asketischen Tendenz zur Keuschheit und zur Vermeidung der Ehe aufgerufen, während Gregor die Ehe ausdrücklich gutgeheißen und das Inzestverbot zum Stein des Anstoßes gemacht habe ${ }^{59}$. Prieurs Argumente für diese Zuschreibung sind stichhaltig. Schließlich passt die Diskreditierung der Cousinenehe besser in den Kontext der Kontroversen im Gallien des 6. als in den griechischen Osten des 2. Jahrhunderts.

Der Bericht Gregors handelt von zwei Brüdern in Philippi, von denen der eine zwei Söhne, der andere zwei Töchter hatte. Beide besaßen beträchtliche Reichtümer und waren von hohem Adel. Einer der beiden Brüder machte nach Gregor folgenden Vorschlag:

„Siehe nur unsere außerordentlichen Reichtümer! Keiner von den anderen Bürgern ist würdig, sich mit unserem Geschlecht zu verbinden. Aber komm, es soll aus allem

55 Siehe 107.

56 Moreau, Inceste 2002, 366-375.

57 Weidemann, Kulturgeschichte 2 1982, 310.

58 Acta Andreae (CCA 5, 12).

59 Acta Andreae (CCA 5, 42 f.). 
ein Haus werden! Meine Söhne sollen deine Töchter zu Frauen nehmen, damit unsere Reichtümer leichter vereinigt werden ${ }^{\text {"60 }}$.

Dieser nicht ganz uneigennützige Vorschlag gefiel dem Bruder, und so schlossen sie einen Ehevertrag durch die Überreichung einer Mitgift. Doch am Tag der Heirat sprach der Herr zu ihnen: „Vermählt eure Kinder nicht, bis mein Diener Andreas zu euch kommt. Er wird euch zeigen, was ihr tun sollt “" ${ }^{\text {}}$. Obwohl die Gäste warteten und die Hochzeitszeremonie vorbereitet war, wurde die Heirat drei Tage bis zur Ankunft des heiligen Andreas verschoben. Dieser riet den Brautlauten:

„Ihr, Kinder, sollt euch nicht versuchen lassen und ihr, Eltern, sollt die jungen Menschen nicht täuschen, denen der Lohn der Gerechtigkeit sich zeigen wird. Tut lieber Buße, weil ihr verfehlt habt gegen den Herrn, indem ihr Blutsverwandte verheiraten wolltet. Wir wollen euch nicht die Heirat ausreden, weil Gott am Anfang der Welt die Verbindung von Mann und Frau geboten hat, aber wir verdammen den Inzest" ${ }^{* 62}$.

Darauf erwiderten Gregor zufolge die Eltern der Brautleute: „Wir bitten dich, Herr, dass du bei Gott Fürbitte für uns einlegst, weil wir unwissend diese Sünde begangen haben "63. Auch die Brautleute beteuerten ihre Unwissenheit und erkannten in der Ermahnung des Andreas die Stimme Gottes. Der Apostel beschloss die Unterredung mit folgenden Worten: „Bewahrt ohne Besudelung, was ihr gehört habt, damit Gott mit euch sei und damit ihr den Lohn eures Tuns empfangt, das ewige Leben, das durch kein Ende beschlossen wird“64.

Diese Anekdote, sehr wahrscheinlich Gregors eigener Phantasie entsprungen, ist in vielerlei Hinsicht bemerkenswert. Erstens bezweckt Gregor mit dieser Anekdote, die Praxis der Cousinenehe bei seiner romanischen Leser- und Hörerschaft ${ }^{65} \mathrm{zu}$ diskreditieren. Gregor rechnete also damit, dass in seiner Zeit tatsächlich romanische Aristokraten Verwandtenehen dieser Art eingingen.

60 Dixitque unus ad alterum: ,Ecce sunt nobis opes eximiae, et non est de civibus qui dignae copuletur generationi nostrae; sed veni, et fiat nobis una domus ex omnibus. Filii mei accipiant filias tuas, ut opes nostrae facilius coniungantur'. Gregor von Tours, Liber de miraculis B. Andreae Apostoli 11 (MGH SS rer. Merov. 1/2, 382).

61 Dato igitur die nuptiarum, factum est verbum Domini ad eos, dicens: 'Nolite coniungere filios vestros, donec veniat famulus meus Andreas. Ipse enim vobis quae agere debeatis ostendet'. Ebd.

62 'Nolite, filioli, nolite seduci, nolite decipere hos iuvenes, quibus potest fructus apparere iustitiae; sed magis paenitentiam agite, quia deliquistis in Dominum, ut proximos sanguine velletis coniugio copulare. Non nos nuptias aut avertimus aut vitamus, cum ab initio Deus masculum iungi praecipisset et feminam, sed potius incesta damnamus.' Ebd.

63 'Oramus, domine, ut depraeceris pro nobis Deum tuum, quia nescientes fecimus hoc delictum'. Ebd.

64 'Custodite sine pollutione quae audistis, ut sit Deus vobiscum, et accipiatis mercedem operis vestri, id est sempiternam vitam, quae nullo clauditur fine.' Ebd.

65 Vgl. Uytfanghe, Audience 2005. 
Zweitens bestätigt sie die Relevanz von erbrechtlichen Erwägungen bei einer Heirat zwischen Cousin und Cousine. Drittens lässt Gregor seinen Heiligen keine biblische Rechtfertigung für das Inzestverbot vortragen. Es wird im Gegenteil suggeriert, Gott selbst habe durch den Mund des Apostels gesprochen. Viertens scheint es für Gregor keine Schande gewesen zu sein, vom Verbot der Cousinenheirat nichts zu wissen. Sowohl die Eltern als auch die Brautleute berufen sich auf ihre Unkenntnis der Rechtslage. Dies überrascht angesichts der eindeutigen Stellungnahme der Konzilien und des weltlichen Rechts. Schließlich hält Gregor den Ratschlag für notwendig, in Zukunft von solchen Ehen zu lassen, wenn man die ewige Seligkeit erlangen will.

Beide Texte aus dem Werk Gregors von Tours belegen die fehlende Akzeptanz des Verbots der Cousinenheirat in der romanischen Bevölkerung. Für die Franken ist ein entsprechender Fall erst aus der zweiten Hälfte des 7. Jahrhunderts überliefert. Es handelt sich um die Heirat zwischen König Childerich II. und seiner Cousine Bilichild, der Tochter Sigiberts III., im Jahre 662/ 663. Diese Heirat ist mit zwei berühmten Ereignissen der merowingischen Geschichte eng verknüpft, dem ersten ,Staatsstreich' der Pippiniden durch Grimoald und dem Bürgerkrieg der 670er Jahre. Ihren Ursprung haben diese Ereignisse in der anfänglichen Kinderlosigkeit des austrasischen Königs Sigibert III. ${ }^{66}$ Dieser ließ sich vom mächtigsten Mann des Reiches, dem Hausmeier Grimoald, dazu überreden, dessen Sohn Childebert zu adoptieren und so seiner Familie die Nachfolge in Aussicht zu stellen ${ }^{67}$. Dies wird als erster Versuch der Vorfahren Karls des Großen gewertet, die Königsherrschaft im Frankenreich an sich zu reißen. Kurz vor Sigiberts Tod gebar Königin Chimnechilde jedoch einen Sohn, den späteren Dagobert II. Grimoald ließ sich aber von seinen Plänen nicht abbringen und schickte den Königssohn Dagobert nach dem Tod seines Vaters ins Exil nach Irland ${ }^{68}$. Grimoald und sein Sohn Childebert übernahmen folglich die Macht in Austrasien. Wie lange sich beide halten konnten, ist in der Forschung umstritten. Grimoald wurde entweder schon gleich nach der Machtergreifung oder erst beim Tod seines Sohnes vom neustrischen König gefangen genommen und „unter heftigen Qualen“ hingerichtet $^{69}$. Die Regierungszeit seines Sohnes Childebert endete im Jahre 662, ohne dass wir über die Art seines Todes Bescheid wissen. Die Vorherrschaft der Familie Grimoalds in Austrasien war damit für einige Zeit gebrochen.

66 Ewig, Merowinger 2001, 142-146; Wood, Kingdoms 1994, 222-225.

67 Die Wertung der Ereignisse ist umstritten: Gerberding, Rise 1987, 47-66; Becher, Staatsstreich 1994; Offergeld, Reges 2001, 241-257; Hamann, Chronologie 2003.

$68 \mathrm{Ob}$ nach dem Tod Sigiberts eine kurze Regierung Dagoberts stattfand, ist umstritten. Bejaht wird dies u.a. von Becher, Staatsstreich 1994, 136, und Hamann, Chronologie 2003, 64-67.

69 ... ipsius mors valido cruciatu finivit. Liber historiae Francorum 43 (MGH SS rer. Merov. 2, 316). 
In dieser Situation konnte sich die neustrische Königsfamilie, angeführt von der Königinmutter und Regentin Balthilde, im östlichen Teilreich durchsetzen. Die Vita Balthilds berichtet betont euphemistisch von der Einsetzung ihres Sohnes Childerich in Austrasien:

„Damals nahmen auf friedvolle Weise die Austrasier ihren (Balthilds) Sohn Childerich als König von Austrasien an, nachdem Balthild dies befohlen und die Großen ihre Zustimmung gegeben hatten. ... Und wir glauben, dass durch die Vorsehung Gottes und gemäß dem großen Glauben Balthilds diese drei Reiche [Neustrien, Austrasien, Burgund] untereinander friedliche Eintracht bewahrten " $"$.

Der friedliche Übergang der Herrschaft wird von anderen Quellen in Zweifel gezogen $^{71}$, gänzlich verschwiegen wird in der Vita die Tatsache, dass Balthild diesen Frieden durch einen Kompromiss mit der austrasischen Königsfamilie zuwege gebracht hatte. Balthild verheiratete ihren Sohn Childerich mit Bilichild, der Tochter Sigiberts III. und Chimnechilds. Dadurch wurde der Königinwitwe Chimnechild die Regentschaft über das austrasische Teilreich zugestanden $^{72}$. Diese verzichtete dafür auf die Rückkehr ihres Sohnes Dagobert aus dem irischen Exil und erkannte die Vorherrschaft der neustrischen Königsfamilie an. Dass man den ungewöhnlichen Weg wählte, die Regentschaft von der Schwiegermutter ausüben zu lassen, zeigt die prekäre Lage dieses Kompromisses deutlich an. Aus diesem Grund erachtete man wohl die Heirat zwischen Cousin und Cousine für opportun. Diese Inzestehe wird verschwiegen, weil sie nicht in das hagiographische Schema der Vita passte. Balthilds Kampf gegen unkanonische Praktiken wie Simonie sowie ihre Unterstützung der irischen Klostergründungen wird von ihrem Hagiograph mit Lob überhäuft ${ }^{73}$. Die Befürwortung einer Inzestehe hätte dieses Bild getrübt.

Trotz der unerlaubten Ehe regierte Childerich zehn Jahre unangefochten in Austrasien. Im Jahre 673 starb sein Bruder, der neustrische König Chlothar III. Der übermächtige Hausmeier Neustriens Ebroin versuchte, den dritten Bruder Theuderich als Nachfolger einzusetzen ${ }^{74}$. Dem Intimfeind Ebroins, Bischof Leodegar von Autun, gelang es in dieser kritischen Phase, die neustrischen Adeligen mehrheitlich auf seine Seite zu ziehen und Childerich II. zum König des gesamten Reichs zu erheben. Ebroin wurde im Kloster Luxeuil, Theuderich im Kloster Saint-Denis inhaftiert. Dem König Childerich II. rang Leudegar das

70 Tunc etenim nuper et Austrasii pacifico ordine, ordinante domna Balthilde per consilium quidem seniorum receperunt Childericum, filium eius in regem Austri. ... Et credimus, Deo gubernante, iuxta domnae Balthildis magnam fidem ipsa tria regna tunc inter se tenebant pacis concordiam. Vita sanctae Balthildis 5 (MGH SS rer. Merov. 2, 487 f.).

71 Hamann, Chronologie 2003, 94.

72 Die Regentschaft wird von Urkunden bezeugt: KöLzer, Merowingerstudien 2 1999, 79-85; Offergeld, Reges 2001, $255 \mathrm{f}$.

73 Vgl. Nelson, Queens 1978, 16-23; Fouracre - Gerberding, France 1996, 97-118.

74 Wood, Kingdoms 1994, 227. 
Zugeständnis ab, die Gewohnheiten der Teilreiche anzuerkennen und keiner Einzelperson eine ähnlich bedeutende Machtfülle anzuvertrauen, wie sie Ebroin hatte $^{75}$. Obwohl Leodegar anfangs zu den engsten Beratern des Königs zählte, zog er wenig später den Zorn des Königs auf sich. In einem Streit zwischen dem Bischof von Clermont und dem Patricius von Marseille unterstützte Leodegar die falsche Partei und wurde 675 gemeinsam mit dem Patricius vom König des Hochverrats bezichtigt. Der Patricius wurde hingerichtet, Leodegar im Kloster Luxeuil gefangen gesetzt. Wenig später wurde auch König Childerich II. gemeinsam mit seiner schwangeren Frau im Verlauf einer Racheaktion ermordet ${ }^{76}$. In Neustrien folgte schließlich Theuderich III., der letzte überlebende Sohn Balthilds, als König nach. Theuderich und der wieder an die Macht gekommene Ebroin ließen Leodegar durch eine Synode absetzen und hinrichten ${ }^{77}$.

In der Regierungszeit Theuderichs III. entstand die Passio Leudgarii ${ }^{78}$. Darin wird erstmals der Vorwurf der Inzestehe gegen Childerich erhoben. Der anonyme Autor dieser Passio sieht den Grund der Entzweiung zwischen Childerich und Leodegar nicht allein in dem Streitfall zwischen Bischof und Patricius, sondern erwähnt zwei weitere Konfliktpunkte. Zum einen habe Leodegar dem König vorgeworfen, die Gewohnheiten der Reiche zu ändern, obwohl er doch deren Einhaltung garantiert hätte. Zum anderen habe er ihm die Ehe mit der Tochter seines Onkels vorgehalten. „Wenn er diese Missetaten nicht genauso wie die übrigen unerlaubten Verbrechen durch Besserung wieder gut macht, werde er bald einsehen, dass ihm die göttliche Rache sicher bevorstehen werde ${ }^{\text {“79 }}$. Mit dieser Bemerkung verknüpft der Autor die Anklage des heiligen Mannes ursächlich mit dem wenig später erfolgten Tod des Königs. Dass eine solche Verknüpfung nur ex post Sinn hat, ist evident. Wie wahrscheinlich ist es aber, dass Leodegar überhaupt den König mit dem Vorwurf des Inzests konfrontierte?

Für die Plausibilität dieses Vorwurfs spricht die Gelehrsamkeit Leodegars. Sein Hagiograph berichtet, er sei sowohl im weltlichen als auch im kirchlichen Recht bewandert gewesen und habe in Autun besonders durch seinen terror iustitiae für Schrecken gesorgt ${ }^{80}$. Leodegar war es auch, der zu Anfang der

75 Woll, Kapitularien 1995, 218-220.

76 Liber historiae Francorum 45 (MGH SS rer. Merov. 2, 318).

77 Mordek, Bischofsabsetzungen 1991; Mordek - Reynolds, Leodegar 1992; Fouracre, Bishops 2003.

78 Fouracre - Gerberding, France 1996, 193-215.

79 Et quia sacerdotalis integritas minas regis nescit metuere, Childericum coepit arguere, cur consuetudinis patrias, quas conservare praeceperat, tam subito inmutasset, simulque fertur dixisse, quod reginam quam habebat coniugem, filia sui esset avunculi; et nisi aut haec facinora cum reliquis inlicitis sceleribus emendatione corregeret, aut divinam certe sibi ultionem subito imminere cognosceret. Passio Leudegarii I 5 (MGH SS rer. Merov. 5, 290).

80 Passio Leudegarii I 1 (MGH SS rer. Merov. 5, 284). Zur Rechtskenntnis: Mordek, Kirchenrecht 1975, 82-85; Mordek - Reynolds, Leodegar 1992. 
Regierungszeit Childerichs II. die Einberufung von Synoden betrieb. Seit über zwanzig Jahren war keine Kirchenversammlung mehr zustande gekommen, und bis in die Zeit des Bonifatius sollte dies das letzte Mal sein, dass zur Disziplin in der Kirche und gegen die Verweltlichung des Klerus aufgerufen wurde. In seiner eigenen Diözese erließ Leodegar ebenfalls Kanones und sorgte für deren Aufnahme in die systematische Sammlung des merowingischen Kirchenrechts, in die Collectio vetus Gallica ${ }^{81}$. In dieser Sammlung konnte er auch etliche Kanones finden, die sich gegen die Ehe von Cousin und Cousine richten und die Trennung solcher Ehen vorschreiben ${ }^{82}$. Leodegar war also in der Tradition des Kirchenrechts hinreichend gebildet und geschult, um Childerichs Ehe als Inzest anzuprangern. Dennoch sprechen m.E. die konkreten Umstände gegen ein solches Vorgehen. Es war die Königin Balthilde, die sowohl die Heirat arrangierte als auch Leodegar im selben Jahr in Autun als Bischof installierte ${ }^{83}$. Die Ehe Childerichs war seit einem Jahrzehnt unangefochten, als Leodegar als treibende Kraft die Einsetzung Childerichs in Neustrien durchsetzte. Er hätte dies kaum betrieben, wenn er irgendwelche Zweifel hinsichtlich der Legitimität des Königs oder seiner Ehe gehegt hätte. Ebenso spricht die Zielsetzung der Passio gegen die Historizität des Vorwurfs. Die Passio wurde während der Herrschaft Theuderichs III. geschrieben und zeichnet absichtlich ein negatives Bild des Thronkonkurrenten Childerich ${ }^{84}$. Krusch und Fouracre haben gezeigt, dass der Autor ein bestimmtes Programm verfolgte und nicht vor Verzerrungen zurückschreckte ${ }^{85}$. So wird zum Beispiel der Patricius von Marseille in den höchsten Tönen gelobt, während er in anderen Quellen als Übeltäter und Entführer von Frauen beschrieben wird $^{86}$. Zuletzt muss auch berücksichtigt werden, dass in der zweiten, aus Poitiers stammenden Passio kein Wort vom Inzestvorwurf verlautet ${ }^{87}$. Insgesamt erscheint die Tatsache wenig wahrscheinlich, Leodegar habe sich vor den König hingestellt und ihm die Inzestehe vorgeworfen, die er im Alter von sieben Jahren auf Befehl Balthilds schließen musste. Der Angelpunkt des Streits zwischen Leodegar und Childerich wird von der Forschung in dem Konflikt austrasischer und neustroburgundischer

81 Mordek - Reynolds, Leodegar 1992.

82 Collectio vetus Gallica IXL 6-7 (558-560).

83 Passio Leudegarii I 2 (MGH SS rer. Merov. 5, 284).

84 Fouracre - Gerberding, France 1996, 202.

85 Krusch, Vita 1891; Fouracre, Hagiography 1990.

86 Passio Praeiecti 23 (MGH SS rer. Merov. 5, 239). Der Frauenraub als Anlass des Prozesses wird in der Passio Leudegarii verschwiegen.

87 Die Passio Leudegarii II zeichnet ein eher freundliches Bild Childerichs II.: Fouracre Gerberding, France 1996, 206-208; Fouracre, Hagiography 1990, 20 f. 
Adelsfraktionen gesehen, der sich im Prozess zwischen Bischof und Patricius entzündete ${ }^{88}$.

Im Rahmen der Frage nach Exogamie und ethnischer Identität ist folgendes festzuhalten. Die Inzestehe von Childerich und Bilichild war politisch motiviert und lässt sich nicht als Beispiel für eine übliche Praxis auffassen. Sie diente dem Ausgleich zwischen den beiden Königsfamilien und der dynastischen Legitimität nach dem ersten ,Staatsstreich ' der Karolinger. Dem Streben der Austrasier nach Eigenständigkeit konnte damit ebenso Genüge getan werden wie dem Anspruch auf Vorherrschaft durch die neustrische Königsfamilie. Der Episkopat war im späten 7. Jahrhundert zu schwach, um gegen diese politische Lösung Front zu machen. Da Synoden nicht mehr regelmäßig tagten und das Bischofsamt in die Hand mächtiger Adelsdynastien überging ${ }^{89}$, verschwand das Selbstbewusstsein und der Zusammenhalt der Bischöfe, die allein ein solches Wagnis ermöglicht hätten. Nur im Umkreis Leodegars, des gebildeten Rechtsgelehrten und Verfechters der synodalen Tradition, ist nachträglich ein solcher Angriff auf die Inzestehe geäußert worden. Diese Kritik war vergeblich, die Ehe wurde von allen Seiten als gültig betrachtet.

In der Merowingerzeit suchen wir sonst vergeblich nach Beispielen für eine Inzestehe unter Blutsverwandten ${ }^{90}$. Aus dem Werk Gregors von Tours lässt sich auf die unzureichende Akzeptanz des Verbots der Cousinenehe bei den Galloromanen schließen. In seiner Vita des Apostels Andreas erscheint die Cousinenehe wie in Rom als Mittel der senatorischen Aristokratie, die Zusammenführung von Erbschaften zu ermöglichen. Bei den Franken ist die Kirche hingegen auf keine gravierenden Probleme bei der Durchsetzung des Eheverbotes der Blutsverwandtschaft gestoßen.

88 Wood, Kingdoms 1994, 225. Praeiectus zählte auf die Unterstützung Chimnechilds, da Clermont zu Austrasien zählte: Passio Praeiecti 24 (MGH SS rer. Merov. 5, 240).

89 Ewig, Milo 1954; Semmler, Potestas 1974; Anton, „Bischofsherrschaften“ 1996.

90 Nach Poly, Chemin 2003, 105, gibt es in der Korrespondenz des Bonifatius einen weiteren Fall. Dies beruht aber auf einem Missverständnis der Wörter consubrina sui in S. Bonifatii et Lulli epistolae 50 (MGH Epp. sel. 1, 84). Die von Bonifatius inkriminierte Frau heiratete zuerst den Cousin von Ego, dann den Onkel von Ego und dann Ego selbst. Poly identifiziert den ersten und den zweiten Mann und bezieht die Worte consubrina sui auf den Onkel selbst, der damit zugleich der Cousin der Frau gewesen sei. Es handelt sich jedoch eindeutig um zwei verschiedene Personen, weil die Frau sich vom ersten Mann scheiden ließ und den zweiten überlebte (vidua avunculi sui). Das sui in consubrina sui bezieht sich daher auf Ego (vgl. die Übersetzung von Reinhold Rau in der Freiherr-vom-Stein Gedächtnisausgabe Bd. 4b, 145). In der Antwort des Papstes, die Poly zur Grundlage nimmt, wird dieser Sachverhalt verkürzt wiedergegeben: S. Bonifatii et Lulli epistolae 51 (MGH Epp. sel. 1, 90). 
Die Schwägerin als zweite Wahl

Im Vergleich zu den Quellen zur Blutsverwandtschaft sind die Dokumente für Ehen zwischen verschwägerten Personen Legion. Beginnen wir mit dem am häufigsten inkriminierten Verwandtschaftsverhältnis, der Ehe mit der Frau des Bruders, dem sog. Levirat. Diese Verbindung ist nur bei Personen fränkischer Herkunft anzutreffen. Erstmals ging Chlothar I. eine solche Ehe ein. Nachdem sein Bruder Chlodomer in einer Schlacht gegen die Burgunder im Jahr 524 ermordet worden war, schloss Chlothar unverzüglich eine Ehe mit dessen Frau Guntheuca $^{91}$. Der politische Charakter dieser Ehe ist evident. Die beiden Brüder Chlothar und Childebert nahmen das Teilreich Chlodomers für sich in Anspruch und beseitigten die Neffen gegen den Widerstand der Großmutter Chrodechilde $^{92}$. Wenn Guntheuca tatsächlich aus der burgundischen Königsfamilie stammte ${ }^{93}$, verschaffte die Heirat Chlothar darüber hinaus weitreichende Ansprüche. Politischen Charakter hatte auch vierzig Jahre später das Angebot der Witwe Chariberts an dessen Bruder Gunthram, eine Ehe mit ihr einzugehen und sich auf diese Weise einen Anteil am Teilreich Chariberts zu sichern ${ }^{94}$. Der kirchlich gesinnte König Gunthram schlug dieses Angebot aus und schickte die Witwe ins Kloster. Unklar ist dagegen der Hintergrund einer anderen Leviratsehe. König Theudebert I. richtete im Jahr 538 einen Brief an Papst Vigilius, um seinen Rat in der Frage der angemessenen Buße für eine Schwagerehe einzuholen. Betroffene Personen werden nicht genannt. Einen weiteren Fall berichtet Gregor von Tours. Magnovaldus, ein Adeliger im Teilreich Austrasien, wurde von Childebert II. auf hinterhältige Weise hingerichtet, als er gemeinsam mit dem König an einer Jagd teilnahm. Die Besitzungen des Magnovaldus wurden dem Staatsschatz einverleibt. Als Grund für diese Hinrichtung diente dem König der Vorwurf, Magnovaldus habe seine Frau ermordet, um nach dem Tod seines Bruders dessen Witwe heiraten zu können" ${ }^{95}$.

Diese Reihe von Fällen aus dem 6. Jahrhundert wird erst wieder im frühen 8. Jahrhundert fortgesetzt. In Bayern widersetzte sich der Missionar und Bischof

91 Nec moratus Chlothacharius uxorem germani sui Guntheucam nomine sibi in matrimonio sociavit. Gregor von Tours, Decem libri historiarum III 6 (MGH SS rer. Merov. 1/1, 103).

92 Gregor von Tours, Decem libri historiarum III 18 (MGH SS rer. Merov. 1/1, 117). Vgl. Ewig, Teilungen 1953, 128; Wood, Kingdoms 1994, 58.

93 Die Vermutung beruht allein auf der Namensform: Binding, Königreich 1868, 346; Favrod, Histoire 1997, 430-433; Kaiser, Burgunder 2004, 188.

94 Gregor von Tours, Decem libri historiarum IV 26 (MGH SS rer. Merov. 1/1, 159). Nach EwIG, Studien 1974, 30, verwies Gunthram Theudegilde ins Kloster, weil sie vor der Ehe mit Charibert ihren Klostereintritt rückgängig gemacht hatte. Esmyol, Ehefrau 2002, 50, macht dafür zu Recht den Inzest verantwortlich.

95 Gregor von Tours, Decem libri historiarum VIII 36 (MGH SS rer. Merov. 1/1, 404). Мгкат, Inzestgesetzgebung 1994, 67, spricht irrtümlich von Chlothar II. 
Corbinian der Ehe des Herzogs Grimoald mit der Witwe seines verstorbenen Bruders Theodoald ${ }^{96}$. Auch hier ging es offensichtlich um die Nachfolge im Teilreich Theodoalds, da das Herzogtum Bayern unter den vier Söhnen Theodos aufgeteilt worden war. Dieselbe Geschichte wird vom Missionar Kilian berichtet. Auch er soll eine Leviratsehe in der thüringischen Herzogsfamilie gebrandmarkt haben ${ }^{97}$. Diese Nachricht wird allerdings erst in einer Lebensbeschreibung aus dem 9. Jahrhundert erwähnt, so dass die Historiker dem Bericht nicht trauen und eine Beeinflussung durch die Vita Corbiniani annehmen ${ }^{98}$. Unbeeinflusst von diesem Muster ist dagegen die Schilderung der Mission Wunnebalds in der Vita der Äbtissin Hugeburc. Wunnebald bekämpfte in der Region von Eichstätt (Sualafeld) verschiedene heidnische Praktiken, brachte den Priesterzölibat wieder zur Geltung und untersagte auch die Leviratsehe ${ }^{99}$. Dieser Bericht ist jedoch von einer anderen Quelle geprägt, der literarischen Hinterlassenschaft des Missionsbischofs für Germanien Bonifatius ${ }^{100}$. Bonifatius hatte den Kampf gegen unzüchtige Kleriker und gegen Überreste des Heidentums zum Kern seiner Mission auf dem Kontinent gemacht. Auch mit einem Verfechter der Leviratsehe, dem Häretiker Clemens, hatte er sich über Jahre hinweg herumschlagen müssen und den Hausmeier Karlmann zu konsequentem Eingreifen aufgefordert. Dieser Clemens war vermutlich irischer Herkunft und wird von der Forschung in Thüringen lokalisiert ${ }^{101}$. Über sein weiteres Schicksal ist nichts bekannt.

Diese acht Fälle von Leviratsehe haben mehrheitlich politischen Charakter und sagen daher wenig über das allgemeine Heiratsverhalten aus. Es ist lediglich festzuhalten, dass ein Verbot dieser Form der Ehe vor der Christianisierung nicht bekannt war, sie aber auch nur dann praktiziert wurde, wenn politische Erwägungen dafür sprachen. Kirchlich gesinnte Könige wie Theudebert und Gunthram hatten kein Problem, das Verbot des Levirats anzuerkennen und die Frage der Nachfolge auf andere Weise zu regeln. Die Fälle aus dem ostrheinischen Frankenreich des 8. Jahrhunderts weisen auf die Defizite der Christia-

96 Arbeo von Freising, Vita Corbiniani 24 (MGH SS rer. Germ. 13, 215). Vgl. Jahn, Ducatus 1991, 101-104; Kolmer, Ehemoral 1995, $85 \mathrm{f}$.

97 Vita Kiliani 8 (MGH SS rer. Merov. 5, 725). Vgl. Weigand, Verständnishintergründe 1989.

98 Erstmals Riezler, Vita 1903, 232-234; SCHäFERdiek, Kilian 1994, 332.

99 ... qui iniuste copulationis coniugio coniuncti contra legem Domini vitialiter victitabant, fornicatiale polluti spurcitia, sed et etiam nonnulli, qui cum suis propriis propinquis et adfinis et cum propria fratris sui uxore in coniugio nupti fuerant ... Hugeburc, Vita Wynnebaldi 7 (MGH SS 15/1, $111 \mathrm{f}$.).

100 Glatthanr, Bonifatius 2004, 610. Bereits Arbeo stilisierte Corbinian zu einem bayerischen Bonifatius: JaHn, Arbeo 1994, 159; Vogel, Werden 2003, 470.

101 Glatthane, Bonifatius 2004, 152. 
nisierung in dieser Region hin. Im zentralen Frankenreich hatte sich das Verbot offensichtlich schon durchgesetzt.

Andere Ergebnisse zeitigt die Untersuchung des sog. Sororats, der Heirat mit der Schwester der Ehefrau. Die beiden frühesten Belege stammen aus der gallo-romanischen Bevölkerung des Burgunderreichs und sind aus der Briefsammlung des bedeutenden Bischofs Avitus von Vienne bekannt. Ich werde im folgenden Kapitel noch ausführlicher auf diese Fälle eingehen ${ }^{102}$, deshalb seien hier nur kurz die betroffenen Personen erwähnt. Das eine Mal handelt es sich um Vincomalus, einen römischen Bürger der Stadt Grenoble. Der zweite Fall betrifft den Schwertträger König Sigismunds namens Stephan. Die ethnische Zugehörigkeit ist bei Stephan umstritten, doch halte ich mit Ian Wood eine romanische Herkunft für wahrscheinlich ${ }^{103}$. In beiden Fällen ist die Ehe erst nach längerer Zeit beanstandet worden, obwohl das Sororat bereits seit dem 4. Jahrhundert durch kirchliche und weltliche Gesetzgebung als Inzest unter Verbot gestellt worden war. Dies wirft ein helles Licht auf die sich nur allmählich vollziehende Umsetzung der spätantiken Gesetzgebung. Weitere Fälle des Sororats sind aus der merowingischen Königsdynastie bekannt. Der Wüstling par excellence, Chlothar I., heiratete die Schwester seiner ersten Frau Ingunde. Diese hatte ihn gebeten, einen angesehenen und wohlhabenden Mann für ihre Schwester Aregunde aufzutreiben. Daraufhin habe Chlothar die Schwester in Augenschein genommen und sei unmittelbar in Leidenschaft zu ihr entbrannt. Da er für sie „keinen besseren Mann gefunden habe als sich selbst“, nahm er auch Aregunde zur Frau ${ }^{104}$. Dasselbe wiederholte sich nochmals bei Chlothars Sohn Charibert. Dieser heiratete Merofledis und ihre Schwester Marcoveifa ${ }^{105}$. Anders als bei den beiden Fällen aus Burgund nahmen sich die merowingischen Könige die Freiheit, noch zu Lebzeiten ihrer Frau deren Schwester zu ehelichen. Möglich war ihnen dieses Vorgehen, das bei den Verwandten der Frau auf Widerstand hätte stoßen müssen, durch den Status der Frauen als Sklavinnen des Herrschers ${ }^{106}$. Diese Art von ungehemmter Polygynie ist bereits von Tacitus als ein Spezifikum der germanischen Fürsten benannt worden und lässt sich in merowingischer Zeit nur bei der Herrscherdynastie belegen ${ }^{107}$.

Die weiteren Fälle von Ehen innerhalb der Schwägerschaft belegen nochmals die Ähnlichkeit von romanischer und fränkischer Haltung zum Inzestverbot. Die Ehe mit der Frau des Onkels ist trotz des eindeutigen biblischen

102 Siehe $121-137$.

103 Siehe 133 Anm. 93.

104 Gregor von Tours, Decem libri historiarum IV 3 (MGH SS rer. Merov. 1/1, 136 f.).

105 Post haec Marcoveifa, Merofledis scilicet sororem, coniugio copulavit. Gregor von Tours,

Decem libri historiarum IV 26 (MGH SS rer. Merov. 1/1, $158 \mathrm{f}$.).

106 Le Jan, Famille 1995, 279; Esmyol, Ehefrau 2002, 56-58.

107 Tacitus, Germania 18 (13). Vgl. Esmyol, Ehefrau 2002, 55 f. 
Verbots (Lev. 18, 14) insgesamt dreimal nachzuweisen. Der erste Fall hat wiederum deutlich politische Querverbindungen. Merovech, Sohn Chilperichs aus erster Ehe, nahm im Jahr 576 die Witwe seines Onkels Brunichilde zur Frau ${ }^{108}$. Die westgotische Königstochter Brunichilde war nach dem Tod ihres Mannes von Chilperich gefangen genommen, ihrer Schätze beraubt und nach Rouen ins Exil verwiesen worden. Ihr erst fünfjähriger Sohn Childebert kam unter die Vormundschaft austrasischer Adeliger und wurde als neuer König anerkannt. Brunichilde war dagegen von der Regierung Austrasiens ausgeschlossen. Ähnlich aussichtslos wie die Lage Brunichildes war diejenige Merovechs. Sein Vater Chilperich hatte die ehemalige Sklavin Fredegunde zur Frau genommen, die mit aller Macht versuchte, ihre Stiefkinder zugunsten ihrer eigenen von der Herrschaft zu verdrängen. Ein Bruder Merovechs wurde 580 auf Befehl Fredegundes ermordet ${ }^{109}$. Aus dieser Not erklärt sich die Zweckheirat zwischen Merovech und Brunichilde. Sie sollte Merovech einen Anspruch auf das austrasische Teilreich verschaffen und Brunichilde die Rückkehr an die Macht ermöglichen $^{110}$.

Den zweiten Fall einer Heirat mit der Frau des Onkels kennen wir ebenfalls durch Gregor von Tours. Gregor berichtet, dass der Graf Eulalius von Clermont seine Frau Tetradia schwer prügelte und ihrer Besitztümer beraubte. „Als sie sich nun in solchem Elend sah und alle Ehre, welche sie im Hause ihres Mannes gehabt hatte, eingebüßt hatte, richtete, während ihr Mann zum König gezogen war, dessen Neffe namens Virus sein Auge auf sie und wollte sie zur Ehe nehmen, denn er hatte seine Frau verloren " ${ }^{\text {"111 }}$. Eulalius konnte durch den Mord an seinem Neffen dieses Heiratsprojekt verhindern. Diese Episode des Jahres 590 zeigt die fehlende Durchsetzung des Eheverbots bei den Galloromanen.

Den dritten Fall überliefert die Korrespondenz des Bonifatius. In seinem Antrittsschreiben an den neu gewählten Papst Zacharias bat Bonifatius in verschiedenen umstrittenen Angelegenheiten um Rat, die an ihn als Missionsbischof der Germania herangetragen worden waren. Unter anderem nannte er den Fall eines Mannes „,on hohem Stand“, der erklärte, „ihm sei von dem Bischof des apostolischen Stuhles Gregorius heiligen Angedenkens die Erlaubnis erteilt

108 Gregor von Tours, Decem libri historiarum V 2 (MGH SS rer. Merov. 1/1, 195). Vgl. SChNeIder, Königswahl 1972, 96 f.; STAFford, Queens 1983, 49; Jussen, Patenschaft 1991, $177-192$.

109 Gregor von Tours, Decem libri historiarum V 39 (MGH SS rer. Merov. 1/1, 245).

110 Ewig, Studien 1974, 33; Nelson, Queens 1978, 12.

111 Denique inter has angustias mulier collocati, cum honorem omnem, quem in domo viri habuerat, perdidissit et ille abisset ad regem, haec a Viro - sic enim erat nomen hominis mariti sui nepote, concupiscitur, scilicet ut, quia ille perdiderat coniugem, huius matrimonio iungeretur. Gregor von Tours, Decem libri historiarum X 8 (MGH SS rer. Merov. 1/1, 489 f.). 
worden, die Witwe seines Oheims zu ehelichen “112. Der Papst bestritt in seiner Antwort die Richtigkeit dieser Angaben und stimmte Bonifatius in der Verurteilung dieser Ehe $\mathrm{zu}^{113}$. Über die ethnische Identität dieses Mannes lässt sich keine Auskunft geben, da Bonifatius zu dieser Zeit im gesamten Reichsteil Karlmanns tätig war.

\section{Die Stiefmutter als Ehefrau}

Den Befund eines weitgehend ähnlichen Heiratsverhaltens von Franken und Romanen hat bislang nur die Leviratsehe durchbrochen. Die Ehe mit der Stiefmutter halten einige Historiker ebenfalls für einen ,germanischen Brauch $^{\text {'114 }}$. Wegen der Dürftigkeit der Quellen zum Frankenreich ist es notwendig, Fälle aus den Nachbarreichen der Warnen und Angelsachsen heranzuziehen.

Das erste Zeugnis einer Ehe mit der Stiefmutter verdanken wir einem Exkurs über das Volk der Warnen im Geschichtswerk des Prokopios ${ }^{115}$. Das Reich der Warnen wird von der modernen Forschung im heutigen Mecklenburg lokalisiert. Der byzantinische Historiker berichtet, dass in der ersten Hälfte des 6 . Jahrhunderts ein Krieg zwischen den Warnen und den Angeln ausgebrochen ist. Anlass für die kriegerischen Auseinandersetzungen war der Bruch der Verlobung zwischen Radigis, dem Sohn des Warnenkönigs Hermegisclus, und einer anglischen Prinzessin. Hermegisclus selbst war in zweiter Ehe mit einer Schwester des Frankenkönigs Theudebert verheiratet, als er bei einem Ausritt das Krächzen eines Vogels vernahm und darin die Weissagung zu verstehen glaubte, er werde binnen vierzig Tagen sterben. In einer Rede an die Vornehmen seines Volks berichtete er von dieser Weissagung und erklärte, es sei für die Warnen wichtiger, mit den benachbarten Franken verschwägert zu sein als mit den Angeln auf der anderen Seite des Kanals. Deshalb befahl er, die Verlobung seines Sohnes rückgängig zu machen und der anglischen Prinzessin als Entschädigung die Verlobungsgeschenke zu belassen. „Mein Sohn Radigis aber soll unserem väterlichen Gesetz entsprechend seine Stiefmutter heiraten". Die Verlobte des Radigis war dagegen entschlossen, den Bruch der Verlobung nicht hinzuneh-

112 Quia laicus quidam magne persone ad nos veniens dicebat sibi ab apostolicae sedis pontificae sanctae memoriae Gregorio datam fuisse licentiam, ut in matrimonium acciperet viduam avunculi sui. S. Bonifatii et Lulli epistolae 50 (MGH Epp. sel. 1, 83 f.).

113 S. Bonifatii et Lulli epistolae 51 (MGH Epp. sel. 1, 90).

114 Grimm, Rechtsalterthümer 1899, 602; Hellmann, Heiraten 1903, 325; Poly, Chemin 2003, 71; dagegen Lancaster, Kinship 1958, 241.

115 Prokop, De bello gothico IV 20 (2, 589-600). Vgl. PohL, Germanen 2000, 40. Matthias Springer, Art. „Thüringen. historisch“, in: RGA 30 ( $\left.{ }^{2} 2005\right)$ 521-530, hier 528, identifiziert die Warnen Prokops mit den Thüringern und sieht in Hermegisclus einen Nachkommen des Bisinus. Die Warnen in Chronicae quae dicuntur Fredegarii IV 15 (MGH SS rer. Merov. 2, 127) werden allgemein als Thüringer angesehen. 
men, und bereitete einen Kriegszug ihres Volkes gegen die Warnen vor. In der Schlacht unterlag Radigis und wurde von der anglischen Prinzessin dazu genötigt, seinerseits die fränkische Königstochter zurückzuschicken und das Verlobungsversprechen einzulösen.

Prokops Worte, die Ehe mit der Stiefmutter sei gemäß väterlichem Gesetz erfolgt, scheinen eindeutig diese Heiratsverbindung als germanischen oder zumindest warnischen Brauch auszuweisen. Grimm, Poly und andere zögerten deshalb nicht, diese Folgerung zu ziehen. Es ist jedoch fraglich, ob man damit nicht die Aussagekraft von Prokops Geschichtswerk überschätzt. Vor allem seine Informationen zu den germanischen Völkern sind, wie die neuere Forschung betont, von den traditionellen Stereotypen der griechischen Ethnographie überformt. Zum Beispiel verdient seine Nachricht kein Vertrauen, sowohl die Warnen als auch die Briten hätten in der Schlacht keine Pferde gebraucht, auf den britischen Inseln seien Pferde sogar vollkommen unbekannt gewesen, so dass man britische Gesandte auf dem Kontinent in den Sattel heben und wieder herunterholen habe müssen. Archäologische sowie andere historiographische Quellen erweisen dies als ethnographisches Stereotyp, das Prokop auch den Slawen und Franken anheftete ${ }^{116}$. Darüber hinaus ist der ganze Exkurs von legendären Elementen durchzogen und als „eine seltsame Melange von Phantasie und Geschichte" ${ }^{\text {"117 }}$ zu bewerten. Darunter fällt etwa das Gespräch des Königs Hermegisclus mit einem Vogel sowie die Nachricht, die Insel Britannien sei durch eine lange Mauer zweigeteilt und in der nördlichen Hälfte könne aufgrund der giftigen Luft kein Mensch überleben. Man wird also nur einen Teil des Warnen-Exkurses als glaubhaft annehmen können. Die fränkischwarnische Eheverbindung erhält eine zusätzliche Stütze durch das Epitaph des Venantius Fortunatus auf Theudeberts Schwester Theudechilde. Darin schreibt der Dichter: „Ihr Bruder, Vater, Ehemann, Großvater und die Ahnen waren königlichen Standes in durchgehender Vollendung "118. Eine Identifizierung ihres Ehemanns mit Hermegisclus ist durchaus möglich. Die anvisierte Ehe zwischen Theudechilde und Radigis erscheint ebenso glaubwürdig. Ludwig Schmidt zog in Erwägung, die Verstoßung Theudechildes habe zu einem Krieg

116 Cameron, Procopius 1985, 214 und 219; Halsall, Warfare 2003, 185. Zu den Informationen über Britannien bei Prokop vgl. auch PohL, Names 1997, 14-19.

117 Cameron, Procopius 1985, 215. Vgl. auch Berthold Rubin, Art. „Prokopios“, in: RE 23/1 (1957) 273-599, hier 515; Matthias Springer, Art. „Warnen“, in: RGA 33 (2006) 274-281, hier 278.

118 Cui frater, genitor, coniunx, avus atque priores culmine succiduo regius ordo fuit. Venantius Fortunatus, Carmina IV 25 (MGH Auct. Ant. 4/1, 94). Es ist jedoch umstritten, ob diese Theudechilde mit der an die Warnenkönige verheirateten Tochter Theuderichs identisch ist. Zustimmend Ewig, Namengebung 1991, $51 \mathrm{f}$; BeIsel, Theudebertus 1993, 38; Wood, Kingdoms 1994, 361; Kaiser, Erbe 2004, 174. Zöllner, Geschichte 1970, 107, und JARNuT, Agilolfingerstudien 1986, 93-97, lehnen die Identität ab. 
zwischen Warnen und Franken geführt und das Ende des Warnenreiches bedeutet ${ }^{119}$. Kritischer muss man dagegen die von Prokop wiedergegebene Rede des Hermegisclus betrachten. Man könnte darin einen Erklärungsversuch Prokops für eine im römischen Recht und im Christentum inkriminierte Eheverbindung sehen, die deshalb irgendwie mit den barbarischen Gewohnheiten in Verbindung stehen müsse. Jedenfalls lässt sich daraus ohne Hinzuziehung anderer Belege kein germanischer Brauch der Ehe mit der Stiefmutter erschließen.

Ein weiteres Kennzeichen der Ehe Radigis' mit seiner Stiefmutter ist ihr politischer Charakter. Hermegisclus selbst betont die Vorteile einer Verschwägerung mit dem Frankenreich und sieht darin eine angemessene Rechtfertigung für sein Vorgehen. Ähnliche Hintergründe spielten auch bei dem nächsten Fall eine Rolle. Im Jahr 616 starb König Aethelbert von Kent, der Initiator der christlichen Mission in England. Sein Sohn Eadbald brach mit der Religionspolitik seines Vaters und setzte eine heidnische Reaktion in Gang ${ }^{120}$. Der angelsächsische Kirchenhistoriker Beda berichtet: „Nicht nur hat er sich geweigert, den Glauben Christi anzunehmen, er hat sich auch durch solch eine Unzucht beschmutzt, welche sogar der Apostel als unerhört unter den Heiden bezeichnete, indem er die Frau seines Vaters nahm “121. Dafür sei er von Gott durch häufige Anfälle von Wahnsinn und durch den Angriff eines bösen Geistes bestraft worden. Später konvertierte Eadbald zum Christentum und war gezwungen, seine Stiefmutter zu verstoßen und eine andere Ehe einzugehen. Dieser Fall zeigt deutlich, dass eine Ehe mit der Stiefmutter nur unter heidnischen Vorzeichen möglich war. Eine heidnische Gewohnheit darin zu sehen, ist dennoch nicht zwingend. Man wird vielmehr auch hier Legitimationsdefizite in der politischen Herrschaft vermuten müssen, obwohl die konkreten Umstände des Herrschaftswechsels nicht bekannt sind. Erst an einer anderen Stelle streut Beda die Information ein, Eadbald habe weniger Königsgewalt besessen als sein Vater $^{122}$.

Probleme der Herrschaftsnachfolge treffen dagegen mit Sicherheit für das nächste Zeugnis einer Heirat mit der Stiefmutter zu. Im Jahr 626/627 starb der übermächtige burgundische Hausmeier Warnachar ${ }^{123}$. Das Amt des Hausmeiers hatte sich seit der vormundschaftlichen Regentschaft in Burgund von einem Hofamt zu einer reichsweiten Schaltzentrale entwickelt ${ }^{124}$. Bereits der Vorgänger Warnachars, der um 598/599 gestorben ist, trug denselben Namen und war

119 Sснмidt, Westgermanen 1 1940, 28; Zöllner, Geschichte 1970, 92; Jarnut, Agilolfingerstudien 1986, 31.

120 Stenton, England 1950, 60 und 112-113; Kirby, Kings 1991, 38-42.

121 Beda, Historia ecclesiastica gentis Anglorum II 5 (150).

122 Beda, Historia ecclesiastica gentis Anglorum II 6 (154). Vgl. Kirby, Kings 1991, 38.

123 Ebling, Prosopographie 1974, 235-238.

124 Ewig, Merowinger 2001, 93 und 117-120; Wood, Kingdoms 1994, 144-146. 
offensichtlich mit ihm verwandt. Im Epochenjahr 613 stand Warnachar an führender Stelle, als die burgundischen Adeligen zum neustrischen König Chlothar II. übergelaufen sind und das Ende der eigenständigen Königsherrschaft in Burgund besiegelten. Als Dank dafür erhielt er von Chlothar das Hausmeieramt auf Lebenszeit. Kurz vor seinem Tod wagte es Warnachar, in einer Streitsache um das Columban-Kloster Luxeuil gegen die Partei des Königs zu agitieren ${ }^{125}$. Als es dann um die Nachfolge in das Hausmeieramt ging, war Chlothar fest dazu entschlossen, die Herrschaft der Familie Warnachars zu brechen. Darauf wird es zurückzuführen sein, dass sich Warnachars Sohn Godinus zur Heirat mit seiner Stiefmutter bewegen ließ. „Darüber entbrannte der König Chlothar in höchstem Zorne gegen ihn und befahl dem Herzog Arnebert ... ihn mit einem Heerhaufen zu töten "126. Godinus gelang jedoch die Flucht in das Kirchenasyl. Durch die Vermittlung von Chlothars Sohn erreichte er eine kurzfristige Versöhnung unter der Bedingung, dass er die Witwe seines Vaters aus der Ehe entlassen und bei verschiedenen heiligen Stätten des Frankenreichs, in Soissons, Paris, Orléans und Tours für die begangene Sünde Buße tun musste ${ }^{127}$. Seine Stiefmutter denunzierte ihn jedoch beim König mit dem Vorwurf, ein Attentat auf ihn im Schilde zu führen. Daraufhin schickte Chlothar zwei Getreue mit einer Schar Bewaffneter aus, um Godinus in einen Hinterhalt zu locken und zu töten. Das Amt des Hausmeiers wurde auf Wunsch des Königs und der burgundischen Großen nicht wieder besetzt ${ }^{128}$.

Dieser Fall einer Ehe mit der Stiefmutter wird nur vor dem Hintergrund der politischen Ereignisse verständlich. Godinus wollte den Erbanspruch seiner Familie auf das Hausmeieramt bewahren und musste befürchten, dass seine Stiefmutter entweder ihre eigenen Kinder, falls solche existierten, oder andere Kandidaten protegieren würde. Zudem war die Erblichkeit des Hausmeieramtes, die in den anderen Teilreichen nicht bestand und die erst die Pippiniden Jahre später durchsetzen konnten, dem Herrscher Chlothar II. ein Dorn im Auge. Bereits im Jahr 616 startete Chlothar einen Versuch, der Macht des Hausmeiers bestimmte Grenzen zu setzen, indem er die lokalen Verwaltungsstrukturen in Burgund stärkte. Die damals erlassene Praeceptio Chlotharii bewertet Stefan Esders als „programmatische Zurückdrängung der Eigenmacht des

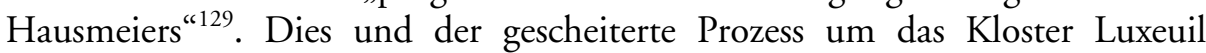
setzten Godinus so unter Druck, dass er sich zu dieser prekären Heirat entschloss, die sogar nach fränkischem Recht mit dem Tod bestraft wurde.

125 Ebling, Prosopographie 1974, 236; Pontal, Synoden 1986, 201.

126 Unde Chlotharius rex adversus eum nimia furore permutus iobet Arneberto duci, qui Godini germanam uxorem habebat, eum cum exercito interficeret. Chronicae quae dicuntur Fredegarii IV 54 (MGH SS rer. Merov. 2, 147).

127 Chronicae quae dicuntur Fredegarii IV 54 (MGH SS rer. Merov. 2, 147).

128 Chronicae quae dicuntur Fredegarii IV 54 (MGH SS rer. Merov. 2, 148).

129 EsDers, Rechtstradition 1997, 381. 
Der letzte hier zu betrachtende Fall datiert bereits aus der Karolingerzeit. Aethelwulf, König von Wessex, begab sich im Jahr 855 auf eine Pilgerfahrt nach Rom, verbrachte dort annähernd ein ganzes Jahr und schloss auf der Rückreise eine Ehe mit der Tochter Karls des Kahlen Judith ${ }^{130}$. Der König des Westfrankenreichs übergab seine dreizehnjährige Tochter nur unter der Bedingung, dass Judith zur Königin gesalbt würde und entgegen dem westsächsischen Zeremoniell neben dem König auf dem Thron Platz nehmen dürfte. Zwei Jahre später, 858, starb Aethelwulf und hinterließ vier Söhne aus seiner ersten Ehe. Der älteste, Aethelbald, gab bereits zuvor eine Kostprobe seines Ehrgeizes ab, als er 856 seinen Vater in einer Revolte an der Rückkehr auf den Thron des Königs von Wessex hinderte und eine Teilung des Landes durchsetzte. Nach dem Tod des Vaters nahm er seine Stiefmutter Judith zur Frau. Gemäß dem übereinstimmenden Urteil der Historiker entsprang diese Heirat politischen Erwägungen ${ }^{131}$. Denn von seinen anderen drei Brüdern war bislang nur einer mit einer Königsherrschaft ausgestattet, während die anderen beiden von Aethelwulf lediglich Besitzungen in Wessex erhalten hatten und daher Konkurrenten waren ${ }^{132}$. Von der Ehe mit einer gesalbten Königin von Wessex, die überdies aus dem prestigeträchtigen Haus der Karolinger entstammte, versprach sich Aethelbald eine symbolische Aufwertung seiner Stellung. Überraschenderweise ließen weder die angelsächsischen noch die fränkischen Bischöfe einen Protest gegen diese klar inzestuöse Verbindung verlauten ${ }^{133}$. Erst Jahre später konnte es sich der Biograph Alfreds des Großen erlauben, die Ehe öffentlich zu brandmarken. „Gegen die Vorschrift Gottes und die Würde der Christen, und nicht zuletzt auch gegen den Brauch aller Heiden hat Aethelbald das Gemach seines Vaters betreten und Judith, die Tochter des Frankenkönigs Karl, mit großer Schande für alle Hörenden zur Frau genommen “134.

In allen vier Fällen einer Ehe mit der Stiefmutter herrschten also politische Erwägungen vor. Es ging darum, die Nachfolge zu sichern, Konkurrenten auszuschalten oder Agitationen der Stiefmutter zu unterbinden. Damit lässt sich dieser Befund mit Beispielen vergleichen, in denen die Ehe mit der Königswitwe als Hebel zur Erringung der Macht diente. Die Beispiele für solche Aktionen sind Legion ${ }^{135}$. So wollte der Aufrührer Alethius im Jahre 613/614 die Königin Berthetrud, noch bevor ihr Mann das Zeitliche gesegnet hat, auf seine Seite

130 Enright, Charles 1979; Nelson, Charles 1992, 182; Abels, Alfred 1998, 78-91.

131 Aвels, Alfred 1998, 90; Story, Connections 2003, 242.

132 AвELs, Alfred 1998, 87.

133 Nach Sproemberg, Judith 1936, 422 f., unterließen sie das, weil der Brauch der Angelsachsen respektiert wurde. Widerspruch bei Hlawitschka, Lotharingien 1968, 238, der Staatsräson vermutet.

134 Asser, De rebus gestis Aelfredi 17 (16).

135 Stafford, Charles 1981, 144; Nelson, Queens 1978, 6-9; Fröhlich, Studien 1 1980, 71; Kasten, Stiefmutter 2001; Pohl, Gender 2004, 38. 
ziehen, um die Wiedererrichtung eines burgundischen Sonderkönigtums ins Werk zu setzen. Die Ehe mit der Stiefmutter muss als Sonderfall dieser umfassenderen Praxis angesehen werden. Es wird dadurch lediglich belegt, dass die Ehe mit der Stiefmutter in der Führungsschicht anders als im römischen und kirchlichen Recht nicht als Inzest angesehen wurde bzw. dass man sich über dieses Verbot hinwegsetzen konnte. Ein häufiges Vorkommen dieser Ehe außerhalb bestimmter politischer Rahmenbedingungen ist dagegen nicht erwie$\operatorname{sen}^{136}$. Weder wird man die Aussage Prokops in diese Richtung deuten können, noch lässt sich aus der Behauptung Assers, die Ehe mit der Stiefmutter sei gegen die Sitte aller Heiden, der gegenteiligen Schluss ziehen. Asser lag die Kirchengeschichte Bedas vor, in der die Worte des Apostel Paulus zitiert werden, „eine solche Unzucht komme selbst unter den Heiden nicht vor" (1. Cor. 5, 1) ${ }^{137}$. Asser überträgt dies auf die Heiden seiner Zeit; aus einer literarischen Reminiszenz wird unversehens eine Aussage über die Gegenwart. Ihr kann man ebenso wenig trauen wie den ethnographischen Vorurteilen Prokops.

Die in der Historiographie greifbaren Fälle von Inzestehen bringen insgesamt ein weitgehend ähnliches Heiratsverhalten von Franken und Romanen zum Vorschein. Wichtig ist vor allem der Befund, dass Ehen zwischen Blutsverwandten am seltensten bezeugt sind. Die Mission der Franken ist in dieser Hinsicht nicht auf große Widerstände gestoßen. Bereits vor der Christianisierung dürften sie exogame Heiratsregeln befolgt haben. Auf die Anpassung an die römische Kultur kann dies nicht zurückgeführt werden, da in der senatorischen Oberschicht die Ehe zwischen Cousin und Cousine nachweislich einen hohen Stellenwert hatte. Ein anderes Muster lässt sich dagegen bei der Heirat zwischen Stiefverwandten erkennen. Das Verbot der Heirat mit den Stiefeltern zählte bereits vor der Christianisierung zum Kern der römischen Inzestverbote. Die entsprechenden Fälle konzentrieren sich daher ausschließlich auf die germanischen Völker der Franken, Angelsachsen und Warnen. Trotz dieses eindeutigen Musters gibt es keine sicheren Indizien für eine Verbreitung in der gesamten Bevölkerung, da diese Form der Ehe immer im Kontext des Problems

136 Hellmann, Heiraten 1903, 294 f., erwähnt einen weiteren Fall: Nach Asser, De rebus gestis Aelfredi 15 (13), soll Karl der Große der angelsächsischen Prinzessin Eadburh die Ehe mit sich selbst oder mit einem seiner Söhne zur Auswahl gestellt haben. Eadburh entschied sich für den Sohn. Karl antwortete verärgert: „Wenn du mich gewählt hättest, hättest du meinen Sohn bekommen; aber weil du meinen Sohn wähltest, sollst du weder mich noch jenen bekommen“. Hellmann schloss daraus, Karl hätte damit die Ehe seines Sohnes mit der Stiefmutter impliziert. Er ergänzt: „... hättest du sowohl mich und meinen Sohn bekommen“. Dies ist jedoch eine Fehlinterpretation. Karl erwartete nur den Respekt Eadburhs, der ihr die Ehe mit seinem Sohn als Belohnung verschafft hätte, wenn sie der Etikette gemäß zuerst Karl gewählt hätte. Die Geschichte wird als Legende zur Diskreditierung Eadburhs gewertet: STORY, Connections 2003, $110 \mathrm{f}$.

137 So der Kommentar zur Stelle: Asser, De rebus gestis Aelfredi (214). 
der Herrschernachfolge auftrat. Derselbe Vorbehalt muss auch beim Levirat gemacht werden, das ausschließlich bei Personen fränkischer Herkunft nachweisbar ist. Festzuhalten bleibt daher, dass ein Inzestverbot unter Stiefverwandten und verschwägerten Personen bei den Franken nicht bekannt war. Auf den ersten Blick erstaunt es daher, dass gerade diese Eheformen in den Rechtsaufzeichnungen arianischer Könige mit besonderer Schärfe ins Visier genommen wurden. Diesen Kodifikationen wollen wir uns jetzt zuwenden.

\subsection{Arianismus und Inzestverbot}

Die ersten Rechtsaufzeichnungen der frühmittelalterlichen Reiche sind von Herrschern erlassen worden, die sich zum arianischen Verständnis der Trinität bekannten und von der katholischen Kirche als Häretiker angesehen wurden. Der Arianismus geht auf die Christianisierung der Goten im 4. Jahrhundert zurück $^{138}$. Der erste Bischof der Goten, Wulfila, übernahm die arianische Konfession in einer abgeschwächten Form, wie sie zu seiner Zeit von den Kaisern der östlichen Reichshälfte vertreten wurde. Der Arianismus in dieser gemäßigten Ausrichtung lehrte, dass Jesus nicht als wesensgleich mit dem Vater, sondern nur als ähnlich (hómoios) bezeichnet werden kann. Dies implizierte eine Ablehnung philosophischer Begrifflichkeit zur Beschreibung des Verhältnisses zwischen Jesus und Gottvater. Diese Formel wurde auf dem Konzil von Konstantinopel (360) als Kompromiss zwischen den verschiedenen Parteien formuliert. Erst Theodosius setzte auf dem Konzil von Konstantinopel im Jahre 381 die Rückkehr zum Nicäanum durch und erreichte dadurch eine Einigung von westlicher und östlicher Reichshälfte. Die christianisierten Teile der Goten blieben beim homöischen Bekenntnis, das Wulfila bis zu seinem Tod im Jahr 383 als Bischof und Primas der Goten bewahrte. Durch seine Übersetzung der Bibel ins Gotische begründete er die christliche Tradition der Goten und sorgte für das dauerhafte Bekenntnis zur arianischen Trinitätslehre.

Der Arianismus verbreitete sich im 5. Jahrhundert durch die hegemoniale Stellung der gotischen Völker auch in anderen germanischen Königreichen. Bei Vandalen, Sueben, Burgundern und Langobarden setzte sich das arianische Bekenntnis durch, obwohl sie zunächst von katholischer Seite missioniert worden waren ${ }^{139}$. Mit Ausnahme der Franken vollzogen alle germanischen Reiche auf dem Kontinent diesen Glaubenswechsel. Dies hat in der Forschung zur Bildung des Begriffs des "germanischen Arianismus "140 geführt. Man meinte

138 Schäferdiek, Anfänge 2001; ders., Arianismus 2002. Zum Hintergrund vgl. WolfRAM, Goten 1990, 84-94.

139 Knut SCHÄFERDIEK, Art. „Arianische Germanenmission“, in: TRE 12 (1984) 506-510.

140 Schubert, Staat 1912. 
eine besondere Affinität der Germanen zu dieser vermeintlich bodenständigen Variante des Christentums erkennen zu können. Darüber hinaus habe sich in dieser Abkehr vom katholischen Episkopat die Herrschaft der Könige über die Religion herausbilden können, wie sie bereits für die heidnische Vorgeschichte der germanischen Völker verankert gewesen sei. Diese Sicht ist von Knut Schäferdiek überwunden worden ${ }^{141}$. Die Verbindung zwischen Arianismus und Germanen ist ihm zufolge nur der kontingenten Situation der Mission Wulfilas zu verdanken, die unter den homöisch orientierten Kaisern des Ostreichs stattfand. Durch die Bibelübersetzung habe sich diese Verbindung verfestigt, da eine volkssprachliche Liturgie innerhalb der orthodoxen Kirche keine Anerkennung gefunden hätte. Die Verbreitung des Arianismus im 5. Jahrhundert sei auf die hegemoniale Stellung der Westgoten zurückzuführen. Zudem macht Schäferdiek auf die durchaus unterschiedlichen Konfessionen in den Herrscherfamilien des burgundischen, ostgotischen, langobardischen und fränkischen Reichs aufmerksam. Diese Tatsache lässt es fraglich erscheinen, ob sich im alltäglichen Leben überhaupt Unterschiede zwischen den beiden Konfessionen bemerkbar gemacht haben ${ }^{142}$. Mit Ausnahme des Gebrauchs der Volkssprache ist darüber wenig bekannt. Man sollte daher im Arianismus nach Schäferdiek eher einen wichtigen Schritt der Christianisierung der germanischen Völker als einen kirchengeschichtlichen Irrweg sehen. Der Arianismus habe die Romanisierung der Germanenreiche nicht wesentlich behindert und sei ohne greifbare Überwerfungen der katholischen Konfession gewichen.

Trotz dieser Einebnung des Unterschieds zwischen nicäanischer und homöischer Orthodoxie ist es lohnend, nach der Behandlung des Inzestverbots in der Gesetzgebung arianischer Könige zu fragen. Denn in einem Punkt haben sich ihre Reiche grundsätzlich von den katholischen Reichen unterschieden: Ihre Könige unterlagen nicht den Forderungen des Episkopats nach einer Aufnahme und Billigung des Kirchenrechts. Sie waren nicht dazu gezwungen, die kirchenrechtliche Kompetenz der katholischen Bischöfe anzuerkennen und sich der spirituellen Macht der das Bischofsamt monopolisierenden Aristokratie unterzuordnen ${ }^{143}$. Es stellt sich daher die Frage, ob die arianischen Könige bereit waren, die von den katholischen Bischöfen eingeforderte Bekämpfung des Inzests ihrer Agenda einzuverleiben. Bruno Krusch hat diese Frage negativ beantwortet. „Die Germanen haben sich gegen solche kirchliche Ehe-Beschränkungen energisch gewehrt, denn sie widersprachen ihren Sitten und ihrem

141 SCHÄFERdiek, Stellung 1978. Radikalisiert wird diese Einschätzung durch AMORY, People 1995, 236, für den die arianische Kirche nicht ethnisch bei den Germanen, sondern lokal in Italien verankert war. In diesem Sinn auch EvERETT, Literacy 2003, 5961. Die Belege dafür sind aber nicht ausreichend.

142 Schäferdiek, Anfänge 2001, 310.

143 Liebeschuetz, Decline 2001, 355. Zu arianischen Klerikern vgl. Mathisen, Bishops 1997. 
Rechtsbewußtsein “144. Kronzeuge ist für ihn das westgotische Recht. Vorschriften gegen den Inzest finden sich darin erst nach der katholischen Bekehrung Reccareds im Jahre $589^{145}$. Auch die burgundische Gesetzgebung nahm erst mit der Hinwendung Sigismunds zum Katholizismus eine Bestimmung über den Inzest auf. Das Inzestverbot im Edictus des langobardischen Königs Rothari führt Krusch auf den Einfluss seiner katholischen Frau Gundeberga zurück. Dieses Argument greift jedoch zu kurz, da sonst keine Bestimmungen im gesamten Edikt die Einwirkung des Kirchenrechts bezeugen. Ob man Gundeberga diesen Einfluss auf das durch die Heeresversammlung beschlossene Edikt zuschreiben kann und warum sich dieser Einfluss nur auf die Inzestvorschrift ausgewirkt haben soll, bleibt unklar ${ }^{146}$. Das Schweigen der burgundischen und westgotischen Gesetzgebung taugt als argumentum e silentio ebenfalls nur wenig. Es ist daher angebracht, das Verhältnis der arianischen Könige zur Inzestgesetzgebung im Detail zu untersuchen. In Frage kommen dafür die Rechtsquellen aus dem Königreich der Ostgoten und die Bestimmungen des Edictus Rothari.

\section{Theoderich und Cassiodor}

Der Ostgotenkönig Theoderich stand wegen seines beherzten Eintretens für Gerechtigkeit und Rechtstaatlichkeit bei den Zeitgenossen in hohem Ansehen ${ }^{147}$. Als Herrscher über die italische Präfektur und als Volkskönig über die Goten in Italien versuchte er, das römische Recht als Grundlage des Zusammenlebens zwischen Römern und Goten zu etablieren. An den Schwertträger Unigis richtete Theoderich die bekannten Worte: „Wir erfreuen uns, nach den Gesetzen der Römer zu leben, die wir mit Waffen zu verteidigen wünschen. ... Was nützt es denn den barbarischen Aufruhr beseitigt zu haben, wenn wir nicht nach den Gesetzen leben? ${ }^{\text {"148 }}$ Für die Regelung des Inzests hatte dies zur Folge, dass Theoderich die Gesetze des römischen Rechts bei allen Teilen der Bevölkerung zur Geltung bringen wollte. Ein Zeugnis davon gibt das in der Briefsammlung des Cassiodor überlieferte Formular einer Einweisung an den Verwalter der kaiserlichen Domänen (comes rerum privatarum). In der Einleitung des Formulars wird der Wechsel der Amtskompetenz erwähnt, da die Verwaltung der kaiserlichen Domänen dem comes patrimonii übertragen worden

144 KRusCh, Forschungen 1927, 101. Zurückhaltender MiкAT, Inzestgesetzgebung 1994, 104, nach dem die Quellen über die Haltung der Arianer nichts überliefern würden.

145 Siehe 207.

146 Das Verhältnis zwischen Rothari und Gundeberga war nicht spannungsfrei: Chronicae quae dicuntur Fredegarii IV 70 (MGH SS rer. Merov. 2, 156).

147 Prokop, De bello gothico I 1, 27 f. (2, 8). Wolfram, Goten 1990, 286-288; KohlhasMüLlER, Untersuchungen 1995.

148 Delectamur iure Romano vivere quos armis cupimus vindicare ... Quid enim proficit barbaros removisse confusos, nisi vivatur ex legibus? Cassiodor, Variae III 43 (CCL 96, 126). 
$\operatorname{war}^{149}$. Als Ausgleich dieses Kompetenzverlustes wird dem comes rerum privatarum die Gerichtsbarkeit über Inzest und Grabschändung anvertraut. Das Formular lässt dies als Aufwertung erscheinen, da er jetzt nicht mehr allein über die Fälle unfreier Sklaven, sondern über die Angelegenheiten freier Bürger zu entscheiden habe ${ }^{150}$. Inzest und Grabschändung waren mit den Aufgaben des Domänenverwalters verbunden, weil beide Vergehen üblicherweise mit Vermögenskonfiskation geahndet wurden und weil auch die Einziehung herrenloser Güter und Schätze in seine Kompetenz gestellt war ${ }^{151}$.

Der Gesetzgeber umschreibt die Befugnis bei Inzestvergehen folgendermaßen:

„Zuerst ist dir - gewissermaßen als öffentlicher Vater - die Überwachung über frevelhafte Ausschweifungen und gottlose Begierden des Menschengeschlechts zuerkannt, damit sich niemand durch schändliche Vermischung beschmutzt, wenn er keine Ehrfurcht vor verwandtem Blut haben sollte. Die öffentliche Majestät unterschied nämlich umsichtig die Heiligkeit der Verwandtschaft und die Gabe der Heirat, weil der Natur der Verwandtschaft etwas ganz anderes geschuldet wird als wir der Zügellosigkeit des Körpers nachsehen können. Du wirst gegen diese als vorzüglicher und sittsamer Untersucher gewählt, damit du das Lob der Keuschheit erlangen sollst, wenn du solch Schändlichem nachspürst" ${ }^{\text {"152 }}$.

Diese Begründung des Inzestverbots bewegt sich ganz in der römischen Tradition und unterscheidet sich kaum von der Argumentation Diocletians in seiner Konstitution aus dem Jahr $295^{153}$. Christliches Gedankengut ist nicht eingeflossen. Die Wirksamkeit der römischen Tradition in der Inkriminierung des Inzests als gottloses Verbrechen wird dadurch unter Beweis gestellt. Christliche Umformung ist innerhalb dieses Diskurses nicht nötig, weil sich die römischen Argumente auch christlich verstehen lassen.

Eine Erweiterung um christliches Gedankengut finden wir dagegen in einem anderen Schriftstück aus der Feder Cassiodors. Dabei handelt es sich um

149 Cassiodor, Variae VI 8 (CCL 96, 234-236). Vgl. STEIN, Histoire 2 1956, 52; Delmaire, Largesses 1989, 690 f.; Brandes, Finanzverwaltung 2002, 33-38; Maier, Amtsträger 2005, 308.

150 ... sed actibus urbanis tunc se felicius occupavit, postquam agrestium causas decenter amisit. Quid enim prius facerent inter servos iura publica, qui personam legibus non habebant? Cassiodor, Variae VI 8 (CCL 96, $234 \mathrm{f}$.).

151 Vgl. EnsLin, Theoderich 1959, 164.

152 Primum tibi contra nefarias libidines et humani generis improbos appetitus quasi parenti publico decreta custodia est, ne quis se probrosa commixtione pollueret, dum vicino sanguini reverentiam non haberet. Gravitas enim publica proximitatis sanctitatem et coniunctionis gratiam habita aestimatione discrevit, quia longe aliud debetur proximitatis naturae quam corporali possumus indulgere licentiae. Contra hos eligeris unicus et continens inquisitor, ut, dum talia probra persequeris, consequaris praeconia castitatis. Cassiodor, Variae VI 8 (CCL 96, 235).

153 Siehe 43-45. 
ein Formular, das die Heirat mit der Cousine durch Gunsterweis des Königs für legitim erklärt. Diese Praxis der Dispensierung im Einzelfall ist seit dem Ende des vierten Jahrhunderts belegt ${ }^{154}$. Im Formular des Ostgotenkönigs verschmelzen römische und christliche Argumentationsmuster:

„Der heilige und durch göttliche Einsetzung unterwiesene Moses bestimmte für das Volk Israel unter anderem, dass es seine Geschlechtsakte von der Nachbarschaft des frommen Blutes fernhalten sollte, damit es sich so durch die Rückkehr zur Verwandtschaft nicht beschmutzt und eine behutsame Erweiterung auf fremde Geschlechter hat. Diesem Beispiel sind die klugen Männer [d.h. die Juristen] gefolgt, indem sie eine viel weitergehende keusche Observanz der Nachwelt überließen und allein dem Fürsten den Gunsterweis vorbehielten, Cousin und Cousine durch das eheliche Band zu verbinden. Denn sie erkannten, dass seltener etwas gewagt werde, das sie vom Fürsten zu erbitten befahlen" ${ }^{\text {"155. }}$.

Deutlich kommt in diesen Worten die Erkenntnis zum Ausdruck, dass die zeitgenössischen Inzestverbote über das mosaische Recht der Bibel hinausgingen und nur durch die Autorität des römischen Rechts Gültigkeit beanspruchten. Aufgrund dessen ist es dem König als Wahrer des Rechts erlaubt, im Einzelfall Dispens zu erteilen. Nach Cassiodor bewirkt die Dispensierung, dass die Eheleute keine Schuld auf sich laden, sondern durch ihr castum matrimonium und ihre gloriosa permixtio Lob verdienen ${ }^{156}$. Diese Worte legen einen fließenden Übergang zwischen gültigen und inzestuösen Ehen nahe.

Die Dominanz des römischen Rechts machte sich auch im Edictum Theoderici geltend. Das Edikt ist vermutlich kurz nach 500 entstanden und besteht im Wesentlichen aus kurzen Extrakten aus römischen Rechtsquellen ${ }^{157}$. Im Epilog des Gesetzbuchs wird ausdrücklich sowohl die gotische als auch die römische Bevölkerung unter Androhung harter Strafen zur Einhaltung der

154 Siehe 65 Anm. 152.

155 Institutio divinarum legum humano iuri ministravit exordium, quando in illis capitibus legitur praeceptum quae duabus tabulis probantur ascripta. Sacer enim Moyses divina institutione formatus Israhelitico populo inter alia definivit, ut concubitus suos a vicinitate pii sanguinis abstinerent, ne et se in proximitatem redeundo polluerent et dilatationem providam in genus extraneum non haberent. Hoc prudentes viri sequentes exemplum multo longius pudicam observantiam posteris transmiserunt, reservantes principi tantum beneficium in consobrinis nuptiali copulatione iungendis, intellegentes rarius posse praesumi quod a principe iusserant postulari. Cassiodor, Variae VII 46 (CCL 96, 294). Die Übersetzung von prudentes viri durch Juristen ist gewährleistet durch: Variae VI 8 (CCL 96, 235) und VIII 20 (CCL 96, 326).

156 Erunt vobis itaque deo favente posteri sollemniter heredes, castum matrimonium, gloriosa permixtio, quoniam quicquid a nobis fieri praecipitur, necesse est ut non culpis, sed laudibus applicetur. Cassiodor, Variae VII 46 (CCL 96, 295).

157 Die Zuschreibung des Edikts an den ostgotischen und nicht an den westgotischen Theoderich hat sich unter Historikern durchgesetzt: Nehlsen, Rezension 1969; Wolfram, Goten 1990, 445; Siems, Handel 1992, 277-284; Amory, People 1995, 78-82; KohlHas-MüLler, Untersuchungen 1995, 228-245. 
Bestimmungen aufgerufen. Theoderich zwingt der gotischen Bevölkerung also ausschließlich römisches Recht auf. Auch das Kirchenrecht findet, sofern es in die theodosianische Kodifikation eingegangen ist, Aufnahme in die Gesetzgebung des Arianerkönigs. Asylrecht, Kirchenschutz, Sonntagsheiligung und heidnische Praktiken werden einer Regelung unterzogen ${ }^{158}$. Im Eherecht vollzieht Theoderich dieselben Einschränkungen der Scheidung, die einst von Constantin erlassen und in den Codex Theodosianus aufgenommen worden waren ${ }^{159}$. In den Bereich des Eherechts fällt auch eine Bestimmung zu ungültigen Ehen: „Wenn sich jemand zu nicht legitimen Ehen versteigt, entkomme er auf keinen Fall einer gesetzlichen Verurteilung; er wisse, dass er weder eine gültige Ehe noch legitime Kinder haben wird"160. Ob sich diese Regelung auf den Inzest bezieht, ist auf den ersten Blick unklar. Halban bezeichnete sie als Rahmengesetz, weil keine Aussage darüber getroffen wurde, was unter ungültigen Ehen zu verstehen $\operatorname{sei}^{161}$. Nach römischem Recht würden darunter nicht nur Inzestehen fallen, sondern auch eheliche Verbindungen zwischen Freien und Sklaven ${ }^{162}$ sowie zwischen Römern und Barbaren ${ }^{163}$, ferner Bigamie ${ }^{164}$, Heirat mit einer Nonne ${ }^{165}$ und Ehen, die aufgrund falscher Angaben vom Kaiser erschlichen worden $\operatorname{sind}^{166}$. Die Rechtsfolgen dieser ungültigen Ehen sind unterschiedlich und können neben Trennung und Infamie der Kinder auch Konfiskation oder Todesstrafe beinhalten. Trotz dieses Charakters als Rahmengesetz ist eine primäre Ausrichtung auf Inzest wahrscheinlich. Im Wortlaut schließt sich das Edikt nämlich deutlich einer Inzestbestimmung des Codex Theodosianus $a n^{167}$. Die verkürzte Formulierung wird man in erster Linie auf den Charakter des Edikts als Kurzfassung des römischen Rechts zurückführen. Da nicht ausdrücklich aufgezählt wird, welche Verbindungen als Inzest zu gelten haben, wird von einer Fortführung der römischen Ehegesetzgebung auszugehen sein, wie sie durch die beiden Formulare Cassiodors bezeugt ist.

158 Edictum Theoderici 70 (MGH LL 5, 160), 108 (MGH LL 5, 164), 125 (MGH LL 5, 165), 154 (MGH LL 5, 168).

159 Edictum Theoderici 54 (MGH LL 5, 157).

160 Si quis ad nuptias non legitimas aspiraverit, legum censuram penitus non evadat; qui nec iustum matrimonium nec filios sciat se habere legitimos. Edictum Theoderici 36 (MGH LL $5,156)$.

161 Halban, Recht 1 1899, 147.

162 Codex Theodosianus 12, 1, 6 (663); Codex Iustinianus 5, 5, 3 (198).

163 Codex Theodosianus 3, 14, 1 (155).

164 Codex Iustinianus 5, 5, 2 (198); Cassiodor, Variae, edictum Athalarici 6 (CCL 96, 368).

165 Lex Romana Burgundionum 9, 4 (132 f.).

166 Codex Theodosianus 3, 10, 1 (147).

167 Codex Theodosianus 3, 12, 3 (151): ... sed neque uxorem neque filios ex ea editos habere credatur. Das Wort legitimus steht in der Interpretatio: Lex Romana Visigothorum, Cod. Theod. 3, 12, 3 Int. (152). Ähnlich formuliert ist auch Gai institutiones 1, 64 (18): Ergo si quis nefarias atque incestas nuptias contraxerit, neque uxorem habere uidetur neque liberos. 
Theoderich der Große stellte sich also trotz seiner arianischen Konfession deutlich in die Tradition der römischen Inzestgesetzgebung. Es bedurfte keiner Einwirkung katholischer Bischöfe, weil der Inzest als Vergehen innerhalb des römischen Rechts verankert war. Es war sogar das Bewusstsein vorhanden, dass die Regelungen des römischen Rechts deutlich über das mosaische Recht hinausgingen und somit allein auf die Wahrung durch den König angewiesen waren. Der König als Stellvertreter des Kaisers delegierte die Strafverfolgung an den Comes rerum privatarum, nachdem dieser zusehends aus der Verwaltung der königlichen Domänen verdrängt worden war. Der Comes erhielt einen inquisitorischen Auftrag, der sich nicht nur auf die Domänen, sondern auf alle freien Leute innerhalb einer bestimmten Region bezog. Vorbild dafür war die Verschiebung der Kompetenzen im östlichen Kaiserreich, wie spätere Gesetze von Justinian wahrscheinlich machen ${ }^{168}$. Die gotische Bevölkerung wurde nach dem Zeugnis des Edikts denselben Gesetzen unterworfen. Ob der Comes rerum privatarum, der stets der römischen Bevölkerung angehörte, auch für die Strafverfolgung des Inzests bei den Goten zuständig war, erscheint fraglich. Für gotische Belange schuf Theoderich ein eigenes Amt, die Comitiva Gothorum ${ }^{169}$.

\section{Das Edikt König Rotharis}

Im Unterschied zum Edictum Theoderici ist das Verhältnis zwischen römischem und germanischem Recht für den langobardischen Edictus Rothari in der Forschung umstritten ${ }^{170}$. Rothari erließ das Edikt am 22. November 643, als er eine Offensive gegen die Herrschaft des oströmischen Reichs in Italien startete und erfolgreiche Vorstöße in Ligurien und in das Exarchat von Ravenna unternahm. Von einigen Historikern ist daher der Edictus als Teil einer antirömischen Reaktion begriffen worden, da nach Auskunft des Prologs die Gesetze auf einer Heeresversammlung durch den alten Ritus des "Speergedinges“ beschlossen wurden ${ }^{171}$. Dem steht allerdings entgegen, dass sowohl im Prolog als auch im Epilog aus den Novellen Justinians zitiert wird ${ }^{172}$. Auch einige inhaltliche Bestimmungen sind deutlich vom römischen Recht geprägt, obwohl Rothari ein freier Umgang mit seinen Quellen zu bescheinigen ist ${ }^{173}$. Zum Beispiel sind die Grenze der Verwandtschaft und die gültigen Motive für Enterbung dem rö-

168 STEIN, Histoire 2 1956, 206, mit Verweis auf Novella 12 (95), 139 (700) und 154 (729).

169 Wolfram, Goten 1990, $290 \mathrm{f}$.

170 Einen guten Überblick gibt Walter PoHL, Art. „Leges Langobardorum“, in: RGA 18 (2001) 208-213.

171 BognetTi, Editto 1970.

172 Tamassia, Fonti 1889; Paradisi, Prologo 1968.

173 Cavanna, Problemi 1968, 272. 
mischen Recht entnommen ${ }^{174}$. Direkte Zitate finden sich mit der Ausnahme der Rahmentexte jedoch nicht. Der Einfluss des römischen Rechts wird im öffentlichen Recht und auch im Privatrecht wirksam, bleibt aber im Ganzen gesehen nur punktuell. Institutionen wie Wergeld, Fehde, Eidhelfer, Gottesurteil und das gesamte Ehegüterrecht sind fest in den germanischen Traditionen verwurzel ${ }^{175}$. In diesen Bereichen werden auch besonders häufig volkssprachliche Wörter in den lateinischen Text eingeflochten ${ }^{176}$. Insgesamt wird man also von langobardischen Grundzügen mit vereinzelten und nur selten gehäuft auftretenden Einsprengseln aus dem römischen Recht sprechen können.

Das Kirchenrecht ist lediglich am Rande präsent. Dies hat Vismara zu der deutlich übertriebenen Behauptung angeregt, Rotharis Gesetzbuch sei vom Heidentum kontaminiert und nur durch eine oberflächliche Patina des Arianismus christianisiert ${ }^{177}$. Dem widersprechen Regelungen zum Kirchenasyl und zum Kirchenschutz, die sich ganz dem Vorbild des römischen Rechts verdanken $^{178}$. Rothari nimmt also kirchliche Anliegen insofern auf, als sie seiner Inszenierung als Gesetzgeber dienen und in der römischen Tradition verankert sind. Andere Vorschriften legen von der Bereitschaft Zeugnis ab, christliche Normen gegen die Hartnäckigkeit heidnischer Gewohnheiten durchzusetzen. Dazu zählt die Regelung, Eide nicht auf Waffen, sondern auf die Heilige Schrift abzulegen ${ }^{179}$. Besonders drastisch kommt dieses Engagement in der Bestimmung zum Ausdruck, dass niemand eine Halbfreie oder eine Magd als Hexe töten solle, weil es für den christlichen Verstand nicht glaubhaft oder möglich sei, dass eine Frau einen lebendigen Menschen innerlich verschlingen könne ${ }^{180}$. Eine christliche Prägung ist also durchaus erkennbar, wenn auch der Einfluss des römischen Rechts ungleich schwerer wiegt.

Die Vorschrift zum Inzestverbot zählt zu den wenigen direkten Übernahmen aus dem römischen Recht. Sie lautet:

„Niemandem ist es erlaubt, seine Stiefmutter, seine Stieftochter oder seine Schwägerin, d.h. die Frau des verstorbenen Bruders, zu ehelichen. Und wenn sie dazu ihren Willen gibt, dann zahlt der Mann zur Strafe an den Königshof 100 Schillinge und wird sofort von ihr getrennt, notfalls mit königlicher Zwangsgewalt. Der Frau aber bleibt nur die Hälfte von all ihrem Gut. Die andere Hälfte verliert sie; die

174 Edictus Rothari 153 (MGH LL 4, 35); 169 (MGH LL 4, 39). Vgl. Tamassia, Fonti $1889,200 \mathrm{f}$.

175 So bereits Halban, Recht 2 1901, 112; Beyerle, Langobarden 1947, XIII; Astuti, Influssi 1975, 679. Eine überspitzte romanistische Deutung befürwortet CorTESE, Thinx 1988; Ders., Processo 1994. Vgl. zuletzt Dilcher, Gairethinx 2006.

176 EveretT, Literacy 2003, 114-122.

177 Vismara, Cristianesimo 1967, 422-433.

178 Edictus Rothari 35 (MGH LL 4, 18 f.); 272 (MGH LL 4, 66).

179 Edictus Rothari 359 (MGH LL 4, 82).

180 Edictus Rothari 376 (MGH LL 4, 87). 
nimmt der Königshof. Und diese Strafe trifft sie beide, weil es ihr Wille war, eine verbotene Ehe einzugehen; und man trennt sie wie gesagt unverzüglich ${ }^{\text {“181 }}$.

Der Form nach hat der erste Satz der Bestimmung deutliche Ähnlichkeiten mit der Gai Epitome des westgotischen Breviars ${ }^{182}$. Da das Breviar jedoch nicht zu den Quellen des Edictus zählt, muss die Frage der Vorlage offen bleiben. Interessanterweise werden als Partner einer inzestuösen Verbindung nur die Stiefverwandten und die Schwägerin genannt. Dies ist wohl nicht als Milderung der römisch-rechtlichen Inzestvorschriften anzusehen. Denn immerhin werden genau diejenigen Verwandtenehen genannt, die man besonders häufig und ausschließlich bei Angehörigen der germanischen Völker nachweisen kann. Das Verbot der Ehe mit der Stiefmutter und mit der Schwägerin zielt auf die am häufigsten nachweisbaren Formen des Inzests.

Eine Abweichung vom römischen Recht liegt in den Straffolgen vor. Obwohl auch in einigen Quellen aus römischer Zeit mit Konfiskation gedroht wird, ist die übliche Bestrafung die Trennung der Ehe und die Infamie der Eheleute $^{183}$. Folgerichtig tritt an die Stelle der Infamisierung die für die germanischen Rechte typische Komposition. Die Buße beträgt zwei Drittel des Wergelds eines Freien und ist daher ebenso wie die Geldbuße für die Frau von beträchtlicher Höhe ${ }^{184}$.

Die Inzestbestimmung des Edikts ist also ein typisches Produkt der Symbiose von römischem und langobardischem Recht, die durch die Kodifikation Rotharis in Gang gekommen war und unter Liutprand im 8. Jahrhundert vollendet wurde. Während die Strafbestimmung aus dem Reservoir der langobardischen Tradition entnommen ist, stammt der Inhalt des Inzestverbots aus dem römischen Recht und betrifft genau jene Fälle, die für die Langobarden eine Neuerung der Heiratspraxis mit sich bringen mussten. Das Gesetz als solches sollte für alle Einwohner des Reichs Gültigkeit beanspruchen, die sich

181 De incestas et inlecetas nuptias. Nulli leciat novercam suam, id est matrinia, qui fuit uxor patris, neque privignam, quod est filiastra, neque cognatam, qui fuit uxor fratris, uxorem ducere. Et si ipsa consenserit, vir, qui eam ducit, conponat pro culpa in curte regis solidos centum, et mox separetur ab ea constrictus a rege; et ipsa mulier habeat medietatem de omnis res suas, et medietatem amittat et curtes regia suscipiat: eo quod inlecitas consenserunt celebrare nuptias, hac poena susteneant et mox, ut dictum est, separentur. Edictus Rothari 185 (MGH LL 4, 44); Übersetzung nach BeyerLe, Langobarden 1947, 69.

182 KRUSCH, Forschungen 1927, 98, verweist auf Lex Romana Visigothorum, Liber Gaii IV 5 u. 7 (318). Tamassia, Fonti 1899, 204, und Halban, Recht 2 1901, 114, nennen Codex Iustinianus 5, 5 (198 f.) und Institutiones 1, 10, 6 (4) als Vorbild, doch finden sich dort weder wörtliche Übereinstimmungen noch alle im Edictus genannten Verwandten. Die Gai institutiones kommen nicht in Frage, weil darin noch das christliche Ehehindernis der Schwägerschaft fehlt.

183 Siehe 68 Anm. 176.

184 Beyerle, Langobarden 1947, 435. 
der Herrschaft des langobardischen Königs unterworfen hatten und die seine Kodifikation als Privileg in Anspruch nehmen konnten ${ }^{185}$.

Die Quellen aus dem ostgotischen und langobardischen Italien haben also alles andere als eine Zurückhaltung der arianischen Könige gegenüber der Verfolgung des Inzests ans Licht gebracht. Theoderich und Rothari traten als Herrscher über Italien in die Nachfolge der römischen Kaiser. Sie übernahmen somit die römische Inzestgesetzgebung als Teil dieser Hinterlassenschaft und versuchten die römisch-christlichen Vorschriften auf ihr Volk auszudehnen. Das Inzestverbot wird nicht primär als Anliegen der katholischen Orthodoxie, sondern als Teil des römischen Rechts aufgefasst. Ist es für Theoderich noch ungewiss, wie weit er in der Übertragung der Inzestgesetzgebung auf die ostgotische Bevölkerung zu gehen bereit war, erließ Rothari Bestimmungen genau in jenen Bereichen, die sich bei der Untersuchung der einzelnen Inzestfälle als besonders sensibel herausgestellt haben. Unabhängig von der Frage der Orthodoxie lässt sich daher eine deutliche Kontinuität feststellen. Unklar bleibt aus Mangel an Quellen, ob die Inzestgesetzgebung auf Widerstand gestoßen ist und ob die Vorschriften ohne die Unterstützung eines politisch anerkannten Episkopats in der Praxis tatsächlich geltend gemacht wurden.

\subsection{Literarische Stilisierung von Ethnizität}

In der anonymen Vita Kiliani aus der Mitte des 9. Jahrhunderts heißt es: „Der Herzog Gozbert hatte die Frau seines Bruders in der Ehe, so wie es seit alters her Brauch gewesen ist “186. Der Herausgeber der Vita, Wilhelm Levison, führt als Beleg für diesen Brauch die Bibelstelle Deut. 25, 5 an, in der das Levirat im Fall der Kinderlosigkeit des Bruders vorgeschrieben wird. Levison dachte nicht einen Augenblick daran, dass der Autor der Vita eine spezifisch germanische Konvention bezeichnen wollte. Überdies setzte Levison die Aussage in Beziehung zum irischen Missionar Clemens, den Bonifatius in den 740er Jahren nicht zuletzt deshalb mit besonderem Eifer verfolgte, weil er das Levirat auf der Grundlage der Bibel verteidigt hatte ${ }^{187}$. Wie bereits erwähnt bezeichnete Prokop im 6. Jahrhundert die Ehe mit der Stiefmutter als „herkömmliches Gesetz“ des germanischen Warnenvolks und reproduzierte damit eher ein ethnographisches Stereotyp als eine gesicherte Information. Am wirkungsvollsten für die literarische Tradition, die den Germanen endogames Verhalten nachsagt, war der

185 Edictus Rothari 367 (MGH LL 4, 85). Vgl. Everett, Law 2005, 347-351.

186 Ipse autem Gozbertus dux in matrimonio habuit uxorem fratris sui, sicut antiquitus fuit consuetudinis. Vita Kiliani 8 (MGH SS rer. Merov. 5, 725).

$187 \mathrm{Zu}$ Clemens vgl. Russell, Boniface 1964; Zeddies, Bonifatius 1995; Glatthaar, Bonifatius 2004, 152. 
Libellus responsionum Gregors des Großen aus dem Jahre $601^{188}$. In diesem weit verbreiteten Dokument verbietet der Papst die Ehe mit der Cousine, mit der Stiefmutter und mit der Schwägerin und schreibt abschließend, dass im Volk der Angeln viele in eine dieser schändlichen Ehen verstrickt seien. Da Gregor unmittelbar auf eine Anfrage des Erzbischofs von Canterbury reagierte und wenig später tatsächlich eine Ehe mit der Stiefmutter durch den heidnischen König Eadbald geschlossen wurde, ist an dem realen Hintergrund des Libellus nicht zu zweifeln. Trotzdem muss auch das Schreiben Gregors des Großen zunächst als literarisches Dokument begriffen werden, das mehr über die Diskussion innerhalb der in England wirkenden christlichen Missionare aussagt als über die tatsächlich praktizierten Eheformen. Wie die Untersuchung der bekannt gewordenen Inzestfälle dieser Zeit aufzeigt, ist nur die Ehe mit der Stiefmutter und der Frau des Bruders bei den Franken und Angeln nachweisbar. Anlass für solche Eheschließungen waren Probleme bei der Abwicklung von Sukzessionskrisen im Königtum. Ob es darüber hinaus bei anderen Schichten der Bevölkerung Zwänge der Sozialstruktur gab, die solche Ehen begünstigten, kann anhand der Quellen nicht überprüft werden ${ }^{189}$.

Die literarische Stilisierung muss auch bei der Bewertung Gregors von Tours in Rechnung gestellt werden. Er schildert minuziös die Anekdoten über die Inzestehen Chlothars I. und Chariberts, weil er damit auf eindrucksvolle Weise sein überwiegend negatives Bild von den Frankenkönigen bestätigen konnte. Gregors Könige, selbst wenn sie wie Gunthram seiner Idealvorstellung nahekamen, waren nämlich vor allem eines: der ungezügelten Leidenschaft unterworfen ${ }^{190}$. Neben dem Zorn, der sich in Gewalttätigkeiten äußerte, war die sexuelle Begierde ein wesentlicher Grundzug von Gregors Herrscherbild. Aus der Perspektive des gesamten 6. Jahrhunderts waren jedoch die Inzestehen Chlothars und Chariberts die Ausnahme. Die meisten Merowingerkönige bemühten sich nämlich um Eheschließungen mit ausländischen Prinzessinnen, die keinen Inzestverdacht erregen konnten ${ }^{191}$. In der Gesetzgebung legten Chlod-

188 Ausführlich zu diesem Dokument unten 220-227.

189 Мікат, Inzestgesetzgebung 1994, 72, äußert die These, vermögensrechtliche Interessen an der Dos der Frau hätten die Praxis der Schwagerehe begünstigt. Dies ist jedoch zum einen in den Quellen nirgends nachweisbar; zum anderen ist die Argumentation selbst nicht überzeugend: Warum sollte der Schwager ein Interesse an der Dos haben, wenn diese im Todesfall den Kindern zusteht?

190 Zum furor regum vgl. Gregor von Tours, Decem libri historiarum, praefatio prima (MGH SS rer. Merov. 1/1, 1). Reydellet, Royauté 1981, 386-389; Buc, Dangers 2001, 95 f.; Shanzer, History 2002, 398.

191 Und zwar Childerich I., Chlodwig, Theuderich, Chlodomer, Childebert I., Theudebert I., Theudebald, Sigibert I. und Chilperich I. 
wig, Theudebert, Chilperich, Gunthram und Childebert II. sogar besonderen Nachdruck auf die Verfolgung von Inzestehen ${ }^{192}$.

Anders als die Ehe mit der Stiefmutter und mit der Frau des Bruders ist die Ehe mit der Cousine kaum belegt. Sie kann daher nicht als fränkischer oder germanischer Brauch klassifiziert werden. Jean-Pierre Poly ist es trotz verzerrender Quellenlektüre nicht gelungen, die Cousinenehe bei den Franken auch nur im Ansatz nachzuweisen. Die bekannt gewordenen Fälle des frühen Mittelalters sprechen eine andere Sprache. Im 6. Jahrhundert war es offensichtlich die romanische Senatorenschicht Galliens, die aus Überlegungen der Besitzübertragung Cousinenehen anbahnte. Die bislang noch nicht herangezogene Stelle aus einem Mirakelbuch Gregors von Tours stellt dies eindeutig unter Beweis. Wenn man bedenkt, dass diese Strategie eine römische Tradition fortsetzt und dass es für die auf Isogamie bedachten Senatoren nur wenig Auswahl an geeigneten Ehepartnern gegeben haben dürfte, kann dieser Befund kaum überraschen. Bei den germanischen Völkern ist dagegen der Feldzug der Bischöfe gegen die Cousinenehe „nirgendwo auf erbitterten Widerstand gestoßen “193. Deshalb hatten auch die arianischen Könige Theoderich und Rothari kein Motiv, die römische Inzestgesetzgebung zu verwerfen, obwohl sie nicht dem Druck der katholischen Bischöfe ausgesetzt waren. Die populäre Theorie, nach der das Inzestverbot der Kirche dazu dienen sollte, die germanischen Sippenverbände zu zerschlagen und dadurch den im Heidentum verwurzelten Ahnenkult zu beseitigen, hat also keine Grundlage.

Von den Unterschieden beim Levirat und bei der Ehe mit der Stiefmutter abgesehen, ist ein weitgehend ähnliches Heiratsverhalten festzustellen. Die Ehe diente bei Franken und Romanen nicht so sehr der Festlegung und Fixierung der Verwandtschaft, sondern wurde unter der Beachtung wirtschaftlicher, politischer und standesrechtlicher Gesichtspunkte geschlossen. Mit der Ehe sollte nicht der Zusammenhalt einer ,Sippe' bewahrt werden, sondern Allianzen mit anderen Familien geknüpft, Besitztümer erworben und der gebührende Stand veranschaulicht werden. Für die im nächsten Kapitel folgende Analyse der frühmittelalterlichen Inzestgesetzgebung ist daher die Bedeutung der ethnischen Identität bedeutend geringer zu veranschlagen. Die Inzestverbote sind nicht Ausdruck ethnischer Divergenzen; sie haben vielmehr ihren Ursprung in der Kommunikation zwischen Bischöfen, Königtum und Aristokratie über die Grundlagen einer weniger von staatlichen und mehr von kirchlichen Institutionen dominierten Gesellschaft.

192 Siehe 175-191.

193 Mitterauer, Geschichte 2003, 227. 


\section{Der Ordnungswille der Bischöfe und das christliche Königtum}

Nach dem Untergang des römischen Reichs im Westen traten germanische Könige in die Stellung eines Nachfolgers des römischen Kaisers ein. Dies zog eine Fortsetzung und Nachahmung der römischen Rechtstradition mit sich. Die germanischen Herrscher knüpften deshalb, wie im vorigen Kapitel gezeigt wurde, unabhängig von ihrem Bekenntnis zu Katholizismus oder Arianismus an die Inzestgesetzgebung der römischen Zeit an. Ohne den katholischen Bischöfen verpflichtet zu sein, schärften die Arianer Theoderich der Große und Rothari das Verbot der Verwandtenehe unter Bezugnahme auf römische Rechtsquellen ein. Die Fortsetzung der Rechtstradition durch die germanischen Könige ist jedoch nur die halbe Wahrheit. In Gallien fungierten auch die Bischöfe als Vermittler der römischen Tradition in Verwaltung und Recht, da sich der Episkopat seit dem 5. Jahrhundert aus der Aristokratie rekrutierte' ${ }^{1}$. Das Bischofsamt ersetzte die immer schwieriger zu realisierende Aussicht auf eine Fortsetzung der Karriere in der überregionalen Bürokratie in Rom und wurde der Fluchtpunkt der aristokratischen Ämterlaufbahn. Viele Bischöfe des 5. und 6. Jahrhunderts amtierten vor ihrer Weihe als Comites oder hatten eine andere Funktion in der öffentlichen Verwaltung inne. Einen solchen Rang konnte das Bischofsamt erwerben, weil es durch die Gesetzgebung Kaiser Constantins und seiner Nachfolger in unterschiedlicher Weise an der Reichsverwaltung beteiligt war $^{2}$. Der Bischof war Gerichtsherr über die Zivilangelegenheiten der Kleriker, wurde als Schiedsrichter zwischen Laien angerufen, vollzog die Freilassung in der Kirche, überwachte die Zustände in den Gefängnissen, nahm den Schutz für Arme, Witwen und Waisen in Anspruch und garantierte den Vollzug des Kirchenasyls. Besonders in Zeiten der Krise, in die Gallien durch den Schwund des Einflusses der Reichsverwaltung und durch die Invasionen der germanischen Völker gestürzt wurde, konnte der Bischof diese Kompetenzen so weit aus-

1 Wieruszowski, Zusammensetzung 1922; Stroherer, Adel 1948; Heinzelmann, Bischofsherrschaft 1976; Mathisen, Aristocrats 1993, 89-104; Baumgart, Bischofsherrschaft 1995, 124-160.

2 Vismara, Audientia 1937; Heinzelmann, Bischof 1988; Cimma, Audientia 1989; Baumgart, Bischofsherrschaft 1995, 17-40; Harries, Law 1999, 191-211; WiesHEU, Bischof 2001; RApp, Bishops 2005. 
dehnen, dass er zum wichtigsten Ansprechpartner für die galloromanische Bevölkerung wurde ${ }^{3}$.

Die Autorität des Bischofs beruhte also zum einen auf der spätantiken Gesetzgebung, zum anderen war sie untrennbar mit seiner liturgischen Funktion und seinem charismatischen Prestige verbunden ${ }^{4}$. Besonders das Werk Gregors von Tours ist ein eindrückliches Beispiel für den Argwohn, mit dem die aristokratischen Bischöfe auf die Umgehung der kirchlichen Hierarchie reagierten. Wundertätige Einsiedler oder aufsehenerregende Säulenheilige, in der östlichen Kirche die Repräsentanten der göttlichen Ordnung par excellence, akzeptierte der Bischof von Tours nur unter der Bedingung, dass sie sich der Autorität des Episkopats unterordneten. Gregor inszenierte den Bischof mit unzähligen Wundergeschichten als „Prophet, Theologe, Augur und Wahrheitszeuge vor Gericht ${ }^{\text {"5 }}$, kurz als einzigen wahrhaften Vermittler von Heiligkeit ${ }^{6}$. Diese große erzählerische Findigkeit war gerade deshalb angebracht, weil die Bischöfe im 6. Jahrhundert in der Regel noch nicht auf ein militärisches Aufgebot zurückgreifen konnten ${ }^{7}$. Das Amt des Comes blieb in weiten Teilen Galliens erhalten und wurde erst im 7. Jahrhundert vereinzelt von den Bischöfen vereinnahmt ${ }^{8}$. Der Bischof war daher auf seine liturgische, rechtliche und sakrale Kompetenz angewiesen, wenn er sich gegenüber dem König und seinen Amtsträgern behaupten wollte.

Der hohe Status des Bischofsamtes führte dazu, dass die juristische Bildung der galloromanischen Aristokratie der Kirche zugute kam? ${ }^{9}$. Die Bischöfe des 5. und 6. Jahrhunderts verfügten in der Regel über eine große Vertrautheit mit dem römischen Recht, die sie in ihre neue Tätigkeit als Leiter einer kirchlichen Gemeinde einbrachten. Infolgedessen erreichte die gesetzgeberische Tätigkeit der Bischöfe auf den Synoden des 6. Jahrhunderts ein bislang unbekanntes Ausmaß. Galten die Konzilien des 4. Jahrhunderts noch vorwiegend dogmatischen Fragen und wurden oft aus konkreten Anlässen einberufen, trafen sich die gallischen Bischöfe des 6. Jahrhunderts in erster Linie zur Regelung rechtlicher

3 VAN DAM, Leadership 1985, 142-149; BAUMGART, Bischofsherrschaft 1995, 96-118.

4 VAN Dam, Leadership 1985, 179-239; Baumgart, Bischofsherrschaft 1995, 161-192; Jussen, 'Bischofsherrschaften' 1995; Rapp, Bishops 2005.

5 Breukelaar, Historiography 1994, 245-257.

6 Heinzelmann, Bischofsherrschaft 1976, 191-200; VAn Dam, Leadership 1985, 179201; BreukelaAr, Historiography 1994, 257-261.

7 Heinzelmann, Bischofsherrschaften 1976, 179-183; ders., Bischof 1988, 37-54; Liebeschütz, Decline 2001, 129-131; Loseby, Decline 2006, 87-92.

8 Zum merowingischen Comitat vgl. Claude, Untersuchungen 1964; Murray, Position 1986. Zur späteren Entwicklung von Bischofsherrschaften vgl. PRInz, Stadtherrschaft 1973; Ders., Episkopat 1981; Heinzelmann, Bischof 1988; Anton, „Bischofsherrschaften“ 1996.

9 Stroheker, Adel 1948, 84; Heinzelmann, Bischofsherrschaft 1976, 179 f. und 239 f.; VAN Dam, Leadership 1985, 154-160; Scheibelreiter, Bischof 1983, 56-65. 
Probleme und schufen dadurch ein bedeutendes Rechtskorpus zur Disziplinierung der kirchlichen Hierarchie ${ }^{10}$. Bereits die Synoden um 500 zeugen davon, dass die Bischöfe bewusst auf die Tradition der gallischen Konzilien seit der Synode von Arles (314) zurückgriffen und durch Wiederholung sowie Ergänzung ein eigenes Corpus an kanonischen Normen schaffen wollten ${ }^{11}$. Ende des 6. Jahrhunderts war dieses Unterfangen so weit gediehen, dass in Lyon eine systematische Sammlung des (vorwiegend) gallischen Kirchenrechts erarbeitet wurde, eine der ersten systematischen Kirchenrechtssammlungen überhaupt ${ }^{12}$. Mehr noch als die Könige konnten daher die Bischöfe für sich in Anspruch nehmen, die legislative Tätigkeit des römischen Staates fortzuführen. Das Inzestverbot zählte zum Kern der römischen Tradition, der sich die Bischöfe verpflichtet fühlten.

In diesem Kapitel stehen die Bischöfe als Protagonisten des Inzestverbots im Mittelpunkt. Eine Schlüsselrolle nimmt Avitus von Vienne ein. Auf ihn geht die Ausdehnung des Inzestverbots auf die gesamte Verwandtschaft nach römischem Recht zurück, die für die nächsten 500 Jahre im wesentlichen Bestand haben sollte. Zudem erwarb er sich durch sein aktives Engagement in der Verfolgung von Inzestfällen den Nimbus der Heiligkeit, da er selbst den Konflikt mit dem burgundischen König Sigismund nicht scheute. Die von Avitus initiierten Kanones übten sowohl auf die gallische als auch auf die spanische Kirche einen maßgeblichen Einfluss aus. Daher werde ich zuerst die Inzestgesetzgebung im burgundischen Königreich behandeln und mich dann dem fränkischen und dem westgotischen Reich zuwenden. Die Bischöfe sollen jedoch im Folgenden nicht nur in ihrer Rolle als Gesetzgeber und Ankläger in den Blick genommen werden, sondern auch als Förderer der Christianisierung des Königtums ${ }^{13}$, die eine intensive weltliche Inzestgesetzgebung zur Folge hatte. Bei den Merowingern wurde das Inzestverbot erst auf die politische Agenda gesetzt, als die Könige sich nicht mehr so sehr als römisch-fränkische Heerführer, sondern als christliche Herrscher präsentieren wollten.

10 Einen Überblick geben Barion, Synodalrecht 1931, 146-166; Pontal, Synoden 1986.

11 Mathisen, Council 1997. Eine andere Bewertung bei SснӓғErdiek, Konzil 1985.

12 Mordek, Kirchenrecht 1975.

13 Ewig, Königsgedanke 1956; Reydellet, Royauté 1981; Hen, Christianisation 2004; ERKens, Herrschersakralität 2006, 102-105. 


\subsection{Avitus von Vienne und die burgundischen Könige}

Die Errichtung des burgundischen Reichs im Südosten Galliens war das Werk König Gundobads ${ }^{14}$. Vor seinem Herrschaftsantritt im Reich der Burgunder nahm er im darniederliegenden Westreich die bedeutende Funktion des Heermeisters ein. In den Jahren 472-474 war er der faktische Herrscher über Reichsitalien und musste erst nach Gallien abziehen, als der oströmische Kaiser einen eigenen Kandidaten für das Westreich favorisierte. Später ließ sich Gundobad in das Bündnissystem des ostgotischen Königs Theoderich einbinden, indem er seinen Sohn Sigismund mit einer Tochter Theoderichs verheiratete. Teil dieses Bündnisses war die Förderung des arianischen Bekenntnisses in seinem Reich, nachdem die Burgunder im frühen 5. Jahrhundert von katholischer Seite missioniert worden waren ${ }^{15}$. Erst die Übermacht der Franken, die sich im Krieg des Jahres 500 manifestierte, bewog Gundobad zu einer Abkehr vom Bündnis mit den Goten. Fortan betrieb er eine Schaukelpolitik zwischen Goten und Franken, zwischen dem eigenen Arianismus und dem öffentlich akzeptierten Katholizismus seiner Söhne. Zu seiner Konsolidierungspolitik zählte auch das Bemühen um ein friedliches Auskommen mit der romanischen Bevölkerung. Gregor von Tours berichtet, Gundobad habe für die Burgunder mildere Gesetze erlassen, damit die Römer nicht von ihnen unterdrückt würden ${ }^{16}$. Diese Gesetzgebung mündete in den von Sigismund erlassenen Liber constitutionum. Diesem burgundischen Gesetzbuch wurde eine Rechtssammlung für die romanische Bevölkerung, die sog. Lex Romana Burgundionum, an die Seite gestellt.

Innerhalb der Gundobad zugeschriebenen Gesetze findet sich keine Bestimmung zu Inzestehen. Dennoch lässt eine Quelle aus dem norditalienischen Raum darauf schließen, dass Gundobad mit ähnlichen Fällen konfrontiert war wie sein Zeitgenosse Theoderich in Ravenna. Der Mailänder Kleriker Ennodius befasste sich in einem Schreiben an den burgundischen Hofbeamten Laconius mit einer Inzestehe. Laconius ist sonst nur aus der Vita Epifanii desselben Ennodius bekannt, in der er als vornehmer Ratgeber und Diskutant in religiösen Fragen am Hofe Gundobads beschrieben wird ${ }^{17}$. Wie aus dem Brief ersichtlich wird, waren Ennodius und Laconius verwandt oder verschwägert ${ }^{18}$. Ennodius hebt deshalb nicht zufällig die konsularische Würde, den hohen Adel und die keusche Tugendhaftigkeit des Laconius lobend hervor, da diese Eigenschaften

14 Grundlegende Informationen bei Wood, Gentes 2003; KaIser, Burgunder 2004.

15 KaISER, Burgunder 2004, 148-152.

16 Gregor von Tours, Decem libri historiarum II 33 (MGH SS rer. Merov. 1/1, 81).

17 Ennodius, Vita Epifani 168 (MGH Auct. Ant. 7, 105). Vgl. Stroherer, Adel 1948, 187.

18 Kennell, Ennodius 2000, $32 \mathrm{f}$., schließt dies aus der Verwendung der Wörter fraternitas und fraterna diligentia. 
auf den Autor zurückstrahlen. Begegnet sind sich die beiden während der Mission des Epiphanius bei den Burgundern, die dazu dienen sollte, durch Gundobad gefangene Einwohner Norditaliens wieder freizukaufen. Ennodius war an dieser Legation beteiligt und konnte von der geglückten Mission berichten. Mit der finanziellen Hilfe bedeutender Familien, darunter derjenigen des Avitus von Vienne, gelang es, 6.000 Kriegsgefangene loszukaufen.

Der Sinn des Briefes an Laconius, der in das Jahr 506 datiert wird ${ }^{19}$, ist nicht in jeder Einzelheit klar ersichtlich. Gegenstand ist die Ehe einer Nichte des Ennodius „mit einem Freier, der nicht weit von unserem Blut entfernt ist ${ }^{“ 20}$. Da Ennodius im südgallischen Raum beheimatet ist ${ }^{21}$, könnte Laconius als hoher Würdenträger des burgundischen Königs mit dem Fall der dort ansässigen Nichte befasst gewesen $\operatorname{sein}^{22}$. Ennodius hätte dann bei ihm um einen Gnadenerweis angesucht. Da solche Gnadenerweise nur im Falle einer Heirat mit einer Cousine üblich waren, wird man auch in dieser Angelegenheit ein derartiges Verwandtschaftsverhältnis annehmen müssen. Ennodius bekennt, dass er kaum das lange Schweigen des Laconius ertragen konnte: „Gott sei gedankt, der eure Brüderlichkeit zum Gebrauch des Griffels und auch der Gefälligkeit zu-

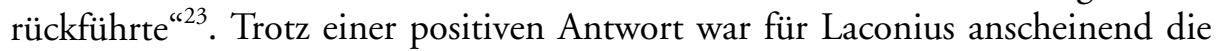
Sache noch nicht endgültig entschieden. Ennodius sollte nämlich zunächst noch einen Bescheid des Papstes in Rom einholen, „damit die Autorität eines

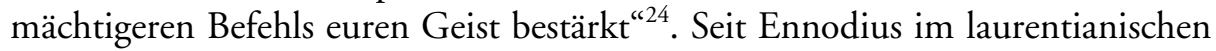
Schisma vehement für Papst Symmachus eingetreten war, erfreute er sich bester Beziehungen zum apostolischen Stuhl. Abschließend versichert Ennodius seinem Adressaten, er werde ihm die Antwort des Papstes sofort durch einen Boten zukommen lassen.

Dieser Brief ist in mehrfacher Hinsicht aufschlussreich. Ennodius hatte wie Cassiodor ein deutliches Bewusstsein davon, dass die zur Diskussion stehende Ehe nicht durch die Bibel untersagt ist: „Wisset, dass es nach den göttlichen Gesetzen zweifellos erlaubt ist, die in der Nachricht erwähnte Verwandtschaft in

19 PRLE 2 1980, 653; KenNell, Ennodius 2000, 32.

20 Hinc caelestis cura nepti meae procum non omnino a sanguine nostro peregrinantem iussit accedere ... Ennodius, Ep. 5, 24 (MGH Auct. Ant. 7, 197).

21 Kennell, Ennodius 2000, 128-167.

22 So die Vermutung von Moreau, Inceste 2002, 374. Kennell, Ennodius 2000, 32, deutet den Brief dagegen als Anfrage des Laconius. Dem widerspricht sowohl die Ungeduld des Ennodius als auch die Bezeichnung der Nichte als mea neptis.

23 Vix sustinebam fateor procurati studia longa silentii, sed interpres mitior putabam adplicandum timori, quod subducebatur affectui. Deo gratias, qui ad usum stili fraternitatem vestram reduxit et gratiae. Ennodius, Ep. 5, 24 (MGH Auct. Ant. 7, 197). Zu diesem für Ennodius typischen Stilmittel vgl. SCHröDER, Bildung 2006, 261.

24 ... ut animum vestrum potioris praecepti firmet auctoritas. Ennodius, Ep. 5, 24 (MGH Auct. Ant. 7, 197). 
der Ehe zu verbinden " 25 . Trotzdem wurde eine einfache Dispensierung von Seiten der weltlichen Herrschaft, die Laconius repräsentiert, nicht als ausreichend angesehen. Ein rechtlich bindender Entscheid des Papstes sollte eingeholt werden. Dies bedeutet wohl auch eine Umgehung des zuständigen Metropoliten Avitus von Vienne. Wie ich weiter unten ausführen werde, vertrat Avitus strenge Ansichten in Fragen des Inzestverbots und hätte kaum für eine Einwilligung in die Ehe gewonnen werden können. Leider ist die Antwort des Papstes nicht erhalten. Bereits hundert Jahre früher hatten sich die Canones synodi Romanorum für das Verbot der Cousinenehe ausgesprochen. Gegen Ende des 6. Jahrhunderts begriff Papst Gregor I. die Heirat mit der Cousine eindeutig als eine durch die Bibel untersagte Inzestehe und schloss eine Dispensierung, wie sie das römische Recht vorsah, explizit aus ${ }^{26}$.

\section{Bischof und König im Einklang}

Die weiteren Quellen zum Inzestverbot im Burgunderreich sind allesamt mit der Persönlichkeit des Avitus von Vienne verbunden ${ }^{27}$. Ennodius bezeichnet Avitus in einer für ihn typischen gestelzten Formulierung als „den hervorragendsten Bischof Galliens, in dem sich die Gelehrsamkeit wie in einem $\mathrm{Zu}$ fluchtsort eines strahlenden Hauses einschloss ${ }^{\text {" } 28}$. Einer gallischen Senatorenfamilie entstammend, zählte er zum engsten Kreis um König Gundobad, den er in Diskussionen um den rechten Glauben zum Katholizismus zu bekehren versuchte. Die Beziehungen zu Sigismund gestalteten sich noch enger, da er Gundobads Sohn schon früh zum Religionsübertritt bewegen konnte ${ }^{29}$. Für Sigismund verfasste er die Korrespondenz mit dem Papst und dem Kaiser in Byzanz, bevor ein von Avitus inkriminierter Inzestfall das Verhältnis zwischen den beiden zerrüttete. Seinen Ruf als Gelehrter begründete er durch ein Bibelepos über die Erschaffung der Welt, den Sündenfall und die Sintflut. Seine fragmentarisch überlieferte Briefsammlung ermöglicht einen unschätzbaren Einblick in die Vorstellungswelt der römischen Elite im burgundischen Reich.

Aus dieser Briefsammlung erfahren wir von einem im Burgunderreich virulenten Inzestfall, der in Kapitel 3 bereits kurz angesprochen wurde. Das Datum der Geschehnisse lässt sich nicht mehr rekonstruieren, die meisten

25 Divinis tamen legibus cognationem indiculo conprehensam in matrimonio licere sociari sine dubitatione noveritis. Ennodius, Ep. 5, 24 (MGH Auct. Ant. 7, 197).

26 Siehe 59 und 223.

27 Grundlegend: Wood, Avitus 1979; Nodes, Doctrine 1993, 55-73.

28 Dedit etiam praestantissimus inter Gallos Avitus Viennensis episcopus, in quo se peritia velut in divorsorio lucidae domus inclusit. Ennodius, Vita Epifani 173 (MGH Auct. Ant. 7, 106).

29 Zum genauen Zeitpunkt der Bekehrung (ca. 502-506) vgl. Shanzer - Wood, Avitus 2003, 221; KaIser, Sigismund 2004. 
Historiker neigen aber zu einer Datierung in zeitlicher Nähe zum Konzil von Epaon im Jahre $517^{30}$. Bischof Victorius von Grenoble berichtet Avitus von einem durch öffentliche Anzeige ans Licht gebrachten Inzestfall. Der in Grenoble wohnhafte Bürger Vincomalus habe vor etlichen Jahren nach dem Tod seiner Frau deren Schwester geheiratet. Für den Bischof steht fest, dass er damit gegen das Inzestverbot verstoßen hat, das ebenso die Ehe mit der Frau des Bruders wie auch die Ehe mit der Schwester der Frau untersagt ${ }^{31}$. Gegenstand der Anfrage ist das Ausmaß der den Sündern aufzuerlegenden Buße. „Daher befehle, unter welchen Bedingungen die Trennung stattfinden soll: belehre uns, ob sie gleich büßen sollen, oder ob eine Exkommunikation auferlegt werden soll, oder welches Maß der Buße passend ist " ${ }^{\text {‘2 }}$. Avitus empört sich in seiner Antwort über die Unwissenheit der Laien: „Welcher Laie ist sich nicht bewusst, dass eine Ehe innerhalb der Schwägerschaft nicht ohne große Schande geschlossen werden kann? “33 Dennoch hält er eine Exkommunikation nur dann für notwendig, wenn die Eheleute weiterhin auf der Gültigkeit ihrer Verbindung bestehen. Sind sie zu einer Trennung bereit, sollen sie unter bestimmten Bußauflagen für einige Zeit nicht am Gottesdienst teilnehmen. Interessant ist der Hinweis des Avitus, dass es sich bei der Trennung nicht um eine regelrechte Scheidung handelt, weil die Ehe selbst verbrecherisch gewesen sei. Hier kommt zum ersten Mal die Vorstellung einer Annullierung der Ehe bei Inzest zum Ausdruck ${ }^{34}$.

Mit dieser Anweisung war der Fall jedoch nicht abgeschlossen. Vincomalus verfolgte den von Avitus mit dem Bescheid ausgesandten Diakon zurück nach Vienne und erhob Beschwerde gegen das Vorgehen der Bischöfe. Er glaubte, das römische Gesetz der Verjährung geltend machen zu können, da er schon länger als dreißig Jahre mit der Schwester seiner ersten Frau verheiratet sei. Avitus war von dieser abenteuerlichen Argumentation nicht wenig überrascht. Ein Gesetz über die Gültigkeit der Ersitzung von Eigentum nach dreißig Jahren war kaum geeignet, in einem eherechtlichen Fall angewandt zu werden. Avitus ließ auch

30 Wood, Incest 1998, 298; Shanzer - Wood, Avitus 2003, 285.

31 Nam non est, ut puto, minus in coniugium germanam coniugis quam uxorem fratris adsciri. Avitus, Ep. 16 (MGH Auct. Ant. 6/2, 48). Wood, Incest 1998, 298, meint dagegen, Victorius sei sich über die Beurteilung der Ehe als Inzest nicht im Klaren gewesen. Doch Victorius fragt nicht, ob die Ehe unter das Inzestverbot fällt, sondern wie darauf zu reagieren ist. Die gleiche Unsicherheit kommt in der Anfrage Theudeberts an Papst Vigilius zum Ausdruck. Vgl. Miкат, Inzestgesetzgebung 1994, 79.

32 Proinde qua sit abstinendus condicione, praecipite: sive ut pariter lugeant, vel si est indicenda sequestratio, vel qui modus paenitentiae, edocete. Avitus, Ep. 16 (MGH Auct. Ant. 6/2, 48).

33 Quis enim vel laicus non advertat non sine grandi macula fieri de affinitatis propinquitate coniugium. Avitus, Ep. 17 (MGH Auct. Ant. 6/2, 49).

34 Мiкат, Epaon 1974, 872. 
sonst an der Persönlichkeit des Vincomalus kein gutes Haar ${ }^{35}$. Besonders beeindruckt war er von dem ungebrochenen Verlangen des älteren Mannes nach sexueller Befriedigung. Hätte er in einer rechtmäßigen Ehe bereits seit langem in Keuschheit leben sollen, so erdreistete sich dieser Wüstling sogar, in einer schändlichen Ehe noch im hohen Alter sexuell aktiv zu sein: „Jung an Laster, ein Greis an Jahren betrügt er sich selbst: er erfriert vor Alter und brennt vor Wollust ${ }^{\text {“'36. }}$. Avitus zögerte nicht, Vincomalus diese Ermahnungen im direkten Gespräch vorzuhalten. Dieser sei allerdings nicht von Reue ergriffen gewesen, sondern habe nur verwirrt aufgeseufzt. Unter diesen Umständen wollte Avitus ihn nicht mit den Lasten der öffentlichen Buße bedrücken, weil er sich dann der sexuellen Enthaltsamkeit hätte unterwerfen müssen. Vincomalus sollte deshalb nur zur Buße ermahnt, aber nicht gezwungen werden. Ein Zwang würde nur die Folge haben, dass neben sein fleischliches Verlangen auch noch die Sünde des Ungehorsams treten würde. „Er soll erst die Buße auf sich nehmen, wenn er das Vermögen zu Sünden verloren hat; er soll beichten, wenn er die Begierde verloren hat ${ }^{\text {"37 }}$.

Verständlich wird die vom Verhalten des Vincomalus angewiderte Haltung des Avitus, wenn man sein Gedicht über Jungfräulichkeit zur Erklärung heranzieht. Er widmete dieses Werk seiner Schwester Fuscina, die vielleicht irgendwelchen nicht näher erkennbaren Verdächtigungen ausgesetzt war $^{38}$. Darin erzählt Avitus von der Geburt seiner Schwester als viertes Kind ihrer gemeinsamen Mutter Audentia. Sofort nach der Geburt habe sich die Mutter entschlossen, von nun an ein keusches Leben zu führen ${ }^{39}$. Der Entschluss, keine Kinder mehr in die Welt zu setzen, war für seine Eltern gleichbedeutend mit dem Führen eines keuschen Lebens. Die Ehe sollte also nur der Zeugung von Kindern dienen. Da der Vater des Avitus, Hesychius, nach einer Karriere im Staatsdienst in das Amt des Bischofs von Vienne berufen worden war, war ein solches Verhalten auch vom Kirchenrecht vorgeschrieben. Avitus machte also aus der Notwendigkeit rückblickend eine Tugend. Ein aktives Sexualleben im

35 ... Vincomalus, quem deus tribuat ut in bono vincat malum. Avitus, Ep. 18 (MGH Auct. Ant. 6/2, 49).

36 Iuvenis vitiis, senex annis se decipit: aevo friget, adulterio calet. Avitus, Ep. 18 (MGH Auct. Ant. 6/2, 49).

37 Patiatur paenitentiam, cum perdit peccandi occasionem; profiteatur, cum amiserit voluntatem. Avitus, Ep. 18 (MGH Auct. Ant. 6/2, 50). Die Schlusspointe ist in der Übersetzung von SHANZER - Wood, Avitus 2003, 290, untergegangen.

38 Spekulationen darüber bei Wood, Avitus 1979, 90 f. Zurückhaltend dagegen SHANZER Wood, Avitus 2003, 262.

39 Avitus, De virginitate v. 19-23 (MGH Auct. Ant. 6/2, 276). 
Greisenalter, wie es Vincomalus praktizierte, konnte Avitus deshalb nur als schamlos empfinden: „Sein ganzes Leben war unredlich/heidnisch“40.

Ein weiterer Aspekt des Briefwechsels zwischen Avitus und Victorius verdient erwähnt zu werden. Bereits im ersten Brief berichtet der Bischof von Grenoble, dass der Fall des Vincomalus durch Anzeige öffentlich gemacht und in der Gegenwart vieler Menschen einer gerichtlichen Anhörung unterzogen wurde $^{41}$. Avitus erwähnt Bürgen, die für die Trennung der Ehepartner einstehen, da dem unredlichen Vincomalus nicht getraut werden könne ${ }^{42}$. Der Fall scheint also vor das weltliche Gericht gebracht worden zu sein. Im Hintergrund standen vermutlich erbschaftliche Interessen des Denunzianten, wie sie auch in anderen Fällen der antiken Rechtsgeschichte bezeugt $\operatorname{sind}^{43}$. Für ein Eingreifen des Königs in diesem Fall geben die Quellen keine Aufschlüsse.

Erst der Tod Gundobads hat die volle Entfaltung des kirchenpolitischen Engagements der burgundischen Bischöfe ermöglicht. Am 15. September 517, ein Jahr nach der Herrschaftsübernahme Sigismunds, fand in Epaon ein Konzil der Bischöfe des burgundischen Königreichs statt ${ }^{44}$. Die Leitung hatten die beiden Metropoliten Avitus von Vienne und Viventiolus von Lyon inne. Als Vorbild der Versammlung dienten die Konzilien des westgotischen und fränkischen Reichs. Bereits 506, ein Jahr vor der Katastrophe von Vouillé, gab der Westgotenkönig Alarich II. den katholischen Bischöfen die Erlaubnis zur Einberufung einer Synode in Agde. Wenige Jahre später (511) versammelte Chlodwig nach der Eroberung des westgotischen Reichs die Bischöfe in Orléans. Diese Konzile auf der Ebene eines Königreichs waren ein Novum, da Kirchenversammlungen bislang nur innerhalb der ganzen Ökumene oder einzelner Kirchenprovinzen stattgefunden hatten ${ }^{45}$. Die Verfassung der Kirche musste sich nach dem Ende des weströmischen Reichs an die politischen Grenzen der einzelnen Nachfolgreiche anpassen. Für die späte Einberufung eines Reichskonzils im Burgunderreich im Vergleich zu Westgoten und Franken lässt sich nicht die abweisende Haltung des arianischen Königs Gundobad haftbar ma-

40 Nec sane promissio eius fidelis putetur, cuius vita extitit infidelis. Avitus, Ep. 18 (MGH Auct. Ant. 6/2, 50).

41 Quod ergo nunc sub multorum praesentia auditus ... Avitus, Ep. 16 (MGH Auct. Ant. 6/2, 48).

42 Ipsis fideiussoribus emendatio secutura credatur, quibus intercedentibus prior culpa laxabitur. Avitus, Ep. 18 (MGH Auct. Ant. 6/2, 50).

43 Offen angesprochen in Novellae Justini 3 (5f.) aus dem Jahr 566. Vgl. auch EvansGrubbs, Law 1995, 99 Anm. 197.

44 Grundlegend: Jean Gaudemet, Art. „Epaone“, in: DHGE 15 (1963) 524-545; PonTAL, Synoden 1986, 34-46. Den Charakter einer Reichssynode leugnet Wood, Avitus 1979, 227, weil er die Initiative zur Einberufung dem Papst zuschreibt.

45 Barion, Synodalrecht 1931, 201-231. Die Kontinuität zum Prinzip der Kongruenz von politischer und kirchlicher Organisation betont dagegen KaIsER, Konstituierung 2002, 86. 
chen, da er genauso wie Alarich II. auf ein gutes Einvernehmen mit dem katholischen Episkopat bedacht gewesen war. Sogar der Papst hatte Avitus mehrfach in „bissigen Briefen“ seine Nachlässigkeit vorgehalten und ihn zur Einberufung von Kirchenversammlungen ermahnt ${ }^{46}$. Der Papst war nämlich auf die Unterstützung der arianischen Könige im Westen angewiesen, nachdem der Kaiser in Konstantinopel die Lehre der Monophysiten unterstützt und dadurch ein Schisma zwischen Ost und West verursacht hatte ${ }^{47}$. Der tolerante Arianismus der Germanenkönige schien dem Papst eine geringere Gefahr als die Unterstützung des Kaisers für eine auf dem Konzil von Chalkedon verurteilte Häresie.

Die späte Einberufung eines Reichskonzils der burgundischen Kirche ist daher nicht auf den Widerstand Gundobads, sondern auf die kompromisslose Haltung des Avitus von Vienne zurückzuführen. Anders als der Papst in Rom war er an der Auseinandersetzung mit der häretischen Kirche der Arianer persönlich beteiligt ${ }^{48}$. Nach dem Herrschaftsantritt Sigismunds lehnte er es strikt ab, die Kirchen der Arianer zu übernehmen und katholisch weihen zu lassen. In Epaon ließ er die harsche Bestimmung verkünden: „Die Kirchen der Häretiker sind uns so gänzlich verhasst, dass wir nicht glauben, dass ihre Besudelung gereinigt werden kann. Wir missbilligen daher, sie für heilige Dienste zu ver-

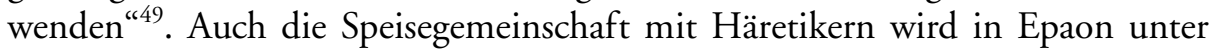
Androhung von temporärer Exkommunikation und Prügelstrafe verboten ${ }^{50}$. Potential für Konflikte mit Gundobad hätte vermutlich auch das Eintreten für die Stärkung der Metropolitangewalt ergeben. Während insbesondere in Orléans das Aufsichtsrecht der Metropoliten über die anderen Bischöfe zurückgedrängt wurde, da es sich mit der Kirchenherrschaft des Königs nicht vertrug, setzte sich Avitus vehement für diese altkirchliche Instanz ein. Im Konzil von Epaon gelang es ihm gemeinsam mit Viventiolus von Lyon, die Bischöfe in Fragen der Finanzverwaltung, der Liturgie und der Kirchenversammlungen unter die Aufsicht der Metropoliten zu stellen ${ }^{51}$. Dieses Anliegen wäre von

46 Nam et venerabilis papae Urbis nobis ob hanc neglegentiam succensentis mordacia mihi non nunquam scripta perlata sunt. Konzil von Epaon (517) Epistola Aviti (MGH Conc. 1, 17). Wood, Avitus 1979, 199, schließt daraus auf eine direkte Einflussnahme des Papstes.

47 CASpar, Geschichte 2 1930, 10-192.

48 Wood, Avitus 1979, 156-164; Shanzer - Wood, Avitus 2003, 163-167.

49 Basilicas hereticorum, quas tanta execrationem habemus exosas, ut pollutionem earum purgabilem non putemus, sanctis usibus adplicare dispicimus. Konzil von Epaon (517) c. 33 (MGH Conc. 1, 27). Diese Haltung begründete Avitus ausführlich in Ep. 7 (MGH Auct. Ant. 6/2, 35-39); vgl. Shanzer - Wood, Avitus 2003, 295 f.

50 Konzil von Epaon (517) c. 15 (MGH Conc. 1, 22).

51 Konzil von Epaon (517) c. 1 (MGH Conc. 1, 19), c. 12 (MGH Conc. 1, 22), c. 19 (MGH Conc. 1, 24), c. 21 (MGH Conc. 1, 27). Vgl. Pontal, Synoden 1986, 45. 
einem starken Herrscher wie Gundobad nicht akzeptiert worden. Selbst Avitus hatte die Kirchenhoheit des Königs anerkennen müssen ${ }^{52}$.

Im Gegensatz zu dieser Härte des Avitus in der Frage des Arianismus sind die Bußbestimmungen des Konzils von Milde und Zurückhaltung geprägt ${ }^{53}$. Wie in seinem Brief an Victorius von Grenoble plädierte Avitus dafür, die Bußzeiten nicht streng nach den Normen der altkirchlichen Konzilien zu verhängen, da einem Büßenden die Rückkehr zur weltlichen Lebensführung verschlossen sei ${ }^{54}$. Milde zeichnet auch die Strafbestimmung zum Inzest in c. 30 aus. Wie im Fall des Vincomalus wird keine Buße verhängt, sondern nur die Trennung der Ehepartner verfügt. Beiden soll eine weitere gültige Ehe offen stehen $^{55}$. Der im Brief an Victorius ausgedrückten Sorge, damit die Möglichkeit zur Ehescheidung zu eröffnen, trägt der Kanon mit folgender Formulierung Rechnung: „Der Inzest soll nicht durch den Namen der Ehe gestärkt werden “56. Der Begriff "Ehe“ wird konsequent zugunsten von „inzestuösen Verbindungen“ vermieden. Folglich gibt es im eigentlichen Sinn keine Ehescheidung und keinen Verstoß gegen das Prinzip der Unauflösbarkeit der Ehe. Dieser Milde in der Bestrafung steht die ungewöhnlich gründliche Auflistung der verbotenen Verwandten entgegen. Außer den engen Verwandten, die ,aus Schamgefühl ${ }^{\prime}$ nicht ausdrücklich erwähnt werden, sind genannt: die Frau des Bruders, die Schwester der Ehefrau, die Stiefmutter, die Cousine ersten und zweiten Grades, die Frau des Onkels und die Stieftochter. Keine andere kirchliche Rechtsquelle dieser Zeit bemüht sich derart gewissenhaft um eine vollständige Erfassung aller verbotenen Verwandten. Neu ist dabei das Verbot der Ehe mit der Cousine zweiten Grades. Ihm werde ich mich daher ausführlich zuwenden.

In der Forschung hat die Ausweitung des Inzestverbots unterschiedliche Deutungen erfahren. Jean Fleury hat als einziger die Tatsache einer Ausweitung bestritten, indem er auf die Zweideutigkeit des Begriffs sobrina verwies ${ }^{57}$. So erwähnt der Grammatiker Donat neben der Bedeutung einer zweiten Cousine auch die Bedeutung von Kindern zweier Schwestern ${ }^{58}$. Unsicherheit über den

52 Avitus, Ep. 44 (MGH Auct. Ant. 6/2,74). Vgl. Kaiser, Burgunder 2004, 156.

53 Jean Gaudemet, Art. „Epaone“, in: DHGE 15 (1963) 524-545, hier 534; Wood, Avitus 1979, 225.

54 Konzil von Epaon (517) c. 23 (MGH Conc. 1, 24), c. 29 (MGH Conc. 1, 25 f.), c. 34 (MGH Conc. 1, 27). Zum Wandel der Buße vgl. Vogel, Discipline 1952; Jong, Transformations 2000.

55 Sane quibus coniunctio inliceta interdicetur, habebunt ineundi melioris coniugii libertatem. Konzil von Epaon (517) c. 30 (MGH Conc. 1, 26).

56 Incestus vero nec ullo coniugii nomine praevalendus ... Konzil von Epaon (517) c. 30 (MGH Conc. 1, 26).

57 Fleury, Recherches 1933, 89.

58 Sobrini sunt de duabus sororibus, consobrini de fratre ac sorore. Donatus, Comm. in Hecyram 3, 5, 9 (2, 271); Sobrini sunt consobrinorum filii - nam sic dicit Menander; 
Begriff sobrinus und consobrinus herrscht auch in den Pauli Sententiae. Propius sobrinus bezeichnet darin den Großonkel, während consobrinus in der Bedeutung des Cousins ersten und zweiten Grades auftaucht ${ }^{59}$. Auch im frühen Mittelalter ist die Bedeutung keineswegs einheitlich. Karl der Große wurde von den Zeitgenossen als sobrinus seines Vetters Tassilo bezeichnet, und Hinkmar von Reims verwendet sobrinus und consobrinus ohne Unterschied ${ }^{60}$. Trotzdem ist Fleurys Deutung des Inzestverbots von Paul Mikat zu Recht zurückgewiesen worden. In der Spätantike beschränkt sich die Unsicherheit auf Donat, während in allen anderen Quellen sobrinus eindeutig dem Cousin zweiten Grades vorbehalten wird ${ }^{61}$. Insbesondere die Rechtsquellen lassen darüber keinen Zweifel zu. Darüber hinaus wurde der Kanon von Epaon stets als Zeugnis für die Erweiterung des Inzestverbots verstanden. Sowohl im westgotischen als auch im fränkischen Kirchenrecht steht er am Anfang einer einheitlich verlaufenden Entwicklung.

Paul Mikat schlägt deshalb eine andere Auslegung vor. Für ihn handelt es sich bei Kanon 30 um die Folge eines Missverständnisses einer römischen Rechtsquelle. Das Gesetz über das Verbot der Ehe mit der Cousine galt wie oben ausgeführt in der westlichen Reichshälfte und ist daher in das westgotische Breviar aufgenommen worden. Im Breviar sind die Gesetze der römischen Kaiser durch abkürzende und verdeutlichende Zusammenfassungen ergänzt. Ob diese Interpretationen schon vor dem Breviar existierten oder erst aus Anlass der Aufzeichnung des Breviars im Jahre 506 redigiert worden sind, ist in der Forschung umstritten ${ }^{62}$. In der Interpretatio zum Verbot der Cousinenehe sind die folgenden Worte zu lesen: „Jeder, der sich entweder mit der Tochter der Schwester und des Bruders oder, zweifelsohne, mit der Cousine des folgenden Grades oder mit der Frau seines Bruders in frevelhafter Ehe verbindet, soll dieser Strafe unterliegen, dass er von einer solchen Verbindung getrennt wird ${ }^{\text {“63. Nach }}$

verum ut alii putant, de sororibus nati, ut sint sobrini quasi sororini. Donatus, Comm. in Andriam 4, 5, 6 (1, 229).

59 Lex Romana Visigothorum, Pauli Sent. IV 10, 4-6 (408). Diesen Bezeichnungen folgen auch die im Breviar überlieferten Arbores consanguinitatis: SснаDт, Arbores 1982, $25-$ 39.

60 Capitulare Francofurtense (794) c. 3 (MGH Conc. 2/1, 165); Annales Bertiniani a. 866 (130): Karl der Kahle und Graf Wilhelm (3/3?); Annales Bertiniani a. 878 (230): Ludwig der Stammler und Ludwig der Jüngere (2/2); Annales Bertiniani a. 880 (243): Karl der Dicke und Ludwig III. (2/3). Vgl. auch Le Jan, Famille 1995, 175.

61 Мikat, Epaon 1974, 886 f.; Moreau, Inceste 2002, 179 f. Vgl. auch Sextus Pompeius Festus, De verborum significatione 420 (379 f.); Isidor, Etymologiae 9, 16, 15; Fragmenta Vaticana iuris anteiustiniani 299 (96).

62 Siehe $159 \mathrm{f}$.

63 Quisque ille aut sororis aut fratris filiam aut certe ulterioris gradus consobrinam aut fratris uxorem sceleratis sibi nuptiis iunxerit, huic poenae subiacet, ut de tali consortio separetur. Lex Romana Visigothorum, Cod. Theod. 3, 12, 3 Int. (90). Vgl. Мiкат, Epaon 1974, 885. 
Mikat hat Avitus die Worte certe ulterioris gradus consobrinam in dem Sinn missverstanden, dass auch die Ehe mit der Cousine zweiten Grades unter das römische Inzestverbot gefallen sei. Diese Auslegung ist jedoch aus verschiedenen Gründen nicht überzeugend. Erstens ist das Breviar erst 506 erlassen worden, und es gibt keinen Hinweis darauf, dass Avitus seine Kenntnisse des römischen Rechts aus dieser Quelle bezogen hätte ${ }^{64}$. Im Gegenteil, Avitus hat als Sprössling einer der höchsten Senatorenfamilien eine profunde Ausbildung im römischen Recht erhalten und war nicht auf die Benutzung der Interpretatio einer westgotischen Kodifikation angewiesen. Zweitens ist ein solches Missverständnis auch deshalb abwegig, weil die Interpretatio zusammen mit dem unmissverständlichen Gesetzestext überliefert wurde. Einem scharfsinnigen Gelehrten wie Avitus wird man einen solchen Irrtum ohnehin nur schwerlich unterstellen dürfen. Fünfzig Jahre später haben die gallischen Bischöfe auf dem Konzil von Tours die missverständliche Formulierung ausdrücklich im Sinne des authentischen Gesetzestextes ausgelegt ${ }^{65}$. Drittens war zu Zeiten von Avitus die Praxis der Dispensierung von Cousinenehen weiterhin in Geltung. Das entsprechende Gesetz ist ebenfalls im Breviar unmittelbar vor dem Verbot der Cousinenehe enthalten $^{66}$. Die oben besprochenen Briefe von Cassiodor und Ennodius bezeugen die Lebendigkeit dieser Praxis. Es ist kaum anzunehmen, dass Avitus das geltende Recht in diesem wichtigen Punkt nicht vertraut war ${ }^{67}$.

Den Deutungen von Fleury und Mikat ist gemeinsam, dass sie eine schleichende, gewissermaßen unbewusste Ausdehnung des Inzestverbots implizieren. Dieser Voraussetzung widerspricht der Wortlaut des Kanons von Epaon. Denn nach der Nennung der Cousine ersten und zweiten Grades folgt ein bedeutender Einschub: „Dieses verbieten wir von jetzt an, deshalb lösen wir solche Verbindungen nicht auf, die früher eingegangen worden sind ${ }^{\text {“68 }}$. Erst dann setzt der Kanon mit der Nennung der Ehefrau des Onkels fort. Sinn dieses Einschubs ist eine Toleranzklausel für alle Ehen, die vor dem Konzil von Epaon geschlossen worden waren ${ }^{69}$. Aus der Formulierung selbst lässt sich nicht er-

Der Deutung Mikats stimmen zu: Weigand, Ausdehnung 1994, 2; Thraede, Blutschande 2002, 82.

64 Selbst die Benützung des Breviars in der Lex Rom. Burg. ist nicht nachweisbar: Hermann Nehlsen, Art. „Lex Romana Burgundionum“, in: HRG 2 (1978) 1927-1934.

65 Konzil von Tours (567) c. 22 (MGH Conc. 1, 132).

66 Lex Romana Visigothorum, Cod. Theod. 3, 10, 1 (86).

67 Dies setzt jedoch Мıкат, Inzestgesetzgebung 1994, 119, voraus.

68 Quod ut a presenti tempore prohebemus, ita ea, quae sunt anterius instituta, non solvemus. Konzil von Epaon (517) c. 30 (MGH Conc. 1, 26).

69 Die Editionen von Maassen und de Clercq beziehen die Klausel im Unterschied zu älteren Ausgaben durch Interpunktion auf die folgenden Verbote der Heirat mit dem Onkel und der Stieftochter. Dies ergibt jedoch keinen Sinn, weil diese Verbote fest in der biblischen und römischen Tradition verankert waren. Die Klausel muss demnach auf den 
kennen, ob diese Klausel nur für die Cousine zweiten oder auch für die ersten Grades gültig sein soll. Beides ist möglich, da auch die Ehe mit der Cousine ersten Grades durch eine Dispensierung des Kaisers Gültigkeit erlangen konnte. Deutlich wird durch die Toleranzklausel jedenfalls, dass bei den Rezipienten offensiv für die Zustimmung zu einer Neuerung geworben werden sollte. Der Autor des Textes, Avitus von Vienne, war sich also durchaus im Klaren über den neuartigen Charakter dieser Inzestvorschrift. Umso dringender stellt sich daher die Frage nach den Motiven für diese vorsätzliche Ausdehnung. Zur Beantwortung lohnt ein Blick auf die kurz vor Epaon entstandene Lex Burgundionum.

Die Lex Burgundionum (oder Liber constitutionum) wurde am 29. März 517 von Sigismund erlassen, geht aber in weiten Teilen auf Gesetze Gundobads zurück $^{70}$. In der dem Gesetzbuch vorangestellten Prima Constitutio verpflichtete Gundobad die gesamte Bevölkerung auf die Einhaltung seiner Gesetze und stellte der romanischen Bevölkerung eine eigene Kodifikation in Aussicht. Ob diese noch unter Gundobad oder erst unter seinem Nachfolger zustande kam, ist in der Forschung nicht geklärt ${ }^{71}$. Da die Kodifikation des römischen Rechts deutliche Parallelen zur Lex Burgundionum aufweist, lässt sich aus der Struktur der Lex Romana der Inhalt der ursprünglichen Kodifikation Gundobads erschließen. Eine Regelung des Inzests wird in der Lex Romana nicht vorgenommen, daher lässt sich dies auch für Gundobads Werk erschließen ${ }^{72}$. Kirchliche Angelegenheiten werden überhaupt nur in einer Bestimmung zum Asylrecht angesprochen. Erst in der Fassung Sigismunds zeugt die Kodifikation vom Einfluss der burgundischen Bischöfe. Besonders offensichtlich ist dieser Einfluss in der Extravagante 20. Darin erklärt Sigismund, er habe bei der Regelung der Kindesaussetzung ein Anliegen des Bischofs Gimmellus von Vaison aufgenommen ${ }^{73}$. Kirchlicher Einfluss kommt auch in den Regelungen zum Kirchen- und Klerikerschutz sowie zur Ehescheidung zum Ausdruck ${ }^{74}$. Die Bestimmung zum Inzestverbot wird man ebenfalls dazu zählen müssen, obwohl der Wortlaut die zugrunde liegende Vorlage nicht zu erkennen gibt. Unklar ist auch, ob die Inzestbestimmung sowohl für die burgundische als auch für die romanische Bevölkerung gelten sollte. Die Lex Burgundionum lässt sich als

vorangehenden Satz bezogen werden wie bei Hefele - LeclercQ, Histoire 2 1908, 1041. Nicht überzeugend sind die Ausführungen von Мiкat, Epaon 1974, 872-874.

70 Den Forschungsstand referieren Hermann Nehlsen, Art. „Lex Burgundionum“, in: HRG 2 (1978) 1901-1915, und KaIsER, Burgunder 2004, 126-133.

71 Hermann Nehlsen, Art. „Lex Romana Burgundionum“, in: HRG 2 (1978) 1927 1934; BAUER-GERLAND, Erbrecht 1995.

72 Beyerle, Textgestalt 1954, 42, schrieb tit. 36 Gundobad zu. Da jedoch ein Gegenstück in der Lex Rom. Burg. fehlt, wurde diese Annahme verworfen: RüEgGer, Einflüsse 1949, 190; Мікат, Inzestgesetzgebung 1994, 104.

73 Lex Burgundionum, extravag. 20 (MGH LL nat. Germ. 2/1, 119).

74 Lex Burgundionum 34, 3-4 (MGH LL nat. Germ. 2/1, 68); 102, 3 (MGH LL nat. Germ. 2/1, 114); extravag. 21, 13 (MGH LL nat. Germ. 2/1, 122). 
Ganzes nicht auf die Alternative Personalitäts- oder Territorialrecht festlegen, da einige Gesetze eindeutig nur an die Burgunder, andere jedoch an beide Bevölkerungsgruppen adressiert sind ${ }^{75}$. Es handelt sich, wie Hermann Nehlsen treffend bemerkte, um „ein Recht in Bewegung ${ }^{\text {"76 }}$ mit „deutlichen Zügen gesetzgeberischer Unrast ${ }^{\text {"77 }}$. Der Charakter einer Novelle würde eher für eine territoriale Geltung der Inzestbestimmung sprechen.

Die Bestimmung (tit. 36) lautet folgendermaßen:

De incesti adulterio. Si quis cum parente sua vel uxoris suae sorore in adulterio fuerit deprehensus, pretium suum ei, qui est proximus mulieri, quam adulteraverat, prout persona fuerit, cogatur exsolvere, multae nomine solidos XII; adulteram vero subdi iubemus regiae servituti ${ }^{78}$.

Die Formulierung ist in mehrerer Hinsicht zweideutig. Die Verwendung des Wortes adulterium lässt zunächst daran denken, dass nur die Kumulation von Ehebruch und Inzest geahndet werden soll. Eine Ehe zwischen verwandten Sexualpartnern scheint gar nicht in Betracht gezogen zu werden. Diese Deutung birgt jedoch Probleme, weil es ungewöhnlich ist, die Kumulation von Ehebruch und Inzest einer Regelung zu unterziehen. Ich folge daher der Auffassung von Hans Rüegger, der den Begriff adulterium mit der Bedeutung „Sittlichkeitsdelikt“ übersetzte ${ }^{79}$. Es ist daher plausibel, das Gesetz auf den Inzest im Allgemeinen zu beziehen und die Vermeidung des Begriffs der Ehe dem Einfluss des Avitus zuzuschreiben. Ein weiteres Problem stellt die Formulierung cum parente sua dar. Mikat argumentiert erstaunlicherweise für die Gleichsetzung mit der Stiefmutter ${ }^{80}$. Als Begründung gibt er an, dass parentes in den Digesten durchwegs für die Aszendenten steht. Da aber der Geschlechtsverkehr mit der Mutter auch bei den Germanen verboten gewesen sei, könne nur die Stiefmutter gemeint sein. Damit seien in tit. 36 zwei typisch christliche Verbote ausgesprochen worden, das Verbot der Ehe mit der Schwester der Ehefrau und das Verbot der Ehe mit der Stiefmutter. Diese Deutung ist unhaltbar, denn die Stiefmutter wurde kaum als "Gebärerin“ (parens) bezeichnet. In allen Inzestbestimmungen bezieht sich der Ausdruck parentes auf Verwandte, während die Mutter stets als mater, die Stiefmutter stets als noverca bezeichnet wird. Auch die Lex Burgundionum verwendet parentes als Begriff für „Verwandte“, so etwa in

75 Frye, Gundobad 1990; Amory, Meaning 1993; Wood, Gentes 2003, 260-265.

76 Hermann Nehlsen, Art. „Lex Burgundionum“, in: HRG 2 (1978) 1901-1915, hier 1908.

77 Sснотт, Formen 1995, 943.

78 Lex Burgundionum 36 (MGH LL nat. Germ. 2/1, 69).

79 RüEGGER, Einflüsse 1949, 190-192.

80 Мікат, Inzestgesetzgebung 1994, 103. Irrtümlich spricht er auf derselben Seite das eine Mal von Schwiegermutter, das andere Mal von Stiefmutter. Der Verweis auf 1. Cor. 5, 1 gibt aber Klarheit. 
dem unmittelbar vorangehenden tit. $35^{81}$. Die Übersetzung von tit. 36 muss demnach lauten:

„Vom Sittlichkeitsdelikt des Inzests: Wird jemand in Unzucht mit seiner Blutsverwandten oder mit einer Schwester seiner Frau angetroffen, so muss er sein Wergeld dem Nächstverwandten der Frau, die er entehrt hat, je nach dem Stand seiner Person zahlen; und als Strafgeld 12 Schillinge (an den Fiskus). Die Blutschänderin aber befehlen wir der Knechtschaft des Königs zu unterstellen ${ }^{\text {“82 }}$.

Oben wurde bereits erwähnt, dass eine Novelle zur Lex Burgundionum auf die Intervention eines Bischofs zurückgeht. Lässt sich eine Einflussnahme des Avitus von Vienne auf die Inzestbestimmung der Lex nachweisen? Rüegger hat aufgrund stilistischer Ähnlichkeiten versucht eine solche Einflussnahme wahrscheinlich zu machen ${ }^{83}$. Die Ähnlichkeiten bewegen sich jedoch auf der Oberfläche und taugen nicht für eine Zuschreibung des Gesetzes an Avitus. Im Vergleich zum Kanon des Konzils von Epaon lässt das zweideutige Gesetz die geschliffene und klare Ausdrucksweise des Avitus vermissen. Dennoch erscheint es plausibel, eine Intervention des Avitus für den Inhalt des Gesetzes verantwortlich zu machen. Dafür spricht zum einen die Vermeidung des Begriffs der Ehe, zum anderen das Verbot des Sororats, also derjenigen Eheform, gegen die der Bischof von Vienne im Fall des Vincomalus einschreiten musste. Auch die Ausdehnung des Inzestverbots spricht für den Einfluss des Avitus. Legt man nämlich dem Gesetz die römisch-rechtliche Definition der Verwandtschaft zugrunde, erstreckt sich das Inzestverbot bis zur Cousine zweiten Grades. Damit würde sich die Bestimmung der Lex Burgundionum mit dem Kanon von Epaon decken. Da das germanische Recht keine feste Grenze der Verwandtschaft kennt, sondern unterschiedliche Kreise bei unterschiedlichen Rechtsbereichen heranzieht, ist die Übernahme aus dem römischen Recht nicht unwahrscheinlich. Auch im langobardischen, westgotischen und sogar im fränkischen Recht bedient man sich der Verwandtschaftsgrenze des römischen Rechts ${ }^{84}$. Es bliebe jedoch auch die von Rüegger vorgeschlagene Deutung möglich, dass in der Lex Burgundionum ein Rahmengesetz verabschiedet wurde, welches die in Epaon versammelten Bischöfe ein halbes Jahr später konkretisierten ${ }^{85}$. Beide Deutungen laufen jedoch darauf hinaus, die Identität von Gesetzbuch und Konzils-

81 Lex Burgundionum 35, 3 (MGH LL nat. Germ. 2/1, 69); vgl. auch Lex Burgundionum 14, 2 (MGH LL nat. Germ. 2/1, 52); 85, 2 (MGH LL nat. Germ. 2/1, 107); 86, 2 (MGH LL nat. Germ. 2/1, 108) u. ö.

82 In Anlehnung an die etwas altertümliche Übersetzung von Beyerle, Burgunden 1936, 57.

83 RüEgGer, Einflüsse 1949, 190-192. Er stützt sich auf die allgemeine Bedeutung von adulterium und auf die Verwendung der Formen incestus, -us und incestum, -i. Beides ist aber in der Spätantike nicht ungewöhnlich.

84 Siehe 21.

85 RüEgGER, Einflüsse 1949, 196. 
kanon zu unterstreichen. Für das Verständnis des Konzilskanons bedeutet dies, dass die Ausweitung des Inzestverbots das Ziel hatte, das Verbot auf die ganze Verwandtschaft des römischen Rechts auszudehnen.

Kehren wir somit zur Deutung des Konzils von Epaon zurück. Wir können jetzt die Zielsetzung der Inzestverbote des Jahres 517 präzisieren: Bischof Avitus von Vienne plädierte für ein Eheverbot innerhalb der gesamten römischrechtlichen Verwandtschaft. Von welcher Tradition ließ er sich bei dieser Forderung leiten? Aus der Perspektive der römischen Inzestgesetzgebung liegt die Vermutung nahe, in der Spätantike sei dieselbe Inzestgrenze reaktiviert worden, die bereits in der Frühzeit der römischen Republik gegolten habe. Die Untersuchungen in Kapitel 2 haben jedoch gezeigt, auf welch unsicherer Quellenbasis das Wissen vom Inzestverbot der römischen Frühzeit beruht. Tacitus bezeugt als einzige Quelle die Kenntnis des Eheverbots mit der Cousine zweiten Grades. Nach dem römischen Recht der Spätantike stand es dagegen außer Zweifel, dass die Verwandtschaft des Erbrechts eine andere war als diejenige des Eherechts. Umfasste das Erbrecht alle Verwandten bis zum 6. oder 7. Grad, war im Eherecht nur der vierte Grad untersagt. Diese Tatsache war dem Bischof von Vienne mit Sicherheit vertraut. Darüber hinaus leuchtet nicht ein, warum Avitus die Rückkehr zu den veteres mores der frührömischen Zeit befürwortet haben sollte. Denn der Schriftsteller Avitus ist im Gegensatz zu seinem Verwandten Sidonius Apollinaris ein Zeuge für die fortgeschrittene Distanz vom römischen Erbe, die bei der gallorömischen Aristokratie des 6. Jahrhunderts zu beobachten ist.

Wenn die römische Tradition als Erklärung nicht taugt, scheint nur die christliche Tradition als Alternative übrig zu bleiben ${ }^{86}$. Man könnte die Ausweitung auf die ganze Verwandtschaft als Folgerung aus Lev. 18, 6 deuten, wo es heißt: „Niemand von euch darf sich einer Blutsverwandten nähern, um ihre Scham zu entblößen" (Omnis homo ad consanguineum suum non accedet, ut revelet turpitudinem eius). In der Tat musste diese Stelle im frühen Mittelalter oft für die Begründung von Inzestverboten herhalten, auch wenn deren Inhalt nicht mit den in Lev. 18 erwähnten Inzesttatbeständen zur Deckung gebracht werden konnte. Doch ist an der Unterscheidung festzuhalten, ob eine Ausdehnung das erste Mal eingeführt oder im Nachhinein legitimiert werden sollte. Lev. 18, 6 diente nur als zusätzliche Stütze einer bereits Gestalt gewordenen Tradition, nicht aber zur erstmaligen Ausweitung auf dem Konzil von Epaon. Zudem war Avitus ein ausgezeichneter Kenner des Alten Testaments, das er in ein versifiziertes Epos umdichtete. Es konnte ihm nicht entgehen, dass die Ausführungsbestimmungen in Lev. 18 die Ausdehnung auf die Cousine ersten und zweiten Grades nicht zu tragen vermochten. Im Bibelepos seines Zeitgenossen

86 JoNG, Riddle 1998, 108: „Barring the consobrina and sobrina, this was in keeping with biblical precept“; Gaudemet, Condamnations 1996, 378. 
Cyprianus Gallus werden diese Bestimmungen ohne Verzerrungen wiedergegeben $^{87}$.

Weder die römische noch die christliche Tradition konnte Avitus eine hinreichende Begründung für die Ausdehnung des Inzestverbots liefern. Die Ausdehnung ist als gesetzgeberische Neuerung anzusehen, für die Avitus selbst keine Erklärung anbietet und die daher nur im Kontext seiner Zeit verständlich gemacht werden kann. Dass der Bischof von Vienne und seine Kollegen auf dem Konzil von Epaon überhaupt die Kühnheit besessen haben, das römische Recht auf derart grundlegende Weise abzuändern, ist vor dem Hintergrund des hohen Ranges des Bischofsamtes nach dem Untergang des weströmischen Reichs zu sehen. Ebenso wie die germanischen Könige bemüht waren, das Recht ihrer Reiche schriftlich niederzulegen und damit die Nachfolge des Kaisers für sich zu reklamieren, wandten sich auch die Bischöfe der Kodifikation des Rechts $\mathrm{zu}$ und versuchten die Anstrengungen der weltlichen Herrscher zu überbieten. Als Repräsentant der galloromanischen Bevölkerung, als Schutzherr über die Armen und Schwachen sowie als oberstes Aufsichtsorgan des Klerus fühlte sich der Bischof ermächtigt, über wichtige Angelegenheiten des täglichen Lebens Normen zu erlassen. So wie besonders in Gallien die Sexualaskese der Mönche strikten Regeln unterworfen und der Aufsicht des Bischofs unterstellt wurde ${ }^{88}$, sollte auch die Ehe einer gültigen Ordnung unterworfen werden. Das Inzestverbot war Ausdruck davon, dass auch die Laien in der Ausübung ihrer Sexualität Regeln unterworfen sein sollten. Wie im Fall des Vincomalus deutlich wurde, zeigte sich Avitus von dem sogar im hohen Alter praktizierten Geschlechtsverkehr des Bürgers aus Grenoble im höchsten Maße schockiert. Auch in anderen Schriften äußerte er seine Sorge um die rechte Ordnung der Ehe. Seiner Schwester Fuscina widmete er ein langes Gedicht über Jungfräulichkeit, in dem die Mühen, Strapazen und Besudelungen des weltlichen Ehelebens der Reinheit keuscher Lebensführung entgegengesetzt werden ${ }^{89}$. „Siehst du nicht, dass das göttliche Vorbild, das der innerlich erwählte Mensch im Geiste be-

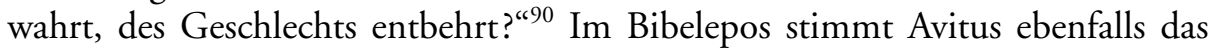
Lob der Jungfräulichkeit an. In seiner Schilderung des Sündenpfuhls von Sodom und Gomorrha erscheint der Inzest als Sinnbild der Zügellosigkeit und als Gegenbild zur christlichen Keuschheit: „Die Leidenschaft der Sünde entzündete einige Städte und erlaubte bürgerliche Verbrechen durch gelockerte Zügel. Inzest galt als Gesetz und die Begierde hatte das ganze Recht ${ }^{(9) 1}$. Vor

87 Cyprianus Gallus, Heptateuchos Lev. 130 (108).

88 Brown, Cult 1981, 93-96; VAn Dam, Saints 1993, 94-105; Brown, Rise 2003, $161 \mathrm{f}$.

89 Wood, Avitus 1979, 89.

90 Adspicis, ut sexu careat caelestis imago, interior sortitus homo quam mente retentat? Avitus, De virginitate v. $221 \mathrm{f}$. (MGH Auct. Ant. 6/2, 281).

91 Peccandi quasdam fervor succenderat urbes civica permittens laxatis crimina frenis. Incestus pro lege fuit totumque libido ius habuit ... Avitus, De originali peccato v. 329 f. (MGH 
diesem Hintergrund macht die Bestimmung von Epaon durchaus Sinn, und es ist abwegig, Missverständnisse für die Ausweitung des Inzestverbots verantwortlich zu machen. Avitus wusste, dass er eine Neuerung auf den Weg brachte, und fügte deshalb die Toleranzklausel ein, nach der erst ab dem Zeitpunkt des Konzils die Ehe mit der Cousine ersten und zweiten Grades ausnahmslos unter Strafe gestellt werden sollte.

\section{Bischof und König im Konflikt}

Abschließend ist auf einen Fall einzugehen, der das gesamte Reich der Burgunder erschütterte und der Avitus den Ruf eines Nachfolgers Johannes' des Täufers einbrachte. Kurz nach dem Konzil von Epaon kam es zum Eklat zwischen Episkopat und König ${ }^{92}$. Durch die Initiative des Avitus wurde der Verwalter des königlichen Fiskus Stephanus aus der Kirche ausgeschlossen, da er die Schwester seiner verstorbenen Ehefrau geheiratet hatte. Die Bischöfe konnten sich bei dieser Entscheidung sowohl auf den eben erlassenen Kanon des Konzils von Epaon als auch auf die Bestimmung der Lex Burgundionum stützen. Stephanus und seine zweite Frau Palladia gehörten dem gallorömischen Adel ${ }^{93}$ an und unterlagen damit auch den Vorschriften des römischen Rechts, das diese Verbindung ebenso untersagte. Trotz dieser eindeutigen Rechtslage beharrten die Eheleute auf ihrer Verbindung. Nach den Worten der Vita Apollinaris schüchterte der König durch einen furchterregenden Wutausbruch und durch massive Gewaltdrohungen die heiligen Bischöfe ein ${ }^{94}$. Daraufhin sind die Bischöfe in Lyon zusammengekommen. Avitus war inzwischen verstorben, und sein Bruder Bischof Apollinaris von Valence übernahm die Initiative. In Lyon wurde ein Schutzbündnis der Bischöfe gegen die Drohungen des Königs geschlossen $^{95}$. Sollte der König weiterhin mit Gewalt auf die Bischöfe eindringen, wurde der Rückzug ins Kloster beschlossen. Dies kam einem Interdikt gleich, da

Auct. Ant. 6/2, 221). Vielleicht spielt auch die Vertrautheit des Avitus mit Augustins De civitate dei und der dort ausgeführten Begründung des Inzestverbots eine Rolle. Zur Kenntnis des Avitus: Mathisen, Reception 1993, 40. Zum Einfluss Augustins auf die Dichtung des Avitus: Nodes, Avitus 1984; Wood, Poet 2001.

92 Wood, Incest 1998, 299-301; KaIser, Burgunder 2004, 164 f. Zum Ruf eines Heiligen siehe 321.

93 Miкat, Inzestgesetzgebung 1994, $114 \mathrm{f}$, setzte burgundische Herkunft voraus. Dem widersprach zu Recht WooD, Incest 1998, 300, aufgrund der Stellung als Verwalter des Fiskus. Der gleichen Meinung ist Maier, Amtsträger 2005, 308. Der Name ist bei Romanen durchaus verbreitet: z. B. hieß der Vorgänger des Bischofs Viventiolus von Lyon Stephanus. Die über dreißig burgundischen Grafen, die in der Lex Burgundionum genannt sind, tragen mit einer Ausnahme germanische Namen. Die Deutung dieses Befundes durch Amory, Names 1994, ist umstritten.

94 Tunc rex dirae insaniae furore permotus, beatissimos pontifices acerrime insidias praetendendo iniuriare non desinebat. Vita Apollinaris 3 (MGH SS rer. Merov. 3, 198).

95 Konzil von Lyon (518/523) c. 1 (MGH Conc. 1, 32 f.). 
wichtige liturgische Funktionen innerhalb der betroffenen Städte nicht mehr ausgeführt werden konnten. Der König selbst war bereits von der Kommunion suspendiert, da er offensichtlich den Ausschluss seines Schatzmeisters aus der Gemeinde der Christen nicht billigte ${ }^{96}$. Erst bei einem Friedensschluss zwischen dem König und allen Bischöfen sollte das Interdikt aufgehoben werden. Weitere Bestimmungen des Konzils von Lyon sahen vor, dass die revoltierenden Bischöfe in ihren Städten nicht durch andere ersetzt werden konnten. Dies deutet auf eine keineswegs geschlossene Front der Bischöfe hin. Denn gegenüber den 25 Teilnehmern des Konzils von Epaon waren in Lyon nur 11 Bischöfe zugegen. Die Front wurde weiter aufgebrochen, als der König um eine Erleichterung der Exkommunikation seines Schatzmeisters ansuchte. Er sollte an der Messe zumindest als Betender teilnehmen dürfen, wenn ihm auch weiterhin die Kommunion versagt blieb ${ }^{97}$. Diese Erleichterung verweigerten zwei Bischöfe.

Auch in der weiteren Folge konnte sich der König durchsetzen. Er untersagte den Bischöfen den Aufenthalt in den Klöstern und beorderte sie zurück zu ihren Bischofssitzen ${ }^{98}$. Als Kontrollinstrument befahl er, dass jeder von ihnen für einen Monat am Hof Dienst leisten sollte. „Daraufhin flehten alle (Bischöfe) die göttliche Herrlichkeit unter Tränen an, damit er sie nicht im Stich lässt. Sie verabschiedeten sich voneinander und brachen nach einem gemeinschaftlichen Gebet auf ${ }^{\mathrm{f}(99}$. Als erster musste Apollinaris den Hof Sigismunds aufsuchen, da er am unnachgiebigsten den Inzest des Stephanus verfolgt hatte. Die weiteren Geschehnisse, wie sie uns die Vita Apollinaris überliefern, werden von Wunderberichten überlagert, ohne dass der Ausgang der Angelegenheit einer Erwähnung für wert befunden wird. Der schwerkranke König sei durch das Gebet des Heiligen genesen und habe sein drakonisches Vorgehen gegen die Bischöfe bereut ${ }^{100}$. Der Fall des Stephanus wird nicht mehr genannt. Man wird also angesichts der resoluten Haltung des Königs davon ausgehen können, dass die

96 Quod si se rex praecellentissimus ab ecclesiae vel sacerdotum communione ultra suspenderit ... Konzil von Lyon (518/523) c. 1 (MGH Conc. 1, 32).

97 Domni quoque gloriosissimi regis sententia secuti id temperamenti praestitimus, ut Stephano praedicto vel Palladiae usque ad orationem plebis, quae post evangelia legitur, orandi in locis sanctis spatium praestarimus. Konzil von Lyon (518/523) (MGH Conc. 1, 34).

98 Videns vero rex ille constantiam eorum incorruptibilem esse, ab ira non desinens, praecepit, ut pontifices, qui ibidem pariter residebant, ad propria reverterentur et singillatim per singulos menses regem operire deberent. Vita Apollinaris 3 (MGH SS rer. Merov. 3, 198).

99 Tunc omnes lacrimis divinam potenciam obsecrantes, ne se derelinqueret, vale dicentes, celebrata oratione, profecti sunt. Vita Apollinaris 3 (MGH SS rer. Merov. 3, 198).

100 Vita Apollinaris 5-6 (MGH SS rer. Merov. 3, 199). Das Nachgeben der Bischöfe am Konzil von Lyon wird in der Vita verschwiegen. Andere Verdächtigungen gegen die Authenzität der Quelle haben sich bislang nicht erhärten lassen: MiкAт, Inzestgesetzgebung 1994, 108; WooD, Incest 1998, 300. 
Heirat zwischen Stephanus und Palladia weiterhin Bestand hatte ${ }^{101}$. Wenn der Autor der Vita von einer erfolgten Trennung gewusst hätte, wäre er kaum mit Schweigen über das Ende der Angelegenheit hinweggegangen.

Mit dem Erlass von Konzilskanones war die Arbeit also nicht getan. Selbst in so einem offensichtlichen Inzestfall wie dem zwischen Stephanus und Palladia war die Durchsetzung der Vorschriften alles andere als einfach. Sigismund unterstützte hartnäckig die Sache seines Schatzmeisters und nahm deswegen eine Spaltung mit Teilen des Episkopats in Kauf. Es war ihm ohne weiteres möglich, die Bischöfe aus ihrem selbst gewählten Exil zurückzubeordern und die Aufnahme ihrer liturgischen Dienste zu verlangen. Den Bischöfen blieb nur der Rückgriff auf spirituelle Macht, indem sie mit Ausschluss von der Kommunion drohten und die Inspiration Gottes für sich in Anspruch nahmen. Sieger dieses Konflikts blieb Sigismund. Vermutlich war aber die Entzweiung zwischen König und Episkopat von längerer Dauer, so dass die Grundlagen der Herrschaft Sigismunds schon vor der Eroberung durch die Franken untergraben wurden ${ }^{102}$.

Dieser Konflikt zeigt auf besonders anschauliche Weise, dass in der Frage des Inzestverbots die Fronten weder zwischen Römern und Barbaren noch zwischen Katholiken und Arianern verliefen. Sigismund und sein Schatzmeister Stephanus waren ebenso Katholiken wie der Bürger aus Grenoble Vincomalus, und trotzdem stellten sie sich einer Inzestbestimmung entgegen, die schon lange zum Kern des Kirchenrechts zählte. Der Arianer Theoderich inszenierte sich dagegen zur selben Zeit in seinen Briefen als unnachgiebiger Hüter der Inzestvorschriften in römischer Tradition. Der Gegensatz zwischen Germanen und Römern ist ebenfalls nicht wirksam, weil Sigismund in der Lex Burgundionum ein halbes Jahr vor dem Konzil im Kern die kirchlichen Vorschriften für sein Reich akzeptiert hatte. Der Germane Sigismund sowie die Galloromanen Vincomalus und Stephanus leisteten Widerstand gegen die Aktion der katholischen Bischöfe. Ein germanischer Widerstand gegen das Inzestverbot, wie ihn Paul Mikat geltend machte ${ }^{103}$, ist nicht nachweisbar.

Umso dringlicher stellt sich die Frage nach der Erklärung von Sigismunds widersprüchlicher Haltung. Einerseits sanktionierte er das Verbot der Ehe mit der Frau der Schwester in einer Novelle zur Lex Burgundionum, zum anderen verhinderte er mit allen Mitteln die Durchsetzung dieses Verbots im Falle des Stephanus und der Palladia. Ein Gegensatz zwischen Germanen und Romanen,

101 Wood, Incest 1998, 299, schließt von der Erleichterung in Lyon auf die erfolgte Trennung der Eheleute. In Lyon wurde jedoch nicht die Buße, sondern die Exkommunikation geregelt. In diesem Sinne Miкат, Inzestgesetzgebung 1994, 113; KaIser, Burgunder 2004, 165. Beide betonen den offenen Ausgang der Angelegenheit.

102 So die Vermutung von Wood, Incest 1998, 301; zurückhaltender KaISER, Burgunder 2004, 165.

103 Мікат, Inzestgesetzgebung 1994, 104 u. 116. 
wie ihn Mikat anführte, ist dafür nicht verantwortlich zu machen. Ian Wood äußerte dagegen die Vermutung, dass die Ehe des Stephanus bereits vor dem Erlass der Lex geschlossen worden sei und daher nach der Auffassung Sigismunds rückwirkend nicht hätte aufgelöst werden können ${ }^{104}$. Allerdings wird in den Quellen nichts über den Zeitpunkt der Eheschließung des Stephanus gesagt. Außerdem setzt diese Deutung voraus, dass das Sororat vor dem Erlass der Lex noch nicht als Inzest angesehen worden war. Dem widersprechen aber die eindeutigen Regelungen des kirchlichen und weltlichen Rechts, die im vierten Jahrhundert nach kontroversen Diskussionen erlassen worden waren. Es gibt keine Zeugnisse dafür, dass diese Diskussion in der Zeit um 500 noch virulent war. Auch der Brief des Victorius von Grenoble lässt in diesem Punkt keine Unsicherheit erkennen. Da jedoch nur Quellen aus dem Umkreis des Avitus von Vienne überliefert sind, lässt es sich nicht vollkommen ausschließen, dass Stephanus auf die fehlende Grundlage des Verbots in der Heiligen Schrift aufmerksam machte.

Für die widersprüchliche Haltung Sigismunds ist noch eine andere Erklärung möglich. In der rechtshistorischen Forschung wurde wiederholt auf den autokratischen Charakter der burgundischen Gesetzgebung hingewiesen. Der König erscheint „als einzige Quelle des Rechts“, während die burgundischen Grafen nur beratend tätig waren ${ }^{105}$. Vielleicht hat Sigismund auf Grund seiner Stellung als Gesetzgeber eine Dispensierung im Fall des Stephanus vorgenommen. Einen Hinweis darauf gibt eine Formulierung der Vita Apollinaris. Darin heißt es, dass die Bischöfe Stephanus von der Kommunion ausschlossen, damit es seine unsittliche Dreistigkeit nicht wagt, den durch das göttliche Recht untersagten Inzest gerichtlich einzuklagen ${ }^{106}$. Der Begriff vindicare suggeriert einen Rechtsanspruch, auf den sich Stephanus berufen konnte ${ }^{107}$. Worauf sich dieser Rechtsanspruch gründet, bleibt offen. Im Gesamtbild der Herrschaft Sigismunds ist dieser Fall jedenfalls nicht singulär. Auch sein Verhalten bei der Ermordung seines Sohnes, die er zunächst in Auftrag gab und später bitter bereute $^{108}$, bezeugt sein Schwanken zwischen autoritärer Herrschaft und Gefügigkeit gegenüber den kirchlichen Forderungen.

Treibende Kraft hinter allen hier besprochenen Quellen war der Bischof Avitus von Vienne. Er hat die Ausweitung des Inzestverbots auf die gesamte Verwandtschaft betrieben und die Zustimmung des Königs zu diesem Vorgehen

104 Wood, Incest 1998, 300.

105 Hermann Nehlsen, Art. „Lex Burgundionum“, in: HRG 2 (1978) 1901-1915; Sснотт, Formen 1995, 959; Kaiser, Burgunder 2004, 128.

106 ... ipsum Stephanum sacra communione privari sanxerunt, ut ... incestum, quod iusticia superna dampnavit, inhonesta praesumptio non audeat vindicare. Vita Apollinaris 2 (MGH SS rer. Merov. 3, 198).

107 So bereits Мiкат, Inzestgesetzgebung 1994, 112-114.

108 Hierzu KaIser, Sigismund 2004, 205-207. 
erlangt. Es ging ihm dabei einerseits um die Unterwerfung der Ehe unter eine christliche Ordnung, anderseits um die Demonstration bischöflicher Macht über einen zentralen Lebensbereich der Laien. Seine Haltung in dieser Frage war vermutlich den Verwandten des Ennodius bekannt, so dass sie für die Legitimierung ihrer Cousinenehe den weiten Weg zum Papst in Rom nicht scheuten. So unnachgiebig Avitus in der Ausweitung des Inzestverbots war, so zurückhaltend verhielt er sich bei der Auferlegung der Buße. Im Gegensatz zu den Konzilien des 4. Jahrhunderts wollte er keine verpflichtende Buße verhängen, da viele Menschen seiner Ansicht nach den Anforderungen eines Lebens im Stand der Büßer nicht gewachsen waren. Die Trennung der Eheleute sollte zur Wiedergutmachung des Inzests genügen.

\subsection{Obsession im merowingischen Kirchenrecht}

Die Zeit zwischen 511 und 626/627 markiert einen Höhepunkt in der konziliaren Gesetzgebung zum Inzestverbot. Jean Gaudemet sprach von einer „einzigartigen Beharrlichkeit“, ja von einer „Besessenheit“ der kirchlichen Gesetzgebung im Frankenreich ${ }^{109}$. Kaum ein anderes Thema wurde so häufig auf die Tagesordnung der Bischofsversammlungen gesetzt wie die Ehe zwischen Verwandten. Auf allen großen Synoden wurde eine Bestimmung zu diesem Thema erlassen ${ }^{110}$. Der dem Inzest gewidmete Kanon 22 des zweiten Konzils von Tours (567) erstreckt sich in der kritischen Edition von Maassen über zwei Seiten und ist die längste Bestimmung der merowingischen Gesetzgebung überhaupt. Von den 17 Synoden zwischen 511 und 626/627 befassten sich nur vier nicht mit dem Inzestverbot, und zwar die beiden Provinzialkonzilien von Eauze (551) und Arles (554) sowie die beiden Synoden von Gunthrams Teilreich in Lyon (567/ 570) und Mâcon (581/583). Erst nach dem Konzil von Clichy (626/627) brach diese kontinuierliche Reihe ab. Da allerdings die Zahl der Bischofsversammlungen im 7. Jahrhundert drastisch zurückging, lässt sich ein abruptes Ende der Inzestbestimmungen, wie es Jean Gaudemet vermutet ${ }^{111}$, nicht feststellen. Nach Clichy fanden nämlich nur mehr zwei Synoden auf Reichsebene sowie eine Provinzial- und eine Diözesansynode statt. Für eine statistische Auswertung ist dieser Quellenbestand zu gering. Darüber hinaus kam es seit der Wende zum 7. Jahrhundert zu einer weltlichen Gesetzgebung zum Inzest, so dass angesichts

109 Gaudemet, Condamnations 1996, 369 u. 379.

110 Vgl. die Aufstellung bei Gaudemet, Condamnations 1996, 376. Die folgenden Zahlen unterscheiden sich von denen Gaudemets, da ich nicht die Synoden unter burgundischer und gotischer Herrschaft aufgenommen habe. Die Inzestbestimmung des 5. Konzils von Orléans hat Gaudemet übersehen, vgl. unten 155.

111 Gaudemet, Condamnations 1996, 378. 
der Mitwirkung des Königs eine bischöfliche Gesetzgebung nicht mehr so dringend erschien.

Die „einzigartige Beharrlichkeit“ der merowingischen Konzilien ist im Vergleich zur altkirchlichen Gesetzgebung noch erstaunlicher. Auf den gallischen Konzilien des 4. und 5. Jahrhunderts, die immerhin auch einen stattlichen Band füllen, wurde das Thema des Inzestverbots kein einziges Mal angesprochen. Auch die Papstbriefe dieser Zeit schweigen mit einer Ausnahme zu diesem Thema. Die anderen Konzilien des römischen Reichs behandelten das Inzestverbot ebenfalls nur ausnahmsweise. Nachdem im vierten Jahrhundert die weltliche Gesetzgebung die Forderungen der Kirche übernommen hatte, erübrigte sich offensichtlich ein weitergehendes Insistieren. Die „Besessenheit“ der merowingischen Gesetzgebung verlangt also nach einer Erklärung. Paul Mikat, der sich wiederholt und sehr präzise mit der Inzestgesetzgebung des 6. Jahrhunderts befasste, machte dafür in erster Linie die „Begegnung von fränkischer und kirchlicher Eheauffassung" verantwortlich. „Das germanische Gewohnheitsrecht" habe Ehen zwischen Stiefverwandten und verschwägerten Personen als legitim angesehen, „die dem kanonischen Recht zufolge als Inzestverbindungen galten “112. „Die überlieferten Fälle lassen den Widerstand deutlich werden, der von einer noch wesentlich von familialem Denken mitgeprägten Form staatlicher Organisation gegen die Durchsetzung der kirchlichen Inzestgebote ausging "113. In Kapitel 3 habe ich mich gegen eine solche Zuspitzung auf die Frage der ethnischen Identität gewandt. Aus der galloromanischen Bevölkerung des 6. Jahrhunderts ist eine Reihe von Inzestfällen bekannt, die von Mikat durchwegs unterschlagen werden. Die Inzestverbindungen unter Franken und Germanen verwertet er, wie zum Beispiel die tendenziöse Schilderung bei Prokopios, ohne die erforderliche Quellenkritik. Andere Belege ohne ethnische Zuordnung deutet er ausnahmslos auf die fränkische Bevölkerung ${ }^{114}$. Doch gerade die beiden Inzestfälle im Burgunderreich zeigen zur Genüge, dass die galloromanische Bevölkerung mit dem Ehehindernis der Schwägerschaft noch nicht vertraut war. Gleiches trifft für die Blutsverwandtschaft zu, da das Verbot der Ehe mit der Cousine ersten und zweiten Grades im römischen Recht nicht hinreichend verankert war.

Auch die geographische Verteilung der beteiligten Bischöfe spricht gegen eine Zuspitzung auf den Widerstand der Franken. Nach den Ergebnissen von Champagne und Szramkiewicz waren die Bischöfe von Bourges, Vienne und Lyon mit Abstand am häufigsten an Bischofsversammlungen der Merowinger-

112 Miкat, Inzestgesetzgebung 1994, 59.

113 Мікат, Inzestgesetzgebung 1994, 67.

114 Z.B. der Fall des Stephanus, das Vorgehen des Albinus von Angers, den Brief Theudeberts I., das 3. Konzil von Orléans: Мiкат, Inzestgesetzgebung 1994, 51-83. 
zeit beteiligt ${ }^{115}$. Die Diözesen des burgundischen Raums und Zentralfrankreichs dominierten die Konzilien des 6. Jahrhunderts, während die Bischöfe aus den Gebieten fränkischer Siedlung nur in Ausnahmefällen präsent waren. Für die Konzilien, die sich der Inzestfrage widmeten, lassen sich die Zahlen weiter präzisieren. Bischöfe aus den Metropolitanbezirken des nordöstlichen Frankenreichs waren äußerst selten präsent. Aus Reims waren Bischöfe auf sechs von 12 Reichskonzilien zugegen, aus Trier und Köln auf vier und aus Mainz auf einem. Fast immer waren dagegen Bischöfe aus Sens (11 von 12), Tours, Rouen und Bourges (10 von 12) sowie Vienne (9 von 12) und Bordeaux (8 von 12) beteiligt. Diese Zahlen können freilich nur einen groben Eindruck von der Prägung der merowingischen Konzilien geben. Wer bestimmte Bestimmungen beeinflusst haben könnte, lässt sich nur im Einzelfall klären. Allerdings verweist die Tatsache, dass sich die merowingische Inzestgesetzgebung ausdrücklich als eine Fortsetzung des Konzils von Epaon begreift, auf den Einfluss der burgundischen Bischöfe. Die Regelung von Epaon steht jedoch in keinem erkennbaren Zusammenhang mit einem Widerstand der germanischen Bevölkerung Burgunds. Es ist daher alles andere als zwingend, die „Besessenheit“ der merowingischen Kirche wie Mikat auf den Widerstand der Franken zurückzuführen.

Das Übergewicht des galloromanischen Episkopats und der galloromanischen Diözesen auf den Konzilien des 6. Jahrhunderts lenkt den Blick weg vom vermeintlichen Widerstand der Germanen auf die Mentalität der beteiligten Bischöfe. Mayke de Jong äußerte dazu in zwei gehaltvollen Aufsätzen eine Hypothese, die von ihr argumentativ mehr angerissen als begründet wurde, aber dennoch auf Zustimmung gestoßen ist. Die Mentalität der Bischöfe ist nach de Jong von einer formalistischen und buchstäblichen Religiosität gekennzeichnet, in deren Mittelpunkt „die Angst vor ritueller Beschmutzung“ (pollutio) gestanden habe. Mit Bezug auf die wegweisenden Arbeiten von Mary Douglas begreift sie pollutio als "Vermischung von Sexualität und Heiligkeit“. Diese Angst vor ritueller Beschmutzung sei in der Antike unbekannt gewesen und habe sich erst im frühen Mittelalter sowohl bei Klerikern als auch bei Laien ausgebreitet ${ }^{116}$. Die Inzestgesetzgebung fasst de Jong als einen „Teil dieses pollutio-orientierten Moralsystems ${ }^{\text {“117 }}$ auf. So wichtig der Ansatz ist, die Aufmerksamkeit auf die Mentalität der Bischöfe zu lenken, so wenig überzeugt meines Erachtens der Verweis auf die Angst vor ritueller Beschmutzung. Gerade der Begriff der pollutio war, wie das Damaskus-Edikt Kaiser Diocletians hinlänglich vor Augen führt, in der heidnisch-römischen Inkrimination des Inzests fest verankert und meinte die unkeusche Beschmutzung mit Sexualität. Die

115 Champagne - Szramkiewicz, Recherches 1971, 19-21.

116 JoNG, Riddle 1998, 118.

117 Jong, Legislation 1989, 154; Lutterbach, Sexualität 1999, 173. 
merowingischen Bischöfe dagegen bringen in keinem einzigen Konzilstext diesen Begriff zur Anwendung. In späteren Quellen wie in den Bußbüchern dient der Begriff ganz allgemein als Umschreibung für Sünde und muss keine Verletzung kultischer Reinheit beinhalten ${ }^{118}$. Es scheint überdies fraglich, ob Verwandtenehen überhaupt als eine Vermischung von Sexualität und Heiligkeit aufgefasst werden können. Heiligkeit ist bei einer Eheschließung ebenso wenig im Spiel wie Reinheit des Kultus. Die Anwendung der Kategorien von Mary Douglas ist daher unpassend, insbesondere wenn man die Rolle des Avitus von Vienne in Betracht zieht. Avitus zeichnete für die Ausdehnung des Inzestverbots im frühen Mittelalter verantwortlich, kann jedoch wegen seiner großen Gelehrsamkeit kaum als Zeuge für den Weg des Christentums zu einer rituellen und formalistischen Einfach-Religion in Anspruch genommen werden. Mit der Verwendung des Begriffs der pollutio manifestiert sich lediglich seine Schulung in der römischen Kultur ${ }^{119}$.

Die bisherigen Erklärungen für die „einzigartige Beharrlichkeit“ der merowingischen Inzestgesetzgebung können also nicht oder nur teilweise befriedigen. Es lohnt sich deshalb, die Quellen einer neuen Lektüre zu unterziehen, bei der insbesondere die Herkunft und Mentalität der Bischöfe berücksichtigt werden sollen.

\section{Vota discordantia auf den Reichskonzilien}

Die Reihe der Inzestbestimmungen beginnt mit dem ersten Konzil des Frankenreichs. Auf Befehl Chlodwigs versammelten sich am 10. Juli 511 in Orléans 32 Bischöfe. Nach dem Vorbild des Konzils von Agde, das in mehreren Bestimmungen zitiert wird, sollte damit die Einheit der unter fränkischer Hoheit stehenden Kirche zum Ausdruck gebracht werden. Die anwesenden Bischöfe kamen sowohl aus den neueroberten Gebieten südlich der Loire als auch aus dem fränkischen Siedlungsgebiet und stellen daher einen repräsentativen Querschnitt des Frankenreichs dar. Wie der einleitende Brief der Bischöfe an Chlodwig berichtet, hatte der König die Einberufung des Konzils befohlen und bestimmte Tagesordnungspunkte festgelegt. Die Bischöfe stellten in dem Brief jedoch klar, dass sie allein über die Erstellung der Kanones bestimmen wür-

118 Vgl. Ludger KöRnTGEN, Rezension von Lutterbach „Sexualität im Mittelalter“, in: DA 58 (2002) 423 f. Zur Kritik an diesem religionsgeschichtlichen Ansatz vgl. auch MAYRHarting, Religion 2002.

119 Pollutio bezeichnet bei Avitus (wie in anderen Quellen der Spätantike) einerseits die Verunreinigung des Glaubens durch Häresie: Avitus, Epistola 7 (MGH Auct. Ant. 6/2, 36 f.); Konzil von Epaon (517) c. 33 (MGH Conc. 1, 27); andererseits die Beschmutzung der Seele durch Sexualität: Avitus, Homiliae V 2 (MGH Auct. Ant. 6/2, 107); De initio mundi v. 3 (MGH Auct. Ant. 6/2, 203). Siehe auch unten 280. 
den ${ }^{120}$. Das erste Konzil von Orléans ist daher zu Recht als ein ,Konkordat', ein Interessensausgleich zwischen Kirche und König bezeichnet worden ${ }^{121}$. Der Einfluss des Königs gewann zum Beispiel in der Bestimmung die Oberhand, dass Weihen zum Kleriker nur auf Befehl des Königs stattfinden dürften ${ }^{122}$. Diese Vorschrift war eine drastische Verschärfung des römischen Rechts und konnte sich langfristig nicht durchsetzen. Die Mehrheit der Kanones geht dagegen deutlich auf die Interessen des Episkopats zurück. Beispielsweise wurde die Macht der Bischöfe über den Klerus, das Kirchengut und die Abteien deutlich gestärkt, die Ausdehnung des Asylrechts festigte ihre Stellung in der Rechtssprechung.

$\mathrm{Zu}$ diesen bischöflich beeinflussten Bestimmungen ist vermutlich auch das Inzestverbot zu zählen. Der Kanon lautet, dass niemand die Frau seines verstorbenen Bruders oder die Schwester seiner verstorbenen Ehefrau heiraten darf. Als Strafe wird mit einer nicht genauer spezifizierten kirchlichen Sanktion gedroht $^{123}$. Als Vorbild für das gemeinsame Verbot von Levirat und Sororat diente vermutlich der Kanon 2 des Konzils von Neocäsarea ${ }^{124}$. Für diese Bestimmung einen „Sitz im Leben“ zu erweisen, fällt schwer. Es wäre jedoch immerhin vorstellbar, dass sie im Zusammenhang mit einem Kriegszug Chlodwigs steht, der von Gregor von Tours dem Ende seiner Regierungszeit zugeordnet wird. Der Krieg richtete sich gegen König Ragnachar von Cambrai, einen Verwandten Chlodwigs. Gregor wirft diesem Kleinkönig vor, er und sein Günstling Farro seien „so der Geilheit ergeben gewesen, dass sie kaum ihre nächsten Verwandten verschonten "125. Es ist denkbar, dass Gregor die Propaganda Chlodwigs wiedergibt, mit der dieser die rücksichtslose Beseitigung der Konkurrenz innerhalb der eigenen Verwandtschaft rechtfertigen wollte. Möglicherweise stellte sich Chlodwig also am Ende seines Lebens als christlicher König dar, der ähnlich wie Theoderich in Italien die Verfolgung des Inzests in seine Hand nahm. Dies bleibt jedoch eine Vermutung, da die Chronologie Gregors von Tours nicht über jeden Zweifel erhaben ist ${ }^{126}$. Die Ausschaltung der fränkischen Kleinkönige

120 ... secundum voluntates vestrae consultationem et titulos, quos dedistis, ea quae nobis visum est definitione respondimus ... 1. Konzil von Orléans (511) Ep. (MGH Conc. 1, 2).

121 Heuclin, Concile 1997.

122 1. Konzil von Orléans (511) c. 4 (MGH Conc. 1, 4); vgl. Godding, Prêtres 2001, $14-$ 23.

123 Ne superstis frater torum defuncti fratris ascendat; ne sibi quisque amissae oxores sororem audeat sociare. Quod si fecerint, ecclesiastica districtione feriantur. 1. Konzil von Orléans (511) c. 18 (MGH Conc. 1, 6).

124 Siehe 51.

125 Erat autem tunc Ragnacharius rex apud Camaracum tam effrenis in luxoria, ut vix vel propinquis quidem parentibus indulgeret. His habebat Farronem consiliarium simili spurcitia lutolentum ... Gregor von Tours, Decem libri historiarum II 42 (MGH SS rer. Merov. 1/1, 92).

126 Wood, Gregory 1985. 
wird von manchen Historikern eher in die Anfangszeit der Regierung Chlodwigs als in die Zeit des Konzils von Orléans datiert ${ }^{127}$.

Zwölf Jahre nach dem ersten Konzil von Orléans verstieß der jüngste Chlodwigsohn Chlothar gegen die Bestimmung der Bischöfe. Chlothar ehelichte die Frau seines Bruders Guntheuca, nachdem dieser im Krieg gegen das burgundische Reich umgekommen war ${ }^{128}$. Offensichtlich wollte sich Chlothar im Kampf um das Erbe seines Bruders eine vorteilhafte Stellung sichern. Chlothar hatte als jüngster Sohn bei der Herrschaftsteilung nach dem Tod Chlodwigs am schlechtesten abgeschnitten und nur einen kleinen Reichsteil nördlich der Somme erhalten ${ }^{129}$. Seine aktive Heiratspolitik war ein Versuch, sich im Konkurrenzkampf der Chlodwigerben zu behaupten. Wenig später führte er nach einem Feldzug die thüringische Königstochter Radegunde an seinen Hof und gesellte sie ca. 540 seinem „Harem“ bei, der schon aus mindestens drei Frauen bestand ${ }^{130}$. Am Ende seines Lebens versuchte Chlothar ein weiteres Mal, eine politisch prestigeträchtige Witwe zu heiraten. Als sein Großneffe Theudebald starb, wollte er dessen Witwe Waldrada, eine langobardische Prinzessin, heiraten, stieß aber auf den heftigen Widerstand der Bischöfe und musste sein Vorhaben aufgeben ${ }^{131}$. Hinter dieser Heiratspolitik steckt nicht allein politisches Kalkül, sondern auch offene Missachtung der kirchlichen Bestimmungen. Dies zeigt sich an einer weiteren Ehe Chlothars mit Aregund, der Schwester seiner ersten Frau Ingund ${ }^{132}$. Eine politische Motivation ist in diesem Fall ausgeschlossen, da beide Frauen zu den Sklavinnen des Königs zählten. Es verwundert nicht, dass Gregor von Tours in Chlothar einen hemmungslosen Wüstling sah.

Die beiden Inzestehen Chlothars wurden in den zwanziger Jahren des 6 . Jahrhunderts geschlossen. Zu dieser Zeit war es noch keineswegs besiegelt, ob das Konzil von Orléans ein Einzelfall bleiben oder Vorbild für weitere Kirchenversammlungen werden sollte. Im 5. Jahrhundert hatten keine Synoden auf der Ebene ganz Galliens und nur wenige Provinzialsynoden stattgefunden. Es fehlte deshalb ein entsprechendes bischöfliches Selbstbewusstsein, um die Ehen Chlothars an den Pranger zu stellen. Kirchliche Kritik an Chlothars Heirat mit der Frau des Bruders und mit der Schwester der Ehefrau wurde nicht geübt.

127 Ewig, Merowinger 2001, 30; Wood, Kingdoms 1994, 49.

128 Gregor von Tours, Decem libri historiarum III 6 (MGH SS rer. Merov. 1/1, 103). Siehe 93.

129 Ewig, Teilungen 1953, 115; Wood, Kings 1977; Offergeld, Reges 2001, 186-192.

130 Esmyol, Geliebte 2002, $49 \mathrm{f}$.

131 Sed increpitus a sacerdotibus, reliquit eam, dans ei Garivaldum ducem, dirigensque Arvernus Chramnum, filium suum. Gregor von Tours, Decem libri historiarum IV 9 (MGH SS rer. Merov. 1/1, 141).

132 Gregor von Tours, Decem libri historiarum IV 3 (MGH SS rer. Merov. 1/1, 136 f.). Siehe 95. 
Auch der Bischof Lupus von Soissons, der in Orléans anwesend war und in der Hauptstadt von Chlothars Reich residierte, erhob in dieser unruhigen und von Expansion geprägten Zeit nicht seine Stimme.

In den Jahren 531/532 errangen die fränkischen Könige drei bedeutende Siege und verschoben die Grenzen des Reiches weit über die von Chlodwig eroberten Gebiete ${ }^{133}$. Theuderich gelang mit Unterstützung Chlothars die Eroberung und Zerschlagung des Thüringerreiches, die Westgoten wurden aus dem Gebiet zwischen der Garonne und den Pyrenäen (Novempopulana) vertrieben, und das Burgunderreich musste 532 eine entscheidende Niederlage hinnehmen. Ein Jahr später kam es in Orléans zu einer Kirchenversammlung, die auf Befehl aller drei Könige zustande kam. Anders als unter Chlodwig beschränkten sich die Könige jedoch auf die Einberufung und nahmen keinen Einfluss auf den Inhalt der konziliaren Beratungen. Im Mittelpunkt des Konzils standen die Stärkung der bischöflichen Hierarchie und die Disziplinierung des Klerus ${ }^{134}$. Die Teilnahme von Bischöfen aus Burgund und der Novempopulana zeigt die Ausweitung des Reichs in den Süden an, während Bischöfe aus dem Norden fast gänzlich fehlten.

Kanon 10 dieses Konzils befasst sich mit dem Inzest: „Niemand soll sich mit seiner Stiefmutter, d.h. mit der Frau seines Vaters, auf irgendeine Weise verbinden. Wenn sich jemand dies herausnehmen sollte, soll er wissen, dass er durch die Strafe des Anathems getroffen wird “135. Mit der Verhängung des Anathems betont der Kanon die Verwerflichkeit des Inzests, da wie in den Kanones des 4. Jahrhunderts keine Rekonziliation vorgesehen ist. Die Rigorosität geht ebenso wie die Fixierung auf die Stiefmutter auf das Vorbild des Apostel Paulus in Korinth zurück (1. Cor. 5). Die Ehe mit der Stiefmutter zählte auch zum Kern der römischen Inzestverbote, so dass eine Ausrichtung auf fränkische Verhältnisse nicht unwahrscheinlich erscheint. Ebenso möglich ist ein konkreter Bezug zur Ehe des Warnenkönigs Radigis mit seiner Stiefmutter Theudechilde, die in Kapitel 3 ausführlich besprochen wurde. Diese Heirat sowie die darauffolgende Verstoßung der Merowingerin Theudechilde zugunsten einer anglischen Prinzessin sind möglicherweise in die Jahre um $533 \mathrm{zu}$ datieren ${ }^{136}$. Warum sich die Bischöfe des Frankenreichs jedoch auf dem 2. Konzil von Orléans gegen die Heirat hätten aussprechen sollen, erscheint unklar.

133 Ewig, Merowinger 2001, 33-41; Wood, Kingdoms 1994, 50-54.

134 Pontal, Synoden 1986, 72-75; Suntrup, Studien 2001, 78.

135 Nullus novercae suae, id est uxore patris sui, ulla copulatione iungatur. Quod si qui presumpserit, noverit se anathema supplicio feriendo. 2. Konzil von Orléans (533) c. 10 (MGH Conc. 1, 63).

136 Zum Folgenden siehe 97-99. Prokop datiert die Geschichte in die Jahre um 550; ihm folgt Ewig, Namengebung 1991, 51. JARnUt, Agilolfingerstudien 1986, 30 f., bevorzugt eine Datierung um das Jahr 533, ebenso Matthias SpRInger, Art. „Warnen“, in: RGA 33 (2006) 274-281, hier 278. 
Denn die Merowinger waren wohl eher von der später erfolgten Verstoßung Theudechildes durch Radigis aufgebracht als von der zuvor geschlossenen Inzestehe. Man müsste also auf Differenzen zwischen den einberufenden Königen und den versammelten Bischöfen schließen, die sich sonst jedoch nur indirekt manifestierten ${ }^{137}$. Eine Kritik an den Herrschern könnte sich hier ebenso geäußert haben wie eine Zurechtweisung bestimmter Kreise innerhalb der Kirche, die ihre Interessen durch eine enge Anbindung an die Wünsche der Könige zu fördern versuchten.

Zwei Jahre nach dem Konzil von Orléans versammelten sich die Bischöfe von Theudeberts Teilreich in Clermont. Nachdem sein Vater Theuderich 533 gestorben war, behauptete sich Theudebert mit der Rückendeckung des Adels und gegen den Willen seiner Onkel als König. Sein Teilreich erstreckte sich von Thüringen und dem Niederrhein bis in das südliche Aquitanien und umfasste weite Teile des eroberten Burgunderreichs. Die Bischöfe kamen daher aus den verschiedensten Gebieten des Frankenreichs. Erstmals waren auch Vertreter der nordöstlichen Bistümer anwesend, nämlich aus Reims, Châlons, Trier, Metz, Verdun und Tongern. Der König erschien wiederum als Initiator der Einberufung des Konzils, ohne auf den Inhalt der Beratungen einzuwirken ${ }^{138}$. Anders als in der Forschung hin und wieder angenommen wird $^{139}$, kommt keine königskritische Tendenz zum Tragen. Im Gegenteil, nach den eigenen Worten der Bischöfe knieten sie vor dem König auf dem Boden und traten bei Gott für sein Reich, dessen Dauer und für das Volk ein ${ }^{140}$. Deutlicher als auf dem 2. Konzil von Orléans richteten sich die Bischöfe jedoch gegen den Einfluss der Mächtigen auf die Kirche, sei es dass sie Kleriker ohne Beteiligung des Bischofs ernannten oder vom König Zuweisungen von Kirchengut erschleichen woll$\operatorname{ten}^{141}$.

Der Inzest wird in Kanon 12 angesprochen. In wörtlicher Anlehnung werden alle Verbote des Konzils von Epaon mit Ausnahme der Stiefmutter wiederholt. Diese Auslassung erklärt sich aus dem bereits auf dem 2. Konzil von Orléans ausgesprochenen Verbot. Der Inzest wird nicht wie in Epaon durch die Wahl des Wortes pollutio, sondern durch die Bezeichnung als Sakrileg geächtet: Er mache sowohl das göttliche als auch das natürliche Gesetz zunichte ${ }^{142}$. Die

137 Zur Bischofswahl vgl. 2. Konzil von Orléans (533) c. 3, 4 u. 7 (MGH Conc. 1, 62).

138 Pontal, Synoden 1986, 76-78.

139 Magnou-Nortier, Géographie 1997, 141; Suntrup, Studien 2001, 82.

140 ... ibique flexis in terram genibus pro regno eius, pro longevitate, pro populo dominum depraecaremur, ut qui nobis congregationis tribuerat potestatem, regnum eius dominus noster felicitatem attolleret, imperio regeret, iustitia gubernaret ... Konzil von Clermont (535) prol. (MGH Conc. 1, 66).

141 Konzil von Clermont (535) c. 2 (66), c. 4-5 (67).

142 Si quis relictam fratres, sororem uxoris, privignam, consubrinam sobrinamvae, relictam idem patrui adque abonculi carnalis contagii credederit consortio violandam et ausu sacrelego 
Bischöfe haben also ein deutliches Bewusstsein von der Tatsache, dass die Bestimmungen des Konzils von Epaon über die biblischen Inzestverbote hinausgehen und nur durch das Naturrecht untersagt werden. Eine weitere Begründung des Inzestverbots wird in dem folgenden Nebensatz nachgeliefert: Der Inzestuöse habe „als Feind und Überwinder der Keuschheit derjenigen Gewalt anzutun versucht, der er Hochachtung und Zuneigung entgegenzubringen verpflichtet gewesen wäre “143. Paul Mikat hat zu Recht auf einen Zusammenhang mit der Begründung des Augustinus in De civitate dei hingewiesen ${ }^{144}$. Wenn auch keine wörtliche Abhängigkeit nachzuweisen ist, so wird in beiden Texten die Unvereinbarkeit von familiärer Verbundenheit und sexueller Begierde hervorgehoben. In der Bestrafung weicht die Bestimmung von der Vorlage aus Epaon deutlich ab. Der Satz, dass die Ehetrennung das Vergehen heilt, wird nicht wiederholt. Stattdessen wird in jedem Fall mit einem Urteil nach apostolischer Konstitution gedroht. Verwiesen wird damit auf das rigorose Vorgehen des Apostel Paulus in Korinth ${ }^{145}$. Der Ausschluss von der Gemeinde und vom Empfang des Abendmahls soll solange währen, bis die Ehe getrennt wurde.

Die auf 15 Bischöfe beschränkte Zahl der Teilnehmer erlaubt die Frage nach Herkunft und Autorschaft des Konzilskanons. Ian Wood zog die Vermittlung durch Gregor von Langres in Erwägung, da dieser Bischof aus Burgund bereits auf dem Konzil von Epaon anwesend war ${ }^{146}$. Dasselbe trifft für Venantius von Viviers zu. Gegen eine solche Vermittlung spricht jedoch die deutliche Verschärfung der Strafbestimmungen. Zudem ist eine persönliche Vermittlung zur Erklärung der Aufnahme des Inzestverbots von Epaon nicht erforderlich. Schon zwei Jahre zuvor lagen in Orléans die Bestimmungen von Epaon vor. Kanon 1 und Kanon 17 des 2. Konzils von Orléans sind zum Teil wörtlich aus dem burgundischen Reichskonzil übernommen ${ }^{147}$. Der Metropolit Honoratus von Bourges war sowohl in Orléans (533) als auch in Clermont anwesend und hatte

auctoretatem divinae legis ac iura naturae perruperet ... Konzil von Clermont (535) c. 12 (MGH Conc. 1, 68).

143 ... et cui caritatis ac pii affectus solacia exibere debuerat, suorum hostis ac pudicitiae expugnator vim inferre timptaverit ... Konzil von Clermont (535) c. 12 (MGH Conc. 1, 68). Übersetzung nach Мıкат, Inzestgesetzgebung 1994, 120.

144 Мікат, Inzestgesetzgebung 1994, 121.

145 ... apostolicae constitutionis sententia feriatur, et quamdiu in tanto versator scelere, a cristeano coetu adque convivio vel aecclesiae matris comunione privabitur. Konzil von Clermont (535) c. 12 (MGH Conc. 1, 68). Maassen bezieht in seiner Edition den Verweis auf eine apostolica constitutio auf die Canones synodi Romanorum ad Gallos episcopos. Dieses Schreiben ist allerdings höchst selten überliefert. Ein Verweis auf den Apostel Paulus erscheint mir daher plausibler; vgl. Fleury, Recherches 1933, 101 f.; Мiкat, Orléans 1993, 27.

146 Wood, Incest 1994, 301.

147 2. Konzil von Orléans (533) c. 1 (MGH Conc. 1, 62); c. 17 (MGH Conc. 1, 63). 
sogar den Vorsitz bei diesen Synoden inne. Dennoch wird auch er nicht unbedingt für den Inzestkanon von Clermont verantwortlich gezeichnet haben, da er in Orléans noch nicht eine ähnlich ausführliche Bestimmung durchgesetzt hatte. Die Kanones von Epaon waren wohl allgemein bekannt, so dass man von dieser Seite aus nicht zu einer Vermutung hinsichtlich der Autorschaft gelangen kann.

Aussagekräftiger ist dagegen die rigorose Strafbestimmung. Der in Clermont anwesende Bischof Nicetius von Trier wird von zwei unabhängigen Quellen als unbeugsamer Verfolger von Inzestvergehen geschildert. Eine Quelle ist seine Lebensbeschreibung aus der Feder Gregors von Tours ${ }^{148}$. „Nachdem er das Amt des Bischofs angenommen hatte, zeigte er sich allen, die Gottes Befehle nicht einhielten, als solch schrecklicher Amtsträger, dass ihm nach dem Zeugnis lobender Stimmen der unmittelbare Tod gedroht habe “149. Gregor berichtet ferner über viele Ermahnungen des Nicetius an die Adresse König Theudeberts. Als eines Tages die sonntägliche Messe bevorstand, kam der König mit seinen Gefolgsleuten, die von Nicetius von der Kommunion ausgeschlossen worden waren, in die Kirche. Nach den Bibellesungen und den Darbringungen der Opfergaben forderte der Bischof die Exkommunizierten zum Verlassen der Kirche auf. Als der König dies verweigerte, schrie plötzlich einer aus dem Volk auf und begann von Dämonen besessen mit lauter Stimme die Verbrechen des Königs anzuklagen. Nicetius kommentierte dies folgendermaßen: „Zuerst sollen jene, die dir gefolgt sind, d.h. die Inzestuösen, Mörder und Ehebrecher, aus der Kirche verwiesen werden, dann wird Gott jenem das Schweigen befehlen "150. Nachdem dies geschehen war und Nicetius solcherart seine Beherrschung des Göttlichen demonstriert hatte, wurde der König milder und hörte auf die Mahnungen des Bischofs ${ }^{151}$.

Das Vorgehen des Nicetius entsprach in diesem Vorfall der allgemeingültigen Praxis. Exkommunizierte, Büßer und Katechumenen mussten vor dem Abendmahl die Kirche verlassen ${ }^{152}$. Eine besondere Strenge lässt sich allein

148 Gregor von Tours, Vitae patrum 6, 3 (MGH SS rer. Merov. 1/2, 232); 17, 1 (MGH SS rer. Merov. 1/2, 278). Über die Herkunft des Nicetius vgl. EwIG, Trier 1954, 98; Gauthier, Évangélisation 1980, 172-189; Anton, Trier 1987, 131-138.

149 Adsumpto vero episcopatu, tam terribilem se praebuit omnibus, si Dei mandata non servarent, inminere mortem proximam, voce praeconia testaretur. Gregor von Tours, Vitae patrum 17, 2 (MGH SS rer. Merov. 1/2, 279).

150 Cumque rex timore concussus peteret, ut hic inerguminus ab eclesia eiceretur, dixit episcopus: 'Prius illi qui te secuti sunt, id est incesti, homicidae, adulteri, ab hac eclesia extrudantur, et hunc Deus silere iubebit. Gregor von Tours, Vitae patrum 17, 2 (MGH SS rer. Merov. 1/ 2, 279). Zum Vorbild des Ambrosius in dieser Szene vgl. Buc, Dangers 2001, 114 und 121.

151 Unde factum est, ut, sacerdote orante, rex mitior fieret ... Gregor von Tours, Vitae patrum 17, 2 (MGH SS rer. Merov. 1/2, 279 f.).

152 Hen, Culture 1995, 68. 
daraus ablesen, dass Nicetius das Inzestdelikt auf eine Stufe mit Mord stellte. Eine zweite Quelle bestätigt diese Bewertung. In einem Brief an Nicetius warnt der Bischof Mapinius von Reims unüberhörbar vor einer Spaltung im Episkopat durch das forsche Auftreten seines Amtskollegen. Er beginnt den um 550 geschriebenen Brief mit dem Bibelzitat: „Wenn ein Reich in sich gespalten ist, kann es keinen Bestand haben“. Er fährt fort: ,Wenn dies von denjenigen, die die Welt lieben und in weltlicher Begierde verharren, zu Recht ausgesagt wird, wird es unzweifelhaft richtiger von den Bischöfen geglaubt, wenn sie erwiesenermaßen durch unterschiedliche Meinungen und unterschiedlichen Eifer untereinander gespalten werden "153. Diese Einleitung dient Mapinius dazu, sein Befremden gegenüber dem Vorgehen des Nicetius zum Ausdruck zu bringen. Er werde nicht der Einberufung eines Konzils durch Theudebald Folge leisten, denn dieser habe den Grund der Versammlung nicht preisgegeben. Erst auf Nachfrage habe er erfahren, dass Nicetius mannigfache Ärgernisse und Kummer erduldet habe, weil er einige Franken aus gottesfürchtigem Eifer ermahnt und wegen Inzest von der Kommunion ausgeschlossen habe ${ }^{154}$. Das Konzil sollte vermutlich dazu dienen, das Vorgehen des Nicetius zu unterstützen und ihn vor Nachstellungen durch die exkommunizierten Franken zu schützen ${ }^{155}$. Mapinius beschwerte sich über das einzelgängerische Vorgehen des Nicetius. Er habe nicht erfahren, ob er die Inzestuösen auf kanonische Weise verurteilt oder ob er sie lediglich aus priesterlicher Fürsorge wegen unerheblicher Schuld ermahnt habe ${ }^{156}$. Trotzdem soll Nicetius nicht darüber besorgt sein, dass er diese Leute wieder in die Kirche aufnehme, weil er sich damit in deren Schuld verstricken würde. Es hätte sich, so schreibt Mapinius in unverhohlener Kritik, eher geziemt, zuerst die Unterstützung der Mitbischöfe einzufordern als gleich den

153 Evangelicae lectionis doctrina testatur: 'Regnum in se divisum stare non posse'. Si hoc de mundi amatoribus et in terrena cupiditate manentibus recte et non inmerito credatur, indubitanter rectius de sacerdotum personis sentitur, si discordantibus votis ac studiis inter se dividi conprobentur. Epistulae Austrasicae 11 (MGH Epp. 3, 126).

154 Iteratis scriptis edocuit, beatitudinem vestram, dum aliquos Francorum pro zelo divini timoris corripit ac pro incestis condicionibus a communione ecclesiastica removit, scandala seu anxietates multimodas sustinere. Epistulae Austrasicae 11 (MGH Epp. 3, 126). Eine Emendierung von incestis condicionibus zu incestis coniunctionibus wäre eventuell angebracht.

155 Eine andere Deutung vertritt Malaspina, Liber 2001, 250. Danach hätten die angeklagten Franken an Theudebald appelliert, und dieser hätte zur Lösung des Konflikts eine Synode einberufen. Dies widerspricht jedoch der unten 148 Anm. 157 zitierten Stelle.

156 De qua re non mediocriter ingemescimus, quod nos relatione vestra scire non feceritis, utrum ex canonica lectione damnantur, an pro pastorali diligentia de mediocris reatibus corrigantur. Epistulae Austrasicae 11 (MGH Epp. 3, 126). 
König in diese Angelegenheit einzubinden und durch ihn ein Konzil einberufen zu lassen ${ }^{157}$.

Der in seiner Offenheit wertvolle Brief des Mapinius lässt also keinen Zweifel über die Meinungsverschiedenheit im fränkischen Episkopat. Mapinius spricht deutlich von discordantia vota. Für Nicetius war der Inzest ein schwerer Verstoß gegen das christliche Eherecht und sollte mit sofortiger Exkommunikation bestraft werden. Für die Betroffenen bedeutete dies einen Ausschluss aus der Gemeinschaft der Christen für eine bestimmte Zeit, in der sie keine neue Ehe eingehen durften. Sie gehörten dem Stand der Büßer an. Diese Auffassung kommt deutlich im Konzil von Clermont zum Ausdruck, als der Inzest als Sakrileg, also als schwerer Religionsfrevel, bezeichnet wurde. Mapinius bezeichnet dagegen den Inzest als „geringe Schuld“ und scheint daher die Auffassung des Avitus von Vienne geteilt zu haben. Die Trennung der Eheleute war nach Avitus eine hinreichende Wiedergutmachung, eine Exkommunikation sollte nur bei dauerhaftem Widerstand gegen eine Ehescheidung ausgesprochen werden $^{158}$.

Diese Meinungsverschiedenheit zog weite Kreise und bestimmte die folgende konziliare Gesetzgebung. Bereits der Vater Theudebalds, König Theudebert, war mit dieser Frage befasst, nachdem er vermutlich vom energischen Vorgehen des Nicetius von Trier überrascht worden war. Im Jahr 538 schickte er eine Gesandtschaft an Papst Vigilius, um über das Strafausmaß bei Inzest Auskunft zu erhalten. Dieser Briefwechsel ist das erste Dokument einer Anfrage eines fränkischen Königs an den Papst. Dass die erste päpstliche Dekretale an einen Frankenkönig das Inzestverbot zum Thema hat, unterstreicht die herausragende Bedeutung dieser Frage. Sowohl die Anfrage des Königs als auch die Antwort des Papstes sind nicht erhalten. Unterrichtet werden wir über den Vorgang nur durch den Bescheid des Papstes an den Bischof von Arles, den päpstlichen Vikar in Gallien. Der Fall drehte sich um eine Heirat mit der Frau eines verstorbenen Bruders. Der Papst gab zur Antwort, dass „ein solches Vergehen nicht durch eine kleine Demütigung des Herzens gesühnt werden

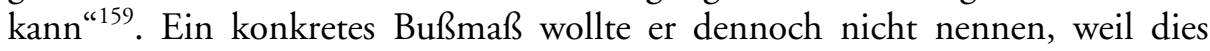

157 Decuerat, ut vestra consolatio pro huiusmodi condicionibus potius quam regiae vocationis nos conserere debuisset ... Epistulae Austrasicae 11 (MGH Epp. 3, 126).

158 Мікат, Inzestgesetzgebung 1994, 81, gibt den Streitpunkt anders wieder. Ihm zufolge forderte Nicetius die Exkommunikation, während Mapinius nur eine Buße verlangte. Diese Deutung erscheint mir jedoch den Sachverhalt nicht zu treffen, da Buße und Exkommunikation dieselben Rechtsfolgen nach sich zogen. Beides bewirkte einen Ausschluss aus der Communio. Das Beispiel des Avitus zeigt m. E. dagegen, dass für ihn und für Gleichgesinnte selbst die Verhängung der Buße problematisch war.

159 Cui nos equidem missis affatibus, quorum tenorem tua fraternitas in subiectis inveniet, hoc indicare curavimus, quoniam tale commissum non parva cordis afflictione valeat expiari. Epistulae Arelatenses genuinae 38 (= JK 906, MGH Epp. 3, 57 f.). 
seiner Auffassung nach in die Kompetenz der ortsansässigen Bischöfe fiel, die über das Ausmaß der persönlichen Reue Bescheid wüssten. Folglich überließ er das konkrete Urteil dem Bischof von Arles und wies nur darauf hin, es solle für eine räumliche Trennung der Eheleute gesorgt werden, damit sie nicht wie ein Hund zu dem zurückkehrten, was sie erbrochen hätten ${ }^{160}$.

Der Bescheid des Papstes befindet sich in Übereinstimmung mit dem Recht der alten Kirche, wie es auf dem Konzil von Neocäsarea festgelegt wurde und in die Kirchenrechtssammlungen Eingang gefunden hat. Der Papst sieht den Inzest als schweres Vergehen an, das durch eine entsprechende Buße gesühnt werden soll. Der befristete Ausschluss von der Kommunion ist darin impliziert. Wenn daher Theudebert eine Auflockerung des Vorgehens von Nicetius, das in Clermont abgesegnet wurde, beabsichtigte, so ist er mit diesem Anliegen gescheitert. Das Votum des Papstes stimmte mit der Regelung von Clermont überein, die die Ehe mit der Frau des verstorbenen Bruders unter dieselbe Strafe gestellt hatte. Wie die abschlägige Antwort konnte auch die Weiterleitung des Falles an Caesarius von Arles von Theudebert als Affront angesehen werden. Denn seit der Eroberung der Provence im Jahre 537 zählte Arles zum Reichsteil seines Bruders Childebert. Eine Unterstellung unter ihn in kirchlichen Fragen hätte er nicht hingenommen. Wegen der Teilung des Frankenreichs ist der gallische Vikariat des Bischofs von Arles zur Wirkungslosigkeit verdammt gewesen ${ }^{161}$.

Ein Wort muss noch zur ethnischen Identität der von Nicetius verfolgten Personen gesagt werden. Im Brief des Mapinius wird eindeutig von „einigen Franken" gesprochen, die der Trierer Bischof um 550 wegen Inzest aus der Gemeinschaft der Kirche ausgeschlossen habe. Dies berechtigt jedoch nicht, das aus Gregor bekannte Vorgehen des Nicetius gegen die Leute Theudeberts im Jahr 533/34 ebenfalls dem Widerstand der fränkischen Germanen zuzuordnen. Das Reich Theudeberts erstreckte sich vorwiegend über Gebiete mit galloromanischer Bevölkerung, und auch seine Berater wie der bekannte Parthenius entstammten zum Teil nicht aus fränkischem Adel $^{162}$. Das gleiche trifft für die Anfrage des Königs bei Papst Vigilius zu. Auch hier sind wir über die ethnische Identität der betroffenen Personen nicht informiert.

Der Brief des Papstes erging am 6. Mai 538. Zwei Tage später tagte in Orléans ein weiteres Reichskonzil. Am 3. Konzil von Orléans nahmen nur Bischöfe aus den Teilreichen Childeberts und Theudeberts teil, weil sich

160 ... illud quam maxime praecavendo, ut nec ipse, qui hoc noscitur admisisse, ad eosdem vomitus revertatur, sed divisis etiam habitationibus commanentes ab omni suspicione commissi facinoris reddantur inmunes. Epistulae Arelatenses genuinae 38 (= JK 906, MGH Epp. 3, 58).

161 Caspar, Geschichte 2 1930, 234-236.

162 Collins, Theodebert I 1983; Beisel, Theudebertus 1993. 
Chlothar mit seinen Brüdern überworfen hatte ${ }^{163}$. Obwohl nur wenige Jahre seit Clermont vergangen waren, gab es keine personellen Überschneidungen zwischen den beiden Konzilien. In Bourges amtierte inzwischen ein anderer Bischof, und die Amtsträger aus dem fränkischen Austrasien waren der Versammlung von Orléans allesamt ferngeblieben. Dominiert wurde das Konzil von den zentral- und westfranzösischen Metropolitanbezirken Bourges, Sens, Rouen, Lyon und Vienne. Diese veränderte geographische Verteilung schlug sich in einer Verschiebung der Mentalität nieder ${ }^{164}$. Anders als in Clermont wurden klare Worte gegen den Einfluss des Adels auf die Kirche vermieden. Die für merowingische Konzilien typische Stärkung der Hierarchie und der Disziplinierung des Klerus kam ohne Seitenhiebe auf den verderblichen Einfluss der Adeligen aus.

Diese mildere Haltung prägte auch die umfangreiche Bestimmung zum Inzest in Kanon 11. Die Regelung beginnt mit der von Mikat so genannten „Toleranzklausel“:

„Hinsichtlich der inzestuösen Verbindungen sollen die Vorschriften in der Weise beachtet werden, dass wir betreffs derjenigen, die entweder gerade zur Taufe kommen oder denen die Vorschriften der Väter durch priesterliche Unterweisung nicht vorher zur Kenntnis gekommen sind, angesichts der Kürze des Glaubenswechsels den Beschluss fassen zu müssen glaubten, dass die bis dahin geschlossenen Ehen nicht aufgelöst werden sollen "165.

Erst in der Zukunft sollten sich alle an die Inzestverbote des Konzils von Epaon halten, die mit Ausnahme des Verbots der Ehe mit der Stieftochter allesamt genannt werden. Diese Toleranzklausel hat ihr Vorbild in der oben beschriebenen Klausel des Konzils von Epaon, wonach das neue Verbot der Ehe mit der Cousine ersten und zweiten Grades erst vom Stichtag des Konzils an zu gelten hatte. Die fränkischen Bischöfe erweiterten diese Klausel in Orléans auf alle Inzestverbindungen innerhalb der erweiterten Verwandtschaft. Eine Dispensierung vom Verbot der Heirat mit den direkten Deszendenten bzw. Aszendenten war selbstverständlich nicht vorgesehen.

163 Pontal, Synoden 1986, 78-85.

164 Unterschiedliche Strömungen innerhalb des Episkopats versucht Magnou-Nortier, Géographie 1997, auszumachen. Königskritische Tendenzen verortet sie vor allem in Burgund. Gerade am 3. Konzil von Orléans nahmen jedoch mehr Bischöfe aus Burgund teil als wenige Jahre zuvor in Clermont.

165 De incestis coniunctionibus ita quae sunt statuta serventur, ut his, qui aut modo ad baptismum veniunt aut quibus patrum statuta sacerdotali praedicatione in notitiam ante non venerunt, ita pro novitate conversationis hac fidei suae credidimus consolendum, ut contracta hucusque coniugia non solvantur, sed in futurum, quod de incestis coniunctionibus in anterioribus canonibus interdictum est, observetur. 3. Konzil von Orléans (538) c. 11 (MGH Conc. 1, 76). 
Mikat hat zu Recht auf das römisch-rechtliche Konzept der ignorantia iuris hingewiesen, das der Toleranzklausel von Orléans Pate gestanden hat ${ }^{166}$. Bereits bei der Ausweitung des römischen Bürgerrechts auf Ägypten mussten die Inzestvorschriften an die örtlichen Gewohnheiten angepasst werden ${ }^{167}$. Fragwürdig ist jedoch Mikats Deutung, die Bischöfe hätten mit der Toleranzklausel auf den Widerstand der Franken gegen die christlichen Inzestvorschriften Rücksicht genommen. Zum einen setzt dies eine vollständige Christianisierung der galloromanischen Bevölkerung auf dem Land voraus, was für diese Zeit kaum zutrifft $^{168}$. Zum anderen spricht der Text eindeutig davon, dass nicht nur die neu Bekehrten anvisiert sind, sondern auch diejenigen, die von der Vorschrift bislang keine Kenntnis genommen hatten. Diese Gruppe muss ohne Zweifel groß gewesen sein, da das Verbot der Heirat mit der Cousine ersten und zweiten Grades hier zum ersten Mal auf gesamtfränkischer Ebene erlassen worden war. Im römischen Recht gab es ja bei der Cousinenehe die Möglichkeit der Dispensierung, und im kirchlichen Recht wurde dieses Verbot erstmals in Epaon und Clermont ausgesprochen. Beide Konzilien hatten jedoch ein geographisch beschränktes Einzugsgebiet. Wenn also die Bischöfe kirchenrechtliche „Vorschriften" erwähnen, so waren diese bislang noch gar nicht existent. Die oben erwähnte Polemik gegen die Cousinenehe, die Gregor von Tours seiner galloromanischen Leserschaft vorhält ${ }^{169}$, bezeugt das Unwissen und den Widerstand gegen eine Ausweitung der Inzestvorschriften innerhalb der nicht-fränkischen Bevölkerung. Unterstützt wird diese Sichtweise von der geographischen Verteilung der Teilnehmer am 3. Konzil von Orléans. Bistümer mit vorwiegend fränkischer Siedlung waren überhaupt nicht vertreten. Die Kanones spiegeln die Sorgen und Nöte des galloromanischen Episkopats mit ihrer galloromanischen Bevölkerung.

Eine eingehende Betrachtung verdient auch der zweite Teil des Kanons 11. Darin heißt es, dass

„es der Prüfung durch den Bischof obliegt, ob die, die in seiner Stadt oder auf deren Gebiet leben und durch eine solche Ordnung verbunden sind, unwissentlich die unerlaubte Ehe eingegangen sind oder ob sie aus Ungehorsam die Verbote zu

166 Miкaт, Inzestgesetzgebung 1994, 52.

167 Siehe 43.

168 Auch Hen, Culture 1995, 154-206, geht von einer vollständigen und flächendeckenden Christianisierung Galliens im 6. Jahrhundert aus. Die gar nicht so seltenen Kanones gegen heidnische Relikte muss er folglich wenig überzeugend als Phantasie der Kleriker entlarven. Neben den Konzilskanones lässt auch das Gesetz Childeberts I. gegen Religionsfrevel andere Zustände erahnen, vgl. WeIdemann, Kulturgeschichte 2 1982, 157 161; Zeddies, Religio 2003, 134 f.; Glatthaar, Bonifatius 2004, 531. Eine ausgewogene Darstellung bei Markus, Caesarius 1992, 159-163; Brown, Rise 2003, 145147.

169 Siehe 88. 
übertreten gewagt haben; denn wie diesen, die aus Unkenntnis gefehlt haben, geholfen wird, so werden gegenüber denjenigen, denen vorher die Satzungen der Väter zur Kenntnis gekommen waren und die sogar gegen priesterliches Verbot in solcher Verbindung verharren, alle Verordnungen der früheren Kanones aufrechterhal$\operatorname{ten}^{\text {“170. }}$

Wie im zeitgleich abgesandten Papstbrief wird also das konkrete Vorgehen in die Zuständigkeit des Bischofs gestellt. Die Strafbestimmung unterscheidet sich jedoch deutlich von der päpstlichen Dekretale. Die Inzestuösen „werden nicht eher wieder in die Gemeinschaft aufgenommen, bis sie das blutschänderische Verhalten, wie geschrieben steht, durch die Trennung wieder gutgemacht haben. ... Daraus folgt, dass wir die, die Gott verflucht hat, nur segnen können, wenn sie ihren Fehler wieder gutgemacht haben "171. Mit den Worten separatione sanaverint zitieren die Bischöfe den Kanon des Konzils von Epaon und bekennen sich zu dessen milder Strafpraxis. Die Trennung der Ehepartner ist mit der Wiedergutmachung gleichzusetzen. Exkommunikation und Buße sind nur dann erforderlich, wenn die Eheleute ein ausdrücklich erlassenes Verbot der Priester missachtet haben.

So mancher Bischof hat sich mit dieser milden Strafpraxis nur schwer abgefunden. Einer von ihnen war sicher der abwesende Nicetius von Trier. Ein anderer war der anwesende Bischof Albinus von Angers. Eine Ironie der Geschichte hat ihn in späteren Quellen zum Autor der Kanones des 3. Konzils von Orléans erhoben ${ }^{172}$. Dass das Gegenteil davon wahr ist, bezeugt die Lebensbeschreibung des Bischofs aus der Feder des Venantius Fortunatus. Als besonderes Zeugnis der Seelengröße des Heiligen wertet Venantius sein Vorgehen gegen Inzestehen in der Nachfolge Johannes' des Täufers.

170 Illud quoque adiciendum esse credidemus, ut in episcopi discussione consistat de his, qui in civitate sua hac territorio consistunt et tali sunt ordine sociati, utrum ignoranter ad inlicita coniugia venerint, an per contumaciam, quae sunt interdicta, praesumpserint; quia, sicut his, qui per ignorantiam lapsi sunt, subvenitur, ita illis, quibus prius patrum statuta in notitia venerunt quique etiam contra sacerdotum interdicta in tali permixtione versantur, priorum canonum in omnibus statuta serventur. 3. Konzil von Orléans (538) c. 11 (MGH Conc. 1, 76 f.).

171 ... ut non prius in communione recipiantur, quam incesti adulterium, sicut scriptum est, separatione sanaverint, quia in lege Domini manifeste legitur: 'Maledictus qui dormierit cum uxore patris sui, cum privigna vel sorore uxoris suae' et reliqua his similia. Quo fit, ut, quos Deus maledixit, nos nisi emendatos benedicere non possimus. 3. Konzil von Orléans (538) c. 11 (MGH Conc. 1, 77).

172 In der Collectio vetus Gallica LXIII 20 (594) firmiert Albinus in der Liste der Bischöfe an erster Stelle. Daraus leitete ein anonymer Autor die Verfasserschaft des Albinus ab: Lippert, Verfasserschaft 1889, 28. Lippert hielt dies für glaubwürdig, obwohl in der authentischen Liste der Subskriptionen Albinus nicht an erster Stelle steht. Pontal, Synoden 1986, 79, stimmte dieser Auffassung zu. Widerspruch erhob erstmals Miкat, Orléans 1993, 17. 
„Wie viel er deswegen erdulden musste, kann niemand auf würdige Weise erzählen. Er hätte ja Märtyrer werden wollen, wenn nicht die Hand des Mörders gefehlt hätte. Aber er, der das Begehren nach diesem Wunsch nicht versteckte, verdiente dennoch ohne Zweifel die Krone des Martyriums. Daher nahm er häufig neben den übrigen Mühsalen noch die Reise zu Synoden auf sich, die deswegen anberaumt worden waren. Schließlich wurde er auf Befehl und sogar mit Gewalt vieler Bischöfe dazu gezwungen, einer von ihm exkommunizierten Person die Absolution zu erteilen. Als man ihn auch noch gebeten hatte, die Eulogien, die die übrigen Bischöfe für diese von der Kommunion suspendierte Person bereits geweiht hatten, auch selbst mit dem Zeichen des Kreuzes zu segnen, sprach er zum bischöflichen Kollegium: ,Wenn ich auf euren Befehl zur Segnung gezwungen werde, ist Gott selbst mächtig genug zu bestrafen, solange ihr euch weigert, die Sache Gottes zu verteidigen'. Nach dieser Rede hauchte die exkommunizierte Person ihr Leben aus, noch bevor sie die Eulogien in den Mund nehmen konnte ${ }^{\text {“173. }}$.

Es ist nicht unwahrscheinlich, dass sich dieser Vorfall auf dem 3. Konzil von Orléans zugetragen hat. Albinus ist nur auf diesem und auf dem folgenden Konzil aus dem Jahre 541 nachweisbar. Für das Jahr 538 spricht der Erlass einer ausdrücklich milden Bestimmung zum Inzest, gegen die Albinus mit einiger Berechtigung opponiert hätte. Die Vita des Venantius macht eine ähnlich rigorose Haltung des Bischofs deutlich, wie sie Nicetius von Trier an den Tag legte. Wegen Inzest exkommunizierte Personen sollten nicht als Zeichen der christlichen Konfession die bei der Messe geweihten Brote, die Eulogien, erhalten. Unklar bleibt aufgrund des dürftigen Berichts, ob die des Inzests überführten Personen sich bereits zur Trennung bereit fanden oder ob sie sich der Trennung noch widersetzten. Letztes erscheint nicht plausibel, da sonst die übrigen Bischöfe kaum auf eine Absolution hingewirkt hätten. Dass der hartnäckige Ungehorsam in dieser Frage die Exkommunikation zur Folge hatte, war Konsens innerhalb des fränkischen Episkopats. Albinus dürfte daher die Trennung nicht als ausreichende Wiedergutmachung für das Inzestvergehen angesehen und eine Buße eingefordert haben.

173 Sed et hoc magnanimitatis exemplum oportunum ducitur explicandum, quod pro dei negotio apud eum non fuerit ulla regum potentumque personalis acceptio. Denique ad cumulum caelestis gratiae conquirendum incestarum nuptiarum execrabiles copulationes iure condempnans, beatum Iohannem inreprehensibiliter imitabatur. Quanta vero inde sustinuerit, nullus digne poterit explicare: siquidem martyr effici cuperet, si non defuisset dextera percussoris, sed procul dubio palmam martyrii meruit qui voti desideria non abscondit. Unde praeter labores reliquos etiam per synodos pro ipsa causa saepius excitatas excurrens, ad postremum quam plurium episcoporum iniunctione ut excommunicatas a se personas absolveret vi fratrum coactus est. Et cum rogaretur, ut eulogias, quas reliqui antestites ad personam communione suspensam dirigentes benedixerant, et ipse signaret, ait ad sacerdotale concilium: 'Etsi ad imperium vestrum ego signare conpellor, dum vos causam dei recusatis defendere, ipse potens est vindicare'. Quo facto, antequam eulogias excommunicata persona in ore susciperet, expiravit, et priusquam portitor perveniret, sermo sacerdotis obtinuit ... Venantius Fortunatus, Vita Albini 18 (MGH Auct. Ant. 4/2, 32). 
Die Vita des Venantius Fortunatus berichtet außerdem von einer Reise des Albinus zu Caesarius von Arles ${ }^{174}$. Albinus suchte bei dem für seine Strenge bekannten päpstlichen Vikar in Gallien Rat und Hilfe für sein Vorgehen gegen Inzestehen. Der Arelatenser Metropolitanbezirk zählte damals schon zum Frankenreich, war aber noch nicht auf dem 3. Konzil von Orléans präsent. Der Bischofssitz des Albinus gehörte ebenso wie Arles zum Teilreich Childeberts. Ob Albinus mit dieser Hinwendung zum päpstlichen Vikar Erfolg hatte, ist unbekannt. Da die herausgehobene Stellung von Arles im Sinken begriffen war, ließen sich die fränkischen Bischöfe wahrscheinlich nicht von Caesarius belehren.

Das nächste Konzil tagte 541 wiederum in Orléans. Die Bischöfe aus der Provence nahmen erstmals teil und machten die Synode mit 54 Teilnehmern zu einer der größten Kirchenversammlungen. Vertreter aus den Kirchenprovinzen Belgica und Germania fehlten allerdings. Im Mittelpunkt standen wieder die Stärkung der kirchlichen Hierarchie und Gerichtsbarkeit. Zwei Kanones, die den Rückfall in das Heidentum unter Kirchenstrafen stellen, belegen die fortwährenden Bemühungen um die Mission im Inneren ${ }^{175}$. Der Inzest wird nur kurz in Kanon 27 angesprochen. „Wir bestimmen, bei inzestuösen Verbindungen folgendes einzuhalten: dass, wenn jemand nach der vor drei Jahren stattgefundenen Synode von Orléans eine unerlaubte Ehe einzugehen wagte, von den Bischöfen der Kirche die Strenge gemäß den Erlassen von Epaon eingehalten wird“176. Wieder wird also die Bestimmung von Epaon als vorbildlich anerkannt. Die vor drei Jahren erlassene Toleranzklausel sollte nicht aufgehoben ${ }^{177}$, sondern mit dem Stichtag des 3. Konzils von Orléans beibehalten werden. Für Neubekehrte sollte weiterhin die Toleranzklausel gelten, während die Unkenntnis des Inzestverbots durch das vorangegangene Konzil als behoben betrachtet wurde. Die starke personelle Kontinuität zwischen dem 3 . und 4. Konzil von Orléans schlägt sich in dieser Bestimmung nieder.

Auf dem 5. Konzil von Orléans erreichte die Anzahl der Teilnehmer einen Höhepunkt in der merowingischen Geschichte. 71 Bischöfe aus dem gesamten Frankenreich fanden sich auf Befehl König Childeberts I., Senior des merowingischen Hauses, zusammen. Nach dem 1. Konzil von Orléans wurde auf dieser Versammlung wieder der drückende Einfluss eines Königs spürbar. Erstmals gestanden die Bischöfe dem König explizit das Mitspracherecht bei

174 ... qui etiam ad beatum Caesarium Arelatensem praesulem pro ipsa causa consulturus occurrit. Venantius Fortunatus, Vita Albini 18 (MGH Auct. Ant. 4/2, 32).

175 4. Konzil von Orléans (541) c. 15-16 (MGH Conc. 1, 90).

176 De incestis coniunctionibus id statuimus observandum, ut si quisquis post synodum Aurilianensem ante hoc triennium constitutam inliciti thori iura praesumpserit, circa eum secundum statuta Epaunensium canonum a sacerdotibus ecclesiae severitas teneatur. 4. Konzil von Orléans (541) c. 27 (MGH Conc. 1, 93).

177 Мікат, Inzestgesetzgebung 1994, 75. 
Bischofswahlen zu, das schon seit Beginn des Frankenreichs ausgeübt worden war ${ }^{178}$. Der Schwerpunkt der Bestimmungen lag jedoch ein weiteres Mal auf der Disziplinierung des Klerus. Das gesamte Programm wird in der Einleitung zu den Kanones als Eintracht zwischen den Wünschen des Königs und dem Standpunkt der Bischöfe ausgegeben ${ }^{179}$. Nicht alle Bischöfe waren mit dieser Scheinwelt der Eintracht zufrieden. Konflikte innerhalb des Episkopats kommen in Kanon 2 zum Ausdruck: „Kein Bischof darf einen rechtgläubigen Menschen wegen kleiner und unerheblicher Gründe von der Kommunion suspendieren, sondern alleine für solche Vergehen, für die die alten Väter den Ausschluss der Übeltäter aus der Kirche beschlossen haben “180. Diese Anordnung entspricht der oben erwähnten Kritik des Mapinius von Reims an Nicetius von Trier. Mapinius zeigte sich von der Eilfertigkeit überrascht, mit der Nicetius „einige Franken“" wegen eines unerheblichen Vergehens von der Kommunion ausschloss. Mapinius stellte ebenso wie der Kanon die „vormalige Sorgfalt der Väter" der übereifrigen Strenge des bischöflichen Amtskollegen gegenüber ${ }^{181}$. Der Brief des Mapinius ist zwar nicht datiert, lässt sich aber derselben Zeit zuordnen wie das 5. Konzil von Orléans, auf dem Mapinius und Nicetius anwesend waren ${ }^{182}$. Der Streit um die Exkommunikation stand auch im Mittelpunkt des Konflikts des Albinus von Angers mit den übrigen Bischöfen des Frankenreichs. Albinus weigerte sich, die wegen Inzest exkommunizierten Personen an der christlichen Gemeinschaft teilhaben zu lassen.

Die Erwähnung der antiqui patres gibt einen Schlüssel für das Verständnis der Ursache dieses Konflikts zwischen den Bischöfen. Die Kanones der alten Kirche haben nur für bestimmte Vergehen die Exkommunikation vorgesehen und zwar für die Verbindung mit der Schwägerin bzw. den Schwager. Die Exkommunikation für eine Ehe unter Stiefverwandten beruhte auf dem exemplarischen Vorgehen des Paulus in Korinth. Die übrigen Inzestvergehen dürften nach der Meinung der Konzilsväter von Orléans nicht mit derselben Strenge geahndet werden. Der Konflikt kreiste daher nicht nur um die konkrete Vorgehensweise gegen inzestuöse Personen, sondern auch um die Grundlage der einzelnen Inzestverbote.

178 5. Konzil von Orléans (549) c. 10 (MGH Conc. 1, 103). Vgl. Claude, Bestellung 1963, 62; NonN, König 1998, 34.

179 Ad divinam gratiam referendum est, quando vota principum concordant animis sacerdotum ... 5. Konzil von Orléans (541) prol. (MGH Conc. 1, 100).

$180 U t$ nullus sacerdotum quemquam recte fidei hominem pro parvis et levibus causis a communione suspendat, praeter eas culpas, pro quibus antiqui patres ab ecclesiam arciri iusserunt committentes. 5. Konzil von Orléans (541) c. 2 (MGH Conc. 1, 101).

181 Licet nibil novi vos de his rebus invenire posse cognoscimus, quod prisca patrum sollertia non potuit repperire ... Epistulae Austrasicae 11 (MGH Epp. 3, 126).

182 Die Herausgeber Gundlach und Malaspina, Liber 2001, 112, datieren ca. 550. 


\section{Verschärfung im Zeichen der Krise}

Mit dem 5. Konzil von Orléans ging die Zeit der intensiven Zusammenarbeit von König und Episkopat zu Ende. Die Konzile von 533 bis 549 trugen den Stempel der kirchenfreundlichen Politik Childeberts I., der als ältester Sohn Chlodwigs nach dem Tod seines Halbbruders Theuderich dominanten Einfluss im Frankenreich ausübte. Die Inzestverbote gingen auf das Vorbild der Bestimmung von Epaon zurück und versuchten vor allem die neuartige Ausweitung auf die Cousine ersten und zweiten Grades mit Zurückhaltung in der Praxis abzumildern. Eine Ausnahme ist das Konzil von Clermont, das unter der Ägide Theudeberts einberufen worden war und zur strengen Handhabung des Inzestverbots mahnte. Diese Minderheitsmeinung ist von den beiden Einzelkämpfern Nicetius von Trier und Albinus von Angers erfolglos verfochten worden. Nach der Jahrhundertmitte verschoben sich die Akzente. Anlass dafür war ein Eklat, der durch zwei Inzestehen merowingischer Könige ausgelöst wurde. Chlothar I. versuchte durch die Heirat mit Waldrada, der Frau seines verstorbenen Großneffen, seine Aussichten auf die Erbschaft des austrasischen Teilreichs zu erhöhen. Anders als dreißig Jahre zuvor, als seine vorangegangenen Inzestehen unbeanstandet geblieben waren, meldete sich diesmal der Episkopat zu Wort und untersagte ihm die Heirat ${ }^{183}$. Die Ehe mit der Witwe des Großneffen war zwar nicht ausdrücklich in den Inzestverboten enthalten ${ }^{184}$, konnte aber aus den bisherigen Verboten abgeleitet worden. Chlothar lenkte ein und gab Waldrada seinem Getreuen Garibald, dem Herzog der Bayern, zur Frau. Einige Jahre später geriet der Sohn Chlothars, Charibert, in das Kreuzfeuer der bischöflichen Kritik. Charibert ahmte die von seinem Vater praktizierte Vielehe nach und gesellte zwei Schwestern, Marcoveifa und Merofledis, seinem ,Harem hinzu. Da die Schwestern Töchter eines Wollarbeiters waren, verbargen sich hinter dieser Heirat keine politischen Motive. Bischof Germanus von Paris, der in der Hauptstadt des Charibert-Reiches residierte, verhängte über den König die Exkommunikation ${ }^{185}$. Anders als sein Vater gab Charibert nicht klein bei

183 ... regnumque eius Chlothacharius rex accepit, copulans Vuldotradam, uxorem eius, stratui suo. Sed increpitus a sacerdotibus, reliquit eam, dans ei Garivaldum ducem. Gregor von Tours, Decem libri historiarum IV 9 (MGH SS rer. Merov. 1/1, 141).

184 Esmyol, Geliebte 2002, 51, führt deshalb die Scheidung auf politische Beweggründe zurück. Warum fühlten sich die Bischöfe dann aber zum Eingriff ermächtigt?

185 Post haec Marcoveifa, Merofledis scilicet sororem, coniugio copulavit. Pro qua causa a sancto Germano episcopo excommunicatus uterque est. Sed cum eam rex relinquere nollit, percussa iuditio dei obiit. Ne multo post et ipse rex post eam decessit. Gregor von Tours, Decem libri historiarum IV 26 (MGH SS rer. Merov. 1/1, 158 f.). EwIG, Studien 1974, 30, meint, die Heirat sei wegen der Zugehörigkeit Marcoveifas zum Stand der Nonnen diskrediert worden. Dagegen spricht jedoch der Bericht Gregors, der die Worte pro qua causa unmittelbar mit der Tatsache der Verwandtschaft der beiden Schwestern zusammenbringt. Vgl. Esmyol, Geliebte 2002, 50. 
und rief damit in den Augen des Chronisten Gregors von Tours die Rache Gottes auf den Plan, der den Tod Marcoveifas herbeiführte. Wenig später starb auch der König.

Zwischen dem Tod Marcoveifas und dem Ableben des Königs fand ein Konzil in Tours statt. Es versammelte die Bischöfe unter Chariberts Herrschaft und gab vor, mit „Duldung des sehr ruhmreichen Königs“ einberufen worden zu $\operatorname{sein}^{186}$. Da das Konzil in einer überaus langen Inzestbestimmung die Ehe Chariberts verurteilte, erschließt die Forschung eine späte Reue des Königs kurz vor seinem $\operatorname{Tod}^{187}$. Nach dem Tod Marcoveifas hatte er keinen Grund, die Bestrebungen der Bischöfe zu durchkreuzen. Auf den Inhalt der Kanones, in denen erstmals offen königskritische Stimmen zum Durchbruch gelangten ${ }^{188}$, hat Charibert aber nicht eingewirkt. Schon in Kanon 1 wurde das Fernbleiben der Bischöfe von Synoden angeprangert und die Dispensierung von Seiten des Königs als ungültig angesehen. „Ein königliches Gebot darf nicht dem geistlichen Werk vorgezogen werden", betonten die Bischöfe in ungewohnter Schär$\mathrm{fe}^{189}$. Hintergrund dieser Bestimmung ist vielleicht die geringe Beteiligung in Tours. Es fanden sich nur 9 Bischöfe ein, obwohl das Reich Chariberts fast 40 Bistümer umfasste. Der Kanon 25 klagte den Bürgerkrieg zwischen den Königen als Ursache für unrechtmäßige Entfremdungen von Kirchengut an und bedrohte jeden Verstoß gegen die Unverletzlichkeit des kirchlichen Eigentums mit dem Anathem. Die Freizügigkeit, mit der auch in anderen Kanones des Konzils das Anathem verhängt wurde, zeugt von der Kampfbereitschaft des selbstbewussten Episkopats ${ }^{190}$.

Diese Härte kommt auch in der Inzestbestimmung zum Ausdruck, dem längsten Kanon der gesamten merowingischen Konzilsgeschichte. Wie Paul Mikat zu Recht diagnostizierte, beginnt der Kanon mit einem „Eingeständnis der Unzulänglichkeit der bisherigen pastoralen Bemühungen“191. Die Bischöfe räumten ein:

„Es war notwendig, die Bestimmungen der Kanones zu wiederholen, weil viele sagen, dass ihnen gewissermaßen aus Nachlässigkeit der Vorgängerbischöfe dies

186 ... iuxta coniventiam gloriosissimi domni Chariberthi regis adnuentis ... 2. Konzil von Tours (567) prol. (MGH Conc. 1, 122).

187 Vgl. Pontal, Synoden 1986, 128-135; Мікат, Inzestgesetzgebung 1994, 48.

188 Clerce, Législation 1 1936, 40; Suntrup, Studien 2001, 98.

189 Non debet spiritali opere etiam regalis preferre praeceptio ... 2. Konzil von Tours (567) c. 1 (MGH Conc. 1, 122).

190 2. Konzil von Tours (567) c. 25 (MGH Conc. 1, 134). Das Anathem wird in Tours ingesamt dreimal verhängt (neben c. 25 noch c. 2 und c. 5), während es in der ersten Jahrhunderthälfte nur ausnahmsweise in Aussicht gestellt wurde: 2. Konzil von Orléans (533) c. 10 (MGH Conc. 1, 63); 5. Konzil von Orléans (549) c. 15 (MGH Conc. 1, 105).

191 Мікат, Inzestgesetzgebung 1994, 82. 
nicht eröffnet wurde. Aber in Wahrheit lügen sie, weil wir wissen, dass Männer von solchem Schlag keineswegs dieser Nachlässigkeit unterlagen, sondern dass sie beharrlich predigten, was die heiligen Schriften darlegen "192.

Um dieser erlogenen Unterstellung ein für allemal den Boden zu entziehen, stellten die Bischöfe in Tours ein umfangreiches Dossier aus Zitaten zusammen. Es beginnt mit den Eheverboten aus Levitikus und den Verfluchungen aus Deuteronomium. Es folgen die Kurzfassungen zweier Gesetze aus dem Codex Theodosianus. Sie werden bezeichnet als „heilige Verfügung der Gesetze, die in dieser Auslegung jedem Menschen, dem ungelehrten und gelehrten, zugänglich sind“193. Abgeschlossen wird das Dossier durch die Bestimmungen des 1. Konzils von Orléans, des Konzils von Epaon und des Konzils von Clermont.

Zuletzt wandten sich die Bischöfe der Frage der Bestrafung zu. Das Bekenntnis zur rigorosen Linie des Albinus von Angers und des Nicetius von Trier ist unüberhörbar: „Wir bekräftigen in jeder Hinsicht die Bestimmungen unserer Väter, weil wir durch Befehl des Herrn und durch die Predigt des Apostels belehrt werden, dass unsere Söhne von uns vielmehr durch Strenge zurechtgewiesen werden, als dass sie durch feige Nachsicht zu schwerwiegenderen Taten entfesselt werden sollen "194. Die Verfluchungen aus Deuteronomium und das Vorgehen des Paulus in Korinth werden zum Maßstab für die Praxis erhoben. Ein langes Zitat aus dem ersten Korintherbrief stützt dieses Bekenntnis ab. Kritik an dem rigorosen Vorgehen wird offen zurückgewiesen: „Niemand soll uns für vermessen halten, wenn wir in der Nachfolge des Apostels jeden von der Kirche trennen, bis er sich besinnt und zum ewigen Leben zurückkehrt, das er durch unseren Herrn Jesus Christus und die Taufe verdient hat "195. Diese übereifrige Abwehr möglicher Widerstände ist ein weiteres Indiz für die unterschiedlichen Standpunkte innerhalb des Episkopats.

Die geringe Teilnehmerzahl am Konzil von Tours macht wie beim Konzil von Clermont die Frage nach persönlichen Einflüssen möglich. An erster Stelle muss Bischof Germanus von Paris genannt werden, denn er hatte kurz vor dem

192 Sed propterea fuit iterare necessarium, quia dicunt plures, quasi quod precessorum neglegentiam sacerdotum illis non fuisset apertum; sed revera mentiuntur, cum sciamus tales et tantos viros nullatenus huic neglegentiae subiacuisse, sed hoc, quod scripturae sanctae testantur, assiduae praedicasse. 2. Konzil von Tours (567) c. 22 (MGH Conc. 1, 131).

193 Itemque ait sacra sententia legum, que in hac explanatione omni homini, tam docto quam indocto aperta est, ... 2. Konzil von Tours (567) c. 22 (MGH Conc. 1, 132).

194 Nos hoc, quod patres nostri statuerunt, in omnibus roboramus, quia praecepto Domini apostolo praedicante docemur, ut a nobis filii nostri severitate potius corrigantur, quam ignava tepiditate ad perpetranda graviora laxentur ... 2. Konzil von Tours (567) c. 22 (MGH Conc. 1, 133).

195 Non nos presumptiosos exestimet homo, si sequentes apostolum quemquam ab ecclesia segregamus, donec reminiscatur et revertatur ad vitam, quam per Dominum nostrum Iesum Christum et baptismum meruit habere perpetuam ... 2. Konzil von Tours (567) c. 22 (MGH Conc. 1, 133). 
Konzil König Charibert und seine Frau Marcoveifa wegen Inzest exkommuniziert. Ian Wood hat ferner auf die verwandtschaftlichen Beziehungen zwischen dem Vorsitzenden Eufronius von Tours und Gregor von Langres hingewiesen ${ }^{196}$. Gregor, Teilnehmer am rigorosen Konzil von Clermont, war der Großvater des Eufronius. Diese Beobachtung wird von der Formulierung gestützt, mit der das Konzil von Clermont in Tours eingeführt wird: die Kanones wurden im Unterschied zu den beiden anderen Konzilien von beatissimi patres erlassen ${ }^{197}$. Die Werke Gregors von Tours belegen, dass sowohl Gregor von Langres als auch zwei weitere Teilnehmer in Clermont, Nicetius von Trier und Gallus von Clermont, als Heilige angesehen wurden. Gregor von Tours selbst war mit allen diesen Personen verwandt ${ }^{198}$.

Auf den kleinen Konzilien von Clermont und Tours setzte sich also die Position einer Minderheit im Episkopat durch, die besonders stark in der gallorömischen Senatorenfamilie des Gregor von Tours verankert war. Mit ihrem rigorosen Eintreten für die Inzestverbote haben sich einzelne Bischöfe den Nimbus der Heiligkeit erworben und konnten von Gregor von Tours als Schutzherrn des Heiligen in Szene gesetzt werden. Richtete sich dieses radikale Vorgehen gegen die Widerstände von fränkischer Seite? Das Konzil von Tours gibt keine direkten Hinweise darauf, wer weiterhin die Unwissenheit über die Gesetzeslage für sich reklamierte. Indirekt gaben die Bischöfe jedoch preis, dass sie kaum auf die in ihren Diözesen nur mäßig vertretene fränkische Bevölkerung abzielten. Die Vorstellung, ,jedem gelehrten und ungelehrten Menschen“ müssten die Gesetze des römischen Rechts bekannt sein, erweist sich bereits für die gallorömische Bevölkerung als eine maßlose Übertreibung und verliert erst recht für die fränkischen Einwohner jeden Sinn. Die Bischöfe haben daher weniger die vergangene Inzestehe Chariberts als die Unwissenheit der gallorömischen Bevölkerung an den Pranger gestellt. Geflissentlich übergangen wurde dabei die Tatsache, dass die Ausweitung der Inzestverbote für viele Einwohner eine erstmals 538 ins Werk gesetzte Neuerung darstellte.

Kurz nach dem Tod Chariberts trafen sich einige Bischöfe seines Reiches erneut zu einer Synode in Paris. Sechs Teilnehmer des Konzils von Tours 567 waren in Paris ebenfalls anwesend, darunter der Bischof Germanus von Paris und die beiden Metropoliten Eufronius von Tours und Praetextatus von Rouen. Nach dem Tod des Herrschers wurde das Reich unter seinen drei Brüdern ohne Rücksicht auf die Bildung geschlossener Herrschaftskomplexe zerstückelt ${ }^{199}$. Die

196 Wood, Incest 1998, 301.

197 In canones Arvenus a beatissimis patribus sic habetur insertum ... 2. Konzil von Tours (567) c. 22 (MGH Conc. 1, 132).

198 Vgl. Stroheker, Adel 1948, 183 f.; Heinzelmann, Gregor 1994, 10-21. Mit Nicetius von Trier war Gregor vielleicht über seine Nichte, die einen Grafen Nicetius aus der Auvergne ehelichte, verschwägert: vgl. EwIG, Trier 1954, 98.

199 Vgl. Ewig, Teilungen 1953, $138 \mathrm{f}$. 
meisten der in Paris anwesenden Bischöfe gehörten nun dem Reich Chilperichs an, ein kleinerer Teil den Herrschaftsgebieten Gunthrams und Sigiberts. Das Herz Galliens um Paris wurde unter gemeinsame Verwaltung gestellt. Der Zeitpunkt der Kirchenversammlung ist umstritten, zumal das Konzil selbst keine Angaben macht und auch der Verweis auf königliche Mitwirkung fehlt. Entscheidend für die Datierung ist jedoch der erste Kanon, in dem das Konzil von Tours wortwörtlich zitiert und um einige redundante Bestimmungen ergänzt wurde ${ }^{200}$. Das Konzil fand demnach zwischen 567, dem Konzil von Tours, und 573, dem Tod des Eufronius von Tours, statt. Die Formulierung der Einleitung zu den Kanones legt nahe, dass der Streit um das Charibert-Erbe bereits im vollen Gange war ${ }^{201}$.

Das Fehlen eines Hinweises auf königliche Mitwirkung macht bereits die königskritische Tendenz sichtbar. Sie erreicht in Paris einen Höhepunkt ${ }^{202}$. In Kanon 1 werden die Schutzbestimmungen für das Kirchengut, die in Tours erlassen worden waren, durch eine Kritik am königlichen Verhalten ergänzt. Die in Tours verhängten Kirchenstrafen sollten auch für diejenigen gelten, die sich Kirchengut durch den Schein königlicher Freigiebigkeit erschlichen haben. „Allzu spät wurden wir, die wir durch die Last der Unrechtstaten belastet worden waren, zum Widerstand angeregt, da uns auch der durch unsere Herren

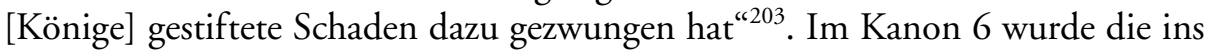
weltliche Recht übergreifende Bestimmung erlassen, dass weder die Bischöfe noch die Fürsten oder das Volk fremdes Eigentum vom König zu erreichen wagen sollen ${ }^{204}$. Eheschließungen auf königlichem Befehl sollten ungültig sein, wenn die Eltern der Ehefrau nicht konsultiert worden waren ${ }^{205}$. Die konziliante Position der Konzilien der ersten Jahrhunderthälfte wird in Kanon 8 vollständig

200 Die Sedenzzeiten der Bischöfe ergeben nur eine Eingrenzung zwischen 556 und 573. ClercQ, Législation 1 1936, 40, hat die Abhängigkeit vom 2. Konzil von Tours richtig erkannt. Auch Gaudemet - Basdevant, Canons 1989, 410, platzieren Paris nach Tours. Eine andere Datierung ist dagegen von PonTal, Synoden 1986, 122-126, verfochten worden. Ihr folgen SunTrup, Studien 2001, 95, und Woll, Untersuchungen 1995, $25-$ 27. Die Argumente Pontals sind jedoch nicht überzeugend und können die Tatsache der Abhängigkeit von Tours nicht entkräften.

201 Admonet pontifices temporum qualitas et inprobe necessitates praecavenda conditio ... si importunorum voluntatibus obviasse noscuntur ... 3. Konzil von Paris (567/573) prol. (MGH Conc. 1, 142).

202 ClercQ, Législation 1 1936, 40; Suntrup, Studien 2001, 94.

203 Nunc tarde iniuriarum mole depressi damnis quoque dominicis compellentibus excitamur. 3. Konzil von Paris (567/573) c. 1 (MGH Conc. 1, 143).

204 ... hoc universitas praecaveri quoque debet, tam sacerdotes quam principis omnesque populus, ut nullus res alienas conpetire a regis audeat potestate. 3. Konzil von Paris (567/573) c. 6 (MGH Conc. 1, 144).

205 3. Konzil von Paris (567/573) c. 6 (144). Pontal, Synoden 1986, 124, bezieht diese Bestimmung auf die Praeceptio Chlotharii. Diese ist jedoch von EsDERs, Rechtstradition 1997, überzeugend Chlothar II. (und nicht Chlothar I.) zugewiesen worden. 
über Bord geworfen, wenn der Eingriff des Königs in die Bischofswahl als Unrecht abqualifiziert wird ${ }^{206}$. Die Wahl durch Klerus und Volk sollte bindend eingehalten werden.

Mit der Radikalität der übrigen Kanones kann die Inzestbestimmung nicht mithalten. Erstmals seit langem wurde nicht auf den Kanon von Epaon zurückgegriffen, der bislang immer als Vorbild für den Umfang des Inzestverbots gedient hatte. Stattdessen beschränkte man sich auf die biblisch autorisierten Verbote: „Niemand soll es wagen, unerlaubte Ehe gegen das Gebot des Herren einzugehen ..." ${ }^{207}$ Zum ersten Mal wurde deshalb die in Lev. 18, 17 genannte Ehe mit der Tochter der Stieftochter erwähnt. Warum die Bischöfe dieses Mal die Cousinenehe übergingen, lässt sich nicht nachvollziehen. Ob sich hierin Zurückhaltung oder Konzentration auf das Wesentliche spiegelt, muss offen bleiben. Jedenfalls bezeugt der Kanon ebenso wie der wenig früher erlassene von Tours, dass die biblische Begründung des Inzestverbots in den Vordergrund getreten ist.

In die Zeit der Konzile von Tours und Paris fällt ein einzigartiges Pastoralschreiben von vier Bischöfen der Provinz Tours an das Kirchenvolk. Als Autor des Schreibens wird der Metropolit Eufronius von Tours angesehen. Mit ihm unterzeichneten die Bischöfe von Angers, Nantes und Le Mans. Da alle vier Bischöfe am Konzil von Tours teilnahmen, wurde der Brief als Anhang zu diesem Konzil ediert ${ }^{208}$. Die Forschung geht deshalb von einer Datierung in das Jahr 567 aus $^{209}$. Diese Annahme ist jedoch aus verschiedenen Gründen nicht haltbar. Zunächst war in Tours auch der Bischof von Rennes anwesend, wo er eine Urkunde für das Kloster der hl. Radegunde in Poitiers als Mitglied der Kirchenprovinz Tours unterzeichnete ${ }^{210}$. Man müsste daher seine Unterschrift auch unter dem Pastoralschreiben erwarten. Zweitens bildet das Pastoralschreiben einen Überlieferungszusammenhang mit dem Konzil von Paris, das nach Tours stattgefunden hat ${ }^{211}$. Auch in Paris waren mit der Ausnahme des Bischofs von Le Mans alle Bischöfe anwesend, die das Pastoralschreiben unterfertigten. Die Überlieferung legt also eher eine Entstehung im Umfeld des

206 3. Konzil von Paris (567/573) c. 8 (MGH Conc. 1, 144).

207 Nullus ergo illicita coniugia contra praeceptum Domini sortire praesumat ... 3. Konzil von Paris (567/573) c. 4 (MGH Conc. 1, 144).

208 Als Epistula episcoporum provinciae Turonensis ad plebem wurde das Schreiben von Maassen und Clercq im Rahmen der merowingischen Konzilien herausgegeben.

209 Clercq, Législation 1 1936, 45; Pontal, Synoden 1986, 130; Suntrup, Studien 2001, 99.

210 Überliefert bei Gregor von Tours, Decem libri historiarum IX 39 (MGH SS rer. Merov. 1/1, 460-463).

211 Das Pastoralschreiben ist in einem Anhang zur Collectio Quesnelliana enthalten: Paris, Bibliothèque nationale, lat. 1454, 1458 und 3842A. Vgl. Mordek, Bibliotheca 1995, $409 \mathrm{f}, 412-414$ und $438 \mathrm{f}$. 
Konzils von Paris nahe. Erst die modernen Editionen haben diesen Zusammenhang zerrissen. Drittens ist das Pastoralschreiben durch ein „unmittelbar drohendes Unheil“" ausgelöst worden. Dieses Unheil wird von der Forschung einhellig mit der Auseinandersetzung um das Charibert-Erbe gleichgesetzt ${ }^{212}$. Charibert lebte aber noch während des Konzils von Tours.

Das Pastoralschreiben dürfte demnach zwischen 567 und dem Tod des Eufronius im Jahre 573 entstanden sein. Die Bischöfe haben sich zu diesem Brief veranlasst gesehen, „weil nach dem jähen Anstieg des Gewichts unserer Sünden die Not eines überaus furchtbaren Unheils zu drohen scheint, wenn wir nicht zu den Geboten desjenigen zurückkehren, der durch seinen Tod unser Leben erneuern wollte ${ }^{\text {“213. }}$. Retrospektiv liegt es nahe, dieses Unheil mit dem verheerenden Bürgerkrieg der folgenden Jahre zu identifizieren ${ }^{214}$. Zwei Stellen, die von dem Rückkauf von Gefangenen handeln, scheinen diese Sichtweise zu bestätigen ${ }^{215}$. Dennoch ist diese Deutung nicht zwingend. Denn der Ausbruch des Bürgerkriegs zwischen Gunthram, Sigibert und Chilperich wird von Gregor von Tours erst in das Jahr 574 datiert ${ }^{216}$. Damals verheerte ein Sohn Chilperichs „die Gegend von Tours mit Feuer, und hätte man sich ihm nicht rechtzeitig unterworfen, so hätte er sie ganz zugrunde gerichtet ${ }^{\text {“217. }}$. Die Soldaten zogen weiter in den Süden Galliens, wo sie ihr Zerstörungswerk fortsetzten: „Damals war schlimmeres Wehklagen in den Kirchen, als zu den Zeiten der Verfolgung unter Diocletian" ${ }^{\text {"218. }}$. Wenige Jahre davor waren die Konflikte noch begrenzt. Chilperich konnte kurzfristig seine Hand auf Tours und Poitiers legen, wurde aber bald von seinen Brüdern aus diesen Städten vertrieben. Kampfhandlungen in Tours werden nicht erwähnt ${ }^{219}$. Die anderen Bistümer der Kirchenprovinz wie Nantes, Le Mans und Angers wurden von diesen Kämpfen nicht berührt, da sie zum Teil bereits im Charibert-Erbe Chilperichs enthalten waren.

212 Pontal, Synoden 1986, 130.

213 ... salubri admonitione opportunum duximus admonere, quoniam peccatorum nostrorum in praecipiti mole crescente videtur cladis gravissimae necessitas imminere nec alibi refugium invenire, nisi ad illius praecepta recurrere, qui vitam nostram sua morte voluit reparare. Epistula episcoporum provinciae Turonensis ad plebem (MGH Conc. 1, 137).

214 Clerco, Législation 1 1936, 45; Pontal, Synoden 1986, 130.

215 Et quod dicendum est verius, suum persolvat pretium, ne se trahi videat peccato dominante captivum ... quod possit in captivorum redemptione conferre ... Epistula episcoporum provinciae Turonensis ad plebem (MGH Conc. 1, $137 \mathrm{f}$.).

216 ClercQ, Législation 1 1936, 45.

217 Sed et de Toronicam regionem maximam partem incendit et, nisi ad tempus manus dedissent, totam continuo debellasset. Gregor von Tours, Decem libri historiarum IV 47 (MGH SS rer. Merov. 1/1, 184).

218 Fuitque tempore illo peior in eclesiis gemitus quam tempore persecutionis Diocliciani. Gregor von Tours, Decem libri historiarum IV 47 (MGH SS rer. Merov. 1/1, 184).

219 Gregor von Tours, Decem libri historiarum IV 45 (MGH SS rer. Merov. 1/1, 180). 
Die Jahre zwischen 567 und 573 sind im Bericht Gregors von Tours nicht durch Vorläufer des Bürgerkriegs, sondern durch das Wüten der Pest im Jahre 571 gekennzeichnet ${ }^{220}$. Gregor selbst lebte damals in der Auvergne und war unmittelbarer Augenzeuge. „Als die Pest heranzog, richtete sie unter dem Volk in jener ganzen Gegend eine solche Verheerung an, dass man nicht zählen kann, wie viele Tausende daran umgekommen sind ${ }^{\text {“221 }}$. Die Seuche erreichte nach den Informationen Gregors auch die Städte Lyon, Dijon, Chalon sowie mit Bourges auch die Nachbardiözese von Tours ${ }^{222}$. Ob Tours selbst betroffen war, ist dem Bericht nicht zu entnehmen, aber auch nicht vollkommen auszuschließen, da Gregor vor seiner Wahl zum Bischof von Tours seine lokalen Informationen vorwiegend aus der Gegend von Clermont bezog ${ }^{223}$. Doch auch ein Wüten der Pest in Bourges wäre Anlass genug für die Bischöfe der Provinz Tours gewesen, von einem unmittelbar bevorstehenden, ,überaus furchtbaren Unheil“ zu sprechen. Der Bezug auf die Pest erklärt einige Charakteristika des Briefes besser als die bisherige Deutung. Die Beteiligung der gesamten Kirchenprovinz Tours fände dadurch eine Erklärung, weil der Krieg nur Tours und das der Provinz Bordeaux angehörende Poitiers betraf, während die Pest das gesamte Gebiet in Angst und Schrecken versetzte. Außerdem wird verständlich, warum die Bischöfe eine so drastische Maßnahme ergriffen, das Volk zu einer Verschiebung bereits geplanter Eheschließungen aufzufordern. Zwei Gründe dafür werden ausdrücklich genannt: zum einen sollte der Zorn Gottes durch die Keuschheit des Körpers und die Reinheit des Herzens besänftigt werden; zum anderen sollte denjenigen, die Gott durch einen grausamen Tod zum Verlassen ihres Körpers vorherbestimmt hatte, die Möglichkeit der Buße gegeben werden ${ }^{224}$. Die Erwähnung des göttlichen Zornes, des grausamen Todes und - wenig später

220 Vgl. Meier, Prokop 2004.

221 Iam vero adveniente ipsa clade, tanta strages de populo per totam regionem illam facta est, ut nec numerare possit, quantae ibidem ceciderunt legiones. Gregor von Tours, Decem libri historiarum IV 31 (MGH SS rer. Merov. 1/1, 165).

222 Gregor von Tours, Decem libri historiarum IV 31 (MGH SS rer. Merov. 1/1, 166).

223 Breukelaar, Historiography 1994, $187 \mathrm{f}$.

224 ... nuptiarum suarum etsi definitum iam tempus sit, licit apostolo vota nuptialia permittente, nos tamen consilium dantes hortamur, ut iusto moderamine debeant ad praesens differre, duplici conditione compulsi, ut aut ira Domini per castimoniam corporis et sinceritatem cordis oratione assidua valeat mitigari ... aut certe, si hoc ille de nobis placuerit qui condidit, ut quoscumque iusserit de corpore cogantur migrare, vel sit iustae consolationis cautela, ut anima de saeculo non abripiatur immunda nec gravior esse incipiat mors futura, quam erat praesenti de funere ... Epistula episcoporum provinciae Turonensis ad plebem (MGH Conc. 1, 137). 
- einer drohenden Krankheit ergibt nur Sinn, wenn der Text auf die Pest bezogen wird ${ }^{225}$.

Ein weiteres Thema des Pastoralschreibens erhält durch diese Interpretation eine neue Bedeutung. Der Brief ist nämlich das erste Zeugnis für die Geltendmachung des Zehnten durch die merowingische Kirche. Raymund Kottje hat im Brief die Aufnahme von Gedanken einer Predigt des Caesarius von Arles nachgewiesen. Von dieser Predigt, die später Augustinus zugeschrieben wurde, nahm die Forderung nach der Verbindlichkeit des Zehnten in der abendländischen Kirche ihren Ausgang. Sowohl bei Caesarius als auch im Pastoralschreiben wird der Gedanke ausgesprochen, die Abgabe des Zehnten bewahre davor, dass Gott durch Seuchen, Missernten oder Unwetter neun Zehntel wegnimmt und nur ein Zehntel überlässt. Deshalb solle man lieber gleich der Abgabe des Zehnten zustimmen ${ }^{226}$. Eine weitere Übernahme aus dem Gedankengut des Caesarius ist die Deutung des Zehnten als Loskauf. „Kauf dich frei, Mensch, solange du lebst; kauf dich selbst frei, solange du kannst; kauf dich frei, sage ich, solange du den Kaufpreis in Händen hältst; kauf dich frei, damit nicht, wenn dir der geizige Tod zuvorkommt, du das Leben und den Kaufpreis verlierst “227. Die Erwähnung des Loskaufs ist also nicht ein Verweis auf den Bürgerkrieg, sondern ein Zitat aus der Predigt des Caesarius. Auch die Verbindung zwischen Pest und Zehnt verdankt sich dem Vorbild der Predigt. Caesarius zitiert Exodus 30, 12, wonach der Zehnt vor Krankheit schützt, und kommentiert: „Da hast du in den heiligen Schriften die Bürgschaft deines Herrn, durch die er dir verspricht, dass du nach der Abgabe des Zehnten nicht nur die Fülle der Ernte empfängst, sondern auch die Gesundheit des Körpers ${ }^{\text {“2228. }}$.

Das Pastoralschreiben rief nicht nur in detaillierten Vorgaben zur Abgabe des Zehnten sowie zur Verschiebung von Eheschließungen auf. In Anbetracht der unmittelbaren Bedrohung durch die Pest wurden noch zwei weitere Forderungen erhoben. Zum einen sollten sich alle, die in Feindschaft zueinander geraten sind, möglichst schnell zur wechselseitigen Vergebung bereit finden. Die erste Aufgabe der Demut sei es, von einem Sünder keine Wiedergutmachung zu

225 ... quia dicitur in illa infirmitate ad divisionem nescio quam venire personas, quasi novem auferat, decimam ut relinquat ... Epistula episcoporum provinciae Turonensis ad plebem (MGH Conc. 1, 138).

226 Caesarius von Arles, Sermo 33, 2 (CCL 103, 144). Vgl. Koтtje, Studien 1970, 63.

227 Redime te, homo, dum vivis; redime te ipse, dum potes; redime te, inquam, dum pretium in manibus habes; redime te, ne dum te mors avara praevenerit, et vitam simul et pretium perdas. Caesarius von Arles, Sermo 33, 3 (CCL 103, 145).

228 Ecce habes in scripturis sanctis cautionem domini tui, per quam tibi promisit, quod, si decimas dederis, non solum abundantiam fructuum recipies, sed etiam sanitatem corporis consequeris. Caesarius von Arles, Sermo 33, 1 (CCL 103, 144). In der Bibelversion des Caesarius bewahrt der Zehnt vor morbi und casus, in der Vulgata vor einer plaga. 
verlangen, sondern Feindseligkeiten mit Wohltaten zu begegnen ${ }^{229}$. Zum anderen sahen sich die Bischöfe der Kirchenprovinz Tours dazu veranlasst, nochmals die Inzestverbote einzuschärfen. Soweit es die Umstände zuließen, sollten inzestuöse Ehen nach dem Kirchenrecht bis zur nächsten größeren Kirchenversammlung getrennt werden. Dies erfordere das eigene Heil der Eheleute und bewahre sie davor, „dass die Trennung durch göttliche Rache geschehe, wenn sie sie nach ihrem Willen herauszögerten “230. Mit der Trennung von inzestuösen Ehen sollte also nicht bis zur nächsten Synode abgewartet werden, sie habe unter der Drohung des „überaus furchtbaren Unheils“ sofort zu erfolgen. Diese Ungeduld der Bischöfe ist wiederum biblisch motiviert. Am Ende der Inzestverbote in Levitikus folgt die Mahnung, ,alle nämlich, die irgendeine dieser Greueltaten begehen, werden aus der Mitte ihres Volkes ausgemerzt" (Lev. 18, 29). Die Einschärfung des Inzestsverbotes ist also in diesem Brief ebenso wie in den Kanones der Konzilien von Tours und Paris in erster Linie biblisch inspiriert. Es scheint kein Zufall zu sein, dass Eufronius von Tours mit diesen drei Texten in Verbindung steht.

Das Pastoralschreiben aus der Kirchenprovinz Tours wurde von vier romanischen Bischöfen unterzeichnet und richtete sich an eine überwiegend romanische Bevölkerung. Gegen einen germanischen Widerstand ist dieses Dokument sicher nicht gerichtet. Das Übergewicht der Bischöfe des romanischen Südens wurde noch drückender in den folgenden Konzilien bis 614. Alle Kirchenversammlungen gingen auf die Initiative König Gunthrams zurück, dem das Teilreich Burgund unterstand und der nur über wenige fränkische Einwohner herrschte ${ }^{231}$. Da Gunthram den Interessen der Bischöfe gewogen war, verschwand die Königskritik der vorangegangenen Konzilien aus den Kanones. Zwei der vier von Gunthram einberufenen Synoden befassten sich mit dem Inzest, das 3. Konzil von Lyon (583) und das 2. Konzil von Mâcon (585). In beiden Konzilien zeigte sich die prominente Rolle Lyons als Zentrum des Kirchenrechts im ausgehenden 6. Jahrhundert. Die anwesenden Bischöfe kamen am 3. Konzil von Lyon ausschließlich aus den Kirchenprovinzen Vienne, Lyon und Sens. In Mâcon waren dagegen insgesamt 65 Bischöfe aus dem ganzen Frankenreich präsent, da erstmals seit dem 5. Konzil von Orléans (549) wieder mehrere Teilreiche zusammengebracht werden konnten. Mit Ausnahme von

229 Illud etiam repetita voce monentes hortamur, ut si quis alterius caritatis offensam, quod absit, incurrit, odium vice mutua relaxantes in amplexu verae concordiae festinent iam celerrime convenire. Epistula episcoporum provinciae Turonensis ad plebem (MGH Conc. 1, $137 \mathrm{f}$.$) .$

230 Si qui vero incesta se coniunctione visi sunt copulasse, in quantum ratio admittit, hortamur etiam et pro salute vestra rogamus, ut iuxta canonum statuta usque ad maiorem synodum separentur, ne si voluntate implere distulerint, caelesti, quod absit, facere incipiant ultionem. Epistula episcoporum provinciae Turonensis ad plebem (MGH Conc. 1, 138).

231 Pontal, Synoden 1986, 156-167. 
Rouen und Le Mans fehlten jedoch Vertreter aus dem Gebiet nördlich der Loire. Der fränkische Widerstand gegen das Inzestverbot war daher sicher nicht für die Beratung über das Inzestverbot verantwortlich.

Die Inzestbestimmung des 3. Konzils von Lyon war konventionell. Es wurden lediglich die gültigen Bestimmungen des Kirchenrechts erneut eingeschärft ${ }^{232}$. Da auf diesem Konzil insgesamt nur sechs kurze Bestimmungen erlassen wurden, fällt dieser Befund nicht überraschend aus. Interessanter ist dagegen der Kanon 18 des 2. Konzils von Mâcon. Die sprachliche Herabsetzung des Inzests erreicht darin einen Höhepunkt:

„Das Recht bestimmte, dass einer inzestuösen Verbindung weder der Begriff ,Ehe noch ,Ehepaar' zukommt. Auch die katholische Kirche verflucht und verabscheut diese in jeder Hinsicht und stellt schwere Strafen für diejenigen in Aussicht, die durch zügellose Leidenschaft die Verwandtschaftsgrade ihrer Geburt missachten und sich - welch Greuel! - wie die abscheulichsten Schweine in ihren Exkrementen wälzen “233.

An dieser drastischen Wortwahl und an den angedrohten Strafen wird deutlich, dass der rigorose Standpunkt innerhalb des merowingischen Episkopats zum Durchbruch gelangt ist. 65 Bischöfe aus dem ganzen Frankenreich bekannten sich zu dieser sprachlichen Radikalisierung. Erstmals wurde ausdrücklich die Strafzumessung des römischen Rechts als ungenügend angesehen. Nicht nur die Auflösung der Ehe und die Infamisierung der Nachkommen sollten über inzestuöse Eheleute verhängt werden, sondern auch kirchliche Bußstrafen. Die milde Position des Konzils von Epaon war endgültig überwunden.

Die Verschärfung der Inzestbestimmungen stand auf dem Konzil von Mâcon im Kontext einer generellen Radikalisierung der bischöflichen Reformagenda ${ }^{234}$. Mit Unterstützung König Gunthrams wurde die Macht der Bischöfe in jeder erdenklichen Hinsicht gestärkt und die Schaffung einer von den Laien getrennten Amtshierarchie gefördert. Das Asylrecht, der Gerichtsstand des Klerus und die bischöfliche Gerichtsbarkeit über die Armen, Witwen und Waisen wurden zu ungunsten der weltlichen Amtsträger ausgeweitet. Pa-

232 De incestis vero coniunctionibus hoc placuit custodiri, quod prisca canonum statuta sanxerunt. 3. Konzil von Lyon (583) c. 4 (MGH Conc. 1, 154).

233 Incestam copulationem, in qua nec coniunx nec nuptiae recte appellare legis sanxerunt, catholicam omnino detestatur atque abominatur ecclesiam et gravioribus penis eos afficere promittit, qui nativitatis suae gradus libidinoso ardore contemnentes in merda, quod nefas est, sua ut sues teterrimi convolvuntur. 2. Konzil von Mâcon (585) c. 18 (MGH Conc. 1, 171). $\mathrm{Zu}$ Anklängen an das römische Recht und an die Bibel vgl. Miкат, Inzestgesetzgebung 1994, $130 \mathrm{f}$.

234 Zur Radikalisierung dieser Konzilien, die bei Clercq und Pontal nicht angemessen wiedergegeben wird, vgl. Heinzelmann, Gregor 1994, 158-167. Mit der Entgegensetzung von königlich vs. gelasianisch hat dies nichts zu tun: MAGNOU-NorTIER, Géographie 1997. 
radigmatisch wird diese Tendenz zur Radikalisierung in Kanon 15 deutlich ${ }^{235}$. Darin wurde die einzigartige Bestimmung erlassen, dass ein Laie bei einer Begegnung mit einem Kleriker sein Haupt neigen oder seine Kopfbedeckung abnehmen müsse. Sei der Kleriker zu Fuß unterwegs und der Laie beritten, müsse dieser vom Pferd herabsteigen und einen Gruß entrichten. Wer diese vom heiligen Geist diktierten Regeln nicht einhalte, solle von der Kirche für eine bestimmte Zeit ausgeschlossen werden. In merowingischer Zeit ist weder früher noch später eine derart kleinliche Regelung erlassen worden. Das Selbstbewusstsein der Bischöfe kannte keine Grenzen.

\section{Fixierung des Erreichten}

Am Ende des 6. Jahrhunderts war die merowingische Kirche zu einem einheitlichen Standpunkt in der Frage des Inzestverbots gelangt. Der Umfang des Verbots bestimmte sich durch das Konzil von Epaon, die Bestrafung sah nach altkirchlichem Vorbild sowohl Trennung als auch Buße für die betroffenen Personen vor. Diese einheitliche Politik kommt in der Diözesansynode von Auxerre, in den beiden Reichssynoden von Paris und Clichy sowie in der zur selben Zeit entstandenen einflussreichsten Sammlung des merowingischen Kirchenrechts, der Collectio vetus Gallica, zum Ausdruck.

Alle bisherigen Kirchenversammlungen fanden auf der Ebene der Bischöfe statt und informieren daher nur ungenügend über den Stand der Inzestverfolgung vor Ort. Diesen Mangel beheben die Kanones der einzigen überlieferten Diözesansynode der Merowingerzeit ${ }^{236}$. Einberufen wurde sie von Bischof Aunacharius von Auxerre in den Jahren zwischen 585 und 592. Auxerre lag in der Kirchenprovinz Sens und gehörte zum burgundischen Teilreich König Gunthrams. Fränkische Siedlung ist in diesem Raum kaum anzunehmen, selbst die Grafschaft befand sich zur Zeit Gregors von Tours noch in Händen einer einheimischen galloromanischen Adelsfamilie ${ }^{237}$. Das Erklärungsmodell des germanischen Widerstands kann also für die breite Aufnahme des Inzestverbots in die Kanones von Auxerre keine Gültigkeit beanspruchen. Von 45 Kanones befassen sich 6 mit dem Inzestverbot. Kein anderes Thema wird so ausführlich behandelt. Die äußerste Kürze der Kanones sowie die verwilderte Sprache verweisen auf die bodenständige Verankerung dieser Synode. Sie sollte vor allem den Priestern auf dem Land einen Leitfaden für die wichtigsten kirchenrechtlichen Belange an die Hand geben. Der Umfang der Inzestverbote entspricht dem Konzil von Epaon. Auch das Verbot der Ehe mit der Cousine zweiten

235 2. Konzil von Mâcon (585) c. 15 (MGH Conc. 1, 170 f.).

236 Atsma, Klöster 1983, 6-9; Pontal, Synoden 1986, 167 f.; Godding, Prêtres 2001, $282-284$ u. $359 \mathrm{f}$.

237 Gregor von Tours, Decem libri historiarum IV 42 (MGH SS rer. Merov. 1/1, 174). Weidemann, Kulturgeschichte 1 1982, 68. 
Grades wird ausdrücklich genannt ${ }^{238}$. Welche Strafe die des Inzests überführten Eheleute zu erwarten haben, wurde nicht ausdrücklich festgelegt.

Die letzten beiden Synoden mit Bestimmungen zum Inzestverbot in Paris und Clichy fanden unter neuen Voraussetzungen statt. Im Jahr 613 gelang es Chlothar II., seine Konkurrenten aus der eigenen Familie auszuschalten und das gesamte Frankenreich unter seiner Herrschaft zu vereinigen ${ }^{239}$. Ein Jahr später ließ er zur Festigung der erreichten Reichseinheit ein Konzil in Paris einberufen. 76 Bischöfe folgten seinem Ruf, ein Bischof und ein Abt aus England komplettierten die größte Kirchenversammlung der Merowingerzeit ${ }^{240}$. Noch einmal wurden alle Themen der kircheninternen Disziplin und der Seelsorge der Laien angesprochen, die zum Kernbestand der früheren Konzilien zählten. Das Inzestverbot durfte dabei nicht fehlen. Der Umfang des Verbots folgte wieder dem Konzil von Epaon. Unklar bleibt nur, ob auch die Ehe mit der Cousine zweiten Grades angesprochen wurde, da von den zwei Handschriften die eine das entscheidende Wort sobrina weglässt ${ }^{241}$. Personen, die des Inzests überführt worden seien, sollten so lange von der Gnade der Kommunion ausgeschlossen sein, bis sie sich durch eine offene Scheidung von der unerlaubten Verbindung getrennt haben ${ }^{242}$. Im Wesentlichen wird also die communis opinio der merowingischen Kirche festgehalten.

Zwölf Jahre später tagte das letzte gesamtfränkische Konzil in Clichy ${ }^{243}$. Die Beteiligung war mit 42 Bischöfen nicht so hoch wie in Paris. Nach einer unterwürfigen Ergebenheitsadresse an König Chlothar II. wurden die Bestimmungen der Synode von Paris erneut eingeschärft und durch weitere Kanones ergänzt. Das Inzestverbot erhielt eine neue Fassung, indem neben den geistlichen Sanktionen auch weltliche Strafen angedroht wurden. Da der Text wörtlich auf das Dekret Childeberts II. von 596 zurückgeht, werde ich diesen Aspekt im nächsten Abschnitt behandeln. Als geistliche Strafe wurde ausdrücklich nach der

238 Non licet consubrinam, hoc est, quod de duos fratres aut de duas sorores procreantur, in coniugium accipere nec, qui de ipsis nati fuerint, in coniugio socientur. Konzil von Auxerre (585/592) c. 31 (MGH Conc. 1, 182). Eine Anlehnung an Formulierungen des Breviars weist Mıкат, Inzestgesetzgebung 1994, 132, nach.

239 Ewig, Merowinger 2001, 117-121; Wood, Kingdoms 1994, 140-144.

240 Pontal, Synoden 1986, $182-188$.

241 Die Überlieferung der Collectio Remensis enthält das Wort subrinam. Maassen und Clercq folgen in ihren Editionen der Collectio Diessensis.

242 Incestas vero coniunctiones ab omni Christianorum populo censuemus specialiter resecari, ita $u t$, si quis relicta fratris, sorore uxoris, privigna, consubrina vel relicta idem patrui atque avunculi vel in religionis habitu dedita coniugii crediderit consortio violanda, tamdiu a communionis gratia segregetur, quamdiu ab inlicitis coniunctionibus sequestratione manifestissima debeat abstenere. 5. Konzil von Paris (614) c. 16 (MGH Conc. 1, 190).

243 Pontal, Synoden 1986, 189-192. 
Trennung der Eheleute eine Kirchenbuße verhängt ${ }^{244}$. Die strenge Auffassung des Nicetius von Trier hatte sich durchgesetzt. Der Umfang des Inzestverbots ist nicht eigens erläutert. Stattdessen wird auf die bereits erlassenen Kanones des Kirchenrechts sowie auf die Gebote Gottes verwiesen.

Auf dem Konzil von Clichy wurde das erste Mal eine systematische Sammlung der gallischen Konzilien verwendet, die sog. Collectio vetus Gallica ${ }^{245}$. Es ist durchaus möglich, dass die Nennung bereits erlassener Kanones zum Inzestverbot auf diese bedeutendste Kirchenrechtssammlung der Merowingerzeit verweist. Die Entstehung der Sammlung hat Hubert Mordek in überzeugender Weise mit Bischof Etherius von Lyon (586-603) in Zusammenhang gebracht $^{246}$. Die Sammlung sollte später die wichtigste Schiene bilden, über die das merowingische Kirchenrecht der späteren Zeit überliefert wurde. Die Inzestbestimmungen sind in Titel 49 versammelt, der sich auch mit Ehescheidung und Ehebruch befasst. An den Anfang stellt der Sammler den Kanon 2 von Neocäsarea ${ }^{247}$. Wie es für die Vetus Gallica allgemein charakteristisch ist, werden also altkirchliche, durch Rom sanktionierte Kanones mit den neuen partikularen Bestimmungen der fränkischen Synoden verbunden. Auf Neocäsarea folgt der Kanon 12 des Konzils von Clermont. Dieser Kanon hat den merowingischen Standpunkt zum Inzestverbot entscheidend geprägt, obwohl auf dieser Synode nur wenige Bischöfe anwesend waren. Der Umfang des Inzestverbots wurde im Sinne von Epaon ausgeweitet, die Strafbestimmung nahm die strenge Disziplin von Neocäsarea zum Vorbild. Erst nach Clermont lässt der Sammler den Kanon von Epaon folgen. Der Vorrang von Neocäsarea und Clermont vor Epaon legt die Parteinahme des Sammlers für eine strenge Disziplinierung des Inzestdelikts nahe. Bestätigt wird diese Vermutung durch eine Auslassung. Die Toleranzklausel des 3. Konzils von Orléans, die dem Sammler durchaus bekannt war $^{248}$, fand keine Aufnahme. Die Collectio vetus Gallica bringt daher die herrschende Auffassung der fränkischen Bischöfe zum Ausdruck.

\section{Motive einer Obsession}

Um 640 starb der heilige Arnulf von Metz, der Stammvater der karolingischen Dynastie. Seine letzte Ruhe sollte er nicht im Kloster Remiremont finden, wo er sich nach dem Abschied vom Bischofsamt niedergelassen hatte. Bald nach seinem Tod wurde der Leichnam auf Betreiben des Nachfolgers Goericus von Metz in die Apostelkirche der Bischofsstadt überführt. Die Bischöfe von Toul

244 ... nisi praefatum scelus sequestrationis separatione et paenitentia feriatur. Konzil von Clichy (626/627) c. 10 (MGH Conc. 1, 198).

245 Mordek, Kirchenrecht 1975, 66-69.

246 Mordek, Kirchenrecht 1975, 63-82.

247 Collectio vetus Gallica XLIX 4 (557).

248 Mordek, Kirchenrecht 1975, 660. 
und Verdun, eine große Schar Kleriker und Laien begleiteten den Leichnam entlang der Mosel nach Metz. Nach dem Bericht eines Augenzeugen ging die Überführung nicht ohne Wunder vonstatten ${ }^{249}$. Als die Nacht hereinbrach, wollte man auf dem Landgut eines gewissen Cionta im Gau Le Chaumontois das Quartier aufschlagen. Dort war eine Kapelle vorhanden, in der man die erforderliche Totenwache für den Heiligen halten konnte. Allerdings war der Landadelige mit dem befremdlichen Namen dem heiligen Arnulf nicht unbekannt gewesen. Cionta lebte in einer Inzestehe und konnte trotz wiederholter Mahnungen Arnulfs nicht von seiner Sünde abgebracht werden. Als die Reisenden die Grenze zu dem Landgut passieren wollten,

„wurde der Transport plötzlich gehemmt, so dass man die heiligen Gebeine nicht mehr weiter befördern konnte. Und das war eine Verlegenheit für die Bischöfe und für das ganze Volk, weil sie nicht wussten, welcher Herberge sie sich zuwenden sollten, vor allem da sich der Tag bereits zum Abend geneigt hatte. Dann sagte der Herzog Noddo, der zu den Reisenden zählte: ,Habt Ihr gesehen, dass der Heilige es verachtet, den Boden dieser inzestuösen Person zu betreten? Eines meiner Landgüter ist sehr nahe, und wir können es erreichen, bevor die Nacht hereinbricht. Mir fehlen zwar dort Getränke und Speisen, um eine so große Menge erfrischen zu können, außer einer kleinen Menge Bier, wie ich vom Iudex Immo erfahren habe‘. Nachdem man dies hörte, wandte sich das ganze Volk zurück und kam in solcher Geschwindigkeit voran, dass man eher meinte, das Reliquiar habe sich selber getragen, als dass es getragen wurde ${ }^{\text {(250. }}$.

Bei Noddo angekommen, war durch den Beistand des heiligen Arnulf das erfrischende Getränk in Überfülle vorhanden.

Diese Anekdote aus der Mitte des 7. Jahrhunderts belegt nicht nur das Eintreten eines Ahnherrn der Karolinger für das Inzestverbot, es stellt auch auf ungewohnte Weise die ethnischen Identitäten auf den Kopf. Auf der einen Seite stehen drei Personen mit germanischen Namen, der heilige Arnulf, Bischof Goericus von Metz und der vermutlich ebenfalls in Metz residierende Herzog Noddo $^{251}$. Auf der anderen Seite steht der des Inzests überführte Adelige mit

249 Vgl. Jarnut, Agilolfingerstudien 1986, 102 - 105; Cracco Ruggini, Vita 1992. Wood, Forgery 1988, 371, glaubt ohne Begründung an eine Fälschung der Vita zu einer späteren Zeit. Für die Echtheit tritt dagegen Halsall, Settlement 1995, 15 Anm. 7, ein.

250 Venientes autem terminos hominis incestuosi, repente figitur comportatio, ita ut ulterius vectandi sacra membra facultatem non haberent. Et ecce! angustiae sacerdotibus et universo populo, quoniam, ad quam mansionem converterentur, ignorabant, presertim cum iam dies declinata esset, ad signum. Tunc Noddo dux, qui unus erat ex euntibus, ait: 'Vidistis, quia terram incestiose huius ingredi despicit? Est enim valde procul villa mea, ubi nos ante nox inclaudit, quam venire valemus; sed et deest mihi inibi putos vel paratos, quod tot multitudinem reficere possum, nisi tantummodo, ut comperi ad Immo iudice, modicum quiddam cervisae. Vita sancti Arnulfi 25 (MGH SS rer. Merov. 2, 443 f.).

251 Zum dux Noddo vgl. Ebling, Prosopographie 1974, 195. 
dem galloromanischen Namen Cionta ${ }^{252}$. Sein Wohnort im Gau Le Chaumontois westlich der späteren Sprachgrenze ist ein weiteres Indiz für seine galloromanische Herkunft. Die Rollen sind also vertauscht: Während sich die fränkischen Amtsträger aus dem höheren Adel für die Verfolgung des Inzests stark machten, beharrte ein galloromanischer Einwohner auf seiner Inzestehe. Die Behauptung eines fränkischen Widerstands gegen das Inzestverbot wird hier eindrücklich ad absurdum geführt.

Die merowingische Obsession mit dem Inzestverbot kann demnach nicht mit dem Hinweis auf den germanischen Widerstand erklärt werden. Nur in Einzelfällen, wie etwa beim Vorgehen des Nicetius von Trier gegen „einige Franken“, lassen sich Konflikte auf eine ethnische Differenz zurückführen. Das Beispiel Arnulfs belegt dagegen die Möglichkeit eines Rollentausches. Die Untersuchung der Inzestfälle des 6. und 7. Jahrhunderts im vorigen Kapitel hat ebenfalls gezeigt, dass Ehen von Personen sowohl fränkischer als auch galloromanischer Herkunft in die Kritik geraten sind. Bei den Franken gab es keine bevorzugten Ehepartner innerhalb der Familie, das Inzestverbot musste also kein Ehegebot verdrängen. Es war daher nicht notwendig, einen Widerstand zu überwinden, sondern vielmehr musste die Kirche die Franken an die Anforderungen des römisch-christlichen Eherechts heranführen. Der bei Chlothar I. und Charibert bezeugte Widerstand gegen das Inzestverbot sollte weder auf die gesamte Merowingerdynastie noch auf die gesamte fränkische Bevölkerung extrapoliert werden.

Neue Erklärungen für die obsessive Thematisierung des Inzestverbots in der Merowingerzeit sind deshalb erforderlich. Zwei Tatsachen müssen dabei besonders im Auge behalten werden. Erstens setzte sich das burgundische Konzil von Epaon als die vorbildliche Regelung bei den merowingischen Bischöfen durch. Zweitens verweist die Teilnahmestruktur der Konzilien sowie die Herkunft der Vorsitzenden der Versammlungen auf eine gallorömische Prägung. Beides legt die Folgerung nahe, dass die merowingischen Inzestverbote als Weiterführung der römischen Rechtstradition anzusehen sind. Nachdem im

252 Quidam autem homo in pago Calvomontinse nomine Cionta incestiosus fuit. Vita sancti Arnulfi 25 (MGH SS rer. Merov. 2, 443). Eine Variante gibt den Namen in der Form Centa wieder. Nach Morlet, Noms 1972, 30, ist der Name keltischen Ursprungs. Zustimmend Haubrichs, Romanen 1998, 386. Ethnische Zuordnungen für diese Region werden dagegen grundsätzlich zurückgewiesen von Halsall, Settlement 1995, 8 12. Ähnlichkeit besteht zu dem im 6. Jahrhundert überlieferten Namen Conda. Einen Mann dieses Namens ehrt Venantius Fortunatus mit einem Gedicht: Carmina VII 16 (MGH Auct. Ant. 4/1, 171). Aufgrund seiner Ämterlaufbahn (tribunus, comes, domesticus) hält ihn BEIsel, Theudebertus 1993, 117, für einen Romanen. Als tribuni sind sonst nur Personen romanischer Herkunft belegt: Weidemann, Kulturgeschichte 1 1982, 88-90. Einer ethnischen Zuordnung enthält sich PLRE 3 1992, 330 f., während George, Venantius 1992, 82, ohne Grund für die fränkische Herkunft Condas optiert. 
5. Jahrhundert die Reichsverwaltung in Gallien allmählich zugrunde gegangen war, waren die Voraussetzungen für eine Verfolgung von Inzestvergehen verschwunden $^{253}$. Im römischen Reich lag die Zuständigkeit im 5. Jahrhundert beim comes rerum privatarum und nicht bei der Kirche. Im merowingischen Gallien ist dieses Amt nicht mehr nachweisbar. Über die Verfolgung des Inzests in der Zeit vor 500 gibt es keine sicheren Informationen. Die Inzestgesetze des römischen Rechts waren in dieser Zeit wohl weitgehend toter Buchstabe. In diese Lücke ist die Kirche eingetreten. Viele der Bischöfe aus gallorömischem Adel hatten vor ihrer geistlichen Karriere ein weltliches Amt inne, verfügten über eine Ausbildung im römischen Recht und waren mit den Anforderungen der neuen Zeit vertraut ${ }^{254}$. Der Staat garantierte nicht mehr die Inzestverfolgung, und so musste der Bischof an seine Stelle treten. Anders als im römischen Recht war es jedoch mit dem Erlass eines Gesetzes nicht getan, weil das Recht nicht durch schulische Ausbildung und richterliche Praxis stabil gehalten wurde. Von regionalen Konzilien erlassene Bestimmungen galten nur insofern, als sie von den Bischöfen rezipiert und in die Praxis umgesetzt wurden. Es war daher nötig, die Bestimmungen immer wieder einzuschärfen und erneut zu Bewusstsein zu bringen. Die ständige Wiederholung der Inzestbestimmungen reagierte daher auf veränderte Rahmenbedingungen der Gesetzgebung nach dem Ende des ausdifferenzierten Rechtssystems der Antike.

Besonders virulent war diese erneute Einschärfung auch deshalb, weil innerhalb des gallischen Episkopats keine Eintracht über das konkrete Vorgehen gegen Inzestehen herrschte. Vor allem in der ersten Jahrhunderthälfte war es umstritten, mit welcher Härte man gegen unerlaubte Ehen vorgehen sollte. Die ersten Protagonisten einer rigorosen Disziplinierung waren innerhalb des Episkopats isoliert. Albinus von Angers ist von seinen Kollegen mit Gewalt dazu gezwungen worden, das Brot für inzestuöse Personen zu weihen und somit ihre Zugehörigkeit zur christlichen Gemeinschaft zu bestätigen. Von Nicetius von Trier berichtet Gregor, dem Bischof sei nach der Exilierung durch König Chlothar I. nur mehr von einem einzelnen Diakon die Treue gehalten worden. „Von den übrigen Bischöfen, die Schmeichler des Königs geworden waren, wurde er verlassen " ${ }^{\text {255. }}$. Beide, Albinus und Nicetius, wurden von ihren Biographen wegen ihrer Hartnäckigkeit und ihres beinahe eingetretenen Martyriums mit Johannes dem Täufer verglichen ${ }^{256}$. Diese Differenzen innerhalb des Episkopats schlugen sich in einer Fülle von Kanones nieder.

253 Vgl. Mathisen, Aristocrats 1993, 7-35; Bruguière, Réflexions 1994.

254 Siehe $115 \mathrm{f}$.

255 Quodam vero tempore cum iam ad exilium ductus, episcopis reliquis, qui adulatores regis effecti fuerant, removeretur atque a suis omnibus derelictus, uni diacono, qui adhuc perstabat in fide ... Gregor von Tours, Vitae patrum 17, 3 (MGH SS rer. Merov. 1/2, 280).

256 Cum autem propinquum transitu tempus migrationis suae cognovisset, fratribus retulit dicens: , Vidi Paulum apostolum cum Iohanne baptista invitantem me ad requiem sempiternam 
Dass die rigorose Auffassung einer Minderheit im Episkopat schließlich auf allgemeine Zustimmung stieß, hängt mit einem bislang nicht in Betracht gezogenen Faktor zusammen: Pest und Bürgerkrieg drückten der Zeit Gregors von Tours ihren Stempel auf. Beides wurde als Strafe Gottes angesehen und für den Aufruf zur Besänftigung des göttlichen Zorns zum Anlass genommen. Erstes Zeugnis dafür ist das Pastoralschreiben des Eufronius von Tours aus den Jahren 567/573. Die Ermahnung zu Enthaltsamkeit, zur Zahlung des Zehnten und zur Trennung inzestuöser Ehen erging an das Volk, um den rächenden Zorn Gottes zu beschwichtigen. Zur gleichen Zeit tagte das 3. Konzil von Paris, auf dem das Inzestverbot allein auf der Grundlage der Gebote des Alten Testaments eingeschärft wurde. Die biblische Begründung begann die Begründung durch das römische Recht zu verdrängen. Der Rückgriff auf das Alte Testament bei Inzest und Zehntzahlung diente dazu, Antworten auf die Krisenphänomene der Zeit zu finden. Auf dem Konzil von Mâcon (585) wurde erstmals die Zehntzahlung durch eine Bischofsversammlung verbindlich eingefordert und der Inzest in beispielloser Schärfe gebrandmarkt. Die alttestamentarisch verbürgte Einhaltung der Sonntagsruhe wurde ebenfalls zum ersten Mal in Mâcon unter dem ausdrücklichen Hinweis auf die Pestepidemien und Hungersnöte angemahnt ${ }^{257}$. König Gunthram, der seine zwei Söhne durch eine Krankheit verlor ${ }^{258}$, unterstützte dieses Vorgehen der Bischöfe und begleitete es durch die Herausgabe eines Gesetzes zur Sonntagsruhe ${ }^{259}$. Im Jahr 588, als die Pest in Marseille wütete, verlangte er die Einberufung eines Konzils, das über Inzest und den Zölibat Entscheidungen treffen sollte ${ }^{260}$. Den Bürgern von Marseille befahl er, durch Almosen, Fasten und Bittgebete das Erbarmen des Herrn zu erzwingen. „Drei Tage hindurch, während seine Almosen noch reichlicher flossen als gewöhnlich, betete er in so banger Sorge für sein Volk, dass er schon damals nicht nur für einen König, sondern zugleich für einen Bischof des Herrn gehalten wurde “261.

...' Gregor von Tours, Vitae patrum 17, 6 (MGH SS rer. Merov. 1/2, 283). Zu Albinus siehe 153 Anm. 173.

257 Haec namque omnia et placabilem erga nos Dei animum reddunt et plagas morborum vel sterelitatum amovent atque repellunt. 2. Konzil von Mâcon (585) c. 1 (MGH Conc. 1, 165).

258 Gregor von Tours, Decem libri historiarum V 17 (MGH SS rer. Merov. 1/1, 215).

259 Guntchramni regis edictum (585) (MGH Capit. 1, 11 f.). Vgl. Heinzelmann, Gregor 1994, $162 \mathrm{f}$.

260 'Sunt multa', inquid, 'quae debeant discerni, quae iniuste gesta sunt, tam de incestis quam de ipsis quae inter nos aguntur causis.' Gregor von Tours, Decem libri historiarum IX 20 (MGH SS rer. Merov. 1/1, 440). Da sein Neffe Childebert II. sich weigerte, eine Synode des Gesamtreichs zu unterstützen, verlief dieses Bemühen im Sand.

261 Per triduum enim ipsius elimosinis largius solito praecurrentibus, ita de cuncto populo formidabat, ut iam tunc non rex tantum, sed etiam sacerdus Domini putaretur ... Gregor von Tours, Decem libri historiarum IX 21 (MGH SS rer. Merov. 1/1, 270). 
Die obsessive Thematisierung des Inzestverbots beruhte also einerseits auf der Aneignung der römischen Rechtstradition durch die Bischöfe, die sich gegen Ende des Jahrhunderts mit einer Aktivierung der alttestamentarischen Vorschriften verband. Andererseits ist dieses Phänomen in Zusammenhang mit der durchgängigen Tendenz der merowingischen Konzilien zu sehen, die Gewalt des Bischofs und der kirchlichen Hierarchie zu stärken. König Chlodwig gab der Kirche Galliens erstmals die Gelegenheit zu einer reichsweiten Kirchenversammlung. Sein Sohn Childebert führte diese Politik fort und ermöglichte damit die Herausbildung eines Gemeinschaftsbewusstseins der gallischen Bischöfe. Dieses bestand zuallererst in der Stärkung der innerkirchlichen Hierarchie. Klöster sollten der strikten Aufsicht des Bischofs unterstellt werden, Geistliche wurden durch die verschärften Zölibatsgesetze vom Stand der Laien abgesondert, regelmäßige Synoden sollten eine gegenseitige Überwachung der Bischöfe erlauben. In Fällen der Interessenkollision mit Königtum und Adel pochten die Bischöfe auf ihren Standpunkt. Den deutlichsten Beleg hierfür liefert die schrittweise Ausschaltung der weltlichen Gerichtsbarkeit über Kleri$\operatorname{ker}^{262}$. Den Bischöfen gelang es, den Klerus in Zivilsachen vollständig der eigenen kirchlichen Gerichtsbarkeit zu unterwerfen. Ein auf den Konzilien stets wiederkehrendes Gebot schrieb den Adeligen vor, die großen Festtage nicht bei den ihnen wohl gesonnenen Landgeistlichen, sondern in den Bischofskirchen zu verbringen. Die Aristokratie sollte der geistlichen Aufsicht der Bischöfe unterstellt werden. Den Höhepunkt dieser Steigerung der Bischofsmacht markierte das 2. Konzil von Mâcon mit seiner einzigartigen Vorschrift über das Begrüßungsritual zwischen Klerikern und Laien. Auf demselben Konzil wurde auch das Inzestverbot in eine ausufernde Rhetorik eingekleidet. Stärkung der Bischofsmacht und Einschärfung des Inzestverbots liefen also Hand in Hand. Zeugnis dafür legen die Viten des Nicetius von Trier und des Albinus von Angers ab. Beide brachen einen Konflikt mit Adeligen vom Zaun ${ }^{263}$ und demonstrierten den Gegnern ihre Verfügungsgewalt über das Heilige. Auch die Wundergeschichte Gregors von Tours über den hl. Andreas bringt das Wirken der Kirche in einem Gegensatz zu den Heiratsstrategien des galloromanischen Adels. Es ging den Bischöfen dabei nicht um eine effektive Kontrolle der adeligen Eheschließungen wie im hohen Mittelalter, sondern um die Wahrung einer Ordnung von Ehe und Familie. Das Inzestverbot bot eine Handhabe, den Adel unter Druck zu setzen und die geistliche Gewalt des Bischofs in Szene zu

262 NissL, Gerichtsstand 1886; Esders, Rechtstradition 1997, 304-310; GodDING, Prêtres 2001, 315-329.

263 Sed et hoc magnanimitatis exemplum oportunum ducitur explicandum, quod pro dei negotio apud eum non fuerit ulla regum potentumque personalis acceptio. Venantius Fortunatus, Vita Albini 18 (MGH Auct. Ant. 4/2, 32). 'Fiet quidem voluntas Dei, nam regis voluntas in omnibus malis, me obsistente, non adimplebitur'. Gregor von Tours, Vitae patrum 17, 1 (MGH SS rer. Merov. 2/1, 279). 
setzen. Das Inzestverbot fügte sich also ein in die durchgängige Stärkung der Bischofsgewalt durch die merowingischen Konzilien.

Eine angemessene Erklärung für die merowingische Obsession muss also verschiedene Faktoren berücksichtigen. Dass das Inzestverbot überhaupt als zentraler Bestandteil der Moral angesehen wurde, ist ohne die Vereinnahmung der römischen Tradition durch die Bischöfe nicht verständlich. An Durchschlagskraft gewann die Inkriminierung des Inzests durch den Rückgriff auf die Begründungslogik des Alten Testaments, die während der Krisen des späten 6 . Jahrhunderts eine besondere Überzeugungskraft annahm. Diese Faktoren waren für das Bewusstsein von einer Gefährdung der göttlichen Ordnung durch Inzestehen verantwortlich. Funktional ist die Obsession der Bischöfe in Zusammenhang mit ihrem Bestreben nach Abgrenzung und Stärkung der episkopalen Gewalt zu sehen, da das Inzestverbot eine Handhabe bot, den potentiell widerspenstigen Adel mit einem Delikt zu konfrontieren, das die göttliche Ordnung gefährdet, den zölibatären Episkopat jedoch eo ipso nicht betreffen konnte.

\subsection{Die Implementierung im weltlichen Recht des Frankenreichs}

Einen Überblick über das weltliche Recht des Frühmittelalters zu geben ist ungleich schwieriger als für das Kirchenrecht, da wichtige Quellen in ihrer Datierung äußerst umstritten sind ${ }^{264}$. Dies trifft für einige Kapitulare der Merowingerzeit zu, aber vor allem für die auf dem Boden des Frankenreichs entstandenen Volksrechte. Das salische, ribuarische, alemannische und bayerische Recht stammen aus der Merowingerzeit, sind jedoch allesamt ohne präzise Datierung überliefert. Die Kontroversen innerhalb der Forschung waren bereits im 19. Jahrhundert heftig und dauern bis in die heutige Zeit an. Das salische Recht wird von einigen Historikern in das 4. Jahrhundert, von anderen in das 6. Jahrhundert verlegt. Beim bayerischen Recht variieren die Datierungen vom 6. bis in das 8. Jahrhundert. Eine entscheidende Rolle bei diesen Kontroversen spielt das Inzestverbot, da es in sämtlichen Volksrechten auftaucht und mit der präzise datierbaren Entwicklung im Kirchenrecht in Bezug gebracht werden kann. Besonders für das salische, alemannische und bayerische Recht diente das Inzestverbot in den Debatten regelrecht als Datierungskriterium. Dieser Ansatz ist jedoch dann problematisch, wenn eine lineare Entwicklung der kirchlichen Inzestverbote vorausgesetzt wird. Selbst auf den Konzilien gibt es nämlich Beispiele von weniger umfassenden Inzestverboten, die zeitlich später erlassen worden sind. Zum Beispiel erwähnte das Konzil von Paris (567/573) nicht das Verbot der Ehe mit der Cousine ersten und zweiten Grades. Dies berechtigt

264 Dies ist ein Grund, warum Rudolf Buchners Plan einer „Geschichte der Quellen und Literatur des weltlichen Rechtes“ nicht verwirklicht worden ist: BuCHNER, Plan 1955. 
jedoch nicht zu dem Schluss auf eine weniger rigorose Mentalität der beteiligten Bischöfe. Ein zweiter Grund, warum das Inzestverbot bei der Datierung der Volksrechte zum Teil überschätzt wurde, ist die Vorstellung eines germanischen Widerstandes gegen das Verbot von Verwandtenehen. Aus diesem Grund verlegte man die Implementierung des Inzestverbots meist in eine möglichst späte Zeit, als der Einfluss der Idee eines christlichen Königtums bei den Franken Fuß fasste. Besonders deutlich hat sich diese Vorstellung eines germanischen Widerstands bei der Befassung mit der Lex Salica ausgewirkt. Da dieses Rechtsbuch im Frankenreich große Bedeutung erlangen sollte und mit über 80 Handschriften das am häufigsten überlieferte Volksrecht ${ }^{265}$ darstellt, ist ein näheres Eingehen auf das Inzestverbot der Lex Salica unentbehrlich.

\section{Chilperich I. und die Lex Salica}

Die Lex Salica ist in mehreren Fassungen erhalten, die teils merowingischer (ABC), teils karolingischer (DEK) Zeit entstammen. Von den 7 Handschriften der merowingischen Fassung steht das Inzestverbot nur in drei Exemplaren ${ }^{266}$. Diese werden als C-Fassung der Lex Salica bezeichnet und von der A-Fassung der anderen vier Überlieferungen abgegrenzt. Die C-Fassung unterscheidet sich auch durch ihren größeren Umfang von der A-Fassung. Insgesamt 1/6 der Bestimmungen sind Sondergut der C-Fassung. In der Forschung des 19. Jahrhunderts hat dies zur Auseinandersetzungen darüber geführt, ob die längere Version authentisch ist und später gekürzt wurde oder ob die kurze Version ursprünglich ist und später erweitert wurde. Georg Heinrich Pertz sprach sich für die längere C-Fassung aus, während Georg Waitz und Jean-Marie Pardessus der A-Fassung den Vorzug gaben ${ }^{267}$. Bruno Krusch gelang es, diese Debatte zugunsten der A-Fassung zu entscheiden, indem er ihren durchgängig heidnischen Charakter erwies ${ }^{268}$. Nach Krusch gibt es in der Handschrift A1 keinen einzigen Hinweis auf die Christianisierung der Franken oder auf eine Berührung der Franken mit einer christlichen Umgebung. A1 müsse daher als die älteste Version und die C-Fassung durch ihre Inzestvorschrift als spätere Überarbeitung betrachtet werden. Da in tit. 47 von A1 bereits eine Siedlung von Franken jenseits der Loire in Betracht gezogen wird, kam für Krusch nur Chlodwig als Initiator der Lex Salica in Frage, der die Herrschaft der Franken durch den Sieg gegen die Westgoten auf Aquitanien ausdehnte. Seit Krusch gilt daher die A-

265 Vgl. den Überblick in der MGH Edition von Karl August Eckhardt.

266 Und zwar in Paris, Bibliothèque Nationale, Lat. 4403b (Sigle C5); Paris, Bibliothèque Nationale, Lat. 18237 (C6) und Leiden, Bibliotheek der Rijksuniversiteit, BPL 2005 (Sigle C6a). Zu diesen Handschriften vgl. Mordek, Bibliotheca 1995.

267 Vgl. EскнаRdt, Einführung 1954, 45-47; Rold, Geschichte 1972, 125-131. Erneut trat Mario Krammer für die C-Fassung ein: Krammer, Untersuchungen 1905.

268 Krusch, Umsturz 1916; Ders., Chlodwig 1935; Ders., Lex 1937. 
Fassung der Lex Salica als ursprünglich heidnisches Gesetzeswerk König Chlodwigs ${ }^{269}$.

Der Datierung der uns interessierenden C-Fassung hat sich erst Karl August Eckhardt eingehend zugewandt ${ }^{270}$. Für ihn erklären sich die überschüssigen Titel der C-Fassung aus einer von ihm postulierten B-Fassung, die er aus dem Erstdruck der Lex Salica durch Herold ableitet. Als Sondergut belässt Eckhardt der C-Fassung nur den Prolog und das Inzestverbot. Beides ist nämlich nicht in die karolingische DE-Fassung eingegangen, die auch aus B entstammen soll. Den Prolog schreibt Eckhardt aufgrund von formelhaften Übereinstimmungen dem unter Gunthram und Childebert II. wirkenden Referendar Asclepiodo$\operatorname{tus}^{271}$ zu. Die Inzestbestimmung datiert er ebenfalls in das späte 6. Jahrhundert, da sie vom Konzil von Tours (567) abhängig sei. Denn sowohl in der Lex Salica als auch auf dem Konzil von Tours wird dieselbe Stelle aus den Interpretationen zum Codex Theodosianus zitiert. Da man in Tours nicht auf das weltliche Recht der Franken habe zurückgreifen können, sondern das römische Recht zitierte, müsse das Inzestverbot der Lex Salica nach 567 entstanden sein. Eckhardt favorisiert König Gunthram als Autor der C-Fassung, weil sein Neffe Childebert II. im Jahr 596 ein eigenes Inzestverbot erließ, das sich mit der Bestimmung der Lex Salica nicht berührt. Er bezeichnet daher die C-Fassung als Recensio Guntchramna.

Eckhardt legte seine Anschauung über die sukzessive Entstehung der Lex Salica-Fassungen seiner maßgeblichen Edition der MGH zugrunde, obwohl bereits kurz nach der erstmaligen Publikation seiner Ergebnisse deutliche Kritik geübt wurde. Unter Beschuss ist besonders die Rekonstruktion der B-Fassung geraten. Schmidt-Wiegand hielt Eckhardt entgegen, dass Herold auch eine DFassung bekannt gewesen sein könnte und daher die Edition Herolds als Zeuge ausscheiden müsse ${ }^{272}$. Nehlsen und Murray haben diese Kritik vertieft ${ }^{273}$, und Harald Siems hat die Unzuverlässigkeit von Herold endgültig erwiesen ${ }^{274}$. Unhaltbar ist auch Eckhardts Zuschreibung der B-Fassung an Theuderich I. Die einzige Quelle, die eine legislative Tätigkeit eines Theuderich belegt, ist der

269 Eckhardt, Einführung 1954, 205; Schmidt-Wiegand, Spuren 1994; Wood, Kingdoms 1994, 112; Anderson, Colonies 1995; Charles-Edwards, Law 2000, 271 f; Wormald, Leges 2003, 29. Die Ansicht von Poly, Corde 1993, die Lex Salica sei Ende des 4. Jahrhunderts entstanden, stieß zu Recht auf Ablehnung: Wood, Law 1996, 6 f.; Wormald, Making 1 1999, 40; Pohl, Völkerwanderung 2005, 181; Siems, Weiterwirken 2006, 246. Einen Kern aus der Zeit vor Chlodwig akzeptieren MAgNou-NorTIER, Remarques 1997, 502, und Guillot, Justice 1995, 678.

270 ECKHARDT, Einführung 1954, 216-218.

271 Zu seiner Person vgl. Beyerle, Leges 1919, 409; Stroheker, Adel 1948, 149; PLRE 3 1992, $134 \mathrm{f}$.

272 Schmidt-Wiegand, Ausgabe 1959, 305-310.

273 Nehlsen, Sklavenrecht 1972, 257; Murray, Structure 1983, 124-127 und 231-233.

274 SiEms, Studien 1980, 58-113. 
Prolog zur Lex Baiuvariorum aus dem frühen 8. Jahrhundert ${ }^{275}$. Roger Collins machte jedoch plausibel, dass der Theuderich der Lex Baiuvariorum nicht mit dem fränkischen Herrscher des 6., sondern mit dem westgotischen König des 5. Jahrhunderts zu identifizieren ist ${ }^{276}$. Die Rekonstruktion der B-Fassung bricht somit in sich zusammen. In der Forschung sind die Konsequenzen daraus noch nicht hinreichend bedacht worden. Denn die B-Fassung diente Eckhardt als missing link zwischen $\mathrm{A}$ und $\mathrm{C}$ sowie zwischen $\mathrm{A}$ und $\mathrm{D}$ und überdeckte somit alle Ungereimtheiten der Überlieferung. Die Ablehnung von B bringt das gesamte Gebäude der Edition Eckhardts zum Einsturz.

Die Datierung der C-Fassung durch Eckhardt wurde zunächst nur im Detail angefochten. Die Zuschreibung des Prologs an Asclepiodotus wies Franz Beyerle zurück, weil die formelhaften Ähnlichkeiten für eine Zuschreibung nicht ausreichten $^{277}$. Eckhardt hat in seiner kritischen Edition den Text überdies zurechtgemacht, um die Übereinstimmung deutlicher hervortreten zu lassen, obwohl die besseren Handschriften den im Obertext edierten Wortlaut nicht abstützen. Dies diente ihm wiederum in einem perfekten Zirkelschluss zur Begründung der Autorschaft des Asclepiodotus ${ }^{278}$. Erst jüngst wurde von William Daly auch die Datierung der Inzestbestimmung in Frage gestellt ${ }^{279}$. Daly macht auf den unterschiedlichen Wortlaut des Breviartextes in der Lex Salica und im Kanon des Konzils von Tours aufmerksam ${ }^{280}$. Das Inzestverbot der Lex Salica könne demnach unmöglich vom Konzilstext abhängig sein und müsse auf eine andere Überlieferung des Breviars zurückgehen. Daly erwägt deshalb eine Zuschreibung des Inzestverbots an Chlodwig, da ihn die zeitgenössischen Quellen im Unterschied zu den romanhaften Anekdoten Gregors von Tours als christlichen Herrscher charakterisieren. In dem Brief an die Bischöfe Aquitaniens, dem einzigen Dokument, das von Chlodwig selbst überliefert ist, gebe er sich eindeutig als christlicher König zu erkennen. Für Daly spricht nichts dagegen, ihn auch zum Autor des Inzestverbots der Lex Salica zu erklären.

Aus dieser Kritik an der Auffassung Eckhardts sind zwei Schlussfolgerungen zu ziehen: Erstens muss die unterschiedliche Denomination der merowingischen und karolingischen Fassung durch Eckhardt endgültig in den Orkus verwiesen werden. Die Unterscheidung zwischen merowingischem Pactus legis Salicae und karolingischer Lex Salica hat keine Grundlage in den Handschrif-

275 Lex Baiuvariorum prol. (MGH LL nat. Germ. 5/2, 201).

276 Collins, Theodebert I 1983, 26.

277 Beyerle, Kleinreich 1956, 384; Murray, Structure 1983, 126.

278 Die Wörter auxiliante domino sind in keiner C-Handschrift, sondern nur in K31 belegt: Lex Salica prol. (MGH LL nat. Germ. 4/1, 2). Diese Formel steht auch im von Asclepiodotus formulierten Vertrag von Andelot und gilt ЕскнавDт, Einführung 1954, 171 , deshalb als authentisch.

279 Daly, Clovis 1994, $652 \mathrm{f}$.

280 DaLY, Clovis 1994, 653. 
$\operatorname{ten}^{281}$ und verdeckt die Tatsache, dass die gravierendsten Unterschiede nicht die merowingische von der karolingischen Version, sondern die A von der C-Fassung trennen. Zweitens müssen alle Zusätze der C-Fassung bei einer Datierung in Betracht gezogen werden, da ihre Ableitung aus der rekonstruierten B-Fassung nicht mehr trägt. Nicht nur Prolog und Inzestverbot sind Sondergut der CFassung, sondern alle nicht in A tradierten Bestimmungen.

Im Rahmen dieser Arbeit ist es nicht möglich, auf alle neuen Bestimmungen der C-Fassung im Einzelnen einzugehen. Beim jetzigen Stand der Forschung erscheint als einziger Fixpunkt die Datierung von tit. 35, 8. Dieser Abschnitt handelt von der Haftung des Herrn für den Mord seines Sklaven. In der CFassung wird der Satz eingefügt: „Wenn der Herr es verstanden hat, kann er von Rechts wegen einwenden, so dass er nichts zahlen muss “282. Die Rechtshistoriker sind sich darin einig, dass dieser Zusatz dem Herrn des Sklaven ermöglichen soll, sich vollkommen von einer Haftung frei zu machen ${ }^{283}$. Die Worte de lege sind demnach als ein Verweis auf das Edictum Chilperici aus der Zeit zwischen 561 und 584 anzusehen. Darin wird dem Herrn eines Sklaven die Möglichkeit gegeben, durch einen Eid mit sechs Eidhelfern sein reines Gewissen kundzutun und die Haftung für den Mord abzuwehren ${ }^{284}$. Voraussetzung für die Haftungsbefreiung ist also ein sog. ,Gefährdeeid', d.h. eine unmittelbar nach der Tat abgelegte eidliche Versicherung, der Mord des Sklaven sei ohne Wissen des Herrn erfolgt. Der Zusatz der C-Fassung legt also eine Datierung in die Zeit Chilperichs nahe. Diese Hypothese wird durch die Inzestbestimmung der CFassung erhärtet. Sie hat gegenüber dem zitierten Breviartext eine charakteristische Erweiterung erfahren: Der Text wurde um das Verbot der Ehe mit der Frau des verstorbenen Onkels erweitert - also genau um das Verbot jener Ehe, die Chilperichs Sohn Merovech im Jahr 576 gegen den Willen seines Vaters einging ${ }^{285}$. „Als Chilperich davon hörte, dass er [Merovech] sich nämlich gegen das Recht und das kirchliche Gebot der Frau seines Onkels verbunden habe, war er überaus erbittert ${ }^{\text {'286 }}$. Chilperich war entschlossen, die Ehe zu trennen, und schickte seinen widerspenstigen Sohn ins Kloster. Merowech konnte entfliehen

281 So bereits NEHLSEN, Sklavenrecht 1972, 257.

282 Et si intellexerit de lege potest se obmallare, ut hoc non solvat. Lex Salica (C) 35, 8 (MGH LL nat. Germ. 4/1, 131).

283 Brunner, Missethat 1890, 502 f.; Geffeken, Lex 1898, 152; Beyerle, Werk 1961, 32; Nehlsen, Sklavenrecht 1972, 298 (mit weiterer Literatur).

284 Edictum Chilperici c. 6 (MGH Capit. 1, 8).

285 Siehe 96.

286 Haec audiens Chilpericus, quod scilicet contra fas legemque canonicam uxorem patrui accepisset, valde amarus dicto citius ad supra memoratum oppidum dirigit. Gregor von Tours, Decem libri historiarum V 2 (MGH SS rer. Merov. 1/1, 195). Vgl. die oben 96 Anm. 108 zitierte Literatur. 
und fand in der Kirche des hl. Martin in Tours Asyl. Im Jahr 577 wurde er in einen Hinterhalt gelockt und ermordet.

Die Zuschreibung an Chilperich passt auch zu den in der Lex Salica erwähnten Grenzen des fränkischen Siedlungsgebiets zwischen Kohlenwald und Loire. Die bisherigen Kandidaten Gunthram und Childebert II. scheiden meines Erachtens allein deshalb aus, weil sie nie über das Gebiet zwischen Kohlenwald und Loire herrschten ${ }^{287}$. Es kommen daher nur Chilperich und sein Sohn Chlothar II. in Frage. Das einzige erhaltene Gesetz Chilperichs, das Edictum Chilperici, sticht unter den anderen Kapitularien des 6. Jahrhunderts durch die enge Bezugnahme auf die Lex Salica hervor ${ }^{288}$. Von Chlothar II. kennen wir eine Überarbeitung der Lex Salica, die für das Reich seines Sohnes Dagobert erlassene Lex Ribuaria. Die Lex Ribuaria ist eine Neufassung der Lex Salica im eigentlichen Sinn, weil die Rechtsnormen an die neue Wirklichkeit angepasst wurden ${ }^{289}$. Der Einfluss der Kirche machte sich deutlicher bemerkbar, wie insbesondere die erstmals erwähnten Klerikerwergelder bezeugen. Seit der Lex Ribuaria wurden in allen fränkischen Volksrechten eigene Wergeldbeträge für Kleriker festgelegt und auch im 8. Jahrhundert der DE-Fassung der Lex Salica angefügt ${ }^{290}$. Chlothar II. kommt deshalb als Autor der C-Fassung nicht in Betracht.

Nach dieser ausführlichen Diskussion der Datierung können wir uns dem Inhalt der Inzestbestimmung der Lex Salica zuwenden ${ }^{291}$. Nach dem Text des Breviars wird die Ehe mit der Nichte, der Cousine und der Schwägerin unter Strafe gestellt. Das Verbot der Ehe mit der Frau des Onkels tritt als durch Lev. 18, 14 begründetes biblisches Verbot zum römischen Recht hinzu. Als Strafe werden die Trennung der Ehepartner und der Ausschluss der Kinder vom Erbe ausgesprochen. Die Infamie trifft aufgrund eines Missverständnisses des Breviars nicht die Eheleute, sondern die Kinder ${ }^{292}$. Chilperich bewegt sich damit

287 Nach Eckhardt ist die C-Fassung nur für die von Gunthram beherrschte civitas Sens erlassen: EскHARDT, Einführung 1954, 218.

288 Beyerle, Werk 1961; Kroeschell, Recht 1995, 751-753; Woll, Untersuchungen 1995, 29-33. Im Edictum begegnen überdies die Eingangsworte des Prologs der CFassung (placuit et convenit): Chilperici Edictum c. 3 und c. 6 (MGH Capit. 1, 8). Aus dieser Ähnlichkeit hat bereits BEyerle, Normtypen 1924, 230, auf die Autorschaft Chilperichs geschlossen. Zum Sinn dieser Worte vgl. Guillot, Justice 1995, 682.

289 Siehe 186-190.

290 Lex Ribuaria 40, 5-9 (MGH LL nat. Germ. 3/2, 93 f.). Erstmals in der von Pippin erlassenen Fassung: Lex Salica (D) 78 (MGH LL nat. Germ. 4/2, 124-126).

291 Si quis sororis aut fratris filiam aut certe ulterius gradus consobrinam aut certe fratris uxorem aut avunculi sceleratis nuptiis sibi iunxerit, hanc poenam subiaceant, ut de tale consortio separentur; atque etiam, si filios habuerint, non habeantur legitimi heredes, sed infamia sint notati. Lex Salica (C) 13, 11 (MGH LL nat. Germ. 4/1, 62 f.).

292 Darauf wies Zeumer, Geschichte 3 1899, 615, hin. Auch der westgotische Gesetzgeber hat den Breviar-Text in diesem Sinn missverstanden. 
wie Theoderich der Große im Rahmen des römischen Rechts. Auffallend bleibt freilich, dass die Infamie als Rechtsinstitut der Lex Salica unbekannt ist und nicht wie im Edictus Rothari durch eine Geldbuße ersetzt wird. Auch die Tatsache eines direkten Zitats aus dem römischen Recht, sonst innerhalb der Lex Salica nicht belegt, verweist auf die Sonderstellung des Inzestverbots. Im Gegensatz zu später erlassenen Verboten erscheint es als wenig angepasst an die Rahmenbedingungen des fränkischen Rechts. Ob von dieser Bestimmung ein Einfluss auf die Praxis ausging, ist deshalb zweifelhaft.

Die Praxisferne der Bestimmung schließt es meiner Ansicht aus, Chilperich ein konkretes Ziel wie die Zerschlagung der fränkischen Sippenverbände als Grund für den Erlass des Inzestverbots zu unterstellen. Michel Rouche schreibt die Inzestbestimmung Chlodwig zu und sieht darin einen Aspekt seiner historischen Größe, da er dadurch die Öffnung der germanischen Sippe erzwungen und die romanisch-germanische Synthese im Frankenreich ermöglicht habe ${ }^{293}$. Eine solche Mutmaßung über die Intentionen und über die politische Programmatik eines Herrschers, über den kaum etwas anderes bekannt ist als die bei Gregor von Tours überlieferten Anekdoten, erscheint mir problematisch. Auch die Voraussetzungen dieser Hypothese sind fragwürdig. Die Geschlossenheit der germanischen Sippe ist bereits seit längerem als Konstrukt der rechtshistorischen Schule des 19. Jahrhunderts entlarvt worden ${ }^{294}$. Eine endogame Ehepraxis der Franken ist gleichfalls historisch nicht nachweisbar. Der fränkische König hätte eine weitaus umfassendere Inzestbestimmung erlassen müssen, um die von Rouche postulierte Wirkung zu erzielen. Das Inzestverbot der Lex Salica, sofern es tatsächlich von Chilperich und nicht von Chlodwig herrührt, sollte dagegen meines Erachtens als ein Bekenntnis zum römischen Erbe gesehen werden. Als Herrscher, der sich in theologische Debatten einmischte, als Literat und Dichter dilettierte und in Paris und Soissons Circusbauten errichten ließ, gab er sich wie kein anderer Merowingerkönig der Nachahmung des römischen Kaisertums hin ${ }^{295}$. Die Übernahme des Inzestverbots aus dem römischen Recht fügt sich in diese retrospektive Politik ein: Ohne praktische Auswirkungen blieb es ebenso ein Fremdkörper in der Lex Salica, wie auch die Circusbauten und die theologischen Ambitionen des Königs auf Unverständnis trafen. Allein eine symbolische Wirkung des Inzestverbots lässt sich feststellen. Nachdem Bischof Praetextatus von Rouen im Jahr 576 der Inzestehe Merovechs zugestimmt und selbst Gregor von Tours keinen nach-

293 Rouche, Clovis 1996, 331.

294 Genzmer, Sippe 1950; Kroeschell, Sippe 1960; Murray, Structure 1983; HechBERGER, Adel 2005, 303-306.

295 Gregor von Tours, Decem libri historiarum V 17 (MGH SS rer. Merov. 1/1, 216); V 44 (MGH SS rer. Merov. 1/1, 252-254). Vgl. Halsall, Chilperic 2002. 
haltigen Widerstand geleistet hatte ${ }^{296}$, konnte sich Chilperich durch den Erlass des Inzestverbots als eigentlicher Wahrer der göttlichen Ordnung inszenieren. Im Rahmen des Hochverratsprozess gegen Praetextatus, der im Jahr 577 den gallischen Episkopat erschütterte, dürfte dieser Schachzug seine Wirkung nicht verfehlt haben. Am ersten Verhandlungstag konfrontierte Chilperich den Bischof vor 45 Amtskollegen mit diesem Vorwurf: „Was kam dir in den Sinn, Bischof, dass du meinen Feind Merovech, der mir gegenüber als Sohn hätte handeln sollen, mit seiner Tante, d.h. mit der Frau des Vaterbruders, trautest? Oder war es dir etwa nicht bekannt, was hierüber die Bestimmungen der Kirche festgesetzt haben? ?97“ $^{27}$

\section{Verschärfung um 600}

Im Jahr 585 verhängte König Childebert II. die Todesstrafe über den vornehmen Franken Magnovaldus. Man erzählte sich, er habe seine Frau umgebracht, um nach dem Tod seines Bruders ungehindert seine Schwägerin zu heiraten. Gregor von Tours lässt es offen, ob Magnovaldus sich die Strafe durch den Inzest oder durch den Mord an seiner Frau zugezogen hat ${ }^{298}$. Aus heutiger Perspektive würde man zweifellos den Mord und nicht den Inzest als Begründung für die Hinrichtung von Magnovaldus annehmen. Für das 6. Jahrhundert ist jedoch beides denkbar. Für Inzest ist nämlich das Bemühen des Königs belegt, dieses Vergehen mit der Todesstrafe zu ahnden. Wenige Jahre nach dem erwähnten Vorfall erließ Childebert ein entsprechendes Gesetz. Die Decretio Childeberti publizierte der König im Jahre 596 auf dem Höhepunkt seiner Macht, als er nach dem Tod Gunthrams weite Teile des Frankenreichs in seiner Hand vereinen konnte ${ }^{299}$. Aus der Kanzlei seines Onkels Gunthram übernahm er den Referendar Asclepiodotus, der die Decretio Childeberti unterfertigte. Später wurde dieser Mann aus dem galloromanischen Senatorenadel Verwalter der Provence und trat in Briefkontakt mit Gregor dem Großen. Seine Ver-

296 Gregor von Tours, Decem libri historiarum V 14 (MGH SS rer. Merov. 1/1, 208). Über Gregors Verzagtheit vgl. Shanzer, History 2002, 406. Ausführlich zum Prozess Jussen, Patenschaft 1991, 177-192.

297 Quid tibi visum est, o episcope, ut inimicum meum Merovechum, qui filius esse debuerat, cum amita sua, id est patrui sui uxore, coniungeres? An ignarus eras, quae pro hac causa canonum statuta sancsexissent? Gregor von Tours, Decem libri historiarum V 18 (MGH SS rer. Merov. 1/1, 217). Praetextatus hatte die Kanones des Konzils von Tours (567) und von Paris (567/573) unterschrieben. Beide Konzilien hatten ausdrücklich die Ehe mit der Frau des Onkels untersagt.

298 Autumabant tamen quidam, eo quod post mortem fratris diversis plagis coniugem affectam interfecisset et uxorem fratris adscisset toro, extetisse causam, qua interimeretur. Gregor von Tours, Decem libri historiarum VIII 36 (MGH SS rer. Merov. 1/1, 404).

299 Zur politischen Situation vg. EwIG, Merowinger 2001, $49 \mathrm{f}$. 
trautheit mit dem römischen Recht bezeugen die von ihm unterfertigten Dokumente $^{300}$.

Die Kenntnis des römischen Rechts wirkte sich auf die Grundzüge der Decretio aus, insbesondere auf das drakonische Strafrecht. Statt den üblichen Geldbußen setzte Childebert für grundlose Tötung und für Frauenraub die Todesstrafe fest ${ }^{301}$. Auch ein Richter, der einen überführten Dieb freigelassen hatte, musste dafür mit seinem Leben büßen ${ }^{302}$. Nicht alle Verfügungen der Todesstrafe lassen sich jedoch auf das Weiterwirken des römischen Rechts zurückführen. Neu war zum Beispiel das Verfahren des sog. ,Übersiebnens'. Bezeugten fünf oder sieben vertrauenswürdige Gewährsleute mit Eid, dass eine Person einen Diebstahl begangen hatte, sollte diese hingerichtet werden ${ }^{303}$. Diese Regelung reagierte auf die weitgehende Privatisierung der Strafverfolgung im 6. Jahrhundert und versuchte für das besonders schwer zu unterdrückende Räuberunwesen eine besonders einfache Methode der Überführung zu etablie$r^{304}$. Ebenfalls neu war die Verhängung der Todesstrafe bei Inzest mit der Stiefmutter. Einige Historiker ${ }^{305}$ erwägen zwar das Vorbild eines Gesetzes von Constantius II., doch betrifft es nur die Ehe mit der blutsverwandten Nichte und wurde später ausdrücklich aufgehoben. Wie Mikat richtig feststellte, ist die drakonische Bestrafung von Lev. 20, 11 abhängig, da dort auch die Todesstrafe für diese Eheform angedroht wird ${ }^{306}$. Die Decretio belegt also den Einfluss des Alten Testaments im Recht des ausgehenden 6. Jahrhunderts. Es wird zwar weder beim Inzest noch bei der Bestrafung der Missachtung der Sonntagsruhe, die den Text der Decretio beschließt ${ }^{307}$, explizit das Alte Testament zitiert, doch sind diese gesetzlichen Neuerungen ohne diesen Hintergrund nicht verständlich.

Im Inzestgesetz der Decretio wird nur im Fall der Stiefmutter die Todesstrafe verhängt ${ }^{308}$. Bei den übrigen Verwandtschaftsverhältnissen sieht die Decretio eine andere Vorgehensweise vor. Der König befahl „Gutmachung gemäß Anordnung der Bischöfe“. Weiter heißt es: „Wer aber auf seinen Bischof nicht hören will und exkommuniziert wird, erdulde ewiges Urteil bei Gott und sei von unserem Hof gänzlich ausgeschlossen; und alle seine Güter soll er, der die

300 Siehe 177 Anm. 271.

301 Decretio Childeberti c. 4-5 (MGH Capit. 1, 16). Vgl. Beyerle, Leges 1929, 412 f.;

Weitzel, Strafe 1994, 89 f.; Woll, Untersuchungen 1995, 87-114.

302 Decretio Childeberti c. 7 (MGH Capit. 1, 17).

303 Decretio Childeberti c. 7 (MGH Capit. 1, 17). Vgl. Esders, Rechtstradition 1997, 148.

304 Weitzel, Strafe 1994, $115 \mathrm{f}$.

305 FLEURY, Recherches 1933, 111, stützt sich auf die vom römischen Recht beeinflussten Formulierungen; WoLL, Untersuchungen 1995, 97.

306 Мікат, Inzestgesetzgebung 1994, 136.

307 Decretio Childeberti c. 14 (MGH Capit. 1, 17).

308 Uxorem patris si quis acceperit, mortis periculum incurrat. Decretio Childeberti c. 2 (MGH Capit. 1, 15). 
Heilmittel seines Seelsorgers nicht annehmen wollte, zugunsten seiner legitimen Verwandten verlieren " ${ }^{\text {309 }}$. Anders als in der realitätsfernen Bestimmung der Lex Salica wird also nicht Trennung und Infamie durch staatliche Organe angedroht. Da im späten 6. Jahrhundert die Amtsträger nur bei Angelegenheiten des Königs von sich aus tätig wurden und andere Fälle allein durch Anklagen vor das Gericht gebracht wurden ${ }^{310}$, musste sich ein solches am römischen Recht ausgerichtetes Procedere als wirkungslos erweisen. Die Decretio trug den neuen Gegebenheiten Rechnung. Die Trennung der Eheleute und die Verhängung der Buße wurden den Bischöfen anvertraut. Erst bei hartnäckigem Widerstand der betroffenen Personen sollte die weltliche Macht eingeschaltet werden. Als Straffolge sah Childebert den Ausschluss vom Hofdienst und die Übertragung der Güter an die nächsten Verwandten vor ${ }^{311}$. Dies lässt ebenfalls den Realitätssinn der Decretio erkennen, weil die erste Maßnahme vom König und die zweite von interessierten Parteien in Gang gesetzt werden konnte. Der Ausschluss vom Hofdienst lässt sich als Aktualisierung der Infamie, die Übertragung der Besitzrechte an die Verwandten als Aktualisierung der Konfiskation verstehen.

Diese Straffolgen wurden dreißig Jahre später auf dem Konzil von Clichy (626/627) wiederholt und konkretisiert. Der Ausschluss vom Hofdienst wurde durch das Verbot ergänzt, vor Gericht Prozesse anzustrengen ${ }^{312}$. Die Bischöfe versuchten also, den vollen Rechtsgehalt der Infamie wiederherzustellen. Außerdem sollte aus der Sicht des Konzils Vorsorge getroffen werden, dass die des Inzests überführten Personen nicht durch Kauf oder königliche Verfügung wieder in den Besitz ihrer Güter gelangten, solange sie nicht durch Trennung und Buße ihre Einsicht bewiesen hätten. Diese Ermahnung an die Adresse der Amtsträger ist ebenfalls eine Ergänzung aus dem römischen $\operatorname{Recht}^{313}$. Mit die-

309 De praeteritis vero coniunctionibus, quae incestae esse videntur, per praedicationem episcoporum iussimus emendare. Qui vero episcopo suo noluerit audire et excommunicatus fuerit, perenni condemnatione apud Deum sustineat et de palatio nostro sit omnino extraneus, et omnes res suas parentibus legitimis amittat, qui noluit sacerdotis sui medicamenta sustinere. Decretio Childeberti c. 2 (MGH Capit. 1, 15).

310 Jürgen Weitzel, Art. „Gerichtsverfahren“, in: RGA 11 (²1998) 153-171.

311 Fleury, Recherches 1933, 111, betont die Parallele zu Cod. Theod. 3, 12, 3, doch dort wird nur den Kindern der Inzestehe die Erbschaft bestritten. - Der Ausschluss vom Hofdienst impliziert vielleicht auch den allgemeinen Ausschluss von öffentlichen Ämtern. Im westgotischen Recht kann palatinum officium diese Bedeutung haben: KING, Law 1972, 56. Dann wäre in dieser Bestrafung eine Parallele zur Niederlegung des cingulum militare zu sehen, die Justinian bei Inzest verordnete: Novella 12, 1 (95).

312 ... utrique communione priventur et neque in palatio habere militiam neque in forum agendarum causarum licentiam non habebunt. Konzil von Clichy (626/627) c. 10 (MGH Conc. 1, 198).

313 Res autem eorum ad proprios parentes usque ad sequestratione perveniant sub ea conditione, ut, antequam segregentur, per nullum ingenium neque per parentes neque per emtionem 
sem Rückgriff auf römisches Recht zeigte der Episkopat auf dem Konzil von Clichy nicht denselben Realitätssinn wie Childebert II. in seiner Decretio.

Zuletzt muss noch ein Blick auf den Umfang des Inzestverbots der Decretio geworfen werden. Die Ehe mit der Stiefmutter nimmt wie gesagt eine Sonderstellung ein, da allein sie mit der Todesstrafe geahndet werden sollte. Die anderen Strafen betreffen die Ehe mit der Frau des Bruders, der Schwester der Frau, der Frau des Onkels sowie mit der Frau eines jeden Blutsverwandten ${ }^{314}$. Mit anderen Worten werden Ehen unter Schwiegerverwandten prinzipiell untersagt. Das Verbot der Ehe unter Blutsverwandten wird dagegen nicht ausdrücklich genannt, sondern bereits vorausgesetzt. Ziel der Bestimmung ist die Gleichstellung von Blutsverwandten und Schwiegerverwandten. Unklar bleibt dabei, wie weit die Verwandtschaft in den Augen des Gesetzgebers reichte. Da die kirchlichen Inzestverbote des 6. Jahrhunderts genau der römischen Verwandtschaftsgrenze entsprachen, ist die Vermutung plausibel, dass auch hier die Definition des römischen Rechts zugrunde gelegt wurde. Childebert II. sanktionierte also die kirchliche Gesetzgebung, setzte ausdrücklich die Schwiegerverwandten mit den Blutsverwandten gleich und aktualisierte die Straffolgen für das Inzestdelikt.

Anders als die Lex Salica ist die Decretio Childeberti nicht folgenlos geblieben. Chlothar II. ließ den mächtigen burgundischen Adeligen Godinus hinrichten, nachdem dieser seine Stiefmutter zur Frau genommen hatte ${ }^{315}$. Hinter dieser Hinrichtung steht aber nicht nur das Gesetz Childeberts II., sondern auch das eminent politische Interesse des Königs. Chlothar wollte verhindern, dass Godinus in eine ähnlich unanfechtbare Machtstellung wie sein Vater, der Hausmeier Warnachar, eintreten und sich als Zwischengewalt zwischen dem König und den burgundischen Adeligen etablieren würde. Die strenge Anwendung der Decretio war dem König willkommen, um einen poli-

neque per auctoritatem regiam ad proprias perveniant facultates, nisi prefatum scelus sequestrationis separatione et paenitentia feriatur. Konzil von Clichy (626/627) c. 10 (MGH Conc. 1, 198). Abhängig von Lex Romana Visigothorum, Cod. Theod. 3, 12, 3 (90): ... aut etiamsi filios habuerint, non per suppositam aut per aliam personam aut per commenticiam donationem ad illos quicquam ex eorum facultate perveniat, sed ipsis mortuis ad legitimos heredes...

314 Decrevimus ut nullus incestuosum sibi societ coningio, hoc est nec fratris sui uxorem, nec uxoris suae sororem, nec uxorem patruo aut parentis consanguinei. Decretio Childeberti c. 2 (MGH Capit. 1, 15). Мікат, Inzestgesetzgebung 1994, 135, zieht uxorem patruo die Lesart uxorem patri vor. Diese ist jedoch nur durch späte Handschriften bezeugt (vgl. Eckhardt, Decretio 1967, 30 f.) und macht keinen Sinn, da die Stiefmutter dann zweifach genannt wäre. Die Erwähnung der Frau des Onkels kann angesichts von Lex Salica (C) 13, 11 (MGH LL nat. Germ. 4/1, 63) nicht überraschen. Mikat will den Verweis de praeteritis coniunctionibus nicht auf diese Inzestformen, sondern auf andere ungenannte beziehen. WoLl, Untersuchungen 1995, 97, übersetzt den Verweis (sicher unzutreffend) mit „über bereits geschlossene Ehen“.

315 Siehe $99 \mathrm{f}$. 
tischen Gegner auszuschalten. Trotz dieses Einzelfalls hat sich auf lange Sicht gesehen die Todesstrafe für Inzest nicht durchgesetzt. Zeitgleich mit der Hinrichtung des Godinus ist die Lex Ribuaria erlassen worden, in der Exilierung und Konfiskation als Strafe für Inzest vorgesehen sind. Dieses Volksrecht der in der civitas von Köln lebenden Franken ${ }^{316}$ ist die letzte Quelle des weltlichen Rechts, mit dem wir uns in diesem Abschnitt befassen müssen.

Die Forschungen Franz Beyerles haben endgültig der These einer Entstehung der Lex Ribuaria im frühen 7. Jahrhundert zum Durchbruch verholfen ${ }^{317}$. Da dieses Gesetzbuch ganz ohne Einleitung oder Epilog überliefert ist, konnte die zeitliche Einordnung nur durch eine Verortung in der rechtshistorischen Entwicklung des Frankenreichs gelingen. Beyerle fand heraus, dass insbesondere das Kirchenrecht der Lex Ribuaria den Zustand des 7. Jahrhunderts widerspiegelt und unmöglich nach der Zeit der bonifatianischen Kirchenreform entstanden sein konnte. Das Recht der Ribuarier beschränkt sich in Hinblick auf kirchliche Belange auf den Schutz des Kirchenguts, der Kirchenhörigen und Kleriker, während das Interesse des Bonifatius für eine tiefere christliche Durchdringung der Lebensbereiche noch keine Spuren hinterließ. Beyerle war zudem davon überzeugt, eine präzise politische Veranlassung für die Aufzeichnung der Lex gefunden zu haben ${ }^{318}$. Die Niederschrift soll demnach stattgefunden haben, als Dagobert im Jahr 633 seinen Sohn Sigibert III. als König eines verkleinerten Teilreichs Austrasien eingesetzt hat. Denn nach Beyerle geht die Lex von einer kleinräumigen Herrschaft eines Königs aus, dessen Eingreifen im alltäglichen Rechtsleben auch bei belanglosen Fällen vorausgesetzt wird. Dies sei nur zur Zeit einer Beschränkung Austrasiens auf das Gebiet um Köln denkbar. Damals habe die Bedrohung Thüringens durch die slawischen Nachbarn eine Neuordnung des Rechts erforderlich gemacht.

Die präzise Datierung auf das Jahr 633 wurde von Karl August Eckhardt und Eugen Ewig in Zweifel gezogen, da sie auf einer falschen Deutung einer Stelle aus der Chronik Fredegars beruht ${ }^{319}$. Darin wird festgehalten, Dagobert habe seinem drei Jahre alten Sohn Sigibert den Aufenthalt in Metz zugewiesen, während die Regierungsgeschäfte Bischof Kunibert von Köln und Herzog Adalgisel übertragen worden seien ${ }^{320}$. Beyerle identifizierte Adalgisel als Herzog Ribuariens und beschränkte seine und Kuniberts Herrschaft auf den Kölner Raum. Ewig wandte ein, dass Metz eindeutig als Residenzort Sigiberts bezeichnet wird und Adalgisel als Herzog des gesamten Austrasien anzusehen ist.

316 Ewig, Civitas 1954; Nonn, Pagus 1983, 164-172; Matthias Springer, Art. „Ribuarier", in: RGA $24\left(^{2} 2003\right) 569-573$.

317 Beyerle, Lex 1928; Ders., Gesetzbuch 1935.

318 Beyerle, Kleinreich 1956.

319 Eскнardt, Lex Ribuaria 1959; Ewig, Teilreiche 1953, 199; Ewig, Stellung 1969, 462 471.

320 Chronicae quae dicuntur Fredegarii IV 75 (MGH SS rer. Merov. 2, 158 f.). 
Das Teilreich Sigiberts umfasste daher neben Ribuarien zumindest die Amtssprengel von Mainz, Worms und Speyer sowie den Maindukat, Thüringen und Hattuarien (Niederrhein). Eine Beschränkung des Teilreichs auf das Gebiet um Köln ist deshalb nicht zu begründen, ein Königreich Ribuarien hat es nicht gegeben. Ewig stellte sich daher erneut die Frage, wie die merkwürdige Tatsache zu erklären ist, dass für den kleinen Raum der civitas Köln ein eigenes Gesetzbuch erlassen wurde ${ }^{321}$. Seine Antwort beruht auf der überzeugenden Vermutung, nur Amtsträger vor Ort könnten an einer geographisch derart eingeschränkten Gesetzgebung Interesse gehabt haben. Eine Persönlichkeit, auf die das zutrifft und die zudem auch für den kirchlichen Einschlag des Gesetzbuchs verantwortlich zeichnen könnte, ist Bischof Kunibert von Köln. Er ist spätestens seit 630 als wichtiger Ratgeber in der Umgebung Dagoberts bezeugt ${ }^{322}$. Damit kommt Ewig zum Schluss, dass die Lex Ribuaria nach der Schaffung des Unterkönigtums für Sigibert im Jahre 633 durch die Initiative Kuniberts von Köln niedergeschrieben worden ist.

Die Datierung Ewigs, so überzeugend sie ist, kann nur zutreffen, wenn man an Beyerles These einer sukzessiven Entstehung der Lex Ribuaria festhält. Dem widerspricht jedoch der im Vergleich zur Lex Salica überraschend stabile textliche Bestand, obwohl die ersten Handschriften erst aus dem 9. Jahrhundert überliefert sind. Die Überlieferung spricht für eine einheitliche Entstehung ${ }^{323}$. Die Datierung sollte daher meines Erachtens von der einzigen Bestimmung der Lex Ribuaria ausgehen, die zeitlich eindeutig zu fixieren ist. Tit. 61, 2 ist nach übereinstimmender Forschungsmeinung ein Gesetz Chlothars II. ${ }^{324}$ Der Gesetzgeber spricht in erster Person Plural und verweist auf eine für die Kirche günstige Bestimmung, die er einst erlassen hatte und nicht widerrufen wolle. „Wir bezeichnen es nämlich als unerlaubt, was wir einst den Kirchen zugestanden, ihnen wieder zu entziehen “325. Der Verweis bezieht sich auf das von Chlothar im Jahr 614 erlassene Edikt von Paris. Nimmt man diesen Titel als Ausgangspunkt, fällt die Niederschrift der Lex Ribuaria in die Regierungszeit Chlothars II. und ist im Zusammenhang mit der Errichtung eines Unterkönigreichs für Dagobert im Jahr 623 zu sehen. In diesem Jahr ist tatsächlich eine Verkleinerung des Teilreichs Austrasien auf ein schmales Gebiet entlang des Rheins dokumentiert. Fredegar schreibt: „Chlothar machte seinen Sohn Dagobert zum Mitherrscher und setzte ihn als König über die Austrasier, wobei er

321 Ewig, Stellung 1969, $470 \mathrm{f}$.

322 Chronicae quae dicuntur Fredegarii IV 58 (MGH SS rer. Merov. 2, 150).

323 Vgl. Mayer, Entstehung 1886, 73-78.

324 Lex Ribuaria 61, 2 (MGH LL nat. Germ. 3/2, 109 f.). Vgl. Beyerle, Lex 1928, 311; Eскнardt, Lex Ribuaria 1959, 112-114; Ewig, Stellung 1969, 464; Ruth SснмidtWiegand, Art. „Lex Ribuaria“, in: RGA 18 (22001) 320-322, hier 320.

325 Quia inlicitum esse dicimus, quod dudum ecclesiis concessimus, iterum ab ecclesiis revocare. Lex Ribuaria 61, 2 (MGH LL nat. Germ. 3/2, 110). 
für sich das zurückbehielt, was zwischen Ardennen und Vogesen einerseits und den Grenzen von Neustrien und Burgund andererseits liegt ${ }^{\text {"326. }}$. Dieser Nachricht zufolge beschränkte sich das Herrschaftsgebiet Dagoberts auf den Raum Köln-Maastricht und Mainz-Worms-Speyer-Straßburg ${ }^{327}$. Nimmt man hinzu, dass allein für Chlothar II. durch sein Edictum und seine Praeceptio ein lebhaftes Interesse an schriftlicher Fixierung des Rechtes nachweisbar ist ${ }^{328}$, erscheint eine Datierung zwischen der Errichtung des Unterkönigtums für Dagobert und dem Tod Chlothars II. (623 bis 629/630) am plausibelsten. Eine Zuschreibung des kirchlichen Einflusses an Kunibert von Köln steht dem nicht entgegen, da der Bischof bereits in dieser Zeit als Ratgeber Dagoberts fungierte ${ }^{329}$.

Hundert Jahre nach der Lex Salica kam es also erneut zu einer Kodifikation des fränkischen Rechts. Wesentliche Teile der Lex Ribuaria sind der Lex Salica nachgebildet und bieten fränkisches Recht in einer aktualisierten Form ${ }^{330}$. Welche Fassung der Lex Salica den Redaktoren als Vorlage diente, ist nicht mehr herauszufinden ${ }^{331}$. Es lässt sich daher auch keine Aussage darüber treffen, ob das Inzestverbot der C-Fassung den Gesetzgebern um Chlothar II. bekannt gewesen war. Die Anlehnung an die Lex Salica manifestierte sich besonders an der Vorherrschaft des Kompositionsstrafrechts. Delikte wie Mord, Diebstahl und Körperverletzungen wurden nicht mit körperlichen Strafen, sondern mit Bußgeldzahlungen geahndet. Damit erteilten die Redaktoren dem Eindringen des peinlichen Strafrechts, wie es in der in Köln erlassenen Decretio Childeberti von 596 in Ansätzen eingeführt worden war, eine Absage. Die Beilegung von Streitfällen sollte weiterhin auf der Grundlage der Schlichtung zwischen den Parteien unter dem Druck öffentlicher Amtsträger stattfinden ${ }^{332}$.

Vor dem Hintergrund der Vorherrschaft des Kompositionsstrafrechts ist es umso bezeichnender, in welchen Fällen dieser Grundsatz durchbrochen wird. Die Todesstrafe wird nur in drei Fällen angedroht: wenn eine Urkunde des

326 ... Dagobertum, filium suum, consortem regni facit eumque super Austrasius regem instituit, retinens sibi, quod Ardinna et Vosacos versus Neuster et Burgundia excludebant. Chronicae quae dicuntur Fredegarii IV 47 (MGH SS rer. Merov. 2, 144).

327 Nach Ewig, Teilreiche 1953, 195 f., ist Fredegar hier einem Irrtum aufgesessen. Seine Argumentation ist jedoch nicht zwingend und wird von DEms., Stellung 1969, $466 \mathrm{f}$, nicht mehr ausdrücklich aufrecht erhalten.

328 ESDERs, Rechtstradition 1997.

329 Nach dem Tod Chlothars II. hörte Dagobert „weiterhin“ auf Kuniberts Ratschläge: Chronicae quae dicuntur Fredegarii IV 58 (MGH SS rer. Merov. 2, 150). - Die Beteiligung des thüringischen Herzogs Heden d.Ä. an der Entstehung der Lex Ribuaria (Mordek, Hedenen 1994) ist nicht hinreichend gesichert.

330 Beyerle, Lex 1928; Eckhardt, Lex Ribuaria 1959.

331 EсKhardt, Lex Ribuaria 1959, 119, ging von der B-Fassung aus, die jedoch in ihrer Existenz umstritten ist. Nach BuchNER, Untersuchungen 1952, lässt sich diese Frage nicht entscheiden.

332 Weitzel, Strafe 1994, 116. 
Königs angefochten wird, wenn Untreue gegenüber dem König nachgewiesen wird und wenn sich die öffentlichen Amtsträger Bestechlichkeit zu schulden kommen lassen ${ }^{333}$. In zwei weiteren Fällen wird die Todesstrafe abgeschwächt zu Exil und Konfiskation, und zwar bei Inzest und bei Verwandtenmord ${ }^{334}$. Im Vergleich zur Todesstrafe für die Ehe mit der Stiefmutter ist eine Milderung gegenüber der Decretio Childeberti eingetreten. Für alle anderen Inzestehen bedeutet die Lex Ribuaria eine Verschärfung, da die gemilderte Kapitalstrafe auf alle Inzestdelikte übertragen wird. Auch ist die Konfiskation härter als die Verhängung der Infamie über die Kinder in der Lex Salica, härter auch als die Übertragung der Eigengüter an die legitimen Verwandten in der Decretio Childeberti $^{335}$. Auf eine Verschärfung deutet zudem die fehlende Übertragung der Strafverfolgung auf die Kirche. Stattdessen wird in der Tradition des römischen Rechts die Durchsetzung des Inzestverbots ausschließlich der staatlichen Rechtspflege übertragen. Inzest zählt dabei zu den wenigen Delikten, bei denen zahlungsfähige Freie einer amtlichen Strafe unterliegen. Öffentliches Strafrecht setzte sich also im Umkreis des Königs ${ }^{336}$, bei Rechtspflegedelikten sowie bei Inzest und Verwandtenmord durch.

Über den Umfang des Inzestverbots gibt die Lex Ribuaria keine Auskunft. Es heißt schlicht: „Wenn aber jemand einen Blutsverwandten tötet oder Inzest begeht, nehme er das Exil auf sich, und alle seine Güter werden dem Fiskus

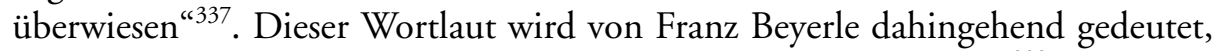
dass die Abgrenzung des Kreises der Verwandten vorausgesetzt ist ${ }^{338}$. Entweder verweist das Inzestverbot auf die kirchlichen Regelungen, oder es sind alle Blutsverwandten eingeschlossen. Beides ist möglich und läuft auf dasselbe Ergebnis heraus, wenn man die römisch-rechtliche Definition der Verwandtschaft zugrunde legt. Da der gesamte Titel, auch der Teil zum Verwandtenmord ${ }^{339}$, auf römischem Vorbild beruht, ist diese Annahme nahe liegend.

Als Neuerung der Lex Ribuaria ist die Verbindung von Inzest und Verwandtenmord anzusehen. In der römischen Tradition bezeichnete incestum auch den unerlaubten Geschlechtsverkehr mit Vestalinnen ${ }^{340}$. Nach der Christiani-

333 Lex Ribuaria 59, 3 (MGH LL nat. Germ. 3/2, 107); 72, 1 (MGH LL nat. Germ. 3/2, 123); 91 (MGH LL nat. Germ. 3/2, 133).

334 Lex Ribuaria 72, 2 (MGH LL nat. Germ. 3/2, 124).

335 Beyerle führt dies im Sachkommentar zur Edition (MGH LL nat. Germ. 3/2, 171) auf die Geldgier Dagoberts zurück.

336 Vgl. Weitzel, Strafe 1994, 137 f.; Ders., Majestätsverbrechen 2002.

337 Si autem quis proximum sanguinis interfecerit vel incestum commiserit, exilio susteneat, et omnes res suas fisco censeantur. Lex Ribuaria 72, 2 (MGH LL nat. Germ. 3/2, 124).

338 Beyerle, Lex 1928, 331 f. Krusch, Forschungen 1927, 160, behauptet eine Abhängigkeit von der Lex Alamannorum. Dort ist jedoch weder Exil noch Konfiskation vorgesehen, siehe 192 Anm. 354.

339 Codex Theodosianus 9, 15, 1 (458 f.).

340 Moreau, Inceste 2002, 137-144. 
sierung wurde deshalb Geschlechtsverkehr mit Nonnen oder geweihten Jungfrauen und Witwen mitunter als Inzest gewertet ${ }^{341}$. Das 5. Konzil von Paris (614) ist ein später Zeuge dieser Tradition ${ }^{342}$. Die Verbindung zwischen Verwandtenmord und Inzest verdankt sich dagegen einer anderen Tradition. Augustinus hatte erstmals die Unvereinbarkeit von familiärer Zuneigung und sexueller Begierde als Begründung für das Inzestverbot herangezogen. Das Konzil von Clermont (535) nahm diese Argumentation ausdrücklich auf und vermittelte sie der Merowingerzeit ${ }^{343}$. Verwandtenmord kann analog dazu als Einbruch der Gewalt in die Familie betrachtet werden. Beide Vergehen versuchen die Familie als Vertrauensgemeinschaft zu untergraben ${ }^{344}$. Eine weitere Parallele zum Inzest besteht darin, dass beide Delikte von einer Rechtsordnung, die auf dem Anklageprinzip beruhte, üblicherweise nicht vor das Gericht gebracht wurden. In beiden Fällen gab es nämlich keine Parteien, die an einem Gerichtsverfahren interessiert waren. Der Eingriff des Königs und seiner Amtsträger war daher in besonderem Maße erforderlich.

Die Lex Ribuaria markiert den Endpunkt der weltlichen Inzestgesetzgebung der Merowingerzeit und ist ähnlich wie das Konzil von Clichy durch eine Verschärfung gekennzeichnet. Gerade die Tatsache, dass der Inzest als eines der wenigen Delikte durch den fränkischen König mit öffentlichen Strafen bedroht wurde, zeigt dies zur Genüge. Bereits in der Lex Salica und in der Decretio Childeberti wurden öffentliche Strafen verhängt, eine Bewertung als Kapitaldelikt ist dagegen erstmals in der Lex Ribuaria ausgesprochen. Dass diese Inzestgesetze zuallererst eine symbolische Bedeutung hatte, zeigt sich besonders krass an der Bestimmung der Lex Salica. Das Inzestgesetz ist im Rahmen der Lex Salica ein absoluter Fremdkörper. Chilperich bezweckte damit in erster Linie, sich als Bewahrer der römischen Rechtsordnung sowie als christlicher Herrscher zu inszenieren. Wieweit die Anstrengungen der Könige über die Selbstdarstellung hinaus die Praxis tatsächlich beeinflussten, lässt sich nur schwer abschätzen. Einige Fälle (Magnovaldus, Godinus) führen vor Augen, wie der Herrscher das Inzestverbot zur Beseitigung unliebsam gewordener Adeliger benutzte. Um das Inzestverbot auch bei der gesamten Bevölkerung geltend $\mathrm{zu}$ machen, fehlten dem merowingischen Staat die Mittel, da nur im Umfeld des Königs von Amts wegen ermittelt wurde. Die Anpassung der Bestrafung an die Voraussetzungen

341 Cassian, Collationes 8, 16 (CSEL 13, 23); Gelasius I., Ep. ad episcopos Lucaniae c. 20 (JK 636, Migne PL 59, 54); Isidor, Etymologiae 5, 26, 24 u. 10, 148.

342 5. Konzil von Paris (614) c. 16 (MGH Conc. 1, 190).

343 Siehe 145.

344 Siehe oben 13. EsDers, Treueidleistung 2005, 49, sieht dagegen als Geltungsgrund für die harte Bestrafung die Leistung des Treueids an. In welchem Sinn das Inzestverbot Bestandteil des Treueids war, bleibt in dieser Argumentation unklar. Das Inzestverbot bedurfte einer solchen sekundären Legimitierung nicht, es war Bestandteil der göttlichen Rechtsordnung. 
des fränkischen Prozessrechts erfolgte nur ausnahmsweise und halbherzig. Im Allgemeinen wird man daher das Einwirken auf die Praxis vor allem als Leistung der Bischöfe ansehen müssen. Diese Anstrengungen waren nicht vergeblich. Im karolingischen Frankenreich westlich des Rheins wurden kaum mehr Fälle einer Heirat innerhalb der engeren Verwandtschaft bekannt. Ehen bis zur Verwandtschaft des vierten Grades (2/2) sind nicht mehr bezeugt, einiges spricht auch dafür, dass selbst Cousinen zweiten Grades (3/3) nicht mehr als Heiratspartner in Frage kamen. Die Gleichsetzung von Blutsverwandtschaft mit Schwägerschaft hat sich, wie besonders die Decretio Childeberti bezeugt, in dieser Zeit auch zunehmend durchgesetzt.

\subsection{Königtum und Kirche im Reich der Westgoten}

Die Inzestgesetzgebung im Reich der Westgoten vereinigt mehrere Fragestellungen aus diesem und dem vorangegangenen Kapitel. Die westgotische Geschichte ist bis zum Jahr 587 von der konfessionellen Spaltung zwischen dem Arianismus der herrschenden Goten und dem Katholizismus der hispano-romanischen Bevölkerung geprägt. Es ist also nochmals nach den Auswirkungen der Glaubensspaltung auf die kirchliche Gesetzgebung dieser Zeit zu fragen. Ein anderes Thema, das uns bei der Analyse der fränkischen Entwicklung begleitet hat, ist die Konkurrenz von weltlicher und kirchlicher Gesetzgebung. Da die weltliche Gesetzgebung der Westgoten in der Datierung weniger umstritten ist, ist diese Konkurrenz weitaus deutlicher zu erfassen. Das Beispiel des Westgotenreichs kann daher ein neues Licht auf die umstrittene Frage nach der Motivation für die ,Besessenheit' der gallischen Bischöfe werfen, mit der sie das Inzestverbot traktierten. Auch die Frage einer angemessenen kirchlichen Bestrafung von Delinquenten, die den gallischen Episkopat in der ersten Hälfte des 6. Jahrhunderts beschäftigte, wurde in der spanischen Kirche diskutiert. Es wird sich zeigen, dass die im Westgotenreich erlassenen Regeln nur unter Berücksichtigung der fränkischen Entwicklung verständlich sind. Der Einfluss, den Gallien schon in der Spätantike auf Spanien ausübte, währte noch im Frühmittelalter fort und sollte sich erst im 7. Jahrhundert teilweise umkehren. Am Beispiel des Inzestverbots lässt sich besonders deutlich der wechselseitige Austausch zwischen den Nachfolgereichen des westlichen Imperiums aufzeigen.

\section{Römisches Recht im neuen Gewand}

Die Anfänge der westgotischen Gesetzgebung sind in Dunkel gehüllt. Schon der erste König des seit 418 bestehenden Reichs von Toulouse Theoderid soll als Gesetzgeber gewirkt haben und das bisherige gotische Gewohnheitsrecht an die 
neuen Bedingungen angepasst haben ${ }^{345}$. Auch für seinen Sohn, Theoderich, lässt sich eine Gesetzesinitiative wahrscheinlich machen ${ }^{346}$. Eine neue Dimension erreichte die Gesetzgebung unter dem zweiten Sohn Theuderids, Eurich, der seinen Bruder beseitigte und im Jahr 466 die Herrschaft über die Westgoten an sich riss ${ }^{347}$. Eurich brach den Vertrag mit dem Kaiser vom Jahr 418, in dem die Ansiedlung der Goten geregelt worden war. Er verstand sich als unabhängiger König und brachte bislang von Römern kontrollierte Gebiete Spaniens und Galliens unter seine Herrschaft. Zeichen dieser neuen Souveränitätspolitik ist Eurichs Erlass eines eigenen Gesetzbuches, des Codex Euricianus ${ }^{348}$. Da nur Bruchstücke des Textes in einem Palimpsest erhalten geblieben sind, lässt sich wenig Sicheres über den Inhalt des Codex sagen. Nach der traditionellen Deutung handelt es sich um ein für das gotische Volk erlassenes Gesetzbuch, das nur ausnahmsweise die romanische Bevölkerung betraf. Isidor von Sevilla betrachtete 150 Jahre später die Gesetze Eurichs ausdrücklich als Beginn der westgotischen Kodifikationen ${ }^{349}$. In der neueren Forschung haben sich dagegen vermehrt Stimmen zu Wort gemeldet, die für eine territoriale Geltung des Codex Euricianus eintreten ${ }^{350}$.

Das Inzestverbot wird in den erhaltenen Fragmenten des Codex Euricianus nicht angesprochen. Da der vollständige Codex im 8. Jahrhundert von den Kompilatoren der Lex Baiuvariorum benutzt wurde, hat Karl Zeumer versucht, das Inzestverbot des bayerischen Volksrechts für den Euricianus zu beanspruchen. Belege für diese Zuschreibung fand Zeumer insbesondere in den Strafandrohungen für Inzest. Höhergestellte Personen sollten ihr Vermögen zugunsten des Fiskus verlieren, niedergestellte sollten ihrer Freiheit beraubt und zu königlichen Sklaven gemacht werden ${ }^{351}$. Diese Strafen sind für das bayerische

345 Wolfram, Goten 1990, 198 f. Die Gesetzgebung Theoderids wird aus einigen Stellen des Codex Euricianus erschlossen, in denen Gesetze von Eurichs Vater genannt werden: Codex Euricianus 277 (MGH LL nat. Germ. 1, 5) und 305 (MGH LL nat. Germ. 1, 16).

346 Sidonius Apollinaris, Epistulae 2, 1, 3 (2, 44) und 8, 3, 3 (3, 87). Harries, Sidonius 1994, 126, sieht dagegen in der Erwähnung von Theudericianas leges allein einen rhetorischen Gegensatz zum Codex Theodosianus.

347 Wolfram, Goten 1990, 186-195.

348 D’Ors, Código 1960; Hermann Nehlsen, Art. „Codex Euricianus“, in: RGA 5 ( $\left.{ }^{2} 1984\right)$ 42-47; Harries, Euric 2001; Liebs, Gallien 2002, 157-163. Nehlsen, Alarich II. 1982, identifiziert den Autor des Codex mit Alarich II. In der Forschung wird jedoch dem Zeugnis Isidors der Vorzug gegeben, siehe unten Anm. 349.

349 Isidor von Sevilla, Historia Gothorum 35 (MGH Auct. Ant. 11, 281); 51 (MGH Auct. Ant. 11, 288). Vgl. Zeumer, Geschichte 1 1898, 426-437; Sснмidt, Geltungsumfang 1978; King, Territoriality 1980; Liebs, Gallien 2002, 158.

350 D’Ors, Territorialidad 1956; Matthews, Roman Law 2000, 32; Collins, Spain 2004, 226.

351 Si quis contra haec fecerit, a loci iudicibus separentur et omnes facultates amittat, quas fiscus adquirat. Si minores personae sunt quae se inlicita coniunctione polluerunt, careant libertate, 
Recht untypisch und haben eindeutige Parallelen im westgotischen Recht. Zeumer sah sich daher dazu berechtigt, die Inzestbestimmung der Lex Baiuvariorum als westgotisches Recht seiner kritischen Edition des Codex Euricianus hinzuzufügen. Die Autorität der MGH-Edition sorgte für eine bis heute anhaltende Zustimmung zu dieser Vermutung ${ }^{352}$, obwohl Bruno Krusch der These von Zeumer mit gewichtigen Argumenten entgegengetreten ist. Krusch wies auf zwei Besonderheiten des Inzestverbots der Lex Baiuvariorum hin, die nicht mit einem westgotischen Ursprung vereinbar $\operatorname{sind}^{353}$. Zum einen lautet die Rubrik De nuptiis inlicitis und nicht De incestis wie in der Lex Visigothorum ${ }^{354}$. Unter der Rubrik De nuptiis inlicitis stehen in der Lex Visigothorum Bestimmungen über nicht standesgemäße Ehen. Zum anderen setzt das Inzestverbot des Bayernrechts mit einer Formulierung in erster Person Plural ein (prohibemus) und steht im Gegensatz zum westgotischen Gebrauch von unpersönlichen Verbotsformeln. Das Wort prohibemus verweist nach Krusch auf die Gesetze der karolingischen Hausmeier, die erstmals diese unklassische Verbotsform verwendet hätten. Allein die Strafandrohung könne auf westgotischen Vorbildern beruhen, die Stilisierung des Inzestverbots als Ganzes gehe aber mit Sicherheit nicht auf den Codex Euricianus zurück. Das Inzestverbot des Codex Euricianus ist nach Krusch aus der MGH-Edition zu streichen.

Auf Eurich folgte im Jahr 484 sein Sohn Alarich II. ${ }^{355}$ Die Regierungszeit Alarichs wird überschattet vom Konflikt mit dem aufstrebenden Frankenkönig Chlodwig. Zweimal, in den Jahren 496 und 498, überschritten die Franken die Loire und drangen tief in westgotisches Gebiet vor ${ }^{356}$. Zur selben Zeit registrierte man in der spanischen Tarraconensis die ersten westgotischen Siedlungen auf der Pyrenäenhalbinsel ${ }^{357}$. $502 \mathrm{kam}$ es zu einem persönlichen Zusammentreffen der beiden Kontrahenten auf einer Loireinsel bei Amboise ${ }^{358}$, doch der Friede hielt nur wenige Jahre. 507 überquerte Chlodwig ein weiteres Mal die Loire und suchte die Entscheidungsschlacht mit dem westgotischen Aufgebot.

servis fiscalibus adgregentur. Lex Baiuvariorum 7, 2-3 (MGH LL nat. Germ. 5/2, 348). Von Zeumer aufgenommen in die Codicis Euriciani leges ex lege Baiuvariorum restitutae 2 (MGH LL nat. Germ. 1, 28). Vgl. Zeumer, Geschichte 2 1899, 104-112.

352 Daly, Clovis 1994, 564.

353 Krusch, Forschungen 1927, 99 f. Zustimmung bei Fleury, Recherches 1933, 125 Anm. 8; D’Ors, Código 1960, 52; Osaba, Adulterio 1997, 294; Fastrich-Sutty, Rezeption 2001, 117.

354 Schwind hat in seiner Ausgabe der Lex Baiuvariorum zwei jüngeren Handschriften den Vorzug gegenüber der Mehrheit der ältesten Zeugen gegeben und De nuptiis incestis in den Obertext gesetzt. Die Lex Alamannorum 39 (MGH LL nat. Germ. 5/1, 98) bezeugt die Richtigkeit der Rubrik De nuptiis inlicitis.

355 Wolfram, Goten 1990, 195-197; Collins, Spain 2004, 33-37.

356 Auctarium Havniense a. 496 und a. 498 (MGH Auct. Ant. 9, 331).

357 Chronica Caesaraugustana a. 494 und a. 497 (MGH Auct. Ant. 11, 222).

358 Gregor von Tours, Decem libri historiarum II 35 (MGH SS rer. Merov. 1/1, 84). 
In der Nähe von Poitiers, auf den vogladensischen Feldern, trafen die beiden Heere in offener Feldschlacht aufeinander, und Alarich II. verlor Reich und Leben. In den vorangegangenen Jahren war der westgotische König unter dem Druck der fränkischen Expansion zu weitreichenden Zugeständnissen an die galloromanische Bevölkerung bereit gewesen. Im Jahr 506 gab er dem apostolischen Vikar Caesarius von Arles die Erlaubnis zur Einberufung eines Reichskonzils der westgotischen Kirche, nachdem Caesarius kurz davor noch von Alarich aus seiner Bischofsstadt ausgewiesen und ins Exil geschickt worden war $^{359}$. Das Reichskonzil von Agde war ein deutliches Zeichen einer Versöhnungspolitik zwischen Arianismus und Orthodoxie, da Alarichs Vater Eurich noch offene Konflikte mit der katholischen Kirche ausgetragen und die Weihe katholischer Bischöfe in seinem Reich hinausgezögert hatte ${ }^{360}$. In die gleiche Richtung einer Versöhnung zielte der Erlass einer Kodifikation zu Anfang des Jahres $506^{361}$.

Die Lex Romana Visigothorum (oder Breviarium Alarici) besteht aus einer gekürzten Fassung des Codex Theodosianus, einer Auswahl posttheodosianischer Novellen, einigen Gesetzen aus den Codices Gregorianus und Hermogenianus, aus einer Überarbeitung der Pauli Sententiae und der Gai Institutiones sowie einem Auszug aus Papinian. Alle Bestandteile sind mit sogenannten Interpretationen versehen, die den Rechtstext deuten und bisweilen an die neue Realität anpassen. Eine Ausnahme bildet der Liber Gaii, der ohne Interpretationen auskommt, weil der Text selbst eine vollständige Überarbeitung des ursprünglichen Textes aus dem 2. Jahrhundert darstellt. Umstritten an dieser Kodifikation sind die territoriale oder personale Geltung sowie der Anteil der westgotischen Gesetzgeber an diesem Werk. Da die Kontroversen bereits seit über hundert Jahren andauern, kann es hier weder das Ziel sein, einen vollständigen Überblick über Argumente und Gegenargumente zu geben noch gar die offenen Fragen einer Lösung zuzuführen. Zum Verständnis der im Breviar enthaltenen Inzestbestimmungen ist es jedoch erforderlich, einen kurzen Einblick in den Forschungsstand zu geben und die Konsequenzen für die Deutung der Inzestbestimmungen zu benennen.

Über die Geltung des Breviars gibt der Text selbst keine eindeutige Auskunft. Die Einführungsworte Alarichs, das sogenannte Commonitorium, können sowohl als Argument für eine personale als auch als Argument für eine territoriale Geltung der Kodifikation in Anspruch genommen werden. In der An-

359 SCHÄFERdiek, Kirche 1967, 37; KLingshirn, Caesarius 1994, 93-97.

360 Schäferdiek, Kirche 1967, 55-67.

361 Harald Siems, Art. „Lex Romana Visigothorum“, in: HRG 2 (1978) 1940 - 1949; Liebs, Gallien 2002, 166-176. SсHÄFERDiek, Kirche 1967, 42-55, sieht das Breviar nicht so sehr als Zugeständnis an die römische Bevölkerung, sondern als Fortführung gotischer Souveränitätspolitik und als Instrument zur Schaffung einer eigenen Landeskirche. Beides muss sich jedoch nicht ausschließen. 
weisung an den Comes Timotheus legte der König fest, dass alle Streitfälle nach dem Inhalt des Breviars und ohne Heranziehung eines anderen Gesetzbuches beigelegt werden sollten. Hält sich der Richter nicht an dieses Gebot, unterliegt er der Todesstrafe oder der Konfiskation seines Vermögens ${ }^{362}$. Unklar bleibt, ob diese Vorschrift nur für die römischen Comites oder für alle Amtsträger des westgotischen Königs Geltung beansprucht. Bei einer territorialen Geltung müsste man die Voraussetzung machen, Alarich habe mit dem Breviar nicht nur andere römische Rechtsquellen, sondern auch den Codex Euricianus für ungültig erklärt. Die Tatsache, dass die Westgoten zwei Generationen später unter Leovigild erneut auf den Codex Euricianus zurückgriffen und diese westgotische Tradition der Gesetzgebung fortführten, scheint eine Geltung des Breviars für die westgotische Bevölkerung auszuschließen. Wie Paul King überzeugend darlegte, setzt die Geschichte der westgotischen Gesetzgebung eine auf die römische Bevölkerung beschränkte Gültigkeit des Breviars voraus ${ }^{363}$. Alarich II. hätte dann zur selben Zeit wie der Burgunderkönig Gundobad den Römern das Privileg ${ }^{364}$ eines personalen Rechtstatus erteilt und zugleich den Anspruch aufgestellt, in souveräner Weise darüber zu entscheiden, welche Gesetze aus dem Fundus des römischen Rechts weiterhin angewandt werden sollten. Für Gundobad ist diese Tatsache hinreichend gesichert, da er in der Prima Constitutio der Lex Burgundionum sein Vorgehen ausdrücklich benennt und begründet. Eine analoge Absicht lässt sich bei Alarich II. mit guten Gründen unterstellen.

Eine zweite Kontroverse ist weit schwieriger zu umreißen. Im Mittelpunkt steht dabei der Ursprung der Interpretationen zum Codex Theodosianus ${ }^{365}$. Während die einen die Interpretationen als Schulprodukt der gallischen Rechtsgelehrsamkeit des 5. Jahrhunderts ansehen, führen sie die anderen auf die Arbeit der Kodifikatoren des Breviars zurück. Das Commonitorium spricht eindeutig für die zweite Ansicht, da sowohl die Auswahl der Gesetze als auch die Abfassung einer „verständlicheren Auslegung" auf die Arbeit von Alarichs Rechtsgelehrten zurückgeführt wird ${ }^{366}$. Gegen diese Auffassung werden im Wesentlichen zwei Gründe angeführt, zum einen die zum Teil stark divergie-

362 Et ideo secundum subscriptum librum, qui in thesauris nostris habetur, oblatum librum tibi pro distringendis negotiis nostra iussit clementia destinari, ut iuxta eius seriem universa causarum sopiatur intentio; nec aliud cuilibet aut de legibus aut de iure liceat in disceptationem proponere ... Lex Romana Visigothorum, Auctoritas Alarici regis (2).

363 King, Territoriality 1980. Vgl. auch Liebs, Gallien 2002, 174.

364 Zum Charakter des Privilegs vgl. Guterman, Principle 1990, 85 f.

365 Einen Überblick verschafft LiEBs, Gallien 2002, 146-156.

366 Quibus omnibus enucleatis atque in unum librum prudentium electione collectis, haec, quae excerpta sunt vel clariori interpretatione composita, venerabilium episcoporum vel electorum provincialium nostrorum roboravit assensus. Lex Romana Visigothorum, Auctoritas Alarici regis (2). 
rende Formulierung der Auslegungen und zum anderen die Überlieferung von Auslegungen außerhalb der Lex Romana Visigothorum ${ }^{367}$. Dies scheint die These nahe zu legen, die westgotischen Kodifikatoren hätten auf Vorlagen aus dem Schulbetrieb zurückgreifen können. Dann würde sich die Arbeit von Alarichs Kommission auf die Auswahl und die Redaktion dieser Vorlagen beschränkt haben. Auch wenn man diese unter Rechtshistorikern dominierende Ansicht teilt, kommt man nicht daran vorbei, das Breviar insgesamt als Werk Alarichs zu deuten und Auslassungen, Umdeutungen und Redaktionen der Absicht des westgotischen Königs zuzuschreiben ${ }^{368}$. Unumstritten ist, dass dies für die Auswahl der 396 Konstitutionen des ca. 3400 Gesetze umfassenden Codex Theodosianus zutrifft. Besonders das Buch XVI zum Kirchenrecht ist starken Kürzungen zum Opfer gefallen, weil Alarich kaum die Übernahme der antiarianischen Gesetzgebung der römischen Kaiser zulassen konnte ${ }^{369}$. Auch die Streichung der Novelle Valentinians III. über die Anerkennung des Primats der römischen Kirche geht auf die Kirchenpolitik Alarichs zurück ${ }^{370}$. Es ist deshalb unabhängig von der Frage der Autorschaft der Interpretationen möglich, die Inzestbestimmungen des Breviars ebenfalls auf Veränderungen und Aktualisierungen durch den westgotischen Gesetzgeber zu untersuchen.

Von den fünf Gesetzen des Codex Theodosianus zum Inzestverbot haben vier im Breviar Aufnahme gefunden ${ }^{371}$. Darin werden die Ehe innerhalb der Blutsverwandtschaft bis zur Cousine sowie die Heirat mit der Schwägerin verboten. Für die Cousinenheirat ist die Möglichkeit einer Dispensierung durch den Princeps vorgesehen. Die Eheleute werden durch die Ungültigkeit ihrer Ehe bestraft, den Kindern einer Inzestehe werden die Legitimität und die Möglichkeit der Erbschaft abgesprochen. Auch Schenkungen zugunsten der Kinder werden untersagt. In der Auslegung zu CTh 3, 12, 3 wird über die Ehepartner zusätzlich die Infamie verhängt, weil sie über ihr Eigengut nur mehr aufgrund der Vergünstigung des Kaisers verfügen dürften ${ }^{372}$. Da die Infamie erhebliche Nachteile vor Gericht nach sich zieht ${ }^{373}$, ist die Interpretatio als Verschärfung zu werten. Getilgt wird aus den Inzestvorschriften des Theodosianus die Verhän-

367 Liebs, Gallien 2002, 146-156, mit Bezug auf die Forschungen von Wieacker, Schellenberg u.a.

368 Eine Reihe von Belegen sammeln Guillot, Justice 1995, 669 f., und Matthews, Interpretationes 2001. Eine Mittelposition nimmt NeLson, Überlieferung 1981, $125-$ 130, ein.

369 Conrat, Auszüge 1911.

370 Schäferdiek, Kirche 1967, 46 f.

371 Lex Romana Visigothorum, Cod. Theod. 3, 10, 1 (86 f.) und 3, 12, 2-4 (90).

372 Atque etiam si filios habuerint, non habeantur legitimi nec heredes, sed infamia sint notatae utrimque personae, ita ut possidere tantum proprias facultates principis beneficio videantur. Lex Romana Visigothorum, Cod. Theod. 3, 12, 3 Int. (90).

373 Conrat, Breviarium 1903, 148-155. 
gung der Todesstrafe über diejenigen, die eine Ehe mit der Nichte eingegangen $\operatorname{sind}^{374}$. Diese drakonische Bestrafung ist durch das später erlassene Gesetz CTh 3, 12, 3, das auch die Nichtenheirat umfasst, revidiert worden. Die Auslassung scheint also vom obsoleten Charakter des Gesetzes herzurühren. Sie passt jedoch auch zur Streichung von zwei weiteren Rechtsquellen, die ebenfalls die Todesstrafe für Inzest vorsahen. Das sind zum einen die Pauli Sententiae. Diese verhängten über Inzest die Strafe der lex Iulia für Ehebruch, also Enthauptung ${ }^{375}$. Zum anderen fehlt auch die Konstitution Diocletians aus dem Jahre 295, die innerhalb des Codex Gregorianus überliefert ist ${ }^{376}$. Der westgotische Gesetzgeber hat demnach alle Rechtsquellen, die eine Todesstrafe für Inzest vorsahen, beseitigt und damit eine einheitliche Bestrafung durchgesetzt. Diese Bestrafung war im Einklang mit der Praxis des 5. Jahrhunderts und wurde nur durch die Verhängung der Infamie verschärft. Das Vermögen der des Inzests überführten Eheleute blieb unberührt.

Neben dem Auszug aus dem Theodosianus begegnet der Inzest noch ein weiteres Mal im Liber Gaii. Die Überarbeitung der Gai institutiones, auch Epitome Gai genannt, wird nicht durch eine Auslegung ergänzt, da der gesamte Text bereits an die neue Rechtswirklichkeit angepasst wurde ${ }^{377}$. Vieles spricht dafür, dass der Liber Gaii tatsächlich auf das Konto des westgotischen Gesetzgebers geht, denn es existiert keine Überlieferung außerhalb des Breviars. Die Argumente, die Max Conrat für eine Entstehung des Liber Gaii im Westgotenreich vorbrachte, sind weiterhin gültig ${ }^{378}$. Besonders der Abschnitt über die Ehe ist nur im Kontext des Breviars verständlich. In Übereinstimmung mit der Aufnahme des im Codex Theodosianus verhängten Verbots der Heirat zwischen Römern und Barbaren ist im Liber Gaii zu lesen: „Rechtmäßig sind Ehen dann, wenn ein Römer eine Römerin nach dem Stattfinden einer Hochzeit oder durch Konsens zur Frau nimmt ${ }^{\text {‘379 }}$. Im selben Abschnitt folgt eine vollständige Auf-

374 Lex Romana Visigothorum, Cod. Theod. 3, 12, 1 (89) ist nur in jüngeren Handschriften des Breviars enthalten und wird von Mommsen als späterer Zusatz gewertet: Moмmsen, Einleitung 1905, LXXXVI.

375 Collatio legum Mosaicarum et Romanarum 6, 3, 3 (157).

376 Collatio legum Mosaicarum et Romanarum 6, 4, 8 (159).

377 Überblick bei Liebs, Gallien 2002, 127-133.

378 Conrat, Entstehung 1905. Widerspruch von Archi, Epitome 1937, 72 f., und von Liebs, Gallien 2002, 127 f. Der Meinung Conrats treten Nehlsen, Alarich II. 1982, 181, und Hein L.W. Nelson, Rezension von Archi: L' „Epitome Gai“, in: Tijdschrift voor Rechtsgeschiedenis 63 (1995) 170-177 bei.

379 Legitimae sunt nuptiae, si Romanus Romanam nuptiis intervenientibus vel consensu ducat uxorem. Lex Romana Visigothorum, Liber Gaii 4 (318). Archi, Epitome 1937, 142, verweist auf Lex Romana Visigothorum, Cod. Theod. 3, 14, 1 (92). Dieses Gesetz wurde erst durch Leovigild aufgehoben: Zeumer, Geschichte 1 1898, 477 f.; STroheKer, Leowigild 1939, 161. Nach Sivan, Frontiers 1996, und Mathisen, Concepts 2006, hatte das Gesetz des Theodosianus ursprünglich einen anderen Sinn gehabt. 
listung der verbotenen Verwandtenehen. Bei Gaius werden die Aszendenten und Deszendenten erwähnt, die Adoptivkinder, Geschwister, die Tante, Schwiegermutter, Schwiegertochter, Stieftochter und Stiefmutter. Die westgotische Version belässt es nicht dabei, sondern fügt die inzwischen hinzugekommenen Inzestverbote hinzu. Untersagt wird folglich auch die Ehe mit der Tochter des Bruders, mit der Frau des Bruders, der Schwester der Frau und mit der Cou$\sin ^{380}$. Besonders das letzte Verbot erregt durch die kategorische Formulierung Aufmerksamkeit: „Auf keine Weise wird es erlaubt, Geschwisterkinder in der Ehe zu verbinden". Dieses kategorische Verbot steht scheinbar im Widerspruch zur Aufnahme von Cod. Theod. 3, 10, 1 in das Breviar, da darin die Dispensierung vom Verbot der Ehe mit der Cousine ermöglicht wird. Die Auslegung zu diesem Gesetz ist jedoch bereits deutlich zurückhaltender als der ursprüngliche Text von Kaiser Honorius: „Gegenüber diesen aber, die eine unrechtmäBige Verbindung im vierten Grad der Abstammung verbunden hat, wird er, obwohl es tadelnswert ist, Nachsicht üben, wenn sie darum bitten sollten "381 ${ }^{\text {"Im }}$ Unterschied zum Gesetzestext wird die Ehe mit der Cousine offen als unrechtmäßig und tadelnswert bezeichnet. Die Toleranz gegenüber dieser Form der Inzestehe ist ebenso wie im Liber Gaii geringer geworden. Die im Liber Gaii vorgesehene Bestrafung befindet sich ebenfalls im deutlichen Einklang mit den Konstitutionen des Breviars. Die Ehe wird für ungültig und die Nachkommenschaft für unehelich erklärt ${ }^{382}$.

Trotz der Kontroversen um Geltung und Ursprung des Breviars hängt die Bewertung der Inzestbestimmungen nicht entscheidend davon ab. Die beobachteten Tendenzen lassen sich nämlich sowohl bei den Auslassungen als auch bei den Interpretationen nachweisen und charakterisieren insgesamt die Lex Romana Visigothorum. Man muss daher die Initiative Alarichs und seiner kirchlichen und weltlichen Berater auf jeden Fall in Rechnung stellen. Auch wenn seine Gesetzgebungskommission auf Schulwerke der vorangegangenen Zeit zurückgegriffen hat, so musste dennoch eine Auswahl aus diesen Vorlagen getroffen werden. Alarich II. erscheint deshalb ebenso wie der Ostgotenkönig Theoderich als Fortführer der römischen Inzestgesetzgebung. Von einem Widerstand des arianischen Königs gegen diese römische Tradition kann keine Rede sein, auch wenn eine Anwendung dieser Bestimmungen auf die gotische

380 Fratris quoque et sororis filiam uxorem ducere non licet. ... Fratres enim amitinos vel consobrinos in matrimonium iungi nulla ratione permittitur. Sed nec uni viro duas sorores uxores habere, nec uni mulieri duobus fratribus iungi permittitur. Lex Romana Visigothorum, Liber Gaii 4, 3-7 (318).

381 His vero, quos in quartum gradum originis coniunctio praesumtiva copulaverit, quia notabile est, tamen si supplicaverint, veniam relaxabit. Lex Romana Visigothorum, Cod. Theod. 3, 10, 1 Int. (88).

382 Quod si quis incestas vel nefarias, id est, quae sunt superius comprehensae, nuptias inierit, nec uxorem habere videtur, nec filios ... Lex Romana Visigothorum, Liber Gaii 4, 8 (318). 
Bevölkerung nicht nachweisbar ist. Alarich hat das römische Recht zum Inzestverbot vereinheitlicht und durchgehend eine im Vergleich zu späteren Zeiten milde Bestrafung durchgesetzt. Im Liber Gaii lässt sich sogar eine Anpassung an die Rechtsentwicklung des 5. Jahrhunderts beobachten, die sich auch in der rückläufigen Toleranz gegenüber der Ehe zwischen Geschwisterkindern niederschlug. Vor diesem Hintergrund wird die Ausdehnung des Inzestverbots auf Geschwisterenkel im Konzil von Epaon verständlicher.

Das Breviar sollte im Frühmittelalter eine bedeutende Wirkung entfalten ${ }^{383}$. Es galt nicht nur im westgotischen Reich bis zur Mitte des 7. Jahrhunderts, es diente auch im südlichen Frankenreich ohne offizielle Autorisierung als Rechtsbuch der galloromanischen Bevölkerung. Mit einer Ausnahme stammen alle Handschriften aus dem Frankenreich. Das Breviar war neben dem authentischen Codex Theodosianus bis in das Hochmittelalter die wichtigste Quelle für die Kenntnis des römischen Rechts. Da in manchen Handschriften nur die Auslegungen der westgotischen Gesetzgeber tradiert wurden und andere Kurzfassungen des Breviars ausschließlich auf den Auslegungen beruhen, kann man diesen Bestandteilen des Breviars größeren Einfluss zuschreiben als den authentischen Konstitutionen. Das Inzestverbot ist ein treffendes Zeugnis für diese schrittweise Vereinfachung („Vulgarisierung“) des römischen Rechts. Bereits in der C-Fassung der Lex Salica wird nicht die Konstitution, sondern die Auslegung zitiert. Auf gleiche Weise verfuhren die Bischöfe der Synode von Tours im Jahre 567 und Ratramnus von Corbie im 9. Jahrhundert. Die Verwandtschaftstafel der Pauli Sententiae wurde durch die Vermittlung Burchards von Worms sogar bis in das Decretum Gratiani überliefert.

\section{Die Kirche unter dem Einfluss Galliens}

Nach dem Untergang Alarichs in der Schlacht von Vouillé verließen die Westgoten fluchtartig den gallischen Raum und verlagerten den Schwerpunkt ihres Reichs nach Spanien ${ }^{384}$. Nach einem Konflikt innerhalb der Königsfamilie übernahm der Ostgotenkönig Theoderich die Verwaltung des Reichs für seinen Enkel Amalarich, den minderjährigen Sohn Alarichs II. Für die nächsten vierzig Jahre kam das Westgotenreich unter ostgotische Vorherrschaft, erlangte jedoch in diesen und den folgenden Jahren keine Stabilität. Die Politik der Rückeroberung durch Justinian zeitigte im Süden der Halbinsel bedeutende Erfolge, während sich die herrschende Schicht durch eine Reihe von Königsmorden selbst schwächte. Bis zur Restauration unter Leovigild steckte das Westgotenreich in einer Krise, die auch die Gesetzgebung einer Periode der Stagnation aussetzte. In dieser Epoche der ostgotischen Vorherrschaft profitierte die spa-

383 Grundlegend noch immer Wretschro, De usu 1905. Ergänzend: Wood, Code 1993. 384 Collins, Spain 2004, 38-41. 
nische Kirche von der auch gegenüber dem Papst praktizierten religiösen Toleranz Theoderichs des Großen ${ }^{385}$. Den spanischen Bischöfen war es ebenso wie dem unter ostgotischer Herrschaft stehenden Caesarius von Arles möglich, die vom kanonischen Recht eingeforderten Provinzialsynoden einzuberufen. Insgesamt fanden zwischen 516 und 546 fünf Synoden in der östlichen Provinz Tarraconensis und zwei in der Cartaginensis statt ${ }^{386}$. Der König übte anders als auf dem Reichskonzil von Agde im Jahre 506 keinen erkennbaren Einfluss auf Einberufung und Inhalt dieser Kirchenversammlungen aus.

Gemeinsames Merkmal dieser Provinzialsynoden auf spanischem Boden ist die Beeinflussung durch eine gallische Kirchenrechtssammlung ${ }^{387}$. Bereits auf dem Konzil von Tarragona im Jahre 516 wird in einer Bestimmung zum Mönchswesen auf die vorbildhaften Bestimmungen der gallischen Kirche verwiesen ${ }^{388}$. Verantwortlich für diese Rezeption war Caesarius von Arles, der im Jahre 514 von Papst Symmachus die Ausweitung seines Vikariats auf Spanien erreicht hatte. Obwohl diese Verleihung mit Ansprüchen anderer Bischöfe in Spanien kollidierte, konnte Caesarius für die östlichen Provinzen sein Vikariat in die Tat umsetzen ${ }^{389}$. Die Weitergabe der gallischen Konzilskanones geht auf seine Initiative zurück. Nach der Rekonstruktion von Schäferdiek umfasste die gallische Sammlung die Konzilien des 4. und 5. Jahrhunderts sowie das Konzil von Agde (506) und als letztes die fränkische Reichssynode von Orléans $(511)^{390}$. Diese gallische Sammlung ging später in ergänzter Form in die Sammlung der spanischen Konzile ein und wurde ein Bestandteil der weit verbreiteten Collectio Hispana.

Das Inzestverbot wurde in Spanien erstmals auf dem 2. Konzil von Toledo $\left(527 / 531^{391}\right)$ thematisiert. Die Formulierung der beteiligten Bischöfe sollte Geschichte machen. Das Verbot von Verwandtenehen wurde nämlich ausdrücklich auf die gesamte Verwandtschaft ausgedehnt: „Denn wir legen unverbrüchlich fest, um auch dies heilbringend zu verhüten, dass kein Gläubiger eine Blutsverwandte bis zu dem Grad, zu dem er die Linien der Verwandtschaft in der Geschlechterfolge kennt, in der Ehe mit sich zu vereinigen begehren

385 SCHÄFERdieK, Kirche 1967, 68-89.

386 Orlandis - Ramos-Lissón, Synoden 1981, 52-76.

387 SCHÄFERDIEK, Kirche 1967, 69-75.

388 Konzil von Tarragona (516) c. 11 (Hispana 4, 278).

389 Epistulae Arelatenses 28 (MGH Epp. 3, 41). Vgl. Schäferdiek, Kirche 1967, 73 und Kampers, Metropolitanstellung 1979, $26 \mathrm{f}$.

390 Schäferdiek, Kirche 1967, 72 f.; vgl. auch Maassen, Geschichte 1870, 662.

391 Die Datierung schwankt, je nachdem ob man der Aera-Datierung oder der Datierung in Herrscherjahren den Vorzug geben will. Collins, Spain 2004, 41, plädierte für 527, da Theoderich bereits vor seinem Tod die Herrschaft an Amalarich weitergegeben habe und daher das fünfte Jahr der Regierung Amalarichs durchaus auf 527 fallen könnte. Sonst überwiegt die Datierung auf 531, d.h. fünf Jahre nach Theoderichs Tod, vgl. OrLANDIS - Ramos-Lissón, Synoden 1981, 61. 


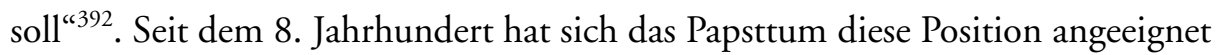
und in Dekretalen immer wieder in Erinnerung gerufen. Das kategorische Verbot von Verwandtenehen sollte, als die römisch-rechtliche Definition der Verwandtschaft keine Grundlage in der Praxis mehr besaß, eine ungeheure Dynamik entfalten und war für die extreme Ausdehnung des Inzestverbots verantwortlich. Im frühen 6. Jahrhundert war die Intention der um Montanus von Toledo versammelten Bischöfe eine andere. Sie handelten in dem Bewusstsein, die Vorschriften der Bibel an die damalige Rechtswirklichkeit anzupassen. Dem kategorischen Verbot folgt nämlich die Begründung,

„weil geschrieben steht: ,Niemand von euch darf sich einer Blutsverwandten nähern, um ihre Scham zu entblößen' (Lev. 18, 6). Und zwar nicht ohne Ankündigung des Urteils, denn wenig später sagt er: ,Alle nämlich, die irgendeine dieser Greueltaten begehen, werden aus der Mitte ihres Volkes ausgemerzt' (Lev. 18, 29). Wenn jemand unser Gebot verletzen und das Verbotene zu entehren wagen sollte, erwarte er durch eine umso größere Strafe bedacht zu werden, je näher die Verwandte, mit der er sich verbinden wollte, zu seiner Herkunft zu stehen keinem Zweifel unterliegt; und er wird durch eine umso dauerhaftere Exkommunikation sowohl vom Leib Christi als auch von der Gemeinschaft der Brüderlichkeit ausgeschlossen, je näher er durch die Berührung verwandten Blutes beschmutzt worden ist ${ }^{\star 393}$.

Unter Berufung auf die Bibel weiteten also die Bischöfe des 2. Konzils von Toledo das Inzestverbot auf die gesamte Verwandtschaft aus. Es besteht kein Zweifel, dass die römisch-rechtliche Definition der Verwandtschaft zugrunde gelegt wurde, da diese sowohl im Breviar als auch später in der Lex Visigothorum übernommen wurde ${ }^{394}$. Verboten war demnach die Ehe unter Blutsverwandten bis zur Cousine zweiten Grades. Die Regelung von Toledo stimmt daher mit dem burgundischen Konzil von Epaon überein, das erstmals zehn Jahre früher eine solche Ausweitung proklamiert hatte. Anders als der bibelfeste Avitus von Vienne beriefen sich die spanischen Bischöfe jedoch ausschließlich (und zu Unrecht) auf die Bibel. Ob ihnen die Bestimmungen von Epaon zur Kenntnis gelangt sind, wurde in der Forschung bislang nicht diskutiert. Chronologisch ist

392 Nam et haec salubriter praecavenda sancimus, ne quis fidelium propinquam sanguinis sui, usquequo affinitatis lineamenta generis successione cognoscit, in matrimonio sibi desideret copulari. 2. Konzil von Toledo (527/531) c. 5 (Hispana 4, 352).

393 ... quoniam scriptum est: 'Omnis homo ad proximam sanguinis sui non accedat ut revelet turpitudinem eius', nec sine denuntiatione sententiae, nam paulo post infert et dicit: 'Anima quae fecerit de abominationibus istis quippiam, peribit de medio populi sui. Si quis ergo huius decreti nostri temerator exstiterit ac vetitum violare praesumpserit, tanto graviori se multandum sententia recognoscat quanto eam propinquiorem, cui copulari se maluit, suae originis esse non ambigit, tantoque annosioris excommunicationis tempore a Christi corpore et fraternitatis consortio sequestretur quanto fuerit propinquioris sanguinis contagione pollutus. 2. Konzil von Toledo (527/531) c. 5 (Hispana 4, 352 f.).

394 Lex Romana Visigothorum, Pauli Sent. 4, 10 (408); Lex Visigothorum 4, 1 (MGH LL nat. Germ. 1, 171-173). 
es ausgeschlossen, dass die Kanones von Epaon zu jener gallischen Sammlung des Kirchenrechts zählten, die Caesarius von Arles vor 516 der spanischen Kirche hatte zukommen lassen. Da das Vikariat des Caesarius jedoch noch in den zwanziger Jahren andauerte ${ }^{395}$, könnte eine spätere Weitergabe der Kanones von Epaon durchaus in Betracht kommen. Caesarius war mit den Bestimmungen von Epaon vertraut und scheute trotz seiner Rivalität mit Avitus von Vienne nicht vor ihrem Einsatz in einem Brief an den Papst zurück ${ }^{396}$. Ein weiteres Argument für die Kenntnis des Konzils von Epaon bietet die Collectio Hispana, die bereits in ihrer ältesten Form einen Anhang zum Konzil von Agde enthält, der im Wesentlichen aus Kanones des burgundischen Reichskonzils besteht ${ }^{397}$. In diesem Anhang befindet sich auch die Inzestbestimmung. Die anderen in Toledo erlassenen Kanones unterstützen die These einer Kenntnis des Anhangs. Kanon 2 verbietet den Wechsel von Klerikern in fremde Bistümer und erneuert damit bereits in Nicäa und Chalkedon erlassene Vorschriften ${ }^{398}$. Die Bedingung, dass dies nur dann strafbar ist, wenn der zuständige Bischof übergangen wurde, enthält jedoch nur eine Vorbildbestimmung des Konzils von Epaon $^{399}$. Kanon 4 hat eine deutliche Übereinstimmung mit einem in seiner Herkunft unbekannten Text, der erstmals im Anhang zum Konzil von Agde auftauchte und daher ebenfalls mit dem Konzil von Epaon in Verbindung steht ${ }^{400}$. Kanon 1 weist eine Parallele zum 3. Konzil von Arles im Jahr 524 auf, das ebenfalls zum ältesten Bestand der Collectio Hispana zählt ${ }^{401}$. Ich halte es daher für hinreichend gesichert, dass die Bischöfe um Montanus von Toledo Kenntnis von den zeitgenössischen Konzilien in Gallien besaßen. Die Auswei-

395 Kampers, Metropolitanstellung 1979, $26 \mathrm{f}$.

396 Epistulae Arelatenses 34 (MGH Epp. 3, 49).

397 Ediert mit Angabe der Quellen von Munier: Konzil von Agde (506) c. 48-70 (CCL 148, 225-228) sowie in der Hispana-Ausgabe (Hispana 4, 141-150). Während es MaAssen, Geschichte 1870, 204, noch im Unklaren lässt, ob dieser Anhang der ältesten Version der Hispana angehörte, entschieden sich die Herausgeber der Hispana für die Ursprünglichkeit. Die gallische Herkunft des Anhangs unterstreicht MaAssen, Geschichte 1870, 203.

398 Loening, Kirchenrecht 1 1878, 142-145.

399 Episcopus vero qui eum suscipere absque conscientia proprii sacerdotis fortasse praesumpserit, ... 2. Konzil von Toledo (527/531) c. 2 (Hispana 4, 350); vgl. mit Konzil von Epaon (517) c. 5 (MGH Conc. 1, 20): Ne presbyter territorii alieni sine conscientia sui episcopi in alterius civitatis territorio praesumat basilicis aut oratoriis observare ...

400 2. Konzil von Toledo (527/531) c. 4 (Hispana 4, 352 f.). Der Herausgeber verweist auf Konzil von Agde (506) c. 33 (CCL 148, 207) und c. 48 (CCL 148, 225). Nur c. 48 aus dem Anhang zum Konzil von Agde behandelt denselben Fall.

401 2. Konzil von Toledo (527/531) c. 1 (Hispana 4, 347-349). Das Erreichen des 25. Lebensjahres wird auch auf dem 3. Konzil von Arles (524) c. 1 (MGH Conc. 1, 36) für das Diakonat als verbindlich angesehen. Vgl. Loening, Kirchenrecht 1 1878, 137. Das 3. Konzil von Arles gehörte bereits der ältesten spanischen Sammlung, der Vorlage der Epitome Hispana, an: MaAssen, Geschichte 1870, 662. 
tung des Inzestverbots auf die ganze Verwandtschaft steht also im Bann des Konzils von Epaon.

Die Strafandrohung der dauerhaften Exkommunikation widerspricht dagegen dem Geist des Konzils von Epaon. Avitus von Vienne hatte sich nach reiflicher Überlegung für eine milde Position entschlossen und nur die Trennung der inzestuösen Eheleute vorgeschrieben. Für das neue Verbot der Ehe mit der Cousine ersten und zweiten Grades hatte er sogar eine Toleranzklausel für bereits geschlossene Ehen vorgesehen. Von dieser Zurückhaltung war auf dem 2. Konzil von Toledo keine Spur. Die in Levitikus ausgesprochene Todesstrafe wurde von kirchlicher Seite in eine dauerhafte Exkommunikation umgemünzt. Auch hier wird man den Einfluss des Caesarius annehmen, der in Gallien für seine rigorose Haltung berüchtigt war $^{402}$.

Ein konkreter Anlass für dieses harsche Vorgehen gegen Inzestehen lässt sich nicht benennen. In der spärlichen historiographischen und hagiographischen Überlieferung des westgotischen Spanien sind keine Fälle von Verwandtenehen dokumentiert. Es lohnt jedoch ein Blick auf die Charakteristik des 2. Konzils von Toledo, um einen Hinweis für die Kontextualisierung der Inzestbestimmung zu erhalten. Primäres Ziel des Bischofs Montanus von Toledo war die Stärkung seiner Stellung als Metropolit der nördlichen Cartaginensis, die keine kirchenrechtliche Grundlage hatte, sondern auf der Stellung der Stadt als Hauptstadt des Westgotenreichs und als Mittelpunkt der gotischen Siedlung beruhte $^{403}$. Zur vollen Durchsetzung dieses Anspruchs gelangte der Bischof von Toledo erst, als Cartagena von byzantinischen Truppen erobert und bei der Rückeroberung Leovigilds der Zerstörung preisgegeben wurde. Das 2. Konzil von Toledo fand dagegen in einer Zeit statt, als dieser Anspruch noch wenig Resonanz bei den umliegenden Bistümern gefunden hat. Lediglich vier Bischöfe des nördlichen Teils der Cartaginensis waren zur Synode erschienen. Besondere Schwierigkeiten musste Montanus von Toledo beim Bistum von Palencia überwinden, da sich Bischöfe aus dem galicischen Suebenreich die Konsekration von Kirchen innerhalb dieser Diözese angemaßt hatten ${ }^{404}$. Zur Disziplinierung des Klerus von Palencia griff Montanus auf den Vorwurf des Priscillianismus zurück, einer Häresie, die auf den Asketen Priscillian von Ávila († 385) zurückging und besonders in Galicien verbreitet gewesen war. In den Augen der katholischen Kirche war der Priscillianismus eine Abart des dualistischen Manichäismus und zeichnete sich durch dieselbe Neigung zu sexuellen Aus-

402 Siehe 154.

403 Kampers, Metropolitanstellung 1979; Orlandis - Ramos-Lissón, Synoden 1981, 62; Collins, Mérida 1980.

404 So der Vorwurf des Montanus in einem Brief an die Einwohner der Diözese Palencia, der im Anhang der Konzilsakten überliefert ist: 2. Konzil von Toledo (527/531) ep. 1 (Hispana 4, 361). 
schweifungen aus ${ }^{405}$. Montanus bezeugt dieses Klischee des Bildes vom äußerlichen Asketen, der sich heimlich der Unzucht hingibt. In einem Brief an die Bewohner der Diözese Palencia, überliefert als Anhang zum 2. Konzil von Toledo, schreibt er: „Die Anhäufung aller Laster fließt darin wie im Abschaum des Schmutzes zusammen, und ihre Taten besiegeln den Gebrauch des Zaubers, damit der schamlose Ehebrecher die Keuschheit der Anhängerinnen entreißt und damit er leichter zum Gelingen des frevelhaften Verbrechens gelangt ${ }^{\text {“406 }}$.

Die Priscillianer galten also als Sexualverbrecher, ihre Askese als Tarnung von Untaten. Bereits zu Zeiten von Priscillian hatte sich das Gerücht verbreitet, dass der Asket Procula, die Tochter der reichen Euchrotia, geschwängert und zur Abtreibung des Fötus getrieben habe ${ }^{407}$. Procula und Euchrotia hatten sich in Aquitanien der Gruppe um Priscillian angeschlossen und gehörten zum engsten Kreis des Asketen. Aus diesem Gerücht ist später - der genaue Zeitpunkt lässt sich nicht feststellen - die Anschuldigung des Inzests mit Mutter und Tochter geworden ${ }^{408}$. Papst Leo I. kannte diese falschen Verunglimpfungen, als er in einem Brief an den Bischof von Astorgia in Spanien die Sekte der Priscillianer folgendermaßen charakterisiert: „Was aber von der überaus hässlichen Frevelei der Manichäer einst in Erfahrung gebracht und weithin bekannt gemacht wurde, das ist auch über die überaus inzestuöse Gewohnheit der Priscillianer bekannt und verbreitet worden, und die, welche in jeder Hinsicht in der Rohheit der Sinne gleich sind, können auch in ihren heiligen Handlungen nicht unähnlich sein “409. Es wäre also gut denkbar, dass sich Montanus zu der strengen Inzestbestimmung veranlasst sah, um den Priscillianismus zu diskreditieren und sich gegenüber dem Bischof von Palencia als Vorkämpfer der Orthodoxie in Szene zu setzen. Damit wäre ein konkreter Anlass für den Inzestkanon gewonnen. Da jedoch Montanus selbst eine solche Verbindung nicht ausdrücklich festhält, muss dies eine Vermutung bleiben.

Auch der zweite Inzestkanon der westgotischen Konzilien verrät eine deutliche Prägung durch die Diskussion in der fränkischen Kirche. Er wurde auf

405 Chadwick, Priscillian 1976; Burrus, Making 1995.

406 Nam ut pauca de eius spurcitiis in notitiam vestri deducam, exceptis his quae in divinitate profanus erupit et ore sacrilego blasphemavit, omnium vitiorum in eodem congeries veluti in sordium sentina confluxit, ut sectatricum pudorem impuderatus adulter eriperet; et ut ad sceleris nefarii effectum facilius perveniret, maleficio usum gesta eius assignant. 2. Konzil von Toledo (527/531) ep. 1 (Hispana 4, $361 \mathrm{f}$.).

407 Sulpicius Severus, Chronicae 2, 46 (CSEL 1, 101). Vgl. Chadwick, Priscillian 1976, 37. Zur weiteren Ausgestaltung des Negativbildes von Priscillian: Burrus, Making 1995.

408 Woher Cacciari, Historia 1751, 998, diesen Vorwurf bezog, ist mir unbekannt geblieben.

409 Quod autem de Manicheorum foedissimo scelere, hoc etiam de Priscillianistarum incestissima consuetudine olim compertum multumque vulgatum est, et qui per omnia sunt in impietate sensuum pares, non possunt in sacris suis esse dissimiles. Leo I., Ep. 15, 16 (Migne PL 54, 689). Kritische Edition dieses Briefes bei Vollmann, Priszillianismus 1965, 135. 
der im Jahre 546 tagenden Synode in Lérida erlassen, einer Kirchenversammlung unter der Leitung des Metropoliten Sergius von Tarragona ${ }^{410}$. Der Kanon befasst sich nur mit der Verhängung der Exkommunikation und lässt gegenüber der Bestimmung von Toledo eine gewisse Mäßigung erkennen. Zwar bezieht er sich wieder auf das Vorgehen des Paulus in Korinth, gesteht den inzestuösen Eheleuten jedoch den Besuch der Messe bis zur Darreichung des Abendmahles zu. „Über diejenigen, die sich mit der Sünde des Inzests beflecken, bestimmen wir, dass sie, solange sie in der unerlaubten Gemeinschaft des Fleisches verharren, nur zu der Messe der Katechumenen in die Kirche eingelassen werden; mit ihnen soll kein Christ das Mahl einnehmen, wie der Apostel befahl“411. Die spanischen Bischöfe gelangten also zur selben Lösung wie die in Lyon versammelten Kirchenführer Burgunds, als sie unter dem Druck König Sigismunds über den königlichen Finanzverwalter Stephanus nur einen bedingten Ausschluss aus der Gemeinde verhängt hatten. Diese Position gewann in der fränkischen Kirche vor der Mitte des 6. Jahrhunderts die Oberhand gegen den Widerstand des Albinus von Angers und des Nicetius von Trier und strahlte in dieser Zeit offenbar auf Spanien aus. Auch andere Bestimmungen des Konzils von Lérida nehmen auf gallische Kanones Bezug ${ }^{412}$. Anders als im Frankenreich ist jedoch nicht erkennbar, ob konkrete Fälle diese milde Regelung motivierten.

Nach der Bekehrung der westgotischen Herrscher zum katholischen Glauben im Jahr 587 erreichte das konziliare Leben eine Blütezeit. Von dem ersten katholischen König Reccared bis zum Untergang des Reiches fanden insgesamt 26 Synoden statt ${ }^{413}$. Die Konzilsakten zählen zu den wichtigsten Quellen für diese Zeit, da nicht nur die Kirche, sondern auch der König an der kirchlichen Gesetzgebung mitwirkte und seine Gesetze auf den Kirchenversammlungen verkündete. Trotz dieses beeindruckenden Umfangs der Gesetzgebung wurde das Thema des Inzests nicht erneut auf die Tagesordnung der Synoden gesetzt ${ }^{414}$. Den Grund dafür wird man in der Tatsache sehen müssen, dass die westgotischen Könige seit der Bekehrung Reccareds dieses Delikt in ihrer weltlichen Gesetzgebung traktierten und alle Wünsche der Bischöfe erfüllten. Wie in römischer Zeit galt der Inzest vorwiegend als ein in die Kompetenz der weltlichen Gerichtsbarkeit fallendes Delikt. Auch in der Kirche des Frankenreichs verstummten die Bischöfe, nachdem sich um 600 die merowingischen

410 SChäFERdieK, Kirche 1967, 86; Orlandis - Ramos-Lissón, Synoden 1981, 68-73.

411 De his qui se incesti pollutione commaculant placuit, ut quousque in ipso detestando et illicito carnis contubernio perseverant, usque ad missam tantum catecuminorum in ecclesia admittantur; cum quibus etiam nec cibum sumere ulli Christianorum, sicut Apostolus iussit, oportet. Konzil von Lérida (546) c. 4 (Hispana 4, 301 f.).

412 Konzil von Lérida (546) c. 3 (Hispana 4, 301).

413 Orlandis - Ramos-Lissón, Synoden 1981; Stocking, Bishops 2000; Suntrup, Studien 2001.

414 KING, Law 1972, 154, drückte sein Erstaunen über diesen Sachverhalt aus. 
Herrscher zu einer Verschärfung der Inzestpolitik bereit erklärt hatten. Ob dieses Verstummen mit einer tatsächlichen Befolgung der strengen Gesetze der Lex Visigothorum gleichzusetzen ist, darf allerdings bezweifelt werden. Aussagen über die konkrete Heiratspraxis der spanischen Bevölkerung verbieten sich angesichts des Schweigens der Quellen.

\section{Verschärfung um 600}

König Reccared bekehrte sich zum katholischen Glauben ein Jahr nach dem Tod seines Vaters Leovigild, eines aggressiven Förderers des arianischen Glaubens ${ }^{415}$. Reccared stellte damit die Einheit der Konfession im Westgotenreich her und ermöglichte ein enges Bündnis zwischen Königtum und Episkopat, das die gesamte Geschichte des 7. Jahrhunderts prägen sollte. Das erste Zeugnis dieses Bündnisses ist das 3. Konzil von Toledo im Jahr $589^{416}$. Es wurde in erster Linie mit dem Ziel einberufen, die Konversion des gotischen Volkes propagandistisch in Szene zu setzen. Reccared wird in den Akten als neuer Constantin gefeiert, sein Werk der Bekehrung als apostolische Pflicht bezeichnet. An den Anfang der Akten stellten die Bischöfe ein Glaubensbekenntnis und die Verdammung der arianischen Häresie. Der König ließ es sich gleichfalls nicht nehmen, in seiner Ansprache vor dem Konzil zur Wiederherstellung der kirchlichen Disziplin aufzurufen. Die Kanones des Konzils befassten sich vorwiegend mit dem Lebenswandel des Klerus und der Sicherung des durch die Kirchenpolitik Leovigilds gefährdeten Kirchenbesitzes. Die Laien gerieten nur an wenigen Stellen ins Blickfeld: Zum einen, wenn sie sich wie Witwen, Jungfrauen und Büßer in einem Lebensstand befinden, den die Kirche zu überwachen beanspruchte ${ }^{417}$. Zum anderen wurden Relikte des Heidentums und die Kindstötung, beide als besonders weit verbreitet bezeichnet, mit kirchlichen Strafen geahndet ${ }^{418}$. In diesen Fällen mahnten die Bischöfe mit ausdrücklicher Billigung Reccareds die Zusammenarbeit von Klerus und weltlichen Amtsträgern an.

Neben dieser konziliaren Gesetzgebung sind drei weltliche Gesetze Reccareds überliefert. Alle drei weisen enge Übereinstimmungen mit den Kanones des 3. Konzils von Toledo auf. Das erste wendet sich gegen Rechtspflegedelikte durch Richter und gegen Ausbeutung durch Fiskalbeamte ${ }^{419}$. Wie in den Kanones von Toledo ruft Reccared den Klerus dazu auf, Ungerechtigkeiten auf-

415 SChäFERdieK, Kirche 1967, 192-205; Collins, Spain 2004, 64-69.

416 Schäferdiek, Kirche 1967, 205-233; Orlandis - Ramos-Lissón, Synoden 1981, 95 117; Stocking, Bishops 2000, 59-88; Suntrup, Studien 2001, 201-227.

417 3. Konzil von Toledo (589) c. 10-12 (Hispana 5, 116-119).

418 3. Konzil von Toledo (589) c. 16-17 (Hispana 5, 122-124).

419 Lex Visigothorum 12, 1, 2 (MGH LL nat. Germ. 1, 407 f.). Zeumer verweist auf 3. Konzil von Toledo (589) c. 18 (Hispana 5, 125 f.). 
zudecken und an den Königshof weiterzumelden. Der Klerus wird vom König in der Tradition des römischen Rechts als Kontrollorgan der weltlichen Verwaltung in Anspruch genommen ${ }^{420}$. Das zweite Gesetz setzt die anti-jüdische Tendenz des römischen Rechts fort und ist der Anfang einer sich immer weiter radikalisierenden Vernichtungspolitik gegen das spanische Judentum ${ }^{421}$. Reccareds drittes Gesetz nimmt ebenfalls einen Kanon des 3. Konzils von Toledo auf, denjenigen zum Schutz von Witwen und Jungfrauen. Darin schließen die Bischöfe alle, die die Erfüllung des Keuschheitsgelübdes verhindern, von der Gemeinschaft der Christen aus ${ }^{422}$. Reccared erweitert diesen Kanon um das Inzestverbot:

„Eben hörte man von vielen, dass sie gottgeweihte Jungfrauen und solche, die das Gelübde der Witwenschaft mit der priesterlichen Weihe nach dem Kirchenrecht abgelegt haben, sowie durch Blutsverwandtschaft verbundene Frauen entweder gewaltsam oder mit ihrem Einverständnis zur Frau nehmen ... Eine solche Verwegenheit, wenn sie von Männern und unter Gelübde stehenden Frauen zugelassen wird, läuft den guten Sitten zuwider und greift den wahren Glauben an “423.

Als Strafe sieht Reccared die Trennung der Eheleute vor sowie die dauerhafte Exilierung. Das Vermögen der Exilierten soll in den Besitz der Kinder übergehen, auch wenn sie aus einer solchen Ehe hervorgegangen sein sollten ${ }^{424}$.

Dieses Gesetz Reccareds ist in mehrfacher Hinsicht bemerkenswert. Zunächst bezeugt es noch vor der fränkischen Gesetzgebung eine Verhärtung der Bestrafung. Vermögensstrafen wurden nicht mehr als ausreichend angesehen, sondern durch Exilierung ergänzt. Vorbildhaft dürfte hierfür die Novellengesetzgebung Justinians gewesen sein, da der wichtigste Protagonist des 3. Konzils

420 Siehe oben 115 f. Zur Verfestigung dieser Aufsichtspflicht unter Justinian vgl. Alivisatos, Gesetzgebung 1913, 111-121. Zum Einfluss auf das Frankenreich vgl. Murray, Immunity 1994, 29.

421 Lex Visigothorum 12, 2, 12 (MGH LL nat. Germ. 1, 417). Zeumer verweist auf 3. Konzil von Toledo (589) c. 14 (Hispana 5, 120 f.).

422 Si quis vero propositum castitatis viduae vel virginis impedierit, a sancta communione et liminibus ecclesiae habeatur extraneus. 3. Konzil von Toledo (589) c. 10 (Hispana 5, 117).

423 Audetur denique a multis contra divine legis monita vel contra honestos vite communis mores devotas Deo virgines et continentiam viduitatis cum benedictionem sacerdotis iuxta morem canonum profitentes seu adfinitatis consanguinitate coniunctas feminas aut violenter aut per consensum sibi coniuges sumere... Que temeritas, dum vel a viris vel a feminis eiusdem professionis admittitur, et castis aborret moribus et fidem veram inpugnat. Lex Visigothorum 3, 5, 2 (MGH LL nat. Germ. 1, 159 f.).

424 ... omnismodis separati exilio perpetuo religentur nec aliqua in defensionem sui longitudine temporis excusentur. Eorum vero bona, qui talia gesserint, si eis de priori coniugio filii defuerint, ipsorum filiis absque infamie notam omnino proficient ... Lex Visigothorum 3, 5, 2 (MGH LL nat. Germ. 1, 160). Zeumer, Geschichte 3 1899, 614, verweist auf das Missverständnis Reccareds, die im Cod. Theod. ausgeprochene Infamie nicht auf die Eheleute, sondern auf die Kinder zu beziehen. Siehe 180 Anm. 292. 
von Toledo, Leander von Sevilla, während der Herrschaft Leovigilds aus seiner Bischofsstadt verbannt worden war und einige Zeit in Konstantinopel verbracht hatte ${ }^{425}$. Das Vorbild Justinians wurde aber nicht unbesehen übernommen, sondern in wesentlichen Punkten an die westgotische Realität angepasst. Ausdrücklich setzte Reccared nämlich fest, das Gesetz wende sich an alle Menschen beiderlei Volkszugehörigkeit, d.h. an Goten und Romanen. Er hielt daher den Hinweis für notwendig, Inzestvergehen könnten auch ohne Anklage durch das Nachforschen des Klerus und der Richter vor Gericht gebracht werden ${ }^{426}$. Das Anklageprinzip des westgotischen Rechts wurde in diesem Punkt aufgehoben. Ein weiteres Charakteristikum von Reccareds Gesetzgebung ist die Zusammenarbeit von Klerus und weltlichen Amtsträgern. Unter der Androhung einer Geldbuße von fünf Pfund Gold war es ihnen untersagt, die Bestrafung eines solchen Falles hinauszuzögern. Falls ihnen von Seiten der Angeklagten Widerstand entgegengesetzt werden sollte, müssten sie den Fall an den König melden, „damit die Strafe des Princeps vollständig verdammt, was ihr Urteil nicht bestrafen konnte ${ }^{\text {“427. }}$.

Den Umfang des Inzestverbots nannte Reccared nicht. Die Definition wurde offensichtlich der Kirche überlassen. Der pauschale Verweis auf kirchliche Kanones ${ }^{428}$ legt eine Ausrichtung auf die Normen der Kirche nahe, wie sie auf dem 2. Konzil von Toledo erlassen worden waren. Die Blutsverwandtschaft wäre damit vollständig erfasst. Wörtliche Anklänge an eine Auslegung des Breviars haben Zeumer zu der Vermutung veranlasst, dass auch die Ehe mit der Schwägerin angesprochen worden $\operatorname{se}^{429}$.

Eine Definition des Inzests reichte erst fünfzig Jahre später König Chindasvinth nach. Unter Chindasvinth erreichte die westgotische Gesetzgebung

425 Novella 12, 1 (95). Zur Lebensgeschichte Leanders vgl. SchäFErdiek, Kirche 1967, 151-153; García Moreno, Prosopografía 1974, 91-93. Zur Annahme byzantinischer Formen der Herrscherrepräsentation seit Leovigild vgl. STROHEKER, Westgotenreich 1963, 230-232; King, Law 1972, 12-15; Stocking, Bishops 2000, 59 f.

426 Hoc vero nefas si agere amodo provinciarum nostrarum cuiuslibet gentis homines sexus utriusque temtaverint, insistente sacerdote vel iudice, etiam si nullus accuset, ... Lex Visigothorum 3, 5, 2 (MGH LL nat. Germ. 1, 160). Zum Anklageprinzip: King, Law 1972, 88-90.

427 Sacerdotes vero vel iudices, si talia cognoscentes ulcisci fortasse distulerint, quinas auri libras fisco cogantur exolvere. Quod si forte id redarguere voluerint, nec potuerint, regis hoc auditibus insinuare procurent; ut, quod eorum non potuit vindicare sententia, principalis damnet omnino censura. Lex Visigothorum 3, 5, 2 (MGH LL nat. Germ. 1, 161).

428 ... ut deinceps, sicut et canones ecclesiastici proibent, nullus Deo devotam virginem ... Lex Visigothorum 3, 5, 2 (MGH LL nat. Germ. 1, 160).

429 ... vel sui proximam generis aut eam, de cuius admixtione incestive notam possit subire infamie, non licito conubio aut vim aut consensu accipiat coniugem. Lex Visigothorum 3, 5, 2 (MGH LL nat. Germ. 1, 160). Zeumer verweist auf Lex Romana Visigothorum, Cod. Theod. 3, 12, 4 Int. (90). 
einen Höhepunkt ${ }^{430}$. Er und sein Sohn Reccesvinth sind für den größten Teil der Gesetze der Lex Visigothorum verantwortlich. Viele Argumente sprechen dafür, dass Chindasvinth (oder Reccesvinth) die personale Rechtsgeltung abschaffte und die alleinige Geltung des westgotischen Rechts für alle Teile der Bevölkerung verbindlich machte ${ }^{431}$. Das enge Bündnis mit dem Episkopat wirkte weiter, wie sich an der Inzestnovelle Chindasvinths zeigt. Ausdrücklich übernahm er die kirchliche Definition des Inzests und erweiterte sie auf alle Fälle der Schwägerschaft und der inzestuösen Verbindung durch uneheliche Unzucht:

„Niemand soll es wagen, jemanden aus dem Geschlecht des Vaters, der Mutter, des Großvaters und der Großmutter oder der Verwandten der Frau sowie auch die Verlobte des Vaters, seine Witwe oder die hinterlassene Frau eines Verwandten zu ehelichen oder durch Unzucht zu beschmutzen; so dass bis zum sechsten Grad der Verwandtschaft niemandem erlaubt ist, die Blutsverwandtschaft unzüchtig zu schänden oder in Ehe zu begehren “432.

Eine Ausnahme machte der König nur bei denjenigen Verbindungen, die vor dem Erlass seines Gesetzes mit Zustimmung der Principes geschlossen worden waren. Als Strafe sah Chindasvinth nicht mehr Exil, sondern die Einweisung ins Kloster vor ${ }^{433}$. Das Vermögen sollte wie in Reccareds Gesetz an die Kinder vererbt werden.

Das Neue an Chindasvinths Novelle besteht in einer Reihe von Gleichsetzungen. Gleichgesetzt wurden Blutsverwandtschaft und Schwägerschaft, Ehe und Verlobung, Ehe und Konkubinat, ehelicher und außerehelicher Geschlechtsverkehr, Mann und Frau ${ }^{434}$. Paradigmatisch dafür ist der Satz: „Dieselbe Verordnung (der Inzestverbote) soll auch für Frauen Geltung besitzen““435.

430 Zeumer, Geschichte 1 1898, 482-492; King, Chindasvind 1980. Collins, Spain 2004, 234, äußert Zweifel an der Zuschreibung.

431 Zeumer, Geschichte 1 1898, 484; King, Chindasvind 1980. Eine allmähliche Verschiebung zur Territorialität nimmt STroheker, Leowigild 1939, 162-164, an.

432 Nullus presumat de genere patris vel matris, avi quoque vel avie seu parentum uxoris, patris etiam disponsatam aut viduam vel propinquorum suorum relictam sibi in matrimonio copulare vel adulterio polluere; ita ut usque ad sextum generis gradum nulli liceat sanguinis propinquitatem libidinose fedare vel coniugio adpetere. Lex Visigothorum 3, 5, 1 (MGH LL nat. Germ. 1, 159).

433 Qui vero contra hanc constitutionem presumserint facere, iudex eos non differat separare, ut a tam nefandam pollutionem divisi iuxta qualitatem sexus in monasteriis delegentur, illic iugiter permansuri. Lex Visigothorum 3, 5, 1 (MGH LL nat. Germ. 1, 159). Fleury, Recherches 1933, 126, nimmt Beeinflussung durch Justinians Nov. 117, 8 (557) an.

434 Ein weiteres Gesetz Chindasvinths in diese Richtung ist Lex Visigothorum 3, 5, 5 (MGH LL nat. Germ. 1, 163).

435 Similis et de mulieribus ordo servandus est. Lex Visigothorum 3, 5, 1 (MGH LL nat. Germ. 1, 159). Diese Gleichbehandlung endete allerdings beim Ehebruch: KING, Law 1972, 234; Osaba, Adulterio 1997, 366. 
Die Ausweitung des Inzestverbots in einer bis dahin nicht dagewesenen Weise erfolgte über eine Logik der Verallgemeinerung. Chindasvinth übertraf damit selbst die Forderungen, die die Kirche im Frankenreich mit ihrer Inzestobsession erhoben hatte.

Zum Thema der westgotischen Gesetzgebung wurde das Inzestverbot nur mehr im Kontext eines traurigen Kapitels der spanischen Geschichte gemacht, und zwar innerhalb der anti-jüdischen Gesetze ${ }^{436}$. Die jüdischen Bewohner wurden als Gefährdung der mühsam errungenen Einheit der Konfession wahrgenommen und einer immer stärkeren rechtlichen und wirtschaftlichen Diskriminierung unterworfen. Die ersten Zwangstaufen datieren aus dem frühen 7. Jahrhundert und wurden im späteren Verlauf zu einer gezielten Ausschaltung des Judentums gesteigert. Als Folge davon wurden auch die westgotischen Inzestverbote für die jüdische Bevölkerung verbindlich gemacht. Reccesvinth untersagte den Juden Inzestehen mit der den anti-jüdischen Gesetzen eigenen unerbittlichen Grausamkeit ${ }^{437}$. Erdrosselung, Steinigung oder Verbrennung drohten inzestuösen Ehepartnern, sofern der König nicht ,Milde walten ließ, die jüdischen Delinquenten zu Sklaven machte und enteignete ${ }^{438}$. König Ervig mäßigte diese Bestimmung zu einer Zeit, als offiziell keine Juden im Westgotenreich existierten und man nur mehr zwischen zwangskonvertierten Juden und solchen, die ein freiwilliges Bekenntnis zum Christentum abgelegt hatten, unterschied ${ }^{439}$. Alle konvertierten Juden unterwarf Ervig denselben Inzestbestimmungen wie Chindasvinth und erhöhte die Strafe für ein Inzestvergehen um die öffentliche Auspeitschung und Scherung ${ }^{440}$. Außerdem war der

436 King, Law 1972, 130 - 145; García Moreno, Judíos 1993; González-Salinero, AntiJudaism 1998; Sivan, Jews 2000; Drews, Juden 2001, 66-88; Bronisch, Judengesetzgebung 2005.

437 Nemo ex Iudeis propinquitatem sanguinis sui coniugio copulet, adulterio polluat, incestu conmaculet. Nullus usque ad sextum generis gradum coitum personam quamcumque contingat. Lex Visigothorum 12, 2, 6 (MGH LL nat. Germ. 1, 415).

438 Im Gesetz Reccesvinths wird nur eine undeutliche Strafandrohung ausgeprochen: Nam detectus damnationis date ultionibus punietur. Lex Visigothorum 12, 2, 6 (MGH LL nat. Germ. 1, 415). Zeumer sieht darin zu Recht einen Verweis auf die brutalen Strafen in Lex Visigothorum 12, 2, 11 (MGH LL nat. Germ. 1, 417): ... ut, quicumque aut superioribus vetita legibus aut suis inexa placitis temerare voluerit vel frustrare presumserit, mox iusta sponsionem ipsorum gentis sue manibus aut lapide perimatur aut igne cremetur. Quod si denotatum crimine reum principalis pietas reservaberit viviturum, ille cui placuerit serviturus a rege donetur, et omnia bona eius aliis possidenda tradantur.

439 King, Law 1972, 133 f.; Bronisch, Judengesetzgebung 2005, 109.

440 Nulli Iudeorum in utroque sexu permittimus ex propinquitate sui sanguinis vel uxoris sue atque etiam virorum iuxta legem que in christianis est lata, usque ad sexti generis gradum conubia ducere vel incesti maculam operari. Huius igitur fede permixtionis inlecebra tali multabitur pena, ut separati ab invicem et centena publice decalvati flagella suscipiant et exilio relegati sub penitentia maneant, eorumque bona ad filios, quos de precedenti coniugio habuerint redeant. Lex Visigothorum 12, 3, 8 (MGH LL nat. Germ. 1, 435). 
Delinquent der Obhut der Bischöfe zugewiesen, die streng darauf achten mussten, dass die zwangskonvertierten Juden nicht ihren Glauben im Untergrund weiter praktizierten. Wahrscheinlich sollte mit der Übertragung des Inzestverbots auf die jüdische Bevölkerung der innere Zusammenhalt dieser überschaubaren Gemeinden erschüttert werden ${ }^{441}$. Die Inzestverbote müssen die Suche nach geeigneten Heiratspartnern erheblich erschwert haben.

Im Gegensatz zum Merowingerreich übernahm im Reich der Westgoten die Kirche nur kurz die Initiative in der Inzestgesetzgebung. Während der Krise des Königtums nach der Niederlage von 507 formulierten die Bischöfe auf zwei Konzilen Regelungen zu verbotenen Verwandtenehen. Sie übernahmen dabei im Kern die Kanones der gallischen Kirche. Davor und danach beanspruchten die Könige die Zuständigkeit in dieser Frage. Alarich II. passte im wesentlichen den Inhalt des Codex Theodosianus an die Normvorstellungen der Zeit um 500 an und beseitigte Widersprüche innerhalb des überlieferten Rechts. Seine Kodifikation übernimmt alle christlichen Eheverbote und bezeugt eine zunehmende Intoleranz gegenüber der Ehe mit der Cousine. Reccared übertrug erstmals ausdrücklich das Inzestverbot auf die gotische Bevölkerung und verschärfte die Bestrafung in Anlehnung an das justinianische Recht. Chindasvinth zog die Definition des Inzestverbots an sich, indem er die Reichweite der verbotenen Verwandtschaft im Sinne der spanischen Bischöfe festlegte. Diese Gesetze wurden durch die Kodifikation der Leges Visigothorum allen Richtern bekannt gemacht. Eine ständige Wiederholung der Vorschriften wie im Frankenreich war nicht erforderlich, da der König die Akzeptanz und Kenntnis des schriftlichen Rechts voraussetzen konnte.

\subsection{Irritation und Stabilisierung}

Die Geschichte der Inzestgesetzgebung im 6. Jahrhundert hinterlässt einen auffälligen Befund: Einerseits sind konvergierende Entwicklung in Ostrom und den westlichen Königreichen festzustellen, andererseits haftet diesen Übereinstimmungen etwas Kontingentes an, da sie nicht durch das Wirken einer zentralen Instanz gesteuert wurden. Weder die Rezeption des burgundischen Reichskonzils von Epaon noch die Rezeption des justinianischen Novellenrechts bei Franken und Westgoten war vorhersehbar. Die These, dass die christliche Inzestgesetzgebung durch eine bestimmte Programmatik der Kirche vorangetrieben wurde, erweist sich vor diesem Hintergrund als äußerst fragwürdig. Das Papsttum als einzige Institution mit universaler Ausstrahlungskraft spielte in der Zeit vom 5. bis zum 7. Jahrhundert keine nennenswerte Rolle in der Formierung der christlichen Inzestlehre. Das wichtigste Dokument zum Inzestverbot

441 García Moreno, Judíos 1993, 157; González-Salinero, Anti-Judaism 1998, 148. 
wurde vom burgundischen Reichskonzil von Epaon erlassen, das wenige Jahre vor dem Zerfall des Burgunderreichs tagte. Seine Rezeption verdankte sich keiner normativen Autorität, sondern ausschließlich der inhaltlichen Überzeugungskraft seiner Kanones. Auch die verschärfte Bestrafung des Inzestdelikts, erstmals nachweisbar in den Novellen Kaiser Justinians, fand auf inoffiziellen Wegen Eingang in das westgotische und fränkische Recht.

Der hohe Stellenwert des Inzestthemas in den Reichen des Frühmittelalters ist daher nicht Ursache einer zentral gesteuerten kirchlichen Programmatik. Am Anfang stand vielmehr die Vereinnahmung der Inzestgesetzgebung durch die christlichen Kaiser des 4. Jahrhunderts. Die Verfolgung von Verwandtenehen zählte zum Pflichtenkatalog eines christlichen Herrschers, da er damit seine Sorge für die göttliche Ordnung unter Beweis stellte. Alle germanischen Herrscher der Zeit um 500, die sich als Gesetzgeber in römischer Tradition verstanden, bekannten sich zur Aufgabe der Bekämpfung von Verwandtenehen. Theoderich, Alarich II., Sigismund und Chilperich I. erließen Inzestverbote, die sich mehr oder weniger eng an den Vorgaben des Codex Theodosianus orientierten. Ein besonderes Engagement in dieser Frage, wie es später Pippin I., Karl der Große oder Heinrich II. an den Tag legten, ist ihnen jedoch nicht zu bescheinigen. Die Initiative zur Formierung einer neuen Inzestlehre übernahmen vielmehr die Bischöfe, die ebenfalls die Nachfolge der römischen Verwaltung antraten und in ihrer Gesetzgebung weite Bereiche des alltäglichen Lebens einer Regelung unterwarfen. Der Ordnungswille der Bischöfe erstreckte sich in besonders intensiver Weise auf das Sexualleben von Klerikern, Mönchen und Laien und bildete den allgemeinen Hintergrund für die Obsession, mit der auf Kirchenversammlungen des 6. Jahrhundert das Inzestverbot eingeschärft wurde. Erst als sich die Könige seit Reccared und Childebert II. zu Anwälten des Verbots von Verwandtenehen machten und die weltliche Bestrafung verschärften, verschwand dieses Thema allmählich von der synodalen Agenda.

Der zentrale Text für die Inzestgesetzgebung des 6. Jahrhunderts ist der von Avitus von Vienne formulierte Kanon 30 des Konzils von Epaon. Die Ausdehnung des Verbots auf die gesamte Verwandtschaft nach römischem Recht sollte bis zu Beginn des 11. Jahrhunderts weithin verbindlich bleiben. Am Anfang des Kapitels habe ich verschiedene Erklärungen für diese Ausdehnung diskutiert und versucht, die Initiative des Avitus vor dem Hintergrund seines Gesamtwerks verständlich zu machen. Die Zurückführung auf eine Tradition (sei es die römische oder die christliche) ist als Erklärungsmuster nicht zielführend, es bleibt vielmehr ein unerklärbarer Rest, da uns der Bischof von Vienne selbst nicht über seine Motive aufgeklärt hat und da keine notwendige Verbindung zwischen der Tendenz seines Werkes und der Ausdehnung des Inzestverbots festzustellen ist. An dieser Stelle möchte ich die Fragestellung verlagern und nicht nach Ursachen für die Ausdehnung, sondern nach den Gründen für die Akzeptanz dieser Ausdehnung fragen. Dass sich Avitus in einer 
Zeit, in der viele Bischöfe zum Inzestverbot Stellung nahmen, auf idiosynkratische Weise äußerte, ist vermutlich weniger aufklärungsbedürftig als die Tatsache, dass dieser ,Versuchsballon' trotz des Untergangs des Burgunderreichs in der gallischen und westgotischen Kirche Aufnahme gefunden hat. Warum setzte sich die Meinung des Avitus von Vienne durch und in welcher Weise diente die ,Selektion' dieser ,Variation' der Stabilisierung der Gesellschaft?

Ich habe bereits an vielen Stellen dieser Untersuchung meine Ablehnung der These zum Ausdruck gebracht, dass die Kirche mit dem erweiterten Inzestverbot die germanischen Sippenverbände zerstören wollte ${ }^{442}$. Wie die Beispiele der Merowingerzeit unmissverständlich zeigen, hatte die galloromanische Oberschicht bedeutend mehr Anpassungsprobleme mit dem Verbot der Cousinenehe als der fränkische Adel. Für das Verständnis der Epoche erscheint es mir überdies verfehlt, einen direkten Konfrontationskurs des Episkopats gegen den fränkischen Adel anzunehmen. Damit ist aber nicht gesagt, dass die Inzestverbote keinen Widerstand hervorriefen. Immerhin bedeutete das Verbot der Ehe mit der Cousine ersten und zweiten Grades eine deutliche Einschränkung der Gattenwahl. Auch die Eheverbote innerhalb der Schwägerschaft stießen sowohl bei Franken als auch bei Romanen zuweilen auf erbitterte Gegnerschaft. Bischöfe wie Avitus von Vienne, Nicetius von Trier, Albinus von Angers und Germanus von Paris sorgten mit ihrem Engagement für erhebliche Irritationen im Verhältnis zu Königtum und Aristokratie. Dieses Engagement diente aber nicht der Zerschlagung vermeintlicher Sippenstrukturen, sondern sollte die neue Hierarchie der Gesellschaft symbolisch veranschaulichen. In dieser Hierarchie fungierten die Bischöfe als Bewahrer der göttlichen Ordnung, und das Königtum sollte sich im Unterschied zum spätantiken Kaisertum diesem Vorrang unterordnen. Es ist kein Zufall, dass Chilperich I., der schärfste Gegner der aufstrebenden Bischofsmacht, als erster Frankenkönig ein Inzestgesetz erließ und damit seinen Anspruch auf die Regelung dieser Rechtsmaterie geltend machte.

Zum angemessenen Verständnis für den Erfolg des erweiterten Inzestverbots muss die Struktur dieses Verbrechens berücksichtigt werden ${ }^{443}$. Wenn die Aristokratie Eheschließungen innerhalb der Verwandtschaft bevorzugt, wird der Segmentierung und Partikularisierung der Gesellschaft Vorschub geleistet. Das auf die Cousine ersten und zweiten Grades erweiterte Inzestverbot regt dagegen einen Kreislauf des Frauentausches an, der zu einer Integration der Gesellschaft führt. Diese Integration der Gesellschaft war für die Nachfolgereiche des Imperiums eine erschwerte Aufgabe, nachdem der Kollaps des römischen Reichs einen dramatischen Einbruch der öffentlichen Ordnung herbeigeführt hatte. Staatliche Institutionen konnten nur mehr in unzureichender Weise die soziale Integration gewährleisten. Dass ein solcher dramatischer Einbruch tatsächlich

442 Siehe $112-114$ und 169-175.

443 Siehe $13 \mathrm{f}$. 
stattfand, ist die Quintessenz der neuesten Veröffentlichungen zum Epochenumbruch von der Spätantike zum Frühmittelalter. Peter Heather, Chris Wickham und Bryan Ward-Perkins betonen im Unterschied zur These einer Transformation der Alten Welt den katastrophenartigen Verlust von Zivilisation, der Britannien im 5. und Byzanz im 7. Jahrhundert erfasste ${ }^{444}$. Chris Wickham hat die Konsequenzen für das aristokratische Selbstverständnis herausgearbeitet. Nach Wickham fand im ganzen Mittelmeerraum als Folge des Niedergangs öffentlicher Strukturen eine Schwächung und Regionalisierung der Aristokratie statt $^{445}$. Die Integration der politisch herrschenden Schicht wurde nicht mehr durch staatliche Institutionen gewährleistet, sondern allein durch das personal konzipierte Königtum. Je mehr die Integration durch Herrschaft schwand, umso mehr musste die Integration durch genossenschaftliche Bindungen und durch Eheschließungen an Bedeutung gewinnen ${ }^{446}$. Diese Integration ,von unten' förderte die Regionalisierung. Zugleich verschwand das genealogische Tiefenbewusstsein des Adels, weil Gentilnamen in einer regionalisierten Gesellschaft ihren Nutzen verloren. Einnamigkeit setzte sich in Britannien im 5., in Gallien im 6., in Byzanz im 7. Jahrhundert durch ${ }^{447}$. Dieser Regionalisierung der Aristokratie konnte durch das Einfordern eines umfassenden Inzestverbots Einhalt geboten werden. Die Aristokratie wurde dadurch gezwungen, an der Etablierung eines überregionalen Heiratsmarktes mitzuwirken. Darüber hinaus machte das Inzestverbot Eheschließungen teilweise vorhersehbar und entzog sie der Willkürlichkeit partikularer Interessen. Die Macht des Stärkeren bei der Wahl von Heiratspartnern wurde damit in ein Regelwerk eingebettet. Dies erklärt, warum der König und der Adel ein Interesse an dem erweiterten Inzestverbot hatten. Der König konnte sich als christlicher Herrscher in Szene setzen, gegen politisch missliebige Ehen vorgehen und der Regionalisierung entgegenwirken. Der Adel konnte darin ein disziplinierendes Mittel sehen, da sowohl der Herrscher als auch besonders mächtige Aristokraten gezwungen waren, ihre Töchter im weiten Umkreis zu verheiraten. Seit dem 7. Jahrhundert ist ein Heiratsmarkt feststellbar, der die gesamte Aristokratie des Frankenreichs umfasste und zu einer Vermischung fränkischer und römischer Adelsfamilien führte $^{448}$. Das erweiterte Inzestverbot war also nicht nur eine Irritation der

444 Wickham, Framing 2005; Heather, Fall 2006; Ward-Perkins, Fall 2006. Vgl. auch Halsall, Migrations 2007.

445 Wichкам, Framing 2005, 153-258.

446 Hierzu vgl. Oexle, Conjuratio 1985; Ders., Kultur 1995; ders., Friede 1996; AltHOFF, Verwandte 1990; Epp, Amicitia 1999.

447 Castritius, Namensystem 1997; Le Jan, Famille 1995, 179-225. Für Byzanz vgl. Winkelmann, Quellenstudien 1987, 209-217; Haldon, Byzantium 1990, $382 \mathrm{f}$.

448 Vgl. Rouche, Aquitaine 1979, 174; Ebling - Jarnut - Kampers, Nomen 1980, 698 700; Geary, Aristocracy 1985, 147. Für das 6. Jahrhundert leitet Réal, Vie 2001, 180, 
Gesellschaft, mit der die Bischöfe eine neue Rangordnung in der Kompetenz über die sakrale Sphäre deutlich machten; es diente auch der Stabilisierung und Integration der Gesellschaft.

Die Heiratsregeln konnten aber nur dann eine stabilisierende Wirkung ausüben, wenn das Inzestverbot als Teil der göttlichen Ordnung begriffen wurde und so der Verfügbarkeit der Menschen entzogen war. Bei Avitus von Vienne spielte überraschenderweise die biblische Begründung des Inzestverbots noch keine Rolle. Avitus bewegte sich bei der Verurteilung des Inzests innerhalb der römischen Tradition. Erst spätere Konzile wie das 2. Konzil von Toledo, das Konzil von Clermont, das 3. Konzil von Orléans, das 2. Konzil von Paris und das 2. Konzil von Tours rückten die biblische Begründung ins Zentrum. Das Verbot der Ehen innerhalb der gesamten Verwandtschaft sahen die Bischöfe dieser Synoden im kategorischen Verbot von Lev. 18, 6 begründet. Wenn man bedenkt, dass die Bibel als Argument in merowingischen Konzilskanones sonst nicht herangezogen wurde ${ }^{449}$, wird deutlich, in welchem Ausmaß das erweiterte Inzestverbot der göttlichen Ordnung der Ehe zugeordnet wurde. Die Vorstellung, ein Verstoß dagegen würde nicht nur eine Bestrafung im Jenseits hervorrufen, sondern auch den Zorn Gottes in dieser Welt erregen, brach sich gegen Ende des 6. Jahrhunderts Bahn. Im Angesicht von Bürgerkrieg und Pest erinnerte man sich an die Warnung in Lev. 18, 29: „Alle, die irgendeine dieser Greueltaten begehen, werden aus der Mitte ihres Volkes ausgemerzt". Dass Byzanz im 7. Jahrhundert vom Sturm arabischer Eroberungen hinweggefegt wurde, begriffen die Zeitgenossen in Ost und West als göttliche Strafe für die Inzestehe des Kaisers Herakleios ${ }^{450}$. Dieser biblischen Begründungslogik konnten sich die christlichen Herrscher nicht entziehen. Gunthram, Childebert II. und die westgotischen Könige verschärften in Anlehnung an das Novellenrecht Justinians die Inzestgesetzgebung und verhängten Todesstrafe, Exilierung und Klostereinweisung über schuldige Personen.

Dieser Gleichschritt im europäischen Kontext täuscht jedoch darüber hinweg, dass im Frankenreich die Voraussetzungen nicht gegeben waren, um eine staatliche Verfolgung des Inzests zu gewährleisten. Die Gesetze der Merowinger passten die Regelungen nur unzureichend an die Voraussetzungen des fränkischen Prozessrechtes an. Da das Grafenamt kein christliches Amtsethos ausgebildet hatte, lag die Verantwortung allein beim König und bei den Bischöfen. Das Bischofsamt durchlebte jedoch im späten 7. Jahrhundert eine Krise und verlor das Anliegen der Inzestverfolgung aus den Augen. Die Herrschaft der merowingischen Könige wich seit dem Tod Dagoberts I. der Gewalt der Her-

aus der anonymen Vita Austrigisili c. 3 (MGH SS rer. Merov. 4, 192) den Vorrang von Ehen innerhalb der gens ab. Der Beleg ist jedoch nicht unanfechtbar.

449 Hartmann, Reform 1986, 60.

450 Chronicae quae dicuntur Fredegarii IV 66 (MGH SS rer. Merov. 2, 154); Nikephoros, Breviarium c. 20 (68). Zur Inzestehe siehe 229 Anm. 61. 
zöge in den äußeren Dukaten sowie dem aufstrebenden Machtanspruch der Karolinger im Zentrum des Reichs. Unter diesen Bedingungen machten die zum Königtum aufgestiegenen Karolinger erneut das Inzestverbot zu einem Schlüsselthema ihrer Herrschaft. 


\section{Das Inzestverbot und die Begründung des karolingischen Königtums}

Im Alter von neun Jahren fertigte der Sohn Karl Martells Hieronymus eine Kopie der Vita Arnulfi an und verewigte sich in einer Notiz am Ende des Textes $^{1}$. Über Hieronymus, einen unehelichen Spross des Karolingers, ist außer dieser handschriftlichen Notiz nicht viel bekannt. Nur einmal taucht sein Name in den zeitgenössischen Geschichtswerken auf, und zwar im Zusammenhang mit einem für die Dynastie der Karolinger einschneidenden Ereignis. Im Jahr 753 ersuchte Papst Stephan II. den Frankenkönig Pippin I. um Hilfe gegen die Bedrohung durch das Langobardenreich, das unter der Führung König Aistulfs Ansprüche auf die Hoheit über den Dukat von Rom stellte ${ }^{2}$. Um Pippin zum Eingriff in Italien zu bewegen, machte sich Stephan als erster Papst in der Geschichte auf den Weg über die Alpen. In seiner Anwesenheit beschloss der fränkische König zu Ostern 754 einen Feldzug gegen die Langobarden und machte dem Papst ausgedehnte Gebietszusagen in Mittelitalien. Vor dem gemeinsamen Aufbruch nach Italien bekräftigte der Papst den „Bund gegenseitiger Liebe" durch die Verleihung des Patricius-Titels an Pippin und durch die Salbung der gesamten Herrscherfamilie. Nicht von allen Franken ist dieser enge Anschluss an das Papsttum und die Aufgabe der traditionellen Allianz mit den Langobarden gutgeheißen worden. Nach dem Bericht Einhards widersetzten sich einige fränkische Adelige den Kriegsplänen und „erklärten offen, sie würden den König verlassen und nach Hause zurückkehren “3. Zu diesen Opponenten zählte auch Karlmann, der Bruder Pippins, der sich im Jahr 747 aus der Politik zurückgezogen hatte und in ein italienisches Kloster eingetreten war. Karlmann kehrte sogar zum ersten Mal ins Frankenreich zurück, vermutlich als Botschafter langobardischer Interessen ${ }^{4}$. Pippin bediente sich jedoch der Autorität des Papstes und ließ den Mönch Karlmann mitsamt seinen Söhnen in ein fränkisches Kloster einweisen. $\mathrm{Zu}$ dieser Zeit war es für Pippin offenbar wichtig, auf

1 Ter ternos habuit annos qui scripserat istut obsequium fidei iuvenis Hieronymus infans. Nobilis antiqua procerum de stirpe creatus, filius hic genitus fulgens ab origine Karli, et genuit fortis regnator Pippinus illum. So lautet die Notiz in Paris, Bibliothèque Nationale, Lat. 5327 (MGH SS rer. Merov. 2, 429).

2 Fritze, Papst 1973; Pohl, Papsttum 2004, 156; Schieffer, Karolinger 2006, 60-63; Scholz, Päpste 2006, 46-77.

3 Einhard, Vita Karoli 6 (MGH SS rer. Germ. 25, 8).

4 TANGL, Sendung 1960. 
die Dienste eines anderen loyalen Familienmitglieds zurückzugreifen. Seinen Halbbruder Hieronymus beauftragte er, an dem Heereszug nach Italien teilzunehmen und gemeinsam mit dem Hofkaplan Fulrad von Saint-Denis den Papst nach Rom zu geleiten. „Der Papst Stephan kehrte unter der Führung des Hieronymus, des Bruders Pippins, nach Rom zurück“5.

Das Schweigen der Quellen über die Karriere des Hieronymus muss jedoch nicht für eine untergeordnete Rolle seiner Person sprechen, denn die Nachrichten aus der ersten Hälfte des 8. Jahrhunderts sind im Allgemeinen rar $^{6}$. Immerhin belegt die Abschrift der Vita Arnulfi das Interesse innerhalb der Karolingerdynastie für ihren heiligen Ahnherrn. Eines der nicht gerade zahlreichen Wunder, die in der Vita geschildert werden, betrifft den Unwillen des verstorbenen Heiligen gegen die Translation seiner Gebeine durch das Land eines in Inzest lebenden Adeligen, der sich zeit seines Lebens den Ermahnungen Arnulfs entzogen hatte ${ }^{7}$. Das Vorgehen gegen den Inzest konnte also rückblickend als eines der ursprünglichen Anliegen der karolingischen Dynastie angesehen werden. Der breite Raum, den Karlmann, Pippin I. und Karl der Große dem Inzestverbot widmeten, erklärt sich vermutlich zum Teil aus dieser Tradierung der merowingischen „Obsession“. Die Verfolgung des Inzests war durch das Zeugnis von Kapitularien und Leges als ein zentrales Anliegen des christlichen Königtums definiert und wurde in diesem Sinn von den karolingischen Herrschern aufgegriffen.

Trotz dieses Rückbezugs zeigt die karolingische Gesetzgebung überraschenderweise - so viel kann vorweggenommen werden - kaum inhaltliche Übereinstimmungen mit der merowingischen Tradition. Die kirchenrechtlichen Standards hatten sich nämlich nach der Mission des Bonifatius grundsätzlich gewandelt. Bonifatius und seine Gefolgsleute brachten zum einen neue Texte aus der irischen und angelsächsischen Kirche mit und förderten zum anderen die Aufnahme der päpstlichen Bestimmungen, die seit dem Anfang des 8 . Jahrhunderts erlassen worden waren. Diese Kombination von Vorschriften aus unterschiedlichen und oft unabhängig voneinander laufenden Traditionen war für die Verwirrung verantwortlich, die dem gewissenhaften Geist des Bonifatius so zusetzte. Das Inzestverbot zählte zwar nicht zum Kernanliegen des angelsächsischen Kirchenreformers - dies war vor allem die Disziplin innerhalb des Klerus -, Bonifatius fühlte sich jedoch durch die teilweise widersprüchlichen Anweisungen der Tradition mehrfach gezwungen, Nachforschungen in Sachen

5 Stephanus papa duce Hieronimo fratre Pippini Romam revertitur. Annales Fuldenses a. 754 (MGH SS rer. Germ. 7, 7). Fulrads Teilnahme wird in Annales regni Francorum a. 755 (MGH SS rer. Germ. 6, 12) erwähnt.

6 Vermutlich war er auch Laienabt von Saint-Quentin: EwIG, Descriptio 1965, 303; Stoclet, Fulrad 1993, 384; Settipani, Préhistoire 1993, 359 f.; Joch, Untersuchungen 1999, 37. Zurückhaltend: Hlawitschka, Vorfahren 1965, 80.

7 Siehe 169-171. 
Inzestverbot anzustellen und sich beim Papst über die geltende Norm zu erkundigen. Das Papsttum ergriff diese Gelegenheit, um seine Autorität in dieser Angelegenheit ins Spiel zu bringen und die christlichen Könige des Westens zu belehren. Der Langobardenkönig Liutprand und der Frankenkönig Pippin erhielten Lehrschreiben des Papstes zum Inzestverbot.

\subsection{Bonifatius und der Zusammenstoß der Kulturen}

Im Alter von vierzig Jahren entschloss sich der Mönch Winfrid, Leiter der Klosterschule im westsächsischen Nursling, zur Mission auf dem Kontinent $(716)^{8}$. Zuerst trat er im Umkreis seines Landsmanns Willibrord in Utrecht auf und beteiligte sich an der Mission der Friesen. Während der Sukzessionskrise nach dem Tod Pippins d. M. im Jahr 714 mussten die Anstrengungen Willibrords jedoch einen Rückschlag hinnehmen, da sich die Friesen im Aufstand gegen das Frankenreich befanden. Für Bonifatius gab es deshalb wenig Chance für Bewährung, und er kehrte in seine Heimat zurück. Schon kurze Zeit später unternahm er einen weiteren Anlauf und suchte dieses Mal den direkten Kontakt zum Papst. Er wollte unabhängig vom etablierten Willibrord in Gegenden missionieren, die politisch nicht so umkämpft waren wie Friesland. Von Papst Gregor II. wurde er 719 mit der Mission im rechtsrheinischen Germanien beauftragt und bekam den römischen Namen Bonifatius. Drei Jahre später, nach ersten Missionsversuchen in Hessen und Thüringen, kehrte Bonifatius nach Rom zurück und erhielt vom Papst die Weihe zum Bischof. Das besonders enge Verhältnis zum Papst kam durch den Gehorsamseid zum Ausdruck, den sonst nur Bischöfe im Metropolitanbezirk Roms zu leisten hatten. Bonifatius unterwarf sich damit den Direktiven des Papstes und musste keine Unterordnung unter einen fränkischen Bischof hinnehmen'. Bei diesem zweiten RomAufenthalt im Jahr 722 nahm der Missionar auch vom Papst eine Kirchenrechtssammlung in Empfang, die Collectio Dionysiana ${ }^{10}$. Sie sollte ihm in $\mathrm{Zu}$ kunft zur Entscheidung in kirchenrechtlichen Zweifelsfällen dienen. Da darin aber mit Ausnahme des Verbots der Schwagerehe aus dem Konzil von Neocaesarea keine Bestimmungen zum Inzestverbot enthalten waren, musste er in den folgenden Jahren mehrfach beim Papst Erkundigungen in dieser Frage einholen.

Über die kirchenrechtliche Grundlage der bonifatianischen Mission nach 722 sind wir also gut unterrichtet. Schwieriger ist dagegen die Präzisierung des

8 SCHIEFFER, Winfrid-Bonifatius 1954, 103-109.

9 SCHiEFFER, Winfrid-Bonifatius 1954, 143-145.

10 Willibald, Vita Bonifatii c. 6 (MGH SS rer. Germ. 57, 30). Glatthane, Bonifatius 2004, 248. 
kirchenrechtlichen Wissens, das sich Bonifatius in England angeeignet hatte ${ }^{11}$. Über die angelsächsischen Missionare ist eine Menge an buß- und kirchenrechtlicher Literatur insularen Ursprungs auf dem Kontinent verbreitet worden, ohne dass sich aufgrund der dürftigen Überlieferung in jedem einzelnen Fall feststellen lassen kann, über welche Bahnen die Vermittlung gelaufen ist ${ }^{12}$. Viele Bußbücher und Kirchenrechtssammlungen, die in Irland oder in England entstanden sind, kennt man heute nur mehr aus kontinentalen Handschriften, so dass bei einigen Schriften auch ihr Ursprungsland umstritten ist. Besonders im bonifatianischen Umkreis sind einige Werke erstmals nachweisbar. Ob diese Vermittlung auf ihn selbst oder auf andere Persönlichkeiten zurückgeht, ist allerdings nicht mehr feststellbar. Es ist daher nötig, die Diskussion um das Inzestverbot bei Iren und Angelsachsen insgesamt zu rekonstruieren, um den Wissenshorizont des Bonifatius bei seiner Ankunft auf dem Kontinent zu klären.

\section{Das Reisegepäck des Bonifatius}

Ein zentrales Dokument für die Geschichte des Inzestverbots auf den britischen Inseln war Bonifatius mit Sicherheit nicht bekannt, der Libellus responsionum Gregors des Großen. Als er um das Jahr 730 Kenntnis von diesem Dokument erlangte, zog er wegen dessen Authentizität Erkundigungen im römischen Archiv ein. Nachdem er in Rom einen negativen Bescheid erhalten hatte, wandte er sich an Erzbischof Nothelm von Canterbury, da Gregor den Libellus an dessen Amtsvorgänger Augustinus geschickt hatte ${ }^{13}$. Da die Antwort Nothelms nicht überliefert ist, kennen wir den Ausgang dieser Erkundigungen nicht. Bonifatius konnte sich jedenfalls nicht vorstellen, dass eine so laxe Regelung des Inzestverbots von dem vorbildhaften Papst und Begründer der Mission in England stammen könnte. In Rom, wo Probleme der Mission nicht unmittelbar vor Augen standen, gab man sich mit der Erklärung zufrieden, Gregor habe für die „rohen und neu konvertierten“ germanischen Völker keine rigorose Bestimmung erlassen wollen, „damit das harte Volk nicht hart tragen muss und alles gänzlich verwirft, was es (vom Glauben) angenommen hatte" ${ }^{\text {"14 }}$. Für Bonifatius war eine solche Auskunft wenig hilfreich, weil er - die Gültigkeit des

11 Schieffer, Winfrid-Bonifatius 1954, 106-108; Kelly, Gregory II 1976, 76-102; Glatthaar, Bonifatius 2004.

12 Коттые, Überlieferung 1982.

13 S. Bonifatii et Lulli epistolae 33 (MGH Epp. sel. 1, 57).

14 ... sed dum rudes erant et invitandi ad fidem, quamquam minime scriptum, ut dictum est, repperimus, credere non ambigimus. Concilium Romanum (743) c. 15 (MGH Conc. 2/1, 21); Sed ipse pius pater ut rudibus et noviter ad Christum venientibus licere quaedam imposuit, ne, si graviora imposuisset, duriter ferrent et dura gens omnia quae suscepissent penitus abicerent. Zacharias, Ep. ad Theodorum (MGH Epp. 3, 711). 
Libellus vorausgesetzt - auch in seiner Mission eine laxe Handhabung des Inzestverbots hätte dulden müssen.

Seit den Zweifeln des Bonifatius hält die Diskussion um die Echtheit des Libellus an. Stein des Anstoßes war dabei stets die Inzestregelung. Erst Heinrich Brechter wollte das gesamte Dokument als Fälschung entlarven ${ }^{15}$. Dieser Extremposition wurde vor allem durch die handschriftliche Forschung von Paul Meyvaert der Boden entzogen ${ }^{16}$. Bereits am Anfang des 8. Jahrhunderts sind ihm zufolge drei verschiedene Fassungen des Libellus im Umlauf gewesen, die von der Urfassung des Textes zum Teil erheblich abweichen. Beda, der den Libellus vollständig in seine Historia ecclesiastica gentis Anglorum von 731 aufnahm, benutzte einen sowohl in seiner Struktur überarbeiteten als auch durch Abschreibfehler korrumpierten Text. Die inhaltlichen Einwände gegen die Authentizität des Libellus hat ebenfalls Meyvaert gemeinsam mit anderen Historikern zurückgewiesen ${ }^{17}$ - mit einer Ausnahme, dem Inzestverbot. Das Verbot der Verwandtenehen im vierten und fünften Kapitel des Libellus bezeichnet Meyvaert als Interpolation, die erst später in den Text aufgenommen worden sei. Hypothetisch verortet er den Eingriff im Langobardenreich, da frühe Überlieferungen auf eine Entstehung des Archetyps in Norditalien hindeuten und da die Germanen eine Rechtfertigung für ihre endogame Ehepraxis benötigt hät$\operatorname{ten}^{18}$. Einen Beleg für diese Vermutung oder auch nur für die Tatsache der Interpolation ist Meyvaert schuldig geblieben. Alle drei Fassungen des Libellus enthalten den Abschnitt über das Inzestverbot, die Überlieferungsgeschichte spricht daher für die Echtheit auch dieses Teils des Libellus.

Am Inhalt des Inzestverbots sind besonders zwei Punkte als unecht verdächtigt worden. Erstens zählt Gregor den Abstand zwischen zwei Eheleuten nicht in Graden wie im römischen Recht, sondern nach Generationen ${ }^{19}$. Die Cousinenehe ist für ihn daher eine Inzestehe im zweiten Grad und nicht im vierten Grad wie im römischen Recht. Da man diese Zählweise bis heute als „germanisch" bezeichnet, haben es viele Historiker als erstaunlich angesehen, dass gerade ein im römischen Recht ausgebildeter und als Funktionär in Konstantinopel tätiger Römer die germanische Komputation eingeführt haben soll. Zweitens verwundert die Zulassung von Ehen zwischen Geschwisterenkeln, die doch sowohl von gallischen als auch von spanischen Konzilien des 6. Jahrhunderts untersagt worden $\operatorname{war}^{20}$. Im 8. Jahrhundert hätten die Päpste - nach

15 BREchter, Quellen 1941.

16 Meyvaert, Text 1971; Ders., Libellus 1986.

17 Meyvaert, Diversity 1963; Kottje, Studien 1970, 100-116; Сhadwick, Gregory 1991; MeEns, Background 1994.

18 Meyvaert, Text 1971, 33; Ders., Libellus 1986, 544 u. 550. Zustimmend Friesen, Answers 2006, 161. Keine Vorbehalte äußert Chadwick, Gregory 1991, $210 \mathrm{f}$.

19 Brechter, Quellen 1941, 75; Deanesly - Grosjean, Edition 1959, 7 f.

20 BRechter, Quellen 1941, 25. 
der unzutreffenden Interpretation vieler Historiker ${ }^{21}$ - das Inzestverbot sogar auf die siebte Generation ,germanischer' Komputation ausgedehnt. Eine derart nachsichtige Bestimmung wie diejenige des Libellus sei daher nicht denkbar.

Beide Kritikpunkte sind bei unvoreingenommener Betrachtung der rechtlichen Situation im Zeitalter Gregors des Großen nicht stichhaltig. Die Zählung nach Generationen ist zwar im Zusammenhang der Verwandtenehen neu, erklärt sich jedoch aus der intensiven Bibellektüre und -interpretation Gregors. Als Kommentator hat Gregor an verschiedenen Stellen die Praxis der Bibel registriert, nach Generationen zu zählen ${ }^{22}$. Das Buch Hiob schließt z. B. mit den Worten: „Hiob lebte danach noch hundertvierzig Jahre; er sah seine Kinder und Kindeskinder, vier Geschlechter. Dann starb Hiob, hochbetagt und satt an Lebenstagen". Gregor gibt dazu in seinen Moralia in Iob folgenden Kommentar: „Es widerspricht nicht der Wahrheit, dass wir durch Generationen die Abfolge der Zeiten bezeichnen. Was ist denn jede Abfolge, wenn nicht ein bestimmter

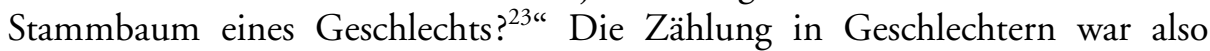
Gregor durchaus vertraut. Zudem erläutert er sehr präzise die Bedeutung von generatio im Libellus, indem er ausdrücklich die Enkel als zweite Generation bezeichnet. Man braucht also nicht die sog. ,germanische Komputation zur Erklärung dieser Textstelle bemühen ${ }^{24}$.

Die Beschränkung des Inzestverbots auf die Ehe zwischen Geschwisterkindern erweckt ebensowenig Misstrauen. Gregor der Große war Bürger des oströmischen Reichs und fühlte sich der Gesetzgebung des Kaisers in jeder Hinsicht verpflichtet ${ }^{25}$. Die Loyalität gegenüber dem römischen Recht kommt in über hundert Verweisen in seinem Briefregister deutlich zum Ausdruck ${ }^{26}$. Selbst in Fällen, in denen er als Vertreter der universalen Kirche mit Gesetzen nicht einverstanden sein konnte, akzeptierte er die legislativen Entscheidungen des Kaisers $^{27}$. Es ist daher nur selbstverständlich, wenn Gregor den Abschnitt über den Inzest mit einem Verweis auf das geltende Recht beginnt: „Ein bestimmtes Gesetz des römischen Staates erlaubt es, dass Sohn und Tochter eines Bruders und einer Schwester, zweier Brüder oder zweier Schwestern sich ehelich ver-

21 BRechter, Quellen 1941, 25. Siehe 237 Anm. 107.

22 Gregor, Moralia in Iob 21, 19, 57 (CCL 143A, 784); 16, 10, 15 (CCL 143A, 807); 28, 8, 19 (CCL 143B, 1410); 35, 16, 42 (CCL 143B, 1803).

23 Nec abhorret a vero quod per generationes dicimus tempora designari. Quid enim unaquaeque successio, nisi quaedam propago est generis? Gregor, Moralia in Iob 35, 20, 48 (CCL 143B, 1808).

24 Siehe 18-25.

25 Markus, Gregory 1997, 83-91.

26 Damizia, Registrum 1948, 222-224.

27 Markus, Gregory 1997, 88. 
binden dürfen" ${ }^{\text {28. }}$. Wie bereits Jean Fleury erkannte, zitiert Gregor den Widerruf des Verbots der Cousinenehe durch Arcadius, der im oströmischen Reich noch Geltung besaß ${ }^{29}$. Wie sich die Päpste bereits im 4. Jahrhundert für ein Verbot der Cousinenehe ausgesprochen hatten ${ }^{30}$, lehnte Gregor eine solche Nachsicht ab.

„Aber wir haben aus der Erfahrung gelernt, dass die Nachkommen einer solchen Ehe nicht (ohne Defekt) heranwachsen können; und das heilige Gesetz verbietet, die Scham der Verwandtschaft zu entblößen. Daher ist es notwendig, dass die dritte und vierte Generation der Gläubigen sich rechtmäßig verbinden darf; denn die zweite, von der wir sprachen, muss sich vollkommen voneinander enthalten “"31.

Gregor befindet sich mit dem Verbot der Cousinenehe also präzise auf dem Stand des päpstlichen Rechts. Die weitergehenden Beschlüsse der gallischen und spanischen Kirche berücksichtigt er nicht, wenn er sie denn überhaupt kannte.

Es gibt also keinen Grund, die Echtheit des Libellus hinsichtlich der Inzestbestimmung in Frage zu stellen. Der gesamte Brief an Augustinus von Canterbury ist authentisch. Warum Bonifatius diesem Brief notwendigerweise mit Misstrauen begegnen musste, werden wir weiter unten zu klären haben.

Verweilen wir an dieser Stelle bei der Interpretation des Libellus. Auffallend ist insbesondere die Begründungsstruktur des Verbots der Cousinenehe. Es wird nur allzu deutlich, dass Gregor in einen Erklärungsnotstand geraten ist. Keine Bibelstelle, kein weltliches Gesetz im römischen Recht Justinians, kein altkirchliches Konzil und keine päpstliche Dekretale ${ }^{32}$ zählten die Cousinenehe unter das Inzestverbot. Er konnte sich daher nicht auf Vorbildbestimmungen berufen, sondern musste eine eigene Begründung entwerfen. Als erstes Argument führt er die Gefahr von Erbschädigungen ins Treffen. Dies ist erstaunlich, denn keine andere Quelle der Antike und des Frühmittelalters erwähnt eine derartige Gefahr ${ }^{33}$. Zudem bleibt unklar, auf welche Erfahrung (experimentum)

28 Et quidem terrena lex in Romana republica permittit, ut sive fratris et sororis seu duorum fratrum germanorum vel duarum sororum filius et filia misceantur. Gregor, Registrum XI 56a (MGH Epp. 2, 335) (JE 1843).

29 FLEURY, Recherches 1933, 115.

30 Siehe $59 \mathrm{f}$.

31 Sed experimento didicimus ex tali coniugio subolem non posse succrescere, et sacra lex probibet cognationis turpitudinem revelare. Unde necesse est, ut iam tertia vel quarta generatio fidelium licenter sibi iungi debeat; nam secunda quam praediximus a se omni modo debet abstinere. Gregor, Registrum XI 56a (MGH Epp. 2, 335) (JE 1843).

32 Die Canones synodi Romanorum sind vollständig nur in einer gallischen Sammlung überliefert: Duval, Décrétale 2005, 8-18.

33 Zur Rezeption dieses Gedankens im Hochmittelalter vgl. Conbet, Burchard 2001, 212 216. Zum wissenschaftsgeschichtlichen Hintergrund vgl. OTtenheimer, Relatives 1996 : Die Gefahr von Erbschädigungen ist bei einer einmaligen Cousinenehe nur unwesentlich größer. Als drohende Strafe Gottes werden dagegen oft Erbschädigungen in Aussicht 
sich Gregor bei seiner Behauptung beruft, dass „aus einer solchen Verbindung eine Nachkommenschaft nicht heranwachsen kann". Das zweite Argument stützt sich auf das mosaische Gesetz in Levitikus (sacra lex), ohne jedoch einen konkreten Vers zu zitieren. Dass ein Verbot der Cousinenehe in Levitikus gerade nicht ausgesprochen wird, verschweigt Gregor. Der Papst bedient sich also einer Technik der Verhüllung, um das Verbot der Cousinenehe als natürlich und biblisch begründet darzustellen. Wörtliche Bibelzitate bringt Gregor dann zum Einsatz, wenn sie in sein Konzept passen. So verbietet er die Ehe mit der Stiefmutter und mit der Frau des Bruders mit wörtlichen Zitaten aus Levitikus. Für erlaubt hält er die Ehe zwischen zwei Brüdern und zwei Schwestern, „da in den heiligen Schriften nichts zu finden ist, was diesem Punkt zu widersprechen scheint ${ }^{\text {“34. }}$.

Im Wesentlichen drehen sich also die Ausführungen Gregors um die richtige Auslegung der Bibel. Dies wirft die Frage auf, aus welchem Grund das Inzestverbot überhaupt in den Fragekatalog des Augustinus von Canterbury aufgenommen worden ist. Gregor scheint darauf eine eindeutige Antwort zu geben. Er schreibt nach der Erläuterung des Inzestverbots:

„Weil es aber im Volk der Angeln viele gibt, von denen gesagt wird, dass sie während ihres Heidentums eine solche unerlaubte Ehe eingegangen sind, sollen die Neubekehrten ermahnt werden, sich zu enthalten und dies als eine schwere Sünde wahrzunehmen. Sie sollen das schreckliche Gericht Gottes fürchten, damit sie nicht für eine fleischliche Lust den Folterungen der ewigen Qual verfallen. Sie sollen aber deswegen dennoch nicht der Kommunion des heiligen Leibes und Blutes des Herrn beraubt werden, damit bei ihnen nicht jenes gerächt zu werden scheint, an das sie sich durch Unwissenheit vor dem Bad der Taufe gebunden haben ${ }^{\text {“35. }}$.

Diese Milde hört aber nach Gregor dann auf, wenn bereits bekehrte Personen eine Inzestehe eingehen. „Wer nicht fürchtet wissentlich zu sündigen“, soll von der Kommunion ausgeschlossen werden ${ }^{36}$.

Das Inzestverbot erscheint damit als Missionsproblem ${ }^{37}$. Abgerundet wird dieses Bild durch den oben besprochenen Fall der Ehe Eadbalds mit seiner

gestellt: Caesarius von Arles, Sermo 44, 7 (CCL 103, 199); Gregor, De virtutibus Martini 2, 24 (MGH SS rer. Merov. 1/2, 617); Gregor, Dialogi 1, 10, 1-5 (2, 92-96).

34 Hoc fieri modis omnibus licet, nec quicquam in sacris eloquiis invenitur, quod huic capitulo contradixisse videatur. Gregor, Registrum XI 56a (MGH Epp. 2, 335) (JE 1843).

35 Quia vero sunt multi in Anglorum gente, qui, dum adhuc in infidelitate essent, huic nefando coniugio dicuntur admixti, ad fidem venientes ammonendi sunt, ut se abstineant et grave hoc esse peccatum agnoscunt; tremendum Dei iudicium timeant, ne pro carnali dilectione tormenta aeterni cruciatus incurrant. Non tamen pro hac re sacri corporis ac sanguinis Domini communione privandi sunt, ne in eis illa ulcisci videantur, in quibus se per ignorantiam ante lavacrum baptismatis astrinxerunt. Gregor, Registrum XI 56a (MGH Epp. 2, 336) (JE 1843).

36 ... ita in his fortiter insequenda, qui non metuunt sciendo peccare. Gregor, Registrum XI 56a (MGH Epp. 2, 336) (JE 1843).

37 Мгкат, Inzestgesetzgebung 1994, $73 \mathrm{f}$. 
Stiefmutter, durch die sich der Königssohn von der Christianisierungspolitik seines Vaters absetzte und nach dem Tod des Augustinus eine heidnische Reaktion in Kent in Gang setzte ${ }^{38}$. Trotz dieser offenbar eindeutigen Beweislage muss dieses Bild nuanciert werden. Nach den Forschungen von Rob Meens sind einige Anfragen des Augustinus nicht aus der Heidenmission zu erklären, sondern können nur vor dem Hintergrund der Mission Englands durch konkurrierende Gruppen verständlich gemacht werden ${ }^{39}$. Augustinus traf nämlich, nachdem er im Jahr 597 von Gregor dem Großen zur Christianisierung Englands ausgeschickt worden war, nicht auf eine durchgehend heidnische Bevölkerung. Zum einen sind Missionsanstrengungen der Briten anzunehmen, die seit fast zweihundert Jahren in Koexistenz mit den herrschenden Angelsachsen ihr Christentum praktizierten ${ }^{40}$. Zum anderen war auch die fränkische Kirche nicht untätig, da König Aethelbert, der Augustinus in sein Königreich Kent aufnahm, mit einer merowingischen Prinzessin verheiratet war. Diese hatte sich ausbedungen, ihre Religion weiterhin pflegen zu dürfen und einen Bischof mit Namen Liuthard an den königlichen Hof mitzunehmen ${ }^{41}$. Die Konfrontation unterschiedlicher christlicher Traditionen musste nach Meens zu Diskussionen führen, die nur durch die Antwort des Papstes beigelegt werden konnten. Konkret nachweisbar ist dies bei der Frage der kultischen Unreinheit sexueller Handlungen $^{42}$. Die im Libellus geführte Diskussion über dieses Thema ist ein Reflex auf die wörtliche Übernahme der mosaischen Gesetze in der britischirischen Kirche. Durch die frühen irischen Bußbücher ist diese Besonderheit hinreichend belegt. Gregor wandte sich gegen diese wörtliche Auslegung und favorisierte eine allegorische Deutung der Schriftstellen.

Man muss also mit der Möglichkeit rechnen, dass die Anfrage des Augustinus von unterschiedlichen Standpunkten innerhalb der christlichen Gemeinschaft veranlasst worden ist. Eine Diskussion um die Tragweite der biblischen Inzestvorschriften wird man auch weniger bei neu konvertierten Angelsachsen als bei in unterschiedlichen Traditionen verankerten Klerikern erwarten können. Die frühen irischen Bußbücher bieten dafür jedoch keinen Beleg, da der Inzest darin mit Ausnahme des Verbots des Geschlechtsverkehrs mit der Mutter bzw. mit der Schwester kein Thema ist ${ }^{43}$. Nur eine Quelle, die in ihrer Datierung umstritten ist, bezeugt die wörtliche Übernahme der mosaischen Inzestverbote. Im Liber ex lege Moysi, einer Sammlung der mosaischen Gesetze,

38 Siehe 99.

39 MeEns, Background 1994.

40 Prinz, Anteil 1984, 330-334; Blair, Church 2005, 43-49.

41 Beda, Historia ecclesiastica gentis Anglorum I 25 (74). Vgl. Wallace-Hadrill, Rome 1960; Prinz, Anteil 1984, 324-330; Wood, Mission 1994, 8-10.

42 Коттје, Studien 1970, 110-116; Meens, Background 1994.

43 Sinodus Luci Victorie 6 (Bieler 68); Excerpta de libro Davidis 11 (Bieler 70); Paenitentiale Cummeani II 7 (BIELER 114). 
die in Irland wohl als vorbildliche Rechtssammlung Verwendung fand, werden auch die Inzestverbote aus Levitikus übernommen ${ }^{44}$. Diese Quelle aus dem 7. Jahrhundert ist ein Beleg dafür, dass in der irischen Kirche nur die biblischen Inzestverbote ohne die Erweiterungen der gallischen und spanischen Kirche beachtet wurden. Möglicherweise ist Augustinus aber auch durch fränkische Missionare wie den oben erwähnten Liuthard mit den besonders weitreichenden Inzestverboten der merowingischen Kirche konfrontiert worden und hat deshalb beim Papst Rückendeckung für eine milde Position gesucht. Die ,Obsession' der merowingischen Kirche wäre dann für die Anfrage des Augustinus verantwortlich zu machen. Dann wäre auch die Tatsache zu erklären, warum Gregor ausgerechnet auf die im Frankenreich des 6. Jahrhunderts besonders umstrittene Frage ausführlich eingeht, ob Inzest mit Ausschluss aus der christlichen Gemeinschaft zu bestrafen sei. Ein weiterer Hinweis auf eine solche Diskussion innerhalb der Missionare ist die vierte Anfrage des Augustinus, ob zwei Brüder mit zwei Schwestern eine Ehe eingehen dürften ${ }^{45}$. Gregor der Große bejahte dies, da ein solches Inzestverbot in der westlichen Kirche unbekannt war. Erst hundert Jahre später hat die Kirche des byzantinischen Reichs auf dem Konzil „in Trullo“ (692) ein solches Verbot erlassen, das in der Ostkirche in späterer Zeit ausgeweitet, im Westen jedoch erst im 12. Jahrhundert übernommen wurde $^{46}$. Obwohl die Quelle für die Bedenken des Augustinus unklar bleiben muss, ist die Anfrage offensichtlich nicht allein von der Missionsproblematik ausgelöst worden. Der Hinweis auf die „vielen Angeln, die eine solche unerlaubte Ehe eingegangen sind“, könnte ein Einschub von Gregor selbst sein, der damit das römische Vorurteil der endogamen Praxis von Barbaren zum Ausdruck gebracht hat.

Eine solche Deutung ist spekulativ, zeigt aber, dass der Text des Libellus responsionum nicht als Spiegelung der Missionsrealität begriffen werden kann. Vermutlich hat es tatsächlich Schwierigkeiten mit der Durchsetzung des Eheverbots zwischen Stiefverwandten gegeben, wie sie uns bei Eadbald im 7. und bei Aethelbald im 9. Jahrhundert überliefert sind. Doch darf man von diesen vereinzelten Fällen nicht auf eine verbreitete Praxis dieser Eheform unter den Angelsachsen oder gar auf häufige Ehen zwischen Blutsverwandten schließen. Wie die Quellen aus dem Frühmittelalter nahe legen, war die Cousinenehe vielmehr ein Problem des östlichen Mittelmeerraums sowie der senatorischen Schicht des Westens als eines der Mission. Gregors Libellus muss also diffe-

44 Fournier, Liber 1909; Котtje, Liber 1987. Der Inhalt des Liber wird wiedergegeben in Hardinge, Church 1972, 209-216.

45 Si debeant duo germani fratres singulas sorores accipere, quae sunt ab illis longa progenie generatae. Gregor, Registrum XI 56a (MGH Epp. 2, 335) (JE 1843).

46 Konzil in Trullo (692) c. 54 (CCO 1, 190-192). Vgl. Pitsakis, Droit 1992, 172-175. 
renziert betrachtet werden und kann nicht einseitig als Zeugnis der endogamen Praxis der Germanen herangezogen werden.

Die Wirkung des Libellus responsionum war enorm ${ }^{47}$. Mit über 200 Handschriften ist es vermutlich einer der am häufigsten überlieferten Texte mit Inzestvorschriften. Erstmals zitierte Beda Venerabilis den Libellus in seiner Vita des hl. Cuthbert (vor 721) und nahm ihn später vollständig in seine Kirchengeschichte auf. Zur selben Zeit tauchte er im Anhang der Collectio vetus Gallica auf, der im nordostfranzösischen Kloster Corbie dieser alten Sammlung beigegeben wurde ${ }^{48}$. Auf dem Kontinent wurde der Libellus ferner häufig in bußund kirchenrechtlichen Sammelhandschriften überliefert. Die milden Vorschriften zum Inzestverbot sollten bis zum 11. Jahrhundert immer wieder Anlass dafür bieten, sich vom Libellus zu distanzieren, ihn zu relativieren, umzuschreiben oder durch fingierte Quellen unschädlich zu machen.

Im England des 7. Jahrhunderts herrschte dagegen Schweigen über den Libellus. Diese Tatsache hat den Angriff auf die Echtheit des Dokuments erleichtert, muss jedoch als schwaches Argument beiseite geschoben werden, da viele Quellen dieser Zeit erst in späteren und oft kontinentalen Handschriften überliefert sind. Zudem ist dieser Befund zu revidieren. Vor kurzem äußerte Roy Flechner die Hyptohese, Erzbischof Theodor von Canterbury (668-690) habe den Libellus für sein Bußbuch herangezogen ${ }^{49}$. Theodor stammte aus Kilikien und war ein Gelehrter höchsten Ranges ${ }^{50}$. Im Alter von 66 Jahren schickte ihn Papst Vitalian als Erzbischof nach Canterbury. Diese Zeit war nach Beda die glücklichste seit der Ankunft der Angeln auf Britannien ${ }^{51}$. Theodor organisierte die englische Kirche nach römischem Vorbild, schuf neue Bistümer und veranstaltete Kirchenversammlungen. Trotz seines hohen Alters zeigte er sich als höchst effektiver Administrator.

Das erste Konzil berief Theodor drei Jahre nach seiner Ankunft in England ein. In Hertford, nördlich von London, versammelte er im Jahr 672 vier Bischöfe sowie den Vertreter seines Gegenspielers Wilfried von York um sich ${ }^{52}$. Gleich zu Beginn ließ er die Bischöfe und die anderen anwesenden Kleriker auf die Gültigkeit des Kirchenrechts einschwören. Die zwölf Kanones der Synode entnahm Theodor ausdrücklich aus einem Buch des Kirchenrechts ${ }^{53}$. Vermutlich handelte es sich dabei um die vom Papsttum favorisierte Sammlung des Dionysius Exiguus, auch wenn keine Bestimmung der Synode ein wörtliches

47 Meyvaert, Libellus 1986, 543.

48 Mordek, Kirchenrecht 1975, 219.

49 FleChNER, Making 2003/2004, 137.

50 Lapidge, Career 1995. Wichtige Korrekturen in der Besprechung von Wolfram BRANDES in: Byzantinische Zeitschrift 92 (1999) $274 \mathrm{f}$.

51 Beda, Historia ecclesiastica gentis Anglorum IV 2 (334).

52 Cuвiтt, Councils 1995, 249 f. u. 298.

53 Beda, Historia ecclesiastica gentis Anglorum IV 5 (350). 
Zitat aus älteren Rechtstexten enthält ${ }^{54}$. Die meisten Kanones betreffen die Durchsetzung der Diözesanverfassung und die Regelung der Disziplin innerhalb des Klerus. Allein der letzte Kanon widmet sich den Laien. Er stellt fest, „dass nur rechtmäßige Ehen erlaubt seien. Niemand soll einen Inzest begehen. Niemand soll seine eigene Frau verlassen außer bei Ehebruch, wie das heilige Evangelium lehrt. Wenn jemand seine Ehefrau, die ihm in rechtmäßiger Ehe verbunden ist, verstößt, soll er, wenn er ein Christ bleiben will, niemand anderen heiraten, sondern so bleiben oder mit seiner eigenen Frau versöhnt werden “55. Theodor setzte sich also für die strenge Lehre der Unauflösbarkeit der Ehe ein, wie sie vom Papsttum seit Innocenz I. verkündet worden war ${ }^{56}$. Das Inzestverbot ist dagegen kurz und kryptisch. Es lässt nur erkennen, dass das Inzestverbot zu den wichtigeren Anliegen zählte, die Theodor bei den Laien zur Geltung bringen wollte.

Ausführlicher gibt uns Theodors Bußbuch über seine Auffassung zum Inzestverbot Auskunft. Das Bußbuch ist in verschiedenen Fassungen erhalten, die kurz nach Theodors Tod im Jahr 690 kompiliert wurden ${ }^{57}$. Dass die Vorschriften auf authentischen Lehrsätzen Theodors beruhen, erkennt man an den häufigen Verweisen auf Unterschiede zwischen griechischen und römischen Regelungen sowie an den Zitaten aus Basilius von Cäsarea, dessen Schriften in der Ostkirche zum Kirchenrecht zählten. Das trifft auch für die Inzestbestimmungen zu, da sie das Recht der griechischen Kirche erwähnen. Die Fassung des sog. Discipulus Umbrensium schreibt:

„In der dritten Blutsverwandtschaft ist die Heirat bei den Griechen erlaubt, wie es im Gesetz geschrieben steht, in der fünften bei den Römern. Dennoch lösen sie die Ehe nicht in der vierten, nachdem sie geschlossen wurde. Daher heiraten sie in der fünften Generation; wenn jemand in der vierten gefunden wurde, trennen sie nicht, in der dritten trennen sie ${ }^{458}$.

54 BRETT, Theodore 1995, 125-128.

55 Ut nulli liceat nisi legitimum habere coniugium; nullus incestum faciat; nullus coniugem propriam nisi, ut sanctum evangelium docet, fornicationis causa relinquat. Quod si quisquam propriam expulerit coniugem legitimo sibi matrimonio coniunctam, si Christianus esse recte voluerit, nulli alteri copuletur, sed ita permaneat, aut propriae reconcilietur coniugi. Beda, Historia ecclesiastica gentis Anglorum IV 5 (352).

56 Im Gegensatz dazu stehen die laxen Regelungen in den Iudicia Theodori vgl. Kelly, Gregory II 1976, 85-93.

57 Einen Überblick verschafft Raymund Коттје, Art. „Paenitentiale Theodori“, in: HRG 3 (1984) 1413-1416.

58 In tertia propinquitate carnis licet nubere secundum Grecos, sicut in lege scriptum est, in quinta secundum Romanos. Tamen in quarta non solvunt, postquam factum fuerit. Ergo in quinta generatione coniungantur, quarta si inventi fuerint, non separentur, tertia separentur. Canones Theodori, Discipulus Umbrensium II, 12, 26 (329). Finsterwalder gibt der Variante Tamen in tertia non solvunt den Vorzug. Dies widerspricht jedoch dem Inhalt des Kanons. In den anderen Fassungen steht wie in einigen Handschriften von U quarta; 
Zum Verständnis dieser Bestimmung ist es zunächst notwendig, die Art der Verwandtschaftszählung bei Theodor zu klären ${ }^{59}$. Die Verwendung des Begriffs generatio scheint die biblische Zählung Gregors nahe zu legen. Dann würde die römische Kirche Ehen zwischen Geschwisterurenkeln, d.h. zwischen Cousin und Cousine im dritten Grad verbieten. Eine solche Position ist jedoch weder vor Theodor noch im 8. Jahrhundert bei den Päpsten zu belegen. Umgekehrt bereitet auch die Unterstellung der römisch-rechtlichen Komputation Schwierigkeiten. Dann wäre nämlich laut Theodor im griechischen Kirchenrecht die Ehe mit der Tante oder mit der Nichte erlaubt. Bezieht man den Verweis sicut in lege scriptum est auf das griechische Kirchenrecht, ergibt dies keinen Sinn ${ }^{60}$. Nur wenn man in der lex einen Bezug auf das mosaische Recht sieht, stimmt die Aussage, weil in Levitikus die Ehe mit der Nichte nicht untersagt wird ${ }^{61}$. Eine Entscheidung für eine bestimmte Zählweise erlaubt die folgende Bestimmung des Bußbuchs. Sie lautet: „Im dritten Verwandtschaftsgrad ist es nicht erlaubt, die Frau eines anderen nach dessen Tod zu heiraten “62. Dieses Verbot betrifft nicht mehr die Blutsverwandtschaft, sondern die Schwägerschaft. Die Erwähnung eines so speziellen Sachverhalts lässt sich nur erklären, wenn Theodor hier die Ehe mit der Frau des Onkels vor Augen hatte, die in Lev. 18, 14 unter das Inzestverbot subsumiert wird. Wenn Theodor mit dem dritten Verwandtschaftsgrad den Onkel gemeint hat, muss er die römisch-rechtliche Zählweise benutzt haben.

Für Theodor war folglich die Verwandtenehe bis zu den Geschwisterkindern verboten. Diese Regelung stimmt mit dem Libellus responsionum Gregors des Großen überein. Möglicherweise ist auch die Verwendung des Begriffs generatio von Gregor veranlasst. Sicherer Einfluss des Libellus ist in einer weiteren Bestimmung zum Inzestverbot wahrzunehmen: „Auch zwei Brüder dürfen zwei Schwestern in der Ehe haben, und der Vater und der Sohn die Mutter und die

tertia wird noch bezeugt durch eine spätere, von Asbach entdeckte Fassung: Canones Basilienses 32a (82).

59 Für die kanonische Komputation sprachen sich Freisen, Geschichte 1893, 409, und SeCKel, Synode 1922, 35, aus; für die römische Esmein, Mariage 1891, 346, und FLEURY, Recherches 1933, 119.

60 So bereits SECKEL, Synode 1922, 35 Anm. 6, der jedoch auch einen Verweis auf die Bibel ausschließen möchte.

61 Ein Fall von Nichtenheirat sorgte im 7. Jahrhundert für großes Aufsehen, die Ehe des byzantinischen Kaisers Herakleios mit seiner Nichte Martina. Vgl. KaEgi, Heraclius 2003, $60 \mathrm{f}$. Darüber wurde auch im Westen berichtet: Chronicae quae dicuntur Fredegarii IV 66 (MGH SS rer. Merov. 2, 154). - Vielleicht ist der Fassung der sog. Canones Gregorii der Vorzug zu geben, da sie als einzige Überlieferung den vierten Verwandtschaftsgrad als Grenze bei den Griechen aufführt: Canones Gregorii 78 (261).

62 In tertia tamen propinquitate non licet uxorem alterius accipere post obitum eius. Canones Theodori, Discipulus Umbrensium II, 12, 27 (329). 


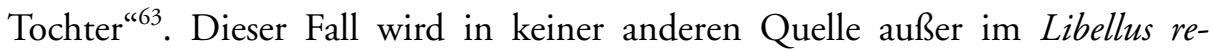
sponsionum diskutiert und geht daher auf dieses Dokument zurück ${ }^{64}$. Vermutlich kam Theodor in Canterbury mit dem an seinen Vorgänger adressierten Gutachten Gregors des Großen in Berührung.

Eine weitere Bestimmung zum Inzestverbot verdient unsere Aufmerksamkeit: „Der Mann wird in der Ehe gleichermaßen (wie) mit seinen Blutsverwandten auch mit den Blutsverwandten seiner Frau nach ihrem Tod verbunden ${ }^{\text {"65 }}$. Damit drückt Theodor die Gleichstellung von Bluts- und Schwiegerverwandtschaft aus. Insgesamt verbietet Theodor in seinen bußrechtlichen Regelungen die Cousinenehe, die Ehe mit der Frau des Onkels und die Ehe zwischen Schwager und Schwägerin.

Die verschiedenen Fassungen der bußrechtlichen Satzungen Theodors fanden auf dem Kontinent große Verbreitung. Insbesondere der Kreis um Bonifatius dürfte für die frühe Aufnahme östlich des Rheins verantwortlich gewesen $\operatorname{sein}^{66}$. Auch die in Corbie arbeitenden Gelehrten griffen bei der Niederschrift des dort entstandenen Excarpsus Cummeani, des am häufigsten überlieferten kontinentalen Bußbuchs, auf die Satzungen Theodors zurück ${ }^{67}$. Andere sog. Paenitentialia composita bedienten sich ihrer ebenfalls ${ }^{68}$. Die Inzestbestimmung war immer Teil dieser breiten Rezeption im Frankenreich.

Nicht nur im Frankenreich, auch in Irland griff man auf die Bußbestimmungen Theodors zurück. Thomas Charles-Edwards konnte wahrscheinlich machen, dass eine irische Synode von Theodor beeinflusst wurde ${ }^{69}$. Diese Synode wird als zweite Synode des hl. Patrick bezeichnet, hat aber erst um 700 unter der Ägide der römischen Partei innerhalb der irischen Geistlichkeit stattgefunden ${ }^{70}$. Diese bemühte sich um die Verdrängung der irischen Eigenheiten in Liturgie und Recht und um die Etablierung des römischen Vorbilds $s^{71}$. Anfang des 8. Jahrhunderts setzte sich die römische Partei in ganz Irland durch.

63 Duo quoque fratres duas sorores in coniugio possunt habere et pater filiusque matrem et filiam. Canones Theodori, Discipulus Umbrensium II, 12, 29 (330).

64 In diesem Sinn FleChNer, Making 2003/2004, 137.

65 Aequaliter vir coniungitur in matrimonio eis qui sibi consanguinei sunt, et uxoris suae consanguineis post mortem uxoris. Canones Theodori, Discipulus Umbrensium II, 12, 28 (330).

66 Glatthaar, Bonifatius 2004, 626. Finsterwalder, Canones 1929, 174, vermutete, dass die Niederschrift der Fassung des Discipulus Umbrensium auf dem Kontinent stattgefunden hat. Diese Ansicht hat sich jedoch gegen den Widerspruch von Levison und Lehmann nicht durchsetzen können, vgl. Raymund КоттJe, Art. „Paenitentiale Theodori“, in: HRG 3 (1984) 1413-1416.

67 Mordek, Kirchenrecht 1975, 86; Körntgen, Excarpsus 2004.

68 MeEns, Boeteboek 1994, 30-36.

69 Charles-Edwards, Penitential 1995.

70 Breen, Date 1995.

71 Hughes, Church 1996, 105-110; Charles-Edwards, Ireland 2000, 391-415. 
Charles-Edwards belegt die Rezeption Theodors mit der Inzestbestimmung, die das Verbot bis zum vierten Grad erwähnt. Der genaue Sinn der Bestimmung ist jedoch unklar, da der Konzilstext in zwei unterschiedlichen Versionen überliefert ist. Die eine Version befindet sich ebenso wie der Libellus responsionum und das Bußbuch Theodors im Anhang der Collectio vetus Gallica aus Corbie ${ }^{72}$. Die zweite Fassung ist in zwei Handschriften aus Bayern überliefert und scheint auf direkte Vermittlung aus Irland zurückzugehen ${ }^{73}$. Nur der Anfang der Bestimmung ist in beiden Versionen identisch: „Hinsichtlich der Blutsverwandtschaft in der Ehe halte dich daran, was das Gesetz sagt, nicht mehr und nicht weniger $^{\text {"77 }}$. Der Sinn dieses Satzes ist klar: Nur die Inzestvorschriften der Bibel sollen eingehalten werden und keine anderen. Die Synode befindet sich damit auf dem Standpunkt des Liber ex lege Moysi, der in Irland entstandenen Sammlung des mosaischen Rechts ${ }^{75}$. In der Vetus Gallica-Version folgt darauf die Ablehnung einer anderen Position: „Was aber bei uns eingehalten wird, dass nämlich vier Geschlechter (Grade) vermieden werden, davon behaupten sie, es weder gesehen noch gelesen zu haben " ${ }^{\text {"7 }}$. Nach der Vermutung von Charles-Edwards ist damit die Position Theodors gemeint, die damit von den Gegnern der römischen Partei wegen fehlender biblischer Autorität abgelehnt worden sei ${ }^{77}$. Umstritten war daher das Verbot der Cousinenehe, das mit den vier Graden gemeint ist, welches in der Bibel jedoch nicht verankert ist. Der Kanon ist damit ein Zeugnis für den in der Synode gefundenen Kompromiss zwischen der irischen und der römischen Partei. In Sachen Inzestverbot konnten sich die Romani offensichtlich nicht durchsetzen ${ }^{78}$.

Aus der Analyse der angelsächsischen und irischen Quellen lässt sich folgendes Fazit ziehen: Das Verbot der Verwandtenehe galt bis zu den Geschwisterkindern, und selbst dann sahen sowohl Gregor als auch Theodor eine maßvolle Anwendung dieser Regel vor. Bei Gregor sollten Neubekehrte wegen einer solchen Ehe nicht von der Kommunion ausgeschlossen werden, Theodor

72 Synodus II Sancti Patricii 29 (Bieler 184-196); vgl. Mordek, Kirchenrecht 1975, 219.

73 Herausgegeben von BreEN, Date 1995, 112-116.

74 De consanguinitate in coniugio, intellige quid lex loquitur, non minos nec plus. Synodus II Sancti Patricii 29 (Bieler 196); BreEn, Date 1995, 116.

75 Hardinge, Church 1972, 212.

76 Quod autem observatur apud nos, ut quattuor genera dividantur, nec vidisse dicunt nec legisse. Synodus II Sancti Patricii 29 (BIELER 196). Nach Bieler muss richtig devitantur gelesen werden; so auch BreEn, Date 1995, 120.

77 Charles-Edwards, Penitential 1995, 160. Der Bezug zum Liber ex lege Moysi ist ihm entgangen.

78 Aidan Breen gibt dagegen der bayerischen Version den Vorzug: Quod autem observatur apud vos, ut IIIIor genera divitantur, neque audisse neque legisse Romanis sedantur. BREEN, Date 1995, 116. Folglich schreibt er die bibeltreue Position der römischen und das Verbot der Cousinenehe der irischen Partei zu: Breen, Date 1995, 102. 
wollte bereits geschlossene Cousinenehen grundsätzlich nicht trennen ${ }^{79}$. Bei den weltlichen Herrschern fand dieses Verbot keinen Anklang. Wenige Jahre nach dem Tod Theodors hat König Wihtraed von Kent ein Gesetz zum Inzestverbot erlassen, das nur die Vorschriften der Bibel umfasste ${ }^{80}$. In Irland hat die Kirche ebenso wenig das Verbot der Cousinenehe akzeptiert und mit den Vorschriften der Bibel Vorlieb genommen. In der Collectio Hibernensis, einer vor 725 in Irland entstandenen Kirchenrechtssammlung, wird dieses Verbot gänzlich übergangen. Vielmehr wird darin indirekt zur Cousinenehe aufgerufen, wenn es erbschaftliche Erwägungen erfordern ${ }^{81}$. Das Verbot der Schwagerehe hat sich dagegen sowohl bei Angelsachsen wie bei Iren durchgesetzt. Im Gegensatz zum Kontinent wird allerdings stets nur das Levirat und nicht das Sororat genannt. Bereits im Libellus responsionum ist es so ${ }^{82}$, und in der Collectio Hibernensis wurde sogar vorsätzlich das biblisch nicht fundierte Verbot des Sororats aus den vorliegenden Quellen gestrichen ${ }^{83}$. Allein Theodor von Canterbury dürfte hier eine Ausnahme gebildet haben ${ }^{84}$.

Wir können also von der Vermutung ausgehen, dass Bonifatius im Wesentlichen die biblischen Vorschriften zum Inzestverbot ernst nahm. Das wird unmissverständlich bestätigt durch einen der seltenen Hinweise des Missionars auf kirchenrechtliche Traditionen in England. Als er bei der Mission mit dem Fall einer Heirat mit der Frau des Onkels konfrontiert war und die betroffene Person sich auf eine päpstliche Dispensierung berief, konnte er in einem Brief an Papst Zacharias seine heftige Empörung nur mühsam unterdrücken.

„Wir halten dafür, dass das nicht wahr ist: die Synode und die Kirche, in der ich geboren und aufgewachsen bin, nämlich die Londoner Synode in Sachsen jenseits des Meeres, die vor allem von Schülern des heiligen Gregors, nämlich von den Erzbischöfen Augustinus, Laurentius, Justus und Milletus, geschaffen und eingerichtet worden ist, hat eine solche Verbindung und Ehe nach Maßgabe der Heiligen Schrift für das größte Verbrechen, für Blutschande, für entsetzlichen Frevel und verdammenswerte Sünde erklärt. Darum möge es Eure Väterlichkeit nicht ableh-

79 Quarta si inventi fuerint, non separentur ... Canones Theodori, Discipulus Umbrensium II, 12, 26 (329).

80 Gesetze der Angelsachsen, Wihtraed 5 (1, 12). Vgl. Wormald, Making 1 1999, 102; Cuвiтt, Bishops 2007, 154-156.

81 In quo intelligendum est quod Dominus ideo dixit: Nemo copuletur uxori nisi de tribu sua, ne hereditas transferatur de tribu in tribum. Collectio Hibernensis 32, 19 (116). Den sozialgeschichtlichen Hintergrund beleuchtet Ó Corrárn, Law 1984, 157-161.

82 Cum cognata quoque miscere prohibitum est, quia per coniunctionem priorem caro fratris fuerat facta. Gregor, Registrum XI 56a (MGH Epp. 2, 335).

83 De thoro fratris defuncti audi decreta synodi: Superstes frater thorum defuncti non ascendat, domino dicente: erunt duo in carne una. Ergo est soror tua uxor fratris tui. Synodus II Sancti Patricii 25 (Bieler 194). Dies ist ein Zitat des c. 18 des 1. Konzils von Orléans, allerdings wird das dort erwähnte Verbot des Sororats unterschlagen. Ebenso in Collectio Hibernensis 46, 35 (194).

84 Siehe 230 Anm. 65. 
nen, uns in dieser Sache die Wahrheit mitzuteilen, damit den Geistlichen der Kirche und dem Christenvolk daraus nicht Ärgernis, Zwiespalt und neue Irrungen entstehen und erwachsen "85.

Über diese Londoner Synode gibt uns nur dieser Brief Auskunft ${ }^{86}$. Bedeutsam ist, dass damals die Ablehnung der Heirat mit der Frau des Onkels durch das Verbot in Levitikus begründet worden war. Der Inzestkatalog von Levitikus hatte also für Bonifatius Geltung. Ob er auch die in der angelsächsischen und irischen Kirche umstrittene Cousinenehe als Tabu betrachtete, muss zunächst offen bleiben.

\section{Römische Neuerungen}

Die in England anerkannte Reichweite des Inzestverbots galt im Bußbuch Theodors als Standpunkt der Romani, also des Papstes. Als Bonifatius das zweite Mal in Rom eintraf, hatte sich der Standpunkt des apostolischen Stuhls allerdings bereits grundlegend gewandelt. Das Papsttum hatte sich von dem althergebrachten Standpunkt des römischen Rechts verabschiedet und den Einflüssen aus dem byzantinischen Reich sowie aus der westgotischen Kirche geöffnet. Urheber dieses Wandels war Gregor II., „der bedeutendste Papst seines Jahrhunderts ${ }^{487}$ und der erste Stadtrömer nach einer langen Reihe von griechischen Päpsten.

Dieser Wandel fand zu einer Zeit der beginnenden Differenzen zwischen Rom und Byzanz statt. Auslöser war die von Kaiser Justinian II. einberufene ökumenische Synode „in Trullo“ $(692)^{88}$. Justinian beabsichtigte mit der Kirchenversammlung eine umfassende Anpassung des Kirchenrechts an die Gegenwart, nachdem die letzten beiden ökumenischen Synoden keine Kanones erlassen hatten. Das Konzil „in Trullo“, auch Quinisextum genannt, zählt mit 104 Bestimmungen zu den bedeutendsten Gesetzgebungsinitiativen des byzantinischen Kirchenrechts. Obwohl zur Synode eingeladen, weigerte sich der Papst, seine Unterschrift unter die Kodifikation zu setzen. Einige Kanones hatten nämlich eine anti-römische Spitze, da sie Gewohnheiten des Ostens zum Gesetz erhoben und die des Westens verwarfen. Zudem setzte der Kaiser an

85 Quod non estimamus esse verum; quia synodus et ecclesia, in qua natus et nutritus fui, id est in transmarina Saxonia Lundunensis synodus, inprimis a discipulis sancti Gregorii id est Augustino, Laurentio, Iusto, Milleto archiepiscopis, constituta et ordinata fuit, talem copulam et matrimonium maximum scelus et incestum et horribile flagitium et damnabile piaculum fieri ex auctoritate sanctae scripture iudicabant. Quapropter paternitas vestra huius rei veritatem nobis iudicare non dedignetur, ut ecclesiae sacerdotibus vel populo christiano inde scandala et scismata vel novi errores non oriantur et concrescant. S. Bonifatii et Lulli epistolae 50 (MGH Epp. sel. 1, 84).

86 Kurz erwähnt bei Cubitt, Councils 1995, 314.

87 Caspar, Gregor II. 1933, 68.

88 Ohme, Quinisextum 1990; Ders., Concilium 2006. 
erster Stelle seine Unterschrift unter die Kanones und ließ einige Bistümer in der Liste der ostkirchlichen Patriarchate unterschreiben, die der Papst zu seinem Jurisdiktionsgebiet zählte ${ }^{89}$. Der Kaiser reagierte auf den Widerstand des Papstes mit nackter Gewalt und versuchte, den Papst durch Zwangsmaßnahmen zur Unterschrift zu zwingen. Papst Sergius I. konnte sich jedoch des Rückhalts der stadtrömischen Miliz erfreuen und leistete den Handlangern des Kaisers erfolgreich Widerstand. Erst als Justinian nach einer zehnjährigen Entmachtung wieder die Herrschaft erlangte und auf friedlichem Weg auf eine Einigung drängte, kam es zum Kompromiss. Papst Konstantin I. reiste im Jahr 711 zum Kaiser in den Osten und akzeptierte die Kanones mit dem Vorbehalt, seine Unterschrift nicht leisten zu müssen und an den in Frage gestellten Gewohnheiten Roms festhalten zu dürfen ${ }^{90}$.

Beteiligt an dem Kompromiss von 711 war der damalige Diakon Gregorius. „Er gab Kaiser Justinian über einige Kapitel beste Antwort und löste jedwede Frage ${ }^{\text {" } 91}$. Wenige Jahre später wurde der Diakon zum Papst gewählt. Als Gregor II. stand er von 715 bis 731 der römischen Kirche vor ${ }^{92}$. Seine erste Stellungnahme zum Inzestverbot ist einer Anweisung an Bischof Martinianus aus dem Jahr 716 zu entnehmen. Gregor schickte den Bischof in Begleitung von zwei römischen Klerikern nach Bayern, um dort Bistümer einzurichten und die kirchliche Organisation an die kanonischen Normen anzupassen ${ }^{93}$. Gregor kam damit dem Wunsch Herzog Theodos nach, der kurz zuvor nach Rom gepilgert war und um eine Unterstützung seiner missionarischen Bemühungen ersucht hatte. Zu einer Zeit, als sich das Frankenreich in einer Sukzessionskrise befand, war es das Ziel Theodos, mit Hilfe des Papstes eine von fränkischer Vorherrschaft unabhängige Landeskirche zu schaffen.

Die Gesandtschaftsinstruktion des Papstes ist eine Mischung von formelhaften Elementen mit eigens für die bayerische Kirche bestimmten Satzungen ${ }^{94}$. Formelhaft ist die anachronistische Warnung vor der Weihe afrikanischer Kleriker, andere Bestimmungen über die Gliederung in Diözesen und die Wahl eines Erzbischofs hatten zweifelsohne einen aktuellen Hintergrund. Dies darf auch für die längste Bestimmung der Instruktion angenommen werden, die sich mit dem Eherecht befasst. Gregor legt darin die päpstliche Doktrin der Unauflösbarkeit der Ehe dar, warnt aber ebenso davor, im Geist der mönchischen Askese die Ehe verächtlich zu machen. Darauf lässt er ein umfassendes Verbot

89 Caspar, Geschichte 2 1930, 633 f.; abschwächend Ohme, Kanones 1995.

90 Der genaue Inhalt wird in den römischen Quellen unterschlagen: CASPAR, Geschichte 2 1930, 639 f. Langfristig fand keine Rezeption des Quinisextum im Westen statt: TodT, Papstreise 2002.

91 Liber Pontificalis, Vita Gregorii II. (1, 396).

92 Paolo Delogu, Art. „Gregorio II“, in: Enciclopedia dei Papi 1 (2000) 647-651.

93 Zuletzt ausführlich besprochen bei Freund, Bischöfe 2004, 31-42.

94 Vgl. Schieffer, Winfrid-Bonifatius 1954, 143. 
von Verwandtenehen folgen. Namentlich nennt er die Ehe mit der Stiefmutter, mit der Frau des Onkels, mit der Schwägerin, mit der (Halb-)Schwester, mit Tante, Nichte und Cousine ${ }^{95}$. Mit Ausnahme von Nichten- und Cousinenehe gibt es für alle Verbote Vorbilder im Buch Levitikus. Die Cousinenehe galt in der Auffassung der Päpste und seit dem Trullanum auch im Recht des oströmischen Reichs als Inzest. Die Sanktion für das Eingehen unerlaubter Ehen war der Ausschluss von der heiligen Kommunion, „ohne deren Empfang niemand erlöst werden könne“"96.

Das Inzestverbot der Instruktion befindet sich noch durchgehend auf dem Boden der päpstlichen Tradition. Diesen verlässt Gregor auf dem römischen Konzil von 721. In seiner Ansprache an die 22 anwesenden Bischöfe hebt er eindringlich seine pastorale Verantwortung für in Italien weit verbreitete Missstände hervor:

„Denn es passiert - und ich sage es nur unter Klagen -, dass ich von einigen christlichen Gemeinden in Italien höre, die verwegen gegen den katholischen Glauben und gegen die Satzungen der Väter sündigen, so dass sie wagen, gottgeweihte Frauen zu heiraten und sich mit Verwandten in der Ehe zu verbinden. Es ist angezeigt, dies mit geistlichem Schwert wegzuschneiden und von Grund auf zu vernichten ..." ${ }^{\text {997 }}$

Der versammelte Klerus antwortete mit Zustimmung und verlangte die Verhängung des Anathems für die Sünder, egal ob es sich um Romanen, Langobarden oder Angehörige anderer Völker handelte ${ }^{98}$. Die darauf folgenden Kanones 1-8 erwähnen dann ausdrücklich das Eheverbot mit der Taufpatin des Sohnes, mit der Schwägerin, der Nichte, der Stiefmutter, der Schwiegertochter und der Cousine. Diese Reihe wird mit einem folgenreichen allgemeinen Verbot

95 Ipsum quoque unius viri et uxoris coniugium doceatur in proximitate sanguinis non esse penitus praesumendum, id est ne quis uxorem patris aut patrui aut fratris sive sororem suam aut sororem patris vel matris sive filiam sororis suae seu etiam filiam [Mansi ergänzt: sororis] patris aut matris audeat sibi coningio copulare aut in adulterio sociare. Gregor II., Capitulare (Mansi 12, 259) (JE 2153). Die Nennung der Cousine hängt allein an der plausiblen Ergänzung von sororis. Andernfalls wäre mit filiam patris aut matris und mit soror sua die Halbschwester und die leibliche Schwester genannt.

96 Quod si quis aut per coniugalem copulam aut adulterandi temerantiam ausus fuerit perpetrare, noverit se incesti facinoris contaminatione obnoxium esse, atque ob hoc indignum fieri sacra communione corporis et sanguinis domini nostri Iesu Christi, sine cuius perceptione nemo poterit salvari. Gregor II., Capitulare (Mansi 12, 259 f.) (JE 2153).

97 Hinc namque est, quod ingemiscens dico, quia populi christiani aliquos per provinciam Italiam commorantes audio temere contra catholicam fidem et patrum statuta patrare [Mansi korrigiert in peccare], ita ut Deo sacratas feminas ducere praesumant mulieres et propinquas in coningio socient. Quod opportunum est spiritali amputare mucrone atque, si vestrae placeat sanctitati, radicitus evelli ... Konzil von Rom (721) prol. (Mansi 12, $262 \mathrm{f}$.).

98 ... quisquam Romanus, Longobardus vel cuiuscumque sit gentis ... Konzil von Rom (721) prol. (Mansi 12, 263). 
beschlossen: „Wenn jemand (eine Frau) aus eigener Verwandtschaft oder eine Frau, die ein Verwandter hatte, heiratet, soll er verflucht sein ${ }^{\text {"99 }}$. In dieser ebenso knappen wie juristisch präzisen Formulierung wird das Inzestverbot auf alle Verwandte ausgedehnt und Blutsverwandtschaft mit Schwägerschaft gleichgesetzt.

Das Konzil von Rom im Jahr 721 führte somit zwei Neuerungen in das päpstliche Kirchenrecht ein. Erstens wurde erstmals im Westen die geistliche Verwandtschaft als Ehehindernis bewertet. In Konstantinopel hatte bereits Kaiser Justinian im Jahre 530 ein Verbot der Ehe zwischen Paten und Patenkindern erlassen ${ }^{100}$. Dieses Gesetz war im Westen nicht übernommen worden, obwohl sich dort die Schaffung von Allianzen durch die Taufpatenschaft seit dem 6. Jahrhundert fest etabliert hatte ${ }^{101}$. Der Grund dafür war nach der Vermutung von Joseph Lynch die Tatsache, dass im Westen Pate und Patenkind gewöhnlich das gleiche Geschlecht hatten und daher eine Ehe nicht in Frage kam $^{102}$. Auf dem Konzil „in Trullo“ ließ Justinian II. dieses Gesetz auf das Verhältnis zwischen Paten und leiblicher Mutter des Patenkindes ausdehnen ${ }^{103}$. Dieses neue Inzestverbot war auch im Westen relevant und fand Aufnahme bei Gregor II., dem Kenner der Beschlüsse des Trullanum. Schon wenige Jahre später nahm man im Frankenreich diese Regelung zur Kenntnis ${ }^{104}$, die seither zum festen Bestand der Inzestverbote zählte.

Die zweite Neuerung setzte Gregor durch das kategorische Verbot der Verwandtenehe ins Werk. Es sollte über dreihundert Jahre die charakteristische Position des apostolischen Stuhls bleiben. Die Konsequenzen dieses kategorischen Verbots für die Praxis waren bereits für Bonifatius ein erhebliches Problem. Mehrfach wandte er sich an die Päpste, um über die Deutung dieses abstrakten Grundsatzes Aufklärung zu erhalten. Gregor II. selbst antwortete im Jahr 726, das Verbot reiche so weit, wie eine Verwandtschaft zwischen den Eheleuten bekannt sei. Für die Praxis der Mission hielt er es jedoch für angemessen, Milde walten zu lassen und nur Verwandtenehen bis zur vierten Generation zu untersagen ${ }^{105}$. Wenige Jahre später erhielt Bonifatius von Gregor III., dem seit 731 amtierenden Nachfolger, die bei weitem unnachgiebigere

99 Si quis de propria cognatione vel quam cognatus habuit duxerit uxorem, anathema sit. Konzil von Rom (721) c. 9 (Mansi 12, 263).

100 Codex Iustinianus 5, 4, 26 (197).

101 Lynch, Godparents 1986; Jussen, Patenschaft 1991.

102 LynCH, Godparents 1986, 223.

103 LYNCH, Godparents 1986, 230.

104 Und zwar in der erfundenen Anekdote über Fredegunde im Liber historiae Francorum 31 (MGH SS rer. Merov. 2, 292 f.). Vgl. LyNCH, Godparents 1986, 278.

105 S. Bonifatii et Lulli epistolae 26 (MGH Epp. sel. 1, 45). 
Auskunft, dass sich die Verwandtschaft bis zum siebten Grad erstreckt und daher auch das Inzestverbot diese Ausdehnung haben muss ${ }^{106}$.

Entscheidend bei der Interpretation dieser päpstlichen Briefe ist wieder einmal die Frage der Zählweise. Die Historiker haben sich zu dieser Frage kontrovers geäußert, ohne dass diese Frage bislang ausführlich zur Diskussion gestellt wurde ${ }^{107}$. Überzeugende Argumente bringt nur die Überblicksdarstellung zur Geschichte der christlichen Ehe durch George H. Joyce vor ${ }^{108}$. Für die Benutzung der römischen Zählung sprechen nach Joyce zwei Argumente: Erstens ist die Annahme nicht plausibel, dass Gregor II. in c. 8 des Konzils von Rom die Ehe mit der Cousine ersten Grades (2/2) und in c. 9. die Ehe mit der Cousine 6. Grades (7/7) verboten hätte. Ein solcher Sprung in der ansonsten auf die nahe Familie beschränkten Aufzählung des Konzils macht wenig Sinn. Zweitens hätte Gregor II. die Ermäßigung auf den vierten Grad, die er 724 Bonifatius zusagte, kaum als temperantia verkaufen können, wenn er damit das bislang in keiner Quelle des Frühmittelalters genannte Verbot mit der Cousine dritten Grades (4/4) gemeint hätte. Als Mäßigung wäre nur die Beschränkung auf die Cousine ersten Grades (2/2) aufgefasst worden. Die weitere Geschichte des 8. Jahrhunderts bestätigt Joyces Argumente. Leo III. erläuterte in einem Schreiben an die bayerischen Bischöfe das kategorische Verbot der Verwandtenehe mit einem Verweis auf die römische Zählung der Verwandtschaft in den Pauli Sententiae ${ }^{109}$. Dies ist eine der wenigen Quellen des römischen Rechts, die eindeutig den siebten (3/4) und nicht den sechsten Grad (3/3) als Grenze der Verwandtschaft bezeichnen. Diese päpstliche Position fand auch bei den weltlichen Herrschern Gehör. König Liutprand untersagte im Jahr 723/4 die Ehe mit der verstorbenen Frau des Cousins zweiten Grades (3/3) und berief sich auf ein Mahnschreiben Gregors II., „des Oberhauptes der Kirchen im ganzen

106 S. Bonifatii et Lulli epistolae 28 (MGH Epp. sel. 1, 51).

107 Für die römische Zählweise sprechen sich LoEning, Geschichte 2 1878, 557, Esmein, Mariage 1891, 347 f., Fleury, Recherches 1933, 142, und Joyce, Ehe 1943, 453, aus. Die kanonische (bzw. „germanische“) Zählweise favorisieren Freisen, Geschichte 1893, 425; Seckel, Synode 1922, 32 Anm. 2; Mordek, Recht 1987, 459; Rouche, Mariages 1986, 861; Le Jan, Famille 1995, 313; Jong, Riddle 1998, 107; Sснмinck, Livius 1982, 155; Weigand, Ausdehnung 1994, 6; Conbet, Burchard 2001, 320. Absurd ist die These von Poly, Chemin 2003, 277: Ihm zufolge handelt es sich beim Brief Gregors III. um eine Fälschung aus dem Mainzer Umfeld des Hrabanus Maurus, dem die Ausweitung des Verbots auf den siebten Grad kanonischer Zählung zuzuschreiben sei. Absurd ist die These deshalb, weil gerade Hraban in seinen Schriften ausführlich von seiner zurückhaltenden Einstellung in Sachen Inzestverbot Zeugnis ablegt; und weil es in der Überlieferung der Bonifatius-Briefe für einen fälschenden Eingriff kein Zeugnis gibt.

108 Joyce, Ehe 1934, 453.

109 Leo III., Epistola 5 (MGH Epp. 5, 62) (JE 2503). 
Erdkreis “110. Mit diesem Gesetz passte der Langobardenkönig die Vorschriften des Edictus Rothari an den neuen päpstlichen Standpunkt an. Ebenso verfuhr der Karolinger Pippin nach seiner Königserhebung, die er der Unterstützung des Papstes verdankte. Auf gesamtfränkischen Synoden wurde die Verwandtschaft des siebten Grades römischer Zählung (3/4) als Inzestgrenze festgesetzt ${ }^{111}$. Es bleibt daher kein Raum für Zweifel an der Tatsache, dass der apostolische Stuhl unter Gregor II. und seinen Nachfolgern die römische Zählung verwendete.

Auf dem Konzil von 721 akzeptierte Gregor II. somit den Standpunkt der westgotischen Kirche, wie er erstmals auf dem 2. Konzil von Toledo formuliert worden war: Alle Ehen unter Bluts- und Schwiegerverwandten sollten kategorisch verboten werden. Dass der Kanon dieses Konzils bei der Formulierung Pate stand, belegt ein wenig später abgefasster Brief des Papstes an Bonifatius, in dem er sich wörtlich der Formulierung der westgotischen Bischöfe bediente ${ }^{112}$. Über die konkrete Vermittlung der westgotischen Quelle gibt die Subskriptionsliste des römischen Konzils Auskunft. Nach der Nennung der anwesenden Bischöfe aus dem römischen Metropolitanbezirk sind noch drei ausländische Bischöfe genannt, Sinderedus aus Spanien, der Iroschotte Sedulius aus Britannien und der Pikte Fergustus aus Schottland ${ }^{113}$. Sinderedus war vor der Eroberung Spaniens durch die Araber Bischof von Toledo und musste 711 nach Rom fliehen ${ }^{114}$. Er dürfte für die Vermittlung westgotischen Kirchenrechts verantwortlich gewesen sein.

Schwieriger als die Auffindung der Quelle für den Erlass des kategorischen Verbots von Verwandtenehen ist die Klärung der Motivation des Papstes. Warum hat der Papst ein derart unbestimmtes Verbot erlassen, und warum sah er sich überhaupt zur Ausdehnung des Inzestverbots veranlasst? Der Vorzug

110 Hoc autem Deo iubante statuere previdimus, ut amodo nullus homo presumat relicta de consubrino aut insubrino suo uxorem ducere... Hoc autem ideo adfiximus, quia deo teste papa urbis Romae, qui in omni mundo caput ecclesiarum dei et sacerdotum est, per suam epistolam nos adortavit, ut tale coniugium fieri nullatinus permitteremus. Leges Liutprandi c. 33 (MGH LL 4, 123 f.). Einen Bezug auf das Konzil von 721 sieht auch Bertolini, Chiese 1960, 459.

111 Siehe $266 \mathrm{f}$.

112 Dicimus, quod oportuerat quidem, quamdiu se agnoscunt affinitate propinquos, ad huius copule non accedere societatem. S. Bonifatii et Lulli epistolae 26 (MGH Epp. sel. 1, 45) (JE 2174). Das Vorbild ist: Nam et haec salubriter praecavenda sancimus, ne quis fidelium propinquam sanguinis sui, usquequo affinitatis lineamenta generis successione cognoscit, in matrimonio sibi desideret copulari. 2. Konzil von Toledo (527/531) c. 5 (Hispana 4, 352).

113 Konzil von Rom (721) subscriptiones (Mansi 12, 265). Vgl. Hartmann, Synoden 1989, 39. Zur Identität des Sedulius hat JaHN, Ducatus 1991, 103, eine Vermutung geäußert.

114 So die Vermutung von García Moreno, Prosopografía 1974, 123. - Bereits Braulio von Saragossa $(\dagger 651)$ hatte eine Sammlung spanischer Konzilien nach Rom geschickt: Caspar, Geschichte 2 1930, 672. 
eines unbestimmten Verbots bestand in erster Linie darin, dass es durch die allgemeine Formulierung in Lev. 18, 6 begründet erschien. Gegenüber der im Frankenreich üblichen Aufzählung der zur Ehe nicht zugelassenen Verwandten konnte derart die fehlende biblische Begründung elegant überdeckt werden. Zudem werden die Tatsache der Ausdehnung des Inzestverbots und die Neuerung gegenüber der altkirchlichen Tradition auf diese Weise kaschiert. Die zweite Frage muss im Zusammenhang der Ablösung der römischen Kirche von der kaiserlichen Vorherrschaft gesehen werden. Nachdem das Papsttum im 7. Jahrhundert die Kirchenherrschaft des oströmischen Kaisers erduldet und eine Reihe von empfindlichen Demütigungen hingenommen hatte, erkämpfte sich der apostolische Stuhl seit dem Widerstand gegen das Konzil „in Trullo“ allmählich eine autonome Stellung ${ }^{115}$. Gregor II. spielte dabei die führende Rolle. Er widersetzte sich dem kaiserlichen Befehl einer erhöhten Besteuerung kirchlicher Besitzungen und rief damit einen Mordplan gegen seine Person hervor. Berühmtheit erlangte später Gregors Widerstand gegen die bilderkritische Politik Kaiser Leons III. Im Zuge dieser Konflikte lenkte der Papst zunehmend seinen Blick auf die westliche Kirche. Er förderte wie erwähnt die kirchliche Organisation in Bayern, nahm Kontakt mit dem Herzog von Aquitanien auf und ging 728 ein Bündnis mit dem langobardischen König Liutprand ein. Diese Hinwendung zum Westen hatte vermutlich die Aufnahme der fortgeschrittenen Inzestverbote der westgotischen und fränkischen Kirche zur Folge. Gregor II. scheute nicht davor zurück, in dieser Sache vom oströmischen Kirchenrecht abzuweichen und die zweihundert Jahre alten Inzestbestimmungen der westlichen Landeskirchen aufzunehmen. Es gelang ihm damit, das Konzil „in Trullo“ zu überbieten und die dort beschlossene Bevorzugung östlichen Gewohnheitsrechts durch die Unterstützung des westlichen Kirchenrechts zu konterkarieren. Das Konzil von Rom ist ein Dokument der Abkehr von der Rechtseinheit mit Konstantinopel.

Gregor II. hat also für bedeutende und wirkmächtige Neuerungen in Sachen Inzestverbot gesorgt. In der Gesandtschaftsinstruktion von 716 war davon noch nichts zu spüren, da er sich darin an der herkömmlichen päpstlichen Tradition orientierte. Diese fehlende Übereinstimmung mit dem römischen Konzil von 721 darf nicht überraschen, da eine Gesandtschaftsinstruktion nicht der angemessene Ort war, um Neuerungen im Kirchenrecht zu verankern. Die Instruktion war nur in Bayern verbreitet und diente Bonifatius im Jahr 739 vielleicht als Vorbild für seine Reform der bayerischen Kirche ${ }^{116}$. Das Konzil von Rom erfreute sich dagegen einer enormen Verbreitung. Es wurde in alle be-

115 Caspar, Geschichte 2 1930, 643-657; Noble, Republic 1984, 23-40; Paolo Delogu, Art. „Gregorio II“, in: Enciclopedia dei Papi 1 (2000) 647-651.

116 GlatthaAr, Bonifatius 2004, 368-392. An eine Verwirklichung der Instruktion unmittelbar nach 716 glaubt Freund, Bischöfe 2004, 32-34. 
deutenden Kirchenrechtssammlungen der Karolingerzeit aufgenommen. In Corbie fügte man es als Anhang der Collectio vetus Gallica hinzu, in Rom der Sammlung des Dionysius Exiguus ${ }^{117}$. Als Bestandteil der Collectio DionysioHadriana, der Collectio Dacheriana und der pseudoisidorischen Dekretalen war es in den wichtigsten Sammlungen der Karolingerzeit präsent. Das Papsttum fühlte sich bis in die Zeit der Kirchenreform des 11. Jahrhunderts an diese Entscheidungen gebunden.

\section{Die Verwirrungen des Bonifatius}

Ein Jahr nach dem römischen Konzil unterbrach Bonifatius seine Missionstätigkeit in Hessen und reiste zu Papst Gregor II. nach Rom. Dort wurde er zum Missionsbischof für Germanien geweiht und leistete dem Papst einen Gehorsamseid, wie ihn die unmittelbaren Suffraganbischöfe des Papstes zu leisten hatten ${ }^{118}$. Diese enge Bindung an den Papst hatte zur Folge, dass sich Bonifatius verpflichtete, über aufkommende Zweifelsfälle nach Rom zu berichten und eine autoritative Stellungnahme des apostolischen Stuhls zu erbitten. Das erste Mal legte er im Jahr 726 dem Papst eine Reihe von Streitpunkten mit der Frage vor, „wie es damit unsere heilige apostolische römische Kirche in Übung und Lehre halte ${ }^{\text {"119. }}$. Gleich an erster Stelle erkundigte sich Bonifatius über die Reichweite des Eheverbots unter Blutsverwandten. Gregor antwortete:

„Wir sagen, dass es zwar richtiger gewesen wäre, dass Verwandte nicht an die Schließung eines solchen Bundes herantreten, solange sie um ihre Verwandtschaft wissen; aber weil uns Mäßigung besser gefällt als die Strenge der Rüge - zumal gegenüber einem so barbarischen Volk -, so muss man zulassen, dass sie sich nach der vierten Generation verbinden “"120.

Gregor hielt also beim Volk der Germanen nur das Eheverbot zwischen Geschwisterkindern für durchsetzbar. Das kategorische Verbot der Verwandtenehe will er nicht angewandt wissen.

Der Verweis auf die barbara gens in der Antwort Gregors II. legt den Schluss nahe, Bonifatius habe aufgrund des germanischen Widerstandes gegen das Inzestverbot die Anfrage an den Papst gerichtet. Die zeitnahen Inzestfälle, in die

117 Mordek, Kirchenrecht 1975, 221; MaAssen, Geschichte 1870, 306 f.

118 S. Bonifatii et Lulli epistolae 16 (MGH Epp. sel. 1, 28 f.). Vgl. Schieffer, WinfridBonifatius 1954, 143-145.

119 In eisdem litteris quibusdam subnexisti capitulis sciscitando, qualiter teneat vel doceat haec sancta apostolica Romana ecclesia. S. Bonifatii et Lulli epistolae 26 (MGH Epp. sel. 1, 44) (JE 2174).

120 Dicimus, quod oportuerat quidem, quamdiu se agnoscunt affinitate propinquos, ad huius copule non accedere societatem; sed quia temperantia magis et presertim in tam barbaram gentem placet plus quam districtione censure, concedendum est, ut post quartam generationem iungantur. S. Bonifatii et Lulli epistolae 26 (MGH Epp. sel. 1, 45) (JE 2174). 
die Missionare Corbinian und Kilian verwickelt waren, taten ein Übriges, um die Anfrage des Bonifatius in diesen Kontext einzubetten. Theodor Schieffer kommentiert die Antwort Gregors mit den Worten: „Es ist also wahrlich kein Zufall, dass die Germanenmissionare ... gerade über Ehefragen mit den Fürsten in heftige Konflikte gerieten und dass diese Probleme auch bei Bonifatius einen

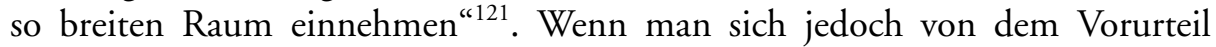
freimacht, das Inzestverbot hätte primär die festen Sippenverbände der Germanen aufbrechen sollen, ist diese Einbettung alles andere als selbstverständlich. Denn einerseits sind aus dem 8. Jahrhundert nur Fälle von Ehen innerhalb der Schwiegerverwandtschaft bekannt, während Bonifatius sich primär mit der Bluts- und mit der geistlichen Verwandtschaft auseinandersetzte. Andererseits hatten die anderen von Bonifatius aufgeworfenen Fragen nicht Probleme der Mission zum Thema, sondern innerkirchliche Streitfälle. Gleich die zweite Frage setzte die Etablierung der Auffassung der Unauflösbarkeit der Ehe voraus $^{122}$. Weitere Fragen befassten sich mit der Anklage gegen einen Kleriker, mit der Konfirmation durch einen Bischof, mit der Darreichung von Kindern an Klöster u.ä. Am Ende beklagte sich Bonifatius über „Priester und Bischöfe, die in vielerlei Laster verstrickt sind und deren Lebenswandel das Priesteramt schändet ${ }^{\text {" }} 23$. Seiner Frage, ob er sich der Gemeinschaft mit ihnen vollständig entziehen sollte, antwortete der Papst mit der Aufforderung, ihre Tischgemeinschaft nicht abzulehnen und sie durch Mahnung auf den Weg der Gerechtigkeit zu bringen. Bonifatius thematisierte nicht vorwiegend Probleme der Mission, sondern Schwierigkeiten, die ihm beim Umgang mit fränkischen Klerikern begegnet sind. Weder Hessen noch Thüringen waren bei der Ankunft des Bonifatius von christlicher Missionierung unberührt, und auch bei seiner Reise an den Hof Karl Martells dürften einige der dem Papst vorgelegten Fragen aufgeworfen worden $\operatorname{sein}^{124}$. Wie bei der Anfrage des Augustinus von Canterbury deutet auch im Fall des Bonifatius vieles darauf hin, dass die Unsicherheit über das Inzestverbot das Ergebnis eines Konflikts innerhalb der christlichen Gemeinschaft war.

Diese Einschätzung erfährt Bestätigung, wenn wir zwei andere Quellen aus dem Umfeld des Bonifatius in die Betrachtung einbeziehen. Denn der angelsächsische Bischof hat sich nicht nur an Gregor II. in der Frage des Inzestverbots gewandt, sondern auch an einen namentlich nicht bekannten Korrespondenten in seiner Heimat. Die Antwort ist in der Forschung als Epistola de gradibus

121 Schieffer, Winfrid-Bonifatius 1954, 155; ähnlich Hauck, Kirchengeschichte 11954 , 444. $\mathrm{Zu}$ Corbinian und Kilian siehe 94.

122 Vgl. Kelly, Gregory II 1976.

123 ... sunt quidam presbiteri seu episcopi in multis vitiis inretiti, quorum vita in se ipsis sacerdotium maculat ... S. Bonifatii et Lulli epistolae 26 (MGH Epp. sel. 1, 47) (JE 2174).

124 SCHIEFFER, Winfrid-Bonifatius 1954, 133-143. 
consanguinitatis oder auch als Dicta Isidori bekannt und wurde von Lambertus Machielsen in den bonifatianischen Kontext gestellt ${ }^{125}$. Michael Glatthaar hat diese Annahme durch die Entdeckung eines weiteren Überlieferungszeugen aus dem Umkreis von Bonifatius bestätigt ${ }^{126}$. Die Epistola selbst gibt vor, während der Amtszeit Papst Gregors II. geschrieben worden zu sein und eine Anfrage über den Umfang der Verwandtschaft zu beantworten. Machielsen datiert die Epistola daher in die Jahre 726-731 und favorisiert eine Zuschreibung an die Erzbischöfe Egbert von York oder Nothelm von Canterbury ${ }^{127}$. Der Anlass für die Anfrage bestand wohl darin, dass Bonifatius der Antwort Gregors II. nicht entnehmen konnte, wieweit der Umfang des kategorischen Verbots von Verwandtenehen reichte. Die Unsicherheit des Bonifatius ist ein Zeichen dafür, dass in Rom zwar die römisch-rechtliche Definition der Verwandtschaft vorausgesetzt wurde, außerhalb Roms jedoch eine solch unbestimmte Regelung für Verwirrung sorgen musste.

Der anonyme Autor der Epistola beantwortet die Anfrage des Bonifatius mit einem Zitat aus der Standardenzyklopädie der angelsächsischen Welt, aus den Etymologien des Isidor von Sevilla ${ }^{128}$. Zuerst gibt der Autor einen bei Isidor enthaltenen Stammbaum in Worten wieder: „Die Folge der Blutsverwandtschaft wird durch sieben Grade abgetrennt, erstens der Sohn und die Tochter, zweitens der Enkel und die Enkelin, ... siebtens der Sohn und die Tochter des Ururururenkels ${ }^{\text {"129. }}$. Nur im letzten, dem siebten Grad ist nach Isidor eine Ehe erlaubt:

„Ehe sich diese Blutsverwandtschaft im Fortgang der Generationen allmählich zu sehr verflüchtigt und bis zum letzten Grad sich entzieht und eine Verwandtschaft zu sein aufhört, fordert sie das Gesetz durch das Band der Ehe wieder zurück und holt die flüchtige (Verwandtschaft) gewissermaßen zurück. Daher ist die Blutsverwandtschaft bis zum sechsten Grad der Abstammung festgelegt, damit wie die Erschaffung der Welt und der Stand des Menschen durch sechs Zeitalter beendet

125 Machielsen, Origine 1963; Ders., Supplément 1963. Die Epistola ist einerseits im Anhang einiger Hanschriften von Bedas Kirchengeschichte (d.h. als Widerlegung des von Beda zitierten Libellus responsionum) und andererseits gemeinsam mit dem Paenitentiale additivum Ps.-Bedae-Egberti überliefert. Vgl. die Einleitung von Mynors und Colgrave zu Bedas Historia (LXII); HagGenmülleR, Überlieferung 1991, $231 \mathrm{f}$. Auch eine Vetus Gallica-Handschrift enthält die Epistola: Mordek, Kirchenrecht 1975, 563.

126 Glatthaar, Bonifatius 2004, 88-91. Damit erübrigt sich die unbewiesene Datierung der Epistola in die Zeit um 800 bei Schminck, Livius 1982, 162, und Fried, Konradiner 2006, 20.

127 Machielsen, Origine 1963, 47.

128 Mayr-Harting, Coming 1972, 199-214; Bischoff, Verbreitung 1966, 180-187.

129 Beatus Hysidorus de consanguinitate sic loquitur, cuius series VII gradibus dirimetur hoc modo: I filius et filia, II nepus et neptis, ... Machielsen, Origine 1963, 38. 
werden, so auch die Verwandtschaft der Abstammung durch so viele Grade beendet wird“130.

Das Inzestverbot erstreckt sich also nach Isidor bis zum sechsten Grad römischer Zählung, wie es die Konzilien und Gesetze des westgotischen Reichs festgehalten haben. An diese Worte schließt der Autor der Epistola die Kanones der römischen Synode von 721 an.

„Ebenso teilen wir euch aus den Dekreten des Papstes Gregors II., der jetzt die römische katholische Mutter Kirche regiert, mit, was die heilige und wahre Autorität über diese von euch nachgefragte Angelegenheit beschlossen hat ${ }^{\text {"131 }}$.

Es folgen die einzelnen Bestimmungen des Konzils, d.h. das Verbot der Cousinenehe und das kategorische Verbot von Verwandtenehen. Beendet wird die Epistola durch einen kryptischen Hinweis auf weitere Dokumente:

„Wir haben auch in Dekreten anderer gefunden, dass Personen nicht getrennt werden, wenn sie in Unkenntnis des Kirchenrechts - wie es häufig wegen der Nachlässigkeit der heutigen Bischöfe geschieht - im vierten, fünften oder sechsten Grad der Verwandtschaft ehelich verbunden worden sind. Wisst jedoch, dass dies nicht nach dem Gesetz, sondern aus Gnade zugestanden ist. Deshalb muss man zuerst verhüten, dass dieses überhaupt geschieht. Wenn eine Ehe allerdings im dritten oder - was fern sei - im zweiten Grad geschlossen wird, muss sie getrennt werden "132.

Emil Seckel hat richtig erkannt, dass hier die Bußbestimmungen des Theodor von Canterbury wiedergegeben werden ${ }^{133}$. Der Autor unterscheidet daher das kategorische Verbot der Verwandtenehe von einer milderen Vorgehensweise in der Praxis. Selbst das Verbot der Cousinenehe konnte, anders als im Brief Gregors II. an Bonifatius vorgesehen, abgemildert werden.

Die Epistola reagierte also auf eine Anfrage des Bonifatius über die Grenze der Verwandtschaft und über das konkrete Vorgehen gegen Inzestehen in der

130 Haec consanguinitas, dum se paulatim propaginum ordinibus dirimens usque ad ultimum gradum sese subtraxit et propinquitas esse desierit, eam rursus lex matrimonii vinculo repetit et quodammodo revocat fugientem. Ideo autem usque ad sextum generis gradum cumsanguinitas constituta est, ut sicut sex aetatibus mundi generatio et hominis status finitur, ita propinquitas generis tot gradibus terminaretur. MaCHIElSEN, Origine 1963, 38. Der erste Satz ist ein retouchiertes Zitat aus Augustinus, De civitate dei XV 16 (CCL 48, 478).

131 Item ex decreto papae Gregorii iunioris, qui nunc Romanam catholicam regit matrem ecclesiam, quid de hac causa quam inquiritis sancxerit sancta et vera auctoritas intimamus. Machielsen, Origine 1963, $38 \mathrm{f}$.

132 Invenimus etiam in aliorum decretis, quod si nescientes sicut et solet ecclesiasticam constitutionem per negligentiam nostri temporis sacerdotum in quarto vel in quinto vel in sexto gradu cognationis, id est cumsanguinitatis, in coniugium copulati fuerunt, non separentur; sed tamen istud non legitime, sed veniabiliter concessum esse noscatis. Idcirco prius cavendum est, ne hoc omnino proveniat. In tertio vero vel secundo quod absit gradu, si contigerit talis copula, separari oportet. Machielsen, Origine 1963, $39 \mathrm{f}$.

133 Seckel, Synode 1922, 38 Anm. 1. 
Praxis. Dass sich Bonifatius darüber den Kopf zerbrach, wird an dem nächsten Brief eines Papstes an ihn deutlich. Kurz nach seiner Wahl zum Papst erhob Gregor III. Bonifatius im Jahr 732 zum Erzbischof und sandte ihm als Zeichen dafür das Pallium. Damit verbunden beantwortete der Papst einen zweiten Katalog von Fragen, den Bonifatius dem apostolischen Stuhl zur Entscheidung vorgelegt hatte. Darunter muss sich eine Frage zur Ausdehnung der Verwandtschaft befunden haben. Denn in der Antwort schreibt Gregor III. ohne ausdrückliche Verknüpfung mit dem Inzestverbot: „Wir setzen fest, dass jeder

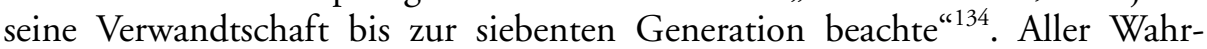
scheinlichkeit nach wandte sich also Bonifatius sowohl an einen befreundeten angelsächsischen Kleriker als auch an den Papst mit der Frage hinsichtlich des Umfangs der Verwandtschaft. Auch später ist er in dieser Weise vorgegangen.

Überlieferungsgeschichtlich eng verbunden mit der Epistola de gradibus consanguinitatis ist eine anonym überlieferte Predigt zum Inzestverbot ${ }^{135}$. Die Herkunft aus dem bonifatianischen Milieu ist durch den handschriftlichen Befund gesichert. Michael Glatthaar hat darüber hinaus einige überzeugende Argumente für die Verfasserschaft des Bonifatius selbst ins Feld geführt ${ }^{136}$. Für diese Hypothese sprechen wörtliche Übereinstimmungen sowie das in der Predigt stark hervorgehobene Ethos der Bischöfe als Wächter, die durch ihr Schweigen Verantwortung für die Sünden der Laien auf sich nehmen würden. Die Erwähnung einer besonderen Legation des Predigers könnte zudem auf die Stellung des Bonifatius als apostolischer Legat hinweisen. Falls diese Argumente zutreffen, wäre eine Entstehung im Rahmen des Konzils von Les Estinnes (743) denkbar, als ein Kanon gegen Inzestehen erlassen wurde. Die Überschrift der Predigt „Ansprache der Bischöfe an das Volk über unerlaubte Ehen “137 würde in diesen Kontext passen, da das Konzil von einer Reichsversammlung der weltlichen Amtsträger begleitet wurde ${ }^{138}$. Die Predigt wäre dann ein Schlüsseldokument für das erste große fränkische Reformkonzil unter der Leitung des

134 Progeniem vero suam quemque usque ad septimam observare decernimus generationem. S. Bonifatii et Lulli epistolae 28 (MGH Epp. sel. 1, 51) (JE 2239).

135 In den Überlieferungen der Epistola, die als Anhang zu Bedas Kirchengeschichte tradiert sind, erscheinen die Anfangssätze der Predigt als Schlussworte der Epistola: Machielsen, Origine 1963, 40. Glatthana, Bonifatius 2004, 485, schließt daraus auf einen Archetyp, der beide Texte umfasst haben soll. Die vollständige Predigt ist nur in einer Handschrift aus dem Bonifatius-Kreis überliefert (Vatikan, Biblioteca Apostolica Vaticana, Pal. Lat. 577, fol. 8r-v): Mordek, Bibliotheca 1995, 774-779; GlatthaAr, Bonifatius 2004, 458-493.

136 Glatthanr, Bonifatius 2004, 485-487. Zustimmend Meens, Aspekte 2007, 214. Machielsen, Fragments 1961, 505, sieht Augustinus von Canterbury als möglichen Autor an, ohne Belege beibringen zu können.

137 Alloquutio sacerdotum de coniugiis inlicitis ad plebem. MaChielsen, Fragments 1961, 535. Die Überschrift ist am Ende der Predigt überliefert.

138 Siehe 253. 
Bonifatius, mit der seine Tätigkeit auf gesamtfränkischer Ebene einsetzte. Ich werde weiter unten ausführen, welche Konsequenzen diese Deutung für das Wirken des Bonifatius in dieser turbulenten Phase seines Lebens hat.

Brisant für die Frage, warum Bonifatius von den in Rom und im Frankenreich kursierenden Inzestverboten verwirrt sein musste, ist der Inhalt der Predigt. Sie setzt ein mit dem Zitat von Ezechiel 3, 17 über das Wächteramt der Propheten.

„Seht geliebte Söhne, welche Gefahr uns droht, wenn wir schweigen. Es sei fern, es sei fern, dass unser Schweigen euer Untergang werde. Wenn wir euch lieben, müssen wir aufdecken, was schadet, damit nicht kommt, was tötet. Deshalb schärft euch sorgsam ein die Aussprüche unseres Gottes, mit denen er euch verbrecherische Ehen verbietet, damit ihr durch seine Gaben in Ewigkeit lebt. Seht da, es ruft unser Gott und beschwört, weil er die unerlaubte Wildheit der Begierde voraussah, dass niemand sich mit seiner Mutter verunreinige ..." ${ }^{139}$

Es folgen wörtlich sämtliche Inzestverbote aus Lev. 18, nicht mehr und nicht weniger. Als Strafe droht der Prediger im Anschluss an das Vorgehen des Paulus in Korinth mit dem Ausschluss vom Kommunionsempfang: „Niemand, der sich mit solchen Personen verbunden hat, soll sich dem Leib des Herrn vor einem würdigen Bußdienst nähern, damit er ein Heilmittel und keine Wunde empfängt ${ }^{\text {“140 }}$.

Die Predigt schließt sich also den Vorgaben der Bibel an und befindet sich in erstaunlich engem Einklang mit der Tradition der angelsächsischen und irischen Kirche. Dies kann als ein weiterer Beleg für die Autorschaft des Bonifatius angesehen werden. Wenn wir von dieser Zuschreibung ausgehen und dem Missionar den in seiner Heimatkirche verbreiteten biblischen Standpunkt zum Inzestverbot unterstellen, gewinnen wir einen Schlüssel für die Interpretation seiner übrigen Äußerungen zu diesem Thema. Unter dieser Voraussetzung lässt sich sein gewissenhafter Umgang und seine fassungslose Reaktion auf ihm vorgelegte Texte erklären. Die häufigen Fragen an den Papst und an befreundete Gelehrte in England ergeben sich aus der fehlenden Vertrautheit mit der Ausdehnung des Inzestverbots auf dem Kontinent.

Für die nächste Verwirrung des Bonifatius sorgte die Kenntnis des Eheverbots der geistlichen Verwandtschaft in den Kanones der römischen Synode von 721. Es ist nicht zu ergründen, ob Bonifatius während seines Romauf-

139 Videte, filii carissimi, quale nobis incumbit periculum, si tacemus. Absit, absit, ut nostrum silentium vestrum fiat exitium. Si vos amamus, prodere debemus quod laedit, ne veniat quod occidit. Ergo diligenter advertite voces Dei nostri, quibus vos vetat a coniugiis criminalibus, ut vivatis aeternis eius muneribus. Clamat ecce Deus noster et humanae libidinis inlicitam rabiem praevidens contestatur, ne quis polluatur cum matre ... MACHIELSEN, Fragments $1961,533 \mathrm{f}$.

140 Nemo talibus sociatus ante poenitentiae dignum servitium ad tanti Domini corpus accedat, ne non remedium, sed vulnus accipiat... Machielsen, Fragments 1961, 534. 
enthalts im Jahr 722 Kenntnis von diesem Dokument erlangt hatte. Spätestens wurde er durch den Empfang der Epistola Isidori mit diesen Kanones vertraut und musste sich mit dem Eheverbot der geistlichen Verwandtschaft auseinandersetzen. Um das Jahr 735 richtete er eine verzweifelte Bitte an Bischof Pehthelm von Whithorn im heutigen Schottland.

„In einer Sache möchten wir noch Rat und Bescheid von Euch hören. Es behaupten die Bischöfe in ganz Francien und Gallien und sogar [in Rom?], des größten Verbrechens sei schuldig, wer eine Witwe heirate, deren Sohn er vorher bei der Taufe als geistlichen Sohn angenommen habe. Diese Art von Sünde, wenn es wirklich eine ist, kannte ich bisher nicht und ich habe nichts davon gehört, dass die Väter sie in alten Satzungen und päpstlichen Dekreten oder die Apostel irgendwo in einer Liste der Sünden aufgezählt hätten. Wenn ihr darüber irgendwo in kirchlichen Schriften etwas abgehandelt findet, so teilt es uns mit; auch möchten wir wissen, was ihr davon haltet ${ }^{\text {"1141. }}$.

In den beiden nächsten Briefen, die zeitnah abgeschickt wurden, argumentiert Bonifatius offen gegen das Konzil von 721. In seinen Anfragen an Erzbischof Nothelm von Canterbury und Abt Duddo bezeichnet er das neue Inzestverbot als Eigenheit der Römer. Im Brief an Nothelm tritt auch zutage, dass Bonifatius in einen derartigen Fall persönlich involviert war: „Außerdem möchte ich Euren Rat hören wegen einer Sünde, die ich unbewusst begangen habe, indem ich einem Mann die Ehe gestattete. Und das ist so gekommen ... "142 $\mathrm{Da}$ der geschilderte Fall genau dem in Rom erlassenen Verbot entspricht, sah er sich Anfeindungen anderer Kleriker ausgesetzt:

„Nach der Behauptung der Römer ist das eine Sünde und zwar eine Todsünde, so dass sie in solchen Fällen die Scheidung der Ehe anordnen; und sie versichern, dass solange christliche Kaiser herrschten, das Verbrechen einer solchen Ehe mit der

141 De una quoque re vestrum consilium et responsum audire desideramus. Adfirmant sacerdotes per totam Franciam et per Gallias nec non et [†] pro his [†] maximi criminis reum esse hominem, qui in matrimonium acciperit illam viduam, cuius antea filium in baptismo adoptivum suscipiebat. Quod peccati genus, si verum est actenus ignorabam et nec in antiquis canonibus nec in decretis pontificum patres nec in calculo peccatorum apostolos usquam enumerasse cognovi. Qua de re si aliquid uspiam in ecclesiasticis scriptis disputatum invenissetis, nobis indicare curate, et, quid vobis videatur, nosse velimus. S. Bonifatii et Lulli epistolae 32 (MGH Epp. sel. 1, 56). Auf die Korruptele machte Reinhold Rau in seiner zweisprachigen Ausgabe aufmerksam. Die überlieferten Buchstaben machen eine Emendation wie p(er) Romam möglich. Wenn diese Emendation korrekt ist, hatte Bonifatius zu diesem Zeitpunkt schon die Kanones von 721 zur Kenntnis genommen. Für Unkenntnis argumentieren Lynch, Godparents 1986, 248; Jussen, Patenschaft 1991, 28.

142 Praeterea de uno peccato commisso vestrum consilium audire desidero, quod cuidam homini in matrimonio concedendo nesciens commisi. Quod hoc modo contigit. S. Bonifatii et Lulli epistolae 33 (MGH Epp. sel. 1, 57). 
Verurteilung zum Tod bestraft oder mit lebenslänglicher Verbannung gebüßt werden musste“143.

Die Kritiker des Bonifatius schossen an diesem Punkt über das Ziel hinaus, da in Konstantinopel bislang nur die Bischöfe des Konzils „in Trullo“ diese Ehe unter das Inzestverbot einreihten. Ein Gesetz des Kaisers gab es zu diesem Zeitpunkt noch nicht ${ }^{144}$. Bonifatius fühlte sich begreiflicherweise persönlich angegriffen und verlangte von Nothelm Unterstützung:

„Denn ich bin durchaus nicht in der Lage zu verstehen, warum in dem einen Fall die geistige Verwandtschaft bei der Herstellung der ehelichen Verbindung eine solche Sünde sein soll, wo doch zugestandenermaßen wir alle in der heiligen Taufe als Christi und der Kirche Söhne und Töchter Brüder und Schwestern werden "145.

Bonifatius war also mit der römischen Synode von 721 vertraut, wollte sich jedoch dieser Neuerung nicht beugen. Dass er sich trotz seiner Verbundenheit zu Rom als Kritiker des Papsttums gerieren konnte, zeigt ein späteres Schreiben an Papst Zacharias ${ }^{146}$. Bonifatius fühlte sich dazu offensichtlich deshalb berechtigt, weil das Eheverbot der geistlichen Verwandtschaft keine biblische Grundlage hatte. Auch hier legte der Angelsachse den Maßstab der Bibel an. Sein Widerstand war jedoch zwecklos. Das neue Inzestverbot setzte sich durch, und schon wenige Jahrzehnte nach dem Tod des Bonifatius kam eine gefälschte Dekretale Innocenz' I. in Umlauf, die das Bedürfnis nach altkirchlicher Beglaubigung des Eheverbots der geistlichen Verwandtschaft stillte und die Neuerung Gregors II. überdeckte ${ }^{147}$.

Die dritte Verwirrung des Bonifatius verursachte das Auftauchen des $\mathrm{Li}$ bellus responsionum. Über welche Kommunikationswege dieses Dokument den angelsächsischen Missionar erreichte, lässt sich nicht mehr eindeutig feststellen. Plausibel ist die Vermutung Glatthaars, der Libellus sei über die kirchenrecht-

143 Quod Romani peccatum esse adserunt et capitale peccatum, ita ut in talibus divortia facere praecipiant; et adfirmant regnantibus christianis imperatoribus illius matrimonii scelus capitali sententia multandum vel peregrinatione perpetua delendum. S. Bonifatii et Lulli epistolae 33 (MGH Epp. sel. 1, 57 f.).

144 Vgl. Lynch, Godparents 1986, 245 f.

145 ... quia nullatenus intellegere possum, quare in uno loco spiritalis propinquitas in coniunctione carnalis copulae tam grande peccatum sit, quando omnes in sacro baptismate Christi et aecclesiae filii et filiae fratres et sorores esse comprobemur. S. Bonifatii et Lulli epistolae 33 (MGH Epp. sel. 1, 58).

146 S. Bonifatii et Lulli epistolae 50 (MGH Epp. sel. 1, 84 f.). Später musste sich der Papst gegen den Vorwurf zu Wehr setzen, er sei ein corruptor canonum: S. Bonifatii et Lulli epistolae 58 (MGH Epp. sel. 1, 107). Zur Kritik am Papst vgl. auch CAspar, Geschichte 2 1930, 712-714; Noble, Boniface 2007, 339.

147 Collectio Herovalliana 54, 19 (Migne PL 99, 1060). Vgl. Lynch, Godparents 1986, 252, mit Verweis auf Mordek, Kirchenrecht 1975, 137. 
liche Drehscheibe Corbie zu Bonifatius gelangt ${ }^{148}$. Zunächst ließ Bonifatius in Rom Nachforschungen anstellen und erhielt von den päpstlichen Kanzleibeamten eine abschlägige Auskunft. Der Libellus sei im Briefregister des Papstes nicht gefunden worden ${ }^{149}$. Dann wandte sich Bonifatius in dem eben zitierten Brief an Nothelm, den Amtsnachfolger des Empfängers. „Ebenso bitte ich Euch eindringlich, mir eine Abschrift von dem Schreiben zu schicken ... und in gewissenhafter Umsicht sorgfältige Nachforschungen anzustellen, ob es sich erweisen lässt, dass diese Aufzeichnung von unserem erwähnten heiligen Vater Gregorius herrührt oder nicht ${ }^{\text {"150 }}$. Befremdlich an diesem Dokument erschien Bonifatius die Erlaubnis der Heirat im dritten Grad der Abstammung ${ }^{151}$.

Dass auch dieser Anfrage ein konkreter Fall zugrund lag, erfahren wir erst Jahre später aus einem der wenigen erhaltenen Briefe des Bonifatius an den apostolischen Stuhl. Im Jahr 742 bat er Papst Zacharias in folgender Sache um Rat:

„Ein Laie von hohem Stand kam zu uns und erklärte, ihm sei von dem Bischof des apostolischen Stuhles Gregorius heiligen Angedenkens die Erlaubnis erteilt worden, die Witwe seines Onkels zu ehelichen. ... mit dem Mann, der sie jetzt zu heiraten wünscht und die Erlaubnis dazu bekommen zu haben behauptet, ist sie, wie man weiß, im dritten Grade verwandt ${ }^{\star 152}$.

Der erwähnte Adelige berief sich also auf die Autorität des Libellus responsionum zur Rechtfertigung einer Ehe, die in Levitikus ausdrücklich unter die Inzestehen eingereiht wird ${ }^{153}$. Bonifatius scheute sich deshalb nicht, die Ehe mit der Frau des Onkels als „größtes Verbrechen, entsetzlichen Frevel und verdammenswerte

148 Glatthan, Bonifatius 2004, 386-389.

149 ... quia in scrinio Romanae aecclesiae, ut adfirmant scrinarii, cum ceteris exemplaribus supradicti pontificis quaesita non inveniebatur. S. Bonifatii et Lulli epistolae 33 (MGH Epp. sel. 1, 57).

150 Similiter et diligenter obsecro, ut illius epistolae, qua continetur, ut dicunt, interrogationes Augustini pontificis ac praedicatoris primi Anglorum et responsiones sancti Gregorii papae, exemplar mibi dirigere curetis ... et ut scrupulosa cautella diligenter investigare studeatis, si illa conscriptio supradicti patris nostri sancti Gregorii esse conprobetur an non. S. Bonifatii et Lulli epistolae 33 (MGH Epp. sel. 1, 57).

$151 \ldots$ in qua inter cetera continetur, quod in tertia generatione propinquitatis fidelibus liceat matrimonia copulare ... S. Bonifatii et Lulli epistolae 33 (MGH Epp. sel. 1, 57).

152 Quia laicus quidam magne personae ad nos veniens dicebat sibi ab apostolicae sedis pontificae sanctae memoriae Gregorio datam fuisse licentiam, ut in matrimonium acciperet viduam avunculi sui. ... et isti viri, qui nunc eam accipere desiderans adfirmat sibi licentiam datam, in tertio ienuculo propinqua illius esse dinoscitur ... S. Bonifatii et Lulli epistolae 50 (MGH Epp. sel. 1, 83 f.).

$153 \mathrm{Im}$ Brief des Bonifatius wird nicht deutlich, welcher Gregor die Erlaubnis erteilt hatte. Papst Zacharias scheint die Dispensierung seinem Vorgänger Gregor III. zu unterstellen: ... a beatae memoriae precessore nostro ... ut decessor noster ... S. Bonifatii et Lulli epistolae 51 (MGH Epp. sel. 1, 90) (JE 2264). 
Sünde“ ${ }^{154}$ zu bezeichnen. Gregor der Große hatte freilich eine solche Erlaubnis nicht gegeben. Er zählte biblisch in Generationen, untersagte sogar die Cousinenehe und erlaubte eine Verbindung erst ab dem dritten Grad kanonischer Komputation. Bonifatius und der „Laie von hohem Stand“ missverstanden jedoch den Papst. Die Päpste Gregor II. und Gregor III. übernahmen den Begriff der generatio, zählten jedoch weiterhin wie die Angelsachsen und Bonifatius nach der römischen Komputation. Aus der Sicht des frühen 8. Jahrhunderts war das Missverständnis fast unausweichlich, Gregor I. die Erlaubnis einer Ehe im dritten Grad römischer Komputation zu unterstellen. Auch die Päpste waren deshalb gezwungen, sich vom Inhalt des Libellus responsionum in deutlichen Worten zu distanzieren.

Zacharias erklärt in seiner Antwort ein derartiges Zugeständnis für unmöglich: „Es sei ferne, dass unser Amtsvorgänger solches verfügt hat. Denn dieser heilige Stuhl trifft nicht solche Entscheidungen, die nachweislich im Widerspruch stehen zu den Weisungen der Väter und der Kanones “155. Er fordert Bonifatius deshalb zur Ermahnung der Eheleute auf, von dieser Sünde zurückzutreten und die Ehe aufzulösen. Andernfalls gingen sie in Ewigkeit verloren. „Auch wir haben zu diesem Zweck Mahnschreiben an ihn gerich-

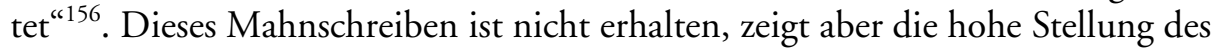
Adeligen, der als Adressat eines Papstsbriefes in Frage kam.

Trotz der von Bonifatius und Zacharias geäußerten Vorbehalte gegen den Libellus responsionum war die Verbreitung dieses Dokuments ungebrochen. Man wird dies nicht allein auf die Inzestproblematik zurückführen, da die Stellungnahme des Libellus zur kultischen Reinheit ebenfalls auf großes Interesse stie $\beta^{157}$. Später versuchte man, die Aussage zum Inzestverbot auf unterschiedliche Weise unschädlich zu machen: In einigen Handschriften wurde der $L i$ bellus mit der Epistola Isidori kombiniert und dadurch mit der strengeren Auffassung des 8. Jahrhunderts konfrontiert ${ }^{158}$; andere Überlieferungen wurden verfälscht ${ }^{159}$, und hundert Jahre nach Bonifatius ersann ein Fälscher im Umkreis

154 ... maximum scelus et incestum et horribile flagitium et damnabile piaculum ... S. Bonifatii et Lulli epistolae 50 (MGH Epp. sel. 1, 84).

155 ... absit hoc, ut decessor noster ista preciperet. Nec enim ab hac apostolica sede illa diriguntur, quae contraria esse patrum sive canonum institutis probentur. S. Bonifatii et Lulli epistolae 51 (MGH Epp. sel. 1, 90) (JE 2264).

156 Nam et nos ei pro hoc commonitoria scripta direximus. S. Bonifatii et Lulli epistolae 51 (MGH Epp. sel. 1, 90) (JE 2264).

157 Meens, Purity 1996.

158 So in einigen kontinentalen Überlieferungen von Bedas Kirchengeschichte, siehe 242 Anm. 125. Die Verbindung geht vermutlich auf die Hofbibliothek Karls des Großen zurück: Bischoff, Hofbibliothek 1965, 56.

159 Mordek, Kirchenrecht 1975, 223. 
Pseudoisidors einen neuen Briefwechsel Gregors des Großen, der sich für ein umfassendes Inzestverbot bis zum siebten Grad aussprach ${ }^{160}$.

\section{Der Starrsinn des Bonifatius}

Protestantische Kirchenhistoriker sahen in den zahlreichen detaillierten Anfragen des Bonifatius an den apostolischen Stuhl ein Anzeichen für seine „peinliche

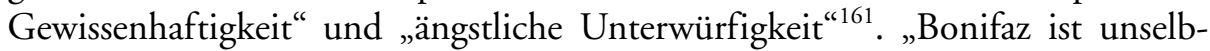
ständig, er fühlt sich unsicher. Was hat er nicht alles zu fragen, was für Zweifel und Bedenken plagen ihn!" ${ }^{162}$ Dieses Urteil ist nicht vollkommen von der Hand zu weisen, auch wenn man in Rechnung stellen muss, dass Bonifatius das Ideal einer „einheitlichen, universalkirchlich-römischen Observanz “"163 auf diese Weise in die Wirklichkeit umsetzen wollte. Im Fall des Inzestverbots trifft dieser Vorwurf jedoch nicht zu. An seinem Standpunkt, der durch die Herkunft aus der angelsächsischen Kirche geprägt war, hielt er zeit seines Lebens fest. Es gibt keine Hinweise für die Befolgung der von den Päpsten betriebenen Ausweitung des Inzestverbots. Die vermutlich ihm zuzuschreibende Predigt de coniugiis inlicitis macht seine Beharrlichkeit deutlich. Weder dem Verbot der geistlichen Verwandtschaft noch der Ausdehnung auf den siebten Grad wurde darin Rechnung getragen. Der Katalog der verbotenen Ehen schloss sich eng den Vorschriften des Alten Testaments an. Auch sein Vorgehen gegen aktuelle Inzestfälle blieb in diesem Rahmen. Einem Laien aus hohem Adel legte er die Ehe mit der Frau des Onkels zur Last, dem Häretiker Clemens ${ }^{164}$ die Verteidigung der Leviratsehe. Die Vorschriften der Bibel blieben der Maßstab, an dem sich auch die Direktiven der Päpste messen lassen mussten. Die vielen Anfragen und Zweifel, die durch die Briefsammlung überliefert sind, sollten nicht so sehr als Zeugnisse für die „peinliche Gewissenhaftigkeit“ gewertet werden, sondern für die fehlende Vertrautheit des Bonifatius mit dem Wandel der päpstlichen Position zu Anfang des 8. Jahrhunderts. Seit Gregor II. wandte sich das Papsttum allmählich von der Rechtseinheit mit Byzanz ab und fand sich zur Akzeptanz der im Westen erfolgten Ausdehnung des Inzestverbots bereit. Ebenfalls unter Gregor II. akzeptierte das römische Konzil von 721 das Eheverbot der geistlichen Verwandtschaft, das schon seit Justinian Bestandteil des byzantinischen Kirchenrechts war. Diese Vermehrung von Sünden durch die Ausdehnung des Inzestverbots ging der Mentalität des Bonifatius radikal gegen den Strich. Aus seiner Sicht schloss nämlich die Vermehrung der Sünden auch die Erschwerung des bischöflichen Auftrags ein, über das anvertraute Volk zu wachen und vor

160 Siehe 336-340.

161 Hauck, Kirchengeschichte 1 1954, 432; Haller, Papsttum 1 1962, 394.

162 Haller, Papsttum 1 1962, 395.

163 SCHIEFFER, Winfrid-Bonifatius 1954, 153.

164 Siehe oben 94. 
Gott für Verfehlungen Rechenschaft abzulegen. Die Gewissenshaftigkeit des Bonifatius ist also nicht Ausdruck von Kleingeistigkeit, sondern Ausdruck eines nicht unsympathischen Starrsinns ${ }^{165}$.

\subsection{Die Etablierung einer Dynastie durch das Eherecht}

Kaum ein anderes Thema prägte die Gesetzgebung des ersten Königs aus der karolingischen Dynastie so sehr wie das Eherecht. Zum einen trat Pippin für das päpstliche Gebot der Unauflösbarkeit der Ehe ein, das bislang weder von den Konzilien der Bischöfe noch von den Kapitularien der Könige zur Geltung gebracht worden war. Diese radikale Abkehr von der Praxis und Norm der Merowingerzeit machte eine Reihe von Ausnahmeregelungen notwendig, um das Gebot der Unauflösbarkeit anwendbar zu machen. Zum anderen setzte sich Pippin für die ebenfalls vom Papst geforderte Ausweitung des Inzestverbots ein. Das erste weltliche Gesetz Pippins, das sein einziges für das gesamte Frankenreich bleiben sollte, hob mit zwei Bestimmungen zum Inzestverbot an. Das Eherecht war auch das dominierende Thema der unter Pippin tagenden Kirchenversammlungen. Karl der Große schloss sich dieser Ehepolitik an und widmete dem Inzestverbot je ein Kapitel in den ersten beiden Kapitularien. Später geriet das Thema allmählich aus dem Blickfeld, da Karl seinen reformerischen Impuls auf eine umfassende Regelung aller Lebensbereiche ausweitete. Berühmtes Zeugnis dafür ist die im Jahre 789 erlassene Admonitio generalis, die zu einer Verchristlichung aller Lebensbereiche aufruft. Das Inzestverbot wird darin nicht ausdrücklich genannt. Die Nachfolger Karls erfassten das Thema der Verwandtenehe nicht mehr gesetzgeberisch, sondern überließen es der konziliaren Regelung durch die Bischöfe. Die mit Diocletian beginnende große Zeit der weltlichen Inzestgesetzgebung nahm ein Ende.

\section{Karlmann und Bonifatius}

Bis zum Tod Karl Martells im Jahre 741 beschränkte sich die missionarische Tätigkeit des Bonifatius auf den Raum östlich des Rheins und südlich der Donau $^{166}$. Karl Martell, der unumschränkte Herrscher im Frankenreich, gewährte ihm deutliche Unterstützung bei der Mission, versagte ihm jedoch das Ausgreifen seines Wirkens auf die fränkische Kirche. Das Urteil des Bonifatius über den Zustand der fränkischen Kirche war vernichtend: „Kein anderes christliches Volk auf der Welt hat ein so großes Verbrechen und so große Sünde gegen die Kirche Gottes und die Klöster wie das Volk der Franken: nicht in

165 Von Starrsinn spricht auch PadBerg, Bonifatius 2003, 114.

166 SCHIEFFER, Winfrid-Bonifatius 1954, 156-161. 
Griechenland, nicht in Italien, nicht in Britannien, nicht in Afrika, nicht in einem anderen Volk der Christen "167. Grund für diese Klage gab es genug ${ }^{168}$. Seit der zweiten Hälfte des 7. Jahrhunderts sind keine Synoden mehr zusammengetreten, die über die Aufrechterhaltung der kirchlichen Disziplin gewacht hätten. Bistümer und Abteien waren vielmehr zu wichtigen Bastionen regionaler Machthaber verkommen und bildeten Zentren von quasi-autonomen Herrschaftsbereichen. Im Zuge der Zentralisierung der Macht zerschlug Karl Martell diese autonomen Bischofsherrschaften und verteilte die erbeuteten Ämter unter seinen Gefolgsleuten. An kirchenrechtliche Richtlinien fühlte er sich dabei nicht gebunden, da er oft mehrere Ämter in der Hand von besonders loyalen Personen vereinigte und die anfallenden Einkünfte aus Kirchengut für seine kriegerischen Unternehmungen zweckentfremdete. Die Zentralisierungspolitik des karolingischen Princeps förderte im beträchtlichen Ausmaß den Niedergang der fränkischen Kirche.

Unmittelbar nach dem Tod Karl Martells entschloss sich der ältere Sohn Karlmann zur bedingungslosen Unterstützung des Bonifatius ${ }^{169}$. Religiöse Motive dürften ihn dabei ebenso geleitet haben wie die Chance der Profilierung im innerdynastischen Wettstreit. Als zuständiger Herrscher für das Gebiet östlich des Rheins gab er dem Missionar erstmals die Erlaubnis, Bischöfe zu ernennen und eine reguläre Kirchenverfassung durchzusetzen. Dokument dieser Zusammenarbeit ist das am 7. April 742 zusammengetretene Concilium germanicum $^{170}$. Neben Bonifatius waren sechs Bischöfe sowie namentlich nicht bezeugte Priester anwesend. Ob es sich dabei um eine regelrechte Reichssynode oder um eine vorbereitende Versammlung des Kreises um Bonifatius handelte, wird in der Forschung kontrovers diskutiert ${ }^{171}$. Karlmann verschaffte den Kanones der Versammlung durch die Veröffentlichung als Kapitular allgemeine Gültigkeit. Die Beschlüsse drehten sich um das Kernanliegen des Bonifatius, um die Durchsetzung der durch das Kirchenrecht vorgesehenen Verfassung und Disziplin des Klerus. An erster Stelle standen die Erneuerung der Metropolitanverfassung, die Rückgabe entfremdeten Kirchenguts und die Abgrenzung des

167 De eo quod nulla gens christiana in toto mundo contra aecclesiam dei et monasteria tam inmane scelus et tam grave peccatum habet quam gens francorum, nec in Grecia nec in italia nec in brittania nec in affrica nec in ulla gente christianorum. Sententiae Bonifatianae Wirceburgenses 54, nach Glatthaar, Bonifatius 2004, 118.

168 Ewig, Milo 1954; Prinz, Episkopat 1981; Semmler, Potestas 1974. Abschwächend REUTER, Kirchenreform 1994.

169 Schieffer, Winfrid-Bonifatius 1954, 191-203; Semmler, Bonifatius 1998, 21-24.

$170 \mathrm{Zu}$ Inhalt und umstrittener Datierung vgl. Hartmann, Synoden 1989, 50-53. Glatthaar, Bonifatius 2004, 164-216, argumentiert überzeugend für eine Frühdatierung.

171 Für eine „réunion regionale et préparatoire“ sprach sich CLerCQ, Législation 1 1936, 118, aus. Ihm folgt Glatthaar, Bonifatius 2004, 203. 
klerikalen vom laikalen Lebenswandel. Die Laien gerieten nur insofern in das Blickfeld der Versammlung, als die Wiederherstellung der Kirchenverfassung auch dazu dienen sollte, die Reste heidnischer Religionspraktiken auszumerzen.

Ein knappes Jahr nach dem Concilium germanicum, am 1. März 743, gelang Bonifatius die Einberufung einer allgemeinen Synode von Karlmanns Teilreich in Les Estinnes ${ }^{172}$. An ihr nahmen die Bischöfe und der höhere Klerus teil, die weltlichen Amtsträger fanden sich am gleichen Ort zu einer Reichsversammlung zusammen. Die Bestimmungen wurden wiederum von Karlmann als Kapitular veröffentlicht. Zuerst wird darin die Verbindlichkeit der Beschlüsse des Concilium germanicum ins Gedächtnis gerufen. „Alle ehrwürdigen Bischöfe Gottes und die Grafen und Befehlshaber bestätigten einstimmig die Beschlüsse der ersten Synode und versprachen, sie zu erfüllen und zu beachten ${ }^{\text {“173. Danach }}$ wurden der Klerus auf die Gültigkeit des überlieferten Kirchenrechts und die Mönche auf die Benediktregel eingeschworen. Neue Kanones sind nur für Belange der Laien erlassen worden. Am bedeutendsten ist sicher der Kompromiss in der Frage des enteigneten Kirchenguts. Gegen die Ableistung eines Zinses und die Anerkennung des kirchlichen Obereigentums konnte „wegen der drohenden Kriege und der Einfälle aller Völker" das Kirchengut in den Händen der Laien verbleiben ${ }^{174}$. Des Weiteren fällte das Konzil einen neuen Beschluss zum Eherecht: „Wir haben ebenso angeordnet, dass entsprechend dem Kirchenrecht Ehebruch und nicht rechtmäßige Inzestehen verboten und nach dem Urteil der Bischöfe gebüßt werden "175. Am Schluss wurde noch ein Verbot des Verkaufs christlicher Sklaven an Heiden erlassen und ein anti-heidnisches Gesetz Karl Martells bestätigt ${ }^{176}$.

Als eines von vier Themen kam der Inzest auf dem ersten fränkischen Reichskonzil nach über achtzig Jahren auf die Tagesordnung. Anlass dafür war mit großer Wahrscheinlichkeit der oben erwähnte Fall einer Inzestehe innerhalb des Hochadels ${ }^{177}$. Bonifatius hatte dem Papst davon in drastischen Worten berichtet und das kirchliche Oberhaupt zur Abfassung eines Mahnschreibens aufgefordert. Vermutlich ergriff Bonifatius die Gelegenheit, um auf dem Konzil gegen die Inzestehe zu predigen. Die „Ansprache der Bischöfe an das Volk über

172 Hartmann, Synoden 1989, 53-55; Glatthaar, Bonifatius 2004, 239-307.

173 Omnes venerabiles sacerdotes Dei et comites et praefecti prioris synodus decreta consentientes firmaverunt, se implere velle et observare promiserunt. Konzil von Les Estinnes (743) c. 1 (MGH Conc. 2/1, 6 f.).

174 Konzil von Les Estinnes (743) c. 2 (MGH Conc. 2/1, 7). Ausführlich dazu Glatthaar, Bonifatius 2004, 253-261.

175 Similiter praecipimus, ut iuxta decreta canonum adulteria et incesta matrimonia, quae non sint legitima, prohibeantur et emendentur episcoporum iudicio. Konzil von Les Estinnes (743) c. 3 (MGH Conc. 2/1, 7).

176 Konzil von Les Estinnes (743) c. 3-4 (MGH Conc. 2/1, 7).

177 Siehe oben 244 Anm. 136. 
unerlaubte Ehen" passt genau in diesen Kontext, da sowohl die Bischöfe als auch die Laien an einem Ort versammelt waren. Bonifatius konnte daher als Sprachrohr der Bischöfe auftreten und den Laien in Sachen Inzest in das Gewissen reden. Bezeichnenderweise hielt sich Bonifatius in der Predigt an die Vorschriften der Bibel. Der Beschluss von Les Estinnes vermied eine klare Aussage über den Umfang des erlassenen Inzestverbots. Man wollte die umstrittene Ausweitung des Inzestverbots offenbar nicht thematisieren.

Diese Zurückhaltung von Les Estinnes ist deutlicher zu greifen, wenn wir die zeitgleichen Aktivitäten des Papstes damit vergleichen. Im Herbst 743 berief Zacharias eine Synode in Rom ein, an der nicht nur Bischöfe des römischen Metropolitanbezirks, sondern auch Vertreter aus dem langobardischen Machtbereich teilnahmen ${ }^{178}$. In den Bestimmungen der Synode nahm Zacharias Anregungen aus dem Reformprogramm des Bonifatius auf, indem er einige Kanones zur Kirchendisziplin und zur richtigen Ordination des Klerus erließ. Der Hauptteil bestand jedoch aus einer Wiederholung der Bestimmungen des römischen Konzils von 721. In c. 5 und 6 wurden auch die Inzestbestimmungen erneuert, allerdings mit charakteristischen Erweiterungen. So hielt es Zacharias für nötig, ausdrücklich auf das Vorbild von Levitikus zu verweisen ${ }^{179}$. Da das biblische Inzestverbot jedoch enger gefasst ist, musste er zu einer waghalsigen Begründung Zuflucht nehmen: „Und wenn Gott dem hebräischen Volk vor der Menschwerdung seines eingeborenen Sohns diese Vorschriften gegeben hat, um wie viel mehr müssen wir uns, die wir die Zeugnisse der christlichen Religion haben, von unerlaubten Ehen fernhalten, damit wir nicht versenkt in den Schlund des ewigen Feuers durch den Brand vernichtet werden “180. Das kategorische Verbot der Verwandtenehe begründete der Papst also durch eine Logik der Überbietung des Judentums durch das Christentum. Die drastische Rhetorik des Konzilstextes wird von verschärften Strafbedingungen begleitet. So wird ein Kleriker, der die Verfluchung kraft apostolischer Autorität missachtet, seines Amtes enthoben ${ }^{181}$. Nach der Trennung der Ehe müssen sich die Sünder einer obligatorischen Bußzeit unterziehen und dürfen in dieser Zeit keine neue Ehe eingehen ${ }^{182}$.

178 Hartmann, Synoden 1989, $43 \mathrm{f}$.

179 ... quia scriptum est in lege Domini: , Turpitudinem uxoris patris, uxoris fratris atque sororis tuae non revelabis; turpitudo enim tua est'. Konzil von Rom (743) c. 6 (MGH Conc. 2/1, 14).

180 Et si Deus Hebraicho populo ante incarnatione unigeniti filii sui haec servanda mandavit, quantum amplius nos, qui Christianae religionis documenta tenemus, ab inlicitis conubiis observare debemus, ne demersi in voragine ignis aeterni concrememur incendio. Konzil von Rom (743) c. 6 (MGH Conc. 2/1, 14).

181 Konzil von Rom (743) c. 6 (MGH Conc. 2/1, 15).

182 Konzil von Rom (743) c. 6 (MGH Conc. 2/1, 15). Das Heiratsverbot folgt aus Zacharias, Ep. ad Theodorum (MGH Epp. 3, 711). 
Im Anhang der Konzilsbeschlüsse kommt der Papst noch einmal ausführlich auf das Inzestverbot zu sprechen ${ }^{183}$. Nach einer Wiederholung der Klagen, die Gregor II. auf dem römischen Konzil von 721 geäußert hatte, wendet sich Zacharias im Besonderen dem von Bonifatius aufgedeckten Fall zu. Er erwähnt die Tatsache, dass man sich in den Gegenden Germaniens auf den Libellus responsionum des heiligen Gregor berufe, um Ehen innerhalb der verbotenen Verwandtschaftsgrade zu schließen ${ }^{184}$. Gregors Rechtsweisung, die im römischen Archiv nicht aufzufinden sei, gelte jedoch nur, „solange sie unzivilisiert waren und zum Glauben eingeladen werden mussten "185. Weiter berichtet Zacharias von einer jüngst ergangenen Anfrage an ihn:

„Im vergangenen Jahr schickten die Erzbischöfe und Könige jener Provinz Briefe zu uns und baten um apostolische Weisungen, auf welche Weise ihnen EheschlieBungen erlaubt sind und wie sie sie einhalten sollen. Wir haben ihnen Mahnbriefe geschickt, so weit Gott sich unser gnädig gezeigt hat ${ }^{\text {"186 }}$.

Da es zu dieser Zeit östlich des Rheins nur einen Erzbischof und nur einen $d u x$ et princeps gab, nämlich Bonifatius und Karlmann, wird man getrost diese Anfrage mit dem Brief des Bonifatius gleichsetzen können und den Rest päpstlicher Übertreibung zuschreiben. Zacharias erwähnt hier vermutlich den mahnenden Brief, von dem er bereits in seiner Korrespondenz mit Bonifatius berichtet hat.

Anders als Gregor II. bemühte sich Zacharias also um eine Argumentation und gab sich nicht mit einer Verhüllung der Neuerung zufrieden. Weiteres Licht auf dieses Bemühen wirft ein wenig später entstandener Brief des Papstes an den Bischof Theodor von Pavia. Auch darin polemisierte er gegen den Libellus responsionum und wies den Bischof der langobardischen Residenz an, sein Volk so zu behandeln, als „sei es von der Wiege an durch die heilige katholische

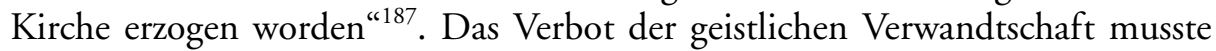
der Papst nochmals einschärfen und begründen. Wieder wählte er die wenig

183 Zur Überlieferung vgl. Nürnberger, Synode 1899.

184 Schieffer, Winfrid-Bonifatius 1954, 212, schreibt irrtümlich, Zacharias habe den Brief Gregors II. vom Jahre 726 widerrufen. Der Papst spricht aber ausdrücklich von der Autorität des sanctus Gregorius, also Gregors I.: Konzil von Rom (743) c. 15 (MGH Conc. 2/1, 20); Zacharias, Ep. ad Theodorum (MGH Epp. 3, 711).

185 Quod quidem licitum Christianis non est, dum usque se generatio cognoverit; sed, dum rudes erant et invitandi ad fidem, quamquam minime scriptum, ut dictum est, repperimus, credere non ambigimus. Konzil von Rom (743) c. 15 (MGH Conc. 2/1, 20 f.).

186 Praeterito anno litteras ad nos miserunt archiepiscopi et reges provinciae illius, petentes apostolica praecepta, qualiter liceat eis coniugia copulare et quomodo debeant observare; quibus quantum Dominus dare dignatus est, admonitionis praecepta direximus. Konzil von Rom (743) c. 15 (MGH Conc. 2/1, 21).

187 Nos autem volumus, ut non populus tibi commissus, sicut qui noviter Christum susceperunt debeat observare, sed sicut qui in sancta catholica sunt a cunabulis nutriti ecclesia ... Zacharias, Ep. ad Theodorum (MGH Epp. 3, 711) (JE 2306). 
passenden Gebote aus Levitikus als Basis, um das Verbot innerhalb der gesamten Blutsverwandtschaft zu begründen ${ }^{188}$ :

„Wir müssen uns noch viel mehr von der Tochter des geistlichen Vaters bei jeder Gelegenheit und unter Hintansetzung jedes Arguments unter großer Strenge fernhalten, damit nicht derjenige, der sich durch eine solche Missetat beschmutzt und die Zügel der Ausschweifung nicht hemmt, dem Zorn des göttlichen Urteils verfällt" ${ }^{“ 189}$.

Mehrfach bemühte Zacharias auch die Autorität des apostolischen Stuhls: „Hüte dich, dass du nicht deinen Untergebenen anderes gewährst, damit man dich nicht vom rechten Weg abweichen sieht, sondern bemühe dich vielmehr die Vorschriften unseres apostolischen Stuhls gänzlich zu befolgen “190. Auch am Briefende bekräftigte der Papst das kategorische Verbot der Verwandtenehe, da „es die heilige katholische und apostolische römische Kirche so festhält und verkündet"191.

Innerhalb von zwanzig Jahren hat sich eine spezifisch päpstliche Inzestgesetzgebung geformt und konnte sich selbst bereits als Tradition ausgeben. Vor Gregor II. gab es nur vereinzelte Stellungnahmen des Papstes zu dem Thema der Verwandtenehe, und keines dieser Dokumente hat Eingang in eine der in Rom benutzten Kirchenrechtssammlungen gefunden. Man hielt sich an die Vorschriften des römischen Rechts und verspürte offensichtlich kein Bedürfnis nach Veränderung. Die Schaffung einer Tradition ist erst durch die Auseinandersetzung mit dem byzantinischen Konzil „in Trullo“ in Gang gesetzt worden. Obwohl sich der apostolische Stuhl von den Beschlüssen des Quinisextum anregen ließ, entstand die erste eigenständige Gesetzgebung von 721 in Abgrenzung von der gemeinsamen römischen Tradition. Sie war ein Schritt der Loslösung von der Rechtseinheit mit Konstantinopel. Wenig später hat auch der Osten eine Erweiterung des Inzestverbots auf die gesamte Verwandtschaft ausgesprochen, jedoch nicht in der von Rom befürworteten Form eines kategorischen Verbots von Verwandtenehen ${ }^{192}$.

188 Sed bene tua sancta fraternitas compertum habet, quod Dominus per Moysen praecipiat dicens: ... Turpitudinem enim revelare dicitur, dum a propria consanguinitate praecipimur abstinere. Zacharias, Ep. ad Theodorum (MGH Epp. 3, 710) (JE 2306).

189 Multo magis a spiritali patris nostri filia omnimodo omni occasione aut argumento reposito, sub nimia districtione cavere nos convenit, ne in iram divini examinis incidat, si quis tali facinore mixtus minime restrinxerit frena luxuriae. Zacharias, Ep. ad Theodorum (MGH Epp. 3, 710) (JE 2306).

190 Cave autem, ne aliter agere subiectis concedas, ne a recto tramite inveniaris deviare, sed magis apostolicae sedis nostrae praecepta omnino assequi elabora ... Zacharias, Ep. ad Theodorum (MGH Epp. 3, 711) (JE 2306).

191 ... sicut hoc sancta Dei catholica et apostolica tenet et praedicat Romana ecclesia. Zacharias, Ep. ad Theodorum (MGH Epp. 3, 711) (JE 2306).

192 Ecloga 2, 2 (170). 
Bonifatius war Zeuge dieser, Erfindung einer Tradition'. So sehr er auch von der Autorität des Papstes überzeugt war und sich als Sendbote Petri ${ }^{193}$ stilisierte, so wenig war er bereit, bei den Erweiterungen des Inzestverbots dem apostolischen Stuhl Folge zu leisten. Auf die waghalsige Argumentation der Überbietung der jüdischen Gebote hat sich Bonifatius nicht eingelassen. Folglich haben die Gedanken des Zacharias keine Spuren in den Quellen der Kirchenreform Karlmanns hinterlassen. Karlmann und Bonifatius haben nicht dazu beigetragen, diese Position im Frankenreich unter die Leute zu bringen. Dies war erst das Werk Pippins I., der sich von Bonifatius allmählich abwandte und den direkten Zugang zum apostolischen Stuhl bevorzugte.

\section{Pippin I. und der Papst}

Pippin überließ anfangs seinem älteren Bruder Karlmann die Initiative bei der Reform der fränkischen Kirche. Ein Jahr nach der Synode von Les Estinnes beschloss er die Einberufung einer Kirchenversammlung in Soissons ${ }^{194}$. $23 \mathrm{Bi}$ schöfe aus dem neustrischen und burgundischen Teil des Frankenreichs fanden sich ein. Wie in Les Estinnes war auch in Soissons die Aristokratie von Pippins Reichsteil anwesend und wurde auf die Gültigkeit der Beschlüsse verpflichtet. Inhaltlich schloss sich Pippin weitgehend den Vorgaben der unter Karlmann tagenden Synoden an. Die Wiederherstellung der unter den Vorgängern zerrütteten Kirchenverfassung war das Hauptanliegen der Versammlung. Mit Abel und Hartbert sollten in Sens und in Reims zwei Erzbischöfe eingesetzt werden, die die regelmäßige Abhaltung von Synoden in Zukunft zu überwachen hatten. Unter den wenigen Vorschriften über den Lebenswandel von Laien ist wieder das Inzestverbot zu finden. „Gleichermaßen legen wir fest, dass kein Laie eine

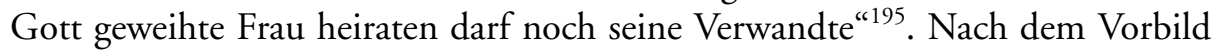
des Konzils von Les Estinnes wurde in einer unbestimmten Formulierung ein Inzestverbot ausgesprochen.

Trotz dieser Anlehnung an Bonifatius kamen in den Beschlüssen von Soissons auch Anliegen zur Sprache, die auf die Prägung durch Pippin und sein Umfeld hinweisen. So wurde neben dem Inzestverbot auch das Thema der Ehescheidung behandelt ${ }^{196}$. Bonifatius zeigte dagegen kein ausgeprägtes Interesse an dieser Thematik ${ }^{197}$. Die Laien gerieten generell mehr in das Blickfeld des Gesetzgebers als in den Kapitularien Karlmanns. In Soissons wurde nämlich

193 Concilium Germanicum c. 1 (MGH Conc. 2/1, 25).

194 Hartmann, Synoden 1989, 56-59; GlatthaAr, Bonifatius 2004, 308-319.

195 Similiter constituemus, ut nullus laicus homo Deo sacrata femina ad mulierem non habeat nec sua parentem. Konzil von Soissons (744) c. 9 (MGH Conc. 2/1, 35).

196 Konzil von Soissons (744) c. 9 (MGH Conc. 2/1, 35). Vgl. Fransen, Rupture 1977, 624; Hartmann, Synoden 1989, 58.

197 Kelly, Gregory II 1976, 93-98. 
auch festgelegt, dass „Laien rechtmäßig leben, nicht Unzucht irgendwelcher Art begehen, Meineide in der Kirche leisten und falsche Zeugenaussagen ablegen sollen " ${ }^{\text {"198 }}$. Wer sich gegen diese Beschlüsse wendet, so schloss Pippin das Gesetz, soll vom Princeps, von den Bischöfen und Grafen verurteilt werden und Buße nach den Bestimmungen der Volksrechte leisten ${ }^{199}$. Anders als Karlmann zeigte der jüngere Bruder ein Interesse an der Regelung der gesamten Rechtsordnung.

In den nächsten Jahren geriet die Kirchenreform unter der Ägide des Bonifatius ins Stocken. Im Teilreich Pippins scheiterte die Erhebung von Erzbischöfen an der Gegnerschaft aus Kreisen des alteingesessenen Klerus ${ }^{200}$. Auch scheint die Zusammenarbeit mit Bonifatius unter der sich allmählich verschärfenden Entfremdung der beiden Brüder gelitten zu haben, da der Missionar als Mann Karlmanns galt und deshalb im Teilreich Pippins auf Widerstand stieß. Denn obwohl der Papst die Zuständigkeit des Bonifatius im November 744 auf ganz Gallien ausdehnte ${ }^{201}$, suchte Pippin den direkten Kontakt zum apostolischen Stuhl. Im Jahr 746 schickte er eine Gesandtschaft mit einem Katalog von 27 Fragen an den Papst. Pippin nahm sich mit diesem Verlangen nach umfassender Belehrung ein Beispiel an Bonifatius, der seit 722 den Papst mit Listen von schwierigen Fällen bedrängte. Zacharias sah sich genötigt, auf diese Umgehung des apostolischen Legaten durch einen Brief an Bonifatius zu reagieren. Er klärte ihn darin auf, dass Pippin „um einige Kapitel über die priesterliche Weihe und über zum Seelenheil gehörige Dinge sowie auch über unerlaubte Ehen, wie man sie beachten muss nach dem Brauch der christlichen Religion und den Weisungen der heiligen Kirchensatzungen, gebeten hat ${ }^{\text {“202 }}$. Zudem weist er Bonifatius an, die Antworten des Papstes auf einer eigenen Synode in Karlmanns Teilreich zu promulgieren. Zacharias versuchte also, die

198 Similiter decrevimus, ut laici homines legitimi vivant et diversis fornicationis non faciant et periurias in ecclesia non consentiant et falsis testimoniis non dicant ... Konzil von Soissons (744) c. 4 (MGH Conc. 2/1, 35).

199 Konzil von Soissons (744) c. 10 (MGH Conc. 2/1, 36).

200 SCHIEFFer, Winfrid-Bonifatius 1954, 225-229.

201 S. Bonifatii et Lulli epistolae 58 (MGH Epp. sel. 1, 108). Ob nach 744 noch eine oder zwei Gesamtreichssynoden (745 und 747) unter Beteiligung Karlmanns, Pippins und des Bonifatius stattfanden, ist umstritten. Dagegen sprechen sich JARNUT, Bonifatius 1979, und Glatthaar, Bonifatius 2004, 319-334, aus. Die communis opinio bei Schieffer, Winfrid-Bonifatius 1954, 229-241; Hartmann, Synoden 1989, 59-63. Die Synode von 747 dürfte sich auf das Teilreich Karlmanns beschränkt haben: SchüssLer, Reichsteilung 1985, 79.

202 His ita se habentibus agnoscas, carissime, flagitasse a nobis Pippinum excellentissimum maiorem domus gentis Francorum ... aliquanta capitula de sacerdotali ordine et quae ad salutem animarum pertinent, simul etiam et pro illicita copula, qualiter sese debeant custodire iuxta ritum christianae religionis et sacrorum canonum instituta. S. Bonifatii et Lulli epistolae 77 (MGH Epp. sel. 1, 160) (JE 2278). 
Stellung seines Legaten durch die außergewöhnliche Anfrage Pippins nicht weiter zu untergraben.

Das Responsum des Zacharias spricht jedoch eine ganz andere Sprache. Pippin - und nicht Bonifatius - trat als Vertreter der Kirche seines Teilreichs auf und erstattete über den Zustand des Klerus Bericht. Statt wie Bonifatius mala et horribilia $^{203}$ nach Rom zu melden, äußerte Pippin kein schlechtes Wort über den Zustand der Kirche. „Groß ist die Freude, die wir empfinden, wenn wir aus dem Bericht unseres Sohnes, des erhabensten und von Gott geschützten Pippin, von dem guten Lebenswandel von euch allen erfahren ... und dass ihr als Bischöfe, Priester und fromme Äbte, wie es sich gebührt, euch in heiliger Haltung und priesterlichem Lebenswandel verhaltet ..." ${ }^{\text {"204 }}$ Diese Initiative Pippins zeigt zur Genüge, dass Bonifatius aus dem Zentrum der Macht verdrängt wurde. Pippin nahm für sich die Herrschaft über die Kirche und die Einberufung von Synoden in Anspruch. Für Bonifatius gab es daneben keinen Platz.

Der Inhalt der im Responsum enthaltenen 27 Kapitel ist weit gespannt, konzentriert sich aber auf Fragen der Kirchenverfassung. Die Welt der Laien wird nur in den Fragen der Ehescheidung, des Inzests und der Buße für Mord und Totschlag berührt. Dabei begnügt sich der Papst in fast allen Fällen mit einem Zitat aus der päpstlichen Kirchenrechtssammlung, der Collectio Dionysiana. Nur zwei Kapitel sind von Zacharias mit eigenem Gedankengut angereichert. Der erste Zusatz befasst sich mit den Kleidervorschriften des Klerus und setzt für Bischöfe eine würdevolle Kleidung fest, auch wenn es sich um zu Bischöfen berufene Mönche handelt ${ }^{205}$. Der zweite Zusatz findet sich im Inzestbeschluss und ergänzt das in Neocäsarea verfügte Verbot der Schwagerehe, der einzigen Vorschrift zu diesem Thema in der Collectio Dionysiana.

„Wir aber sagen mit Hilfe der göttlichen Gnade, indem wir gemäß den Entscheidungen der Päpste, unserer Vor- und Vorvorgänger noch viel weitergehen, dass Ehen nach Brauch und Regel des Christentums sowie nach dem Glauben der Römer nicht geschlossen werden, solange wie sich eine Nachkommenschaft gegenseitig kennt ${ }^{\text {‘206 }}$.

203 S. Bonifatii et Lulli epistolae 60 (MGH Epp. sel. 1, 122).

204 Gaudio magno gaudemus in Domino, addiscentes per relationem sublimissimi et a Deo servati praedicti filii nostri Pippini vestram omnium bonam conversationem ... adque earum praesules, sacerdotes et religiosi abbates, ut condecet, in sancto habitu et conversacione sacerdotali conversetis ... Codex Carolinus 3 (MGH Epp. 3, 479) (JE 2277).

205 Codex Carolinus 3 (MGH Epp. 3, 480) (JE 2277).

206 Nos autem, gracia divina suffragante, iuxta praedecessorum et antecessorum pontificum decreta multo amplius confirmantes dicimus, ut, dum usquae sese generacio cognoverit, iuxta ritum et normam christianitatis et religionem Romanorum non copulentur coniugiis. Codex Carolinus 3 (MGH Epp. 3, 485) (JE 2277). 
Wie in seinen anderen Äußerungen, die wir bereits besprochen haben, betont Zacharias die ehrwürdige Tradition dieses Verbots und die Autorität der römischen Kirche, um die Neuheit der Bestimmung zu überdecken. Ebenso verfährt er mit dem Verbot der geistlichen Verwandtschaft:

„Niemand soll auch nicht die geistliche Patenmutter oder Patentochter (was ferne sei) in verwegener Weise zur Frau nehmen, denn es ist ein Frevel und eine Todsünde vor Gott und seinen Engeln. Es ist nämlich eine so schwere Sünde, dass keiner der heiligen Väter und keine Kanones der heiligen Synoden [darüber etwas sagen] oder auch in den kaiserlichen Gesetzen etwas darüber entschieden worden ist, sondern aus Furcht vor dem schrecklichen Gericht Gottes haben sie es unterlassen, ein Urteil zu geben ${ }^{\text {“207 }}$.

Der Streit mit Bonifatius über das Inzestverbot bei geistlicher Verwandtschaft steht deutlich im Hintergrund dieser gewundenen Argumentation. Bonifatius hatte sich noch mit der unwahren Behauptung der Römer auseinandersetzen müssen, dass die Kaiser die Übertretung dieses Verbots mit der Todesstrafe oder mit Exil bestraft hätten. Jetzt gesteht Zacharias die Tatsache ein, keine Autoritäten des römischen Rechts für dieses Inzestverbot aufführen zu können. Gerade das Schweigen der Tradition interpretiert er jedoch als Bestätigung für die Selbstverständlichkeit des Verbots. Diese Begründung stammt aus dem Konzil „in Trullo“. Auch dort hieß es bei der Rechtfertigung neuer Eheverbote, der Kirchenvater Basilius habe einige verbotene Ehen nicht namentlich genannt, damit er seine Rede nicht mit hässlichen Worten beschmutze ${ }^{208}$.

Zacharias unternahm in seinem Responsum also erneut den Versuch, für die Position des apostolischen Stuhls in Sachen Inzestverbot bei den fränkischen Herrschern und Bischöfen zu werben. Die Karolinger bewahrten das Responsum als erstes ausführliches Dokument der Zusammenarbeit mit dem Papsttum in Ehren. Als Karl der Große im Jahr 791 die Korrespondenz mit dem Papsttum sammelte, wurde die Beantwortung der 27 Kapitel als dritter Text aufgenom$m^{209}{ }^{209}$. In der Geschichtsschreibung wird dieses erste Responsum als vorbildhaft angesehen für die im Jahr 751 an den Papst gerichtete Anfrage, ob die Absetzung des machtlosen Merowingerkönigs gerechtfertigt sei ${ }^{210}$. Der direkte Kontakt zum Papsttum war seit 747 hergestellt und die Autorität des Papsttums im

207 Sed nec spiritalem cummatrem aut filiam, quod absit, quis ducat temerario ausu uxorem; est namque nefas et perneciosum peccatum coram Deo et angelis eius. In tantum enim grave est, ut nullus sanctorum patrum atque sacrarum sinodorum adsertiones vel etiam in imperialibus legibus quippiam iudicatum sit; sed, terribile Dei iudicium metuentes, siluerunt sententiam dare. Codex Carolinus 3 (MGH Epp. 3, 485) (JE 2277).

208 Konzil in Trullo (692) c. 54 (CCO 1, 190-192).

209 Vgl. Hack, Codex 2006.

210 Affeldt, Untersuchungen 1980, 129-167; Semmler, Dynastiewechsel 2003, 87-110; Schieffer, Zeit 2005, 25; gegen die Existenz des zweiten Responsum spricht sich McKitterick, Illusion 2000, aus. Vgl. auch UbL, Schatten 2007. 
Frankenreich anerkannt. Bei der Legitimation der karolingischen Königsherrschaft spielte dieser privilegierte Kontakt zum Papsttum eine entscheidende Rolle, und das unabhängig davon, ob man eine Königssalbung im Jahr 751 annimmt oder nicht ${ }^{211}$. Verstärkt wurde diese Legitimation durch das päpstlichfränkische Bündnis von 754 gegen die Langobarden, das mit der päpstlichen Anerkennung der gesamten Familie Pippins als fränkischer Königsdynastie besiegelt wurde ${ }^{212}$.

Gleich in den ersten Jahren nach seiner Erhebung zum König unternahm Pippin die Realisierung des päpstlichen Programms. Auf einer Versammlung von geistlichen und weltlichen Würdenträgern, die zwischen 751 und 755 stattfand, hat er sein einziges erhalten gebliebenes Kapitular für das ganze Frankenreich erlassen ${ }^{213}$. Für eine Anwesenheit des apostolischen Legaten Bonifatius gibt es keine Hinweise, zumal auch nicht erwiesen ist, ob der am 5. Juni 754 verstorbene Missionar während der Tagung der Versammlung noch am Leben war. Für die letzten Jahre seines Lebens nimmt man allgemein eine Entfremdung zwischen Bonifatius und dem Hof an, da er seine Bitten nicht mehr direkt vor Pippin, sondern vor den neuen führenden Kirchenmännern des Frankenreichs vortragen musste ${ }^{214}$. Auch die Beschlüsse zum Inzestverbot sprechen, wie wir sehen werden, gegen eine aktive Beteiligung des Bonifatius.

Der hohe Stellenwert des Inzestverbots lässt sich daran ermessen, dass von sieben Kapiteln die ersten zwei dieser Thematik gewidmet sind und auch das dritte den Inzest im Nebensatz anspricht. Das erste Kapitel enthält eine Liste von verbotenen Eheverbindungen und macht mit der Abfolge der Verwandten die Beeinflussung durch das päpstliche Responsum deutlich: „Wenn ein Mann Inzest begeht in folgenden Fällen: mit einer Gott geweihten Frau, mit der

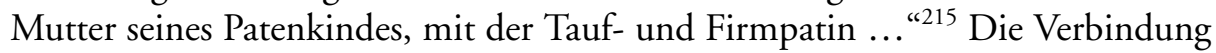
von Inzestverbot und Verbot der Ehe mit einer Nonne geht auf die römischen Konzile von 721 und 743 zurück. Die Ehe unter geistlichen Verwandten wurde ebenfalls auf den römischen Konzilien und dann nochmals im Responsum des Zacharias untersagt. Pippin erhob damit das vom Papst propagierte und von

211 Gegen eine Salbung spricht sich Semmler, Dynastiewechsel 2003, aus. Vgl. zuletzt die traditionelle Sicht bei Angenendt, Königserhebung 2004, und Schieffer, Zeit 2005, 26.

212 Angenendt, Bündnis 1980, 32-57; siehe oben 217 Anm. 2.

213 Clercq, Législation 1 1936, 132; Hartmann, Synoden 1989, 67 f. Glatthaar, Bonifatius 2004, 338-355, datiert das Kapitular auf Herbst/Winter 751/752.

214 S. Bonifatii et Lulli epistolae 93 (MGH Epp. sel. 1, 212-214). Vgl. Schieffer, Winfrid-Bonifatius 1954, 257. Dagegen argumentieren Jarnut, Pippin 1982, 56, und GlatthaAr, Bonifatius 2004, 335-357.

215 Si homo incestum commiserit de istis causis, de Deo sacrata, aut commatre sua, aut cum matrina sua spiritali de fonte et confirmatione episcopi ... Pippini regis capitulare c. 1 (MGH Capit. 1, 31). 
Bonifatius abgelehnte Verbot der geistlichen Verwandtschaft erstmals innerhalb des Frankenreichs zum verbindlichen Gesetz.

Eingehende Betrachtung verdient die Erwähnung der Firmpatin. Papst Zacharias hatte dieser Form der geistlichen Verwandtschaft keine Beachtung geschenkt, weil in Rom die Firmung üblicherweise im Anschluss an die Taufe gespendet wurde ${ }^{216}$. Zwei verschiedene Paten waren daher nicht nötig. Erst bei den Angelsachsen ist die Loslösung der beiden Formen der Patenschaft nachweisbar. Aufgrund der räumlich ausgedehnten Diözesen konnte die Salbung durch den Bischof erst in zeitlichem Abstand zur Taufe gespendet werden. Den angelsächsischen Missionaren auf dem Kontinent war es dann ein besonderes Anliegen, diese Praxis im Frankenreich zu verankern und die Bischöfe zur Salbungsreise durch ihre Diözese aufzurufen. Bonifatius korrespondierte in dieser Sache mehrfach mit dem Papst und sah die Spendung der Firmung als eine seiner zentralen Aufgaben $a^{217}$. Er selbst ist bei einer Firmreise durch Friesland den Martyrertod gestorben. Die Durchsetzung der sog. postbaptismalen Firmung war Teil der Kirchenreform und wurde als solche auch von Pippin gefördert. Pippin selbst benutzte dieses Instrument, um das politische Bündnis mit dem Papst auf eine verbindliche Basis zu stellen, indem er seine Söhne durch Papst Stephan II. konfirmieren ließ ${ }^{218}$. Dies geschah im Rahmen der Salbung Pippins und seiner Gemahlin in Saint-Denis (28.7.754). Fortan waren König und Papst durch die compaternitas verwandtschaftlich verbunden.

Die Etablierung der Firmung musste zwangsläufig die Frage aufwerfen, ob das Verbot der geistlichen Verwandtschaft auch für die Firmpatenschaft zutrifft. Pippin legte diese Frage Papst Stephan II. vor, als dieser sich zum Abschluss des fränkisch-päpstlichen Bündnisses im Frankenreich aufhielt. In einem in Quierzy ausgefertigten Responsum hat der Papst entschieden, dass die Firmpatenschaft ebenso ein Ehehindernis nach sich zieht wie die Taufpatenschaft ${ }^{219}$. Pippin zögerte nicht, diesen Beschluss in sein Kapitular einfließen zu lassen.

Nach der geistlichen Verwandtschaft wird im ersten Kapitular Pippins die Schwägerschaft angesprochen. Die sukzessive Ehe mit Tochter und Mutter sowie mit zwei Schwestern fällt laut Kapitular unter das Inzestverbot ${ }^{220}$. Die Blutsverwandtschaft wird als letztes erwähnt. Hier reicht das Verbot bis zur

216 AngENENDT, Kaiserherrschaft 1984, 75-77.

217 ANGENENDT, Kaiserherrschaft 1984, 81-87.

218 ANGENENDT, Kaiserherrschaft 1984, 155.

219 Ut nullus habeat commatrem suam spiritalem, tam de fonte sacro quam de confirmatione, neque sibi clam in neutra parte coningio sociatam. Quod si coniuncti fuerint, separentur. Responsa Stephani papae II, c. 4 (Migne PL 89, 1025) (JE 2315). Ausführlich dazu UBL, Schatten 2007.

220 ... aut cum matre et filia aut cum duabus sororibus ... Pippini regis capitulare c. 1 (MGH Capit. 1, 31). 
Cousine zweiten Grades (subrina) ${ }^{221}$. Pippin hielt sich mit der namentlichen Auflistung der Verwandten nicht an das kategorische Verbot der Verwandtenehe, wie es von den Päpsten propagiert wurde, sondern schloss sich der Tradition der merowingischen Kirche an. 140 Jahre zuvor, auf dem Konzil von Paris im Jahr 614, hatte der merowingische Episkopat das letzte Mal ein ähnlich weitreichendes Verbot erlassen.

Auch die Strafbestimmung richtet sich nach den Vorbildern der Merowingerzeit. Wie in der Lex Ribuaria droht der Gesetzgeber mit Konfiskation. Hat der Schuldige kein Vermögen wird er entweder in den Kerker geworfen oder bei persönlicher Unfreiheit „durch viele Hiebe geschlagen “222. Sollte sich der Inzestuöse einer Auflösung der Ehe entgegenstellen, darf ihn bei der Androhung des Königsbannes niemand aufnehmen oder ihm Kost darbieten ${ }^{223}$. Er gilt wie im merowingischen Recht als outlaw ${ }^{224}$. Ohne Vorbild ist dagegen die folgende Bestimmung: „Kirchenhörige, wenn es ehrenwerte Personen sind, sollen ihr Amt verlieren, Niedriggestellte werden ausgepeitscht oder in den Kerker geworfen "225. Das nächste Kapitel befasst sich mit Inzestvergehen von Klerikern. Der Archidiakon und der Graf sind verpflichtet, verdächtige Kleriker unter Androhung des Königsbannes vor das bischöfliche Gericht zu bringen. Sollten sich Kleriker oder Laien dauerhaft dem gerichtlichen Urteil entziehen, müssten die Delinquenten Bürgen stellen und vor dem Gericht des Königs erscheinen. „Und der König straft, damit die übrigen gebessert werden“226.

221 ... aut cum fratris filia aut sororis filia aut nepta aut cum consobrina atque subrina, aut cum amita vel matertera ... Pippini regis capitulare c. 1 (MGH Capit. 1, 31).

222 ... de istis capitulis pecuniam suam perdat, si habet ... Et si pecuniam non habet, si liber est, mittatur in carcere usque ad satisfactionem. Si servus aut libertus est, vapuletur plagis multis. Pippini regis capitulare c. 1 (MGH Capit. 1, 31).

223 Et si emendare noluerit, nullus eum recipiat nec cibum ei donet. Et si fecerit, LX solidos domno regi componat, usque dum se ipse homo correxerit. Pippini regis capitulare c. 1 (MGH Capit. 1, 31). Mit der Verweigerung der Mahlgemeinschaft ist freilich nicht ein realer Speiseentzug gemeint (so jedoch KASTEN, Ruf 2001, 164). Der Königsbann wird mitunter fälschlicherweise als Strafe für den Inzest angesehen: CLERCQ, Législation 1 1936, 132; Hartmann, Synoden 1989, 68.

224 Siehe $189 \mathrm{f}$.

225 De ecclesiasticis vero, si bona persona fuerit, perdat honorem suum; minores vero vapulentur aut in carcerem recludantur. Pippini regis capitulare c. 2 (MGH Capit. 1, 31). ClercQ, Législation 1 1936, 132, und HartmanN, Synoden 1989, 68, übersetzen ecclesiastici mit Kleriker.

226 De presbyteris et clericis sic ordinamus, ut archidiaconus episcopi eos ad synodum commoneat una cum comite. Et si quis contempserit, comes eum distringere faciat, ut ipse presbyter aut defensor suus $L X$ solidos componat, et ad synodum eat. Et episcopus ipsum presbyterum aut clericum iuxta canonicam auctoritatem deiudicare faciat. Solidi vero LX de ipsa causa in sacello regis veniant. Et si aliquis per violentiam presbyterum aut clericum aut incestuosum contradixerit, tunc comes ipsam personam per fideiussores positam ante regem faciat una cum 
Das erste Kapitular Pippins ist also ein bedeutendes Zeugnis für das politische Bündnis zwischen Papst und König. Der Gleichschritt in der Frage des Inzestverbots sollte dieses Bündnis zum Ausdruck bringen. Wenige Monate später brach Pippin mit dem fränkischen Heer nach Italien auf und besiegte die Streitmacht der Langobarden ${ }^{227}$. Ihr König Aistulf fand sich zum Abschluss eines Friedensvertrags bereit, und Pippin ließ den Papst in Begleitung Fulrads von Saint-Denis und seines Halbbruders Hieronymus nach Rom ziehen. Als Nachfolger des Bonifatius war zu dieser Zeit schon der Metzer Bischof Chrodegang vom Papst anerkannt. Chrodegang erhielt aus Rom das Pallium und somit auch die Führung der fränkischen Kirche ${ }^{228}$. Im Sommer 755 berief er das erste gesamtfränkische Konzil unter karolingischer Herrschaft in Ver-sur-Launette ein. Bonifatius war dieser Erfolg nicht mehr vergönnt gewesen. Sowohl in Ver als auch auf den nachfolgenden Synoden von Verberie und Compiègne setzte sich die fränkische Kirche erneut mit dem Problem des Inzestverbots auseinander.

Das Konzil von Ver beginnt ungewöhnlicherweise mit einer programmatischen Vorrede ${ }^{229}$. Darin wird offen die Nachlässigkeit der Befolgung des Kirchenrechts angeprangert und als Motiv für die Einberufung der Synode herangezogen. Pippin ließ fast den gesamten Episkopat Galliens in seiner Pfalz zusammenkommen, weil er die kanonischen Bestimmungen wieder zur Geltung bringen wollte. „Und weil die Mittel zur vollständigen Wiederherstellung nicht zu Gebote stehen, will er dennoch zum Teil eine Verbesserung von dem, was

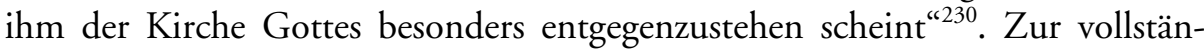
digen Wiederherstellung des Kirchenrechts sollten glücklichere und ruhigere Zeiten abgewartet werden. Trotz dieser bescheidenen Worte bemühten sich die um Chrodegang versammelten Bischöfe um eine systematische Behandlung wichtiger Bereiche des Kirchenrechts. An erster Stelle stehen wie bei Bonifatius die Stärkung der kirchlichen Hierarchie und die regelmäßige Einberufung von Kirchenversammlungen. Das Eherecht wird an zwei Stellen erwähnt. In c. 9 werden die Folgen einer Exkommunikation nach der Weigerung, eine Inzestehe aufzulösen, ausführlich beschrieben. Das Kapitel liest sich wie eine Ausführungsbestimmung der im Kapitular angedrohten Exkommunikation. Der Inzestuöse darf keine Kirche betreten, mit anderen Christen weder essen noch

misso episcopi venire; et domnus rex distringat, ut ceteri emendentur. Pippini regis capitulare c. 3 (MGH Capit. 1, 31 f.).

227 Schieffer, Karolinger 2006, $63 \mathrm{f}$.

228 Clausssen, Chrodegang 2004.

229 Eckhardt, Lex Salica 1953, 50-55; Hartmann, Synoden 1989, 68-72; Garrison, Franks 2000, 132.

230 Et quia facultas modo non suppetit ad integrum, tamen aliqua ex parte vult esse correctum quod aecclesiae Dei valde cognoscit esse contrarium. Konzil von Ver (755) prol. (MGH Capit. 1, 33). 
trinken, keine Geschenke annehmen oder einen Kuss darbieten, sich nicht im Gebet jemandem anschließen und niemanden grüßen ${ }^{231}$. Werde dadurch kein Einlenken erreicht, soll die Exilierung durch das Urteil des Königs erfolgen ${ }^{232}$. In c. 15 werden alle Laien adeliger und niederer Herkunft zur öffentlichen Eheschließung verpflichtet ${ }^{233}$. Diese Bestimmung muss ebenfalls im Zusammenhang mit dem Inzestverbot gesehen werden, weil die Geistlichen nur bei einem öffentlichen Vollzug der Ehe intervenieren und eine Heirat unter Verwandten verhindern konnten.

Gemäß dem Kanon von Ver über die regelmäßige Abhaltung von Kirchenversammlungen fanden in den nächsten beiden Jahren erneut Synoden statt. 756 tagte man in Verberie, 757 in Compiègne ${ }^{234}$. Da auch dieses Mal die Synoden in königlichen Pfalzen stattfanden, ist die Initiative Pippins vorauszusetzen. Beide Kirchenversammlungen widmeten sich fast ausschließlich dem Eherecht, und zwar der Scheidung und dem Inzest. Das Inzestverbot stand jeweils an der Spitze der Tagesordnung. Beide Kanonesreihen setzten mit diesem Thema ein. Das Kapitular Pippins wurde anscheinend nicht als ausreichend angesehen.

Die ersten Kanones von Verberie und Compiègne statuieren jeweils die Grenze des Inzestverbots. Charakteristisch ist in beiden Vorschriften die Anwendung der kanonischen Zählweise. Diese Tatsache ist unbestritten, da in Compiègne der Fall einer Verwandtschaft im Verhältnis 3/4 erörtert wurde. Diese Zahlenangabe macht nur unter der Voraussetzung der kanonischen Zählweise Sinn. Ich habe bereits in der Einleitung eine Erklärung für diesen überraschenden Sachverhalt vorgeschlagen. Bischof Chrodegang von Metz, der Nachfolger des Bonifatius im Amt des apostolischen Legaten, hat seine Erziehung vermutlich im Kloster Saint-Trond im austrasischen Haspengau erhalten und ist später als Referendar am Hof Karl Martells nachweisbar ${ }^{235}$. Dass er über die monastische Bildung hinaus auch mit dem römischen Recht vertraut war, ist unwahrscheinlich. Chrodegang orientierte sich daher nicht mehr an der Zählweise des römischen Rechts, sondern an der Zählweise des weithin bekannten

231 Et ut sciatis, qualis sit modus istius excommunicationis: in ecclesia non debet intrare, nec cum nullo christiano cybum vel potum sumere; nec eius munera accipere debet, vel osculum porregere, nec in oratione iungere, nec salutare, antequam ab episcopo suo sit reconciliatus. Konzil von Ver (755) c. 9 (MGH Capit. 1, 35).

232 Quod si aliquis ista omnia contempserit, et episcopus hoc minime emendare potuerit, regis iudicio exilio condamnetur. Konzil von Ver (755) c. 9 (MGH Capit. 1, 35).

233 Ut omnes homines laici publicas nuptias faciant, tam nobiles quam innobiles. Konzil von Ver (755) c. 15 (MGH Capit. 1, 36). Den Bezug zum Inzestverbot hebt Esmyol, Geliebte 2002, 187, gegen andere Interpretationen zu Recht hervor.

234 Die Chronologie sicherte Oelsner, Jahrbücher 1871, 270-281 und 455-460. Vgl. auch Hartmann, Synoden 1989, 73-79.

235 Claussen, Chrodegang 2004, 20-24. 
Libellus responsionum. Auch in der späteren Karolingerzeit ist zu beobachten, dass sich die kanonische Zählung dort am schnellsten durchsetzen sollte, wo die Tradition des römischen Rechts entweder nie verankert oder schon lange überdeckt worden war. In den Rechtsschulen von Italien hielt sich die römische Zählweise dagegen am längsten und konnte erst durch die Gesetzgebung des Reformpapsttums überwunden werden.

In Verberie entschied man sich für den vierten Verwandtschaftsgrad, d.h. für die Verbindung zwischen Cousin und Cousine dritten Grades (4/4). Als Strafe wurde die Buße verhängt, eine Scheidung sollte erst bei Ehen innerhalb des dritten Grades erfolgen. Eine erneute Heirat wurde den betroffenen Personen zugestanden. Im vierten Grad durfte die Ehe weiter geführt werden, wenn sie bereits geschlossen worden war. Wurde die Verwandtschaft vor der Heirat bekannt, durfte die Ehe nicht eingegangen werden ${ }^{236}$. Ein Jahr später modifizierte man in Compiègne diese Regelung. Für eine Heirat im vierten Grad wurden keine Konsequenzen gezogen. Eine Ehe im Verhältnis von 3/4, die also zwischen drittem und viertem Grad steht, unterwarfen die Bischöfe dagegen ausdrücklich der Trennung ${ }^{237}$. Diese Grenze sollte auch für Verhältnisse der Schwägerschaft gelten. Ein Mann durfte nicht die Frau eines Verwandten bis zum Verhältnis von 3/4 ehelichen ${ }^{238}$.

Es ist nicht einfach, die unterschiedlichen Bestimmungen von Verberie und Compiègne in Bezug zueinander zu setzen. Bislang wurde stets der Kanon aus dem späteren Konzil von Compiègne als Verschärfung angesehen, da eine Ehetrennung auch für das Verhältnis 3/4 ausgesprochen wurde ${ }^{239}$. Man kann die Beziehung jedoch auch anders bewerten. Denn nur in Verberie betrachteten die Bischöfe den vierten Grad überhaupt als Inzestfall, obwohl sie von einer strikten Bestrafung durch Ehetrennung absahen. Unter diesem Blickwinkel verschob das Konzil von Compiégne die Inzestschranke vom 4. Grad auf das Verhältnis 3/4. Das spätere Konzil hätte dann eine mildere Regelung beschlossen. Diese Einschätzung passt besser zum generellen Tenor der beiden Synoden. In Compiègne sprach man sich nämlich in einigen Fällen für eine laxere Handhabung des

236 In tertio genuclum separantur, et post penitentiam actam, si ita voluerint, licentiam habent aliis se coniungere. In quarta autem coniunctione si inventi fuerint, eos non separamus, sed poenitentiam eis iudicamus. Attamen si factum non fuerit, nullam facultatem coniungendi in quarta generatione damus. Decretum Vermeriense c. 1 (MGH Capit. 1, 40).

$237 \mathrm{Si}$ in quarta progenie reperti fuerint coniuncti, non separamus. In tercia vero si reperti fuerint, separentur. Et eos, qui unus in quarta alius in tercia sibi pertinent et coniuncti inveniuntur, separamus. Decretum Compendiense c. 1-3 (MGH Capit. 1, 38 f.).

238 Si duo in tercio loco sibi pertinent, sive vir sive femina, aut unus in tercio et alter in quarto, uno mortuo, non licet alterum accipere uxorem eius; et si inventi fuerint, separentur. Decretum Compendiense c. 4 (MGH Capit. 1, 39).

239 Oelsner, Jahrbücher 1871, 307. 
Prinzips der Unauflösbarkeit der Ehe aus, während in Verberie an einer rigoroseren Disziplin festgehalten worden war $^{240}$.

Dies führt zur bereits mehrfach erörterten Frage, warum innerhalb eines Jahres zum großen Teil ähnliche, in manchen Punkten jedoch abweichende Beschlüsse zu denselben Themen gefasst wurden. Carlo de Clercq vermutete, dass es sich um zwei gleichwertige Memoranden für die Reichsversammlung von Compiègne handelt, von denen das eine approbiert, das andere verworfen wurde ${ }^{241}$. Diese Ansicht konnte sich nicht durchsetzen, weil es für die Verwerfung der Beschlüsse von Verberie keine ausreichenden Argumente gibt. Immerhin werden sie in den Handschriften als Dekret einer Synode bezeichnet. So schätzt man üblicherweise beide Synodaltexte als gleichwertig ein ${ }^{242}$. Das Problem der Wiederholung gleicher Themen mit ähnlichen Beschlüssen bleibt jedoch bestehen. Ein Schlüssel zur Lösung dieses Problems bietet die Tatsache, dass allein für die Synode von Compiègne eine gleichzeitig stattfindende Reichsversammlung belegt ist. Nach dem Bericht der Reichsannalen übertrug Pippin damals Herzog Tassilo III. das Herzogtum Bayern nach dem Schwur eines Vasalleneides ${ }^{243}$. Der König war also auf der Synode zugegen, ebenso wie zwei Legaten des Papstes, die einige Beschlüsse der Synoden ausdrücklich bil$\operatorname{ligten}^{244}$. Die Synode von Compiègne entspricht der in Ver 755 erlassenen Vorschrift, dass stets am Anfang des Jahres eine Synode im Beisein des Königs und der Reichsversammlung zusammentreten soll ${ }^{245}$. Bei Verberie könnte es sich dagegen um die in Ver vorgeschriebene Herbstsynode handeln, an der nur die Bischöfe unter dem Vorsitz des Metropoliten teilnehmen mussten ${ }^{246}$. Die Wiederholung derselben Beschlüsse macht also Sinn, wenn in Compiègne ein größeres Publikum erreicht, der König direkt einbezogen und die Zustimmung päpstlicher Gesandten erwirkt werden konnte. Es versteht sich von selbst, dass die Beschlüsse von Verberie deshalb nicht weniger gültig waren. Die inhaltlichen Unterschiede bewegen sich ja im Bereich von Nuancen.

240 Der Eintritt einer Frau ins Kloster ist in Verberie kein Freibrief für eine neue Ehe: Decretum Vermeriense c. 21 (MGH Capit. 1, 41); vgl. dagegen Decretum Compendiense c. 16 (MGH Capit. 1, 38). Unnachgiebig sind auch Decretum Vermeriense c. 8, 19 u. 20 (MGH Capit. 1, 40 f.).

241 ClercQ, Législation 1 1936, 142.

242 Hartmann, Synoden 1989, 73-79.

$243 \mathrm{BM}^{2}$ 84a. Annales regni Francorum a. 757 (MGH SS rer. Germ. 6, 1895, 14). Zur umstrittenen Deutung des Ereignisses vgl. Jahn, Ducatus 1991, 335-344; Becher, Eid 1993, 35-45; Wolfram, Salzburg 1995, 338-344.

244 Decretum Compendiense c. 14, 16 u. 20 (MGH Capit. 1, 38 f.).

245 Primus sinodus mense primo, quod est Martias Kalendas, ubi domnus rex iusserit, eius praesentia. Konzil von Ver (755) c. 4 (MGH Capit. 1, 34). Zur Frage der Verlegung der Versammlung vom März in den Mai vgl. Springer, Wiederkehr 1995.

246 Konzil von Ver (755) c. 4 (MGH Capit. 1, 34). So bereits Oelsner, Jahrbücher 1871, 457. 
Für die Festlegung der Verwandtschaftsgrenze haben diese Überlegungen folgende Konsequenzen. In Verberie waren sich die Bischöfe einig, dass das erste Kapitular von Pippin nicht ausreichte und dass sich das Inzestverbot weiter als bis zur Cousine zweiten Grades (sobrina) erstrecken sollte. Wenn man dem kategorischen Verbot der Verwandtenehe durch den Papst gerecht werden wollte, musste auch der vierte Grad unter Strafe gestellt werden. In Compiègne wurde dies präzisiert. Die Grenze wurde mit dem Verhältnis 3/4 festgelegt, was dem siebten Grad römischer Zählung entspricht. Papst Gregor III. hatte in einem Brief an Bonifatius genau diesen siebten Grad als Grenze der Verwandtschaft angegeben ${ }^{247}$. In Compiègne machte sich die fränkische Kirche vor den Augen der päpstlichen Gesandten die Auffassung des apostolischen Stuhls vollständig zu Eigen. Das Inzestverbot der merowingischen Kirche wurde somit geringfügig um einen Grad erweitert.

Das Inzestverbot stand nicht nur hinsichtlich der Frage nach der Grenze der Verwandtschaft zur Debatte. In Verberie und Compiègne wurde darüber hinaus in jeweils sechs Kanones eine Reihe von konkreten Fällen zur Sprache gebracht. Zum einen drehten sich die Fälle um die geistliche Verwandtschaft. Wenn jemand beispielsweise bei der Firmung seines Stiefkindes als Pate vor den Bischof trete, sollte er von seiner Frau geschieden werden und ehelos bleiben ${ }^{248}$. Zum anderen wurden Fälle der Kombination von Ehebruch und Inzest behandelt. Die Bischöfe folgten dabei stets der Maxime, dass die Strafe der Ehelosigkeit nur dann eintritt, wenn die Beteiligten über den Inzestcharakter Bescheid wussten. Hatte zum Beispiel ein Sohn mit seiner Stiefmutter Geschlechtsverkehr, wurden beide zur Ehelosigkeit verurteilt, der unbeteiligte und unwissende Vater des Sohnes durfte dagegen eine neue Ehe eingehen ${ }^{249}$. Ebenso konnten Tochter und Mutter, die in Unwissenheit mit demselben Mann Geschlechtsverkehr hatten, nach geleisteter Buße erneut heiraten ${ }^{250}$.

247 Siehe 244 Anm. 134. Welche Texte den Konzilsteilnehmern als Diskussionsgrundlage dienten, lässt sich erahnen. Die Bußbestimmungen Theodors von Canterbury gehörten sehr wahrscheinlich dazu: Finsterwalder, Canones 1929, $226 \mathrm{f}$. Weitere Texte sind aus einer Sammlung der Zeit Pippins I. zu erschließen, der Collectio capitularium Laudunensis in Laon, Bibliothèque Municipale, 265; vgl. Mordek, Bibliotheca 1995, $200-$ 205; UBL, Schatten 2007, 428-430. Darin befinden sich den Bestimmungen von Verberie und Compiègne vorgeschaltet der c. 30 des Konzils von Epaon, der c. 22 des Konzils von Tours (567) und die Auflistung der sieben Verwandtschaftsgrade in der Lex Romana Visigothorum.

248 Si quis filiastram aut filiastrum ante episcopum ad confirmationem tenuerit, separetur ab uxore sua et alteram non accipiat. Similiter et femina alterum non accipiat. Decretum Compendiense c. 15 (MGH Capit. 1, 38).

249 Si filius cum noverca sua, uxore patris sui, dormierit, nec ille nec illa possunt ad coniugium pervenire. Sed ille vir, si vult, potest aliam uxorem habere; sed melius est abstinere. Decretum Vermeriense c. 10 (MGH Capit. 1, 41).

250 Decretum Compendiense c. 17 (MGH Capit. 1, 39). 
$\mathrm{Zu}$ keiner anderen Zeit wurde im Frankenreich dem Inzestverbot so viel Bedeutung zugemessen wie in den Jahren kurz nach der Königserhebung Pippins I. Zwischen 754 und 757 stellten drei Gesetzgebungsakte des neuen Königs den Inzest an die erste Stelle der Beschlüsse. Pippin beabsichtigte damit, angeregt durch die wiederholten Ermahnungen des Papstes, die Unsicherheiten über Geltungsumfang und Rechtsfolgen des Inzestverbots aus dem Weg zu räumen. Trotz der umfassenden Kodifizierung muss sein Versuch als gescheitert angesehen werden. Im karolingischen Kirchenrecht des 9. Jahrhunderts blieben genau dieselben Fragen umstritten, die durch Pippin einer Entscheidung zugeführt worden waren. Für die Gelehrten des 9. Jahrhunderts galten diese Fragen weiterhin als offen. Nur so erklärt sich die Tatsache, dass seit der Mitte des 9. Jahrhunderts eine intensive Diskussion über Umfang und Rechtswirkung des Inzests entbrannt ist, an der sich Hrabanus Maurus, Benedictus Levita, Hinkmar von Reims, Nikolaus I. und die ostfränkischen Bischöfe beteiligten. Warum es dazu kam, erklärt die Überlieferung. Im Vergleich zu der massenhaften Verbreitung des Libellus responsionum oder des römischen Konzils von 721 ist die Überlieferung der unter Pippin entstandenen Gesetze bescheiden. Das Kapitular und die Synoden sind in jeweils 9-11 Handschriften erhalten. Die älteste Sammlung mit allen drei Texten (Kapitular, Verberie und Compiègne) stammt noch aus der Zeit Pippins und verbindet die neuen Gesetze mit älteren Bestimmungen zum Inzest ${ }^{251}$. In der Zeit Karls wurden ebenfalls alle drei Texte von Erzbischof Magnus von Sens in einer Sammelhandschrift vereinigt ${ }^{252}$. Das Kapitular und die Synode von Compiègne finden sich außerdem in einer ca. 813 entstandenen Schulhandschrift ${ }^{253}$. In Tours kopierte man in den Jahren 805/813 das Kapitular ${ }^{254}$. Die anderen Handschriften leiten sich von diesen Sammlungen $\mathrm{ab}^{255}$. Die meisten Zeugen für ein Interesse an den Gesetzen Pippins sind demnach aus der Zeit Karls des Großen erhalten. Dies wird man als Folge der ausdrücklichen Einschärfung dieser Gesetze durch Karl ansehen müssen. Im Kapitular von Herstal (779) schrieb er vor: „Die Kapitel aber, die unser Vater seligen Angedenkens auf seinen Versammlungen und Synoden

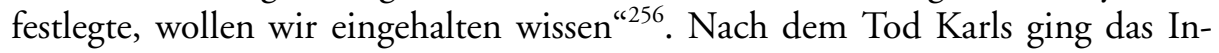

251 Laon, Bibliothèque municipale, 265. Vgl. Mordek, Bibliotheca 1995, 200-205.

252 Vatikan, Biblioteca Apostolica Vaticana, Pal. Lat. 582, vgl. Mordex, Bibliotheca 1995, 780-790; Paris, Bibliothèque Nationale, Lat. 9654, vgl. Mordek, Bibliotheca 1995, $562-571$.

253 Paris, Bibliothèque Nationale, Lat. 2796, vgl. Mordek, Bibliotheca 1995, 430-432.

254 Leiden, Bibliotheek der Rijksuniversiteit, Voss. Lat. Q. 199, vgl. Mordek, Bibliotheca 1995, 210-217.

255 Mit der Ausnahme der Sammlung von Beauvais in Vatikan, Biblioteca Apostolica Vaticana, Vat. Lat. 3827 nach Mordek, Bibliotheca 1995, 858-863.

256 Capitula vero quae bonae memoriae genitor noster in sua placita constituit et sinodus conservare volumus. Capitulare Haristallense c. 12 (MGH Capit. 1, 50). 
teresse an der Inzestgesetzgebung Pippins zurück. Mit der Ausnahme von Benedictus Levita und Regino von Prüm zitierte weder ein Konzil noch ein Gelehrter diese Bestimmungen. Entscheidend dafür war, dass die mit über 60 Handschriften maßgebliche Kapitulariensammlung des Ansegis von Fontenelle nur die Gesetze Karls des Großen und Ludwigs des Frommen vereinigte. Die gelehrte Diskussion bewegte sich deshalb um andere Referenztexte aus der kirchlichen und päpstlichen Tradition. Dass ein König die wichtigen Streitfragen in der Frage des Inzestverbots beigelegt hatte, erschien umso unwahrscheinlicher, je mehr das Eherecht von den karolingischen Herrschern vernachlässigt und von der Kirche monopolisiert wurde. Die von Pippin festgelegte Inzestgrenze hielt sich nur dort, wo sie wiederholt auf Konzilien eingeschärft wurde. Dies war in Mainz 813 und 847 der Fall. Obwohl fast alle Handschriften der Inzestgesetzgebung Pippins aus dem Nordosten des heutigen Frankreichs stammen, wurde offensichtlich nur im Ostfrankenreich des Erzbischofs von Mainz an der Inzestgrenze der Jahre 754-757 festgehalten.

\section{Karl der Große und die Reform des Strafrechts}

Das beherrschende Thema der Gesetzgebung unter Pippin war der Umfang des Inzestverbots. Drei von vier Gesetzestexten aus seiner Zeit als König der Franken werden durch eine Bestimmung zu diesem Thema eröffnet. Karl der Große hingegen sah sich zu keiner Stellungnahme zum Umfang des Inzestverbots veranlasst, sondern schärfte im Jahre 779 die Gesetze seines Vaters ohne Änderung erneut ein ${ }^{257}$. Sein Interesse galt vielmehr der Frage, wie das Verbot von Verwandtenehen in der Praxis zur Geltung gebracht werden konnte. Seine Kapitularien zur Strafverfolgung des Inzests sollten für die folgende Zeit richtungsweisenden Charakter annehmen und den Wandel des Strafrechts maßgeblich beeinflussen.

Im römischen Reich lag die Verantwortung für die Verfolgung von Verstößen gegen das Inzestverbot bei öffentlichen Amtsträgern. Aus den Quellen des 6. Jahrhunderts lässt sich der comes rerum privatarum als zuständiges Organ

257 Allein zwei in ihrer Herkunft umstrittene Kapitulare enthalten eine Festlegung der Grenze des Inzestverbots: Capitula missorum c. 6 (MGH Capit. 1, 182) befürwortet den 6. Grad in einem an das römische Konzil von 721 erinnernden Wortlaut. FinsterWALDER, Untersuchungen 1938, 425, und Brommer, Capitula 1985, 56, sahen in den Kapiteln ein Bischofskapitular; Pokorny (Einleitung zu MGH Capit. episc. 2, IX) sprach sich wegen c. 9 dagegen aus. Die Überlieferung in einer Handschrift aus der Mitte des 9. Jahrhunderts verweist ev. auf Corbie: Ganz, Corbie 1990, $36 \mathrm{f}$. Zum Inhalt vgl. Mordek, Bibliotheca 1995, 827-830. Capitula e conciliorum canonibus collecta c. 2 (MGH Capit. 1, 232) verbietet den vierten und fünften Grad. Dieses Kapitel ist wohl kirchlichen Ursprungs und stammt aus Oberitalien: Mordek, Bibliotheca 1995, $920-$ 943. Beide Kapitel gehen vermutlich nicht auf Karl den Großen zurück. In diesem Sinn bereits SECKEL, Synode 1922, $39 \mathrm{f}$. 
erkennen $^{258}$. Er hatte den Auftrag, als Inquisitor tätig zu werden und nach unerlaubten Inzestehen zu fahnden. Da aber auch in der Spätantike in der Regel Gerichtsverfahren nur dann in Gang gekommen sind, wenn die geschädigte Partei Anklage erhoben hatte, wird man diesem Inquisitionsauftrag nicht allzu hohe Effektivität beimessen können ${ }^{259}$. Einige Quellen berechtigen zur Vermutung, dass nur Denunziationen zur Aufdeckung von Inzestfällen führten. Durch die Strafen der Infamie und der Vermögenskonfiskation konnte die Denunziation für manche Personen einträglich sein, die entweder als Erbe zum Zuge kommen oder auf eine Belohnung aus der Enteignung der schuldigen Eheleute durch den Fiskus hoffen konnten. Es blieb allerdings durchgehend ein Problem, dass im römischen Recht Ehen keine öffentliche Beglaubigung erfahren mussten, sondern auf dem Weg des faktischen Zusammenlebens geschlossen wurden ${ }^{260}$. Die Ehe war primär eine private und keine öffentliche oder rechtliche Angelegenheit. Aus diesem Grund sind Inzestehen wohl oft der Aufmerksamkeit der öffentlichen Behörden entgangen.

Im Recht der frühmittelalterlichen Reiche hielt man an der staatlichen Zuständigkeit der Verfolgung von Inzestehen fest. Die Rechte der Ostgoten, Westgoten, Burgunder, Langobarden und Franken sind in diesem Punkt eindeutig. Wie in Kapitel 3 und 4 deutlich gemacht wurde, war die Verfolgung des Inzests ein wichtiger Eckpunkt in der Demonstration einer legitimen Herrschaft in der Nachfolge der antiken Kaiser. Im langobardischen Recht ermutigte der Gesetzgeber die öffentlichen Amtsträger ausdrücklich zur Verfolgung von Inzestehen. König Aistulf, ein Zeitgenosse und Gegner Pippins I., verhängte die Trennung von Ehen, die durch die Kanones und die Gesetze seiner Vorgänger verboten worden waren, und drohte nachlässigen Richtern empfindliche Strafen an. „Und wenn vom gegenwärtigen Verbot an jemand von unseren Richtern es versäumt, diese Fälle zu richten und dagegen einzuschreiten, dann zahlt er sein Wergeld. Denn von einer solchen Sache schien es uns und allen, dass, wer so etwas zulässt, gegen Gott und seine Seele handelt und dass so die Verdorbenheit überhand nimmt ${ }^{\text {'261 }}$. Ob diese Drohungen eine Wirkung entfalteten, kann für das langobardische Reich wegen Quellenmangels nicht beurteilt werden. Die Ahndung von Rechtspflegedelikten zeigt jedoch immerhin das Bemühen des Gesetzgebers, die Durchsetzung seiner Gesetze zu überwachen. Ähnliches gilt für das Reich der Westgoten. In seinem Gesetz gegen Inzest hob Reccared

258 Siehe 106 Anm. 149.

259 Harries, Law 1999, 93-98; Krause, Kriminalgeschichte 2004, 51-60.

260 Treggiari, Marriage 1991; Reynolds, Marriage 1994, 3-43.

261 Et quis intra presentem indictionem causam istam de nostris iudices neglexerit ad iudicandum aut distringendum, conponat widrigild suum: quia de causa ista apparet nobis et omnibus: qui talia consentiunt, contra deum et animam suam faciunt, et malitia amplius crescit. Leges Langobardorum, Aistulf 8 (MGH LL 4, 197). Vgl. hierzu SснмiтTWeIgand, Rechtspflegedelikte 1962, 53. 
ausdrücklich hervor, dass im Fall einer Verwandtenehe auch ohne Anklage durch die Initiative des Richters oder eines Priesters ein Prozess eröffnet werden könnte ${ }^{262}$. Das Anklageprinzip wurde vom König ausdrücklich suspendiert. Den Priestern und öffentlichen Amtsträgern drohte er bei Nachlässigkeit mit einer Strafe: „Wenn aber Priester und Richter solches entdecken und die Strafe vielleicht hinausgezögert haben, werden sie gezwungen, dem Fiskus fünf Pfund Gold abzuliefern. Wenn sie jedoch verklagen wollten, aber nicht konnten, sollen sie dafür Sorge tragen, dass es den Ohren des Königs bekannt gemacht

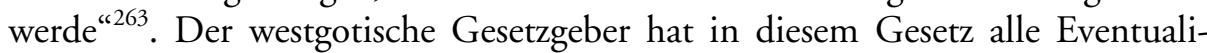
täten berücksichtigt. Der König erscheint als letzte Instanz in einer scheinbar lückenlosen Strafverfolgung. Eigentümlich für das westgotische Recht ist die prominente Stellung des Klerus. Seit Reccared sind die Bischöfe zur Kontrolle der weltlichen Rechtsprechung herangezogen worden. In Nachahmung der justinianischen Gesetzgebung wurden die Bischöfe zu einem Teil der öffentlichen Verwaltung und hatten gegen Korruption und Bestechlichkeit niederer Amtsträger vorzugehen.

Die Verhältnisse im Frankenreich waren grundverschieden. Die schriftliche Gesetzgebung war in weiten Teilen viel weniger eng mit der in den Bahnen des Gewohnheitsrechts laufenden Praxis verknüpft. Kodifikationen dienten vielmehr Zwecken der herrscherlichen Selbstdarstellung sowie der ethnischen Traditionsbildung ${ }^{264}$. Rechtspflegedelikte wurden in den Gesetzbüchern aus dem Frankenreich deshalb äußerst selten zur Sprache gebracht ${ }^{265}$. Besonders die Inzestgesetzgebung macht die Kluft zwischen der Übernahme von Gesetzen aus dem römischen Recht und der fehlenden Durchsetzung in der Praxis deutlich. In allen Kodifikationen aus dem Frankenreich der Merowinger gab es Verbote von Verwandtenehen, für eine Strafverfolgung in der Praxis wurde jedoch keine Sorge getragen. Dass die Grafen dies als Teil ihres Amtsauftrages verstanden hätten, wird durch keine Quelle belegt ${ }^{266}$. Wenn ein Inzestfall durch weltliche Behörden aufgedeckt wurde, so stand immer der König im Hintergrund. Beispielhaft lässt sich hier das Vorgehen von Chilperich gegen seinen Sohn Merovech, von Childebert II. gegen Magnovaldus und von Chlothar II. gegen Godinus nennen. Bezeichnend für die Untätigkeit auf unterer Ebene ist der Bericht der Vita Arnulfi ${ }^{267}$. Dem heiligen Arnulf gelang es trotz seiner bedeu-

262 Siehe 208 Anm. 426.

263 Lex Visigothorum 3, 5, 2 (MGH LL nat. Germ. 1, 161). Siehe 209 Anm. 433.

264 Nehlsen, Aktualität 1977; Wormald, Lex 1977.

265 Schmitt-Weigand, Rechtspflegedelikte 1962. Zur Rolle von Schriftlichkeit im fränkischen Recht vgl. auch Weitzel, Versuch 1995.

266 Claude, Untersuchungen 1964; Murray, Position 1986. Durch Grafen verhängte Konfiskationen wegen Inzest sind erst aus der Zeit Ludwigs des Frommen nachweisbar: siehe 373 Anm. 409.

267 Siehe 169-171. 
tenden Stellung nicht, einen des Inzests überführten Landbesitzer zum Nachgeben und zur Buße zu bewegen. Auch der Herzog Noddo, der zu den Verehrern des Heiligen zählte und an der Überführung von dessen Leichnam beteiligt war, ging nicht gegen diese Person vor. Das königliche Inzestverbot hing also in der Merowingerzeit gewissermaßen in der Luft und diente in erster Linie der herrscherlichen Selbstdarstellung als Gesetzgeber und christlicher König. Das Grafenamt war dagegen nicht durch ein christliches Ethos geprägt und erstreckte sich daher nicht auf das Aufspüren von Inzestehen.

Wie die Decretio Childeberts II. aus dem Jahre 596 zeigt, wurde die fehlende Durchsetzung in der Praxis als Problem empfunden. Die Todesstrafe als unmittelbare Folge setzte Childebert nur für die Ehe mit der Stiefmutter fest. Hinsichtlich der übrigen Delikte befahl er, den Inzest „durch die Verkündigung der Bischöfe zu züchtigen “268. Erst wenn die Ermahnung des Bischofs missachtet und die Exkommunikation ausgesprochen wurde, hat eine Bestrafung durch die weltliche Gerichtsbarkeit zu erfolgen. Der Schuldige sollte vom Hof des Königs verwiesen und zugunsten seiner legitimen Verwandten enteignet werden. Es ist bezeichnend, dass in dieser deutlich an der Praxis orientierten Regelung der König und nicht der Graf tätig wurde. Im Frankenreich trat somit die $\mathrm{Zu}$ sammenarbeit von König und Bischof in den Vordergrund. Die praxisnahe Bestimmung der Decretio blieb im Merowingerreich jedoch eine Ausnahme. Drei Jahrzehnte später trafen die Bischöfe auf dem Konzil von Clichy nochmals detaillierte Bestimmungen zum Ineinandergreifen von geistlicher und weltlicher Strafverfolgung bei Inzest ${ }^{269}$. Priester und Bischöfe sollten Inzestfälle an die Richter bzw. an den König melden, damit die beschuldigten Personen vom Hofdienst und von der Teilnahme an Gerichtsverfahren ausgeschlossen sowie ihrer Güter beraubt werden konnten. Diese am römischen Recht orientierte Strafverfolgung hat in der Praxis kaum Folgen gezeitigt.

Trotz dieser Bemühungen war dem Modell der Zusammenarbeit von weltlicher und geistlicher Gewalt im Frankenreich kein Erfolg beschieden gewesen. Es beruhte auf einer starken monarchischen Gewalt sowie auf einer funktionierenden kirchlichen Hierarchie. Beides ist nach der Herrschaft Dagoberts I. zugrunde gegangen ${ }^{270}$. Zwischen dem heiligen Arnulf und der Mission des Bonifatius ist das Thema des Inzestverbots aus den Quellen weitgehend verschwunden. Die Rechtsquellen des frühen 8. Jahrhunderts stehen in keiner Verbindung zur Decretio Childeberti, sondern setzten die römisch-rechtliche Tradition einer staatlichen Bestrafung des Inzests fort. Sowohl in den beiden süddeutschen Volksrechten der Bayern und Alemannen als auch im ersten

268 De praeteritis vero coniunctionibus, quae incestae esse videntur, per praedicationem episcoporum iussimus emendare. Decretio Childeberti c. 2 (MGH Capit. 1, 15).

269 Konzil von Clichy (626/627) c. 10 (MGH Conc. 1, 198).

270 KaISER, Erbe 2003, 97-100. 
Kapitular Pippins wurde inzestuösen Eheleuten direkt mit Konfiskation gedroht $^{271}$. Der Gesetzgeber setzte ohne Bezug zur Realität voraus, dass der König und seine Amtsträger für die Verfolgung des Inzests Sorge tragen könnten. Man wird daraus schließen, dass dem Gesetzgeber die symbolische Wirkung dieser Inzestverbote wichtiger war als eine praktische Realisierung.

Im Gegensatz dazu hat sich Karl der Große mit dieser Frage intensiv befasst. Während seiner 46 Jahre dauernden Herrschaft hat er mehrfach Regelungen zur Strafverfolgung bei Verstößen gegen das Inzestverbot erlassen. Es kann zwar nicht behauptet werden, dass dies eines seiner vordringlichen Anliegen gewesen sei, wie es für die Festlegung der Inzestgrenze bei Pippin der Fall gewesen war. Doch belegen 25 Regelungen in 22 Kapitularien die Sorge Karls um eine effektive und nachdrückliche Strafverfolgung.

Die früheste Regelung zum Inzestverbot findet sich im sog. ersten Kapitular Karls. Die Echtheit dieses Dokuments gilt nach der neuesten Forschung als wahrscheinlich, wenn nicht sogar als gesichert ${ }^{272}$. Vermutlich ließ es Karl bald nach dem Tod seines Vaters verkünden, als er noch gemeinsam mit seinem Bruder Karlmann das Frankenreich regierte ${ }^{273}$. Aufgrund der Reichsteilung von 768 herrschte Karl über Austrasien, Teile Neustriens sowie über die ostrheinischen Gebiete ${ }^{274}$. Er folgte somit annähernd in das Teilreich seines Onkels Karlmann nach, bevor dieser 747 der weltlichen Herrschaft entsagt hatte und in ein Kloster eingetreten war. Es überrascht daher nicht, im ersten Kapitular Bestimmungen des von Karlmann als Gesetz veröffentlichten Concilium germanicum zu finden. Karl der Große wollte an das Programm des Bonifatius anknüpfen, dessen Schüler wichtige Positionen in der Kirche seines Teilreichs einnahmen. Bereits in der zweiten Urkunde nach seiner Erhebung zum König hatte er dem Musterschüler des Bonifatius, Gregor von Utrecht, die Einnahme des Zehnten bestätigt, um die Christianisierung der Friesen finanziell zu un-

271 Lex Alamannorum 39 (MHG LL nat. Germ. 5/1, 99); Lex Baiuvariorum VII 2 (MGH LL nat. Germ. 5/2, 348); Pippini regis capitulare c. 1 (MGH Capit. 1, 31). Zur umstrittenen Datierung der süddeutschen Leges vgl. zuletzt (jeweils mit älterer Literatur) Hartmann, Fragen 2004; Landau, Lex 2004. Wie oben 193 bemerkt, vertrat Bruno Krusch die These, das gleich lautende Inzestverbot der beiden Leges gehe auf ein Gesetz des Hausmeiers Karlmann zurück und habe sich als Vorlage des westgotischen Liber Gaii bedient. Andere Historiker sehen in der Bestimmung des bayerischen Volksrechts eine nach der Synode von Aschheim (756) hinzugefügte Ergänzung: Rотн, Entstehung 1848, 71; Johannes Merkel in MGH LL 3, 229; Beyerle, Lex 1926, LXXX. Diese Frage ist beim derzeitigen Stand der Forschung nicht zu entscheiden.

272 Der Fälschungsverdacht wird überzeugend zurückgewiesen von Sснмiтz, Waffe 1988, 82-94. Für die Echtheit auch Mordek, Kapitularien 2000, 13, und Glatthaar, Bonifatius 2004, 419-424.

273 So die Datierung bei BM² 139 und bei Schmitz, Waffe 1988, 82; Hägermann, Karl 2000, $96 \mathrm{f}$.

274 Classen, Karl 1972, 124-130; Hägermann, Karl 2000, 79. 
terstützen ${ }^{275}$. Der Anschluss an die Bonifatius-Schüler war also, abgesehen von der persönlichen Verehrung Karls für den Martyrer ${ }^{276}$, ein Gebot der Stunde in der Zeit des „Bruderkampfs“.

Ein Großteil der Beschlüsse des ersten Kapitulars gibt Bestimmungen des Concilium germanicum wieder und hatte demnach vor allem die Disziplin des Klerus sowie die Ausrottung heidnischer Überreste im Visier. Karl bediente sich allerdings einer unbekannten Vorlage, die auch andere Quellen als das Concilium germanicum enthielt ${ }^{277}$. So ist das wichtige Kapitel 7 eine Übernahme aus den verlorenen Kanones des Konzils von 747, das noch unter Karlmann stattgefunden hatte und durch einen Brief des Bonifatius bezeugt ist ${ }^{278}$. Dieses Kapitel 7, das uns noch beschäftigen wird, enthält die Anweisung an die Bischöfe, jährlich die Diözese zu bereisen, das Volk zu konfirmieren, zu belehren und zu prüfen sowie heidnische Gebräuche zu verbieten. Bei der Inzestbestimmung könnte es sich ebenfalls um einen Kanon aus bonifatianischer Tradition handeln. Sie lautet: (wir setzen fest,) „dass die Bischöfe große Sorge um Inzestuöse und Verbrecher haben, damit sie nicht durch ihren Frevel zugrunde gehen und damit ihnen ihre Seelen nicht vom gestrengen Richter Christus entrissen werden “279. Anders als in den Gesetzen Pippins erging hier die Anweisung nicht an die betroffenen Laien, sondern an die zur Strafverfolgung ermutigten Kleriker. Wie in der bonifatianischen „Ansprache über unerlaubte Ehen" wird die Verantwortung des Bischofs für das Seelenheil der Christen in den Mittelpunkt gerückt. Das Verbot nimmt also den Umweg über die Ermahnung des Episkopats.

Die bonifatianische Tradition prägt auch das zweite Kapitular Karls des Großen, erlassen auf einer Reichsversammlung in der Pfalz Herstal $(779)^{280}$. Das erste Kapitel über die Wiederherstellung der Metropolitanverfassung ist als Fortsetzung der von Bonifatius betriebenen Kirchenreform zu verstehen. Bei zwei anderen Kapiteln über den Kirchenzins und über den Verkauf christlicher Sklaven wird zu Recht als Vorlage das Konzil von Les Estinnes (743) genannt ${ }^{281}$. Die Übereinstimmungen gehen so weit, dass eine wörtliche Entlehnung aus dem Reformkonzil des Bonifatius für möglich gehalten wird ${ }^{282}$. Auch die Inzestbestimmung des Kapitulars von Herstal steht in dieser Tradition. In Les

$275 \mathrm{BM}^{2} 132(1.3 .769)$.

276 KeHL, Kult 1993, 77-79.

277 Glatthane, Bonifatius 2004, 420-423.

278 So erstmals Seckel, Studien VIII/1 1914, 356; Schmitz, Waffe 1988, 89.

279 Ut de incestis et criminosis magnam curam habeant sacerdotes, ne in suis pereant sceleribus, et animae eorum a districto iudice Christo eis requirantur. Karoli M. Capitulare primum c. 10 (MGH Capit. 1, 45).

280 Hartmann, Synoden 1989, 99-101; Mordek, Kapitular 2005, 39-42.

281 Hartmann, Synoden 1989, 100.

282 Glatthane, Bonifatius 2004, 357. 
Estinnes wurde verfügt, dass „Inzestehen durch das Urteil der Bischöfe gezüchtigt werden sollen “283. Kapitel 5 des Kapitulars von Herstal besagt, „dass die Bischöfe die Befugnis haben sollen, inzestuöse Personen zu züchtigen "284. Auch hier ist an eine wörtliche Abhängigkeit zu denken.

Bereits die ersten beiden Kapitularien weisen auf eine eigenständige Konzeption Karls des Großen hin. Statt sich an den Beschlüssen seines Vaters zu orientieren, folgte er teilweise wörtlich den von Bonifatius inspirierten und von seinem Onkel Karlmann publizierten Regelungen. Ein unmittelbares Einschreiten weltlicher Organe war nicht mehr vorgesehen, die Strafverfolgung bei Inzest sollte in der Hand der Bischöfe liegen. In den Zusätzen zum Kapitular von Herstal, die dem Text im 9. Jahrhundert in Italien beigefügt wurden ${ }^{285}$, wird dieser Sachverhalt klar ausgesprochen. „Und wenn jemand von diesen Inzestuösen nach dem Urteil des Bischofs noch einmal dieselbe Inzestehe aufnimmt, soll das Eigengut, falls er eines hat, dem königlichen Fiskus zukommen $^{\text {"286 }}$. Konfiskation erfolgte also erst, wenn der Eingriff durch den Bischof keine Wirkung erzielt hatte und die Inzestehe erneuert worden war.

Die Zuständigkeit des Bischofs für Verwandtenehen bleibt die durchgehende Linie von Karls Inzestgesetzgebung. Nur zwei Kapitularien machen hier eine Ausnahme ${ }^{287}$. Erstens ist die sog. Capitulatio de partibus Saxoniae zu nennen. Dieses Gesetz für die unterworfenen Sachsen, erlassen vermutlich in den Jahren 782 oder 785, sollte die Christianisierung durch die Androhung harter weltlicher Strafen abstützen ${ }^{288}$. Offenes oder verdecktes Heidentum wurde mit der Todesstrafe geahndet. Unerlaubte Ehen hatten die Strafe des Königsbanns, d.h. die Zahlung von 60 Schillingen, zur Folge ${ }^{289}$. Diese direkte weltliche Strafe ist durch den Charakter der Capitulatio als ein Ausnahmegesetz zur Christianisierung der Sachsen zu erklären. Zweitens verfügte Karl in den nur

283 ... adulteria et incesta matrimonia, quae non sint legitima, probibeantur et emendentur episcoporum iudicio. Konzil von Les Estinnes (743) c. 3 (MGH Conc. 2/1, 7).

284 Ut episcopi de incestuosis hominibus emendandi licentiam habeant ... Capitulare Haristallense c. 5 (MGH Capit. 1, 48).

285 Mordek, Bibliotheca 1995, 677; ders., Anfänge 2005, 7.

286 Et si de ipsis incestuosis aliquis post iudicium episcopi in ipso incestu se iterum miserit, si alodem habuerit, ipso fisco regis recipiat. Capitulare Haristallense c. 5 (MGH Capit. 1, 48).

287 Unklar muss bleiben, ob der in MGH DD Kar. 1, 274 f. Nr. 205 genannte Godebert die Konfiskation seiner Güter durch Karl wegen seiner Inzestehe oder wegen der anderen, nicht genannten Verbrechen hinnehmen musste. Siehe 373 Anm. 409.

288 Theuerkauf, Lex 1968, 38-54; Schubert, Capitulatio 1993; Springer, Sachsen 2004, 221-230. Spekulativ und nicht hinreichend begründet sind die Ausführungen von Hen, Jihad 2006.

289 Si quis prohibitum vel inlicitum coniugium sibi sortitus fuerit, si nobilis solidos sexaginta, si ingenuus triginta, si litus quindecim. Capitulatio de partibus Saxoniae c. 20 (MGH Capit. 1, 69). 
in der Sammlung von Sens überlieferten Capitula die Enteignung bei Unzucht unter nahen Verwandten. „Wenn jemand mit seiner Mutter, Schwester, Tante oder Nichte Geschlechtsverkehr hatte, soll er seine Erbgüter verlieren "290. Eindeutig wurde hier nicht die Ehe, sondern der außereheliche Geschlechtsverkehr unter besonders nahen Verwandten bestraft. Darin wird man den Grund für die unmittelbare weltliche Bestrafung sehen müssen.

Die Bedeutung von Karls Inzestgesetzgebung erschöpft sich jedoch nicht in der Verlagerung in die Zuständigkeit der Bischöfe. Karl nahm darüber hinaus zwei Veränderungen vor, um die Strafverfolgung durch die Bischöfe zum Erfolg zu führen. Zum einen erhob er die voreheliche Befragung durch den Klerus zum Gesetz, zum anderen erteilte er den Bischöfen inquisitorische Vollmachten bei der Aufspürung von Inzestfällen. Beide Veränderungen sind erstmals in italienischen Quellen nachweisbar und wurden dann von Karl mit reichsweiter Geltung versehen.

Die erste Veränderung geht auf das Wirken des Patriarchen Paulinus von Aquileia zurück. Paulinus zählte zu jenen Personen, die Karl wegen ihrer überragenden Gelehrsamkeit an seinen Hof holte ${ }^{291}$. Dort wirkte er als Lehrer an der Hofschule und schloss Freundschaft mit Alkuin, dem wichtigsten Berater des Königs in jener Zeit. Im Jahr 787 wurde er von Karl zum Patriarchen von Aquileia ernannt und kehrte in seine ursprüngliche Heimat zurück. Auf einen Befehl Karls geht die Einberufung einer Synode durch Paulinus zurück ${ }^{292}$. Sie fand im Jahr 796/797 in Cividale statt und sollte der Durchsetzung der Beschlüsse des großen Frankfurter Konzils von 794 dienen. Paulinus war im Kampf gegen die in Frankfurt verdammte Häresie des Adoptianismus aktiv engagiert und wollte auf Provinzebene die dogmatischen Festlegungen bekräftigen.

In Ehefragen sind die Kanones des Konzils von Cividale von besonderer Härte und Rigorosität gekennzeichnet. Dies zeigt sich in der Scheidungsfrage ebenso wie in der Formulierung des Inzestverbots. Als Strafe für dieses „überaus schwere und raue" Verbrechen sieht das Kirchenrecht nach Paulinus den dauerhaften Ausschluss von der Kommunion vor.

„Um die Gefahr einer solchen Schande zu verhindern, ... haben wir beschlossen, dass es niemandem erlaubt sein soll, heimliche Ehen zu schließen, damit nicht etwa durch die irrtümliche Trägheit oder, was schlimmer ist, durch Anstachelung teuflischer Liebe unerlaubte Ehen gefeiert werden ${ }^{\text {“293. }}$.

290 Et si quis mechatus fuerit matrem, sororem, amitam aut neptam, similiter hereditatem perdat. Capitula Karoli Magni c. 4 (MGH Capit. 1, 143). Zur Überlieferung vgl. Mordek, Bibliotheca 1995, 781.

291 Everett, Paulinus 2003.

292 Hartmann, Synoden 1989, 117-119.

293 ... idcirco tanti praecaventes flagitii periculum, ut melius cautiusque prospeximus, dignum duximus diffinire, ita dumtaxat, ut nemini liceat furtim raptimque nuptias contrahere, ne 
Paulinus erneuerte also in etwas weitschweifiger Formulierung die Forderung nach Öffentlichkeit der Eheschließung. Dies tat er in Anlehnung an den Beschluss des Konzils von Ver (755), eine auch sonst von Paulinus herangezogene Quelle $^{294}$. Der Patriarch von Aquileia blieb bei dieser Forderung jedoch nicht stehen, sondern entwarf einen idealen Ablauf der Eheschließung. Nach der Verlobung sollten die Nachbarn und vornehmen Leute des Ortes sorgfältig über die Verwandtschaftsverhältnisse der Brautleute befragt werden. Diese Befragung sollte nicht ohne Wissen des Ortspriesters vonstatten gehen ${ }^{295}$. Wenn dann die Ehe für unbedenklich erklärt und später trotzdem eine Verwandtschaft durch Zeugen aufgedeckt worden sei, müssten die Eheleute getrennt und einer Buße unterworfen werden. Eine neue Ehe kann ihnen nach Paulinus nicht verwehrt werden. Wenn allerdings das obige Verfahren nicht angewandt und später eine Verwandtschaft festgestellt worden sei, müssten die des Inzests überführten Eheleute eine Buße auf sich nehmen und zu ständiger Ehelosigkeit verpflichtet werden. Die Kinder aus einer solchen Ehe hatten als illegitim zu gelten und konnten nicht das Erbe antreten.

Diese umfassende Regelung ist in ihrer Kasuistik höchst aufschlussreich. Die Unterstellung, die Nachbarn wüssten über die "Linie der Generationenfolge“ Bescheid, zeigt, dass man nicht mit Inzestfällen unter engen Angehörigen, sondern mit Ehen unter entfernt verwandten Personen rechnete. Das Inzestverbot hatte also bereits in der Praxis eine deutliche Wirksamkeit entfaltet. Außerdem verweist das Verbot von heimlichen Eheschließungen auf das oben erwähnte Grundproblem der Strafverfolgung des Inzests. Weil die Eheschließung keine rechtliche Angelegenheit war, konnte sie ohne Wissen der Amtsträger und der Priester vollzogen werden. Mit dem Verfahren der Überwachung durch Priester und Laien packte Paulinus das Problem an der Wurzel an.

Karl der Große übernahm das von Paulinus entworfene Verfahren in seinem ersten nach der Kaiserkrönung verkündeten Kapitular. François-Louis Ganshof hat es als „programmatisches Kapitular" der Kaiserzeit bezeichnet, da Karl sich darin zu den mit der Kaiserwürde verbundenen neuen Verpflichtungen äußer$\mathrm{te}^{296}$. Anfang des Jahres 802 nahm Karl für über ein Jahr Residenz in der Pfalz Aachen und widmete sich der inneren Reform des Frankenreichs. Wie die Lorscher Annalen berichten, schickte er Königsboten in das gesamte Reich aus,

forte per erroris ignaviam vel certe, quod peius est, diabolico instigante amore inlicita conubia celebrentur ... Konzil von Cividale (796/797) c. 8 (MGH Conc. 2/1, 191 f.).

294 Konzil von Cividale (796/797) c. 12 (MGH Conc. 2/1, 193 f.) beruht auf Konzil von Ver (755) c. 5, 6 und 10 (MGH Capit. 1, 34 f.). Vgl. Hartmann, Synoden 1989, 118 f.

295 ... requisiti quin etiam diligenti cura vicini vel maiores natu loci illius, qui possint scire lineam generationum utrorumque, sponsi scilicet et sponsae, in eo etiam, ut sine notitia sacerdotis plebis illius nullatenus fiat, quatenus nulla deinceps separationis tribulatio intercedat. Konzil von Cividale (796/797) c. 8 (MGH Conc. 2/1, 192).

296 Ganshof, Programme 1963; Buck, Capitularia 2002. 
um ihn über Missstände und Ungerechtigkeiten zu informieren ${ }^{297}$. Er gab ihnen auch die Anweisung mit auf den Weg, dass jeder Einwohner des Reichs, ob Kleriker oder Laie, den Treueid gegenüber dem Herrscher erneuern und ihn auf den Namen des Kaisers ablegen sollte ${ }^{298}$. Der Inhalt des Treueids wurde im Kapitular von 802 detailliert auseinandergesetzt. Er umfasste nicht nur die Befolgung der herrscherlichen Befehle und die Bewahrung kaiserlicher Rechte,

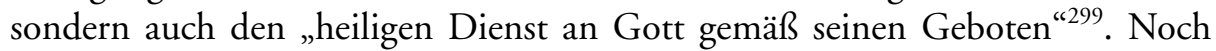
eindringlicher als bisher sorgte sich Karl um die „Heilsführung des christlichen Volkes ${ }^{\text {'300 }}$, weltliches Recht und göttliches Gebot sollten in Übereinstimmung gebracht werden.

Die Inzestbestimmungen des „programmatischen Kapitulars“ sind mit besonderem Nachdruck abgefasst. Ganshof hält die Formulierungen im Ton für so individuell, dass sie ihm wie in letzter Minute auf Befehl des Kaisers selbst eingeschaltete Zusätze erscheinen ${ }^{301}$. Besonders frappant ist die im Rahmen des Kapitulars ungewöhnliche subjektive Formulierung zu Beginn: „Das Verbrechen des Inzests verbieten wir ganz und gar ${ }^{\text {“302 }}$. Der weitere Inhalt ist durch besondere Schärfe charakterisiert.

„Wenn jemand durch diese schändliche Unzucht befleckt ist, soll er keinesfalls ohne schwere Bestrafung entlassen werden, sondern er soll auf solche Weise bestraft werden, dass die Übrigen Angst haben, solches zu begehen, damit dieser Schmutz gänzlich vom christlichen Volk genommen werde; und der Schuldige soll durch die Buße vollständig büßen, so wie es ihm von seinem Bischof verordnet wird ${ }^{“ 303}$.

Erst wenn das Urteil des Bischofs missachtet wird, schaltet sich die weltliche Gewalt ein:

„Dann soll er in unsere Gegenwart gebracht werden, eingedenk des Beispiels, das vom Inzest gemacht wurde, den Fricco gegen eine Nonne begangen hat ${ }^{\text {«\$04 }}$.

297 Annales Laureshamenses a. 802 (MGH SS 1, 39). Vgl. auch Hartmann, Karl 1997.

298 Capitulare missorum generale c. 2 (MGH Capit. 1, 92). Vgl. BeCHER, Eid 1993, 165175.

299 Capitulare missorum generale c. 3 (MGH Capit. 1, 92).

300 Anton, Fürstenspiegel 1968, 201.

301 Ganshof, Programme 1963, 65. Zur Problematik der Zuschreibung von Kapitularien vgl. Nelson, Voice 2001.

302 Incestuosum scelus omnino prohibemus. Capitulare missorum generale c. 33 (MGH Capit. 1, 97).

303 Si quis nefanda autem fornicatione contaminatus fuerit, nullatenus sine districtione gravi relaxetur, sed taliter ex hoc corripiantur, ut caeteri metum habeant talia perpetrandi, ut auferetur penitus et inmunditia populo christiano, et ut reus ex hoc per poenitentia ammittat pleniter, sicut ei ab episcopo suo disponatur. Capitulare missorum generale c. 33 (MGH Capit. 1, 97).

304 Si autem iudicium episcopi ad suam emendationem consentire noluerit, tunc ad nostra presentia perducantur, memores exemplo, quod de incestis factum est quod Fricco perpetravit in sanctimoniali Dei. Capitulare missorum generale c. 33 (MGH Capit. 1, 97). 
Dieser von Karl erwähnte Fall ist sonst unbekannt, zeigt aber, dass Karl unter Inzest wie in der römischen Zeit nicht nur die Ehe unter Verwandten, sondern auch die Heirat mit einer Nonne verstanden hat. In einem weiteren Kapitel wird präzisiert, wie sich Karl die Vorladung vor das königliche Pfalzgericht vorgestellt hat.

„Die Königsboten und Grafen sollen sie in solcher Bewachung wegsperren, dass sie unversehrt bleiben, aber nicht das restliche Volk anstecken, bis sie in unsere Gegenwart gebracht werden. Und von ihrem Eigengut sollen sie unterdessen nichts behalten dürfen ${ }^{\text {“305 }}$.

Karl kombinierte also die bislang übliche Einschaltung des Königsgerichts bei Ungehorsam gegen niedere Amtsträger mit einem Zwangsverfahren durch Haft und Konfiskation. War die provisorische Einziehung des Vermögens regelmäBiger Bestandteil eines Verfahrens wegen Ungehorsam ${ }^{306}$, stellte die Inhaftierung eine besondere Verschärfung der Zwangsvollstreckung dar. Sie wurde von Karl sonst nur verhängt, wenn die betreffende Person nicht dazu in der Lage war, Bürgen zu stellen und so ihr Erscheinen vor dem Pfalzgericht zu garantieren ${ }^{307}$. Begründet wird diese Bestimmung mit dem Argument, die Inzestuösen sollten (ebenso wie Verwandtenmörder) keine Gelegenheit haben, das übrige Volk zu „beschmutzen “308.

Bezeichnender noch als diese strenge Ausgestaltung des Ungehorsamsverfahrens ist die Bestimmung über die Verhinderung von Inzestehen. Im Anschluss an den Konzilskanon des Paulinus von Aquileia schrieb Karl vor:

$305 \ldots$ quod ad salutem animae suae iustumque iudicium solvendum missi nostri et comitis in tali custodia coartent, ut salvi sint nec caeterum populum quoinquinent usque dum in nostra presentia perducatur; et de res propria sua interim nibil habeant. Capitulare missorum generale c. 37 (MGH Capit. 1, 98). Die Bestimmung steht im Kapitel zum Verwandtenmord, wird aber im nächsten Kapitel auf Verstöße gegen das Inzestverbot übertragen: Similiter et his fiat qui inlicitis et incestis coniunctionibus reprehensi sunt correcti et nec se emendare volunt neque episcopis neque presbiteris suis obtemperare, et bannum nostrum praesumunt contempnere. Capitulare missorum generale c. 37 (MGH Capit. 1, 98).

306 BRUNNER - SCHWERIN, Rechtsgeschichte 2 1928, 604-611.

307 Deutlich ausgesprochen in Capitulare missorum c. 4 (MGH Capit. 1, 67): Et si fuerint aliquis qui per ingenio fugitando de comitatu ad aliud comitatu se propter ipsum sacramentum distulerit aut per superbia iurare noluerint, semoti per brebem renuntiare sciant, et tales aut per fideiussores mittant aut si ipsi fideiussores non habuerint, qui in praesentia domni regis illos abducant, sub custodia servent. Capitulare Carisiacense c. 1 (MGH Capit. 2, 343). Die Anwendung einer solchen ,Beugehaft' hat Vorbilder in der antiken Gesetzgebung: Krause, Gefängnisse 1996, 80-83.

308 Dies ist eine der Hauptbelegstellen für Mayke de Jong, das Inzestverbot mit der Angst vor kultischer Verunreinigung in Beziehung zu setzen und diese Angst den Laien als Beweggrund zu unterstellen: Jong, Kinship 1989; Dies., Riddle 1998. Dagegen spricht, dass Karl der Große dieselbe (antik-römische) Begrifflichkeit auch für Verwandtenmord verwendet, für einen Tatbestand, der offensichtlich nichts mit der Frage des Kults und seiner Verunreinigung zu tun hat. Siehe $139 \mathrm{f}$. 
„Damit man nicht wagt, sich und die Übrigen durch Inzestehen zu beschmutzen, soll man Eheschließungen nicht vornehmen, bevor die Bischöfe und Priester gemeinsam mit den Vornehmen des Volkes die Blutsverwandtschaft der Eheleute sorgsam geprüft haben; und dann sollen sie mit dem priesterlichen Segen verbunden werden "309. Die voreheliche Befragung durch den Klerus sollte also reichsweite Geltung besitzen. Nur unter dieser Voraussetzung durfte der priesterliche Segen erteilt werden. Die Verchristlichung des Eheritus sollte also die Schließung von Ehen innerhalb der Verwandtschaft verhindern.

Trotz der großen Bedeutung des „programmatischen Kapitulars“ war seine Wirkung gering. Nur eine Handschrift des Textes ist überliefert ${ }^{310}$. Die obligatorische voreheliche Befragung durch den Klerus setzte sich folglich kaum durch. Da im Frühmittelalter gesetzgeberische Neuerungen nur durch Wiederholung in der Praxis Geltung entfalten konnten, ist die dürftige Wirkung des Kapitulars aussagekräftig. Lediglich in einem Bischofskapitular aus Bayern aus dem ersten Jahrzehnt des 9. Jahrhunderts und in der Kapitulariensammlung des Benedictus Levita hat diese Regelung Eingang gefunden ${ }^{311}$. Weder die Forderung nach öffentlicher Eheschließung noch die nach einer vorehelichen Befragung sind in der Karolingerzeit in die Praxis umgesetzt worden. Die Eheschließung blieb weitgehend eine weltliche Angelegenheit. Erst in der Zeit der gregorianischen Reform im 11. Jahrhundert wurden diese Anliegen erneut aufgegriffen $^{312}$.

Der zweiten Veränderung der Strafverfolgung bei Inzest, der wir uns jetzt zuwenden, sollte ein größerer Erfolg beschieden sein. Der Ursprung dieser Neuerung ging ebenfalls von Italien aus. Im Namen seines noch unmündigen Sohnes Pippin erließ Karl zwischen den Jahren 782 und 787 ein Kapitular für Italien. In c. 8 des Kapitulars wird den Richtern die Möglichkeit eines Rügeverfahrens eröffnet: „Jeder Richter soll in den Städten oder außerhalb auf den Höfen oder Dörfern glaubwürdige Menschen - soviel er ausgewählt hat - auf

309 Ne incestis nuptiis et se ipsos et caeteros maculare audeant, coniunctiones facere non praesumat, antequam episcopi, presbyteri cum senioribus populi consanguinitatem coniungentium diligenter exquirant; et tunc cum benedictionem iungantur. Capitulare missorum generale c. 35 (MGH Capit. 1, 98).

310 Mordek, Bibliotheca 1995, 474.

311 Capitula Bavarica c. 12 (MGH Capit. episc. 3, 197). Bis zur Neuedition von Pokorny waren diese Kapitel als Concilium Baiuwaricum (a. 740-750) bekannt. Nach Pokorny ist dieses Bischofskapitel unter Arn von Salzburg zwischen 800 und 813 entstanden. Auch c. 12 und c. 13 hängen mit c. 35 des Capitulare missorum generale zusammen. Arn war mit Paulinus von Aquileia gut bekannt: Sie wirkten gemeinsam als Königsboten und hielten ein Konzil am Donauufer ab: Everett, Paulinus 2003, 129-132. Eine weitere Rezeption bei Benedictus Levita 3, 179 (MGH LL 2/2, 113) mit Einfluss auf Isaak von Langres, Capitula V 6 (MGH Capit. episc. 2, 215-217) und (?) Capitula Ottoboniana c. 13 (MGH Capit. episc. 3, 126).

312 Daudet, Établissement 1941; Corbet, Burchard 2001, 295 f. 
Reliquien vereidigen, damit niemand, dem Mord, Diebstahl, Ehebruch und Inzestehen bekannt geworden sind, diese (Untaten) verheimlicht ${ }^{\star 313}$. Die Amtsträger waren damit nicht auf Anklagen angewiesen, um ein Verfahren zu eröffnen. Die Denunziation eines angesehenen und vereidigten Rügezeugen war einer Anklage ebenbürtig und setzte die Tätigkeit des Gerichtes in Gang. Bedeutsam war diese Möglichkeit der Verfahrenseröffnung aus dem Grund, weil die Anklage mit der Haftung durch das Vermögen des Klägers verbunden war und deshalb ein hohes Risiko mit sich brachte. Das Rügeverfahren setzte diese Hürde außer Kraft.

Die Herkunft des Rügeverfahrens wird in der Forschung unterschiedlich bewertet. Bereits Heinrich Brunner urteilte, dass „die Anfänge der Einrichtung im Dunklen liegen “314. Da es zuerst in einem karolingischen Kapitular für Italien „als eine nach fränkischem Vorbilde von oben her eingeführte Neuerung“" begegnet, votierte Brunner für eine Ableitung aus fränkisch-germanischen Wurzeln ${ }^{315}$. Dem steht entgegen, dass man in der jüngeren Forschung eher geneigt ist, den inquisitorischen Beweis bei der Feststellung von Besitzverhältnissen des Fiskus als einen Überrest antiker Staatlichkeit anzusehen ${ }^{316}$. Nach François Bougard war die Anwendung des inquisitorischen Beweises im Langobardenreich des 7. Jahrhunderts „gängige Münze“317. Die Ähnlichkeit zwischen diesem inquisitorischen Beweis im Fiskalprozess und der inquisitorische Voruntersuchung im Strafprozess liegt auf der Hand ${ }^{318}$. Bereits in den Gesetzen König Liutprands wird den Richtern der Auftrag der Inquisition bei Diebstahl übertragen, doch bleibt unklar, in welchen Formen diese Inquisition stattfand ${ }^{319}$. Ein langobardischer Ursprung wird damit immerhin wahrscheinlich gemacht. Dafür spricht auch die langobardische Prägung des Kapitulars insgesamt. Unmittelbar nach der ersten Erwähnung des Rügeverfahrens wird Richtern auch die Fahndung nach entflohenen Sklaven übertragen. In dem darin zitierten Vorbildgesetz Liutprands steht ebenfalls das Wort inquisitio ${ }^{320}$.

313 Index unusquisque per civitatem faciat iurare ad Dei iudicia homines credentes iuxta quantos previderit, seu foris per curtes vel vicoras ibi mansuros, ut, cui ex ipsis cognitum fuerit id est homicidia, furta, adulteria et de inlicitas coniunctiones, ut nemo eas concelet. Pippini Italiae regis capitulare c. 8 (MGH Capit, 1, 192). Zur Bedeutung von ad Dei iudicia vgl. Brunner - Schwerin, Rechtsgeschichte 2 1928, 640 Anm. 14.

314 BRUNner - SCHWERIn, Rechtsgeschichte 2 1928, 639.

315 Brunner - SChwerin, Rechtsgeschichte 2 1928, 640.

316 Bougard, Justice 1995, 194-203; Esders, Inquisitio 1999, 99-103. Eine kirchliche Herkunft macht dagegen Müller, Amira 1999, 282-286, geltend, doch sind die von ihm zitierten Quellen allesamt später.

317 Bougard, Justice 1995, 197.

318 BrunNer, Inquisitionsbeweis 1865, 93 u. 220.

319 Leges Langobardorum, Liutprand 81 (MGH LL 4, 140).

320 De servis et ancillis fugacibus ut unusquisque iudex studium ponat ad perquirendum iuxta ut edictus continet. Pippini Italiae regis capitulare c. 9 (MGH Capit. 1, 193). Et ipse iudex 
Wird das Inzestverbot im eben besprochenen Kapitular nur in einer Reihe von anderen Kapitalverbrechen genannt, ist es wenige Jahre später Gegenstand einer ausdrücklichen Inquisitionsanweisung. In dem italienischen Kapitular von 790/800 heißt es:

„Gleichfalls befragt jeder die ihm anvertrauten Personen, wo er sie jeweils antrifft, wo unerlaubte Ehen geschlossen wurden; so dass derjenige, der die Frau des Cousins ersten oder zweiten Grades zur Frau genommen oder mit irgendeiner Verwandten sich verbunden hat, ohne jede Milderung von seiner Frau geschieden wird“"321.

Obwohl in diesem Kapitel nicht ausdrücklich gesagt wird, ob die Anweisung an die Richter oder an die Bischöfe adressiert ist, lässt die folgende Regelung des Kapitulars keinen Zweifel offen. Dort heißt es: Wer Inzestehen, Verstöße gegen das nebeneheliche Konkubinat und heidnische Gebräuche nicht bestraft, soll dem König sein Wergeld als Strafe entrichten ${ }^{322}$. Die Inquisitionsanweisung ergeht also an die weltlichen Amtsträger. Der Inhalt der Anweisung ist auch in diesem Kapitular durch ein Gesetz Liutprands beeinflusst. Das Verbot der Ehe mit der Witwe des Cousins ersten und zweiten Grades steht in dieser Form wörtlich in einem im Jahr 723/724 erlassenen Gesetz des langobardischen Königs ${ }^{323}$.

Karl der Große übertrug diese langobardische Rechtsnorm nicht tel quel in das fränkische Recht. Dies hätte seiner grundsätzlichen Linie widersprochen, die er bereits in seinen beiden ersten Gesetzen festgelegt hatte und die darin bestand, den Klerus mit der Strafverfolgung zu betrauen. Er übertrug die Institution des Rügeverfahrens, indem er den Bischöfen dieselbe Inquisitionsanweisung erteilte, die in den italienischen Kapitularien den Richtern und Grafen erteilt worden war. Karl ließ dies im Aachener Kapitular von 802/803 als Gesetz verkünden ${ }^{324}$. Dieses Kapitular steht vermutlich im Zusammenhang mit der großen Rechtsreform, die der Kaiser auf der Aachener Reichsversammlung im

potestatem habeat eum inquirendum, unde ipse est. Leges Langobardorum, Liutprand 44 (MGH LL 4, 126).

321 Similiter inquirat unusquisque homines sibi commissos, ubi forsitan invenitur, ubi facte sunt inlicitas coniunctiones: ita ut qui uxorem consobrino aut insobrino suo uxorem duxisset, aut etiam qualibet parentem suam sibimetipsos uxorem copulasset, sine omnem moderatione eos ab invicem separentur, et eos ad penitentiae remedium faciat destinari. Capitula cum Italiae episcopis deliberata c. 4 (MGH Capit. 1, 202).

322 Sic placuit domni regi, ut qui as nefandas criminas emendare de terminibus sibi commissis, ut diximus, emendare neglexerit, ut in sacro palatio widrigildum suum componat. Capitula cum Italiae episcopis deliberata c. 6 (MGH Capit. 1, 203).

323 Leges Langobardorum, Liutprand 33 (MGH LL 4, 123 f.). Siehe 238 Anm. 110. Nur die Erweiterung des Inzestverbots auf qualibet parentem suam geht bezeichnenderweise auf die karolingischen Herrscher zurück und entspricht dem kategorischen Verbot der Päpste.

324 Capitulare Aquisgranense c. 1 (MGH Capit. 1, 170). Zur Datierung vgl. Ganshof, Datierung 1954; Mordek, Kapitularien 2000, 42. 
Oktober 802 in Gang setzte. Nach dem Bericht der Lorscher Annalen ließ Karl alle Volksrechte des Frankenreichs verlesen, verbessern und niederschreiben und gab den Richtern die Anweisung, nach dem geschriebenen Recht zu urteilen ${ }^{325}$. Ergebnis dieser Rechtsreform sind die überarbeiteten Fassungen der merowingischen Volksrechte sowie die erstmalige Niederschrift des friesischen, thüringischen und chamavischen Rechts ${ }^{326}$.

Das erste Kapitel des in Aachen verabschiedeten Kapitulars enthält die Übertragung der Inquisitionsgewalt an die Bischöfe: „Dass die Bischöfe die ihnen anvertrauten Pfarreien visitieren und dort Nachforschungen anstellen in Sachen Inzest, Vatermord, Brudermord, Unzucht, Hospize und anderer Übel, die gegen Gott sind, welche in der heiligen Schrift den Christen zu meiden befohlen wird“'327. Die Nähe zur Beauftragung weltlicher Amtsträger in den italienischen Kapitularien ist an den ähnlichen Formulierungen zu erkennen. Die homines sibi commissos werden durch die parrochias sibi commissas ersetzt. Die Anpassung an die Verhältnisse nördlich der Alpen geht noch weiter. Die Auflistung der Tatbestände weicht nämlich in charakteristischer Weise ab. Nur jene Kapitalverbrechen werden genannt, die im Frankenreich nicht durch das Anklageprinzip vor das Gericht gebracht wurden. Weder bei Inzest noch bei Verwandtenmord oder Unzucht gab es in der Regel eine geschädigte Partei, die an einem Prozess interessiert sein konnte. Den Bischöfen wurde nur für solche Kapitalverbrechen die Inquisitionsvollmacht erteilt, nicht dagegen für Mord und Diebstahl wie im italienischen Kapitular. Diese Delikte blieben selbstverständlich in der Zuständigkeit der staatlichen Organe.

Die Inquisition der Bischöfe sollte nach den Vorstellungen Karls im Rahmen der Visitation ihrer Diözese erfolgen. Die Praxis der Visitation ist seit dem 4. Jahrhundert belegt, beschränkte sich aber stets auf die Begutachtung der kirchlichen Zustände ${ }^{328}$. Der Bischof sollte den Lebenswandel der Priester und den Zustand der Kirchenbauten untersuchen. Erst mit der Kirchenreform des Bonifatius wurde auch der Zustand der Laienseelsorge Thema der Visitation ${ }^{329}$. Bonifatius setzte sich, wie oben bereits erwähnt, für die Verbreitung der

325 Annales Laureshamenses a. 802 (MGH SS 1, 39).

326 Siems, Studien 1980; Hartmann, Karl 1997, 183 f.; Wormald, Making 1 1999, 4548; LaNDAU, Lex 2001, 30.

327 Ut episcopi circumeant parrochias sibi commissas et ibi inquirendi studium habeant de incestu, de patricidiis, fratricidiis, adulteriis, cenodoxiis et alia mala quae contraria sunt Deo, quae in sacris scripturis leguntur quae christiani devitare debent. Capitulare Aquisgranense c. 1 (MGH Capit. 1, 170). Nach SeEliger, Kapitularien 1893, 20 Anm. 1, wurde das Kapitular von Ludwig dem Frommen erneut erlassen. Zustimmend Mordek, Bibliotheca 1995, 14.

328 Georges Baccrabère, Art. „Visite canonique de l'évêque“, in: DDC 7 (1965) 15121594, hier 1512 f. Eine während der Visitation zu haltende Predigt an die Laien erwähnt das 2. Konzil von Braga (572) c. 1 (Vives 81).

329 ANGENENDT, Bonifatius 1977, 152-158. 
Firmsalbung durch den Bischof ein, die dieser dem Volk bei der Gelegenheit der Visitation spenden sollte. Zugleich sollte der Bischof auch prüfen, ob sich unter der Oberfläche des christlichen Glaubens noch Reste heidnischen Aberglaubens verborgen hielten. So hatte es das Konzil von 747 unter der Leitung des Bonifatius beschlossen, so wiederholte es Karl der Große in seinem ersten Kapitular von ca. $770^{330}$. Dreißig Jahre später erweiterte Karl die Pflichten der Bischöfe und gab ihnen den offiziellen Auftrag, bei der Visitation nach Verbrechen gegen die christliche Moral zu fahnden ${ }^{331}$. Wie sich die Bischöfe dieses Auftrags erledigten, wird nicht ausdrücklich festgelegt. Spätere Quellen lassen erkennen, dass sie die Fahndung nach öffentlichen Verbrechen an den untergeordneten Klerus delegierten und für diese Zwecke Bischofskapitulare abfassten $^{332}$. Erst um 900 nahm der Episkopat im Ostfrankrenreich die Aufgabe in die eigene Hand, indem das bischöfliche Sendgericht etabliert wurde. Im Sendgericht hat das Rügeverfahren, anders als das stets ephemer bleibende weltliche Pendant ${ }^{333}$, zu einer festen institutionellen Gestaltung gefunden.

Die Bilanz von Karls Inzestgesetzgebung ist ambivalent. Während die voreheliche Befragung keine spürbare Wirkung entfaltete, erwies sich die Delegation der Strafverfolgung an den Klerus und die Ausstattung der Bischöfe mit der Inquisitionsgewalt als langfristig erfolgreich. Karl war sich in seiner bekannt rastlosen Art der Schwierigkeiten bei der Durchsetzung des Inzestverbots durchaus bewusst. Im letzten Jahr seiner Regierungszeit stellte er nochmals seine gesamte bisherige Gesetzgebung auf den Prüfstand ${ }^{334}$. In einem der vielen um 813 erlassenen Texte stellt er resigniert und gleichzeitig voller Tatendrang fest:

„Von diesen Gesetzen sowie von allen anderen, die wir durch viele Jahre hindurch in unser Reich verschickten, wollen wir jetzt vollständig durch unsere Boten in Erfahrung bringen, was davon durchgeführt wird oder wer sich an die Vorschriften hält oder wer sie missachtet und vernachlässigt, damit wir wissen, was wir mit denen tun sollen, die über so viel Jahre die Vorschriften Gottes und unser Gebot missachtet haben ${ }^{\text {“3335. }}$

330 Statuimus, ut singulis annis unusquisque episcopus parrochiam suam sollicite circumeat, populum confirmare et plebes docere et investigare et prohibere paganas observationes ... S. Bonifatii et Lulli epistolae 78 (MGH Epp. sel. 1, 163 f.); Karoli M. capitulare primum c. 7 (MGH Capit. 1, 45).

331 Vgl. Hartmann, Bischof 1986, 109.

332 Siehe 302.

333 Es gab weder ständige Rügegerichte noch ständige Rügegeschworene in fränkischer Zeit: BrunNer -Schwerin, Rechtsgeschichte 2 1928, 643.

334 Mordek - Schmitz, Kapitularien 1987, 374-378; Hartmann, Synoden 1989, 128 140; Hägermann, Karl 2000, 608-613. Eine eigenwillige Deutung der Reform gibt Fried, Elite 1998, 73-93; siehe 379 Anm. 428.

335 De istis autem capitulariis atque de aliis omnibus, quae a multis annis misimus per regnum nostrum, volumus nunc pleniter per missos nostros scire, quid ex his omnibus factum sit vel quis haec observet, quae ibi praecepta sunt, vel quis illa condempnat et neglegat, ut sciamus, 
Verbunden mit dieser erneuten Prüfung der Gesetzgebung ließ Karl an fünf Orten in seinem Reich Synoden einberufen, um alle Bischöfe des Frankenreichs an der Reform zu beteiligen. In Aachen wurden dann die verschiedenen Reformvorschläge gebündelt und in dem letzten großen Kapitular Karls zusammengefasst. Veröffentlicht wurde es im September 813, als Karls Sohn Ludwig der Fromme zum Mitkaiser erhoben wurde ${ }^{336}$.

Das letzte Kapitular Karls des Großen ist nicht erhalten ${ }^{337}$. Dennoch lassen die überlieferten Aktenstücke erkennen, dass auch im Jahr 813 das Thema der Strafverfolgung bei Inzest nochmals auf die Tagesordnung gesetzt wurde. Vielleicht ist die singulär überlieferte Anweisung aus einer Laoner Handschrift Teil des Fragekatalogs, den Karl den Bischöfen vorgelegt hatte. Sie lautet: „Über Inzest und andere Dinge soll nachgeforscht werden, ob sie wegen der Nachlässigkeit der Bischöfe darin verharren, oder ob die Grafen ihnen (den Bischöfen) bei der Ausführung ihrer Amtspflicht keine Unterstützung zukommen lassen “338. Beide möglichen Gründe für Mängel in der Strafverfolgung wurden in den Konzilien des Jahres 813 angesprochen. In Tours stellte man resignativ die große Anzahl von Inzestehen fest. Da sich einige nicht den Mahnungen der Bischöfe beugten und sogar die Exkommunikation missachteten, erging der Ruf der Konzilsteilnehmer nach harter Bestrafung durch staatliche Organe. Nachdem diese ausgeblieben war, wendete sich das Konzil direkt an den Kaiser: „Deshalb soll euer Gnaden entscheiden, was von jetzt an bei solchen Leuten

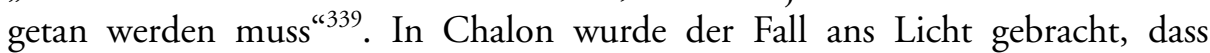
Grafen und Bischöfe in der Vertuschung von Inzestehen gemeinsame Sache machten und von den schuldigen Personen Schweigegelder in Empfang nahmen. „Das haben wir befohlen vollkommen auszurotten, ... und wir bestimmen, dass Inzestuöse nach kanonischem Urteil zur Buße verurteilt werden ${ }^{\text {“340 }}$.

quid de his agere debeamus, qui tam multis annis dei praecepta et decretum nostrum contempserunt. Capitulare generale Caroli Magni c. 40, hg. von Mordek - Schmitz, Kapitularien 1987, 423.

336 Chronicon Moissiacense a. 813 (MGH SS 1, 310).

337 Mordek - Schmitz, Kapitularien 1987, 373, erwägen eine Identifikation mit dem neu entdeckten Capitulare ecclesiasticum Caroli Magni. Sснмiтz, Reformkonzilien 2000, 3, meint, das Kapitular sei wegen des baldigen Todes des Kaisers nicht mehr zustande gekommen.

338 De incestis et ceteris talibus ut inquiratur, utrum per neglegentiam episcoporum sic remanserint, an comites neglegissent eis opem ferre ad suum ministerium peragendum. Capitulum de incestis, hg. von Mordek, Bibliotheca 1995, 981.

339 Incestuosi, parricidae, homicidae multi apud nos, heu pro dolor, repperiuntur. ... Quorum aliquos iam excommunicavimus. Sed illi hoc parvipendentes in eisdem perdurarunt criminibus. Quamobrem vestra decernat mansuetudo, quid de talibus deinceps agendum sit. Konzil von Tours (813) c. 41 (MGH Conc. 2/1, 292).

340 Dictum est nobis, quod in quibusdam locis episcopi et comites ab incestuosis et ab his, qui decimas non dant, wadios accipiant et a presbyteris pro quibusdam neglegentiis et inter se pecuniam dividant. Quod paenitus abolendum decrevimus, ne forte avaritiae locus detur, et 
In Mainz nahm man dagegen nur die Bischöfe ins Visier und verpflichtete sie zu größerem Eifer in der Nachforschung von Inzestehen ${ }^{341}$.

\subsection{Das Inzestverbot auf der Bühne der Politik}

Die Bedeutung des Inzestverbots in den Quellen des 8. Jahrhunderts hatte unterschiedliche Gründe. Bonifatius griff zu wiederholtem Male zur Feder, um sich bei seinen Zeitgenossen und bei seinem Vorgesetzten, dem Papst, Auskünfte erteilen zu lassen. Doch dieses Interesse hatte der Angelsachse nicht aus seiner Heimat mitgebracht, und es war auch nicht Folge der Mission bei den rechtsrheinischen Germanen. Die vielen Briefe zum Umfang des Inzestverbots verdankten sich vielmehr dem Zusammenstoß verschiedener Standpunkte zu dieser Frage. Bei den Angelsachsen ist die von Avitus und dem burgundischen Konzil von Epaon initiierte Ausdehnung des Inzestverbots nicht heimisch geworden. Auf den britischen Inseln ist man weder mit der kaiserlichen Inzestgesetzgebung der Spätantike noch mit der Obsession der merowingischen Kirche in Berührung gekommen. Man orientierte sich vielmehr ausschließlich an den im Buch Levitikus festgeschriebenen Verboten. In Ansätzen ist eine Diskussion zwischen der angelsächsischen und der irischen Kirche greifbar, die sich um die Gültigkeit der Cousinenehe drehte. Theodor von Canterbury akzeptierte dieses von Gregor I. im Libellus responsionum propagierte Verbot, sah jedoch eine milde Anwendung in der Praxis vor. Bonifatius selbst kannte den Libellus nicht und scheint die Cousinenehe für unbedenklich gehalten zu haben. Wenn die Alloquutio sacerdotum de coniugiis inlicitis ad plebem tatsächlich von ihm gehalten wurde, beschränkte er das Inzestverbot auf die biblischen Verbote. Erst im Frankenreich sah sich Bonifatius heftigen Anfeindungen ausgesetzt, weil er weder mit dem Eheverbot der geistlichen Verwandtschaft noch mit dem

constituimus, ut incestuosi iuxta canonicam sententiam paenitentia multentur. Konzil von Chalon (813) c. 18 (MGH Conc. 2/1, 277). Ein anschauliches Beispiel eines Bestechungsversuches enthält Altfrids Vita Liudgeri I 28 (33 f.): Venit quoque sacerdos idem ad ecclesiam suam in loco sitam, qui vocatur Billurbeki, et ecce mulier quaedam, quae inlicito conubio suo erat copulata marito, eius volens mitigare terrorem misit illi mel quasi pro benedictione. At ille tale munus suscipere dispiciendo rennuit. Quidam tamen iuvenes ex discipulis eius illud mel concupientes acceperunt et in ecclesia retro altare occulte posuerunt. Cumque vir Dei ad idem altare missam celebraturus accederet et os aperuisset ad preces, confestim vas testeum, in illud inoboedientiae mel habebatur, minutatim crepuit, et dispersum est mel, quod colligentes proiecerunt foras. Non cessavit autem miles Christi, quominus illud inlicitum destrueret coniugium, sed et virum ipsum, qui illud perpetrare ausus est, exterminavit a patria.

341 Ut episcopi incestuosos puriter investigare studeant, omnino praecipimus, ut, si penitere noluerint, de eclesia expellantur, donec ad paenitentiam revertantur. Konzil von Mainz (813) c. 53 (MGH Conc. 2/1, 272). 
Eheverbot innerhalb der gesamten römisch-rechtlichen Verwandtschaft vertraut war. Eine andere Art der Verwirrung wurde durch die unterschiedliche Zählweise gestiftet. So wollte Bonifatius die Echtheit des Libellus responsionum nicht wahrhaben, weil er die Zählung Gregors des Großen missverstanden hatte. Bei den Angelsachsen war allein die römische Zählweise bekannt

Die häufige Erwähnung des Inzestverbots in der Briefsammlung des Bonifatius ist also auf die Verwirrungen des Missionars zurückzuführen. Die gute Quellenlage sagt deshalb nichts über die Frage aus, ob das Inzestverbot in der Zeit Karl Martells zu den in der Gesellschaft virulenten Problemen zählte. Erst nach dem Tod Karl Martells stieg das Inzestverbot zu einem der zentralen Themen der Gesetzgebung auf. Dies war jedoch nicht das Werk des Bonifatius. Als der Missionar zum wichtigsten Berater Karlmanns aufstieg, befasste er sich auf dem Concilium germanicum in erster Linie mit der Wiederherstellung der kirchlichen Disziplin. In Les Estinnes beschäftigten sich die Bischöfe nur deshalb mit dem Thema der Verwandtenehe, weil der konkrete Fall einer Ehe mit der Frau des Onkels vorlag. Aus diesem Grund fasste Papst Zacharias ein Mahnschreiben ab, und Bonifatius hielt vermutlich die oben genannte Predigt zum Inzest, in der er die biblischen Eheverbote einschärfte. Dieser konkrete Fall darf nicht darüber hinwegtäuschen, dass das Verbot von Verwandtenehen nicht zum Kern der Reformanliegen des Bonifatius zählte. Seine Ansicht zur Ausdehnung des Inzestverbots stand im diametralen Gegensatz zur vorherrschenden Meinung in der fränkischen und römischen Kirche.

Erst Pippin machte nach seiner Königswahl mit dem Inzestverbot regelrecht Politik. Sein erstes Kapitular als König regelte vorwiegend das Verbot von Verwandtenehen. Welchen Zwecken diente dieser Schachzug? Zum einen muss man darin konkret eine Folge des Bündnisses mit dem Papsttum sehen. Papst Zacharias verwandte in seinem Responsum von 747 besondere Sorgfalt auf die Redaktion des Inzestkapitels. Zitierte er sonst nur aus der Kirchenrechtssammlung des Dionysius Exiguus, formulierte er beim Inzestverbot ausführlich die neue päpstliche Position und stellte sie als altehrwürdige römische Tradition dar. Das Inzestverbot sollte die gesamte Bluts- und Schwiegerverwandtschaft nach römischem Recht sowie die geistliche Verwandtschaft erfassen. Pippin konnte es nicht verborgen bleiben, dass der Papst damit den Widerspruch des Bonifatius argumentativ entkräften wollte. Als wenige Jahre später Pippin mit Papst Stephan II. ein Bündnis gegen die Langobarden schloss, hielt es der König für angebracht, nochmals ein Responsum beim Papst zu erwirken und sich durch ein Kapitular zur päpstlichen Position zu bekennen. Zugleich erwirkte er die päpstliche Salbung für seine Söhne und seine Frau, die ihm eine Überlegenheit über seine innderdynastischen Rivalen verschaffte.

Zum anderen bekannte sich Pippin mit der Inzestgesetzgebung zur Idee des christlichen Königtums. Seit der Gesetzgebung des 4. Jahrhunderts zählte es zum Auftrag des Herrschers, die göttliche Ordnung der Ehe aufrechtzuerhalten. 
Nach seiner Königserhebung von 751 konnte ein solches Bekenntnis zur Bekämpfung von Verwandtenehen besonders notwendig erscheinen, um einen fundamentalen Rangunterschied zwischen dem Ethos des Königtums und dem Adelsethos festzuschreiben. Auf diese Weise konnte sich Pippin sowohl von den anderen Adelsfamilien als auch von den nicht zur Königsfamilie zählenden Verwandten distanzieren. Die Inzestgesetzgebung Pippins ist folglich in erster Linie als königliche Propaganda zu werten, d.h. als „symbolische Gesetzgebung“. Sie diente dazu, mit Bezug auf eine anerkannte christliche Norm Zustimmung zur gerade errungenen Königsherrschaft zu erzwingen. Das Inzestverbot als Teil der göttlichen Ordnung war der konsensualen Mitbestimmung des Adels entzogen, der die weltliche Gesetzgebung weitgehend unterlag. Mit Gesetzen zum Verbot von Verwandtenehen konnte der König seinen monarchischen Machtanspruch zu einem Zeitpunkt demonstrieren, als er einen Rangunterschied gegenüber seinen Standesgenossen festschreiben wollte.

Als „symbolisch“ sind Pippins Ehegesetze deshalb zu bezeichnen, weil er der effektiven Strafverfolgung wenig Aufmerksamkeit schenkte. In der Tradition der fränkischen Volksrechte verhängte Pippin I. staatliche Strafen über Gesetzesbrecher, ohne dass die ordnungsgemäße Rechtspflege durch die gräflichen Amtsträger gewährleistet gewesen wäre. Karl der Große erkannte dieses Defizit und widmete einen wichtigen Teil seiner gesetzgeberischen Tätigkeit der Beseitigung dieses Missstandes. Er übertrug die Kompetenz zur Verfolgung von Inzestdelikten den Bischöfen und gab ihnen ein Instrumentarium an die Hand, das eine lückenlose Überwachung der Bevölkerung möglich machen sollte. Einerseits waren die Bischöfe dazu ermächtigt, bei ihren Visitationsreisen ein Rügeverfahren anzuwenden und dadurch das Schweigen über bestehende Inzestehen zu brechen. Alle Gläubigen wurden durch Eid zur Denunziation von Inzestdelikten verpflichtet. Andererseits schrieb er eine voreheliche Befragung der Nachbarn und Vornehmen des Ortes durch den Ortspriester vor, um bereits vor der Eheschließung eingreifen zu können. Darüber hinaus verschärfte er die Strafmaßnahmen, indem er ein besonders hartes Verfahren für Gesetzesbrecher etablierte, die sich den Ermahnungen der Bischöfe nicht beugen wollten. Inzestuöse Personen sollten bis zum Prozess vor dem Königsgericht enteignet und eingesperrt werden, damit sie ihre Umgebung nicht „anstecken“ konnten. Mit diesem „autokratischen “342 Überwachungsregiment war Karl seiner eigenen Zeit weit voraus. Erst die gregorianische Reform hat seine Innovationen, so weit sie die Kirche betreffen, in die Praxis umsetzen können.

Karls Engagement für die Bestrafung von Inzestdelikten übersteigt daher weit die Grenzen symbolischer Gesetzgebung. Die Effizienz der Normsetzung stand im Mittelpunkt seiner Anstrengungen. Auf die Frage, welchen politischen Nutzen er sich davon versprach, gab Paul Fouracre eine überzeugende Antwort:

342 Wallace-Hadrill, Kingship 1971, 107. 
Die Karolinger bestanden auf exogamen Eheschließungen, um die regionalen Aristokratien des Frankenreichs zu wechselseitigen Allianzen zu zwingen ${ }^{343}$. Die Schaffung einer ,Reichsaristokratie ${ }^{\text {(344 }}$ sollte die Abschottung lokaler Eliten verhindern, die sich seit der Schwächung des merowingischen Königtums in den Randgebieten des Frankenreichs herausgebildet hatten. Quellen belegen, dass dieses Projekt von Karl dem Großen bewusst in die Tat umgesetzt wurde. Im Jahr 786 beauftragte er einen Gesandten damit, die Tochter eines thüringischen Adeligen wegzuführen, die einem fränkischen Großen versprochen worden war. Als sich der Thüringer weigerte und Unterstützung vom ansässigen Grafen Hardrad erhielt, fasste Karl dies als Rebellion auf und verhängte drakonische Strafen über die Aufständischen ${ }^{345}$. Auch bei der Integration der Sachsen förderte der Herrscher die Eheverbindungen zwischen sächsischer und fränkischer Aristokratie $^{346}$. In seinem politischen Testament von 806 ließ Karl eigens festschreiben, dass trotz der zukünftig anvisierten Reichsteilungen Eheschließungen über die Grenzen hinweg erlaubt bleiben sollten ${ }^{347}$. Das Inzestverbot konnte einer solchen integrativen Politik die religiös-ethische Legitimation verschaffen. Wollte man die Eheverbote des Kirchenrechts einhalten, war es geboten, die engere Verwandtschaft bei der Eheschließung zu umgehen und sich an einem überregionalen Heiratsmarkt zu beteiligen.

343 Fouracre, Origins 2000, 18. Er bezieht sich auf Le Jan, Famille 1995, 98 u. 310-315, die jedoch als Movens der karolingischen Gesetzgebung die Zerstörung der Sippenstruktur angibt.

344 Dieser Begriff wurde geprägt von Tellenbach, Königtum 1939. Vgl. zuletzt Airlie, Aristocracy 1995, 434; Hechberger, Adel 2005, 186-194.

345 Annales Nazariani a. 786 (MGH SS 1, 41-43). Vgl. zuletzt Le Jan, Élites 2006, $404-$ 410; Depreux, Défense 2008, 98-104.

346 Vgl. Depreux, Intégration 2006; Ehlers, Integration 2007, 153-192.

347 Divisio regnorum c. 12 (MGH Capit. 1, 129). Vgl. Nelson, Siting 1997, 154. 


\section{Theorie und Praxis des Inzestverbots im Karolingerreich}

Die Reform von Bildung und Kirche durch Karl den Großen zielte in den Worten Percy Ernst Schramms auf die „Wiederherstellung des Wahren und Richtigen, sofern es entstellt war" . Aus diesem Streben nach „Correctio" ergab sich für Karl die Notwendigkeit einer Vereinheitlichung des kirchlichen und schulischen Lebens. Am deutlichsten hat sich dies in der sich während seiner Herrschaftszeit vollziehenden Schriftreform niedergeschlagen ${ }^{2}$. Die karolingische Minuskel verdankte zwar ihre Entstehung nicht ursprünglich einer Anweisung Karls, verbreitete sich aber im Zuge der Reformen allmählich im ganzen Frankenreich und ermöglichte damit die Schaffung eines reibungslos funktionierenden Kommunikationsraums. Im Bereich des Kirchenrechts war das Streben nach Vereinheitlichung ebenfalls spürbar. Bei seinem ersten Rombesuch zu Ostern des Jahres 774 erhielt Karl vermutlich auf eigenen Wunsch von Papst Hadrian eine Kirchenrechtssammlung, die Collectio Dionysio-Hadriana ${ }^{3}$. Karl benutzte die Dionysio-Hadriana in seiner eigenen Gesetzgebung als vorbildliche Sammlung und ließ sie möglicherweise im Jahr 802 als authentisches Rechtsbuch der Kirche, ratifizieren ${ }^{64}$. Mit über 80 Handschriften wurde sie zum wichtigsten kirchenrechtlichen Handbuch der Karolingerzeit ${ }^{5}$. Später richtete Karl auch wegen liturgischer und monastischer Schriften Anfragen an Rom als den „eigentlichen Hort der rechten Tradition“".

Karls Bevorzugung der Dionysio-Hadriana führte jedoch nicht zu ihrer ausschließlichen Geltung ${ }^{7}$. Der Kaiser ließ auch andere Sammlungen an seinem Hof abschreiben und bediente sich ihrer in seiner Gesetzgebung. Hubert Mordek zufolge konnte die päpstliche Sammlung aus zwei Gründen für den praktischen Gebrauch nicht ausreichen ${ }^{8}$. Zum einen erschloss sie sich dem Leser wegen der historischen Anordnung erst durch gründliches Studium oder durch

1 Schramm, Karl 1964, $341 \mathrm{f}$. Zum Begriff der Renaissance vgl. zuletzt Brown, Renaissance 1994; Fried, Karl 1997; Depreux, Ambitions 2002; McKitterick, Renaissance 2005.

2 Bischoff, Minuskel 1965; Ganz, Minuscule 2004.

3 Eine Initiative Karls vermutet Mordek, Autoritäten 1977, 239.

4 So Madssen, Geschichte 1870, 470. Skepsis dagegen bei Mordek, Autoritäten 1977, 245, und Fuhrmann, Papsttum 1981, 436 Anm. 26.

5 Kéry, Collections 1999, 13-20; ZeChiel-Eckes, Kirchenrecht 2005, 219-224.

6 Mordek, Autoritäten 1977, 241. Vgl. auch Schieffer, Redeamus 1989.

7 Коттје, Einheit 1965, 335-340; Reynolds, Unity 1983; Mordek, Autoritäten 1977.

8 Mordek, Autoritäten 1977, 245-247. 
entsprechende Vorkenntnisse. Systematische Sammlungen waren deshalb für die Praxis von größerem Wert. Zum anderen „konnte sie in keiner Weise allen Ansprüchen des täglichen kirchlichen Lebens genügen" ". Der gelehrte Erzbischof Agobard von Lyon stellte fest, dass die altkirchlichen Normen in vielen dringlichen Rechtsfällen keine angemessenen Entscheidungen bereithielten ${ }^{10}$. Eine Ergänzung durch die in der päpstlichen Sammlung nicht enthaltenen Beschlüsse der fränkischen und westgotischen Konzilien hielt Agobard deshalb für unbedingt erforderlich.

In der Frage des Inzestverbots bot die Dionysio-Hadriana ebenfalls nicht in jeder Hinsicht eine angemessene Entscheidungshilfe. Als Strafe für Inzest war nur die harsche Regelung des Konzils von Neocäsarea vorgesehen, d.h. der lebenslängliche Ausschluss von der Kommunion. Dies entsprach jedoch schon lange nicht mehr der kirchlichen Praxis, in der eine erneute Heirat der Delinquenten durchaus akzeptiert war. Überdies hielt die päpstliche Sammlung in der Frage des Umfangs des Inzestverbots nur die Beschlüsse der römischen Synode von 721 bereit. Darin wurde erstmals von päpstlicher Seite das kategorische Verbot der Verwandtenehe ausgesprochen. Unklar musste jedoch bleiben, wie weit die Verwandtschaft reichen sollte. Eine eindeutige Grenze der Verwandtschaft war nur im römischen Recht vorhanden, während das fränkische Recht je nach Rechtsmaterie unterschiedliche Gruppen aus der Verwandtschaft heranzog. Auch die anderen Volksrechte der Karolingerzeit sind von einer flexiblen Auslegung der Verwandtschaft geprägt ${ }^{11}$. Vor dem Hintergrund dieses rechtlichen Pluralismus und des diffusen Verwandtschaftsbegriffs der Zeit war das kategorische Verbot der Verwandtenehe jedweder Art nicht praktikabel.

Die Unzulänglichkeit der Regelungen der Dionysio-Hadriana im Fall des Inzestverbots zeigte sich bereits am Ende der Regierungszeit Karls des Großen. Im Rahmen der Reformkonzilien des Jahres 813 kam erneut die Frage nach dem Umfang des Inzestverbots auf die Tagesordnung. Eine beratende Bischofsversammlung kurz vor 813 stellte die Frage in den Raum, „mit welchen [Verwandten] man sich ehelich verbinden darf, mit welchen nicht ${ }^{\text {"12 }}$. Die Antworten fielen so verschieden aus, wie die herangezogenen Rechtssammlungen verschieden waren ${ }^{13}$. In Arles zitierte man das Konzil von Epaon nach der Collectio Hispana $^{14}$, in Mainz wiederholte man in etwas strengerer Form die Beschlüsse

9 Mordek, Autoritäten 1977, 245.

10 Agobard von Lyon, Ep. 3, c. 12 (MGH Epp. 5, 163). Zu ihm siehe 297 f.

11 Murray, Structure 1983; Le Jan, Famille 1995, 166.

12 De iudicio poenitentiae ad interrogandum reliquimus ...; et de incestibus, quibus liceat iungere, quibus non. Capitula ecclesiastica c. 20 (MGH Capit. 1, 179). Zum Charakter dieses Kapitulars vgl. Schmitz, Einleitung (MGH Capit. N.S. 1, 29 f.).

13 Fuhrmann, Papsttum 1981, 441-444; Hartmann, Synoden 1989, 133.

14 Konzil von Arles (813) c. 11 (MGH Conc. 2/1, 251). Vgl. Fuhrmann, Papsttum 1981, 443 Anm. 41. 
von Pippins Kapitularen ${ }^{15}$, und in Chalon verwies man pauschal auf die Kanones, ohne eine autoritative Quelle eigens zu erwähnen ${ }^{16}$. Möglicherweise bezogen sich die in Chalon tagenden Bischöfe auf die Hispana, die auch sonst als Quelle herangezogen wurde. Der Umfang des Inzestverbots reicht daher in Mainz bis zum Verwandtschaftsverhältnis von $4 / 4$, in Arles bis $2 / 2$, und in Chalon ist er unbestimmt. Von einer Einigung war man denkbar weit entfernt.

Im 9. Jahrhundert entzündete sich folglich an dieser Frage eine lebhafte Debatte, an der sich die wichtigsten Kirchenpolitiker des Frankenreichs beteiligten. Bevor ich mich vier Protagonisten dieser Debatte zuwende, werde ich in einem Überblick die verschiedenen im Frankenreich kursierenden Positionen charakterisieren, um die Vielfalt der überlieferten Inzestverbote deutlich zu machen. Dabei ist zu beachten, dass nicht in jedem Fall mit hinreichender Sicherheit festgestellt werden kann, welche Zählweise verwendet wurde. Obwohl sich die Bischöfe zur Zeit Pippins für die kanonische Komputation entschieden hatten, machte dieses Vorbild nicht Schule. Wenn Gelehrte im 9. Jahrhundert die Zählung der Verwandtschaft nachschlagen wollten, griffen sie zu den Etymologiae des Isidor von Sevilla, der Standardenzyklopädie des frühen Mittelalters ${ }^{17}$. Darin zählte der spanische Gelehrte die Verwandtschaft nach römischem Recht und fügte dem Text eine graphische Darstellung hinzu. Allein aus dem 9. Jahrhundert sind 30 graphische Stammbäume mit römischer Zählweise erhalten ${ }^{18}$. Die kanonische Komputation wurde dagegen erst im 12. Jahrhundert graphisch umgesetzt. Es ist daher begründet, von einer Vorherrschaft der römischen Zählweise auszugehen ${ }^{19}$.

15 Konzil von Mainz (813) c. 54-56 (MGH Conc. 2/1, 273). Die Quelle ist Pippini regis capitulare c. 1 (MGH Capit. 1, 31).

16 Interrogaverunt nos quidam de adfinitate propinquitatum et in quibus gradibus matrimonia iungenda sint. Quibus nos ad canones currere praecipimus ... Konzil von Chalon (813) c. 28 (MGH Conc. 2/1, 279).

17 Zur Überlieferung vgl. BeEson, Isidor-Studien 1913; Bischoff, Verbreitung 1961. Exemplarisch soll hier die Schulhandschrift Laon, Bibliothèque municipale, 468, genannt sein. Auf fol. 15r-17v wird die Verwandtschaft nach Isidor erläutert, vgl. CONTRENI, Codex 1984.

18 Nach Schadt, Arbores 1982. Besondere Aufmerksamkeit verdienen die Stammbäume in Leiden, Bibliotheek der Rijksuniversiteit, BPL 114, fol. 1v-8v. Den Ursprung der Kapitulariensammlung dieser Handschrift vermutet Mordek, Bibliotheca 1995, 503, am Hof Karls des Großen.

19 Siehe auch oben $26 \mathrm{f}$. 


\subsection{Einheit und Vielfalt: Eine Reise durch das Frankenreich}

In der Anfangszeit Ludwigs des Frommen versuchte eine Bischofsversammlung erneut, eine definitive Entscheidung hinsichtlich des Umfangs des Inzestverbots herbeizuführen. Ludwig der Fromme war ein noch entschiedenerer Verfechter der Vereinheitlichung des kirchlichen Lebens als sein Vater ${ }^{20}$. Gleich nach seinem Herrschaftsantritt im Jahr 814 ließ er für Kleriker, Mönche und Kanonissen einheitliche Regeln mit reichsweiter Gültigkeit verabschieden. Entscheidenden Anteil an diesem Programm hatten seine kirchlichen Ratgeber Helisachar und Benedikt von Aniane, die er bereits während seiner Herrschaft in Aquitanien um sich geschart hatte. Ihnen wird es auch zuzuschreiben sein, dass auf der Aachener Reichsversammlung zum Jahreswechsel 818/819 erneut über das Inzestverbot diskutiert wurde. Wie Emil Seckel herausgefunden hat, haben die Bischöfe zunächst getrennt beraten und eigenständig Beschlüsse gefasst ${ }^{21}$. An erster Stelle der Tagesordnung stand die umstrittene Frage des Umfangs des Inzestverbots. Die Bischöfe beriefen sich auf das von Gregor II. erlassene kategorische Verbot und interpretierten es durch die Übernahme der römischrechtlichen Definition der Verwandtschaft:

„Und weil der selige Gregor in einer synodalen Satzung jene, die Frauen aus der eigenen Verwandtschaft nehmen, verflucht, und weil die Verwandtschaft nach natürlichem Gesetz im sechsten Grad beendet ist, so dass man ungehindert im siebten Grad die Rechte der Ehe erhalten kann, muss man von nun an beachten, dass nur in diesem siebten Grad Ehen geschlossen werden" ${ }^{\text {“22 }}$.

Bei der Bestrafung des Inzests bemühten sich die Bischöfe um eine je nach der Schwere des Verbrechens abgestufte Regelung. Geschlechtsverkehr zwischen Verwandten im ersten und zweiten Grad wurde nach dem Kanon von Neocäsarea mit Anathem und dauerhafter Ehelosigkeit bestraft; bei Ehen im dritten und vierten Grad durfte erneut geheiratet werden; Eheleute, die im fünften und sechsten Grad verwandt waren, sollten nur zur Aufgabe ihrer Ehe überredet werden. ${ }^{23}$

20 Boshof, Ludwig 1996, 108-128 (mit weiterer Literatur).

21 SeCKel, Synode 1922.

22 Et quia beatus Gregorius in sinodali constitutione eos, qui, de propria cognatione uxores duxerint, anathematizat' et cognatio iuxta legem naturalem in sexto gradu terminetur, ita ut libere in septimo possint coniugii iura sortiri: observandum est deinceps, ut non nisi in eodem septimo gradu coniugio copulentur et, si fecerint, omnimodis separentur. Konzil von Aachen (819) c. 1, hg. von SECKEL, Synode 1922, 18.

23 Illi autem, qui in primo vel secundo gradu corrupti vel copulati inveniuntur, separentur, quia anathemate canonico geriuntur, et usque ad finem vitae absque coniugio in publica paenitentia permaneant. Eos vero, qui in tercio vel quarto copulati fuerint, separentur et, paenitentia iuxta arbitrium episcopi peracta, licita coniugia sortiantur. Qui autem in quinto vel 
Diese Beschlüsse sind erstaunlich zurückhaltend. Gegenüber den Gesetzen Pippins bedeuten sie eine Mäßigung, da nur Ehen im Verhältnis von 3/3 verboten wurden. Trotzdem weigerte sich Ludwig der Fromme, den Inzestbeschluss des Konzils von Aachen in seine Gesetzgebung aufzunehmen. Im wichtigen Kapitular von 819, das den Abschluss des ehrgeizigsten Reformprogramms seiner Regierungszeit bildete, heißt es am Schluss:

„Einige Bestimmungen, wie über Inzestehen .... die wir wegen der kurzen Zeit nicht zu Ende bringen konnten, haben wir beschlossen so lange zu vertagen, bis uns durch Gottes Hilfe und durch den Rat der Getreuen die Gelegenheit zur Vollendung gegeben werde" ${ }^{\prime 24}$.

Die anderen offen gelassenen Themen wie die Frage der Rückgabe enteigneten Kirchengutes waren noch brisanter und sollten zu den wichtigsten Streitthemen der folgenden Jahre zählen ${ }^{25}$. Man kann daher vermuten, dass die von den Bischöfen formulierte Inzestbestimmung beim Kaiser und bei den weltlichen Amtsträgern auf Ablehnung gestoßen ist. Was war jedoch der Grund für diese Ablehnung? Emil Seckel, der den abgelehnten Beschluss in einer Handschrift entdeckte, unterstellte den Bischöfen die kanonische Komputation und nahm daher eine Erweiterung des Inzestverbots an. „Ludwig dem Frommen gegenüber wagt die fränkische Kirche, was sie Karl dem Großen gegenüber niemals gewagt hatte“, und erhielt „eine in höfliche Form gekleidete Ablehnung “26. Seckel ging von der Annahme aus, dass bereits die Päpste des 8. Jahrhunderts den siebten Grad kanonischer Zählung als Inzestgrenze eingefordert hätten. Diese Einschätzung hat sich jedoch als falsch erwiesen ${ }^{27}$. Die fränkischen Bischöfe werden daher kaum eine solche bislang nicht geäußerte Forderung erhoben haben. Überdies verweist der Text des Konzilskanons selbst mit dem Begriff lex naturalis auf das römische Recht oder seine Wiedergabe bei Isidor von Sevilla ${ }^{28}$.

Dass der Text Isidors von Sevilla als Diskussionsgrundlage am Hof der karolingischen Herrscher diente, belegen auch zwei Handschriften aus der Zeit um 800. Nach den Erkenntnissen Bernhard Bischoffs befand sich die älteste Handschrift von Bedas Kirchengeschichte am Hof Karls des Großen und wurde dort um eine Abschrift der Epistola de gradibus consanguinitatis aus dem Um-

sexto nunc inventi fuerint, persuadeantur, ut de inlicitis ad licita transeant. Konzil von Aachen (819) c. 1, hg. von SECKEL, Synode 1922, $18 \mathrm{f}$.

24 Nonnulla vero capitula, sicut de incestis nuptiis ... quae pro temporis brevitate efficere nequivimus, in tantum differendum illud dignum iudicavimus, donec Domino favente consultu fidelium facultas nobis id efficiendi ab eo tribuatur. Capitulare ecclesiasticum c. 29 (MGH Capit. 1, 279 f.).

25 Boshof, Agobard 1969, 75-97.

26 Seckel, Synode 1922, 25 u. 41.

27 Siehe $237 \mathrm{f}$.

28 So bereits SeCKel, Synode 1922, 28 Anm. 4. 
kreis des Bonifatius ergänzt ${ }^{29}$. Zweck dieser Ergänzung war es, den von Beda zitierten Libellus responsionum Gregors I. unschädlich zu machen. In der Epistola werden nicht nur die beiden Quellen des Konzils von Aachen (Konzil von Rom 721 und Isidor) zitiert, es wird auch in einem eigenständig formulierten Text eine abgestufte Strafregelung wie in Aachen vorgeschlagen. Die zweite Handschrift enthält ebenso die beiden Quellen des Konzils, und zwar als Anhang zur Dionysio-Hadriana. Dieser Anhang umfasst zudem das römische Konzil von 743 und ein Exzerpt aus dem Brief Gregors III. an Bonifatius. Der Zweck dieses Anhangs ist bereits vertraut: der Libellus responsionum sollte widerlegt werden. Die Kapitelfolge beginnt nämlich mit der ausdrücklichen Zurückweisung der Autorität des Libellus auf dem Konzil von Rom. Entgegengestellt wird dem Zugeständnis Gregors des Großen das kategorische Verbot von Verwandtenehen und die von Gregor III. genannte Grenze des siebten Grads. Die Handschrift stammt aus dem Umkreis des Erzbischofs und Erzkaplans Hildebald von Köln $(\dagger 818)$ und ist noch im ersten Viertel des 9. Jahrhunderts entstanden ${ }^{30}$.

Vor diesem Hintergrund lässt sich die Zielsetzung der in Aachen versammelten Bischöfe präziser fassen. Sie wollten die Verwandtschaftsgrenze des römischen Rechts für verbindlich erklären und damit der Geltung des Libellus responsionum die Grundlage entziehen. Dabei ließen sie durchaus Augenmaß erkennen, indem sie eine nachträgliche Trennung der Ehe nur bei der Cousinenehe vorschrieben. Umso mehr erstaunt es, dass der Kaiser und die weltlichen Amtsträger sich weigerten, diese Bestimmung zu approbieren und in das Kapitular aufzunehmen. Eine Antwort auf diese Frage erhalten wir, wenn wir uns im Folgenden einigen Sammlungen privaten Charakters aus dieser Zeit zuwenden. Privat waren diese Sammlungen insofern, als sie weder von staatlicher noch von konziliarer Autorität abgestützt wurden. Trotzdem erwarben sie im Lauf der Zeit eine oft bedeutende normative Geltung. Die normative Geltung von Rechtssätzen hing im Frühmittelalter nämlich nicht ausschließlich von der rechtssetzenden Instanz, sondern von der Wirkung ab, die sie innerhalb der

29 Cambridge, University Library, Kk.V.16, fol. 128v. Vgl. Bischoff, Hofbibliothek 1964, 56; Ders., Katalog 1 1998, 186. Zur Epistola siehe 241-243.

30 Köln, Erzbischöfliche Diözesan- und Dombibliothek, 115, fol. 225rb-vb. Zur Handschrift vgl. Bischoff, Katalog 1 1998, 399. Derselbe Anhang befindet sich auch in folgenden Dionysio-Hadriana Handschriften: St. Gallen, Stiftsbibliothek, 671, p. 437 (siehe 363 Anm. 366); München, Bayerische Staatsbibliothek, Clm 6242, fol. 311r. Des weiteren in der Sammlung Theoderichs von Cambrai (siehe 306) sowie in der Freisinger Sammlung München, Bayerische Staatsbibliothek, Clm 6245, fol. 57v-58r. Davon abhängig sind (Mordek, Bibliotheca 1995, 325-328; Kéry, Collections 1999, 185 f.) München, Bayerische Staatsbibliothek, Clm 6241, fol. 82r-85r; Wien, Österreichische Nationalbibliothek, Lat. 2198, fol. 81v; Bamberg, Staatsbibliothek, Can. 9, fol. 199v. Weitere Überlieferungen in Vatikan, Biblioteca Apostolica Vaticana, Vat. lat. 1339, fol. 307v; München, Bayerische Staatsbibliothek, Clm 3852, fol. 68; München, Bayerische Staatsbibliothek, Clm 3860a, fol. 177r. 
Sammlungen entfalteten. Peter Landau bringt diesen Sachverhalt auf den Punkt: „Kanones werden auf Konzilien formuliert, erlangen aber Rechtsgeltung in der universalen Kirche nicht durch einen Gesetzesbefehl, sondern durch allgemeine Rezeption. Diese Rezeption wird ... über die Kanonessammlungen vermittelt ${ }^{\text {‘31 }}$. Damit ist jedoch nicht gesagt, dass allein die subjektive und willkürliche Auswahl der Sammler und Gelehrten über die Akzeptanz von Rechtsnormen entschieden hätte. Nach Hans Barion musste sich nämlich das Kirchenrecht durchaus an bestimmten Vorstellungen über die Hierarchie von Rechtsquellen messen lassen. Der Vorrang der alten ökumenischen Konzilien, vor allem desjenigen von Nicäa, sei ohne einen offiziell vorgeschriebenen Autoritätenindex und ohne die Hilfe einer kirchlichen Rechtswissenschaft unbestritten gewesen. Die Übereinstimmung mit der Tradition war der Garant für die Geltung von Rechtssätzen: „Die verpflichtende Kraft des Beschlusses ist an die Überein-

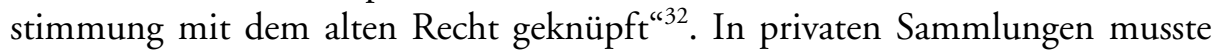
man daher die Bindung an die überkommene Tradition berücksichtigen, konnte aber daneben den eigenen Präferenzen Ausdruck verleihen und so den Gang der Rezeption entscheidend beeinflussen. Die Folge dieses dynamischen Prozesses waren „sekundäre Normbildungen “33.

\section{Lyon 800}

Im Jahr 797/798 betraute Karl der Große seinen Vertrauten und Hofkaplan Leidrad mit dem Amt des Erzbischofs von Lyon. Er sollte das Bistum, das „in vielen Dingen innerlich und äußerlich verkommen war ${ }^{\text {“34 }}$, wieder aufrichten und an die Standards der im Gang befindlichen Kirchenreform heranführen. Leidrad, ein Sohn aus bayerischem Adel, führte diesen Auftrag gewissenhaft aus. Er ließ aus Metz, wo Karl als Muster für das ganze Frankenreich den römischen Kirchengesang eingeführt hatte, einen Kleriker für den Gesangsunterricht holen und bemühte sich um die Durchsetzung der ebenfalls mit römischer Autorität behafteten Benediktregel ${ }^{35}$. Unter seiner Amtszeit ist darüber hinaus eine systematische Kirchenrechtssammlung erstellt worden, die Collectio Dacheriana. Nach einer ansprechenden Vermutung Hubert Mordeks ist der Kompilator mit Agobard von Lyon identisch, der später Leidrads Nachfolger werden sollte ${ }^{36}$. Wegen der Überlieferung in über 50 Handschriften schreibt ihr Gabriel Le Bras

31 Landau, Kirche 2006, 220.

32 BARION, Synodalrecht 1933, 190.

33 Thier, Schriftlichkeit 2007, 7.

34 Erat enim tunc supradicta ecclesia in multis rebus destituta interius exteriusque ... Leidrad, Epistola (MGH Epp. 4, 542). Zur Persönlichkeit vgl. Semmler, Beziehungen 1966, 402-415.

35 Leidrad, Epistola (MGH Epp. 4, 542 f.).

36 Mordek, Kirchenrecht 1975, 13; DERs., Autoritäten 1977, 253. 
eine zentrale Rolle für die Kirchenreform der Karolingerzeit zu: „Sie krönt das Bemühen um Emendation, Abstimmung und Klassifikation der Texte ${ }^{\text {‘37 }}$.

Die Quellen der Dacheriana sind im wesentlichen die päpstliche DionysioHadriana und eine systematische Fassung der Collectio Hispana. Aus diesen beiden Sammlungen stellt der Kompilator alle Regelungen zum Inzestverbot in annährend chronologischer Reihenfolge zusammen. Im Vordergrund steht dabei das kategorische Verbot von Verwandtenehen, das in der Form des Konzils von Toledo und des Konzils von Rom zitiert wird. Zwischen diesen beiden Kanones steht der Beschluss des Konzils von Epaon mit der ausführlichen Auflistung aller verbotenen Verwandten ${ }^{38}$. Dadurch entsteht eine Spannung, die durch die unterschiedlichen Strafsanktionen intensiviert wird. Während das Konzil von Epaon von einer Buße der Delinquenten absieht, schreiben die anderen vier Kanones einen sofortigen Ausschluss und eine kanonische Buße vor. Da sich der Kompilator keine Eingriffe in den Textbestand erlaubt, treffen die unterschiedlichen Regelungen unvermittelt aufeinander.

In der Rezeption der Dacheriana wurden diese Divergenzen beseitigt. Die beiden wichtigsten Benützer der Sammlung, Halitgar von Cambrai und der anonyme Kompilator des Quadripartitus, eliminierten den Kanon von Epaon. Beide Autoren waren ebenso wie der Kompilator der Dacheriana dem Ziel verpflichtet, die irische Tarifbuße zu bekämpfen und die altkirchliche kanonische Buße wieder zu beleben ${ }^{39}$. Der Kampf gegen die Bußbücher hatte sich zwischen der Kompilation der Dacheriana und der Zeit Halitgars so weit verschärft, dass man auf dem Konzil von Paris 829 die Verbrennung der Bußbücher beschloss ${ }^{40}$. Halitgar übernahm auf Bitten der Kirchenreformer den Auftrag, ein aus kanonischen Quellen kompiliertes Bußbuch abzufassen. Seine wichtigste Quelle dafür war die Dacheriana. Zum Inzestverbot kopierte er jedoch lediglich die Kanones von Neocäsarea, Toledo II und Rom (721) ${ }^{41}$. Der Kanon von Epaon wurde gestrichen ${ }^{42}$. Der Quadripartitus, entstanden zwischen

37 Fournier - Le Bras, Histoire 1 1931, 104. Vgl. Kéry, Collections 1999, 87-92.

38 Collectio Dacheriana I 92 (528). Ob das Fehlen der sobrina in der Edition d'Acherys richtig ist, wird erst die von Daniel Ziemann vorbereitete kritische Edition entscheiden. In den Handschriften Köln, Erzbischöfliche Diözesan- und Dombibliothek, 122 (fol. 47r) und 123 (fol. 55r), ist das Wort enthalten. Zum Fehlen der sobrina in den Hispana-Handschriften vgl. Weigand, Ausdehnung 1994, 2 Anm. 7.

39 Zum Ziel der Dacheriana vgl. Le Bras, Dacheriana 1931, 397. Zu Halitgar vgl. Коттje, Bußbücher 1980, 173-190.

40 Konzil von Paris (829) c. 32 (MGH Conc. 2/2, 633). Vgl. hierzu Kоттje, Bußbücher 1980, 3; Jong, Penance 1997, 867-876.

41 Halitgar, Paenitentiale IV 14 (282), IV 21 (283) und IV 22 (284).

42 Mit Ausnahme des letzten Satzes, der dem Kanon von Toledo angehängt ist: Halitgar, Paenitentiale IV 21 (283). - Bei Schmitz ist als IV 21b der Kanon 6 des Konzils von Rom (MGH Conc. 2/1, 14) abgedruckt. Dies ist jedoch ein Zusatz, der sich nur in einer späten Handschrift findet: Коттје, Bußbücher 1980, 17. 
825 und 875 in Reims ${ }^{43}$, übernahm neben den drei Kanones, die auch bei Halitgar stehen, noch den Beschluss von Lérida, eliminierte jedoch ebenfalls den Kanon von Epaon ${ }^{44}$. Beide Werke, das Bußbuch Halitgars und der Quadripartitus, waren mit über 60 bzw. 9 Handschriften ${ }^{45}$ gut verbreitet und sorgten so für einen engen Anschluss an die altkirchlich-päpstliche Tradition. Das kategorische Verbot von Verwandtenehen erkannten sie als verbindliche Regel an.

\section{Salzburg 800}

Ein Weggefährte - und möglicherweise auch ein Verwandter - Leidrads von Lyon war Bischof Arn von Salzburg ${ }^{46}$. Beide begannen ihre Karriere als Domkleriker in Freising und stiegen über die Drehscheibe des königlichen Hofes zu Bischöfen auf. Arn wurde im Jahr 785 zum Bischof von Salzburg erhoben und genoss das unumschränkte Vertrauen Karls des Großen. Mehrfach wurde er vom Herrscher mit schwierigen diplomatischen Gesandtschaften betraut. Auch an der Vorbereitung der Kaiserkrönung war er unmittelbar beteiligt. Im Jahr 798 erhielt er durch die Vermittlung Karls die Würde des Erzbischofs und stand somit an der Spitze der gesamten bayerischen Kirche. In dieser Funktion berief er mehrmals Synoden in Bayern ein und sorgte als Königsbote für die Wahrung karolingischer Interessen.

In seiner Zeit als Bischof wurde in Salzburg ein Bußbuch kompiliert, das unter dem Namen Paenitentiale Vindobonense $B$ bekannt ist ${ }^{47}$. Die Lokalisierung ist durch die Benutzung Salzburger Handschriften und nur dort bezeugter Quellen hinlänglich gesichert. Einzigartig ist die Kombination des am stärksten verbreiteten fränkischen Bußbuches (Excarpsus Cummeani) mit selten überlieferten alten irischen Quellen, die über Arns Amtsvorgänger, den Iren Virgil, nach Salzburg gelangt waren. Darüber hinaus verbindet der Autor diese Quellen mit Kanones merowingischer Synoden. Im Unterschied zur Dacheriana findet hier also eine Vermischung von ,kanonischen' mit ,unkanonischen' Autoritäten statt. Im Fall des Inzestverbots sind die Quellen auf besondere Weise zurechtgemacht worden. Aus den merowingischen Synoden wird zwar der bedeutende Kanon des Konzils von Epaon zitiert, doch in einer redigierten Fassung, die weder den Umfang des Inzestverbots noch die milde Strafbestimmung enthält ${ }^{48}$. Für die Frage des Umfangs hält das Bußbuch die Bestimmung Theodors von

43 KerfF, Quadripartitus 1982, 77-81.

44 Quadripartitus IV 65-68 nach KerfF, Quadripartitus 1982, 94.

45 Vgl. Коттје, Bußbücher 1980, 14-83 (fragmentarische und vollständige Handschriften); KerfF, Quadripartitus 1982, 67.

46 Störmer, Arn 2004, $19 \mathrm{f}$.

47 MeEns, Boeteboek 1994, 105-137; DERs., Recht 1996.

48 Incesti coniunctionibus nihil prursus venie reservamus, nisi cum adulterium separatione sanaverint. Paenitentiale Vindobonense B 30, 1b (398). 
Canterbury aus dem Excarpsus Cummeani bereit, die bereits der Gesetzgebung Pippins I. als Diskussionsgrundlage gedient hatte ${ }^{49}$. Doch auch diese weicht vom Original $a b$, da der Verweis auf die unterschiedlichen Gebräuche der Griechen und Römer fehlt. Es wird lediglich bestimmt, dass Ehen im dritten Verwandtschaftsgrad getrennt werden und im vierten Grad unerlaubt, aber geduldet $\operatorname{sind}^{50}$. Welche Zählweise verwendet wurde, ist nicht mehr feststellbar. Da die Bestimmung in der Formulierung mit den Erlassen der Konzilien von Verberie (756) und Mainz (813) übereinstimmt, erscheint mir die Anwendung der kanonischen Zählweise plausibel.

Auch die Bestimmungen hinsichtlich der Bestrafung des Inzests wurden redigiert. Aus dem milden Kanon von Epaon wurde nur der erste Satz übernommen, der wie das andere zitierte merowingische Konzil eine strenge Ahndung nahe legt ${ }^{51}$. Dieser Eindruck wird verstärkt durch die Deformation eines Kanons des altkirchlichen Konzils von Ankyra, die bereits im Excarpsus Cummeani begegnet. Dort wird die strenge kanonische Buße für Sodomisten auf Inzestuöse übertragen.

„Wenn jemand mit einem Blutsverwandten vor seinem 20. Lebensjahr Inzest begangen hat, büßt er 10 Jahre ... Wenn jemand dieses Verbrechen im fortgeschrittenen Alter von über 20 Jahren begangen hat, so dass er bei bestehender Ehe in dieses Verbrechen geraten ist, wird er erst nach 25-jähriger Buße zur Kommunion der Betenden zugelassen "52.

Trotz der Benützung irischer Bußbücher wurde also im Fall des Inzests an der kanonischen Buße festgehalten.

Das Paenitentiale Vindobonense B befand sich also auf der Höhe der karolingischen Reform. Die altkirchliche kanonische Buße erhielt gegenüber milderen Formen der Bestrafung den Vorzug. Wie in Karls Gesetzgebung ${ }^{53}$ wurden bei der Frage des Umfangs des Inzestverbots möglicherweise die Beschlüsse

49 Siehe 268 Anm. 247.

50 In quinta generatione coniungantur, quarta, si inventa fuerit, non separantur, in tertia separantur. Paenitentiale Vindobonense B 30, 4 (400). Diese Verkürzung begegnet schon im Excarpsus Cummeani III 24 (615), dort allerdings noch mit explizitem Verweis auf Theodor.

51 Paenitentiale Vindobonense B 30, 1a-1b (398).

52 ... de his qui cum pecoribus coitum mixti sunt aut more pecorum incesta cum consanguineis commiserunt aut cum masculis concubuerunt, quodquod igitur ante vicissimum aetatis sue annum tale crimen admiserunt, $X V$ annos in penitentia exactis, orationi tantum incipiant participare ... Quodquod vero exacti XX annorum etate ut uxores habentes in hoc crimine inciderint XXV anno penitentiam acta ad communionem orationum tantum ... Paenitentiale Vindobonense B 30, 1c (400). Die Nennung des Inzests begegnet schon in den frühen lateinischen Übersetzungen der Kanones von Ankyra: Concilium Ancyritanum c. 16 (EOMIA 2, 92 f.). Im Excarpsus wird nur der Inzest genannt: Excarpsus Cummeani III 21 (615).

53 Siehe 269 Anm. 256. 
Pippins als verbindlich erachtet. Das Inzestverbot sorgte in Salzburg jedoch weiterhin für Diskussionsbedarf. Anlass dafür war der Libellus responsionum Gregors des Großen. Der Libellus war in zwei Handschriften überliefert, die der Kompilator des Bußbuchs nachweislich in Salzburg benutzte ${ }^{54}$. Im November 799, als Arn die Gerichtsversammlung über die Papst-Attentäter in Rom leitete $^{55}$, richtete er an Leo III. eine Anfrage über die Gültigkeit des Libellus und den Umfang des Inzestverbots. Leo beantwortete die Anfrage wenige Monate später in einem Brief an die Bischöfe und den Klerus des bayerischen Metropolitanverbands, der hauptsächlich dazu dienen sollte, den Gehorsam gegenüber dem neuen Metropoliten Arn einzuschärfen. Am Ende des Briefes berichtet Leo über die Anfrage Arns bezüglich des Inzestverbots, das „bis jetzt an vielen Orten nicht nach dem Kirchenrecht eingehalten wird" ${ }^{\text {"56 }}$. Grund dafür sei, so Leo III. ausdrücklich, die unzulässige Berufung auf den Libellus responsionum Gregors des Großen und die darin enthaltene Erlaubnis von Ehen im dritten Verwandtschaftsgrad. Dies widersprach offensichtlich auch dem salzburgischen Paenitentiale Vindobonense B. Leo stritt wie seine Vorgänger die Existenz des Libellus im päpstlichen Archiv ab und verwies auf den Beschluss des römischen Konzils von 743. Demnach sei die Erlaubnis nur für neu bekehrte Völker gegeben worden und habe jetzt dem kategorischen Verbot von Verwandtenehen zu weichen. Anders als seine Vorgänger präzisierte Leo das kategorische Verbot: „Allerdings haben wir beim seligen Isidor, dem Bischof von Sevilla, gefunden, dass man bis zur siebten Generation [das Verbot] einhält und dann Ehen eingeht, weil Gott am siebten Tag von seinem Werk ruhte; das Gleiche findet man auch in den Novellen der Römer ${ }^{\text {"57 }}$. Der Verweis auf Isidor und auf das römische Recht lässt keinen Zweifel darüber zu, dass Leo den siebten Grad römischer Komputation (3/4) im Auge hatte.

In den synodalen Beschlüssen dieser Zeit hat sich Arn nicht ausdrücklich zum Umfang des Inzestverbots geäußert. Er schärfte zwar den Laien wiederholt das Inzestverbot ein und übernahm auch das Gesetz Karls des Großen über die voreheliche Befragung bei Nachbarn und Verwandten, um Verwandtenehen vor

54 Wien, Österreichische Nationalbibliothek, Lat. 2195 und 2233. Vgl. MeEns, Recht 1996, 18.

55 SChiefFer, Arn 2001.

56 ... archiepiscopus rogavit nos de incestis coniunctionibus, quae usque nunc multis in locis non canonice observabantur, quamquam sunt, qui dicant sanctum Gregorium scripsisse Augustino ad Anglorum gentem: tertia propinquitate posse copulare, quod omnino in scrinio Sancti Petri non invenitur. Leo III., Epistola 5 (MGH Epp. 5, 62) (JE 2503).

57 Repperimus quippe in beato Ysidoro Spaniensi episcopo usque in septimam generationem observare et sic copulare, quia in septimo die quievit Deus ex omnibus operibus suis, et in novellis Romanorum legibus instar invenitur. Leo III., Epistola 5 (MGH Epp. 5, 62) (JE 2503). Der Herausgeber und Emil Seckel verweisen beim römischen Recht auf die Verwandtschaftstafel in Pauli Sent. IV 10: Seckel, Synode 1922, 34 Anm. 1. 
der Hochzeit zu verhindern ${ }^{58}$. Das kategorische Verbot der Päpste verkündete er jedoch nicht, er hielt offenbar an der Tradition der fränkischen Kirche fest, wie sie auch auf dem Konzil von Mainz von 813 unter seiner Beteiligung eingeschärft wurde ${ }^{59}$.

\section{Lüttich 802-809}

Aus der Kirchenreform Karls ging eine neue Quellengattung hervor, die Bischofskapitularien ${ }^{60}$. Sie gaben die herrscherlichen und konziliaren Beschlüsse an die Landpriester der Diözesen weiter und dienten damit der Umsetzung der Reformbestrebungen vor Ort. Die ersten Bischöfe, die sich dieses Instruments bedienten, waren eng mit dem Hof Karls des Großen verbunden und versuchten auf diese Weise, ihren Eifer für die Erneuerung der kirchlichen Disziplin unter Beweis zu stellen. Einer von ihnen war Bischof Gerbald von Lüttich $^{61}$. Vermutlich geht sein Bischofskapitel auf eine brieflich überlieferte Mahnung Karls des Großen zurück, eine Synode abzuhalten und verschiedene Missstände in seiner Diözese abzustellen. Gerbald war ein ausgewiesener Kenner des fränkischen Rechts und bezog sich in seinen Beschlüssen fast durchgehend auf bestimmte Vorlagen. Auch die drei von Gerbald formulierten Inzestkapitel lehnen sich eng an bestimmte Vorlagen an, nämlich an die Gesetzgebung Pippins I. Wörtlich übernimmt er das Verbot der Ehe bei geistlicher Verwandtschaft aus dem Dekret von Compiègne und aus dem ersten Kapitular Pippins $^{62}$. Die Bestimmung Gerbalds zum Umfang des Inzestverbots bei Blutsverwandtschaft ist von besonderem Interesse. Gerbald erläutert nämlich ausführlich, wie man die von Pippin erlassene Grenze des vierten Grades verstehen soll. Er zählt alle verbotenen Verwandten namentlich auf und setzt gemäß der kanonischen Zählweise den Cousin mit dem zweiten Grad gleich ${ }^{63}$.

58 In drei normativen Texten kommt Arn auf den Inzest zu sprechen: Konzil von Freising (799/800) c. 23 (MGH Conc. 2/1, 210); Capitula Bavarica c. 12 (MGH Capit. episc. 3, 197), siehe 281 Anm. 311; Capitula de examinandis ecclesiasticis c. 15 (MGH Capit. 1, 110). Zur Zuschreibung des letzten Textes an Arn vgl. Mordek - Glatthaar, Wahrsagerinnen 1993, 48.

59 Siehe 293 Anm. 15.

60 Grundlegend jetzt Pokornys Einleitung zu MGH Capit. episc. 4. Vgl. auch RhijN, Shepherds 2007.

61 Zum Folgenden vgl. EскнаRdt, Kapitulariensammlung 1955.

62 Gerbald von Lüttich, Zweites Kapitular c. 16 (MGH Capit. episc. 1, 31) nach Pippini regis capitulare c. 1 (MGH Capit. 1, 31); c. 17 ist ein Zitat von Decretum Compendiense c. 15 (MGH Capit. episc. 1, 38).

63 ... primum non matris incestor, non sororis, non materterae id est matris sororis, non amitae id est sororis patris, non privignae id est filiastram, non fratris uxorem, non avunculi uxorem, non nepotis uxorem, non quis patris uxorem concubito illicito violet, non consobrinam, id est de fratre et sorore natam aut de duobus fratribus vel de duabus sororibus, non sobrinam id est 
Wie das Konzil von Verberie lässt er das Inzestverbot bis zum Verwandtschaftsverhältnis von $4 / 4$ reichen. Ausdrücklich hält er fest, dass diese Grenze auch für verschwägerte Verwandte Geltung besitzen soll. Nach dem Dekret von Compiègne müsse nämlich ein Gesetz herrschen über Mann und Frau: Una lex id est sive de viro sive de femina ${ }^{64}$.

\section{Basel 806-813}

Bischof Haito von Basel war wie Leidrad und Arn ein führender Prälat am Hof Karls des Großen ${ }^{65}$. Gemeinsam mit zwei weltlichen Amtsträgern leitete er im Jahr 811 die Gesandtschaft nach Byzanz, um über den Kaisertitel Karls des Großen zu verhandeln und eine Anerkennung durch den oströmischen Kaiser zu erwirken. Wie Gerbald wurde er durch Karl den Großen zur Niederschrift einer bischöflichen Gesetzgebung veranlasst. In seinem Bischofskapitular versucht er, den Priestern genaue Anweisungen für die Seelsorge weiterzugeben: „Sie sollen wissen und verstehen, was das Inzestdelikt ist; und jeder soll in seiner Pfarrei Vorsorge treffen, damit das nicht geschieht; und wenn es geschehen ist, soll er möglichst schnell bestrafen "666. Der Umfang des Inzestverbots wird präzise nach dem Dekret von Verberie (756) bestimmt. Ehen im vierten Grad unterliegen der Buße, Ehen im dritten Grad werden getrennt, Ehen im ersten und zweiten Grad haben lebenslange Ehelosigkeit zur Folge ${ }^{67}$. Das Verbot der geistlichen Verwandtschaft wird gleichfalls wiederholt. Am Ende gibt Haito zu verstehen, dass er nicht alle Fälle aufgelistet hat: „Es gibt vieles, was zum Inzestverbrechen geschrieben werden könnte, so wie bei Mutter-Tochter-Inzest oder Inzest mit der Stiefmutter, und fast Zahlloses, was dem Geist beim Schreiben nicht vor Augen tritt" ${ }^{\text {"68 }}$.

Mit 15 Handschriften zählt Haitos Kapitular zu den gut bezeugten Texten der karolingischen Gesetzgebung und übertrifft deutlich die 5 Codices von Gerbalds Kapitular. Beide belegen die Anstrengungen in der Zeit Karls des Großen, die Inzestgesetzgebung Pippins im Gedächtnis des Pfarrklerus zu ver-

in tertiam generationem vel de una in tertiam de alia in quartam vel ambabus in quartam generationem ... Gerbald von Lüttich, Zweites Kapitular c. 4 (MGH Capit. episc. 1, 27).

64 Gerbald von Lüttich, Zweites Kapitular c. 4 (MGH Capit. episc. 1, 27).

65 Depreux, Prosopographie 1997, $239 \mathrm{f}$.

66 Ut sciant et intellegant, quid sit incesti crimen, et hoc unusquisque in sua parrochia praevideat, ne fiat; et si factum fuerit, quantum celerrime potuerit, emendetur. Haito von Basel, Kapitular c. 21 (MGH Capit. episc. 1, 217).

67 Id est, ut nullus sibi accipiat de propinquitate usque in quinto genu. ... Et non separentur in quarto genu, sed paenitentia cunctis diebus coniunctionis suae perseverent. ... In primo vero genu vel secundo, si inventi fuerint scelus perpetrasse fornicationis, matrimonii iura ulterius sciant se funditus perdidisse. Haito von Basel, Kapitular c. 21 (MGH Capit. episc. 1, 217).

68 Plura sunt, quae ad incesti crimen scribi poterant, sicut in matre et filia et noverca, et paene innumera, quae menti ad scribendum non occurunt. Haito von Basel, Kapitular c. 21 (MGH Capit. episc. 1, 218). 
ankern. Sie belegen auch, dass am Hof Karls weiterhin an diesen Beschlüssen festgehalten wurde. Eine Rezeption des in der Praxis untauglichen kategorischen Verbots der Verwandtenehe, wie es von den Päpsten favorisiert wurde, fand nicht statt.

\section{Orléans 820}

Mit Jonas von Orléans machen wir einen Sprung von den Vertrauten Karls des Großen zu den kirchlichen Ratgebern Ludwigs des Frommen. Jonas gehörte dem Hof Ludwigs schon in dessen Zeit als Unterkönig von Aquitanien an und wurde im Sommer 818 zum Bischof von Orléans erhoben ${ }^{69}$. Er war einer der wenigen Prälaten, die Ludwig auch in der Zeit der Aufstände und Rebellionen von 830-833 die Treue hielten und stets zu den engsten theologischen Ratgebern zählten. Kurz nach seiner Weihe zum Bischof verfasste er einen Laienspiegel (De institutione laicali) und widmete ihn dem einflussreichsten weltlichen Amtsträger am Hof, dem Grafen Matfrid von Orléans ${ }^{70}$. Seinen Laienspiegel verstand Jonas als Pendant zu den 816 verabschiedeten Regelwerken für Mönche, Kanoniker und Kanonissen. Er sollte dazu dienen, den Laien als einen in Krieg und Ehe verwickelten Stand der Gesellschaft einen Leitfaden der christlichen Lebensführung an die Hand zu geben und den Weg zur Erlösung zu weisen. Wie seine Äußerungen zur Sexualität nur allzu deutlich zeigen, war Jonas nicht gewillt war, Abstriche von den Standards der christlichen Morallehre zu machen. So setzte er sich als einer der wenigen vehement für die voreheliche Enthaltsamkeit von Männern ein und erlaubte keine Ausnahmen von dem Prinzip der Unauflösbarkeit der Ehe ${ }^{71}$.

Seine Stellungnahme zum Inzestverbot ist von ähnlicher Strenge. Im Anschluss an Augustinus hält er Inzestehen für illegitim, weil dadurch mehrere Verwandtschaftsbezeichnungen vermischt würden. Deshalb ,sollen nach der Vorschrift der christlichen Religion und der Autorität der heiligen Kirche Ehen unter Verwandten so lange vermieden werden, wie die Bezeichnungen der Verwandtschaft fortbestehen "72. Die Grenze bestimmt er mit dem siebten Grad und beruft sich erneut auf die Autorität der Kirche, auf das weltliche Recht und auf die natürliche Ordnung ${ }^{73}$. Diese unbestimmten Argumente konkretisiert er

69 DubreucQ, Jonas 1995, 13; Depreux, Prosopographie 1997, 276.

70 DubreucQ, Jonas 1995, 28; zu Matfrid vgl. Depreux, Prosopographie 1997, 329-331.

71 Jonas von Orléans, De institutione laicali II 2 (Migne PL 106, 170 f.). Reynolds, Marriage 1994, 336.

72 Tandiu vero, ut christiana religio et auctoritas sanctae ecclesiae sanxit, coniugia inter propinquos vitanda sunt, quandiu necessitudinum nomina perseverant. Jonas von Orléans, De institutione laicali II 8 (Migne PL 106, 183).

73 Auctoritate quippe sanctae dei ecclesiae, quam apostolis sibi traditam creditur observare, cui refragari fas non est; et mundanae legis censura, nec non et ipsius naturae honestissimo ordine 
nicht mit einem Verweis auf die Bibel, sondern lediglich mit einem ausführlichen Zitat des römischen Konzils von 721. Den Standard setzt also das kategorische Verbot von Verwandtenehen durch den Papst. „Und wenn jemand einwerfen wollte, dass der heilige Papst Gregor anders über die Grade der Verwandtschaft an Bischof Augustinus geschrieben hat, soll er wissen, dass er nicht der Autorität der Kirche widersprach, sondern eher dem wilden Volk Ratschläge erteilte" ${ }^{\text {“74 }}$. Zur Abschreckung vor Inzestehen erwähnt Jonas nicht nur die „apostolische Verfluchung“ des Sünders, sondern auch die weltliche Strafe der Infamie: „Wer in eine solche Ehe verstrickt ist, geht seines Adels verlustig, und die aus dieser Ehe hervorgegangenen Kinder werden nach der Vorschrift des weltlichen Gesetzes nicht zur Erbschaft zugelassen “75. Für das von Jonas anvisierte Lesepublikum war dies eine wirksame Drohung, weil mit der Verhängung der Infamie der Kern des adeligen Selbstverständnisses in Gefahr gebracht wurde.

Nachdem im Jahr 828 Graf Matfrid von Orléans in Ungnade gefallen und seines Amtes enthoben worden war, tilgte Jonas den Namen des Widmungsträgers aus seinem Laienspiegel ${ }^{76}$. Darüber hinaus brachte er Ergänzungen an und erweiterte den Text um einige Stellen. Davon war auch das Inzestkapitel betroffen. Nach der Bestimmung über die Grenze des siebten Verwandtschaftsgrads fügte er ein Zitat aus der Epistola Isidori de gradibus consanguinitatis ein. Diese Epistola aus dem Umkreis des Bonifatius war inzwischen durch die Koppelung mit Bedas Kirchengeschichte im Frankenreich bekannt geworden ${ }^{77}$. Jonas übernahm aus der Epistola nur die Bestimmung der Verwandtschaft nach den Etymologien Isidors von Sevilla ${ }^{78}$. Damit bekannte er sich ausdrücklich zur Verwendung der römischen Komputation.

\section{Cambrai 840}

Im Jahr 831 wurde Theoderich Nachfolger Halitgars von Cambrai. Anders als Jonas zählte er nicht zum inneren Kreis der kirchlichen Ratgeber Ludwigs des Frommen. Er blieb diesem jedoch durch die Zeit der Aufstände treu und wirkte

perdocetur, propinquitatis coniugia usque in septimum gradum differenda. Jonas von Orléans, De institutione laicali II 8 (Migne PL 106, 183).

74 At si quis obiicere voluerit aliter beatum papam Gregorium de gradibus propinquitatis Augustino Anglorum episcopo scripsisse, noverit illum non ut auctoritati ecclesiae contrairet, sed potius ut eidem rudi populo consuleret id fecisse. Jonas von Orléans, De institutione laicali II 8 (Migne PL 106, 184). An der Echtheit des Libellus zweifelte Jonas nicht.

75 ... qui tali coniugio innectitur, denobilitatur, et filii qui ex tali coniugio nascuntur, in haereditatem secundum humanae legis censuram non admittuntur. Jonas von Orléans, De institutione laicali II 8 (Migne PL 106, 184).

76 SCHröDER, Überlieferung 1988, 92; DubreucQ, Jonas 1995, $29 \mathrm{f}$.

77 Siehe 249 Anm. 158.

78 Isidorus itaque de consanguinitate sic loquitur: ... Jonas von Orléans, De institutione laicali II 8 (Migne PL 106, 183 f.). 
an der Absetzung des Sündenbocks Ebo von Reims im Jahr 835 mit. Später war er kaum mehr an den verschiedenen Kontroversen im fränkischen Episkopat beteiligt und führte ein eher unauffälliges Leben ${ }^{79}$.

Über die kirchenrechtlichen Anschauungen Theoderichs sind wir durch die Überlieferung seines Handbuchs in zwei Handschriften informiert. Wann er dieses Handbuch des Kirchenrechts zum Abschluss brachte, ist unklar. Mordek und Fournier votieren für eine Entstehung um 840, ohne dass sich diese Datierung näher begründen ließ $\mathrm{e}^{80}$. Wie Fournier feststellte, war das Handbuch vom Geist der karolingischen Kirchenreform geprägt. Dies äußert sich im ersten Kanon der Sammlung, dem Brief Papst Innocenz' I. an Decentius von Gubbio $^{81}$. Darin wird in unmissverständlicher Deutlichkeit die Anpassung an die Lehre der römischen Kirche in Fragen der Liturgie, der Disziplin und des Rechts gefordert. Diese Bindung an den Papst ist auch das hervorstechende Merkmal der aufgenommenen Inzestbestimmungen. Theoderich versammelt 10 Bestimmungen verschiedenster Herkunft und legt dadurch Zeugnis seines auch sonst nachweisbaren weiten Quellenhorizonts ab. Die Reihe beginnt mit einem Kapitular Karls des Großen, es folgt der Kanon von Epaon, das Aachener Konzil von 818/819, das römische Konzil von 743 (zweimal), ein Brief Gregors III., Isidor von Sevilla, das römische Konzil von 721 und Lev. 18, 682. Die Position der Päpste stellt alle anderen Quellen in den Schatten. Bezieht man ein, dass in Aachen die päpstliche Position verbindlich gemacht werden sollte und dass in Lev. 18, 6 scheinbar ein kategorisches Verbot von Verwandtenehen ausgesprochen wird, sind fast alle Inzestbestimmungen auf einer Linie. Dass dieses Verbot im Sinne der römischen Zählweise bis zum 7. Grad verstanden wurde, belegt das Zitat aus Isidor von Sevilla.

Theoderich von Cambrai ist daher wie Jonas von Orléans ein Zeuge dafür, dass die Kirchenreformer unter Ludwig dem Frommen für die päpstliche Formulierung des kategorischen Verbots von Verwandtenehen und für die römische Zählung eintraten. Als Dämon, der ausgetrieben werden sollte, galt ihnen der Libellus responsionum Gregors I. ${ }^{83}$ Gegen die Gültigkeit dieses Dokument hatte

79 Finsterwalder, Kundgebung 1928, 413-415.

80 Fournier, Notices 1926, 171; Mordek, Kirchenrecht 1975, 165; Ders., Bibliotheca 1995, 195. Die Handschriften sind: Laon, Bibliothèque Municipale, 201 und St. Petersburg, Rossiyskaya National'naya Biblioteka, Q.v.II.5. Die Identifikation der Kanones entnehme ich einem unpublizierten Manuskript von Emil Seckel im Archiv der MGH. Gerhard Schmitz bereitet eine ausführliche Untersuchung der Sammlung vor.

81 Fournier, Notices 1926, 162-173.

82 Hinzu kommt noch Capitula Cameracensia c. 8 (MGH Capit. episc. 3, 338). Der Kanon von Epaon wurde stark überarbeitet.

83 U.a. taucht der Libellus noch in drei Sammlungen des späten 8. Jahrhunderts auf, in der Collectio Herovalliana c. 71 (Migne PL 99, 1076-1081); in der Collectio Sangermanensis, vgl. Stadelmaier, Collectio 2004, 342, und in der Collectio Sancti Amandi, vgl. MaAssen, Geschichte 1870, 780-784; Kéry, Collections 1999, 84 f. Die Collectio 
sich bereits Arn von Salzburg engagiert. Diese Kontinuität täuscht jedoch über einen wichtigen Bruch hinweg. Dieser Bruch war weniger inhaltlicher als formaler Natur. In der Zeit Karls des Großen stand die Autorität von Pippins Inzestgesetzgebung unverbrüchlich fest. Karl der Große bestätigte sie im Kapitular von Herstal (779), Bischöfe im Umkreis des Hofes wie Arn von Salzburg, Haito von Basel und Gerbald von Lüttich schlossen sich daran ebenfalls an wie das Konzil von Mainz im Jahr 813. Erst nach 820 ging die Meinungsführung auf Befürworter der römischen Zählweise über. Inhaltlich unterschieden sich diese beiden Positionen kaum. Beide traten für annähernd denselben Umfang des Inzestverbots ein (3/4), beide sprachen sich für eine an der kanonischen Buße orientierte Bestrafung aus. Die Begründung war jedoch eine andere. Man berief sich nicht mehr auf die fränkische, sondern auf die päpstliche Tradition. Dies war nicht immer mit einer Unterwerfung unter den päpstlichen Primat verbunden wie bei Theoderich von Cambrai, bedeutete aber auf jeden Fall eine Bevorzugung der römischen Zählweise der Verwandtschaft. Jonas von Orléans war beispielsweise alles andere als ein Anhänger des päpstlichen Primats ${ }^{84}$, doch durch seine Herkunft aus Aquitanien war er mit den römischen Rechtsquellen vertraut. Der Wandel vollzog sich also weniger auf der inhaltlichen Ebene als auf der Ebene der Begründungsstruktur. Im Jahr 818/819 war dieser Wandel noch nicht absehbar. Der Beschluss des Aachener Konzils, die Inzestgrenze mit dem 6. Grad festzulegen, hätte als Erweiterung des Inzestverbots missverstanden werden können, zumal einige Bischöfe wenige Jahre zuvor in Mainz noch die kanonische Komputation verwendet hatten. Vermutlich wollte der Kaiser gerade wegen der umstrittenen Zählweise von einer Regelung dieser diffizilen Materie Abstand nehmen. Die Entscheidung ließ Ludwig der Fromme in seinem Kapitular ausdrücklich vertagen. Die Diskussion war eröffnet.

Sancti Amandi entschärft den Libellus durch Gregor II. JE 2174 und das römische Konzil von 721. In den 70er Jahren des 9. Jahrhunderts ist das Inzestkapitel des Libellus Teil einer Sammlung in 11 Kapitel geworden, die in 5 Handschriften als Anhang zu Hrabans Paenitentiale ad Heribaldum verbreitet war: Коттје, Bußbücher 1980, 111-131. Erstmals fassbar ist diese Sammlung zum Inzestverbot in München, Bayerische Staatsbibliothek, Clm 3851 aus Lothringen, Ende 9. Jahrhundert: Bischoff, Katalog 2 2004, 226. Ferner begegnet dieses Kapitel des Libellus auch in einem bislang unbekannten Gutachten zum Konzil von Mainz 861-863, siehe 363 Anm. 367.

84 DubreucQ, Jonas 1995, 76-78. 


\subsection{Der Standpunkt des Theologen: Hrabanus Maurus}

Das umfangreichste Dossier zum Inzestverbot aus der Karolingerzeit stammt von Hrabanus Maurus ${ }^{85}$. In zwei Bußbüchern, mehreren Gutachten und auf drei von ihm geleiteten Synoden bezog er zum Teil mit großer Ausführlichkeit Stellung. Die Gutachten und Bußbücher widmete er bedeutenden Bischöfen im westlichen und östlichen Frankenreich. Somit ist mit einer großen Ausstrahlung seines Standpunkts zu rechnen. Darüber hinaus befand er sich in engem Kontakt mit den karolingischen Herrschern. Bereits als Abt von Fulda griff er für Kaiser Ludwig den Frommen und seine Gemahlin Judith zur Feder, später widmete er den Söhnen Ludwigs (Lothar I. und Ludwig dem Deutschen) einige exegetische Werke. Seine Parteinahme für Ludwig den Frommen in den Jahren der innerdynastischen Konflikte hatte zur Folge, dass er im Jahr 841/842 vom Amt des Abtes von Fulda zurücktrat. Nach der Versöhnung mit seinem neuen Herrscher, Ludwig dem Deutschen, erlangte er im Jahr 847 das Erzbistum von Mainz $^{86}$. Als führender Prälat des ostfränkischen Reichs stand er den Synoden von 847,848 und 852 vor und lenkte die Kirchenpolitik Ludwigs bis zu seinem Tod im Jahr 856.

\section{Der Umfang des Inzestverbots}

Von seinen Zeitgenossen wurde Hrabanus vor allem als Fachmann für Bibelexegese geschätzt ${ }^{87}$. Er verfasste Kommentare zu fast allen Büchern des Alten und Neuen Testaments und konnte sich so bei den karolingischen Herrschern als Spezialist für das biblische Gesetz empfehlen. Im Rahmen dieser exegetischen Tätigkeit befasste er sich erstmals mit dem Inzestverbot ${ }^{88}$. In den zwanziger Jahren des 9. Jahrhunderts ${ }^{89}$ fertigte er auf Bitten seines Freundes, des Bischofs Frechulf von Lisieux, einen Kommentar zum Buch Levitikus an. Eine persönliche Stellungnahme suchen wir darin allerdings vergebens. Wie auch in seinen anderen Kommentaren beschränkt er sich auf Zitate aus Werken anerkannter Autoritäten und äußert nur gelegentlich einen eigenen Standpunkt ${ }^{90}$. In erster Linie stellt Hrabanus seine enge Vertrautheit mit der exegetischen Tradition zu den biblischen Inzestverboten unter Beweis. Besonders ein langes Zitat aus Augustins Quaestiones in Heptateuchum ist von Bedeutung. Augustinus stellt sich darin die Frage, wie das kategorische Verbot von Verwandtenehen in Lev. 18, 6

85 Zur Biographie vgl. Raymund Kоттје, Art. „Hrabanus Maurus“, in: VL 24 (1983) 166196; Depreux, Prosopographie 1997, 250-252.

86 Vgl. Hartmann, Ludwig 2002, 174 f.; Bigott, Ludwig 2002, 98 f.

87 Raymund Коттје, Art. „Hrabanus Maurus“, in: VL² 4 (1983) 172; Jong, Hrabanus 1995; DIEs., Empire 2000.

88 Unbeachtet bei Corbet, Burchard 2001, 10-16.

89 Zur Datierung vgl. Hrabanus, Ep. 10 (MGH Epp. 5, 396 f.).

90 Vgl. Heil, Juden 1998, 252-274. 
zu verstehen ist $^{91}$. Er gibt dabei zu bedenken, dass bei weit entfernter Verwandtschaft keine Bedenken gegen eine Eheschließung erhoben werden können. Das kategorische Verbot sei daher auf die in Levitikus namentlich genannten Eheverbindungen in der näheren Verwandtschaft zu beschränken. Des weiteren macht Augustinus auf den Widerspruch zwischen dem Verbot des Levirats in Levitikus und dem Gebot der Leviratsehe in Deuteronomium aufmerksam $^{92}$. Er erwägt deshalb eine Einschränkung dieses Verbots: Es soll verbindlich sein, wenn der Bruder Söhne hinterlassen hat oder wenn die Frau vom Bruder verstoßen wurde. Das Sororat hält Augustinus nur für verboten, wenn jemand zu Lebzeiten seiner Frau ihre Schwester heiratet.

Beide Stellungnahmen Augustins stehen im Widerspruch zur etablierten Gesetzgebung im Frankenreich. Seit dem 6. Jahrhundert sahen die fränkischen Bischöfe in Lev. 18, 6 eine Legitimationsquelle für die Ausdehnung des Inzestverbots. Ebenso wird die lange Tradition innerhalb der Kirche, Sororat und Levirat gleichermaßen zu verbieten, durch Augustinus deutlich in Frage gestellt. Hraban nahm diese Stellungnahmen zur Kenntnis und zog sie später für seine Gutachten heran. Innerhalb der Bibelkommentare äußert er sich nur einmal selbständig zum Inzestverbot. Im Kommentar zu Deuteronomium verweist er bei den Verwünschungen auf Levitikus, wo das Verbrechen des Inzests mit dem Feuertod bestraft wird: „weil derjenige dem Feuer der Hölle verfallen ist, der sich nicht durch das Feuer der Buße von diesem Schandfleck gereinigt hat ${ }^{\text {(93 }}$.

Dieser theologische Standpunkt sollte seine späteren Expertisen zum Inzestverbot entscheidend prägen. Die erste Anfrage richtete Bischof Humbert von Würzburg an Hrabanus in den Jahren zwischen 832 und 842. Anlass für die Verwirrung Humberts war der Widerspruch zwischen dem Libellus responsionum auf der einen Seite und dem Konzil von Rom (743) und Isidor von Sevilla auf der anderen Seite ${ }^{94}$. Die Kombination dieser Quellen lässt vermuten, dass Humbert den im östlichen Frankenreich verbreiteten Anhang zur Dionysio-

91 Quaeritur quousque sit intelligenda ista cognatio, cum ex longo gradu licet utique accipere uxorem, semperque licuerit. Sed intelligendum est ex his gradibus, quos prohibuit non licere; et secundum ipsos dictum: ,Quicunque dormierit cum cognata sua'. Augustinus, Quaestiones in Heptateuchum, Lev. 76 (CSEL 28/2, 299 f.). Zitiert von Hrabanus, Expositiones in Leviticum V 12 (Migne PL 108, 469).

92 Augustinus, Quaestiones in Heptateuchum, Lev. 61 (CSEL 28/2, 291 f.). Zitiert von Hrabanus, Expositiones in Leviticum V 11 (Migne PL 108, 437).

93 ... quia ut in Levitico de hoc scelere sancitum est, igne vivus debet comburi qui hoc perpetraverit, quia reus est gehennae ignis si non poenitentiae igne se ab hac macula diluerit. Hrabanus Maurus, Enarratio in Deuteronomium III 25 (Migne PL 108, 951).

94 Ubi et commemorabas te quaedam capitula legisse papae Gregorii ad Augustinum, gentis Anglorum pontificem, necnon et decreta Zachariae papae de eadem re; similiter quoque quid Isidorus Hispaniensis episcopus in Ethimologiis suis inde senserit, notum habere. Hrabanus, Ep. 29 (MGH Epp. 5, 445). 
Hadriana vor Augen hatte ${ }^{95}$. Hraban beginnt sein Gutachten mit dem vollständigen Zitat von Levitikus 18, 1-18 und rückt damit gemäß seiner exegetischen Ausbildung das biblische Gesetz in den Mittelpunkt. Er erklärt, Gott habe zwar zuerst mit einer allgemeinen Bezeichnung Verwandtenehen generell untersagt, dies aber mit der Nennung von 12 verbotenen Verwandten konkretisiert. Dieses Verbot „geht nicht über die dritte oder vierte Generation hinaus ${ }^{\text {"96. }}$. Daher ist nach Hrabanus der Standpunkt des Libellus responsionum durchaus gerechtfertigt, weil dieser ebenfalls Ehen im dritten und vierten Grad zulasse. Im gleichen Sinn habe auch Bischof Theodor von Canterbury in seinem Bußbuch geurteilt. Dem stehe die Ausdehnung des Inzestverbots auf den sechsten oder siebten Grad durch die Päpste entgegen. Diese Position hält Hrabanus jedoch nicht für verbindlich, weil bereits Bonifatius sie abgelehnt und deshalb eine Anfrage an angelsächsische Bischöfe gerichtet habe. „Man soll glauben, dass sie dies eher aus menschlicher Gewohnheit als aus göttlichem Recht vorgeschrieben haben "97.

Hrabans Stellungnahme ist alles andere als leicht verständlich. Insbesondere die Zählweise hat in der Forschung für divergente Erklärungen gesorgt. Während Joseph Freisen Hraban die kanonische Zählweise zuschreibt, unterstellen Jean Fleury und Patrick Corbet die römische Komputation ${ }^{98}$. Ich halte die Meinung Fleurys und Corbets für richtig. Nur so ist seine Aussage verständlich, dass die Bibel nicht über den dritten oder vierten Grad hinausgeht, denn in Levitikus bildet die Heirat mit der Tante (2/1) die Grenze des Inzestverbots. Hraban lässt wohl absichtlich eine Ungenauigkeit einfließen, indem er den in der Bibel nicht angesprochenen vierten Grad ins Spiel bringt. Dieser Kunstgriff erlaubt es ihm, die Position der Bibel mit derjenigen Gregors des Großen gleichzusetzen, der die Heirat im dritten oder vierten Grad erlaubt. Die kanonische Zählweise Gregors I. im Libellus hat Hraban entweder wie Bonifatius nicht zur Kenntnis genommen oder absichtlich verschwiegen. Angesichts dieser Unsicherheit ist man geneigt, der rhetorischen captatio benevolentiae Glauben zu schenken, wonach Hrabanus keine Zeit für eine sorgfältige Prüfung der Sach-

95 Siehe 297 Anm. 30. In diesem Dossier ist der Libellus indirekt im Text des Konzils von Rom (743) zitiert.

96 Deinde ipsam generalitatem formae in XII species subdivisit, quae tamen ultra tertiam vel quartam generationem non procedunt. Hrabanus, Ep. 29 (MGH Epp. 5, 446).

97 Quod autem proximis temporibus Romanorum pontificum scripta continent usque ad sextam vel septimam generationem coniugii usum esse differendum magis ex consuetudine humana quam ex lege divina hoc eos precepisse credendum est. Hrabanus, Ep. 29 (MGH Epp. 5, 446). Die Festlegung auf den sechsten bzw. siebten Grad war Hraban aus dem Briefwechsel des Bonifatius bekannt (siehe 244 Anm. 134), vielleicht auch aus der Epistola de gradibus consanguinitatis.

98 Freisen, Geschichte 1893, 412; Fleury, Recherches 1933, 237; Corbet, Burchard 2001, 10 . 
frage gehabt und nur in Eile aus seinem Gedächtnis die wichtigsten Autoritäten zusammengetragen habe ${ }^{99}$. Andererseits ist die Intention Hrabans nur allzu deutlich. Er nimmt absichtlich für eine bestimmte Tradition Stellung, für die Tradition der Bibel, Gregors I. und Theodors von Canterbury. Ablehnend steht er dagegen dem kategorischen Verbot von Verwandtenehen durch die Päpste gegenüber. Obwohl er die Bestimmungen des römischen Konzils von 721 mit Sicherheit gekannt hat ${ }^{100}$, zitiert er sie nicht ausdrücklich. Hrabans Bibelexegese, in der das kategorische Verbot ausdrücklich als falsche Interpretation von Lev. 18, 6 zurückgewiesen wird, ist im Hintergrund präsent. Ebenso rückt er deutlich von der Ausweitung auf den sechsten oder siebten Grad ab. Er kennzeichnet diese Position der Päpste als Neuheit ${ }^{101}$ und stellt ihr die ältere Tradition gegenüber, die von Gregor I. und von Theodor von Canterbury repräsentiert wird. Bei Theodor stellt er ausdrücklich fest, dass er in Kilikien geboren wurde und von Papst Vitalian nach Britannien geschickt wurde. „Deshalb war er sowohl mit den Gebräuchen der östlichen wie der westlichen Kirchen vollkommen vertraut, und nichts konnte ihm verborgen sein, was die Griechen oder Römer damals als rechtmäßige Observanzen einhielten “102.

Seit Bonifatius wurde also erstmals wieder der Widerspruch der verschiedenen Traditionen deutlich angesprochen und eine Lanze für die Beschränkung auf das biblische Inzestverbot gebrochen. Hrabanus rechtfertigte sein Eintreten für die ältere und mildere Position durch eine seelsorgerliche Erwägung. „Im Übrigen muss man vor allem in Betracht ziehen, dass die disziplinäre Strafe so abgemildert wird, dass nicht durch die Unverhältnismäßigkeit der Strafe die Masse der Sünden vermehrt werde ${ }^{\text {“103 }}$. Besondere Sorge bereiteten Hraban zwei Folgen eines zu umfassenden Inzestverbots. Erstens könnte das Auffinden einer „auch noch so weit entfernten Blutsverwandtschaft" der Eheleute als Vorwand für eine Ehescheidung herangezogen werden ${ }^{104}$. Zweitens würde man den Jugendlichen unnötig hohe Hürden für die Suche nach einer Gattin aufbauen und

99 ... breviter haec commemorans quae legisse me recordatus sum vel quae subito dictanti in mentem venerant. Hrabanus, Ep. 29 (MGH Epp. 5, 445).

100 Bereits in De institutione clericorum verwendet er die Dionysio-Hadriana: PICKer, Pastor 2001, 37.

101 ... proximis temporibus ... Hrabanus, Ep. 29 (MGH Epp. 5, 446).

102 ... unde et tam orientalium quam occidentalium ecclesiarum consuetudinibus pleniter institutus fuerat, nec eum aliqua latere potuerunt, quae in observationibus legitimis Greci vel Romani eo tempore habuerunt, maxime cum in utraque lingua perfecte instructus esset. Hrabanus, Ep. 29 (MGH Epp. 5, 446).

103 Caeterum ante omnia considerandum est, ut sic censura disciplinae temperetur, ne per inmoderationem correptionis peccati cumulus augeatur. Hrabanus, Ep. 29 (MGH Epp. 5, 447).

104 Si enim, ubicumque aliquid proximitatis vel consanguinitatis licet longinquae inter coniugatos invenire potest, statim matrimonium dissolvitur, vereor, quod adulterium et fornicationis scelus multiplicetur... Hrabanus, Ep. 29 (MGH Epp. 5, 447). 
sie so zu Ehebruch und Unzucht verleiten ${ }^{105}$. „In Anbetracht dessen halte ich es für gut, dass die Vorschrift des heiligen Gesetzes unverletzt eingehalten und ein Ärgernis für die Menschen abgewendet wird “106. Abschließend votierte Hraban daher für einen Mittelweg zwischen der Position Gregors I. und dem Standpunkt der zeitgenössischen Päpste. Das Inzestverbot sollte bis in den vierten Grad (2/2) Geltung besitzen, Eheleute, die im fünften Grad verwandt waren, sollten nur der Buße unterworfen werden ${ }^{107}$.

Diese Position behielt Hraban in allen weiteren Stellungnahmen bei. In dem Gutachten an den Chorbischof von Mainz Reginbald (vor 842) zitierte er ausdrücklich seine Schrift an Humbert und schärfte eigens nochmals die Vorschriften der Bibel (lex divina) ein ${ }^{108}$. Ein anderer Gesprächspartner, sein Nachfolger Abt Hatto von Fulda, gab sich mit dieser Auskunft nicht zufrieden und bat um ein ausführlicheres Gutachten (842). Hatto hatte „gemäß seiner Gewohnheit hartnäckiger nachgeforscht und sorgfältiger nachgeprüft ${ }^{\text {“109 }}$ und ist dabei auf die Schwierigkeit gestoßen, ob man das Alte Testament als Grundlage für das Inzestverbot des christlichen Zeitalters heranziehen dürfe. Hatto wandte ein, dass die von Hraban angeführten Zeugnisse des Alten Testaments nicht für die Gegenwart der christlichen Religion Geltung beanspruchen könnten ${ }^{110}$. Dieser Einwand zielt mit Sicherheit nicht auf eine vollständige Aufhebung der Inzestverbote aus Levitikus, sondern auf die notwendige Überbietung des Judentums durch das Christentum, wie sie in den päpstlichen Äußerungen zum Inzestverbot gefordert worden war ${ }^{111}$. Hraban entgegnet diesem Einwand mit langen Ausführungen zur Gültigkeit des Alten Testaments. In Anlehnung an Ambrosius und Augustinus kommt er zu dem Schluss, die moralischen Vorschriften seien als lex naturalis „nicht zu verachten“ und sollten als Richtschnur

105 ... cum coniugato adolescenti vel iuveni societas conparis suae denegetur, ... libidine inflammatus per diaboli instigationem multiplici fornicatione forsan polluitur. Hrabanus, Ep. 29 (MGH Epp. 5, 447).

106 His ergo omnibus consideratis bonum mihi videtur, ut legis divinae constitutio inviolata servetur et scandalum, quantum ad homines pertinet, pro facultate virium declinetur... Hrabanus, Ep. 29 (MGH Epp. 5, 447).

107 ... reor hoc quod Theodorus archiepiscopus, inter Gregorium et Isidorum medius incedens, in suis capitulis definivit, magis sequendum, ut post quintam generationem iam licitum conubium sit ... Si autem et in quinta ab insciis copula fuerit peracta, melius mihi videtur, ut cum paenitentiae humiliatione, si se uxoratus continere non vult, Deo satisfaciat ... Hrabanus, Ep. 29 (MGH Epp. 5, 447).

108 Sed illud ibi praecipue considerandum est, quid lex divina inde praecipiat. Hrabanus, Ep. 30, 3 (MGH Epp. 5, 450).

109 ... semper iuxta consuetudinem tuam astutius inquirebas et diligentius investigabas ... Hrabanus, Ep. 31 (MGH Epp. 5, 455).

110 Hrabanus, Ep. 31 (MGH Epp. 5, 455).

111 Siehe 254 Anm. 180. 
für die Gegenwart dienen ${ }^{112}$. „Wenn man dem Gesetz Gottes zustimmt und seinem Inhalt Glauben schenkt, bewährt man sich als ergebener Schüler der Wahrheit und als überaus sorgfältiger Wächter der göttlichen Befehle“113.

Aufgrund der Einwände Hattos fühlte sich Hraban ein weiteres Mal genötigt, den Libellus responsionum Gregors des Großen gegen Anfeindungen in Schutz zu nehmen. An seiner Gültigkeit gebe es keinen Zweifel, weil Gregors Ansicht mit den Vorschriften aus Levitikus und mit der Auslegung dieser Vorschriften durch Augustinus harmoniere. An zwei Stellen betont er, dass Gregor mit dem Gesetz Gottes und den Aussprüchen der Kirchenväter übereinstimmen und nicht „aus sich heraus etwas Neues festlegen wollte ${ }^{\text {“114 }}$. Zur Bestätigung dieses Standpunktes führt Hraban noch eine Reihe von Konzilskanones an. Daran ist sein Bestreben zu erkennen, die gesamte kirchenrechtliche Tradition mit einzubeziehen. Im ersten Gutachten an Humbert hatte ihm offensichtlich die Zeit dazu gefehlt. Im Brief an Hatto stellt Hraban einige Kanones aus der Collectio Hispana und aus der Collectio Dionysio-Hadriana zusammen ${ }^{115}$. Bezeichnend ist, dass er jeweils das in ihnen enthaltene kategorische Verbot von Verwandtenehen außer Acht lässt. Sowohl der fünfte Kanon des 2. Konzils von Toledo als auch der Kanon 9 des römischen Konzils von 721 werden von Hraban stillschweigend unterdrückt. Besonders erstaunlich ist das Fehlen des Kanons von Rom 721, da er die anderen einschlägigen Beschlüsse dieses Konzils sehr wohl zitiert ${ }^{116}$. Als einzige Bestimmung über den Umfang des Inzestverbots bleibt deshalb der Kanon von Epaon in der Fassung der Hispana ${ }^{117}$. Da dort das Wort sobrina fehlt, erstreckt sich das Inzestverbot nur bis zur Ehe mit der Cousine (2/2). Hraban beendet seinen Überblick mit der gegen die päpstliche Position gerichteten bissigen Bemerkung, in den Kanones werden weder der Ururururenkel, die Ururururenkelin noch der Enkel und die Enkelin des Ururururenkels erwähnt ${ }^{118}$.

„Deshalb glaube ich, das sei eher zu befolgen, was die göttliche Autorität in den beiden Testamenten als heilig festsetzte und was nach ihrem Beispiel die Aussprüche

112 Hrabanus, Ep. 31 (MGH Epp. 5, 456).

113 ... quia in hoc se quisque probat ipsius veritatis devotum esse discipulum et mandatorum Dei custodem diligentissimum, si consentiat legi Dei et credit illis, quae in ea scripta sunt. Hrabanus, Ep. 31 (MGH Epp. 5, 457).

114 ... quia legi Dei et sanctorum patrum sententiis magis studuit concordare, quam nova ex suo sensu condere ... an de suo aliquid noviter constituerit. Hrabanus, Ep. 31 (MGH Epp. 5, 457).

$115 \mathrm{Zu}$ diesen Quellen Hrabans vgl. Коттje, Bußbücher 1980, 192-198.

116 Dies hat bereits Corbet, Burchard 2001, 14, beobachtet.

117 Hrabanus, Ep. 31 (MGH Epp. 5, 458), zitiert als Kanon von Agde, vgl. Коттје, Bußbücher 1980, 194.

118 Non enim hic de trinepote sive de trinepte aut de trinepotis nepote seu trinepotis nepte aliquid dicitur aut specialiter enumeratur. Hrabanus, Ep. 31 (MGH Epp. 5, 458). Vgl. Corbet, Burchard 2001, 14. 
vieler Väter auf Synoden als Recht bekräftigte, als was jeder nach seinem Gutdünken und durch eigenes Dafürhalten anordnete"119.

Wenn sich jemand trotzdem bis zum fünften, sechsten oder siebten Grad enthalten wolle, solle er dies als asketische Regel, nicht aber als bindende Vorschrift auffassen $^{120}$.

Wie in der Literatur schon mehrfach beobachtet wurde, kämpft Hraban für seine Position mit harten Bandagen ${ }^{121}$. Die gegnerische Position wird absichtlich ins Lächerliche gezogen und als neuerungssüchtige Abkehr von der biblischen Tradition diffamiert. In dieser sich zunehmend verhärtenden Argumentation schreckt Hraban auch nicht vor Verfälschungen zurück, indem er die ihm nicht genehmen Konzilsbeschlüsse unterdrückt. Besonders auffällig ist sein Insistieren auf der Verhinderung von Neuerungen: „Ich habe nicht gewagt, aus mir heraus etwas Neues vorzutragen “122. In einer anderen, noch viel härter ausgefochtenen Debatte spricht Hraban seine konservative Grundeinstellung ohne Umschweife aus. Im Rahmen des Konflikts mit Gottschalk dem Sachsen ${ }^{123}$ schreibt er:

„Die Vermessenheit der Neuerung ist nämlich die Mutter der häretischen Verkehrtheit. ... Warum ist es notwendig, jetzt wegen des Beifalls menschlichen Lobs überflüssige Dogmen neu vorzutragen, was die heiligen Lehrer von Anfang an immer in Schrift und Predigt vermieden haben?"124

Hraban sieht sich also als Verfechter der biblischen und altkirchlichen Tradition gegen die Neuerungen seiner Zeit.

In den Bußbüchern und Konzilskanones bleibt Hraban dieser Linie treu. Die beiden Bußbücher, gewidmet an Erzbischof Otgar von Mainz und Bischof Heribald von Auxerre, enthalten im Wesentlichen dieselben oben erwähnten Kanones aus der Dionysio-Hadriana und aus der Hispana ${ }^{125}$. Er vermeidet auch in diesen Schriften die Erwähnung des kategorischen Verbots sowie die Nen-

119 Unde magis arbitror hoc sequendum, quod divina auctoritas in duobus testamentis sancivit et quod iuxta eius exemplum plurimorum patrum sententia in communi conventu servandum constituit, quam quod quilibet iuxta libitum suum coniectura propria sequendum esse decreverit. Hrabanus, Ep. 31 (MGH Epp. 5, 458).

120 Hrabanus, Ep. 31 (MGH Epp. 5, 458).

121 Fleury, Recherches 1933, 237-240; Corbet, Burchard 2001, 13.

122 Ego quoque, quia ex meo aliquid noviter non ausus sum proferre ... Hrabanus, Ep. 31 (MGH Epp. 5, 458).

123 JoNG, Oblation 1996, 73-91.

124 Novitatis enim presumptio mater est hereticae pravitatis ... Quid enim necesse est modo propter favorem humanae laudis in dogmatibus superfluis noviter proferre quod sancti doctores ab initio semper refugierunt scribere atque predicare. Hrabanus, Ep. 45 (MGH Epp. 5, 499). Vgl. auch Ep. 39 (MGH Epp. 5, 477). Zu dieser Grundeinstellung vgl. Picker, Pastor 2001, 92-96.

125 Hrabanus, Paenitentiale ad Otgarium c. 2 (Migne PL 112, 1405 f.); Hrabanus, Paenitentiale ad Heribaldum c. 20 (Migne PL 110, 485-487). 
nung der sobrina (3/3) als verbotene Verwandte. Auf dem Konzil von Mainz, das Hraban kurz nach seiner Erhebung zum Erzbischof leitete, kombinierte er geschickt verschiedene Vorlagen, um seine eigene Position zur Geltung zu bringen. Scheinbar wiederholt er den Kanon von Mainz 813 mit dem bis zum vierten Grad reichenden Inzestverbot, versteht dieses Verbot allerdings im Sinne der römischen Zählung ${ }^{126}$. Dies macht er dadurch deutlich, dass er zuvor in einer abenteuerlichen Camouflage verschiedener Quellen alle verbotenen Verwandten ausdrücklich auflistet ${ }^{127}$. Diese Liste reicht wie auch sonst bei Hraban nur bis zur Cousine (2/2). Denselben Umfang des Inzestverbots bestätigt er nochmals in einem kurz danach abgehaltenen Konzil ${ }^{128}$.

Die Konsequenz, mit der Hraban seinen Standpunkt propagierte, ist beeindruckend. $\mathrm{Zu}$ Recht hat Patrick Corbet ihm in der Frage des Inzestverbots „modération et indépendance d'esprit“ zugeschrieben ${ }^{129}$. Er stand weder dem unter Pippin I. und Karl dem Großen erreichten Standard nahe noch dem Anliegen der Kirchenreformer unter Ludwig dem Frommen. Hatten diese Kreise in der Ausdehnung des Inzestverbots auf den siebten Grad (3/4) übereingestimmt, hielt Hraban an den biblischen Inzestverboten fest. Dass er mit dieser Einstellung nicht vollkommen alleine dastand, zeigt sein Hinweis auf die Verwunderung des Bonifatius hinsichtlich der damals neu erlassenen Inzestverbote des Papstes ${ }^{130}$. Er war mit der von Bonifatius befürworteten angelsächsischen Tradition der Inzestgesetzgebung bestens vertraut, da er eine neue Ausgabe seiner Briefe herstellte ${ }^{131}$. Diese angelsächsische Tradition war mit dem Tod des Bonifatius im Jahr 754 nicht untergegangen. In den Bußbüchern aus dem Schülerkreis des Missionars lässt sich weiterhin eine Beschränkung auf die biblischen Inzestverbote beobachten ${ }^{132}$. Das beste Zeugnis dafür ist das erst

126 Contradicimus quoque, ut in quarta generatione nullus amplius coniugio copuletur; ubi autem post interdictum factum inventum fuerit, separetur. Konzil von Mainz (847) c. 30 (MGH Conc. 3, 175 f.).

127 Konzil von Mainz (847) c. 29 (MGH Conc. 3, 175). Hrabanus kombiniert Konzil von Mainz (813) c. 56 mit dem Konzil von Epaon (517) c. 30.

128 Dieses Mainzer Konzil zitiert er im Paenitentiale ad Heribaldum c. 20 (Migne PL 110, 487). Nach Коттје, Bußbücher 1980, 203, zählt der Kanon „zu im übrigen nicht erhaltenen Mainzer Konzilsbeschlüssen aus der Zeit Hrabans“.

129 CORBEt, Burchard 2001, 16.

130 Quod ita sentiens beatus Bonifatius martyr nosterque patronus de eadem re episcopos gentis suae credidit consulendos, ut ipsi, quid in sanctorum patrum sententiis inde explanatum invenirent, sibi rescriberent. Hrabanus, Ep. 29 (MGH Epp. 5, 446). Machielsen, Supplément 1963, bezieht dies auf die verlorene Anfrage, der die Epistola de gradibus consanguinitatis Antwort gibt.

131 TANGL, Studien 1916, 687.

132 In den unter den Namen Bedas und Egberts kursierenden Bußbüchern wird nur die enge Verwandtschaft genannt: Paenitentiale Ps.-Bedae II 17-18 (557); Paenitentiale Ps.-Egberti IV 3-6 (576). Beide sind vermutlich Ende des 8. Jahrhunderts in Lorsch 
jüngst entdeckte Paenitentiale Oxoniense II. Nach Ludger Körntgen ist es um 750 im Bereich der friesischen Mission entstanden ${ }^{133}$. Dort war der Musterschüler des Bonifatius Gregor von Utrecht gemeinsam mit Missionaren angelsächsischer Herkunft tätig ${ }^{134}$. Der Autor des Bußbuchs beschränkte sich wie Bonifatius auf die biblisch verbürgten Inzestverbote der Schwägerschaft und unterschlug völlig das Ehehindernis der geistlichen Verwandtschaft ${ }^{135}$. Ein anderer Angelsachse, Alkuin von York, ist möglicherweise ebenfalls dieser Tradition zuzurechnen. In der von ihm verfassten Admonitio generalis heißt es, unerlaubte Ehen sollten insoweit verboten werden, wie es das Gesetz des Herrn verbiete $^{136}$. Wenn dies ein Verweis auf Levitikus ist und die unerlaubten Ehen als Inzestehen zu verstehen sind ${ }^{137}$, wäre diese Bestimmung als deutlicher Hinweis auf sein Eintreten für die biblische Tradition zu werten. Alkuins Vorbehalte gegen das Kirchenrecht kamen auch in seinen anderen Schriften zum Ausdruck $^{138}$. An der Hofschule Karls des Großen wirkte der angelsächsische Gelehrte als Lehrer Hrabans und gab ihm den Beinamen Maurus. Es ist also durchaus denkbar, dass Hrabanus sich diese angelsächsische Tradition nicht nur später angeeignet hat, sondern dass er über Alkuin direkt mit ihr verbunden $\operatorname{war}^{139}$.

\section{Öffentliche und private Buße}

Corbets Urteil über Hrabans „Zurückhaltung“ bedarf jedoch der Einschränkung. Zurückhaltend war er nämlich nicht aus Prinzip, sondern aus Treue zum biblischen Text und aus seelsorgerlichen Erwägungen. Dies zeigt sich in seinen durchaus unnachgiebigen und strengen Ausführungen zur Buß- und Strafpraxis

entstanden: HaggenmüLler, Rezeption 1992, 158. Für den Kreis um Bonifatius votiert Glatthaar, Bonifatius 2004, 626.

133 Körntgen, Studien 1993, 192-205. Meens, Christentum 2000, will das Bußbuch Willibrord zuschreiben. Da er sich aber nur auf sehr allgemeine Argumente stützen kann, wird diese Zuschreibung von КоттјЕ, Einleitung (CCL 156, XXX), zurückgewiesen.

134 Liudger, Vita Gregorii c. 9 (MGH SS 15/1, 74); vgl. Schipperges, Bonifatius 1996, 79-81.

135 Paenitentiale Oxoniense II, c. 3, 11, 12, 22 (CC 156, 191-195); vgl. Körntgen, Studien 1993, 179-181. Die Unterschlagung der geistlichen Verwandtschaft korreliert mit der Haltung des Bonifatius.

136 Item et furta et iniusta conubia necnon et falsa testimonia, sicut saepe rogavimus, prohibete diligenter, sicut et lex domini prohibet. Admonitio generalis c. 68 (MGH Capit. 1, 59). Bereits auf der von Alkuin dominierten Synode des Legaten Georg von Ostia in England (786) ist von einem Verbot von iniusta connubia et incaestuosa zu lesen: Alkuin, Ep. 3 c. 15 (MGH Epp. 4, 25). Zur Synode vgl. Cubitt, Councils 1995, 153-190; Story, Connections 2003, 55-92. Vgl. außerdem Alkuin, Ep. 16 (MGH Epp. 4, 43).

137 In diesem Sinn Hartmann, Reform 1986, 62.

138 Vgl. Wallach, Alcuin 1959, 133-140; Hartmann, Reform 1986, 64.

139 Die Prägung durch die Geisteshaltung Alkuins betont neuerdings überzeugend Picker, Pastor 2001, $249 \mathrm{f}$. 
des Inzests. Bereits in seinen Bibelkommentaren stellt er unmissverständlich fest, dass die im Alten Testament für einige Inzestdelikte angedrohte Todesstrafe im Neuen Testament in die Strafe der ewigen Höllenqualen umgewandelt wird ${ }^{140}$. Dieser Grundsatz durchzieht sein gesamtes bußtheoretisches Werk ${ }^{141}$. Am deutlichsten hat er ihn im Widmungsbrief an Heribald von Auxerre ausgesprochen:

„Wenn nämlich gemäß dem historischen Schriftsinn der Gesetzgeber den Übertretern der göttlichen Vorschriften mit dem fleischlichen Tod und dem Ende des zeitlichen Lebens gedroht hat, müssen wir dann nicht umso mehr gemäß der evangelischen und apostolischen Doktrin des Heilands den Tod der Seele und die ewige Strafe fürchten? ... Deshalb ist es notwendig, dass wir im gegenwärtigen Leben unsere Glieder abtöten ..." ${ }^{\text {142 }}$

Die altkirchliche kanonische Buße ist für Hraban die angemessene Form, um in diesem Leben die Bestrafung durch Höllenqualen abzuwenden. Seine Bußbücher beabsichtigen in der Tradition der unter Karl dem Großen einsetzenden Kirchenreform die irische und angelsächsische Tarifbuße zu verdrängen und stattdessen die Vorschriften der Alten Kirche über die öffentliche Buße wieder zu beleben ${ }^{143}$.

Die Konsequenzen dieser Wiederbelebung der altkirchlichen Tradition hat Hraban in den unter seiner Leitung tagenden Konzilien angesprochen. Auf dem Konzil von 847 heißt es, dass die Eheleute getrennt und einer Buße unterworfen werden sollten. Das Recht auf eine weitere Eheschließung hätten die des Inzests überführten Eheleute verwirkt ${ }^{144}$. Den konkreten Ablauf der Buße hat Hrabanus mit bislang unbekannter Präzision in einem anderen Mainzer Konzil festgelegt:

„Von dem Besuch der Kirche soll (der Büßer) sich ein Jahr enthalten, und in demselben Jahr soll er außer an den besonderen Festtagen nur Brot, Wasser und Salz verzehren. Kriegswaffen darf er nicht tragen, niemandem den Kuss darreichen, die Kommunion nicht nehmen außer im Todesfall. Die folgenden sechs Jahre kann er das Gotteshaus betreten, aber Fleisch, Wein und gegorene Getränke darf er nicht verzehren außer an den herausragenden Festtagen. In Hinsicht auf Waffen, Kuss und Eucharistie bleibt es wie oben festgelegt. Danach soll er sich die nächsten zwei

140 Siehe 309 Anm. 93. Vgl. Augustinus, Quaestiones in Heptateuchum V 39 (CSEL 28/2, 399).

141 Коттје, Bußbücher 1980, 213-216; Jong, Hrabanus 1995.

142 Si enim iuxta historiam legislator transgressoribus mandatorum dei minatus est carnis mortem et praesentis vitae terminum, quanto magis nobis iuxta mandatum salvatoris et evangelicam atque apostolicam doctrinam formidanda est mors animae et poena perpetua?... Unde necesse est, ut in praesenti vita iuxta apostolum mortificemus membra nostra ... Hrabanus, Ep. ad Heribaldum (Migne PL 110, 470). Hier zitiert nach der kritischen Edition in Коттје, Bußbücher 1980, 278.

143 Коттје, Bußbücher 1980, 5-9.

144 ... eos disiungi et ulterius numquam coniugio copulari, sed sub magna districtione fieri volumus. Konzil von Mainz (847) c. 29 (MGH Conc. 3, 175). 
Jahre, wenn er Fleisch essen darf, von jedem berauschenden Getränk enthalten. Sollte er ein solches Getränk trinken, darf er kein Fleisch verzehren, außer an den besonderen Festtagen. Auf diese Weise soll er sich vom Fleisch bis zu seinem Tod enthalten außer an den besonderen Festtagen. Drei Tage in der Woche und dreimal vierzig Tage im Jahr soll er fasten. In Hinsicht auf Waffen bleibt alles beim Alten, und niemals soll er eine Ehe eingehen "145.

Mit dem Insistieren auf der Ehelosigkeit der Delinquenten nahm Hraban eine unnachgiebige Haltung ein, die für die Kirchenreformer des 9. Jahrhunderts typisch ist. Die Erlaubnis des Konzils von Epaon, nach einer Inzestehe eine weitere, „bessere Ehe“ einzugehen, traf wie oben ausgeführt in dieser Zeit auf wenig Zustimmung ${ }^{146}$. Bereits das Konzil von Aachen (819) und Haito von Basel traten für die Strafe der Ehelosigkeit bei besonders nah verwandten Eheleuten ein ${ }^{147}$. Da Hraban den Umfang des Inzestverbots auf diese Nahverwandten einschränkte, wurde die Ehelosigkeit zur allgemeinen Strafe bei der Übertretung des Inzestverbots.

Auf dem Konzil von Mainz des Jahres 852 kam Hraban nochmals kurz auf die Strafe bei Inzest zu sprechen und stellte klar, dass die öffentliche Buße nur dann erfolgen dürfe, wenn das Inzestdelikt an die Öffentlichkeit gelangt sei. „Wenn jemand heimlich Inzest begangen und dem Priester heimlich eine Beichte abgelegt hat, soll ihm ein kanonisches Heilmittel angezeigt werden, das er auf sich nehmen hätte müssen, wenn seine Schandtat öffentlich gewesen wäre"148 . Die geheime Buße soll nach Hraban durch Fasten, Almosen, Nacht-

145 Abstineat se ab ingressione domus Dei anno uno et eodem anno nisi festis diebus et praecipuis solummodo pane et aqua et sale utatur; arma pugnatoria non ferat; osculum nulli praebeat; sacrificium nisi pro viatico minime sumat. Sex deinde annis ingrediatur domum Dei, sed carnibus et vino ac sicera minime utatur, nisi festis praecipuisque diebus. De armis vero vel osculo sive sacrificio, sicut supra dictum est, faciat. Postea vero duobus annis, quando carne vescitur, a potu omni, qui potest inebriare, se contineat. Quem potum, si biberit, non carne vescitur absque praecipuis festis diebus. Inde usque ad obitum suum nisi praedictis festis diebus a carne abstineat. Tres legitimas ferias in omni hebdomada et tres quadragesimas in anno legitime custodiat. De armis vero, sicut iam dictum est, faciat et nunquam coniugio copuletur. Haec eadem poenitentia imponenda est parricidis ... Paenitentiale ad Heribaldum c. 20 (Migne PL 110, 487). Eine ähnlich präzise Beschreibung der Bußzeit bei Paulinus von Aquileia, Ep. ad Heistulfum (Migne PL 99, 181-186). Diesen Brief empfiehlt Hrabanus dem Straßburger Chorbischof: Ep. 53 (MGH Epp. 5, 507). In einer Mainzer Handschrift des 9. Jahrhunderts ist er überliefert: КоттJE, Bußbücher 1980, 90-92. Konzil von Mainz (852) c. 11 (MGH Conc. 3, 248 Anm. 67) ist ebenso auf diese Quelle zurückzuführen, und nicht auf das Vorbild angelsächsischer Bußbücher.

146 Siehe 298 f. und 306 Anm. 82.

147 Siehe 294 Anm. 23 und 303 Anm. 67.

148 Si quis incestum occulte commiserit et sacerdoti occulte confessionem egerit, indicetur ei remedium canonicum, quod subire debuerat, si eius facinus publicum fuisset; verum quia latet commissum, detur ei a sacerdote consilium, ut saluti animae suae per occultam penitentiam prospiciat. Konzil von Mainz (852) c. 10 (MGH Conc. 3, 247). 
wachen und Beten erfolgen, weil dadurch die innere Reue über die Schwere des Verbrechens zum Ausdruck gebracht werde. Hraban trennte also im Sinne der Kirchenreform sorgfältig die öffentliche von der geheimen Buße. Dass solche heimlichen Bußübungen oft nicht ohne Kenntnis der Umgebung durchgeführt werden konnten, steht auf einem anderen Blatt ${ }^{149}$.

\section{Entstehung des Sendgerichts?}

Das Dossier des Hrabanus zum Inzestverbot erlaubt einen Blick auf die Entwicklung der Strafverfolgung. Karl der Große hatte die Bischöfe offiziell damit beauftragt, in ihren Sprengeln nach verbotenen Verwandtenehen zu fahnden und sie mit kanonischer Buße zu bestrafen. Auf dem Konzil von Mainz des Jahres 847 ließ Hrabanus diese Beauftragung der Bischöfe mit der Verfolgung von Inzestdelikten wiederholen ${ }^{150}$. Er fügte der wörtlichen Wiedergabe des Mainzer Konzils von 813 allerdings selbständig einen Satz hinzu: „Wenn sie den Ermahnungen der Bischöfe kein Gehör schenken und in ihren früheren Verbrechen verharren wollen, sollen sie durch eine Strafe der weltlichen Macht von

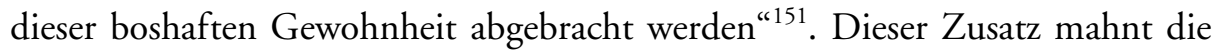
Zusammenarbeit zwischen Grafen und Bischöfen an, wie sie bereits von Karl dem Großen gefordert worden war. Die Reformbemühungen des Jahres 813 hatten vor Augen geführt, dass es damit nicht zum Besten stand. Die Wiederholung dieser Forderung in einer Kirchenversammlung, an der der zuständige König nicht teilnahm ${ }^{152}$, zeigt die andauernde Problematik bei der Zusammenarbeit zwischen geistlicher und weltlicher Macht.

Einen punktuellen Einblick in die Probleme der Praxis geben die Briefe des Hrabanus. Zwischen 847 und 856 fragte die Straßburger Kirche beim Mainzer Metropoliten wegen eines besonders haarsträubenden Falles an. Ein Mann hatte mit der Frau eines Verwandten Unzucht getrieben und dann beide ermordet. Hraban ordnete lebenslange Buße für den Verbrecher an und gab genaue Anweisungen über die zu befolgenden disziplinarischen Regeln ${ }^{133}$. Mit ähnlich gelagerten Fällen hat sich Hraban des öfteren auseinandersetzen müssen. Die wenigsten Briefe sind jedoch im Original erhalten, für den größeren Bestand der Briefsammlung ist man auf die Exzerpte der Magdeburger Centuriatoren aus

149 JoNG, Penance 1997, 865.

150 Ut episcopi incestuosos puriter investigare studeant, omnino decrevimus. Konzil von Mainz (847) c. 28 (MGH Conc. 3, 175).

151 Quod sacerdotum noluerint admonitionibus aurem accomodare volentes in pristinis perdurare criminibus, oportet eos per saecularis potentiae disciplinam a tam prava consuetudine coerceri. Konzil von Mainz (847) c. 28 (MGH Conc. 3, 175).

152 Hartmann, Ludwig 2002, $193 \mathrm{f}$.

153 Hrabanus, Ep. 53 (MGH Epp. 5, 507 f.). 
dem 16. Jahrhundert angewiesen. Die dort angesprochenen Fälle können deshalb nur ansatzweise rekonstruiert werden.

Wie die Bischöfe auf den Reformkonzilien des Jahres 813 stellte Hraban in seinen Briefen sowohl die Nachlässigkeit des Klerus als auch die fehlende Kooperation der weltlichen Macht an den Pranger. In einer Antwort auf eine Anfrage Humberts von Würzburg beschwerte er sich über die Erschlaffung der kirchlichen Disziplin. Verwandtenmord, Ehebruch, Inzest, Meineid, Diebstahl und Mord würden für nichts erachtet und ungestraft getan, ohne dass der Klerus die Übeltäter aus der Kirche ausschließe und exkommuniziere: „Gute und Böse besuchen ohne Unterschied die Kirche “154. Hraban beharrte auf der „schweren Strenge der Strafe“. Besonders empört war er über den Inzestfall einer Nonne, die „unter dem Vorwand der Blutsverwandtschaft den niederträchtigen Unflat verborgen hat". Sie sollte streng bestraft werden ${ }^{155}$. Ein anderer Fall wurde dem Bischof aus Thüringen gemeldet: Eine Frau wurde von ihrem Schwager im Schlaf vergewaltigt. Hraban hielt lebenslange Buße und dauerhafte Ehelosigkeit für die angemessene Strafe des Ehebrechers, während das Opfer nach einer kurzen Buße ihre Ehe weiterführen durfte ${ }^{156}$.

Indirekt wurde der Inzest noch in einem weiteren verlorenen Brief an Humbert von Würzburg angesprochen. Hrabanus beklagt sich darin über die fehlende Kooperation der weltlichen Amtsträger: „Keine weltliche Macht darf den Seelsorger einschüchtern und die Unnachgiebigkeit der Bischöfe durch weltliche Schmeicheleien erweichen "157. Als Vorbild für das Vorgehen der Bischöfe nennt Hraban Ambrosius von Mailand und Avitus von Vienne, die es

154 ... vigor ecclesiasticae disciplinae in aliquantis locis his temporibus ita mollescit, ut parricidium committere plurimi non vereantur, adulteria et incaestus impune fiant, periuria quaeque, furta et homicidia pro nihilo ducantur, nemo tales corripit, nemo excommunicat, nemo extra ecclesiae societatem fieri anathematizando compellit, sed boni malique, iusti et impii indifferenter ecclesiam intrant ... Epistolarum Fuldensium fragmenta 19 (MGH Epp. 5, 525).

155 ... et maxime in illis locis, ubi sanctimonialium foeminarum casta debuit esse conversatio. Tam spurca enim ibidem in aliquibus locis fieri narrantur libidinis inquinamenta, ut incaesti crimen pro nibilo ducatur. ... sed sub praetextu ac velamine consanguinitatis quasi sub specie pietatis celant sordes impietatis. In huiusmodi Rabanus gravem vindictae severitatem, si tam nefandae rei veritas cognoscatur, vult exerceri. Epistolarum Fuldensium fragmenta 19 (MGH Epp. 5, 525).

156 Quidam in partibus Thuringiae germani sui uxorem, ipsa nesciente noctu oppressit. Ea de re Rabanus iudicat: quod si mulier queat probare se delusam et invitam tale peccatum patrasse, debeat poenitentia legitime peracta ad mariti sui thorum redire, moechum vero iure matrimonii privat et perpetuae subiicit poenitentiae. Epistolarum Fuldensium fragmenta 21 (MGH Epp. 5, 527).

$157 \mathrm{Nec}$ debet illa terrena potestas terrere rectorem animarum nec mollire secularibus blandimentis rigorem Christi pontificum ... Epistolarum Fuldensium fragmenta 20 (MGH Epp. 5, 526). 
gewagt hätten, ihre Herrscher zu exkommunizieren ${ }^{158}$. Wie Hraban zur Ansicht gelangt ist, Avitus von Vienne habe den burgundischen „Herzog“ Gundobad exkommuniziert, ist nicht mehr feststellbar. Hinter dieser Legende verbirgt sich das Vorgehen des Avitus und der burgundischen Bischöfe gegen die Inzestehe des königlichen Fiskalverwalters, das zu einem Konflikt mit Gundobads Nachfolger, König Sigismund, geführt hatte ${ }^{159}$. Das von Hraban gewählte Vorbild legt nahe, dass er in der brieflichen Ermahnung an die Adresse der weltlichen Macht einen Inzestfall vor Augen gehabt hat.

Das Briefcorpus des Hrabanus vermittelt, so weit es erhalten ist, den Eindruck einer Umsetzung der von Karl dem Großen durchgeführten Reformen der Strafverfolgung. Obwohl durchaus weiterhin mit Nachlässigkeit des Klerus wie mit Obstruktion durch die weltlichen Machthaber zu rechnen war, hatte sich die Zuständigkeit des Bischofs für kriminelle Vergehen der Laien fest etabliert. Besonders oft wurden Inzest und Verwandtenmord thematisiert, da diese Verbrechen im Normalfall nicht zu einer Gerichtsverhandlung im Grafengericht führten ${ }^{160}$. Beispielsweise ist ein Ehebrecher und zweifacher Verwandtenmörder in Straßburg entweder gar nicht vor Gericht angeklagt worden oder mit einer milden Vermögensstrafe davon gekommen. In der Diözese Würzburg ist eine Fehde eskaliert, als jemand den Mörder seines Bruders sowie dessen Verwandte, die sich in das Kirchenasyl geflüchtet hatten, in der Nähe des Altars umbrachte ${ }^{161}$. Mit der Forderung nach öffentlicher Buße für solche notorische Verbrechen war die Kirche die einzige Instanz, die für die Wahrung des Strafrechts in Belangen von rein öffentlicher Zuständigkeit sorgte. Diese Tatsache wird mit aller Deutlichkeit durch die Konzilsbeschlüsse zum Verfahrensrecht vor dem geistlichen Gericht bezeugt. Die von Hraban initiierten Kanones zum Gottesurteil und Reinigungseid setzen voraus, dass die Schuldfrage nicht vom weltlichen, sondern allein vom geistlichen Gericht geklärt werden musste ${ }^{162}$. Konkret fassbar ist dies auf dem Konzil von 852, das als Gerichtshof über die Buße für zwei Verbrecher entschied ${ }^{163}$. Der eine Angeklagte hatte eine Frau zum Ehebruch verführt und diese dann an die Heiden verkauft, der andere hatte fünf Menschen umgebracht.

Hrabans Insistenz auf öffentlicher Kirchenbuße war gerade deshalb dringend geboten, weil das Ostfrankenreich im Gegensatz zum romanischen Westen

158 ... copiosa testantur exempla, ut Ambrosii, qui Theodosium imperatorem et Aviti, qui Gundobatum Burgundionum ducem excommunicavit. Epistolarum Fuldensium fragmenta 20 (MGH Epp. 5, 526).

159 Siehe 133-137.

160 Hartmann, Ludwig 2002, $159 \mathrm{f}$.

161 Epistolarum Fuldensium fragmenta 20 (MGH Epp. 5, 525).

162 Konzil von Mainz (847) c. 24 (MGH Conc. 3, 173); Konzil von Mainz (852) c. 13 (MGH Conc. 3, 249 f.).

163 Konzil von Mainz (852) c. 11 (MGH Conc. 3, 248 f.); Hartmann, Ludwig 2002, 198. 
keine Kontinuität dieser Institution gekannt hat ${ }^{164}$. Die Kirchenreformer mussten, nachdem im 8. Jahrhundert durch das Werk der irischen und angelsächsischen Missionare die Tarifbuße Fuß gefasst hatte, ihr Werk von Grund auf neu beginnen. Die Synode war für sie der geeignete Ort, um die für ein Verfahren und eine Verurteilung notwendige Öffentlichkeit herzustellen. Hraban hat diesen Weg besonders oft beschritten und ihn anderen Prälaten empfohlen. Bischof Humbert von Würzburg gab er zum Beispiel den Ratschlag, einen Mörder und Missachter des Kirchenasyls auf einer Synode zur Rechenschaft zu ziehen und so zu einer Kirchenbuße zu zwingen ${ }^{165}$. Für eine Weiterentwicklung dieser Zuständigkeit für kriminelle Vergehen von Laien hin zum späteren Sendgericht gibt es dagegen keine Belege ${ }^{166}$. Hraban bevorzugte als „Buß-Gerichtshof" die zentrale Synode in der Bischofsstadt und nicht das visitierende Sendgericht vor Ort. Dass die Bischöfe bei ihren Visitationen die Befragung der Bevölkerung nachweislich in der Form des Rügeverfahrens mit ständigen Sendzeugen vorgenommen haben, lässt sich nicht erkennen ${ }^{167}$. Eine Institutionalisierung des Sendgerichts ist in den Quellen noch nicht greifbar.

Das umfangreichste Dossier zum Inzestverbot in der Karolingerzeit gibt überaus wertvolle Einblicke in die Praxis der Inzestverfolgung. Hrabans Innovation hält sich dabei jedoch in Grenzen, auffällig sind dagegen sein Eifer und die Härte der von ihm geforderten Bestrafung. Diese Härte kontrastiert deutlich mit der Milde, die man ihm gewöhnlich wegen des geringen Umfangs des Inzestverbots in seinen Schriften zuschreibt. Wie bislang noch nicht bekannt, bewegte er sich mit der Reduzierung des Inzestverbots auf die biblischen Gebote im Fahrwasser der bonifatianischen Tradition. Hraban war der einzige Gelehrte im 9. Jahrhundert, der diese Überlieferung aufgriff und das kategorische Verbot von Verwandtenehen aus seelsorgerlichen Gründen strikt ablehnte. Die akzentuierte Berufung auf das Alte Testament, die sein gesamtes Werk charakterisiert $^{168}$, überdeckt jedoch, dass Hraban durchaus Modifikationen gegenüber der Bibel zugelassen hat. So war ihm das Verbot der Cousinenehe und das Verbot der Heirat in der geistlichen Verwandtschaft eine nicht bezweifelte Selbstver-

164 Zur Kontinuität in Gallien vgl. Vogel, Discipline 1952, 149-203; Jong, Transformations 2000.

165 Sic Rabanus suadet Humberto, ut in generali concilio accuset parricidam illum, qui in templo ad altare interfecerat homines innocentes. Epistolarum Fuldensium fragmenta 20 (MGH Epp. 5, 525).

166 Anders Hartmann, Ludwig 2002, 200.

167 Der c. 8 des Konzils von Mainz (852) (MGH Conc. 3, 245) ist dafür kein Beleg, weil dort die Vereidigung der Bevölkerung (und nicht ständiger Sendzeugen) nur ad hoc wegen bereits bestehender Infamie vorgenommen wurde. Überdies handelt es sich nicht um Vergehen von Laien, sondern von Klerikern. Andere Deutung bei Koeniger, Sendgerichte 1907, 47.

168 So das allgemeine Urteil von Коттје, Bußbücher 1980, 253. 
ständlichkeit, obwohl beide Verbote keine biblische Grundlage vorzuweisen hatten und von Bonifatius noch abgelehnt worden waren ${ }^{169}$. Eine Rechtfertigung hat er im Gegensatz zu der skrupulösen Haltung, die er sonst an den Tag legte, nicht für notwendig erachtet. Die Autorität der Bibel hat ihm als Vorwand gedient, um seine eigene Stellungnahme für eine bestimmte gemäßigte Tradition und gegen die herrschende Meinung seiner Zeit zu legitimieren. Ausschlaggebend waren wohl seine aus der Seelsorge begründeten Bedenken gegen eine allzu weite Ausdehnung des Inzestverbots.

\subsection{Der Standpunkt der Fälscher: Pseudoisidor und Benedictus Levita}

Die „kühnste und großartigste Fälschung kirchlicher Rechtsquellen “170 hat auch in der Geschichte des Inzestverbots deutliche Spuren hinterlassen. Erst kürzlich konnte Patrick Corbet den bedeutenden Einfluss der Fälschung auf das spätere Kirchenrecht nachweisen ${ }^{171}$. Die Attraktivität dieser Quelle bestand für die Benutzer in ihrer Homogenität. Waren die frühmittelalterlichen Inzestverbote durch ihre unterschiedliche Reichweite und Zählweise gekennzeichnet, verstanden es die Fälscher aus dem Kloster Corbie, alle vorliegenden Rechtsquellen durch Streichung und Interpolation auf eine Linie zu bringen. Der Standpunkt der Fälscher übte deshalb großen Einfluss auf die Formierung des wissenschaftlichen Kirchenrechts im 11. Jahrhundert aus.

Das Dossier zum Inzestverbot ist ungleich auf die beiden großen Fälschungskomplexe verteilt, die mit den Namen Pseudoisidor und Benedictus Levita bezeichnet werden. Während in den gefälschten Dekretalen Pseudoisidors das Inzestverbot nur am Rand auftaucht, wird es in den gefälschten Kapitularien Benedikts zu einem der Leitthemen erhoben. Von insgesamt 1721 Kapiteln sind 59 diesem Thema gewidmet. Diese Zahl wäre nicht so bedeutend, wenn sich nicht sechs Fälschungen und elf interpolierte Kapitel darunter befinden würden ${ }^{172}$. Denn in der überwiegenden Mehrzahl enthalten die von

169 Zur Cousinenheirat vgl. die Retusche oben 315 Anm. 127. Zur geistlichen Verwandtschaft vgl. die aus Gregors Dialogi zitierte Anekdote im Paenitentiale ad Heribaldum c. 20 (Migne PL 110, 487): Quam detestabile et quam exsecrabile scelus sit unicuique christiano ...

170 SeCkel, Pseudoisidor 1905, 267.

171 CoRbet, Burchard 2001, 88.

172 Der Inzest wird angesprochen in: 1,$3 ; 1,9 ; 1,10 ; 1,12 ; 1,62 ; 1,82 ; 1,91 ; 1,165-$ $168 ; 1,226 ; 1,241 ; 1,274 ; 1,304 ; 1,310 ; 2,31 ; 2,37 ; 2,71 ; 2,80 ; 2,87 ; 2,106 ; 2$, $130 ; 2,191 ; 2,209 ; 2,240 ; 2,409-2,411 ; 2,419 ; 2,421 ; 2,424 ; 3,143 ; 3,179 ; 3$, $258 ; 3,356 ; 3,377 ; 3,381 ; 3,432-434 ; 3$, 463; Additio 2, 23; Additio 3, 5; Additio 3, 92; Additio 4, 2; Additio 4, 74. Hinzu kommen zwölf Dubletten. Die Fälschungen sind 1,$310 ; 2,71 ; 3,143 ; 3,179 ; 3,432$ und $3,433$. 
Benedictus Levita gesammelten Texte durchaus authentische Rechtsquellen ${ }^{173}$. Er zog u.a. die Bibel, die Kirchenväter, römisches und westgotisches Recht, Konzilskanones, Papstbriefe, die Lex Baiuvariorum und Kapitularien heran. Nur einen geringen Teil dieser 1721 Kapitel hat der Fälscher selbst ersonnen (ca. 40 Stück $\left.{ }^{174}\right)$. Einige Hundert dieser Kapitel hat er jedoch auf seine Linie gebracht, indem er sie interpolierte oder mit Hilfe seiner „Mosaiktechnik“ (Seckel) in ihre Bestandteile zerlegte und zu neuen Bestimmungen umformte. Die eigentliche Fälschung besteht darin, dass er diese aus heterogenen Sammlungen stammenden Rechtsquellen als karolingische Kapitularien und daher als geltendes Recht ausgab. Benedikt behauptete, sein Werk auf eine Anordnung Erzbischof Otgars von Mainz abgefasst zu haben, und widmete es den drei Herrschern im Frankenreich, Lothar I., Ludwig dem Deutschen und Karl dem Kahlen. Benedikt empfahl ihnen, das Gesetzbuch stets mit sich zu führen, allen Amtsträgern bekannt zu machen und in der Rechtsprechung anzuwenden ${ }^{175}$.

Diese unterschiedliche Intensität in der Behandlung des Inzestverbots wirft die Frage des Verhältnisses der beiden Fälschungen zueinander auf. Emil Seckel hat für diese Frage eine kongeniale Lösung gefunden, die über hundert Jahre unwidersprochen Geltung beanspruchte ${ }^{176}$. Seckel konnte aufgrund mehrerer Indizien nachweisen, dass die Fälschung Benedikts am selben Ort entstanden sein musste wie die pseudoisidorischen Dekretalen. Nach Seckel hat nicht nur Pseudoisidor die Sammlung Benedikts verwendet (wie Hinschius annahm), sondern umgekehrt auch Benedikt die falschen Dekretalen. Eine wechselseitige "Hin- und Herbenutzung" sei aber nur dann möglich gewesen, wenn die Fälscher am selben Ort gearbeitet hätten. Eine Identifikation von Benedikt und Pseudoisidor lehnte Seckel jedoch ab, weil die Fälschungen in ihrer Qualität zu unterschiedlich seien. Er befürwortete vielmehr die These des „gemeinsamen Wirkens einer Fälschergruppe". Trotz dieser gemeinschaftlichen Entstehung beanspruchte Seckel für Benedikt die „zeitliche und innere Priorität“. Benedikt habe nämlich erst in den Additionen eine genauere Kenntnis der pseudoisidorischen Dekretalen besessen. Außerdem habe er die Leitideen Pseudoisidors noch in einem unfertigen Zustand übernommen, weil in den Dekretalen „die Tendenzen an Entschiedenheit und Einheitlichkeit, die ihnen dienstbar gemachten Scheinbelege an Reichhaltigkeit gewonnen haben“. Das Werk Benedikts, so ließe sich aus Seckels Überlegungen folgern, sei demnach als erster Versuch der Fälschergruppe zu verstehen, ihre Ideen durch gefälschte Kapitu-

173 Und zwar oft mit hohem quellenkritischen Wert: LuKas, Beobachtungen 2002; DIEs., Sammlung 2004; Sснмiтz, Echtes 2004.

174 Nach der Zählung von Seckel, Studien VI 1906, 62; SEckel, Studien VII/2 1910, 107; Seckel - Juncker, Studien VIII/4 1934, 272.

175 Benedictus Levita, Praefatio und Versus (MGH LL 2/2, 40 f.).

176 Für das Folgende vgl. SECKel, Pseudoisidor 1905, 296, 298, 301, 304 und 305. 
larien in Umlauf zu bringen. Der große Bestandteil an unverfälschten Rechtsquellen diente nach Seckel zur Verschleierung der Fälschungsabsicht.

Dieser Deutung hat die bahnbrechende Identifizierung Pseudoisidors durch Klaus Zechiel-Eckes den Boden entzogen ${ }^{177}$. Durch Handschriftenstudien gelang es Zechiel-Eckes, den Theologen Radbert von Corbie (alias Paschasius Radbertus) als Haupt der pseudoisidorischen Fälschergruppe zu entlarven. Ebenso wichtig wie diese Identifizierung ist der neue zeitliche Ansatz, den Zechiel-Eckes zur Diskussion gestellt hat. Demnach ging der Impuls zur Fälschung päpstlicher Dekretalen von den Ereignissen der Jahre 833-835 aus. Nachdem die Absetzung Kaiser Ludwigs des Frommen an der Jahreswende 833/ 834 rückgängig gemacht worden war, wurden mehrere am Aufstand beteiligte Bischöfe dazu gezwungen, ihre Sitze zu verlassen und gemeinsam mit Ludwigs ältestem Sohn Lothar nach Italien ins Exil zu gehen. Erzbischof Ebo von Reims wurde auf Befehl Ludwigs des Frommen von einer Synode abgesetzt (835). Diese Ereignisse haben nach Zechiel-Eckes Radbert und seine Mitarbeiter dazu veranlasst, päpstliche Dekretalen mit dem Ziel zu fälschen, die Bischöfe vor Anklagen zu schützen und somit das Vorgehen Ludwigs gegen die abtrünnigen Bischöfe zu diskreditieren. Der „Episkopalismus“ Pseudoisidors sei diesen Ereignissen entsprungen. Wenn aber schon nach 835 der Plan für dieses Unternehmen gefasst wurde, fällt es schwer, den sicher nach 847 fertig gestellten falschen Kapitularien die „zeitliche und inhaltliche Priorität" gegenüber den Dekretalen zuzuschreiben. Zechiel-Eckes zieht deshalb die Hypothese in Erwägung, dass zumindest die erste Version der falschen Dekretalen (Version A2) vor den falschen Kapitularien entstanden ist. Das Werk des Diakons Benedikt kann daher, setzt man die Richtigkeit dieser Hypothese voraus, nicht mehr als erster Versuch der Fälschergruppe gewertet werden.

Die folgenden Ausführungen haben den zeitlichen Ansatz von Zechiel-Eckes zur Grundlage. In einem ersten Abschnitt werde ich mich der kurzen Stellungnahme Pseudoisidors in der A2-Fassung widmen, dem frühesten Produkt der Fälscherwerkstatt. Darauf wird eine Untersuchung der gefälschten Kapitularien folgen. Eine genauere Analyse verdient das für das Inzestverbot zentrale Kapitel 3, 432, da seine Echtheit in der Forschung nicht geklärt ist. Im dritten Teil soll dann auf den fingierten Briefwechsel Gregors des Großen näher eingegangen werden, der ebenfalls aus der pseudoisidorischen Werkstatt stammt, jedoch erst nach dem Abschluss des Fälschungswerks angefertigt wurde.

177 Zechiel-Eckes, Blick 2002; ders., Spur 2002; Ders., Exterminator 2004. 


\section{Andere Sorgen bei Pseudoisidor}

Die Enthauptung Johannes des Täufers veranlasste Radbert von Corbie alias Pseudoisidor in seinem Matthäuskommentar zu einer für ihn typischen Zeitklage:

„Deshalb sind in dieser Zeit diejenigen zu tadeln, die behaupten, dass man die Könige und Mächte dieser Welt weder rügen noch hart anklagen darf, damit sie nicht umso heftiger von Zorn ergriffen werden. So habe ich es von einem der Bischöfe gehört. Er sagte, dass der König keiner Macht unterworfen sei und nicht unter der Obhut irgendeiner Herrschaft stehe, weil er allen gemeinsam und nicht auf einen Sprengel beschränkt sei. Wenn es sich so verhält, ist Johannes der Täufer, der aus der Einöde vor den König kam und ihn des Inzests anklagte, zu tadeln und als unbesonnen zu verurteilen. Doch weil Johannes ein Freund Christi war, konnte er die Inzestuösen nicht dulden, welche dieser Höfling eher zu schmeicheln und mit Lob zu besänftigen wünscht als anzuklagen “178.

Die Geschichte von der Ehe des Herodes mit Herodias und des vergeblichen Widerstands Johannes des Täufers trug für Theologen des 9. Jahrhunderts das deutliche Odium eines Skandals. Herodes verstieß seine Ehefrau und nahm Herodias, seine Schwägerin und Nichte, zur Frau, die ihrerseits ihrem Mann die Ehe aufkündigte. Doch Radbert empörte sich nicht wegen des doppelten Verstoßes gegen das Inzestverbot, sondern wegen der Kleinmütigkeit mancher Kirchenfürsten. In einer Epoche der Wirren, Rebellionen und Bürgerkriege, der Bischofsabsetzungen und der Veruntreuung von Kirchengut galt es vor allem, die Belange der Kirche gegen den Zugriff durch den König und seine weltlichen Amtsträger zu schützen ${ }^{179}$. Um den Inzest war es dagegen seit der Herrschaft Karls des Großen erstaunlich ruhig geworden. Wenn in den Schriften der Reformkreise Sexualdelikte als Ursache für die als Gottesstrafe wahrgenommene Krisenzeit an den Pranger gestellt wurden, so hielt man sich nicht an den Inzest, sondern an das Delikt der Sodomie ${ }^{180}$.

Angesichts dieser Zeitstimmung überrascht das Schweigen Pseudoisidors zum Inzestverbot nicht weiter. In der ersten Pseudo-Evaristus Dekretale kommt

178 Quapropter arguendi sunt nunc in tempore quidam qui dicunt non debere arguere reges aut potestates huius saeculi neque durius increpare ne forte atrocius commoveantur ad iram sicut a quodam audivi episcoporum. Quia rex sub nullius inquit redactus est potestate neque sub cura alicuius regiminis eo quod omnibus in commune est et non in una commoratur parroechia. Quod si ita est Iohannes reprehensibilis et temerarius censendus est qui ex heremo venit ad regis praesentiam ut increparet adulterum. Sed quia amicus sponsi erat Iohannes incestuosos ferre non poterat quos hic adulator magis palpare gaudet et delinire laudibus quam increpare. In quo sane vitio multi periclitantur qui videntur gerere curam pastoris. Paschasius Radbertus, Expositio in Matheo VII (14, 4) (CCM 56A, 735).

179 Zechiel-Eckes, Spur 2002, 18-22.

180 Haito von Basel, Visio Wettini c. 19 (MGH Poetae 2, 273); Episcoporum ad Hludowicum imperatorem relatio c. 54 (MGH Capit. 2, 44); Konzil von Paris (829) c. 34 (MGH Conc. 2/2, 634); Konzil von Aachen (836) c. 36 u. 38 (MGH Conc. 2/2, 713). 
der Fälscher auf die Voraussetzungen einer legitimen Ehe zu sprechen, ohne das Problem der Inzestehe auch nur anzusprechen. Dieser kurze Abschnitt sollte eine beträchtliche Wirkung im mittelalterlichen Kirchenrecht entfalten ${ }^{181}$. Hinschius war der Meinung, dass Pseudoisidor hier weitgehend ein Kapitel aus Benedictus Levita abgeschrieben hat ${ }^{182}$. Seckel und Juncker traten dieser Ansicht bei $^{183}$. Juncker griff auch die Hypothese von Hinschius wieder auf und vermutete eine echte Rechtsquelle als Benedikts Vorlage. Hinschius dachte dabei an ein verlorenes Konzil, während Juncker die abwegige Position vertrat, „ein echtes weltliches Gesetz fränkischer Zeit "184 habe Benedikt als Grundlage gedient. Seckel hatte dagegen deutlichere Worte zu dieser Bestimmung gefunden: „So wie sie lautet, kann ich die Norm nicht für einen echten Kanon halten

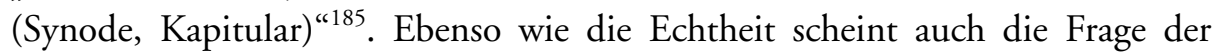
Abhängigkeit zweifelhaft. Ohne der kritischen Edition vorgreifen zu wollen, ist es nicht glaubwürdig, dass Benedikt sich als Kapitularienfälscher auf die „Väter, die heiligen Apostel und ihre Nachfolger" berufen sollte ${ }^{186}$. Diese Legitimationsformel passt viel eher zu Pseudoisidor und ist wohl durch die oft wenig umsichtige Quellenbehandlung Benedikts in seine Sammlung, hineingerutscht ${ }^{\star}$. Benedikt hätte es vermutlich auch nicht versäumt, in diesem Text noch einen Hinweis auf das Inzestverbot unterzubringen, das ihm ja ein besonderes Anliegen war. Es sollte daher erwogen werden, an dieser Stelle Benedikt als Rezipienten von Pseudoisidor anzusehen ${ }^{187}$.

Das Inzestverbot behandelt Pseudoisidor nur an einer Stelle der A2-Fassung, in dem zweiten auf den Namen Papst Calixts gefälschten Brief. Der Fälscher macht dies in einer rätselhaften Weise, die sein zwiespältiges Engagement in dieser Richtung unterstreicht. Er setzt mit folgendem Satz des Pseudopapstes ein: „Ihr sollt aber verbieten, dass Verwandtenehen eingegangen werden, wenn sie sowohl göttliche und weltliche Gesetze verbieten “188. Dieser Satz geht nicht auf Benedikt zurück, wie Hinschius zu wissen glaubte. Weder wörtlich noch inhaltlich deckt sich diese Aussage mit dem von Hinschius herangezogenen Kapitel $^{189}$. In dieser Form hätte Benedikt nicht formuliert, weil er alle Ver-

181 Fuhrmann, Einfluss 1972, 794.

182 Decretales Pseudo-Isidorianae, Ps.-Evarist c. 2 (87).

183 SeCKel - Juncker, Studien VIII/5 1935, 40.

184 Seckel - Juncker, Studien VIII/5 1935, 41.

185 Seckel - Juncker, Studien VIII/5 1935, 40.

186 ... ut a Patribus accepimus et a sanctis Apostolis eorumque successoribus traditum invenimus ... Benedictus Levita 3, 463 (MGH LL 2/2, 132); Decretales Pseudo-Isidorianae,

Ps.-Evarist c. 2 (87).

187 In diesem Sinn bereits Scherer, Eherecht 1879, 45.

188 Coniunctiones autem consanguineorum fieri prohibete, quando has et divinae et saeculi prohibent leges. Decretales Pseudo-Isidorianae, Ps.-Calixt c. 16 (140).

189 So bereits SCHERER, Eherecht 1879, 45. 
wandtenehen bis zum siebten Grad für ungültig erklärte, nicht nur diejenigen, die vom Recht verboten sind. Pseudo-Calixt spezifiziert die Berufung auf göttliches und weltliches Recht mit Zitaten von Lev. 18, 24 und Cod. Theod. 3, 12, 3: Gott habe die Völker verworfen, die sich nicht an seine Reinheitsgebote gehalten hätten, und dem weltlichen Recht zufolge verfielen Inzestuöse der Infamie $^{190}$. Im nächsten Satz lässt Pseudoisidor eine Definition von Verwandtschaft folgen: „Diejenigen nennen wir Verwandte, die die göttlichen Gesetze und die Gesetze der römischen und griechischen Kaiser Verwandte nennen und in der Erbschaft anerkennen und dabei nicht übergangen werden können "191. Das göttliche Gesetz verweist auf Lev. 18, 1-18, wo der sexuelle Umgang mit verschiedenen nahen Verwandten untersagt wird. Der Bezug auf die weltlichen Gesetze ist aus verschiedenen Gründen undurchsichtig. Zunächst hat der Fälscher offensichtlich übersehen, dass ein im Jahre 222 verstorbener Papst kaum die Gesetze griechischer Kaiser hätte zitieren können. Besonders merkwürdig ist aber die Zurückhaltung des Fälschers: Warum spricht er nicht wie Benedikt direkt aus, bis zu welchem Grad die Verwandtschaft reicht? Ist es nicht über die Maßen umständlich, dem Leser das Nachschlagen im römischen Recht abzuverlangen?

Die Dekretale von Pseudo-Calixt ist demnach durch fehlende Klarheit gekennzeichnet. Aus ihr allein lässt sich nur undeutlich eine Zielsetzung des Fälschers erkennen. Man gewinnt den Eindruck, Pseudoisidor habe keinen besonderen Reformbedarf in der Frage des Inzestverbots wahrgenommen. Er schloss sich offenbar dem kategorischen Verbot von Verwandtenehen an, wie es erstmals auf der römischen Synode von 721 erlassen worden war. Dass Pseudoisidor an diese Tradition anknüpfte, lässt sich auch an der Rezeption des Kanons von Epaon erkennen. In der zweiten Fassung des Fälschungswerks (A1 und $\mathrm{A} / \mathrm{B}$ Klasse) wurden die gefälschten päpstlichen Dekretalen durch eine Sammlung altkirchlicher, gallischer und westgotischer Konzilskanones ergänzt. Pseudoisidor verwendete dafür die Collectio Hispana in einer von ihm selbst verfälschten Version. Die Bestimmung von Epaon war darin enthalten, jedoch unter überlieferungsbedingter Weglassung des Wortes subrinaeve ${ }^{192}$. Damit enthielt das Verbot nur die Verwandtschaft zwischen Vetter und Base (2/2). Pseudoisidor konnte dies nicht genügen. Er fälschte den Konzilskanon in sei-

190 Leges ergo divinae haec agentes et eos qui ex eis prodeunt, non solum eiciunt, sed et maledictos appellant. Leges ergo saeculi infames tales vocant et ab hereditate repellunt. Decretales Pseudo-Isidorianae, Ps.-Calixt c. 16 (140).

191 Eos autem consanguineos dicimus, quos divinae et imperatorum Romanorum atque Grecorum leges consanguineos appellant et in hereditate suscipiunt nec repellere possunt. Decretales Pseudo-Isidorianae, Ps.-Calixt c. 16 (140).

192 Konzil von Agde (506) c. 61 (Hispana 4, 146). Die Varianten der Handschrift F geben die pseudoisidorische Verfälschung in der sog. Collectio Hispana Gallica Augustodunensis wieder. 
nem Sinn und fügte die Bestimmung von Rom 721 in den Text ein ${ }^{193}$. Der verfälschte Kanon beinhaltete jetzt ein generelles Verbot von Ehen unter Verwandten. In einer daran anschließenden Interpolation verweist der Fälscher auf ältere Bestimmungen in dieser Angelegenheit und zitiert damit implizit die gefälschte Pseudo-Calixt-Dekretale der A2-Version ${ }^{194}$. Pseudoisidor konstruiert auf diese Weise eine kontinuierliche Linie von Papst Calixt über das Konzil von Epaon bis zum römischen Konzil des Jahres 721. Dieses Konzil beschließt die pseudoisidorische Sammlung.

Die fehlende Klarheit der A2-Fassung scheint in der erweiterten Redaktion des Fälschungswerks (A1 und A/B) zugunsten der päpstlichen Position des kategorischen Verbots beseitigt worden zu sein. Dieser Schein trügt jedoch. Denn der Fälscher ergänzte die A2-Fassung nicht bloß durch die in der Collectio Hispana überlieferten Konzilsbeschlüsse und päpstlichen Dekretalen, er fügte auch weitere, ihm besonders wichtig erscheinende Papstbriefe hinzu. Dazu zählte der Libellus responsionum Gregors des Großen ${ }^{195}$. Die darin enthaltene Erlaubnis von Ehen im dritten und vierten Grad der Verwandtschaft wurde so Teil des pseudoisidorischen Fälschungswerks. Der Widerspruch zum kategorischen Verbot ist merkwürdigerweise in diesem Stadium der Fälschung nicht aufgefallen. Dies ist ein weiterer Beleg für das fehlende Engagement Pseudoisidors in dieser Frage.

\section{Benedictus Levita und die Gleichschaltung der Tradition}

Benedikts Einstellung zum Inzestverbot unterscheidet sich deutlich von der Pseudoisidors. Er hat seiner Sammlung eine Unmenge an verschiedenen Inzestverboten einverleibt und mit großer Gründlichkeit durch Streichungen und Interpolationen in den Wortlaut eingegriffen, um alle Bestimmungen auf eine Linie zu bringen. Welche Bedeutung der Fälscher den Verwandtenehen beigemessen hat, wird besonders an zwei Produkten aus seiner Werkstatt deutlich. In Kapitel 3, 143 beschreibt er die abscheulichen Verbrechen, deretwegen Königreiche zugrunde gegangen seien. Verstöße gegen das Inzestverbot werden ebenso

193 ... aut qui ex propria consanguinitate aliquam aut quam consanguineus habuit concubitu polluat aut duxerit uxorem. Konzil von Agde (506) c. 61 (Hispana 4, 147, Handschrift F); Decretales Pseudo-Isidorianae, Conc. Agath. c. 61 (336). Vgl. Seckel - Juncker, Studien VIII/4 1934, 328.

194 Quos omnes et olim atque sub hac constitutione incestos esse non dubitamus. Konzil von Agde (506) c. 61 (Hispana 4, 147, Handschrift F); Decretales Pseudo-Isidorianae, Conc. Agath. c. 61 (336).

195 Nach der im Internet verfügbaren Kollation von Karl-Georg Schon befindet sich der Libellus responsionum in den drei frühen Überlieferungszeugen Paris, Bibliothèque nationale, Lat. 9629, Vatikan, Biblioteca Apostolica Vaticana, Vat. Lat. 630 und New Haven, Yale University, Beinecke Library 442: www.pseudoisidor.mgh.de. 
dazu gezählt wie Ehebruch, Unzucht, Sodomie, Mord und andere Kapitaldelikte ${ }^{196}$.

„Wie der Herr erlaubte, solchen Übeltätern rächende Strafen durch die Sarazenen und andere Völker zu schicken, leuchtet allen ein, die die Chroniken dieser Völker lesen. Und wenn wir uns nicht vor solchen Dingen hüten, zweifeln wir nicht, dass uns Ähnliches heimsucht ${ }^{\star 197}$.

In Kapitel 3, 179 steigert Benedikt dieses Bedrohungsszenario: Nicht nur das öffentliche Wohl werde durch Verstöße gegen das Inzestverbot bedroht, auch die Gesundheit der Kinder bringe man in Gefahr. Aus Inzestehen

„werden nämlich oft blinde, lahme, bucklige, triefäugige oder mit anderen hässlichen Merkmalen behaftete Kinder geboren. Damit dies nicht weiterhin geschieht, müssen alle das vermeiden. Deshalb muss man zuerst in der Kirche mit dem Priester, in dessen Gemeinde die Ehe geschlossen wird, vor dem Volk zusammenkommen. Und dort soll der Priester gemeinsam mit dem Volk untersuchen, ob die Frau seine Verwandte sei, ob sie eines anderen Frau oder Verlobte oder eine Ehebrecherin sei. Und wenn er alles rechtmäßig und anständig vorgefunden hat, soll der Mann sich ihr mit Rat und Weihe des Priesters sowie mit dem Rat anderer ehrenwerter Männer verloben und sie rechtmäßig ausstatten “198.

Benedikt nimmt in dieser Stelle das eugenische Thema aus Gregors Libellus responsionum auf und stellt es in einen neuen Zusammenhang ${ }^{199}$. Die Behinderung von Kindern wird nicht wie bei Gregor in einen natürlichen Wirkungszusammenhang eingebettet, sondern als eine Strafe Gottes für den Verstoß gegen das Inzestverbot begriffen.

Gegenüber den überlieferten Normen wendet Benedikt die Methode der Gleichschaltung der Vorlagen vor allem in zwei Punkten an. Erstens passt er alle Umschreibungen der Reichweite des Inzestverbots an die Norm des siebten Grades an. Beispielhaft lässt sich dieses Vorgehen an der Interpolation des Kanons des Konzils von Mainz beobachten. Benedikt fügt dem Verbot des vierten Grades die Worte vel quinta sextaque ein und dehnt so das Inzestverbot

196 Benedictus Levita 3, 143 (MGH LL 2/2, 111).

197 Et qualiter Dominus talium criminum patratoribus ultrices poenas per Sarracenos et alios populos venire et servire permisit, cunctis earum gesta legentibus liquet. Et nisi nos ab his caveamus, similia nobis supervenire non dubitamus. Benedictus Levita 3, 143 (MGH LL 2/ 2, 111).

198 Ex his autem procreari solent coeci, claudi, gibbi et lippi, sive aliis turpibus maculis aspersi. Et hoc ne deinceps fiat omnibus cavendum est. Sed prius conveniendus est sacerdos, in cuius parochia nuptiae fieri debent, in ecclesia coram populo. Et ibi inquirere una cum populo ipse sacerdos debet, si eius propinqua sit an non, aut alterius uxor vel sponsa vel adultera. Et si licita et honesta omnia pariter invenerit, tunc per consilium et benedictionem sacerdotis, et consultu aliorum bonorum hominum, eam sponsare et legitime dotare debet. Benedictus Levita 3, 179 (MGH LL 2/2, 113).

199 Siehe 223. 
vom vierten auf den siebten Grad aus ${ }^{200}$. Bei vier weiteren Kapiteln geht er ähnlich vor ${ }^{201}$. Er bedient sich dabei jeweils einer anderen Begrifflichkeit (generatio, gradus, propinquitas, geniculum, progenies), um damit jeden Zweifel beiseite zu schieben. Welche Zählweise er dabei verwendete, gibt er nicht zu erkennen. Seine umfassende Vertrautheit mit den Quellen des römischen und westgotischen Rechts macht es jedoch wahrscheinlich, dass er so wie die anderen Gelehrten des Westfrankenreichs die römische Zählweise benutzte ${ }^{202}$. Die zweite Anpassung erfolgt in der Frage der kirchlichen Bestrafung von Verwandtenehen. Benedikt lässt keinen Zweifel an der Notwendigkeit einer öffentlichen Buße aufkommen ${ }^{203}$. Der Kanon des Konzils von Epaon, der noch Milde walten ließ, wird durch radikale Kürzung entschärft. Von der ausführlichen Bestimmung bleibt nur der Satz stehen, dass "Inzestverbindungen nicht durch den Begriff der Ehe gestärkt werden sollen “204. Die Bußzeit variiert von sieben bis zu zwanzig oder sogar dreißig Jahren ${ }^{205}$.

Eingehende Betrachtung verdient das ausführlichste Inzestkapitel 3, 432. Dieses Kapitel ist von übergeordnetem Interesse, weil die darin enthaltenen weltlichen Strafbestimmungen in ihrer Ausführlichkeit und in ihrer Härte einzigartig dastehen. Wenn es auf einen echten Kapitularientext zurückgehen sollte, hätte es seit Karl dem Großen eine einschneidende Veränderung in der Strafverfolgung gegeben.

Die Forschung hat dieses Kapitel unterschiedlich bewertet. Pertz und Boretius nahmen es nicht in ihre Ausgaben der karolingischen Kapitularien auf. In der Edition von Benedictus Levita bewertete es Knust als „zweifelhaftes“ Stück ${ }^{206}$. Paul Hinschius qualifizierte es ohne nähere Begründung als Fälschung $^{207}$. Seckel und Juncker traten dagegen für seine Echtheit ein und da-

200 Benedictus Levita 1, 166 (MGH LL 2/2, 54). Vgl. Seckel, Studien VI 1906, 85. Benedikt verstand den siebten Grad daher exklusiv, d.h. das Inzestverbot sollte bis $3 / 3$ reichen.

201 Benedictus Levita 1, 82 (MGH LL 2/2, 50); 2, 130 (MGH LL 2/2, 80); 2, 209 (MGH LL 2/2, 84); Additio 4, 2 (MGH LL 2/2, 146).

202 In diesem Sinn bereits Fleury, Recherches 1933, 247. Die römische Zählweise wird belegt durch die Umformung des ersten Kapitulars Pippins I. in Benedictus Levita 1, 9 (MGH LL 2/2, 47). Die Liste der verbotenen Verwandten erstreckt sich darin bis zur sobrina (3/3). Benedikt ergänzt die Worte aut cum his quibus canones probibent copulari. Mit einem solchen obiter dictum wollte er kaum alle Verwandten von 3/3 bis 6/6 unter das Inzestverbot einreihen; es ging ihm vielmehr darum, die Unvollständigkeit der Aufzählung in Pippins Kapitular zu korrigieren.

203 Benedictus Levita 1, 82 (MGH LL 2/2, 50); 1, 274 (MGH LL 2/2, 61); 2, 71 (MGH LL 2/2, 77); 2, 409 (MGH LL 2/2, 96) u. ö.

204 Incestos nullo coniugii nomine praevalendos esse censemus. Benedictus Levita 3, 434 (MGH LL 2/2, 130).

205 Benedictus Levita 3, 258 (MGH LL 2/2, 118); 3, 356 (MGH LL 2/2, 121).

$206 \mathrm{MGH}$ LL 2/2, 28.

207 Hinschius, Kirchenrecht 5 1893, 43 Anm. 5. 
tierten es in das Jahr 826 oder $827^{208}$. In ihrer ausführlichen stilistischen und inhaltlichen Untersuchung erachteten sie nur die Ausweitung auf den siebten Grad als interpoliert. Ihr Versuch, den Text einem Kapitular von 826/7 zuzuordnen, das auf die Beschlüsse einer Reformsynode von Ingelheim 826 reagiert hätte, muss allerdings als gescheitert angesehen werden. Nach den Erkenntnissen von Gerhard Schmitz sind diese Beschlüsse in Wahrheit Exzerpte aus früheren Konzilskanones und stehen in keiner Verbindung zur Ingelheimer Synode ${ }^{209}$. Es gibt damit keinen Beleg für eine erneute Beratung über das Inzestverbot nach dem Scheitern des Konzils von Aachen im Jahr 819. Die jüngste Stellungnahme zur Echtheit des Kapitels 3, 432 stammt von Mordek, der es unter die zweifelhaften Stücke einreiht ${ }^{210}$. Im Folgenden soll die stilistische Untersuchung Seckels und Juncker nicht wieder aufgenommen werden. Da die formale Gestaltung der Kapitularien keiner Regel gehorcht ${ }^{211}$, ist der Fälschungsfrage mit dem Mittel einer Stilanalyse nicht beizukommen. Für die Frage der Echtheit ist vielmehr die inhaltliche Untersuchung entscheidend. Die ausführlichen und in ihrer Zeit ungewöhnlichen strafrechtlichen Regelungen sollen daher genauer untersucht werden.

Bemerkenswert ist die unmittelbare Strafandrohung für Inzest am Beginn des Kapitulars: Jeder, der diesen Frevel wissentlich begeht, wird mit Königsbann und öffentlicher Kirchenbuße bestraft. Der Inzest von Unfreien oder Hörigen der Kirche soll mit öffentlicher Geißelung, Dekalvation (Scherung) und Kirchenbuße geahndet werden ${ }^{212}$.

Bleiben wir zunächst bei der Strafe des Königsbanns. Der Königsbann als fränkische Strafe ist erstmals auf dem Boden Austrasiens und hier vor allem in der Lex Ribuaria nachweisbar ${ }^{213}$. Mit ihr sollte das öffentliche Strafinteresse des Königs signalisiert und mit einem Offizialverfahren gedroht werden. Zur Anwendung kam diese Strafe zum einen bei dem speziellen Königsschutz für die Kirche sowie für Witwen und Waisen, denen eine eigene Anklage vor Gericht

208 Seckel - Juncker, Studien VIII/4 1934, 309.

209 Sснмiтz, Kapitulariengesetzgebung 1986, 481-484; DERs., Einleitung (MGH Capit. N.S. 1, 21 und $27 \mathrm{f}$.).

210 Mordek, Bibliotheca 1995, 1023.

211 Mordex, Kapitularien 2000, 29-33. Es sei jedoch nicht verschwiegen, dass zahlreiche Stellen deutlich von der Sprache des Kirchenrechts gefärbt sind, u. a. die Wörter luat, iuxta canonicos gradus, sub magna aerumna, humanius, quod non optamus. Andere Begriffe sind in den karolingischen Kapitularien nicht gebräuchlich: temerare, decalvetur, contendantur. Die Nachweise liefern Seckel - Juncker, Studien VIII/4 1934, 316-324.

212 Si quis vero hoc scienter temerare praesumpserit, si liber est, bannum nostrum, id est, sexaginta solidos, fisco nostro persolvat, et insuper canonice ut incestus luat, ac publice iuxta canonicos gradus poeniteat. Si autem servus vel ecclesiasticus fuerit, publice flagelletur ac decalvetur, et iuxta proprii episcopi iussionem poenitentiam publice et canonice gerat. Benedictus Levita 3, 432 (MGH LL 2/2, 129).

213 Brunner - Schwerin, Rechtsgeschichte 2 1928, 46-55. 
oft nicht möglich war. Zum anderen sollte die Gefährdung der öffentlichen Ordnung bei Fällen wie Brandstiftung, Heimsuchung und Missachtung der Heerfolge bestraft werden. Daraus leiteten sich die seit Karl dem Großen standardisierten acht Bannfälle ab. Einen weiteren Anwendungsfall hat kürzlich Harald Siems beschrieben ${ }^{214}$. Die Zahlung des Königsbanns sei demnach eingefordert worden, wenn eine Norm erneut gezielt bekannt gemacht wurde und dadurch ein Verstoß als schwerer Ungehorsam zu werten war. Bei Inzest begegnen wir dem Königsbann nicht ${ }^{215}$. In den germanischen Leges wird den Inzestuösen vielmehr mit Exil oder Konfiskation gedroht ${ }^{216}$. Noch im ersten Kapitular Pippins aus dem Jahre 754 wurde Inzest mit Verlust des Vermögens bestraft ${ }^{217}$. Diese Tradition fand bei Karl dem Großen ein abruptes Ende, da er die Strafverfolgung an die Bischöfe und Priester delegierte ${ }^{218}$. Bei Benedikt wird dagegen neben der Kirchenbuße sofort der Königsbann verhängt. Sklaven und Hörige der Kirche sollen als Ausgleich für ihre Zahlungsunfähigkeit Dekalvation und Stockschläge erleiden. Beides ist im Rahmen der karolingischen Gesetzgebung ungewöhnlich. Eine direkte weltliche Strafe ist seit Karl für Inzest nicht vorgesehen, und die Dekalvation trifft man in den Kapitularien sonst nicht $\mathrm{an}^{219}$.

Der nächste Teil des Kapitels 3, 432 befasst sich mit dem Ungehorsamsverfahren und bestätigt den Verdacht gegen die Echtheit des Kapitels. Demnach soll jemand, der sich der Buße des Bischofs nicht beugen will, durch eine vom Grafen durchgeführte Konfiskation zum Nachgeben gezwungen werden. Reagiert der Straftäter auch darauf nicht, „soll er vom Grafen eingesperrt und als Gefangener unter großer Drangsal in einem Kerker festgehalten werden; und die Verfügung über seinen Besitz soll er nicht haben, bis es der Bischof befiehlt ${ }^{\text {"220 }}$. Hieran sind mehrere Punkte verdächtig. Eine Gefängnishaft diente in

214 Siems, Handel 1992, 790.

215 Eine Ausnahme ist die Capitulatio de partibus Saxoniae c. 20 (MGH Capit. 1, 69). Siehe 276 Anm. 289.

216 Lex Visigothorum 3, 5, 1 (MGH LL nat. Germ. 1, 159); Lex Ribuaria 72, 2 (MGH LL nat. Germ. 3/2, 124); Lex Alamannorum 39 (MGH LL nat. Germ. 5/1, 99); Lex Baiuvariorum VII 2 (MGH LL nat. Germ. 5/2, 348); Leges Langobardorum, Liutprand 33 (MGH LL 4, 123 f.).

217 Pippini regis capitulare c. 1 (MGH Capit. 1, 31).

218 Siehe 274-276.

219 Der Begriff decalvatio ist in den Kapitularien nicht gebräuchlich. Benedikt entlehnt ihn einem Kapitel aus dem westgotischen Recht: Additio 4, 2 (MGH LL 2/2, 146) nach Lex Visigothorum 12, 3, 8 (MGH LL nat. Germ. 1, 436). Zur Frage der Ausführung dieser Strafe vgl. Nehlsen, Sklavenrecht 1972, 224-226.

220 Quod si aliquis, tam liber quam servus, aut ecclesiasticus vel fiscalinus, episcopo proprio vel suo sacerdoti aut suo archidiacono inobediens vel contumax, sive de hoc sive de alio quolibet scelere, extiterit, omnes res eius a comite et a misso episcopi ei contendantur usque dum episcopo suo obediat, ut canonice poeniteat. Quod si nec se ita correxerit, et ad episcopum et 
echten Kapitularien fast durchwegs dazu, renitente Straftäter vor das Königsgericht zu bringen ${ }^{221}$. So sah es Karl der Große im programmatischen Kapitular von 802 für diejenigen vor, die eine Verwandtenehe eingegangen waren und sich nicht zu einer Scheidung bereit gefunden hatten ${ }^{222}$. Dieses Ungehorsamsverfahren brachten auch Ludwig der Fromme und Lothar I. dann zur Anwendung, wenn sich der Bischof mit seinen Anliegen nicht durchsetzen konnte ${ }^{223}$. Es handelte sich um ein in der Gesetzgebung fest etabliertes Verfahren. In Benedikts Kapitel ist dagegen weder ein neues Urteil noch ein Weiterleiten des Falles vor das Königsgericht vorgesehen, es geht lediglich um die Durchsetzung der vom Bischof angeordneten Buße. Das Ungehorsamsverfahren Karls des Großen wird in ein Zwangsverfahren umgewandelt ${ }^{224}$. Der Bischof tritt an die Stelle des Königs. Er allein kann über das Ende der Haft bzw. der Konfiskation entscheiden.

Die letzten beiden Bestimmungen des Kapitels lassen den Fälschungsverdacht zur Gewissheit werden. Sie beschäftigen sich mit einem Rechtspflegedelikt von Seiten der weltlichen Amtsträger. Wenn der Graf (oder sein Mitarbeiter) die Ausführung der bischöflichen Anordnung hintertreibt, soll er exkommuniziert werden, solange es dem Bischof gefällt. Missachtet der Graf den Ausschluss aus der Kirchengemeinschaft, soll er des Amtes enthoben und vor das Königsgericht gebracht werden: „damit wir ihn durch bischöfliche Autorität und kaiserliche Einschüchterung so bestrafen, dass auch die Übrigen Angst haben und von nun an nicht wagen, jemals solche Verbrechen zu begehen " ${ }^{\text {225. }}$. Bei Benedikt wird also nicht der des Inzests überführte Straftäter vor das Königsgericht gebracht, sondern der Graf, der dem Bischof nicht gehorcht. Die Amtsenthebung erfolgt offensichtlich allein durch die Initiative des Bischofs. Das Urteil des Königsgerichts wird nach Benedikt nicht zur Vermittlung zwi-

canonicam poenitentiam venire distulerit, a comite comprehendatur, et in carcerem sub magna aerumna retrusus teneatur, nec rerum suarum potestatem habeat quousque episcopus iusserit. Benedictus Levita 3, 432 (MGH LL 2/2, 129).

221 Vgl. u.a. Capitulare missorum c. 4 (MGH Capit. 1, 67); Capitulare missorum in Theodonis villa datum secundum, generale c. 8 (MGH Capit. 1, 124); Capitula de Iudaeis c. 3 (MGH Capit. 1, 258).

222 Siehe $279 \mathrm{f}$.

223 Capitulare Olonnense ecclesiasticum primum c. 1 (MGH Capit. 1, 326); Capitulare pro lege habendum Wormatiense c. 3 (MGH Capit. 2, 18 f.).

224 So bereits Seckel - Juncker, Studien VIII/4 1934, 311.

225 Quod si comes vel eius ministri haec adimplere distulerint, canonice ab episcopo vel a suo ministro excommunicetur, et usque dum haec pleniter adimpleat, semper communione catholicorum careat, usque dum ipsi episcopo humanius erga eum aliquid agere placuerit. Si vero, quod non optamus, ipse comes aut de praedictis causis aut de ipsa excommunicatione inobediens aut neglegens apparuerit, honore comitatus pariter et communione careat usque dum ambo in nostram praesentiam veniant, ut nos illum episcopali auctoritate atque imperiali metu ita corrigamus, ut et caeteri timorem habeant, nec deinceps talia committere ullatenus audeant. Benedictus Levita 3, 432 (MGH LL 2/2, 129 f.). 
schen Bischof und Graf angerufen, sondern allein zur Aburteilung des weltlichen Amtsträgers. Diese Aburteilung geschieht episcopali auctoritate atque imperiali metu, eine für Benedikt typische Vermischung weltlicher und kirchlicher Zuständigkeit ${ }^{226}$. Die Formulierung des Strafzwecks (ut et ceteri timorem habeant) übernimmt der Fälscher aus echten Kapitularien ${ }^{227}$, dient aber dort der Abschreckung von Verbrechern und nicht der Drohung gegenüber Nachlässigkeiten der Amtsträger.

Fasst man die Ergebnisse zum Kapitel 3, 432 zusammen, so sticht vor allem der Episkopalismus des Fälschers heraus. Das gesamte Strafverfahren ist von der Kompetenz des Bischofs gekennzeichnet, die sich auch auf die weltliche Jurisdiktion erstreckt. Der Bischof ist für die Überwachung der Grafen verantwortlich und ersetzt die für diese Aufgabe vorgesehenen Königsboten. Eine solche Kompetenzverschiebung ist in echten Kapitularien nicht bezeugt. Auch der restliche Inhalt der Strafbestimmung steht im deutlichen Kontrast zur Gesetzgebung Karls des Großen und Ludwigs des Frommen. Dies trifft für den Königsbann, die Dekalvation, das Ungehorsamsverfahren und die Strafe für ein Rechtspflegedelikt zu. Ich halte das Kapitel 3, 432 daher für gefälscht. Wenn alle der Fälschung verdächtigten Teile weggelassen würden, bliebe lediglich ein Gerippe an Formulierungen übrig, das durchaus als echt angesehen werden könnte. Diese Formulierungen hat der Fälscher jedoch aus echten Kapitularien entnehmen können, so dass die Postulierung einer echten Vorlage überflüssig ist.

Die Tatsache der Fälschung von 3, 432 unterstreicht nochmals die Bedeutung des Inzestthemas bei Benedictus Levita. Gegenüber den frühen pseudoisidorischen Dekretalen ist eine deutliche Verschärfung zu konstatieren. Benedikt trat vehement für eine Ausdehnung des Inzestverbots auf den siebten Grad ein und forderte eine strenge Strafpraxis sowohl von weltlicher als auch von geistlicher Seite. In zwei verfälschten Kapiteln hielt er sogar die Todesstrafe für angemessen ${ }^{228}$. Es stellt sich daher die dringende Frage, warum das Inzestverbot erneut zu einem Thema geworden ist, nachdem es seit 819 aus der Agenda der Kirchenreformer ausgeschieden war. Selbst auf dem Doppelkonzil von MeauxParis im Jahre 845/846, das früher wegen der ablehnenden Reaktion des Königs als Auslöser für das Fälschungswerk angesehen wurde ${ }^{229}$, ist das Inzestverbot

226 Seckel spricht vom „System des ius utrumque“: SECKEL, Studien VII/1 1909, 353.

227 Belege bei Seckel - Juncker, Studien VIII/4 1934, 324 mit Verweis auf die biblische Vorlage (Deut. 19, 20).

228 Benedictus Levita 2, 421 (MGH LL 2/2, 97); 3, 356 (MGH LL 2/2, 124). Wirkung entfaltete die Position Benedikts in zwei Bischofskapitularien: Herard von Tours, Kapitular c. 36 (MGH Capit. episc. 2, 136); Isaak von Langres, Kapitular IV 1-15 (MGH Capit. episc. 2, 207-213).

229 Vgl. Hartmann, Synoden 1989, 208 -217; Zechiel-Eckes, Exterminator 2004, 181 185. 
nicht thematisiert worden. Man wird also den Blick über das Westfrankenreich hinaus richten müssen, um der Ursache für die Radikalisierung des Inzestverbots nachzuspüren. Gerade zu der Zeit, als Benedikt sein Werk abschloss, wurde Hrabanus Maurus von Ludwig dem Deutschen zum Erzbischof von Mainz erhoben. Er folgte Otgar von Mainz nach, den Benedikt als Auftraggeber seines Werkes bezeichnete ${ }^{230}$. Hrabanus durchbrach den Konsens der fränkischen Kirche und ergriff Partei für eine moderate Position zum Inzestverbot. Er lehnte ausdrücklich den Standpunkt des Papstes ab, weil er die Ausdehnung auf den siebten Grad für nicht praktikabel hielt. Als einziger Gelehrter des 9. Jahrhunderts brach er eine Lanze für die Beschränkung auf die biblischen Inzestverbote und für die Gültigkeit des Libellus responsionum Gregors des Großen. Diese Position vertrat er in Schriften an den Chorbischof Reginbald, an Hatto von Fulda, an Otgar von Mainz und an Heribald von Auxerre. Es liegt durchaus im Bereich des Möglichen, dass man in Corbie mit der Haltung Hrabans vertraut war. Dazu muss man nicht den autobiographischen Bericht Benedikts über seinen Aufenthalt bei Erzbischof Otgar in Mainz für authentisch halten ${ }^{231}$, denn Hraban stand mit den führenden west- und ostfränkischen Theologen und Kirchenpolitikern in engem Kontakt. Er tauschte sich wegen des Prädestinationsstreits mit Hinkmar von Reims aus, beteiligte sich an der Debatte um den Chorepiskopat und nahm in der Deutung der Eucharistie gegen Radbert von Corbie Stellung ${ }^{232}$. An allen diesen intellektuellen Auseinandersetzungen waren auch die Mönche des Klosters Corbie an führender Stelle beteiligt. Hrabans Schriften hätten also durchaus den Weg in das Fälschungszentrum an der Somme finden können ${ }^{233}$.

\section{Nochmals Pseudoisidor}

Die Verfälschung der Rechtsquellen durch Benedictus Levita kann somit als eine Reaktion auf die vom Konsens abweichende Meinung des Hrabanus Maurus begriffen werden. Der Fälscher bog alle verfügbaren Rechtsquellen im Sinne der päpstlichen Position zurecht - mit Ausnahme des Libellus responsionum. Gerade

230 Benedictus Levita, Versiculi (MGH LL 2/2, 39).

231 Wie Wasserschleben, Frage 1864, 300, und Krusch, Forschungen 1927, 56. Ob die Benützung ostfränkischer Quellen diese Vermutung erhärten kann, ist noch nicht hinlänglich geklärt. Ablehnend Lukas, Neues 2002; Dies., Beobachtungen 2002; DiEs., Sammlung 2004.

232 Zusammenfassend vgl. Raymund Коттје, Art. „Hrabanus Maurus“, VL ${ }^{2}$ (1983) 166196.

233 Hrabans Bußbücher waren vorwiegend im ostfränkischen Reich verbreitet: КоттJE, Bußbücher 1980, 111-141. Ende des 9. Jahrhunderts sind die Bußbücher Hrabans in einer Handschrift aus der Reimser Kirchenprovinz nachweisbar (Köln, Erzbischöfliche Diözesan- und Dombibliothek, 118): vgl. КоттJE, Bußbücher 1980, 29 f. Andere Werke Hrabans waren in Corbie durchaus greifbar, vgl. Ganz, Corbie 1990, 65. Siehe auch 342 Anm. 260. 
dieses Dokument bildete aber eine zentrale Stütze für die Argumentation des Mainzer Erzbischofs ${ }^{234}$ und ist auch in die zweite Redaktion der pseudoisidorischen Dekretalen aufgenommen worden. Dort stand es im deutlichen Kontrast zum eigenen Standpunkt des Fälschers, der sich am kategorischen Verbot sowie an der Inzestgrenze des siebten Grades orientierte. Es ist daher nur folgerichtig, dass die pseudoisidorische Werkstatt auch diese Rechtsquelle unter ihre Fittiche nahm. Herausgekommen ist ein gefälschter Briefwechsel zwischen Bischof Felix von Messina und Papst Gregor I. über das Inzestverbot.

Die Überlieferung dieses Briefwechsels bedarf noch weiterer Erforschung, die in diesem Rahmen nicht geleistet werden kann. Deshalb sollen hier nur die bekannten Fakten zusammengetragen werden. Innerhalb der falschen Dekretalen ist der Briefwechsel erst im 10. Jahrhundert fassbar, und zwar in einem aus Gregorbriefen bestehenden Anhang zu einer A2-Handschrift ${ }^{235}$. Im Hochmittelalter ging er dann eine feste Verbindung mit den C-Handschriften ein. AuBerhalb der Fälschung begegnet er u.a. in der Sammlung aus dem Kloster Fécamp und in zwei Handschriften des Registers Gregors I. Die früheste Überlieferung bietet eine Handschrift aus dem Besitz Hinkmars von Reims. Vermutlich war Hinkmar mit dem gefälschten Briefwechsel schon im Jahre 852 vertraut, sicher aber seit $860^{236}$. Hinkmar zitierte mehrfach daraus in seinen Schriften ${ }^{237}$. Wenig später sind die Falsifikate in Rom eingetroffen, wo sie Johannes Diaconus in seine Vita Gregors des Großen aufnahm ${ }^{238}$. Diese Belege legen den Schluss nahe, dass der Briefwechsel zunächst unabhängig von der pseudoisidorischen Sammlung zirkulierte und erst später der C-Fassung angefügt wurde. Trotz der Überlieferung außerhalb der Fälschung ist die von Hinschius vorgenommene Zuschreibung an die pseudoisidorische Werkstatt gut begründet. Der Briefwechsel befasst sich nämlich noch mit zwei anderen Themen, der Verfolgung von Bischöfen durch Laien und der Wiederholung einer Weihehandlung. Beide Themen wurden bereits an anderen Stellen der

234 Hrabanus Maurus, Ep. 29 (MGH Epp. 5, 445); Ep. 31 (MGH Epp. 5, 457).

235 Köln, Erzbischöfliche Diözesan- und Dombibliothek, Cod. 114, fol. 242vb-247vb. Zum Folgenden Fuhrmann, Einfluss 1972, 190.

236 Berlin, Staatsbibliothek Preußischer Kulturbesitz, Phill. 1741, fol. 3v-7v. Hinkmar zitiert in seinem Bischofskapitel von 852 eine Dekretale Gregors II., die in der Berliner Handschrift (fol. 3r-v) unmittelbar vorangeht. Nach Martina Stratmann (MGH Capit. episc. 2, 17 Anm. 53) hat Hinkmar direkt aus der Berliner Handschrift zitiert und somit schon damals Kenntnis von Pseudo-Gregor gehabt. Zu dieser Frage vgl. auch FurrManN, Einfluss 1972, 200; Schmitz, Memorandum 2004, 51.

237 Vgl. Hinkmar von Reims, De divortio Lotharii regis et Theutbergae reginae (MGH Conc. 4 Suppl. 1, 140, 194, 218, 223 und 252); Epistola 136 (MGH Epp. 8/1, 96); Konzil von Douzy (874) (MGH Conc. 4, 582).

238 Johannes Diaconus, Vita S. Gregorii magni II 38 (Migne PL 75, 101). 
falschen Dekretalen in gleicher Weise traktiert ${ }^{239}$ und dienen hier nach der für den Fälscher typischen Methode als „Hülle der Fälschung “240.

Im Mittelpunkt des gefälschten Briefwechsels steht das Inzestverbot. Als Anlass für seine Anfrage bezeichnet Felix die Tatsache, dass er von einem Schreiben des Papstes an Bischof Augustinus, dem Missionar der Angelsachsen, gehört habe ${ }^{241}$. Darin - es handelt sich um den Libellus responsionum - gebe der Papst die Anweisung, Ehen ab dem vierten Verwandtschaftsgrad nicht zu trennen.

„Diese Gewohnheit gab es in jenen und diesen Regionen nicht, als ich gemeinsam mit Euch aufgezogen und unterrichtet wurde, und auch habe ich es nicht in einem Dekret von euch oder von einem eurer Vorgänger oder in einer Anordnung der Väter gelesen; bislang habe ich nicht erfahren, dass dies von irgendwelchen Gelehrten zugestanden wurde, sondern ich habe immer vorgefunden, dass man das Verbot bis zum siebten Grad der Verwandtschaft einhalten muss: von euren Vorgängern, von den heiligen Vätern, die auf dem Konzil von Nicäa und auf anderen Synoden versammelt waren "242.

Diese offensichtliche Diskrepanz habe Felix zur Anfrage bewogen, wie der Papst seine Anweisung an Augustinus mit der Lehrtradition in Einklang bringen könne.

Der Hinweis des Bischofs auf frühere päpstliche Bestimmungen soll den Eindruck einer kontinuierlichen Position des Papsttums zum Inzestverbot erwecken und ist als interner Verweis auf die Dekretale Pseudo-Calixts zu verstehen. Die Berufung auf das Konzil von Nicäa entbehrt dagegen jeder Grundlage. Weder in den echten noch in den von Pseudoisidor an anderer Stelle erdichteten Kanones von Nicäa ${ }^{243}$ findet sich eine Bestimmung zum Inzestverbot. Es nimmt daher nicht wunder, dass Pseudo-Gregor auf diese erfundene Quelle in seiner Antwort nicht näher eingeht. Er deutet dagegen die Anweisung an Augustinus als eine spezielle Erlaubnis für die erst jüngst missionierten Angelsachsen, die durch eine strikte Einforderung der Inzestgebote vom

239 Die Verfolgung von Bischöfen ist das Leitthema der Fälschung: Zechiel-Eckes, Spur 2002; zur Frage der Wiederholung einer Weihehandlung vgl. Decretales Pseudo-Isidorianae, Ps.-Felix IV. (701).

240 SeCKel, Pseudoisidor 1905, 298.

241 Decretales Pseudo-Isidorianae, Ps.-Felix v. Sizilien (747).

242 Que consuetudo dudum in illis aut istis in partibus, quando una vobiscum infantia nutritus atque edoctus fui, non erat, nec in ullis praecessorum vestrorum decretis aut reliquorum generaliter aut specialiter patrum institutis legi aut hactenus ab ullis sapientibus esse concessum didici, sed semper usque septimum originis sue gradum hec a sanctis antecessoribus vestris et ceteris sanctis patribus, tam in Nicena synodo quam et in aliis sanctis conciliis congregatis servari debere repperi ... Decretales Pseudo-Isidorianae, Ps.-Felix v. Sizilien (747 f.).

243 Die gefälschten Kanones befinden sich in: Decretales Pseudo-Isidorianae, Ps.-Julius c. 12 (467-471). Hierzu Zechiel-Eckes, Spur 2002, 22-24. 
Glauben abgeschreckt worden wären ${ }^{244}$. Der Fälscher schließt sich damit der Interpretation an, die schon Zacharias, Leo III. und Jonas von Orléans diesem Schreiben gegeben hatten ${ }^{245}$, und erteilt ihr ex post das Placet Gregors des Großen. „Denn wenn ich das vernichtet hätte, was meine Vorgänger festgesetzt haben, müsste ich zu Recht nicht als Erbauer, sondern als Umstürzler bezeichnet werden “246.

Am Ende der Dekretale, nachdem er die beiden anderen Anfragen beantwortet hatte, wendet sich Pseudo-Gregor erneut dem Inzestverbot zu. In Worten, die einem Kapitel aus Benedikts Werk entnommen sind, wird die Inzestgrenze ausdrücklich auf den siebten Grad festgesetzt ${ }^{247}$. Diese Grenze soll sowohl in der Bluts- wie in der Schwiegerverwandtschaft Geltung haben. Auf diese Bestimmung folgt die Strafandrohung, alle Inzestuösen aus der Kirche auszuschließen, d. h. vom Besuch des Gottesdienstes fernzuhalten. Wenn sie sich dem Urteil der Kirche unterwerfen, müssen sie eine öffentliche Kirchenbuße auf sich nehmen, um wieder in den Kreis der Kirche aufgenommen zu werden. Bei Ungehorsam soll ihnen mit der Exkommunikation gedroht werden. Die Begründung lautet wie folgt:

„Die Bösen sind von den Guten zu trennen, damit nicht die Gerechten für die Ungerechten verdammt werden. ... Und es wundert nicht, wenn unter Menschen diese Vorschrift eingehalten wird, weil wir auch unter den Tieren denselben Vorgang des Öfteren beobachten können, dass Tiere mit Hautausschlag und Krätze von den Gesunden getrennt werden, damit nicht durch die Krankheit jener die übrigen zugrunde gehen. Besser ist es daher, dass die Bösen öffentlich gezüchtigt werden, als dass die Guten für jene zugrunde gehen. ${ }^{\text {"248 }}$

244 ... ne a bono quod coeperat, metuendo austeriora recederet, specialiter et non generaliter ceteris me scripsisse congnoscas. Decretales Pseudo-Isidorianae, Ps.-Gregor (749).

$245 \mathrm{Zu}$ Zacharias siehe 225; zu Leo siehe 301; zu Jonas siehe 305.

246 Nam si ea destruerem quae antecessores nostri statuerunt, non constructor, sed eversor iuste comprobarer ... Decretales Pseudo-Isidorianae, Ps.-Gregor (749).

247 Progeniem vero suam unumquemque ... usque ad septimam observare decernimus generationem et quamdiu se agnoscunt affinitate propinquos ad huius copule non accedere societatem nec eam quam aliquis ex propria consanguinitate coniugem habuit vel aliqua inlicita pollutione maculavit in coniugium ducere ulli profecto christianorum licet vel licebit, quia incestuosus est talis coitus et abhominabilis deo et cunctis bonis hominibus. Decretales Pseudo-Isidorianae, Ps.-Gregor (751). Diese Zusammenstellung zweier Zitate aus der Briefsammlung des Bonifatius findet sich nur bei Benedictus Levita 2, 80 (MHG LL 2/2, 77); Additio 4, 75 (MGH LL 2/2, 151); vgl. hierzu Seckel, Studien VII/1 1909, 341 Anm. 6.

248 ... segregandi sunt mali a bonis, ne pereant iusti pro iniustis, sicut scriptum est: Periit iustus pro impio. ... Nec mirum, si inter homines haec ratio custoditur, cum et inter iumenta haec fieri persepe cognovimus, et ea quae scabiem aut impetiginem habere videntur, separentur a sanis, ne illorum morbo cetera dampnentur vel pereant. Satius est enim ut mali manifeste corrigantur, quam pro illis boni pereant. Decretales Pseudo-Isidorianae, Ps.-Gregor (752). 
Mit dieser Fälschung erreichte Pseudoisidor sein Ziel, der Geltung des Libellus responsionum endgültig ein Ende setzen. Durch die Rezeption dieses Machwerks im 11. Jahrhundert ist der Berufung auf diese Autorität endgültig der Boden entzogen worden. In seiner ursprünglichen Fälschung sah Pseudoisidor noch keinen Reformbedarf in dieser Frage und äußerte sich dazu nur an einer Stelle in einer wenig engagierten Weise. Ihm schienen die Bestimmungen der römischen Synode von 721 zu genügen, die er in den Brief Calixts I. und in das Konzil von Epaon interpolierte sowie programmatisch an das Ende der ganzen Sammlung stellte $^{249}$. Durch die Aufnahme des Libellus responsionum in die erweiterte Fassung der gefälschten Dekretalen wurde diese Stellungnahme jedoch unterlaufen. Das Kirchenrecht Pseudoisidors, so wie es in der am meisten verbreiteten Form benutzt wurde, repräsentierte keinen eindeutigen Standpunkt zur Grenze des Inzestverbots. Ein Bedürfnis nach Verfälschung der Rechtsquellen ist erst entstanden, als Hrabanus Maurus gegenüber bedeutenden Prälaten des Frankenreichs mit Vehemenz und Gelehrsamkeit für eine moderate Position eintrat und den Libellus responsionum verteidigte. Zuerst reagierte Benedictus Levita auf diese Herausforderung, indem er durch Texteingriffe die überlieferten Rechtsnormen auf eine Linie brachte und die weltliche Strafe gegen Delinquenten verschärfte. Später griff auch ein Mitglied der pseudoisidorischen Werkstatt zur Feder und erfand einen neuen Briefwechsel Gregors des Großen. Das Beispiel des Inzestverbots bestätigt die durch Zechiel-Eckes eingebrachte Frühdatierung der gefälschten Dekretalen und wirft ein neues Licht auf die „Hin- und Herbenutzung" zwischen den beiden Fälschungswerken.

\subsection{Der Standpunkt des Kirchenpolitikers: Hinkmar von Reims}

Fast vierzig Jahre amtierte Hinkmar als Erzbischof von Reims und entfaltete in dieser Zeit eine kirchenpolitische Aktivität, die im 9. Jahrhundert einzigartig dasteht ${ }^{250}$. Er war lange Jahre einer der führenden Berater Karls des Kahlen, trat als Verfasser einiger Kapitularien des Herrschers hervor, scheute jedoch auch vor Kritik an der Politik des Westfrankenkönigs nicht zurück. Durch seine rege schriftstellerische Tätigkeit gibt es kaum ein Ereignis der Politik seiner Zeit, das nicht von ihm in irgendeiner Weise kommentiert wurde. Dadurch kann man leicht der Versuchung unterliegen, seinen Einfluss auf die Zeitgenossen zu überschätzen und die Konflikte des 9. Jahrhunderts durch seine Brille zu sehen. Zieht man jedoch die handschriftliche Überlieferung seiner Werke in Betracht, ergibt sich eine deutliche Korrektur dieses Bildes. Denn viele seiner Schriften, die von der Forschung als zentrale Quellen herangezogen werden, sind nur in

249 Decretales Pseudo-Isidorianae, Decreta Gregorii iunioris (754).

250 Maßgeblich sind Schrörs, Hinkmar 1884; Devisse, Hincmar 1975. 
wenigen Handschriften überliefert. Sein Einfluss auf das spätere Kirchenrecht kann überhaupt als marginal bezeichnet werden. Nur einige Abschnitte aus seinen Bischofskapitularien gingen über die Vermittlung Reginos von Prüm in das Kirchenrecht des Hochmittelalters ein ${ }^{251}$.

Im Gegensatz zu dieser bescheidenen Wirkung seiner Werke fungierte er in der Geschichte der Inzestgesetzgebung als wichtige ,Relaisstation' für die Verbreitung der pseudoisidorischen Fälschungen. Sein Bischofskapitular von 852 ist das erste Zeugnis für ein Zitat aus den gefälschten Papstbriefen ${ }^{252}$. Zur selben Zeit lag ihm vermutlich schon der gefälschte Briefwechsel zwischen Gregor dem Großen und Felix von Messina über die Ausdehnung des Inzestverbots vor ${ }^{253}$. Erstmals zitierte er daraus im Jahr 860 in einem Gutachten zur Eheaffäre König Lothars II. Fortan gehörte der Briefwechsel zum Kernbestand seines Inzestdossiers, das er zu verschiedenen Zeitpunkten zum Einsatz brachte. Hinkmar ist es vermutlich auch zuzuschreiben, dass die päpstliche Kurie in Rom von dem gefälschten Briefwechsel erfuhr. Der Reimser Erzbischof stand nämlich in regem Austausch mit Anastasius Bibliothecarius, dem Kanzler, Archivar und wichtigen Ratgeber von Nikolaus I., Hadrian II. und Johannes VIII. ${ }^{254}$ Im Jahr 868 sandte Hinkmar ihm einige Werke aus seiner Feder ${ }^{255}$. Wenige Jahre später, zwischen 873 und 876, verfasste der römische Diakon Johannes im Auftrag Johannes' VIII. eine vierbändige Vita Gregors des Großen. Darin wird aus dem gefälschten Briefwechsel die Ausdehnung des Inzestverbots auf den siebten Grad zitiert $^{256}$. Johannes Diaconus und Anastasius Bibliothecarius waren gute Bekannte und planten gemeinsam die Abfassung einer umfassenden Kirchengeschichte, zu der es jedoch nicht $\mathrm{kam}^{257}$. Vermutlich wurde Johannes von Anastasius über den gefälschten Briefwechsel in Kenntnis gesetzt. Er und Hinkmar waren die Einzigen, die im 9. Jahrhundert den Briefwechsel nachweislich kannten. Für die Verbreitung im ganzen Abendland sorgten nicht die zahlreichen Zitate Hinkmars, sondern die Überlieferung der Vita Gregorii. Sie erfreute sich im gesamten Mittelalter einer großen Popularität und ist abgesehen von gekürzten und fragmentarischen Fassungen in 146 Handschriften erhal$\operatorname{ten}^{258}$.

251 Hartmann, Synoden 1989, 482-492; Stratmann, Wirkungsgeschichte 1995, 18; РокоRny, Einleitung (MGH Capit. episc. 4, 143-149).

252 Furhmann, Einfluss 1972, 200-210.

253 Siehe 337 Anm. 236.

254 Vgl. Perels, Nikolaus I. 1920.

255 Flodoard, Historia Remensis ecclesiae III 24 (MGH SS 36, 323).

256 Johannes Diaconus, Vita Gregorii Magni II 38 (Migne PL 75, 101 f.).

257 Anastasius Bibliothecarius, ep. 7 (MGH Epp. 5, 419).

258 Wilhelmi, Vita 1998; Castaldi, Vita 2004. 


\section{Idées fixes am Konzil von Douzy}

Wenn Hinkmar für die Bekanntmachung der pseudoisidorischen Fälschung zum Inzestverbot verantwortlich war, ist es geboten, nach seinen Motiven dafür zu fragen. Hinkmar benutzte den Briefwechsel stets dazu, die Autorität des Libellus responsionum zu diskreditieren. Die Fixierung auf dieses Dokument ist möglicherweise auch bei Hinkmar darauf zurückzuführen, dass sich Hrabanus Maurus für seine Geltung stark gemacht hatte. Hinkmar wurde bald nach seiner Wahl zum Erzbischof von Reims von Hrabanus in die Debatte um Gottschalk den Sachsen mit hineingezogen, da das Kloster Gottschalks Orbais in seiner Kirchenprovinz $\mathrm{lag}^{259}$. Beide vertraten dieselbe gemäßigte Position im Prädestinationsstreit und verkehrten in dieser Sache brieflich miteinander. Man wird es daher für sehr wahrscheinlich halten können, dass Hinkmar mit der Position des Mainzer Metropoliten vertraut war und den Libellus deshalb als gefährliches Dokument einstufte ${ }^{260}$. Wie bereits bei Jonas von Orléans war der Libellus die bête noir der Kirchenreformer.

Am deutlichsten kommt diese Fixierung auf den Libellus in den Akten des Konzils von Douzy (874) zum Ausdruck. Der von Hinkmar verfasste Synodalbrief enthält das umfassendste Inzest-Dossier des Erzbischofs und kann als repräsentative Stellungnahme angesehen werden. Den Anlass für sein Eingreifen gibt er folgendermaßen zu Protokoll:

„Wie es durch einen klaren Bericht und daraufhin durch eine Konsultation an unsere Ergebenheit gelangt ist, gehen in jenen Regionen [Aquitaniens] ziemlich viele und besonders adelige und durch zeitliche Würden herausgehobene Personen durch eine unheilvolle Seuche zugrunde, weil sie sich neben anderem, was Gott und ihrem Heil zuwiderläuft, inzestuösen Verbindungen und Plünderungen von Kirchengut hingeben. Sie nehmen sich als sichere Hülle für die Befleckung mit Inzest die verkehrte und perverse Doktrin von gewissen Leuten darüber, was der heilige Gregor ... dem ersten Bischof der Angeln Augustinus ... befohlen hat ${ }^{\text {“261 }}$.

Nach einer langen und mit Anspielungen auf die Endzeit gespickten Beschimpfung und Diskreditierung dieser „Unheil stiftenden“" Lehre zitiert

259 Коттје, Beziehungen 1981.

260 Eine Handschrift von Hrabans Epistola ad Humbertum aus dem 9. Jahrhundert ist aus dem Reimser Umfeld überliefert: Vatikan, Pal. lat. 567, 8v-11v. In diesem Brief verteidigt Hraban den Libellus responsionum, siehe 309-311. Hrabans Bußbücher sind Ende des 9. Jahrhunderts ebenfalls in Reims greifbar, siehe 336 Anm. 233.

261 Sicut ad humilitatem nostram non incerta relatione atque exinde consultatione perventum, quamplures et maxime carne nobiles et honore temporali sublimes, inter alia deo et suae saluti contraria incestis coniunctionibus et rerum ecclesiasticarum pervasionibus pestilentia exitiosa in regionibus illis depereunt; assumentes de incesti pollutione velamentum securitatis quorundam prava et perversa doctrina, de hoc, quod sanctus Gregorius ... Augustino primo Anglorum episcopo ... rescripsit. Konzil von Douzy (874) Ep. synodica (MGH Conc. 4, 581). 
Hinkmar ausführlich aus dem gefälschten Briefwechsel, um die Geltung des Libellus zu untergraben. Darauf lässt er ein langes, aber nicht kenntlich gemachtes Zitat aus De institutione laicali des Jonas von Orléans folgen, das er für seine Zwecke zurechtmacht ${ }^{262}$. Er unterschlägt die Festlegung des Jonas auf den sechsten Grad und setzt an ihrer Stelle eine verschleierte Falschaussage:

„Und der Stammbaum des römischen Rechts stimmt mit den kirchlichen Gesetzen überein, indem er niemandem erlaubt, sich mit jemandem von den Vor- und Nachfahren, links und rechts (des Stammbaums) bis zum siebten Grad rechtmäßig zu verbinden" ${ }^{\text {"263. }}$.

Die undeutliche Formulierung durch die Worte legaliter sociari will den Unterschied zwischen der Regelung der Erbfolge und der Eheverbote im römischen Recht verwischen, die Hinkmar als Zweck des Stammbaums ausgibt. Anschließend listet Hinkmar alle verbotenen Verwandten namentlich auf und gibt damit auf singuläre Weise zu erkennen, wieweit das Inzestverbot in seinen Augen reicht. Da er den Stammbaum Isidors von Sevilla benutzt, ist die Ehe bis zum Cousin dritten Grades (4/4) untersagt ${ }^{264}$. Den Abschluss der Ausführungen zum Inzestverbot bildet eine Zitatreihe aus dem traditionellen Kirchenrecht ${ }^{265}$.

Der Synodalbrief Hinkmars erweckt durch die Anfangsworte den Eindruck, dass in Aquitanien besonders viele Inzestfälle der Verfolgung durch die Kirche entgehen und dass die Adeligen sich in ihrem Eheverhalten auf die Autorität des Libellus responsionum stützen ${ }^{266}$. Bei einer Persönlichkeit wie Hinkmar muss man sich jedoch vor solchen Folgerungen in Acht nehmen, da er jede Gelegenheit nützt, um seine Interessen, seine idées fixes ins Spiel zu bringen. Das andere Thema des Synodalbriefes, die Veruntreuung von Kirchengut, zählt wie

262 Konzil von Douzy (874) Ep. synodica (MGH Conc. 4, 583 Z. 23-584 Z. 17) beruht auf Jonas von Orléans, De institutione laicali II 8 (Migne PL 106, 183 f.). Das Zitat ist in der Edition nicht identifiziert. Falsch ist die Annahme Frieds, Hinkmar beziehe sich auf das Paenitentiale Martenianum: Fried, Konradiner 2006, 23. Dieses Bußbuch ist entgegen der Datierung des Herausgebers Hörmann (um 800) erst kurz vor der Mitte des 9. Jahrhunderts entstanden (KoTTJE, Bußbücher 1980, 206; HaggenmüLler, Rezeption 1992, 155; MeENs, Boeteboek 1994, 55) und übte keinen nennenswerten Einfluss aus.

263 Et arbor iuris legis Romanae ecclesiasticis concordans legibus a praecedentibus et subsequentibus dextra laevaque usque ultra septimum gradum neminem nemini legaliter sociari permittit. Konzil von Douzy (874) Ep. synodica (MGH Conc. 4, 583).

264 Conrat, Arbor 1909, 40 f., weist nach, dass Hinkmar den am weitesten verbreiteten Stammbaum Isidors verwendete, den SснаDт, Arbores 1982, als Typ 5b bezeichnet und der geringfügig um einen Grad von der römischen Zählung abweicht. Siehe 25 Anm. 119.

265 Und zwar das Konzil von Rom (721) sowie die Kanones von Lérida, Toledo II und Epaon: Konzil von Douzy (874) Ep. synodica (MGH Conc. 4, 584 f.).

266 So z. B. Hartmann, Synoden 1989, 331 f.; Corbet, Burchard 2001, 43 f. 
der Inzest zu den „Dauerthemen karolingischer Synoden“267 und dient Hinkmar wohl in erster Linie dazu, für den Schutz des Kirchenguts der Reimser Kirche in Aquitanien zu werben. Seine Tätigkeit in diese Richtung ist durch das bei Flodoard erhaltene Register seines Briefwechsels überaus reichlich dokumentiert $^{268}$. Im Synodalbrief von Douzy zitiert er das übliche Dossier zur Kirchengutsfrage, das er bereits bei zahlreichen Gelegenheiten zum Einsatz gebracht hatte.

Die Kanones des Konzils von Douzy geben einen Anhaltspunkt für die Frage, warum Hinkmar im Synodalbrief an die Bischöfe Aquitaniens das Thema des Inzests angesprochen hat. Sie beschäftigten sich nämlich ausschließlich mit dem Fall einer Nonne Duda, der verschiedene Anklagepunkte vorgehalten wurden. Sie soll den Priester Huntbert dazu überredet haben, ihre Äbtissin durch gefälschte Dokumente zu verleumden, damit sie selbst die Leitung der Abtei übernehmen könnte ${ }^{269}$. Die Sache ist von Königsboten untersucht worden, die den Priester in allen Punkten überführen konnten. Darüber hinaus beschuldigte Duda den Priester, der Vater ihres Kindes zu sein. Die Synode bestimmte, ihn deshalb nicht erneut zum Reinigungseid zuzulassen, und legte das Strafmaß für die beteiligten Personen fest. Wo sich dieser Fall zutrug, ist nicht bekannt. Wenn das Kloster in Aquitanien lag, so könnte sich das Inzestdossier Hinkmars leicht erklären. Denn Hinkmar bezeichnete im Synodalbrief ausdrücklich auch die Verbindung mit einer Nonne als Inzest ${ }^{270}$, wie es seit der Spätantike üblich gewesen war. Das Inzestdossier wäre dann eine Extrapolation ausgehend von dem konkreten Fall der Unzucht zwischen Duda und Huntbert. Es spräche dann viel dafür, dass der Bericht Hinkmars über die Verwendung des Libellus responsionum durch den aquitanischen Adel seine eigenen Sorgen widerspiegelt. Wenige Jahre später, als Papst Johannes VIII. einige aquitanische Bischöfe in derselben Sache maßregelte, war von einer Berufung auf das umstrittene Dokument nicht die Rede ${ }^{271}$.

267 Hartmann, Synoden 1989, 331.

268 Stratmann, Hinkmar 1991, 45-53.

269 Konzil von Douzy (874) c. 2 (MGH Conc. 4, 588).

270 Konzil von Douzy (874) Ep. synodica (MGH Conc. 4, 583 u. 584).

271 Preterea unum valde illicitum et execrabile malum contra venerabilia sanctorum patrum decreta eosdem vestros parrochianos committere audimus, hoc est, ut nulla generis consanguinitate custodita, nulla propinquitatis parentela observata unusquisque suam propinquam, in quocumque fuerint gadu, accipiat in uxorem ... Johannes VIII., Registrum 189 (MGH Epp. 7, 151) (JE 3263). 


\section{Die Eheaffäre König Lothars II.}

Die Affäre um die Ehe Lothars II. bringt uns zurück in die Anfangsjahre von Hinkmars Amtszeit. Der erste große politische Auftritt des Reimser Metropoliten fand im Jahr 858 statt, als Ludwig der Deutsche aufgrund einer Einladung opponierender Adeliger in das Reich seines Halbbruders Karls des Kahlen einfiel $^{272}$. Ludwig gelang es zunächst, Karl aus dem Zentrum seines Reiches zu verdrängen und die Herrschaft an sich zu reißen. Sein Versuch, die Bischöfe des Westfrankenreichs auf seine Seite zu ziehen, scheiterte jedoch am Widerstand Hinkmars von Reims. Hinkmar leistete der Einberufung einer Synode durch Ludwig nicht Folge und kritisierte mit deutlichen Worten das gegen bisherige Abmachungen verstoßende Vorgehen des ostfränkischen Königs. Er leitete damit die Wende zugunsten Karls des Kahlen ein, der zu Beginn des Jahres 859 seinen Bruder vertreiben und wieder als unumschränkter Herrscher im Westfrankenreich agieren konnte.

In diese Zeit des noch gerade abgewendeten Bruderkriegs fallen die ersten Anzeichen für die Ehekrise des im Mittelreich herrschenden Lothars II. Mehr als zehn Jahre sollte die Eheaffäre das ganze fränkische Reich in Atem halten und schließlich zum Untergang des Mittelreichs führen ${ }^{273}$. Begonnen hat die Affäre mit dem Plan Lothars, sich von seiner 855 rechtmäßig angetrauten Frau Theutberga scheiden zu lassen und seine Konkubine Waldrada zu ehelichen. Als Scheidungsgrund führte er die Behauptung ins Feld, Theutberga habe vor ihrer Ehe mit ihrem Bruder Hugbert Unzucht getrieben und das gemeinsame Kind abgetrieben. Lothar brachte diesen Fall zuerst vor das weltliche Gericht, musste jedoch eine Niederlage hinnehmen, weil ein Stellvertreter Theutbergas das Gottesurteil erfolgreich bestanden hatte. Anfang des Jahres 860 rief er das geistliche Gericht der Bischöfe seines Reichs an. Auf zwei Synoden im Januar und Februar sind die Bischöfe zu dem Urteil gelangt, der voreheliche Inzest habe Theutberga für jede weitere Ehe disqualifiziert, da sie sich lebenslänglicher Buße unterziehen hätte müssen. Man wies sie daher in ein Kloster ein. An diesem Urteil waren neben den Drahtziehern Gunthar von Köln und Thietgaud von Trier auch Bischöfe aus dem Westfrankenreich beteiligt. An Hinkmar von Reims ist man vergeblich mit dem Ansuchen herangetreten, sich an dem synodalen Verfahren zu beteiligen. Er winkte aus gesundheitlichen Gründen ab, nahm aber wenig später auf die Anfrage einiger ungenannter Personen ein umfassendes Gutachten zu dem Fall in Arbeit. Daraus entstand die noch im selben Jahr fertiggestellte Schrift De divortio Lotharii regis et Theutbergae reginae.

272 Nelson, Charles 1992, 181-188; Hartmann, Ludwig 2002, 49-52.

273 Die ausführlichsten Darstellungen sind Dümmler, Geschichte 2 1887, 1-218; РARIsot, Royaume 1899, 143-324. Einen präzisen Überblick gibt Böhringers Einleitung zu Hinkmar von Reims, De devortio Lotharii regis et Theutbergae reginae (MGH Conc. 4 Suppl. 1). Neuere Literatur bei Heidecker, Kerk 1997; Arrlie, Bodies 1998. 
Die Motive für die Scheidungsabsichten Lothars sind in der Forschung umstritten. Einige Historiker sehen die Unfruchtbarkeit Theutbergas als entscheidend an, denn Lothar hatte mit Waldrada bereits einen Sohn gezeugt. Aus Gründen der Erbfolge habe er die Legitimierung dieser Beziehung angestrebt ${ }^{274}$. Andere schätzen die politische Komponente höher ein ${ }^{275}$. Lothar nahm nämlich Theutberga zur Frau, als er sich durch die Allianz mit ihrer Familie Rückhalt in der Alpenregion versprach und als über die Erbfolgeregelung nach dem Tod seines Vaters noch nicht endgültig entschieden war. Nachdem jedoch sein Herrschaftsgebiet auf das spätere Lothringen fixiert worden war, erwies sich die Allianz als nutzlos. Konflikte mit dem Bruder Theutbergas sowie persönliche Dissonanzen hätten dann die Scheidungsabsicht hervortreten lassen. Unabhängig davon, welcher Position man sich anschließen will, liegt beiden Deutungen die Voraussetzung zugrunde, dass Lothar seine Ehe politischen Interessen unterordnen wollte. Der Konflikt drehte sich also im Kern um die Geltung des kirchlichen Eherechts, besonders um die Forderung nach Unauflösbarkeit der Ehe. Karl der Große war der letzte Herrscher gewesen, der sich noch über die Geltung des kirchlichen Eherechts hinweggesetzt hatte. Er hatte seine Frau aus dem langobardischen Königshaus verstoßen, Verhältnisse zu nebenehelichen Konkubinen gepflegt und nach 800 überhaupt die Schließung einer Ehe verweigert ${ }^{276}$. Gleichzeitig war er so wie sein Vater Pippin dafür verantwortlich, dass die päpstliche Forderung nach Unauflösbarkeit der Ehe im fränkischen Kirchenrecht Geltung erlangte ${ }^{277}$. Sowohl die Admonitio generalis Karls des Großen als auch die vom Herrscher geförderte Collectio DionysioHadriana machten das Prinzip der Unauflösbarkeit populär. Im 9. Jahrhundert gibt es mit der Ausnahme von anonym überlieferten Bußbüchern ${ }^{278}$ keinen Autor mehr, der die Unauflösbarkeit der Ehe in Frage gestellt hätte. Dass Lothar II. und die lothringischen Bischöfe dies prinzipiell anerkannten ${ }^{279}$, beweisen die ungeheuerlichen Vorwürfe, die man Theutberga machte, um dennoch die nachträgliche Auflösung der Ehe zu erwirken. Inzest, Abtreibung und ,unnatürlicher' Geschlechtsverkehr zählten zu den abscheulichsten moralischen Verfehlungen, die man einer Frau nachsagen konnte. Nur auf diese Weise glaubte man die Ehe Lothars auflösen zu können. Gleichzeitig war man in der Lage, den Bruder Theutbergas und politischen Gegner Lothars zu diffamieren.

274 Vgl. u.a. Haller, Nikolaus I. 1936, 6 f.; BrüHL, Hinkmariana 1964, 56; BAUer, Implikationen 1994, 79.

275 Konecny, Frauen 1976, 103-117; BöHringer, Einleitung (MGH Conc. 4 Suppl. 1, 15-17).

276 Die Fakten sind zusammengestellt bei Hellmann, Heiraten 1903, 370-374. Vgl. Konecny, Frauen 1976, 65-81; Nelson, Pater 2002.

277 Fahrner, Geschichte 1903, 82-86; Gaudemet, Mariage 1987, 122.

278 Коттje, Ehe 1981; Körntgen, Studien 1993, 177-182.

279 Anderer Meinung ist BAUER, Implikationen 1994, 76-78. 
Im Zentrum der Eheaffäre stand also die Unauflösbarkeit der Ehe. Der gebildete Kanonist Hinkmar war auf keinen Fall bereit, bei dieser Rechtsmaterie Abstriche zu machen. Diese Tatsache, zusammen mit dem negativen Bild Lothars in den von Hinkmar ab 861 verfassten westfränkischen Annalen, hat zur Wertung von Hinkmar als Gegner der Scheidungsabsichten Lothars und als Wegbereiter für die Annexion des Mittelreichs durch Karl den Kahlen geführt ${ }^{280}$. Diesem Urteil hat Letha Böhringer zu Recht widersprochen. Im Jahr 860 war nämlich die Nachfolgefrage im Mittelreich noch außer Sichtweite, und auch die Intransigenz Lothars war noch nicht vollends deutlich geworden. Hinkmar verschloss sich in seinem Gutachten nicht dem Ansinnen Lothars, er räumte sogar die Möglichkeit einer Scheidung und Wiederheirat in diesem speziellen Fall ein. Bedenken erhob er vielmehr gegen das angewandte Beweisrecht und verlangte daher die Einberufung einer gesamtfränkischen Synode unter seiner Leitung. „Er trachtete danach, sich selbst ,ins Gespräch zu bringen“, seine politische und moralische Autorität geltend zu machen und zu signalisieren, dass ohne ihn ... nichts entschieden werden kann". Hinkmar benutzte die Eheaffäre, um „seinen Führungsanspruch innerhalb des fränkischen Episkopats zu untermauern" 281 .

Für Hinkmars Handhabung des Inzestverbots ist besonders die Art und Weise von Interesse, wie er die Scheidung und Wiederheirat Lothars legitimierte. Wie gesagt war Hinkmar ein vehementer Verfechter des Prinzips der Unauflösbarkeit der Ehe ${ }^{282}$. Im Fall Lothars eine Ausnahme davon zu machen, stellte für ihn eine schwierige Gratwanderung dar. Hierbei ist er Lothar sehr weit entgegengekommen. Dies lässt sich daran ermessen, dass die Bischöfe des Mittelreichs Lothar noch nicht ausdrücklich zu einer erneuten Heirat ermächtigt hatten. Auf den beiden Aachener Synoden hatten sie bloß die Eheunfähigkeit Theutbergas festgestellt, ohne Lothar ausdrücklich eine erneute Heirat zuzugestehen $^{283}$. Die Eheunfähigkeit folgerten sie aus der notwendigen öffentlichen Buße nach dem schweren Vergehen eines Bruder-Schwester-Inzests, damit „sie die unzüchtige Seuche und das unheilbare Verderben nicht dem Menschengeschlecht übergibt, damit so nämlich der gefährliche Anfang von Grund auf ausgerottet wird, wodurch sie den Schwachen kein Beispiel und keine Gelegenheit abgibt, damit nicht etwa, was fern sei, eine solche Gewohnheit um sich greift ... ${ }^{\text {"284 }}$ Mit welchen Sätzen des Kirchenrechts die

280 Haller, Nikolaus I. 1936, 9; BRÜHL, Hinkmariana 1964, 59.

281 BöHringer, Einleitung (MGH Conc. 4 Suppl. 1, 19 f.).

282 Devisse, Hincmar 1976, 431-435.

283 Hartmann, Synoden 1989, 274.

284 ... ne morbosam pestem et incurabilem luem generi transmittat humano, ut ita, videlicet origo pernitiosa, funditus exstirpetur, quo nullum exemplum nullamque fragilibus relinquat occasionem, ne forte, quod absit, talis consuetudo inolescat ... Konzil von Aachen (860) c. 18 (MGH Conc. 4, 10). 
lothringischen Bischöfe dies untermauerten, ist nicht bekannt. Es war jedoch ein schwieriges Unterfangen. Nach der herrschenden Meinung der Kirchenreformer musste Inzest mit kanonischer Buße bestraft werden, und während der Bußzeit durfte keine neue Ehe eingegangen werden. Einige Quellen besagen auch, dass Inzest unter besonders nahen Verwandten lebenslängliche Ehelosigkeit zur Folge haben müsse ${ }^{285}$. Diese Konsequenz auch dann zu fordern, wenn der Vorfall im jugendlichen Alter stattfand und inzwischen eine neue Ehe eingegangen wurde, stellte jedoch eine besondere Härte dar, die durch keinen Kanon aus dem Kirchenrecht abgesichert war.

Hinkmar stand folglich bei der Legitimation von Lothars Scheidung vor keiner einfachen Aufgabe. Er konnte sie nur lösen, indem er in „rabulistischer ${ }^{\text {“286 }}$ Manier die Quellen in seinem Sinn zurechtbog. Joseph Freisen und Max Sdralek haben erstmals eindringlich auf diese Manipulationen hingewie$\operatorname{sen}^{287}$. Besonders hilfreich war Hinkmar dabei der von Pseudoisidor gefälschte Briefwechsel. Er zitiert daraus die Ausweitung auf den siebten Grad und den folgenden aus dem Konzil von Epaon übernommenen, aber leicht veränderten Satz: „Wir lesen, dass es einst von den heiligen Vätern erlassen wurde, dass inzestuöse Personen nicht den Titel der Ehe beanspruchen dürfen “288. Pseudoisidor verfälschte den Sinn, indem er das Wort incestus durch incestuosos ersetzte. In Epaon war den Inzestehen (und nicht inzestuösen Personen) der Name der Ehe abgesprochen worden. Wenige Zeilen unter dem Pseudoisidorzitat verweist Hinkmar erneut auf das Konzil von Epaon und ersetzt diesmal aus eigenem Antrieb das Wort incestus durch incestuosos ${ }^{289}$. Dadurch wurde der Kirchenrechtssatz auf die incestuosa Theutberga anwendbar. Sie müsste folglich nach ihrem Verbrechen ehelos bleiben. Eine weitere Stelle aus dem gefälschten Briefwechsel dient durch ein absichtsvolles Missverständnis ebenfalls zur Legitimation der Scheidung. Aus dem Verbot der Heirat mit einer von seinem Verwandten „beschmutzten“ Frau macht die Lektüre Hinkmars das Verbot der Heirat mit einer von ihrem Verwandten (Hugbert) „beschmutzten“ Frau (Theutberga) ${ }^{290}$. Der Reimser Metropolit zieht daher den Schluss, Theutberga müsse vom königlichen Gemach und von jeder ehelichen Verbindung entfernt werden $^{291}$. Lothar hingegen hält er einer neuen Ehe für fähig und zitiert ausgerechnet den Schlusssatz des Konzilskanons von Epaon, der in karolingischer

285 Siehe 294 Anm. 23 und 303 Anm. 67.

286 Freisen, Geschichte 1893, 579.

287 Freisen, Geschichte 1893, 578 f.; SDraleK, Gutachten 1881, 122-136.

288 Incestuosos vero nullo coniugii nomine deputandos a sanctis patribus dudum legimus constitutum ... Hinkmar, De devortio, resp. 12 (MGH Conc. 4 Suppl. 1, 194).

289 Hinkmar, De devortio, resp. 12 (MGH Conc. 4 Suppl. 1, 195).

290 Hinkmar, De devortio, resp. 12 (MGH Conc. 4 Suppl. 1, 194).

291 ... segregata non solum a toro regio, verum etiam ab omni coniugali consortio ... Hinkmar, De devortio, resp. 12 (MGH Conc. 4 Suppl. 1, 194). 
Zeit wegen seiner Milde nicht hoch im Kurs stand: „Durchaus sollen jene, denen eine unrechtmäßige Verbindung untersagt wird, die Möglichkeit haben, eine bessere Ehe einzugehen " ${ }^{\text {292 }}$. Auch diesen Satz unterzieht Hinkmar einem absichtlichen Missverständnis. Er galt den des Inzests überführten Eheleuten und wird von Hinkmar auf Lothar angewandt, obwohl nicht er, sondern Theutberga des Inzests angeklagt wurde.

Die Manipulationen Hinkmars bezeugen seine Bereitschaft, große Anstrengungen für die Legitimation von Lothars Scheidungsplänen auf sich zu nehmen. Er konstruierte Rechtsquellen für einen Fall, der von den kirchenrechtlichen Quellen nicht abgedeckt war. Die Wirkung seiner Argumente war gering. Vermutlich hat Hinkmar selbst sein Gutachten in der Schublade verschwinden lassen, nachdem die Allianz zwischen Karl dem Kahlen und Lothar II. zerbrochen und Theutberga an den Hof des westfränkischen Königs geflohen war $^{293}$. Hinkmar engagierte sich fortan gemeinsam mit seinem König gegen die Scheidungsabsichten Lothars und unterstützte die unnachgiebige Haltung des Papstes Nikolaus I. Dieser zog den Fall an sich und erteilte dem Vorhaben einer Scheidung eine deutliche Absage.

Die Bischöfe des Mittelreichs, die sich im April 862 nochmals zu einer Synode in Aachen versammelten und endgültig die Pläne ihres Königs sanktionierten, haben die verfälschten Zitate Hinkmars teilweise zum Einsatz gebracht. Sie übernahmen von Hinkmar die Legitimierung der Bestrafung Theutbergas mit Ehelosigkeit durch den Kanon des Konzils von Epaon, jedoch ohne den verfälschenden Texteingriff zu kopieren ${ }^{294}$. Entscheidend für das synodale Urteil blieb wie zwei Jahre zuvor die Wertung der Ehe zwischen Lothar und Theutberga als unwürdige Inzestehe: „Deshalb verwehren wir unserem ruhmvollen Fürsten ..., dem nicht wir allein, sondern auch die Autorität des Kirchenrechts eine inzestuöse Ehe untersagt, nicht eine rechtmäßige, geeignete und von Gott zugestandene Ehe, gemäß der Nachsicht des Apostels: ,Es ist

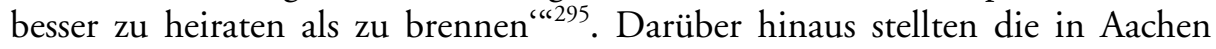
versammelten Bischöfe im Unterschied zu Hinkmar die Geltung des Prinzips der Unauflösbarkeit der Ehe in Frage. Gestützt auf die Autorität einer dem Ambrosius von Mailand zugeschriebenen Schrift schränkten sie die Gültigkeit des Prinzips auf Frauen ein und erteilten Männern bei Sexualvergehen ihrer

292 Hinkmar, De devortio, resp. 19 (MGH Conc. 4 Suppl. 1, 219). Zur Wertung dieses Satzes siehe 298 f. und 306 Anm. 82.

293 Böhringer, Einleitung (MGH Conc. 4 Suppl. 1, 26 f.).

294 Vgl. Staubach, Herrscherbild 1981, 186 f. Wie Böhringer, Einleitung (MGH Conc. 4 Suppl. 1, 27), veranschlage ich die Wirkung von Hinkmars Gutachten eher gering.

295 Quocirca glorioso principi nostro ..., cui non solum nos, verum etiam canonica auctoritas incestuosum coniugium interdicit, legitimum atque idoneum coniugium a deo illi concessum non denegamus, iuxta indulgentiam dicentis apostoli: Melius est nubere quam uri. Konzil von Aachen (862) c. 10 (MGH Conc. 4, 74). 
Gattinnen die Erlaubnis zur Wiederheirat ${ }^{296}$. Die Einschränkung des Prinzips der Unauflösbarkeit der Ehe musste vor dem Hintergrund des geltenden Kirchenrechts auf heftigem Widerstand stoßen. Insbesondere Nikolaus I., der auf eine bis ins frühe 5. Jahrhundert zurückgehende päpstliche Tradition zurückblicken konnte, reagierte empört auf die Stellungnahme der lothringischen Bischöfe. Er bezeichnete die Aachener Synode als Hurenhaus, weil mit ihren Beschlüssen der Ehebruch legalisiert worden $\operatorname{se}^{297}$. Die beiden führenden Bischöfe Gunthar von Köln und Thietgaud von Trier wurden nach Rom zitiert und ohne öffentliche Anhörung abgesetzt. Dieser beispiellose Vorgang der Absetzung zweier Metropoliten durch den Papst war allerdings nicht nur Folge der unorthodoxen Stellungnahme zum Scheidungsrecht, sondern auch eine Folge der persönlichen Kränkung des Papstes. Nikolaus fühlte sich durch die lothringischen Bischöfe übergangen und verdächtigte sie des Ungehorsams gegenüber dem apostolischen Stuhl ${ }^{298}$.

Bei den Zeitgenossen ist nicht allein die Leugnung des Prinzips der Unauflösbarkeit der Ehe auf Unverständnis gestoßen, auch die Verhängung der Strafe der Ehelosigkeit über Theutberga wurde der übertriebenen Härte bezichtigt. In seiner Chronik bezeichnete Regino von Prüm die Verhängung einer solchen Buße als „verruchte List" und machte die fehlende kirchenrechtliche Bildung der Protagonisten dafür verantwortlich ${ }^{299}$. Ein anderer unbekannter Gelehrter - vielleicht war es Ratramnus von Corbie ${ }^{300}$ - hat unmittelbar nach dem Konzil von Aachen in einem Gutachten die Argumentation der Bischöfe verworfen. Er trat sowohl für die Geltung des Prinzips der Unauflösbarkeit der Ehe als auch für die Rechtmäßigkeit der Ehe zwischen Lothar und Theutberga ein. Für die Geschichte des Inzestverbots ist besonders der zweite Punkt von hohem Interesse. Zunächst weist der anonyme Gelehrte die falsche Interpretation des Kanons von Epaon zurück. Der von Hinkmar und den Bischöfen unterdrückte Teil des Kanons zeige, dass dort nur Ehen zwischen Verwandten als Inzestehen bezeichnet würden. Die Ehe zwischen einer schuldlosen und einer

296 Konzil von Aachen (862) c. 8 (MGH Conc. 4, 73).

297 Nikolaus I., Ep. 53 (MGH Epp. 6, 347).

298 Коттје, Recht 1983.

299 Regino, Chronica a. 864 (MGH SS rer. Germ. 50, 81).

300 Auf Corbie verweist die Benutzung der Collectio Hispana Gallica Augustodunensis, einer nur in Corbie überlieferten Verfälschung der echten Hispana durch Pseudoisidor. Der Kanon 30 des Konzils von Epaon (=Agde c. 61) ist in der verfälschten Version Pseudoisidors zitiert; die Edition macht dies nicht kenntlich: Konzil von Aachen (860) 1. Gutachten (MGH Conc. 4, 84). Ratramnus war für Karl den Kahlen und den hofnahen Bischof Odo von Beauvais als Gutachter tätig (MGH Epp. 6, 151-153); Вочнот, Ratramne 1976, 61. Zu Odos Verwicklung in den Ehestreit vgl. Grierson, Eudes I ${ }^{\text {er }}$ 1935, 168 f.; Boshof, Odo 1989, 41. [Das Gutachten enthält ein weiteres unerkanntes Zitat von Jonas von Orléans, De institutione laicali II 8 (Migne PL 106, 183): Konzil von Aachen (860) 1. Gutachten (MGH Conc. 4, 85 Z. 33).] 
des Inzests überführten Person zähle nicht dazu ${ }^{301}$. Ebenso verwirft der Gutachter das bereits 860 vorgebrachte Argument, die „Beschmutzung“ durch Inzest würde auf den Ehepartner und auf die Nachkommenschaft übergehen. „Der Ehemann wird durch das Vergehen der Frau nicht beschmutzt, solange er weder durch Tat noch durch Konsens darin verwickelt war. ... Was immer sie vor der Ehe getan hat, fällt auf sie zurück, nicht auf ihren Mann “302. Überdies wird im Gutachten die Strafe der Ehelosigkeit als zu hart zurückgewiesen. Erstens seien Vergehen im jugendlichen Alter durch zeitlich befristete Buße zu ahnden, und zweitens sei durch das bei der Ehe gegebene Versprechen der Treue die innere Umkehr der Theutberga hinlänglich deutlich geworden. Genauso wenig wie ein Mann, der vor seiner Ehe Unzucht getrieben hat, nach der Ehe noch als Unzüchtiger gelte, gelte auch die Frau nach der Eheschließung noch als Inzestuöse. Ansonsten könnte man sich aufgrund einer solchen Anklage leicht von jedem Ehepartner scheiden: „Selten oder gar nicht gibt es einen Mann, der mit der Ehefrau als Unberührter zusammenkommt - und von Frauen ganz zu schweigen “303.

Das anonyme Gutachten führt deutlich vor Augen, auf welch wackeligem Fundament die Argumentation Hinkmars und der lothringischen Bischöfe ruhte. Hinkmar gelang es nur durch offensichtliche Manipulationen und durch den Einsatz der pseudoisidorischen Fälschungen zu erweisen, dass die Ehe Lothars eine Inzestehe ist und dass Theutberga mit lebenslänglicher Ehelosigkeit bestraft werden soll. Der Inzest spielte in diesem Konflikt deshalb eine so große Rolle, weil er für Diffamierungen bestens geeignet war und vom Kirchenrecht als einziger Scheidungsgrund anerkannt wurde. Die Bischöfe des Mittelreichs sahen anfangs diese diffamierende Wirkung als ausreichend an und bedienten sich des Diskurses der „Ansteckung“ und „Beschmutzung“, um Theutberga als für das königliche Gemach unwürdige Person hinzustellen. Hinkmar gab diesem Vorgehen die kanonistische Legitimation und musste zusehen, wie sich zwei Jahre später, als er die Fronten gewechselt hatte, die lothringischen Bischöfe teilweise seiner Argumentation bedienten. Da sie jedoch auch ungeschickterweise das Prinzip der Unauflösbarkeit der Ehe außer Kraft setzen wollten, sahen sie sich einer unüberwindbaren Opposition gegenüber. Lothar II. scheiterte mit

301 Hactenus ex praesenti capitulo in litteris, quas meministis, positum recognoscitis, volentes qui posuerunt probare, quod coniugium, de quo agitur, incestum potius quam coniugium sit appellandum. Sed videamus sequentia ... Konzil von Aachen (860) 1. Gutachten (MGH Conc. 4, 84).

302 ... nec maritus in uxoris lapsu polluitur, si nec opere nec consensu miscetur. ... Quicquid enim, antequam nupserit, egerit, in eam redundat, non in maritum ... Konzil von Aachen (860) 1. Gutachten (MGH Conc. 4, 85).

303 Ut de mulieribus taceamus, rarus aut nullus est vir, qui cum uxore virgo conveniat. Konzil von Aachen (860) 1. Gutachten (MGH Conc. 4, 86). 
seinen Scheidungsplänen, das Mittelreich verschwand nach seinem Tod mangels legitimer Nachfolger von der politischen Landkarte.

\section{Die Eheaffäre des Grafen Stephan}

Kurz nach der Fertigstellung des Gutachtens zur Ehe zwischen Lothar und Theutberga wurde Hinkmar in eine weitere Eheaffäre verwickelt. Auf der Synode von Tusey, die im Oktober und November 860 stattfand und ca. 50 Bischöfe des Frankenreichs vereinigte ${ }^{304}$, reichte Graf Raimund von Toulouse eine Klageschrift ein ${ }^{305}$. Er beschwerte sich darin über das Verhalten seines Schwiegersohnes, des Grafen Stephan, der sich geweigert habe, die Ehe mit seiner Tochter zu vollziehen. Als Grund führe Stephan an, dass er vor der Ehe mit einer Verwandten der Braut Geschlechtsverkehr hatte und deshalb durch den Vollzug der Ehe gegen das Inzestverbot der Schwiegerverwandtschaft verstoßen würde. Wer diese Verwandte sei, habe Stephan jedoch nicht preisgegeben. Die Bischöfe nahmen die Anklage Raimunds aus formalrechtlichen Gründen nicht an, befragten jedoch auf vertrauliche Weise den auf der Synode ,zufällig' anwesenden Stephan. Seine Version der Geschichte lautet folgendermaßen: „Wie üblich“ habe er vor seiner Ehe mit einer Frau unehelich zusammengelebt ${ }^{306}$. Nach der Verlobung mit der Tochter des Grafen Raimund sei ihm bewusst geworden, dass die Braut mit seiner Konkubine verwandt sei. Da er gehört habe, dass man sich vom vierten Grad an von Inzestverbindungen fernhalten sollte, habe er seinen Beichtvater befragt. Dieser habe ihm die Auskunft gegeben, jede Verbindung innerhalb der Verwandtschaft stelle ein Inzestvergehen dar. Deshalb habe er zuerst die Hochzeit und dann auch den Vollzug der Ehe hinausgezögert. Jetzt sei er zur Versöhnung mit Raimund bereit, wenn ihm die Synode einen Weg aus diesem Dilemma weisen könne.

Die Synode entschied, den Fall an eine Provinzialsynode der zuständigen Bischöfe weiterzuleiten, die unter dem Vorsitz des Königs von Aquitanien, des gleichnamigen Sohnes Karls des Kahlen, stattfinden sollte ${ }^{307}$. Gleichzeitig wurde Hinkmar von Reims mit der Abfassung eines Gutachtens betraut. Dieses Gutachten, gerichtet an die zuständigen Erzbischöfe von Bordeaux und Bourges, ist die einzige Quelle, die über die Eheaffäre berichtet. Hinkmar schlug vor, die Ehe wegen des Inzesttatbestandes aufzulösen und Stephan als Strafe für sein fahrlässiges Handeln den Verlust des Brautgeldes aufzubürden ${ }^{308}$. Vorher sollte jedoch die ehemalige Konkubine Stephans über die Wahrheit seiner Aussagen

304 Hartmann, Synoden 1989, 265 f.

305 So der Bericht Hinkmars in Ep. 136 (MGH Epp. 8/1, 88).

306 'Ut adsolet', inquiens Stephanus, in fragili iuventutis aetate cum quadam femina iuvene mihi convenit. Hinkmar, Ep. 136 (MGH Epp. 8/1, 89).

307 Hinkmar, Ep. 136 (MGH Epp. 8/1, 90).

308 Hinkmar, Ep. 136 (MGH Epp. 8/1, 98). 
befragt werden, weil oft unwahre Dinge behauptet würden, um von der Kirche die Zustimmung zur Ehescheidungen zu erreichen. Im Kern drehte sich also der Konflikt wieder um die Vereinbarkeit von Inzestverbot und Unauflösbarkeit der Ehe. Anders als bei der Eheaffäre Lothars stützte sich Hinkmar in diesem Fall auf den Grundsatz, der fehlende Vollzug der Ehe durch Geschlechtsverkehr würde die nachträgliche Annullierung ermöglichen. Er nahm zu diesem Zweck den Vollzug in die Definition einer gültigen Ehe auf, um zu erweisen, dass die Ehe gar nicht zustande gekommen sei. Dies gelang ihm durch eine eigenwillige Neuinterpretation einer Dekretale Leos des Großen. Eine Verfälschung war nicht notwendig ${ }^{309}$.

Ein anderes Problem war brisanter: Auf welcher Grundlage konnte Hinkmar überhaupt behaupten, dass ein vorehelicher Geschlechtsverkehr mit einer Verwandten der späteren Braut ein Inzestvergehen darstellt? Die älteren Vorschriften zur Schwiegerverwandtschaft hatten in erster Linie die Ehe im Visier. Sie untersagten die Heirat mit einer Verwandten der Ehefrau bzw. die Heirat mit der Witwe eines Verwandten. Erst seit den Konzilien Pippins I. trat der Geschlechtsverkehr als Auslöser für Inzest in den Vordergrund. Das Konzil von Compiègne bestimmte beispielsweise, dass eine Ehe ungültig ist, wenn die Ehefrau vor der Heirat mit dem Bruder des Ehemanns Geschlechtsverkehr hatte. Auch wenn ein Vater mit der Braut seines Sohnes Unzucht getrieben hat, sollte die Ehe aufgelöst werden ${ }^{310}$. Diese Formen des Inzests wurden in der Scholastik des Hochmittelalters als affinitas ex copula illicita zusammengefasst (Schwiegerverwandtschaft wegen unerlaubten Geschlechtsverkehrs). Auf den Konzilien zur Zeit Pippins I. beschränkte man sich auf einige ausgewählte Fälle innerhalb der engeren Verwandtschaft. Dass diese Form der Affinität prinzipiell und für alle Verwandten zu gelten hat, war keiner kirchlichen Rechtsquelle zu entnehmen. Erst der gefälschte Briefwechsel Pseudoisidors sprach dies in aller Deutlichkeit aus: Man dürfe diejenige nicht als Ehefrau nehmen, die ,jemand aus seiner Verwandtschaft durch irgendeine Sünde beschmutzt habe“"311. Der Fälscher hat damit zwar keine „exorbitante Neuerung ${ }^{\text {“312 }}$ ins Werk gesetzt, wie noch Rudolf von Scherer behauptete, aber er hat „zum ersten Male einem Papste in den Mund gelegt, was vorher nur Particularconcilien bestimmten “313. Für Hinkmar von Reims war der Pseudo-Gregor Briefwechsel erneut ein Schlüsseldokument in der Argumentation.

309 Vgl. hierzu Fransen, Lettre 1983; Reynolds, Marriage 1994, 353-361.

310 Decretum Compendiense c. 10 und c. 15 (MGH Capit. 1, 38).

311 ... nec eam quam aliquis ex propria consanguinitate coniugem habuit vel aliqua inlicita pollutione maculavit in coniugium ducere ulli profecto christianorum licet vel licebit, quia incestuosus est talis coitus et abhominabilis deo et cunctis bonis hominibus. Decretales Pseudo-Isidorianae, Ps.-Gregor (751).

312 SCHERER, Eherecht 1879, 48.

313 Freisen, Geschichte 1893, 457. 
Für die Geschichte des Inzestverbots ist ferner die von Hinkmar geschilderte Rechtskenntnis des Grafen Stephan von Interesse. Stephan, so lautet der Bericht Hinkmars, berief sich auf den Libellus responsionum und wurde deshalb von seinem Beichtvater zurechtgewiesen. Der Beichtvater berief sich dagegen auf ein Dossier von drei fragmentarisch zitierten Quellen: auf einen an Bonifatius gerichteten Brief Gregors II., auf das römische Konzil von 721 und auf das Konzil von Epaon ${ }^{314}$. Diese Zusammenstellung lässt aufhorchen. Sie begegnet nur in der Collectio Sancti Amandi, einer Ende des 8. Jahrhunderts im nördlichen Frankenreich entstandenen Sammlung von gallischen und spanischen Konzili$\mathrm{en}^{315}$. Das Konzil von Epaon zählt zum Kern der Sammlung, als Anhang wurden mehrere Quellen zum Inzestverbot vereinigt: der Libellus responsionum, der oben erwähnte Brief Gregors II., die Inzestbestimmungen aus dem Paenitentiale Theodori und das römische Konzil von $721^{316}$. Die Sammlung ist in drei Handschriften aus Corbie, Saint-Amand und aus der Gegend von Reims erhalten. Besonders aussagekräftig ist dieser überlieferungsgeschichtliche Befund deshalb, weil der Brief Gregors II. außerhalb von Mainz und Fulda kaum bekannt war. Neben der Collectio Sancti Amandi ist er nur in einer Arbeitshandschrift Hinkmars enthalten, unmittelbar vor der ältesten Abschrift des gefälschten Briefwechsels Pseudoisidors ${ }^{317}$. Dass also der aquitanische Adelige Stephan durch seinen Beichtvater mit diesen Zeugnissen konfrontiert worden ist, erscheint äußerst zweifelhaft. Der ganze Abschnitt über den Umfang des Inzestverbots erscheint mir deshalb als eine Spiegelung der Interessen Hinkmars und seiner Agitation gegen den Libellus responsionum.

Trotz dieser Bedenken war Stephan zweifellos mit dem Inzestverbot vertraut und benutzte es als Argument für eine Scheidung. Mayke de Jong hat aus dieser Tatsache weitergehende Schlussfolgerungen gezogen ${ }^{318}$. Für sie ist dieser Fall ein zentraler Beleg für die Behauptung, nicht nur die Kirche, auch die Laien hätten sich an der strengen Verfolgung von Verwandtenehen beteiligt, weil sie von der Angst vor sexueller „Beschmutzung“ angetrieben gewesen seien. Das Hinauszögern des Ehevollzugs durch Stephan sei von dieser Angst motiviert gewesen. Ein Blick auf den politischen Hintergrund der Eheaffäre belehrt jedoch eines

314 Diese drei Quellen sind im folgenden Satz verarbeitet: Qui ostendit mihi librum, quem, ut spero, canones appellavit, et legit coram me, quoniam, quamdiu potest adfinitatis propinquitas computari, mihi nec cuiquam Christiano cum cognata sua vel quam cognatus habuit vel cum duabus cognatis salubriter liceret coniungi, et quamdiu in tali incestu maneremus, nec ego nec illa fructuosam paenitentiam agere possemus neque talis incestus nisi separatione nostra ab invicem sanari valeret. Hinkmar, Ep. 136 (MGH Epp. 8/1, 89).

315 Kéry, Collections 1999, $84 \mathrm{f}$.

316 Mordek, Kirchenrecht 1975, 249 f.; Glatthaar, Bonifatius 2004, 389.

317 Berlin, Staatsbibliothek Preußischer Kulturbesitz, Phill. 1741, f. 3r-v. Die Überlieferung ist fragmentarisch.

318 Jong, Kinship 1989, $44 \mathrm{f}$. 
Besseren. Janet Nelson hat diesen Hintergrund überzeugend aus den Angaben Hinkmars von Reims rekonstruiert ${ }^{319}$. Die Ehe Stephans ging demnach aus einem politischen Kompromiss zwischen zwei der mächtigsten Adelsfamilien Aquitaniens hervor und sollte im Jahr 855 die stets gefährdete Herrschaft Karls des Kahlen über dieses Gebiet sichern. Stephan, vielleicht Angehöriger der mächtigen Dynastie der Etichonen ${ }^{320}$, war jedoch ein typischer troublemaker und hielt sich nicht an diese Abmachung. Er beteiligte sich an einem Aufstand gegen Karl und stellte sich dadurch gegen den loyalen königlichen Parteigänger Raimund. Zwei Jahre blieb er den Reichsversammlungen des Königs fern. Aus unbekannten Gründen ist es dann wieder zu einer Verständigung zwischen Karl dem Kahlen und Stephan gekommen. Stephan war fortan eine wichtige Stütze für Karls gleichnamigen Sohn, der als Unterkönig in Aquitanien installiert worden war. In dieser Zeit fällt die Beratung der Synode. Hinkmar schreibt, Stephan habe sich während der Synode „im Gefolge des Herrn Königs“ befunden $^{321}$. Nach der Synode betätigte Stephan sich weiterhin als Störenfried, indem er im Jahr 862 den 15 Jahre alten Karl zu einer Ehe gegen den Willen seines Vaters anstiftete ${ }^{322}$. Im Jahr 864 war er an einer Revolte in Toulouse beteiligt, bei der vermutlich Graf Raimund ums Leben gekommen ist ${ }^{323}$. Er bemächtigte sich der Stadt Clermont und zog dort den Ärger des Papstes Nikolaus I. auf sich, nachdem er den Bischof von Clermont verjagt und einen Günstling aus seinen Reihen zum Nachfolger bestellt hatte ${ }^{324}$. Noch im gleichen Jahr fiel er einem Eroberungszug der Normannen zum Opfer, die im Einverständnis mit Karl dem Kahlen in Clermont eingefallen waren ${ }^{325}$.

Angesichts dieser krassen Missachtung des Kirchenrechts in Clermont wird man kaum geneigt sein anzunehmen, dass Stephans Motive bei der Ehescheidung edler Natur gewesen sind. Es ging vielmehr um die Vorherrschaft in Aquitanien und um die Nähe zum jeweiligen Regenten. Stephan hat sein Wohl offensichtlich darin gesehen, gegen die Familie Raimunds von Toulouse vorzugehen, und bediente sich des Inzestvorwurfs zur Beendigung einer politischen Allianz. Dass er den Namen der mit seiner Braut verwandten Konkubine nicht nennen wollte, offenbart zur Genüge diese Scheinargumentation. Warum hat sich Hinkmar vor die Zügel dieser zynischen Machtpolitik spannen lassen?

319 Nelson, Charles 1992, 185-202. Im Detail anders gewichtet bei AuZias, Aquitaine 1937, 293-307. Zweifel äußert BöHringer, Gewaltverzicht 2007, 282.

320 Nach einer Vermutung von Chaume, Origines 1926, 235, war Stephan ein Enkel des mächtigen Grafen Hugo von Tours (gest. 837, vgl. Depreux, Prosopographie 1997, 262-264). Keine Bestätigung dieser Vermutung bei WILSDORF, Étichonides 1967.

321 ... in domni regis erat obsequio ... Hinkmar, Ep. 136 (MGH Epp. 8/1, 88).

322 Annales Bertiniani a. 862 (90 f.).

323 Nelson, Charles 1992, 202.

324 Nikolaus I., Ep. 108 (MGH Epp. 6, 623) (JE 2706).

325 Annales Bertiniani a. 864 (105). 
Diese Frage ist deshalb besonders brisant, weil Hinkmar mit Graf Raimund von Toulouse verwandt war und mit dessen Sohn Bernhard brieflich verkehrte ${ }^{326}$. Der Schlüssel für eine Antwort ist in der mehrfach wiederholten Forderung Hinkmars zu sehen, die Streitsache solle auf einer aquitanischen Synode im Beisein des princeps und rex friedlich beigelegt werden ${ }^{327}$. Damit meinte der Erzbischof den jüngeren Karl, dessen Stellung alles andere als gefestigt war. Noch immer machte ihm der Sohn des einstigen Königs von Aquitanien und Neffe Karls des Kahlen, Pippin II., die Herrschaft streitig, der 856 aus der Haft entkam und fortan ständig für Unruhe sorgte ${ }^{328}$. Die Delegation der Streitsache an Karl den Jüngeren diente dazu, dessen Stellung zu stärken und ihm als Mittler zwischen den zwei rivalisierenden Adelsfamilien Kredit zu verschaffen. Er „soll sich gemeinsam mit den Adeligen eifrig bemühen, damit nicht wegen dieser Angelegenheit in Kirche und Reich Ärgernisse und Bürgerkriege ins Land ziehen “329. Diese Entscheidung ist nicht von Hinkmar alleine, sondern von der Synode in Tousey unter der Leitung Karls des Kahlen gefällt worden. Das Gutachten Hinkmars folgte der königlichen Linie: Es fiel deutlich zugunsten Stephans aus und war allenfalls geeignet, durch die umständliche kanonistische Argumentation das Gesicht Raimunds von Toulouse zu wahren.

\section{Strafverfolgung vor dem Forum der Synode}

Bislang sind in erster Linie Stellungnahmen Hinkmars zu Eheaffären mit politischer Tragweite untersucht worden. Seine umfassende literarische Hinterlassenschaft ermöglicht es darüber hinaus, den Blick auf das alltägliche Geschäft der Inzestverfolgung zu lenken und jeden einzelnen Schritt eines derartigen Verfahrens zu rekonstruieren. Man muss sich allerdings dabei bewusst sein, dass Hinkmar in seinen Briefen und Rechtstexten ein Ideal beschreibt, das wohl nicht immer der Praxis entsprochen haben wird.

Die Strafverfolgung bei Inzest beruhte im 9. Jahrhundert auf dem Inquisitionsauftrag Karls des Großen aus dem Jahre 802. Karl hatte die Bischöfe zur Ausforschung von schweren Sünden in ihrer Diözese ermächtigt und ihnen dafür die Hilfe der weltlichen Gewalt in Aussicht gestellt. In der Regel entledigten sich die Bischöfe dieses Auftrags, indem sie ihn an den Pfarrklerus weiterleiteten und die Landpfarrer zur Fahndung nach öffentlichen Sündern ermunterten. Die bischöfliche Gesetzgebung des 9. Jahrhunderts belegt dieses

326 Freilich nicht immer freundschaftlich: Flodoard, Historia Remensis ecclesiae III c. 24 u. 26 (MGH SS 36, 325 u. 338).

327 Hinkmar, Ep. 136 (MGH Epp. 8/1, 90 u. 106).

328 NeLSON, Charles 1992, 185.

329 Et terrae princeps cum primoribus hoc debet satagare, ne pro hac causa in ecclesia et in regno scandala et seditiones fiant. Hinkmar, Ep. 136 (MGH Epp. 8/1, 106). 
Vorgehen sowohl für das westliche als auch für das östliche Frankenreich ${ }^{330}$. Hinkmar beschreibt das Procedere ausführlich in seinem dritten Bischofskapitular von 856. „Jeder einzelne Priester soll die größte Sorge tragen, dass, wenn in seiner Gemeinde etwa ein öffentlicher Mord, ein Ehebruch, ein Meineid oder irgendein Kapitalverbrechen öffentlich begangen wurde, der Täter ... sofort zur Buße ermahnt wird ..."331 Das Verbrechen sollte vom Priester gemeinsam mit seinen Kollegen und dem Dekan untersucht und den Amtsträgern des Bischofs bekannt gemacht werden. Dann sei der Täter verpflichtet, innerhalb von 15 Tagen vor dem Bischof zu erscheinen und die öffentliche Buße auf sich zu nehmen. Die Priester sollten sorgfältig Buch führen und die Fortschritte des Büßenden überwachen. Verweigert sich ein Verbrecher der Buße, soll er von der Kirche ausgeschlossen werden.

Ein Jahr später gelang es Hinkmar, dieses Verfahren im Königsrecht zu verankern. In einer 857 an die Königsboten gerichteten Anweisung Karls des Kahlen ist zu lesen: „Dass ein jeder Priester in seiner Gemeinde alle Verbrecher, nämlich Räuber, Ehebrecher, Inzestuöse, Mörder und Diebe in Listen aufschreibt und sie aus der Kirche ausschließt, wenn sie nicht Buße tun wollen. Wenn sie sich weigern, sollen sie vor den Bischof gebracht werden “332. Da der Exkommunikation nicht selten Widerstand entgegengebracht wurde, forderte Hinkmar auch die Unterstützung der weltlichen Amtsträger ein. Bereits 853 hat er von Karl dem Kahlen eine entsprechende Unterstützungserklärung eingeholt $^{333}$, die er im Jahr 858 erneut einklagte: „Befiehlt, dass der Amtsträger des Staates, d.h. der Amtsmann des Grafen, mit den Bischöfen auf deren Befehl hingeht und die inzestuösen freien Männer zum Gericht des Bischofs kommen lässt, wenn sie nach der Mahnung der Priester nicht zum Bischof kommen wollen “334. Diese Zusammenarbeit von Bischof und Graf war seit Karl dem Großen der Dreh- und Angelpunkt einer erfolgreichen Inzestverfolgung.

330 Capitula Silvanectensia prima c. 5 (MGH Capit. episc. 3, 81); Capitula Frisingensia tertia c. 7 u. c. 12 (MGH Capit. episc. 3, 223-225). Siehe auch 370 Anm. 397.

331 Ut unusquisque sacerdos maximam providentiam habeat, quatenus, si forte in parrochia sua publicum homicidium aut adulterium sive periurium vel quodcumque criminale peccatum publice perpetratum fuerit, statim ... hortetur eum, quatenus ad paenitentiam veniat. Hinkmar, 3. Kapitular c. 1 (MGH Capit. epis. 2, 73).

332 Ut unusquisque presbyter inbreviat in sua parrochia omnes malefactores, videlicet raptores, rapaces, adulteros, incestos, homicidas, latrones; et eos extra ecclesiam faciat, nisi paenitentiam agere voluerint. Si se emendare noluerint, ad episcopi praesentiam perducantur. Allocutio missi cuiusdam Divionensis c. 8 (MGH Capit. 2, 292). Die Anweisung ist nur in einer Handschrift aus Burgund erhalten (MGH Conc. 3, 397 f.).

333 Optentum est etiam a principe, ut incesti et quilibet alii perditi examen episcoporum refugientes per iudices publicos ad eorum praesentiam deducantur, ne alterius illecebram peccandi nutriat impunitas vitiorum. Konzil von Soissons (853) c. 11 (MGH Conc. 3, 284).

334 Ut missus rei publicae, id est minister comitis, cum episcopis, si iusserint, eat, qui liberos homines incestuosos, si per admonitionem presbyterorum venire ad episcopum noluerint, eos 
Trotz der Zustimmung des Königs zu dieser Forderung konnte sich der Erzbischof von Reims nicht immer Gehör verschaffen. Dies bezeugt ein Rundbrief, den Hinkmar auf einer Reimser Synode unbekannten Jahres ausstellen lie ${ }^{335}$. Er informierte darin alle Laien und Kleriker von der erfolgten Exkommunikation Fulchers und Hardoisas, die als Blutsverwandte eine Ehe eingegangen waren: „wie es durch geeignete und wahrhaftige Zeugen durch

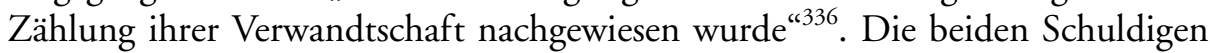
verweigerten sich jedoch der erzwungenen Ehetrennung und wurden deshalb auf der Synode öffentlich aus der Kirche ausgeschlossen. Zur Begründung seines Vorgehens stellte Hinkmar ein Potpourri aus verschiedenen kirchenrechtlichen Zitaten zusammen, die er zum Teil bis zur Unkenntlichkeit veränderte. Er zitierte das römische Konzil von 721, den gefälschten Briefwechsel Pseudoisidors und die Kanones von Epaon und Lérida ${ }^{337}$. Eine Aufnahme in die Kirche stellte Hinkmar den Sündern nur bei Auflösung der Ehe oder bei schwerer Krankheit in Aussicht, wobei sie im letzteren Fall durch Bürgen die Aufnahme der Buße nach der Genesung versprechen müssten. Der Zweck dieses Schreibens ist die Bekanntmachung der Exkommunikation, um eine Lossprechung der Sünder durch andere Bischöfe zu verhindern. In einem anderen eherechtlichen Fall hat auch dies nichts genützt: Der einer Ehescheidung bezichtigte Fulkrich flüchtete zum Erzbischof von Trier und ließ sich dann vom Papst in Rom vom Bann lossprechen, den Hinkmar über ihn ausgesprochen hatte ${ }^{338}$. Das Verfahren der Strafverfolgung konnte also auf vielerlei Weise obstruiert werden.

Der Rundbrief Hinkmars zeigt nochmals in nuce den Standpunkt des Kirchenpolitikers zum Inzestverbot auf. Als gewiefter Jurist drehte und wendete er die kirchenrechtlichen Autoritäten nach seinem Geschmack. Hatte er im Lothar-Gutachten den Kanon von Epaon absichtlich falsch interpretiert, zitierte er ihn hier in der richtigen Lesart ${ }^{339}$. Er duldete zwar nicht, dass das Eherecht durch Laien politischen Interessen untergeordnet wurde, ordnete es aber selbst kirchenpolitischen Interessen unter. Seine Stellungnahmen für Lothar II. und für den Grafen Stephan zeigen, dass ihm fast jedes Mittel recht war, um seine Interessen und diejenigen des Königs zu wahren. In beiden Fällen manipulierte

ad episcopi placitum venire faciat, commendate. Konzil von Quierzy (858) c. 7 (MGH Conc. 3, 414).

335 Der Brief enthält nur eine Indiktionsdatierung. Schrörs, Hinkmar 1884, 552 (Nr. 455), schlägt das Jahr 879 vor.

336 ... sicut idoneis et veracibus testibus computata utriusque cognatione comprobatum est. Hinkmar, Ep. 36 (Migne PL 126, 255).

337 Hinkmar, Ep. 36 (Migne PL 126, 255 f.).

338 Flodoard, Historia Remensis ecclesiae III 26 (MGH SS 36, 332); Schrörs, Hinkmar $1884,58 \mathrm{f}$.

339 Incestus nullo coniugii nomine deputatur. Hinkmar, Ep. 36 (Migne PL 126, 255 f.). Im Gegensatz zu der Verfälschung (siehe 348 Anm. 288) ist eindeutig der Inzest und nicht der Inzestuöse das Subjekt. 
er Rechtstexte zum Inzestverbot, um das Prinzip der Unauflösbarkeit der Ehe zu umgehen und eine Trennung der Ehe zu ermöglichen ${ }^{340}$. Den gefälschten Briefwechsel Pseudoisidors brachte er bei jeder Gelegenheit an den Mann. Merkwürdigerweise konnte Hinkmar dieser Quelle genau jene Argumente entnehmen, die er für die Begründung seines Standpunkts benötigte. Auch in einem bislang nicht erwähnten Gutachten an Karl den Kahlen zum Umfang des Inzestverbots, das wegen der fragmentarischen Überlieferung schwer zu deuten ist, zitierte er den gefälschten Brief Gregors I. ${ }^{341}$ Mit diesem Brief nur wenige Jahre nach der Fälschung derart häufig zu argumentieren, offenbart ein gehöriges Maß an Chuzpe. Auf Akzeptanz konnte er deshalb hoffen, weil der Libellus responsionum bereits lange als Ärgernis der Kirchenrechtler galt und durch den gefälschten Briefwechsel endgültig in den Orkus verwiesen werden konnte. Vermutlich hat er als zu seiner Zeit bester Kenner der kirchenrechtlichen Tradition den Fälschungscharakter des Briefwechsels durchschaut - wenn er nicht selbst an seiner Fabrikation beteiligt war ${ }^{342}$.

\subsection{Der Standpunkt des Sammlers: Regino von Prüm}

Die Gegenüberstellung von Hinkmar von Reims und Regino von Prüm zeigt, wie weit gegenwärtiger Einfluss und langfristige Wirkung auseinanderklaffen können. Während Hinkmar seiner Zeit in mancher Hinsicht den Stempel aufgedrückt hat, führte Regino ein eher unscheinbares Leben als Abt von Prüm (892-899) und von St. Martin in Trier (bis 915). Dennoch übertraf Reginos kanonistisches Werk ,über die Rechtsfälle des Sendgerichts und über die kirchliche Zucht" alle Schriften des Reimser Erzbischofs an historischer Wirk$\mathrm{kraft}^{343}$. Bereits im 10. Jahrhundert diente Reginos Handbuch als wichtige Referenz auf den Synoden des ottonischen Reichs. Anfang des 11. Jahrhunderts griff Burchard von Worms in weiten Teilen auf die Sammlung Reginos zurück und verschaffte den darin überlieferten Kanones europaweite Geltung.

Das Besondere am Sendhandbuch ist die Orientierung an den Erfordernissen der Praxis. Im Widmungsbrief an Hatto von Mainz schreibt Regino, er

340 Zum manipulativen Umgang Hinkmars mit seinen Quellen vgl. FuHrmann, Einfluss 1972, 115-122; Ders., Fälscher 1981; Wallace-Hadrill, Church 1983, 303; Hartmann, Vetera 1983, 91-95.

341 Hinkmar, Ep. 170 (MGH Epp. 8/1, 163). Der Hauptteil des 864 entstandenen Gutachtens beschäftigt sich mit der Bußauflage für den in Klosterhaft befindlichen Pippin II. von Aquitanien.

342 Vermutlich durchschaute Hinkmar das Fälschungswerk Pseudoisidors, vgl. WAsserschleben, Frage 1864, 302; Seckel, Pseudoisidor 1905, 289; Fuhrmann, Einfluss 1972, $112-114$.

343 Hartmann, Einleitung 2004, 7. 
wolle dem Erzbischof ein Handbuch zur Verfügung stellen, um ihn von der beschwerlichen Reise mit „sehr vielen Konzilsbänden“ zu entlasten ${ }^{344}$. Der Plan des Sendhandbuchs bestand darin, das gesamte Kirchenrecht in einer systematischen Sammlung zu erfassen und gleichzeitig überflüssige Wiederholungen oder weitschweifige Begründungen zu vermeiden. Dabei hat Regino besonders den Konzilsbestimmungen seiner eigenen Zeit breiten Raum gewährt und so die Errungenschaften der Karolingerzeit in der kirchenrechtlichen Tradition verankert. Er begründet dieses Vorgehen mit dem Argument, „dass in dieser sehr schlimmen Zeit in der Kirche viele Arten von Schandtaten begangen wurden und begangen werden, von denen man in den alten Zeiten nichts gehört hat weil sie nicht begangen wurden “345.

$\mathrm{Zu}$ diesen Schandtaten zählt insbesondere der Inzest. Bei einem Vergleich mit den Sammlungen der alten Kirche sowie des 8. und 9. Jahrhunderts fällt nämlich auf, dass kein anderes Werk dem Inzestverbot eine derart große Bedeutung beimisst wie Reginos Sendhandbuch. Regino reiht über 50 Bestimmungen zum Inzestverbot aneinander ${ }^{346}$. Innerhalb des zweiten Buchs, das sich den Laien widmet und 450 Kapitel enthält, zählt der Inzest damit zu den am ausführlichsten behandelten Delikten. In der ältesten systematischen Kirchenrechtssammlung des Frankenreichs, der Vetus Gallica, sind dagegen in der ursprünglichen Fassung lediglich drei Kanones zum Verbot von Verwandtenehen aufgenommen ${ }^{347}$. Die gleiche Anzahl weisen die irische Collectio Hibernensis, die Collectio Sangermanensis und die von der Vetus Gallica abhängige Collectio Herovalliana auf ${ }^{348}$. In der von Papst Hadrian an Karl den Großen adressierten Sammlung, der Dionysio-Hadriana, widmen sich gar nur zwei Bestimmungen den Verwandtenehen ${ }^{349}$. Die Collectio Dacheriana, die auch Regino vorlag, kommt auf fünf Inzestvorschriften ${ }^{350}$. In der Collectio Bonaevallensis sind es

344 Regino, De synodalibus causis, prol. (1). Zum Konzept der Sammlung vgl. zuletzt Hartmann, Effektivität 2006; Siems, Begrifflichkeit 2007; UbL, Doppelmoral 2007.

345 ... quod multa flagitiorum genera hoc pessimo tempore in ecclesia et perpetrata sunt et perpetrantur, quae priscis temporibus inaudita, quia non facta ... Regino, De synodalibus causis, prol. (2).

346 Corbet, Burchard 2001, 35, zählt 45; Hartmann, Sozialdisziplinierung 2005, 107, dagegen 38. Ausführlicher dazu UBL, Doppelmoral 2007.

347 Collectio vetus Gallica 49, 4 u. 6-7 (557-560).

348 Collectio Hibernensis 46, 35 (194); Collectio Sangermanensis XXI 3, 4 u. 8 (342 f. u. 347); Collectio Herovalliana 54, 5-7 (Migne PL 99, 1058) und 71 (Migne PL 99, 1078). Die erweiterte Fassung der Sammlung enthält zusätzliche Kapitel aus Benedictus Levita: Seckel - Juncker, Studien VIII/4 1934, 314 f.; Mordek, Kirchenrecht 1975, 113.

349 Siehe 292. Eine einzige Inzestbestimmung findet sich in der breit überlieferten Sammlung des Cresconius: Concordia canonum 112 (2, 620).

350 Siehe 297-299. 
neun $^{351}$. Ebenfalls an untergeordneter Stelle wird der Inzest in den pseudoisidorischen Dekretalen behandelt. Kleinere Sammlungen des 9. Jahrhunderts gehen über dieses Repertoire kaum hinaus. Das einzige Werk, das sich ähnlich intensiv wie Regino mit dem Inzestverbot befasst, ist die Fälschung des Benedictus Levita.

\section{Hinwendung zum Papsttum}

Der Rang der Inzestproblematik bei Regino korreliert mit der inhaltlichen Orientierung der ostfränkischen Synoden seiner Zeit. Alle Synoden der zweiten Jahrhunderthälfte, deren Kanones überliefert sind, befassten sich mit dem Inzestverbot $^{352}$. Den Anfang machte eine zwischen 861 und 863 in Mainz zusammengetretene Kirchenversammlung. Über die Synode berichtet nur ein lange Zeit als Fälschung angesehener Brief Nikolaus' I. ${ }^{353}$ Darin berichtet der Papst von einer Anfrage der auf der Mainzer Synode versammelten Bischöfe des Ostfrankenreichs. Diese Hinwendung zum Papst war eine Neuerung ${ }^{354}$. In der Zeit Karls des Großen sah man zwar mit Bewunderung und Achtung auf die apostolische Tradition des Papsttums, verstand dies jedoch nicht als Unterordnung unter den lebenden Inhaber des römischen Bischofsstuhls. Die Gesetzgebungskompetenz in kirchlichen Angelegenheiten übte der fränkische Episkopat gemeinsam mit dem Kaiser aus ${ }^{355}$. Unter Ludwig dem Frommen gewannen sogar romkritische Stimmen zum Teil die Oberhand, die sich für die Gültigkeit der alten gallischen Konzilskanones einsetzten und diese gegen die Kritik „römischer Neuerer" verteidigten ${ }^{356}$. Die Situation der synodalen Gesetzgebung veränderte sich einschneidend, als das Frankenreich in drei Teilreiche auseinander gefallen ist und das Kaisertum nicht mehr als Legitimation für eine gesamtfränkische kirchliche Gesetzgebung dienen konnte. Im Ostfrankenreich unternahm Ludwig der Deutsche keine Anstrengungen, von sich aus eine konziliare Tätigkeit in Gang zu setzen und in die kirchliche Gesetzgebung einzugreifen ${ }^{357}$. Dieser Bruch wurde so lange verdeckt, als mit Hrabanus Maurus ein Vertreter der älteren Generation die Führungsrolle des ostfränkischen Epi-

351 Collectio Bonnaevallensis prima XIV 7, 17, 20, 22, 2438 und 40-42; vgl. die Identifikation der Kapitel durch Mordek, Rechtssammlungen 1968, 389-392.

352 Konzil von Mainz (861/3) (MGH Conc. 4, 130 f.); Konzil von Worms (868) c. 8, c. 14, c. 15, c. 19 (MGH Conc. 4, 266-272); Konzil von Köln (887) c. 6 (Mansi 18A, 48); Konzil von Mainz (888) c. 18 (Mansi 18A, 69); Konzil von Metz (893) c. 11 (Mansi 18A, 80 f.); Konzil von Tribur (895) c. 43-45 und c. 47-48 (MGH Capit. 2, 238240).

353 Die Echtheit ist nachgewiesen bei Hartmann, Konzil 1977.

354 SChieffer, Redeamus 1989; Ders., Beziehungen 1995.

355 Barion, Synodalrecht 1931, 253.

356 Kontrovers diskutiert bei Boshof, Agobard 1969, 97-101; Fried, Ludwig 1990; Depreux, Empereur 1992; Hartmann, Autorität 1998.

357 Hartmann, Ludwig 2002, 192-201. 
skopats übernahm. Hrabanus fühlte sich zwar dem römischen Primat verpflichtet und betrachtete Rom als „Hort der authentischen Tradition“, nahm jedoch in einigen Punkten eine durchaus kritische Distanz zum Papsttum seiner eigenen Zeit ein ${ }^{358}$. Die Diskussion um den Umfang des Inzestverbots ist ein wichtiges Exempel für diese kritische Haltung. Nach dem Tod Hrabans fehlte eine unbestrittene Führungsgestalt des ostfränkischen Episkopats. Hatte man sich zu seinen Lebzeiten in kirchenrechtlichen Zweifelsfällen noch an ihn gewandt, beschritten die Bischöfe nach 856 den Weg nach Rom. Die ersten Anfragen bezüglich der Buße von Verwandtenmördern trafen unter Benedikt III. in Rom ein und wurden von Ratold von Straßburg und Salomo I. von Konstanz abgeschickt ${ }^{359}$. Während des Pontifikats Nikolaus' I. vermehrten sich diese Konsultationen ${ }^{360}$, da Nikolaus von sich aus den Primat des apostolischen Stuhles im Frankenreich zur Geltung bringen wollte und deshalb auch bereit war, die Entscheidung bestimmter Fälle wie die über die Eheaffäre Lothars II. an sich zu ziehen.

Im Zentrum der Mainzer Anfrage an Nikolaus I. stand der Fall eines sonst nicht näher bekannten Abbo. Wenn dem Bericht des Papstes Glauben geschenkt werden darf, hat Nikolaus selbst die Untersuchung des Falles durch eine Synode angeordnet ${ }^{361}$. Auf dieser Synode in Mainz hätten glaubwürdige Zeugen Abbos Verwandtschaft mit seiner Frau in der vierten Generation nachgewiesen. Auf dieser Grundlage traf der Papst folgende Entscheidung: „Deshalb verordnen und entscheiden wir durch apostolische Verkündigung, dass die Verbindung dieser unseligen Heirat gänzlich aufgelöst wird, weil sie nachweislich der eigenen Blutsverwandtschaft zugehörig ist ${ }^{\text {‘362 }}$. Den Fall Abbos nahm Nikolaus zum Anlass, den in dieser Frage schwankenden Bischöfen des Ostfrankenreichs nochmals die päpstliche Position des kategorischen Verbots von Verwandtenehen darzulegen. „Kein Christ darf sich eine Ehefrau aus seiner eigenen Blutsoder sonstigen Verwandtschaft nehmen, und zwar so lange nicht, wie die gemeinsame Abstammung erinnert, erkannt oder im Gedächtnis bewahrt wird“'363. Eine Festlegung auf einen bestimmten Grad lehnte der Papst ausdrücklich ab:

358 Picker, Pastor 2001, 137-140.

359 Acta pontificum Romanorum inedita 3, Nr. 3-4 (3 f.).

360 Einen Überblick geben Hartmann, Konzil 1977, 49-76; DERs., Autorität 1998, 120 f., und Scholz, Päpste 2006, 185-211.

361 ... cum Abbonis causam, de quo fertis, vestra praesentia episcoporum coetu subtili inquisitione examinare decrevimus ... Konzil von Mainz (861/863) (MGH Conc. 4, 130) (=JE 2709).

362 ... sancimus et apostolica promulgatione decernimus: huius infausti coniugii omnimodis copula dissolvatur, quia propriae consanguinitatis et cognationis demonstratur atque cognoscitur esse. Konzil von Mainz (861/863) (MGH Conc. 4, 130) (JE 2709).

363 Et hoc vobis interrogantibus statuimus, ut nulli liceat Christiano de propria consanguinitate sive cognatione uxorem accipere, usque dum generatio recordatur, cognoscitur aut memoria retinetur. Konzil von Mainz (861/863) (MGH Conc. 4, 130) (JE 2709). 
„Wir legen in dieser Sache keine Zahl der Generationen fest, sondern mahnen eine sofortige Befolgung an ${ }^{\text {“364. }}$. Mit dieser Auskunft legte Nikolaus deutlicher als seine Vorgänger den Schwerpunkt auf das subjektive Moment. Denn im Unterschied zu früheren Päpsten, die ausdrücklich das römisch-rechtliche Verständnis von Verwandtschaft anwandten ${ }^{365}$, schloss Nikolaus diese Möglichkeit aus. Es sollte von nun an nicht mehr der Grad der Verwandtschaft gezählt werden, sondern die Verwandtschaftsauffassung der Gläubigen selbst sollte über das Vorliegen einer Inzestehe entscheiden.

Diese Subjektivierung des kategorischen Verbots von Verwandtenehen ist nur vor dem Hintergrund der Anfrage zu erklären. Wie der Brief des Papstes erkennen lässt, waren die ostfränkischen Bischöfe mit der päpstlichen Position vertraut, wie sie von Gregor II. und Zacharias etabliert worden war ${ }^{366}$. Vermutlich kannten sie auch die Festlegung auf den siebten Grad durch Gregor III. in einem Brief an Bonifatius ${ }^{367}$. Fünfzehn Jahre zuvor hatte hingegen die Mainzer Synode von 847 den vierten Grad als Inzestgrenze fixiert. Salomo von Konstanz nahm an beiden Mainzer Synoden teil und musste die Diskrepanz wahrgenommen haben. Diese Diskrepanz wurde durch die unterschiedliche Handhabung der Verwandtschaftszählung verschärft. Während die Päpste die römische Zählung verwendeten, ist Abbo vermutlich aufgrund der kanonischen Zählung überführt worden ${ }^{368}$. Diese Unsicherheiten waren der Grund für die Anfrage an Nikolaus I. und bewogen ihn, die Frage der Zählweise durch die Subjektivierung des Verbots im Unklaren zu lassen.

Der Fall des Abbo ist nicht die einzige Inzestbestimmung der päpstlichen Dekretale. Von insgesamt zehn Bestimmungen widmen sich drei dem Inzestverbot. Die anderen Kanones betreffen die Schwägerschaft, die Art der Buße

364 Nos autem generationum in hac re numerum non diffinimus, sed, ut supra protulimus, incunctanter observare monemus. Konzil von Mainz (861/863) (MGH Conc. 4, 130) (JE 2709).

365 Siehe oben 237.

366 ... quia sententias in hac re beatissimorum antecessorum nostrorum Gregorii et Zachariae pontificum hactenus in vestris parrochiis, ut vestris protulistis in litteris, observando tenetis. Konzil von Mainz (861/863) (MGH Conc. 4, 130) (JE 2709). Vermutlich ist damit das als Anhang der Dionysio-Hadriana überlieferte Dossier gemeint, dazu siehe 296 Anm. 30. Grimald von St. Gallen, Teilnehmer des Konzils, war im Besitz des Dossiers, vgl. Bischoff, Bücher 1981, 199 f. (zu St. Gallen, Stiftsbibliothek, 671).

367 Enthalten im oben genannten Dossier. Ein weiteres, bislang unbekanntes Gutachten zum Fall des Abbo ist in den Handschriften München, Bayerische Staatsbibliothek, Clm 14690, fol. 184r-188r, und Münster, Staatsarchiv, msc. VII. 5201, S. 107-117, überliefert. Eine Edition des Gutachtens ist in Vorbereitung. Der Anonymus schließt sich dem Standpunkt des Hrabanus Maurus an.

368 Eine Ehe im vierten Grad der römischen Zählweise hätte kaum eine Anfrage an den Papst ausgelöst, weil das Verbot der Verbindung zwischen Cousin und Cousine zweifellos allen Beteiligten bekannt war. Selbst Hrabanus befürwortete das Verbot der Cousinenehe. 
und die geistliche Verwandtschaft ${ }^{369}$. Im Gegensatz zu Hrabanus Maurus gab der Papst den des Inzests überführten Eheleuten die Möglichkeit einer neuen Eheschließung nach der Ableistung der Bußzeit, sofern sie sich noch im jugendlichen Alter befänden ${ }^{370}$. Wenige Jahre später verkündeten die Bischöfe des Ostfrankenreichs auf der Synode von Worms (868) diese Bestimmungen Nikolaus' I. wörtlich als Konzilskanones. Da die Quellen der Kanones nicht ausdrücklich genannt wurden, erschienen die päpstlichen Inzestbestimmungen als ,autonome Gesetzgebung “371 der ostfränkischen Bischöfe. Regino von Prüm nahm den Kanon von Worms über das kategorische Verbot der Verwandtenehen in sein Sendhandbuch auf und sicherte ihm dadurch eine langfristige Wirkung auf das spätere Kirchenrecht. Damit war der zurückhaltende Standpunkt des Hrabanus Maurus endgültig überwunden. Nicht mehr die Bibel war als Standard des Inzestverbots anerkannt, sondern das kategorische Verbot von Verwandtenehen durch den apostolischen Stuhl. Nachdem die Päpste seit Gregor II. dieses Verbot auf Konzilien bzw. in Dekretalen ständig wiederholt und in Erinnerung gerufen hatten ${ }^{372}$, war nach dem Tod Hrabans der Widerstand gebrochen.

\section{Der Umfang des Inzestverbots}

Mit der Anerkennung des kategorischen Verbots war jedoch für Männer der Praxis wie Regino das Problem der Anwendung nicht beseitigt. Wie praktikabel war das kategorische Verbot von Verwandtenehen jedweder Art, wenn wir es vor dem Hintergrund des diffusen Verwandtschaftsbegriffs der Zeit betrachten? Weder den normativen noch den deskriptiven Quellen ist eine klare Festlegung auf die Begrenzung der Verwandtschaft zu entnehmen. Das kategorische Verbot von Verwandtenehen war nur dann praktikabel, wenn man die römisch-rechtliche Definition der Verwandtschaft zugrunde legte. Dieser Möglichkeit hatte aber Nikolaus I. durch das Verbot der Zählung und durch die Subjektivierung des kategorischen Verbots die Basis entzogen. Nun war die Entscheidung über die Verwandtschaft zwischen Ehegatten den Zeugen vor der bischöflichen Synode überlassen. Der Manipulation war damit Tür und Tor geöffnet worden, denn eine Ehe konnte nachträglich gelöst werden, wenn später eine entfernte Verwandtschaft ausfindig gemacht wurde. Inzest war der einzige Scheidungs-

369 Konzil von Mainz (861/863) (MGH Conc. 4, 130 f.) (JE 2709).

370 Konzil von Mainz (861/863) (MGH Conc. 4, 131) (JE 2709). Zur Position des Papstes vgl. Hartmann, Konzil 1977, 71-75.

371 Hartmann, Konzil 1977, 123.

372 Nach den beiden Konzilien von Rom in den Jahren 721 und 743 sind zu nennen: Leo III., Ep. 5 (MGH Epp. 5, 62) (JE 2503); Concilium Romanum (826) c. 38 (MGH Conc. 2/2, 583 f.); Leo IV., Ep. 16 (MGH Epp. 5, 595) (JE 2599); Concilium Romanum (853) c. 38 (MGH Conc. 3, 329); Nikolaus I., Ep. 123 c. 2 (MGH Epp. 6, 642) (JE 2787); Johannes VIII., Registrum 189 (MGH Epp. 7, 150 f.) (JE 3263). 
grund, der von allen Seiten anerkannt wurde und der überdies zu einer Wiederheirat ermächtigte. Mehrere Quellen aus der Karolingerzeit bezeugen die Manipulation des Inzestverbots durch die Laien ${ }^{373}$.

Die Unsicherheit, die das kategorische Verbot des Konzils von Worms auslöste, wird in einer Anfrage an den Gelehrten Ratramnus von Corbie manifest. Abt Adalgar von Corvey und Bischof Rimbert von Hamburg-Bremen, beide Teilnehmer des Konzils von Worms, nutzten die guten Verbindungen Corveys zum Mutterkloster Corbie, um an den bedeutenden Gelehrten des westfränkischen Klosters eine Anfrage zum Umfang des Inzestverbots zu richten. Vermutlich entstand dieser Briefwechsel unmittelbar nach dem Konzil von Worms des Jahres $868^{374}$. In seiner Antwort berief sich Ratramnus auf die Autorität der Tradition sowie auf die Gewohnheit seiner Heimat und deutete indirekt einen Unterschied zwischen Theorie und Praxis an. „Die Bischöfe unserer Kirche verdammen alle solche Ehen und erlauben es keineswegs, dass Blutsverwandte sich durch das Band der Ehe verbinden dürfen. Weil aber in unserer Region häufig solche Ehen geschehen, kommt es vor, dass nicht immer dieselben Urteile gefällt werden “375. Ehen bis zum dritten Grad sollten immer aufgelöst, Ehen im vierten Grad bei einsichtiger Begründung oder Berücksichtigung eines Notfalls erlaubt, Ehen im fünften, sechsten und siebten Grad nicht getrennt werden. Diesen Standpunkt begründete Ratramnus mit einem Zitat aus dem römischen Recht, und zwar aus dem Dispensgesetz des Kaisers Honorius für Ehen im vierten $\mathrm{Grad}^{376}$. Aufgrund der Kenntnis des römischen Rechts dürfen wir annehmen, dass sich Ratramnus der römischen Zählweise bediente. Ob dieses Gutachten von den Auftraggebern im Ostfrankenreich auch in diesem Sinn gedeutet wurde, muss allerdings unklar bleiben. Die Notwendigkeit eines Gutachtens bezeugt in jedem Fall die Praxisferne des kategorischen Verbots von Verwandtenehen.

373 Siehe 381 f. Anm. 438-442.

374 In der Edition Dümmlers ist der Brief zw. 865 und 877 eingeordnet.

375 ... sequens auctoritatem maiorum et consuetudinem regionis. Ecclesiae inquam nostrae sacerdotes omnes huiusmodi nuptias condempnant nec consanguineos invicem sibi coniugii foedere sociari paenitus concedunt. Quia vero frequenter in nostra regione tales contingunt nuptiae, fit ex hoc, ut iuditia proferantur non semper eadem. Ratramnus von Corbie, Ep. (MGH Epp. 6, 157).

376 Siquidem quos primus, secundus tertiusque gradus sotiat, omnino dissotiant. In quarto vero gradu coniunctos, quamvis huiusmodi coniugium incertum [besser: incestum] vocitent, non semper dividunt, intercedente vel rationabili peticione vel necessitatis cuiusquam consideratione. Quos vero reliqui gradus, quintus videlicet, sextus et septimus coniungunt, quamvis non approbent, non tamen dissociant. SECULI LEGES. Sed videamus seculi leges, quid ex hoc praecipiant. In libro Theodosii tertio ita legitur: His quos in tertio et quarto gradu ... Ratramnus von Corbie, Ep. (MGH Epp. 6, 157). Der fragmentarisch erhaltene Brief bricht mitten im Zitat von Codex Theodosianus 3, 10, $1 \mathrm{ab}$. 
Regino war als Mann der Praxis mit demselben Dilemma konfrontiert wie die in der nordischen Mission engagierten Kirchenmänner Rimbert und Adalgar. Regino musste der Widerspruch zwischen den Traditionen besonders in die Augen fallen, weil er beinahe die gesamte Inzestgesetzgebung des Frankenreichs überblickte und auch mit dem kategorischen Verbot der Päpste gut vertraut war. Sein Sendhandbuch vereinigte die Bestimmungen des 9. Jahrhunderts, so weit sie ihm bekannt waren, mit den älteren Regelungen aus der Zeit Pippins, die er auf diese Weise der Vergessenheit entrissen hat. Das Werk reflektiert die gesamte Entwicklung des 8. und 9. Jahrhunderts und hinterlässt auf den ersten Blick den Eindruck eines nicht aufeinander abgestimmten Sammelsuriums. In der Forschung ist daher Regino wiederholt Meinungslosigkeit oder mangelnde Deutlichkeit bescheinigt worden ${ }^{377}$. Er habe es, so Patrick Corbet, letztlich seinen Lesern überlassen, zwischen den unterschiedlichen Vorschriften auszuwählen ${ }^{378}$. Demgegenüber habe ich an anderer Stelle deutlich zu machen versucht, dass der Sammler auf subtile Weise - durch Gestaltung der Rubriken, durch Randbemerkungen und durch hierarchische Anordnung der Kanones - einen eigenen Standpunkt vertritt ${ }^{379}$. Dies gilt besonders für die Frage des Umfangs des Inzestverbots.

An prominenter Stelle steht bei Regino das kategorische Verbot der Päpste, Verwandtenehen jedweder Art zu unterlassen. Diese Regel zitiert Regino zu Beginn des Inzestabschnittes und sie dient auch als Vorlage für die Frage, die der Bischof bei der Sendreise an die Gläubigen zu richten hat ${ }^{380}$. Sie lautet in der von Regino selbst stammenden Formulierung: „Hat jemand seine Verwandte und Blutsverwandte geehelicht oder mit ihr Unzucht getrieben?"381 Beim Sendgericht sollte also nicht zwischen erlaubten und unerlaubten Verwandtenehen unterschieden, sondern grundsätzlich jede geschlechtliche Verbindung zwischen Verwandten unterbunden werden. Eine Zählung der Verwandtschaftsgrade wollte Regino jedoch nicht ausschließen. Den Kanon des Konzils von Worms, der in der Nachfolge Papst Nikolaus' I. die Zählung von Verwandtschaftsgraden untersagt hatte, trennte der Sammler von den anderen Wormser Inzestvorschriften und verbannte ihn an das Ende des Abschnitts über Ehebruch und Unzucht ${ }^{382}$. Damit war dieser missliebige Kanon außerhalb der eigentlichen Inzestbestimmungen platziert. Mit diesem Kunstgriff wollte Regino den Widerspruch zwischen der praxisfernen Regel von Worms und der Festlegung auf einen bestimmten Grad als Grenze der Verwandtschaft verschleiern.

377 Freisen, Geschichte 1893, 392; Gaudemet, Lien 1970, $104 \mathrm{f}$.

378 Conbet, Burchard 2001, 33-41.

379 UbL, Doppelmoral 2007.

380 Regino, De synodalibus causis II 185 (286) und 187 (287).

381 Si quis propinquam et consanguineam suam in matrimonium accepit, aut cum ea fornicatus est? Regino, De synodalibus causis II 5 (211).

382 Regino, De synodalibus causis II 263 (316). 
Bei der Anwendung des kategorischen Verbots wird der Leser von Reginos Sendhandbuch auf die zahlreich versammelten Kanones zur Inzestgrenze verwiesen. Insgesamt zitiert Regino dreimal den vierten Grad als Inzestgrenze ${ }^{383}$. Dass er selbst diese Meinung geteilt hat, lässt sich aus einer kleinen Manipulation an einem Text des Hrabanus Maurus erschließen. Hraban schreibt als Ergebnis einer über zwei Seiten langen Erörterung, er wolle die Mitte zwischen Gregor dem Großen und Isidor einhalten und folge deshalb Bischof Theodor, der Ehen nach dem fünften Grad für legitim erklärt habe. Regino lässt in seiner Version die Präposition post aus und ändert quintam generationem in quinta generatione, so dass bereits der fünfte Grad genehmigt wird ${ }^{384}$. Mit dieser kleinen Änderung bringt Regino das Gutachten Hrabans mit der Synode von Verberie und dem Konzil von Mainz (813) in Einklang. Dieser Text wird durch die Rubrik In quota generatione copulentur fideles ${ }^{385}$ hervorgehoben und drängt sich daher dem Leser als autoritative Entscheidung auf. Ein Leser von Reginos Sendhandbuch wird daher die Ehe zwischen Verwandten im dritten Grad für verboten gehalten und den vierten Grad als gültiges, aber umstrittenes Ehehindernis angesehen haben. Das entsprach den Bestimmungen der unter der Leitung Pippins I. tagenden Synoden und wird auch durch die Mainzer Synoden als geltendes Kirchenrecht des Ostfrankenreichs ausgewiesen ${ }^{386}$. Wie umkämpft der vierte Grad gewesen ist, zeigt das oben erwähnte Vorgehen der Mainzer Synode gegen Abbo aus dem Jahr 861/863.

Eine Frage muss jedoch offen bleiben. Regino äußerte sich nicht dazu, welcher Zählweise er sich bei seiner Parteinahme für den vierten Grad als Inzestgrenze bediente. Die Praxisnähe Reginos hat darin seine Grenze, dass er es nicht für nötig erachtete, seiner Sammlung eine Stammtafel beizulegen ${ }^{387}$. Die

383 Regino, De synodalibus causis II 201 (292-294); II 213 (299); II 227 (303).

384 Igitur, qui a mea parvitate voluisti, quid sentirem de hac re, tibi rescribi, propter fragilitatem praesentis temporis reor hoc, quod Theodorus episcopus inter Gregorium et Isidorum medius incedens in suis capitulis definivit, magis sequendum, ut quinta generatione iam licitum connubium fiat ... Regino, De synodalibus causis II 202 (294). Ausführlich hierzu UBL, Doppelmoral 2007, 108-119.

385 Regino, De synodalibus causis II 202 (292).

386 Konzil von Mainz (813) c. 54 (MGH Conc. 2/1, 273); Konzil von Mainz (847) c. 30 (MGH Conc. 3, 175 f.).

387 In Rechtshandschriften der Karolingerzeit sind bildliche Darstellungen der Verwandtschaft keine Seltenheit. Ich nenne nur zwei Beispiele: Eine Handschrift vom Hof Karls des Großen (Leiden, Bibliotheek der Rijksuniversiteit, BPL 114, fol. 1v-8v) vereinigt am Beginn gleich mehrere Stammbäume: Mordek, Bibliotheca 1995, 503. Die Collectio Sancti Mauri beginnt in den beiden vollständigen Handschriften (Paris, Bibliothèque nationale, Lat. 1451 und Vatikan, Biblioteca Apostolica Vaticana, Reg. 1127, beide aus dem 9. Jahrhundert) mit einem Stammbaum, vgl. MaAssen, Geschichte 1870, 613; Schadt, Arbores 1982, 110 Anm. 298. Die älteste Handschrift (Den Haag, Museum Meermanno-Westreenianum, 10.B.4) ist am Anfang unvollständig. Die verlorene Laoner 
namentliche Auflistung von Verwandten geht nie über die Cousine (2/2) hinaus. Insofern wäre die Anwendung der römischen Zählweise durchaus im Bereich des Möglichen. Trotzdem sprechen einige Indizien dagegen. Erstens hätte er dann ohne ersichtlichen Grund die Position Hrabans nochmals abgemildert, da Hraban auch den fünften Grad untersagt hatte. Zweitens wäre so kaum dem kategorischen Verbot von Verwandtenehen Rechnung getragen worden, das Regino im Unterschied zu Hraban ausdrücklich billigte. Drittens herrschte im Ostfrankenreich des 9. Jahrhunderts weitgehend die kanonische Zählweise vor $^{388}$. Ich bin daher der Meinung, dass Regino Ehen bis zum Verwandtschaftsverhältnis von $4 / 4$ unter das Inzestverbot stellte. Neben diesem eigenen Standpunkt eröffnete das Sendhandbuch allerdings verschiedene Deutungsmöglichkeiten für spätere Generationen. Im 10. Jahrhundert griff ein Konzil auf die Grenze des vierten Grades, ein anderes auf das kategorische Verbot von Verwandtenehen zurück ${ }^{389}$.

\section{Von der Visitation zum Sendgericht}

Bedeutung erlangte Reginos Sendhandbuch in erster Linie durch die Normierung des Sendgerichts. Sein Handbuch ist die erste Quelle, die diese nur im Ostfrankenreich etablierte Institution in allen Details vor Augen führt. Nach Regino sollte der Bischof jährlich seine Diözese visitieren und sowohl die kirchlichen Zustände als auch das Verhalten der Laien überprüfen ${ }^{390}$. Die Visitation der Laien war von Amtsträgern des Bischofs, den Archipresbytern und Archidiakonen, vorher anzukündigen, damit unter Androhung der Exkommunikation alle Gläubigen zum Sendgericht des Bischofs erschienen. Einfache und weniger bedeutsame Rechtsfälle konnten bereits von den untergeordneten Amtsträgern behandelt werden, damit „der Bischof bei seiner Ankunft auf keinen Fall durch allzu geringfügige Geschäfte ermüdet wird oder genötigt ist, sich dort länger aufzuhalten als es die Kosten zulassen ${ }^{\text {“391 }}$. Nach einer Predigt vor den Gläubigen sollte der Bischof „sieben reife, ehrenhafte und ehrliche Männer aus dem Volk der Pfarrei zu sich rufen" und sie durch einen Eid zur Denunziation aller Vergehen gegen die christliche Religion verpflichten ${ }^{392}$. Um den Geschworenen alle Varianten der Sünde ins Gedächtnis zu rufen, sollte

Handschrift der Collectio begann ebenfalls mit einem Stammbaum: Contreni, Descriptions 1980, 48. Literatur bei Kéry, Collections 1999, $45 \mathrm{f}$.

388 Siehe oben 27.

389 Allgemeines Verbot: Konzil von Ingelheim (948) c. 12 (MGH Conc. 6/1, 162); der vierte Grad: Konzil von Koblenz (922) c. 1 (MGH Conc. 6/1, 69). Vgl. Corbet, Burchard 2001, 53-58.

390 Vorschriften zur Visitation: Regino, De synodalibus causis I 2-13 (27-33).

391 ... ut pontifex veniens nequaquam in facilioribus negotiis fatigetur, aut ibi immorari amplius necesse sit, quam expensa sufficiat. Regino, De synodalibus causis II 1 (206 f.).

392 Regino, De synodalibus causis II 2-3 (207 f.). 
ihnen ein Fragekatalog vorgelesen werden, der bei Regino 89 Punkte umfasst. Er erstreckt sich von Mord, Körperverletzung, Unzucht, Ehebruch und Inzest bis zu Diebstahl, Meineid und Zauberei.

Dieses sendgerichtliche Verfahren entspricht dem Rügeverfahren, wie es erstmals in einem Kapitular für das langobardische Italien nachweisbar ist. Wie oben ausgeführt, übertrug Karl der Große dieses Rügeverfahren vom weltlichen in den kirchlichen Bereich und gab den Bischöfen den Auftrag, nach Vergehen gegen das Christentum wie Inzest, Verwandtenmord und Unzucht im Rahmen der Visitation zu fahnden ${ }^{393}$. Karl führte jedoch nicht aus, auf welche Weise dieser Inquisitionsauftrag ausgeführt werden sollte. Ebenso unklar ist, inwiefern die Gesetze des Kaisers in der Praxis umgesetzt worden sind. Albert Michael Koeniger hat in seiner grundlegenden Studie zum Sendgericht für eine allmähliche und kontinuierliche Entstehung des Sendgerichts im frühen 9. Jahrhundert plädiert. Seit 860 hat sich nach Koeniger das Sendgericht als „fortdauerndes geistliches Rügegericht" mit ständigen Rügegeschworenen fest etabliert $^{394}$. Diese Datierung bereitet jedoch Schwierigkeiten, da die beiden zentralen Belegstellen zweifelhafter Herkunft sind und erst im 10. Jahrhundert handschriftlich überliefert werden ${ }^{395}$. Die oben angestellten Überlegungen zu Hrabanus Maurus und Hinkmar von Reims lassen darüber hinaus eine Institutionalisierung des Sendgerichts bereits in der Jahrhundertmitte als unwahrscheinlich erscheinen. Als Bußgerichtshof des Bischofs betrachteten sie nicht das Sendgericht vor Ort, sondern die Synode am Bischofssitz. Auch das Vergehen Abbos gegen das Inzestverbot wurde in den Jahren 861/863 auf einer zentralen Versammlung der Bischöfe in Mainz erörtert.

Die bischöfliche Gesetzgebung des 9. Jahrhunderts spricht ebenfalls gegen eine bruchlose Entwicklung von Karls Inquisitionsauftrag zur Entstehung des

393 Siehe $284-286$.

394 Koeniger, Sendgerichte 1907, 62-75; ihm folgen Hartmann, Sozialdisziplinierung 2005, 99; Kéry, Gottesfurcht 2006, 65-118; SCHIEffer, Entstehung 2007.

395 Koeniger stützt sich zum einen auf den Kanon Scelerosi, den er für authentisch hält (Koeniger, Beschlüsse 1906, 384-390), der jedoch erst im 10. Jahrhundert dem Konzil von Meaux-Paris (845/6) zugeschrieben wird (MGH Conc. 3, 129-131). Krause hat die Zuschreibung abgelehnt (MGH Capit. 2, 388-421). Die Überlieferung konzentriert sich auf den bayerischen Raum: EsDers - Mierau, Klerikereid 2000, 259-269, sowie auf die notorisch unzuverlässige Handschrift Salzburg, St. Peter, Stiftsbibliothek, a.IX.32, deren Ursprung in Köln lokalisiert wird: Mordek, Bibliotheca 1995, 644652; Kéry, Collections 1999, 188 f. Zum anderen beruft sich Koeniger auf das von Regino, De synodalibus causis II 1 (206), zitierte Konzil von Rouen. Die Einschätzung dieses Konzils ist kontrovers: Fournier - Le Bras, Histoire 1 1931, 263, gehen zumindest von einer falschen Inskription aus, da das Sendgericht in Rouen nie Fuß gefasst hat; gleichfalls Landau, Recht 1988, 23-25. SECKel, Canones 1910, hält dagegen die Zuschreibung für authentisch und datiert die Kanones in die Mitte des 9. Jahrhunderts. Zustimmend Hartmann, Capita 2004, 216-218. 
Sendgerichts. Einige Quellen sind bereits oben besprochen worden ${ }^{396}$. Besonders deutlich kommt dieser Sachverhalt in einem Konzilskanon aus dem westfränkischen Bereich zum Ausdruck. Darin wird der Auftrag zur Fahndung nach Inzestehen von den Bischöfen an die Priester weitergegeben.

„Die Priester sollen mit großem Eifer durch die Heranziehung von wahrhaftigen und gottesfürchtigen Menschen nach Inzestehen fahnden. Und wenn eine ausfindig gemacht wurde, sollen sie sofort selbst oder durch die Hilfe des Archidiakons strafend eingreifen. Und die Bischöfe sollen sich eifrig um die Ausrottung bemühen, damit nicht sowohl jene durch ein solches schändliches Verbrechen beschmutzt werden und zugrunde gehen als auch andere durch die Nachbarschaft mit ihnen dem Zorn des allmächtigen Gottes verfallen ${ }^{\text {“3977 }}$.

Die Bischöfe entledigten sich also der Aufgabe der Inquisition durch die Weiterleitung an die Priester, da diese im Allgemeinen besser über die Verhältnisse in den Pfarreien Bescheid wussten. Die primäre Zuständigkeit der Priester war auch für Hinkmar von Reims selbstverständlich. Daneben bildete sich in der Mitte des 9. Jahrhunderts mit den Archidiakonaten eine Instanz zwischen den Bischöfen und dem Landklerus heraus, die in den Quellen unterschiedliche Namen erhalten hat und erst allmählich einer Normierung unterworfen wurde $^{398}$. Ende des 9. Jahrhunderts mehrten sich die Anzeichen, dass dieses Verfahren in der Praxis nicht die erwünschten Erfolge zeitigte. Im Jahr 878 beschwerte sich Bischof Salomo II. von Konstanz über den Widerstand eines adeligen Ehepaares, das an einem unbekannten Ort geflohen war, um sich der auf einer Synode verhängten Ehetrennung zu entziehen ${ }^{399}$. Auf dem Konzil von Köln im Jahr 887 verlangte man von Personen, die des Inzest überführt worden waren, eine eidliche Bestätigung der Ehetrennung. Sollten die Delinquenten

396 Siehe 357 Anm. 330.

397 De incestis omni studio perquirendum est sacerdotibus per homines veraces et timorem dei ante oculos habentes. Et si repertum fuerit, statim aut per se emendare studeant aut cum adiutorio archidiaconi. Et episcopi hoc ipsum extirpare satagant, ne tanto flagitii scelere et illi et polluantur et pereant et alii eorum vicinitate omnipotentis dei iram incurrant. Theodulf, 2. Kapitular II, 2 (MGH Capit. episc. 1, 154). Die Zuschreibung an Theodulf hat Pokorny, Einleitung (MGH Capit. episc. 4, 96-100), überzeugend zurückgewiesen

398 Vgl. die Bemerkungen von Rudolf Pokorny in MGH Capit. episc. 3, 218; Stratmann, Hinkmar 1991, 24.

399 Collectio Sangallensis 30 (MGH Formulae, 415 f.). Dieser Brief wird zumeist in das Jahr 878 datiert und stammt aus dem Formelbuch Notkers von St. Gallen (gest. 912). Nach STEINEN, Formelband 1945, 468, sind die Briefe „mindestens zu drei Vierteln von Notker". An dem Brief 30 irritiert vor allem die Tatsache, dass dieselbe Geschichte zweimal erzählt wird. Während im ersten Teil der Bischof die im Grad 4/5 verwandten Eheleute vor sich zum Bischofsgericht zitiert, verurteilt er sie im zweiten Teil auf einer Sendversammlung vor Ort. Man hat den Eindruck, dass im zweiten Teil das Vorgehen Salomos II. an die kirchenrechtlichen Normen der Zeit Notkers angepasst wird. Ich sehe daher in dem Brief kein authentisches Zeugnis der Praxis wie Daudet, Origines 1933, 155, und Corbet, Burchard 2001, 21-24. 
trotzdem wieder ihre Ehe aufnehmen, habe der Bischof sie zur strengen Buße im Kloster zu verurteilen. Falls sich die Eheleute dieser Strafe entzögen, sollte sowohl über sie als auch über ihre Helfershelfer die Exkommunikation und das Anathem ausgesprochen werden ${ }^{400}$. Konkrete Fälle eines solchen Widerstands wurden auf den nächsten beiden Synoden thematisiert. In Mainz (888) verhängten die Bischöfe des Ostfrankenreichs über einen gewissen Altmann aus der Diözese Würzburg das Anathem, weil er seine Inzestehe wieder aufgenommen hatte ${ }^{401}$. Dasselbe Urteil sprach die Synode von Metz (893) über einen Lantbert aus, der einen Blutsverwandten umgebracht und dessen Frau geehelicht hatte. Ausdrücklich beschwerten sich die Bischöfe über die fehlende Akzeptanz der am Bischofsort tagenden Synode: Einige befolgten die Vorladung vor die Synode von Metz, andere entzogen sich ihr und waren abwesend ${ }^{402}$.

In diese Zeit, als den Bischöfen ihre Machtlosigkeit zunehmend vor Augen getreten ist, fallen die ersten eindeutigen Belege für das Funktionieren des Sendgerichts. Sie stammen allesamt aus dem lothringischen Raum. Eine anonyme Anordnung für das Sendgericht, mit der Regino vertraut war, schreibt die Vereidigung von sieben ehrenwerten Männern durch den visitierenden Bischof vor, die dann über den Zustand der Kirche und über den Lebenswandel des Ortspriesters befragt werden sollten ${ }^{403}$. Auch Vergehen von Laien wie Mord,

400 Quod si conventi fuerint et ad poenitentiae remedia convolaverint, seque sacramento constrinxerint, ulterius tam nefanda et prorsus abominanda pollutione non esse polluendos, iterumque ad recidiva malitiae et vitae pristinae sordes relapsi fuerint, ab episcopo civitatis comprehensi, sicut in concilio Toletano capite septimo reperitur, in cuius territorio sunt, rursum legibus poenitentiae in monasteriis subdantur inviti. Quod si facere per aliquem potestatis vigorem difficile fuerit, tunc sicuti priscorum canonum statuerunt decreta, quousque iterum respuerint, excommunicati et anathemate condemnati habeantur, sed et hi qui post excommunicationem vel interdictum cum eis communicaverint. Konzil von Köln (887) c. 6 (Mansi 18A, 48).

401 Perlatus est ad nos, quod quidam Altmannus nomine sibi commatrem spiritualem, ex parochia Arnonis episcopi, scelesto coniugio associasset; sed postea per sacramenta ab ea separatus, modo iterum eam sibi impia copulatione habet sociatam. Quam quia tale scelus perpetratum habere audivimus, secundum constitutionem sancti Gregorii papae gladio spirituali percutimus, eumque anathematis vinculo innodamus. Konzil von Mainz (888) c. 18 (MAnsI 18A, 69).

402 Viri pestilentes vastabant miserabiliter istam provinciam. Pro quo scelere ad synodum vocati ... alii venerunt, alii venire noluerunt. Illi qui adfuerunt, synodo satisfecerunt, caeteri autem canonice excommunicati sunt. ... Quidam vir nomine Lantbertus interficiens consanguineum suum et ducens eius uxorem nomine Waldradam iuravit coram archiepiscopo quod tale coniugium dimitteret, et iterum ei se sociavit et adhuc eam habet; idcirco excommunicatus est. Konzil von Metz (893) c. 11 (Mansi 18A, 80 f.).

403 Bekannt als Augsburger Sendordnung, vgl. Koeniger, Sendgerichte 1907, $191-194$. Da die Handschrift (München, Bayerische Staatsbibliothek, Clm 3851) vermutlich in Lothringen geschrieben wurde und erst später nach Augsburg gelangte, ist diese Bezeichnung irreführend. Ediert von Krause, Handschriften 1894, 118-121. Nach Po- 
Sakrileg, Meineid und Inzest sollten durch die Geschworenen an die Öffentlichkeit gebracht werden ${ }^{404}$. Dasselbe Vorgehen wird in einer anonym überlieferten Ansprache eines Bischofs vorausgesetzt, die aus Trier, der Wirkungsstätte Reginos, stammt und Ende des 9. Jahrhunderts niedergeschrieben wurde ${ }^{405}$. Der Inzest wurde darin neben vielen anderen Delikten erwähnt ${ }^{406}$.

Das Sendgericht ist also nicht unmittelbar aus der Inquisitionsanweisung Karls des Großen entstanden. Erst Ende des 9. Jahrhunderts und nur im Bereich der Erzdiözese Trier nahm diese Institution feste Formen an. Auch später beschränkte sich die Verbreitung des Sendgerichts auf die drei Kirchenprovinzen Trier, Köln und Mainz, während das Westfrankenreich und auch die Kirchenprovinz Salzburg von dieser Entwicklung unberührt blieben ${ }^{407}$. Im Westfrankenreich blieb das Bußverfahren bestehen, wie es Hinkmar in seinen Bischofskapitularien geschildert hatte. Primär waren die Priester für die Aufdeckung von schweren Sünden verantwortlich, die Absolution sollte jedoch nur durch den Bischof erfolgen und zentral in der Bischofskirche stattfinden. Die Sünder waren daher zum Besuch der Bischofskirche verpflichtet. Noch im 13. Jahrhundert ist diese Praxis mit nur wenigen Änderungen nachweisbar ${ }^{408}$. Den Grund für die Entstehung des Sendgerichts im Ostfrankenreich wird man in zwei Besonderheiten sehen müssen: Zum einen war durch die fehlende Kontinuität zur Spätantike das kanonische Bußverfahren nicht im gleichem Ausmaß verankert, zum andern erwiesen sich die räumlichen Distanzen als zu ausgedehnt, als dass der Weg zum Bußgericht der Bischofskirche in den durch die Eroberung Sachsens erweiterten Diözesen hätte beschritten werden können. Diese Probleme kamen auf den Synoden der letzten Jahre des 9. Jahrhunderts zur Sprache und wurden insbesondere an der unbefriedigenden Strafverfolgung von Inzestdelikten sichtbar.

Das Sendgericht ist also um 900 in wenigen und selten überlieferten Quellen fassbar. Erst das Handbuch Reginos von Prüm verschaffte dieser Institution eine überregionale Bekanntheit und wirkte normierend auf ihre Ausgestaltung ein. Regino gelang es, die Zuständigkeit der Kirche für die Bestrafung

KORNY, Einleitung (MGH Capit. episc. 4, 45), handelt es sich um sekundär zusammengefügtes Material.

404 De viris et mulieribus, si sit aliquis homo vel aliqua femina homicida, sacrilegus, periurus, raptor; si parentibus coniunctus ... KRAUSE, Handschriften 1894, 121.

405 Ediert als Capitula Treverensia (MGH Capit. episc. 1, 55 f.). Pokorny, Einleitung (MGH Capit. episc. 4, 74), bezeichnet die Quelle als „Sendansprache“.

406 Capitula Treverensia c. 4 (MGH Capit. episc. 1, 55). Der Text folgt dem 2. Kapitular Gerbalds von Lüttich, das Inzestverbot wird jedoch auf den fünften Grad erweitert.

407 Das ergibt der Überblick über die Quellen bei Koeniger, Quellen 1910. Die Beispiele von BüHrer-Thierry, Évêques 1997, 213, beziehen sich auf Gerichtsversammlungen in der Bischofsstadt (Passau, Freising) und nicht auf ein Bußgericht vor Ort.

408 Mansfield, Humiliation 1995. Für das frühe 11. Jahrhundert vgl. Hartmann, Briefe 2000. 
von Delikten zu festigen, die der privaten Strafverfolgung entzogen waren und die in der öffentlichen Rechtswahrung des Königs nicht wirksam erfasst waren. Der Inzest war neben dem Mord unter Verwandten das exemplarische Delikt für das Sendgericht. Waren Karl der Große und Ludwig der Fromme noch selbst vereinzelt bei der Verfolgung von Verstößen gegen das Inzestverbot tätig geworden $^{409}$, so zogen sich die folgenden Generationen der Karolinger aus diesem Bereich zurück. Die Intensivierung der Strafverfolgung in den beiden letzten Dekaden des 9. Jahrhunderts ging ausschließlich auf die Initiative der ostfränkischen Bischöfe zurück. Mit den Mitteln des Eides und der Exkommunikation versuchten sie, verbindliche Verhaltensweisen beim widerspenstigen Adel durchzusetzen. Das Rügeverfahren dürfte zur selben Zeit erstmals massiv zum Einsatz gebracht worden sein, um fehlende Anklagen zu ersetzen und ein Verfahren in Gang zu bringen. Regino hat diese Anstrengungen systematisiert und durch die Aufnahme von Eidformularen für die Praxis anwendbar gemacht. Seine Praxisnähe äußert sich auch darin, dass er das kategorische Verbot von Verwandtenehen durch den Papst zwar vorderhand akzeptierte, sich jedoch indirekt für den vierten Grad als Grenze des Inzestverbots aussprach.

\subsection{Gelebte Praxis oder klerikales Wunschdenken?}

In ihrem Buch über die fränkische Kirche der Karolingerzeit zog Rosamond McKitterick ein positives Fazit der kirchlichen Reformanstrengungen. Allein der Umfang und die Diversität der überlieferten Quellen sowie ihre kontinuierliche und systematische Produktion in Handschriften seien ein hinreichendes Zeugnis für den dauerhaften Erfolg der Reform. Am Ende des karolingischen Zeitalters habe eine durchgehend christianisierte fränkische Gesellschaft gestanden ${ }^{410}$. Diesem pauschalen Befund schloss sich die neuere Forschung weitgehend $a{ }^{411}$. Nur in der Frage des Eherechts überwiegen weiterhin die skeptischen Stimmen. Die Geringschätzung der karolingischen Reform im

409 MGH D. Kar. 1, 274 Nr. 205 (28.4.807): „Karl der Große schenkt dem Kloster Prüm den wegen Incest und anderer Verbrechen eingezogenen Besitz Godeberts in den Gauen Anjou und Rennois“. Formulae Augienses Coll. B, 21 (MGH Formulae, 357): Königsboten Karls des Große oder Ludwigs des Frommen machen die durch einen Grafen verhängte Konfiskation wegen Inzest rückgängig. Vgl. hierzu Weitzel, Dinggenossenschaft 1985, 360-362. Capitula missorum (821) c. 6 (MGH Capit. 1, 301): Konfiskationen wegen Inzest, die vor mehr als fünf Jahren verhängt worden waren, werden nicht rückgängig gemacht.

410 McKitTerick, Church 1977, 206-210.

411 Wallace-Hadrill, Church 1983, 292; Hartmann, Synoden 1989, 28-34; Smith, Religion 1995, 677; Meens, Frequency 1998; Patzold, Bischöfe 2006; Rhijn, Shepherds 2007. Die skeptische Sicht herrscht dagegen vor bei Nelson, Limits 1977. 
Eherecht ist in erster Linie dem Einfluss Georges Dubys zu verdanken ${ }^{412}$. Nach Duby sind noch im frühen 11. Jahrhundert das christliche und das aristokratische Verständnis der Ehe unversöhnlich gegenübergestanden. Die Kirche sei mit der Unterordnung der Eheschließung unter ständische, erbrechtliche und machtpolitische Erwägungen konfrontiert gewesen und habe vor dem Erstarken des Papsttums unter Gregor VII. keine Möglichkeit gehabt, gegen die Willkür von Scheidungen und Inzestehen vorzugehen. Das Prinzip der Unauflösbarkeit der Ehe und das Verbot von Verwandtenehen bis in den siebten Grad kanonischer Zählung seien von den Laien in der Regel ignoriert worden. Régine Le Jan stimmt diesem Befund zu und weist nach, dass in der Königsdynastie Eheschließungen zustande kamen, die dem Kirchenrecht widersprochen hät$\operatorname{ten}^{413}$. Auch Bernhard Jussen und Johannes Fried attestieren der karolingischen Inzestgesetzgebung weitgehende Wirkungslosigkeit ${ }^{414}$. Beide erschließen diesen Befund aus dem diffusen Zustand der Rechtsnormen, denen kein „gemeinsames semantisches Konzept von Verwandtschaft und Exogamie" zugrunde lag. Über die gültigen Inzestregeln habe eine „große Unsicherheit unter Klerus und Laien “ ${ }^{\text {“415 }}$ bestanden.

Dieser Befund der Wirkungslosigkeit beruht auf einer falschen Voraussetzung: der Gültigkeit des Inzestverbots bis in den siebten Grad kanonischer Zählweise. Obwohl diese Voraussetzung von allen Historikern geteilt wird ${ }^{416}$, ist sie noch nie an den Quellen überprüft worden. Sie geht vielmehr auf die Überzeugung aus dem 19. Jahrhundert zurück, dass alle germanischen Quellen des Frankenreichs auch die ,germanische' Zählung benutzten. Doch die ,germanische' Zählung hat sich als Fiktion der Forschung erwiesen, und somit musste auch die Interpretation der Quellen des 9. Jahrhunderts erneut auf den Prüfstand gestellt werden. Als Ergebnis dieses Kapitels ist festzuhalten, dass nur dort der siebte (oder sechste) Grad als Inzestgrenze geltend gemacht wurde, wo mit Sicherheit oder doch mit einiger Gewissheit die römische Zählweise unterstellt werden muss. Die Päpste von Gregor II. bis Leo III., die westfränkischen Kirchenmänner Jonas von Orléans, Pseudoisidor, Hinkmar von Reims und Ratramnus von Corbie benutzten ausdrücklich die römische Zählweise. Für

412 Duby, Chevalier 1981. Siehe auch $387 \mathrm{f}$.

413 Le Jan, Famille 1995, 314-318. Vgl. auch Aurell, Jalons 1991; Ders., Noces 1995; D’Avray, Marriage 2002, 82.

414 Jussen, Patenschaft 1991, 33-35; Fried, Konradiner 2006, 19-22.

415 Fried, Konradiner 2006, 19-22.

416 Esmein, Mariage 1 1891, 349; Freisen, Geschichte 1893, 425; Seckel, Synode 1922, 32; Duby, Chevalier 1981, 40; Sснмілск, Livius 1982, 155; Rouche, Mariages 1986, 861; Mordek, Recht 1987, 459; Guerreau-Jalabert, Parenté 1989, 83; Chélini, Aube 1991, 186; Weigand, Ausdehnung 1994, 6; Aurell, Noces 1995, 48; Le Jan, Famille 1995, 313; Jong, Riddle 1998, 107; Corbet, Burchard 2001, 320; Poly, Chemin 2003, 277. 
den Fälscher Benedictus Levita kann dies mit hoher Wahrscheinlichkeit angenommen werden. Das Eheverbot erstreckte sich demnach auf die Cousine zweiten oder dritten Grades (3/3 oder 4/4) - je nachdem, ob man am sechsten oder siebten Grad festhielt, ob man die Grenze inklusiv oder exklusiv verstand und ob man die authentische römische Zählweise oder die durch Isidor modifizierte Komputation verwendete. Wenn man allein die westfränkischen Quellen in Betracht zieht, waren die Unterschiede in der Auffassung marginal. Im Vergleich zur Merowingerzeit wurden keine "völlig neuen Verhältnisse“ geschaffen, und auch nicht „unzählige Prozesse“ sowie „eheliche, adelsgeschichtliche und individuelle Katastrophen "417 verursacht.

Im Ostfrankenreich war der siebte Grad als Inzestgrenze dagegen wenig bekannt. Kontinuität schufen die Mainzer Konzilien, die stets am vierten Grad als Inzestgrenze festhielten. Auch Regino von Prüm schloss sich dieser Auffassung an. Da diese Quellen eng an die Konzilien der Zeit Pippins I. anknüpfen, ist die Anwendung der kanonischen Komputation anzunehmen. Bei Haito von Basel und Gerbald von Lüttich ist dies gewiss, bei den anderen Quellen kann man es nur indirekt erschließen. In einer Region, wo das römische Recht weder in der Praxis noch in der Schule gepflegt wurde, bediente man sich der durch Gregor I. und Pippin I. eingeführten kanonischen Zählweise. Auch im Ostfrankenreich herrschte folglich die Inzestgrenze von 4/4 vor, wobei die Gültigkeit des vierten Grades umstritten war.

In der Karolingerzeit stellte die Kirche also noch keine maßlosen Forderungen an die Ehedisziplin der Laien. Das Urteil über die „große Unsicherheit bei Kleriker und Laien" trifft nur zum Teil zu. Es gab einen Konsens, auch wenn dieser Konsens in unterschiedlichen Zählweisen zum Ausdruck gebracht und durch ein diffuses Konzept der Verwandtschaft getrübt wurde. In Einzelfällen wurden durchaus abweichende Meinungen geäußert. Das karolingische Kirchenrecht hat nie die Uniformität erreicht, die durch den päpstlichen Zentralismus des Hochmittelalters möglich werden sollte. Einheit und Vielfalt standen immer in einem Spannungsverhältnis zueinander. Dies war bereits den karolingischen Gelehrten bewusst, die der Einheit des Glaubens die Vielfalt der kirchlichen Gewohnheiten gegenüberstellten ${ }^{418}$. Die karolingischen Herrscher von Pippin I. bis Ludwig dem Frommen versuchten, in bestimmten, ihnen wichtig erscheinenden Angelegenheiten eine einheitliche Praxis in der Kirche durchzusetzen. Erfolg war ihnen nur teilweise vergönnt. Pippins Definition des

417 Fried, Konradiner 2006, 20.

418 Gregor I., Libellus responsionum (MGH Epp. 2, 334); Ratramnus von Corbie, Contra Graecorum opposita IV 1 (Migne PL 121, 303-306); Hinkmar, De praedestinatione c. 37 (Migne PL 125, 413 f.); Regino von Prüm, De synodalibus causis, prol. (2). Vgl. Meyvaert, Diversity 1963; Fuhrmann, Einfluss 1972, 437; Mordek, Autoritäten 1977, 250. 
Inzestverbots fiel im 9. Jahrhundert weitgehend der Vergessenheit anheim, der Versuch Ludwigs des Frommen, den Umfang des Inzestverbots zu bestimmen, scheiterte auf der Reichsversammlung von Aachen (818/819). Nach dem Zerfall der Einheit des Frankenreichs gab es keine Institution mehr, die das Recht der Kirche eindeutig festzulegen vermochte. Päpste, Bischöfe, Könige und Gelehrte rangen um die Meinungsherrschaft über kirchenrechtliche Fragen. Weder das Papsttum noch prägende Kirchenpolitiker wie Hrabanus Maurus und Hinkmar von Reims schafften es, die unterschiedlichen Inzestvorschriften auch nur in ihrem näheren Umkreis vollständig zu vereinheitlichen. Das Papsttum ist mit dem kategorischen Verbot und mit dem Verbot der Verwandtschaftszählung nie ganz durchgedrungen, Hrabanus war ein einsamer Kämpfer für die antiquierte angelsächsische Tradition, und Hinkmar musste in seiner Kirchenprovinz die moderate Stellungnahme des Ratramnus von Corbie tolerieren.

Den Rahmen des karolingischen Konsenses sprengten am deutlichsten Hrabanus Maurus und ein anonymer Bischof aus Senlis. Hrabanus schloss sich der angelsächsischen Tradition an und akzeptierte nur wenige Veränderungen am Inzestkatalog des Alten Testaments. Wie Bonifatius scheute er davor zurück, den Laien neue Sünden aufzubürden, für die es keine biblische Grundlage anzuführen gab. Er verbarg jedoch seinen eigenen Standpunkt so geschickt hinter den kirchenrechtlichen Autoritäten, dass man seine Stellungnahmen ohne weiteres im Sinn des geltenden fränkischen Kirchenrechts interpretieren konnte. Den Gegenpol bildet ein erst unlängst durch Rudolf Pokorny, entdecktes' Bischofskapitular. Das in einer singulären Handschrift tradierte Kapitular ist eine redigierte Fassung der bischöflichen Gesetzgebung Gerbalds von Lüttich. Es wurde daher sowohl als Variante in der Edition von Gerbalds Text als auch als eigenständiges Werk veröffentlicht. Der Autor, vermutlich ist es Bischof Erpuin von Senlis (gest. 872), änderte das Inzestverbot Gerbalds, indem er die Grenze vom vierten auf den sechsten Grad verschob ${ }^{419}$. Da Gerbald ausdrücklich die kanonische Zählweise verwendete, wäre es folgerichtig, dies auch der Redaktion Erpuins zu unterstellen. Dann müssten wir darin das einzige Zeugnis für die Ausdehnung des Inzestverbots auf den siebten Grad kanonischer Zählweise erblicken. Vielleicht ist dieser Eindruck aber auch nur der ungeschickten Manipulation einer Quellenvorlage geschuldet. Dieses vereinzelte Zeugnis ist jedenfalls im Vergleich zur gesamten kirchenrechtlichen Überlieferung der Karolingerzeit unerheblich.

Der Konsens über die Grenze des Inzestverbots war also, bedenkt man die Bedingungen der Kommunikation und der Gesetzgebung im Frankenreich,

$419 . .$. non sobrinam id est in tertiam generationem vel de una in tertiam vel de alia in quartam vel ambabus in quartam vel quintam aut sextam generationem ... Capitula Silvanectensia prima 5 (MGH Capit. episc. 3, 81). Die Wörter vel quintam aut sextam sind in den Gerbald-Text interpoliert. 
überwiegend stabil und wurde nur durch die unterschiedliche Zählweise der Verwandtschaft im Ost- und Westfrankenreich überdeckt. Ein Unterschied zwischen dem Osten und dem Westen des Frankenreichs ist auch bei den Methoden der Strafverfolgung festzustellen. Im Westen delegierten die Bischöfe den Auftrag Karls des Großen, die Missstände und insbesondere die Verwandtenehen im Volk aufzudecken und zu bestrafen, an die zuständigen Ortspriester. Die Nachforschungen der Priester hatten jedoch keine gerichtlichen Formen, da den Priestern nicht die Ausübung der Banngewalt zustand. Erst bei Widerstand sollte der Priester die schuldigen Personen exkommunizieren und den Fall an das bischöfliche Gericht weiterleiten. Dieses Bußgericht tagte in der Bischofsstadt und stellte eine Öffentlichkeit her, die ausreichenden Druck auf die widerspenstigen Laien ausüben konnte. Im Ostfrankenreich mit seinen großen Diözesen und dem viel weniger engmaschigen Netz an Pfarreien wurde der Inquisitionsauftrag Karls des Großen mit anderem Inhalt gefüllt. Ende des 9. Jahrhunderts belegen Quellen aus der Diözese Trier, dass der Bischof selbst die Inquisition in die Hand nahm und bei den Visitationen mit seiner Banngewalt örtliche Gerichtsversammlungen einberief, um über Vergehen gegen das Kirchenrecht vorzugehen. Dieses Sendgericht nahm durch die Vereidigung ständiger Geschworener Formen des weltlichen Gerichtsverfahrens an und konnte so den sozialen Druck auf widerspenstige Laien erhöhen.

Das Strafverfahren bei Vergehen gegen das Inzestverbot hing sowohl im Westen als auch im Osten des Frankenreichs am seidenen Faden der bischöflichen Initiative. Der Bischof musste den Pfarrklerus über das christliche Eherecht instruieren, bei Widerstand genügend machtpolitischen Rückhalt anbieten und im Notfall auch die Hilfe der weltlichen Gewalt einfordern. Nach der Herrschaft Ludwigs des Frommen versuchte nur mehr der König des Westfrankenreichs, durch Kapitularien eine Kontrolle über das Engagement der Bischöfe auszuüben. Die zahlreichen Zeugnisse der bischöflichen Gesetzgebung belegen, dass im 9. Jahrhundert dieses Engagement nicht nachgelassen hat. Sind diese Anstrengungen jedoch bei den Laien auf ein positives Echo gestoßen? Darüber können die normativen Quellen allein keinen Aufschluss geben. Die häufigen Klagen über bestehende Verwandtenehen erfüllen unterschiedliche Funktionen in der Gesetzgebung und sagen wenig über das tatsächliche Eheverhalten aus. Interessanter sind die von der Kirche angeklagten Inzestfälle. Wie in der Merowingerzeit überwiegen nicht die Ehen unter Blutsverwandten (5 Fälle), sondern unter Schwiegerverwandten (9 Fälle $)^{420}$. Erst im 11. Jahrhun-

420 Blutsverwandtschaft: Epistularum Fuldensium fragmenta 19 (MGH Epp. 5, 525); Hinkmar von Reims, Epistola synodalis (Migne PL 125, 255); Collectio Sangallensis 30 (MGH Formulae, 415 f.); Konzil von Mainz (861/863) (MGH Conc. 4, 130); Johannes VIII., Registrum 261 (MGH Epp. 7, 231 f.) (JE 3325). Schwiegerverwandtschaft: Hrabanus, Ep. 53 (MGH Epp. 5, 507 f.); Epistularum Fuldensium fragmenta 21 
dert, als die Inzestgrenze tatsächlich auf den 7. Grad kanonischer Zählweise ausgedehnt wurde, sollte sich dieses Verhältnis drastisch ändern. In dieser Zeit standen fast ausschließlich Ehen zwischen Blutsverwandten unter Anklage. Der Grad der Verwandtschaft wird nur in zwei Fällen aus dem Ostfrankenreich ausdrücklich erwähnt. Es handelt sich um den vierten Grad (4/4) bzw. um ein Verhältnis von $4 / 5^{421}$. Auch dies bestätigt die These, dass der siebte Grad kanonischer Zählweise noch nicht ins Visier der Kirche geraten war. Anders als in der Merowingerzeit spielte die Stiefverwandtschaft keine Rolle mehr. Dagegen sind drei Fälle von Eheschließungen innerhalb der geistlichen Verwandtschaft nachweisbar ${ }^{422}$.

Dieses Bild der adeligen Ehepraxis lässt sich durch genealogische Daten nur unwesentlich präzisieren. Aufgrund der Einnamigkeit sind Verwandtschaftsverhältnisse äußert selten so dicht bezeugt, dass die Vorfahren zweier Ehegatten lückenlos zurückverfolgt werden können. Selbst innerhalb der Königsdynastie gibt es Zweifelsfälle. Beispielsweise steht zwar die Verwandtschaft Karls des Kahlen mit seiner ersten Frau Ermentrude, die er am 13. Dezember 842 ehelichte, außer Zweifel. Hinkmar von Reims bezeichnet den Bruder Ermentrudes als sobrinus des Königs ${ }^{423}$. Die genaue Verwandtschaft ist jedoch dadurch nicht geklärt, weil Hinkmar den Begriff sobrinus auf verschiedene Beziehungen anwendete $^{424}$. In der Forschung sind zwei verschiedene Rekonstruktionen vorgeschlagen worden. Entweder waren Karl und Ermentrude über Karl Martell im Verhältnis 4/4 oder über den fränkischen Grafen Gerold im Verhältnis 3/4 verwandt ${ }^{425}$. In beiden Fällen wäre die Ehe von dem Fälscher Benedictus Levita nicht angegriffen worden, da er für eine Inzestgrenze von 3/3 plädierte. Zwei weitere Ehen in der Nachkommenschaft Karls des Kahlen sind ebenfalls hart an

(MGH Epp. 5, 527); Hinkmar von Reims, Ep. 136 (MGH Epp. 8/1, 89); Konzil von Metz (893) c. 11 (Mansi 18A, 80 f.); Flodoard von Reims, Historia Remensis ecclesiae III 29 (MGH SS 36, 361); Johannes VIII., Epistola dubia 3** (MGH Epp. 7, 331) (JE 3025); Stephan V., Fragmentum Registri 21 (MGH Epp. 7, 344 f.) (JL 3439); Konzil von Tribur (895) Iudicium 6 u. 7 (MGH Capit. 2, 207).

421 Siehe 363 Anm. 368 und 370 Anm. 399.

422 Konzil von Mainz (888) c. 18 (Mansi 18A, 69); Johannes VIII., Registrum 198 (MGH Epp. 7, 158 f.) (JE 3265); Konzil von Chalon (813) c. 31 (MGH Conc. 2/1, 279). Die ersten beiden Quellen werden von Jussen, Patenschaft 1991, nicht berücksichtigt.

423 Annales Bertiniani a. 866 (130).

424 Siehe 126 Anm. 60.

425 Die zweite Variante vertreten Levillain, Nibelungen 2 1938, 37 f.; Mitterauer, Markgrafen 1963, 11-13; GoCKel, Königshöfe 1971, 246 Anm. 204; Nelson, Charles 1992, 131; Le Jan, Famille 1995, 318. Sie beruht auf der fragwürdigen Gleichsetzung zweier Grafen mit Namen Odo (ablehnend: Depreux, Prosopographie 1997, 190 f.) sowie auf der nicht zweifelsfrei geklärten Beziehung zwischen Adrian (dem präsumtiven Vater Odos) und dem bayerischen Präfekten Gerold. Die erste Variante beruht ebenfalls auf genealogischen Hypothesen: Hlawitschka, Anfänge 1969, 166-168. Jackman, Konrad 2006, 80, behauptet dagegen ohne Begründung eine Verwandtschaft von 3/3. 
der Grenze des Inzestverbots geschlossen worden. Auf Befehl Karls trennte sich sein Sohn Ludwig der Stammler von seiner ersten Frau Ansgard und heiratete Adelheid, die wie Ludwigs Mutter vom Grafen Gerhard von Paris abstammte ${ }^{426}$. Die Eheleute waren im Verhältnis 4/4 verwandt. Ludwigs Sohn Karlmann nahm eine Tochter König Bosos von der Provence zur Frau, mit der er über den gemeinsamen Urahn Ludwig den Frommen im Verhältnis 3/4 verwandt $\operatorname{war}^{427}$. Die Ehen der westfränkischen Karolinger bewegten sich also genau an der Grenze des Inzestverbots. Eine Ehe im Verhältnis 3/3, die von allen Gelehrten und Bischöfen der Karolingerzeit (mit Ausnahme Hrabans) als Inzest gebrandmarkt wurde, kann nicht nachgewiesen werden ${ }^{428}$.

Dieser Befund beruht zugegebenermaßen auf einer sehr dünnen Quellenlage. Man muss jedoch berücksichtigen, dass andere Ehestrategien des Hochadels durchaus aus diesem dürftigen Quellenmaterial deutlich herausgelesen werden können. So ist oft bezeugt, dass einflussreiche Familien die Wiederholung von Eheverbindungen mit den Karolingern und untereinander gesucht haben, ohne dabei das Inzestverbot zu durchbrechen ${ }^{429}$. Diese Erneuerung von

426 Hlawitschka, Anfänge 1969, 168; Le Jan, Famille 1995, 320. Werner, Nachkommen 1967, 429-441 u. 445 f., vermutet dagegen ein Verhältnis von 2/4 über Ludwig den Frommen; BrüHL, Hinkmariana 1964, 66 und Settipani, Préhistoire 1998, 316, votieren für ein Verhältnis von 3/4 über Karl den Großen. Die Frage lässt sich nicht entscheiden, weil die Genealogien mit zu vielen Variabeln operieren, als dass man daraus eine eindeutige Folgerung für die Einhaltung des Inzestverbots ziehen könnte.

427 Werner, Nachkommen 1967 (Stammtafel); Le Jan, Famille 1995, 322 Anm. 203. Bouchard, Families 2001, 78, bestreitet die Gültigkeit der Genealogie. Sie lässt die Frau Karlmanns nicht aus der Ehe Bosos mit der Karolingerin Irmingard entstammen, sondern aus seiner ersten Ehe. Die Frage der Zuschreibung von Nachkommen, wenn mehrere Ehen hintereinander eingegangen wurden, stellt die Forschung vor ein oft nicht zu lösendes Dilemma.

428 Hier ist es angebracht auf die These von FrIED, Elite 1998, 90-95, einzugehen, nach der Pippin von Italien, Urenkel Karl Martells, eine 2/3 Ehe mit Theodrada, einer Enkelin Karl Martells, eingegangen ist. Die Ausschaltung der Linie Pippins von Italien durch Ludwig den Frommen führt Fried auf den Vorwurf der Inzestehe zurück. FrIEd, Konradiner 2006, 21: „Dies war der Anfang vom Ende des großen Karl-Reiches.“ Diese weit ausgreifenden Spekulationen beruhen einzig und allein auf Ähnlichkeiten der Namensgebung zwischen Pippins Kindern und der Familie seiner angeblichen Frau. Dem stehen jedoch mehrere Tatsachen entgegen: Thegan, Gesta Hludowici imperatoris c. 22 (MGH SS rer. Germ. 64, 210) wirft eindeutig dem Sohn Pippins, Bernhard von Italien, seine Abstammung von einer Konkubine vor, nicht die Herkunft aus einer Inzestehe; eine 2/3 Ehe wäre (entgegen der Meinung von FrIED, Elite 1998, 96) unter das von Pippin I. und Karl dem Großen erlassene Inzestverbot gefallen; das Lob, welches Radbert von Corbie über die Keuschheit und das heilige Leben der Theodrada ausschüttet [Paschasius Radbertus, Vita Adalhardi c. 33 (Migne PL 120, 1527)], ist kaum vereinbar mit der Kritik dieses charakterfesten Gelehrten an kleinmütigen Bischöfen, die sich keine Anklage von Inzestehen der Herrscher zutrauen würden: siehe 326 Anm. 178.

429 Le Jan, Famille 1995, 315-317. 
Allianzen fand zwischen den Grafen von Paris und den Karolingern, zwischen Welfen und Karolingern, Bosoniden und Karolingern, Liudolfingern und Karolingern sowie zwischen den Robertinern und den Grafen von Vermandois statt. Wie Gerd Tellenbach feststellte, war die durch Eheschließungen zum Ausdruck gebrachte Königsnähe für den Aufstieg und den Machterhalt des Hochadels wichtiger als ererbter Besitz und adelige Abkunft ${ }^{430}$. Am Hof des Königs wurde über die Verleihung der Ämter entschieden, die für die Teilhabe an der Ausübung öffentlicher Gewalt benötigt wurden. Eheschließungen mit der Herrscherdynastie waren begehrt, weil sie den Zugang zum Hof eröffneten. Das Inzestverbot verlieh dem Verhältnis von Reichsaristokratie und Königtum eine Ordnung, weil die als Inzest wahrgenommenen Verbindungen zwischen denselben Familien offensichtlich nicht praktiziert wurden. Dadurch wurde eine Dynamik entfacht, die immer wieder neuen Familien den Zugang zum Königshof ermöglichte ${ }^{431}$.

Das Beispiel Kataloniens zeigt, dass trotz der dürftigen Quellenlage auch ganz andere Verhältnisse sichtbar werden können. Diese Region am äußersten Rand des Westfrankenreichs hat sich besonders früh vom Königshof abgekoppelt und war seit der Mitte des 9. Jahrhunderts zu einem autonomen Fürstentum aufgestiegen ${ }^{432}$. Die Grafschaften Kataloniens sind seit Wifred „dem Haarigen" als Eigengut der Familie betrachtet worden, an das sowohl die Söhne als auch die Töchter Erbansprüche anmelden konnten. Diese Herrschaft einer Familie wurde durch Eheschließungen innerhalb der Verwandtschaft zementiert. Wie oft und in welchem Umfang Inzestehen geschlossen wurden, ist auch in diesem Fall wegen der Quellenarmut nur unter Vorbehalt zu rekonstruieren. Akzeptiert man die genealogischen Hypothesen d'Abadals, sind mehrfach Ehen mit der Cousine ersten und zweiten Grades eingegangen worden ${ }^{433}$. Von Martin Aurell wird sogar die Ehe zwischen Nichte und Onkel unter den Nachkommen Wifreds „des Haarigen“ für möglich gehalten ${ }^{434}$. Aurell führt diese Ehepraxis in

430 Tellenbach, Königtum 1939, 56-60.

431 Dieses Argument wird ausführlich von Bouchard, Families 2001, 13-38, entfaltet. Vgl. auch Le Jan, Famille 1995, 98.

432 D'Abadal, Comtes 1958; Vones, Geschichte 1993, 52-63.

433 Die Nachweise erbringt Aurell, Jalons 1991; Ders., Noces 1995, 35-51. Die Genealogie der katalanischen Grafenfamilien stützt sich auf die Forschungen von D'ABADAL, Comtes 1958, der alle Grafen Kataloniens von Belló von Carcassonne abstammen lässt. Skepsis äußern Engels, Abhängigkeit 1961, 37 Anm. 190; Vones-Liebenstein, Katalonien 1997, 469. Während d'Abadal seine Rekonstruktionen durch Striche in der Genealogie kenntlich macht, verschwindet bei Aurell dieser Vorbehalt.

434 Nach Aurell, Noces 1995, 46, nahm Graf Sunifred II. von Urgell die Tochter seines Bruders Sunyer I. von Barcelona, Adelaida, zur Frau. Er stützt sich auf eine Vermutung von Udina Martorell, Archivo 1951, XXII. Dieser identifizierte Adelaida, die nach dem Tod ihres Gatten Sunifred II. am 16.8.949 zur Äbtissin von Sant Joan de les Abadesses erhoben wurde, mit Adelaida Bonafilla, die als comitissa (und nicht als 
erster Linie auf die Herrschaftsstruktur zurück, die durch Matrilinearität und Samtherrschaft der Familie geprägt gewesen sei. Erst die Kirchenreform des 11. Jahrhunderts habe diese aristokratische Ehepraxis außer Kraft gesetzt und damit einen Strukturwandel in der Herrschaftsorganisation verursacht ${ }^{435}$. Da Aurell Dubys skeptische Sicht auf die Errungenschaften der karolingischen Reform teilt, ignoriert er die Sonderstellung Kataloniens innerhalb des Frankenreichs und nimmt die Brisanz dieser Frage nicht wahr. Neben dem politischen Faktor wird man deshalb auch andere Faktoren wie die Kirchenorganisation in Betracht ziehen müssen. Nach der Eingliederung der spanischen Mark in das Frankenreich unter Karl dem Großen dauerte es ein ganzes Jahrhundert, bis sich die kirchliche Organisation nach dem Zerfall während der Maurenzeit konsolidierte ${ }^{436}$. Die Grafen griffen während des 9. Jahrhunderts willkürlich in die Kirchenverfassung ein und besetzten die Bistümer mit Angehörigen aus der eigenen Familie ${ }^{437}$. Erst um 900 war die Kirchenverfassung mit der Unterordnung der katalanischen Bischöfe unter das Erzbistum Narbonne fest verankert. Einen unabhängigen Episkopat, der den Angriff auf die Inzestehen der herrschenden Dynastie hätte riskieren können, scheint es nicht gegeben zu haben.

Im Frankenreich sind solche Fälle von Ehen innerhalb der engeren Verwandtschaft nicht bezeugt. Es gibt sogar Hinweise darauf, dass die Laien die Inzestverbote in ihre Überlegungen zur Eheschließung einbezogen und die Geltung der christlichen Ehemoral für ihre Zwecke missbraucht haben. Am Konzil von Chalon (813) wurde der Fall diskutiert, dass eine Frau absichtlich die Firmpatenschaft für ihr Kind übernahm, um eine Scheidung von ihrem Mann wegen geistlicher Verwandtschaft zu erreichen. Das Ansinnen der Frau wurde von den Bischöfen zurückgewiesen. Die Frau musste ihre Ehe weiterführen und sich einer öffentlichen Buße unterziehen ${ }^{438}$. Derselbe Fall wurde auch Hrabanus Maurus von Bischof Heribald von Auxerre vorgelegt. Hraban verfügte die Trennung der Ehe und erlaubte der Frau keine weitere Eheschlie-

abatissa) am 24.6.950 eine Schenkung an dieselbe Abtei tätigte und sich als Tochter Sunyers I. bezeichnete. Die Urkunden sind ediert bei Udina Martorell, Archivo 1951, 285-290. Die Identität ist m. E. zweifelhaft.

435 Aurell, Noces 1995.

436 Vones-Liebenstein, Katalonien 1997, 502.

437 D'Abadal, Comtes 1958, 151-168 u. 261-263. Zu dem dadurch ausgelösten Widerstand des Metropoliten von Narbonne vgl. die Regesten von SchröDER, Synoden 1980; Vones-Liebenstein, Katalonien 1997.

438 Dictum etiam nobis est quasdam feminas desidiose, quasdam vero fraudulenter, ut a viris suis separentur, proprios filios coram episcopis ad confirmandum tenuisse. Unde nos dignum duximus, ut si qua mulier filium suum desidia aut fraude aliqua coram episcopo ad confirmandum tenuerit, propter fallatiam suam paenitentiam agat, a viro tamen suo non separetur. Konzil von Chalon (813) c. 31 (MGH Conc. 2/1, 279). Vgl. Hartmann, Rechtskenntnis 1992, $15 \mathrm{f}$. 
Bung ${ }^{439}$. Die Schriften des Mainzer Erzbischofs belegen auch die Manipulation des Eheverbots der Blutsverwandtschaft. In einem Brief an Humbert von Würzburg warnte er vor der Gefahr, dass bei einer Ausdehnung des Inzestverbots Ehen nachträglich unter dem Vorwand einer Verwandtschaft aufgelöst werden könnten. Ehebruch und Unzucht würden auf diese Weise vermehrt werden $^{440}$. Dasselbe Problem wurde auch in einem anonymen Bischofskapitular aus der Mitte des 9. Jahrhunderts angesprochen. Ein bayerischer Bischof ermahnte die Priester zur Überprüfung der geltend gemachten Verwandtschaft, wenn Männer versuchen sollten, mit der Begründung des Inzestverbots ihre Frauen loszuwerden. Die Verwandtschaft müsste von geeigneten Zeugen beeidet werden ${ }^{441}$. Wenige Jahre später war Hinkmar von Reims mit einem derartigen Fall direkt konfrontiert. Der Graf Stephan benutzte das Argument eines angeblichen Geschlechtsverkehrs mit einer Verwandten seiner Verlobten, um sich vor dem Vollzug der Ehe zu drücken und eine politisch nicht mehr opportune Allianz zu beenden ${ }^{442}$. Diese Beispiele beweisen eindeutig die Vertrautheit mit den Inzestverboten. Nur wenn die Verbote regelmäßig beachtet wurden, war es möglich, sie in bestimmten Fällen für andere Zwecke zu manipulieren. Dieser Befund ist nicht überraschend, bedenkt man, dass die fränkischen Bischöfe seit dem 6. Jahrhundert kontinuierlich die gleichen Inzestverbote auf Synoden einschärften, dass sowohl Merowinger wie Karolinger dieses Anliegen mit zum Teil drastischen Strafen unterstützten, dass die Bischöfe ein immenses Corpus an Vorschriften zum christlichen Eherecht für den Pfarrklerus erließen und dass auch die Bußbücher der Landpfarrer seit der Karolingerzeit das Verbot von Verwandtenehen ausführlich thematisierten ${ }^{443}$. Die Exogamie der fränkischen

439 De eo vero, quod interrogasti: Si ille, qui filiolam suam, quam de sacro fonte baptismatis suscepit, et de eo, qui concubuit cum commatre sua spirituali, et de illo, qui filium suum baptizatum, et cuius uxor eum de fonte suscepit, postea in tali copulatione permanere possent? Omnino illicitum esse iudicamus. Paenitentiale ad Heribaldum c. 20 (Migne PL 110, 486). Dieses Urteil übernahm Regino, De synodalibus causis II 197 (290). Vgl. Hartmann, Rechtskenntnis 1992, 16.

440 Siehe 311 Anm. 104.

441 De hominibus, qui abominantur uxores suas et ob hoc sanguinitate propinquitatis eam sibi dicunt esse coniunctam, ut illam possint dimittere et alteram ducere uxorem, cum qualibus testibus causa veritatis in eo negotio probetur, necessarium est inquirendum. Capitula Frisingensia tertia c. 21 (MGH Capit. episc. 3, 227).

442 ... quia non pro dolo neque pro alia qualibet causa Stephanus se a carnali copula puellae huius subtraxerit nisi pro ea, quam ipse synodo indicavit, videlicet quia cum puellae sibi desponsatae consanguinea et carnis cognatione propinqua carnaliter concubuerit. Hinkmar, Ep. 136 (MGH Epp. 8/1, 91).

$443 \mathrm{Zu}$ den Bußbüchern vgl. die Reformschriften Halitgars (siehe 298 f.) und Hrabans sowie den Quadripartitus (siehe 299 Anm. 43) und das Paenitentiale Martenianum c. 25-31 (372-375). Besonders charakteristisch ist die Entwicklung der unter den Namen Bedas und Egberts überlieferten Bußbücher. Während in den frühen Fassungen nur die engste Verwandtschaft berücksichtigt wird (siehe 315 Anm. 132), findet in späteren Stufen eine 
Reichsaristokratie, von Pippin I. und Karl dem Großen zum gesetzgeberischen Programm erhoben, galt als Unterscheidungsmerkmal zu den Verhältnissen bei den benachbarten Völkern der Bretonen und Angelsachsen ${ }^{444}$. Als im 11. Jahrhundert erneut ein Kaiser mit dem Thema des Inzestverbots Politik machen wollte, musste daher das Verbot ausgeweitet werden, um neue Inzestdelikte zu konstruieren. Durch die Ausdehnung auf den siebten Grad kanonischer Zählung gelang es Heinrich II., die Anzahl der inkriminierten Eheschließungen um ein Vielfaches zu vergrößern.

Anpassung an das fränkische Kirchenrecht statt: Die Epistola de gradibus consanguinitatis wird in einigen Handschriften des Paenitentiale additivum Ps.-Bedae-Egberti (vgl. HAGGENMÜLLER, Überlieferung 1991, 231 f.) ergänzt, und die Inzestgrenze von 3/3 wird genannt im Paenitentiale mixtum Ps.-Bedae-Egberti II 3 (686 f.); zur Entstehung in Lothringen zwischen 870 und 890 vgl. HagGenmüLLER, Überlieferung 1991, 293; Körntgen, Bußbuch 2007, 206-211.

444 Bretonen: Ermoldus Nigellus, Carmen in honorem Hludowici III v. $48-50$ (102). Angelsachsen: Johannes VIII., Ep. 75 (MGH Epp. 7, 72) (JE 3125); Flodoard, Historia Remensis ecclesiae IV c. 5 (MGH SS 36, 385); IV c. 6 (MGH SS 36, 389 f.). 


\section{Die Radikalisierung des Inzestverbots im 11. Jahrhundert}

Die Regierungszeit Kaiser Heinrichs II. (1002-1024) markiert den letzten Höhepunkt der staatlichen Verfolgung von Inzestdelikten. Im Gegensatz zu den ersten Karolingerkönigen hat er sein Engagement nicht durch den Erlass neuer Gesetze zum Ausdruck gebracht, sondern durch die an die Bischöfe adressierte Aufforderung, Inzestehen nachhaltig zu bekämpfen. Heinrich II. erkannte die alleinige Kompetenz der Kirche zur Gestaltung des christlichen Eherechts an und beschränkte seine Rolle auf die Ermutigung und Unterstützung des bischöflichen Vorgehens. Das Besondere an der Inzestpolitik unter dem letzten sächsischen Kaiser war die eminent politische Bedeutung der angeklagten Ehen. Gleich der erste Prozess, den Heinrich II. persönlich anregte, richtete sich gegen den Salier Konrad, den Sohn Herzog Ottos von Kärnten. Konrad war durch seine Ehe mit Mathilde der Schwiegersohn Hermanns II. von Schwaben, der im Kampf um die Herrscherwürde gegen Heinrich unterlegen war und deshalb zu den erklärten Feinden des Königs zählte. Der berühmteste Prozess dieser Jahre richtete sich gegen die Ehe des Konradiners Otto von Hammerstein, des letzten männlichen Nachkommens König Konrads I. Auch die Verbindung seines Nachfolgers, des späteren salischen Kaisers Konrad II., soll Heinrich unter Inzestverdacht gestellt haben. Die Verfolgung von Inzestehen richtete sich also genau gegen jene Adelsgeschlechter der Konradiner und Salier, die zu den mächtigsten Dynastien im Reich zählten und die in der Historiographie als potentielle Gegner des Königs angesehen werden. Es überrascht daher nicht, dass die Forschung seit dem Beginn des 20. Jahrhunderts den Eheprozessen Heinrichs eine politische Motivation unterstellte ${ }^{1}$. Um diese These hat sich in den letzten Jahren eine Debatte entzündet, die auch die Einschätzung Heinrichs als Herrscherpersönlichkeit berührt. Wenn tatsächlich die politischen Motive ausschlaggebend waren, scheint das Bild vom „König der Konflikte" ${ }^{\text {“2 }}$ eine deutliche Bestätigung zu erfahren. Sind jedoch religiöse Beweggründe höher einzuschätzen ${ }^{3}$, kann nicht vorausgesetzt werden, dass Heinrich die Konflikte tatsächlich provozierte.

1 Kessler, Eheprozess 1923, 64; Holtzmann, Geschichte 1941, 446; Mikoletzkry, Heinrich II. 1946, 25; KRAH, Absetzungsverfahren 1987, 343; Wolter, Synoden 1988, 273; Fried, Weg 1994, 621 f.; Weinfurter, Heinrich II. 1999, $201 \mathrm{f}$.

2 Weinfurter, Heinrich II. 2003, 108.

3 Hoffmann, Mönchskönig 1993, 55; Körntgen, Ottonen 2008, 50. 
Die Bewertung von Heinrichs Inzestpolitik ist sehr eng mit der Einschätzung des Kirchenrechts in der Zeit der Jahrtausendwende verbunden. Nur vor dem Hintergrund des Eherechts und der Ehepraxis der Zeit lässt sich beurteilen, ob Heinrichs Vorgehen als politischer Willkürakt oder als Exekution von dauerhaft etablierten Normen zu bewerten ist. Patrick Corbet widmete dem Thema des Eherechts und der Ehepraxis im Deutschland des 11. Jahrhunderts vor wenigen Jahren ein hervorragendes Buch ${ }^{4}$. Corbet untersuchte erstmals die wichtigste Kirchenrechtssammlung des 11. Jahrhunderts, das Decretum Burchards von Worms, eingehend zur Inzestproblematik und situierte es in der Rechtsentwicklung der Zeit. Aus den vielfältigen Ergebnissen der Studie soll nur das wichtigste hervorgehoben werden: Corbet gelang der Nachweis, dass die Repression des Inzests in Deutschland zwischen 1000 und 1050 in einzigartiger Weise betrieben wurde und neben der hohen Aristokratie auch den niederen Adel erfasste. Das Reich erwies sich nach Corbet als „Laboratorium der Kirchenreform" ". Nach 1050 übernahm das Reformpapsttum die im Reich erarbeiteten Normen des Eherechts, forderte ihre Einhaltung in Frankreich und England ein und brachte auf diese Weise den Primat des apostolischen Stuhls zur Geltung. Erst dann kam es auch außerhalb Deutschlands zu einer Reihe von Eherechtsprozessen, die bis zur Eindämmung des Inzestverbots durch Innocenz III. (1215) anhielt.

Der Schwerpunkt von Corbets Buch liegt auf der Entwicklung von Eherecht und Ehepraxis der ottonisch-salischen Zeit. Über das Interesse des Königs an Eheprozessen hat Corbet dagegen erstaunlich wenig zu sagen. So enthält er sich einer eindeutigen Stellungnahme zur Diskussion über die Beweggründe Heinrichs II. ${ }^{6}$ Die Beurteilung der Motive ist jedoch entscheidend, da Heinrich eine Bewegung ins Rollen gebracht hat, die in die Formierung der päpstlichen Doktrin im Jahr 1063 mündete. Im Mittelpunkt der folgenden Darstellung soll daher die Frage nach der Motivation des Herrschers stehen. Ein zweiter kritischer Punkt an der Untersuchung Corbets ist die von ihm geteilte Voraussetzung, dass bereits die Päpste des frühen 8. Jahrhunderts das Inzestverbot auf den 7. Grad kanonischer Zählung ausgedehnt hatten ${ }^{7}$. Die Reformpäpste des 11. Jahrhunderts werden durch diese Annahme zu Vollstreckern einer alten päpstlichen Doktrin, die zuerst im Ostfrankenreich des 9. Jahrhunderts rezipiert und erneut durch Burchard von Worms im 11. Jahrhundert propagiert worden sei. Diese Annahme teilen die meisten Historiker ${ }^{8}$, sie ist jedoch nach den hier

4 Corbet, Burchard 2001.

5 Corbet, Burchard 2001, 321.

6 CoRBet, Burchard 2001, 252-254, votiert vorsichtig für den Standpunkt Hartmut Hoffmanns.

7 Conbet, Burchard 2001, 320.

8 Siehe 374 Anm. 416. 
erzielten Ergebnissen nicht haltbar. Vor dem 11. Jahrhundert gibt es keine Belege für eine Ausdehnung auf den 7. Grad kanonischer Zählung. Im vorigen Kapitel habe ich plausibel zu machen versucht, dass nur im Ostfrankenreich die kanonische Zählung verwendet wurde, dort jedoch der siebte Grad als geltende Inzestgrenze nicht anerkannt war. Die Zeit Heinrichs II. erscheint folglich gegenüber Corbet in einem ganz neuen Licht: Erst seit der Jahrtausendwende wurde das Inzestverbot in genealogische Tiefen ausgedehnt, die durch mündliche Erinnerung allein nicht mehr ausgelotet werden konnten. Für die Geschichte des Inzestverbots ist die Epoche Heinrichs II. und Burchards von Worms also eine Schlüsselzeit. Erst dann erreichte die abendländische Entwicklung des Inzestverbots einen ,Sonderweg'.

Im folgenden Kapitel befasse ich mich daher mit der Frage, wie es zur Ausdehnung des Inzestverbots auf den 7. Grad kanonischer Zählung gekommen ist. Oberflächlich betrachtet erscheint diese Ausdehnung als logische Entwicklung aus der Kombination der ost- und westfränkischen Tradition: Während im Ostfrankenreich die kanonische Zählung vorherrschte, setzte sich im Westfrankenreich der siebte Grad (römischer Zählung) als Inzestgrenze durch und wurde durch die pseudoisidorischen Fälschungen als Standpunkt des Papstes ausgegeben. Als Pseudoisidor allmählich überall verbreitet war und die Autorität päpstlichen Rechts gegenüber dem karolingischen Synodalrecht an Geltung gewann ${ }^{9}$, musste es scheinbar so kommen, dass in Deutschland der siebte Grad übernommen und im Sinne der kanonischen Zählung missverstanden wurde. Dieser Schluss lag auch deshalb nahe, weil Gregor I. im Libellus responsionum ausdrücklich kanonisch zählte und die Fälschung Pseudoisidors als Replik auf den Libellus gestaltet ist. Diese Kombination führt noch heute die Forschung in die Irre. Wie jedoch das Beispiel Hinkmars von Reims belegt, konnte man trotz dieser Kombination die Fälschung Pseudoisidors (den Pseudo-Gregor Briefwechsel) vor dem Hintergrund der römischen Zählweise verstehen ${ }^{10}$. Auch im frühen 11. Jahrhundert zog Papst Benedikt VIII. nicht diese scheinbar nahe liegende Konsequenz ${ }^{11}$. Die Ausweitung des Inzestverbots in genealogische Tiefen war also keineswegs eine ,logische Entwicklung'. Im Gegenteil, im folgenden Kapitel will ich zeigen, dass ein mehr oder weniger zufälliges Zusammenspiel verschiedener Ereignisse und Umstände zu diesem Ergebnis führte. Heutige Historiker stehen perplex vor der Tatsache, dass Ehen zwischen zwei Nachfahren des Urururururgroßvaters nach dem Kirchenrecht des 11. und 12. Jahrhunderts untersagt waren. Diese Fassungslosigkeit müssen wir auch den Menschen des Mittelalters zugestehen. Eine Ausdehnung in solche entfernte

9 Zu diesem Prozess vgl. Fuhrmann, Einfluss 1972.

10 Siehe $342 \mathrm{f}$.

11 Siehe $424 \mathrm{f}$. 
Verwandtschaftsverhältnisse muss als „evolutionäre Unwahrscheinlichkeit “12 betrachtet werden.

\subsection{Der Eklat um König Robert II. von Frankreich}

Ausgangspunkt für die Inzestkampagne Heinrichs II. war der Eklat um die zweite Ehe König Roberts II. von Frankreich. Kurz nach dem Tod seines Vaters Hugo Capet heiratete Robert im Jahr 996 seine Cousine zweiten Grades Berta. Im Jahr darauf versammelte Papst Gregor V. in Pavia eine Synode und drohte dem König mit dem Entzug der Kommunion, wenn er sich nicht vor dem geistlichen Gericht wegen seiner Ehe rechtfertigen würde. Zwei Jahre später wiederholte der Papst auf einer Synode in Rom seine Drohung. Falls sich der König nicht einer siebenjährigen Buße unterwerfen sollte, würde über ihn der Bannfluch ausgesprochen. Auf dieser Synode nahm nicht nur Kaiser Otto III. teil, auch Herzog Heinrich IV. von Bayern, der spätere König und Kaiser, hielt sich im Gefolge des Kaisers in Rom auf ${ }^{13}$. Heinrich kam damals das erste Mal als Augenzeuge des spektakulären Angriffs auf die Ehe des französischen Königs mit dieser Problematik in Berührung. Seit der Merowingerzeit war keine königliche Ehe wegen Inzest angegriffen worden, seit dem 9. Jahrhundert sind in den Quellen keine Inzestprozesse mehr nachweisbar. Die Verurteilung von Roberts Ehe stellte daher in mehrfacher Hinsicht einen Neuanfang dar.

Das Spektakuläre am Fall Roberts II. hat auch die Historiker zu verschiedenen Interpretationen veranlasst. Georges Duby verwendete diesen Fall in seinem Klassiker zur Geschichte der Ehe im Mittelalter als Paradebeispiel für die Kluft zwischen adeliger Kriegermoral und christlicher Ehemoral ${ }^{14}$. Robert nahm nämlich nicht nur seine Blutsverwandte Berta zur Frau, die mit ihm überdies in geistlicher Verwandtschaft verbunden war, er verstieß auch sonst auf verblüffende Weise gegen die christliche Ehemoral. So ließ er sich ohne angemessenen Grund von seiner ersten Ehefrau Rozala/Susanna scheiden und löste einseitig die Ehe mit Berta auf, nachdem auch sie nicht den erwarteten Thronerben in die Welt gesetzt hatte. Seine dritte Frau Konstanze stellte er hart auf die Probe, als er die Rückkehr zu seiner zweiten Frau erwog und aus diesem Grund nach Rom pilgerte, um eine Ehedispens zu erhalten. $\mathrm{Zu}$ guter Letzt war er nach der Auffassung Dubys mit allen drei Frauen innerhalb der verbotenen Grade blutsverwandt. Aus diesen Tatsachen zog Duby den Schluss, dass in der Welt des Adels Eheschließungen vollständig politischen Nützlichkeitserwägungen unter-

12 Luhmann, Gesellschaft 1998, 413.

13 Hirsch, Jahrbücher 1 1862, 183; BöHmer - Uhlirz, Regesta Imperii II/3, 704, Nr. 1300.

14 Duby, Chevalier 1981, 83-93. 
geordnet wurden. Das Kirchenrecht habe erst Wirkung gezeigt, als das Reformpapsttum im späten 11. Jahrhundert eine universale Ausstrahlungskraft christlicher Normen herbeiführte.

Dubys Konfrontation zweier unterschiedlicher Moralvorstellungen setzt einen ursprünglich germanisch-heidnischen Hintergrund der aristokratischen Lebenswelt voraus und stellt das Christentum in Konfrontation zu dieser Lebenswelt. Dieses Modell ist, wie ich in der Einleitung ausgeführt habe, zu schematisch, um der Komplexität der kirchlichen Normsetzung im Frühmittelalter gerecht $\mathrm{zu}$ werden ${ }^{15}$. Das Prinzip der Unauflösbarkeit der Ehe, das Robert II. offen missachtete, ist vom fränkischen Klerus selbst erst im 8. Jahrhundert auf der Initiative karolingischer Herrscher und ihrer kirchlichen Berater akzeptiert worden. Noch im berühmten Eheprozess Lothars II. stützte sich die Partei des scheidungswilligen Königs auf eine großzügige Auslegung der entsprechenden Bibelstellen ${ }^{16}$. Dieser Partei gehörten führende Bischöfe wie der Erzbischof von Köln an. Dass um 1000 die Durchsetzung des Prinzips der Unauflösbarkeit der Ehe auf Widerstand stieß, war also Folge des allmählichen dogmatischen Klärungsprozesses innerhalb der Kirche. Wie die ambivalente Position Burchards von Worms zeigt ${ }^{17}$, war dieser Prozess selbst im Kirchenrecht noch nicht abgeschlossen. Erst nach der Formierung des wissenschaftlichen Kirchenrechts gelang es dem Papsttum, das Prinzip der Unauflösbarkeit theoretisch zu verankern und praktisch durchzusetzen. Die historisch und interkulturell einzigartige Verbindung von Monogamie und Unauflösbarkeit hatte nur deshalb Erfolg, weil die Eheschließung seit dem Hochmittelalter dem Konsens der Ehepartner und nicht der Entscheidung der Eltern oder Verwandten überlassen wurde ${ }^{18}$. Somit konnte die Unauflösbarkeit von den Laien als Selbst-Bindung verstanden werden, die symbolisch mit der Bindung Gottes an den Menschen oder des Bischofs an seine Kirche gleichgesetzt wurde.

Das Inzestverbot ist in seiner historischen Entfaltung nicht mit der Geschichte des Prinzips der Unauflösbarkeit der Ehe vergleichbar. Die Normen waren im Frankenreich seit dem 6. Jahrhundert konstant geblieben und trafen nicht auf fundamentalen Widerstand der Laien. In der Frage des Inzestverbots lässt sich eine Konfrontation zwischen adeliger und kirchlicher Moral nicht aufrechterhalten. Die Einordnung der Eheaffäre Roberts II. in den Kontext des 10. Jahrhunderts wird dies unter Beweis stellen.

15 Siehe 7-9. Deutliche Kritik an Duby äußert BRooke, Idea 1989, 126-143.

16 Siehe 350 Anm. 296.

17 Hartmann, Eherecht 2000. Zu Reginos Standpunkt vgl. Ubl, Doppelmoral 2007.

18 D'Avray, Marriage 2005, 74-130. 
Ein Blick ins Dunkel des 10. Jahrhunderts

Die Quellenarmut des 10. Jahrhunderts macht es besonders schwierig, sich einen Überblick über Eherecht und Ehepraxis dieser Zeit zu verschaffen. Es fehlt ein Chronist wie Gregor von Tours oder Thietmar von Merseburg, der abseits von hochpolitischen Ereignissen auch Anekdoten aus dem Alltag des Adels berichtet. Ferner ist die synodale Gesetzgebung viel lückenhafter als in der Karolingerzeit. Besonders im Westfrankenreich markiert das Konzil von Trosly im Jahr 909 den Endpunkt der karolingischen Reformbestrebungen innerhalb der Kirche ${ }^{19}$. Unter der Leitung des Erzbischofs von Reims wurden in Trosly nochmals in wenigen, aber desto weitschweifigeren Kapiteln die grundlegenden Forderungen der Kirchenreform in Erinnerung gerufen. Auch das Inzestverbot und die Forderung nach Öffentlichkeit der Eheschließung schärften die Bischöfe der Reimser Kirchenprovinz nochmals ein ${ }^{20}$. Wenig später hat ein in Trosly anwesender Bischof diesen Kanon in der diözesanen Gesetzgebung erneut zur Geltung gebracht ${ }^{21}$. Die Forderung nach Öffentlichkeit der Eheschließung und nach einer vorehelichen Kontrolle der Verwandtschaft blieb also in Reims Anfang des 10. Jahrhunderts im Bewusstsein. Nach Trosly hat jedoch bis in die Zeit Roberts II. keine Synode Kanones erlassen. Die synodale Gesetzgebung war vollkommen versiegt. Dies wird man wohl nicht allein auf den Rückgang der Schriftlichkeit im Allgemeinen, sondern besonders auf das nachlassende Engagement des Königs zurückführen ${ }^{22}$. Das 10. Jahrhundert stand im Zeichen der Konsolidierung der großen Fürstentümer, die dem König nur wenig Spielraum zur Machtentfaltung ließen ${ }^{23}$. Die Einberufung einer bedeutenden Anzahl von Bischöfen war ihm nicht mehr möglich. Reichssynoden unter der Leitung des Königs fanden überhaupt nicht statt, meist nahmen nur eine Handvoll Bischöfe an den mit konkreten Angelegenheiten des kirchlichen Lebens befassten lokalen Kirchenversammlungen teil. Die Zersplitterung in Fürstentümer führte zur Schwächung der westfränkischen Kirche als handelnder Institution ${ }^{24}$.

Anders waren die Verhältnisse im Ostfrankenreich ${ }^{25}$. Die Führungsstellung von Mainz und die Macht der im Vergleich zum Westen großräumigen Diözesen ermöglichte eine Fortführung der karolingischen Reformbestrebungen.

19 Schmitz, Konzil 1977; SchröDEr, Synoden 1980, 189-197.

20 Konzil von Trosly (909) c. 8 (Mansi 18, 287). Der Kanon ist identisch mit Benedictus Levita 3, 179 (MGH LL 2/2, 113).

21 Capitula Trosleiana c. 3 (MGH Capit. episc. 3, 144). Eine ähnliche Bestimmung aus der Kirchenprovinz Reims (um 900) enthält Capitula Ottoboniana 13 (MGH Capit. episc. 3, 126).

22 Schröder, Synoden 1980, 90-92; Hehl, Synoden 2007, 141.

23 DhOndt, Naissance 1948; Werner, Ursprünge 1989, 464-470.

24 Kaiser, Bischofsherrschaft 1981, 631; Parisse, Princes 1991, 501-508, spricht von der Apathie der südfranzösischen Bischöfe im 10. Jahrhundert.

25 Wolter, Synoden 1988; BüHrer-Thierry, Évêques 1997, 71-138. 
Zudem gelang es Otto I. den Herzögen die Verfügungsgewalt über die Bistümer zu entziehen und das Bischofsamt auf den König auszurichten. Die Einheit der Reichskirche blieb somit erhalten ${ }^{26}$. Die Rekrutierung einer beträchtlichen Zahl von Bischöfen aus der königlichen Hofkapelle und der Zugriff des Königs auf die Ressourcen der Kirche führten zu dem, was in der Forschung als ottonischsalisches Reichskirchensystem beschrieben wird ${ }^{27}$. Unter dem Schutz des Königs entfaltete die Kirche eine rege synodale Tätigkeit im 10. Jahrhundert und erließ Bestimmungen in der Tradition der Karolingerzeit.

Die Kontinuität zur karolingischen Kirchenreform äußerte sich auch in dem Erlass von Inzestbestimmungen. In der ersten Jahrhunderthälfte wurde auf drei von fünf Synoden das Thema der Verwandtenehen angesprochen ${ }^{28}$. Das Konzil von Koblenz ist im Jahr 922 von Heinrich I. gemeinsam mit Karl dem Einfältigen einberufen worden und versammelte Bischöfe aus der Kölner und Mainzer Kirchenprovinz. Entscheidenden Einfluss auf die Bestimmungen übte Erzbischof Heriger von Mainz aus ${ }^{29}$. Die ersten beiden Kanones sind dem Thema des Inzests gewidmet und wiederholen die Mainzer Bestimmungen des Jahres 813. Ehen bis zum vierten Verwandtschaftsgrad sowie zwischen Personen, die eine geistliche Verwandtschaft verbindet, werden strikt untersagt. Im Unterschied zur Vorlage betonten die Bischöfe ausdrücklich, dass dieser Beschluss „höchst notwendig“ sei und „im Augenblick wegen der überaus häufigen Missachtung" besonders in Erinnerung gerufen werden müsse ${ }^{30}$. Mangels Quellen lässt sich die Berechtigung dieser Klage nicht verifizieren, sie verleiht jedoch dem Engagement der Bischöfe deutlichen Ausdruck. Sie wiederholten nicht bloß einen alten und anerkannten Kanon, sie stellten ihn mit Nachdruck in das Zentrum der Kirchenversammlung.

Diese Nachdrücklichkeit ist auch bei den anderen beiden konziliaren Inzestbestimmungen festzustellen. Auf einer Trierer Provinzialsynode wurde die Ehe zwischen verschwägerten Personen sowie in der Blutsverwandtschaft verboten und eine Buße von neun Jahren verhängt ${ }^{31}$. Während die Bestimmung zur Schwiegerverwandtschaft auf die vom Trierer Erzbischof durchgehend be-

26 Vgl. Laudage, Otto I. 2001, 253-259.

27 Vgl. Santifaller, Geschichte 1964; Reuter, System 1982; Fleckenstein, Problem 1985; Schieffer, Ort 1998; Körntgen, Ottonen 2008, 30-32.

28 Beiseite gelassen werden die bayerischen Konzilien, die nur wenige Kanones erließen.

29 Hent, Einfluss 1991, $123 \mathrm{f}$.

30 ... inter caetera quae statuerunt hoc maxime necessarium et instanti, pro dolor, tempore per abusionem frequentissimum cognationis incestum summa cautela vitandum firmaverunt. Hoc est, ne ullus christianus infra quintam generationem nuptias copulare praesumat. Konzil von Koblenz (922) c. 1 (MGH Conc. 6, 68 f.).

31 Qui cum duabus sororibus dormierit, VIIII annos peniteat inter excommunicatos. Similiter mulier, quae duobus fratribus nupserit. Si quis consanguineam suam vel quam consanguineus acceperit in uxorem, separentur. Konzil von Trier (927) c. 24 (MGH Conc. 6, 87). 
nutzte Vorlage zurückgeht, findet sich der Kanon zur Blutsverwandtschaft nicht in der Vorlage. Er entstammt der eigenen Initiative des Bischofs, ebenso wie der neuartige Nachsatz über das Verbot der Opfergabe und des Friedenskusses für Inzestuöse $^{32}$. Im Unterschied zu Koblenz berief man sich in Trier auf das kategorische Verbot von Verwandtenehen, wie es die Päpste im 8. Jahrhundert formuliert hatten. Dieses kategorische Verbot wurde auch auf der vielleicht bedeutendsten Synode des 10. Jahrhunderts erlassen, auf der Synode von Ingelheim im Jahr 948. In Ingelheim versammelten sich auf Befehl Ottos I. und Ludwigs IV. alle fünf Erzbischöfe Deutschlands, der Erzbischof von Reims, 26 Bischöfe sowie der päpstliche Legat Bischof Marinus von Bomarzo. Am ersten Tag der Synode wurde nach dem Bericht Flodoards von Reims um die Regelung des Streites um die Reimser Bischofswürde gerungen. Als es auf den restlichen Tagen um kirchliche Angelegenheiten ging, führt Flodoard an erster Stelle Bestimmungen über Inzestehen $\mathrm{an}^{33}$. Obwohl diese erst am Ende der Kanones stehen $^{34}$, nehmen sie in der Wahrnehmung des Zeitgenossen die erste Stelle ein.

Während man sich in Koblenz an der Mainzer Tradition orientierte, diente in Trier und Ingelheim das kategorische Verbot der Päpste als Vorlage. Im Unterschied zu Corbet möchte ich dies nicht als „Verhärtung“ bezeichnen ${ }^{35}$. Schließlich ist nichts darüber bekannt, wie Ruotger von Trier und die in Ingelheim versammelten Bischöfe das Verbot von Ehen, „so weit die Folge der Abstammung erinnert werden kann", interpretierten. Zudem beweist das Beispiel Reginos von Prüm, dass beide Positionen nicht unbedingt als Gegensatz wahrgenommen werden mussten. Das kategorische Verbot hatte jedenfalls den Vorteil, dass sich die aus unterschiedlichen Traditionen stammenden Bischöfe nicht auf einen bestimmten Grad einigen mussten. Da in Reims seit den Zeiten Hinkmars der siebte Grad als Inzestgrenze fest verankert war, wäre eine Einigung in Ingelheim nur schwer zustande gekommen. Das kategorische Verbot stellte die Eintracht zwischen den ost- und westfränkischen Bischöfen her und konnte auch mit der Zustimmung des anwesenden päpstlichen Legaten rechnen.

Die konziliare Gesetzgebung im Reich der Ottonen stellt die Geltung der karolingischen Normen unter Beweis. Sie wurden sowohl von der Geistlichkeit

32 Quod si noluerint, excommunicentur; et quousque sunt insimul, eorum oblatio in ecclesia non recipiatur nec osculentur a christianis. Quod si penitere voluerint, VIIII annos peniteant. Konzil von Trier (927) c. 24 (MGH Conc. 6, 87).

33 Ceteris quoque diebus synodi tractata sunt quaedam necessaria de incestis coningiis et aecclesiis quae praesbiteris in partibus Germaniae dabantur, immo vendebantur indebite ... Flodoard, Annales a. 948 (115).

34 Omnimodis postmodum caveatur, ne aliquis christianus de propria cognatione uxorem ducat, sed huiusmodi copulam tamdiu fugiat, quoadusque series generationis recordari potest. Konzil von Ingelheim (948) c. 12 (MGH Conc. 6, 162).

35 Conbet, Burchard 2001, 57. 
als auch von den Herrschern nachdrücklich eingefordert. Die Ehepraxis dieser Zeit ist dagegen ungleich schwerer zu erhellen ${ }^{36}$. Aufgrund fehlender Nachrichten bleiben die Verwandtschaftsbeziehungen der in den Quellen genannten Führungsschicht des Reichs in den meisten Fällen im Dunkeln ${ }^{37}$. Nur für die Königsdynastie selbst ist die Einhaltung der kirchlichen Normen festzustellen. Hatte noch der erste König aus der sächsischen Dynastie seine Frau, eine verschleierte Witwe, verstoßen und zu ihren Lebzeiten nochmals geheirate ${ }^{38}$, machte sich Otto I. keiner Verfehlung gegen das Eherecht schuldig. Das voreheliche Konkubinat mit einer Slawin, aus dem der spätere Erzbischof Wilhelm von Mainz entstammte, war durchaus mit den von Regino überlieferten Normen vereinbar ${ }^{39}$. Seine zweite Frau Adelheid von Burgund heiratete er erst nach dem Tod seiner ersten Frau Edgitha, einer angelsächsischen Prinzessin. Diese Verbindung mit ausländischen Königstöchtern lässt auf die Absicht schließen, eine Verwandtenehe innerhalb des fränkisch-sächsischen Adels zu vermeiden. Für die Heirat seines Sohnes Otto II. ist dies durch Quellen bezeugt. Die Annalen von Magdeburg berichten, dass der Kaiser seinen Sohn mit der Nichte des byzantinischen Kaisers verheiratete, weil er keine standesgemäße Frau im Okzident habe finden können, die nicht mit ihm verwandt gewesen $\operatorname{se}^{40}$. Die

36 Den Fall einer Verurteilung wegen Inzest hat Fried, Prolepsis 1995, 103-105, hinter drei Urkunden Ottos I. (MGH D O I. 331-333) erkannt. Eberhard und Konrad, vermutlich aus der Familie der Konradiner, werden als enterbt (exheredes et inlegales) und als non legitimi bezeichnet. Corbet, Burchard 2001, 188, akzeptiert diese Deutung. Ebenso möglich ist die Annahme unehelicher Geburt (Köpke - Dümmler, Otto 1876, 409). Vgl. Regino, De synodalibus causis I 427-429 (193 f.); Kasten, Chancen 2002.

37 Wie Corbet, Burchard 2001, 224, möchte ich in der Kontroverse um Arnim Wolfs „Richlind“-These Neutralität bewahren. Wäre diese These stimmig, hätte es mehr Inzestehen um das Jahr 1000 gegeben. Vgl. Wolf, Königskandidatur 1991; DERs., Kontroverse 1995. Die These lässt sich jedoch weder einwandfrei nachweisen noch durch Quellen widerlegen. Vgl. Althoff, Thronbewerber 1989; Settipani - Poly, Conradiens 1996. Weitere Ehen unter nahen Verwandten, die JACKMAN, Eherecht 1995, glaubhaft machen will, sind m.E. zu Recht von Hlawitschka, Konradiner-Genealogie 2003, in Zweifel gezogen worden. Zuletzt äußerte sich Fried, Konradiner 2006, und verteidigte die Position Wolfs und Jackmans.

38 Thietmar von Merseburg, Chronica I 5 (MGH SS rer. Germ. N.S. 9, 8).

39 Zum Eheleben Ottos vgl. Laudage, Otto 2001, 24. Das voreheliche Konkubinat ist erlaubt nach dem 1. Konzil von Toledo (400) c. 17 (Hispana 3, 336) bei Regino, De synodalibus causis II 99 (252). Vgl. Esmyol, Geliebte 2002, 84-92.

40 Otto Romanorum imperator augustus filio suo unice dilecto Ottoni, agnomine Rufo, hisce regionibus nullam tantae copulationi dignam nisi in sua cognatione, cui nequaquam iungi licebat, repperiri non nesciens feminam, Greciam misit ... Annales Magdeburgenses a. 972 (MGH SS 16, 152). Die Quelle schöpfte an dieser Stelle vermutlich aus den gut informierten Quedlinburger Annalen: Martina Giese, Einleitung (MGH SS rer. Germ. 62). Dass das Inzestverbrechen zur Diffamierung gut geeignet war, bezeugt die Invektive gegen Johannes XII. in Liutprand von Cremona, De Ottone rege c. 12 (CCM 
Unterwerfung unter das christliche Eherecht war also ein Bestandteil der Politik Ottos des Großen. Sie sicherte den Anspruch des Herrschers ab, die Gewalt über die Reichskirche geltend zu machen und eine Mittlerstellung zwischen der Kirche und dem Volk einzunehmen ${ }^{41}$.

Für das entstehende Frankreich lässt sich mehr über die Ehepraxis aussagen. Dubys These einer Konfrontation von adeliger und christlicher Ehemoral hat eine Kontroverse zwischen Constance Bouchard und Régine Le Jan ausgelöst. Bouchard zog die Ehen der Nachkommen des Grafen Otto-Wilhelm von Burgund heran, um die Anerkennung der christlichen Inzestregeln beim hohen Adel zu belegen ${ }^{42}$. Im 10. und 11. Jahrhundert seien Ehen nur im 5. und 6. Grad kanonischer Zählung geschlossen worden. In diesen Fällen müsse man den Adeligen Unwissenheit unterstellen, weil in der damaligen Zeit noch keine ausreichenden Informationen über die genealogische Herkunft verfügbar gewesen seien. Der Adel hat sich nach Bouchard keine Verstöße gegen das Eherecht leisten können, da Eheschließungen für die strategische Positionierung eines Adelsgeschlechts viel zu wichtig waren, als dass man sie den Anfeindungen der Bischöfe aussetzen wollte. Diesem Befund ist von Régine Le Jan widersprochen worden, indem sie eine Reihe von Ehen innerhalb des 7. kanonischen Grades während des 10. Jahrhunderts namhaft machen konnte ${ }^{43}$. Bouchard zieht in ihrem jüngsten Beitrag die Rekonstruktion der in Frage stehenden Ehen in Zweifel und hält an ihrer Position fest ${ }^{44}$.

Vor dem Hintergrund der in Kapitel 6 erbrachten Ergebnisse erweist sich diese Kontroverse als überflüssig. Die Inzestgrenze des 7. Grades kanonischer Zählung gab es im Frankreich des 10. Jahrhunderts nicht, und deshalb sind auch die Ehen innerhalb dieser Grenze nicht als Verstöße gegen die christliche Moral und als Äußerung des adeligen Kriegerethos zu werten ${ }^{45}$. Zu fragen bleibt trotzdem, inwieweit die karolingischen Normen Eingang in die Wirklichkeit gefunden haben. Ich werde dafür nur solche Verwandtschaftsverhältnisse heranziehen, die durch die Quellen mit hinreichender Eindeutigkeit benannt werden ${ }^{46}$. Dieser Schritt ist unbedenklich, weil es auch unter den umstrittenen

156, 177); c. 15 (CCM 156, 179). Zum Hintergrund der Ehepolitik der Ottonen vgl. jetzt Lubich, Verwandtsein 2008, 206-216.

41 Mit unterschiedlicher Akzentuierung: Leyser, Herrschaft 1984, 124-173; Keller, Grundlagen 1985, 30-33; SCHiEfFER, Mediator 1998; KöRntgen, Königsherrschaft 2001; ERKens, Herrschersakralität 2006, 157-189.

42 Bouchard, Consanguinity 1981.

43 Le Jan, Famille 1995, 313-327.

44 Bouchard, Families 2001, 39-58.

45 Zum großen Teil wertlos ist deshalb der auf dieser Grundlage aufbauende Aufsatz von BruguiÈre, Law 1992.

46 LE JAN, Famille 1995, 319, erwähnt z. B. die Ehe Berengars „von Lomme“ im Verhältnis 3/4. Die Herkunft Berengars ist jedoch umstritten; Werner, Nachkommen 1967, listet ihn nicht unter den Nachkommen Ludwigs des Frommen auf. 
Fällen keine Ehe gibt, die wie die Ehe Roberts II. im dritten Grad kanonischer Zählung geschlossen wurde. Man kann also schon vorweg die Folgerung ziehen, dass die von führenden Kirchenpolitikern des 9. Jahrhunderts erhobenen Forderungen beim hohen Adel auf Akzeptanz gestoßen sind. Innerhalb der römisch-rechtlich definierten Verwandtschaft (bis 3/3) wurde nicht geheiratet. Dieser Befund kann nicht überraschen, da diese Norm bereits seit dem frühen 6. Jahrhundert durch die vielfältigen pastoralen Anstrengungen der Kirche in der adeligen Bevölkerung verankert war.

Einer Inzestehe am nächsten kam die Heirat des Grafen Boso in den zwanziger Jahren des 10. Jahrhunderts ${ }^{47}$. Boso, ein politisch „höchst unruhiger Geist $^{\text {“48 }}$, war der jüngere Bruder des seit 923 amtierenden Königs des Westfrankenreichs Rudolf und Nachkomme der sogenannten Bosoniden ${ }^{49}$. Er heiratete eine Frau namens Berta, die man mit guten Gründen als Tochter des Grafen Boso von Arles identifiziert ${ }^{50}$. Sie ist daher ebenfalls der Familie der Bosoniden zuzuordnen. Ihr gemeinsamer Stammvater ist der Graf Boso des 9. Jahrhunderts, der es geschafft hatte, seine eigene Familie eng mit den westfränkischen Karolingern zu verschwägern. Die Verwandtschaft zwischen den Eheleuten beläuft sich auf 3/4, d. h. genau auf den 7. Grad römischer Zählung. Nur eine weitere bekannte Ehe ist in einer ähnlich nahen Verwandtschaft geschlossen worden. Etwa zur selben Zeit wie Graf Boso heiratete der Graf Karl Konstantin eine Frau mit Namen Theutberga. Vieles spricht dafür, in Theutberga eine Urenkelin König Lothars II. zu sehen ${ }^{51}$. Karl Konstantin war der Sohn Kaiser Ludwigs III. und stammte vom Bruder Lothars, Kaiser Ludwig II., ab. Die Ehepartner waren daher im Verhältnis $4 / 4$ verwandt. Eine weitere Ehe dieser Jahre (ca. 936), diejenige zwischen Berengar II. und Willa, war um einen Grad entfernter $(4 / 5)^{52}$.

Insgesamt lassen sich also nur drei Ehen rund um den vierten Grad kanonischer Zählung namhaft machen. Weiter entfernt geschlossene Ehen waren dagegen häufiger. Zum Beispiel haben die Grafen von Flandern, selbst Abkömmlinge der Karolinger, im 10. Jahrhundert zweimal andere Nachfahren des Herrschergeschlechts geheiratet, die im 5. und 6. Grad kanonischer Zählung

47 Zur Datierung vgl. Werner, Nachkommen 1967, 466.

48 BrüHL, Deutschland 1990, 441.

$49 \mathrm{Zu}$ den Bosoniden vgl. Bouchard, Families 2001, 74-97.

50 Vgl. Liutprand von Cremona, Antapodosis 5, 31 (CCM 156, 142). Vgl. Werner, Nachkommen 1967, 466; BRÜHL, Deutschland 1990, 441; Le Jan, Famille 1995, 319. Ohne Begründung lehnt Bouchard, Families 2001, 212, die Identifikation ab.

51 Die Identifikation beruht auf der Übertragung von Leitnamen: Werner, Nachkommen 1967, 464. Zustimmend Le Jan, Famille 1995, 321; ablehnend Bouchard, Families 2001,82 u. 212.

52 Werner, Nachkommen 1967 (Stammtafel). 
entfernt waren ${ }^{53}$. Dasselbe trifft nach Bouchard für die Nachkommen OttoWilhelms von Burgund zu. Trotz der geringen Zahl an Beispielen lässt sich eines mit Sicherheit festhalten: Im Rahmen der adeligen Heiratspraxis des 10. Jahrhunderts war die Ehe zwischen Robert II. und Berta eine Ausnahme. Der Eklat war nicht unbegründet.

König Robert II. und die Frauen

Bevor ich mich den Frauen König Roberts zuwende, muss zunächst ein Quellenproblem benannt werden. Die Details der Eheschließungen lassen sich nicht mit hinreichender Eindeutigkeit klären, da die wichtigste Quelle, die Lebensbeschreibung Roberts durch Helgaud von Fleury, einen bedeutenden Makel hat: Helgaud nimmt den Eklat um Roberts doppelten Inzest zum Anlass, die gesamte Vita im Sinne einer Bekehrung des sündhaften Königs zu stilisieren ${ }^{54}$. Im Zentrum der Vita begegnet er der Kritik an der Inzestehe mit dem Entwurf einer zukunftsweisenden Herrschaftstheologie. Deren Kern ist die Aussage, dass der König keinen Gesetzen unterworfen ist, aber freiwillig in sich den sündhaften Menschen wahrnimmt und in Demut seine Sünden bekennt, ohne sich einer kirchlichen Autorität unterwerfen zu müssen. Helgaud lässt den König wie den biblischen David durch die Abkehr von der Sünde einer besonderen göttlichen Gnade teilhaftig werden ${ }^{55}$. Diese Herrschaftstheologie zwingt Helgaud, einige für seine Geschichtsklitterung unangenehme Details aus seiner Darstellung zu verbannen. Der moderne Historiker ist nur zu gerne dazu bereit, diese Lücken mit Verdächtigungen und Vermutungen über, eigentliche` Motive zu füllen. Bei Georges Duby wird hinter der Fassade des frommen Königs die adelige Kriegermoral enthüllt ${ }^{56}$. Doch kann man angesichts der einseitigen Quellen überhaupt zum ,wahren' Charakter des Königs vordringen?

Roberts Eheaffären beginnen mit der Wahl seines Vaters Hugo Capet zum König von Frankreich im Jahr $987^{57}$. Den wichtigsten Helfer bei der Abkehr von der Dynastie der Karolinger fand Hugo in Erzbischof Adalbero von Reims. Ihm konnte er noch im selben Jahr das Zugeständnis abringen, seinen Sohn Robert zum Mitkönig zu krönen und dadurch die Grundlage für eine dynastische Erbfolge zu legen. $\mathrm{Zu}$ diesem Zeitpunkt musste die Frage nach einer Verheiratung des Sohnes aufkommen. Hugo erbat sich vom Erzbischof ein

53 Graf Arnulf I. von Flandern und Adela von Vermandois sind im Verhältnis 5/6, Graf Arnulf II. von Flandern und Rozala im Verhältnis 6/5 verwandt: vgl. Werner, Nachkommen 1967 (Stammtafel); Le Jan, Famille 1995, 326.

54 Carozzi, Vie 1980.

55 Hamilton, Model 1997.

56 Duby, Chevalier 1981, 83-93.

57 Lot, Hugues 1903, 1-30; BRÜHL, Deutschland 1990, 589-596; Ehlers, Kapetinger $2000,29-31$. 
Schreiben an den Kaiser in Byzanz. Adalbero delegierte die Abfassung des Briefes an den Leiter der Reimser Schule Gerbert von Aurillac, den bedeutendsten Gelehrte seiner Zeit. Hugo Capet verfolgte mit dem Brief das Ziel, um eine Gemahlin aus der kaiserlichen Familie für den Thronfolger Robert zu werben. Als Begründung für dieses Ansinnen nannte Gerbert im Namen Hugos die Tatsache, dass alle Herrscherhäuser im Abendland mit der französischen Königsfamilie verwandt wären und dass deshalb keine standesgemäße Partnerin gefunden werden könnte ${ }^{58}$. Gleichzeitig versuchte Gerbert, die Kapetinger als neue Bündnispartner des Kaisers ins Spiel zu bringen, weil sie anders als die Ottonen nicht die Grenzen des byzantinischen Reichs in Italien gefährden würden.

Diese Heiratsallianz zwischen Frankreich und Byzanz wurde nicht realisiert. Außer dem in der Sammlung Gerberts überlieferten Brief sind keine Nachrichten über dieses Projekt überliefert. In der Geschichtsschreibung überwiegen daher die Zweifel, ob der Brief jemals im Zuge einer Gesandtschaft in den Osten expediert worden ist ${ }^{59}$. Pierre Riché stellt überhaupt die Ernsthaftigkeit des Projekts in Frage und schreibt die Initiative eher dem klerikal gelehrten Umkreis des Königs als dem König selbst $\mathrm{zu}^{60}$. Bouchard wies dagegen auf die enge Verwandtschaft der Kapetinger mit allen anderen abendländischen Königshäusern hin, so dass eine Ehe jenseits der verbotenen Grade tatsächlich ausgeschlossen war $^{61}$. Für die Ernsthaftigkeit des Briefes spricht auch eine frappierende Übereinstimmung: Auch die Ottonen haben u.a. deshalb eine Heirat mit dem byzantinischen Kaiserhaus angestrebt, weil die Regeln von Isogamie und Exogamie sonst nicht in Einklang gebracht werden konnten ${ }^{62}$. Das Inzestverbot spielte also bei der Suche nach einem geeigneten Heiratspartner durchaus eine wichtige Rolle.

Nach dem gescheiterten Heiratsprojekt mit Byzanz erwählte Hugo die Witwe des jüngst verstorbenen Grafen Arnulf II. von Flandern als Frau für seinen Sohn ${ }^{63}$. Sie trägt in den Quellen die Namen Rozala bzw. Susanna und war Tochter König Berengars II. von Italien. Hugo gelang es, eine Königstochter zu finden und damit an die isogame Ehepraxis der abgesetzten Karolingerdynastie anzuschließen ${ }^{64}$. Zudem barg die Ehe die Aussicht auf Kontrolle der

58 ... quoniam est nobis unicus filius et ipse rex, nec ei parem in matrimonio aptare possumus propter affinitatem vicinorum regum, filiam sancti imperii praecipuo affectu quaerimus. Gerbert von Aurillac, Ep. 111 (MGH Briefe d. dt. Kaiserzeit 2, 139).

59 Vgl. den Kommentar zur MGH Edition sowie BRüHL, Deutschland 1990, 597.

60 Riché, Gerbert 1989, 67.

61 Bouchard, Families 2001, 46. Zustimmend Woll, Königinnen 2002, 50.

62 Siehe 392 Anm. 40.

63 Die Fakten bei Pfister, Robert 1885, 41-69.

64 Hartmut Hoffmann hält den von Richer von Reims, Historiae IV 11 (MGH SS 38, 238) kolportierten Vorwurf gegen Karl von Lothringen, er habe keine standesgemäße Frau 
autonomen Grafschaft Flandern und war politisch von hohem Nutzen. Der einzige Nachteil bestand darin, dass Susanna ungefähr doppelt so alt war wie ihr Ehemann. Robert konnte sich daher mit dieser Ehe nicht abfinden und verstieß seine Frau nach einigen Jahren aufgrund ihres Alters ${ }^{65}$. Zweifellos war diese Scheidung nicht mit dem Kirchenrecht vereinbar. Der Zeitgenosse Richer von Reims verlieh den Kritikern der Zeit seine Stimme ${ }^{66}$. Der König zeigte sich von der Kritik nicht beeindruckt. Seine Missachtung des Kirchenrechts ging jedoch nicht so weit, dass er bereits in seiner ersten Ehe gegen das Inzestverbot verstoßen hätte. Duby meint, eine Verwandtschaft zwischen Robert und Rozala im 6. Grad kanonischer Zählung feststellen zu können, und sieht sich deshalb veranlasst, die Bemühungen um die Vermeidung von Inzestehen durch die Kapetinger grundsätzlich in Zweifel zu ziehen ${ }^{67}$. Der 6. Grad kanonischer Zählung fiel allerdings, wie nochmals wiederholt werden muss, nicht innerhalb des in Frankreich anerkannten Inzesttatbestands.

Im Oktober 996 starb Hugo Capet. Damit erlangte Robert II. die Freiheit der Partnerwahl. Er nahm sie sofort in Anspruch und heiratete Berta, die Witwe des mächtigen Grafen Odo von Blois und Tochter König Konrads III. von Burgund. Bereits kurz nachdem Bertas erster Ehemann gestorben war, hatte sie sich in die Obhut König Roberts begeben und ihre Familie, die im Konflikt mit dem Grafen Fulco Nerra von Anjou stand, seinem Schutz anvertraut ${ }^{68}$. Während Hugo Capet noch Neutralität im Zwist seiner beiden mächtigsten Vasallen eingehalten hatte, legte sich Robert auf die Partei der Grafen von Blois fest. Nach der Eheschließung zog er in den Krieg gegen Fulco Nerra und entriss ihm die Stadt Tours. Die gesamte Regierungszeit Roberts war fortan von diesem Konflikt und der wechselnden Parteinahme des Königs überschattet ${ }^{69}$.

Das Prekäre an Roberts Ehe mit Berta war der doppelte Inzest. Die Eheleute waren im 3. Grad kanonischer Zählung über ihren gemeinsamen Urgroßvater König Heinrich I. verwandt ${ }^{70}$. Überdies hatte Robert die Taufpatenschaft über ein Kind aus Bertas erster Ehe übernommen und war somit ,Gevatter von Berta. Die Verbindung zwischen Cousin und Cousine zweiten Grades stand schon seit dem 6. Jahrhundert unter Verbot, und es wäre in der Tat ein Zeugnis

und sei deshalb in der Königswahl von 987 übergangen worden, für authentisch. Zustimmend WolL, Königinnen 2002, 61; anders BRÜHL, Deutschland 1990, 591 mit weiterer Literatur.

65 Richer von Reims, Historiae IV 87 (MGH SS 38, 290 f.). Vgl. dazu Woll, Königinnen 2002, 51-56.

66 Richer von Reims, Historiae IV 88 (MGH SS 38, 291).

67 Duby, Chevalier 1981, 87. Beide waren Nachkommen Karls des Großen im Verhältnis 8/6. Eine nähere Verwandtschaft von 4/4 bestand angeblich nach BRUGuière, Law 1992, 479.

68 Richer von Reims, Historiae IV 108 (MGH SS 38, 307).

69 Guillot, Comte 1 1972, 24-43; Bachrach, Fulc 1993, 62-161.

70 Vgl. die Tafel bei Bouchard, Families 2001, 46. 
für die fruchtlosen Bemühungen der Kirche, wenn Robert und Berta mit reinem Gewissen geheiratet hätten. Dem war jedoch nicht so. Richer von Reims berichtet uns aus erster Hand, dass Berta noch zu Lebzeiten König Hugos bei Gerbert von Aurillac um Rat gefragt hatte: „Berta wollte Robert heiraten und bat Gerbert um Rat, wurde aber von ihm zurückgewiesen "71. Berta war sich daher über den Verstoß gegen die Normen des christlichen Eherechts durchaus im Klaren. Hugo Capet trat vermutlich der Meinung Gerberts bei und verhinderte die Eheschließung zeit seines Lebens, um einen Eklat zu vermeiden. Erst nach seinem Tod konnten Robert und Berta ihren Wunsch in die Tat umsetzen. Um ihr Gewissen zu beruhigen, holten sie die Zustimmung der königsnahen Bischöfe ein und ließen ihre Ehe durch einen der ranghöchsten Prälaten, durch Erzbischof Erkanbald von Tours, konsekrieren.

Sobald die Nachricht von der Ehe in Italien angekommen war, protestierte Papst Gregor V. vehement. Gregor hatte unmittelbar davor eine Synode in Pavia einberufen, weil er die französischen Bischöfe in der Sache des Reimser Bischofsstreits maßregeln wollte ${ }^{72}$. In Reims hatte Hugo Capet den Erzbischof wegen Landesverrat absetzen und ihn durch Gerbert von Aurillac ersetzen lassen. Dieses Vorgehen sowie andere Sticheleien gegen den apostolischen Stuhl hatte der Papst übel aufgenommen und deswegen die französischen Bischöfe nach Pavia berufen. In Pavia sprach Gregor V. im ersten Kanon die Suspension über alle Bischöfe aus, die die Ladung vor das Konzil missachtet hatten und an der Absetzung des Reimser Bischofs beteiligt gewesen waren ${ }^{73}$. Im zweiten Kanon befasste sich der Papst mit der unerlaubten Ehe König Roberts. Sowohl der König als auch die an der Ehe beteiligten Bischöfe wurden „zur Genugtuung" vor den Papst zitiert. Bei Missachtung der Ladung sollte ihnen der Kommunionsempfang untersagt werden ${ }^{74}$.

Der Papst reagierte also mit handfesten Drohungen. Er sorgte für die $\mathrm{Pu}-$ blizität der Affäre, indem er die Kanones in einem Brief an Erzbischof Willigis von Mainz mit der Bitte übersandte, für die Durchsetzung der Beschlüsse einzutreten. Zugleich schickte er einen Legaten nach Frankreich, um über eine Einigung zu verhandeln ${ }^{75}$. Am Hof Roberts war man zuversichtlich, diese Streitpunkte mit dem Papst durch einen politischen Kuhhandel aus der Welt zu schaffen. Robert erklärte sich zum Nachgeben im Reimser Bischofsstreit bereit,

71 Berta, Rotberto nubere volens, Gerbertum consulit, ac ab eo confutatur. Richer von Reims, Historiae IV 108 (MGH SS 38, 307).

72 Vgl. Zimmermann, Studien 1962, 23.

73 Konzil von Pavia (997) c. 1 (MGH Conc. 6, 539 f.).

74 Decretum est etiam, ut rex Robbertus, qui consanguineam suam contra interdictionem apostolicam in coniugium duxit, ad satisfactionem convocetur cum episcopis his nuptiis incestis consentientibus. Si autem renuerint, communione priventur. Konzil von Pavia (997) c. 1 (MGH Conc. 6, 540).

75 Hehl, Herrscher 1997, $170 \mathrm{f}$. 
falls er vom Papst zur Führung seiner Inzestehe mit Berta ermächtigt werden sollte. Ob der päpstliche Legat tatsächlich seine Zustimmung zu dieser Übereinkunft erteilte, ist äußerst fragwürdig ${ }^{76}$. Jedenfalls kam Robert dem Papst entgegen und erlaubte die Restitution des abgesetzten Reimser Bischofs. An seiner Ehe mit Berta hielt er dagegen fest. In Rom ist man auf diesen Kuhhandel nicht eingegangen. Zum Jahreswechsel 998/999 fand in Rom erneut eine Synode statt, dieses Mal unter der Beteiligung Kaiser Ottos III. und anderer Fürsten aus Deutschland ${ }^{77}$. Gleich der erste Kanon verhängte ein strenges Urteil über den König von Frankreich: „Es ist beschlossen worden, dass König Robert seine Verwandte Berta, die er gegen das Recht zur Frau nahm, verlässt und eine siebenjährige Buße nach den bekannten Bußgraden auf sich nimmt. Falls er es nicht macht, sei er verflucht ${ }^{\text {“78 }}$. Dasselbe Urteil traf die Königin Berta. Die beteiligten Bischöfe, allen voran Erkanbald von Tours, wurden von der Teilnahme an der Kommunion ausgeschlossen ${ }^{79}$.

Es kann also keine Rede davon sein, dass der Papst „nur zum Schein “80 an den Sanktionen gegen Robert und die Bischöfe festhielt. Die Verurteilung auf einer gut besuchten Synode war dazu geeignet, den französischen König öffentlich zu demütigen und unter Druck zu setzen. Das Verfahren versiegte erst, als Gregor V. wenig später am 18. Februar 999 verstarb. Der nächste Papst, es war der schon mehrfach erwähnte Gerbert von Aurillac, leitete keine weiteren öffentlichen Schritte gegen den französischen König ein. Erst zwischen 1003 und 1005 trennte sich Robert von Berta ${ }^{81}$. Helgaud von Fleury verschweigt die zeitliche Distanz zwischen Anklage und Scheidung, um die Bekehrung Roberts zu einem christlichen Lebenswandel herauszustellen. Seiner Vita zufolge zeigte

76 Entsprechende Gerüchte notierte Gerbert, Ep. 181 (MGH Briefe d. dt. Kaiserzeit 2, 211): ... quia Leo Romanus abba, ut absolvatur, obtinuit, ob confirmandum senioris mei regis Roberti novum coniugium, ut michi a Remensibus per litteras significatum est. Vielleicht betraute der König den Gelehrten Abbo von Fleury, der eine Reise zu Papst Gregor unternahm, mit einer Vermittlung. Die Datierung dieser Reise ist in der Forschung umstritten. Für Herbst 996 sprechen sich aus UHLiRz, Jahrbücher 2 1954, 518-525; Werner, Vorbilder 1960, 91-93; Zimmermann, Papstregesten 1998, 237 Nr. 776. Nach Lot, Hugues 1903, 272, und Riché, Abbon 2004, 209 f., fand die Reise ein Jahr später statt.

77 Wolter, Synoden 1988, 164-169.

78 Ut rex Robertus consanguineam suam Bertam, quam contra leges in uxorem duxit, derelinquat et septem annorum poentiantiam agat secundum praefixos ecclesiasticos gradus, iudicatum est. Quod si non fecerit, anathema sit. Idemque de eadem Berta fieri praeceptum est. Konzil von Rom (998/999) c. 1 (MGH Conc. 6, 574).

79 Konzil von Rom (999) c. 2 (MGH Conc. 6, 574).

80 Dubr, Chevalier 1981, 91.

81 Die genaue Datierung ist umstritten. Lot, Hugues 1903, 127 Anm. 2, zitiert als letzte Nennung Bertas als Königin eine Urkunde vom April 1004 zweifelhafter Echtheit: vgl. Zimmermann, Papstregesten 1998, 299 Nr. 991. Ausführlich hierzu Woll, Königinnen 2002, 62. 
sich der König nach heftigen Ermahnungen Abbos von Fleury einsichtig und beendete die inzestuöse Verbindung ${ }^{82}$. Die Geschichtsschreibung stellt diese Bekehrung unter Verdacht, weil Helgaud die Dauer der Ehe und die Kontroverse mit dem apostolischen Stuhl geflissentlich übergeht. Robert habe sich, so lautet das allgemeine Verdikt, seiner Frau entledigt, da die Ehe ohne Nachkommen geblieben sei und der König zur Sicherung der Herrschaft einen Thronerben benötigt habe ${ }^{83}$. So wahrscheinlich diese Vermutung ist, steht ihr die Tatsache entgegen, dass Berta in ihrer ersten Ehe ihre Fruchtbarkeit unter Beweis gestellt hatte und dass nach wenigen Jahren die Hoffnung auf Nachkommen nicht zwingendermaßen aufgegeben werden musste. Die ,eigentlichen Motive, falls es solche gegeben hat, müssen daher offen gelassen werden. Dass der König die enge Verwandtschaft zumindest als Vorwand für die Auflösung der Ehe benutzt hat, erscheint dagegen als sicher ${ }^{84}$.

Wenn man sich die Kalamitäten vor Augen hält, die sich Robert II. durch die Ehe mit Berta eingehandelt hat, stellt sich unweigerlich die Frage nach dem Grund für sein Handeln. Wenn ihm und seiner Frau die Verletzung der Normen des christlichen Eherechts bewusst gewesen war, warum haben sie dann einen solchen Eklat provoziert? Politische Motive konnten nicht entscheidend gewesen sein, weil der Widerstand Gerberts von Aurillac den Eheleuten deutlich machte, dass die Heirat in den Augen der Kirchenleute anfechtbar blieb und somit eine dauerhafte Gefahr für die Stabilität der Königsherrschaft darstellte. Ausschlaggebend war vielmehr die enge emotionale Bindung von Robert und Berta, die von den Quellen unzweifelhaft bezeugt wird. Die Spottverse des Zeitgenossen Adalbero von Laon berichten über die voreheliche Affäre zwischen Robert und Berta, bei der sich der Graf Landricus von Nevers als Kuppler betätigt haben soll ${ }^{85}$. Noch im Jahr 1009 soll, wie ein unverdächtiger Chronist überliefert, Berta einen Versuch gewagt haben, die dritte Frau Roberts zu verdrängen und in Absprache mit dem König für dieses Vorgehen den apostolischen Segen in Rom einzuholen ${ }^{86}$. Bevor also dieser Eklat auf die Rechnung einer grundsätzlichen Konfrontation zwischen adeliger und christlicher Ehemoral gestellt wird, muss dieser emotionale Hintergrund angemessen berücksichtigt werden. Die Bischöfe, die der Ehe zwischen Berta und Robert den Segen

82 Helgaud von Fleury, Vita Roberti regis 17 (94).

83 Lot, Hugues 1903, 127; Daudet, Établissement 1941, 81; Dноndt, Femmes 1964, 46; Duby, Chevalier 1981, 89; Theis, Robert 1999, 131; Riché, Abbon 2004, 215. Unentschieden noch Pfister, Robert 1885, 60, und jüngst auch Guerreau-Jalabert, Prohibitions 1994, 304.

84 Das berichtet nicht nur Helgaud von Fleury, sondern auch Odorannus von Sens, Chronica 2 (100).

85 Adalbero von Laon, Rhythmus satiricus. Zur Datierung vgl. Lот, Hugues 1903, $414-$ 423; Hohl, Landri 1982; BrunhöLzL, Geschichte 2 1992, 273 f.

86 Odorannus von Sens, Chronica 2 (100). Vgl. Wolt, Königinnen 2002, 70-74. 
erteilten, ließen sich jedoch durch solche Gründe sicher nicht überzeugen. Auf welcher Grundlage erteilten sie eine Dispensierung? Dazu muss zum einen gesagt werden, dass sich zwar im 9. Jahrhundert die Inzestgrenze des 6. oder 7. Grads römischer Zählung (3/3 bzw. 3/4) im Westfrankenreich durchgesetzt hatte, dass aber noch immer eine Unzahl anderer Texte mit eingeschränkten Verboten im Umlauf war. Es war ein Leichtes, solche Texte aus der Schublade zu holen und die Ehe Roberts II. damit zu rechtfertigen. Zum anderen sahen manche Quellen des karolingischen Kirchenrechts ein nach der Schwere des Inzests abgestuftes Procedere vor ${ }^{87}$. Ratramnus von Corbie nennt ein „dazwischentretendes oder vernünftiges Gesuch oder die Erwägung irgendeiner Notwendigkeit" als Gründe für die Dispensierung von Ehen im vierten Grad (2/ $2)^{88}$. Einen solchen Grund nennt der Zeitgenosse Richer von Reims: „Robert nahm Berta zur Frau unter dem Vorwand, es sei besser, ein kleines Übel hinzunehmen, um das größte Übel zu vermieden ${ }^{\text {“89. }}$. Bei dieser Aussage schwingt sicher ein wenig Ironie mit, doch gibt Richer auch zu erkennen, dass die Bischöfe lieber eine Inzestehe durch Dispensierung zulassen wollten, als weiter die durch Adalbero von Laon gut bezeugte ehebrecherische Beziehung zwischen Robert und Berta dulden zu müssen. Die Bischöfe könnten darauf gepocht haben, dass solche Umstände nur durch die Bischöfe vor Ort beurteilt werden konnten und nicht durch den Papst in Rom.

Dies sind freilich nur Mutmaßungen über die möglichen Gründe, die die Bischöfe ins Feld geführt haben könnten. Die Beteiligung der Bischöfe an der Eheschließung führt auf jeden Fall Dubys These einer Konfrontation von adeliger und christlicher Ehemoral ad absurdum. Roberts Ehe ist nicht ein exemplarischer Fall dieser Konfrontation. Die Inzestehe mit einer Cousine zweiten Grades war im 10. Jahrhundert ein Ausnahmefall und sorgte nicht von ungefähr für einen Eklat. Anders als Duby meint ${ }^{90}$, konnten die anderen beiden Ehen Roberts wegen Inzest nicht beanstandet werden. Das Gebot der Unauflösbarkeit fand zwar in dieser Zeit keine Anerkennung, doch den Inzestverboten zollte Robert Tribut: Zuletzt war er gezwungen, mit Konstanze, der Tochter Wilhelms von der Provence, eine Frau aus nicht-königlichem Haus zu heiraten und den Anspruch auf die Fortführung der ständischen Heiratspraxis aufzugeben. Exogamie siegte über Isogamie.

87 Siehe 294 Anm. 23, 303 Anm. 67 und 365 Anm. 376.

88 In quarto gradu coniunctos, quamvis incertum [besser: incestum] vocitent, non semper dividunt intercedente vel rationabili peticione vel necessitatis cuiusquam consideratione. Ratramnus von Corbie, Ep. 13 (MGH Epp. 6, 157 f.).

89 Rotbertus rex patri succedens, suorum consilio Bertam duxit uxorem ea usus ratione, quod melius sit parvum aggredi malum, ut maximum evitetur. Richer von Reims, Historiae IV 109 (MGH SS 38, 308). Nicht überzeugend ist die politische Deutung dieses Passus bei WolL, Königinnen 2002, 59.

90 Dubr, Chevalier 1981, 87. 
Statt auf die Konfrontation zwischen Aristokratie und Kirche möchte ich den Blick auf eine andere Diskrepanz richten. Die Nachgiebigkeit der französischen Bischöfe und die Strenge des deutschen Papstes legt nämlich eine Bruchlinie nahe, die sich im 10. Jahrhundert in der kirchlichen Entwicklung in den beiden Nachfolgereichen des Frankenreichs aufgetan hat ${ }^{91}$. Während im ottonischen Reich die Kirche universal am Königtum und am Kirchenrecht ausgerichtet war, zerbrach die Handlungsfähigkeit des französischen Episkopats, und die Bischöfe wurden Parteigänger partikularer politischer Interessen. Eine synodale Gesetzgebung fand im 10. Jahrhundert nicht mehr statt. Diese Bruchlinie war in Fragen des Eherechts besonders stark. In Frankreich war nachweislich nur Reims ein Hort der Propagierung des christlichen Eherechts, und aus dieser Metropole fand Robert keine Zustimmung zu seiner Ehe mit Berta, sondern Ablehnung in der Person Gerberts von Aurillac. Die ottonische Reichskirche führte dagegen die karolingische Tradition weiter und bestand auf einer nachhaltigen Repression von Verwandtenehen. Da Gregor V. vorher als Bischof von Augsburg amtiert hatte und ein entfernter Verwandter Kaiser Ottos III. war, darf man mit Patrick Corbet annehmen, die strenge Handhabung des Eherechts bei den Ottonen habe den Hintergrund für diese unnachgiebige Haltung des Papstes gebildet ${ }^{92}$. Die Konzile des 10. Jahrhunderts sind ein untrügliches Zeichen dafür, dass im ottonischen Reich sowohl die Unauflösbarkeit der Ehe ${ }^{93}$ als auch die Eheverbote strikter gehandhabt wurden als in Frankreich. Diese Tatsache ist auch für die Inzestkampagne Heinrichs II. im Auge zu behalten.

\subsection{Die Inzestkampagne Heinrichs II.}

Heinrich II. hat während seiner Herrschaft Konflikte scheinbar magisch ange$\operatorname{zogen}^{94}$. Seine gesamte Regierungszeit war von der erbittert geführten kriegerischen Auseinandersetzung mit dem polnischen Fürsten Boleslaw Chrobry

91 Dies betont Hoffmann, König 2000.

92 Corbet, Burchard 2001, 75. Nicht teilen kann ich jedoch Corbets Einschätzung, dass Otto III. maßgeblich an der Verfolgung des Inzests beteiligt war. Im Fall Roberts kann die Initiative nur dem Papst zugeschrieben werden, da das Verfahren mit seinem Tod endete. Das Inzestverbot Herzog Boleslavs von Böhmen (vgl. BöHmer - Uhlirz, Regesta Imperii II/3 1956, 551 Nr. 1074b) datiert noch in die Zeit vor dem Beginn der selbständigen Regierung Ottos im Jahre 994: Althoff, Otto III. 1996, 73. Im Übrigen halte ich die Formulierung imperante domino Ottone III. rege augusto nicht für das Zeugnis eines kaiserlichen Befehls, sondern für eine Datierungsformel, vgl. die Beispiele bei Fichtenau, Datierungen 1973. Die Inzestkampagne Heinrichs II. ist also tatsächlich ein Neuanfang.

93 Vgl. Konzil von Ingelheim (948) c. 10 (MGH Conc. 6, 161).

94 Zum Folgenden vgl. Weinfurter, Heinrich II. 1999; Ders., Heinrich II. 2003. 
überschattet. Mit der Familie seiner Frau zog Heinrich es vor, eine jahrelange Fehde um die Besetzung des Trierer Bischofsstuhls in Kauf zu nehmen, statt seinen Anspruch auf die Herrschaft über die Reichskirche aufzugeben. Selbst seinen Bruder Bischof Brun von Augsburg trieb er in die Rebellion, als er ein Versprechen über die Vergabe des Herzogtums Bayern gegenüber Heinrich von Schweinfurt nicht einhielt. Die Gründung des Bistums Bamberg im Jahre 1007 sorgte bei den durch die Verkleinerung ihrer Diözesen betroffenen Bischöfen für Entsetzen und konnte erst durch eine Selbstdemütigung des Königs durchgesetzt werden. Die Lieblinge des ,Mönchskönigs' mussten besonders unter dem straffen Regiment leiden, da Heinrich bei der Reformierung der Klöster nicht zur Duldung von Insassen bereit war, die der Benediktregel nicht gehorchten. Der Adel war von dieser unnachgiebigen Haltung des Königs besonders überrascht. Wie Gerd Althoff und Stefan Weinfurter herausstellten, klagten sowohl geistliche als auch weltliche Adelige vergeblich die unter den ottonischen Vorgängern praktizierte Milde des Herrschers ein ${ }^{95}$. Nach Althoff orientierte sich Heinrich weniger an der Verwandtschafts- und Freundschaftsmoral des hohen Adels als an der strafenden Autorität des biblischen Königtums. Weinfurter machte für diese Haltung das Vorbild eines „Moseskönigtums“ verantwortlich. Darunter versteht Weinfurter Heinrichs Idee, „wie ein neuer Moses dafür zu sorgen, dass die Gebote Gottes Grundlage und Inhalt des Lebens aller Menschen seines Volkes würden"96. Die Inzestkampagne des Herrschers scheint bestens in dieses Bild zu passen, da die christlichen Eheverbote auf die mosaischen Gesetze des Alten Testaments im Buch Levitikus zurückgehen.

Die Inzestkampagne steht also im Kontext des neu geltend gemachten Hoheitsanspruchs des Herrschers. Zudem wird sie von einem überwiegenden Teil der Forschung auch als Ausdruck einer adelsfeindlichen Politik angesehen. Heinrich habe mit seinem unerbittlichen Vorgehen gegen Konrad von Kärnten und Otto von Hammerstein die ihm „verhassten Adelsgeschlechter" der Salier

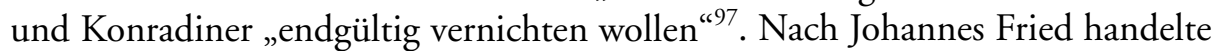
es sich bei der Inzestkampagne „um ein Musterbeispiel politischer Agitation“. Das Kirchenrecht habe als opportuner Hebel gedient, um dem „Hass des Herrschers freien Lauf zu lassen "98. Stefan Weinfurter differenziert diese Einschätzung und sieht die Politik Heinrichs nicht gegen ein spezifisches Adelsgeschlecht gerichtet, sondern gegen den Zusammenhalt des Adels insgesamt. Er

95 Althoff, Spielregeln 1997, 21 -56; Ders., Otto III. 1997; Weinfurter, Zentralisierung 1986; DERs., Heinrich II. 1999.

96 Weinfurter, Heinrich II. 1999, 269.

97 Kessler, Eheprozess 1923, 65; Holtzmann, Geschichte 1941, 447; Mikoletzky, Heinrich II. 1946, 25; Reicke, Ehehandel 1974, 214; MüLler, Heribert 1977, 187; Krah, Absetzungsverfahren 1987, 343; Fried, Weg 1994, 621-623; Ders., Prolepsis 1995, 72; Erkens, Konrad II. 1998, 51.

98 Fried, Prolepsis 1995, $71 \mathrm{f}$. 
interpretiert das Vorgehen Heinrichs als „Disziplinierungsmaßnahme“ des Adels und als Mittel der "Zentralisierung der Herrschergewalt ${ }^{\text {"999 }}$. Durch die Zerschlagung von Sippenverbänden und die Verleihung von Ämtern an die Kirche sollte der Gewalt des Königs keine Konkurrenz mehr erwachsen. Gegen diese politische Deutung der Inzestkampagne wandte sich Hartmut Hoffmann ${ }^{100}$. Nach seiner nur knapp skizzierten Ansicht ist es Heinrich primär um die Durchsetzung des kirchlichen Rechts gegangen. Da dieses Vorgehen in den meisten Fällen dem Herrscher zum Schaden gereicht habe, könne man die Inzestkampagne nicht unter dem Aspekt der politischen Nützlichkeit betrachten. Hoffmanns Gegenargument macht freilich nur ex post Sinn. Heinrich selbst konnte die Vergeblichkeit seiner Bemühungen nicht ahnen.

Im Folgenden soll diese Kontroverse nicht im Mittelpunkt stehen. Die Alternative von politischer oder religiöser Motivation ist meines Erachtens nicht geeignet, den Hintergrund für die Inzestkampagne Heinrichs II. zu erhellen. Die adeligen Eheschließungen dieser Zeit fanden allesamt in der Sphäre der Öffentlichkeit statt und waren sowohl Teil der politischen Auseinandersetzungen als auch Objekt kirchlicher Kontrolle. Auch wenn Heinrichs Handeln ausschließlich religiös motiviert gewesen sein sollte, mussten ihm die Konsequenzen eines derart umfassenden Inzestverbots bewusst gewesen sein. Religion und Politik sind in einer Zeit, als das Königtum vorwiegend mit Anliegen der christlichen Moral einen universalen Anspruch auf Gehorsam stellen konnte, nicht als getrennte Funktionsbereiche der Gesellschaft aufzufassen. Für die Frage der Motivation ist es vorab entscheidend zu klären, zu welchem Zeitpunkt und in welcher Intensität Heinrich während seiner Herrschaft eine Kampagne gegen Ehen innerhalb der Verwandtschaft geführt hat.

\section{Rebellion auf der Synode}

Gerade ein halbes Jahr war seit seiner Krönung und Salbung in Mainz vergangen, als Heinrich II. mit aller Vehemenz zur Bekämpfung von Inzestehen aufrief. Der Herrscher verkündete diesen Aufruf auf einer Synode in der königlichen Pfalz Diedenhofen im Januar $1003^{101}$. Gleichzeitig mit der Synode fand eine Reichsversammlung statt. In erster Linie ging es um hochpolitische Angelegenheiten. Heinrich übertrug in einer Urkunde förmlich das Frauenkloster St. Stephan in Straßburg an den Ortsbischof und setzte damit einen Schlusspunkt unter den Konflikt mit seinem Konkurrenten Herzog Hermann

99 WeInfurter, Heinrich II. 1999, 200-204.

100 Hoffmann, Mönchskönig 1993, 54-56.

101 Eine abweichende Datierung vertritt Schilling, Datierung 1991. Die Mehrheit der Forschung bleibt bei der geläufigen Identifikation mit der Reichsversammlung in Diedenhofen: Hlawitschka, Thronwechsel 1993, 189; Hoffmann, Mönchskönig 1993, 53; Weinfurter, Heinrich II. 1999, 76. 
II. von Schwaben ${ }^{102}$. Erst nach kriegerischen Auseinandersetzungen hatte dieser den Thronanspruch Heinrichs akzeptiert und sich in einem öffentlichen Ritual der Herrschaft des neuen Königs unterworfen. Heinrich II. benutzte das Protokoll der Urkunde, um seinen Anspruch auf die Königswürde mit dem Hinweis auf die Wahl der Fürsten und die Verwandtschaft mit den Ottonen programmatisch zu rechtfertigen ${ }^{103}$. Doch die Aussöhnung mit Hermann von Schwaben war offenbar nur von kurzer Dauer. Denn noch auf der Reichsversammlung versuchte Hermann gemeinsam mit Herzog Dietrich von Oberlothringen die Rechtssprechung des Königs zu behindern. Nach dem Bericht Thietmars von Merseburg „sollten sie sich jedoch dem Urheber der Gerechtigkeit verdientermaßen unterlegen sehen ${ }^{\text {"104. }}$. Herzog Dietrich musste wegen einer Beschwerde des Volkes die Schleifung seiner Burg Morsberg hinnehmen. Die Bedingungen der Schlichtung mit Hermann von Schwaben benennt die oben erwähnte Urkunde.

Mehr Unruhe als die politischen Angelegenheiten erregte jedoch die in ihrer Art einzigartige Ansprache des Königs vor den versammelten Bischöfen. Von ihr berichtet die Lebensbeschreibung des Bischofs Adalbero von Metz aus der Feder des Constantin von St. Symphorian ${ }^{105}$. An der Authentizität dieses Berichts wird zu Recht nicht gezweifelt, da die Vita noch vor 1014 niedergeschrieben wurde und aus erster Hand berichtet. Man wird vielleicht nicht jedes Detail über die heldenhafte Rolle Adalberos für bare Münze nehmen können, doch die Initiative des Königs steht außer Zweifel. Heinrich II. löste mit Absicht einen Eklat auf der Synode aus, der beinahe in eine Rebellion mündete.

Vor den Erzbischöfen von Mainz und Köln sowie weiteren Mitgliedern des Episkopats ergriff der König das Wort und richtete mahnende Worte an die Kirchenfürsten. Er fragte in die Runde, warum sie es unterließen, durch das Schwert des Heiligen Geistes faule und ungesunde Glieder unter den Gläubigen abzuschneiden ${ }^{106}$. Als die verdutzten Bischöfe die Absicht des Königs nicht durchschauten, wurde er deutlicher. In „überaus harten Worten“ tadelte er die Verwandtenehen, die gegen die kirchenrechtliche Inzestgrenze des 7. Grads verstießen. Es seien sogar Ehen im dritten Grad geschlossen worden, was selbst

102 Weinfurter, Heinrich II. 1999, 36-58.

103 MGH D H II. 34. Zur Interpretation vgl. Weinfurter, Anspruch 1995, $121-134$; Körntgen, Funktion 2000.

104 Thietmar von Merseburg, Chronica V 27 (MGH SS rer. Germ. N.S. 9, 253).

105 Folz, Adalbéron 1991; Corbet, Burchard 2001, 117-123; HaArländer, Vitae 2000, $475 \mathrm{f}$.

106 ... ipsos eosdem sacerdotes acerrime congreditur, cur videlicet in suis diocesis et diocesianis ea quae synodali ac per hoc spirituali falce secanda erant non resecarent, ac gladio spiritus sancti putrida et male sana a membris fidelium abscidere supersederent. Constantin, Vita Adalberonis 15 (MGH SS 4, 663). 
die Juden und Heiden nicht gewagt hätten ${ }^{107}$. Nach dieser Brandrede breitete sich ein betretenes Schweigen in der Versammlung aus. Nur ein Teil der Bischöfe, so der Bericht Constantins, war in das Vorgehen des Königs eingeweiht, doch auch dieser fand sich aus Furcht vor der Macht der vom König indirekt angesprochenen Person zu keiner Stellungnahme bereit. Daraufhin benannte Heinrich selbst die von ihm anvisierte Person:

„Seht her, Konrad, der Herzog der Austrasier, der uns durch Blutsverwandtschaft und allen hohen Adeligen dieses Landes durch Verschwägerung verbunden ist, hat eine mit ihm so eng verwandte Frau geheiratet, dass, wie wir fürchten, nicht nur ihm selbst, sondern dem ganzen Land die Kränkung durch Gott schnellstens und, wie man sagt, vor den Türen bevorzustehen scheint. Denn nicht viel weniger wird uns, die wir schweigen, das Verbrechen angerechnet als ihm, der diese Untat kühn und ohne Rücksicht auf die Sünde begangen hat ${ }^{\star 108}$.

Erst dann ergriff der Held dieser Geschichte, Bischof Adalbero von Metz, das Wort. Er wird als einer der Adeligen eingeführt, die ebenso wie der König, Herzog Konrad und der restliche Hochadel der Nachkommenschaft König Heinrichs I. entstammten ${ }^{109}$. Adalbero brach das „schändliche“ Schweigen der Bischöfe und machte die Verwandtschaft zwischen Herzog Konrad und seiner Frau Mathilde öffentlich, indem er ihre Vorfahren benannte. Er kam zu dem Schluss, dass die Eheleute sogar im zweiten Grad miteinander verwandt waren ${ }^{110}$.

Mit der Intervention Adalberos war der Skandal perfekt. Der Autor Constantin war noch Jahre später so ergriffen, dass er nicht genug drastische Worte für das Ereignis finden konnte. In Bezug auf die Teilnehmer der Synode spricht er von „Zorn“, „Feindschaft", „Raserei“, „Tollheit", „Zwietracht" und „Zerwürfnis“111. Während Herzog Dietrich das Vorgehen des Königs unterstützte,

107 Inter multa, inquit, quae in regno nostro vestrisque barrochiis corrigenda sunt, parentes sic sibi proxime coniugio copulantur, ut ... etiam tertii loci consanguinitatem, quod dictu nefas est, ad copulam asscissere non refugiant, et lineam, quae ad septimam usque generationem sacris canonum institutionibus illibata conservari iubetur, Iudaeis paganisque infeliciores in ipsis sui exordiis abrumpere non formidant. Constantin, Vita Adalberonis 16 (MGH SS 4, 663).

108 Ecce, inquit, Conradus dux Austrasiorum, consanguinitate nobis et quicumque in tota patria nobiliores sunt cunctis affinitate coniunctus, uxorem duxit sic sibi propinquam, sic proximam, ut, sicut timemus, non modo ipsi, verum omni patriae offensa dei citissime et, ut dicitur, pro foribus adesse videatur, parumque minus crimen nobis tacentibus indicitur, quam ei qui idem scelus audacter et sine peccati estimatione perpetrare cernitur. Constantin, Vita Adalberonis 16 (MGH SS 4, 663 f.).

109 Constantin, Vita Adalberonis 17 (MGH SS 4, 664).

110 Hoc ergo genealogiae ordine, quia frater sororque in supputatione non admittuntur, consanguinitas horum non plus quam secundo loco elongari praevalet. Constantin, Vita Adalberonis 17 (MGH SS 4, 664).

111 Constantin, Vita Adalberonis 17-18 (MGH SS 4, 664). 
griffen die Parteigänger Herzog Konrads beinahe zu den Waffen. Dem König gelang es nicht, den von ihm hervorgerufenen Konflikt zu schlichten ${ }^{112}$. Die Synode brach unter der Bekundung ,überaus aggressiver Feindschaften “ auseinander. Bischof Adalbero machte auf der Heimreise nach Metz einen Umweg, weil er ohne militärische Begleitung angereist war und einen Hinterhalt befürchtete. Auch Herzog Konrad befand sich zwei Tage lang auf der Flucht ${ }^{113}$.

Ein langfristiges Nachspiel hatte dieser Skandal nicht. Ein Jahr später folgte Konrad als Herzog von Kärnten seinem Vater nach und behielt zeit seines Lebens seine Ehefrau. Ihrer Ehe entstammte mit Konrad dem Jüngeren einer der beiden Kandidaten der Königswahl von 1024. Konrad selbst sah seine Ehe wohl nicht als Inzestfall an. Als Bruder Papst Gregors V., der sich im Fall Roberts II. von Frankreich persönlich für die Verurteilung des Königs engagiert hatte, waren ihm sicher die kirchlichen Inzestgebote vertraut. Schon der Verlauf der Synode macht deutlich, dass die Mehrheit der anwesenden Bischöfe und Laien von der Anklage des Königs überrascht war ${ }^{114}$. Eine Konfrontation zwischen adeliger und klerikaler Ehemoral anzunehmen, ist also abwegig. Alle beteiligten Parteien gehörten dem Hochadel an und rühmten sich ihrer Herkunft von König Heinrich I. Der Konflikt drehte sich vielmehr um die Auslegung der christlichen Inzestvorschriften, nicht um deren prinzipielle Akzeptanz. Der Bericht Constantins gibt einige Hinweise über den strittigen Punkt, die in der Forschung jedoch unterschiedliche Deutungen erfahren haben. Unsicherheit besteht vor allem in der von Constantin bzw. Heinrich und Adalbero angewandten Komputation. Einerseits geht es um die Frage, ob die römische oder kanonische Zählweise verwendet wurde, andererseits um den Grund für das Auftauchen einer vollkommen neuen Methode, der Zählung nach Vetterschaften $^{115}$. Die Eigenart dieser Methode besteht darin, die Zählung der Verwandten erst mit den Vettern (d.h. den Enkeln eines Stammvaters) zu beginnen. Gegenüber der kanonischen Komputation ergibt sich dadurch eine Verringerung um einen Grad.

Nach dem Bericht Constantins bezeichnete Heinrich II. die Verbindung zwischen Konrad und Mathilde als Ehe im 3. Grad und Adalbero als Ehe im 2. Grad. Die Auflistung der Vorfahren durch Adalbero ergibt dagegen eine Verwandtschaft von 4/4 über König Heinrich I. Die Anwendung der römischen Zählweise ist also auf jeden Fall ausgeschlossen. Der König verwendete die Zählung nach Vetterschaften. Die Zählung des Bischofs von Metz ist dagegen

112 ... ut inter verum falsumque discidii et discordiae non modica disceptatio fieret, quam etiam ipse rex omnino sedare non potuit. Constantin, Vita Adalberonis 18 (MGH SS 4, 664).

113 Constantin, Vita Adalberonis 19-20 (MGH SS 4, 664 f.).

114 Mirantibus omnibus, quid sibi verba regis tam districtissima vellent quove tenderent ... Constantin, Vita Adalberonis 15 (MGH SS 4, 663).

115 Dazu siehe $20-25$. 
rätselhaft. Vielleicht überzog er bewusst und trieb dadurch den Skandal auf den Höhepunkt ${ }^{116}$. Eigenartig mutet auch an, dass Heinrich II. in seiner allgemeinen Ermahnung die Inzestgrenze des siebten Grades ins Spiel bringt. Dies erweckt den Eindruck, als habe er eine unerreichbare Norm in den Raum gestellt, ohne auf den umstrittenen Fall Bezug zu nehmen. Robert Folz machte daher den Vorschlag, Heinrich habe zwei unterschiedliche Zählweisen verwendet ${ }^{117}$. Der 7. Grad setze die römische Zählweise voraus. Da die Ehe Konrads im 8. römischen Grad aber mit dieser Inzestgrenze nicht angreifbar gewesen wäre, habe man sich der Zählung nach Vetterschaften bedient, um die Grenze um eine Generation zu verschieben. Donald Jackman, Patrick Corbet und Eduard Hlawitschka sind dieser Deutung beigetreten ${ }^{118}$. Sie sind davon überzeugt, dass die neue Methode der Zählung nach Vetterschaften den Zweck hatte, bislang vom Inzestverbot nicht erfasste Eheschließungen wie diejenige Konrads zu unterbinden. Damit erscheint das Vorgehen des Königs als „politische Agitation“ im Sinne Johannes Frieds. Heinrich II. hätte dann das Eherecht bewusst manipuliert, um die Ehe eines politischen Gegners zu inkriminieren.

Dieser Deutung kann ich mich aus verschiedenen Gründen nicht anschließen. Erstens gibt es keine Belege für die Verwendung der römischen Komputation im ottonisch-salischen Reich des 10. und 11. Jahrhunderts. Regino von Prüm, das Konzil von Koblenz (922), Burchard von Worms, die Bischofsgeschichte aus Cambrai und Siegfried von Gorze zählen die Generationen nach kanonischem und nicht die Zeugungen nach römischem Recht ${ }^{119}$. Ein unverdächtiges Zeugnis dafür ist die von Adalbold von Utrecht verfasste Vita Heinrichs II. Darin ist zu lesen, dass Otto III. und Heinrich II. über ihren gemeinsamen Urgroßvater Heinrich I. im „dritten Grad verwandt waren “120. Adalbold verwendete also die kanonische Komputation. Zweitens ist es schwer verständlich, wie Heinrich II. die Zählung nach Vetterschaften auf die römische Komputation angewendet haben sollte. Die Zählung nach Vetterschaften setzt die Zählung in Generationen voraus, denn sie beginnt erst mit der Enkelgeneration und ist deshalb mit der römischen Zählung in Zeugungen unvereinbar.

116 So auch die Meinung von Hlawitschka, Thronwechsel 1993, 187-194, und Corbet, Burchard 2001, 122. An eine engere Verwandtschaft, die von Constantin absichtlich verschwiegen worden sei, glaubt dagegen WoLF, Königskandidatur 1991, 82-85.

117 Folz, Adalbéron 1991, 412.

118 Hlawitschka, Thronwechsel 1993, 187 f.; Jackman, Eherecht 1995, 197; Corbet, Burchard 2001, 121; Hlawitschka, Konradiner-Genealogie 2003, 95.

$119 \mathrm{Zu}$ Regino siehe 368; zum Konzil von Koblenz siehe 390 Anm. 330; zu den Gesta siehe 415 f.; zu Burchard siehe 431-433; zu Siegfried siehe 447.

120 Insuper tertius Otto, post cuius obitum in regem eligebatur, et ipse tertium ad invicem consanguinitatis gradum tenebant. Adalbold von Utrecht, Vita Heinrici II. c. 1 (48). Der kanonischen Zählung bediente sich auch die Vita Mathildis antiquior c. 14 (MGH SS rer. Germ. 66, 139). 
Keine Quelle des 11. und 12. Jahrhunderts kombiniert die Zählung nach Vetterschaften mit der römischen Zählweise, und so hat auch die ältere Forschung der Rede Heinrichs II. die kanonische Komputation unterstellt. Drittens lässt der Text selbst eine solche Deutung nicht zu. Constantin gibt keinen Hinweis auf die Verwendung zweier unterschiedlicher Zählweisen, obwohl er durchaus an dieser Frage Interesse zeigte und es für angebracht hielt, die neuartige Zählung nach Vetterschaften eigens zu erläutern. Die von Constantin wiedergegebene Entrüstung des Königs bliebe unverständlich, wenn es sich nur um einen Grenzfall von Inzest handeln würde. Heinrich akzentuierte in seiner Rede deutlich die besondere verwandtschaftliche Nähe der Eheleute, die weit innerhalb der Grenze des 7. Grades geschlossen worden sei und dadurch eine göttliche Bestrafung geradezu herausfordern würde ${ }^{121}$.

Als entscheidend sehe ich jedoch ein viertes Argument an. Die Unterstellung zweier unterschiedlicher Zählweisen geht davon aus, dass die Inzestgrenze des 7. Grades anerkannt war und durch die Zählung nach Vetterschaften auf die Ehe Konrads von Kärnten ausgedehnt werden konnte. Diese Voraussetzung trifft jedoch nicht zu. Die im ottonischen Reich viel beachtete Sammlung Reginos von Prüm setzte den dritten und vierten Grad als Inzestgrenze fest. Auf dem Konzil von Koblenz im Jahr 922 entschied man sich für die Formulierung infra quintam generationem und bezeichnete damit den vierten Grad als Grenze der verbotenen Verwandtschaft ${ }^{122}$. Die Kirchenrechtssammlungen aus dem ottonischen Reich stehen ebenfalls in dieser ostfränkischen Tradition ${ }^{123}$. Erst Burchard

121 ... tertii loci consanguinitatem, quod dictu nefas est, ... uxorem duxit sic sibi propinquam, sic proximam ... Constantin, Vita Adalberonis 16 (MGH SS 4, 663).

122 Siehe 390 Anm. 30.

123 Die Kirchenrechtssammlungen des 10. Jahrhunderts sind erst zum Teil erforscht. Hier ein Überblick über einige bekannte Sammlungen: 1) Die Sammlung zum Inzestverbot in 11 Kapitel (siehe 307 Anm. 83) wurde im 10. Jahrhundert weiter tradiert (München, Bayerische Staatsbibliothek, Clm 3853, fol. 69v-81v; Heiligenkreuz, Stiftsbibliothek, 217, fol. 94r-106r; Köln, Erzbischöfliche Diözesan- und Dombibliothek, 118, p. $33-$ 53; Köln, Erzbischöfliche Diözesan- und Dombibliothek, 120, fol. 150v-162v; Salzburg, Stiftsbibliothek St. Peter, a.IX.32, fol. 134r-142v), aber auch einer charakteristischen Veränderung unterzogen: Das Kapitel aus dem Libellus responsionum wurde in zwei Handschriften getilgt (Köln, 120 und St. Peter, a.IX.32). Es sind darin somit nur Kanones enthalten, die wie Regino die Inzestgrenze des vierten Grades dem kategorischen Verbot der Päpste gegenüberstellen. An anderer Stelle der Handschrift aus St. Peter wurde der siebte Grad erwähnt als Teil eines Zitats aus Jonas von Orléans (und nicht aus dem Konzil von Douzy, wie Philipps, Codex 1864, 457 und Corbet, Burchard 2001, 61, behaupten). In Clm 3853 wurde in einem anderen Teil der Handschrift der PseudoGregor-Brief als Exzerpt nachgetragen (fol. 263r-v), um den Libellus unschädlich zu machen, vgl. Mordex, Bibliotheca 1995, 299; Hoffmann, Schreibschulen 2004, 33. 2) Die Kombination von kategorischem Verbot mit der Grenze des fünften und siebten Grades begegnet in einer Hildesheimer Sammlung aus der Zeit um 1000 in Wolfenbüttel, Herzog August Bibliothek, Helmst. 454, fol. 13-22, vgl. Corbet, Burchard 
von Worms machte sich in seiner spätestens 1023 fertiggestellten Sammlung vehement für den siebten Grad stark ${ }^{124}$.

Heinrich II. erhob daher 1003 in Diedenhofen eine Forderung, mit deren Anerkennung er nicht rechnen konnte, weil sie im Rahmen des ottonischen Kirchenrechts eine Neuerung darstellte. Deshalb bediente er sich darüber hinaus der Zählung nach Vetterschaften. Die Verwandtschaft des vierten Grades zwischen Konrad von Kärnten und Mathilde von Schwaben war nach dem Standard des ottonischen Kirchenrechts ein Grenzfall. Die Regelung des Konzils von Koblenz haben die beiden Eheleute zwar missachtet, doch muss man bedenken, dass das Kirchenrecht der Zeit noch nicht die Eindeutigkeit späterer Zeiten erreicht hatte. Noch Regino tradierte eine Reihe weniger anspruchsvoller Inzestvorschriften, die nur ein Verbot der Ehe im dritten Grad aussprachen. Auch war es weiterhin möglich, sich auf die Autorität des Libellus responsionum zu berufen, wie es noch für die Regierungszeit Heinrichs II. aus dem Bistum Cambrai überliefert ist ${ }^{125}$. Die Zählung nach Vetterschaften machte aus der Ehe im vierten Grad eine Ehe im dritten Grad und steigerte dadurch die Inzestqualität des Delikts. Heinrichs Vorgehen wird somit nicht das Stigma der Manipulation des Kirchenrechts los, weil die Zählung nach Vetterschaften im Eherecht eine Neuerung darstellte und mit dem Zweck zum Einsatz gebracht wurde, die Ehe Konrads von Kärnten als besonders verabscheuungswürdiges Verbrechen in die Nähe jüdischer und heidnischer Praktiken zu rücken.

König Heinrich II. unternahm folglich auf der Synode von Diedenhofen eine doppelte Provokation: Er erhob die Forderung der Inzestgrenze des 7. Grades kanonischer Zählung und er brachte die Zählung nach Vetterschaften als

2001, 62-64 und 323-325 mit weiterer Literatur. 3) Die sog. Vier-Bücher-Sammlung aus dem frühen 10. Jahrhundert tradiert ausschließlich das kategorische Verbot, vgl. Corbet, Burchard 2001, 61 f. mit Verweis auf Sснмiтz, Vier-Bücher-Sammlung 1991, mit Ergänzungen in Sснмітz, Sammlung 2005. 4) Das anonyme Gutachten von 861/ 863 (siehe 410 Anm. 123) ist in zwei Handschriften des 10. Jahrhunderts enthalten: Münster, Staatsarchiv, Msc. VII 5021, p. 107-126 aus Corvey und München, Bayerische Staatsbibliothek, Clm 14690, fol. 184r-187v aus Regensburg. (Ich danke Roman Deutinger, München, für den Hinweis auf diese Handschrift.) Das kategorische Verbot ist darin ebenso zu finden wie der Libellus responsionum, das Bußbuch Theodors sowie der Brief des Ambrosius an Paternus. Zusammenfassend lässt sich also festhalten, dass der siebte Grad als Inzestgrenze erst um das Jahr 1000 in drei Handschriften auftaucht: München, Clm 3853 (Augsburg, 950-1000), Wolfenbüttel, Helmst. 454 (Hildesheim, Ende 10. Jahrhundert), St. Peter, Cod. a.IX.32 (Salzburg, 1000-1030). In dieser Zeit fand der Pseudo-Gregor Brief auch Aufnahme in den Appendix II zu Reginos Sendhandbuch. Siehe 429 Anm. 235.

124 Dazu ausführlicher unten.

125 Siehe 415 Anm. 152. Erzbischof Heribert von Köln (999-1021) ließ eine Kopie der pseudoisidorischen Dekretalen herstellen, die den unverfälschten Libellus responsionum tradierte (Köln, Erzbischöfliche Diözesan- und Dombibliothek, 113). Zudem enthält die Handschrift das Konzil von Rom von 721, während der Pseudo-Gregor-Brief fehlt. 
neue Zählweise ins Spiel. Es kann nicht überraschen, dass nicht nur die Partei des von der königlichen Anklage betroffenen Konrad von Kärnten Sturm gegen eine derartige Ausdehnung des Inzestverbots lief, sondern dass auch derjenige Teil des Episkopats mit großer Verwunderung reagierte, der nicht in die Pläne eingeweiht worden war $^{126}$.

Angesichts der Neuheit der erhobenen Forderungen stellt sich besonders dringend die Frage nach der Motivation des Königs. Zum Zeitpunkt der Synode war Heinrich gerade ein halbes Jahr König. Er beendete in Diedenhofen den Huldigungsumritt, der ihn durch weite Teile des Reichs geführt hatte ${ }^{127}$. Seine Stellung war nach der Unterwerfung Hermanns von Schwaben unangefochten, die Intensität seiner Herrschaft musste jedoch erst auf die Probe gestellt werden. Zwei mächtige Fürsten, die Herzöge Dietrich von Lothringen und Hermann von Schwaben, stellten sich in Diedenhofen der königlichen Rechtswahrung entgegen. Nachdem Heinrich als Herzog von Bayern auf derselben Rangstufe wie seine Opponenten gestanden hatte, musste er seinen neuen Rang erst zur Geltung bringen ${ }^{128}$. Dafür schien die Einforderung des Inzestverbots das geeignete Mittel gewesen zu sein. Zum einen konnte sich der König dabei auf eine universale christliche Norm stützen, deren Durchsetzung nicht den Konsens der Adeligen erforderte. In der weltlichen Rechtssprechung war es hingegen Usus, das gerichtliche Urteil durch den Konsens der Gerichtsgemeinde zu bestätigen ${ }^{129}$ und außergerichtliche Verfahren der gütlichen Konfliktregelung zu benützen ${ }^{130}$. Ein einzelrichterliches, autoritäres Handeln des Königs war nur in Ausnahmefällen akzeptabel. Genau dies beanspruchte Heinrich, indem er in der Diedenhofener Urkunde programmatisch feststellte, ihm stehe die erbliche Nachfolge in der Herrschaft „ohne jede Schmälerung“ $\mathrm{zu}^{131}$. Er nahm es sich gegen die ,Spielregeln' der Zeit heraus, die Ehe Konrads ohne vorhergehende Absprachen öffentlich als Verbrechen anzuprangern. Zum anderen herrschte im ottonischen Reich ein "geistiges Klima“"132, das der Inzestkampagne Heinrichs förderlich war. Seit dem Ende des 9. Jahrhunderts zählte das Verbot von Verwandtenehen zum Kern der Reformanliegen der ostfränkischen Kirche. Die Ottonen unterwarfen sich bewusst den Forderungen des christlichen Eherechts

126 Dies betont der Berichterstatter mehrfach: Constantin, Vita Adalberonis 15-17 (MGH SS 4, 663 f.).

127 Weinfurter, Heinrich II. 1999, $76 \mathrm{f}$.

128 Die Rangfrage ist insbesondere von Althoff, Spielregeln 1997, zu einem Schlüsselthema der Ottonen-Forschung erhoben worden: Althoff, Compositio 1995; Görich, Wende 1997; DERs., Bücher 2002.

129 Weitzel, Dinggenossenschaft 1985.

130 Keller, Gerechtigkeit 1997; Althoff, Spielregeln 1997; Kamp, Friedensstifter 2001.

131 MGH D H. II. 34. Zur Interpretation vgl. Weinfurter, Heinrich II. 1999, 55 f.; KöRnTGEN, Funktion 2000.

132 Weinfurter, Heinrich II. 1999, 200. 
und unterschieden sich darin von den französischen Königen. Insbesondere der Fall Roberts II. hatte auch im Reich die Gemüter erregt. Heinrich II. war selbst auf der Synode von Rom anwesend, Erzbischof Willigis von Mainz bekam die Paveser Beschlüsse von Gregor V. zugesandt. Willigis, der Königsmacher Heinrichs II., nahm an der Synode von Diedenhofen teil, die er vermutlich auch leitete ${ }^{133}$. Die Inzestkampagne konnte daher dazu dienen, die Konformität mit den Anforderungen eines christlichen Königtums ${ }^{134}$ und mithin die sakrale Legitimation des Herrschers unter Beweis zu stellen.

Die Ziele Heinrichs waren also meines Erachtens eher allgemeiner als spezieller Natur. Wie die ältere Forschung von einer gezielten Vernichtung der Salier zu sprechen, erscheint mir nicht haltbar. Allenfalls könnte man von einer Strafaktion gegen Konrad sprechen, wenn wir der Nachricht von dessen Unterstützung der Thronkandidatur Hermanns von Schwaben trauen können ${ }^{135}$. Eine Intimfeindschaft ist jedoch nicht plausibel, da Konrad 1004 zum Herzog von Kärnten erhoben wurde. Konrads Vater Otto von Worms stand auf gutem Fuß mit dem Herrscher. Thietmar von Merseburg verdanken wir die Nachricht, dass Heinrich II. im Jahr 1002 zunächst Otto von Worms für die Übernahme der Königsherrschaft im Reich vorschlug. Otto wies diese „schwere Last“ zurück und erklärte Heinrich selbst für geeigneter. Fortan „unterstützte er ihn stets

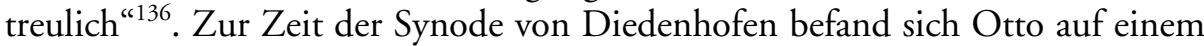
Feldzug, um den König von Italien zu bekämpfen und den Anspruch Heinrichs II. auf die Herrschaft über Italien geltend zu machen. Eine „alte Feindschaft“ zwischen Otto von Worms und Heinrich II. oder zwischen dem Haus der Salier und dem der ,Heinriche‘ lässt sich nicht wahrnehmen. Die Vernichtung eines konkreten Adelsgeschlechts war also nicht der Zweck der Inzestkampagne. Ebenso wenig zielte er auf eine Disziplinierung des Adels insgesamt. Abgesehen von der Frage, ob der Adel überhaupt eine politische Einheit eigener Ordnung in dieser Zeit darstellte, ist in den letzten Jahren wiederholt auf die Angewiesenheit des Königs auf adelige Herrschaftsträger hingewiesen worden ${ }^{137}$. Der

133 Wolter, Synoden 1988, 216.

134 Dies betont Conbet, Burchard 2001, 254.

135 Thietmar von Merseburg, Chronica V 12 (MGH SS rer. Germ. N.S. 9, 234). In der Dresdner Handschrift wird der an der Plünderung Straßburgs beteiligte Konrad als Hermanns gero [!] bezeichnet. Der Herausgeber hat sich für die Emendation genero entschieden und daher den erwähnten Konrad mit dem Salier gleichgesetzt. In der Corveyer Handschrift steht dagegen germano. Zum Verhältnis der beiden Handschriften vgl. Hoffmann, Mönchskönig 1993, 151-176.

136 Thietmar von Merseburg, Chronica V 25 (MGH SS rer. Germ. N.S. 9, 249). Zu seiner Person vgl. Glocker, Verwandten 1989, 220-224; ZотZ, Adelsherrschaften 2000; Wolfram, Konrad II. 2000, 35-45.

137 Keller, Grundlagen 1985, 20-28; DERs., Reichsorganisation 1991, 179-182; ALthoff, Verwandte 1990; Ders., Amicitiae 1992, 97-103; Reuter, Nobility 1997, 183; KöRntGen, Königsherrschaft 2001, 14-16. 
König konnte es sich nur leisten, bestimmte Adelige gegen andere auszuspielen, jedoch nicht den Adel insgesamt zu verprellen. Wenn ein konkretes Ziel (außer der Ehe Konrads und Mathildes) von Heinrich ausdrücklich anvisiert worden war, so scheint mir dieses eher in der Disziplinierung der Reichskirche zu liegen. In seiner Ansprache an den Klerus inszenierte sich der König ausdrücklich als Aufseher über das seelsorgerliche Engagement der Bischöfe. Nach Constantin von St. Symphorian hat der König sehr scharf die Bischöfe angegriffen und auf Missstände in den Pfarreien aufmerksam gemacht:

„Seht her, sagte er, ihr habt die Plätze heiliger Bischöfe inne und sitzt auf einem besseren Bischofsstuhl als Moses, da ihr ja die Stellvertreterschaft Gottes besitzt, und doch seid ihr, die ihr sowohl gute Hunde als auch heilige Widder für das Verdienst des Lebens genannt werden solltet, in Umkehr der Ordnung stumme Hunde geworden, die nicht bellen können. Während ihr selbst durch Blindheit geschlagen genötigt seid, den Untertanen Anleitung zu geben, fällt ihr beide, der Führer und der Begleiter, in die Grube ${ }^{\text {“138. }}$.

Heinrich II. verfolgte mit der Inzestkampagne also das Ziel, die veränderte Rangordnung im Reich, die unumschränkte Königsherrschaft und die Hoheit über die Reichskirche durch die Maßregelung der Bischöfe geltend zu machen. $\mathrm{Da}$ er darüber hinaus die Normen des Inzestverbots veränderte und die Einhaltung des 7. Grades kanonischer Zählung einforderte, provozierte er einen heftigen Konflikt auf der Synode von Diedenhofen. Wie es ihm noch öfters passieren sollte, unterschätzte er das Konfliktpotential und brachte damit das prekäre Gleichgewicht der Reichsverfassung ins Wanken. Sein Vorgehen war alles andere als konsensual ${ }^{139}$. Zustimmung dafür konnte er auf diese Weise nicht erlangen. Es schien sich zu bewahrheiten, was die Männer aus der Umgebung des verstorbenen Kaisers Otto III. befürchtet hatten: Heinrich II. sei wegen seiner Härte zur Herrschaft im Reich nicht geeignet ${ }^{140}$.

\section{Die Bischöfe in Aktion}

Heinrich II. beließ es nicht bei der Brandrede von 1003. Nach einem aus der Sicht des Königs gelungenen Feldzug gegen Boleslaw Chrobry nutzte Heinrich seine erstarkte Position, um sich an denjenigen zu rächen, die im Krieg nicht die erwartete Loyalität gezeigt hatten. Drei Verräter verurteilte er zum Tod durch

138 Ecce, inquit, ecce, vos estis loca quidem sanctorum sacerdotum tenentes, et in meliori cathedra quam sedisset Moyses sedentes, utpote vices Domini possidentes, qui et boni canes et sancti arietes pro vitae merito dici debueratis, contraria vice inversoque ordine canes muti non valentes latrare estis effecti, ipsique cecitate multati dum subditis ducatum praebere cogimini, et ductor et sequens ambo in foveam praecipitamini. Constantin, Vita Adalberonis 16 (MGH SS 4, 663). Diese Ansprache ist von Bibelzitaten durchwoben.

139 Dies betont zuletzt eindringlich Weinfurter, Konfliktverhalten 2007.

140 Thietmar von Merseburg, Chronica IV 54 (MGH SS rer. Germ. N.S. 9, 192). 
den Strick ${ }^{141}$. In den Rahmen dieser drakonischen königlichen Rechtssprechung fällt die Einberufung einer Synode an unbekanntem Ort in Sachsen ${ }^{142}$. Wie Thietmar berichtet, wurde auf Befehl des Königs erneut ein Verbot von Inzestehen durch die Synode beschlossen. Zudem untersagte man den Verkauf von Christen an Heiden. Verächter der Gerechtigkeit sollten durch das geistliche Schwert „ermordet“ werden. Dies wurde nach Thietmar mit der Autorität des Kirchenrechts und des apostolischen Stuhls beschlossen ${ }^{143}$. In diesen Worten hat man zu Recht einen Hinweis gesehen, dass sich Heinrich für seine Inzestkampagne Rückendeckung vom apostolischen Stuhl geholt hat. Die Ernsthaftigkeit seines Vorgehens musste nach dieser Wiederholung allen klar vor Augen gestanden haben.

Die Bischöfe blieben nicht untätig. Der erste Eheprozess ereignete sich ein Jahr später in der sächsischen Diözese Halberstadt. Thietmar berichtet, sein Onkel Markgraf Liuthar von Walbeck habe eine Frau namens Godila hinterlassen, die vier Jahre im Witwenstand verblieben sei und sich um das Totengedenken für ihren verstorbenen Gemahl gesorgt habe. „Dann vermählte sie sich mit ihrem Verwandten Hermann, ohne sich darum zu bekümmern, dass Bischof Arnulf (von Halberstadt) sie gebannt hatte und dass sie ihr drei Bischöfen gegebenes Versprechen brach, die ihr das im Namen Gottes verboten hatten “144. Diesem Bericht ist zu entnehmen, dass Godila sich vor einer Synode rechtfertigen und mit einem Eid die Trennung von ihrem neuen Ehemann bestätigen musste $^{145}$. In welchem Grad Hermann und Godila verwandt waren, ist nicht mehr feststellbar. Der Bischof ließ sich durch den Widerstand der Eheleute jedoch nicht beeindrucken und sprach die Exkommunikation über Godila aus. „Durch das Schwert der Exkommunikation ermordet“, musste sie in den Büßerstand eintreten und konnte keine Nachkommenschaft mehr zeugen ${ }^{146}$. Bischof Arnulf von Halberstadt hatte sich durchgesetzt.

Der zweite Fall verlief für den beteiligten Bischof weniger erfolgreich. In Lothringen lieferten sich die Grafen von Hennegau und das Haus der Ardenner-

141 Thietmar von Merseburg, Chronica VI 28 (MGH SS rer. Germ. N.S. 9, 308).

142 Wolter, Synoden 1988, 224-227; Corbet, Burchard 2001, $119 \mathrm{f}$.

143 Sinodali iudicio iniustas fieri nuptias christianosque gentilibus venundari presens ipse canonica et auctoritate apostolica prohibuit Deique iusticiam spernentes spirituali mucrone interfici precepit. Thietmar von Merseburg, Chronica VI 28 (MGH SS rer. Germ. N.S. 9, 308).

144 Et tunc consanguineo suimet Hirimanno nupsit, nil curans inpositum ab Arnulfo presule bannum et, quod dexteras episcoporum sibi hoc a deo interdicencium fefellit trium. Thietmar von Merseburg, Chronica VI 86 (MGH SS rer. Germ. N.S. 9, 378). Es handelte sich wohl um Hermann von Werl: Rupp, Ekkehardiner 1996, $134 \mathrm{f}$.

145 Conbet, Burchard 2001, $147 \mathrm{f}$.

146 Propter hoc est excomunicationis gladio ab antistite predicto iugulata nullamque in procreanda prole spem deinceps adipiscitur. Thietmar von Merseburg, Chronica VI 86 (MGH SS rer. Germ. N.S. 9, 378). 
Grafen einen erbitterten Kampf um die Vorherrschaft ${ }^{147}$. Graf Lambert von Löwen, ein Bruder Reginars IV. von Hennegau, wird von den zeitgenössischen Historikern als großer Schurke beschrieben, der Männer in den Kirchen am Glockenstrang aufhängen ließ und inzestuöse Verbindungen zu Nonnen unterhielt ${ }^{148}$. Lambert und Reginar bekämpften die königlichen Statthalter Herzog Gottfried von Lothringen und Graf Hermann von Ename aus der Linie der Ardenner-Grafen. Die Fehde mündete in der Schlacht von Florennes, bei der die königliche Partei die Oberhand behielt und Graf Lambert das Leben ließ. Bischof Gerhard von Cambrai gelang es gemeinsam mit den Bischöfen Adalbold von Utrecht und Haimo von Verdun, für den unterlegenen Reginar V. von Hennegau die Huld des Kaisers wiederzuerlangen ${ }^{149}$. Teil dieses Friedensschlusses war eine Heirat zwischen den verfeindeten Familien ${ }^{150}$. Reginar V. sollte Mathilde, die Tochter Hermanns von Ename, heiraten. Die einzige Quelle zu diesem Ereignis, die Bischofsgeschichte von Cambrai, begegnet diesem Vorhaben auf ambivalente Weise. Zum einen wird die Rolle des Bischofs Gerhard in der Friedensvermittlung unterstrichen, zum anderen soll er sich dem Heiratsprojekt gegenüber abweisend verhalten haben. „Wegen der Blutsverwandtschaft, die man erwähnte, missfiel die Heirat dem Bischof Gerhard, weil er sie für gänzlich unerlaubt hielt “151. Erst nach der Beratschlagung mit anderen Bischöfen habe er "widerwillig geschwiegen“ und sein Einverständnis erklärt. Die Bischöfe hätten ihn nämlich auf die Antwort Gregors des Großen auf die Anfrage des Augustinus von Canterbury verwiesen, d.h. auf den Libellus responsionum, der die Ehe im vierten und fünften Grad für erlaubt erklärt ${ }^{152}$. Dieses Zugeständnis habe der Papst zwar in Hinblick auf die Missionierung der Angelsachsen ausgesprochen, es sei aber auch gültig, wenn der etablierten Christenheit ein großer Nutzen erwachse: „Wenn er (Reginar) nämlich der Schwager eines so bedeutenden Mannes werde, gibt es Hoffnung auf Frieden;

147 VANderkindere, Formation 2 1902, 89 f.; Schieffer, Bischof 1937, 338-341.

148 Thietmar von Merseburg, Chronica VII 46 (MGH SS rer. Germ. N.S. 9, 454); Gesta episcoporum Cameracensium III 12 (MGH SS 7, 469).

149 ... sibique coepiscopis Albaldo videlicet et Haimone adhibitis, gratiam imperatoris ipsis malefactoribus pace interveniente optinuit. Gesta episcoporum Cameracensium III 9 (MGH SS 7, 469).

150 Hiis ita gestis, Rainerus ad integrandam amicitiam filiam Herimanni comitis sibi quaesivit matrimonio copulari. Gesta episcoporum Cameracensium III 10 (MGH SS 7, 469).

151 Sed hoc, pro consanguinitate quae dicebatur, esse illicitum Gerardo episcopo estimanti omnino displicuit. Gesta episcoporum Cameracensium III 10 (MGH SS 7, 469).

152 Et tamen postea consilio coepiscoporum usus, invitus siluit, quippe proponentium beati Gregorii monitus suo discipulo Augustino collatos. Gesta episcoporum Cameracensium III 10 (MGH SS 7, 469). Die Erwähnung des vierten und fünften Grades (statt des originären dritten und vierten) führt CORBET, Burchard 2001, 150, auf die Benutzung der verfälschten Version Burchards von Worms zurück. 
wenn nicht, folgt der Untergang der Heimat ${ }^{\text {“153 }}$. Die Bischöfe trösteten sich damit, dass die Nachkommenschaft das Gesetz besser einhalten würde ${ }^{154}$.

Der Chronist aus Cambrai hatte also offensichtliche Schwierigkeiten, das Verhalten seines Oberhirten zu rechtfertigen, zu dessen engstem Vertrautenkreis er mit Sicherheit zählte ${ }^{155}$. Man wird die Quelle daher gegen den Strich lesen müssen und in Gerhard, wenn nicht den Urheber, so doch den Unterstützer des Heiratsprojekts sehen, der gleichzeitig die kirchenrechtliche Legitimation verschaffte. Die juristische Argumentation war notwendig, um die anderen beteiligten Bischöfe, Adalbold von Utrecht und Haimo von Verdun, zu beruhigen. Adalbold war ein enger Vertrauter Heinrichs II., und Haimo nahm nachweislich an der Diedenhofener Synode teil ${ }^{156}$. Das Problem der Verwandtenehe konnte also nicht unter den Teppich gekehrt werden. Reginar und Mathilde waren im Verhältnis von $4 / 5$ oder $5 / 5$ verwandt ${ }^{157}$. Die Ehe geriet unter den Verdacht des Inzests, weil sie innerhalb des 7. Grades kanonischer Zählung lag. Die Botschaft Heinrichs II. war also vor Ort angekommen, wenn auch der Bischof Gerhard von Cambrai mit Erfolg die Eheschließung betrieb. Vielleicht gelang ihm das Manöver auch nur deshalb, weil der Kaiser, wie der Chronist schreibt, „wegen

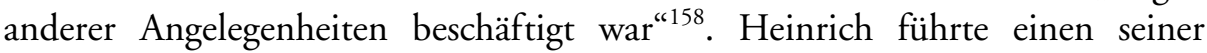
zahlreichen und wenig erfolgreichen Kriegszüge gegen den Polenfürsten Boleslaw Chrobry.

Ein dritter Fall bischöflicher Initiative ereignete sich auf der Synode von Goslar im Jahre 1019. Bischof Bernward von Hildesheim trennte die Ehe zwischen Gottschalk, dem Sohn eines Grafen Eckhard, und Gertrude, der Tochter eines Grafen Egbert ${ }^{159}$. Aus welchem Grund der Bischof sich zu diesem Vorgehen berechtigt sah, wird von der einzigen Quelle zu diesem Vorfall nicht erwähnt. Es besteht jedoch der begründete Verdacht, dass die beiden Eheleute Blutsverwandte waren und die Ehe aus diesem Grund aufgehoben wurde ${ }^{160}$.

153 Si enim tanti viri gener fieret, spem fore pacis; sin autem, naufragium patriae. Gesta episcoporum Cameracensium III 10 (MGH SS 7, 469).

154 Prolem enim esse futuram, quae melius legem servarent. Gesta episcoporum Cameracensium III 10 (MGH SS 7, 469).

155 Zum Autor vgl. Michel Sот, Art. „Gesta episcoporum Cameracensium“, in: LexMA 4 (1989) $1407 \mathrm{f}$.

156 Constantin, Vita Adalberonis 18 (MGH SS 4, 664).

157 Vgl. die genealogischen Daten bei Corbet, Burchard 2001, 150.

158 Videns autem Gerardus episcopus domnum imperatorem circa alia negotia occupatum ... Gesta episcoporum Cameracensium III 9 (MGH SS 7, 469).

159 Eo anno domnus Bernwardus episcopus tempore quadragesimae Goslare, presente imperatore cum episcopis ceterisque regni primoribus sinodo habita, Godescalcum, Eggihardi presidis filium, et Gerdrudam, Egberhdi comitis filiam separavit. Annales Hildesheimenses a. 1018 (MGH SS rer. Germ. 8, 32).

160 Wolters, Synoden 1988, 278; Weinfurter, Heinrich II. 1999, 166; Corbet, Burchard 2001, 151 
Anwesend auf dieser Synode waren auch der Kaiser mit seiner Frau Kunigunde, die Erzbischöfe von Magdeburg und Hamburg-Bremen, weitere elf Bischöfe sowie die Herzöge von Sachsen und Niederlothringen. Die vor solch großer Öffentlichkeit vollzogene Trennung war effektiv. Gertrud heiratete später Graf Liudolf von Braunschweig aus dem Haus der Brunonen ${ }^{161}$.

Der mit Abstand bedeutendste Fall soll zuletzt in aller Ausführlichkeit geschildert werden. Es handelt sich um die Ehe Ottos und Irmingards von Hammerstein ${ }^{162}$. Über zehn Jahre hielt das Verfahren um die Rechtmäßigkeit dieser Ehe das Reich in Atem und involvierte nacheinander die Könige Heinrich II. und Konrad II. sowie den Papst Benedikt VIII. Dies lag einerseits in dem heftigen persönlichen Widerstand der Eheleute begründet, andererseits in ihrer Prominenz. Die Benennung nach ihrer Hauptburg Hammerstein am Mittelrhein verdeckt die Tatsache, dass sowohl Otto als auch Irmingard dem Hochadel des Reichs angehörten. Otto stammte aus der Nachkommenschaft König Konrads I. und gilt als letzter männlicher Agnat dieser Dynastie ${ }^{163}$. Irmingards Vater war Gottfried „der Gefangene“ aus dem Haus der Ardenner-Grafen ${ }^{164}$. Beide Eheleute waren mit Personen eng verwandt, die bereits mit der Inzestkampagne unter Heinrich II. in Berührung gekommen waren. Ottos Vetter war Herzog Hermann II. von Schwaben, dessen Tochter die in Diedenhofen inkriminierte Ehe mit Konrad von Kärnten geschlossen hatte. Irmingard war eine entfernte Nichte Adalberos von Metz, der in Diedenhofen die Initiative der Anklage auf sich genommen hatte. Ihr Bruder Herzog Gottfried von Niederlothringen beteiligte sich an der Eheschließung seiner Nichte mit Reginar von Hennegau, die den Konflikt um die Vorherrschaft in Niederlothringen beendete. Man findet also Verwandte der Eheleute sowohl auf der einen wie auf der anderen Seite der Eheprozesse, als Verfolger und als Verfolgte. Dies traf auch für den Konflikt in Diedenhofen zu. Der durch die Erweiterung des Inzestverbots entstandene Riss entzweite Mitglieder ein- und derselben Familie.

161 BRÜsCH, Brunonen 2000, 33-36.

162 Einen Überblick geben Kessler, Eheprozess 1923; Reicke, Ehehandel 1974; Косн, Irmgard 2000. Die zuletzt geäußerte Spekulation von Jongbloed, Wanburtich 2006, über die Identität Ottos von Hammerstein mit Otto „von Zutphen“ beruht auf äußerst fragwürdigen Hypothesen. Vor allem leuchtet nicht ein, warum Otto nach einem Ort (Zutphen) benannt worden sein sollte, der möglicherweise zum Herrschaftsgebiet der Familie seiner Frau gehörte. Jongbloeds Äußerungen über die Motive Heinrichs II. im Hammersteiner Eheprozess sind vollends an den Haaren herbeigezogen. Auch wenn man die (quellenmäßig nicht belegte) Ehe der Tochter Ottos mit einem Ezzonen für plausibel halten sollte, bleibt unklar, auf welche Weise das Thronfolgerecht der Ezzonen durch die Verurteilung der Ehe der Schwiegereltern (Ottos und Irmingards) hätte beeinträchtigt werden können. Schließlich ist mit Konrad II. jemand zum König gewählt worden, obwohl seine eigene Ehe mit Gisela Angriffen ausgesetzt war.

163 JACKMAN, Konradiner 1990, $19 \mathrm{f}$.

164 Hlawitschka, Anfänge 1969, 49-54. 
Der politische Charakter des Hammersteiner Eheprozesses ist unumstritten und erfährt sogar bei denjenigen Historikern Zustimmung, die ansonsten den König von einer machtpolitischen Instrumentalisierung des Inzestverbots freisprechen wollen. So räumt Hartmut Hoffmann ein, Heinrich habe im Fall des Hammersteiner Prozesses tatsächlich durch die Konfiskation der Güter einen ökonomischen Nutzen davongetragen ${ }^{165}$. Auch der Verlust der Grafschaften Ottos wird immer wieder ins Feld geführt, um die politische Dimension dieses Verfahrens hervorzuheben ${ }^{166}$. Nach Robert Holtzmann „mussten Otto und Irmingard, um leben zu können, ihre Güter verpfänden, aber sie hielten, in Armut und Elend umherirrend, an ihrer Liebe fest". Sie stünden deshalb „würdig neben den berühmtesten Liebespaaren der Weltgeschichte“167. Diese dramatische Zuspitzung wird von den Quellen nur unzureichend gestützt. Die Deutung des Eheprozesses hängt davon ab, inwieweit man bereit ist, Lücken der Überlieferung durch Vermutungen und Verdächtigungen zu füllen. Der Spekulation ist dabei ein weites Feld überlassen. Es wird daher im Folgenden darum gehen, Plausibilitäten gegeneinander abzuwägen und die Quellen selbst in den Vordergrund zu stellen.

Bereits der Beginn des Eheprozesses nährt Verdächtigungen gegen die redlichen Motive Heinrichs II. Thietmar von Merseburg berichtet in einem kurzen Satz über die Verurteilung der Eheleute auf einer Synode in der königlichen Pfalz Nimwegen: „Mein Vetter Otto und seine Gemahlin Irmingard, die trotz naher Verwandtschaft lange Zeit eine rechtswidrige Ehe geführt hatten, wurden exkommuniziert, weil sie wiederholten Vorladungen keine Folge geleistet hat-

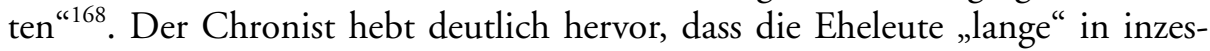
tuöser Verbindung zusammengelebt hatten. Der Prozess fand also in zeitlichem Abstand zur Eheschließung statt. Über ihren genauen Zeitpunkt ist zwar nichts bekannt, doch Otto und Irmingard waren beide schon im fortgeschrittenen Alter ${ }^{169}$. Dieser Abstand zwischen Eheschließung und Prozess wirft die Frage auf, warum gerade in diesem Jahr die Aktivität der Bischöfe einsetzte. Den Grund sehen die meisten Historiker im Ableben von Ottos Bruder Gebhard ${ }^{170}$.

165 Hoffmann, Mönchskönig 1993, 55.

166 MüLler, Heribert 1977, 187; КraH, Absetzungsverfahren 1987, 342-345; Косн, Irmingard 2000, 13.

167 Holtzmann, Geschichte 1941, 446.

168 ... nepos meus Oddo et uxor eius Irmirgerd, consanguinitate proxima iniuste diu coniuncti, ob inobedienciam continuae vocacionis excommunicati sunt; cooperatores vero eorum ab episcopis vocantur suis ad satisfaccionem. Thietmar von Merseburg, Chronica VIII 7 (MGH SS rer. Germ. N.S. 9, 500).

169 Das Geburtsjahr Ottos gibt Hlawitschka, Anfänge 1969, 48, mit ca. 975 an. Hirsch Bresslau, Jahrbücher 3 1875, 72, sprechen vorsichtiger von einem Alter über 30 Jahre.

170 Krah, Absetzungsverfahren 1987, 342; Jackman, Eherecht 1995, 195; Fried, Prolepsis 1995, $71 \mathrm{f}$. 
Dieser starb am 8.11. 1016 ohne Erben. Otto von Hammerstein verblieb als letzter Agnat aus dem Haus der Konradiner und vereinigte „eine Macht, wie sie am Mittelrhein, im Zentrum des ottonischen Reichs, um 1020 kaum ein zweiter Adelsherr aufweisen konnte ${ }^{\text {"171 }}$. Hinzu kamen die „reichen Allodien“ der Irmingard, die „wohl bis nach Friesland und nach Oberfranken reichten “172. Vor diesem Hintergrund erscheint es verständlich, dass der König „die Zeit für gekommen hielt, ohne Waffen, allein auf das Recht gestützt, zum Vernichtungsschlag gegen die Konradiner auszuholen “173. Diese Deutung ist möglich, jedoch nicht zwingend. Über die Besitzungen der Hammersteiner ist nämlich weniger bekannt, als es den Anschein hat. Der Gedanke einer Erbfeindschaft zwischen der Familie Heinrichs II. und den Konradinern ist jedenfalls abwegig. Thietmar berichtet von Ottos Bruder Gebhard, dass „er bei der königlichen Majestät damals viel galt und sich durch große Rechtlichkeit auszeichnete. Er ließ den Kaiser und alle seine Landsleute in großer Trauer zurück “174. Irmingard war die Schwester Gottfrieds von Niederlothringen, den der König erst wenige Jahre zuvor gegen erheblichen Widerstand zum Herzog ernannt hatte und der stets als Wahrer der herrscherlichen Interessen auftrat ${ }^{175}$. Überdies spricht Thietmar von „wiederholten Vorladungen“, die Otto und Irmingard missachtet hätten. Sollten diese Ladungen nur innerhalb von 17 Monaten, zwischen dem Tod Gebhards (8.11.1016) und der Synode von Nimwegen (12.4. 1018) stattgefunden haben?

Einen weiteren Einblick in den Beginn des Prozesses gewähren die Nennungen Ottos in den Urkunden des Königs. In der Forschung ist man der Meinung, Otto habe seine beiden Grafschaften in der Wetterau und im Engersgau im Laufe des Prozesses verloren ${ }^{176}$. Der Befund ist jedoch komplizierter. Otto ist erstmals als Graf der Wetterau, eines konradinischen Erbamtes, am 18.5. 1016 bezeugt $^{177}$. Ein Jahr später, am 8.5. 1017 amtierte dagegen in demselben Gebiet ein Graf Bruning ${ }^{178}$. Hat also Otto die konradinische Grafschaft nach dem Tod seines Bruders am 8.11. 1016 aufgrund des Eheprozesses verloren? Das ist gleichfalls nicht zwingend, da die Synode erst im Jahr 1018 stattfand. Graf Bruning amtierte vermutlich bereits am 17.10. 1016 als Graf und befand sich damals ebenso wie der Konradiner Gebhard im Umkreis

171 Fried, Prolepsis 1995, 71.

172 Fried, Prolepsis 1995, 71.

173 Fried, Prolepsis 1995, 71.

174 Thietmar von Merseburg, Chronica VII 49 (MGH SS rer. Germ. N.S. 9, 458). Darauf weist bereits Weinfurter, Heinrich II. 1999, 200, hin.

175 Weinfurter, Heinrich II. 1999, 224.

176 Müller, Heribert 1977, 187; KRAH, Absetzungsverfahren 1987, 342-345; КосH, Irmgard 2000, 13.

177 MGH D H II. 351. Vgl. Kropat, Reich 1965, 42.

178 MGH D H II. 366. 
des Kaisers in Frankfurt ${ }^{179}$. Wenige Tage danach starb Gebhard. Die Wetterau scheint also bereits vor Gebhards Tod an Bruning gegangen zu sein. Otto war dagegen selbst nach der Synode von Nimwegen noch nicht der Huld des Kaisers verlustig gegangen. Im Sommer 1019 wird er erstmals als Graf im Engersgau erwähnt, in jenem Gebiet, in dem die Burg Hammerstein lag $^{180}$. Erst am 10.8. 1021 ist in diesem Gau ein anderer Graf nachweisbar ${ }^{181}$. Der Befund der Quellen weist folglich weder auf eine Erbfeindschaft zwischen Heinrich II. und Otto von Hammerstein hin noch auf einen Huldverlust des letzteren. Möglicherweise entzog Heinrich dem „letzten Konradiner" nur die Grafschaft Wetterau und verlieh ihm stattdessen die Grafschaft im Engersgau. Ob die Grafennennungen jedoch überhaupt im Zusammenhang mit dem Eheprozess stehen, muss offen bleiben.

Auch der weitere Verlauf des Verfahrens weist nicht auf eine Gegnerschaft zwischen König und Graf, sondern zwischen Graf und Bischof. Wenige Wochen nach der Exkommunikation von Nimwegen unterwarf sich Otto in Gegenwart des Kaisers und des zuständigen Erzbischofs Erkanbald von Mainz auf einer Fürstenversammlung in Bürgel bei Offenbach. Vor drei Bischöfen musste er einen Eid schwören, sich von seiner Frau Irmingard zu trennen ${ }^{182}$. Den Schuldigen für die Verurteilung seiner Ehe machte Otto in Erzbischof Erkanbald von Mainz aus. Erkanbald hatte die Ladungen und die Exkommunikation betrieben und sich erst in Nimwegen der Unterstützung des Kaisers versichert. In Bürgel kannte er keine Milde mit dem „um Gnade flehenden“ Grafen. Dieses unnachgiebige Verhalten forderte nach den ,Spielregeln' der Zeit eine Vergeltungsaktion geradezu heraus. Ein Jahr später eröffnete Otto eine Fehde gegen den Erzbischof. Die Annalen von Quedlinburg berichten uns darüber in einer hochdramatischen Erzählung. Otto habe gegen Erkanbald von Mainz einen Mordanschlag verüben wollen, da ihn dieser nach kirchlichem Herkommen mehrfach wegen seiner unerlaubten Ehe getadelt hätte ${ }^{183}$. Als Erkanbald nur

179 MGH D H II. 358. Vgl. Hirsch - Bresslau, Jahrbücher 3 1875, 39. Der Name Bruning ist nicht häufig. Im 10. Jahrhundert war ein Mann desselben Namens ein Verbündeter der Konradiner in Sachsen: Wenskus, Stammesadel 1976, 237.

180 MGH D H II. 417. Zum Engersgau vgl. Schulze, Grafschaftsverfassung 1973, $211-$ 213.

181 MGH D H II. 446.

182 Quibus expletis fit magna in Birgilun principum confluentia, ut ibi corrigeretur per iudicia quod diu viciatum est populi istius neglegentia, et temeritas magna. Post haec Oddo comes predictus in presentiam imperatoris et Ercanbaldi archipresulis supplex veniens iniustam uxorem suam tribus sacramentis amisit. Thietmar von Merseburg, Chronica VIII 18 (MGH SS rer. Germ. N.S. 9, 514).

183 Interim Otto quidam, nobilium satus prosapia Francorum, illicito sibimet matrimonio incaute asscito, dum ab Arkanbaldo, Moguntinae sedis archiepiscopo, saepius ecclesiastico more pro hoc eodem corriperetur incestu, coeco furibundus amore dispositis circumquaque 
durch den Eingriff Gottes dem Anschlag entkommen sei, habe der Graf die Genossen des Bischofs ergriffen, im Kerker eingesperrt und „vielen Gewalttätigkeiten" ausgesetzt. Als dies dem Kaiser zu Ohren gekommen sei, habe er nach Beratschlagung mit den Fürsten den Grafen zuerst durch Boten, dann durch Vermittler und schließlich persönlich von dieser "nutzlosen Tollheit“ abbringen wollen ${ }^{184}$. Erst nach weiterem Ungehorsam habe man erneut das Anathem über den Grafen ausgesprochen und sei zur Belagerung der Burg Hammerstein aufgebrochen. Dort habe der Kaiser sogar das Weihnachtsfest gefeiert, um den Rebellen in die Knie zu zwingen. Wegen der uneinnehmbaren Lage der Burg sei es jedoch erst der Hunger gewesen, der die Belagerten am 26.12. 1020 zur Aufgabe gezwungen habe. Weil dies am Tag des heiligen Stephan geschehen sei, habe der Graf eine friedliche Aussöhnung erreicht ${ }^{185}$.

Was waren die Bedingungen dieser Aussöhnung? Gewiss akzeptierte der Kaiser Otto von Hammerstein nicht mehr als Amtsträger und entzog ihm die Grafschaft im Engersgau, nachdem er ihn drei Monate in seiner Burg belagert hatte ${ }^{186}$. Die Geschichtsschreibung geht zudem von einer umfassenden Konfiskation der Güter Ottos und Irmingards aus. Dafür scheint ein Beleg aus dem Werdener Heberegister zu sprechen, nach dem die beiden Eheleute dem Kloster ein Gut in Friesland gegen den Wert von 50 Schillingen verpfändeten ${ }^{187}$. Waren Otto und Irmingard also in Geldnot? Auch dieser Befund erweist sich als eine weitgehend haltlose Konstruktion. Die Quelle aus dem Werdener Urbar ist nicht datiert und passt besser in eine spätere Zeit, als die Hammersteiner unter Konrad II. wieder rehabilitiert waren ${ }^{188}$. Die vermeintlichen Konfiskationen wurden bislang nur von dem Hobbyhistoriker August Ortegel in einem Aufsatz aus dem Jahr 1944 untersucht. Diese Arbeit strotzt vor ,genealogischem Beziehungswahn'. Der Autor setzt Irmingard von Hammerstein aufgrund un-

insidiis nefandam eidem christo domini parat inferre manum. Annales Quedlinburgenses a. 1020 (MGH SS rer. Germ. 72, 557).

184 Quod cum imperatori augusto celeri legatione defertur, habita cum episcopis totiusque regni primatibus deliberatione primo per nuncios, deinde per amicos perque semetipsum ab hac inani tentat revocare vesania. Annales Quedlinburgenses a. 1020 (MGH SS rer. Germ. 72, 557).

185 ... sola huius vitae suspiria paciscendo instante celebri per orbem Stephani protomartyris festo se suaque omnia imperatoriae dedunt potestati. Dignum namque erat et iustum, ut, qui eodem die pro inimicis inter cruentos lapidantium ictus pie exoraverat, amicis, matris videlicet ecclesiae filiis, pacem suo reconciliaret interventu. Annales Quedlinburgenses a. 1020 (MGH SS rer. Germ. 72, 558).

186 Siehe $419 \mathrm{f}$.

187 Die Urbare der Abtei Werden (109 f.). Auf diese Quelle machte erstmals Bresslau, Otto 1881, aufmerksam. Bestätigt wurde die Identifikation von Helmolt, Otto 1895.

188 Zwei Zeugen waren Ministerialen unter Abt Gerold (1033 - 1050): Die Urbare der Abtei Werden (109f.). ORTEGEL, Irmingard 1944, 27, setzt den Beleg in Verbindung zu MGH D Ko II. 111 vom 29.10. 1027. 
haltbarer Argumente mit zwei anderen Personen desselben Namens gleich ${ }^{189}$; auf Otto bezieht er Nachrichten, die von der Geschichtsschreibung anderen Personen zugeordnet werden ${ }^{190}$. Nur scheinbar beeindruckend ist die lange Liste an Schenkungen Heinrichs II., die aus konfisziertem Hammersteiner Gut erfolgt sein sollen ${ }^{191}$. Keine einzige Urkunde nennt die Herkunft aus dem Besitz Ottos oder Irmingards, obwohl gerade solche Informationen gewöhnlich erwähnt wurden, weil sie zur Identifikation von Besitzungen nützlich waren. Im Gegenteil, fast alle angeführten Schenkungen nennen die Herkunft aus dem Besitz anderer Personen. Das einzige Argument für Ortegel bestand darin, dass diese Schenkungen während des Prozesses getätigt wurden und an das neu gegründete Bistum Bamberg ergingen. Eine erdrückende Beweislast!

Ausführliche Erläuterung verdient nur ein von Ortegel angeführter Beleg, die Schenkung der umfangreichen Höfe Herzogenaurach und Langenzenn an das Bistum Bamberg, datiert vom 13.11. 1021 ${ }^{192}$. Aus einer undatierten Urkunde aus Bamberg wissen wir, dass diese Schenkung nicht sofort in Kraft trat. Zunächst behielt eine gewisse Irmingard diese Güter bis zu ihrem Todesfall, und erst dann sollten sie zwischen dem Bischof und dem Domkapitel aufgeteilt werden ${ }^{193}$. Ortegel setzt diese Irmingard mit der Gemahlin des Hammersteiners gleich und erschließt daraus große Besitzungen der Familie in Unterfranken ${ }^{194}$. Ungeklärt bleibt in dieser Deutung ein anderer Umstand. Dieselbe undatierte Urkunde nennt nämlich auch den ursprünglichen Besitzer der Güter, und zwar einen gewissen Konrad. Dieser habe den Kaiser in den Besitz eingewiesen, der Kaiser den Bischof, und Irmingard erneut den Bischof ${ }^{195}$. Guttenberg hat aus dieser Besitzfolge die Folgerung gezogen, dass es sich bei Irmingard vermutlich um die Frau Konrads handelt, die als „Leibgeding“, also als Versorgung nach

189 Mit Irmingard von Rees (dagegen Oediger, Irmingard 1949; Косн, Irmgard 2000, 23) und mit der Irmingard in den Bamberger Urkunden (siehe 422 Anm. 194). U.a. beruft er sich für die Identifikationen auf architektonisch ähnliche Kirchenbauten: OrTEGEL, Irmingard 1944, 28.

190 Vgl. ORTegel, Irmingard 1944, 16-19: z. B. die Nennung eines Otto in Thietmar von Merseburg, Chronica V 35 (MGH SS rer. Germ. N.S. 9, 260, vgl. dagegen den Kommentar Holtzmanns zur Stelle). Auch Hicila, die Tochter eines Grafen Otto, wird nicht als eine Tochter des Hammersteiners anzusehen sein, da dieser sonst noch am 8.3. 1024 als Graf amtiert hätte: MGH D H II. 506. Sie wird als Tochter Ottos von Schweinfurt angesehen: Kat. Kaiser Heinrich II. 2002, 210 (Wilhelm Störmer).

191 MGH D H II. 401 vom 12.5. 1019; MGH D H II. 417 nach 15.8. 1019; MGH D H II. 438 vom Januar 1021; MGH D H II. 454 vom 11.11. 1022; MGH D H II. 456458 vom 13.11. 1021; MGH D H. II. 496 vom 2.9. 1023; MGH D H II. 506 vom 8.3. 1024. Die Liste wird weitgehend reproduziert von Wolter, Synoden 1988, 275.

192 MGH D H II. 456-458.

193 Guttenberg, Regesta 1963, 181 (84 f.).

194 Ortegel, Irmingard 1944, 22-29. Ihm folgen Wolter, Synoden 1988, 275; Reicke, Ehehandel 1974, 209; Fried, Prolepsis 1995, 71; Weinfurter, Heinrich II. 1999, 199.

195 Guttenberg, Regesta 1963, 181 (84f.). 
dem Tod ihres Mannes, diese Güter an sich genommen hatte ${ }^{196}$. Die landesgeschichtliche Forschung hat sich dieser Deutung angeschlossen ${ }^{197}$. Sie ist überzeugender als Ortegels These, die Tochter eines lothringischen Grafen habe ihren Besitzschwerpunkt in Unterfranken besessen.

Das gesamte Gebäude einer Konfiskation des konradinischen Besitzes bricht also in sich zusammen. Selbst die Einziehung der Burg Hammerstein ist nicht belegt und angesichts der Benennung Ottos in den Quellen auch nicht wahrscheinlich ${ }^{198}$. Die weitere Geschichte des Eheprozesses wird diese Sichtweise bekräftigen. Im Jahr 1023 verhandelte eine weitere Synode in Mainz über die Ehe Ottos und Irmingards. Der Erzbischof Erkanbald war inzwischen im Jahr 1021 verstorben und durch den Bayern Aribo ersetzt worden ${ }^{199}$. Aribo lud auch den Kaiser zur Teilnahme an der Synode nach Mainz ein. Das wichtigste Verhandlungsthema war das weitere Zusammenleben von Otto und Irmingard von Hammerstein $^{200}$. Aribo verfügte nochmals die dauerhafte Trennung. „Dies gelang ihm jedoch nicht vollständig, weil jener teils aus Angst vor dem König, teils aus Angst vor der bischöflichen Ermahnung nachgab, jene aber öffentlich den Bann übertrat und dort vollkommen Recht und Gesetz verlor, wie selbst heute

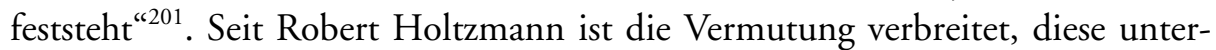
schiedliche Reaktion gehe auf taktische Erwägungen der Eheleute zurück ${ }^{202}$. Dies mag sein. Das Nachgeben Ottos macht jedoch nur Sinn, wenn er noch etwas zu verlieren hatte, eben seine Eigengüter. Ebenso stellt die Quelle eindeutig fest, dass Irmingard erst jetzt vollständig die Huld des Kaisers verlor und die Konfiskation ihres Besitzes zu erwarten hatte. Nach der Synode von Mainz ist jedoch keine der von Ortegel angeführten Schenkungen aus Königsgut ergangen. Es ist also in Zweifel zu ziehen, ob Heinrich II. die Konfiskation der Güter überhaupt jemals in die Tat umgesetzt hat.

Der Ablauf der Ereignisse nach der Synode von Mainz bestätigt die Einschätzung, dass der Eheprozess gegen die Hammersteiner vor allem eine Sache des Mainzer Erzbischofs war. Irmingard hatte sich nämlich bereits vor der Synode auf den Weg nach Rom gemacht, um bei Benedikt VIII. gegen das

196 Guttenberg, Regesta 1963, 181 (84f.).

197 Guttenberg, Rangau 1949, 44; Hofmann, Herzogenaurach 1950, 31 f; Störmer, Schenkungen 1996, $397 \mathrm{f}$.

198 Bresslau, Jahrbücher 2 1915, 360.

199 Vgl. MüLler, Aribo 1881, 25-36.

200 Wolter, Synoden 1988, 292-294.

201 Praecipue tamen Ottonem comitem de Hamerstein et Yrmingardam inlicite commanentes separare disposuit; quod tamen penitus perficere non potuit, quia ille se partim regali timore, partim episcopali commonitione utcumque correxit, illa vero publice bannos praevaricans, ibidem ius legemque, ut vel hodie claret, funditus perdidit. Wolfhere, Vita Godehardi posterior c. 19 (MGH SS 11, 206).

202 Holtzmann, Geschichte 1941, 447; Reicke, Ehehandel 1974, 218; Wolter, Synoden 1988, 294. 
Vorgehen des Erzbischofs Berufung einzulegen. Aribo reagierte umgehend und versammelte wenige Wochen später erneut eine Synode am 12.8. $1023 \mathrm{im}$ Kloster Seligenstadt ${ }^{203}$. Anwesend waren die Bischöfe Burchard von Worms, Werner von Straßburg, Brun von Augsburg, Eberhard von Bamberg und Meginhard von Würzburg. Obwohl insgesamt 20 Kanones unterschiedlichen Inhalts verabschiedet wurden, stand der Hammersteiner Eheprozess offenbar im Mittelpunkt der Versammlung. Dies wird an zwei Bestimmungen deutlich. Kanon 11 legt die Zählung nach Vetterschaften bei der Berechnung der Verwandtschaft fest ${ }^{204}$. Kanon 18 verbietet denjenigen, denen eine Buße vom zuständigen Bischof auferlegt wurde, vor der Leistung der Buße und ohne $\mathrm{Zu}$ stimmung des Bischofs nach Rom zu pilgern: „weil viele durch eine solche geistige Dummheit getäuscht werden, dass sie eines bestimmten Kapitalverbrechens überführt sich weigern, die Buße von ihren Bischöfen anzunehmen, darauf vertrauend, dass der Papst den Rompilgern alle Sünden erlässt ${ }^{\text {“205. Beide }}$ Bestimmungen beziehen sich auf den Hammersteiner Prozess, und beide Bestimmungen haben ihre Grundlage im Dekret Burchards von Worms ${ }^{206}$. In Seligenstadt legte man erstmals diese neue Sammlung des Kirchenrechts, die im 11. Jahrhundert eine breite Wirkung entfalten sollte, der Beratung zugrunde. Der Papst in Rom saß jedoch kirchenrechtlich gesehen am längeren Hebel und war nicht gewillt, einen derartigen Eingriff in seine Rechte hinzunehmen. Benedikt VIII. schickte einen Legaten mit der Botschaft nach Mainz, Aribo sei es von nun an untersagt, das Pallium als Abzeichen der erzbischöflichen Würde $\mathrm{zu}$ tragen $^{207}$. Der Eheprozess wurde somit zu einem Konflikt innerhalb der kirchlichen Hierarchie. Benedikt nahm wohl weniger an der Verfolgung des Inzestdelikts Anstoß als an den romfeindlichen Beschlüssen des Konzils von

203 Wolter, Synoden 1988, 297-306.

204 De computatione consanguinitatis. Quidam generationem consanguinitatis ita volunt numerare, ut frater et soror sint primi. Statuit autem sancta synodus, sicut etiam ab antiquis patribus decretum est, ut ita non sit, sed ut nepos et neptis vel filius fratris ac filia sororis primi habeantur. Konzil von Seligenstadt (1023) c. 11 (MGH Const. 1, 638). Der Verweis auf die antiqui patres bezieht sich auf Burchards Interpolation eines Textes von Isidor von Sevilla. Siehe 430 Anm. 242.

205 Quia multi tanta mentis suae falluntur astutia, ut in aliquo capitali crimine inculpati paenitentiam a suis sacerdotibus accipere nolunt, in hoc maxime confisi, ut Romam petentibus apostolicus omnia dimittat peccata ... Konzil von Seligenstadt (1023) c. 18 (MGH Const. 1, 638).

206 C. 11 bezieht sich auf Burchard, Decretum VII 10 (Migne PL 140, 781) und c. 18 auf Decretum II 80 (Migne PL 140, 640) und XIX 51 (Migne PL 140, 995). Vgl. Fournier - Le Bras, Histoire 1 1931, 392. Siehe auch 426 Anm. 216.

207 De legatione sedis apostolicae quid facturus sim. Quia, sicut antea tibi per epistolam meam mandavi, ex delatione anathematizatae Imme apostolicus mihi interdixit ornatus primos dignitatis meae. Epistolae Moguntinae 23 (359) [Brief Aribos an Bischof Meginhard von Würzburg]. 
Seligenstadt. Den Jurisdiktionsprimat des apostolischen Stuhles hatte er bereits in einem anderen Konflikt mit König Knut dem Großen zur Geltung gebracht ${ }^{208}$. Erzbischof Aribo war jedoch nicht leicht zum Schweigen zu bringen. Er berief erneut eine Synode in Höchst ein und setzte sich mit einem vertraulichen Schreiben bei Kaiserin Kunigunde für eine möglichst zahlreiche Teilnahme der Reichsbischöfe ein ${ }^{209}$. Die Bischöfe seiner Kirchenprovinz schickten einen Protestbrief an den Papst und beklagten darin, dass einer exkommunizierten Frau in Rom mehr Vertrauen geschenkt werde als den auf einer Synode versammelten Bischöfen. Nochmals wurde die Forderung erhoben, dass Irmingard entweder in Ewigkeit verflucht oder sich bis ans Ende ihres Lebens der Kirchenbuße unterwerfen sollte ${ }^{210}$.

Der Konflikt zwischen Benedikt und Aribo fand durch den Tod des Papstes am 9.4. 1024 ein vorzeitiges Ende. Die Synode von Höchst, die für den 13.5. 1024 anberaumt war, ist vermutlich nicht mehr zusammengetreten ${ }^{211}$. Dennoch musste sich Aribo letztlich geschlagen geben. Als er im Jahr 1027 auf einer Reichssynode in Frankfurt erneut den Fall der Hammersteiner Ehe vorbrachte, wies Kaiser Konrad II. dieses Ansinnen öffentlich ab. Auf seine Bitte hin wurde der Fall nicht nochmals aufgenommen ${ }^{212}$. Otto und Irmingard erfreuten sich der Gunst des ersten Saliers und konnten von nun an ungestört ihre Ehe fortzusetzen $^{213}$.

Das Ende des Hammersteiner Eheprozesses führt nochmals deutlich vor Augen, dass die Angelegenheit ein Politikum ersten Ranges war. Selbst ein so mächtiger Mann wie Aribo von Mainz war bei der Verfolgung dieser Inzestehe auf die Unterstützung des Königs angewiesen. Heinrich II. hatte den Bischöfen auf Synoden in Diedenhofen und Sachsen einen Freibrief zur Verfolgung von Inzestvergehen gegeben und sie unmissverständlich zu härterem Vorgehen aufgefordert. Danach ging die Initiative auf die Bischöfe über. Die Quellen

208 Herrmann, Tuskulanerpapsttum 1973, 109-117.

209 Epistolae Moguntinae 24 (360-362). Aribo befürchtet, dass Erzbischof Pilgrim von Köln senioris mei artificioso consilio nicht an der Synode teilnehmen werde. Wenn damit tatsächlich der Kaiser angesprochen ist (so Wolter, Synoden 1988, 307 und WeinFURTER, Heinrich II. 1999, 102), dann hätte Heinrich zu diesem Zeitpunkt kein Interesse an der Verfolgung der Hammersteiner gezeigt. HAUCK, Kirchengeschichte 31954 , 359, sieht darin jedoch eine Bezugnahme auf den Papst.

210 Epistolae Moguntinae 25 (363).

211 Die verschiedenen Positionen hat Wolter, Synoden 1988, 308-311, zusammengetragen. Ich halte die Vermutung Wolters, man habe auf der Synode mit Absicht den Brief an den bereits verstorbenen Papst adressiert, für abwegig. Nach dem Tod des Papstes war es wohl angemessener, die Haltung des Nachfolgers zu erkunden.

212 De Ottone vero, illo Hamerstaenensi eiusque coniuge Hirmingarda pro iniusta eorum copulatione ratio est sinodaliter incepta, attamen praece imperatoris intercepta. Wolfhere, Vita Godehardi prior c. 31 (MGH SS 11, 190). Vgl. Wolter, Synoden 1988, 335 f.

213 Siehe unten $442 \mathrm{f}$. 
schreiben übereinstimmend die Prozesse der folgenden Jahre den Bischöfen und nicht dem König zu. Der Herrscher griff stets erst dann in das Geschehen ein, wenn die Bischöfe auf Widerstand stießen und die Verhängung der Exkommunikation offen missachtet wurde. Dann war eine Synode mit Beteiligung des Königs das probate Mittel, um die Eheleute durch die Bloßstellung vor einer breiten Öffentlichkeit in die Knie zu zwingen. Widerstand durch die betroffenen Personen war nicht die Ausnahme, sondern die Regel. Die Forderung nach Einhaltung der Inzestgrenze des 7. Grades kanonischer Zählung war ein Bruch mit der bisherigen Tradition des Kirchenrechts und musste zwangsläufig Unverständnis und Widerstand hervorrufen. Was wir bei den anderen Fällen nur vermuten können, ist im Fall Konrads von Kärnten ausgesprochen. Er habe seine Ehe mit Mathilde „ohne Bewusstsein der Sündhaftigkeit ${ }^{\text {“214 }}$ geschlossen. In der Regierungszeit Heinrichs II. sieht man die Bischöfe an der Arbeit, dieses Bewusstsein zu verändern. Die Schwierigkeiten zeigen sich an der Erfolgsquote: In drei von fünf Fällen setzten sich die Eheleute gegen die Anschuldigungen zur Wehr und konnten an ihrer Ehe festhalten. Die Eheschließung Reginars V. von Hennegau zeigt, woran es den Bischöfen gefehlt hat: an einer anerkannten Kirchenrechtssammlung, die dem 7. Grad kanonischer Zählung endgültig gegen die Persistenz abweichender Texte wie den Libellus responsionum zum Durchbruch verhalf. Diese Sammlung befand sich erst in Arbeit: das Decretum Burchards von Worms.

\section{Das Dekret Burchards von Worms}

In die Regierungszeit Heinrichs II. fällt die Entstehung der Kirchenrechtssammlung Bischof Burchards von Worms. Die Fertigstellung des Dekrets datiert in die Jahre nach $1012^{215}$. Im Jahr 1023 wird das Handbuch erstmals auf der Synode von Seligenstadt herangezogen, um u. a. die Verwandtschaftszählung bei Inzestprozessen festzulegen ${ }^{216}$. Auch andere Quellen weisen auf eine überaus schnelle Verbreitung und Vervielfältigung des Dekrets im Reich nördlich und südlich der Alpen ${ }^{217}$. Die Überlieferung in ca. 80 vollständigen und weiteren fragmentarischen Handschriften bezeugt die Beliebtheit von Burchards Werk. Man geht davon aus, dass es kaum „ein bedeutenderes Bistum oder Kloster in

214 Siehe 406 Anm. 108.

215 Zum Forschungsstand vgl. zuletzt Hoffmann - Pokorny, Dekret 1991; Hartmann, Dekret 2000; Austin, Jurisprudence 2004; DiEs., Freising 2007.

216 Zur Benützung des Dekrets vgl. Амiet, Gesetzgebung 1976, 261; Ritzer, Formen 1962, 293; Laudage, Priesterbild 1984, 87 f. Die Skepsis von Wolter, Synoden 1988, $304 \mathrm{f}$, ist nicht berechtigt. Die neuartige Vorschrift über das Heiratsverbot zu bestimmten Festzeiten konnten die Bischöfe nur in Burchards Decretum IX 4 (Migne PL 140, 816) finden: Konzil von Seligenstadt (1023) c. 3 (MGH Const. 1, 637).

217 Hoffmann - Pokorny, Dekret 1991; Jasper, Dekret 2000, 168-171. 
Deutschland oder Italien gab, dass nicht seinen Burchard besessen hätte ${ }^{\text {«218 }}$. Der Erfolg der Sammlung liegt in der Kombination mehrerer Eigenschaften begründet. Am wichtigsten war sicher die praktische Ausrichtung als ein Handbuch für die bischöfliche Verwaltung, die Burchard von seiner Hauptquelle Regino von Prüm übernahm ${ }^{219}$. Durch systematische Gliederung in 20 Bücher gelang es ihm, die Benutzbarkeit der Sammlung noch zu steigern. Anders als Regino war Burchard auch bestrebt, das Kirchenrecht durch die Auswahl der Bestimmungen und durch Eingriffe in den Text zu vereinheitlichen. Gerade die Widersprüchlichkeit und Dissonanz des überkommenen Rechts war nach Auskunft des Prologs der Anlass für die verbreiteten Missstände in der Diözese, die den Bischof zur Abfassung der Sammlung motivierten ${ }^{220}$. Die von Regino tradierten Unterschiede in der Bemessung der Bußzeiten wurden von Burchard rigoros vereinheitlicht ${ }^{221}$. In den Zeiten einer fehlenden Positivierung des Rechts war es für Burchard unvermeidlich, sich der Methode eines Fälschers zu bedienen, wenn er die Systematisierung der Tradition vorantreiben wollte.

Besonders einschneidend sind die Bestimmungen zum Inzestverbot in Buch 7 durch Eingriffe Burchards verändert worden. In der Forschung ist bereits mehrfach festgestellt worden, dass die Frage der Verwandtenehe die Aufmerksamkeit des Kanonisten auf sich gezogen und ihn zu einer Reihe von Fälschungen angeregt hat ${ }^{222}$. Es liegt nahe, von dieser Tatsache eine Verbindung zur Inzestkampagne Heinrichs II. zu ziehen. Burchard befand sich nämlich von Beginn an im Lager des bayerischen Thronprätendenten und sagte ihm gemeinsam mit Erzbischof Willigis von Mainz seine Unterstützung $\mathrm{zu}^{223}$. Willigis hatte in den letzten Jahren Ottos III. die Erfahrung machen müssen, dass der junge Kaiser nicht mehr den Mainzer Erzbischof als bevorzugten Partner behandelte, sondern mit Hilfe des von ihm eingesetzten Papstes die Reichskirche beherrschte ${ }^{224}$. Willigis und Burchard schlugen sich deshalb im Unterschied zur engeren Umgebung Ottos III. sofort auf die Seite Heinrichs. Dieser soll den beiden Bischöfen damals die Erfüllung ihrer Wünsche zugesagt haben ${ }^{225}$. Nach der Krönung in Mainz am 7.6. 1002 zog Heinrich weiter nach Worms, um dort

218 Jasper, Dekret 2000, 168; Mordek, Kanonistik 1985, 73. Die Überlieferung sichtet KÉry, Collections 1999, 133-148.

219 Vgl. Fournier - Le Bras, Histoire 1 1931, 413; Fuhrmann, Einfluss 1972, 472; Austin, Jurisprudence 2004.

220 Burchard von Worms, Decretum prol. (45 f.).

221 Körntgen, Fortschreibung 2000; Ders., Law 2006.

222 Fournier - Le Bras, Histoire 1 1931, 407 f.; Landau, Recht 1988, 31; Corbet, Burchard 2001, 91.

223 Weinfurter, Heinrich II. 1999, 48; Schieffer, Burchard 2000.

224 Hehl, Herrscher 1997; Ders., Willigis 2000. Daneben spielten bei der Entscheidung gegen Hermann von Schwaben auch territorialpolitische Interessen eine Rolle.

225 Deinde omnia, quae voluissent, si voluntati consentirent, se facturum promisit. Vita Burchardi 9 (109). 
den Rhein zu überqueren und zum Angriff auf seinen Konkurrenten Hermann von Schwaben anzusetzen. Dort erließ der König seine erste Urkunde, eine Übertragung des Wildbannes an die Bischofskirche von Worms ${ }^{226}$. Kurze Zeit später übergab er Burchard die Hauptburg der Salier in Worms und beendete damit den Konflikt zwischen dem Bischof und der mächtigen Adelsdynastie um die Stadtherrschaft ${ }^{227}$. Die insgesamt 13 Königsurkunden an Burchard zeugen von einem engen Vertrauensverhältnis, obwohl sich der Bischof nach den Anfangsjahren zunehmend aus dem Reichsdienst zurückzog und sich der Verwaltung des Bistums sowie der Abfassung der Kirchenrechtssammlung widmete ${ }^{228}$.

Trotz des engen Vertrauensverhältnisses ist oft nach der Vereinbarkeit von Heinrichs straffem Kirchenregiment mit den im Dekret überlieferten Normen gefragt worden. Ohne Heinrichs Zustimmung war es nicht möglich, ein Bischofsamt im Reich zu erlangen. Dies widersprach den Regeln des Kirchenrechts, wie sie auch Burchard in seinem Dekret wiedergibt ${ }^{229}$. Burchard ist jedoch nicht zu einer grundsätzlichen Kritik am Kirchenregiment des Königs vorgedrungen ${ }^{230}$. Der König engagierte sich selbst massiv für kirchliche Belange und förderte durch Schenkungen die Eigenständigkeit der Bischöfe gegenüber der adeligen Konkurrenz vor Ort. Der Bischof von Worms hatte keinen Anlass, die Normen des Kirchenrechts gegen den König in Stellung zu bringen. Schließlich war das königliche Kirchenregiment nicht der einzige Punkt, in dem das Kirchenrecht nicht mit der Realität harmonierte.

Die enge Kooperation zwischen Bischof und König wird durch das Inzestrecht bestätigt. So wie Heinrich als erster König im Ostfrankenreich in Diedenhofen (1003) für die Inzestgrenze des 7. Grades eine Lanze brach, machte sich Burchard im Dekret für dasselbe Anliegen stark. Angesichts der Quellen des 9. und 10. Jahrhunderts war dies keineswegs selbstverständlich. Die Grenze des 7. Grades war im Ostfrankenreich weder anerkannt noch hinreichend verbreitet. Die wichtigsten Quellen dafür, Pseudo-Gregor und Benedictus Levita, zirkulierten fast ausschließlich im Westfrankenreich ${ }^{231}$. Entscheidend für

226 MGH D H. II. 1.

227 MGH D H. II. 20. Vgl. Weinfurter, Zentralisierung 1986, 280 f.; Zotz, Adelsherrschaften 2000, 365-368.

228 SCHIEFFer, Burchard 2000, 40.

229 Vgl. Laudage, Priesterbild 1984, 62.

230 Vgl. Fournier - Le Bras, Histoire 1 1931, 381-388; Fuhrmann, Einfluss 1972, 485; SCHIEFFER, Priesterbild 1986, 484 f.; DERs., Burchard 2000, 48 f.

231 Benedictus Levita war nur in Mainz bekannt: Gotha, Forschungs- und Landesbibliothek, Mbr. I.84; Vatikan, Biblioteca Apostolica Vaticana, Pal. lat. 583. Vgl. die Literatur bei KÉrY, Collections 1999, $118 \mathrm{f}$. Der Pseudo-Gregor-Brief ist erstmals in folgenden Handschriften aus dem Reichsgebiet bezeugt: Köln, Erzbischöfliche Diözesan- und Dombibliothek 114, aus der Zeit Erzbischof Heriberts: Hoffmann, Buchkunst 1986, 410; John, Collectio 1976, 62; Williams, Codices 1971, S. 26 f.; München, Bayerische Staatsbibliothek, Clm 3853, fol. 263r-v: siehe 409 Anm. 123. 
die Rezeption der Grenze des 7. Grades im Osten war die Lebensbeschreibung Gregors des Großen durch Johannes Diaconus aus dem ausgehenden 9. Jahrhundert. Der Autor widmete dem Briefwechsel mit Augustinus von Canterbury ein Kapitel seiner Vita und setzte dem Libellus responsionum die Fälschung Pseudoisidors entgegen. Die Vita war im Mittelalter ein Bestseller und verbreitete sich rasch im Ostfrankenreich. Bereits um 900 zitierte Notker von St. Gallen aus dem Werk des römischen Diakons ${ }^{232}$. Aus dem 10. Jahrhundert sind 15 Handschriften erhalten, acht davon stammen aus dem Reich nördlich der Alpen $^{233}$. Die beiden Bischöfe Abraham von Freising und Wolfgang von Regensburg, die in den Quellen als Erzieher Heinrichs II. genannt werden, hatten in ihren Bibliotheken Zugang zur Vita Gregorii ${ }^{234}$ und könnten die Norm des 7. Grades an den zukünftigen König vermittelt haben.

Die Dekretale Pseudo-Gregors erlangte also im Lauf des 10. Jahrhunderts Bekanntheit durch die Verbreitung der Vita Gregorii. Es musste allerdings noch der Schritt gemacht werden, die in der Vita überlieferte Dekretale für das Kirchenrecht fruchtbar zu machen. Dies geschah in einem durch drei Handschriften überlieferten Anhang zu Reginos Sendhandbuch. Dieser Anhang entstand um das Jahr 1000 und enthält den Pseudo-Gregor-Brief aus der Vita Gregorii als eigenständigen Kanon des Kirchenrechts ${ }^{235}$. Eine dieser drei Handschriften entstand in Mainz und wurde darüber hinaus durch einige nur dort verfügbare Schriftstücke ergänzt. Z.B. findet sich in der Handschrift der Brief Gregors V. an Willigis von Mainz, in dem der Papst die gegen Robert von Frankreich gerichteten Beschlüsse der Synode von Pavia mitteilte ${ }^{236}$. Dieser Brief scheint ein besonderes Interesse des Urhebers der Handschrift am Inzestverbot ausgelöst zu haben. Denn am Ende der Handschrift steht ein Verwandtschaftsstemma, das von der Epistola de gradibus consanguinitatis aus der Um-

232 Wilhelmi, Vita 1998, 14-27. In Sankt Gallen waren zwei Handschriften aus dem ausgehenden 9. Jahrhundert vorhanden: Stiftsbibliothek, 554 und 578, vgl. CASTALDI, Vita 2004, 318-323.

233 Vgl. die Übersicht bei Castaldi, Vita 2004, XLV-XLVIII.

234 Einsiedeln, Stiftsbibliothek, 254, vgl. Castaldi, Vita 2004, 110-113; Hoffmann, Schreibschulen 2004, 104 f.; München, Bayerische Staatsbibliothek, Clm 6255, vgl. Castaldi, Vita 2004, 214-217.

235 Regino von Prüm, De synodalibus causis App. II 2 (423 f.). Dieser Appendix ist enthalten in Wolfenbüttel, Herzog August Bibliothek, Aug. 83.21, Wien, Österreichische Nationalbibliothek, Lat. 694 (beide Handschriften sind in Mainz um 1000 entstanden, vgl. Hoffmann, Buchkunst 1986, 262 u. 266) und in Paris, Bibliothèque Nationale, lat. 17527 aus der ersten Hälfte des 11. Jahrhunderts (vgl. Kéry, Collections 1999, 129). Der Appendix II ist erstmals in Mainz fassbar; ob er tatsächlich dort entstanden ist, muss erst eine eigenständige Untersuchung klären.

236 Eine eingehende Beschreibung der Handschrift liefert LotTER, Brief 1975, 13-21. Zur Überlieferung des Papstbriefes an Willigis vgl. HeHL, Herrscher 1997, $170 \mathrm{f}$. 
gebung des Bonifatius umrahmt wird ${ }^{237}$. Dieselbe Kombination von der um den Pseudo-Gregor-Brief erweiterten Sammlung Reginos mit einem Stammbaum bietet auch die Handschrift, die Burchard von Worms für sein Decretum benutzte $^{238}$. Diese Handschrift ist ebenfalls in Mainz um die Jahrtausendwende entstanden. Burchard fungierte vor seiner Ernennung zum Bischof im Jahr 1000 als Kämmerer des Erzbischofs in Mainz ${ }^{239}$ und war mit diesen Handschriften vertraut.

Wenn man nach der Herkunft der Grenze des 7. Grades in der Diedenhofener Rede Heinrichs II. fragt, weisen folglich alle Indizien nach Mainz und Worms. Nur dort hat man um das Jahr 1000 mit der Tradition des 9. und 10. Jahrhunderts gebrochen und sich eindeutig für diese Inzestgrenze ausgesprochen. In seinem Decretum scheut Burchard nicht vor offenkundigen Fälschungen zurück, um diese Grenze durch konziliare Quellen abzusichern. Zwei Kanones verfälscht er in diesem Sinn. Darüber hinaus greift er auf vier Kapitel aus Benedictus Levita zurück, die den 7. Grad befürworten und mit denen Burchard ebenfalls in Mainz in Berührung gekommen ist ${ }^{240}$. Insgesamt enthalten 13 von 30 Kapiteln des siebten Buchs die Vorschrift, dass Ehen bis in den 7. Grad der Verwandtschaft als Inzest zu gelten haben. Darin ist die zentrale Botschaft Burchards zu sehen ${ }^{241}$.

Eine weitere Übereinstimmung zwischen Heinrich II. und Burchard ist die sog. Zählung nach Vetterschaften. Der König vertrat in Diedenhofen die Ansicht, bei der Zählung von Verwandten sollte erst bei den Enkeln des Stammvaters begonnen werden. Die inkriminierte Ehe Konrads von Kärnten (4/4) hielt er deshalb für eine Ehe im dritten und nicht im vierten Grad. Auch Burchard spricht sich für eine solche Zählung aus, jedoch mit anderer Begründung. Ihm zufolge bilden die Eltern gemeinsam mit den Kindern den Stamm, aus dessen Wurzeln die Nachkommen wie Zweige hervorgehen ${ }^{242}$. Dementsprechend verändert er den Wortlaut der von ihm zitierten Epistola de gradibus consanguinitatis, indem er den ersten Grad nicht mit den Kindern, sondern mit den Enkeln gleichsetzt. Worauf sich Burchard bei dieser Begrün-

237 Wolfenbüttel, Herzog August Bibliothek, Aug. 83.21, fol. 172v.

238 Kerner u.a., Textidentifikation 1976, 53-55, weisen nach, dass Burchard eine Handschrift in der Art von Wien, Österreichische Nationalbibliothek, 694, benützte. Das Stemma befindet sich auf fol. 1r. Siehe Abb. 3.

239 Vita Burchardi 2 (103).

240 Siehe 428 Anm. 231.

241 Corbet, Burchard 2001, 94 f., legt dagegen den Akzent auf das zu Beginn stehende kategorische Verbot von Verwandtenehen. M.E. ist es jedoch nicht verwunderlich, dass Burchard die Reihe der Inzestvorschriften mit einem unumstrittenen Kanon beginnt.

242 Filius et filia, quod est frater et soror, sit ipse truncus. Illis seorsum seiunctis, ex radice illius trunci egrediuntur isti ramusculi, nepos et neptis primus, ... Burchard, Decretum VII 10 (Migne PL 140, 781). Eine Gegenüberstellung mit der Vorlage findet sich bei Corbet, Burchard 2001, $99 \mathrm{f}$. 
dung bezieht, ist unklar. In den mit dem Decretum verbundenen Stammbäumen wird die gesamte Nachkommenschaft als Stamm abgebildet, während die Vorfahren als Zweige dargestellt sind ${ }^{243}$. Burchards Beschreibung der Nachkommen als Zweige eines Stammbaumes steht in Widerspruch dazu.

Dies ist nicht die einzige Unstimmigkeit in Burchards Text. Mit der Zählung nach Vetterschaften stimmt nämlich c. 28 des siebten Buchs nicht überein. Darin listet Burchard alle Verwandtschaftsnamen nach den spätantiken Pauli Sententiae auf, die er einem Anhang der Etymologien Isidors von Sevilla entnommen hat ${ }^{244}$. Dieser Text zählt nach der unverfälschten römischen Komputation und lässt die Zählung nach Vetterschaften außer Acht. Dies führt zu der grundsätzlichen Frage, welche Zählung Burchard verwendet hat. In der älteren Forschung sind nie Zweifel daran geäußert worden, dass der Wormser Bischof die Zählung nach Vetterschaften mit der kanonischen Komputation in Generationen kombinierte ${ }^{245}$. Schließlich wurde er auch von den mittelalterlichen Benutzern seiner Sammlung in dieser Weise verstanden. Da Burchard die Grenze des 7. Grades ausdrücklich exklusiv versteht ${ }^{246}$, hat er somit Ehen bis zur Verwandtschaft von 7/7 für verboten gehalten ${ }^{247}$. Erst jüngst zog Patrick Corbet diese Deutung des Decretum in Zweifel. Er beruft sich dabei auf dasselbe Argument, das auch für die Unterstellung der römischen Zählung bei Heinrich II. verwendet wird: Die Anwendung der Zählung nach Vetterschaften mache nur dann Sinn, wenn auf diese Weise bislang nicht verdächtigte Ehen unter das Inzestverbot fielen. Corbet unterstellt Burchard mit der Einführung der Zählung nach Vetterschaften eine kirchenrechtliche Manipulation zu politischen Zwecken ${ }^{248}$.

Wie im Fall Heinrichs II. halte ich diese Argumentation auch bei Burchard von Worms für verfehlt ${ }^{249}$. Die Verwendung der römischen Komputation hätte es nicht erlaubt, Ehen wie diejenige zwischen Reginar V. von Hennegau und

243 Vgl. Sснаdт, Arbores 1982, 109-122. Dies trifft auch für die Abbildung aus der Handschrift Saint-Omer, Bibliothèque Municipale, 194 bei Fried, Prolepsis 1995, 76, zu.

244 Burchard, Decretum VII 28 (Migne PL 140, 784 f.). Die Herkunft aus Isidor erkannte Conrat, Arbor 1909, 25.

245 Freisen, Geschichte 1893, 417 (der diese Art der Zählung als „germanisch“ bezeichnete); Esmein, Mariage 1 1891, 351 f.; Koeniger, Burchard 1905, 157 f.; Fournier Le Bras, Histoire 1 1931, 407.

246 Das zeigen die Interpolationen Burchards in Decretum VII 18 (Migne PL 140, 782): Contradicimus quoque ut in quarta <vel quinta sextaque $>$ generatione ... und in Decretum 7, 30 (Migne PL 140, 786). Vgl. Koeniger, Burchard 1905, 158.

247 Und nicht bis zu 8/8, wie Corbet der von ihm abgelehnten Deutung unterstellt: Corbet, Burchard 2001, 103.

248 Corbet, Burchard 2001, 102 f. Ihm folgt Hlawitschka, Konradiner-Genealogie 2003, 95.

249 Zum Folgenden siehe 408-410. 
Mathilde oder zwischen Konrad II. und Gisela als Verstöße gegen das Inzestverbot wahrzunehmen. Selbst die Ehe Konrads von Kärnten wäre als ein Grenzfall nur schwer einer derart vehementen Anklage unterzogen worden, zumal die Ehe ja schon einige Zeit bestanden hatte. Prozesse gegen einen Grenzfall des Inzests hätten kaum Aussicht auf Erfolg gehabt. Burchard von Worms war jedoch 1003 in Diedenhofen mit Sicherheit auf der Seite Heinrichs II. und unterstützte den König bei seiner Wertung der Ehe Konrads als einen besonders schwerwiegenden Falls von Inzest. Als treibende Kraft wird man den Wormser Bischof auch auf der Synode von Seligenstadt (1023) ansehen müssen. Dort wurde die Zählung nach Vetterschaften in einer Weise in das Kirchenrecht aufgenommen, die eindeutig eine Zählung in Generationen voraussetzt. Außerdem verdient nochmals festgehalten zu werden, dass eine Kombination von römischer Zählung und Zählung nach Vetterschaften keinen Sinn macht und historisch nicht nachweisbar ist.

Neben diesen allgemeinen Gründen spricht auch das Dekret selbst gegen die Zuschreibung der römischen Komputation. Der einzige Kanon, der mit Sicherheit auf Burchard selbst zurückgeht, ist der Stammbaum der Verwandtschaft. Burchard orientierte sich an dem Vorbild des von Isidor überlieferten Stammbaums, veränderte diesen jedoch auf charakteristische Weise. Dass wir diese Veränderungen dem Bischof von Worms zuschreiben können, ist durch die Herkunft der frühen Handschriften aus dem Skriptorium von Worms hinreichend abgesichert ${ }^{250}$. Die Vorlage von Burchards Stammbaum ist bekannt. Es handelt sich um den Stammbaum aus Isidors Etymologiae, der die römische Komputation verwendet und in der Seitenverwandtschaft bis zum achten römischen Grad (4/4) zählt ${ }^{251}$. Burchard verändert diesen Stammbaum in zwei Punkten ${ }^{252}$. Erstens lässt er die numerische Zählung in der Seitenverwandtschaft weg und zählt nur die Generationen der Aszendenz bis zum 6. Grad. Damit distanziert er sich von der römischen Zählweise, die ja erst in der Anwendung auf die Seitenverwandtschaft zum Ausdruck gekommen wäre. Zweitens manipuliert er die Aufzählung der Namen in der Seitenverwandtschaft in der Weise,

250 Es handelt sich um Typ 5c nach SснаDт, Arbores 1982, 112-114 (Deutsche Handschriftengruppe). Eine Abbildung des Stemmas aus der ursprünglich Wormser Handschrift Frankfurt, Stadtbibliothek, Barth. 50, findet sich bei FrIED, Prolepsis 1995, 75, und Corbet, Burchard 2001, 97.

251 Und nicht bis 3/4, wie Conbet, Burchard 2001, 98, auch für das von ihm abgedruckte Stemma Burchards behauptet. Die fehlende Befassung mit den Stemmata ist einer der zentralen Mängel des Buchs von Corbet.

252 Diese Veränderungen sind bereits im Stammbaum von Wien, Österreichische Nationalbibliothek, 694, fol. 1r fassbar, und zwar durch Rasuren und Korrekturen bei den Verwandtschaftsbezeichnungen. Einen unverfälschten Stammbaum nach Isidor enthält dagegen die Schwesterhandschrift Wolfenbüttel, Herzog August Bibliothek, Aug. 83.21. Nach Kerner u.a., Textidentifikation 1976, 53-55, benutzte Burchard eine Handschrift des Wiener Typs. 
dass Verwandte bis zum 10. Grad römischer Zählung erfasst sind (4/5 bzw. 2/ $8)^{253}$. Damit ist zwar nicht die Grenze von 7/7 erreicht, die Burchard meines Erachtens vertritt. Doch völlig neu konzipierte Stammbäume mit allen Seitenverwandten bis in den 7. Grad sind erst in der Mitte des 12. Jahrhunderts aufgekommen $^{254}$, als die Grenze von 7/7 bereits über hundert Jahre im ganzen Abendland durch die Initiative des Papsttums bekannt gemacht worden war. Burchard hat dagegen keinen neuen Stammbaum entworfen, sondern er passte den überkommenen Typ möglichst weitgehend an die neuen Gegebenheiten an. Sein Stammbaum erfasst so viele Verwandte wie sonst kein anderer zuvor und ist mit einer römischen Zählung unvereinbar ${ }^{255}$.

Aus diesen Gründen halte ich an der Deutung der älteren Forschung fest und schreibe Burchard die kanonische Komputation, kombiniert mit der Zählung nach Vetterschaften, zu. Das Dekret spiegelt daher exakt die Position Heinrichs II. wider. Diese Verbindung zwischen Bischof und König lässt sich an zwei weiteren Stellen der Inzestvorschriften deutlich vor Augen führen. Auf die eine Stelle wies bereits Patrick Corbet hin ${ }^{256}$. Bei der Überarbeitung des Dekrets nahm Burchard zusätzlich einen Kanon über die Hilfe des Königs bei der Verfolgung von Inzestdelikten auf, wenn die Exkommunikation des Bischofs missachtet worden sei ${ }^{257}$. Diese Ergänzung führt Corbet auf die Schwierigkeiten des Episkopats bei der Durchsetzung des Inzestverbots zurück, wie sie im Fall der Godila und im Fall der Hammersteiner Ehe offensichtlich geworden waren. Die zweite Stelle findet sich in Buch 19. Dort formuliert Burchard in der Nachfolge Reginos eine Liste von 190 Fragen, um dem Beichtvater einen Leitfaden für die Befragung der Gläubigen zur Verfügung zu stellen ${ }^{258}$. Diese Fragen geben aufgrund ihrer Originalität den besten Zugang zur Einstellung des Sammlers selbst. In der Frage zum Inzestverbot fügt Burchard eine Warnung

253 Das Stemma erwähnt die consobrini trinepotes (2/8) und die propatrui abnepotes bzw. proavunculi abnepotes (je 4/5). Vgl. Wien, Österreichische Nationalbibliothek, 694, fol. 1r und Frankfurt, Stadt- und Universitätsbibliothek, Barth. 50, fol. 143v. Auf einige Widersprüche des Stemmas sei nur am Rand hingewiesen: Die zweite Zeile der Seitenverwandtschaft ist gegenüber dem Vorbildstemma (Typ 5b) ausgefallen: SCHADT, Arbores 1982, 113. Zudem sind die linke und rechte Seite des Stemmas nicht symmetrisch aufgebaut.

254 Schadt, Arbores 1982, 144-148. Siehe Abb. 2.

255 Die Auflistung der Verwandten nach römischer Zählweise in Decretum VII 28 (siehe 431 Anm. 244) widerspricht dieser Einschätzung nicht, da dieser Kanon auch in das Decretum Gratiani übernommen wurde, als die kanonische Komputation fest etabliert war: C. 35 q. 5 c. 6 (1275-1277). Er diente dazu, einen Überblick über die lateinischen Verwandtschaftsnamen zu geben.

256 CoRbet, Burchard 2001, $104 \mathrm{f}$.

257 Burchard, Decretum VII 29 (Migne PL 140, 786). Zu den Nachträgen allgemein Hoffmann - PoKorny, Dekret 1991.

258 Vgl. Körntgen, Fortschreibung 2000; Ders., Law 2006. 


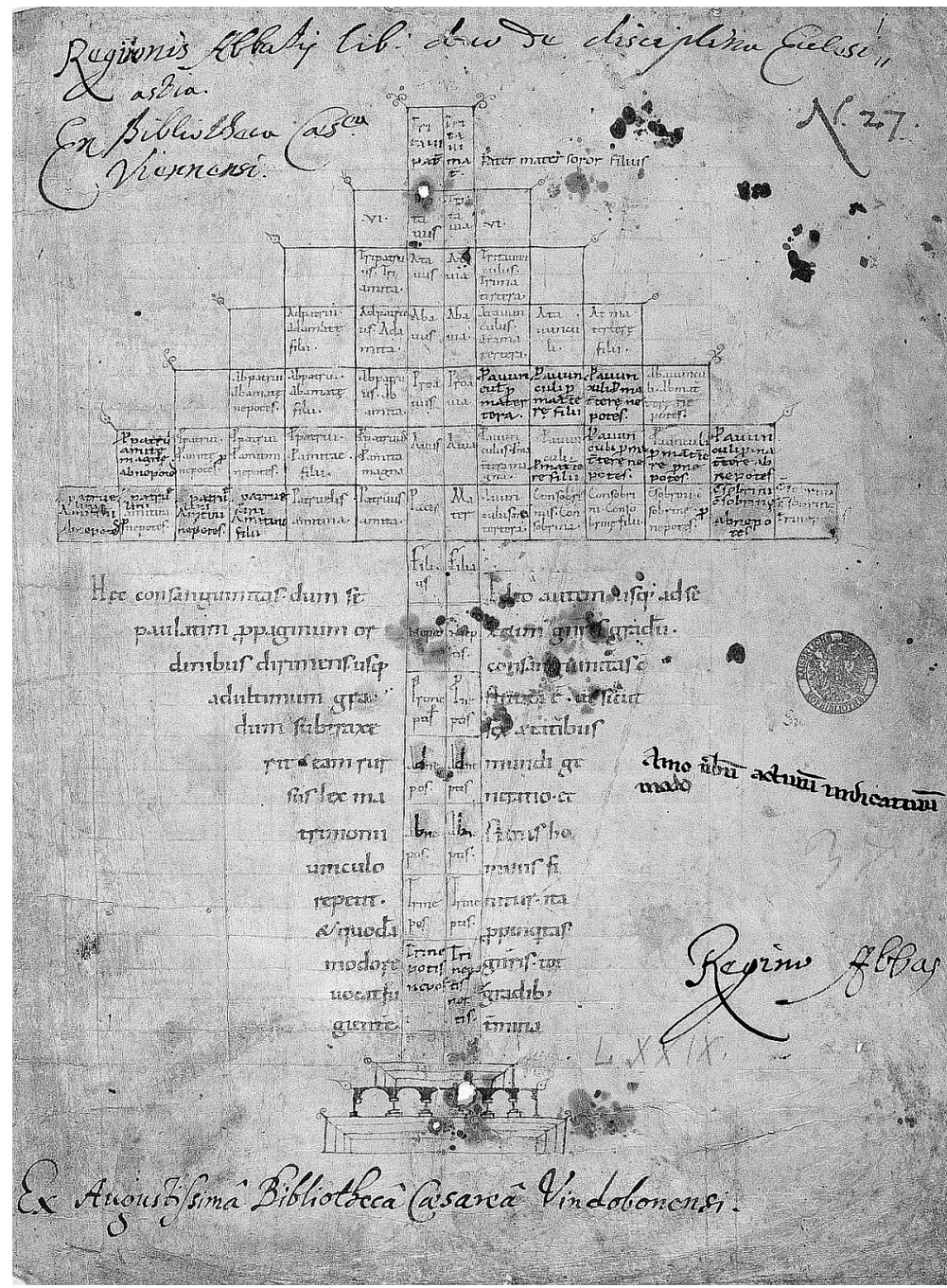

Abb. 3: Stammbaum mit römischer Zählung in einer Handschrift von Reginos Senhandbuch (Wien, Österreichische Nationalbibliothek, Lat. 694, fol. 1r, Mainz um 1000). Durch Korrekturen wurde dieser Stammbaum an den in den Dekret-Handschriften überlieferten Stammbaum angeglichen und reicht bis zu den consobrini trinepotes (2/8).

hinzu: „Deshalb sollst du wissen, dass es nicht so ist, wie viele Priester viele verführen, indem sie sagen, dass es in dieser Sünde eine Buße gebe. ... vielmehr ist die Buße der Sünde nichts wert, solange du in derselben Sünde verharrst ${ }^{\text {“259. }}$.

259 Quapropter scire debes, qui non est ita ut multi sacerdotes multos seducunt, dicentes quod in ipso peccato poenitentia esse possit ... Quapropter scias vere, dum in ipso peccato fueris, poenitentia eiusdem peccati nihil valet. Burchard, Decretum XIX 5 (Migne PL 140, 959). 
Burchard wendet sich also gegen nachgiebiges Verhalten des Klerus, wie wir es bei der Zustimmung Gerhards von Cambrai zur Ehe Reginars V. von Hennegau vermuten können. Aus späterer Zeit sind weitere Fälle belegt, in denen Inzestehen durch eine als Buße getarnte Schenkung oder Klostergründung das Placet des Bischofs erhalten haben ${ }^{260}$.

Wie die Untersuchung von Burchards Dekret ergeben hat, können wir darin zu Recht das Handbuch für die Inzestkampagne des Königs erblicken. Da das Dekret jedoch erst während der Herrschaft Heinrichs II. niedergeschrieben wurde, kann sein Programm nicht schon auf der Synode von Diedenhofen zur Verfügung gestanden haben. Es stellt sich daher die Frage, woher der König die Idee zu seiner Inzestkampagne empfangen hat. Heinrich hatte in Ansätzen eine geistliche Erziehung genossen, vielleicht weil man den Sohn des in Gefangenschaft befindlichen Heinrichs „des Zänkers“ auf diese Weise politisch unschädlich machen wollte ${ }^{261}$. Seine Zeitgenossen bescheinigten ihm eine gute Kenntnis des kanonischen Rechts ${ }^{262}$. Ob er sich diese bei seinem Aufenthalt in Hildesheim oder durch den Unterricht bei Abraham von Freising oder Wolfgang von Regensburg erworben hat, kann nicht beantwortet werden. Es ist jedenfalls ohne weiteres denkbar, dass der König unabhängig von der Mainzer Kanonistik die Idee zu einer Inzestkampagne entwickelt hat. Als Auslöser könnte der Eklat um König Robert von Frankreich gewirkt haben, denn der bayerische Herzog hatte an der Verurteilung auf der römischen Synode von 999 teilgenommen. Trotzdem wird man mit der Annahme kaum fehlgehen, dass Heinrich im Vorfeld der Synode von Diedenhofen mit seinen engen Beratern Willigis von Mainz und Burchard von Worms zusammengekommen ist und sich ihrer Zustimmung zu seinem Vorgehen versichert hat. Die Inzestkampagne kam also durch das Zusammenwirken von König Heinrich II. mit den Vertretern der Mainzer Kanonistik zustande.

\section{Exogamie und Isogamie}

Die Verfolgung des Inzests nahm in der Zeit Heinrichs II. durch die Radikalisierung der Ehehindernisse ganz neue Ausmaße an. Hatten im Frühmittelalter mehrheitlich Ehen innerhalb der Schwiegerverwandtschaft unter Anklage gestanden, konzentrierten sich die Fälle seit der Heirat Roberts II. folglich auf die Blutsverwandtschaft. Vor diesem Hintergrund halte ich die Frage nach der Motivation von Heinrichs Inzestkampagne für müßig. Religiöse und politische Beweggründe sind untrennbar verbunden. Die Frömmigkeit und kirchen-

260 Stiegler, Dispensation 1901, 258 f.; Corbet, Burchard 2001, 228-240.

261 Hirsch, Jahrbücher 1 1862, 91; Weinfurter, Heinrich II. 1999, 25 f.

262 ... vir in omni aecclesiastica perfeccione precipuus ... Annales Hildesheimenses a. 1002 (MGH SS rer. Germ. 8, 28). 
rechtliche Bildung des Herrschers steht ebenso wenig in Frage wie sein Bewusstsein von der politischen Tragweite des von ihm favorisierten Inzestverbots. Es ist zwar wenig wahrscheinlich, dass Heinrich sich über die Neuheit der Inzestgrenze des siebten Grades kanonischer Zählung im Klaren war, als er diese Forderung erstmals auf der Synode von Diedenhofen erhob. Die Konsequenzen für die adelige Ehepraxis blieben ihm jedoch sicher nicht verborgen. Mit der Entscheidung für eine Inzestkampagne ergriff Heinrich klar für das christliche Prinzip der Exogamie und gegen das adelige Prinzip der Isogamie Partei. Dies musste zwangsläufig Widerstand hervorrufen. Gerade in der sächsischen Gesellschaft achtete man nämlich streng auf standesgemäße Eheschließungen. Nach einem berühmten Bericht Rudolfs von Fulda aus dem 9. Jahrhundert stand in Sachsen die Todesstrafe für die Übertretung der Standesgrenzen bei der Heirat $^{263}$. Die Historiker Widukind von Corvey und Thietmar von Merseburg bezeugen zwar nicht die Verhängung einer solch brutalen Strafe, legen jedoch in ihrer Bewertung von Eheschließungen ebenfalls viel Wert auf die Beachtung der Standesgrenzen ${ }^{264}$. Bedenkt man, dass die Führungsschicht des ottonisch-salischen Reichs auf ca. 150-200 Personen geschätzt wird ${ }^{265}$ und dass Eheschließungen über die Reichsgrenzen des ehemaligen Frankenreichs hinweg kaum stattfanden ${ }^{266}$, musste es fast unmöglich werden, standesgemäße Partner unter Beachtung des Inzestverbots zu finden. Verschärft wurde dieses Problem durch das häufig frühe Ableben eines Ehepartners, das eine erneute Heirat des Witwers oder der Witwe erforderlich machte. Beispielsweise führten die beiden Töchter Hermanns II. von Schwaben, Mathilde und Gisela, nacheinander drei Ehen. Als Nachkommen der Karolinger, der Ottonen und der Könige von Burgund war ihnen durch das ausgedehnte Inzestverbot die Verbindung mit anderen Nachkommen aus diesen Königsfamilien verwehrt. Sie gingen trotzdem solche Ehen ein und wurden des Inzests beschuldigt.

Während also Exogamie und Isogamie in Widerspruch zueinander gerieten, war eine andere Ehepraxis nicht grundsätzlich diskreditiert. Wie in der Karolingerzeit war es auch in der Epoche um 1000 üblich, Eheverbindungen zwi-

263 ... et id legibus firmatum, ut nulla pars in copulandis coniugiis propriae sortis terminos transferat, sed nobilis nobilem ducat uxorem, liber liberam, libertus coniungatur libertae, servus ancillae. Si vero quispiam horum sibi non congruentem et genere praestantem duxerit uxorem, cum vitae suae damno componat. Rudolf von Fulda, Translatio S. Alexandri c. 1 (424). Zur Interpretation vgl. Lintzel, Rechtsgeschichte 1932, 438-445; BECHER, Rex 1996, 34. Springer, Sachsen 2004, 249, schreibt die Nachricht ohne Begründung der Phantasie des Autors zu.

264 Widukind, Res gestae saxonicae I 9 (MGH SS rer. Germ. 60, 11 f.); vgl. hierzu Lubich, Wortfeld 2003; Thietmar von Merseburg, Chronica IV 40 (MGH SS rer. Germ. N.S. 9, 178); IV 60 (MGH SS rer. Germ. N.S. 9, 200).

265 Reuter, König 2001, 141; Althoff, Ottonen 2005, 239.

266 Leyser, Herrschaft 1984, 78 f.; Röckelein, Heiraten 2006. 
schen Adelsfamilien zu erneuern ${ }^{267}$. So heirateten die Schwestern Mathilde und Gisela beide in das Haus der Salier ein: Mathilde wurde die Ehefrau Konrads von Kärnten, Gisela die Ehefrau des späteren Kaisers Konrad II. Im byzantinischen Eherecht des 11. Jahrhunderts wäre eine solche doppelte Allianz unter das Inzestverbot gefallen ${ }^{268}$. In Byzanz bildeten Ehen zwischen zwei Brüdern und zwei Cousinen oder zwischen Tante und Nichte und Onkel und Neffe den Kern der Auseinandersetzung um das Inzestverbot. Angeliki Laiou sieht darin ein zwischen Kaiser und Klerus abgestimmtes Vorhaben, die Tendenz zur Verfestigung adeliger Bündnisse aufzubrechen ${ }^{269}$. Allerdings fühlten sich einzelne Kaiser wie Alexios I. an diese Inzestvorschriften nicht gebunden und erlaubten doppelte Allianzen in der eigenen Familie. Der Adel bediente sich wie im Westen dieser neuen Vorschrift zur Ehescheidung und unterlief damit die Intention des Klerus. Diese Widerstände und Manipulationen machen die Bedeutung dieser Ehestrategie für den Adel deutlich. Im Westen wurde diese Art von Verbot in der Schwiegerverwandtschaft erst im 12. Jahrhundert etabliert, durch Innocenz III. jedoch bald wieder abgeschafft ${ }^{270}$.

Die Inzestkampagne des Jahres 1003 bewirkte also weniger das „Aufbrechen adeliger Verwandtschaftsblöcke“" wie in Byzanz als die Durchlöcherung der Standesgrenzen und kann daher als „ein Element der gesellschaftspolitischen Verdichtung und Vernetzung “'271 bezeichnet werden. Stefan Weinfurter hat zu Recht die Frage in den Raum gestellt, ob Heinrich alle Konsequenzen seines Handelns im Blick gehabt hat. Diese Frage führt in den Kern eines nur schwer fassbaren Problems: Wie umfangreich war das genealogische Wissen des Herrschers und seiner Zeitgenossen? Wie Julius von Ficker anhand einiger Quellen nahe legen konnte, reichte in der Karolingerzeit das Wissen von den Vorfahren in der Regel nicht weiter als bis in die vierte Generation ${ }^{272}$. Die

267 Siehe oben $379 \mathrm{f}$.

268 Zhishman, Eherecht 1864, 290-347; Joyce, Ehe 1934, 484-491.

269 Laiou, Mariage 1991. Siehe $487 \mathrm{f}$.

270 Freisen, Geschichte 1893, 474-489.

271 Weinfurter, Heinrich II. 1999, 202.

272 FiCKER, Untersuchungen 1 1891, 87. Ohne die Kenntnis von Fickers Werk kommt LE JAN, Famille 1995, 166, zu ähnlichen Ergebnissen. Einen engeren Horizont erfasst Wollasch, Familie 1957, im Handbuch der Dhuoda. Nach Lubich, Verwandtsein 2008, 126, war der „Verwandtschaftshorizont“ mit dem „Erlebnishorizont“ identisch. FrIED, Konradiner 2006, meint, erst das Inzestverbot habe zur „Erfindung des Adelsgeschlechts“ geführt. Damit überschätzt er wohl die Wirkung der Inzestverbote. Denn in der Adelsforschung setzt sich zunehmend die Ansicht durch, die Entstehung von agnatischen Adelsgeschlechtern habe nicht abrupt nach der Jahrtausendwende (sog. 'Duby-Schmid These'), sondern allmählich seit dem 9. Jahrhundert stattgefunden. Vgl. Bouchard, Families 2001. Einen Überblick über die Diskussion verschaffen HechBerger, Adel 2005, 306-328, und Crouch, Birth 2005, 101-123. Zudem ist zu beachten, dass erbrechtlich-dynastische und eherechtliche Verwandtschaft verschieden 
Dynastie der Karolinger, die sich ihrer Herkunft von Arnulf von Metz erinnerte und weitere legendäre Vorfahren nennen konnte, ist als Ausnahme zu werten. Für die Zeit um 1000 gewähren die Geschichtsschreiber Adalbold und Wipo einen guten Einblick in das verfügbare genealogische Wissen. Adalbold bestimmte richtig die Herkunft Heinrichs II. von König Heinrich I. in der dritten Generation, glaubte aber darüber hinaus an eine Abstammung des Herrschers von Karl dem Großen. Über den Vater sollten ihn 17, über die Mutter 16 „Linien der Fortpflanzung“" von Karl trennen ${ }^{273}$. In seinen Gesta Chuonradi macht Wipo eine ähnlich entfernte Verwandtschaft der Kaiserin Gisela mit Karl dem Großen in der „14. Linie“ geltend ${ }^{274}$. In diesen Nachrichten manifestiert sich deutlich die Unkenntnis über die Verwandtschaft mit den Karolingern. Eine Verbindung der Eltern Heinrichs II. zu den Karolingern ist nicht bekannt; Gisela ist zwar tatsächlich verwandt, jedoch bereits in einem Abstand von neun Generationen $^{275}$. Das Gedächtnis reichte also selbst in den führenden Dynastien nicht weiter als 100 Jahre zurück, während die genealogischen Beziehungen zu den Karolingern nicht mehr präsent waren.

Andere Verhältnisse trifft man im Westfrankenreich an. Dort sorgte die Kontinuität der karolingischen Dynastie bis zum Jahre 987 für ein politisch motiviertes Interesse an der genealogischen Legitimation durch die Verwandtschaft mit der Herrscherfamilie. Die früheste bildliche Darstellung der Karolingerdynastie in einem aus Medaillons gebildeten Stammbaum entstand in der Umgebung des letzten Karolingers Karl von Lothringen ${ }^{276}$. Sie ist nicht mehr

sind. Während dynastische Genealogien selektiv sind und nur die politisch legitimierende Abstammungslinie berücksichtigen, muss die eherechtliche Verwandtschaft alle Ahnen (und seien es 128) ergründen. Ein dynastischer Stammbaum verzweigt sich nach unten, ein eherechtlicher nach oben. Frieds These lässt sich abwandeln: Die Inzestverbote führten nicht zur „Erfindung des Adelsgeschlechts“, sondern das seit dem 9. Jahrhundert zunehmende Abstammungsbewusstsein ermöglichte die Radikalisierung des Inzestverbots im 11. Jahrhundert. Weil man begann, aus legitimatorischen Gründen Nachrichten über die Vorfahren zu sammeln, konnte eine derart extreme Ausdehnung des Verbots plausibel erscheinen.

273 Hereditarium dicimus, quia ut ab his, qui genealogias computare noverant, audivimus, a Carolo Magno ex parte patris decimam septimam, ex parte matris decimam sextam lineam propagationis tenebat. Insuper tertius Otto et ipse tertium ad invicem consanguinitatis gradum tenebant: mater autem sua Conradi regis fuit filia. Adalbold von Utrecht, Vita Heinrici II 1 (48). Zur Deutung der Stelle vgl. SchneIdmüller, Otto III. 1997, 11 - 13, mit weiterer Literatur.

274 Quando post decimam numeratur linea quarta, de Carolo magno procedit Gisela prudens. Wipo, Gesta Chuonradi c. 4 (MGH SS rer. Germ. 61, 25).

275 Werner, Nachkommen 1967, 479. Vgl. jetzt auch die Tafeln bei Hlawitschka, Ahnen 2006.

276 Zum Folgenden vgl. Gädeke, Zeugnisse 1992, 219-236; Schmid, Stemma 1994; Weinfurter, Heinrich II. 1999, 236 f. Die These von Geldner, Tatsachen 1973, 42, über die nahe Verwandtschaft von Heinrich und Kunigunde fand kein Anklang: GLOCKer, Verwandten 1989, 225 f.; Schieffer, Familienbild 1995, 44 Anm. 61. 
erhalten, diente jedoch zwei Abschriften als Vorlage. Die eine ließ man in Prüm kopieren, die andere kam an den Hof Heinrichs II. und wurde im Interesse des Herrschers verändert. Dieses älteste erhaltene Exemplar zeigt die Abstammung von Heinrichs Frau Kunigunde von Karl dem Großen in der siebten Generation sowie die Abstammung Heinrichs von Heinrich I. in der dritten Generation. Die unrichtige Bezeichnung des ersten sächsischen Herrschers als Kaiser gibt Aufschluss über den Zweck dieser doppelten Kaisergenealogie: Sowohl Heinrich II. als auch seine Frau Kunigunde sollten als Nachfahren von Kaisern ausgewiesen werden. Die Forschung vermutet daher eine Entstehung dieser genealogischen Tafel in der Zeit der Kaiserkrönung um das Jahr 1014.

Als Heinrich II. im Jahr 1003 seine Inzestkampagne startete, nahm er deshalb kaum die im Osten weitgehend in Vergessenheit geratene Abstammung von den Karolingern ins Visier. Es musste ihm dagegen durchaus bewusst sein, dass mit der Ausweitung des Inzestverbots Eheschließungen unter Nachkommen König Heinrichs I., d.h. innerhalb der regierenden sächsischen Dynastie, unmöglich gemacht wurden. Solche Ehen waren jetzt nicht mehr Grenzfälle, sondern fielen eindeutig unter das Inzestverbot. Dies war die wesentliche Botschaft der Rede Heinrichs II. auf der Reichsversammlung von Diedenhofen. Genau die „väterliche Nachfolge“ von König Heinrich I. war aber auch die Legitimationsgrundlage für den Anspruch Heinrichs II. auf die Königswürde nach dem erbenlosen Tod Ottos III. ${ }^{277}$ Heinrich war der einzige überlebende Nachfahre Heinrichs I. in direkter männlicher Linie. Mit diesem Rechtsanspruch sowie mit einer ,Strategie der Überrumpelung' gelang es ihm, gegen den Widerstand weiter Teile der Aristokratie das Königtum an sich zu reißen. Das erweiterte Inzestverbot ermöglichte Heinrich den Angriff auf Ehen, die ihm gefährlich zu werden drohten, weil sie sein Monopol auf das Erbe der sächsischen Dynastie in Frage stellten. Die Heirat zwischen Konrad von Kärnten und Mathilde, beide Nachkommen Heinrichs I., musste dem König sowohl aus politischen Gründen wie auch aus Rücksicht auf das Kirchenrecht missfallen. Kurz nach seiner gelungenen Usurpation der Herrscherwürde war ihm die Diffamierung dieser Ehe das richtige Mittel, um seinen Anspruch auf ungeschmälerte Königsgewalt eindrucksvoll zu demonstrieren.

Die Inzestkampagne des Königs ist also nur vor dem Hintergrund der Legitimitätsprobleme im Jahr 1002 verständlich. Sie diente dazu, die Nachfolge Heinrichs I. zu monopolisieren, monarchische Herrschaft auszuüben und der Reichskirche die programmatische Richtung vorzugeben. Nachdem die Königsherrschaft gefestigt gewesen war, schwand zunehmend das Interesse des

277 Weinfurter, Heinrich II. 1999, 36-44. Ausführlich wird dieses Thema in der Vita Mathildis posterior behandelt: Sснüтte, Untersuchungen 1994, 85-93. Zur unterschiedlichen Wertung der Verwandtschaft in den Quellen vgl. auch Patzold, Königserhebungen 2002. 
Königs an der Fortführung der Inzestkampagne. Schon das Vorgehen gegen Konrad von Kärnten blieb aus Rücksicht auf die heftigen Widerstände ohne Folgen. Ein Jahr nach Diedenhofen stieg Konrad sogar zum Herzog von Kärnten auf. Die abermalige Eheschließung zweier Nachkommen Heinrichs I. (Konrad II. und Gisela) konnte Heinrich II. nicht mehr gefährlich werden und wurde trotz ihres eindeutigen Inzestcharakters nicht beanstandet ${ }^{278}$. Heinrich hatte bereits 1003 die Initiative den Bischöfen übertragen, die er als Nachfolger Mose und als Hüter über das mosaische Gesetz bezeichnete ${ }^{279}$. Der König trat nur mehr dann auf, wenn der Widerstand von Seiten der betroffenen Adeligen eine öffentliche Verhandlung vor einer Synode notwendig machte. Im Fall Ottos von Hammerstein habe ich für eine Neubewertung der Rolle des Königs plädiert. Der Hammersteiner Graf verlor die Huld des Herrschers erst, nachdem er einen Angriff auf seinen Intimfeind, den Erzbischof von Mainz, verübt hatte. Eine Konfiskation der Eigengüter Ottos scheint nicht stattgefunden zu haben. Das Engagement Heinrichs II. für die Bekämpfung von Inzestehen hatte also nach der Etablierung seiner Königsherrschaft sowie nach der Erlangung der Kaiserwürde deutlich nachgelassen. Dieses Urteil harmoniert mit der zunehmend sichtbar werdenden Konzilianz des Herrschers ${ }^{280}$, die er etwa im Fall des Pfalzgrafen Ezzo (1012) oder in dem Frieden mit Boleslaw Chrobry (1018) an den Tag legte. Der ,König der Konflikte‘ konnte Konflikten auch aus dem Weg gehen oder sie bereinigen.

\subsection{Die Formierung der päpstlichen Doktrin}

Die gregorianische Reform hat vielleicht nicht die Welt, mit Sicherheit aber die Organisation der Kirche und die Struktur des Kirchenrechts radikal verändert $^{281}$. Das Papsttum machte die universale Zuständigkeit in der gesamten Kirche geltend, schuf eine zentrale Bürokratie in Rom und etablierte allmählich die alleinige gesetzgeberische Kompetenz des apostolischen Stuhls. Als Folge dieses monarchischen Regiments begann das Nachdenken über die Autorität des

278 Siehe $442-444$.

279 Siehe 413 Anm. 138. Wie Engelbert, Papsttum 2002, 119 Anm. 159, klarstellt, bezeichnete sich Heinrich nie als Mitbischof oder Bischof (gegen HeHL, Herrscher 1997, 185). Es ist daher fraglich, ob sich Heinrich als Nachfolger Mose stilisierte. Vgl. KörntGen, Königsherrschaft 2001, 225 f.

280 Vgl. Althoff, Heinrich II. 1997, 93 f.

281 Als Revolution wertet die Epoche Berman, Law 1983. Schieffer, Revolution 1998, argumentiert dagegen, während LANDAu, Development 2004, 113, diese Charakterisierung für die Rechtsgeschichte ausdrücklich befürwortet. Vgl. außerdem LEYSER, Vorabend 1993; Borgolte, Einheit 1996; Moore, Revolution 2001; Hartmann, Investiturstreit 2007, $122 \mathrm{f}$. 
Kirchenrechts und seiner Quellen, die in einem langsamen Prozess zur Verwissenschaftlichung und Ausdifferenzierung des kanonischen Rechts im 12. Jahrhundert führte ${ }^{282}$.

Diese Charakteristika der erneuerten Kirche kamen erstmals unter Gregor VII. voll zum Tragen, als der Papst im Konflikt mit Heinrich IV. um die Vorherrschaft in der abendländischen Christenheit zu einer Klärung der Positionen drängte. In der Epoche zwischen der Etablierung deutscher Päpste in Rom (1046) und dem Pontifikat Gregors VII. standen dagegen andere Probleme im Vordergrund. In erster Linie ging es um die Bekämpfung von Priesterehe und Simonie, also um zwei Anliegen, die fest in der kirchenrechtlichen Tradition verankert waren und mit neuer Schärfe sowie leicht veränderten Inhalten vorgebracht wurden ${ }^{283}$. Der päpstliche Primat diente in dieser frühen Phase vor allem dazu, diese Missstände innerhalb der gesamten Kirche dadurch zu beseitigen, dass Widerstände durch die Berufung auf die unangreifbare Autorität des apostolischen Stuhls im Keim erstickt wurden. Neben Priesterehe und Simonie war der Inzest ein zentrales, aber in Überblicksdarstellungen zumeist vernachlässigtes Thema der Frühphase der Reform. Bereits auf dem ersten Konzil Leos IX. in Rom wurde das Inzestverbot als eines von drei Themen behandelt, ferner gehörte es zur Tagesordnung der berühmten Synode von 1059, auf der das Papstwahldekret verabschiedet wurde, und es ist der Gegenstand mehrerer Dekretalen Alexanders II. Unter denjenigen Themen der Reform, die die Laien betreffen, wurde das Inzestverbot mit Abstand am häufigsten auf die Tagesordnung gebracht. Seitdem Rudolf Schieffer klarstellte ${ }^{284}$, dass die Laieninvestitur erst im Pontifikat Gregors VII. zum Prüfstein für die Akzeptanz der Kirchenreform gemacht wurde, muss das Inzestverbot in der Frühphase der Reform als das Hauptthema im Umgang der Kirche mit den Laien betrachtet werden.

Wenn man nach den Ursachen für die Prominenz des Inzestverbots sucht, bietet sich eine nahe liegende Erklärung an: Da die Reform durch die Ernennung deutscher Päpste einsetzte, die mit dem Dekret Burchards von Worms „groß geworden“ sind, kann man die herausragende Bedeutung des Themas als Folge des deutschen Einflusses betrachten. Die Reichskirche des frühen 11. Jahrhunderts erscheint dann als „Laboratorium der Kirchenreform“285. Diese Vermutung trifft sich mit der alten These Augustin Fliches, der die gregorianische Reform auf den Einfluss von in Lüttich geschulten lothringischen

282 Fournier, Tournant 1917; Kuttner, Liber 1947; Fuhrmann, Reformpapsttum 1973; Mordek, Kanonistik 1985; Hartmann, Autoritäten 1991; ders., Centralismo 1993; Cushing, Papacy 1993; Landau, Development 2004.

283 Blumenthal, Investiturstreit 1982, 80-87; Tellenbach, Kirche 1988, 133-145.

284 SChieffer, Entstehung 1981.

285 Corbet, Burchard 2001, 321. 
Geistlichen zurückführte ${ }^{286}$. Diese These erhält jedoch in der gegenwärtigen Geschichtsschreibung nur mehr geteilte Zustimmung, denn die Lütticher Rechtsschule hat sich als Phantom erwiesen ${ }^{287}$. Zudem kamen wichtige Protagonisten der Reform wie Petrus Damiani und der spätere Gregor VII. aus einem ganz anderen Milieu und hatten bereits vor dem Kontakt mit den lothringischen Geistlichen ähnliche Gedanken ausgesprochen. Dieser Einwand gegen Fliche trifft auch auf die Geschichte des Inzestverbots zu. Denn bereits vor der Etablierung der deutschen Päpste in Rom sprach sich Petrus Damiani in einem Brief für die Position Burchards von Worms aus und warb bei der italienischen Geistlichkeit für Zustimmung. Damiani - und nicht die lothringischen Reformer - war es auch, der die Päpste Nikolaus II. und Alexander II. zu einer Änderung des bislang gültigen päpstlichen Rechts bewogen hat. Vor Damiani haben die deutschen Päpste zwar auch die Einhaltung des Inzestverbots wiederholt angemahnt, eine autoritäre Rechtsänderung nahmen sie jedoch nicht vor. Leo IX. und sein Kreis waren vielmehr von der Haltung im Umgang mit dem Inzestverbot geprägt, die sich unter den ersten Saliern im Reich etabliert hatte.

\section{Das Inzestverbot unter den ersten Saliern}

Die Inzestkampagne Heinrichs II. hätte durchaus Episode bleiben können. Mit Konrad II. kam 1024 eine dem adeligen „Comment “" ${ }^{\text {"88 }}$ verpflichtete Persönlichkeit an die Macht, die kein Verständnis für eine übertriebene Ausdehnung des Inzestverbots hatte. Im vorigen Kapitel wurde bereits erwähnt, dass er für die Niederschlagung des Verfahrens gegen Otto und Irmingard von Hammerstein auf der Frankfurter Synode von 1027 verantwortlich war. Diese Ablehnung des erweiterten Inzestverbots hatte auch persönliche Gründe. Im Jahr 1016 oder 1017 heiratete er die Witwe des Herzogs Ernst von Schwaben Gisela. Beide waren Nachfahren Heinrichs I. und daher im Verhältnis von 5/4 verwandt ${ }^{289}$. Thietmar von Merseburg berichtet von dieser Eheschließung in einem seiner letzten Zusätze zur Chronik und bezeichnet sie als „unerlaubt“ ${ }^{\text {“290 }}$. Es unterliegt keinem Zweifel, dass Thietmar auf den Inzestcharakter der Verbindung anspielt $^{291}$. Seit Harry Bresslau ist man der Meinung, Kaiser Heinrich II. habe mit

286 FliChE, Réforme 1924.

287 Fuhrmann, Einfluss 1972, $463 \mathrm{f}$.

288 Wolfram, Konrad II. 2000, 338.

289 Corbet, Burchard 2001, 128-133; Wolfram, Konrad II. 2000, 49-56.

290 Sauciatus est ibi Cono, cui iam illicite nupsit neptis sua, Ernesti ducis vidua. Thietmar von Merseburg, Chronica VII 62 (MGH SS rer. Germ. N.S. 9, 476).

291 Die Legende einer Entführung Giselas durch Konrad ist erst später entstanden: Wolfram, Konrad II. 2000, 55. 
einer politischen Maßnahme auf diese unkanonische Heirat reagiert ${ }^{292}$. Gisela ist nämlich kurz nach dem Tod ihres Mannes als Vormund des gemeinsamen Sohnes und daher auch als Verwalterin des Herzogtums Schwaben belegt ${ }^{293}$. Diese Vormundschaft musste sie vor 1024 an den Bruder Herzog Ernsts, Erzbischof Poppo von Trier, abgeben ${ }^{294}$. Aus diesem Befund schloss Bresslau auf einen Entzug der Vormundschaft durch Heinrich II. aufgrund der Inzestehe Giselas mit Konrad. Der Kaiser habe die Verbindung abgelehnt, weil dadurch ein weiteres Mal (nach der Heirat Konrads von Kärnten mit Mathilde) die mächtigen Familien der Salier und Konradiner ein Heiratsbündnis geschlossen hätten. Wie er sich 1003 gegen die Verbindung Konrads von Kärnten aussprach, habe er auch in diesem Fall das Kirchenrecht zum Vorgehen gegen das „verhasste Adelsgeschlecht" benutzt.

Dieser Zusammenhang zwischen Inzestehe und Entzug der Vormundschaft ist jüngst von Herwig Wolfram überzeugend bestritten worden. Für ihn erklärt sich der Entzug hinlänglich durch das Ausscheiden Giselas aus dem babenbergischen Familienverband Herzog Ernsts ${ }^{295}$. Nach ihrer Heirat mit Konrad vertrat sie andere Familieninteressen und wurde von den Babenbergern nicht mehr als Verwalterin der Interessen ihres unmündigen Sohnes angesehen. Die Babenberger lehnten eine Fortführung von Giselas Vormundschaft ab und bewogen Heinrich II. zur Übertragung auf Poppo von Trier. Die Inzestehe Konrads brauchte dafür nicht ins Spiel gebracht werden. Das Verhältnis zwischen Heinrich und Konrad war weniger durch die Inzestehe als durch die politische Gegnerschaft getrübt. Zweimal ergriff der Salier Partei für Gegner des Kaisers und musste infolgedessen eine kurzzeitige Exilierung im Jahr 1019 hinnehmen ${ }^{296}$. Im folgenden Jahr befand er sich wieder in der Huld des Kaisers und unterzeichnete aller Wahrscheinlichkeit nach die Prachturkunde für Papst Benedikt VIII. (das sogenannte „Heinricianum“) ${ }^{297}$. Warum der Herrscher die Ehe Konrads nicht beanstandete, muss demnach offen bleiben. Da Heinrich nach 1003 die Initiative bei der Verfolgung von Inzestdelikten den Bischöfen überließ, liegt der Grund vielleicht im mangelnden Interesse des Klerus an einer Auseinandersetzung mit dem mächtigen Dynasten. Möglicherweise spielte auch das konziliante Verhalten Heinrichs in den letzten Jahren seiner Herrschaft eine Rolle.

292 Hirsch - Bresslau, Jahrbücher 3 1875, 111; Kessler, Eheprozess 1923, 62; Wolter, Synoden 1988, 274; Corbet, Burchard 2001, 129; Hlawitschka, Konradiner-Genealogie 2003, 109. Skeptisch äußert sich Erkens, Konrad II. 1999, 34.

293 Thietmar von Merseburg, Chronica VII 16 (MGH SS rer. Germ. N.S. 9, 416).

294 Wipo, Gesta Chuonradi 1 (MGH SS rer. Germ. 61, 10).

295 Wolfram, Konrad II. 2000, 54.

296 Wolfram, Konrad II. 2000, 57-59.

297 Bresslau, Jahrbücher 1 1912, 9; Erkens, Konrad III. 1999, 36; Wolfram, Konrad II. 2000, 58. 
Erst im Jahr 1024, im Zuge der Königswahl von Kamba, stand die Heirat zwischen Konrad und Gisela im Mittelpunkt der Aufmerksamkeit. Rodulfus Glaber berichtet aus einer Entfernung von gut zwanzig Jahren, Erzbischof Aribo von Mainz habe die Salbung Giselas wegen ihrer Inzestehe verweigert ${ }^{298}$. Erst nachdem der angehende König Konrad II. den Bischöfen die Auflösung der Ehe versprochen hätte, hätten sie gemeinsam mit dem Papst der Erhebung zum König zugestimmt. Als Konrad schließlich vom Papst zum Kaiser gekrönt worden sei, habe er sich nicht mehr an das Versprechen gebunden gefühlt und seine Ehefrau trotz des päpstlichen Widerspruchs behalten. In dieser Geschichte des Mönchs aus Cluny stecken so viele faktische Fehler, dass sie von der Forschung rundweg abgelehnt wurde ${ }^{299}$. Man suchte daher nach anderen Gründen für die auch von Wipo ${ }^{300}$ belegte Weigerung Aribos von Mainz, Gisela in Mainz gemeinsam mit ihrem Ehemann zur Königin zu salben. Keine dieser Erklärungen wird jedoch von den Quellen erhärtet ${ }^{301}$. Dagegen ist es Patrick Corbet aufgrund einer erstmals herangezogenen Quelle gelungen, die Aussagen Glabers zumindest teilweise zu rehabilitieren $^{302}$. Im September 1024 ist es wohl tatsächlich um die Inzestehe zwischen Gisela und Konrad gegangen, und Aribo verweigerte die Krönung und Salbung Giselas, weil damit die Inzestehe ein weiteres Mal sanktioniert worden wäre. Corbet hält es sogar für wahrscheinlich, dass Konrad dem Erzbischof ein vertrauliches Versprechen über eine Scheidung gegeben hat. Dem möchte ich mich nicht anschließen. Vermutlich war die Lage so, wie Herwig Wolfram sie beschreibt ${ }^{303}$ : Gisela hat aus der Not eine Tugend gemacht und sich an den im gegnerischen Lager befindlichen Erzbischof von Köln gewandt, damit er die Salbung an ihr vollziehen sollte. Dadurch gelang ihr die Integration der lothringischen Partei, die der Königswahl Konrads zunächst feindlich gesonnen war. Weil die Krönung Giselas innerhalb von 14 Tagen geschah, nimmt Wolfram eine vorhergehende Absprache der beteiligten Parteien an. Erzbischof Aribo, in dem Prozess gegen die Hammersteiner heftig engagiert, wollte sich durch die Beteiligung an der Krönung Giselas keine Blöße geben

298 Cum enim diu multumque de constituendo regni principe, ac precipue inter presules, retractatum fuisset, visum est eis ipsum Chuonradum debere eligere, nisi quod unum intererat, propter quod Heinricus etiam illum valde exosum habuerat. Habebat enim coniugem quae illi erat affinis, quam etiam primitus quidam cognatus ipsius duxerat. Rodulfus Glaber, Historiae IV 1 (170-172).

299 Bresslau, Jahrbücher 1 1912, 15-17; Jäschke, Hofkapellan 1991, 433-437; Boshof, Salier 2000, 39; Wolfram, Konrad II. 2000, 65.

300 Wipo, Gesta Chuonradi 4 (MGH SS rer. Germ. 61, 25).

301 Einen Überblick über die verschiedenen Thesen geben HLawiтschкa, Untersuchungen 1987, 132-134, Wolfram, Konrad II. 2000, 64-66, und Corbet, Burchard 2001, $132 \mathrm{f}$.

302 Corbet, Interdits 1996; Ders., Burchard 2001, 133-137.

303 Wolfram, Konrad II. 2000, 66. 
und ein konsistentes Verhalten an den Tag legen. Die Weigerung war offenbar durchaus mit seiner Unterstützung von Konrads Thronkandidatur vereinbar.

Die Erhebung zum König war die letzte Möglichkeit für die Bischöfe, an der Inzestehe Konrads II. Anstoß zu nehmen. Aribo nutzte sie, die anderen Bischöfe schwiegen. Dieser Umschwung der Stimmung im Episkopat ist auch den anderen Quellen zur Inzestverfolgung unter den Saliern anzumerken. Nach der Synode von Frankfurt, als ein Schlussstrich unter den Hammersteiner Eheprozess gezogen worden war, befasste sich erneut die Synode von Tribur im Jahr 1036 mit einem Inzestfall ${ }^{304}$. Die Angelegenheit wird nicht in den Kanones der Synode angesprochen, da sich die Bischöfe schwerlich offiziell zu dem zwielichtigen Vorgehen in diesem Fall bekennen konnten. Die einzige Quelle ist eine Urkunde Erzbischof Poppos von Trier. Poppo berichtet darin von dem Wunsch seines Vogtes Thiefried, trotz einer entfernten Verwandtschaft im Grad 5/6 die Ehe mit einer gewissen Liutchart zu vollziehen ${ }^{305}$. Thiefried habe dem Erzbischof eine Schenkung von 12 Hufen angeboten, wenn er ihm eine Dispensierung von dem Eheverbot der Verwandtschaft gewähren würde. Der Erzbischof habe daraufhin auf der Synode von Tribur die Bischöfe von Köln, Mainz und Verdun befragt und von ihnen einen positiven Bescheid erhalten. Mit der Urkunde ließ Poppo diese Transaktion durch sieben Zeugen bestätigen und erklärte die Ehe seines Amtsträgers für rechtmäßig ${ }^{306}$.

Das Vorgehen Poppos steht im deutlichen Kontrast zu den Regeln des Dekrets Burchards von Worms. Eine Trennung der inzestuösen Ehepartner galt als verbindlich, und Burchard warnte ausdrücklich vor der Nachgiebigkeit mancher Bischöfe, die eine Buße für ausreichend hielten ${ }^{307}$. Genau dieser Weg wurde hier eingeschlagen. Den Ehepartnern ist nur eine Buße verordnet wor$\operatorname{den}^{308}$, und die Schenkung von 12 Hufen diente als Wiedergutmachung für die Verletzung des Kirchenrechts. Der Erzbischof versuchte im Text der Urkunde das unkanonische Vorgehen mit verschiedenen Argumenten zu verschleiern. So betonte er die weit entfernte Verwandtschaft im Grad 5/6 $6^{309}$ sowie die Unwis-

304 Wolter, Synoden 1988, 353-357. Ob auch die in Tribur beschlossene Auflösung der Verlobung zwischen Otto von Schweinfurt und Mathilde von Polen auf ein Verwandtschaftsverhältnis zwischen den beiden zurückzuführen ist, lässt sich nicht entscheiden: Bresslau, Jahrbücher 2 1915, 162; Wolter, Synoden 1988, 355; Corbet, Burchard 2001, $153 \mathrm{f}$.

305 Mittelrheinisches Urkundenbuch 1 Nr. 307 (359 f.). Vgl. Wolter, Synoden 1988, 355; Corbet, Burchard 2001, 155-157.

306 Vgl. Reuter, Bonds 1995, 263.

307 Siehe 434 Anm. 259.

308 ... verum in poenitentia simul manere ... Mittelrheinisches Urkundenbuch 1 Nr. 307 (359).

309 Namque a quibusdam ut deprehensum est erant cognati, sed quinto generationis actu et sexto vicissim alterati ... Mittelrheinisches Urkundenbuch 1 Nr. 307 (359). 
senheit Thietfrieds bei seiner Verlobung mit Liutchart ${ }^{310}$. Die Konsultation Erzbischof Pilgrims von Köln, eines „Mannes von bewundernswerter Heiligkeit “311, erwähnte er als Entlastung von seiner eigenen Beteiligung an dieser Angelegenheit. Schließlich merkte Poppo von Trier unverhohlen an, die Kirche dürfte nicht der Schenkung solch großer Landgüter verlustig gehen ${ }^{312}$. Der Wortlaut der Frage an die in Tribur versammelten Bischöfe weist zudem auf ein weiteres Dilemma hin: Wenn man die bereits beschlossene Verlobung aufheben würde, hätte man nach den damaligen Vorstellungen eine Scheidung gutgeheißen, da Verlobung und Eheschließung gleichgesetzt wurden. Man wog daher ab zwischen der Erlaubnis einer entfernten Inzestehe oder der Befürwortung einer Scheidung ${ }^{313}$. Die Bischöfe entschieden sich für die Inzestehe und gegen eine Scheidung. Dieser Kompromiss war weit entfernt von den Vorstellungen Burchards, sollte aber in den folgenden Jahren zur gängigen Praxis des geistlichen Gerichts werden.

Ein weiteres Beispiel für den Stimmungswandel innerhalb des Reichsepiskopats ist die Heirat König Heinrichs III. im Jahr 1043. Konrad hatte zunächst zwei Heiratsprojekte für seinen Sohn verfolgt, die keine Verdächtigung einer Inzestehe aufkommen ließen. Zunächst wurde im Jahr 1028 eine hochrangige Gesandtschaft nach Konstantinopel geschickt, um eine Heirat mit einer byzantinischen Prinzessin anzubahnen ${ }^{314}$. Dieses Projekt scheiterte jedoch nach einem Machtwechsel in Byzanz aus unbekannten Gründen. Die Heirat mit Gunhild von Dänemark im Jahr 1036 war ebenfalls über jeden Verdacht des Inzests erhaben. Dass diese exogame Heiratspolitik nicht einer grundsätzlichen Erwägung Konrads II. geschuldet ist, zeigt die kurz davor beschlossene Verlobung einer Tochter des Kaisers mit dem französischen König Heinrich I. Die beiden Ehepartner waren im Verhältnis 5/4 über den sächsischen König Heinrich I. verwandt ${ }^{315}$. Diese Ehe kam nur deshalb nicht zustande, weil die Tochter bereits kurz nach der Verlobung gestorben ist. Vermutlich haben sich damals auch kritische Stimmen zu diesem Eheprojekt zu Wort gemeldet, die jedoch durch den Verweis auf den friedensstiftenden Charakter der Verbindung

310 ... sed ignoranter desponsasse ... Mittelrheinisches Urkundenbuch 1 Nr. 307 (359).

311 Quos inter plures Piligrinum Coloniensem mirae sanctitatis virum ... Mittelrheinisches Urkundenbuch 1 Nr. 307 (359).

312 ... tum sanctae Dei aecclesiae tanta predii bona perditum iri nequaquam debere. Mittelrheinisches Urkundenbuch 1 Nr. 307 (359).

313 ... questione utrum cuiquam iura conubii ad huiusmodi contiguam licerent, quam sibi lege sua quis pridem desponsatam haberet. Mittelrheinisches Urkundenbuch 1 Nr. 307 (359).

314 SteIndorfF, Jahrbücher 1 1874, 13-15.

315 Bresslau, Jahrbücher 2 1915, 78; Wolfram, Konrad II. 2000, 259-262; Corbet, Burchard 2001, 140. 
zum Schweigen gebracht werden konnten ${ }^{316}$. Der kaiserliche Hof fühlte sich also nicht an die strengen Regeln Burchards von Worms gebunden. Dies zeigen auch die Umstände der zweiten Ehe Heinrichs mit Agnes von Poitou.

Nach vier Jahren eheloser Zeit begann Heinrich III. zu Pfingsten 1042 seine Werbung um die Tochter des Herzogs von Aquitanien ${ }^{317}$. Über ein Jahr verging, bis im November 1043 die Verlobung in Besançon, die Krönung in Mainz und die Hochzeit in der Pfalz Ingelheim gefeiert wurden. In diese Zeit fallen die Verhandlungen mit König Heinrich I. von Frankreich im April $1043^{318}$. Der deutsche König benutzte dieses Treffen an der Grenze der beiden Reiche in Ivois vermutlich dazu, die Zustimmung des französischen Monarchen zu seinem Heiratsprojekt zu erhalten. Probleme dürften bei diesen Verhandlungen nicht aufgetreten sein, da die Heirat den Interessen des französischen Königs nicht zuwiderlief ${ }^{319}$. Die Heirat sollte nämlich in erster Linie die Bindung Heinrichs III. zum unlängst erworbenen Königreich Burgund stärken, weil Agnes als Enkelin Otto Wilhelms von Burgund enge Beziehungen zu dieser Region unterhielt. Ein zweites Thema, das zwischen Pfingsten 1042 und November 1043 für Aufregung sorgte, war die Blutsverwandtschaft zwischen den Eheleuten. Über die Diskussionen berichten Briefe der Äbte Siegfried von Gorze und Bern von Reichenau. Nach Siegfrieds Brief hatte bereits Abt Poppo von Stablo, der als Experte für Klosterfragen unter den Saliern hohes Ansehen genoss ${ }^{320}$, den König auf die Verwandtschaft mit Agnes hingewiesen. Der König habe Poppo damit beauftragt, genauere Informationen über diese Verwandtschaft beizubringen ${ }^{321}$. Poppo habe dann Siegfried in einem persönlichen Gespräch von diesem Auftrag berichtet und vom Abt aus Gorze sogleich die notwendigen Fakten erhalten. Nur zwei Namen waren Siegfried damals entfallen, so dass er den heute bekannten Brief mit den erforderlichen Details nachreichen musste ${ }^{322}$. Darin tritt er für eine Verwandtschaft von $4 / 4$ über die gemeinsame Ururgroßmutter Gerberga ein und spricht unter Verwendung der Zählung nach Vetterschaften von einer Ehe im dritten Grad $^{323}$.

316 Siegfried von Gorze, Brief an Poppo von Stablo (717). Über den Autor siehe Wagner, Gorze 1996, 57-62; Parisse, Sigefroid 2004.

317 STEINDORFF, Jahrbücher 1 1874, 154-156.

318 STEIndorfF, Jahrbücher 1 1874, 176; Boshof, Lothringen 1978, 73-75.

319 Zum Folgenden vgl. Boshof, Lothringen 1978, 73; DERs., Salier 2000, $115 \mathrm{f}$.

320 Wolfram, Konrad II. 2000, 311-315.

321 ... respondistis, nec vos tacuisse nec illum contra Dominum velle facere, sed potius plurimum postulasse, ut veritatem inquireretis et eum, antequam contra fas quicquam perpetraret, certum faceretis. Siegfried von Gorze, Brief an Poppo von Stablo (714).

322 Igitur de bona eius intentione plurimum confortatus, quicquid de illa parentela iampridem cognoveram, vobis retuli, sed duarum feminarum nomina, quae tunc memoriae deerant, dicere non potui. Siegfried von Gorze, Brief an Poppo von Stablo (714).

323 Agnes ipsa videlicet, de qua hoc totum agitur, in tertia genealogiae linea invenitur. Siegfried von Gorze, Brief an Poppo von Stablo (715). 
Am königlichen Hof ist man dieser Rekonstruktion der Verwandtschaft entgegengetreten. Nach Siegfrieds Bericht wurde dem König von einigen Leuten weisgemacht, seine Großmutter sei nicht die Tochter Mathildes, sondern der ersten Frau König Konrads von Burgund (Adelana) gewesen ${ }^{324}$. Siegfried wendete sich mit überzeugenden Argumenten gegen diese Mutmaßung, da sich aus seiner Rekonstruktion die auch sonst übliche Übernahme des Namens der Großmutter durch die Enkelin ergab. Siegfried war nicht der einzige, der sich für eine Verwandtschaft von 4/4 aussprach. Der Abt Bern von Reichenau, auch er ein Zögling der lothringischen Reform von Gorze, wandte sich direkt an König Heinrich, um unter dem Deckmantel eines Lobes der edlen Herkunft von karolingischen und ottonischen Vorfahren auf die Abstammung von Gerberga zu verweisen ${ }^{325}$. Obwohl Bern nicht ausdrücklich das Eheprojekt Heinrichs III. mit Agnes von Poitou erwähnte, sondern vielmehr die edle Abkunft zum Herrscherlob benutzte, sieht Heinz Thomas darin zu Recht eine Stellungnahme im Sinne Siegfrieds von Gorze ${ }^{326}$. Der lothringische Abt war also bei seinen Bemühungen, die Eheschließung zu verhindern, nicht auf sich allein gestellt. Eine später entstandene Quelle aus dem französischen Burgund belegt, dass die Diskussion um die Inzestehe auch außerhalb des Reichs für Aufsehen gesorgt hat ${ }^{327}$.

Die Umgebung Heinrichs III. wehrte sich jedoch gegen den Inzestvorwurf und lehnte eine enge Verwandtschaft im Verhältnis $4 / 4 \mathrm{ab}$. Siegfried führte deshalb in seinem Brief an Poppo von Stablo noch eine andere Genealogie an, nach der die Ehepartner im Verhältnis 5/6 über König Heinrich I. verwandt $\operatorname{sind}^{328}$. Zur Demonstration dieser Verwandtschaft legte Siegfried dem Brief noch ein Bild über die Abstammung Heinrichs I. bei. Dieses Bild sollte dem Kaiser vor Augen führen, dass aus der „überaus edlen und zahlreichen Nachkommenschaft“ des sächsischen Königs „nur wenige übrig geblieben sind“329. Inzestehen, wie sie unter den Nachkommen Heinrichs des öfteren geschlossen worden seien, würden nämlich eine Bestrafung Gottes nach sich ziehen. Siegfried warnte den König daher eindringlich davor, durch seine Inzestehe seinem

324 Audivi autem dictum esse regi, aviam suam Gepam non ex Mathilde, sed ex priore Cuonradi regis uxore fuisse progenitam. Quod non ita esse et veridicorum hominum asserit relatio et ipse feminarum ostendit equivocatio. Siegfried von Gorze, Brief an Poppo von Stablo (715).

325 Cuius Hludovici filiam Chunradus rex Burgundionum duxit uxorem, de qua genuit vestram aviam ... Bern von Reichenau, Brief 26 (56).

326 Thomas, Kritik 1977; Corbet, Burchard 2001, $144 \mathrm{f}$.

327 De ordinando pontifice (94).

328 Et sic iste in quinto, puella vero Agnes in quarto genealogiae computatur loco. Siegfried von Gorze, Brief an Poppo von Stablo (715).

329 Hoc sane quam verum sit, liquido potest agnoscere, si de eius nobilissima olimque amplissima parentela quam pauci supersint, prudenter voluerit attendere. Siegfried von Gorze, Brief an Poppo von Stablo (715). Die Überlieferung der figura behandelt GäDEKE, Zeugnisse 1992. 
Volk ein schlechtes Vorbild abzugeben und die Nachahmung durch seine Untertanen heraufzubeschwören. Mit der Fortführung der inzestuösen Ehepraxis seiner Vorfahren bringe er Unheil über sich sowie über sein Reich, da er seinen eigenen Willen über den Willen Gottes stelle ${ }^{330}$. Der Friede - und als Friedenskönig inszenierte sich der Herrscher in diesen Jahren ${ }^{331}$ - sei unvereinbar mit der Übertretung des göttlichen Gesetzes, das in den kanonischen Vorschriften verkörpert sei. „Und weil der festgelegte Tag der Eheschließung bereits nahe liegt, flehe ich dich, heiligster Vater, an, dass ihr nicht zögert, an den König heranzutreten und ihm dies deutlich zu machen, zumal da er selbst euch um Informationen gebeten hatte und weil euch ein großes Unheil droht, wenn er durch euer Zögern ein so großes Übel in die Tat umsetzt ${ }^{\text {‘332 }}$. Zum Abschluss drohte Siegfried damit, nach der Ehe "noch schärfer und daher noch mehr Gefahr bringend anzuklagen “333.

Siegfried versuchte nicht nur den angesehenen Reformabt Poppo von Stablo auf seine Seite zu ziehen, auch einen Bischof wollte er in seinem Sinne beeinflussen. In einem kurzen Brief riet er dem Bischof Bruno von Toul von der Beteiligung an der Eheschließung dringend $a b$ und rief zu dem gleichen Widerstand auf, den der heilige Ambrosius gegen den Kaiser Theodosius an den Tag gelegt hatte ${ }^{334}$. Siegfrieds Appell blieb wirkungslos. An der Verlobung in Besançon nahmen 28 Bischöfe teil, die Hochzeit in Ingelheim wurde durch die Anwesenheit zweier päpstlicher Legaten sanktioniert, und bei der Krönung in Mainz gaben „alle Fürsten des Reichs“ ihr Einverständnis ${ }^{335}$. Vermutlich hielt der König an seiner Rekonstruktion der Verwandtschaft fest und betrachtete das Verhältnis von 5/6 über Heinrich I. nicht als ausreichende Begründung für den Inzestcharakter der Ehe. Mit einigem Recht ist vermutet worden, die Reise Erzbischof Hermanns von Köln nach Rom im Sommer 1043 habe das Ziel

330 ... ne, quod absit, parentum delicta faciat esse sua. Hinc enim culpa eorum simul et culpae vindicta in ipsum redundabit, si eos in malo imitatus fuerit. Siegfried von Gorze, Brief an Poppo von Stablo (715).

331 Schnith, Recht 1961; Weinfurter, Jahrhundert 2004, 101-105. Minninger, Friedensmaßnahmen 1979, 47, und Black-Veldtrup, Agnes 1995, 191, begreifen die Friedensmaßnahmen als Ablenkung von der Kritik an der Inzestehe. Vgl. dagegen Corbet, Burchard 2001, 145.

332 Et quia constitutus dies nuptiarum iam prope est, obsecro, beatissime pater, ut regem adire et haec ei manifestare non differatis, cum et ipse hoc vos inquirere petierit et multum vobis periculum immineat, si vobis tardante tantum malum peregerit. Siegfried von Gorze, Brief an Poppo von Stablo (718).

333 Verum convenientius esse duximus, eum ante factum humiliter commonere, quam post factum mordacius ac per hoc periculosius arguere. Siegfried von Gorze, Brief an Poppo von Stablo (718).

334 Siegfried von Gorze, Brief an Bruno von Toul (719).

335 Steindorff, Jahrbücher 1 1874, 192; Frech, Papstregesten 2006, 170 (Nr. 245). 
verfolgt, die Zustimmung des Papstes zu dieser Sicht zu erhalten ${ }^{336}$. Hermann II. von Köln war als wichtiger Ratgeber des Königs für eine solch heikle Mission bei Papst Benedikt IX. besonders geeignet ${ }^{337}$. Vielleicht ist damals die Diskussion bis zu Petrus Damiani vorgedrungen, der zu dieser Zeit in einen Streit um die Ausdehnung des Inzestverbots verwickelt wurde ${ }^{338}$.

In Rom ebenso wie im Reich hielt man sich nicht an das strenge Eherecht Burchards von Worms. Folglich wird man Konrads Ablehnung der Ausdehnung des Inzestverbots nicht als Ausdruck seiner „Laienfrömmigkeit“"339 und seiner fehlenden kirchlichen Bildung verstehen müssen. Denn auch sein Sohn schlug sich trotz der durch seine berühmten Bußakte bezeugten Frömmigkeit auf die Seite einer moderaten Auslegung der Inzestvorschriften. Mit den Anliegen der Kirchenreform war dies durchaus nicht unvereinbar, da er sich offen als Gegner der Simonie und der Priesterehe deklarierte und für die Durchsetzung der Reform in Rom verantwortlich war ${ }^{340}$. Auch das Inzestverbot als solches hieß er gut, wie die im Jahr 1052 erlassene Konstitution für das italienische Reichsgebiet bezeugt. Diese Konstitution, an dessen Entstehung sicher auch der Erzkanzler für Italien Hermann von Köln beteiligt gewesen war, bekräftigte alle Inzestvorschriften der Kirche sowie der kaiserlichen Vorgänger und bestimmte für Ehen innerhalb der Schwägerschaft die Enteignung ${ }^{341}$. Die eine Hälfte des Vermögens sollte an den Fiskus, die andere an die erbberechtigten Verwandten gehen, während die Kinder aus einer solchen Ehe als enterbt zu betrachten seien. Diese Bestimmungen brachten zwar im Rahmen des Liber Papiensis keine wesentlichen Neuerungen ${ }^{342}$, unterstrichen jedoch den Ernst des Königs bei der Verfolgung von Inzestdelikten. Im Jahr 1056 enteignete er den bayerischen Markgrafen Otto wegen eines Inzestvergehens ${ }^{343}$. Nur die übertriebene Ausdehnung auf den 7. Grad kanonischer Zählung, die im lothringischen Reformkreis auf Zustimmung stieß, lehnte Heinrich III. nicht nur aus eigenem Interesse ab. Auch im Episkopat sprach man sich für eine moderate Handhabung des Inzestverbots aus.

336 Herrmann, Tuskulanerpapsttum 1973, 44; Corbet, Burchard 2001, 145.

337 STEINDORFF, Jahrbücher 1 1874, 52.

338 Siehe unten 452.

339 Vgl. Hoffmann, Mönchskönig 1993, 144. Kritisch hierzu Wolfram, Konrad II. 2000, $331-333$.

340 Boshof, Salier 2000, 125-138; Weinfurter, Jahrhundert 2004, 89-112.

341 MGH D H III. 294. Vgl. den Kommentar von Corbet, Burchard 2001, 166 f.

342 Liber Papiensis Liutp. 33 (MGH LL 4, 423).

343 MGH D H III. 360. Die Identität des Markgrafen ist umstritten, vgl. STÖrmer, Bayern 1991, 542; Corbet, Burchard 2001, 159-161. 
Petrus Damiani und die Omnipräsenz des Inzests

Im Reich nördlich der Alpen bewirkte die Verfälschung des Kirchenrechts durch Burchard von Worms allein noch keine radikale Änderung. Auch in Rom konnte Heinrich III. erfolgreich für die Zustimmung zu seiner Heirat werben, da Benedikt IX., einer der letzten Vertreter des stadtrömischen Papsttums, an einer moderaten Auslegung der Inzestverbote festhiel ${ }^{344}$. Er führte damit die Politik seines Vorgängers Benedikt VIII. fort, der im Hammersteiner Eheprozess die Partei der verfolgten Eheleute ergriffen hatte. Vermutlich orientierte sich das vorreformerische Papsttum noch immer am kategorischen Verbot von Verwandtenehen und benutzte weiterhin die römische Zählweise der Verwandtschaft $^{345}$. Einen Wandel des päpstlichen Standpunkts bewirkte erst Petrus Damiani. Zu einer Stellungnahme herausgefordert wurde der populäre Asket und Eremit von Fonte Avellana durch einen Disput, über dessen Hintergründe wir nur unzureichend informiert sind. Als sich Damiani im Jahr 1044 in seiner Heimatstadt Ravenna aufhielt, kam es zu einer „bedeutenden Debatte" ${ }^{\text {“346 }}$ über die Frage, wie die Inzestgrenze des siebten Grades im kanonischen Recht zu verstehen sei. Gegenüber der Anfrage von Boten aus Florenz nahmen die Juristen der Stadt Ravenna den Standpunkt ein, dass der siebte Grad mit der römischen Komputation gezählt werden müsste ${ }^{347}$. Eine Verbindung im Verhältnis 3/4 hielten die Juristen folglich für erlaubt. Als Begründung zogen sie nach dem Bericht Damianis eine Stelle aus den Institutionen Justinians heran. Der Standpunkt der Florentiner ist unklar. Möglicherweise befürworteten sie die kanonische Zählung, machten aber von der Erlaubnis einer Ehe im vierten Grad durch den Libellus responsionum Gebrauch ${ }^{348}$. Petrus Damiani hat „mit einfachen Worten“ dieser „im Entstehen befindlichen Häresie“ widersprochen und sie mit Zeugnissen aus dem Kirchenrecht „aufgerieben“349. Mit seiner

344 Angeblich wollte Benedikt später das Papsttum niederlegen, um seine Cousine zu heiraten: Frech, Papstregesten 2006, 173 (Nr. 250). Engelbert, Heinrich III. 1999, 235, hält dies für eine „ganz und gar unglaubwürdige Geschichte“.

345 CoRbet, Burchard 2001, $246 \mathrm{f}$.

346 Erat autem de consanguinitatis gradibus plurima disceptatio ... Petrus Damiani, Brief 19 (MGH Briefe d. dt. Kaiserzeit 4/1, 180). Zum Aufenthalt Damianis vgl. Lucchesi, Vita 1 1972, $68 \mathrm{f}$.

347 ... atque iam res eo usque processerat, ut sapientes civitatis in unum convenientes sciscitantibus Florentinorum veredariis in commune rescripserint, septimam generationem canonica auctoritate praefixam ita debere intelligi, ut numeratis ex uno generis latere quattuor gradibus atque ex alio tribus iure iam matrimonium posse contrahi videretur. Petrus Damiani, Brief 19 (MGH Briefe d. dt. Kaiserzeit 4/1, 180).

348 Petrus Damiani, Brief 19 (MGH Briefe d. dt. Kaiserzeit 4/1, 190).

349 Et quidem ego nudis verbis ista dogmatizantibus restiti ac prout in expeditione licuerat emergentem, ut ita fatear, heresim canonicae testimoniis auctoritatis attrivi. Petrus Damiani, Brief 19 (MGH Briefe d. dt. Kaiserzeit 4/1, 181). 
Antwort war man jedoch nicht zufrieden ${ }^{350}$, wodurch sich Damiani zu einer schriftlichen Widerlegung aller Argumente der Gegenseite herausgefordert sah. Er richtete den Brief an Bischof Johannes von Cesena und an den Archidiakon Amelrich von Ravenna, erreichte damit jedoch einen weiteren Kreis von reformerisch gesinnten Kirchenleuten ${ }^{351}$.

Den Anlass für diese „bedeutende Debatte“ sieht Jean-Pierre Poly in der Kontroverse um die Ehe Heinrichs III. mit Agnes von Poitou ${ }^{352}$. Er deutet die Anfrage der Florentiner als Konsultation im Interesse des salischen Herrschers, da Florenz im Herrschaftsbereich des königstreuen Markgrafen Bonifaz von Tuszien lag. Die Juristen aus Ravenna seien für die Legitimität der Ehe Heinrichs III. eingetreten, indem sie sich für die Geltung der römischen Zählweise ausgesprochen hätten. Nach dem Bericht Damianis schränkten sie das Inzestverbot auf das Verhältnis von 3/4 ein und würden damit die Ehe mit Agnes von Poitou (4/4) als legitim angesehen haben. So hätten die Juristen den Weg für die Kaiserkrönung durch den Papst geebnet, die für das folgende Jahr geplant gewesen sei. Das Schweigen Damianis über den Hintergrund der Debatte führt Poly auf das Bündnis zwischen dem König und den italienischen Reformkräften zurück. Damiani, der in seinem Engagement für die Reform der Kirche von der Unterstützung Heinrichs III. abhängig gewesen sei, habe sich eine offene Kritik an der Ehepraxis des Herrschers nicht erlauben können. Poly gelingt es erstmals den sonst rätselhaft erscheinenden Brief Damianis in einen plausiblen Kontext einzubetten.

Der Streitpunkt im Brief Damianis war die zwischen den Gelehrten aus Florenz und Ravenna umstrittene Frage der Zählweise. Die Inzestgrenze des siebten Grades schien in Ravenna bereits auf Akzeptanz gestoßen zu sein. Dafür war wohl zum einen die breite Überlieferung der Vita Gregorii mit der PseudoGregor-Dekretale verantwortlich ${ }^{353}$, zum anderen die zügige Rezeption der Sammlung Burchards von Worms. Bereits um 1035 gibt es den ersten Beleg für eine Handschrift des Decretum in Oberitalien ${ }^{354}$. Petrus Damiani selbst war mit dem Werk Burchards gut vertraut und verwendete das Decretum neben der Dionysio-Hadriana als sein wichtigstes Referenzwerk für kanonistische Fragen ${ }^{355}$. Selbst als Damiani im Brief kurz auf den Libellus responsionum zu sprechen kommt, beschimpft er zwar den Florentiner Befürworter dieses Dokuments mit

350 Quo tamen vos minime contenti ... Petrus Damiani, Brief 19 (MGH Briefe d. dt. Kaiserzeit 4/1, 181).

351 Berschin, Bonizo 1992, 83-90; Freund, Studien 1995, 98 f. u. $118 \mathrm{f}$.

352 Poly, Chemin 2003, 368-370. Davidsohn, Geschichte 1 1896, 182, macht darauf aufmerksam, dass einer der auf der Hochzeit von 1043 anwesenden päpstlichen Legaten der Sohn des Bischofs von Florenz war.

353 Wilhelmi, Vita 1998; Castaldi, Vita 2004.

354 Jasper, Dekret 2000, 170.

355 Ryan, Damiani 1956, 21. 
drastischen Worten ${ }^{356}$, hält es aber nicht für nötig, auf die Aufhebung der milden Bestimmung durch die Pseudo-Gregor-Dekretale ausdrücklich hinzuweisen. Der siebte Grad war somit weitgehend etabliert, abweichende Stimmen sind aus dem Italien des 11. Jahrhunderts nicht zu vernehmen.

Der Brief Damianis ist die erste ausführliche Erörterung über die Frage der Zählweise, über ein Problem also, das die Kanonisten seit dem 8. Jahrhundert immer wieder beschäftigt hat. Die Argumentation Damianis verdient daher eine eingehende Untersuchung. Der Einsiedler von Fonte Avellana führt eine Reihe von Argumenten für die Richtigkeit der kanonischen Zählung ins Feld. Das erste Argument stützt sich auf die Gleichsetzung von erbrechtlicher und eherechtlicher Verwandtschaft, wie sie in einer pseudoisidorischen Dekretale festgehalten wird. Der Fälscher lässt darin den Papst Calixt verkünden, dass „diejenigen blutsverwandt genannt werden, die das göttliche und das weltliche Gesetz in der Erbschaft annehmen und nicht zurückweisen können “357. Damiani richtet an die Rechtsgelehrten die Frage, ob in der Erbschaft nicht auch Abkömmlinge im siebten Grad nachfolgen könnten, wenn nähere Verwandte fehlen würden ${ }^{358}$. Folglich müsse man auch im Eherecht eine entsprechend weite Auslegung der Verwandtschaft befürworten. Damianis Verknüpfung ist aber wenig überzeugend. Schließlich geht es in der Frage der Eheschließung nicht um die Verwandtschaft zwischen Deszendenten - niemand heiratet einen Nachfahren im siebten Grad! - sondern um die Verwandtschaft zwischen Seitenverwandten. Und in diesem Fall wäre es auch nach dem Erbrecht der Zeit nicht selbstverständlich gewesen, seinen Cousin fünften oder sechsten Grades (6/6 oder 7/7) im Erbe nachfolgen zu können ${ }^{359}$. Der Vergleich mit dem Erbrecht hatte in den Zeiten Pseudoisidors Sinn gemacht, als man sich noch der römischen Zählweise bediente. Die Verwendung der kanonischen Zählweise lässt sich damit kaum begründen.

Auch das zweite Argument bleibt an der Oberfläche. Nach Damiani ist der Aufbau des Verwandtschaftsstemmas mit der Nennung von Aszendenten und Deszendenten bis in den 7. Grad unverständlich, weil mit diesen Personen keine Ehe eingegangen werden könne. Der Sinn der Auflistung bis zum Ururururgroßvater und Ururururenkel habe für die "Gesetzgeber des Kirchenrechts"

356 Petrus Damiani, Brief 19 (MGH Briefe d. dt. Kaiserzeit 4/1, 190).

357 Eos autem consanguineos dicimus, quos divinae et saeculi leges consanguineos appellant et in haereditatem suscipiunt nec repelli possunt. Petrus Damiani, Brief 19 (MGH Briefe d. dt. Kaiserzeit 4/1, 181) nach Decretales Pseudoisidorianae, Ps.-Calixtus 16 (140); Ryan, Damiani 1956, 24 (Quelle ist Burchard von Worms).

358 Interrogentur igitur, qui in tribunalibus iudicant, qui causarum negotia dirimunt, qui scrutandis legum decretis insistunt, numquid si propinquiores desint usque ad septimum gradum agnati, sive in hereditatem sive in tutelam non admittuntur. Petrus Damiani, Brief 19 (MGH Briefe d. dt. Kaiserzeit 4/1, 181).

359 Liber Papiensis Roth. 153 (MGH LL 4, 317 u. 322 f.). 
darin bestanden, das Eheverbot bis in den 7. Grad kanonischer Zählweise darzulegen ${ }^{360}$. Damiani geht in diesem Argument davon aus, dass der Stammbaum für das Eherecht konzipiert worden sei. Diese Annahme ist, wie wir heute wissen, falsch. Da der erbrechtliche Stammbaum jedoch schon seit mehreren Jahrhunderten auch für das Eherecht nutzbar gemacht wurde, können wir dies Damiani nicht zum Vorwurf machen. Doch Damiani irrt sich nicht nur darin, er versteht den Stammbaum absichtlich falsch. Denn im weiteren Verlauf des Briefes gibt er zu erkennen, welchen Stammbaum er für verbindlich hält und wie er zu benutzen ist. Formen dieses Stammbaums begegnen in den frühesten italienischen Handschriften von Burchards Dekret sowie in anderen italienischen Kirchenrechtssammlungen ${ }^{361}$. Sie sind durch eine Präsentationsfigur gekennzeichnet, deren ausgestreckte Arme die äußersten Grade der Seitenverwandtschaft berühren ${ }^{362}$. Die römisch gezählte Verwandtschaft reicht in den italienischen Burchard-Handschriften bis zum Verhältnis $2 / 8$ und $4 / 5$, aber nicht bis zu dem von Damiani favorisierten 7. Grad kanonischer Zählung. Damiani gibt eine mit der Konzeption des Stammbaums unvereinbare Benutzungsanleitung: Der rechte Zeigefinger als letztes Gelenk des ausgestreckten Armes soll den trinepos (Ururururenkel) repräsentieren, der linke Zeigefinger die trineptis (Ururururenkelin). Die beiden Zeigefinger seien Teil eines Körpers, weshalb zwischen diesen beiden Nachkommen eines Stammvaters keine Ehe stattfinden dürfe. Damiani zitiert als Beweis das reichlich unpassende Wort von Paulus: „Denn wie der Leib eine Einheit ist, doch viele Glieder hat, bilden alle Glieder des Leibes aber, obgleich es viele sind, einen einzigen Leib“363. Im zugrunde liegenden Stammbaum stehen jedoch der patruelini abnepos (2/6) und der consobrini trinepos (2/8) an der Stelle der Zeigefinger und beziehen sich nicht aufeinander, sondern auf den in der Mitte befindlichen Ego. Trinepos und trineptis befinden sich dagegen bei den Füßen der Präsentationsfigur ${ }^{364}$.

360 Ut quid etiam tam operosa inter sacros canones figura dipingitur, ut non modo supra vel infra sed ex utroque etiam latere sex gradibus terminetur, si septima generatio, ut asserunt, tribus hinc enumeratis personis atque illinc quattuor expleatur? Petrus Damiani, Brief 19 (MGH Briefe d. dt. Kaiserzeit 4/1, 181 f.).

361 Schadt, Arbores 1982, 92 (Collectio in V libros) u. 118-121 (Burchard). Die Präsentationsfigur begegnet erstmals in spanischen Handschriften des 10. Jahrhunderts mit Isidors Etymologiae. Zur Collectio in V libros vgl. Kéry, Collections 1999, 157-160.

362 Unde mos inolevit, ut sub figura humani corporis illa consanguinitatis descriptio pingeretur. Petrus Damiani, Brief 19 (MGH Briefe d. dt. Kaiserzeit 4/1, 183).

363 Atque ut quod dicimus liquidius elucescat: qui trinepotem ab ea, quae altrinsecus est trinepte, affinitatis vinculo solutum iudicat, inter digitos, quibus haec scribo, et sinistrae manus articulos communionem deesse contendat. Sed huic pravae assertioni reclamat apostolus, cum dicit: ,Sicut enim corpus unum est et membra habet multa, omnia autem membra corporis, cum sint multa, unum corpus sunt'. Petrus Damiani, Brief 19 (MGH Briefe d. dt. Kaiserzeit 4/1,183).

364 Schadt, Arbores 1982, Abb. 42, 44 u. 45. 
Damiani gibt vor, die Aszendenz und Deszendenz würden zur Feststellung der Verwandtschaft benützt, obwohl offensichtlich nur die Seitenverwandtschaft diesen Zweck erfüllt.

In seinem dritten Argument für die kanonische Zählung beruft sich Damiani auf die Bibel ${ }^{365}$. Wie bereits Gregor I. feststellte, wird darin die Nachkommenschaft in Generationen gezählt. Für Damiani war dies gewiss die Grundlage seines Eintretens für die kanonische Zählweise. Das Problem dieses Arguments besteht darin, dass in der Bibel nur die Nachkommenschaft und nicht die Seitenverwandtschaft auf diese Weise gezählt wird. In der Nachkommenschaft unterscheidet sich aber die kanonische nicht von der römischen Zählweise. Damiani führt deshalb als Beleg für die Übertragung der Generationenzählung auf die Seitenverwandtschaft des Eherechts den Libellus responsionum $\mathrm{an}^{366}$. Gregor der Große weist darin eindeutig der Ehe mit der Cousine (2/2) den zweiten Grad zu und lehnt diese vom römischen Recht seiner Zeit erlaubte Form der Nahehe ab. Damiani hat dagegen ganz andere Sorgen: Ihm geht es um das Verbot der Ehe mit der Cousine fünften oder sechsten Grades. Er benützt den Text Gregors daher nur zur Untermauerung der kanonischen Zählweise sowie für die Ablehnung des römischen Rechts insgesamt. Der Widerspruch zum römischen Recht bereitet ihm keine Schwierigkeit, sondern ist für ihn geradezu ein Ausweis der Richtigkeit der kanonischen Zählung: „weil nicht immer das Unterste mit dem Höchsten, das Weltliche mit dem Heiligen, das Menschliche mit dem Göttlichen übereinstimmt ${ }^{\text {“367 }}$.

Auch wenn sich die Argumentation Damianis über viele Seiten erstreckt und er noch andere Belege anzuführen weiß, besteht sie im wesentlichen aus einigen Scheinargumenten sowie aus einer auf der Bibel begründeten festen Überzeugung. Wie ist diese Überzeugung in das Weltbild des Einsiedlers einzuordnen? David d'Avray unternahm einen interessanten Versuch, den Kontext der Argumentation aufzuklären. Ausgangspunkt seines Aufsatzes sind die Überlegungen Damianis im Anschluss an die berühmte Rechtfertigung des Inzestverbots durch Augustinus ${ }^{368}$. Demnach ist die Ehe ein Mittel, die „brüderliche Nächstenliebe" nach dem Ende verwandtschaftlicher Bindungen durch Verschwägerung zu erweitern. Damiani kleidet den Gedanken Augustins in eine bildhafte Sprache: „Wenn die entfernte Nähe der Abstammung aufhört, erkaltet durch das Laster der menschlichen Bösartigkeit das Feuer der Liebe, als ob der

365 Petrus Damiani, Brief 19 (MGH Briefe d. dt. Kaiserzeit 4/1, 188 f.).

366 Petrus Damiani, Brief 19 (MGH Briefe d. dt. Kaiserzeit 4/1, 191). Zur Autorität der Bibel vgl. WüNsCH, Bibelinterpretation 2002, 40-43.

367 ... quia non semper ima summis, non mundana sacris, non concordant humana divinis. Petrus Damiani, Brief 19 (MGH Briefe d. dt. Kaiserzeit 4/1, 192). Zur Kenntnis und Einschätzung des römischen Rechts bei Damiani vgl. Conrat, Geschichte 1891, $601-$ 606; Cantin, Sciences 1975, 505-533.

368 Siehe oben $61 \mathrm{f}$. 
Zunder entzogen wurde. Um das Feuerchen der gegenseitigen Liebe wieder-

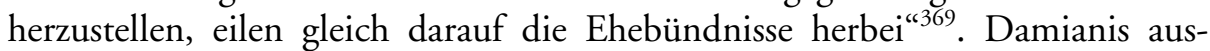
drückliche Begründung des weiten Inzestverbots müsse man, so d'Avray, in Ermangelung einer besseren Erklärung für bare Münze nehmen. Gerade vor dem Hintergrund der Bedeutung von Adelsgeschlechtern in den Städten des mittelalterlichen Italiens sei die Position Damianis verständlich, „durch die Schaffung von Bündnissen gesellschaftliche Harmonie“ zu fördern ${ }^{370}$. Das Eintreten für die kanonische Zählung entpuppt sich dann als ein Mittel der Friedenspolitik des Klerus.

Diese Deutung hängt aus einem wichtigen Grund in der Luft. Es gelingt d'Avray nicht, Damianis Rechtfertigung eines ausgedehnten Inzestverbots in das Leben und die Mentalität des Eremiten einzubetten. Es ist weder belegt, dass sich Damiani als Vermittler zwischen Geschlechterverbänden in italienischen Städten betätigt hat, noch dass er überhaupt den unversöhnlichen Kampf solcher Verbände als akutes Problem seiner Zeit wahrgenommen hat. Zudem ist eine grundsätzliche Frage an d'Avray zu stellen: Hätte zur Etablierung von innerdynastischen Bündnissen nicht auch ein eingeschränktes Inzestverbot ausgereicht? Schließlich waren die italienischen Clans nicht so fest umrissene Verbände, dass sie Verwandte bis in den 7. Grad kanonischer Zählung umfasst hätten ${ }^{371}$. Zur Etablierung „gesellschaftlicher Harmonie“ hätte auch ein eingeschränktes Inzestverbot ausgereicht. Man muss daher Damianis Aussage über die Ausbreitung der Nächstenliebe in einem anderen Sinn auffassen. Neben dem ziemlich banalen Bekenntnis zur christlichen Caritas versteckt sich dahinter die feste Überzeugung, die Verwandtschaftsgrenze des römischen Rechts nicht mehr als Autorität anzuerkennen. Während im frühen Mittelalter bis Papst Nikolaus I. das römische Recht als selbstverständliche Grundlage des kanonischen Rechts akzeptiert worden war $^{372}$, verstand Damiani das Recht der Kirche als eigenständiges Rechtssystem. Die Institution Kirche hatte im Zuge der Kirchenreform an Autonomie gewonnen und ihr Recht gegenüber äußeren Einflüssen verselbständigt. Bereits Burchard von Worms tilgte im Gegensatz zu Regino alle Verweise auf die königliche oder kaiserliche Urheberschaft kirchlicher Normen $^{373}$. Für Damiani sind römisches und kanonisches Recht zwei unter-

369 Verumtamen cum affinitas generis elongata discedit, humanae pravitatis vitio quasi submoto fomite amoris flamma frigescit. Ad reparandum ergo mutuae charitatis igniculum accurrunt subinde foedera nuptiarum. Petrus Damiani, Brief 19 (MGH Briefe d. dt. Kaiserzeit 4/1, 184).

370 D’Avray, Damian 1992, 79.

371 Vgl. Heers, Clan 1974, 101-104.

$372 \mathrm{Zu}$ Gregor I. siehe 222. Vgl. Conrat, Recht 1911; Fürst, Ecclesia 1975.

373 Fournier - Le Bras, Histoire 1 1931, 378. 
schiedliche Rechtssysteme, das eine gilt für die Laien, das andere für die Kleriker $^{374}$.

Anders als d'Avray bin ich der Meinung, die Ausdehnung des Inzestverbots müsse im Rahmen der Ehelehre Damianis betrachtet werden. Diesen Weg hat bereits Christopher Brooke beschritten. Ihm zufolge verstand der Einsiedler die Ehe als Institution, die nur durch ein „seltsames und unverständliches Rätsel der göttlichen Vorsehung" erlaubt worden sei $^{375}$. Geschlechtsverkehr erschien Damiani, einem vehementen Kämpfer für den Zölibat, als unvereinbar mit persönlicher Heiligkeit sowie mit der kirchlichen Amtsausübung. Christus habe für alle Menschen eine keusche Lebensweise gewünscht und den Geschlechtsverkehr nur „ungern“ erlaubt $^{376}$. Damiani befürwortete strikte Enthaltsamkeit ebenso wie das Verbot von Eheschließungen an Festtagen und zu den Fastenzeiten $^{377}$. Als Ideal stellte er in einem Brief an Papst Alexander II. die Vermehrung der Bienen hin, die ganz ohne Geschlechtsverkehr stattfinden würde ${ }^{378}$. Erlaubt sei die Ehe nur wegen der von Gott gewollten Fortpflanzung der Menschen. Dies treffe jedoch in Zeiten der „schon in Dämmerung befindlichen Welt" nicht mehr zu, wenn das nahe Weltende bevorstehe. Dann diene die Ehe nur mehr der Verhinderung der Unzucht, einer noch viel schlimmeren Sünde ${ }^{379}$. Brooke zieht aus dieser abwertenden Charakterisierung der Ehe die Folgerung, Damiani habe das Inzestverbot dazu benutzt, die Suche von geeigneten Ehepartnern zu erschweren und damit der Sünde des Geschlechtsverkehrs grundsätzlich einen Riegel vorzuschieben ${ }^{380}$. Diese Folgerung schießt wohl über das Ziel hinaus. In gewisser Weise konnte Damiani nämlich der Ehe doch etwas Positives abgewinnen: Er sah in ihr ein Instrument der Förderung christlicher Nächstenliebe ${ }^{381}$. Der Zusammenhang zwischen ausgeweitetem Inzestverbot und asketischer Ehelehre muss also ein anderer sein: Das Inzestverbot diente Damiani dazu, die Ehe aus der Sicht eines strengen Asketen

374 Zur Gegenüberstellung von carnales und spiritales vgl. D’Acunto, Laici 1999, 46-57.

375 Brooke, Idea 1989, 73.

376 ... admixtionem vero carnis permittit invitus. Petrus Damiani, Brief 172 (MGH Briefe d. dt. Kaiserzeit 4/4, 263).

377 Petrus Damiani, Brief 172 (MGH Briefe d. dt. Kaiserzeit 4/4, 259). Damiani stützt sich auf Burchard (Ryan, Damiani 1956, 131), der erstmals dieses Verbot erwähnte, siehe 426 Anm. 216.

378 Petrus Damiani, Brief 96 (MGH Briefe d. dt. Kaiserzeit 4/4, 59).

379 Et haec antiquitus, ut praedictum est, ad propagandam tantummodo sobolem, nunc autem advesperascente iam mundo et illius coruscante doctrina, qui de virgine virgo est, ad evitandam spectant proculdubio fornicationem. Petrus Damiani, Brief 172 (MGH Briefe d. dt. Kaiserzeit 4/4, 262 f.).

380 Brooke, Idea 1989, 135 f. Zur Kritik an dieser Idee vgl. D’Avray, Damian 1992.

381 Zur Debatte um Damianis Ehelehre vgl. Вultot, Doctrine 4/1 1968, 17-30; Littre, Development 1976; Grandjean, Laïcs 1994, 96-108. Eine Ehrenrettung Damianis versuchen LeclercQ, Damien 1973, und Gattucci, Damiani 1989, 746. 
und Weltverächters akzeptabel zu machen: Nur die exogame Ehe gehorcht den Regeln der „Reinheit kirchlicher Keuschheit ${ }^{\text {“382 }}$ und kann zur Versöhnung der Gesellschaft durch die Förderung von Nächstenliebe beitragen.

Dieses Argumentationsmuster ist keine Errungenschaft Damianis, sondern wurde von Augustinus zur Begründung der Cousinenehe entworfen und diente im 9. Jahrhundert zur Begründung des Inzestverbots innerhalb der gesamten römisch-rechtlichen Verwandtschaft. Man muss sich also auch hier fragen, warum es im 11. Jahrhundert für eine nochmalige Ausweitung der Eheverbote geeignet sein sollte? Hätte nicht ein eingeschränktes Exogamiegebot für diesen Zweck gereicht? Zur Beantwortung dieser Frage muss die idiosynkratische Weltsicht Damianis herangezogen werden. Er war der Überzeugung, dass „die Welt nichts anderes ist außer Völlerei, Habsucht und Begierde" ${ }^{\text {“383. Diese }}$ Sündhaftigkeit der Welt, Ausdruck des nahen Weltendes ${ }^{384}$, spiegelt sich in der von Damiani wahrgenommenen Omnipräsenz des Inzestdelikts wider. Mit der Ausdehnung des Inzestverbots in genealogisch nicht fassbare Tiefen gelang es dem Eremiten, die Verstöße gegen das Inzestverbot radikal zu vermehren und seine Weltsicht von der universalen Sündhaftigkeit zu bestätigen. Aus dieser Misere konnte Damiani zufolge nur der apostolische Stuhl Rettung versprechen. In dem berühmten Brief 48 an seine Kardinalskollegen stilisierte er den Papst und seine Mitstreiter als den letzten Halt für eine im Untergang befindliche Welt ${ }^{385}$. Zeichen des Untergangs seien neben den Missständen in der Kirche (Simonie, Priesterehe) auch Meineid, Raub - und Inzest: „Ferner wird bei der Eheschließung die rechtmäßige Ordnung umgestürzt, und - welch ein Frevel! sie, die mit dem Namen des Christen geschmückt werden, leben in Wahrheit auf jüdische Weise ${ }^{\text {“386. }}$. Wie andere Stellen belegen, begreift Damiani den Inzest als eine jüdische Gewohnheit, die durch das Herannahen des Antichristen in der Gegenwart erneut Wurzeln schlagen würde. Bereits den Ravennater Juristen hielt er diese Drohung vor: „Denn es ist bekannt, dass der Antichrist kommt, den Menschen jüdische Sitten lehrt und die Heiligkeitsgesetze des alten Men-

382 Animadvertitis igitur, o iudices, quia dum male numeratis ... aecclesiasticae castitatis munditiam foedare tentatis. Petrus Damiani, Brief 19 (MGH Briefe d. dt. Kaiserzeit 4/1, 189).

383 Totus itaque mundus hoc tempore nichil est aliud, nisi gula, avaricia atque libido. Petrus Damiani, Brief 96 (MGH Briefe d. dt. Kaiserzeit 4/3, 59). Eine Kontextualisierung dieses Briefes in die persönliche Entwicklung Damianis versucht D’Acunto, Laici 1999, $34-46$.

$384 \mathrm{Zu}$ diesem Thema vgl. Fried, Endzeiterwartung 1989; LoHmer, Endzeiterwartung 1995.

385 Zur ausführlichen Literatur über diesen Brief vgl. den Kommentar Reindels in Petrus Damiani, Brief 48 (MGH Briefe d. dt. Kaiserzeit 4/2, 53).

386 In foederandis porro coniugiis legitimus ordo confunditur, et o nefas, ab eis in veritate iudaice vivitur, qui superficietenus christiano vocabulo palliantur. Petrus Damiani, Brief 48 (MGH Briefe d. dt. Kaiserzeit 4/2, 54). 
schen den neuen Gesetzen der evangelischen Gnade vorzieht ${ }^{\text {“3837 }}$. Heilmittel gegen dieses Schreckensszenario sei allein der Glaube an die Erneuerung der Gesellschaft durch den apostolischen Stuhl - der Leitgedanke der sog. „gregorianischen Kirchenreform “388.

Petrus Damiani war es vergönnt zu sehen, wie seine Argumentation für die kanonische Zählung durch Papst Alexander II. zum allgemeinen Kirchengesetz erhoben wurde ${ }^{389}$. Die Wirkung dieses Gesetzes beschreibt der seit 1063 wieder als Einsiedler lebende Kardinal in dem Brief „Über die Verachtung der Welt" aus seinen letzten Lebensjahren ${ }^{390}$. Als Werbung für das Leben der Einsiedler gedenkt er der Tatsache, dass man es in der Welt kaum vermeiden könne, mit Exkommunizierten in Berührung zu kommen und somit selbst eine Sünde zu begehen $^{391}$. Beispielhaft nennt er die in Inzest lebenden Ehepartner:

„Wer, frage ich, kann jetzt Inzestehen durch eine wie auch immer nachdrückliche Mahnung aufheben? Wer kann - ich will nicht sagen ein Volk - auch nur einen Menschen zur Auflösung einer unrechtmäßigen Ehe ermuntern? Es schreien die kirchlichen Gesetze, es strafen die weltlichen Gesetze das Verbrechen so sehr, es stellen sich die Prediger der Kirche entgegen: und bei den verworfenen Menschen erregt dies alles wie Ammenmärchen eher ein Lachen, als dass es sie zur Klage über die zu verbessernde Sünde reizt. ... Wer sieht aus so vielen Tausenden Menschen wenigsten einen, der sich von dem Greuel eines unseligen Ehebandes wegreißt? ${ }^{\text {‘392 }}$

Diese Missachtung des Kirchenrechts war für Damiani nur eine Seite des Übels. Die andere bestand darin, dass unlautere Motive ausschlaggebend waren, wenn tatsächlich eine Ehescheidung wegen Inzest stattfand: Zur Legitimierung der

387 Videtis igitur iam, quia cum filii sitis aecclesiae ad matris iniuriam ritus inducitis sinagogae et sub professione nominis Christiani haeresim praecurritis antichristi. Notum namque est, quod antichristus veniens iudaizare homines doceat et vetusti hominis cerimonias novis evangelicae gratiae legibus anteponat. Petrus Damiani, Brief 19 (MGH Briefe d. dt. Kaiserzeit 4/1, 189).

388 Congar, Kirche 1971, 56-68; Fuhrmann, Einfluss 1972, 352; Blumenthal, Investiturstreit 1982, 83.

389 Siehe 469 f.. Nur am Rande sei erwähnt, dass Damiani seine Position später in einem Punkt korrigierte: Petrus Damiani, Brief 36 (MGH Briefe d. dt. Kaiserzeit 4/1, $340-$ 345): Hatte er in seinem ersten Brief für die Zählung nach Vetterschaften plädiert, trat er in diesem Brief (ca. 1050) für die, reine` kanonische Zählung ein, die Alexander II. später festschreiben sollte: CORBET, Burchard 2001, 283-285.

390 Zur umstrittenen Datierung siehe 469 Anm. 447.

391 Petrus Damiani, Brief 165 (MGH Briefe d. dt. Kaiserzeit 4/4, 192).

392 Quis, rogo, nunc possit incestuosa coniugia quantumvis instantissima praedicatione rescindere? Quis valeat, non dicam populum, sed vel unum hominem ad illiciti matrimonii repudium provocare? Clamant sacri canones, humanae in tantum scelus vindicant leges, obsistunt praedicatores aecclesiae et cuncta hec perditis hominibus velut aniles neniae risum potius movent, quam ad corrigendi piaculi lamenta compungant. ... Sed quis ex tot milibus hominum saltim unum vidit ab infausti foederis abhominatione divulsum? Petrus Damiani, Brief 165 (MGH Briefe d. dt. Kaiserzeit 4/4, 219 f.). 
Scheidung „verfertigt der Mann eine falsche Abstammungstafel, erfindet mit vielen Argumenten bis dahin unbekannte Namen von Urgroßvätern und lässt irgendwelche alten Männer zur Bezeugung dieser Tatsachen herbeizitieren, von denen er jedoch weiß, dass sie durch das Ende des Lebens aus ihrer Mitte genommen worden waren. Er selbst wirft sich dann als Ankläger und Schuldiger das Verbrechen vor, übertreibt die Schandtat und forscht nach Beistand, durch den er aus einer so gefährlichen Notlage entkommen kann ${ }^{\text {“393. }}$. Durch die Radikalisierung des Inzestverbots eröffneten sich also neue Möglichkeiten der Manipulation, die erneut die universale Sündhaftigkeit der Welt bestätigen.

Auch nach der Gesetzgebung Alexanders II. hatte sich für Damiani nichts zum Guten gewendet: „Alles im Erdkreis ist in Unordnung, alle Gesetze der Frömmigkeit und des Glaubens sind zerrissen “394. Für sich und seine Eremiten zog Damiani den Schluss: „Deshalb ist entweder das Buch des Kirchenrechts zu schließen oder von der Bemessung von zu erteilender Buße abzusehen “395. Der Weg des Papsttums war ein anderer. Was Damiani seinen Einsiedlerfreunden als Szenario des drohenden Weltendes ausmalte, konnte von aktivistisch gesinnten Reformern als Programm der Weltveränderung aufgefasst werden ${ }^{396}$. Das Papsttum nahm sich dieses Anliegens an, es schuf Normen und Institutionen, um die Erneuerung der Inzestgesetzgebung in die Tat umzusetzen. Diese Erneuerung spielte zu Beginn der gregorianischen Reform eine bedeutende Rolle. Man kann es als Ironie der Geschichte auffassen, dass der Kirchenreformer Damiani selbst erst durch die Radikalisierung des Inzestverbots die Notwendigkeit geschaffen hatte, die bisherige Praxis einer Reform zu unterziehen. Damit bestätigt sich die Einschätzung Gerd Tellenbachs ${ }^{397}$ : Nicht der Widerspruch zwischen Kirchenrecht und Realität war der Auslöser der Kirchenreform, vielmehr verschärften die Reformer selbst diese Widersprüche, die sie dann mit der ihnen eigenen Vehemenz anklagten.

393 Si vero his contraria luxuriae calamitatis incommoditate percellitur, ipse vir falsae consanguinitatis lineam texit et inaudita proavorum nomina per multa argumenta confingit atque senes quosdam in huius allegationis testimonium advocat, quos tamen per vitae terminum sublatos e medio non ignorat. Ipse itaque sibimet accusator et reus crimen impingit, scelus exaggerat atque adminiculum, quo ex tam periculoso naufragio enatare possit, inquirit. Petrus Damiani, Brief 165 (MGH Briefe d. dt. Kaiserzeit 4/4, 220 f.).

394 Omnia in orbe confusa, cuncta pietatis ac fidei decreta convulsa. Petrus Damiani, Brief 165 (MGH Briefe d. dt. Kaiserzeit 4/4, 221).

395 Quamobrem aut liber omnino claudendus est canonum, aut a delegandae paenitentiae taxatione cessandum. Petrus Damiani, Brief 96 (MGH Briefe d. dt. Kaiserzeit 4/3, 57). Ähnlich resignative Sätze in Petrus Damiani, Brief 165 (MGH Briefe d. dt. Kaiserzeit 4/ 4, 223).

396 Zur Dialektik von Eschatologie und Weltveränderung vgl. Fried, Aufstieg 2001, 32 f.

397 Tellenbach, Kirche 1988. 


\section{Inzestpolitik der Päpste}

Als Heinrich III. im Dezember 1046 in Sutri und Rom drei italienische Päpste zur Demission drängte und einem Mann seines Vertrauens die Leitung des apostolischen Stuhls anvertraute, erreichte er auf einen Schlag mehrere Ziele ${ }^{398}$. Er ließ die Kaiserkrönung durch einen von Simonie freien Papst durchführen, entzog das Papsttum dem Einfluss der stadtrömischen Adelsgeschlechter, verhalf der kirchlichen Reformbewegung in Rom zum Durchbruch und konnte den Inhaber des apostolischen Stuhls, der weiterhin als Reichsbischof amtierte, auf die Ziele seiner eigenen Königsherrschaft verpflichten. Die ersten beiden deutschen Päpste, Clemens II. und Damasus II., regierten zu kurz, um einen nachhaltigen Einfluss auf die Verfassung der Kurie auszuüben. Erst Leo IX., dem wir als Bischof Bruno von Toul in der Angelegenheit Heinrichs III. bereits begegnet sind, griff in die Struktur der päpstlichen Verwaltung ein und beauftragte Gefährten aus der lothringischen Zeit mit wichtigen Ämtern an der Kurie $^{399}$. Ein weiterer Aspekt dieses Wandels ist die intensive synodale Tätigkeit Leos IX. Der Papst veranstaltete in Rom jährlich eine Ostersynode und nahm weite Reisen durch Italien, Deutschland und Frankreich in Kauf, um auch dort auf Kirchenversammlungen für eine Reform des Klerus einzutreten ${ }^{400}$. Zu dieser neuartigen Reisetätigkeit bewog Leo seine Vorstellung von der gesamtkirchlichen Kompetenz und der damit verbundenen Notwendigkeit der Visitation der einzelnen Ortskirchen. Unter Leo wandelte sich das Papsttum von einer stadtrömischen zu einer universalen Institution.

Bereits auf der ersten Ostersynode in Rom (1049) kam der Papst auf das Inzestverbot zu sprechen. Der Biograph Leos berichtet: „Er zertrennte die inzestuösen Ehen von Blutsverwandten, die in vielen Teilen der Welt bedenkenlos geschlossen wurden, und verhängte die Scheidung über viele von dieser schändlichen Verbindung betroffene Adelige “401. Konkrete Fälle sind uns von dieser Aktion des Papstes nicht überliefert. Im Vordergrund der Synode stand das Thema der Simonie. Leo verlangte von den der Simonie verdächtigten Bischöfen einen Reinigungseid, konnte sich aber bei der Bestrafung nicht mit seiner strengen Forderung nach Absetzung durchsetzen. Seinen Kreuzzug gegen die Simonie führte der Papst wenige Monate später auf einer Synode in Reims

$398 \mathrm{Zu}$ den Ereignissen vgl. Blumenthal, Investiturstreit 1982, 66-69; Boshof, Salier 2000, 128-132.

399 Blumenthal, Investiturstreit 1982, 80-90; Tellenbach, Kirche 1988, 152-156; GoEz, Lebensbilder 1998, 150-168.

400 Johrendt, Reisen 2001; Gresser, Synoden 2006, 11-30.

401 Incestas consanguineorum nuptias, in multis orbis partibus indiscrete habitas discidit pluresque nobilium hoc turpi devinctos nexu separavit. Vita Leonis IX papae II 10 (MGH SS rer. Germ. 70, 194). 
fort $^{402}$. Die französischen Bischöfe entzogen sich jedoch zum großen Teil der Ladung durch den Papst und folgten ihrem König auf einen Feldzug gegen Gottfried Martell von Anjou. Bereits zur Synode von Rom hatte sie der Papst geladen und war auf keine Resonanz gestoßen ${ }^{403}$. Ihrem Selbstverständnis widersprach es, sich der Reform durch den apostolischen Stuhl zu unterwerfen, zumal der Papst weiterhin als Reichsbischof amtierte und somit als Interessensvertreter Heinrichs III. gelten musste. Zudem fürchtete man wohl auch das rigorose Vorgehen Leos gegen Simonisten. In Reims legte er deutliches Zeugnis davon ab. Zwei Bischöfe ließ er wegen Simonie absetzen, drei Bischöfe traf die Exkommunikation wegen unentschuldigter Abwesenheit vom Konzil.

Das Inzestverbot wurde auf dem Konzil von Reims sowohl in den Synodalbeschlüssen behandelt ${ }^{404}$ als auch durch konkrete Fälle angesprochen. Leo IX. exkommunizierte die Grafen Enguerrand von Ponthieu und Eustache von Boulogne ${ }^{405}$. Außerdem untersagte er dem mächtigen Grafen Balduin V. von Flandern, seine Tochter Mathilde mit Wilhelm II. von der Normandie, dem späteren Eroberer von England, zu verheiraten ${ }^{406}$. Graf Tedbald von BloisChampagne wurde vor die nächste Synode in Mainz geladen, weil er seine rechtmäßige Frau verlassen hatte ${ }^{407}$. Aus einer späteren Quelle erfahren wir von Tedbalds zweiter Heirat, die er nach der Scheidung mit einer Verwandten einging $^{408}$. Diese Inzestehe sowie diejenige Herzog Roberts von Burgund, des Bruders des französischen Königs, lagen dem Papst kurz nach dem Konzil von Reims zur Verhandlung vor. Vielleicht steht mit diesen Prozessen auch ein Brief Leos an den französischen König Heinrich I. in Zusammenhang. Dieses Schreiben ist nur fragmentarisch überliefert und hat den Inzest Roberts II. zum Thema, des gemeinsamen Vaters König Heinrichs I. und Herzog Roberts von Burgund $^{409}$. Leo IX. schreckte also nicht davor zurück, den Bruder des Königs

402 Blumenthal, Text 1976; Gresser, Synoden 2006, 17-21.

403 Gresser, Synoden 2006, 14. Zur Motivation der französischen Bischöfe vgl. Ehlers, Kapetinger 2000, 56.

404 Consanguinei consanguineas aut uxores consanguineorum non accipiant et qui in consanguinitate iacent, resipiscant et peniteant. Konzil von Reims (1049) c. 10, hg. von BLUMENTHAL, Text 1976, $31 \mathrm{f}$.

405 Excommunicavit etiam comites Angelari, et Eustacium propter incestum. Anselm von SaintRémy, Historia dedicationis (252). Zur Identifikation vgl. die Textanmerkungen der Edition Hourliers sowie CORBET, Burchard 2001, 261.

406 Interdixit et Balduino comiti Flandrensi, ne filiam suam Willelmo Normanno nuptui daret, et illi ne eam acciperet. Anselm von Saint-Rémy, Historia dedicationis (252). Zum politischen Hintergrund vgl. BoshoF, Lothringen 1978, 98-102.

407 Vocavit etiam comitem Tetbaldum, quoniam suam dimiserat uxorem. Anselm von SaintRémy, Historia dedicationis (252).

408 Johannes von Fécamp, Brief an Leo IX. (Migne PL 143, 799).

409 Leo IX., Brief an Heinrich I. (JL 4307, Migne PL 143, 736). Die Informationen hierin sind ebenso legendär wie der Bericht von Petrus Damiani, Brief 102 (MGH Briefe d. dt. 
mit dem Vorwurf einer Inzestehe zu konfrontieren. Mit Tedbald von Blois und Wilhelm von der Normandie klagte er zwei der mächtigsten Fürsten Frankreichs wegen Inzest an und drohte mit der Verhängung der Exkommunikation ${ }^{410}$. Möglicherweise ging Leo wenig später gegen die 1051 geschlossene Ehe Graf Balduins VI. von Flandern mit Richilde von Hennegau vor, wie Quellen des 12. Jahrhunderts berichten ${ }^{411}$. Auch weniger einflussreiche Grafen wie Enguerrand und Eustache wurden auf dem Konzil an den Pranger gestellt. Dieses Vorgehen erweckt den Eindruck, als ob der Papst in Frankreich nachholen musste, was im Reich seit der Inzestkampagne Heinrichs II. erreicht worden war ${ }^{412}$. War also Frankreich um 1050 ein Hort des Inzests?

Nach Georges Duby sind die Unauflösbarkeit der Ehe sowie das kirchliche Inzestverbot in Frankreich vor der gregorianischen Reform mit Füßen getreten worden ${ }^{413}$. Diese Sicht wird von zwei zeitgenössischen Chronisten vordergründig bestätigt: Thietmar von Merseburg war um 1015 der festen Überzeugung, das westliche Frankreich sei wegen der unerlaubten Eheschließungen und wegen anderer unaussprechbarer Bösartigkeiten und Verschlagenheiten dem Untergang geweiht ${ }^{414}$. Eine Generation später (aber noch vor der Ankunft Leos IX. in Reims) rechtfertigte Rodulfus Glaber seine Weltuntergangsstimmung mit der Klage über die zahlreichen Verstöße gegen das Inzestverbot: „Wer hat denn jemals vorher so viele Inzestehen, so viele Ehebrüche, so viele unerlaubte Verbindungen von Blutsverwandten, so viele Schändungen von Konkubinen, so viel Wetteifer im Bösen wahrgenommen? “415 Diese Quellen müssen allerdings in ihren Kontext eingebettet werden. Thietmar war bereits mit der Ausweitung des Inzestverbots durch Heinrich II. vertraut und erlebte als Zeitgenosse die Wirren um die Ehe König Roberts II. Der antiquierte Inzestbegriff in Frankreich musste in ihm Abscheu erwecken. Die Weltsicht des Rodulfus Glaber war durch seine zutiefst pessimistische Einstellung geprägt und zeichnet

Kaiserzeit 4/3, 132-134). Nach Dhondt, Femmes 1964, 58, und Corbet, Burchard 2001, 264, wollte der Papst mit diesem Brief die Heirat Heinrichs I. mit Anna von Kiew unterstützen.

410 Zur Frage des politischen Hintergrunds dieser Anklagen vgl. Boshof, Lothringen 1978, 98; CoRbet, Burchard 2001, 259-261.

411 Vgl. Mohr, Richilde 1980/1981; Corbet, Burchard 2001, 260-262.

412 Corbet, Burchard 2001, 264.

413 Duby, Chevalier 1981, 95. Das Urteil beruht im Wesentlichen auf den von Daudet, Établissement 1941, zusammengetragenen Fakten. Diesem Bild stimmt Corbet, Burchard 2001, 264, zu. Gegen Duby argumentiert Bouchard, Families 2001, 39-58, mit beschränkter Quellenauswahl.

414 ... quia ob illicitas coniunctiones aliasque ineffabiles malicie versucias hos prope interitum esse non dubito. Thietmar von Merseburg, Chronica IV 14 (MGH SS rer. Germ. N.S. 9, 149).

415 Quis enim umquam antea tantos incestus, tanta adulteria, tantas consanguinitatis illicitas permixtiones tot concubinarum ludibria, tot malorum emulationes audiverat? Rodulfus Glaber, Historiae IV 5, 17 (198). 
sich durch so viele Idiosynkrasien aus, dass man kaum eine neutrale Beschreibung der Realität erwarten $\mathrm{kann}^{416}$. Zu bedenken ist auch, dass die Briefsammlung Bischof Fulberts von Chartres, eine der wichtigsten Quellen zum Kirchenrecht des frühen 11. Jahrhunderts, ein völlig konträres Bild vermittelt. Anders als sein Nachfolger Ivo 100 Jahre später musste er kein einziges Mal eine Anfrage über die Gültigkeit von Ehen in der Bluts- oder Schwiegerverwandtschaft beantworten ${ }^{417}$. Das Inzestverbot war nach der Auskunft seiner Briefsammlung nicht umstritten.

Von dem grellen Sittengemälde Dubys müssen wir uns aber vor allem deshalb verabschieden, weil es auf einer falschen Vorstellung vom Umfang des Inzestverbots beruht. Wie die Konzile von Toulouges (1027) und Bourges (1031) zeigen ${ }^{418}$, war der siebte Grad zwar tatsächlich die anerkannte Inzestgrenze, jedoch nicht in der kanonischen, sondern in der römischen Zählweise. Die von Duby als Beleg angeführten Inzestehen Gottfried Martells von Anjou bewegten sich daher alle am äußersten Rand des Inzestverbots. Mit seiner ersten Frau Agnes war Gottfried Martell nur entfernt verschwägert. Der verstorbene Mann der Agnes, Wilhelm V. von Aquitanien, stand im Verhältnis 3/4 zu Gottfried Martell ${ }^{419}$. Die Ehe zwischen Gottfried Martell und Agnes konnte also von den Zeitgenossen nur durch eine überaus strenge Auslegung als Inzestehe

416 Grund, Anschauungen 1910, 102; Landes, Rodulfus 1996.

417 In seiner Epistola 77 (Migne PL 141, 238) behandelt Fulbert das Eheverbot der geistlichen Verwandtschaft. Vgl. Hartmann, Briefe 2000. Zu Ivo vgl. BasdevantGaudemet, Mariage 1983.

418 Konzil von Toulouges (1027) (Mansi 19, 483); Konzil von Bourges (1031) c. 17 (Mansi 19, 505). Das Konzil von Toulouges wurde unter der Leitung Bischof Olibas von Vic abgehalten. Wenige Jahre zuvor hatte Oliba vergeblich die Ehe zwischen Sancho III. von Navarra und Urraca von León zu verhindern versucht. Der Brief Olibas an Sancho III. ist überliefert. Die Ehepartner waren Urenkel von Fernan Gonzales von Kastilien und somit im Grad 3/3 miteinander verwandt: Pérez de Urbel, España 1964, 177. Nach Fuhrmann, Einfluss 1972, 405, und Corbet, Burchard 2001, 211, zitierte Oliba zur Rechtfertigung eine Kanonesreihe aus Reginos Sendhandbuch. Dieselbe Kanonesreihe findet sich jedoch auch in der Dacheriana. Dass Oliba die Dacheriana und nicht Regino heranzog, beweist die Kenntnis der vollständigen Fassung des 2. Konzils von Toledo und des römischen Konzils von 721. Ob Oliba in diese Quellen selbständig den siebten Grad interpolierte oder diesen Einschub schon in seiner Vorlage fand, muss bis zur Edition der Dacheriana offenbleiben. Oliba hat jedenfalls seinen Standpunkt auf dem Konzil von Toulouges zum Ausdruck gebracht und vielleicht auch auf das Konzil von Bourges eingewirkt, da er mit Erzbischof Gauzlin von Bourges (gest. 1030) in engem Briefkontakt stand.

419 Das Verhältnis 3/4 begründet Werner, Nachkommen 1967, $474 \mathrm{f}$. Ihm folgt BouCHARD, Families 2001, 23 u. 151. In der französischen Forschung hält sich die Meinung von Halphen, Comté 1906, 56 f., dem zufolge Gottfried Martells Großmutter Adela eine Tochter (und nicht eine Enkelin) Heriberts II. von Vermandois war: DAudET, Établissement 1941, 86; Guillot, Comte 1 1972, 46; Duby, Chevalier 1981, 99; Bachrach, Fulk 1993, 8; Corbet, Burchard 2001, 263. 
wegen Schwägerschaft wahrgenommen werden ${ }^{420}$. Die dritte Ehe Gottfrieds mit Adela von Blois zog keine Kritik auf sich, da beide im Verhältnis 4/4 blutsverwandt waren ${ }^{421}$.

Duby stützt sich für sein Urteil über die Zustände in der ersten Hälfte des 11. Jahrhunderts ausschließlich auf die Ehen Gottfried Martells von Anjou. Eine präzise Untersuchung der adeligen Heiratspraxis in dieser Zeit steht noch aus ${ }^{422}$. Im Rahmen dieser Arbeit kann dies nicht geleistet werden, zumal die Rekonstruktion genealogischer Tafeln auf sehr dürftigen Quellen aufbauen muss. Ich werde daher nur einige repräsentative Eheschließungen nennen und mit den bekannteren Fällen vergleichen, die nach der Initiative der Päpste vor Gericht behandelt wurden. Eine Ehe im dritten Grad (3/3), wie sie König Robert II. für kurze Zeit durchzusetzen wusste, ist möglicherweise in einem anderen Fall geschlossen worden. Der Sohn des Königs, Robert I. von Burgund, nahm Ermengard von Anjou zur Frau, die ebenso von Graf Fulko dem Guten von Anjou abstammte wie ihr Mann ${ }^{423}$. Ansonsten sind nur Ehen im vierten Grad belegt. Der spätere Erzbischof von Reims, Graf Ebalus von Roucy, war mit seiner Frau Beatrix von Hennegau in diesem Verhältnis verwandt ${ }^{424}$. Gleich nah verwandt war auch König Heinrich I. von Frankreich mit der Tochter Konrads II. Mathilde $^{425}$. Der fünfte Grad der Verwandtschaft bestand zwischen Wilhelm

420 Historia Monasterii S. Florentii Salmurensis (Bouquet 11, 278).

421 Duby, Chevalier 1981, 99. Der gemeinsame Stammvater war ebenfalls Heribert II. von Vermandois.

422 Einige Beispiele nennen Guerreau-Jalabert, Prohibitions 1994, und Bouchard, Families 2001; DIEs., Divorce 2003. Da beide wie Duby falsche Vorstellungen über die Ausdehnung des Inzestverbots haben, betrachten sie Ehen innerhalb des 7. Grades kanonischer Zählung als ein „neues Phänomen“ des 11. Jahrhunderts.

423 Vgl. Bouchard, Divorce 2003, 229. Duby, Chevalier 1981, 98, nennt sie im vierten Grad verwandt. Die Rekonstruktion beruht auf der Zuordnung von Roberts Großmutter zur Familie der Grafen von Anjou, die erstmals Lот, Carolingiens 1891, 365-367, begründete. Diese Zuordnung wird allgemein anerkannt, vgl. STAsser, Adélaïde 1997. Vielleicht war auch Roberts erste Frau Helia von Semur mit ihm im Verhältnis 3/3 verwandt. Umstritten ist die Herkunft von Helias Mutter Aremburgis. Wenn ihr Vater Otto-Heinrich von Burgund war, dann war sie wie ihr Mann Urenkelin von Hugo Magnus. In diesem Sinn Richard, Cartulaire 1957, 240 (Stammtafel); Wischermann, Marcigny-sur-Loire 1986, 228; Kohnle, Hugo 1993, 21. Contra: Bouchard, Sword 1987, 359. Wenn die Rekonstruktion Richards zutrifft, waren die Ehepartner Aremburgis und Dalmatius von Semur Stiefgeschwister: in Mathilde von Donzy ist dann die Mutter von Aremburgis und die Stiefmutter von Dalmatius zu sehen. Dies wäre als weiterer Inzestfall zu betrachten. Glocker, Verwandten 1989, 328, reiht die Ehe mit Ermengard fälschlicherweise vor die Ehe mit Helia.

424 Bur, Formation 1977, 136 u. 161; Conbet, Burchard 2001, 310. Ihr gemeinsamer Stammvater war Heinrich I.

425 Siehe 446 Anm. 315. Falls Heinrichs I. zweite Frau Mathilde die Nichte der ersten Mathilde war, war dies eine Ehe im Verhältnis 6/4. Die Herkunft der zweiten Mathilde ist jedoch nicht gesichert: Dhondt, Femmes 1964, 54 f.; Ehlers, Kapetinger 2000, 51. 
von der Normandie und Mathilde von Flandern ${ }^{426}$. Wie die Beispiele zeigen, waren Ehen im vierten und fünften Grad durchaus nicht ungewöhnlich und wurden vor dem Auftritt Leos IX. in Frankreich nicht beanstandet. Erst durch das Wirken des Reformpapsttums kamen solche Eheschließungen ins Visier der Kirche. Die bekannten Eheprozesse des späten 11. und 12. Jahrhunderts (Philipp I. und Bertrada von Montfort, Ludwig VII. und Eleonore von Aquitanien u. a.) wurden um diese Verwandtschaftsgrade geführt ${ }^{427}$. Bis 1050 waren weiterhin die karolingischen Normen in Geltung. Seit der Karolingerzeit ist das Kirchenrecht in Frankreich im Unterschied zum ottonisch-salischen Reich keiner Veränderung unterworfen worden. Das Sittengemälde von feudalen Anarchen, dekadenten Bischöfen und missachtetem Kirchenrecht bedarf also einer Revision.

Für das Vorgehen Leos IX. auf dem Konzil von Reims ergibt sich folglich eine neue Bewertung: Er hatte nicht deshalb Grund zum Einschreiten gegen Inzestehen, weil das sittliche Leben in Frankreich auf einem Tiefpunkt angelangt war, sondern weil er die neuen Normen der salischen Reichskirche in Frankreich erstmals zur Geltung brachte. In Reims nahm der Papst die Haltung des unbeugsamen Reformers an. Dass er trotzdem „in manchen Fällen auffallende Konzilianz “ ${ }^{\text { } 28}$ an den Tag legen konnte, zeigt ein Brief von Abt Johannes von Fécamp ${ }^{429}$. Der Normanne Johannes beklagte sich darin über die schlechte Behandlung seiner Landsleute in Italien und erstattete dem Papst Bericht über umlaufende Gerüchte: „Ich kann nicht verschweigen, was ich an übelwollenden Gerüchten von meinem Herrn Papst höre, den ich mit besonderer Demut umarme und den ich in Sicherheit bei Gott und den Menschen sehen will ${ }^{\star 430}$. Das Gerücht bezieht sich auf Graf Tedbald von Blois-Champagne und Herzog Robert von Burgund, die beide ihre Frauen verstoßen und eine erneute Ehe mit einer Verwandten geschlossen hatten. Johannes war zu Ohren gekommen, dass Tedbald mit dem Papst zusammengekommen sei und keine würdige Strafe empfangen habe, sondern durch apostolische Autorität in seiner Ehe bestätigt worden $\operatorname{se}^{431}$. „Ich bitte euch, sehr kluger Bischof, ihr mögt selbst in dieser

426 Prentout, Étude 1916, 24; Daudet, Établissement 1941, 92 f.; Corbet, Burchard 2001, 301. Der gemeinsame Stammvater war demnach der Normanne Rollo.

427 Einen Überblick geben Stiegler, Dispensation 1901, 233-312; Maleczek, Stammbäume 1988; Basdevant-Gaudemet, Mariage 1983; Bouchard, Divorce 2003; Hlawitschka, Auflösung 2005.

428 Tellenbach, Kirche 1988, 155.

429 Über seine Person vgl. Bulst, Untersuchungen 1973, 159-161.

430 Non possum non indicare quae audio de domino meo apostolico ventilari sinistra interpretatione, quem ego amplector speciali devotione et quem volo tutum esse apud deum et homines. Johannes von Fécamp, Brief an Leo IX. (Migne PL 143, 799).

431 ... obiiciunt et in faciem ostendunt, quod Tedbaldus etiam vestrum colloquium adierit, nihilque dignum hac culpa actum sit; imo magis quasi auctoritate vestra roboratus ... Johannes von Fécamp, Brief an Leo IX. (Migne PL 143, 800). 
Sache genau erwägen, was die Angelegenheit der Besserung erfordert, damit nicht das Werk und der Eifer eurer kirchlichen Verordnungen zunichte gemacht oder auch nur gestört werden “432. Diese drastische Mahnung an einen Papst konnte nur dann gerechtfertigt erscheinen, wenn das Gerücht eine wahre Grundlage hatte. Johannes von Fécamp tarnte die Wahrheit als Gerücht, um den Papst nicht direkt angreifen zu müssen und seinen Vorwurf in eine akzeptable Form zu kleiden. Wir können es daher als gesicherte Tatsache nehmen, dass Leo IX. in diesem Fall von der strikten Anwendung des christlichen Eherechts absah und eine Dispens für Tedbald von Blois erteilte.

Diese konziliante Haltung Leos ist vor dem Hintergrund seiner Zeit als Bischof von Toul zu verstehen ${ }^{433}$. Bruno war Mitglied der Hofkapelle, als er im Jahr 1026 von König Konrad II. zum Bischof von Toul ernannt wurde. Er verhielt sich loyal zu den mit ihm weitläufig verwandten salischen Königen und leistete seinen Reichsdienst als Bischof. Im Jahr 1033 beauftragte ihn Konrad II. mit einer Reise an den französischen Königshof, um eine Eheverbindung zwischen Heinrich I. und den Saliern anzubahnen ${ }^{434}$. Bruno führte diesen Auftrag erfolgreich durch, und nur durch den frühen Tod der Königstochter Mathilde fand die Eheschließung nicht statt. Dem Bischof dürfte es ebenso wenig wie dem Königshof verborgen geblieben sein, dass Heinrich und Mathilde im Verhältnis 5/4 über den ostfränkischen König Heinrich I. verwandt waren. Wie bereits erwähnt, wurden die Bedenken damals mit dem Hinweis auf die friedensstiftende Wirkung der Ehe beiseite geschoben ${ }^{435}$. Auch im Jahr 1043 erhob Bruno keinen Einspruch gegen die Ehe zwischen Heinrich III. und Agnes von Poitou im vierten Grad, obwohl Siegfried von Gorze ihn dazu gedrängt hatte ${ }^{436}$. Der spätere Papst war also durchaus zu Kompromissen fähig, auch wenn er an der prinzipiellen Geltung der Inzestgrenze des 7. kanonischen Grads festhielt ${ }^{437}$. Dies unterschied den um die Seelsorge bemühten Bischof von der rigorosen Haltung der Mönche Siegfried von Gorze und Johannes von Fécamp.

Bei Leo IX. treffen wir also bereits in nuce die päpstliche Doktrin an, wie sie die spätere Zeit prägen sollte. Einerseits stand die rechtliche Gültigkeit des ausgedehnten Inzestverbots außer Frage, andererseits wurde die Strenge des Rechts in der Praxis durch Dispensierungen abgemildert. Diese Doktrin ist auch bei dem letzten der deutschen Päpste nachweisbar. Stephan IX. veranstaltete kurz nach seiner Wahl zum Papst eine Synode in Rom und verurteilte die

432 Qua de re perpendat ipse, quaeso prudentissimus antistes, quid postulet res huius emendationis, ne annulletur, ne irritetur opera et studium ecclesiasticae suae sanctionis. Johannes von Fécamp, Brief an Leo IX. (Migne PL 143, 800).

433 Dazu vgl. Goez, Lebensbilder 1998, 150-168.

434 Vita Leonis IX I 17 (58). Wolfram, Konrad II. 2000, 259.

435 Siehe 447 Anm. 316.

436 Siehe oben 449.

437 Sonst hätte er nicht die Ehe Wilhelms von der Normandie (5/5) attackiert. 
Priesterehe sowie den Inzest ${ }^{438}$. Vermutlich kam es auf dieser Kirchenversammlung auch zu einem beachtenswerten Ereignis. Der ehemalige Herzog Gottfried von Lothringen und Beatrix von Tuszien erklärten sich bereit, ihre als Inzest gebrandmarkte Verbindung in beiderseitiger Enthaltsamkeit fortzuführen und damit der Kritik der Kirche nachzugeben ${ }^{439}$. Die Eheleute waren im Verhältnis $5 / 5$ verwandt und hätten nach dem strengen Recht Burchards von Worms getrennt werden müssen. Petrus Damiani zeigte sich in einem Glückwunschschreiben an Beatrix entzückt über die Verpflichtung zur Enthaltsamkeit und forderte unverhohlen zu Schenkungen an die Kirche auf, um der Bußgesinnung Ausdruck zu verleihen: „Gib Land und nimm den Himmel“440. Die gleiche Aufforderung erging an Wilhelm den Eroberer. Seine Ehe mit Mathilde (ebenfalls 5/5), von Leo IX. in Reims untersagt, wurde durch Papst Nikolaus II. im Jahr 1059 unter der Bedingung gebilligt, dass beide als Zeichen ihrer Buße ein Kloster gründen sollten ${ }^{441}$. Nach der Errichtung eines Frauen- und eines Männerklosters in Caen wurde die Ehe fortan nicht mehr beanstandet. Wie Corbet sehe ich darin eine Fortführung der Inzestpolitik der salischen Bischöfe, die im Fall des Trierer Vogtes erstmals aktenkundig geworden ist, vielleicht aber bereits früher Anwendung gefunden hatte ${ }^{442}$. Bei Inzestehen in entfernter Verwandtschaft gab es demnach die Möglichkeit einer Dispensierung. War diese Dispensierung bei den salischen Bischöfen auf unsicherer Rechtslage gegründet, weil kein einzelner Bischof sich einen solchen Eingriff in die Rechtsordnung leisten konnte, blickte das Papsttum auf eine lange Geschichte der Dispensierung vom Recht zurück.

So sehr sich die deutschen Päpste um eine Durchsetzung des ausgedehnten Inzestverbots bemühten, tasteten sie dennoch die durch Gregor II. im 8. Jahrhundert etablierte Grundlinie der päpstlichen Politik nicht an. Sie verkündeten stets das kategorische Verbot von Verwandtenehen, ohne sich auf eine bestimmte Grenze des Verwandtschaftsgrades festzulegen. Mit dieser Politik brach

438 Chronica monasterii Casinensis II 94 (MGH SS 34, 353). Gresser, Synoden 2006, 32 34.

439 Die Zuweisung dieses Ereignisses beruht auf der Datierung des Glückwunschschreibens von Petrus Damiani, Brief 51 (MGH Briefe d. dt. Kaiserzeit 4/2, 132-137). Der Herausgeber Kurt Reindel stellt eine Beziehung zur Synode von 1057 her. Für eine Datierung gibt der Brief selbst keine Hinweise. Es muss deshalb auch in Betracht gezogen werden, dass der Brief erst bei der Inkriminierung der Ehe durch Alexander II. im Jahr 1068 entstanden ist. Die Eheleute zogen sich durch die Gründung eines Priorates aus der Affäre: Goez, Beatrix 1995, 214; Conвet, Burchard 2001, $302 \mathrm{f}$.

$440 \mathrm{Da}$ terram et tolle caelum. Possessiones transitoriae transferantur in titulos haereditatis aeternae. Petrus Damiani, Brief 51 (MGH Briefe d. dt. Kaiserzeit 4/2, 135).

441 Ordericus Vitalis, Gesta Normannorum ducum (2, 146-149). Corbet, Burchard 2001, $300-302$.

442 Stiegler, Dispensation 1901, 302-304; Corbet, Burchard 2001, 234-236. 
der erste „italienische“ Papst $^{443}$. Bischof Gerhard von Florenz, der sich Nikolaus II. nennen sollte, wurde auf Betreiben der kurialen Reformkräfte gewählt, als Klerus und Volk von Rom bereits einen eigenen Kandidaten zum Papst erhoben hatten. Unter dem Schutz Gottfrieds des Bärtigen und Beatrix von Tuszien gelang es Nikolaus II., in Rom Fuß zu fassen und den gegnerischen Kandidaten abzusetzen. Nachträglich rechtfertigte man dieses Vorgehen mit dem ersten Dekret zur Papstwahl, das auf der Ostersynode 1059 verabschiedet wurde. Auf derselben von 113 Bischöfen besuchten Kirchenversammlung legte der Papst auch die Inzestgrenze des 7. Grades fest: „dass niemand eine Frau aus seiner Blutsverwandtschaft bis zur siebten Generation nimmt oder so weit er seine Verwandtschaft überblicken kann “444. Nikolaus verkündete diese und die restlichen Bestimmungen durch das Synodalschreiben Vigilantia universalis. Päpstliche Legaten sollten es der gesamten Christenheit bekannt machen ${ }^{445}$. Von den insgesamt 13 Kanones befassen sich vier mit den Laien: neben dem Inzestverbot werden das Zehntgebot, das Verbot der Vergabe von (Nieder-)Kirchen durch Laien und das Verbot der Bigamie genannt. Daran ist ersichtlich, welchen Stellenwert das Inzestverbot in der ersten Phase der Kirchenreform hatte.

Im nächsten Pontifikat erfolgte eine weitere Klarstellung. Alexander II. ließ nicht nur die Bestimmungen von 1059 zu Beginn seines Pontifikats erneuern ${ }^{446}$, er setzte sich auch in zwei Dekretalen entschieden für die Anwendung der kanonischen Zählweise ein. Beide Briefe sind undatiert ${ }^{447}$. Der eine richtet sich an die Kleriker Neapels, der andere an alle Kleriker und Richter Italiens. Wird man schon bei der Fixierung des siebten Grades im Jahr 1059 den Einfluss

443 Ursprünglich stammte Gerhard aus Burgund: Davidsohn, Geschichte 1 1896, 183. Zur Diskussion um das Papstwahldekret vgl. JASPER, Papstwahldekret 1986, sowie den Überblick bei HaRtManN, Investiturstreit 2007, 85-87.

$444 U t$ de consanguinitate sua nullus uxorem ducat usque ad generationem septimam vel quousque parentela cognosci poterit. Nikolaus II., Vigilantia universalis (JL 4405), hg. von Schieffer, Entstehung 1981, $222 \mathrm{f}$.

445 Die Überlieferung der Dekretale war allerdings nicht überwältigend: SchiefFER, Entstehung 1981, 48-84.

446 SCHIEFFER, Entstehung 1981, 84-95.

447 Gewöhnlich datiert man JL 4500 (Migne PL 146, 1379-1383) auf 1063 und verbindet die darin erwähnte Synode mit der Nachricht Damianis in Brief 165 (MGH Briefe d. dt. Kaiserzeit 4/4, 220), dass innerhalb eines Jahres zwei Synoden zum Thema des Inzests in Rom stattfanden: Freisen, Geschichte 1893, 425; Joyce, Ehe 1934, 457; Schmale, Synoden 1979, 317; Conbet, Burchard 2001, $283 \mathrm{f}$. Da der Brief allerdings von LucCHESI, Vita 2 1972, 107-115, und vom Herausgeber auf das Jahr 1069 datiert wird (ebenso D’Acunto, Laici 1999, 40), bricht diese Argumentation zusammen. Gresser, Synoden 2006, 81, verlegt die beiden von Damiani erwähnten Synoden ohne Begründung auf 1065. Der Brief Damianis muss jedoch mit JL 4500 gar nicht in Beziehung stehen. Es erscheint trotzdem wahrscheinlich, dass Alexander II. diese Frage zu Beginn seines Pontifikats klärte. 
Damianis vermuten können ${ }^{448}$, so wird diese Vermutung bei diesen Dekretalen zur Gewissheit. Die Argumentation, die Belegstellen und die geistige Grundhaltung entsprechen vollständig dem Brief 19 des Einsiedlers und Abtes von Fonte Avellana. Im Jahr 1057 ist Damiani zum Kardinalbischof von Ostia erhoben worden. Er stand in dieser Zeit auf dem Höhepunkt seines Einflusses in der Kurie ${ }^{449}$. Mit Alexander II., der Damiani als Kenner des Rechts und der Theologie schätzte, verband ihn eine enge Freundschaft ${ }^{450}$. Der Papst wies daher wie Damiani die Ansicht der Juristen vehement zurück, die weiterhin die römische Zählweise befürworteten. Insbesondere in der (vermutlich früheren) Dekretale an die Kleriker Neapels ließ sich Alexander zu wüsten Beschimpfungen der Juristen hinreißen. „Auf einem verseuchten Lehrstuhl sitzend beten sie Gesetze vor, die sie nicht kennen ... Wenn sie die Speise der heiligen Schrift durch den Schlund des lebhaften Verstandes wiederkäuen würden, hätten sie freilich nie ein solch stinkendes Rülpsen wie eine Seuche hervorgebrochen “451. Gerade dieser Brief erweist aber, dass nicht allein die Juristen die römische Zählweise weiter aufrechterhielten, sondern dass auch die Kleriker in Neapel diese Ansicht vertraten ${ }^{452}$. Der Papst bemühte sich zwar, die römische Zählweise als „neuen und unerhörten Irrtum “"453 abzukanzeln, musste jedoch die feste Verankerung der römischen Zählweise in Italien offen eingestehen. Noch ein halbes Jahrhundert später war Paschalis II. in einer Dekretale an Klerus und Volk von Piacenza zur Erneuerung des Verbots der römischen Zählweise gezwungen, weil selbst Mitglieder des Klerus nicht die neue kanonische Komputation zur Anwendung gebracht hatten ${ }^{454}$. Die Zählung in Generationen war in Italien eine erst durch Burchard und Petrus Damiani eingeführte Neuerung und traf deshalb auf lang anhaltenden Widerstand.

In den zwölf Jahren des Pontifikats Alexanders II. war der Streit um die Zählweise nicht die einzige offene Frage in der päpstlichen Inzestpolitik. Durch die vielen überlieferten Briefe Alexanders wird hinreichend deutlich, in welchem Ausmaß die neu formierte päpstliche Doktrin unter dem Druck der Anpassung an die Realität stand. Bereits die Konstitution Nikolaus' II. aus dem Jahr 1059

448 Damiani war nach der plausiblen Argumentation von KRause, Papstwahldekret 1960, an der Niederschrift des Papstwahldekrets von 1059 beteiligt. Sein Einfluss könnte sich deshalb auch auf die Kanones ausgewirkt haben.

449 Dressler, Damiani 1954, $142-147$.

450 Sснміdт, Alexander II. 1977, 179-187.

451 Sedentes autem in cathedra pestilencie dictant iura, que nesciunt ... Qui nimirum nequaquam in huius fetoris eructus pestilenter erumperent, si sacre scripture pabulum vivacis ingenii faucibus ruminarent. Alexander II. (JL 4506), hg. von HüFFER, Beiträge 1862, 120.

452 De parentele gradibus famose iam aput alios questionis scrupulum nuper etiam inter vos emersisse cognovimus ... Alexander II. (JL 4506), hg. von HüfFer, Beiträge 1862, 119.

453 ... novo et inaudito errore ... Alexander II. (JL 4500, Migne PL 146, 1379).

454 Ediert ist die Dekretale bei S̈̈GMüLlER, Dekretale 1913, 58-62. 
hatte für Verwunderung gesorgt, als sie durch einen Kardinallegaten im Königreich Dalmatien bekannt gemacht worden war $^{455}$. Der Erzbischof von Split formulierte eine Bittschrift an den Papst, um die Beibehaltung aller Ehen im vierten Grad zu erreichen. Diese Bittschrift ist erst nach dem Tod Nikolaus' II. in Rom angekommen und wurde von dessen Nachfolger Alexander II. beantwortet. In seinem Brief an den König und an die Bischöfe von Dalmatien bekundete Alexander zwar sein Beileid über das in dieser Gegend verbreitete Übel der Verwandtenehen, sah sich aber keinesfalls in der Lage, eine so weitreichende Dispensierung von der Strenge des Gesetzes in Erwägung zu ziehen ${ }^{456}$. Stattdessen gab er den Einwohnern Dalmatiens die zeitlich beschränkte Erlaubnis, Ehen im fünften Grad bei der Verpflichtung zur Keuschheit nicht trennen zu müssen ${ }^{457}$. Ehen im sechsten Grad scheint der Papst stillschweigend akzeptiert zu haben. „Wir erlauben in dieser Angelegenheit nicht ein Gut, das wir wollen, sondern ein Übel, das wir nicht wollen, in der Hoffnung auf ein zukünftiges Gut ${ }^{\text {“ } 458}$. Die Berechtigung zu dieser Milderung zog der Papst aus der Autorität des Libellus responsionum Gregors des Großen.

Der Papst konnte jedoch auch Härte zeigen. Einem sonst nicht bekannten Richter gab er den Bescheid, dass eine Ehe im dritten Grad der Blutsverwandtschaft „verabscheuenswert" ist ${ }^{459}$. Kinder aus dieser Ehe sollten nicht als legitime Erben anerkannt werden, ein Aufstieg in der kirchlichen Hierarchie sollte ihnen verweigert werden. Für eine strenge Bestrafung trat Alexander auch bei einer Schwägerschaft im vierten Grad ein, die durch Unzucht mit einer Verwandten entstanden ist - man nannte dieses Delikt später in der Kirchenrechtswissenschaft „Verschwägerung durch unerlaubten Geschlechtsverkehr“ (affinitas ex copula illicita) ${ }^{460}$. Auf eine Anfrage des Bischofs von Venedig reagierte Alexander ebenfalls abschlägig. Der Bischof brachte das Anliegen eines Mannes vor, der seine in Inzestehe verbundene Frau behalten und sich durch „Gebete, Fasten und die Schenkung von Erbgut sowie Almosen“ eine Dispensierung erkaufen wollte. Der Papst behauptete, keine Autorität zu kennen, die ihm ein solches Verfahren erlauben würde ${ }^{461}$. Vielleicht steht dieser nur verkürzt

455 Waldmüller, Synoden 1987, 55-68; Gresser, Synoden 2006, 67-69.

456 ... quia voluntatem vestram atque supplicationem, ut in quarto gradu quicumque estis permaneatis, nullo modo sequi audemus ... Alexander II. (JL 4477), hg. von MikLošić RačKi, Spomenici 1875, 222.

457 Qui vero in quinto, si caste vivere possunt et volunt, cum penitentia maneant. Quod si non possunt, separari [separati ?] ab invicem legitime nubant. Alexander II. (JL 4477), hg. von Miklošić - RačKi, Spomenici 1875, 222.

458 Non enim hac in re bonum, quod volumus, sed quod nolumus malum in spe futuri boni permittimus. Alexander II. (JL 4477), hg. von Miklošıć - RAČKI, Spomenici 1875, 222.

459 Alexander II. (JL 4582).

460 Alexander II. (JL 4617, Migne PL 146, 1403 f.). Siehe oben 353.

461 Huius viri causam super qua apostolicam sedem consuluisti retractantes, si quo modo misericorditer coniunctam sibi illicite consanguineam retinere posset et orationibus, ieiuniis ac 
überlieferte Brief im Zusammenhang mit einem Problem, das wenige Jahre später von Gregor VII. thematisiert wurde. Gregor untersagte den örtlichen Bischöfen, von sich aus Dispensierungen vom strengen Inzestverbot auszusprechen ${ }^{462}$. Aus der Sicht des Reformpapsttums sollte allein der apostolische Stuhl zu einer solchen Milderung des Kirchenrechts autorisiert sein. Das Inzestverbot stellte somit auch ein Mittel dar, innerhalb der Kirche klare hierarchische Verhältnisse zu schaffen. Die wenigen Fälle vor 1046 zeigen, dass sich Bischöfe durchaus in der Lage sahen, alleine oder im Zusammenspiel mit einer Synode das strenge Inzestrecht abzumildern ${ }^{463}$. Diesem eigenmächtigen Vorgehen der Ortsbischöfe wollte das Papsttum einen Riegel vorschieben. Erst als der apostolische Stuhl selbst von Anfragen wegen Ehedispense überschwemmt wurde, delegierte Alexander III. im 12. Jahrhundert die Kompetenz wieder teilweise an die Ortsbischöfe ${ }^{464}$.

Papst Alexander II. trat nicht nur gegen den Missbrauch von Dispensierungen ein, er hatte auch mit einem weiteren Missbrauch zu kämpfen. An Wilhelm von Montreuil schrieb Alexander, er habe durch den Bericht vieler Leute erfahren, dass er seine Ehefrau unter dem Vorwand der Verwandtschaft verstoßen wollte, um eine andere Frau zu ehelichen ${ }^{465}$. „Mit apostolischer Autorität“ untersagte der Papst dieses Vorgehen, „bis ein Konzil von frommen Bischöfen diesen Rechtsfall untersucht hat ${ }^{\text {“466 }}$. Bereits unmittelbar nach der Geltendmachung des ausgedehnten Inzestverbots durch das Reformpapsttum wussten die Laien also diese Neuerung als Vorwand für Scheidungen auszunützen. Auch Petrus Damiani berichtete am Ende seines Lebens von solchen Prozessen, die durch die Nennung falscher Zeugen und falscher Vorfahren beeinträchtigt worden seien ${ }^{467}$. Der Missbrauch der Regel verschärfte sich mehr oder weniger gleichzeitig mit ihrer Durchsetzung. Missbräuche solcher Art sind aus der Karolingerzeit nicht in dieser Dichte bezeugt ${ }^{468}$. Sie machen deutlich, dass die Vorschriften des Kirchenrechts zügig bekannt gemacht und von den Laien zur Kenntnis genommen wurden. Das Bekanntsein der Normen hatte

haereditatis et eleemosynarum se largitione redimere, nullam auctoritatem comperimus qua sibi concederemus. Alexander II. (JL 4523, Migne PL 146, 1406).

462 Gregor VII., Registrum VI 5b (MGH Epp. sel. 2/2, 402). Vgl. STIEGLer, Dispensation 1901, 308-311; Corbet, Burchard 2001, 296-307.

463 Corbet, Burchard 2001, 234.

464 Joyce, Ehe 1934, 458; Baldwin, Masters 1970, 333.

465 Multorum relatione cognovimus te propriam velle abiicere uxorem et adhaerere alteri, praetendentem consanguinitatis occasionem. Alexander II. (JL 4524, Migne PL 146, 1387).

466 .... donec episcoporum religiosorum concilium causam istam examinaverit. Alexander II. (JL 4524, Migne PL 146, 1387).

467 Siehe 460 Anm. 393. Vgl. auch die Beobachtungen von DAudet, Établissement 1941, 95, und Corbet, Burchard 2001, 307-311.

468 Siehe $381 \mathrm{f}$. 
jedoch noch nicht deren Befolgung im Sinne der Kirche zur Folge. Gerade die Ausdehnung der Verwandtschaftsgrade machte es möglich, bei der Eheschließung im guten Glauben die Konformität mit den kanonischen Normen vorzutäuschen und dann später bei Bedarf eine verbotene Verwandtschaft aus dem Ärmel zu ziehen ${ }^{469}$. Im Lauf des 12. Jahrhunderts reifte unter den Juristen der Kirche folglich die Erkenntnis, der Missbrauch des Inzestverbots untergrabe allmählich ein viel wichtigeres Prinzip des christlichen Eherechts, das durch Christus verkündete Prinzip der Unauflösbarkeit ${ }^{470}$. Nach einigen Reformvorstößen unter Alexander III. zog Innocenz III. auf dem IV. Laterankonzil von 1215 die Konsequenz aus dieser Entwicklung ${ }^{471}$. Der lang andauernde Prozess um die Legitimität der Ehe Philipps II. von Frankreich mit Ingeborg von Dänemark führte dem Papst deutlich die Schwächen des überkommenen Eherechts vor Augen ${ }^{472}$. Das Inzestverbot der Blutsverwandtschaft wurde auf den vierten Grad abgemildert, das Verbot der Schwägerschaft „zweiter" und „dritter Ordnung “473 wurde gänzlich beseitigt. Darüber hinaus führte der Papst schwere prozessrechtliche Hürden gegen eine Scheidung wegen Inzest ein ${ }^{474}$. Im Zweifelsfall sollte für die Aufrechterhaltung der Ehe entschieden werden: In dubio pro matrimonio.

\subsection{Ausdehnung als Zufall und Chance}

Die Ausdehnung des Inzestverbots auf den 7. Grad kanonischer Zählung war das Ergebnis eines mehr oder weniger zufälligen Aufeinandertreffens verschiedener historischer Entwicklungen und Ereignisse. Mit Heinrich II. kam in Deutschland eine eigenwillige Herrscherpersönlichkeit an die Macht. Er war von der Vorstellung autoritärer Königsherrschaft durchdrungen und wachte mit viel religiösem Ernst über die Einhaltung der christlichen Gebote. Im Epochenjahr 1002 suchte er ein Mittel, um das neue Ranggefälle gegenüber den bislang ebenbürtigen Herzögen anschaulich zu machen. Durch seine kanonistische Gelehrsamkeit wurde er darauf aufmerksam, dass die von der Kirche eingeforderten Inzestverbote immer noch nicht voll zur Geltung gebracht worden waren. Der Fall König Roberts II. von Frankreich, bei dessen Verur-

469 Stiegler, Dispensation 1901, 295-301; Joyce, Ehe 1934, 458-460; Maleczek, Stammbäume 1988.

470 Baldwin, Masters 1970, 332-337.

471 IV. Lateranum (1215) c. 50 (COD 257 f.).

472 Siehe oben $1-3$.

473 Hierzu Freisen, Geschichte 1893, 474-489.

474 IV. Lateranum (1215) c. 52 (COD 259); c. 66 (COD 265). Zur Anwendung im Spätmittelalter vgl. Kroppmann, Ehedispensübung 1937; Helmholz, Litigation 1974, 77-87; D’Avray, Marriage 2005, $111-115$. 
teilung er anwesend war, führte ihm dies deutlich vor Augen. Andere Fälle in seiner weiteren Verwandtschaft unterschieden sich davon seiner Ansicht nach nur geringfügig. Als König sah er die Zeit gekommen, diese Inzestehen öffentlich anzuprangern und damit Zustimmung zu seiner Königsherrschaft zu erzwingen, da sich niemand diesem im abendländischen Christentum und besonders im ottonischen Reich fest verankerten Anliegen entziehen konnte. Um jedoch eine solche Kampagne zu starten, bedurfte es klarer kirchenrechtlicher Normen. Diese bezog er aus der Mainzer Kanonistik, wo die pseudoisidorischen Fälschungen zum Inzestverbot bekannt waren und im Sinne der kanonischen Zählung missverstanden wurden. Erst hier wurde die kanonische Zählung mit der Inzestgrenze des siebten Grades kombiniert. Diese Kombination gab dem König die juristische Legitimation für seinen Angriff auf die Ehe Konrads von Kärnten. Durch Fälschungen gab Burchard von Worms diese Normen als seit langem gültiges Kirchenrecht aus und verschaffte ihnen Beachtung im ganzen christlichen Abendland. Burchards Dekret stellt den Ausgangspunkt für die Durchsetzung der Inzestgrenze des 7. Grades kanonischer Zählung dar.

Erst durch die Inzestkampagne Heinrichs II. vollzog sich die Ausweitung des Inzestverbots in genealogisch nicht mehr fassbare Tiefen. Während in der Karolingerzeit das Inzestverbot die erlebte Verwandtschaft nicht wesentlich überstieg, musste jetzt der Blick 200 Jahre zurück in die Vergangenheit gerichtet werden, um alle verbotenen Verwandten zu erfassen. War diese Entwicklung schon nicht unvermeidlich, so hätten auch die Ereignisse von 1003 Episode bleiben können. Bereits Heinrich II. beteiligte sich, nachdem er seine Königsherrschaft etabliert hatte, nicht mehr an vorderster Front am Kampf gegen Inzestehen, sondern überließ die Initiative den zuständigen Bischöfen. Im Fall Ottos von Hammerstein und Konrads II. hat Heinrichs Eifer bereits deutlich nachgelassen. Nach der Machtübernahme Konrads II., der selbst in einer vom Mainzer Erzbischof missbilligten Ehe lebte, setzte sich ein pragmatischer Umgang mit dem ausgedehnten Inzestverbot durch. Obwohl an den Normen Burchards offiziell nicht gerüttelt wurde, ließen sich die um die Seelsorge bemühten Bischöfe auf notwendige Kompromisse mit der Laienwelt ein. Das ausgedehnte Inzestverbot ließ sich in einer Welt, in der etwa 150-200 Adelsfamilien das politische Geschehen beherrschten und untereinander wegen des adeligen Prinzips der Isogamie zu Heiratsbündnissen gezwungen waren, nicht in die Tat umsetzen. Die salischen Bischöfe waren zu stillschweigender Duldung oder zum Erkauf von Gunsterweisen bereit und legten damit den Grundstein für die Abmilderung des Verbots durch päpstliche Dispensierungen. Nur die Mönche der strengen reformorientierten Richtung (Siegfried von Gorze, Johannes von Fécamp) hielten an der Geltung des ausgedehnten Inzestverbots fest und machten es gegen die Ehebündnisse der Salier geltend. Sie waren nicht der Seelsorge verpflichtet und konnten sich eine solch rigorose Haltung erlauben. 
Exemplarisch für diese Entwicklung ist der Disput um die Heirat Heinrichs III. mit Agnes von Poitou.

Entscheidend für die Durchsetzung des ausgedehnten Inzestverbots war die durch Heinrich III. angestoßene Kirchenreform in Rom. Die vom Kaiser eingesetzten deutschen Päpste bewirkten die Verankerung der Lehre Burchards von Worms in der durch die salischen Bischöfe abgeschwächten Form an der römischen Kurie. Gleichzeitig machte sich der Asket und Eremit Petrus Damiani für die Übernahme von Burchards Inzestvorschriften stark. Durch seine engen Kontakte zur römischen Kurie gelang es ihm, sowohl den siebten Grad als auch die kanonische Zählung als päpstliches Kirchenrecht zu verankern. Damit vollzog das Papsttum einen Bruch mit der seit Gregor II. verfestigten Tradition des kategorischen Verbots von Verwandtenehen. Das Papsttum brach die letzten Brücken zur Geltung des römischen Rechts ab und setzte dagegen die Schaffung eines eigenen von Rom diktierten Kirchenrechts durch. Die Aktivität der Päpste richtete sich zunächst auf Frankreich, dann unter Alexander II. verstärkt auf Italien. In beiden Regionen wurde das ausgedehnte Inzestverbot als radikale Neuerung wahrgenommen. Insbesondere in Frankreich sollten noch Gregor VII. und seine Nachfolger jahrzehntelang mit der Etablierung der neuen Normen beschäftigt sein. Die deutschen Päpste sorgten nicht nur für die Durchsetzung des ausgedehnten Inzestverbots, sie brachten auch die pragmatische Haltung zur Anwendung dieser Normen nach Rom mit. Leo IX. sah sich wie bereits in seiner Zeit als Reichsbischof zu Kompromissen genötigt und erteilte Dispensierungen vom strengen Eherecht. Jetzt stand diese Praxis jedoch auf einer gesicherten Grundlage, da der Papst im Unterschied zum Ortsbischof durch seine Stellung als Apostelfürst zu einer Dispensierung vom Recht ermächtigt war. Das Beispiel Gregors I., der den Angelsachsen nicht die Härte des Gesetzes hatte zumuten wollen, diente als legitimierendes Vorbild. Auch in anderen Bereichen des Kirchenrechts setzte sich die Vorstellung von der dispensatorischen Kompetenz des apostolischen Stuhls durch.

Die Berücksichtigung der „evolutionären Unwahrscheinlichkeit“ bewahrt davor, allein finstere Machenschaften der Kirche hinter der Ausdehnung des Inzestverbots zu vermuten. Die Radikalisierung des Inzestverbots geht auf Heinrich II. und Burchard von Worms zurück, die noch nichts von der segensreichen Wirkung päpstlicher Dispensierungen ahnen konnten, da es ein solches Rechtsinstitut noch nicht gab. Burchard von Worms lehnte überdies eine Milderung des Inzestverbots grundsätzlich ab. Erst als die Unvereinbarkeit dieser Regel mit der Praxis erkannt wurde, ist der Zufall der Ausdehnung als Chance für die Kirche genützt worden. Diese Chance bestand nicht nur im Erwerb von Landbesitz oder in der Veranlassung zu Klosterstiftungen, sie bestand für das Papsttum auch darin, die alleinige Kompetenz zur Dispensierung zu beanspruchen und gegenüber den Bischöfen auf den Jurisdiktionsprimat zu pochen. Insgesamt zog die Kirche jedoch nicht den größten Nutzen auf diese 
materielle oder machtpolitische Weise. Der größte Gewinn war eher symbolischer Natur: Es gelang der Kirche endgültig, den Diskurs über Ehe und Sexualität zu monopolisieren. Nach dem ausgedehnten Inzestverbot, zu dem durch die Systematisierung der Kirchenrechtswissenschaft noch die Schwägerschaft zweiter und dritter Ordnung hinzuerfunden wurde, waren alle Ehen potentiell sündhaft und ungültig. Petrus Damiani sprach diese Konsequenz offen aus und verzweifelte an der Omnipräsenz der Sünde. Die Kirche profitierte davon, weil sie jederzeit von jedermann aktiviert werden konnte, um Eheschließungen in Frage zu stellen und vor Gericht zu bringen. Dabei störte es zunächst nicht, wenn ein Missbrauch stattfand und Verwandtschaft nur als Vorwand für eine Scheidung benutzt wurde. Das Inzestverbot erfüllte auch dann seine Funktion, denn es nötigte dazu, für die erschlichene Scheidung das kirchliche Gericht einzuschalten und die Monopolisierung der Ehe durch die Kirche anzuerkennen. Durch das Ausnützen der Eheverbote gewöhnten sich die Laien an die kirchliche Zuständigkeit in Ehefragen ${ }^{475}$. Zudem verstärkte der Missbrauch den Anreiz zum Erlass neuer Gesetze, die ihrerseits den Anspruch der Kirche auf die Regelung dieses Lebensbereichs verstärkten. Als das kirchliche Monopol über die Ehe durchgesetzt war, konnte das Inzestverbot unter Innocenz III. wieder zurückgeschraubt werden und allmählich aus dem Blickfeld der Kirche verschwinden.

475 d'Avray, Marriage 2005, 99. 


\section{Die abendländische Inzestgesetzgebung im Kontext}

Im 12. Jahrhundert erstreckte sich das Inzestverbot auf eine unüberschaubare Anzahl von Verwandten. Niemand war zu dieser Zeit in der Lage, alle 128 Vorfahren in der siebten Generation namentlich zu kennen, mit deren Nachkommen er nach dem kirchlichen Eherecht verwandt war. Genauso wenig konnte man alle Personen erfassen, die aufgrund der Regeln über die drei Arten der Schwiegerverwandtschaft von der Eheschließung ausgeschlossen waren. Eine Befolgung der kirchlichen Inzestverbote musste zwangsläufig am verfügbaren genealogischen Wissen scheitern. Wie kam es dazu, dass die Kirche von den Laien die Einhaltung eines Verbots einforderte, das prinzipiell unmöglich zu befolgen war? Allein diese eklatante Diskrepanz zwischen Verbot und Realität legt den Schluss nahe, dass eine einfache Erklärung durch die Isolierung eines einzelnen entscheidenden Faktors der historischen Entwicklung nicht gerecht wird. Die komplexe und in mehreren Schüben stattfindende Entfaltung des Inzestverbots wirft die grundsätzliche Frage auf, ob die Suche nach einer Erklärung für eine „evolutionäre Unwahrscheinlichkeit“ dieses Ausmaßes überhaupt erfolgversprechend sein kann. Zufälle, das Zusammenwirken unterschiedlicher und nicht aufeinander abgestimmter Faktoren, spielten eine entscheidende Rolle und machen die Rekonstruktion einer ,organischen' Entwicklung zu einem fruchtlosen Unternehmen. Der Historiker ist mit einem unergründlichen Rest konfrontiert, dem nicht durch Erklärung, sondern nur durch Erzählung beizukommen ist.

Dies muss bedacht werden, wenn wir uns in diesem Kapitel systematisch den Entstehungsbedingungen der frühmittelalterlichen Inzestgesetzgebung zuwenden. Michael Mitterauer hat eindringlich darauf hingewiesen, dass diese Entstehungsbedingungen nicht ausschließlich in der Eigenart der abendländischen Geschichte gesucht werden dürfen. In der byzantinischen Kirche sowie in den von ihr beeinflussten orientalischen Kirchen ist es zu einer ähnlich weitgehenden Ausdehnung des Inzestverbots gekommen wie im Westen. Die Besitzgier der westlichen Kirche, die Jack Goody für den Wandel verantwortlich machte, kann daher ebenso wenig für eine Erklärung herangezogen werden wie die von vielen Historikern vorausgesetzte Abwehrhaltung der Kirche gegen die endogamen germanischen Völker. Mitterauers Vorschlag, die Inzestverbote auf die ursprüngliche Abstammungsfeindlichkeit des Christentums zurückzuführen, ist aus einem anderen Grund problematisch ${ }^{1}$. Sowohl im frühen Christentum

1 Ausführlich dazu oben 9-13. 
als auch im Christentum des Spätmittelalters und der Neuzeit zählte das Inzestverbot nicht zu den in der Gesellschaft virulenten Fragen. Selbst in der Zeit vom 4. bis ins 11. Jahrhundert wurden einige ,Mikro-Christenheiten ' nicht von der Ausdehnung der Ehehindernisse erfasst. Die irische Christenheit blieb davon unberührt, ebenso die nestorianische Christenheit im Perserreich. $\mathrm{Zu}$ den Entstehungsbedingungen der Ausdehnung zählt also die Zugehörigkeit zum römischen Reich und seinen Nachfolgereichen. Genauer: Nur dort, wo die römische Gesetzgebungstradition wirksam blieb und einem spezifischen Wandel unterworfen wurde, drehten Bischöfe und Herrscher an der Schraube des Inzestverbots. In diesem Kapitel soll daher die abendländische und byzantinische Gesetzgebung vergleichend behandelt werden, um die in Hinblick auf den lateinischen Westen gewonnenen Einsichten zu überprüfen. Eine eingehende Darstellung der byzantinischen Ehegesetzgebung ist in diesem Rahmen nicht möglich.

\section{Funktionswandel des Rechts}

Eine kontinuierliche Entfaltung des Inzestverbots, wie viele Darstellungen suggerieren, hat im Abendland nicht stattgefunden. Die Entwicklung vollzog sich vielmehr in zwei Schüben. Der erste Schub ereignete sich um das Jahr 500 und geht auf das Wirken des burgundischen Bischofs Avitus von Vienne zurück. Der zweite Schub erfolgte um das Jahr 1000 und verdankte sich der Inzestkampagne Heinrichs II. sowie der kanonistischen Gelehrsamkeit Burchards von Worms. Avitus von Vienne stellte alle Ehen innerhalb der römisch-rechtlich definierten Verwandtschaft unter das Inzestverbot, Burchard von Worms führte die Grenze des siebten Grades kanonischer Zählung in das Kirchenrecht ein. Eine analoge Entwicklung fand im byzantinischen Reich statt. Dort ordnete Kaiser Leon III. in seinem 741 veröffentlichten Gesetzbuch (Ekloge) die Ausdehnung des Inzestverbots auf die gesamte Verwandtschaft nach römischem Recht an. Den zweiten Schub setzte der Patriarch Sisinnios II. von Konstantinopel in Gang. Kurz vor der Jahrtausendwende erhob er in seinem Tomos die Forderung, auch die Ehen innerhalb der Schwiegerverwandtschaft sollten bis zum 6. Grad untersagt werden. Um diesen Tomos des Sisinnios entfaltete sich im Lauf des 11. Jahrhunderts eine Diskussion, die schließlich in die Akzeptanz der neuen Eheverbote mündete. In welcher Hinsicht sind die Entstehungsbedingungen der abendländischen und byzantinischen Entwicklung vergleichbar?

Wenden wir uns zunächst dem ersten Schub der Ausdehnung auf die gesamte römisch-rechtliche Verwandtschaft zu. Die Vorgeschichte dieser Ausdehnung beginnt mit dem Damaskusedikt Kaiser Diocletians. Dieses Edikt ist insofern als Wendepunkt zu werten, als der Gesetzgeber das Inzestverbot dem Bereich der göttlichen Ordnung zuordnete, für die der vergöttlichte Kaiser Sorge zu tragen hatte. Mit dem Ziel, der Relativierung der Moral Einhalt zu gebieten, verschärfte Diocletian die Bestrafung des Inzestdelikts. Fortan gehörte 
diese Rechtsmaterie zu den vorrangigen Anliegen der kaiserlichen Gesetzgebung. Die christlichen Bischöfe, die bis zur Konstantinischen Wende dem Problem des Inzestverbots keine Aufmerksamkeit geschenkt hatten, konnten dem Kaiser in dieser Sorge für die göttliche Ordnung nicht nachstehen. Die ersten Synoden der tolerierten Kirche setzten sich für eine interpretatio christiana des Inzestverbots ein. Christliche Bischöfe waren es auch, die bei den Kaisern des 4. Jahrhunderts eine strengere Auffassung des Inzestverbots einforderten. Das Beispiel der Cousinenehe zeigt allerdings, dass die Juristen am Kaiserhof der Ausdehnung des Inzestverbots Widerstand entgegensetzten. Anders als im Frühmittelalter, als rechtliche Normen vielfach Bekenntnischarakter hatten, nahm das römische Recht eine pragmatische Haltung zur Wirklichkeit ein und setzte keine sozialen Umwälzungen in Gang ${ }^{2}$. Das Verbot der Cousinenehe wurde daher im Osten des Reichs zurückgenommen, im Westen wurde es durch die Möglichkeit der Dispensierung abgeschwächt. Dieses Schwanken zwischen einer Annäherung an die neue christliche Ehelehre und der Fortführung der römischen Rechtstradition kennzeichnete auch die Gesetzgebung der Kaiser zum Scheidungsrecht. Zu einem Verbot der einvernehmlichen Scheidung ist es in der Spätantike nicht gekommen, weil dies zu einem eklatanten Bruch mit der römischen Praxis geführt hätte, an dem die Gesetzgeber mit ihrem pragmatischen Zugang nicht interessiert waren.

Als Avitus zum Bischof von Vienne erhoben wurde, galt das Inzestverbot als Teil der göttlichen Ordnung der Ehe, sein Umfang blieb aber weitgehend auf die traditionellen Verbote des römischen Rechts beschränkt. Avitus musste schmerzlich zur Kenntnis nehmen, dass selbst das Verbot des Sororats, im 4. Jahrhundert durch kaiserliche und bischöfliche Gesetze etabliert, von der romanischen Bevölkerung nicht beachtet wurde. Diese Verstöße gegen das Gesetz wogen für ihn schwer, da er mit Augustinus eine pessimistische Auffassung von Sexualität teilte und es daher für notwendig erachtete, die Sexualität der Laien einer strikten Ordnung zu unterwerfen. Überdies betrachtete Avitus nach dem Kollaps des weströmischen Reichs und seiner Verwaltung die Bischöfe als die kompetenten Wächter über die Einhaltung des Inzestverbots. Sie waren aus seiner Sicht dazu berechtigt, in der Nachfolge der römischen Kaiser neue Inzestverbote zu erlassen. Die Bischöfe fühlten sich jedoch anders als die gesetzgebenden Kaiser nicht an die Forderung der Realisierbarkeit gebunden, sondern bekannten sich zu einem Ideal der christlichen Lebensordnung, an das sich die Realität anzupassen hatte. Vor diesem Hintergrund ist die Ausdehnung des Inzestverbots auf die gesamte Verwandtschaft des römischen Rechts zu verstehen. Auf dem Konzil von Epaon setzte Avitus die Geltung des neuen Eheverbots ausdrücklich mit dem Zeitpunkt des Erlasses fest und nahm bereits

2 Hunt, Christianising 1993, 158; Reynolds, Marriage 1994, 61-65; Harries, Law 1999, 96-98; Rapp, Bishops 2005, 239-260. 
geschlossene Ehen mit der Cousine zweiten Grades von der Regelung aus. Er kennzeichnete damit den Kanon als ein neues, in Zukunft einzuhaltendes Verbot.

Im Osten ist die Ehegesetzgebung länger in der Hand des Kaisers verblieben. Justinian I. widmete sich in mehreren Novellen dem Inzestverbot und hielt an den praxisnahen Regelungen seiner Vorgänger fest. Seine einzige Neuerung, die Einführung des Eheverbots der geistlichen Verwandtschaft, konnte sich auf eine verbreitete Ablehnung solcher Verbindungen in der Bevölkerung stützen. Die Cousinenehe traf zwar auch in manchen christlichen Kreisen des Ostens auf Vorbehalte, wurde jedoch von Justinian nicht angetastet. Erst auf der Synode „in Trullo" im Jahr 692 setzte sich die strenge Auffassung durch. Justinian II. approbierte die Kanones des Konzils, setzte aber keine weltlichen Strafen für die Übertretung des Inzestverbots fest. Erst Leon III. erweiterte in seiner Ekloge das byzantinische Kaiserrecht um das Verbot der Ehe mit der Cousine ersten und zweiten Grades und verhängte drakonische Strafen über Delinquenten. Auch er kennzeichnete das Verbot als eine in Zukunft einzuhaltende Regelung ${ }^{3}$.

Zum Verständnis der gesetzgeberischen Initiativen Justinians II. und Leons III. ist von entscheidender Bedeutung, dass sie in Phasen der Stabilisierung des byzantinischen Reichs stattfanden ${ }^{4}$. Die Expansion der muslimischen Araber erfasste innerhalb weniger Jahre die Hälfte des Reichsgebiets und kulminierte während der Jahre 674-678 in einer dauerhaften Belagerung Konstantinopels. Die Zerschlagung des christlichen Kaiserreichs am Bosporus, das eigentliche Kriegsziel der Araber, schien unmittelbar bevorzustehen. Nachdem alle Versuche, die stärkste Festung der Mittelmeerwelt zu bezwingen, gescheitert waren und die arabischen Truppen erhebliche Verluste erlitten hatten, willigte der Kalif Mu'awiya in einen Friedensvertrag mit den Byzantinern ein. Die Araber verpflichteten sich zu Tributzahlungen an Konstantinopel. Nach dem Tod Mu'awiyas wurde das Kalifat durch schwere Nachfolgekämpfe weiter geschwächt. Die arabische Bedrohung war gebändigt, das Reich konnte sich regenerieren. In dieser Phase von 678-695 beendete der Kaiser durch das 5. ökumenische Konzil von Konstantinopel die Glaubensspaltung und ermutigte die Bischöfe auf dem Trullanum zur Aktualisierung des Kirchenrechts. Die Stabilisierung war aber nicht dauerhaft, denn die Entmachtung Justinians II. im Jahr 695 stürzte das Reich in eine weitere tiefe Krise. Das durch Usurpationen und innere Machtkämpfe geschwächte Reich verlor Nordafrika an die Araber und wurde durch bulgarische Einfälle heimgesucht. In den Jahren 717/718 stand erneut die Armee des Kalifen vor den Toren der Hauptstadt. Dem im März 717 erhobenen Kaiser Leon III., einem Emporkömmling nordsyrischer Herkunft, gelang es, diese letzte große Belagerung Konstantinopels abzuwen-

3 Ecloga 17, 37 (238).

4 Zur Ereignisgeschichte vgl. LiLie, Byzanz 2003, 95-125. 
den. Nach weiteren Kämpfen errang der Kaiser im Jahr 740 einen entscheidenden Sieg bei Akroinon und konnte so die Herrschaft über Kleinasien für die kommenden Jahrhunderte sichern.

Ein Jahr nach diesem Sieg, im Jahr 741, erließ Leon III. gemeinsam mit seinem Sohn Konstantin V. die Ecloga, das erste kaiserliche Gesetzbuch seit den Kodifikationen Justinians 200 Jahren zuvor ${ }^{5}$. Diese Hinwendung zur Reform des Rechts fand in einer Periode der Restrukturierung des byzantinischen Reichs statt. Leon widmete sich der Anpassung der Verwaltung an die drastische Verkleinerung des Reichsgebietes und unterzog den Steuerkataster einer grundlegenden Aktualisierung ${ }^{6}$. Zu dieser Politik der Restrukturierung zählte auch die Überprüfung der religiösen Grundlagen des Reichs ${ }^{7}$. Die Frage, warum Gott dem Reich der Römer über eine so lange Zeit nicht gewogen war, vielmehr strenge Prüfungen über es hat ergehen lassen, führte zu einer Debatte um die richtige Gottesverehrung. Leon III. stieß diese Debatte an, als er im Jahr 726 die Christusikone vom Tor des Kaiserpalastes entfernen und durch ein Kreuz ersetzen ließ $\beta^{8}$. Die Verehrung von Ikonen erschien dem Kaiser und den bilderkritischen Theologen als Götzendienst: als Götzendienst, den Gott im Alten Testament mit dem Entzug der Gnade und entsetzlichen Heimsuchungen bestraft hatte?. Wie weit Leons bilderkritische Haltung ging, ob er tatsächlich ein Edikt erlassen hat und ob er zur Bilderzerstörung aufrief, wird in der byzantinistischen Forschung kontrovers diskutiert; sicher ist, dass er den Konflikt mit dem Patriarchen und dem Papst nicht scheute, um seinen Standpunkt zur Geltung zu bringen ${ }^{10}$.

Die Rechtsreform in der Ecloga reagierte ebenfalls auf dramatische Entwicklungen ${ }^{11}$. Recht war im 8 . Jahrhundert nur mehr unzureichend in einer schulischen oder wissenschaftlichen Ausbildung verankert, die Kluft zwischen schriftlicher Rechtsordnung und lokaler Rechtspraxis wurde immer größer. Die

5 Pieler, Rechtsliteratur 1978, 438 f.; Simon, Legislation 1994, 12-16; Brubaker Haldon, Byzantium 2001, $286 \mathrm{f}$.

6 Lilie, Reaktion 1976; DERs., Byzanz 2003, 116-119; Brandes, Finanzverwaltung 2002, 368-384.

7 Zum Ausbruch des Bilderstreits vgl. Gero, Iconoclasm 1973; SteIn, Beginn 1980; Schreiner, Bilderstreit 1988; Brubaker, Icons 1998; Brubaker - Haldon, Byzantium 2001; Brown, Rise 2003, 387-391; AuzÉpy, Enjeux 2004.

8 Zweifel an dieser Episode äußert Auzépy, Destruction 1990. Haldon - Ward-Perkins, Evidence 1999, verteidigen die Glaubwürdigkeit.

9 Vgl. Haldon, Byzantium 1990, 87 f.; AuzÉpy, Enjeux 2004, 143 f.

10 Wichtig ist eine neu entdeckte Predigt des Patriarchen Germanos: Esвroeck, Discours 1999. Die These von Speck, Leon III. 2002, über die Entstehung des Ikonoklasmus unter Konstantin V. (und nicht unter Leon III.) beruht auf einer tendenziösen Deutung der römischen Quellen. Vgl. Zuckerman, Learning 2005, 85-107; Scholz, Päpste 2006, 29-36 (mit weiterer Literatur).

11 Pieler, Rechtsliteratur 1978; Haldon, Byzantium 1990, 254-280. 
kaiserliche Gesetzgebung setzte im 7. Jahrhundert weitgehend aus und konzentrierte sich auf die mühevollen Versuche der Herstellung eines Konsenses über die dogmatischen Zerwürfnisse. Eines der wenigen Themen, das in der Zeit zwischen Justinian und der Wiederbelebung des Rechts im 9. Jahrhundert immer wieder Gegenstand kaiserlicher Novellen wurde, war das Eherecht. Marie Theres Fögen charakterisierte diese nachjustinianischen Novellen als „symbolische Gesetzgebung "12. Seit dem 8. Jahrhundert sei nicht mehr die effektive Verhaltenssteuerung durch Gesetze im Vordergrund gestanden, sondern die Funktion des Rechts als „Transporteur von Bewusstseins- und Sinngehalten“. Durch den Erlass von erstrebenswerten Normen des Zusammenlebens sollte die Identifikation der Bevölkerung mit der politischen Herrschaft herbeigeführt werden. John Haldon schreibt: „Imperial action was thus not directed at emending laws to conform to reality, but rather at emending reality to conform to the inherited legal-moral apparatus “"13. Die Ehe war zentraler Bestandteil dieser rechtlich-moralischen Weltordnung.

Auch in der Ecloga Leons III. nimmt das Eherecht eine führende Stelle ein ${ }^{14}$. Die ersten drei Titel befassen sich mit Ehe- und Ehegüterrecht. Titel 1 behandelt die Verlobung, Titel 2 die Eheschließung, die Ehehindernisse, die Mitgift, die Zweitehe und die Scheidung. In diesem Rahmen dehnte Leon III. das Inzestverbot auf die Cousine zweiten Grades aus: „Eine Eheschließung ist denen verboten, ... die miteinander blutsverwandt sind, also die Ehe von Eltern mit ihren Kindern, von Brüdern mit ihren Schwestern und von deren Kindern untereinander, den sogenannten Vettern und Basen, und schließlich auch noch

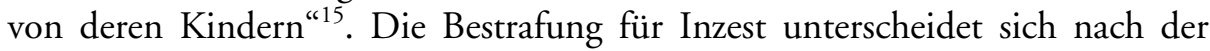
Schwere des Delikts. Bei Geschlechtsverkehr innerhalb der Kernfamilie droht die Hinrichtung durch das Schwert, beim Verstoß gegen die traditionellen Eheverbote das Abschneiden der Nase, beim Verstoß gegen das neue Verbot der Ehe mit der Cousine ersten und zweiten Grades die Auspeitschung ${ }^{16}$.

Abgesehen von dieser Innovation hält sich jedoch die Neuheit der Ecloga in Grenzen. Inhaltlich gehen die meisten Bestimmungen auf Vorbildregelungen

12 FöGEN, Gesetz 1987, 147.

13 Haldon, Byzantium 1990, 259.

14 Nach Simon, Ehegesetzgebung 1976, 34 f., erließ Leon bereits im Jahr 7267/727 ein ausführliches Gesetz (nomothesia) zum Eherecht. Darin wird u.a. das Eheverbot der geistlichen Verwandtschaft ausgedehnt und der Missbrauch dieses Verbots zur Ehescheidung bestraft. Vgl. Dölger, Regesten 1924, 40 f. (Nr. 338, Leon IV. zugeschrieben).

15 Ecloga 2, 2 (170 f.). Auch das Eheverbot der geistlichen Verwandtschaft wurde ausgeweitet, und zwar auf die Verbindung der Patentochter mit dem Sohn des Paten. Vgl. LyNCH, Godparents 1986, 232-234.

16 Ecloga 17, 33 (236); 17, 34 (238); 17, 37 (238). Vgl. hierzu Vgl. Pitsakis, Droit 1992; Troianos, Wirkungsgeschichte 1992, 95-98. 
aus dem Corpus iuris civilis zurück. Neu ist nicht der Inhalt, sondern - wie die Arbeiten von Dieter Simon und Ludwig Burgmann klarstellten - die Form ${ }^{17}$. Der Gesetzgeber vermeidet das technische Vokabular der antiken Jurisprudenz und formuliert in knapper und volkstümlicher Diktion. Gerechtfertigt wird diese Abkehr von der wissenschaftlichen Jurisprudenz im Vorwort. Das komplexe Rechtsgebäude Justinians - so heißt es darin - würde außerhalb der Hauptstadt auf Unverständnis stoßen und bei der ländlichen Bevölkerung für Verwirrung sorgen ${ }^{18}$. Statt die Rechtwissenschaft zu zitieren zieht die Ecloga wie kein anderes Gesetzeswerk aus früheren Zeiten die Bibel als Legitimationsquelle heran ${ }^{19}$. Im Prolog schöpft Leon ausgiebig aus der Heiligen Schrift, und selbst in den dispositiven Teilen der Kodifikation wird auf Texte der Bibel verwiesen. Der Kaiser erscheint damit als göttlicher Beauftragter, die Gesetzgebung als Fortsetzung göttlicher Rechtssetzung mit anderen Mitteln. „Der Kaiser setzt nicht selbst Recht, er verhilft nur Gottes Anordnungen zum Durchbruch “20, so beschreibt Marie Theres Fögen die Ideologie der Ecloga. Die Ehe bot sich für eine solche Gesetzgebung besonders an. Sie wurde nach Gen. 2, 24 als eine von Gott gestiftete Institution wahrgenommen ${ }^{21}$.

Die Parallelen des Bilderstreits mit der Regelung des Eherechts springen in die Augen. Erstens setzte sich Leon in beiden Bereichen für die Umsetzung biblischer Vorschriften ein: Hier das Verbot der Idolatrie, dort das Verbot von Scheidung und Verwandtenehen. Zweitens dienten beide Initiativen der Stärkung kaiserlicher Gewalt in einer Phase der Restabilisierung des byzantinischen Reichs $^{22}$. Hier im Bereich des Glaubens, dort im Bereich der Rechtsreform. Drittens spiegelt sich in beiden Bereichen eine Abgrenzung vom Erzfeind des getauften Volks wider, von den muslimischen Arabern. Der byzantinische Ikonoklasmus distanzierte sich von der bilderkritischen Diskussion im Judentum und im Islam und stellte mit dem Kreuz ein Symbol in den Mittelpunkt, das die Eigenheit des Christentums noch mehr unterstreichen sollte als die Ikonen. Im Eherecht festigte das Verbot der Scheidung und die Regelung der Zweitehe das christliche Ideal der Monogamie. Polygamie, Ehescheidung und

17 Simon, Epochen 1988, 82-85; Burgmann, Ehegüterrecht 1992.

18 Ecloga, prooimion (162).

19 Burgmann, Ehegüterrecht 1992, 41. In etwa zur selben Zeit wie die Ekloge entstand eine Zusammenstellung des mosaischen Rechts. In diesem Rechtsbuch sind auch die Inzestverbote aus Levitikus vertreten: Nomos mosaikos c. 30-41 (157-159). Gegen die bisher übliche Datierung in das 8. Jahrhundert vertritt allerdings Sснміncк, Bemerkungen 2005, eine Entstehung in der Zeit des Photios. Die Parallele zum Liber ex lege Moysi (siehe $225 \mathrm{f}$.) ist frappierend.

20 FöGEN, Codierung 2007, 16.

21 Ecloga 2, 9, 1 (180).

22 Für den Ikonoklasmus betonen diesen Faktor Ladner, Origin 1940, 140; Gero, Iconoclasm 1973, 55-58; HaLdon, Remarks 1977, 181. 
Cousinenehe waren dagegen durch den Koran legitimiert ${ }^{23}$. Die Regelung der Ehe durch Leon III. sollte demnach als ein Symbol für das kaiserliche Monopol angesehen werden, über das normative Selbstverständnis der Gesellschaft zu bestimmen.

Inwieweit sich der Kaiser in der Praxis für die Durchsetzung der neuen Eheverbote einsetzte, muss eine offene Frage bleiben ${ }^{24}$. Vor dem 11. Jahrhundert sind keine Quellen erhalten, die einen Einblick in die Rechtspraxis bei Eheprozessen gewähren. „Die Normanwendung lässt sich für den Zeitraum vom 7. bis zum 10. Jahrhundert kaum oder gar nicht dokumentieren“25. Die Gesetze der makedonischen Kaiser aus der Zeit um 900 bezeugen lediglich, dass weiterhin an den Normen Leons III. festgehalten wurde ${ }^{26}$, obwohl dieser Kaiser als Initiator des Ikonoklasmus keine positive Erinnerung hinterließ.

Sowohl im Westen als auch im Osten erfolgte demnach der erste Schub der Ausdehnung des Inzestverbots im Kontext des Funktionswandels des Rechts. Dieser Wandel muss als eine Folge der in Kapitel 1 beschriebenen Entdifferenzierung des Rechts betrachtet werden. Das pragmatische Rechtsverständnis der Antike, das in erster Linie auf die Bewältigung der Realität abzielte, wurde durch eine neue Konzeption des Rechts verdrängt. Nachdem das ausdifferenzierte Rechtssystem des römischen Reichs zugrunde gegangen war, sollte Gesetzgebung über die Normen der christlichen Lebensführung die Zustimmung zur politischen Herrschaft herbeiführen. Pragmatische Gesetzgebung wurde durch symbolische Gesetzgebung abgelöst. Die Funktion der Rechtsetzung erschöpfte sich jedoch nicht in dieser symbolischen Komponente. Recht sollte darüber hinaus die Realität in die Richtung einer christlichen Gesellschaft verändern. In Anlehnung an Ronald Dworkin könnte man von einem „aspirational concept of law ${ }^{\text {“27 }}$ sprechen, von einer in die Zukunft gerichteten Zielgesetzgebung. Die Effektivität der Normen wurde nämlich nicht vollkommen außer Acht gelassen, sondern der zukünftigen Seelsorge als Aufgabe anheim gestellt. Im Westen lag diese Aufgabe in der Hand der Bischöfe, im Osten beanspruchte Leon III. das oberste Hirtenamt für sich selbst ${ }^{28}$. Die Anpassung an die neuen normativen Erwartungen erzwang man hier wie dort, indem bei Zuwiderhandeln die Heimsuchung durch den Zorn Gottes in Aussicht gestellt

23 Polygamie und Ehescheidung wurden bereits von Johannes von Damaskus († ca. 750) als sarazenische Irrlehren diffamiert: Liber de haeresibus 100 (64 f.). Vgl. SAHAs, John 1972, 90 f. Die Inzestverbote finden sich in Sure 4, 23-24. Vgl. Sмітн, Kinship 1885, $162-$ 185; Conte, Choisir 1994; Mitterauer, Europa 2003, 98-103.

24 Skeptisch äußert sich Haldon, Byzantium 1990, 328. Die Regelung der Ehescheidung stieß noch im 11. Jahrhundert auf Widerstand: Hunger, Christliches 1967, 310.

25 Brandes, Krisenbewältigung 1998, 141. Vgl. auch Haldon, Byzantium 1990, 269.

26 Zhishman, Eherecht 1864, 238.

27 Dworkin, Justice 2006, 5.

28 Ecloga, prooimion (161). 
wurde. Die Pest im Frankenreich des 6. Jahrhunderts und der Einfall der Araber im 7. Jahrhundert wurden als göttliche Strafen für die Missachtung des Inzestverbots angesehen ${ }^{29}$.

Der zweite Schub der Ausdehnung wurde angestoßen, als die Christianisierung des Rechts ein neues Niveau erreicht hatte. Sowohl im Westen als auch im Osten galt seit der Jahrtausendwende die unumschränkte Kompetenz der Kirche in Fragen des Eherechts. Im Westen setzte diese Entwicklung bereits nach der Herrschaft Ludwigs des Frommen ein, der als letzter Herrscher ein Gesetz über den Umfang des Inzestverbots erlassen wollte. Er scheiterte auf dem Konzil von Aachen bei dem Versuch, einen Konsens im karolingischen Episkopat herzustellen. Seitdem ging die Regelung des Inzestverbots in die Kompetenz der Bischöfe über. Die Kirche verfügte im Frühmittelalter jedoch nicht über eine zentrale Institution, die eine letztinstanzliche Entscheidung über die Ausdehnung des Inzestverbots hätte treffen können. Das kanonische Recht dieser Zeit erfüllte nicht die Bedingungen, die man heute an ein Rechtssystem zu stellen gewohnt ist. Es gab keine allseits anerkannte Kodifikation des kanonischen Rechts, sondern nur private Sammlungen, deren Verbreitung teils durch offizielle Approbation des Papstes, teils durch die praktische Benutzbarkeit, teils durch den Zufall der Überlieferung bedingt war. Ebenso wenig gab es klare Regeln darüber, welche Normen zum Kirchenrecht zu zählen sind. In den Sammlungen wurden Bestimmungen der ökumenischen Konzilien und Dekretalen der Päpste konfrontiert mit Gesetzen römischer oder fränkischer Kaiser sowie mit Satzungen einzelner Bischöfe oder mit Meinungen angesehener Gelehrter. Diese fehlende Kohärenz des Rechtssystems war einzig begrenzt durch undeutlich artikulierte, aber dennoch fest verankerte Vorstellungen über die Hierarchie der Rechtsquellen. Das kanonische Recht an den Vorschriften der Heiligen Schrift zu messen und darin letztlich seinen Ursprung zu sehen, war allgemein anerkannt. Ebenso galten die vier ökumenischen Konzilien - allen voran dasjenige von Nicäa - als vorbildlich und als Maßstab für die Geltung neuer Kanones. Daneben maß man auch den frühen Papstbriefen eine erhöhte Autorität zu und stellte sie seit der Zeit um 500 gleichberechtigt den alten Konzilien zur Seite. Diese Hierarchie der Rechtsquellen galt eher implizit und wurde selten ausdrücklich thematisiert. Eine feste Regel für den Umgang mit divergentem Kirchenrecht wurde daraus nicht gewonnen.

Im Allgemeinen bereitete diese fehlende Kohärenz des Rechtssystems keine gravierenden Probleme. Auf den Konzilien betonten die Bischöfe stets, dass sie nur zusammengekommen seien, um das alte Kirchenrecht zu erneuern und neu aufgetretene Fälle einer Entscheidung zuzuführen. Die Bischöfe setzten die Stabilität des Kirchenrechts voraus und blendeten Rechtsänderungen still-

29 Siehe $161-165$ und 215. 
schweigend aus ${ }^{30}$. In den meisten Rechtsbereichen hat dieses Ideal der Stabilität des Rechts erstaunlich weit getragen, da die Normen der spätantiken Kirche kaum einer substantiellen Veränderung unterworfen waren. Selbst bei den heiß umkämpften Themen während des Investiturstreits wie Priesterehe und Simonie konnte man sich auf die Errungenschaften der alten Kirche berufen, ohne substantielle Änderungen im Recht befürworten zu müssen. Im Fall der Inzestgesetzgebung stieß dieses Ideal der Stabilität des Rechts jedoch an seine Grenze. Seit dem 4. Jahrhundert war der Umfang des Inzestverbots einem durchgreifenden Wandel ausgesetzt. Im frühen 6. und im frühen 11. Jahrhundert kam es in zwei Schüben zu einer substantiellen Ausdehnung des Inzestverbots, die mit den Normen der Bibel und der alten Kirche nicht zu begründen war. Innerhalb des gesamten Kirchenrechts fand in diesem Bereich mit Abstand der größte Wandel statt. Die Männer der Kirche waren daher mit der grundsätzlichen Frage konfrontiert, wie mit dieser Veränderbarkeit der Normen umgegangen werden sollte. Regino von Prüm versuchte durch ein subtiles Arrangement der Quellen seine eigene Meinung in den Vordergrund zu stellen, konnte jedoch in letzter Instanz nur zur eigenständigen Beurteilung durch den Benutzer seiner Sammlung aufrufen. Benedictus Levita, Pseudoisidor und Burchard von Worms gingen einen anderen Weg. Sie griffen in den authentischen Bestand an kanonischen Texten ein und veränderten die Tradition nach ihrem eigenen Gutdünken. Das Inzestverbot war sowohl bei Benedictus wie bei Burchard ein zentrales Objekt der Fälschung, weil die Veränderbarkeit der Normen unter den Tisch gekehrt werden musste. Noch im Decretum Gratiani besteht der Abschnitt zum Inzestverbot fast zur Hälfte aus Fälschungen ${ }^{31}$.

Diese Versuche der Vereinheitlichung der Tradition durch Fälschung waren zum Scheitern verurteilt. Immer wurden auch andere Sammlungen mit anderen Rechtsinhalten überliefert und zur Argumentation vor Gericht herangezogen. Die häufige Berufung auf die milde Bestimmung des Libellus responsionum führt dies deutlich vor Augen. Eine endgültige Fixierung der Inzestgesetzgebung konnte erst dann gelingen, als eine eindeutige Regel über die Zugehörigkeit von Normen zum System des Kirchenrechts formuliert wurde. Diese „rule of recognition" (H.L.A. Hart ${ }^{32}$ ) etablierte sich im 11. Jahrhundert im Verlauf der päpstlichen Kirchenreform. Sie lautet, dass allein der Papst als Stellvertreter des Apostelfürsten zur letztinstanzlichen Definition von strittigen Fragen des Kirchenrechts befugt ist. Papst Alexander II. nahm diese Kompetenz in Anspruch

30 BARION, Synodalrecht 1931, 173-185.

31 Fälschungen sind: Decretum Gratiani C. 35 q. 2 c. $1-4$, c. 7 , c. 10 , c. 12 , c. 16 und c. $20(1264-1270)$.

32 Mit diesem Begriff bezeichnet Hart, Concept 1961, 92, in Anlehnung an Kelsens "Grundnorm“ die gesellschaftlich anerkannte Regel, die über Geltung und Nicht-Geltung von Rechtsnormen entscheidet. 
und setzte in zwei Konstitutionen die Ausdehnung des Inzestverbots in der Blutsverwandtschaft fest.

Entscheidend für den zweiten Schub der Ausdehnung war, dass das römische Recht seine Verbindlichkeit für die Definition der Verwandtschaft allmählich verloren hatte. Vor allem im Ostfrankenreich bediente man sich der durch Gregor I. eingeführten kanonischen Zählung und überschritt daher bald die Verwandtschaftsgrenze des römischen Rechts. Bereits im frühen 9. Jahrhundert wurde mit dem vierten Grad kanonischer Zählweise ein Verhältnis ins Visier genommen, das außerhalb der römischen Verwandtschaftsgrenze lag. Der vierte Grad blieb fortan im Ostfrankenreich geltendes Kirchenrecht. Gegen den Konsens der bisherigen Forschung hat diese Untersuchung das Ergebnis erbracht, dass erst um das Jahr 1000 die Radikalisierung des Inzestverbots durch die Kombination der kanonischen Zählweise mit der Inzestgrenze des siebten Grades erfolgte. Verboten war dann die Ehe mit den Nachkommen der Urururururgroßeltern (7/7). Erst dann hat die westliche Kirche einen Sonderweg eingeschlagen und potentiell alle Ehen unter Inzestverdacht gestellt. Das Papsttum übernahm diese Auffassung, als es das Projekt der Schaffung eines eigenen Rechtssystems in Angriff nahm und daher der stabilisierenden Funktion des römischen Rechts nicht mehr bedurfte. Die römische Zählung der Verwandtschaft verwarf Alexander II. als „unerhörten Irrtum“.

In Byzanz stand die Definition der römischen Verwandtschaft nicht zur Diskussion. Der sechste bzw. siebte Grad römischer Komputation war unangefochten die Grenze des Inzestverbots in der Blutsverwandtschaft ${ }^{33}$. Diskussionen wurden dagegen durch die Ausdehnung des Ehehindernisses der Schwiegerverwandtschaft hervorgerufen. Nach Ludwig Burgmann wurde kein anderer Text so häufig kopiert und so heftig diskutiert wie der Tomos des Patriarchen Sisinnios II. ${ }^{34}$ Kurz vor der Jahrtausendwende ergriff Sisinnios darin Partei für die Ausdehnung auf den sechsten $\mathrm{Grad}^{35}$. Die Ehe von Onkel und Neffe mit Tante und Nichte oder von zwei Brüdern mit zwei Cousinen sollte untersagt werden. Zur Rechtfertigung bediente sich Sisinnios der traditionellen Argumente des Basilius von Cäsarea: Da Mann und Frau durch die Ehe ein Fleisch würden, sollte es keinen Unterschied zwischen Bluts- und Schwiegerverwandtschaft geben. Diese Erweiterung des Inzestverbots fand in einer Zeit statt, als es zur Ausbildung eines Dekretalenrechts des Patriarchen kam, der für sich die Kompetenz über Fragen des Eherechts in Anspruch nahm ${ }^{36}$. Der Tomos wurde nicht vom Kaiser sanktioniert, sondern auf der „permanenten Synode“

33 Zhishman, Eherecht 1864, 233-252.

34 Burgmann, Sisinnios 2003, 175. Grundlegend ist Sснminck, Kritik 1977.

35 Grumel - Darrouzès, Regestes 1989, 318 f. (Nr. 804). Vgl. Zhishman, Eherecht 1864, 290-347; Sсhмinck, Kritik 1977; Laiou, Mariage 1992.

36 BЕСK, Kirche 1980, 132. 
durch den Patriarchen erlassen und als „kanonisma“ den spätantiken Kanones zur Seite gestellt ${ }^{37}$. Seit dem frühen 10. Jahrhundert zog sich der Kaiser für 150 Jahre aus der Regelung des Eherechts zurück und überließ dieses Feld der Kirche. Diese konnte sich darauf berufen, dass die kirchliche Einsegnung der Ehe durch eine Novelle Leons VI. (ca. 894) konstitutiven Charakter erlangt hatte $^{38}$. Nach der Loslösung von der kaiserlichen Gesetzgebung, die in Byzanz jedoch noch lange umstritten blieb, konnten die Bischöfe Maßstäbe einfordern, ohne auf den Kaiser oder den Adel Rücksicht nehmen zu müssen. Unter diesen Umständen setzte die Kirche die ausgedehnten Inzestverbote durch und erlangte somit die Kontrolle über das Eheverhalten der Laien. Wie im Westen waren jedoch auch in Byzanz die Laien in der Lage, einen Nutzen aus der Geltung der neuen Inzestverbote zu ziehen ${ }^{39}$. Der Kaiser konnte eine Kontrolle über die Eheschließungen des Hochadels ausüben und enge Allianzen durch Eheschließung bedeutender Adelsfamilien verhindern. Die Laien unterwanderten das Verbot, indem sie es wie im Westen zur Rechtfertigung von Scheidungen benutzten.

Die Ausdehnung des Inzestverbots durch Sisinnios ordnet sich also wie im Westen in den Prozess der Monopolisierung des Eherechts durch die Kirche ein. Der Patriarch bezweckte damit, seine Entscheidungsbefugnis über strittige Fragen des Eherechts zu demonstrieren. Angeliki Laiou geht noch einen Schritt weiter und unterstellt der Kirche die Absicht, in der byzantinischen Aristokratie verbreitete Strategien der Besitzkonsolidierung zu konterkarieren ${ }^{40}$. Die von Sisinnios untersagten Eheschließungen von zwei Brüdern mit zwei Cousinen hätten dazu gedient, die Besitzungen zweier Familien zu vereinen und somit Reichtum zu konsolidieren. Laiou erschließt diesen Zusammenhang aus späteren Quellen, in denen der Gemeinschaftsbesitz von Brüdern und Cousins bezeugt sei. Sisinnios habe somit ein Gesetz beschlossen, das in erster Linie die adelsfeindliche Politik Kaiser Basileios II. habe unterstützen sollen ${ }^{41}$.

Der westlichen Inzestgesetzgebung möchte ich eine solche unmittelbar adelsfeindliche Intention nicht bescheinigen. Die Radikalisierung des Inzestverbots wurde nicht durch eine maliziöse Strategie der Kirche herbeigeführt, sondern sie ergab sich aus der Kombination des west- und ostfränkischen Kirchenrechts sowie aus den spezifischen Bedingungen des Thronwechsels von 1002. Kurzfristig konnte König Heinrich II. Vorteile daraus ziehen. Er stellte seine monarchische Herrschaft unter Beweis, inszenierte sich als Herr über die

37 Burgmann, Sisinnios 2003, 178.

38 Haldon, Byzantium 1990, 377; Beaucamp, Christianisation 2004, 954.

39 Laiou, Mariage 1992, 30-53. Für das 11. und 12. Jahrhundert sind 31 Fälle eines Rechtsstreits über eine Inzestehe bekannt.

40 Laiou, Mariage 1992, $170 \mathrm{f}$.

41 Kritik an diesem Paradigma der adelsfeindlichen Politik üben jedoch LiLIE, Byzanz 2003, 252-256, und Holmes, Basil II 2005, 461-475. 
Reichskirche und monopolisierte die für seine Legitimation so wichtige Herkunft von König Heinrich I. Langfristig war jedoch weder dem Königtum noch der Kirche damit gedient: Der Monarch gefährdete mit der radikalen Ausweitung der Exogamie die Grundlagen seines auf Adelsherrschaft beruhenden Königtums; die Kirche musste Verstöße gegen das biblische Prinzip der Unauflösbarkeit der Ehe in Kauf nehmen, da mit einem Mal alle Ehen unter Inzestverdacht standen. Die Kirche geriet zudem in bedenkliche Nähe zu häretischen Strömungen, die den sakramentalen Charakter der Ehe grundsätzlich in Frage stellten und die Institution der Ehe als Werk des Teufels diffamierten ${ }^{42}$. Die von Damiani empfundene Omnipräsenz des Inzests war in der Kirche nicht mehrheitsfähig, weil dann jede Ehe als sündhaft hätte aufgefasst werden müssen. Trotz dieser Dysfunktionalität des ausgedehnten Inzestverbots konnten sich Kirche und Laien auf ihre Weise damit arrangieren. Die Kirche betrachtete es als Mittel zum Erwerb von Schenkungen und zur Durchsetzung ihrer alleinigen Kompetenz im Eherecht, der Hochadel verschaffte sich die Zustimmung zur ansonsten diskreditierten Ehescheidung.

Diese nachträgliche Funktionalisierung des ausgedehnten Inzestverbots durch die Kirche war vorübergehend erfolgreich. Den Laien wurde mit der Eröffnung der Scheidungsmöglichkeit ein Anreiz gegeben, die kirchliche Kompetenz im Eherecht zu akzeptieren ${ }^{43}$. Wenn man vor dem geistlichen Gericht mit Erfolg die Scheidung einklagen konnte, empfahl sich dieser rechtlich korrekte Weg gegenüber der bislang praktizierten formlosen Verstoßung. Je mehr die Kirche in dieser Hinsicht Erfolg hatte und Scheidungen ermöglichte, desto mehr musste sich der Widerspruch zum biblischen Prinzip der Unauflösbarkeit der Ehe aufdrängen. Im späten 12. Jahrhundert nahmen die Theologen deshalb die ausgedehnten Inzestverbote nur mehr als Ärgernis wahr. Als Papst Innocenz III. selbst mehrfach und besonders eindringlich im Fall Philipps II. von Frankreich ${ }^{44}$ mit dieser Tatsache konfrontiert worden war, entschloss er sich zur Reduktion des Inzestverbots auf dem IV. Laterankonzil von 1215. Er stützte sich dabei auf die Vorarbeiten der kanonistischen Rechtswissenschaft, die im 12. Jahrhundert den Unterschied zwischen ewiggültigen und wandelbaren Vorschriften des Kirchenrechts herausgearbeitet hatte ${ }^{45}$. Konnte im Frühmittelalter das Inzestverbot die stabilisierende Wirkung auf die Gesellschaft nur entfalten, weil es als Teil der lex divina ausgegeben worden war, deren Missachtung die Heimsuchung durch den Zorn Gottes hervorrufen sollte, hielten die Juristen des 12. Jahrhunderts dies nur mehr für die biblischen Verbote aufrecht.

42 Borst, Katharer 1953, 180-182; Duby, Chevalier 1981, 117-132.

43 D’Avray, Marriage 2005, 99.

44 Siehe oben $1-3$.

45 WEIGAND, Naturrechtslehre 1967. 
Die restlichen Eheverbote waren der Dispensationsgewalt des Papstes unterworfen.

Das Inzestverbot hat demnach nach 1100 den Zenit seiner Ausdehnung überschritten und ist Opfer einer allmählichen Reduzierung geworden. Einige Theologen des Spätmittelalters stellten sogar die Eheverbote von Levitikus zur Diskussion, weil sie die Gültigkeit der Reinheitsvorschriften des Alten Testaments für die Zeit der Gnade leugneten ${ }^{46}$. Unbestritten blieb nur mehr das Eheverbot zwischen Aszendenten und Deszendenten sowie zwischen Geschwistern, das dem Naturrecht zugeordnet und damit der Dispensationsgewalt des Papstes entzogen wurde. Dem hohen Stellenwert von Exogamie im Frühmittelalter steht also eine Marginalisierung von Exogamie im Spätmittelalter entgegen $^{47}$.

\section{Inzestverbot und Sozialstruktur}

Wie der Vergleich der abendländischen mit der byzantinischen Gesetzgebung zeigt, widersteht das Inzestverbot einer durchgehenden funktionalen Einordnung. Die funktionalistischen Erklärungen der Sozialwissenschaften erweisen sich in der einen oder anderen Weise als unzulänglich. Dies lässt sich für die beiden vorherrschenden Modelle demonstrieren, die in der Einleitung kurz skizziert wurden ${ }^{48}$. Das Inzestverbot wie Malinowski auf die Funktion der Verhinderung innerfamiliärer Konflikte zurückzuführen, kann in dem Maß nicht überzeugen, in dem sich das Inzestverbot auf immer weiter entfernte Verwandtschaftskreise ausdehnte. Nur in römischer Zeit ruhte das Gebot der Exogamie in erster Linie auf dieser Grundlage. Wenn das Inzestverbot begründet wurde, bezogen sich die Autoren der Antike auf die Unvereinbarkeit zwischen dem formellen Begrüßungskuss innerhalb der Familie und der sexuellen Begierde eines Liebespaares ${ }^{49}$. Noch für Augustinus war es selbstverständlich, dass die sexuelle Leidenschaft (libido) im Gegensatz zur achtungsvollen Zuneigung steht, die man den Verwandten schuldet ${ }^{50}$. Die Gesetzgeber bedienten sich ebenfalls dieses Arguments. Constantius II. beharrte auf der

46 Joyce, Ehe 1934, 460-464.

47 Zur moralischen Einordnung im Verhältnis zur Sodomie vgl. JoRdan, Invention 1997, 95-98 u. 105. Zur Praxis vgl. Spгеß, Familie 1993, 61-73. Der Inzest zwischen nahen Verwandten blieb in der Literatur ein wichtiges Sujet. Vgl. Archibald, Incest 2001; Timeo, Edipo 2005; SABEAn, Inzestdiskurse 2002; Eming u.a. (Hg.), Inzestdiskurse 2003.

48 Siehe $13 \mathrm{f}$.

49 Siehe $39 \mathrm{f}$.

50 Sed etiam quia nescio quo modo inest humanae uerecundiae quiddam naturale atque laudabile, ut, cui debet causa propinquitatis reuerendum honorem, ab ea contineat, quamuis generatricem, tamen libidinem, de qua erubescere uidemus et ipsam pudicitiam coniugalem. Augustinus, De civitate dei XV 16 (CCL 48, 478). 
Differenz zwischen der Umarmung (amplexus) durch den Onkel und dem Beischlaf (amplexus) mit einer Ehefrau ${ }^{51}$. Justinian begründete mit diesem Argument die Ausweitung der Ehehindernisse auf die geistliche Verwandtschaft ${ }^{52}$. Die fränkischen Bischöfe sahen im Jahr 535 den Ehemann sogar als „Feind und Überwinder der Keuschheit“, der seiner Verwandten „Gewalt zufügt“, wenn er sie heiratet und ihr nicht mit der geschuldeten „Hochachtung und Zuneigung“ begegnet $^{53}$. Die Verknüpfung zwischen Inzestverbot und Verwandtenmord in der Lex Ribuaria sowie in den Gesetzen Karls des Großen zeigt an, dass dieses Argumentationsmuster weiterhin Bestand hatte ${ }^{54}$. Beide Verbrechen zeichnen sich dadurch aus, dass sie die Familiensolidarität untergraben. Erst seit dem 9. Jahrhundert ist es weitgehend aus den Quellen verschwunden.

In dieser Zeit gewann ein anderes Erklärungsmodell die Oberhand. Jonas von Orléans zitierte ausführlich aus Augustins De civitate dei, um die Vermehrung der Nächstenliebe (caritas) durch die Heirat außerhalb der Verwandtschaft unter Beweis zu stellen ${ }^{55}$. Im 11. Jahrhundert bediente sich Petrus Damiani derselben Worte des Kirchenvaters und konnte folglich der ansonsten von ihm geschmähten Institution der Ehe etwas Positives abgewinnen ${ }^{56}$. Gegen Ende des Jahrhunderts sicherte Ivo von Chartres dem Text Augustins einen Platz im Kirchenrecht ${ }^{57}$. Magister Gratian von Bologna machte daraus das erste Kapitel zum Inzestverbot in seiner Kirchenrechtssammlung, die Gesetzeskraft erlangen sollte. An einer kleinen Veränderung am Text wird der Rang deutlich, den das Erklärungsmodell Augustins inzwischen eingenommen hatte. Gratian bezeichnete die Verbindung zwischen Mann und Frau nicht mehr wie der Kirchenvater als „Keimzelle des Staates“ (seminarium civitatis), sondern als „Keimzelle der Nächstenliebe“ (seminarium caritatis) $)^{58}$. Die mittelalterlichen Autoren haben somit in emphatischer Weise die gleiche Argumentation umrissen, die Lévi-Strauss in nüchterner Prosa am Beispiel einfacher Gesellschaften entwickelte. Das Inzestverbot diente nach Lévi-Strauss der sozialen Integration der Familienverbände in Gesellschaften ohne staatliche Institutionen; es hatte nicht primär eine inner-, sondern eine intrafamiliäre Funktion. Doch auch

51 Siehe 49 Anm. 73.

52 LyNCH, Godparents 1986, 261.

53 Siehe 145 Anm. 143.

54 Siehe 189 und 280.

55 Siehe $304 \mathrm{f}$.

56 Siehe oben 456. Eustathios Rhomaios, Vorsitzender des Hofgerichts in Konstantinopel, bediente sich im 11. Jahrhundert eines ähnlichen Arguments: LaIou, Mariage 1992, 28 ; Burgmann, Sisinnios 2003, 173.

57 Ivo von Chartres, Decretum VIII 39 (Migne PL 161, 592); Panormia VII 52 (Migne PL 161, 1293). Dieser Auszug aus Augustinus befand sich bereits in der ersten Sammlung Ivos, in der bislang unedierten Collectio tripartita. Zu den Sammlungen vgl. Kéry, Collections 1999, 244-260.

58 Decretum Gratiani C. 35 q. 1. c. 1 (1262). 
dieses Erklärungsmodell stößt an seine Grenzen. Das ausgedehnte Inzestverbot des Hochmittelalters war offensichtlich unter diesem Gesichtspunkt dysfunktional, weil es prinzipiell unmöglich wurde, nicht des Inzests verdächtige Ehen zu schließen. Erst geraume Zeit nach der Etablierung des 7. Grades im kanonischen Recht versuchten Kleriker und Laien, dem Verbot auf unterschiedliche Weise eine Funktion zu verleihen. Diese Versuche waren nicht von Erfolg gekrönt und führten letztlich zur Aufhebung des Verbots im Jahr 1215.

Diese Überlegungen bestätigen die Kritik am Funktionalismus, wie er in den letzten Jahrzehnten in den Sozialwissenschaften geübt wurde ${ }^{59}$. Anthony Giddens macht funktionalistischen Erklärungen den Vorwurf, sie gingen von einem stabilen Systemzustand der Gesellschaft aus, der durch die Leistungen von bestimmten Institutionen und Strukturen notwendig im Gleichgewicht gehalten werden müsse ${ }^{60}$. Dagegen schätzt Giddens die Dynamik der Gesellschaft höher ein, da Strukturen erst durch die Handlungen der Individuen Gestalt gewinnen und durch sie verändert werden können. Der Funktionalismus unterstelle eine Notwendigkeit, die den einzelnen Akteur zu Unrecht zum Verschwinden bringe. Auch Pierre Bourdieu macht auf die Unvorhersehbarkeit bei der Regelanwendung durch Individuen aufmerksam ${ }^{61}$. Gegen den Legalismus von Lévi-Strauss wendet er ein, dass Inzestregeln nicht immer im Sinn der gesellschaftlichen Funktion ausgeführt, sondern von den Akteuren für ihre Zwecke instrumentalisiert werden. Funktionen werden oft erst nachträglich etabliert. Darüber hinaus stellt Bourdieu grundsätzlich die Einheit der Gesellschaft in Frage, die der Funktionalismus notwendig voraussetzt. Er schlägt dagegen vor, von verschiedenen Feldern innerhalb der Gesellschaft zu sprechen, die nicht zwingendermaßen miteinander koordiniert sind.

Muss man deshalb auf jede funktionalistische Erklärung in der Geschichte der Inzestgesetzgebung verzichten? Michael Mitterauer zog aus dem Scheitern von Goodys Versuch, die Inzestverbote als Instrument der Kirche zu erweisen, implizit diese Folgerung. Er beschränkte sich darauf, die Komplexität und Vielschichtigkeit der christlichen Inzestgesetzgebung in ihrer historischen Entwicklung hervorzuheben. Zur Erklärung der Ausdehnung des Inzestverbots bediente sich Mitterauer nicht der Strategie der Funktionalisierung, sondern der Strategie der Zurückführung auf einen Ursprung. Ihm zufolge steht am Anfang der Entwicklung die prinzipielle Abstammungsfeindlichkeit des Christentums. Die vorliegende Arbeit hat dagegen zu dem Ergebnis geführt, dass die obsessive

59 Einen Überblick geben JoAs - KNÖBL, Sozialtheorien 2004, 90-95 u. ö. Mit anderem theoretischen Hintergrund wendet sich Buc, Dangers 2001, gegen eine funktionalistische Deutung mittelalterlicher Rituale.

60 Giddens, Konstituierung 1998, 51-90.

61 Bourdieu, Stratégies 1972; Ders., Entwurf 1979, 203-227; DERs., Sinn 1987, $264-$ 351. 
Beschäftigung mit dem Inzestverbot nicht das Christentum als solches auszeichnet, sondern ein Charakteristikum der Zeit vom 4. bis ins 11. Jahrhundert war und sowohl die abendländische als auch die byzantinische Gesetzgebung dieser Zeit prägte. In irgendeiner Weise muss daher das Inzestverbot einem Bedürfnis der Gesellschaft nach der Ordnung von Ehe und Familie entsprochen haben. Ich halte es daher für legitim, nach der Funktion der Eheverbote zu fragen. Die Isolierung einer oder mehrerer Funktionen soll jedoch nicht dazu dienen, „den Verlauf der Geschichte oder auch nur bestimmte Ereignisse kausal zu erklären“, sondern die „möglicherweise kausal relevanten Ursachen“ einzuschränken ${ }^{62}$. Dabei muss man die Kritik am Funktionalismus ernst nehmen. Einerseits ist zu berücksichtigen, dass die Diskussion um die Ausdehnung des Inzestverbots sich vorwiegend in der Kommunikation zwischen Adel, Königtum und Kirche abspielte und andere Schichten der stratifizierten Gesellschaft erst sekundär erfasste. Die Einheit der Gesellschaft sollte nicht vorausgesetzt werden. Andererseits gab oft das Handeln einzelner Akteure wie Avitus von Vienne und Heinrich II. der Geschichte der Inzestgesetzgebung eine überraschende Wendung. Die anderen Akteure konnten auf solche „evolutionären Unwahrscheinlichkeiten" mit Ablehnung oder Zustimmung reagieren, oder der neuen Norm eine neue Deutung verpassen und sie auf diese Weise instrumentalisieren.

In der bisherigen Forschung wurde der erste Schub der Erweiterung des Inzestverbots stets als dysfunktional bewertet. Die Kirche habe vorwiegend Irritationen innerhalb der Gesellschaft hervorgerufen, weil sie mit Absicht die Zerstörung der germanischen Sippenverbände angestrebt habe. Diese Strategie habe dem Ziel gedient, die in der Sippe verankerte Ahnenverehrung der Germanen zu untergraben und die Verdrängung des Heidentums zu beschleunigen. Die Wertschätzung der Blutsverwandtschaft und des gentilen Bewusstseins sei durch das Christentum zugunsten der universalen Zugehörigkeit zum christlichen Glauben verdrängt worden. Wäre diese Sichtweise zutreffend, könnte man den Inzestverboten eine ähnliche Funktion zuweisen, wie sie Mary Douglas den Reinheitsgesetzen des Alten Testamens unterstellt hat. In ihrem wegweisenden Buch über „Purity and Danger" betrachtete sie die Reinheitsgesetze (und die daran anschließenden Inzestverbote) als Mittel, die stets gefährdete Identität Israels in einem dem Monotheismus feindlichen Umfeld zu bewahren ${ }^{63}$. Die Gesetze hätten der äußerlichen Sichtbarmachung des nicht sichtbaren Glaubensunterschieds gedient.

In der vorliegenden Arbeit habe ich für eine andere Bewertung der Inzestgesetzgebung plädiert. Gegen eine ethnische Deutung sprechen meines Erachtens mehrere Gründe. Zunächst ist auf die analoge Entwicklung der Ausdehnung der Ehehindernisse in Byzanz hinzuweisen. Das oströmische Reich war

62 Luhmann, Gesellschaft 1998, 570.

63 Douglas, Purity 1966. 
aber nicht von massiver Einwanderung betroffen. Darüber hinaus hat Kapitel 3 ergeben, dass der Widerstand ,der Germanen' gegen das Inzestverbot kaum ins Gewicht fiel. Die Akkulturation der germanischen Völker in der Spätantike führte zu einer Angleichung der Sozialstruktur. Seit den Reichsgründungen auf dem Boden des römischen Reichs sind feste Sippenverbände ebenso wenig feststellbar wie endogame Eheschließungen. Die burgundischen, fränkischen und westgotischen Könige machten sich in ihrer Gesetzgebung ohne Vorbehalte die verschiedenen Inzestverbote zu eigen. Im Frankenreich des 6. Jahrhunderts sind zwar Anpassungsschwierigkeiten zu verzeichnen, die sich in der hagiographischen Literatur der Zeit niederschlugen. Diese Schwierigkeiten bezogen sich jedoch nicht vorwiegend auf die fränkische Bevölkerung und betrafen weniger das Verbot der Bluts- als dasjenige der Schwieger- und Stiefverwandtschaft. Erst im 11. Jahrhundert, als das Inzestverbot prinzipiell nicht mehr befolgt werden konnte, kam es zu massivem Widerstand gegen das Eherecht der Kirche. Zuletzt ist auch auf das Ergebnis von Kapitel 4 hinzuweisen. Die obsessive Thematisierung des Inzestverbots auf gallischen Konzilien des 6. Jahrhunderts fand in einem fast ausschließlich romanischen Kontext statt. Gallo-römische Bischöfe schärften das Inzestverbot einer vorwiegend gallo-römischen Bevölkerung ein. Die Bischöfe signalisierten damit eine neue Hierarchie innerhalb der Gesellschaft, in der sie neben den Königen für die Durchsetzung öffentlicher Ordnung verantwortlich waren. Die Thematisierung des Inzestverbots ist nicht vor dem Hintergrund einer ethnischen Trennlinie zu interpretieren, sondern im Kontext der Kommunikation zwischen Adeligen, Königen und Bischöfen über eine neue gesellschaftliche Ordnung.

Das Inzestverbot sollte also - wie das Recht der Kirche insgesamt - im frühen Mittelalter nicht in erster Linie als Irritation der Gesellschaft betrachtet werden. In einer Zeit der Entdifferenzierung des Rechts war es vielmehr gerade das Christentum, das in vielerlei Hinsicht die Stabilität des Rechts auf neue Weise gewährleisten konnte. Die Kirche war der Zufluchtsort des römischen Rechts und entwickelte neue Mechanismen der Stabilisierung des Rechts (Exkommunikation, Tarifbuße, Sendgericht, Gottesfrieden) ${ }^{64}$. Auch wenn in der Spätantike die christliche Dogmatik zum Teil irritierend auf das Funktionieren des Rechtssystems gewirkt hatte ${ }^{65}$, diente nach der Verchristlichung des Herrscheramts gerade die Einforderung christlicher Grundsätze der Stabilisierung politischer Macht. Das Königtum verfügte über das symbolische Kapital christlicher Werte, um eine neue Differenz zwischen sich und dem Adel einzuführen und um die Macht des Amtes ohne institutionelle oder finanzielle Grundlage zu stärken. Besonders wichtig wurde dieses Instrument nach einem Dynastiewechsel, wie die Inzestgesetzgebung besonders eindrücklich zeigt. Ein

64 Siehe oben $29 \mathrm{f}$.

65 Siehe 29. 
Höhepunkt der königlichen Inzestgesetzgebung ist zu verzeichnen, als Pippin I. nach der Absetzung der Merowinger ein Bündnis mit Kirche und Papsttum zur Legitimierung seiner eigenen Dynastie eingegangen war und die Legitimationsformel „König von Gottes Gnaden“ annahm. 250 Jahre später setzte Kaiser Heinrich II. die Radikalisierung der Inzestgesetzgebung ins Werk - auch er reklamierte ein besonderes Gottesgnadentum für sich und war nicht durch Abstammung, sondern durch eine umstrittene Erhebung ins Amt gekommen. Heinrich provozierte heftig ausgefochtene Konflikte mit mächtigen Adelsfamilien, die er in Kauf nahm, um seine eigene Position als christlicher Herrscher zu festigen. Ein Dynastiewechsel ging auch in Byzanz der Ausweitung des Inzestverbots auf die gesamte römische Verwandtschaft voraus. Leon III. verschärfte das Eherecht, nachdem er als Emporkömmling seine Familie als neue Königsdynastie etabliert hatte.

Eine stabilisierende Wirkung konnte das Inzestverbot auch auf andere Weise entfalten. Claude Lévi-Strauss legte seinen ethnologischen Untersuchungen die Annahme zugrunde, Inzestverbote müssten immer auch als Tauschgebote interpretiert werden. In einfachen Gesellschaften regeln Inzestverbote den Austausch von Frauen und führen auf diese Weise zur sozialen Integration zwischen den Familienverbänden. Im frühen Mittelalter gab es keine Ehegebote wie in den von Lévi-Strauss untersuchten Gesellschaften, sondern nur Eheverbote. In seiner Terminologie handelt es sich daher um eine komplexe Struktur der Verwandtschaft. Trotz dieses Unterschieds übte das Inzestverbot auch im Frühmittelalter eine integrative Funktion aus. Nach dem Niedergang des antiken Staates standen Ehe und Familie erneut im Brennpunkt der gesellschaftlichen Organisation. Die soziale Integration durch Herrschaft nahm ab, die soziale Integration durch Genossenschaft gewann an Bedeutung. Diese Integration durch Freundschaft, Verwandtschaft und Klientelismus fand auf lokaler Ebene statt und führte zu einer Regionalisierung der Eliten. Inzestverbote wirkten dieser Regionalisierung entgegen, indem sie Regeln für die Eheschließung zur Verfügung stellten und die Etablierung eines überregionalen Heiratsmarktes erzwangen. Die soziale Interaktion war durch diese Ordnung der Ehe berechenbar. Darüber hinaus bot die Einhaltung des Inzestverbots die Chance zum Aufstieg in der Gesellschaft, da es für die politisch bestimmende Schicht unmöglich war, nur im eigenen Stand nach Ehepartnern zu suchen. Exogamie und Isogamie standen immer in einem Spannungsverhältnis zueinander. Inzestverbote waren Regeln des Zusammenlebens und dienten der Reduktion von Kontingenz, um auf der Ebene der Politik frühmittelalterlicher Reiche höhere Komplexität zu ermöglichen. Sie sollten nicht den Zusammenhalt der Verwandtschaft zerstören, sondern den Zusammenhalt der Reichsaristokratie garantieren. Es ist daher kein Zufall, dass sowohl im Westen wie auch im Osten das Ende des römischen Staates der Ausdehnung des Inzestverbots vorausging. Die gallischen Bischöfe im 6. sowie Pippin I. und Leon III. im 8. Jahrhundert 
setzten dieses Mittel ein, um nach einer einschneidenden Krise der öffentlichen Ordnung die überregionale Kommunikation zu intensivieren.

Vor diesem Hintergrund erklärt sich auch, warum die Verwandtenehe zum paradigmatischen Verbrechen des frühen Mittelalters werden konnte. Sie war für die symbolische und in die Zukunft gerichtete Form der Gesetzgebung, wie sie oben skizziert wurde, aus vier Gründen besonders geeignet: Erstens setzt sie die biblischen Eheverbote fort und konnte als Erfüllung eines göttlichen Auftrags an Kaiser, Könige und Bischöfe verstanden werden - sie ist sakral legitimiert. Zweitens weist sie als Regulativ der ursprünglichen menschlichen Reproduktion ihrer Natur nach in die Zukunft, die durch symbolische Gesetzgebung einer Veränderung unterworfen werden sollte - sie ist zukunftsorientiert. Drittens betrifft sie mit der Verwandtschaft ein soziales Feld, in dem sich nach dem Kollaps des römischen Reichs regionale Partikularinteressen am stärksten organisierten und in dem die Durchsetzung öffentlicher Ordnung zum Zeitpunkt ihrer zunehmenden Erosion besonders dringlich erschien - sie ist paradigmatisch. Viertens dient sie als Gesetz nicht nur der Kommunikation von Ordnung, sondern durch die Etablierung eines überregionalen Heiratsmarktes in besonderem Maße auch der Herstellung von Ordnung - sie ist reflexiv.

Zuletzt muss noch die Frage angesprochen werden, ob das Inzestverbot diejenigen Wirkungen auf den Verlauf der europäischen Geschichte ausübte, die ihm von Jack Goody zugeschrieben wurden. Goody sah in der Ausdehnung der Ehehindernisse einen wesentlichen Grund für die Herausbildung der europäischen Familienstruktur. Die Inzestverbote hätten die Bildung von traditionalistischen Clanstrukturen verhindert und dazu geführt, dass die Kernfamilie zum dominanten Modell der sozialen Organisation geworden $\operatorname{sei}^{66}$. Die althistorische Forschung hat dieser These entgegengehalten, dass die Familienstruktur durch die Ausdehnung der Inzestverbote nicht entscheidend beeinflusst wurde. Bereits vor dem Einsetzen der Inzestgesetzgebung war die Kernfamilie in der spätantiken Gesellschaft vorherrschend ${ }^{67}$. Die Ehe mit der Cousine, sofern sie außerhalb der hohen Aristokratie praktiziert wurde, war nicht Ausdruck einer tribalen Kultur, sondern eine akzeptierte, aber nicht bevorzugte und deshalb vermutlich auch eher seltene Eheform. Michael Mitterauer hat dieses Bild weiter korrigiert, indem er die Inzestverbote weniger als eine Ursache als ein Symptom für die Herausbildung der europäischen Familienstruktur behandelte. Als Ursache scheidet, so argumentiert Mitterauer einleuchtend, die Ausdehnung der Inzestverbote deshalb aus, weil sie in Osteuropa mit patrilinearen Clanstrukturen durchaus vereinbar waren ${ }^{68}$. Er gewichtet daher andere Faktoren wie die

66 Siehe 5-7.

67 Vgl. Haldon, Byzantium 1990, 380; Nathan, Family 2000, 160-168; Wickham, Framing 2005, 551; Kuefler, Revolution 2007, 351.

68 Mitterauer, Europa 2003, 70-108, mit Verweis auf Levin, Sex 1989, 136-159. 
herrschaftliche Durchdringung der Familie in der Grundherrschaft sowie die ökologischen Voraussetzungen stärker. Anhand der Ausdehnung der Ehehindernisse lässt sich nach Mitterauer lediglich ablesen, dass alle Arten der Verwandtschaft aneinander angeglichen wurden und dass die Abstammungsgemeinschaft als soziale Organisationsform immer mehr in den Hintergrund gerückt sei.

Die vorliegende Untersuchung führt noch weiter weg von Goodys ursprünglicher Annahme. Gegenstand der Inzestgesetzgebung ist nicht die gesamtgesellschaftliche Familienstruktur, nicht die Frage der Organisation in Kernfamilien oder in traditionalistischen Clanstrukturen. Die Gefahr der Tribalisierung bestand nur in Randgesellschaften des römischen Reichs, die bereits in der Antike nur unzureichend oder gar nicht an die überregionalen Strukturen des römischen Staates angebunden waren ${ }^{69}$. Das bekannteste Beispiel ist Irland, wo sich die Cousinenehe noch im 8. Jahrhundert einer großen Wertschätzung erfreute. Die Inzestgesetzgebung ist dort das gesamte frühe Mittelalter nur am Rande thematisiert und nie einer grundlegenden Ausweitung unterzogen wor$\operatorname{den}^{70}$. Britannien wurde im 5. Jahrhundert nach dem Rückzug römischer Institutionen ebenso von einem Prozess der Tribalisierung erfasst. Dieser Prozess sowie die Weiterentwicklung zu einer aristokratischen Gesellschaft im 8. Jahrhundert vollzogen sich, ohne dass die ausgedehnten Inzestverbote der gallischen und westgotischen Kirche Anklang gefunden haben. Erst an der Jahrtausendwende, nach der Ausbildung eines angelsächsischen Großreichs, ist in den Werken Erzbischof Wulfstans von York ein Interesse an den ausgedehnten Eheverboten zu erkennen ${ }^{71}$.

Daraus ergibt sich folgende These: Gesetze zur Ausdehnung von Exogamie wurden nicht in Gesellschaften erlassen, die von Tribalisierung erfasst wurden; sie standen vielmehr dort im Mittelpunkt der Gesetzgebung, wo Großreiche nach dem Zerfall antiker Staatlichkeit an der Intensivierung überregionaler Kommunikation innerhalb des Adels interessiert waren und auf den Fundus römischer Rechtstradition zurückgreifen konnten. Dies trifft für Gallien im 6., Spanien im 7., für das Frankenreich Pippins I. und das Kaiserreich Leons III. im 8. Jahrhundert zu. Karl der Große formulierte das Programm der Schaffung einer Reichsaristokratie so explizit wie kein anderer Herrscher vor ihm. Die Ausweitung der Ehehindernisse sollte verhindern, dass sich lokale Eliten von der Zentrale abkoppelten und eigene Herrschaftsstrukturen aufbauten. Als Beispiel

69 Vgl. zum Folgenden Wiскнам, Framing 2005, 303-379.

70 Siehe 225-233. Für Wales vgl. Pryce, Law 1993, 83-86.

71 Wulfstan, Collectio canonum B 137-148 (153-158); ders., Predigt 50 (271) u. 59 (308); Gesetze der Angelsachsen, Aethelred VI 12 (1, 250). Die Gesetze Aethelreds sind von Wulfstan inspiriert: vgl. WormaLd, Making 1 1999, 330-345. 
für diese Entwicklung eignet sich Katalonien im 9. Jahrhundert ${ }^{72}$. Die katalanischen Grafen hielten seit der Mitte des 9. Jahrhunderts nur mehr sporadischen Kontakt zur Zentrale des westfränkischen Reichs aufrecht und beteiligten sich nicht mehr am überregionalen Heiratsmarkt der fränkischen Reichsaristokratie. Ihre Frauen nahmen sie aus der regionalen Aristokratie sowie aus der eigenen Verwandtschaft. Aus verschiedenen Gründen war das westfränkische Königtum und die lokale Kirche nicht dazu in der Lage, dieser endogamen Heiratspraxis Einhalt zu gebieten. Ich möchte daher die Inzestverbote nicht als Weichenstellung für die Entstehung der modernen Familienstruktur, sondern als Zeichen dafür werten, dass Staat und Kirche im Frühmittelalter den Versuch unternahmen, nach dem Zerfall römischer Staatlichkeit die Regionalisierung der Eliten zu unterbinden. Der hohe Stellenwert der Inzestgesetzgebung in der abendländischen und byzantinischen Gesellschaft des frühen Mittelalters entsprang dem Bedürfnis nach der Herstellung einer öffentlichen Ordnung in einem Zeitalter ihrer zunehmenden Erosion. Dieses Bedürfnis war deswegen besonders stark, weil Ehe und Familie unter den Bedingungen der Entdifferenzierung des Rechtswesens in höherem Maße als Grundlagen der sozialen Integration angesehen wurden und infolgedessen einer höheren Aufmerksamkeit und Regulierung in moralischer, theologischer und auch juristischer Hinsicht für nötig befunden wurden.

72 Siehe $380 \mathrm{f}$. 


\section{Quellen- und Literaturverzeichnis}

\section{Abkürzungen}

AHC

AKG

BIELER

$\mathrm{BM}^{2}$

BOUQueT

CCA

CCL

CCM

$\mathrm{CCO}$

COD

CSEL

DA

DDC

DHGE

EME

EOMIA

FmSt

Hispana

HJb

HRG

$\mathrm{HZ}$

JE

JK

JL

LexMA

MANSI

MGH

Migne PL

NA

PLRE

RAC
Annuarium historiae conciliorum

Archiv für Kulturgeschichte

Bieler (Hg.), The Irish Penitentials

Böhmer - Mühlbacher, Die Regesten des Kaiserreichs

Bouquet (Hg.), Recueil des Historiens des Gaules et de la France

Corpus Christianorum, Series Apocryphorum

Corpus Christianorum, Series Latina

Corpus Christianorum, Continuatio Mediaevalis

Joannou (Hg.), Les Canons des conciles œcuméniques

Conciliorum oecumenicorum decreta

Corpus scriptorum ecclesiasticorum latinorum

Deutsches Archiv

Dictionnaire de droit canonique

Dictionnaire d'histoire et de géographie écclesiastiques

Early Medieval Europe

Turner (Hg.), Ecclesiae occidentalis monumenta iuris antiquissima

Frühmittelalterliche Studien

Martínez Díez - Rodríguez (Hg.), La colección canónica

Hispana

Historisches Jahrbuch

Handwörterbuch zur deutschen Rechtsgeschichte

Historische Zeitschrift

Jaffé - Ewald, Regesta Pontificum Romanorum

Jaffé - Kaltenbrunner, Regesta Pontificum Romanorum

Jaffé - Löwenfeld, Regesta Pontificum Romanorum

Lexikon des Mittelalters

Mansi (Hg.), Sacrorum Conciliorum nova et amplissima collectio

Monumenta Germaniae Historica

Migne (Hg.), Patrologiae latinae cursus completus

Neues Archiv

Jones - Martindale - Morris, Prosopography of the Later

Roman Empire

Reallexikon für Antike und Christentum 


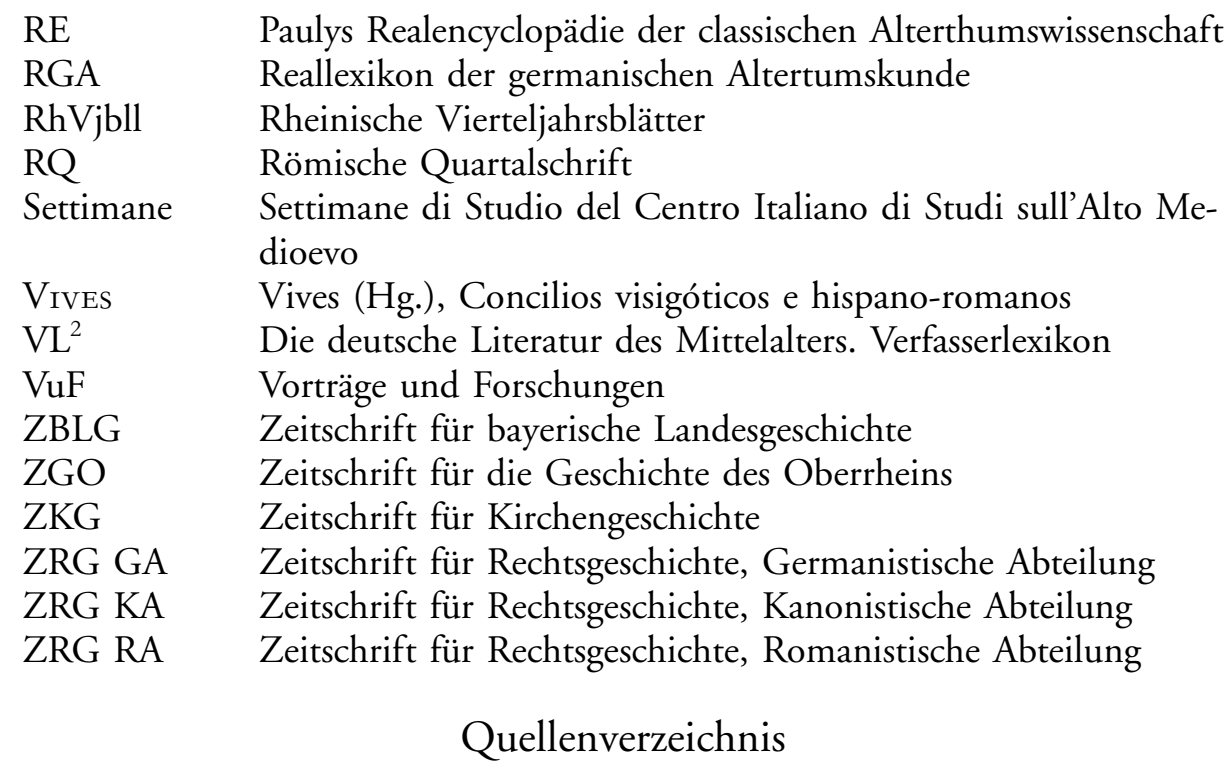

Acta Andreae, hg. von Jean-Marc Prieur (CCA 5-6, Turnhout 1989)

Acta pontificum Romanorum inedita, hg. von Julius von Pflugk-Harttung (Tübingen 1881-1886) 3 Bde.

Adalbero von Laon, Rhythmus satiricus, hg. von Claude Hohl, Le comte Landri de Nevers dans l'histoire et dans la geste de Gérart de Roussillon, in: La Chanson de geste et le mythe carolingien. Mélanges René Louis (Saint-Père-sous-Velay 1982) 2, 779-866, hier 791-796

Adalbold von Utrecht, Vita Heinrici II. imperatoris, hg. von Hans van Rij, in: Nederlandse Historische Bronnen 3 (Amsterdam 1983) 44-95

Agathias, Historiae, hg. von Rudolf Keydell (Corpus fontium historiae Byzantinae 2, Berlin 1967)

Alexander II., Epistolae (Migne PL 146, 1297-1436)

Altfrid, Vita Liudgeri, hg. von Wilhelm Diekamp, in: Geschichtsquellen des Bistums Münster 4 (Münster 1881) 3-53

Ambrosius, Epistulae, hg. von Otto Faller - Michaela Zelzer (CSEL 82, Wien 1968 1996) 4 Bde.

Anastasius bibliothecarius, Epistolae et praefationes, hg. von Ernst Perels - Gerhard Laehr (MGH Epp. 7, Berlin 1928) 395-442

Annales Bertiniani, hg. von Félix Grat - Jeanne Vieillard - Suzanne Clémencet - Léon

Levillain (Publications de la Société de l'Histoire de France 470, Paris 1964)

Annales Fuldenses, hg. von Friedrich Kurze (MGH SS rer. Germ. 7, Hannover 1891)

Annales Hildesheimenses, hg. von Georg Waitz (MGH SS rer. Germ. 8, Hannover 1878)

Annales Laureshamenses, hg. von Georg Heinrich Pertz (MGH SS 1, Hannover 1826) $22-39$

Annales Magdeburgenses, hg. von Georg Heinrich Pertz (MGH SS 16, Hannover 1859) $105-196$

Annales Nazariani, hg. von Georg Heinrich Pertz (MGH SS 1, Hannover 1826) 23-44 
Annales Quedlinburgenses, hg. von Martina Giese (MGH SS rer. Germ. 72, Hannover 2004)

Ansegis von Fontenelle, Collectio capitularium, hg. von Gerhard Schmitz (MGH Capit. N.S. 1, Hannover 1996)

Anselm von Saint-Remi, Historia dedicationis ecclesiae beati Remigii Remensis, hg. von Jacques Hourlier, Anselm de Saint-Remy: Histoire de la dédicace de Saint-Remi, in: Contribution à l'année Saint Benoît (480-1980). La Champagne bénédictine (Travaux de l'Académie Nationale de Reims 160, Reims 1981) 179-297

Arbeo von Freising, Vita Corbiniani, hg. von Bruno Krusch (MGH SS rer. Germ. 13, Hannover 1920)

Asser, De rebus gestis Aelfredi, ed. William Henry Stevenson (Oxford 1959)

Auctarium Havniense, hg. von Theodor Mommsen (MGH Auct. Ant. 9, Berlin 1892) $298-339$

Augustinus, De civitate dei, hg. von Bernhard Dombart - Alphons Kalb (CCL 47-48, Turnhout 1955)

Augustinus, Quaestiones in Heptateuchum, hg. von Joseph Zycha (CSEL 28/2, Wien 1895)

Avitus von Vienne, Opera, hg. von Rudolf Peiper (MGH Auct. Ant. 6/2, Berlin 1883)

Basilius von Caesarea, Lettres, hg. von Yves Courtonne (Paris 1957-1966) 3 Bde.

$B e d a$, Historia ecclesiastica gentis Anglorum, ed. Bertram Colgrave - R.A.B. Mynors (Oxford 1969)

Benedictus Levita, Collectio capitularium, hg. von Georg Heinrich Pertz (MGH LL 2/2, Hannover 1837)

Bern von Reichenau, Briefe, hg. von Franz-Josef Schmale (Veröffentlichungen der Kommission für geschichtliche Landeskunde in Baden-Württemberg Reihe A, 6, Stuttgart 1961)

S. Bonifatii et Lulli epistolae, hg. von Michael Tangl (MGH Epp. sel. 1, Berlin 1916) Burchard von Worms, Decretum (Migne PL 140, 537-1058)

Caesarius von Arles, Opera, hg. von Germain Morin (CCL 103-104, Turnhout 1953)

Canones Basilienses, hg. von Franz Bernd Asbach, Das Poenitentiale Remense und der sogen. Excarpsus Cummeani: Überlieferung, Quellen und Entwicklung zweier kontinentaler Bußbücher aus der 1. Hälfte des 8. Jahrhunderts (Diss. Regensburg 1975) Anhang 78-89

Canones Gregorii, hg. von Paul Willem Finsterwalder, Die Canones Theodori Cantuarensis und ihre Überlieferungsformen (Untersuchungen zu den Bußbüchern des 7., 8. und 9. Jahrhunderts 1, Weimar 1929) 253-270

Canones synodi Romanorum ad Gallos episcopos, hg. von Yves-Marie Duval, La décrétale Ad Gallos Episcopos: son texte et son auteur (Supplements to Vigiliae Christianae 73, Leiden - Boston 2005)

Les Canons des conciles æecuméniques, hg. von Périclès-Pierre Joannou (Discipline générale antique, $\mathrm{II}^{\mathrm{e}}-\mathrm{IX}^{\mathrm{e}}$ s. 1/1, Rom 1962)

Capitula episcoporum 1, hg. von Peter Brommer (MGH Capit. episc. 1, Hannover 1984)

Capitula episcoporum 2, hg. von Martina Stratmann - Rudolf Pokorny (MGH Capit. episc. 2, Hannover 1995)

Capitula episcoporum 3, hg. von Rudolf Pokorny (MGH Capit. episc. 3, Hannover 1995)

Capitularia regum Francorum, hg. von Alfred Boretius - Viktor Krause (MGH Capit. 1-2, Hannover 1883-1897)

Cassian, Collationes XXIIII, hg. von Michael Petschenig - Gottfried Kreuz (CSEL 13, Wien ${ }^{2} 2004$ ) 
Cassiodor, Variae, ed. Åke Josefsson Fridh (CCL 96, Turnhout 1973)

Cassiodor/Epiphanius, Historia ecclesiastica tripartita, hg. von Walter Jacob - Rudolph Hanslik (CSEL 71, Wien 1952)

Chronica Caesaraugustana, hg. von Theodor Mommsen (MGH Auct. Ant. 11, Berlin 1894) $163-220$

Chronica monasterii Casinensis, hg. von Hartmut Hoffmann (MGH SS 34, Hannover 1980)

Chronicae quae dicuntur Fredegarii, hg. von Bruno Krusch (MGH SS rer. Merov. 2, Hannover 1888) 1-193

Cicero, Pro A. Cluentio Habito oratio, hg. von Silvia Rizzo (Rom 1991)

Codex Carolinus, hg. von Wilhelm Gundlach (MGH Epp. 3, Berlin 1892) 469-657

Codex Theodosianus, hg. von Theodor Mommsen - Paul Meyer (Berlin 1905) 2 Bde.

Collatio legum Mosaicarum et Romanarum, hg. von Theodor Mommsen (Collectio librorum iuris anteiustiniani 3, Berlin 1890) 107-198

La colección canónica Hispana, hg. von Gonzalo Martínez Díez - Félix Rodríguez (Barcelona 1966-2002) 6 Bde.

Collectio Dacheriana, hg. von Louis-François-Joseph De la Barre, Spicilegium sive collectio veterum aliquot scriptorum qui in Galliae Bibliothecis delituerant (Paris 1723) 1, 509-564

Collectio Herovalliana (Migne PL 99, 989-1086)

Collectio Hibernensis, hg. von Friedrich Wilhelm Wasserschleben (Leipzig 1885)

Collectio Sangermanensis, hg. von Michael Stadelmaier, Die Collectio Sangermanensis XXI titulorum. Eine systematische Kanonessammlung der frühen Karolingerzeit. Studien und Edition (Freiburger Beiträge zur mittelalterlichen Geschichte 16, Frankfurt u. a. 2004)

Collectio vetus Gallica, hg. von Hubert Mordek, Kirchenrecht und Reform im Frankenreich: Die Collectio Vetus Gallica, die älteste systematische Kanonessammlung des fränkischen Gallien. Studien und Edition (Beiträge zur Geschichte und Quellenkunde des Mittelalters 1, Berlin/New York 1975)

Concilia aevi Karolini, hg. von Albert Werminghoff (MGH Conc. 2, Hannover Leipzig 1906-1908)

Concilia aevi Merovingici, hg. von Friedrich Maassen (MGH Conc. 1, Hannover 1893)

Conciliorum oecumenicorum decreta, hg. von Giuseppe Alberigo u.a. (Bologna ${ }^{3} 1973$ )

Concilios visigóticos e hispano-romanos, hg. von José Vives (España cristiana 1, Barcelona - Madrid 1963)

Constantin von St. Symphorian, Vita Adalberonis II. episcopi Mettensis, hg. von Georg Heinrich Pertz (MGH SS 4, Hannover 1841) 659-672

Constitutiones et acta publica imperatorum et regum, 911-1197, hg. von Ludwig Weiland (MGH Const. 1, Hannover 1893)

Constitutiones Sirmondianae, in: Codex Theodosianus, hg. von Theodor MommsenPaul Meyer (Berlin 1905) 2, 907-921

Corpus iuris civilis, 1: Institutiones, Digesta, hg. von Paul Krüger - Theodor Mommsen (Berlin 1908)

Corpus iuris civilis, 2: Codex Iustinianus, hg. von Paul Krüger (Berlin 1915)

Corpus iuris civilis, 3: Novellae, hg. von Rudolf Schoell - Wilhelm Kroll (Berlin 1895)

Cresconius, Concordia canonum, hg. von Klaus Zechiel-Eckes (Freiburger Beiträge zur mittelalterlichen Geschichte 5, Frankfurt 1992) 2 Bde.

Cyprianus Gallus, Heptateuchos, ed. Rudolf Peiper (CSEL 23, Wien 1891)

Damaskusschrift, hg. von Eduard Lohse, Die Texte aus Qumran (München ${ }^{3} 1981$ ) 63107 
De ordinando pontifice, hg. von Erwin Frauenknecht (MGH Studien und Texte 5, Hannover 1992)

Declamationes minores, hg. von David R. Shackleton Bailey (Stuttgart 1989)

Decretales Pseudo-Isidorianae et Capitula Angilramni, hg. von Paul Hinschius (Leipzig 1863)

Decretum Gratiani, hg. von Emil Friedberg (Corpus iuris canonici 1, Leipzig 18791881)

Discipulus Umbrensium, Canones Theodori, hg. von Paul Willem Finsterwalder, Die Canones Theodori Cantuarensis und ihre Überlieferungsformen (Untersuchungen zu den Bußbüchern des 7., 8. und 9. Jahrhunderts 1, Weimar 1929) 285-334

Donatus, Commentum Terenti, hg. von Paul Wessner (Leipzig 1902-1908) 3 Bde.

Ecclesiae occidentalis monumenta iuris antiquissima, canonum et conciliorum Graecorum interpretationes Latinae, hg. von Cuthbert Hamilton Turner (Oxford 1899-1939) 2 Bde.

Ecloga, hg. von Ludwig Burgmann (Forschungen zur byzantinischen Rechtsgeschichte 10, Frankfurt 1983)

Edictum Theodorici, hg. von Friedrich Bluhme (MGH LL 5, Hannover 1875-1889) $149-168$

Edictus Rothari, hg. von Friedrich Bluhme (MGH LL 4, Hannover 1868) 3-90

Eike von Repgow, Sachsenspiegel, hg. von Karl August Eckhardt (MGH Fontes iuris N.S. 1, Göttingen 1955-1956)

Einhard, Vita Karoli, hg. von Georg Waitz - Oswald Holder-Egger (MGH SS rer. Germ. 25, Hannover - Leipzig 1911)

Ennodius, Opera, hg. von Friedrich Vogel (MGH Auct. Ant. 7, Berlin 1885)

Epistolae Arelatenses genuinae, hg. von Wilhelm Gundlach (MGH Epp. 3, Berlin 1892) $1-83$

Epistolae Austrasicae, hg. von Wilhelm Gundlach (MGH Epp. 3, Berlin 1892) 110-153

Epistolae Moguntinae, hg. von Philipp Jaffé, Monumenta Moguntina (Bibliotheca rerum Germanicarum 3, Berlin 1866) 316-421

Epitome de Caesaribus, hg. von Franz Pichlmayr (Leipzig 1911)

Ermoldus Nigellus, Carmen in honorem Hludowici, hg. von Edmond Faral, Poème sur Louis le Pieux et épitres au roi Pépin (Les Classiques de l'histoire de France au moyen âge 14, Paris 1964)

Excarpsus Cummeani, hg. von Hermann Josef Schmitz, Die Bußbücher und die Bußdisciplin der Kirche, 2: Die Bußbücher und das kanonische Bußverfahren (Düsseldorf 1898) 597-644

Sextus Pompeius Festus, De verborum significatione, hg. von Wallace M. Lindsay (Leipzig 1913)

Firmicus Maternus, Mathesis, hg. von Wilhelm Kroll - Franz Skutsch (Leipzig 18971913)

Flodoard von Reims, Annales, hg. von Philippe Lauer (Paris 1905)

Flodoard von Reims, Historia Remensis ecclesiae, hg. von Martina Stratmann (MGH SS 36, Hannover 1998)

Formulae Merovingici et Karolini Aevi, hg. von Karl Zeumer (MGH Formulae 1, Hannover 1886)

Fragmenta Vaticana iuris anteiustiniani, hg. von Theodor Mommsen (Collectio librorum iuris anteiustiniani 3, Berlin 1890) 1-106

Gai institutiones, hg. von Bernhard Kübler - Emil Seckel (Stuttgart 1935)

Gelasius I., Epistulae et decreta (Migne PL 59, 13-190) 
Gerbert von Aurillac, Epistolae, hg. von Fritz Weigle (MGH Briefe d. dt. Kaiserzeit 2, Weimar 1966)

Die Gesetze der Angelsachsen, hg. von Felix Liebermann (Halle 1903-1916) 3 Bde.

Gesta episcoporum Cameracensium, hg. von Ludwig C. Bethmann (MGH SS 7, Hannover 1846) 393-489

Gesta Innocentii III, hg. von David Richard Gress-Wright (Bryn Mawr College Diss. 1981)

Giselbert von Mons, Chronicon Hanoniense, hg. von Leo Vanderkindere (Brüssel 1904)

Gregor I., Dialogi, hg. von Adalbert de Vogüé (Paris 1978-1980) 3 Bde.

Gregor I., Moralia in Iob, hg. von Marcus Adriaen (CCL 143, Turnhout 1979-1985) 3 Bde.

Gregor I., Registrum epistolarum, hg. von Paul Ewald und Ludo M. Hartmann (MGH Epp. 2, Berlin 1887-1899)

Gregor VII., Registrum, hg. von Erich Caspar (MGH Epp. sel. 2, Berlin 1920-1923)

Gregor von Tours, Decem libri historiarum, hg. von Bruno Krusch (MGH SS rer. Merov. 1/1, Hannover 1937)

Gregor von Tours, De virtutibus s. Martini episcopi, hg. von Bruno Krusch (MGH SS rer. Merov. 2/1, Hannover 1885) 584-661

Gregor von Tours, Liber de miraculis B. Andreae Apostoli, hg. von Max Bonnet (MGH SS rer. Merov. 2/1, Hannover 1885) 821-847

Gregor von Tours, Vitae patrum, hg. von Bruno Krusch (MGH SS rer. Merov. 2/1, Hannover 1885) 661-774

Haito von Basel, Visio Wettini, hg. von Ernst Dümmler (MGH Poetae 2, Berlin 1884) $267-275$

Halitgar von Cambrai, Paenitentiale, hg. von Hermann Josef Schmitz, Die Bußbücher und die Bußdisciplin der Kirche, 2: Die Bußbücher und das kanonische Bußverfahren (Düsseldorf 1898) 264-300

Helgaud von Fleury, Vita Roberti regis, hg. von Robert-Henri Bautier - Gillette Labory (Sources d'histoire médiévale 1, Paris 1965)

Hinkmar von Reims, De divortio Lotharii regis et Theutbergae reginae, hg. von Letha Böhringer (MGH Conc. 4 Suppl. 1, Hannover 1992)

Hinkmar von Reims, Epistolae, hg. von Ernst Perels (MGH Epp. 8/1, Berlin 1939)

Historia Monasterii S. Florentii Salmurensis (BouQuet 11, 276-281)

Hrabanus Maurus, Enarratio in Deuteronomium (Migne PL 108, 837-998)

Hrabanus Maurus, Expositiones in Leviticum (Migne PL 108, 245-586)

Hrabanus Maurus, Epistolae, hg. von Ernst Dümmler (MGH Epp. 5, Berlin 1899) $379-516$

Hrabanus Maurus, Paenitentiale ad Heribaldum (Migne PL 110, 467-494)

Hrabanus Maurus, Paenitentiale ad Otgarium (Migne PL 112, 1397-1424)

Hugeburc, Vita Wynnebaldi, hg. von Oswald Holder-Egger (MGH SS 15/1, Hannover 1887) 106-117

The Irish Penitentials, hg. von Ludwig Bieler (Scriptores Latini Hiberniae 5, Dublin 1963)

Isidor von Sevilla, Etymologiae, ed. Wallace Martin Lindsay (Oxford 1911) 2 Bde.

Isidor von Sevilla, Historia Gothorum, hg. von Theodor Mommsen (MGH Auct. Ant. 11, Berlin 1894) 241-303

Ivo von Chartres, Decretum (Migne PL 161, 59-1022)

Ivo von Chartres, Panormia (Migne PL 161, 1041-1344)

Johannes VIII., Epistolae dubiae, hg. von Erich Caspar (MGH Epp. 7, Berlin 1928) $330-333$ 
Johannes VIII., Registrum, hg. von Erich Caspar (MGH Epp. 7, Berlin 1928) 1-272 Johannes Diaconus, Vita Gregorii Magni (Migne PL 75, 59-242)

Johannes von Damaskus, Liber de haeresibus, hg. von Bonifatius Kotter, Die Schriften des Johannes von Damaskos 4 (Patristische Texte und Studien 22, Berlin-New York 1981) $19-67$

Johannes von Fécamp, Brief an Leo IX. (Migne PL 143, 797-800)

Johannes Scholasticus, Synagoga L titulorum, hg. von Vladimir Beneševič (Abhandlungen der Bayerischen Akademie der Wissenschaften, philosophisch-historische Abt., N.F. 14, München 1937)

Jonas von Orléans, De institutione laicali (Migne PL 106, 121-278)

Die Konzilien der karolingischen Teilreiche 843-859, hg. von Wilfried Hartmann (MGH Conc. 3, Hannover 1984)

Die Konzilien der karolingischen Teilreiche 860-874, hg. von Wilfried Hartmann (MGH Conc. 4, Hannover 1998)

Die Konzilien Deutschlands und Reichsitaliens 916-1001, hg. von Ernst-Dieter Hehl (MGH Conc. 6, Hannover 1987-2007)

Leges Langobardorum, hg. von Friedrich Bluhme (MGH LL 4, Hannover 1868)

Leidrad von Lyon, Epistolae, hg. von Ernst Dümmler (MGH Epp. 4, Berlin 1895) 539546

Leo III., Epistolae, hg. von Karl Hampe (MGH Epp. 5, Berlin 1899) 85-104

Leo IV., Epistolae, hg. von Adolf von Hirsch-Gereuth (MGH Epp. 5, Berlin 1899) $581-614$

Lex Alamannorum, hg. von Karl Lehmann (MGH LL nat. Germ. 5/1, Hannover ${ }^{2} 1966$ )

Lex Baiuvariorum, hg. von Ernst von Schwind (MGH LL nat. Germ. 5/2, Hannover 1926)

Lex Burgundionum, hg. von Ludwig Rudolf von Salis (MGH LL nat. Germ. 2/1, Hannover 1892)

Lex Ribuaria, hg. von Franz Beyerle - Rudolf Buchner (MGH LL nat. Germ. 3/2, Hannover 1954)

Lex Romana Burgundionum, hg. von Ludwig Rudolf von Salis (MGH LL nat. Germ. 2/ 1, Hannover 1892)

Lex Romana Visigothorum (Breviarium Alarici), hg. von Gustav Haenel (Leipzig 1849)

Lex Salica, hg. von Karl August Eckhardt (MGH LL nat. Germ. 4/1-2, Hannover 1962-1969)

Lex Visigothorum, hg. von Karl Zeumer (MGH LL nat. Germ. 1, Hannover - Leipzig 1902)

Libanios, Opera, hg. von Richard Foerster (Leipzig 1903-1923) 13 Bde.

Liber historiae Francorum, hg. von Bruno Krusch (MGH SS rer. Merov. 2, Hannover 1888) 215-328

Liber Papiensis, hg. von Alfred Boretius (MGH LL 4, Hannover 1868) 289-585

Liber Pontificalis, hg. von Louis Duchesne (Paris 1886-1957) 3 Bde.

Liudger, Vita Gregorii abbatis Traiectensis, hg. von Oswald Holder-Egger (MGH SS 15/ 1, Hannover 1887) 63-79

Liutprand von Cremona, Antapodosis, hg. von Paolo Chiesa (CCM 156, Turnhout 1998) 3-150

Liutprand von Cremona, De Ottone rege, hg. von Paolo Chiesa (CCM 156, Turnhout 1998) 169-183

Livius, Ab urbe condita, hg. von John Briscoe (Stuttgart 1986-1991) 3 Bde.

Mittelrheinisches Urkundenbuch 1, hg. von Heinrich Beyer (Koblenz 1860) 
Nikephoros, Breviarium historicum, hg. von Cyril Mango (Corpus fontium historiae Byzantinae, Series Washingtoniensis 13, Washington 1990)

Nikolaus I., Epistolae, hg. von Ernst Perels (MGH Epp. 6, Berlin 1925) 257-690

Nomos mosaikos, hg. von Ludwig Burgmann - Spyros Troianos, in: Fontes minores 3, hg. von Dieter Simon (Forschungen zur byzantinischen Rechtsgeschichte 4, Frankfurt 1979) 126-167

Novellae Justini, in: Novellae et aureae bullae imperatorum post Justinianum, hg. von Karl Eduard Zachariä von Lingenthal (Ius Graecoromanum 1, ND Aalen 1962)

Odorannus von Sens, Chronica, hg. von Robert-Henri Bautier - Monique Gilles (Sources d'histoire médiévale 4, Paris 1972)

Oliba von Vic, Brief an Sancho III., hg. von Eduard Junyent i Subirà, Diplomatari i escrits literaris de l'abat i bisbe Oliba (Barcelona 1992) 327-331

Ordericus Vitalis, Gesta Normannorum ducum, hg. von Elisabeth M. C. van Houts (Oxford 1992-1998)

Paenitentiale Ps.-Bedae, hg. von Hermann Josef Schmitz, Die Bußbücher und die Bußdisziplin der Kirche 1 (Mainz 1883) 556-564

Paenitentiale Ps.-Egberti, hg. von Hermann Josef Schmitz, Die Bußbücher und die Bußdisziplin der Kirche 1 (Mainz 1883) 573-587

Paenitentiale Martenianum, hg. von Walter Hörmann, Bußbücherstudien 4, in: ZRG KA 4 (1914) 360-480

Paenitentiale mixtum Ps.-Bedae-Egberti, hg. von Hermann Josef Schmitz, Die Bußbücher und die Bußdisciplin der Kirche, 2: Die Bußbücher und das kanonische Bußverfahren (Düsseldorf 1898) 679-701

Paenitentiale Oxoniense II, hg. von Raymund Kottje, Paenitentialia minora Franciae et Italiae saeculi VIII - IX (CCL 156, Turnhout 1994) 181-205

Paenitentiale Vindobonense B, hg. von Rob Meens, Het tripartite boeteboek. Overlevering en betekenis van vroegmiddeleeuwse biechtvoorschriften (met editie en vertaling van vier tripartita) (Middeleeuwse studies en bronnen 41, Hilversum 1994) $354-433$

Panegyrici latini, hg. von R.A.B. Mynors (Oxford 1964)

Paschasius Radbertus, Expositio in Matheo, hg. von Paulus Beda (CCM 56, Turnhout 1984) 3 Bde.

Paschasius Radbertus, Vita Adalhardi (Migne PL 120, 1507-1556)

Passio Leudegarii I, hg. von Bruno Krusch (MGH SS rer. Merov. 5, Hannover - Leipzig 1910) 282-322

Passio Praeiecti, hg. von Bruno Krusch (MGH SS rer. Merov. 5, Hannover - Leipzig 1910) 212-248

Petrus Damiani, Briefe, hg. von Kurt Reindel (MGH Briefe d. dt. Kaiserzeit 4, Hannover 1983-1993) 4 Bde.

Plutarch, Aetia Romana, hg. von Wilhelm Nachstädt - Wilhelm Sieveking - John Bradford Titchener (Moralia 2, Leipzig 1935) 273-336

Polybius, Historiae, hg. von Theodor Büttner-Wobst (Leipzig 1889-1904)

Prokop, Anecdota, hg. von Jakob Haury (Leipzig 1906)

Prokop, De bellis, hg. von Jakob Haury (Leipzig 1905) 2 Bde.

Ratramnus von Corbie, Epistolae, hg. von Ernst Dümmler (MGH Epp. 6, Berlin 1925) 149-158

Regino von Prüm, Chronica, hg. von Friedrich Kurze (MGH SS rer. Germ. 50, Hannover 1890)

Regino von Prüm, De synodalibus causis et disciplinis ecclesiasticis, hg. von Friedrich Wilhelm Wasserschleben (Leipzig 1840) 
Les Registres de Philippe Auguste, hg. von John W. Baldwin (Recueil des historiens de la France, Documents financiers et administratifs 7, Paris 1992)

Richer von Reims, Historiae, hg. von Hartmut Hoffmann (MGH SS 38, Hannover 2000)

Rodulfus Glaber, Historiae, hg. von John France (Oxford 1989)

Rudolf von Fulda, Translatio sancti Alexandri, hg. von Bruno Krusch, Die Übertragung des heiligen Alexander von Rom nach Wildeshausen durch den Enkel Widukinds 851. Das älteste niedersächsische Geschichtsdenkmal (Nachrichten der Gesellschaft der Wissenschaften zu Göttingen, Göttingen 1933) 405-436

Sidonius Apollinaris, Epistulae, hg. von André Loyen (Paris 1970)

Siegfried von Gorze, Briefe, hg. von Wilhelm von Giesebrecht, Geschichte der deutschen Kaiserzeit 2 (Leipzig ${ }^{5} 1885$ ) 714-720

Socrates Scholasticus, Historia ecclesiastica, hg. von Günther Christian Hansen (Die griechischen christlichen Schriftsteller der ersten Jahrhunderte N.F. 1, Berlin 1995)

Stephan II., Responsa (Migne PL 89, 1024-1030)

Stephan V., Fragmentum registri, hg. von Erich Caspar (MGH Epp. 7, Berlin 1928) $334-353$

Sueton, De vita Caesarum, hg. von Max Ihm (Stuttgart-Leipzig 1993)

Sulpicius Severus, Chronicae, hg. von Karl Halm (CSEL 1, Wien 1866)

Q. Aurelius Symmachus, Opera, hg. von Otto Seeck (MGH Auct. Ant. 6/1, Berlin 1883)

Das syrisch-römische Rechtsbuch, hg. von Walter Selb - Hubert Kaufhold (Denkschriften der Österreichischen Akademie der Wissenschaften 295, Wien 2002) 3 Bde.Tacitus, Germania, hg. von Alf Önnerfors (Stuttgart 1983)

Thegan, Gesta Hludowici imperatoris, hg. von Ernst Tremp (MGH SS rer. Germ. 64, Hannover 1995)

Thietmar von Merseburg, Chronica, hg. von Robert Holtzmann (MGH SS rer. Germ. N.S. 9, Berlin 1935)

Translatio S. Pusinnae, hg. von Georg Heinrich Pertz (MGH SS 2, Hannover 1829) $681-683$

Die Urbare der Abtei Werden an der Ruhr, 1: Die Urbare vom 9. - 13. Jahrhundert, hg. von Rudolf Kötzschke (Publikationen der Gesellschaft für Rheinische Geschichtskunde 20/2, Düsseldorf 1906)

Die Urkunden Heinrichs II. und Arduins, hg. von Harry Bresslau (MGH Diplomata regum et imperatorum Germaniae 3, Hannover 1900-1903)

Die Urkunden Heinrichs III., hg. von Harry Bresslau - Paul Fridolin Kehr (MGH Diplomata regum et imperatorum Germaniae 5, Berlin 1931)

Die Urkunden Konrads II. mit Nachträgen zu den Urkunden Heinrichs II., hg von Harry Bresslau (MGH Diplomata regum et imperatorum Germaniae 4, Hannover 1909)

Die Urkunden Konrad I., Heinrich I. und Otto I., hg. von Theodor Sickel (MGH Diplomata regum et imperatorum Germaniae 1, 1879-1884)

Die Urkunden Pippins, Karlmanns und Karls des Großen, hg. von Engelbert Mühlbacher (MGH Diplomata Karolinorum 1, Hannover 1906)

Venantius Fortunatus, Opera pedestria, hg. von Bruno Krusch (MGH Auct. Ant. 4/2, Berlin 1885)

Venantius Fortunatus, Opera poetica, hg. von Friedrich Leo (MGH Auct. Ant. 4/1, Berlin 1881)

Vita Apollinaris, hg. von Bruno Krusch (MGH SS rer. Merov. 3, Hannover 1896) 194203

Vita s. Arnulfi, hg. von Bruno Krusch (MGH SS rer. Merov. 2, Hannover 1888) 426446 
Vita Austrigisili, hg. von Bruno Krusch (MGH SS rer. Merov. 4, Hannover 1902) $191-$ 200

Vita s. Balthildis, hg. von Bruno Krusch (MGH SS rer. Merov. 2, Hannover 1888) 475508

Vita Burchardi episcopi, hg. von Heinrich Boos, Monumenta Wormatiensia. Annalen und Chroniken (Quellen zur Geschichte der Stadt Worms 3, Berlin 1893) 99-126

Vita Kiliani, hg. von Wilhelm Levison (MGH SS rer. Merov. 5, Hannover - Leipzig 1910) $711-728$

Vita Leonis IX. papae, hg. von Hans-Georg Krause (MGH SS rer. Germ. 70, Hannover 2007)

Vita Mathildis antiquior, hg. von Bernd Schütte (MGH SS rer. Germ. 66, Hannover 1994)

Widukind von Corvey, Res gestae Saxonicae, hg. von Paul Hirsch - Hans-Eberhard Lohmann (MGH SS rer. Germ. 60, Hannover 1935)

Willibald, Vita Bonifatii, hg. von Wilhelm Levison (MGH SS rer. Germ. 57, Hannover - Leipzig 1905) Wipo, Gesta Chuonradi imperatoris, hg. von Harry Bresslau (MGH SS rer. Germ. 61, Hannover - Leipzig 1915)

Wolfhere, Vita Godehardi posterior, hg. von Georg Heinrich Pertz (MGH SS 11, Hannover 1854) 196-218

Wolfhere, Vita Godehardi prior, hg. von Georg Heinrich Pertz (MGH SS 11, Hannover 1854) 167-196

Wulfstan, Collectio canonum, hg. von James E. Cross - Andrew Hamer (Anglo-Saxon Texts 1, Woodbridge 1999)

Wulfstan, Predigten, hg. von Arthur S. Napir, Wulfstan: Sammlung der ihm zugeschriebenen Homilien nebst Untersuchungen über ihre Echtheit (Sammlung englischer Denkmäler in kritischen Ausgaben 4, Berlin 1883)

Zacharias, Epistola ad Theodorum, hg. von Wilhelm Gundlach (MGH Epp. 3, Berlin 1892) 709-711

Zosimos, Historia nova, ed. François Paschoud (Paris 1971-1989)

\section{Literaturverzeichnis}

D’Abadal i de Vinyals, Ramon, Els primers comtes catalans (Biografies catalanes, serie histórica 1, Barcelona 1958)

Abels, Richard, Alfred the Great. War, Kingship and Culture in Anglo-Saxon England (London - New York 1998)

D’Acunto, Nicolangelo, I laici nella Chiesa e nella società secondo Pier Damiani. Ceti dominanti e riforma ecclesiastica nel secolo XI (Nuovi studi storici 50, Rom 1999)

Affeldt, Werner, Untersuchungen zur Königserhebung Pippins. Das Papsttum und die Begründung des karolingischen Königtums im Jahre 751, in: FmSt 14 (1980) 95187

Airlie, Stuart, Aristocracy, in: The New Cambridge Medieval History, 2: c. 700 - c. 900, hg. von Rosamond McKitterick (Cambridge 1995) 431-450

Airlie, Stuart, Private Bodies and the Body Politic in the Divorce Case of Lothar II, in: Past and Present 161 (1998) 3-38

Alivisatos, S. Hamilcar, Die kirchliche Gesetzgebung des Kaisers Justinian I. (Berlin 1913)

Altfranzösisches Wörterbuch, hg. von Adolf Tobler u.a. (Berlin 1925 ff.) 
Althoff, Gerd, Die Thronbewerber von 1002 und ihre Verwandtschaft mit den Ottonen, in: ZGO 137 (1989) 453-459

Althoff, Gerd, Verwandte, Freunde und Getreue. Zum politischen Stellenwert der Gruppenbindungen im früheren Mittelalter (Darmstadt 1990)

Althoff, Gerd, Amicitiae et Pacta. Bündnis, Einung, Politik und Gebetsgedenken im beginnenden 10. Jahrhundert (MGH Schriften 37, Hannover 1992)

Althoff, Gerd, Compositio. Wiederherstellung verletzter Ehre im Rahmen gütlicher Konfliktbeendigung, in: Verletzte Ehre. Ehrkonflikte in Gesellschaften des Mittelalters und der Frühen Neuzeit, hg. von Klaus Schreiner - Gerd Schwerhoff (Norm und Struktur 5, Köln - Weimar - Wien 1995) 63-76

Althoff, Gerd, Otto III. (Darmstadt 1996)

Althoff, Gerd, Otto III. und Heinrich II. in Konflikten, in: Otto III. - Heinrich II. Eine Wende?, hg. von Bernd Schneidmüller - Stefan Weinfurter (Sigmaringen 1997) $77-94$

Althoff, Gerd, Spielregeln der Politik im Mittelalter. Kommunikation in Frieden und Fehde (Darmstadt 1997)

Althoff, Gerd, Die Ottonen (Stuttgart ${ }^{2} 2005$ )

Amiet, Andreas, Die liturgische Gesetzgebung der deutschen Reichskirche in der Zeit der sächsischen Kaiser (922-1023), in: Zeitschrift für Schweizerische Kirchengeschichte 70 (1976) 1-106 und 209-307

Amira, Karl von, Erbenfolge und Verwandtschafts-Gliederung nach den alt-niederdeutschen Rechten (München 1874)

Amory, Patrick, The Meaning and Purpose of Ethnic Terminology in the Burgundian Laws, in: EME 2 (1993) 1-28

Amory, Patrick, Names, Ethnic Identity and Community in Fifth- and Sixth-Century Burgundy, in: Viator 25 (1994) 1-30

Amory, Patrick, People and Identity in Ostrogothic Italy, 489-544 (Cambridge 1997)

Anderson, Thomas Jr., Roman military colonies in Gaul, Salian ethnogenesis and the forgotten meaning of Pactus Legis Salicae 59,5, in: EME 4 (1995) 129-144

Angenendt, Arnold, Bonifatius und das Sacramentum initiationis, in: RQ 72 (1977) $133-183$

Angenendt, Arnold, Das geistliche Bündnis der Päpste mit den Karolingern (754-796), in: HJb 100 (1980) 1-94

Angenendt, Arnold, Kaiserherrschaft und Königstaufe. Kaiser, Könige und Päpste als geistliche Patrone in der abendländischen Missionsgeschichte (Arbeiten zur Frühmittelalterforschung 15, Berlin - New York 1984)

Angenendt, Arnold, Der eine Adam und die vielen Stammväter. Idee und Wirklichkeit der Origo gentis im Mittelalter, in: Herkunft und Ursprung. Historische und mythische Formen der Legitimation, hg. von Peter Wunderli (Sigmaringen 1994) $27-52$

Angenendt, Arnold, Geschichte der Religiosität im Mittelalter (Darmstadt 1997)

Angenendt, Arnold, Pippins Königserhebung und Salbung, in: Der Dynastiewechsel von 751. Vorgeschichte, Legitimationsstrategien und Erinnerung, hg. von Matthias Becher - Jörg Jarnut (Münster 2004) 179-209

Anton, Hans Hubert, Fürstenspiegel und Herrscherethos in der Karolingerzeit (Bonner historische Forschungen 32, Bonn 1968)

Anton, Hans Hubert, Trier im frühen Mittelalter (Quellen und Forschungen aus dem Gebiete der Geschichte N.F., 9, Paderborn u.a. 1987)

Anton, Hans Hubert, „Bischofsherrschaften“ und „Bischofsstaaten“ in Spätantike und Frühmittelalter. Reflexionen zu ihrer Genese, Struktur und Typologie, in: Liber 
amicorum necnon et amicarum für Alfred Heit. Beiträge zur mittelalterlichen Geschichte und geschichtlichen Landeskunde, hg. von Friedhelm Burgard u. a. (Trierer historische Forschungen 28, Trier 1996) 461-473

Archi, Gian Gualberto, L',Epitome Gai“. Studio sul tardo diritto romano in occidente (Fondazione Guglielmo Castelli 15, Mailand 1937)

Archibald, Elizabeth, Incest and the Medieval Imagination (Oxford 2001)

Arjava, Antti, Women and Law in Late Antiquity (Oxford 1996)

Arlinghaus, Franz-Josef, Mittelalterliche Rituale in systemtheoretischer Perspektive. Übergangsriten als basale Kommunikationsform in einer stratifikatorisch-segmentären Gesellschaft, in: Systemtheorie und Geschichte. Exemplarische Fallstudien, hg. von Frank Becker (Campus Historische Studien 37, Frankfurt - New York 2004) $108-156$

Asbach, Franz Bernd, Das Poenitentiale Remense und der sogen. Excarpsus Cummeani: Überlieferung, Quellen und Entwicklung zweier kontinentaler Bußbücher aus der 1. Hälfte des 8. Jahrhunderts (Diss. Regensburg 1975).

Astuti, Guido, Influssi romanistici nelle fonti del diritto longobardo, in: La cultura antica nell'occidente latino del VII all'XI secolo (Settimane 22, Spoleto 1975) 653695

Atsma, Hartmut, Klöster und Mönchtum im Bistum Auxerre bis zum Ende des 6 . Jahrhunderts, in: Francia 11 (1983) 1-96

Aurell, Martin, Jalons pour une enquête sur les strategies matrimoniales des comtes catalans (IXe-XIe siècles), in: Symposium internacional sobre els orígens de Catalunya (segles VIII-XI) 1 (Barcelona 1991) 181-364

Aurell, Martin, Les noces du comte. Mariage et pouvoir en Catalogne (785-1213) (Publications de la Sorbonne, Histoire ancienne et médiévale 32, Paris 1995)

Austin, Greta, Jurisprudence in the Service of Pastoral Care. The Decretum of Burchard of Worms, in: Speculum 79 (2004) 929-959

Austin, Greta, Freising und Worms in the Early Eleventh Century: Revisiting the Relationship between the Collectio duodecim partium and Burchard's Decretum, in: ZRG KA 93 (2007) 45-108

Auzépy, Marie-France, La destruction de l'icône du Christ de la Chalcé par Léon III: propagande ou verité?, in: Byzantion 60 (1990) 445-492

Auzépy, Marie-France, Les enjeux de l'iconoclasme, in: Cristianità d'Occidente e cristianità d'Oriente (Settimane 51, 2004) 127-165

Auzias, Léonce, L'Aquitaine carolingienne (778-987) (Bibliothèque méridionale 2/28, Toulouse 1937)

d'Avray, David L., Peter Damian, consanguinity and church property, in: Intellectual life in the Middle Ages. Essays presented to Margaret Gibson, hg. von Lesley Smith - Benedicta Ward (London 1992) 71-80

d'Avray, David L., Medieval Marriage. Symbolism and Society (Oxford 2005)

Babut, Ernest Ch., La plus ancienne décrétale (Paris 1904)

Baccrabère, Georges, Art. „Visite canonique de l'évêque“, in: DDC 7 (1965) 1512 1594

Bachrach, Bernard S., Fulk Nerra, the Neo-Roman Consul, 987-1040. A Political Biography of the Angevin Count (Berkeley u.a. 1993)

Baldwin, John W., Masters, princes and merchants. The social views of Peter the Chanter and his circle (Princeton 1970)

Baldwin, John W., The Government of Philip Augustus. Foundations of French Royal Power in the Middle Ages (Berkeley u. a. 1986) 
Barceló, Pedro, Constantius II. und seine Zeit. Die Anfänge des Staatskirchentums (Stuttgart 2004)

Barion, Hans, Das fränkisch-deutsche Synodalrecht des Frühmittelalters (Kanonistische Studien und Texte 5-6, Bonn 1931)

Barnes, Timothy D., The New Empire of Diocletian and Constantine (Cambridge/ Mass. 1982)

Barnes, Timothy D., Athanasius and Constantius. Theology and politics in the Constantinian empire (Cambridge/Mass. 1993)

Barreda, Pere-Enric - Vilella, Josep, Los cánones de la Hispana atribuidos a un concilio iliberritano: estudio filológico, in: I concili della cristianità occidentale (sec. III-V) (Studia Ephemeridis Augustinianum 78, Rom 2002) 545-579

Basdevant-Gaudemet, Brigitte, Le mariage d'après la correspondance d'Yves de Chartres, in: Revue historique de droit français et étranger 61 (1983) 195-215

Bauer, Thomas, Rechtliche Implikationen des Ehestreites Lothars II. Eine Fallstudie zu Theorie und Praxis des geltenden Eherechts in der späten Karolingerzeit, in: ZRG KA 80 (1994) 41-87

Bauer-Gerland, Friederike, Das Erbrecht der Lex Romana Burgundionum (Freiburger rechtsgeschichtliche Abhandlungen N.F. 23, Frankfurt 1995)

Baumgart, Susanne, Die Bischofsherrschaft im Gallien des 5. Jahrhunderts. Eine Untersuchung zu den Gründen und Anfängen weltlicher Herrschaft der Kirche (Münchener Arbeiten zur Alten Geschichte 8, München 1995)

Beaucamp, Joëlle, La christianisation du droit à Byzance: L'exemple du statut des femmes, in: Cristianità d'Occidente e cristianità d'Oriente (Settimane 51, Spoleto 2004) 917-955

Becher, Matthias, Eid und Herrschaft. Untersuchungen zum Herrscherethos Karls des Großen (VuF Sonderband 39, Sigmaringen 1993)

Becher, Matthias, Der sogenannte Staatsstreich Grimoalds. Versuch einer Neubewertung, in: Karl Martell in seiner Zeit, hg. von Matthias Becher u.a. (Beihefte der Francia 37, Sigmaringen 1994) 119-147

Becher, Matthias, Rex, Dux und Gens. Untersuchungen zur Entstehung des sächsischen Herzogtums im 9. und 10. Jahrhundert (Historische Studien 444, Husum 1996)

Beck, Hans-Georg, Geschichte der orthodoxen Kirche im Byzantinischen Reich (Die Kirche in ihrer Geschichte 1/D 1, Göttingen 1980)

Beeson, Charles H., Isidor-Studien (Quellen und Untersuchungen zur lateinischen Philologie des Mittelalters 4/2, München 1913)

Beisel, Fritz, Theudebertus magnus rex Francorum: Persönlichkeit und Zeit (Idstein 1993)

Berman, Harold J., Law and Revolution, 1: The Formation of the Western Legal Tradition (Cambridge/Mass. 1983)

Berschin, Walter, Bonizo von Sutri. Leben und Werk (Beiträge zur Geschichte und Quellenkunde des Mittelalters 2, Berlin u.a. 1992)

Bertolini, Ottorino, Le chiese longobarde dopo la conversione al cattolicesimo ed i loro rapporti con il papato, in: Le chiese nei regni dell'Europa occidentale e i loro rapporti con Roma sino all'800 (Settimane 7, Spoleto 1960) 455-492

Bettini, Maurizio, Familie und Verwandtschaft im antiken Rom (Historische Studien 8, Frankfurt 1992)

Beyerle, Franz, Über Normtypen und Erweiterungen der Lex Salica, in: ZRG GA 44 (1924) 216-261

Beyerle, Franz, Die Lex Ribuaria. Volksrechtliche Studien I, in: ZRG GA 48 (1928) $264-378$ 
Beyerle, Franz, Die süddeutschen Leges und die merowingische Gesetzgebung. Volksrechtliche Studien II, in: ZRG GA 49 (1929) 264-432

Beyerle, Franz, Das Gesetzbuch Ribvariens. Volksrechtliche Studien III, in: ZRG GA 55 (1935) $1-80$

Beyerle, Franz, Gesetze der Burgunden (Germanenrecht 10, Weimar 1936)

Beyerle, Franz, Die Gesetze der Langobarden (Weimar 1947)

Beyerle, Franz, Zur Textgestalt und Textgeschichte der Lex Burgundionum, in: ZRG GA 71 (1954) 23-54

Beyerle, Franz, Zum Kleinreich Sigiberts III. und zur Datierung der Lex Ribvaria, in: RhVjbll 21 (1956) 357-362

Beyerle, Franz, Das legislative Werk Chilperichs I., in: ZRG GA 78 (1961) 1-38

Beyerle, Konrad, Lex Baiuvariorum. Lichtdruckwiedergabe der Ingolstädter Handschrift (München 1926)

Bigott, Boris, Ludwig der Deutsche und die Reichskirche im Ostfränkischen Reich (826-876) (Historische Studien 470, Husum 2002)

Binding, Karl, Das burgundisch-romanische Koenigreich (von 443-532 n. Chr.). Eine reichs- und rechtsgeschichtliche Untersuchung (Leipzig 1868)

Biondi, Biondo, Il diritto romano cristiano (Mailand 1952-1954)

Bischoff, Bernhard, Die Hofbibliothek Karls des Großen, in: Karl der Große. Lebenswerk und Nachleben, 2: Das geistige Leben, hg. von Bernhard Bischoff (Düsseldorf 1964) 42-62

Bischoff, Bernhard, Die europäische Verbreitung der Werke Isidors von Sevilla, in: ders., Mittelalterliche Studien. Ausgewählte Aufsätze zur Schriftkunde und Literaturgeschichte 1 (Stuttgart 1966) 171-194 (erstmals 1961)

Bischoff, Bernhard, Bücher am Hofe Ludwigs des Deutschen und die Privatbibliothek des Kanzlers Grimalt, in: ders., Mittelalterliche Studien. Ausgewählte Aufsätze zur Schriftkunde und Literaturgeschichte 3 (Stuttgart 1981) 187-212

Bischoff, Bernhard, Die karolingische Minuskel, in: ders., Mittelalterliche Studien. Ausgewählte Aufsätze zur Schriftkunde und Literaturgeschichte 3 (Stuttgart 1981) 1-4 (erstmals 1965)

Bischoff, Bernhard, Katalog der festländischen Handschriften des neunten Jahrhunderts 1-2 (Wiesbaden 1998-2004)

Black-Veldtrup, Mechthild, Kaiserin Agnes (1043-1077). Quellenkritische Studien (Münstersche historische Forschungen 7, Köln 1995)

Blair, John, The Church in Anglo-Saxon Society (Oxford 2005)

Blumenthal, Uta-Renate, Ein neuer Text für das Reimser Konzil Leos IX. (1049)?, in: DA 32 (1976) 23-48

Blumenthal, Uta-Renate, Der Investiturstreit (Stuttgart u.a. 1982)

Böhmer, Johann Friedrich - Mühlbacher, Engelbert, Die Regesten des Kaiserreichs unter den Karolingern, 751 -918 (Regesta Imperii I, Innsbruck ${ }^{2}$ 1908)

Böhmer, Johann Friedrich - Uhlirz, Mathilde, Die Regesten des Kaiserreichs unter Otto III. 980 (983)-1002 (Regesta Imperii II/3, Graz - Köln 1956/1957)

Böhringer, Letha, Gewaltverzicht, Gesichtswahrung und Befriedung durch Öffentlichkeit. Beobachtungen zur Entstehung des kirchlichen Eherechts im 9. Jahrhundert am Beispiel Hinkmars von Reims, in: Rechtsverständnis und Konfliktbewältigung. Gerichtliche und außergerichtliche Strategien im Mittelalter, hg. von Stefan Esders (Köln u.a. 2007) 255-289

Bognetti, Gian Piero, L'Editto di Rotari come espediente politico di una monarchia barbarica, in: ders., L'età longobarda 4 (Mailand 1970) 113-136 
Bonini, Roberto, Considerazioni in tema di impedimenti matrimoniali nel diritto postclassico e giustinianeo, in: Studi Biondo Biondi (Milano 1965) 1, 485-516

Borgolte, Michael, Einheit, Reform, Revolution. Das Hochmittelalter im Urteil der Modernen, in: Göttingische gelehrte Anzeigen 248 (1996) 225-258

Borst, Arno, Die Katharer (MGH Schriften 12, Stuttgart 1953)

Boshof, Egon, Erzbischof Agobard von Lyon. Leben und Werk (Kölner Historische Abhandlungen 17, Köln - Wien 1969)

Boshof, Egon, Lothringen, Frankreich und das Reich in der Regierungszeit Heinrichs III., in: RhVjbll 42 (1978) 63-127

Boshof, Egon, Odo von Beauvais, Hinkmar von Reims und die kirchenpolitischen Auseinandersetzungen im westfränkischen Reich, in: Ecclesia et regnum. Beiträge zur Geschichte von Kirche, Recht und Staat im Mittelalter. Festschrift Franz-Josef Schmale, hg. von Dieter Berg - Hans-Werner Goetz (Bochum 1989) 41-59

Boshof, Egon, Ludwig der Fromme (Darmstadt 1996)

Boshof, Egon, Die Salier (Stuttgart u. a. ${ }^{4} 2000$ )

Bouchard, Constance B., Consanguinity and Noble Marriages in the Tenth and Eleventh Centuries, in: Speculum 56 (1981) 268-287

Bouchard, Constance B., Sword, Miter, and Cloister. Nobility and the Church in Burgundy, 980-1198 (Ithaca - London 1987)

Bouchard, Constance B., Those of my blood. Constructing noble families in medieval Francia (Philadelphia 2001)

Bouchard, Constance B., Eleanor's Divorce form Louis VII: The Uses of Consanguinity, in: Eleanor of Aquitaine. Lord and Lady, hg. von Bonnie Wheeler - John Carmi Parsons (New York u. a. 2003) 223-235

Bougard, François, La justice dans le royaume d'Italie de la fin du VIIIe siècle au début du XIe siècle (Bibliothèque des Écoles Françaises d'Athènes et de Rome 291, Rom 1995)

Bouhot, Jean-Paul, Ratramne de Corbie. Histoire littéraire et controverses doctrinales (Études Augustiniennes, Paris 1976)

Bourdieu, Pierre, Les stratégies matrimoniales dans le système de reproduction, in: Annales ESC 27 (1972) 1105-1127

Bourdieu, Pierre, Entwurf einer Theorie der Praxis (Frankfurt 1979)

Bourdieu, Pierre, Sozialer Sinn. Kritik der theoretischen Vernunft (Frankfurt 1987)

Brandes, Wolfram, „Juristische“ Krisenbewältigung im 7. Jahrhundert? Die Prozesse gegen Papst Martin I. und Maximos Homologetes, in: Fontes minores 10, hg. von Ludwig Burgmann (Forschungen zur byzantinischen Rechtsgeschichte 22, Frankfurt 1998) $141-212$

Brandes, Wolfram, Finanzverwaltung in Krisenzeiten. Untersuchungen zur byzantinischen Administration im 6.-9. Jahrhundert (Forschungen zur byzantinischen Rechtsgeschichte 25, Frankfurt 2002)

Brechter, Heinrich Suso, Die Quellen zur Angelsachsenmission Gregors des Grossen. Eine historiographische Studie (Beiträge zur Geschichte des alten Mönchtums und des Benediktinerordens 22, Münster 1941)

Breen, Aidan, The date, provenance and authorship of the pseudo-Patrician canonical materials, in: ZRG KA 81 (1995) 83-129

Bresslau, Harry, Otto von Hammerstein und sein Haus, in: Forschungen zur deutschen Geschichte 21 (1881) 401-406

Bresslau, Harry, Jahrbücher des Deutschen Reichs unter Konrad II. 1-2 (Leipzig 1912 1915) 
Bretone, Mario, Geschichte des römischen Rechts. Von den Anfängen bis Justinian (München 1992)

Brett, Martin, Theodore and Latin canon law, in: Archbishop Theodore. Comemmorative studies on his life and influence, hg. von Michael Lapidge (Cambridge 1995) $120-140$

Breukelaar, Adriaan H.B., Historiography and Episcopal Authority in Sixth-Century Gaul. The Histories of Gregory of Tours interpreted in their historical context (Forschungen zur Kirchen- und Dogmengeschichte 57, Göttingen 1994)

Brommer, Peter, „Capitula episcoporum“. Die bischöflichen Kapitularien des 9. und 10. Jahrhunderts (Typologie des sources du Moyen Age occidental 43, Turnhout 1985)

Bronisch, Alexander Pierre, Die Judengesetzgebung im katholischen Westgotenreich von Toledo (Forschungen zur Geschichte der Juden, Abt. A: Abhandlungen 17, Hannover 2005)

Brooke, Christopher N.L., The Medieval Idea of Marriage (Oxford 1989)

Brown, Giles, Introduction: the Carolingian Renaissance, in: Carolingian culture: emulation and innovation, hg. von Rosamond McKitterick (Cambridge 1994) 1 51

Brown, Peter, The cult of the saints. Its rise and function in Latin Christianity (Chicago 1981)

Brown, Peter, Die Keuschheit der Engel. Sexuelle Entsagung, Askese und Körperlichkeit am Anfang des Christentums (München - Wien 1991)

Brown, Peter, Power and Persuasion in Late Antiquity. Towards a Christian Empire (Madison/Wisc. 1992)

Brown, Peter, The Rise of Western Christendom. Triumph and Diversity 200-1000 AD (Malden ${ }^{2} 2003$ )

Brubaker, Leslie, Icons before Iconoclasm?, in: Morfologie sociali e culturali in Europa fra tarda Antichità e alto Medioevo (Settiname 45, Spoleto 1998) 1215-1254

Brubaker, Leslie - Haldon, John F., Byzantium in the Iconoclast Era (c.a 680-850): The sources. An annotated survey (Birmingham Byzantine and Ottoman monographs 7, Aldershot 2001)

Brühl, Carlrichard, Hinkmariana, in: DA 20 (1964) 48-77

Brühl, Carlrichard, Deutschland - Frankreich. Die Geburt zweier Völker (Köln - Wien 1990)

Brüsch, Tanja, Die Brunonen, ihre Grafschaften und die sächsische Geschichte. Herrschaftsbildung und Adelsbewußtsein im 11. Jahrhundert (Historische Studien 459, Husum 2000)

Bruguière, Marie-Bernadette, Le mariage de Philippe Auguste et d'Isambour de Danemark: aspects canoniques et politiques, in: Mélanges Jean Dauvillier (Toulouse 1979) $135-156$

Bruguière, Marie-Bernadette, Canon law and royal weddings, theory and practice: The French example, 987-1215, in: Proceedings of the Eigth International Congress of Medieval Canon Law, hg. von Stanley Chodorow (Monumenta Iuris Canonici C/9, Vatikan 1992) 473-496

Bruguière, Marie-Bernadette, Réflexions sur la crise de la justice en Occident à la fin de l'Antiquité: L'apport de la littérature, in: La giustizia nell'alto Medioevo, secoli VVIII (Settimane 42, Spoleto 1994) 165-218

Brundage, James A., Law, Sex and, Christian Society in Medieval Europe (Chicago London 1988) 
Brunhölzl, Franz, Geschichte der lateinischen Literatur des Mittelalters, 2: Die Zwischenzeit vom Ausgang des karolingischen Zeitalters bis zur Mitte des elften Jahrhunderts (München 1992)

Brunner, Heinrich, Zeugen- und Inquisitionsbeweis der karolingischen Zeit, in: ders., Forschungen zur Geschichte des deutschen und französischen Rechtes. Gesammelte Aufsätze (Stuttgart 1894) 88-247 (erstmals 1865)

Brunner, Heinrich, Über absichtslose Missethat im altdeutschen Strafrechte, in: ders., Forschungen zur Geschichte des deutschen und französischen Rechtes. Gesammelte Aufsätze (Stuttgart 1894) 487-523 (erstmals 1890)

Brunner, Heinrich, Zu Lex Salica tit. 44: De reipus, in: ders., Abhandlungen zur Rechtsgeschichte. Gesammelte Aufsätze (Weimar 1931) 2, 67-78 (erstmals 1894)

Brunner, Heinrich, Zur fränkisch-romanischen dos, in: ders., Abhandlungen zur Rechtsgeschichte. Gesammelte Aufsätze (Weimar 1931) 2, 78-116 (erstmals 1894)

Brunner, Heinrich - Schwerin, Claudius von, Deutsche Rechtsgeschichte (Systematisches Handbuch der deutschen Rechtswissenschaft 2/1, München - Leipzig ${ }^{2} 1906-$ 1928)

Buc, Philippe, The Dangers of Ritual. Between Early Medieval Texts and Social Scientific Theory (Princeton - Oxford 2001)

Buchner, Rudolf, Kleine Untersuchungen zu den fränkischen Stammesrechten, in: DA 9 (1952) 59- 102

Buchner, Rudolf, Deutschlands Geschichtsquellen im Mittelalter. Vorzeit und Karolinger, Beiheft: Die Rechtsquellen (Weimar 1953)

Buchner, Rudolf, Plan einer „Geschichte der Quellen und Literatur des weltlichen Rechtes von 450 bis 900“, in: Aus Verfassungs- und Landesgeschichte. Festschrift Theodor Mayer, 2: Geschichtliche Landesforschung. Wirtschaftsgeschichte. Hilfswissenschaften, hg. von Heinrich Büttner (Konstanz 1955) 391-402

Buchner, Rudolf, Die römischen und germanischen Wesenszüge in der neuen politischen Ordnung des Abendlandes, in: Caratteri del secolo VII in occidente (Settimane 5, Spoleto 1958) 223-270

Buck, Thomas Martin, „Capitularia imperatoria“. Zur Kaisergesetzgebung Karls des Großen von 802, in: HJb 122 (2002) 3-26

Budge, E.A. Wallis, Coptic Martyrdoms etc. in the Dialect of Upper Egypt (Coptic Texts 4, London 1914)

Bührer-Thierry, Geneviève, Évêques et pouvoir dans le royaume de Germanie. Les Églises de Bavière et de Souabe 876-973 (Paris 1997)

Bulst, Neithard, Untersuchungen zu den Kosterreformen Wilhelms von Dijon (9621031) (Pariser Historische Studien 11, Bonn 1973)

Bultot, Robert, La doctrine du mépris du monde, 4: Le XIe siècle. 1: Pierre Damien (Louvain-Paris 1968)

Bur, Michel, La formation du comté de Champagne v. 950- v. 1150 (Nancy 1977)

Burgmann, Ludwig, Reformation oder Restauration? Zum Ehegüterrecht der Ecloga, in: Eherecht und Familiengut in Antike und Mittelalter, hg. von Dieter Simon (Schriften des Historischen Kollegs, Kolloquien 22, München 1992) 29-42

Burgmann, Ludwig, Turning Sisinnios against the Sisinnians: Eustathios Romaios on a disputed marriage, in: Byzantium in the Year 1000, hg. von Paul Magdalino (The Medieval Mediterranean 45, Leiden - Boston 2003) 161-181

Burrus, Virginia, The Making of a Heretic: Gender, Authority, and the Priscillianist Controversy (Berkeley 1995)

Busch, Jürgen, Das Germanenbild der deutschen Rechtsgeschichte. Zwischen Wissenschaft und Ideologie (Rechtshistorische Reihe 299, Frankfurt u.a. 2004) 
Cacciari, Pietro Tommaso, De priscillianistarum haeresi et historia (Rom 1751, Migne PL 55, 991-1066)

Cameron, Averil, Agathias on the early Merovingians, in: Annali della Scuola Normale Superiore di Pisa. Classe di lettere e filosofia ser. 2, 37 (1968) 95-140

Cameron, Averil, Procopius and the sixth century (London 1985)

Cantin, André, Les sciences séculières et la foi. Les deux voies de la science au jugement de S. Pierre Damien (1007-1072) (Centro italiano di Studi sull'Alto Medioevo 5, Spoleto 1975)

Carozzi, Claude, La vie du roi Robert par Helgaud de Fleury: historiographie et hagiographie, in: Annales de Bretagne et des pays de l'ouest 87 (1980) 219-235

Caspar, Erich, Geschichte des Papsttums von den Anfängen bis zur Höhe der Weltherrschaft (Tübingen 1930) 2 Bde.

Caspar, Erich, Papst Gregor II. und der Bilderstreit, in: ZKG 52 (1933) 29-89

Castaldi, Lucia, Iohannes Hymmonides: Vita Gregorii I papae (B.H.L. 3641-3642), 1: La tradizione manoscritta (Archivum Gregorianum 1, Florenz 2004)

Castritius, Helmut, Das römische Namensystem. Von der Dreinamigkeit zur Einnamigkeit?, in: Nomen et gens. Zur historischen Aussagekraft frühmittelalterlicher Personennamen, hg. von Dieter Geuenich u.a. (RGA Erg.-Bd. 16, Berlin 1997) $30-40$

Cavanna, Adriano, Nuovi problemi intorno alle fonti dell'Editto di Rotari, in: Studia et documenta historiae et iuris 34 (1968) 269-361

Chadwick, Henry, Priscillian of Avila. The occult and the charismatic in the early church (Oxford 1976)

Chadwick, Henry, The Relativity of Moral Codes: Rome and Persia in Late Antiquity, in: Early Christian Literature and the Classical Intellectual Tradition. In honorem R.M. Grant, hg. von William R. Schoedel - Robert L. Wilken (Théologie historique 53, Paris 1979) $135-163$

Chadwick, Henry, Gregory the Great and the Mission to the Anglo-Saxons, in: Gregorio Magno e il suo tempo (Studia ephemeridis „Augustinianum“ 33-34, Roma 1991) $1,199-212$

Champagne, Jean - Szramkiewicz, Romuald, Recherches sur les conciles des temps mérovingiens, in: Revue historique de droit français et étranger 49 (1971) 5-49

Champeaux, Ernest, Jus sanguinis. Trois façons de calculer la parenté au Moyen Age, in: Revue historique du droit français et étranger 12 (1933) 241-290

Champeaux, Ernest, La parenté fraternelle et le „prima stemma“ d'Isidore, in: Revue historique du droit français et étranger 16 (1937) 1 -19

Charles-Edwards, Thomas, The Penitential of Theodore and the Iudicia Theodori, in: Archbishop Theodore. Comemmorative studies on his life and influence, hg. von Michael Lapidge (Cambridge 1995) 141-174

Charles-Edwards, Thomas, Early Christian Ireland (Cambridge 2000)

Charles-Edwards, Thomas, Law in the Western Kingdoms between the Fith and the Seventh Century, in: The Cambridge Ancient History, 14: Late Antiquity: Empire and Successors, AD 425-600, hg. von Averil Cameron u.a. (Cambridge 2000) $260-287$

Chaume, Maurice, Les origines du Duché de Bourgogne, 1: Histoire politique (Dijon 1926)

Chélini, Jean, L'Aube du Moyen Age. Naissance de la chrétienté occidentale. La vie religieuse des laïcs dans l'Europe carolingienne (750-900) (Paris 1991)

Cimma, Maria Rosa, L'episcopalis audientia nelle costituzione imperiali da Costantino a Giustiniano (Turin 1989) 
Classen, Peter, Karl der Grosse und die Thronfolge im Frankenreich. in: Festschrift für Hermann Heimpel (Göttingen 1972) 3, 109-134

Claude, Dietrich, Die Bestellung der Bischöfe im merowingischen Reich, in: ZRG KA 49 (1963) $1-75$

Claude, Dietrich, Untersuchungen zum frühfränkischen Comitat, in: ZRG GA 81 (1964) $1-79$

Clauss, Manfred, Kaiser und Gott. Herrscherkult im römischen Reich (Stuttgart Leipzig 1999)

Clausssen, Martin A., The Reform of the Frankish Church. Chrodegang of Metz and the Regula canonicorum in the eighth century (Cambridge studies in medieval life and thought 4th ser. 61, Cambridge 2004)

Clercq, Charles de, La législation religieuse franque. Étude sur les actes de conciles et les capitulaires, les statuts diocésains et les règles monastiques 1-2 (Louvain 1936/ 1958)

Clercq, Victor C. de, Ossius of Cordova. A contribution to the history of the Constantinian period (Studies in Christian antiquity 13, Washington 1954)

Collins, Roger, Mérida and Toledo: 550-585, in: Visigothic Spain. New Approaches, hg. von Edward James (Oxford 1980) 189-219

Collins, Roger, Theodebert I, rex magnus Francorum, in: Ideal and Reality in Frankish and Anglo-Saxon Society. Studies presented to J. M. Wallace-Hadrill, hg. von Patrick C. Wormald u. a. (Oxford 1983) 7-33

Collins, Roger, Law and Ethnic Identity in the Western Kingdoms in the Fifth and Sixth Centuries, in: Medieval Europeans. Studies in Ethnic Identity and National Perspectives in Medieval Europe, hg. von Alfred P. Smyth (Basingstoke 1998) 1-23

Collins, Roger, Visigothic Spain, 409-711 (Oxford 2004)

Congar, Yves M.-J., Die Lehre von der Kirche. Von Augustinus bis zum abendländischen Schisma (Handbuch der Dogmengeschichte 3/3c, Freiburg 1971)

Conrat (Cohn), Max, Geschichte der Quellen und Literatur des römischen Rechts im frühen Mittelalter (Leipzig 1891)

Conrat (Cohn), Max, Breviarium Alaricianum. Römisches Recht im fränkischen Reich in systematischer Darstellung (Leipzig 1903)

Conrat (Cohn), Max, Die Entstehung des westgotischen Gaius (Verhandelingen der Koninklijke Akademie van Wetenschappen te Amsterdam, Afdeeling Letterkunde N.R. 6/4, Amsterdam 1905)

Conrat (Cohn), Max, Arbor iuris des frühen Mittelalters mit eigenartiger Komputation (Abhandlungen der Preußischen Akademie der Wissenschaften, Berlin 1909)

Conrat (Cohn), Max, Römisches Recht bei Papst Nikolaus I., in: NA 36 (1911) 719_ 727

Conrat (Cohn), Max, Westgotische und katholische Auszüge aus dem 16. Buch des Theodosianus, in: ZRG KA 1 (1911) 67-125

Conte, Edouard, Choisir ses parents dans la société arabe. La situation à l'avènnement de l'islam, in: Epouser au plus proche. Inceste, prohibitions et stratégies matrimoniales autour de la Méditerranée, hg. von Paul Bonte (Paris 1994) 165-187

Contreni, John J., Two descriptions of the lost Laon copy of the 'Collection of SaintMaur', in: Bulletin of Medieval Canon Law 10 (1980) 45-51

Contreni, John J., Codex Laudunensis 468. A ninth-century guide to Virgil, Sedulius, and the liberal arts (Armarium Codicum insignium 3, Turnhout 1984)

Corbet, Patrick, Interdits de parenté, hagiographie et politique. La Passio Friderici episcopi Traiectensis (ca. 1024), in: Ius commune 23 (1996) 1-98 
Corbet, Patrick, Autour de Burchard de Worms. L'Église allemande et les interdits de parenté (IX ${ }^{\text {ème }}-X^{\text {XII }}{ }^{\text {ème }}$ siècle) (Ius commune Sonderhefte 142, Frankfurt 2001)

Corbet, Patrick, In multis orbis partibus. Léon IX et les interdits de parenté (10491054), in: Léon IX et son temps, hg. von Georges Bischoff - Benoît-Michel Tock (Atelier de Recherches sur les Textes Médiévaux 8, Turnhout 2006) 343-353

Corcoran, Simon, The empire of the Tetrarchs: Imperial pronouncements and government, AD 284-324 (Oxford 1996)

Corcoran, Simon, The Sins of the Fathers: a Neglected Constitution of Diocletian on incest, in: The Journal of Legal History 21 (2000) 1-34

Cortese, Ennio, Thinx, garethinx, thingatio, thingare, in gaida et gisil. Divagazione longobardistiche in tema di legislazione, manumissione dei servi, succcessioni volontarie, in: Rivista di storia del diritto italiano 61 (1988) 33-64

Cortese, Ennio, Il processo longobardo tra romanità e germanismo, in: La giustizia nell'alto Medioevo, secoli V-VIII (Settimane 42, Spoleto 1994) 621-647

Cracco Ruggini, Lellia, The Crisis of the noble Saint: The Vita Arnulfi, in: The Seventh Century. Change and Continuity, hg. von Jacques Fontaine - John N. Hillgarth (Studies of the Warburg Institute 42, London 1992) 116-149

Crouch, David, The birth of nobility. Constructing aristocracy in England and France, $900-1300$ (Harlow u. a. 2005)

Cubitt, Catherine, Anglo-Saxon Church Councils c. 650-c. 850 (London 1995)

Cubitt, Catherine, Bishops and Councils in late Saxon England: the intersection of secular and ecclesiastical law, in: Recht und Gericht in Kirche und Welt um 900, hg. von Wilfried Hartmann (Schriften des Historischen Kollegs, Kolloquium 69, München 2007) 151-167

Cuneo, Paola Ombretta, La legislazione di Costantino II, Costanzo II e Costante (337361) (Accademia Romanistica Costantiniana Ser. 2, 2, Mailand 1997)

Cushing, Kathleen G., Papacy and law in the Gregorian revolution: the canonistic work of Anselm of Lucca (Oxford 1993)

Daly, William M., Clovis: How Barbaric, How Pagan?, in: Speculum 69 (1994) 619_ 664

Damizia, Giuseppe, Il „Registrum epistolarum“ di S. Gregorio Magno ed il „Corpus Juris Civilis", in: Benedictina 2 (1948) 195-226

Dassmann, Ernst, Ambrosius von Mailand. Leben und Werk (Stuttgart 2004)

Daudet, Pierre, Études sur l'histoire de la juridiction matrimoniale. L'établissement de la compétence de l'Église en matière de divorce et consanguinité (France, $\mathrm{X}^{\text {ème }}$-XII ${ }^{\text {ème }}$ siècle) (Paris 1941)

Daudet, Pierre, Études sur l'histoire de la juridiction matrimoniale. Les origines carolingiennes de la compétence exclusive de l'Église (France et Germanie) (Paris 1933)

Dauvillier, Jean - Clercq, Charles de, Le mariage en droit canonique oriental (Paris 1936)

Davidsohn, Robert, Philipp II. August und Ingeborg (Stuttgart 1888)

Davidsohn, Robert, Geschichte von Florenz, 1: Ältere Geschichte (Berlin 1896)

Davies, Wendy - Fouracre, Paul, The Settlements of Disputes in Early Medieval Europe (Cambridge 1986)

Deanesly, Margaret - Grosjean, Paul, The Canterbury edition of the answers of pope Gregory I to St Augustine, in: Journal of Ecclesiastical History 10 (1959) 1-49

Delmaire, Roland, Largesses sacrées et 'Res Privata'. L'Aerarium' impérial et son administration du IVe au VIe siècle (Collection de l'École française de Rome 121, Rom 1989) 
Demandt, Alexander, Die Spätantike. Römische Geschichte von Diocletian bis Justinian, 284-565 n. Chr (Handbuch der Altertumswissenschaft 3/6, München ${ }^{2} 2007$ )

Denzler, Georg, Geschichte des Zölibats (Freiburg 1993)

Depreux, Philippe, Empereur, Empereur associé et Pape au temps de Louis le Pieux, in: Revue belge de philologie et d'histoire 70 (1992) 893-906

Depreux, Philippe, Prosopographie de l'entourage de Louis le Pieux (781-840) (Instrumenta 1, Sigmaringen 1997)

Depreux, Philippe, Ambitions et limites des réformes culturelle à l'époque carolingienne, in: Revue historique 307 (2002) 721-753

Depreux, Philippe, La loi et le droit. La part des échanges culturels dans la référence à la norme et les pratiques juridiques durant le haut Moyen Age, in : Les échanges culturels au Moyen Age (Publications de la Sorbonne. Histoire ancienne et médiévale 70, Paris 2002) 41-70

Depreux, Philippe, L'intégration des élites aristocratiques de Bavière et de Saxe au royaume des Francs - crise ou opportunité?, in: Les élites au Haut Moyen Âge. Crises et renouvellements, hg. von François Bougard u.a. (Collection Haut Moyen Âge 1, Turnhout 2006) 225-252

Depreux, Philippe, Défense d'un statut et contestation d'un modèle de société. Conjuration, révolte et répression dans l'Occident du Haut Moyen Âge, in: Revolte und Sozialstatus von der Spätantike bis zur Frühen Neuzeit, hg. von Philippe Depreux (Pariser Historische Studien 87, München 2008) 93-109

Deutsches Rechtswörterbuch. Wörterbuch der älteren deutschen Rechtssprache (Weimar 1914 ff.)

Devisse, Jean, Hincmar Archevêque de Reims, 845-882 (Travaux d'histoire éthicopolitique 29, Genf 1975-1976)

Dhondt, Jan, Études sur la naissance des principautés territoriales en France: IXe-Xe siècle (Brügge 1948)

Dhondt, Jan, Sept femmes et un trio de rois, in: Contributions à l'histoire économique et sociale 3 (1964-65) 35-70

Dilcher, Gerhard, Mittelalterliche Rechtsgewohnheit als methodisch-theoretisches Problem, in: Gewohnheitsrecht und Rechtsgewohnheiten im Mittelalter, hg. von Gerhard Dilcher u.a. (Schriften zur Europäischen Rechts- und Verfassungsgeschichte 6, Berlin 1992) 21-65

Dilcher, Gerhard, „Per gairethinx secundum ritus gentis nostrae confirmantes“. Zu Recht und Ritual im Langobardenrecht, in: Leges - Gentes - Regna. Zur Rolle von germanischen Rechtsgewohnheiten und lateinischer Schrifttradition bei der Ausbildung der frühmittelalterlichen Rechtskultur, hg. von Gerhard Dilcher - EvaMarie Distler (Berlin 2006) 419-448

Dilcher, Gerhard, Leges - Gentes - Regna. Zur Rolle normativer Traditionen germanischer Völkerschaften bei der Ausbildung der mittelalterlichen Rechtskultur: Fragen und Probleme, in: Leges - Gentes - Regna. Zur Rolle von germanischen Rechtsgewohnheiten und lateinischer Schrifttradition bei der Ausbildung der frühmittelalterlichen Rechtskultur, hg. von Gerhard Dilcher - Eva-Marie Distler (Berlin 2006) 15-42

Dixon, Suzanne, The Roman Family (Baltimore 1992)

Dobesch, Gerhard, Forschungsreferat zur Germania des Tacitus. Dieter Timpe, Romano-Germanica. Gesammelte Studien zur Germania des Tacitus, in: Tyche 13 (1998) 61-105 
Dölger, Franz, Regesten der Kaiserurkunden des oströmischen Reiches, 1: Regesten von 565-1025 (Corpus der griechischen Urkunden des Mittelalters und der neueren Zeit, Reihe A: Regesten 1, München - Berlin 1924)

Dots et douaires dans le haut Moyen Âge, hg. von François Bougard u. a. (Collection de l'École française de Rome 295, Rom 2002)

Douglas, Mary, Purity and danger. An analysis of concepts of pollution and taboo (New York 1966)

Drake, Harold A., Constantine and the Bishops. The Politics of Intolerance (Baltimore - London 2000)

Dreher, Martin, Die Ursprünge des Kirchenasyls und die Gesetzgebung Theodosius' II., in: Staatlichkeit und politisches Handeln in der römischen Kaiserzeit, hg. von Hans-Ulrich Wiemer (Millennium-Studien 10, Berlin - New York 2006) 151-174

Dressler, Fridolin, Petrus Damiani. Leben und Werk (Studia Anselmiana 34, Rom 1954)

Drews, Wolfram, Juden und Judentum bei Isidor von Sevilla. Studien zum Traktat „De fide catholica contra Iudaeos" (Berliner historische Studien 34, Berlin 2001)

Drummond, Andrew, Rome in the Fifth Century. The Social and Economic Framework, in: Cambridge Ancient History, 7/2: The rise of Rome to 220 B.C., hg. von Frank W. Walbank (Cambridge ${ }^{2} 1989$ ) $113-171$

Dubreucq, Alain, Jonas d'Orléans: Le métier du roi (Sources chrétiennes 407, Paris 1995)

Duby, Georges, Le chevalier, la femme et le prêtre. Le mariage dans la France féodale (Paris 1981)

Du Cange, Charles du Fresne, Glossarium mediae et infimae latinitatis 1-10 (Niort 1883-1887)

Ducloux, Anne, Ad ecclesiam confugere. Naissance du droit d'asile dans les églises (IV ${ }^{\mathrm{e}}$ milieu du V ${ }^{\mathrm{e}}$ s.) (Paris 1994)

Dümmler, Ernst, Geschichte des Ostfränkischen Reichs 1-3 (Leipzig ${ }^{2} 1887-1888$ )

Duval, Yves-Marie, La décrétale Ad Gallos Episcopos: son texte et son auteur (Supplements to Vigiliae Christianae 73, Leiden - Boston 2005)

Dworkin, Ronald, Justice in Robes (Cambridge/Mass. 2006)

Ebel, Else, Der Konkubinat nach altwestnordischen Quellen. Philologische Studien zur sogenannten „Friedelehe“ (RGA Erg.-Bd. 8, Berlin 1993)

Ebling, Horst, Prosopographie der Amtsträger des Merowingerreiches von Chlothar II. (613) bis Karl Martell (714) (München 1974)

Ebling, Horst - Jarnut, Jörg - Kampers, Gerd, Nomen et gens. Untersuchungen zu den Führungsschichten des Franken-, Langobarden- und Westgotenreiches im 6. und 7. Jahrhundert, in: Francia 8 (1980) 687-745

Eckhardt, Karl August, Zur Entstehungszeit der Lex Salica, in: Festschrift der Akademie der Wissenschaften in Göttingen (Göttingen 1951) 2, 1-31

Eckhardt, Karl August, Lex Salica. Der 100 Titel-Text (Germanenrechte N.F., Westgermanisches Recht 3, Weimar 1953)

Eckhardt, Karl August, Pactus Legis Salicae. Einführung und 80-Titel Text (Germanenrechte N.F., Westgermanisches Recht 1/1, Göttingen 1954)

Eckhardt, Karl August, Lex Ribuaria, 1: Austrasisches Recht im 7. Jahrhundert (Germanenrechte N.F., Westgermanisches Recht 7, Göttingen u.a. 1959)

Eckhardt, Wilhelm A., Die Kapitulariensammlung Bischof Ghaerbalds von Lüttich (Germanenrechte N. F., Deutschrechtliches Archiv 5, Göttingen u. a. 1955)

Eckhardt, Wilhelm A., Die Decretio Childeberti und ihre Überlieferung, in: ZRG GA 84 (1967) $1-71$ 
Ehlers, Caspar, Die Integration Sachsens in das fränkische Reich (Veröffentlichungen des Max-Planck-Instituts für Geschichte 231, Göttingen 2007)

Ehlers, Joachim, Die Kapetinger (Stuttgart u. a. 2000)

Eichhorn, Karl Friedrich, Grundsätze des Kirchenrechts der Katholischen und der Evangelischen Religionspartei in Deutschland 1-2 (Göttingen 1831-1833)

Engelbert, Pius, Das Papsttum in der Chronik Thietmars von Merseburg, in: RQ 97 (2002) 89-122

Engelbert, Pius, Heinrich III. und die Synoden von Sutri und Rom im Dezember 1046, in: RQ 94 (1999) 228-266

Engels, Odilo, Abhängigkeit und Unabhängigkeit der Spanischen Mark, in: ders., Reconquista und Landesherrschaft. Studien zur Rechts- und Verfassungsgeschichte Spaniens im Mittelalter (Rechts- und Staatswissenschaftliche Veröffentlichungen der Görres-Gesellschaft, N.F. 53, Paderborn u.a. 1989) 3-49 (erstmals 1961)

Enright, Michael J., Charles the Bald and Aethelwulf of Wessex: the alliance of 856 and strategies of royal succession, in: Journal of Medieval History 5 (1979) 291-302

Enßlin, Wilhelm, Die Religionspolitik des Kaisers Theodosius des Großen (Sitzungsberichte München, 1953)

Enßlin, Wilhelm, Theoderich der Große (München ${ }^{2} 1959$ )

Epp, Verena, Amicitia. Zur Geschichte personaler, sozialer, politischer und geistlicher Beziehungen im frühen Mittelalter (Monographien zur Geschichte des Mittelalters 44, Stuttgart 1999)

Erkens, Franz-Reiner, Konrad II. (um 990-1039). Herrschaft und Reich des ersten Salierkaisers (Regensburg 1998)

Erkens, Franz-Reiner, Herrschersakralität im Mittelalter. Von den Anfängen bis zum Investiturstreit (Stuttgart 2006)

Ernesti, Jörg, Princeps christianus und Kaiser aller Römer. Theodosius der Große im Lichte zeitgenössischer Quellen (Paderborner Theologische Studien 25, Paderborn u.a. 1998)

Errington, R. Malcolm, Christian Accounts of the Religious Legislation of Theodosius I., in: Klio 79 (1997) 398-443

Errington, R. Malcolm, Church and State in the First Years of Theodosius I., in: Chiron 27 (1997) $21-72$

Esbroek, Michel van, Un discours inédit de Germain de Constantinople sur la Croix et les Icônes, in: Orientalia Christiana Periodica 65 (1999) 19-51

Esders, Stefan, Rechtsdenken und Traditionsbewußtsein in der gallischen Kirche zwischen Spätantike und Frühmittelalter. Zur Anwendbarkeit soziologischer Rechtsbegriffe am Beispiel des kirchlichen Asylrechts im 6. Jahrhundert, in: Francia 20/1 (1993) 97-125

Esders, Stefan, Römische Rechtstradition und merowingisches Königtum. Zum Rechtscharakter politischer Herrschaft in Burgund im 6. und 7. Jahrhundert (Veröffentlichungen des Max-Planck-Instituts für Geschichte 134, Göttingen 1997)

Esders, Stefan, Regionale Selbstbehauptung zwischen Byzanz und dem Frankenreich. Die Inquisitio der Rechtsgewohnheiten Istriens durch die Sendboten Karls des Großen und Pippins von Italien, in: Eid und Wahrheitssuche. Studien zu rechtlichen Befragungspraktiken in Mittelalter und früher Neuzeit, hg. von Stefan Esders Thomas Scharff (Gesellschaft, Kultur und Schrift. Mediävistische Beiträge 7, Frankfurt/M. u. a. 1999) 49-112

Esders, Stefan, Treueidleistung und Rechtsveränderung im früheren Mittelalter, in: Rechtsveränderung im politischen und sozialen Kontext mittelalterlicher Rechts- 
vielfalt, hg. von Stefan Esders - Christine Reinle (Neue Aspekte der europäischen Mittelalterforschung 5, Münster 2005) 25-61

Esders, Stefan, Der Reinigungseid mit Helfern. Individuelle und kollektive Rechtsvorstellungen in der Wahrnehmung und Darstellung frühmittelalterlicher Konflikte, in: Rechtsverständnis und Konfliktbewältigung. Gerichtliche und außergerichtliche Strategien im Mittelalter, hg. von Stefan Esders (Köln u.a. 2007) 55-77

Esders, Stefan - Mierau, Heike Johanna, Der althochdeutsche Klerikereid. Bischöfliche Diözesangewalt, kirchliches Benefizialwesen und volkssprachliche Rechtspraxis im frühmittelalterlichen Baiern (MGH Studien und Texte 28, Hannover 2000)

Esmein, Adhémar, Le mariage en droit canonique 1-2 (Paris 1891)

Esmyol, Andrea, Geliebte oder Ehefrau? Konkubinen im frühen Mittelalter (AKG Beiheft 52, Köln/Weimar/Wien 2002)

Evans, James A., The Emperor Justinian and the Byzantine Empire (London u.a. 2005)

Evans-Grubbs, Judith, Law and Family in Late Antiquity: The Emperor Constantine's Marriage Legislation (Oxford 1995)

Evans-Pritchard, Edward E., Kinship and marriage among the Nuer (Oxford 1951)

Everett, Nicholas, Literacy in Lombard Italy, c. 568-774 (Cambridge studies in medieval life and thought 4th ser. 53, Cambridge 2003)

Everett, Nicholas, Paulinus, the Carolingians and famosissima Aquileia, in: Paolino d'Aquileia e il contributo italiano all'Europa carolingia, hg. von Paolo Chiesa (Udine 2003) 115-154

Everett, Nicholas, How territorial was Lombard Law?, in: Die Langobarden. Herrschaft und Identität, hg. von Walter Pohl - Peter Erhart (Forschungen zur Geschichte des Mittelalters 9, Wien 2005) 345-360

Ewig, Eugen, Die fränkischen Teilreiche im 7. Jahrhundert (613-714), in: ders., Spätantikes und fränkisches Gallien. Gesammelte Schriften, hg. von Hartmut Atsma (Beihefte der Francia 3, München 1976) 1, 172-230 (erstmals 1953)

Ewig, Eugen, Die fränkischen Teilungen und Teilreiche (511-613), in: ders., Spätantikes und fränkisches Gallien. Gesammelte Schriften, hg. von Hartmut Atsma (Beihefte der Francia 3, München 1976) 1, 114-171 (erstmals 1953)

Ewig, Eugen, Trier im Merowingerreich: Civitas, Stadt, Bistum (Trier 1954)

Ewig, Eugen, Die Civitas Ubiorum, die Francia Rinensis und das Land Ribuarien, in: ders., Spätantikes und fränkisches Gallien. Gesammelte Schriften, hg. von Hartmut Atsma (Beihefte der Francia 3, München 1976) 1, 450-471 (erstmals 1954)

Ewig, Eugen, Milo et eiusmodi similes, in: ders., Spätantikes und fränkisches Gallien. Gesammelte Schriften, hg. von Hartmut Atsma (Beihefte der Francia 3, München 1979) 2, 189-219 (erstmals 1954)

Ewig, Eugen, Zum christlichen Königsgedanken im Frühmittelalter, in: Das Königtum. Seine geistigen und rechtlichen Grundlagen (VuF 3, Sigmaringen 1956) 7-73

Ewig, Eugen, Descriptio Franciae, in: ders., Spätantikes und fränkisches Gallien. Gesammelte Schriften, hg. von Hartmut Atsma (Beihefte der Francia 3, München 1976) 1, 274-322 (erstmals 1965)

Ewig, Eugen, Die Stellung Ribuariens in der Verfassungsgeschichte der Merowingerzeit, in: ders., Spätantikes und fränkisches Gallien. Gesammelte Schriften, hg. von Hartmut Atsma (Beihefte der Francia 3, München 1976) 1, 450-471 (erstmals 1969)

Ewig, Eugen, Studien zur merowingischen Dynastie, in: FmSt 8 (1974) 15-59

Ewig, Eugen, Die Namengebung bei den ältesten Frankenkönigen und im merowingischen Königshaus, in: Francia 18/1 (1991) 21-69

Ewig, Eugen, Die Merowinger und das Frankenreich (Stuttgart u.a. ${ }^{4} 2001$ ) 
Fahrner, Ignaz, Geschichte des Unauflöslichkeitsprinzips und der vollkommenen Scheidung der Ehe im kanonischen Recht (Freiburg 1903)

Fastrich-Sutty, Isabella, Die Rezeption des Westgotischen Rechts in der Lex Baiuvariorum. Eine Studie zur Bearbeitung von Rechtstexten im frühen Mittelalter (Erlanger juristische Abhandlungen 51, Erlangen 2001)

Favrod, Justin, Histoire politique du royaume burgonde (443-534) (Lausanne 1997)

Fedwick, Paul J., The Translations of the Works of Basil Before 1400, in: Basil of Caesarea. Christian, Humanist, Ascetic, hg. von Paul J. Fedwick (Toronto 1981) 439-512

Fichtenau, Heinrich, Politische Datierungen des frühen Mittelalters, in: ders., Beiträge zur Mediävistik, 3: Lebensordnungen - Urkundenforschung - Mittellatein (Stuttgart 1986) 186-285 (erstmals 1973)

Ficker, Julius von, Untersuchungen zur Erbenfolge der ostgermanischen Rechte 1-6 (Innsbruck 1891-1904)

Fifth-Century Gaul. A Crisis of Identity?, hg. von John Drinkwater - Hugh Elton (Cambridge 1992)

Finsterwalder, Paul Willem, Eine parteipolitische Kundgebung eines Anhängers Lothars I., in: Neues Archiv 47 (1928) 393-415

Finsterwalder, Paul Willem, Die Canones Theodori Cantuarensis und ihre Überlieferungsformen (Untersuchungen zu den Bußbüchern des 7., 8. und 9. Jahrhunderts 1, Weimar 1929)

Finsterwalder, Paul Willem, Quellenkritische Untersuchungen zu den Capitularien Karls des Großen, in: HJb 58 (1938) 419-34

Fischer, Joseph Anton - Lumpe, Adolf, Die Synoden von den Anfängen bis zum Vorabend des Nicaenums (Konziliengeschichte, Reihe A: Darstellungen, Paderborn u.a. 1997)

Flandrin, Jean-Louis, Familien. Soziologie, Ökonomie, Sexualität (Frankfurt 1978)

Flechner, Roy, The Making of the Canons of Theodore, in: Peritia 17/18 (2003/2004) $121-143$

Fleckenstein, Josef, Problem und Gestalt der ottonisch-salischen Reichskirche, in: Reich und Kirche vor dem Investiturstreit. Festschrift Gerd Tellenbach, hg. von Karl Schmid (Sigmaringen 1985) 83-98

Fleury, Jean, Recherches historiques sur les empêchements de parenté dans le mariage canonique. Des origines aux Fausses Décretales (Paris 1933)

Fliche, Augustin, La réforme grégorienne, 1: La formation des idées grégoriennes (Spicilegium sacrum Lovaniense 6, Louvain - Paris 1924)

Fögen, Marie Theres, Gesetz und Gesetzgebung in Byzanz. Versuch einer Funktionsanalyse, in: Ius commune 14 (1987) $140-148$

Fögen, Marie Theres, Die Enteignung der Wahrsager. Studien zum kaiserlichen Wissensmonopol in der Spätantike (Frankfurt 1997)

Fögen, Marie Theres, Römische Rechtsgeschichten. Über Ursprung und Evolution eines sozialen Systems (Göttingen 2002)

Fögen, Marie Theres, Rechtsgeschichte - Geschichte der Evolution eines sozialen Systems. Ein Vorschlag, in: Rechtsgeschichte 1 (2002) 14-20

Fögen, Marie Theres, Armis et legibus gubernare. Zur Codierung von politischer Macht in Byzanz, in: Bilder der Macht in Mittelalter und Neuzeit. Byzanz - Okzident Russland, hg. von Otto Gerhard Oexle - Michail A. Bojcov (Veröffentlichungen des Max-Planck-Instituts für Geschichte 226, Göttingen 2007) 11-22 
Folz, Robert, Adalbéron II, évêque de Metz (984-1005), in: Ex ipsis rerum documentis. Beiträge zur Mediävistik. Festschrift Harald Zimmermann, hg. von Klaus Herbers u. a. (Sigmaringen 1991) 399-415

Foreville, Raymonde, Le pape Innocent III et la France (Päpste und Papsttum 26, Stuttgart 1992)

Foucault, Michel, Geschichte der Sexualität 1-3 (Frankfurt 1977-1986)

Fouracre, Paul, Merovingian History and Merovingian Hagiography, in: Past and Present 127 (1990) 3-38

Fouracre, Paul, Why were so many bishops killed in Merovingian Francia?, in: Bischofsmord im Mittelalter, hg. von Natalie M. Fryde - Dirk Reitz (Veröffentlichungen des Max-Planck-Instituts für Geschichte 191, Göttingen 2003) 13-35

Fouracre, Paul, The Origins of the Nobility in Francia, in: Nobles and Nobility in Medieval Europe. Concepts, Origins, Transformations, hg. von Anne J. Duggan (Woodbridge 2000) 17-24

Fouracre, Paul - Gerberding, Richard A., Late Merovingian France. History and Hagiography 640-720 (Manchester 1996)

Fournier, Paul, Le Liber ex lege Moysi et les tendances bibliques du droit canonique irlandais, in: Revue Celtique 30 (1909) 221-234

Fournier, Paul, Un tournant de l'histoire du droit: 1060-1140, in: Nouvelle Revue d'Histoire de Droit Français et Étranger 41 (1917) 129-180

Fournier, Paul, Notices sur trois collections canoniques inédites de l'époque carolingienne, in: ders., Mélanges de droit canonique (Aalen 1983) 145-187 (erstmals 1926)

Fournier, Paul - Le Bras, Gabriel, Histoire des collections canoniques en Occident depuis les fausses décrétales jusqu'au décret de Gratien, 1: De la réforme carolingienne à la réforme grégorienne (Paris 1931)

Fowler-Magerl, Linda, Clavis Canonum. Selected Canon Law Collections Before 1140 (MGH Hilfsmittel 21, Hannover 2005)

Franciosi, Gennaro, Clan gentilizio e strutture monogamiche. Contributo alla storia della famiglia romana (Napoli ${ }^{6} 1999$ )

Fransen, Gérard, La rupture du mariage, in: Il matrimonio nella società altomedievale (Settimane 24, Spoleto 1977) 604-630

Fransen, Gérard, La lettre de Hincmar de Reims au sujet du mariage d'Etienne. Une relecture, in: Pascua Mediaevalia. Studies J. M. De Smet, hg. von Robrecht Lievens u. a. (Mediaevalia Lovaniensia 1/10, Leuven 1983) 133-146

Frantzen, Allen J., The Literature of Penance in Anglo-Saxon England (New Brunswick 1983)

Frech, Karl Augustin, Papstregesten 1024-1058, 1: 1024-1046 (Regesta Imperii III/5, Köln u. a. 2006)

Freisen, Joseph, Geschichtliche Untersuchungen über die Verwandtschaftszählung nach kanonischem Recht, in: Archiv für Kirchenrecht 56 (1886) 217-263

Freisen, Joseph, Geschichte des kanonischen Eherechts bis zum Verfall der Glossenliteratur (Paderborn 1893)

Freund, Stephan, Studien zur literarischen Wirksamkeit des Petrus Damiani (MGH Studien und Texte 13, 1995)

Freund, Stephan, Von den Agilolfingern zu den Karolingern. Bayerns Bischöfe zwischen Kirchenorganisation, Reichsintegration und Karolingischer Reform (700-847) (Schriftenreihe zur Bayerischen Landesgeschichte 144, München 2004)

Fried, Johannes, Endzeiterwartung um die Jahrtausendwende, in: DA 45 (1989) 381473 
Fried, Johannes, Ludwig der Fromme, das Papsttum und die fränkische Kirche, in: Charlemagne's Heir. New Perspectives on the Reign of Louis the Pious (814-840), hg. von Peter Godman - Roger Collins (Oxford 1990) 231-273

Fried, Johannes, Der Weg in die Geschichte. Die Ursprünge Deutschlands bis 1024 (Propyläen Geschichte Deutschlands 1, Berlin 1994)

Fried, Johannes, Prolepsis oder Tod? Methodische und andere Bemerkungen zur Konradinergenealogie im 10. und frühen 11. Jahrhundert, in: Papstgeschichte und Landesgeschichte. Festschrift Hermann Jakobs, hg. von Joachim Dahlhaus - Armin Kohnle (AKG Beiheft 39, Köln u.a. 1995) 69-119

Fried, Johannes, Karl der Große, die Artes liberales und die karolingische Renaissance, in: Karl der Grosse und sein Nachwirken. 1200 Jahre Kultur und Wissenschaft in Europa, hg. von Paul L. Butzer u.a. (Turnhout 1997) 25-43

Fried, Johannes, Elite und Ideologie oder Die Nachfolgeordnung Karls des Großen vom Jahre 813, in: La royauté et les élites dans l'Europe carolingienne, hg. von Régine Le Jan (Collection Histoire et littérature régionales 17, Villeneuve d'Ascq 1998) 71 109

Fried, Johannes, Aufstieg aus dem Untergang. Apokalyptisches Denken und die Entstehung der modernen Naturwissenschaft im Mittelalter (München 2001)

Fried, Johannes, Konradiner und kein Ende oder Die Erfindung des Adelsgeschlechtes aus dem Geist der Kanonistik. Eine Auseinandersetzung mit Eduard Hlawitschka, in: ZRG GA 123 (2006) 1-66

Friell, Gerard - Williams, Stephen, Theodosius I. The empire at bay (London 1994)

Friesen, Bill, Answers and echoes: the Libellus responsionum and the hagiography of north-western European mission, in: EME 14 (2006) 153-172

Fritze, Wolfgang, Papst und Frankenkönig. Studien zu den päpstlich-fränkischen Rechtsbeziehungen von 754 bis 824 (VuF Sonderbad 10, Sigmaringen 1973)

Fröhlich, Hermann, Studien zur langobardischen Thronfolge von den Anfängen bis zur Eroberung des italienischen Reiches durch Karl den Großen (774) 1-2 (Diss. Tübingen 1980)

Fruscione, Daniela, Zur Frage eines germanischen Rechtswortschatzes, in: ZRG GA 122 (2005) $1-41$

Fruscione, Daniela, Ansätze übergreifender germanischer Rechtssprachen, in: Leges Gentes - Regna. Zur Rolle von germanischen Rechtsgewohnheiten und lateinischer Schrifttradition bei der Ausbildung der frühmittelalterlichen Rechtskultur, hg. von Gerhard Dilcher - Eva-Marie Distler (Berlin 2006) 167-182

Fürst, Carl Gerold, Ecclesia vivit lege Romana?, in: ZRG KA 61 (1975) 17-36

Fuhrmann, Horst, Einfluss und Verbreitung der pseudoisidorischen Fälschungen (MGH Schriften 24/1-3, Hannover 1972)

Fuhrmann, Horst, Das Reformpapsttum und die Rechtswissenschaft, in: Investiturstreit und Reichsverfassung, hg. von Josef Fleckenstein (VuF 17, Sigmaringen 1973) $175-203$

Fuhrmann, Horst, Fälscher unter sich: Zum Streit zwischen Hinkmar von Reims und Hinkmar von Laon, in: Charles the Bald. Court and Kingdom, hg. von Margaret T. Gibson - Janet Nelson (Oxford 1981) 237-254

Fuhrmann, Horst, Das Papsttum und das kirchliche Leben im Frankenreich, in: Nascita dell'Europa ed Europa Carolingia. Un'equazione da verificare (Settimane 27, Spoleto 1981) 419-456

Fuhrmann, Horst, Überall ist Mittelalter. Von der Gegenwart einer vergangenen Zeit (München 1989) 
Frye, David, Gundobad, the Leges Burgundionum, and the Struggle for Sovereignty in Burgundy, in: Classica et Mediaevalia 41 (1990) 199-212

Gaca, Kathy L., The Making of Fornication. Eros, Ethics, and Political Reform in Greek Philosophy and Early Christianity (Hellenistic culture and society 40, Berkeley 2003)

Gädeke, Nora, Zeugnisse bildlicher Darstellung der Nachkommenschaft Heinrichs I. (Arbeiten zur Frühmittelalterforschung 22, Berlin - New York 1992)

Ganshof, François-Louis, Zur Datierung eines Aachener Kapitulars Karls des Großen, in: Annalen des Historischen Vereins für den Niederrhein 155/156 (1954) 62-66

Ganshof, François-Louis, Le statut de la femme dans la monarchie franque, in: Recueils de la Société Jean Bodin 12 (1962) 5-58

Ganshof, François-Louis, Charlemagne's programme of imperial government, in: ders., The Carolingians and the Frankish Monarchy. Studies in Carolingian History (London 1971) 55-85 (erstmals 1963)

Ganz, David, Corbie in the Carolingian Renaissance (Beihefte der Francia 20, Sigmaringen 1990)

Ganz, David, The Study of Caroline Minuscule 1953-2004, in: Archiv für Diplomatik 50 (2004) 387-398

García Moreno, Luis A., Prosopografía del reino visigodo de Toledo (Acta Salmanticensia, Filosofía y letras 77, Salamanca 1974)

García Moreno, Luis A., Los judíos de la España antigua. Del primer encuentro al primer repudio (Madrid 1993)

Garrison, Mary, The Franks as the New Israel?, in: The Uses of the Past in the Early Middle Ages, hg. von Yitzhak Hen - Matthew Innes (Cambridge 2000) 114-161

Gattucci, Adriano, San Pier Damiani, il matrimonio, la castità e l'esemplarità animalesca, in: Studi Medievali 30 (1989) 697-748

Gaudemet, Jean, Le lien matrimonial: les incertitudes du Haut Moyen-Age, in: Le lien matrimonial, hg. von René Metz (Straßburg 1970) 81-105

Gaudemet, Jean, Les sources du droit de l'Église en occident du $\mathrm{II}^{\mathrm{e}}$ au VII $\mathrm{VI}^{\mathrm{e}}$ siècle (Paris 1985)

Gaudemet, Jean, Le mariage en Occident. Les mœurs et le droit (Paris 1987)

Gaudemet, Jean - Basdevant, Brigitte, Les canons des conciles mérovingiens (VIe - VIIe siècles) 1-2 (Paris 1989)

Gaudemet, Jean, Du droit romain tardif aux conciles mérovingiens: Les condamnations de l'inceste, in: ZRG KA 82 (1996) 369-379

Gauthier, Nancy, Lévangélisation des pays de la Moselle. La province romaine de Première Belgique entre Antiquité et Moyen-Âge (III. - VIII. siècles) (Paris 1980)

Geary, Patrick, Aristocracy in Provence. The Rhône Basin at the dawn of the Carolingian age (Monographien zur Geschichte des Mittelalters 31, Stuttgart 1985)

Geary, Patrick, Extra-judicial means of conflict resolution, in: La giustizia nell'Alto Medioevo (secoli V-VIII) (Settimane 42, Spoleto 1995) 569-601

Geffcken, Heinrich, Lex Salica zum akademischen Gebrauche (Leipzig 1898)

Geldner, Ferdinand, Tatsachen und Probleme der Vor- und Frühgeschichte des Hochstifts Bamberg (Bamberger Studien zur fränkischen und deutschen Geschichte 2, Bamberg 1973)

Genzmer, Felix, Die germanische Sippe als Rechtsgebilde, in: ZRG GA 67 (1950) $34-$ 49

George, Judith W., Venantius Fortunatus. A Latin poet in Merovingian Gaul (Oxford 1992) 
Gerberding, Richard A., The rise of the Carolingians and the „Liber Historiae Francorum" (Oxford 1987)

Gero, Stephen, Byzantine Iconoclasm during the Reign of Leo III. (Corpus scriptorum christianorum orientalium, Subsidia 41, Louvain 1973)

Getzeny, Heinrich, Stil und Form der ältesten Papstbriefe bis auf Leo d. Großen. Ein Beitrag zur Geschichte des römischen Primats (Günzburg 1922)

Giardina, Andrea, The Family in the Late Roman World, in: The Cambridge Ancient History 14: Late Antiquity: Empire and Successors, AD 425-600, hg. von Averil Cameron u.a. (Cambridge 2000) 392-415

Giddens, Anthony, Die Konstitution der Gesellschaft. Grundzüge einer Theorie der Strukturierung (Frankfurt 1988)

Girardet, Klaus Martin, Die Konstantinische Wende. Voraussetzungen und geistige Grundlagen der Religionspolitik Konstantins des Großen (Darmstadt 2006)

Glatthaar, Michael, Bonifatius und das Sakrileg. Zur politischen Dimension eines Rechtsbegriffs (Freiburger Beiträge zur mittelalterlichen Geschichte 17, Frankfurt u.a. 2004)

Glocker, Winfrid, Die Verwandten der Ottonen und ihre Bedeutung in der Politik. Studien zur Familienpolitik und zur Genealogie des sächsischen Kaiserhauses (Dissertationen zur mittelalterlichen Geschichte 5, Köln - Wien 1989)

Gockel, Michael, Karolingische Königshöfe am Mittelrhein (Veröffentlichungen des Max-Planck-Instituts für Geschichte 31, Göttingen 1971)

Godding, Robert, Prêtres en Gaule mérovingienne (Subsidia hagiographica 82, Brüssel 2001).

Godefroy, Frédéric, Dictionnaire de l'ancienne langue française et de tous ses dialectes du IXe au XVe siècle 1-10 (Paris 1881-1902)

Görich, Knut, Eine Wende im Osten: Heinrich II. und Boleslaw Chrobry, in: Otto III. - Heinrich II. Eine Wende?, hg. von Bernd Schneidmüller - Stefan Weinfurter (Sigmaringen 1997) 95-167

Görich, Knut, Neue Bücher zum hochmittelalterlichen Königtum, in: HZ 275 (2002) $105-125$

Goetz, Hans-Werner, Gentes in der Wahrnehmung frühmittelalterlicher Autoren und moderner Ethnogeneseforschung. Zur Problematik einer gentilen Zuordnung von Personennamen, in: Person und Name. Methodische Probleme bei der Erstellung eines Personennamenbuches des Frühmittelalters, hg. von Dieter Geuenich u.a. (RGA Erg.-Bd. 32, Berlin 2002) 204-220

Goetz, Hans-Werner, Die Gottesfrieden im Licht neuerer Forschungen, in: Landfrieden. Anspruch und Wirklichkeit, hg. von Arno Buschmann - Elmar Wadle (Rechts und Staatswissenschaftliche Veröffentlichungen der Görres-Gesellschaft N.F. 98, Paderborn u. a. 2002) 31-54

Goez, Elke, Beatrix von Canossa und Tuszien. Eine Untersuchung zur Geschichte des 11. Jahrhunderts (VuF Sonderband 41, Sigmaringen 1995)

Goez, Werner, Lebensbilder aus dem Mittelalter. Die Zeit der Ottonen, Salier und Staufer (Darmstadt ${ }^{2} 1998$ )

González-Salinero, Raúl, Catholic Anti-Judaism in Visigothic Spain, in: The Visigoths. Studies in Culture and Society, hg. von Alberto Ferreiro (The Medieval Mediterranean 20, Leiden u.a. 1998) 123-150

Goody, Jack, A comparative approach to incest and adultery, in: The British Journal of Sociology 7 (1956) 286-305

Goody, Jack, The development of the family and marriage in Europe (Cambridge 1983) 
Goody, Jack, The oriental, the ancient and the primitive. Systems of marriage and the family in the pre-industrial societies of Eurasia (Cambridge 1990)

Goody, Jack, Geschichte der Familie (München 2002)

Grandjean, Michel, Laïcs dans l'Église. Regards de Pierre Damien, Anselme de Cantorbéry, Ives de Chartres (Paris 1994)

Gresser, Georg, Die Synoden und Konzilien in der Zeit des Reformpapsttums in Deutschland und Italien von Leo IX. bis Calixt II. 1049-1123 (Konziliengeschichte, Reihe A: Darstellungen, Paderborn u. a. 2006)

Grierson, Philip, Eudes I ${ }^{\text {er }}$ Evêque de Beauvais, in: Le Moyen Âge 45 (1935) 160-198

Grimm, Jacob, Deutsche Rechtsalterthümer (Leipzig ${ }^{4} 1899$ )

Grönbech, Wilhelm, Kultur und Religion der Germanen 1-2 (Darmstadt ${ }^{8} 1978$ )

Grumel, Venance - Darrouzès, Jean, Les regestes des actes du patriarcat de Constantinople, $1 / 2-3$ : Les regestes de 715 à 1206 (Paris 1989)

Grund, Karl, Die Anschauungen des Rodulphus Glaber in seinen Historien (Greifswald 1910)

Guarino, Antonio, Studi sul incestum, in: ZRG RA 63 (1943) 175-268

Guerreau-Jalabert, Anita, La parenté dans l'Europe médiévale et moderne: à propos d'une synthèse récente, in : L'Homme 110 (1989) 69-93

Guerreau-Jalabert, Anita, Prohibitions canoniques et stratégies matrimoniales dans l'aristocratie médiévale de la France du Nord, in: Epouser au plus proche. Inceste, prohibitions et stratégies matrimoniales autour de la Méditerranée, hg. von Paul Bonte (Paris 1994) 293-321

Guillot, Olivier, Le comte d'Anjou et son entourage au XI ${ }^{\mathrm{e}}$ siècle 1-2 (Paris 1972)

Guillot, Olivier, La justice dans le royaume franc à l'époque mérovingienne, in: La giustizia nell'Alto Medioevo (secoli V-VIII) (Settimane 42, Spoleto 1995) 653731

Guterman, Simeon L., The Principle of the Personality of Law in the Germanic Kingdoms of Western Europe from the Fifth to the Eleventh Century (New York u. a. 1990)

Guttenberg, Erich Freiherr von, Über den Rangau, in: Herzogenaurach. Ein Heimatbuch, hg. von Valentin Fröhlich (Herzogenaurach 1949) 29-45

Guttenberg, Erich Freiherr von, Die Regesten der Bischöfe und des Domkapitels von Bamberg (Würzburg 1932-1963)

Haarländer, Stephanie, Vitae episcoporum. Eine Quellengattung zwischen Hagiographie und Historiographie, untersucht an Lebensbeschreibungen von Bischöfen des Regnum Teutonicum im Zeitalter der Ottonen und Salier (Monographien zur Geschichte des Mittelalters 47, Stuttgart 2000)

Hack, Achim Thomas, Codex Carolinus. Päpstliche Epistolographie im 8. Jahrhundert (Päpste und Papsttum 35, Stuttgart 2006)

Hacking, Ian, The Social Construction of What? (Cambridge/Mass. 1999)

Hägermann, Dieter, Karl der Große. Herrscher des Abendlandes (Berlin - München 2000)

Hage, Athanase, Les empêchements de mariage en droit canonique oriental. Étude historico-canonique (Beirut 1954)

Haggenmüller, Reinhold, Die Überlieferung der Beda und Egbert zugeschriebenen Bußbücher (Europäische Hochschulschriften 3/461, Frankfurt 1991)

Haggenmüller, Reinhold, Zur Rezeption der Beda und Egbert zugeschriebenen Bußbücher, in: Aus Archiven und Bibliotheken. Festschrift für Raymund Kottje zum 65. Geburtstag, hg. von Hubert Mordek (Freiburger Beiträge zur mittelalterlichen Geschichte 3, Frankfurt u.a. 1992) 149-159 
Hahn, Johannes, Gewalt und religiöser Konflikt. Studien zu den Auseinandersetzungen zwischen Christen, Heiden und Juden im Osten des Römischen Reiches (von Konstantin bis Theodosius II.) (Klio, Beihefte N.F. 8, Berlin 2004)

Halban, Alfred von, Das römische Recht in den germanischen Volksstaaten. Ein Beitrag zur deutschen Rechtsgeschichte 1-3 (Untersuchungen zur deutschen Staats- und Rechts-Geschichte 56, 64, 89, Breslau 1899-1907)

Haldon, John F., Some Remarks on the Background to the Iconoclast Controversy, in: Byzantinoslavica 38 (1977) $161-184$

Haldon, John F., Byzantium in the seventh century. The transformation of a culture (Cambridge 1990)

Haldon, John F. - Ward-Perkins, Bryan, Evidence from Rome for the image of Christ on the Chalke gate in Constantinople, in: Byzantine and Modern Greek Studies 23 (1999) 286-296

Haller, Johannes, Nikolaus I. und Pseudoisidor (Stuttgart 1936)

Haller, Johannes, Das Papstum. Idee und Wirklichkeit 1-5 (Darmstadt 1962)

Halphen, Louis, Le comté d'Anjou au XI ${ }^{\mathrm{e}}$ siècle (Paris 1906)

Halsall, Guy, Settlement and social organization. The Merovingian region of Metz (Oxford 1995)

Halsall, Guy, Nero and Herod? The death of Chilperic and Gregory's writing of history, in: The World of Gregory of Tours, hg. von Kathleen A. Mitchell - Ian N. Wood (Cultures, beliefs and traditions 8, Leiden u. a. 2002) 337-350

Halsall, Guy, Warfare and Society in the Barbarian West, 450-900 (London - New York 2003)

Halsall, Guy, Barbarian Migrations and the Roman West, 376-568 (Cambridge 2007)

Hamann, Stefanie, Zur Chronologie des Staatsstreiches Grimoalds, in: DA 59 (2003) 49-96

Hamer, Mary, Incest. A new perspective (Cambridge/Mass. 2002)

Hamilton, Bernard, Die christliche Welt des Mittelalters. Der Osten und der Westen (Düsseldorf - Zürich 2004)

Hamilton, Sarah, A new model for royal penance? Helgaud of Fleury's Life of Robert the Pious, in: EME 6 (1997) 189-200

Hanard, Gilbert, Inceste et société romaine républicaine: un essai d'interprétation ethnojuridique du fragment du livre XX de l'histoire romaine de Tite-Live, in: Revue belge de philologie et d'histoire 64 (1986) 32-61

Hardinge, Leslie, The Celtic Church in Britain (London 1972)

Harries, Jill, Sidonius Apollinaris and the fall of Rome, AD 407-485 (Oxford 1994)

Harries, Jill, How to Make a Law Code, in: Modus Operandi: Essays in Honour of Geoffrey Rickman, hg. von Michael M. Austin u.a. (Bulletin of the Institute of Classical Studies of the University of London Suppl. 71, London 1998) 63-78

Harries, Jill, Law and Empire in Late Antiquity (Cambridge 1999)

Harries, Jill, Not the Theodosian Code: Euric's Law and Late Fifth-Century Gaul, in: Society and culture in late antique Gaul: revisiting the sources, hg. von Ralph W. Mathisen - Danuta Shanzer (Ashgate 2001) 39-51

Hart, H.L.A., The concept of law (Oxford 1961)

Hartmann, Wilfried, Das Konzil von Worms 868. Überlieferung und Bedeutung (Abhandlungen Göttingen 3/105, Göttingen 1977)

Hartmann, Wilfried, Der rechtliche Zustand der Kirchen auf dem Lande: Die Eigenkirche in der fränkischen Gesetzgebung des 7. bis 9. Jahrhunderts, in: Cristianizzazione ed organizzazione ecclesiastica delle campagne nell'Alto Medioevo: Espansione e resistenze (Settimane 28, 1982) 397-441 
Hartmann, Wilfried, Vetera et nova. Altes und neues Kirchenrecht in den Beschlüssen karolingischer Konzilien, in: AHC 15 (1983) 79-95

Hartmann, Wilfried, Die karolingische Reform und die Bibel, in: AHC 18 (1986) 5874

Hartmann, Wilfried, Der Bischof als Richter. Zum geistlichen Gericht über kriminelle Vergehen von Laien im früheren Mittelalter (6.-11. Jahrhundert), in: Römische Historische Mitteilungen 28 (1986) 103-124

Hartmann, Wilfried, Die Synoden der Karolingerzeit im Frankenreich und in Italien (Konziliengeschichte, Reihe A: Darstellungen, Paderborn u.a. 1989)

Hartmann, Wilfried, Autoritäten im Kirchenrecht und Autorität des Kirchenrechts in der Salierzeit, in: Die Salier und das Reich, hg. von Stefan Weinfurter (Sigmaringen 1991) 3, 425-446

Hartmann, Wilfried, Rechtskenntnis und Rechtsverständnis bei den Laien des früheren Mittelalters, in: Aus Archiven und Bibliotheken. Festschrift für Raymund Kottje zum 65. Geburtstag, hg. von Hubert Mordek (Freiburger Beiträge zur mittelalterlichen Geschichte 3, Frankfurt u.a. 1992) 1-20

Hartmann, Wilfried, Verso il centralismo papale. Leone IX, Niccolò II, Gregorio VII, Urbano II, in: Il secolo XI. Una svolta?, hg. von Cinzio Violante - Johannes Fried (Annali dell'Istituto storico italo-germanico in Trento. Quaderno 35, Bologna 1993) 99- 130

Hartmann, Wilfried, Über Liebe und Ehe im früheren Mittelalter. Einige Bemerkungen zu einer Geschichte des Gefühls, in: De iure canonico Medii Aevi. Festschrift Rudolf Weigand, hg. von Peter Landau (Studia Gratiana 27, Rom 1996) 189-216

Hartmann, Wilfried, Der Investiturstreit (Enzyklopädie deutscher Geschichte 21, München ${ }^{3}$ 2007)

Hartmann, Wilfried, Karl der Große und das Recht, in: Karl der Grosse und sein Nachwirken. 1200 Jahre Kultur und Wissenschaft in Europa, hg. von Paul L. Butzer u.a. (Turnhout 1997) 173-192

Hartmann, Wilfried, Zur Autorität des Papsttums im karolingischen Frankenreich, in: Mönchtum - Kirche - Herrschaft: 750-1000, hg. von Dieter R. Bauer (Sigmaringen 1998) $113-132$

Hartmann, Wilfried, Burchards Dekret. Stand der Forschung und offene Fragen, in: Bischof Burchard von Worms 1000-1025, hg. von Wilfried Hartmann (Quellen und Abhandlungen zur mittelrheinischen Kirchengeschichte 100, Mainz 2000) $161-166$

Hartmann, Wilfried, Bemerkungen zum Eherecht nach Burchard von Worms, in: Bischof Burchard von Worms 1000-1025, hg. von Wilfried Hartmann (Quellen und Abhandlungen zur mittelrheinischen Kirchengeschichte 100, Mainz 2000) 227250

Hartmann, Wilfried, Die Briefe Fulberts von Chartres als Quelle für die Praxis des bischöflichen Gerichts in Frankreich am Beginn des 11. Jahrhunderts, in: Grundlagen des Rechts. Festschrift für Peter Landau zum 65. Geburtstag, hg. von Richard H. Helmholz u.a. (Rechts- und Staatswissenschaftliche Veröffentlichungen der Görres-Gesellschaft N.F. 91, Paderborn 2000) 93-103

Hartmann, Wilfried, Ludwig der Deutsche (Darmstadt 2002)

Hartmann, Wilfried, Die Capita incerta im Sendhandbuch Reginos von Prüm, in: Scientia veritatis. Festschrift für Hubert Mordek zum 65. Geburtstag, hg. von Oliver Münsch - Thomas Zotz (Ostfildern 2004) 207-216 
Hartmann, Wilfried, Einige Fragen zur Lex Alamannorum, in: Der Südwesten im 8. Jahrhundert aus historischer und archäologischer Sicht, hg. von Hans Ulrich Nuber u. a. (Archäologie und Geschichte 13, Ostfildern 2004) 313-333

Hartmann, Wilfried, Einleitung, in: Das Sendhandbuch des Regino von Prüm, hg. von Wilfried Hartmann (Freiherr vom Stein-Gedächtnisausgabe 42, Darmstadt 2004)

Hartmann, Wilfried, „Sozialdisziplinierung“ und „Sündenzucht“ im frühen Mittelalter? Das bischöfliche Sendgericht in der Zeit um 900, in: Jahrbuch des Historischen Kollegs 2005, 95-119

Hartmann, Wilfried, Zur Effektivität und Aktualität von Reginos Sendhandbuch, in: Medieval Church Law and the Origins of the Western Legal Tradition. A Tribute to Kenneth Pennington, hg. von Wolfgang P. Müller - Mary E. Sommar (Washington 2006) 32-49

Haubrichs, Wolfgang, Romanen an Rhein und Mosel. Onomastische Reflexionen, in: Deutsche Sprache in Raum und Zeit. Festschrift P. Wiesinger, hg. von Peter Ernst Franz Patocka (Wien 1998) 379-413

Haubrichs, Wolfgang, Identität und Name. Akkulturationsvorgänge in Namen und die Traditionsgesellschaften des frühen Mittelalters, in: Die Suche nach den Ursprüngen. Von der Bedeutung des frühen Mittelalters, hg. von Walther Pohl (Forschungen zur Geschichte des Mittelalters 8, Wien 2004) 85-105

Hauck, Albert, Kirchengeschichte Deutschlands 1-5 (Berlin $\left.{ }^{8} 1954\right)$

Head, Thomas F. - Landes, Richard, The peace of God. Social violence and religious response in France around the year 1000 (Ithaca 1992)

Heather, Peter, The fall of the Roman Empire. A new history of Rome and the barbarians (Oxford 2006)

Hechberger, Werner, Adel im fränkisch-deutschen Mittelalter. Zur Anatomie eines Forschungsproblems (Mittelalter-Forschungen 17, Ostfildern 2005)

Heers, Jacques, Le clan familial au Moyen Age (Paris 1974)

Hefele, Karl Joseph - Leclercq, Henri, Histoire des conciles 1-5 (Paris 1907-1921)

Hehl, Ernst-Dieter, Iuxta canones et instituta sanctorum patrum. Zum Mainzer Einfluß auf Synoden des 10. Jahrhunderts, in: Papsttum, Kirche und Recht im Mittelalter. Festschrift Horst Fuhrmann, hg. von Hubert Mordek (Tübingen 1991) 117-133

Hehl, Ernst-Dieter, Herrscher, Kirche und Kirchenrecht im spätottonischen Reich, in: Otto III. - Heinrich II. Eine Wende?, hg. von Bernd Schneidmüller - Stefan Weinfurter (Sigmaringen 1997) 169-203

Hehl, Ernst-Dieter, Willigis von Mainz. Päpstlicher Vikar, Metropolit und Reichspolitiker, in: Bischof Burchard von Worms 1000-1025, hg. von Wilfried Hartmann (Quellen und Abhandlungen zur mittelrheinischen Kirchengeschichte 100, Mainz 2000) $51-77$

Hehl, Ernst-Dieter, Die Synoden des ostfränkisch-deutschen und des westfränkischen Reichs im 10. Jahrhundert. Karolingische Traditionen und Neuansätze, in: Recht und Gericht in Kirche und Welt um 900, hg. von Wilfried Hartmann (Schriften des Historischen Kollegs, Kolloquium 69, München 2007) 125-150

Heidecker, Karl, Kerk, huwelijk en politieke macht: de zaak Lotharius II 855-869 (Amsterdam 1997)

Heil, Johannes, Kompilation oder Konstruktion? Die Juden in den Pauluskommentaren des 9. Jahrhunderts (Forschungen zur Geschichte der Juden, Abhandlungen 6, Hannover 1998)

Heinzelmann, Martin, Bischofsherrschaft in Gallien. Zur Kontinuität römischer Führungsschichten vom 5 . bis zum 7. Jahrhundert. Soziale, prosopographische und bildungsgeschichtliche Aspekte (Beihefte der Francia 5, München 1976) 
Heinzelmann, Martin, Bischof und Herrschaft vom spätantiken Gallien bis zu den karolingischen Hausmeiern. Die institutionellen Grundlagen, in: Herrschaft und Kirche. Beiträge zur Entstehung und Wirkungsweise episkopaler und monastischer Organisationsformen, hg. von Friedrich Prinz (Monographien zur Geschichte des Mittelalters 33, Stuttgart 1988) 23-82

Heinzelmann, Martin, Gregor von Tours (538-594): „Zehn Bücher Geschichte“. Historiographie und Gesellschaftskonzept im 6. Jahrhundert (Darmstadt 1994)

Hellmann, Siegmund, Die Heiraten der Karolinger, in: ders., Ausgewählte Abhandlungen zur Historiographie und Geistesgeschichte des Mittelalters (Darmstadt 1961) 293-391 (erstmals 1903)

Helmholz, Richard Henry, Marriage litigation in Medieval England (Cambridge 1974)

Helmolt, Hans F., Zu Otto von Hammerstein, in: NA 21 (1895) 221-222

Hen, Yitzhak, Culture and Religion in Merovingian Gaul, A.D. 481-751 (Cultures, Beliefs and Traditions 1, Leiden u.a. 1995).

Hen, Yitzhak, The Christianisation of Kingship, in: Der Dynastiewechsel von 751. Vorgeschichte, Legitimationsstrategien und Erinnerung, hg. von Matthias Becher Jörg Jarnut (Münster 2004) 163-177

Hen, Yitzhak, Charlemagne's Jihad, in: Viator 37 (2006) 33-51

Héritier, Françoise, Les deux sœurs et leur mère. Anthropologie de l'inceste (Paris 1994) Herlihy, David, Making sens of incest: women and the marriage rules of the Early Middle Ages, in: Law, custom and the social fabric in Medieval Europe. Essays in honour of Bryce Lyon, hg. von Bernard S. Bachrach - David Nicholas (Studies in Medieval Culture 28, Kalamazoo 1990) 1-16

Herrmann, Klaus-Jürgen, Das Tuskulanerpapsttum (1012-1046). Benedikt VIII., Johannes XIX., Benedikt IX. (Päpste und Papsttum 4, Stuttgart 1973)

Hess, Hamilton, The early development of Canon law and the Council of Serdica (Oxford 2002)

Heuclin, Jean, Le concile d'Orléans de 511, un premier concordat?, in: Clovis. Histoire et mémoire, 1: Le baptême de Clovis, l'événement, hg. von Michel Rouche (Paris 1997) 435-449

Hinschius, Paul, System des katholischen Kirchenrechts mit besonderer Rücksicht auf Deutschland 1-5 (Berlin 1869-1897)

Hirsch, Siegfried - Bresslau, Harry, Jahrbücher des Deutschen Reichs unter Heinrich II. 1-3 (Berlin 1862-1875)

Historische Inzestdiskurse. Interdisziplinäre Zugänge, hg. von Jutta Eming - Claudia Jarzebowski - Claudia Ulbrich (Königstein/Ts. 2003)

Hlawitschka, Eduard, Die Vorfahren Karls des Großen, in: Karl der Grosse, 1: Lebenswerk und Nachleben, hg. von Helmut Beumann (Düsseldorf 1965) 51-82

Hlawitschka, Eduard, Lotharingien und das Reich an der Schwelle der deutschen Geschichte (MGH Schriften 21, Stuttgart 1968)

Hlawitschka, Eduard, Die Anfänge des Hauses Habsburg-Lothringen. Genealogische Untersuchungen zur Geschichte Lothringens und des Reiches im 9., 10. und 11. Jahrhundert (Veröffentlichungen der Kommission für Saarländische Landesgeschichte und Volksforschung 4, Saarbrücken 1969)

Hlawitschka, Eduard, Untersuchungen zu den Thronwechseln der ersten Hälfte des 11. Jahrhunderts und zur Adelsgeschichte Süddeutschlands. Zugleich klärende Forschungen um „Kuno von Öhningen“ (VuF Sonderband 35, Sigmaringen 1987)

Hlawitschka, Eduard, Der Thronwechsel des Jahres 1002 und die Konradiner. Eine Auseinandersetzung mit zwei Arbeiten von Armin Wolf u. Donald C. Jackman, in: ZRG GA 110 (1993) 149-248 
Hlawitschka, Eduard, Konradiner-Genealogie, unstatthafte Verwandtenehen und spätottonisch-frühsalische Thronbesetzungspraxis. Ein Rückblick auf 25 Jahre Forschungsdisput (MGH Studien und Texte 32, Hannover 2003)

Hlawitschka, Eduard, Warum war die Auflösung der Ehe Friedrich Barbarossas und Adelas von Vohburg möglich?, in: DA 61 (2005) 509-536

Hlawitschka, Eduard, Die Ahnen der hochmittelalterlichen deutschen Könige, Kaiser und ihrer Gemahlinnen, 1: 911-1137 (MGH Hilfsmittel 25, Hannover 2006)

Hoareau-Dodinau, Jacqueline, Dieu et le roi. La répression du blasphème et de l'injure au roi à la fin du Moyen Age (Limoges 2002)

Hoffmann, Hartmut, Gottesfriede und Treuga Dei (MGH Schriften 20, Stuttgart 1964)

Hoffmann, Hartmut, Buchkunst und Königtum im ottonischen und frühsalischen Reich (MGH Schriften 30, Stuttgart 1986)

Hoffmann, Hartmut, Mönchskönig und rex idiota. Studien zur Kirchenpolitik Heinrichs II. und Konrads II. (MGH Studien und Texte 8, Hannover 1993)

Hoffmann, Hartmut, Der König und seine Bischöfe in Frankreich und im Deutschen Reich 936-1060, in: Bischof Burchard von Worms. 1000-1025, hg. von Wilfried Hartmann (Quellen und Abhandlungen zur mittelrheinischen Kirchengeschichte 100, Mainz 2000) 79-127

Hoffmann, Hartmut, Schreibschulen des 10. und 11. Jahrhunderts im Südwesten des Deutschen Reichs (MGH Schriften 53/1-2, Hannover 2004)

Hoffmann, Hartmut - Pokorny, Rudolf, Das Dekret des Bischofs Burchard von Worms. Textstufen - Frühe Verbreitung - Vorlagen (MGH Hilfsmittel 12, München 1991)

Hofmann, Hanns Hubert, Herzogenaurach. Die Geschichte eines Grenzraumes in Franken (Schriften des Instituts für fränkische Landesforschung 2, Nürnberg 1950)

Hohl, Claude, Le comte Landri de Nevers dans l'histoire et dans la geste de Gérart de Roussillon, in: La Chanson de geste et le mythe carolingien. Mélanges René Louis (Saint-Père-sous-Velay 1982) 2, 779-866

Holmes, Catherine, Basil II and the Governance of Empire (976-1025) (Oxford 2005)

Holthausen, Ferdinand - Hoffmann, Dietrich, Altfriesisches Wörterbuch (Heidelberg $\left.{ }^{2} 1985\right)$

Holtzmann, Robert, Geschichte der sächsischen Kaiserzeit (900-1024) (München 1941)

Honoré, Tony, Tribonian (London 1978)

Honoré, Tony, The Making of the Theodosian Code, in: ZRG RA 104 (1986) 133222

Honoré, Tony, Law in the Crisis of Empire, 379-455 A.D. The Theodosian Dynasty and its quaestors (Oxford 1998)

Hopkins, Keith, Brother-Sister Marriage in Roman Egypt, in: Comparative Studies in society and history 22 (1980) 303-354

Hopkins, Keith, Le mariage frère-sœur en Égypte romaine, in: Épouser au plus proche. Inceste, prohibitions et stratégies matrimoniales autour de la Méditerranée, hg. von Pierre Bonté (Civilisations et sociétés 89, Paris 1994) 79-95

Hüffer, Hermann, Beiträge zur Geschichte der Quellen des Kirchenrechts und des römischen Rechts im Mittelalter (Münster 1862)

Hughes, Diane Owen, From Brideprice to Dowry in Mediterranean Europe, in: Journal of Family History 3 (1978) 262-96

Hughes, Kathleen, The Church in Early Irish Society (London 1966)

Humfress, Caroline, Law and Legal practice in the Age of Justinian, in: Cambridge History of Justinian, hg. von Michael Maas (Cambridge 2004) 161-184 
Hunger, Herbert, Christliches und Nichtchristliches im byzantinischen Eherecht, in: Österreichisches Archiv für Kirchenrecht 18 (1967) 305-325

Hunt, David, Did Constantius II. have Court Bishops?, in: Studia Patristica 19 (1989) $86-90$

Hunt, David, Christianising the Roman Empire: the evidence of the Code, in: The Theodosian Code. Studies in the Imperial Law of Late Antiquity, hg. von Jill Harries - Ian Wood (London 1993) 143-158

Jackman, Donald C., The Konradiner. A Study in Genealogical Methodology (Studien zur Europäischen Rechtsgeschichte 47, Frankfurt 1990)

Jackman, Donald C., Das Eherecht und der frühdeutsche Adel, in: ZRG GA 112 (1995) $158-201$

Jackman, Donald C., König Konrad, die letzten Karolinger und ihre sächsischen Verwandten, in: Konrad I. - Auf dem Weg zum „Deutschen Reich“?, hg. von HansWerner Goetz (Bochum 2006) 77-92

Jacob, Robert, La parole des mains. Genèse de l'ordalie carolingienne de la croix, in: Les rites de la justice. Gestes et rituels judiciaires au Moyen Age, hg. von Claude Gauvard - Robert Jacob (Paris 1999) 19-62

Jäschke, Kurt-Ulrich, „Tamen virilis probitas in femina vicit“: Ein hochmittelalterlicher Hofkapellan und die Herrscherinnen - Wipos Äußerungen über Kaiserinnen und Königinnen seiner Zeit, in: Ex ipsis rerum documentis. Beiträge zur Mediävistik. Festschrift Harald Zimmermann, hg. von Klaus Herbers u. a. (Sigmaringen 1991) 429-448

Jahn, Joachim, Ducatus Baiuvariorum. Das bairische Herzogtum der Agilolfinger (Monographien zur Geschichte des Mittelalters 35, Stuttgart 1991)

Jahn, Joachim, Bischof Arbeo von Freising und die Politik seiner Zeit, in: Ethnogenese und Überlieferung. Angewandte Methoden der Frühmittelalterforschung, hg. von Karl Brunner - Brigitte Merta (Veröffentlichungen des Instituts für Österreichische Geschichtsforschung 31, München 1994) 157-162

Jarnut, Jörg, Bonifatius und die fränkischen Reformkonzilien (743-748), in: ZRG KA 65 (1979) $1-26$

Jarnut, Jörg, Quierzy und Rom. Bemerkungen zu den „Promissiones Donationis“ Pippins und Karls, in: HZ 220 (1975) 265-297

Jarnut, Jörg, Wer hat Pippin 751 zum König gesalbt?, in: FmSt16 (1982) 45-57

Jarnut, Jörg, Agilolfingerstudien. Untersuchungen zur Geschichte einer adeligen Familie im 6. und 7. Jahrhundert (Monographien zur Geschichte des Mittelalters 32, Stuttgart 1986)

Jarnut, Jörg, Ein Bruderkampf und seine Folgen. Die Krise des Frankenreiches (768771), in: Herrschaft, Kirche, Kultur. Beiträge zur Geschichte des Mittelalters. Festschrift Friedrich Prinz, hg. von Georg Jenal (Monographien zur Geschichte des Mittelalters 37, Stuttgart 1993) 165-176

Jarzebowski, Claudia, Inzest. Verwandtschaft und Sexualität im 18. Jahrhundert (L'Homme Schriften 12, Köln u. a. 2006)

Jasper, Detlev, Das Papstwahldekret von 1059. Überlieferung und Textgestalt (Beiträge zur Geschichte und Quellenkunde des Mittelalters 12, Sigmaringen 1986)

Jasper, Detlev, Die Canones synodi Romanorum ad Gallos episcopos - die älteste Dekretale?, in: ZKG 107 (1996) 319-326

Jasper, Detlev, Burchards Dekret in der Sicht der Gregorianer, in: Bischof Burchard von Worms 1000-1025, hg. von Wilfried Hartmann (Quellen und Abhandlungen zur mittelrheinischen Kirchengeschichte 100, Mainz 2000) 167-198 
Jasper, Detlev, The Beginning of the Decretal Tradition, in: Horst Fuhrmann/Detlev Jasper, Papal Letters in the Early Middle Ages (History of Medieval Canon Law 2, Washington 2001) 3-133

Joas, Hans - Knöbl, Wolfgang, Sozialtheorie (Frankfurt 2004)

Joch, Waltraud, Legitimität und Integration. Untersuchungen zu den Anfängen Karl Martells (Historische Studien 456, Husum 1999)

Jochens, Jenny M., The church and sexuality in medieval Iceland, in: Journal of Medieval History 6 (1980) 377-392

John, Herwig, Collectio canonum Remedio Curiensi episcopo perperam ascripta (Monumenta iuris canonici B 2, Vatikan 1976)

Johrendt, Jochen, Die Reisen der frühen Reformpäpste. Ihre Ursachen und Funktionen, in: RQ 96 (2001) 57-91

Jones, Arnold H.M. - Martindale, John R. - Morris, John, The Prosopography of the Later Roman Empire 1-3 (Cambridge 1971-1992)

Jones, Huguette, Justiniani Novellae ou l'autoportrait d'un legislateur, in: Revue internationale de droits de l'antiquité 35 (1988) 149-208

Jong, Mayke de, To the limits of Kinship: anti-incest legislation in the early medieval West (500-900), in: From Sappho to De Sade: moments in the history of sexuality, hg. von Jan Bremmer (London - New York 1989) 36-59

Jong, Mayke de, Old Law and New-Found Power: Hrabanus Maurus and the Old Testament, in: Centres of Learning. Learning and Location in Pre-Modern Europe and the Near East, hg. von Jan Willem Drijvers - Alasdair A. MacDonald (Brill's studies in intellectual history 61, Leiden 1995) 229-244

Jong, Mayke de, In Samuel's Image. Child Oblation in the Early Medieval West (Brill's Studies in Intellectual History 12, Leiden u.a. 1996)

Jong, Mayke de, What was public about public penance? Paenitentia publica and justice in the Carolingian world, in: La Giustizia nell'alto medioevo (secoli IX - XI) (Settimane 45, Spoleto 1997) 863-902

Jong, Mayke de, An unsolved riddle: early medieval incest legislation, in: The Franks and Alamanni in the Merovingian period: an ethnographic perspective, hg. von Ian N. Wood (Woodbridge 1998) 107-140

Jong, Mayke de, The empire as ecclesia: Hrabanus Maurus and biblical historia for rulers, in: The Uses of the Past, hg. von Yitzhak Hen - Matthew Innes (Cambridge 2000) $191-226$

Jong, Mayke de, Transformations of Penance, in: Rituals of Power. From Late Antiquity to the Early Middle Ages, hg. von Janet Nelson - Frans Theuws (Leiden 2000) $185-224$

Jongbloed, Hein H., Wanburtich: Heinrichs II. Beteiligung an der Wahl von Kamba (1024), in: DA 62 (2006) 1-63

Jordan, Mark D., The Invention of Sodomy in Christian Theology (Chicago 1997)

Joyce, George H., Die christliche Ehe. Eine geschichtliche und dogmatische Studie (Leipzig 1934)

Jussen, Bernhard, Patenschaft und Adoption im frühen Mittelalter. Künstliche Verwandtschaft als soziale Praxis (Veröffentlichungen des Max-Planck-Instituts für Geschichte 98, Göttingen 1991)

Jussen, Bernhard, Über „Bischofsherrschaften“ und die Prozeduren politisch sozialer Umordnung in Gallien zwischen „Antike“ und „Mittelalter“, in: HZ 260 (1995) $673-718$

Kaegi, Walter E., Heraclius. Emperor of Byzantium (Cambridge 2003) 
Kaiser, Reinhold, Bischofsherrschaft zwischen Königtum und Fürstenmacht. Studien zur bischöflichen Stadtherrschaft im westfränkisch-französischen Reich im frühen und hohen Mittelalter (Pariser Historische Studien 17, Bonn 1981)

Kaiser, Reinhold, Konstituierung der fränkischen Zivilisation I: Das merowingische Frankenreich, in: Deutschland und der Westen Europas, hg. von Joachim Ehlers (VuF 56, Stuttgart 2002) 53-97

Kaiser, Reinhold, Der Burgunderkönig Sigismund (+ 523/524): erster heiliger König des Mittelalters und erster königlicher Romfahrer, Bußpilger und Mönch, in: Päpste, Pilger, Pönitentiarie. Festschrift für Ludwig Schmugge zum 65. Geburtstag, hg. von Andreas Meyer u.a. (Tübingen 2004) 199-210

Kaiser, Reinhold, Die Burgunder (Stuttgart 2004)

Kaiser, Reinhold, Das römische Erbe und das Merowingerreich (Enzyklopädie deutscher Geschichte 26, München ${ }^{3} 2004$ )

Kamp, Hermann, Friedensstifter und Vermittler im Mittelalter (Darmstadt 2001)

Kampers, Gerd, Zum Ursprung der Metropolitanstellung Toledos, in: HJb 99 (1979) $1-27$

Karras, Ruth Mazo, The History of Marriage and the myth of Friedelehe, in: EME 14 (2006) 119-151

Kaser, Max, Das römische Privatrecht 1 -2 (Handbuch der Altertumswissenschaft 10/3/ 3, München $\left.{ }^{2} 1971-1975\right)$

Kasten, Brigitte, Noverca venefica. Zum bösen Ruf der Stiefmutter in der gallischen und fränkischen Gesellschaft, in: FmSt 35 (2001) 145-181

Kasten, Brigitte, Chancen und Schicksale „unehelicher“ Karolinger im 9. Jahrhundert, in: Kaiser Arnolf. Das ostfränkische Reich am Ende des 9. Jahrhunderts, hg. von Franz Fuchs - Peter Schmid (ZBLG Beiheft 19, München 2002) 17-52

Katalog Kaiser Heinrich II. (1002-1024), hg. von Josef Kirmeier u. a. (Augsburg 2002)

Kehl, Petra, Kult und Nachleben des heiligen Bonifatius im Mittelalter (754-1200) (Quellen und Abhandlungen zur Geschichte der Abtei und Diözese Fulda 26, Fulda 1993)

Keller, Hagen, Grundlagen ottonischer Königsherrschaft, in: ders., Ottonische Königsherrschaft. Organisation und Legitimität königlicher Macht (Darmstadt 2002) 22-33 (erstmals 1985)

Keller, Hagen, Reichsorganisation, Herrschaftsformen und Gesellschaftsstrukturen im Regnum Teutonicum, in: Il secolo di ferro: mito e realtà del secolo X (Settimane 38, Spoleto 1991) 159-203

Keller, Hagen, Die Idee der Gerechtigkeit und die Praxis königlicher Rechtswahrung im Reich der Ottonen, in: La giustizia nell'alto medioevo: secoli IX-XI (Settimane 43, Spoleto 1997) 91-128

Kelly, William, Pope Gregory II. on divorce and remarriage. A canonical-historical investigation of the letter Desiderabilem mihi (Analecta Gregoriana 203, Rom 1976)

Kennell, Stefanie A.H., Magnus Felix Ennodius: A Gentleman of the Church (Ann Arbor 2000)

Kerff, Franz, Der Quadripartitus. Ein Handbuch der karolingischen Kirchenreform. Überlieferung, Quellen und Rezeption (Quellen und Forschungen zum Recht im Mittelalter 1, Sigmaringen 1982)

Kerner, Max, Der Reinigungseid Leos III. vom Dezember 800. Die Frage seiner Echtheit und frühen kanonistischen Überlieferung. Eine Studie zum Problem der päpstlichen Immunität im früheren Mittelalter, in: Zeitschrift des Aachener Geschichtsvereins 84/85 (1977/1978) 131-160 
Kerner, Max - Kerff, Franz - Pokorny, Rudolf - Schon, Karl Georg - Tills, Hubert, Textidentifikation und Provenienzanalyse im Decretum Burchardi, in: Studia Gratiana 20 (1976) 19-63

Kéry, Lotte, Canonical Collections of the Early Middle Ages (ca. 400-1140). A Bibliographical Guide to the Manuscripts and Literature (History of Medieval Canon Law 1, Washington 1999)

Kéry, Lotte, Gottesfurcht und irdische Strafe. Der Beitrag des mittelalterlichen Kirchenrechts zur Entstehung des öffentlichen Strafrechts (Konflikt, Verbrechen und Sanktion in der Gesellschaft Alteuropas, Symposien und Synthesen 10, Köln u.a. 2006)

Kessler, Dorothea von, Der Eheprozess Ottos und Irmingards von Hammerstein. Studie zur Geschichte des katholischen Eherechts im Mittelalter (Historische Studien 157, Berlin 1923)

Kienast, Walther, Studien über die französischen Volksstämme des Frühmittelalters (Pariser Historische Studien 7, Stuttgart 1968)

King, Noel Q., The emperor Theodosius and the establishment of Christianity (London 1961)

King, Paul David, Law and Society in the Visigothic Kingdom (Cambridge studies in medieval life and thought 3rd ser. 5, Cambridge 1972)

King, Paul David, The Alleged Territoriality of Visigothic Law, in: Authority and Power. Studies on medieval law and government presented to Walter Ullmann, hg. von Brian Tierney - Peter Linehan (Cambridge 1980) 1-11

King, Paul David, King Chindasvind and the First Territorial Law-code of the Visigothic Kingdom, in: Visigothic Spain. New Approaches, hg. von Edward James (Oxford 1980) 131-157

Kirby, David P., The Earliest English Kings (London 1991)

Klapisch-Zuber, Christiane, L’ombre des ancêtres. Essai sur l'imaginaire médiéval de la parenté (Paris 2000)

Klingshirn, William E., Caesarius of Arles. The Making of a Christian Community in Late Antique Gaul (Cambridge studies in medieval life and thought 4th ser. 22, Cambridge 1994)

Koch, Matthias, Irmgard von Hammerstein $(+1042)$, in: Rheinische Lebensbilder 18 (2000) 7-26

Kölzer, Theo, Merowingerstudien 1-2 (MGH Studien und Texte 21 u. 26, Hannover 1998-1999)

Koeniger, Albert Maria, Burchard I. von Worms und die deutsche Kirche seiner Zeit (1000-1025). Ein kirchen- und sittengeschichtliches Zeitbild (Veröffentlichungen aus dem Kirchenhistorischen Seminar München 2/6, München 1905)

Koeniger, Albert Maria, Zu den Beschlüssen der Synoden von Meaux 845 und Koblenz 922, in: NA 31 (1906) 377-398

Koeniger, Albert Maria, Die Sendgerichte in Deutschland (Veröffentlichungen aus dem Kirchenhistorischen Seminar München 3, München 1907)

Koeniger, Albert Maria, Quellen zur Geschichte der Sendgerichte in Deutschland (München 1910)

Köpke, Rudolf - Dümmler, Ernst, Kaiser Otto der Große (Leipzig 1876)

Körntgen, Ludger, Studien zu den Quellen der frühmittelalterlichen Bußbücher (Quellen und Forschungen zum Recht im Mittelalter 7, Sigmaringen 1993)

Körntgen, Ludger, Inprimis Herimanni ducis assensu. Zur Funktion von D. H.II. 34 im Konflikt zwischen Heinrich II. und Hermann von Schwaben, in: FmSt 34 (2000) 159-185 
Körntgen, Ludger, Fortschreibung frühmittelalterlicher Bußpraxis. Burchards „Liber corrector" und seine Quellen, in: Bischof Burchard von Worms. 1000-1025, hg. von Wilfried Hartmann (Quellen und Abhandlungen zur mittelrheinischen Kirchengeschichte 100, Mainz 2000) 199-226

Körntgen, Ludger, Königsherrschaft und Gottes Gnade. Zu Kontext und Funktion sakraler Vorstellungen in Historiographie und Bildzeugnissen der ottonisch-frühsalischen Zeit (Orbis Mediaevalis. Vorstellungswelten des Mittelalters 2, Berlin 2001)

Körntgen, Ludger, Der Excarpsus Cummeani, ein Bußbuch aus Corbie? in: Scientia veritatis. Festschrift für Hubert Mordek zum 65. Geburtstag, hg. von Oliver Münsch - Thomas Zotz (Ostfildern 2004) 59-75

Körntgen, Ludger, Canon law and the practice of penance: Burchard of Worm's penitential, in: EME 14 (2006) 103-117

Körntgen, Ludger, Bußbuch und Bußpraxis in der zweiten Hälfte des 9. Jahrhunderts, in: Recht und Gericht in Kirche und Welt um 900, hg. von Wilfried Hartmann (Schriften des Historischen Kollegs, Kolloquium 69, München 2007) 197-215

Körntgen, Ludger, Ottonen und Salier (Geschichte kompakt - Mittelalter, Darmstadt $\left.{ }^{2} 2008\right)$

Kohlhas-Müller, Dorothee, Untersuchungen zur Rechtsstellung Theoderichs des Großen (Rechtshistorische Reihe 119, Frankfurt am Main u.a. 1995)

Kohnle, Armin, Abt Hugo von Cluny (1049-1109) (Beihefte der Francia 32, Sigmaringen 1993)

Kolb, Frank, Diocletian und die erste Tetrarchie: Improvisation oder Experiment in der Organisation monarchischer Herrschaft? (Untersuchungen zur antiken Literatur und Geschichte 27, Berlin 1987)

Kolb, Frank, Herrscherideologie in der Spätantike (Berlin 2001)

Kolmer, Lothar, Ehemoral und Herrschaftslegitimation im 8. Jahrhundert, in: Regensburg, Bayern und Europa. Festschrift Kurt Reindel, hg. von Lothar Kolmer Peter Segl (Regensburg 1995) 71-89

Konecny, Silvia, Die Frauen des karolingischen Königshauses. Die politische Bedeutung der Ehe und die Stellung der Frau in der fränkischen Herrscherfamilie vom 7. bis zum 10. Jahrhundert (Dissertationen der Universität Wien 132, Wien 1976)

Kottje, Raymund, Einheit und Vielfalt des kirchlichen Lebens in der Karolingerzeit, in: ZKG 76 (1965) 323-342

Kottje, Raymund, Studien zum Einfluss des Alten Testaments auf Recht und Liturgie des frühen Mittelalters (6. - 8. Jahrhundert) (Bonner historische Forschungen 23, Bonn 1970)

Kottje, Raymund, Die Bußbücher Halitgars von Cambrai und des Hrabanus Maurus. Ihre Überlieferung und ihre Quellen (Beiträge zur Geschichte und Quellenkunde des Mittelalters 8, Berlin 1980)

Kottje, Raymund, Ehe und Eheverständnis in den vorgratianischen Bußbüchern, in: Love and Marriage in the Twelfth-Century, hg. von Willy van Hoecke - Andries Welkenhuysen (Leuven 1981) 18-40

Kottje, Raymund, Zu den Beziehungen zwischen Hinkmar von Reims und Hrbanus Maurus, in: Charles the Bald. Court and Kingdom, hg. von Margaret T. Gibson Janet Nelson (Oxford 1981) 255-263

Kottje, Raymund, Überlieferung und Rezeption der irischen Bußbücher auf dem Kontinent, in: Die Iren und Europa im früheren Mittelalter, hg. von Heinz Löwe (Stuttgart 1982) 511-524 
Kottje, Raymund, Kirchliches Recht und päpstlicher Autoritätsanspruch. Zu den Auseinandersetzungen über die Ehe Lothars II., in: Aus Kirche und Reich. Studien zu Theologie, Politik und Recht im Mittelalter. Festschrift für Friedrich Kempf, hg. von Hubert Mordek (Sigmaringen 1983) 97-103

Kottje, Raymund, Der Liber ex lege Moysis, in: Irland und die Christenheit. Bibelstudien und Mission, hg. von Próinséas Ní Chatháin - Michael Richter (Stuttgart 1987) 59-69

Krah, Adelheid, Absetzungsverfahren als Spiegelbild von Königsmacht. Untersuchungen zum Kräfteverhältnis zwischen Königtum und Adel im Karolingerreich und seinen Nachfolgestaaten (Untersuchungen zur deutschen Staats- und Rechts-Geschichte N.F. 26, Aalen 1987)

Krammer, Mario, Kritische Untersuchungen zur Lex Salica, in: NA 30 (1905) 263-319

Krause, Hans-Georg, Das Papstwahldekret von 1059 und seine Rolle im Investiturstreit (Studi Gregoriani 7, Rom 1960)

Krause, Jens-Uwe, Gefängnisse im Römischen Reich (Heidelberger althistorische Beiträge und epigraphische Studien 23, Stuttgart 1996)

Krause, Jens-Uwe, Kriminalgeschichte der Antike (München 2004)

Krause, Jens-Uwe, Überlegungen zur Sozialgeschichte des Klerus im 5./6. Jh. n. Chr., in: Die Stadt in der Spätantike - Niedergang oder Wandel?, hg. von Jens-Uwe Krause Christian Witschel (Historia-Einzelschriften 190, Stuttgart 2006) 413-439

Krause, Victor, Die Münchener Handschriften 3851. 3853 mit einer Compilation von 181 Wormser Schlüssen, in: NA 19 (1894) 85-139

Kroeschell, Karl, Die Sippe im germanischen Recht, in: ZRG GA 77 (1960) 1-26

Kroeschell, Karl, Germanisches Recht als Forschungsproblem, in: Festschrift für Hans Thieme, hg. von Karl Kroeschell (Sigmaringen 1986) 3-19

Kroeschell, Karl, Recht und Gericht in den merowingischen „Kapitularien“, in: La giustizia nell'Alto Medioevo (secoli V-VIII) (Settimane 42, Spoleto 1995) 737 765

Kropat, Wolf-Arno, Reich, Adel und Kirche in der Wetterau von der Karolinger- bis zur Stauferzeit (Schriften des Hessischen Landesamtes für Geschichtliche Landeskunde 28, Marburg 1965)

Kroppmann, Hubert, Ehedispensübung und Stauferkampf unter Innozenz IV. Ein Beitrag zur Geschichte des päpstlichen Ehedispensrechtes (Abhandlungen zur mittleren und neueren Geschichte 79, Berlin 1937)

Krusch, Bruno, Die älteste Vita Leudegarii, in: NA 16 (1891) 563-596

Krusch, Bruno, Der Umsturz der kritischen Grundlagen der Lex Salica. Eine textkritische Studie aus der alten Schule, in: NA 40 (1916) 497-579

Krusch, Bruno, Neue Forschungen über die drei oberdeutschen Leges: Bajuvariorum, Alamannorum, Ribuariorum (Abhandlungen Göttingen 20/1, 1927)

Krusch, Bruno, König Chlodwig als Gesetzgeber in: Historische Vierteljahrschrift 29 (1935) $801-807$

Krusch, Bruno, Die Lex Salica: Textkritik, Entstehung und Münzsystem, in: Historische Vierteljahrschrift 31 (1937) 417-437

Kuefler, Mathew, The Marriage Revolution in Late Antiquity: The Theodosian Code and Later Roman Marriage Law, in: Journal of Family History 32 (2007) 343-370

Kuhoff, Wolfgang, Diokletian und die Epoche der Tetrarchie. Das römische Reich zwischen Krisenbewältigung und Neuaufbau (284-313 n. Chr.) (Frankfurt u.a. 2001)

Kuttner, Stephan, Liber canonicus. A note on „Dictatus Papae“ c. 17, in: Studi Gregoriani 2 (1947) 387-401 
Ladner, Gerhart B., Origin and Significance of the Byzantine Iconoclastic Controversy, in: Medieval Studies 2 (1940) 127-149

Laiou, Angeliki E., Mariage, amour et parenté à Byzance aux $\mathrm{XI}^{\mathrm{e}}-\mathrm{XIII}^{\mathrm{e}}$ siècles (Travaux et mémoires du Centre de Recherche d'Histoire et Civilisation de Byzance, Monographies 7, Paris 1992)

Lampe, Ernst-Joachim (Hg.), Rechtsgleichheit und Rechtspluralismus (Interdisziplinäre Studien zu Recht und Staat 2, Baden-Baden 1995)

Lancaster, Lorraine, Kinship in Anglo-Saxon Society, in: The British Journal of Sociology 9 (1958) 230-250 u. 359-377

Landau, Peter, Gefälschtes Recht in den Rechtssammlungen bis Gratian, in: Fälschungen im Mittelalter, 2: Gefälschte Rechtstexte. Der bestrafte Fälscher (MGH Schriften 33/2, Hannover 1988) 11-49

Landau, Peter, Ehetrennung als Strafe. Zum Wandel des kanonischen Eherechts im 12. Jahrhundert, in: ZRG KA 81 (1995) 148-188

Landau, Peter, Die Lex Thuringorum - Karls des Großen Gesetz für die Thüringer, in: ZRG GA 118 (2001) 23-57

Landau, Peter, Die Lex Baiuvariorum. Entstehungszeit, Entstehungsort und Charakter von Bayerns ältester Rechts- und Geschichtsquelle (Sitzungsberichte München, 2004/3)

Landau, Peter, The development of law, in: The New Cambridge Medieval History 4 (c. 1024 - c. 1198), hg. von David E. Luscombe - Jonathan Riley-Smith (Cambridge 2004) $1,113-147$

Landau, Peter, Die Kirche als Vermittlerin schriftlichen Rechts, in: Leges - Gentes Regna. Zur Rolle von germanischen Rechtsgewohnheiten und lateinischer Schrifttradition bei der Ausbildung der frühmittelalterlichen Rechtskultur, hg. von Gerhard Dilcher - Eva-Marie Distler (Berlin 2006) 219-229

Landes, Richard, Rodulfus Glaber and the Dawn of the New Millennium: Eschatology, Historiography and the Year 1000, in: Revue Mabillon n.s 7 [=68] (1996) 1-21

Langenfeld, Hans, Christianisierungspolitik und Sklavengesetzgebung der römischen Kaiser von Konstantin bis Theodosius II. (Bonn 1977)

Lapidge, Michael, The Career of Archbishop Theodore, in: Archbishop Theodore. Commemorative Studies on his Life and Influence, hg. von Michael Lapidge (Cambridge studies in Anglo-Saxon England 11, Cambridge 1995) 1-29

Laudage, Johannes, Priesterbild und Reformpapsttum im 11. Jahrhundert (AKG Beiheft 22, Köln 1984)

Laudage, Johannes, Otto der Grosse (912-973). Eine Biographie (Regensburg 2001)

Le Bras, Gabriel, Les deux formes de la Dacheriana, in: Mélanges Paul Fournier (Paris 1929) 395-414

Le Jan, Régine, Famille et pouvoir dans le monde franc (VII ${ }^{\mathrm{e}}-\mathrm{IX}^{\mathrm{e}}$ siècle). Essai d'anthropologie sociale (Paris 1995)

Le Jan, Régine, Élites et révoltes à l'epoque carolingienne: crise des élites ou crise des modèles?, in: Les élites au Haut Moyen Âge. Crises et renouvellements, hg. von François Bougard u.a. (Collection Haut Moyen Âge 1, Turnhout 2006) 403-423

Leclercq, Jean, S. Pierre Damien et les femmes, in: Studia monastica 15 (1973) 43-55

Lee, A.D., Close-Kin Marriage in Late Antique Mesopotamia, in: Greek, Roman and Byzantine Studies 29 (1988) 403-413

Leitmaier, Charlotte, Die Kirche und die Gottesurteile (Wiener rechtsgeschichtliche Arbeiten 2, Wien 1953)

Leppin, Hartmut, Theodosius der Große (Darmstadt 2003) 
Levillain, Léon, Les Nibelungen historiques et leurs alliances de famille, in: Annales du midi 49 (1937) 337-408; 50 (1938) 5-66

Levin, Eve, Sex and Society in the World of the Orthodox Slaves, 900-1700 (Ithaca 1989)

Levy, Ernst, West Roman Vulgar Law. The Law of Property (Philadelphia 1951)

Levy, Ernst, Weströmisches Vulgarrecht. Das Obligationenrecht (Forschungen zum römischen Recht 7, Weimar 1956)

Lévy-Strauss, Claude, Die elementaren Strukturen der Verwandtschaft (Frankfurt 1981, erstmals 1949)

Lewald, Ursula, An der Schwelle der Scholastik. Bonizo von Sutri und das Kirchenrecht seiner Tage (Weimar 1938)

Leyser, Karl J., Herrschaft und Konflikt. König und Adel im ottonischen Sachsen (Veröffentlichungen des Max-Planck-Instituts für Geschichte 76, Göttingen 1984)

Leyser, Karl J., Am Vorabend der ersten europäischen Revolution. Das 11. Jahrhundert als Umbruchszeit, in: HZ 257 (1993) 1-28

Liebeschuetz, J.H.W.G., Barbarians and Bishops. Army, Church, and State in the Age of Arcadius and Chrysostom (Oxford 1990)

Liebeschuetz, J.H.W.G., The Decline and Fall of the Ancient City (Oxford 2001)

Liebs, Detlef, Die Jurisprudenz im spätantiken Italien (260-640 n. Chr.) (Freiburger Rechtsgeschichtliche Abhandlungen N.F. 8, Berlin 1987)

Liebs, Detlef, Römische Jurisprudenz in Gallien (2. bis 8. Jahrhundert) (Freiburger Rechtsgeschichtliche Abhandlungen N.F. 38, Berlin 2002)

Lilie, Ralph-Johannes, Die byzantinische Reaktion auf die Ausbreitung der Araber. Studien zur Strukturwandlung des byzantinischen Staates im 7. und 8. Jahrhundert (Miscellanea Byzantina Monacensia, München 1976)

Lilie, Ralph-Johannes, Byzanz. Das zweite Rom (Berlin 2003)

Linke, Bernhard, Von der Verwandtschaft zum Staat. Die Entstehung politischer Organisationsformen in der frührömischen Geschichte (Stuttgart 1995)

Lintzel, Martin, Zur altsächsischen Rechtsgeschichte, in: ders., Ausgewählte Schriften, 1: Zur altsächsischen Stammesgeschichte (Berlin 1961) 420-445 (erstmals 1932)

Lippert, Woldemar, Die Verfasserschaft der Canonen gallischer Concilien des V. und VI. Jahrhunderts, in: NA 14 (1889) 9-58

Little, Lester K., The Personal Development of Peter Damian, in: Order and Innovation in the Middle Ages. Essays in Honor of J.R. Strayer, ed. William C. Jordan u.a. (Princeton 1976) 317-341

Loening, Edgar, Geschichte des deutschen Kirchenrechts. Das Kirchenrecht in Gallien von Constantin bis Chlodovech 1-2 (Straßburg 1878)

Loetz, Francisca, Mit Gott handeln. Von den Zürcher Gotteslästerern der Frühen Neuzeit zu einer Kulturgeschichte des Religiösen (Veröffentlichungen des MaxPlanck-Instituts für Geschichte 177, Göttingen 2002)

Lohmer, Christian, Endzeiterwartung bei Petrus Damiani: Überlegungen zu seinen Briefen Nr. 92 und 93, in: Regensburg, Bayern und Europa. Festschrift Kurt Reindel, hg. von Lothar Kolmer - Peter Segl (Regensburg 1995) 175-187

Loseby, Simon T., Decline and Change in the Cities of Later Antique Gaul, in: Die Stadt in der Spätantike - Niedergang oder Wandel?, hg. von Jens Uwe Krause Christian Witschel (Historia-Einzelschriften 190, Stuttgart 2006) 67-104

Lot, Ferdinand, Les derniers Carolingiens. Lothaire, Louis V, Charles de Lorraine (954991) (Bibliothèque de l'École des Hautes Études, Sciences Philologiques et Historiques 87 , Paris 1891) 
Lot, Ferdinand, Études sur le règne de Hugues Capet et la fin du $\mathrm{X}^{\mathrm{e}}$ siècle (Bibliothèque de l'École des Hautes Études, Sciences Philologiques et Historiques 147, Paris 1903)

Lotter, Friedrich, Der Brief des Priesters Gerhard an den Erzbischof Friedrich von Mainz. Ein kanonistisches Gutachten aus frühottonischer Zeit (VuF Sonderband 17, Sigmaringen 1975)

Lottermoser, Barbara, Oströmische Religionsgesetzgebung und Kirchenpolitik unter den Kaisern Arcadius (395-408) und Theodosius II. (408-450) (Diss. Marburg 2001)

Lubich, Gerhard, Das Wortfeld „Verwandtschaft“ im Mittelalter. Kontextuell-semantisches Arbeiten im historischen Feld, in: sozialersinn 1 (2003) 21-36

Lubich, Gerhard, Verwandtsein. Lesarten einer politisch-sozialen Beziehung im Frühmittelalter (6.-11. Jahrhundert) (Europäische Geschichtsdarstellungen 16, Köln u.a. 2008)

Lucchesi, Giovanni, Per una Vita di San Pier Damiani, in: San Pier Damiano nel IX centenario della morte (Cesena 1972) 1, 13-179 u. 2, 13-160

Luhmann, Niklas, Ausdifferenzierung des Rechts. Beiträge zur Rechtssoziologie und Rechtstheorie (Frankfurt 1981)

Luhmann, Niklas, Rechtssoziologie (Opladen ${ }^{3} 1987$ )

Luhmann, Niklas, Das Recht der Gesellschaft (Frankfurt 1993)

Luhmann, Niklas, Die Gesellschaft der Gesellschaft (Frankfurt 1998)

Lukas, Veronika, Neues aus einer Salzburger Handschrift aus Köln. Zur Überlieferung der Episcoporum ad Hludowicum imperatorem relatio (829), in: DA 58 (2002) $539-548$

Lukas, Veronika, Philologische Beobachtungen zur Rezeption der Relatio episcoporum von 829 bei Benedictus Levita, in: Fortschritt durch Fälschungen? Ursprung, Gestalt und Wirkungen der pseudoisidorischen Fälschungen, hg. von Wilfried Hartmann - Gerhard Schmitz (MGH Studien und Texte 31, Hannover 2002) 61-87

Lukas, Veronika, Eine Sammlung von Kapitularien Karls des Großen bei Benedictus Levita, in: ZRG KA 90 (2004) 1-26

Lutterbach, Hubertus, Sexualität im Mittelalter. Eine Kulturstudie anhand von Bußbüchern des 6. bis 12. Jahrhunderts (AKG Beiheft 43, Köln u.a. 1999)

Lynch, Joseph H., Godparents and Kinship in Early Medieval Europe (Princeton 1986)

Maas, Michael, Roman History and Christian ideology in Justinianic Reform legislation, in: Dumbarton Oaks Papers 40 (1986) 17-31

Maassen, Friedrich, Geschichte der Quellen und der Literatur des canonischen Rechts im Abendlande bis zum Ausgange des Mittelalters (Graz 1870)

Maccarone, Michele, Sacramentalità e indissolubilità del matrimonio nella dottrina di Innocenzo III, in: ders., Nuovi studi su Innocenzo III (Nuovi studi storici 25, Rom 1995) 47-110 (erstmals 1978)

Machielsen, Lambertus, Fragments patristiques non-identifiés du ms. Vat. Pal. 577, in: Sacris erudiri 12 (1961) 488-539

Machielsen, Lambertus, L’origine anglo-saxonne du supplément à l'histoire ecclésiastique de Bède, in: Revue bénédictine 73 (1963) 33-47

Machielsen, Lambertus, Le supplément à l'histoire ecclésiastique de Bède dans la littérature canonique jusqu'au Décret de Gratien, in: Revue bénédictine 73 (1963) $314-316$

MacMullen, Ramsey, Curruption and the Decline of Rome (New Haven 1988)

Magnou-Nortier, Elisabeth, Existe-t-il une géographie des courants de pensée dans le clergé de Gaule au VI ${ }^{\mathrm{e}}$ siècle?, in: Grégoire de Tours et l'espace gaulois, hg. von 
Nancy Gauthier - Henri Galinié (Revue Archéologique du Centre de la France, supplément 13, Tours 1997) 139-157

Magnou-Nortier, Elisabeth, Remarques sur la genèse du Pactus Legis Salicae et sur le privilège d'immunité (IV-VII siècles), in: Clovis. Histoire et mémoire, 1: Le baptême de Clovis, l'événement, hg. von Michel Rouche (Paris 1997) 495-537

Maier, Gideon, Amtsträger und Herrscher in der Romania Gothica. Vergleichende Untersuchungen zu den Institutionen der ostgermanischen Völkerwanderungsreiche (Historia. Einzelschriften 181, Stuttgart 2005)

Malaspina, Elena, Il Liber epistolarum della cancelleria austrasiaca (Biblioteca di Cultura Romanobarbarica 4, Rom 2001)

Maleczek, Werner, Echte und zweifelhafte Stammbäume bei kanonischen Eheprozessen bis ins frühe 13. Jahrhundert, in: Staaten, Wappen, Dynastien. XVIII. Internationaler Kongress für Genealogie und Heraldik (Veröffentlichungen des Innsbrucker Stadtarchivs N.F. 18, Innsbruck 1988) 123-143

Malinowski, Bronislaw, Mutterschaft und Inzestversuchung, in: ders., Schriften zur Anthropologie 4/2 (Frankfurt 1986) 129-134 (erstmals 1927)

Mansfield, Mary C., The humiliation of sinners. Public penance in thirteenth-century France (Ithaca 1995)

Markus, Robert A., From Caesarius to Boniface: Christianity and Paganism in Gaul, in: The Seventh Century. Change and Continuity, hg. von Jacques Fontaine - John N. Hillgarth (Studies of the Warburg Institute 42, London 1992) 154-172

Markus, Robert A., Gregory the Great and His World (Cambridge 1997)

Martin, Jochen, Zur Anthropologie von Heiratsregeln und Besitzübergabe. 10 Jahre nach den Goody-Thesen, in: Historische Anthropologie 1 (1993) 149-162

Mathisen, Ralph W., Epistolography, literary circles, and family ties in late Roman Gaul, in: Transactions of the American Philological Association 111 (1981) 95-109

Mathisen, Ralph W., For Specialists Only: The Reception of Augustine's Theology in Fifth-Century Gaul, in: Augustine. Presbyter factus sum, hg. von Joseph T. Lienhard u. a. (Collectanea Augustiniana 2, Frankfurt u. a. 1993) 29-41.

Mathisen, Ralph W., Roman aristocrats in barbarian Gaul: strategies for survival in an age of transition (Austin 1993)

Mathisen, Ralph W., The „Second Council of Arles“ and the Spirit of Compilation and Codification in Late Roman Gaul, in: Journal of early Christian studies 5 (1997) $511-554$

Mathisen, Ralph W., Barbarian Bishops and the Churches „in barbaricis gentibus“ during Late Antiquity, in: Speculum 72 (1997) 664-697

Mathisen, Ralph W., Peregrini, Barbari, and Cives Romani. Concepts of Citizenship and the Legal Identity of Barbarians in the Later Roman Empire, in: AHR 111 (2006) 1011-1040

Matthews, John F., Western Aristocracies and Imperial Court, A. D. 364-425 (Oxford 1975)

Matthews, John F., The Making of the Text, in: The Theodosian Code. Studies in the Late Imperial Law of Late Antiquity, hg. von Jill Harries - Ian Wood (London 1993) 19-44

Matthews, John F., Roman Law and Barbarian Identity in the Late Roman West, in: Ethnicity and Culture in Late Antiquity, hg. von Stephen Mitchell - Geoffrey Greatrex (London 2000) 31-44

Matthews, John F., Laying down the Law. A Study of the Theodosian Code (New Haven u. a. 2000) 
Matthews, John F., Interpreting the Interpretationes of the Breviarium, in: Society and culture in late antique Gaul: revisiting the sources, hg. von Ralph W. Mathisen Danuta Shanzer (Ashgate 2001) 11-32.

Mayer, Ernst, Zur Entstehung der Lex Ribuariorum. Eine rechtsgeschichtliche Untersuchung (München 1886)

Mayer, Hans Eberhard, Geschichte der Kreuzzüge (Stuttgart u. a. ${ }^{9} 2000$ )

Mayr-Harting, Henry, The Coming of Christianity to Anglo-Saxon England (London 1972)

Mayr-Harting, Henry, Charlemagne's Religion, in: Am Vorabend der Kaiserkrönung. Das Epos „Karolus Magnus et Leo papa“ und der Papstbesuch in Paderborn 799, hg. von Peter Godman u. a. (Berlin 2002) 113-124

McKitterick, Rosamond, The Frankish Church and the Carolingian Reforms, 789-895 (London 1977)

McKitterick, Rosamond, The Carolingians and the Written Word (Cambridge 1989)

McKitterick, Rosamond, The Illusion of Royal Power in the Carolingian Annals, in: English Historical Review 115 (2000) 1-20

McKitterick, Rosamond, The Carolingian renaissance of culture and learning, in: Charlemagne. Empire and Society, hg. von Joanna Story (Manchester 2005) 151 166

McLynn, Neil B., Ambrose of Milan. Church and Court in a Christian Capital (The Transformation of the Classical Heritage 22, Berkeley u. a. 1994)

Meens, Rob, A background to Augustine's mission to Anglo-Saxon England, in: AngloSaxon England 23 (1994) 5-17

Meens, Rob, Het tripartite boeteboek. Overlevering en betekenis van vroegmiddeleeuwse biechtvoorschriften (met editie en vertaling van vier tripartita) (Middeleeuwse studies en bronnen 41, Hilversum 1994)

Meens, Rob, Ritual purity and the influence of Gregory the Great in the early Middle Ages, in: Unity and diversity in the church, hg. von Robert N. Swanson (Studies in Church History 32, Oxford 1996) 31-43

Meens, Rob, Kanonisches Recht in Salzburg am Ende des 8. Jahrhunderts. Das Zeugnis des Paenitentiale Vindobonense B, in: ZRG KA 82 (1996) 13-34

Meens, Rob, The Frequency and Nature of Early Medieval Penance, in: Handling Sin. Confession in the Middle Ages, hg. von Peter Biller - A.J. Minnis (York Studies in Medieval Theology, Bury St Edmunds 1998) 35-61

Meens, Rob, Christentum und Heidentum aus der Sicht Willibrords? Überlegungen zum Paenitentiale Oxoniense II, in: L'évangelisation des régions entre Meuse et Moselle et la fondation de l'abbaye d'Echternach ( $V^{e}-I^{e}$ siècle), hg. von Michel Polfer (Publications de la Section Historique de l'Institut G.-D. de Luxembourg 117, Luxemburg 2000) 415-428

Meens, Rob, Aspekte der Christianisierung des Volkes, in: Bonifaitus - Leben und Nachwirken. Die Gestaltung des christlichen Europa im Frühmittelalter, hg. von Franz J. Felten u.a. (Quellen und Abhandlungen zur mittelrheinischen Kirchengeschichte 121, Mainz 2007) 211-229

Meier, Mischa, Das andere Zeitalter Justinians. Kontingenzerfahrung und Kontingenzbewältigung im 6. Jahrhundert n. Chr. (Hypomnemata 147, Göttingen 2003)

Meier, Mischa, Von Prokop zu Gregor von Tours. Kultur- und mentalitätengeschichtlich relevante Folgen der ,Pest' im 6. Jahrhundert, in: Gesundheit - Krankheit. Kulturtransfer medizinischen Wissens von der Spätantike bis in die Frühe Neuzeit, hg. von Kay-Peter Jankrift - Florian Steger (AKG Beiheft 55, Köln u. a. 2004) 19-40 
Meigne, Maurice, Concile au collection d'Elvire, in: Revue d'histoire ecclésiastique 120 (1975) 361-387

Meijers, E.M., Eine germanische Zählung der Verwandtschaftsgrade, in: Tijdschrift voor Rechtsgeschiedenis 6 (1925) $1-52$

Mejer, Otto, Über die sog. Gregorische Computation, in: Zeitschrift für deutsches Recht und deutsche Rechtswissenschaft 7 (1842) 173-221

Mette-Dittmann, Angelika, Die Ehegesetze des Augustus: Eine Untersuchung im Rahmen der Gesellschaftspolitik des Princeps (Historia. Einzelschriften 67, Stuttgart 1991)

Meuten, Ludger, Die Erbfolgeordnung des Sachsenspiegels und des Magdeburger Rechts. Ein Beitrag zur Geschichte des sächsisch-magdeburgischen Rechts (Rechtshistorische Reihe 218, Frankfurt u.a. 2000)

Meyvaert, Paul, Diversity within Unity: A Gregorian Theme, in: Heythrop Journal 4 (1963) $141-162$

Meyvaert, Paul, Bede's Text of the Libellus responsionum of Gregory the Great to Augustine of Canterbury, in: England before the Conquest. Studies in primary sources presented to Dorothy Whitelock, hg. von Peter Clemoes (Cambridge 1971) 15-33

Meyvaert, Paul, Le Libellus responsionum à Augustin de Cantorbéry: une œuvre authentique de Saint Grégoire le Grand, in: Grégoire le Grand, hg. von Jacques Fontaine (Paris 1986) 543-550

Mikat, Paul, Die Inzestverbote des Konzils von Epaon. Ein Beitrag zur Geschichte des fränkischen Eherechts, in: ders., Religionsrechtliche Schriften. Abhandlungen zum Staatskirchenrecht und Eherecht, hg. von Joseph Listl (Staatskirchenrechtliche Abhandlungen 5, Berlin 1974) 2, 869-888 (erstmals 1970)

Mikat, Paul, Die Inzestverbote des Dritten Konzils von Orléans (538). Ein Beitrag zur Geschichte des fränkischen Eherechts (Rheinisch-Westfälische Akademie der Wissenschaften, Vorträge G 323, Opladen 1993)

Mikat, Paul, Die Inzestgesetzgebung der merowingisch-fränkischen Konzilien (511626/27) (Rechts- und Staatswissenschaftliche Veröffentlichungen der Görres-Gesellschaft N.F. 74, Paderborn u.a. 1994)

Miklošić, Franc - Rački, Franjo, Novo nadjeni spomenici iz IX. i XI. vieka za panonskomoravsku, bugasku i hrvatsku poviest, in: Starine. Hrvatska Akademija Znanosti i Umjetnosti 12 (1875) 206-223

Mikoletzky, Hanns Leo, Kaiser Heinrich II. und die Kirche (Veröffentlichungen des Instituts für österreichische Geschichtsforschung 8, Wien 1946)

Millar, Fergus, The emperor in the Roman world (31 BC - AD 337) (London 1977)

Minninger, Monika, Heinrichs III. interne Friedensmaßnahmen und ihre etwaigen Gegner in Lothringen, in: Jahrbuch für westdeutsche Landesgeschichte 5 (1979) $33-52$

Mitterauer, Michael, Karolingische Markgrafen im Südosten. Fränkische Reichsaristokratie und bayerischer Stammesadel im österreichischen Raum (Archiv für österreichische Geschichte 123, Wien 1963)

Mitterauer, Michael, Christentum und Endogamie, in: ders., Historisch-anthropologische Familienforschung. Fragestellungen und Zugangsweisen (Wien - Köln 1990) 41-85

Mitterauer, Michael, Warum Europa? Mittelalterliche Grundlagen eines Sonderwegs (München 2003)

Mitterauer, Michael, Geschichte der Familie. Mittelalter, in: Andreas Gestrich - JensUwe Krause - Michael Mitterauer, Geschichte der Familie (Stuttgart 2003) 160 363 
Mohr, Walter, Richilde vom Hennegau und Robert der Friese. Thesen zu einer Neubewertung der Quellen, in: Revue belge de philologie et d'histoire 88 (1980) 777 796; 89 (1981) 265-291

Mommsen, Theodor - Krüger, Paul, Anecdoton Livianum, in: ders., Gesammelte Schriften 7 (Berlin 1909) 163-167 (erstmals 1870)

Moore, Robert I., Die erste europäische Revolution. Gesellschaft und Kultur im Hochmittelalter (München 2001)

Moorhead, John, Justinian (London - New York 1994)

Mordek, Hubert, Die Rechtssammlungen der Handschrift von Bonneval - ein Werk der karolingischen Reform, in: DA 24 (1968) 339-434

Mordek, Hubert, Kirchenrecht und Reform im Frankenreich: Die Collectio Vetus Gallica, die älteste systematische Kanonessammlung des fränkischen Gallien. Studien und Edition (Beiträge zur Geschichte und Quellenkunde des Mittelalters 1, Berlin/New York 1975)

Mordek, Hubert, Kirchenrechtliche Autoritäten im Frühmittelalter, in: Recht und Schrift im Mittelalter, hg. von Peter Classen (VuF 23, Sigmaringen 1977) 237-255

Mordek, Hubert, Kanonistik und gregorianische Reform. Marginalien zu einem nichtmarginalen Thema, in: Reich und Kirche vor dem Investiturstreit. Festschrift Gerd Tellenbach, hg. von Karl Schmid (Sigmaringen 1985) 65-82

Mordek, Hubert, Das kirchliche Recht im Übergang von der Antike zum Mittelalter, in: Akten des 26. deutschen Rechtshistorikertages, hg. von Dieter Simon (Studien zur europäischen Rechtsgeschichte 30, Frankfurt 1987) 455-464

Mordek, Hubert, Bischofsabsetzungen in spätmerowingischer Zeit. Justelliana, Bernensis und das Konzil von Mâlay (677), in: Papsttum, Kirche und Recht im Mittelalter. Festschrift Horst Fuhrmann, hg. von Hubert Mordek (Tübingen 1991) 31-53

Mordek, Hubert, Die Hedenen als politische Kraft im austrasischen Frankenreich, in: Karl Martell in seiner Zeit, hg. von Matthias Becher u. a. (Beihefte der Francia 37, Sigmaringen 1994) 345-366

Mordek, Hubert, Bibliotheca capitularium regum Francorum manuscripta. Überlieferung und Traditionszusammenhang der fränkischen Herrschererlasse (MGH Hilfsmittel 15, München 1995)

Mordek, Hubert, Kapitularien und Schriftlichkeit, in: Schriftkultur und Reichsverwaltung unter den Karolingern, hg. von Rudolf Schieffer (Rheinisch-Westfälische Akademie der Wissenschaften. Geisteswissenschaftliche Abhandlungen 97, Opladen 1996) 35-66

Mordek, Hubert, Fränkische Kapitularien und Kapitulariensammlungen. Eine Einführung, in: ders., Studien zur fränkischen Herrschergesetzgebung. Aufsätze über Kapitularien und Kapitulariensammlungen ausgewählt zum 60. Geburtstag (Frankfurt u. a. 2000) 1-53

Mordek, Hubert, Karls des Großen zweites Kapitular von Herstal und die Hungersnot der Jahre 778/779, in: DA 61 (2005) 1-52

Mordek, Hubert, Die Anfänge der fränkischen Gesetzgebung für Italien, in: QFIAB 85 (2005) $1-35$

Mordek, Hubert - Glatthaar, Michael, Von Wahrsagerinnen und Zauberern. Ein Beitrag zur Religionspolitik Karls des Großen, in: AKG 75 (1993) 33-64

Mordek, Hubert - Reynolds, Roger E., Bischof Leodegar und das Konzil von Autun, in: Aus Archiven und Bibliotheken. Festschrift Raymund Kottje, hg. von Hubert Mordek (Freiburger Beiträge zur mittelalterlichen Geschichte 3, Frankfurt 1992) $71-92$ 
Mordek, Hubert - Schmitz, Gerhard, Neue Kapitularien und Kapitulariensammlungen, in: DA 43 (1987) 361-439

Moreau, Philippe, Plutarque, Augustin, Lévi-Strauss: prohibition de l'inceste et mariage préferentiel dans la Rome primitive, in: Revue belge de philologie et d'histoire 56 (1978) 41-54

Moreau, Philippe, Incestus et prohibitae nuptiae. L'inceste à Rome (Collection d'études anciennes 62, Paris 2002)

Morlet, Marie-Thérèse, Les noms de personne sur le territoire de l'ancienne Gaule, 2: Les noms latins ou transmis par le latin (Paris 1972)

Morris, Colin, The Papal Monarchy. The Western Church from 1050 to 1250 (Oxford 1989)

Müller, Heribert, Heribert, Kanzler Ottos III. und Erzbischof von Köln (Veröffentlichungen des Kölnischen Geschichtsvereins 33, Köln 1977)

Müller, Jörg, Karl von Amira und das kanonische Recht am Beispiel des Rügeverfahrens, in: Karl von Amira zum Gedächtnis, hg. von Peter Landau u.a. (Rechtshistorische Reihe 206, Frankfurt u.a. 1999) 273-289

Müller, Richard, Erzbischof Aribo von Mainz 1021-1031 (Historische Studien 3, Leipzig 1881)

Murray, Alexander C., Germanic Kinship Structure. Studies in Law and Society in Antiquity and the Early Middle Ages (Studies and Texts 65, Toronto 1983)

Murray, Alexander C., The Position of the Grafio in the Constitutional History of Merovingian Gaul, in: Speculum 64 (1986) 787-805

Murray, Alexander C., From Roman to Frankish Gaul: Centenarii and Centenae in the administration of the Frankish Kingdom, in: Traditio 44 (1988) 59-100

Murray, Alexander C., Immunity, nobility and the Edict of Paris, in: Speculum 69 (1994) 17-39

Nathan, Geoffrey S., The Family in Late Antiquity. The rise of Christianity and the endurance of tradition (London - New York 2000)

Nehlsen, Hermann, Rezension Vismara, Edictum Theoderici, in: ZRG GA 86 (1969) 246-260

Nehlsen, Hermann, Sklavenrecht zwischen Antike und Mittelalter. Germanisches und römisches Recht in den germanischen Rechtsaufzeichnungen, 1: Ostgoten, Westgoten, Franken, Langobarden (Göttinger Studien zur Rechtsgeschichte 7, Göttingen 1972)

Nehlsen, Hermann, Zur Aktualität und Effektivität germanischer Rechtsaufzeichnungen, in: Recht und Schrift im Mittelalter, hg. von Peter Classen (VuF 23, Sigmaringen 1977) 449-502

Nehlsen, Hermann, Entstehung des öffentlichen Strafrechts bei den germanischen Völkern, in: Gerichtslauben-Vorträge, Freiburger Festkolloquium zum 75. Geburtstag von Hans Thieme, hg. von Karl Kroeschell (Sigmaringen 1983) 3-16

Nehlsen, Hermann, Alarich II. als Gesetzgeber. Zur Geschichte der Lex Romana Visigothorum, in: Studien zu den germanischen Volksrechten. Gedächtnisschrift für Wilhelm Ebel, hg. von Götz Landwehr (Rechtshistorische Reihe 1, Frankfurt - Bern 1982) $143-203$.

Nelson, Hein L.W., Überlieferung, Aufbau und Stil von Gai Institutiones (Studia Gaiana 6, Leiden 1981)

Nelson, Janet, On the Limits of the Carolingian Renaissance, in: dies., Politics and Ritual in Early Medieval Europe (London 1986) 49-67 (erstmals 1977) 
Nelson, Janet, Queens as Jezebels: Brunhild and Balthild in Merovingian History, in: dies., Politics and Ritual in Early Medieval Europe (London 1986) 1-48 (erstmals 1978)

Nelson, Janet, Charles the Bald (London - New York 1992)

Nelson, Janet, The siting of the Council at Frankfort: Some Reflections on Family and Politics, in: Das Frankfurter Konzil von 794. Kristallisationspunkt karolingischer Kultur, 1: Politik und Kirche, hg. von Rainer Berndt (Quellen und Abhandlungen zur mittelrheinischen Kirchengeschichte 80, Mainz 1997) 148-165

Nelson, Janet, Charlemagne - pater optimus?, in: Am Vorabend der Kaiserkrönung. Das Epos „Karolus Magnus et Leo papa“ und der Papstbesuch in Paderborn 799, hg. von Peter Godman u. a. (Berlin 2002) 269-281

Nelson, Janet, The voice of Charlemange, in: Belief and Culture in the Middle Ages. Studies presented to Henry Mayr-Harting, hg. von Richard Gameson - Henrietta Leyser (Oxford 2001) 77-88

Niederhellmann, Annette, Arzt und Heilkunde in den frühmittelalterlichen Leges (Arbeiten zur Frühmittelalterforschung 12, Berlin-New York 1983)

Nissl, Anton, Der Gerichtsstand des Clerus im fränkischen Reich (Innsburck 1886)

Niermeyer, Jan Frederik - Kieft, Co van - Burgers, Jan W.J., Mediae latinitatis lexicon minus. Mittellateinisches Wörterbuch (Darmstadt 2002)

Noble, Thomas F.X., The Republic of St. Peter. The Birth of the Papal State, 680-825 (Philadelphia 1984)

Noble, Thomas F.X., Boniface and the Roman Church, in: Bonifaitus - Leben und Nachwirken. Die Gestaltung des christlichen Europa im Frühmittelalter, hg. von Franz J. Felten u.a. (Quellen und Abhandlungen zur mittelrheinischen Kirchengeschichte 121, Mainz 2007) 327-339

Nodes, Daniel J., Avitus of Vienne's Spiritual History and the Semipelagian Controversy: The Doctrinal Implications of Books 1-3, in: Vigiliae Christianae 38 (1984) $185-195$

Nodes, Daniel J., Doctrine and exegesis in biblical Latin poetry (Leeds 1993)

Noethlichs, Karl Leo, Die gesetzgeberischen Maßnahmen der christlichen Kaiser des vierten Jahrhunderts gegen Häretiker, Heiden und Juden (masch. Diss Köln 1971)

Noethlichs, Karl Leo, Das Judentum und der römische Staat. Minderheitenpolitik im antiken Rom (Darmstadt 1996)

Noethlichs, Karl Leo, „Quid possit antiquitas nostris legibus abrogare?" Politische Propaganda und praktische Politik bei Justinian I. im Lichte der kaiserlichen Gesetzgebung und der außerjustinianischen Überlieferung, in: Zeitschrift für antikes Christentum 4 (2000) 116-132

Noethlichs, Karl Leo, Art. „Iustinianus“, in: RAC 19 (2001) 668-763.

Noll, Peter, Symbolische Gesetzgebung, in: Zeitschrift für Schweizerisches Recht 100 (1981) 347-364

Nonn, Ulrich, Zwischen König, Hausmeier und Aristokratie. Die Bischofserhebung im spätmerowingisch-frühkarolingischen Frankenreich, in: Die früh- und hochmittelalterliche Bischofserhebung im europäischen Vergleich, hg. von Franz-Reiner Erkens (AKG Beiheft 48, Köln u.a. 1998) 33-58

Noonan, John T., Novel 22, in: The Bond of Marriage. An Ecumenical and Interdisciplinary Study, hg. von William W. Basset (Notre Dame 1968) 41-90

Norman, Albert F., Selected Works of Libanios, 2: Selected Orations (Oxford 1977)

Nottarp, Hermann, Gottesurteilstudien (München 1956)

Nürnberger, Richard, Die römische Synode vom Jahre 743, in: Archiv für katholisches Kirchenrecht 79 (1899) 20-54 
Ó Corráin, Donnchadh, Irish law and canon law, in: Irland und Europa. Die Kirche im Frühmittelalter, hg. von Próinséas Ní Chatháin - Michael Richter (Stuttgart 1984) $157-166$

Oediger, Friedrich Wilhelm, Die ältesten Urkunden des Stiftes Rees und die Gräfin Irmgardis, in: Annalen des Historischen Vereins für den Niederrhein 148 (1949) 531

Oelsner, Ludwig, Jahrbücher des fränkischen Reiches unter König Pippin (Leipzig 1871)

Oexle, Otto Gerhard, Conjuratio und Gilden im frühen Mittelalter. Ein Beitrag der sozialen Kontinuität zwischen Antike und Mittelalter, in: Gilden und Zünfte. Kaufmännische und gewerbliche Genossenschaften im frühen und hohen Mittelalter, hg. von Berent Schwineköper (VuF 29, Sigmaringen 1985) 151-214

Oexle, Otto Gerhard, Die Kultur der Rebellion: Schwureinung und Verschwörung im früh- und hochmittelalterlichen Okzident, in: Ordnung und Aufruhr im Mittelalter. Historische und juristische Studien zur Rebellion, hg. von Marie Theres Fögen (Studien zur Europäischen Rechtsgeschichte 70, Frankfurt 1995) 119-137

Oexle, Otto Gerhard, Friede durch Verschwörung, in: Träger und Instrumentarien des Friedens im hohen und späten Mittelalter, hg. von Johannes Fried (VuF 43, Sigmaringen 1996) 115-150

Offergeld, Thilo, Reges pueri. Das Königtum Minderjähriger im frühen Mittelalter (MGH Schriften 50, Hannover 2001)

Ohme, Heinz, Das Concilium Quinisextum und seine Bischofsliste. Studien zum Konstantinopeler Konzil von 692 (Arbeiten zur Kirchengeschichte 56, Berlin-New York 1990)

Ohme, Heinz, Die sogenannten ,anti-römischen' Kanones des Concilium Quinisextum, in: The Council in Trullo Revisited, hg. von George Nedungatt - Michael Featherstone (Kanonika 6, Rom 1995) 307-321

Ohme, Heinz, Concilium Quinisextum - Das Konzil Quinisextum (Fontes christiani 82, Turnhout 2006)

Orlandis, José - Ramos-Lissón, Domingo, Die Synoden auf der Iberischen Halbinsel bis zum Einbruch des Islams 711 (Konziliengeschichte, Reihe A: Darstellungen, Paderborn u.a. 1981)

O'Roark, Douglas, Close-Kin Marriage in Late Antiquity: The Evidence of Chrysostom, in: Greek, Roman and Byzantine Studies 37 (1996) 399-412

D’Ors, Alvaro, El Código de Eurico (Estudios visigóticos 2, Rom 1960).

D’Ors, Alvaro, La territorialidad del derecho de los visigodos, in: Estudios Visigóticos 1, hg. von Giulio Vismara (Rom 1956) 91-150

Ortegel, August, Irmingard von Hammerstein im östlichen Franken, in: Mitteilungen des Vereins für Geschichte der Stadt Nürnberg 39 (1944) 5-50

Osaba García, Esperanza, El adulterio uxorio en la Lex Visigothorum (Madrid 1997)

Ottenheimer, Martin, Forbidden Relatives. The American Myth of Cousin Marriage (Urbana - Chicago 1996)

The Oxford English dictionary 1-10, hg. von John A. Simpson u. a. (Oxford ${ }^{2} 1989$ )

Padberg, Lutz E. von, Bonifatius. Missionar und Reformer (München 2003)

Paradisi, Bruno, Il prologo e l'epilogo dell'Editto di Rotari, in: Studia et documenta historiae et iuris 34 (1968) $1-31$

Parisot, Robert, Le royaume de Lorraine sous les Carolingiens (843-923) (Paris 1899)

Parisse, Michel, Princes laïques et / ou moines. Les évêques du $\mathrm{X}^{\mathrm{e}}$ siècle, in: Il secolo di ferro: mito e realtà del secolo X (Settimane 38, Spoleto 1991) 449-516 
Parisse, Michel, Sigefroid, abbé de Gorze, et le mariage du roi Henri III avec Agnès de Poitou (1043). Un aspect de la réforme lotharingienne, in: Revue du Nord 86 (2004) 543-565

Parsons, Talcott, The incest taboo in relation to social structure and the socialization of the child, in: British Journal of Sociology 5 (1954) 101-117

Patzold, Steffen, Königserhebungen zwischen Erbrecht und Wahlrecht? Thronfolge und Rechtsmentalität um das Jahr 1000, in: DA 58 (2002) 467-507

Patzold, Steffen, Die Bischöfe im karolingischen Staat. Praktisches Wissen über die politische Ordnung im Frankenreich des 9. Jahrhunderts, in: Staat im frühen Mittelalter, hg. von Stuart Airlie u.a. (Forschungen zur Geschichte des Mittelalters 11, Wien 2006) 133-162

Perels, Ernst, Papst Nikolaus I. und Anastasius Bibliothecarius. Ein Beitrag zur Geschichte des Papsttums im 9. Jahrhundert (Berlin 1920)

Pérez de Urbel, Justo, España cristiana. Comienzo de la reconquista (711-1038) (Historia de España 6, Madrid 1964)

Pfister, Charles, Études sur le règne de Robert le Pieux (996-1031) (Bibliothèque de l'École des Hautes Études 64, Paris 1885)

Picker, Hanns-Christoph, Pastor doctus: Klerikerbild und karolingische Reformen bei Hrabanus Maurus (Veröffentlichungen des Instituts für Europäische Geschichte Mainz, Abt. für abendländische Religionsgeschichte 186, Mainz 2001)

Pieler, Peter E., Byzantinische Rechtsliteratur, in: Die hochsprachliche profane Literatur der Byzantiner 2, hg. von Herbert Hunger (Byzantinisches Handbuch 5, München 1978) 343-480

Piepenbrink, Karen, Konstantin der Große und seine Zeit (Darmstadt 2002)

Pietri, Charles, Roma Christiana. Recherches sur l'Église de Rome, son organisation, sa politique, son idéologie de Miltiade à Sixte III (311-440) (Bibliothèque des Écoles françaises d'Athènes et de Rome 224, Rom-Paris 1976)

Pitsakis, Constantin G., Le droit matrimonial dans les canons du concile in Trullo, in: AHC 24 (1992) 158-185

Pohl, Walter, Ethnic names and identities in the British Isles: a comparative perspective, in: The Anglo-Saxons from the Migration Period to the Eighth Century: An ethnographic Perspective, hg. von John Hines (Woodbridge 1997) 7-32

Pohl, Walter, Die Germanen (Enzyklopädie deutscher Geschichte 57, München 2000)

Pohl, Walter, Das Papsttum und die Langobarden, in: Der Dynastiewechsel von 751. Vorgeschichte, Legitimationsstrategien und Erinnerung, hg. von Matthias Becher Jörg Jarnut (Münster 2004) 145-161

Pohl, Walter, Gender and Ethnicity in the Early Middle Ages, in: Gender in the Early Medieval World. East and West, 300-900, hg. von Leslie Brubaker - Julia M.H. Smith (Cambridge 2004) 23-43

Pohl, Walter, Der Germanenbegriff vom 3. bis 8. Jahrhundert - Identifikationen und Abgrenzungen, in: Zur Geschichte der Gleichung „germanisch - deutsch“, hg. von Dieter Geuenich - Heiko Steuer (RGA Erg.-Bd. 34, Berlin 2004) 163-184

Pohl, Walter, Die Völkerwanderung. Eroberung und Integration (Stuttgart u.a. ${ }^{2} 2005$ )

Pokorny, Rudolf, Einleitung, in: Capitula episcoporum 4, hg. von Rudolf Pokorby (MGH Capit. episc. 4, Hannover 2005) 1-67

Poly, Jean-Pierre, La corde au cou. Les Francs, la France et la loi salique, in: Genèse de l'état moderne en Méditerranée. Approches historique et anthropologique des pratiques et des représentations, hg. von Henri Bresc (Collection de l'École Française de Rome 168, Rom 1993) 287-320 
Poly, Jean-Pierre, La cousine germaine et le rapt des Saliques. Mariage et parenté dans la coutume d'Ing, in: Mariage et sexualité au Moyen Age - Accord ou crise?, hg. von Michel Rouche (Cultures et civilisations médiévales 21, Paris 2000) 17-35

Poly, Jean-Pierre, Le chemin des amours barbares: Genèse médiévale de la sexualité européenne (Paris 2003)

Pontal, Odette, Die Synoden im Merowingerreich (Konziliengeschichte, Reihe A: Darstellungen, Paderborn u. a. 1986)

Pospísil, Leopold, Anthropology of Law. A comparative theory (New York u.a. 1971)

Prentout, Henri, Étude critique sur Dudon de Saint-Quentin et son histoire des premiers ducs normands (Paris 1916)

Prinz, Friedrich, Die bischöfliche Stadtherrschaft im Frankenreich vom 5. bis 7. Jahrhundert, in: HZ 217 (1973) 1-35

Prinz, Friedrich, Der fränkische Episkopat zwischen Merowinger- und Karolingerzeit, in: Nascita dell'Europa ed Europa Carolingia. Un'equazione da verificare (Settimane 27, Spoleto 1981) 1, 101-133

Prinz, Friedrich, Zum fränkischen und irischen Anteil an der Bekehrung der Angelsachsen, in: ZKG 95 (1984) 315-336

Pryce, Huw, Native Law and the Church in Medieval Wales (Oxford 1993)

Puff, Helmut, Sodomy in Reformation Germany and Switzerland, 1400-1600 (Chicago - London 2003)

Puliatti, Salvatore, Incesti crimina. Regime giuridico da Augusto a Giustiniano (Mailand 2001)

Rapp, Claudia, Holy bishops in late Antiquity. The nature of Christian leadership in an age of transition (The transformation of the classical heritage 37, Berkeley 2005)

Réal, Isabelle, Vies de saints, vie de famille. Représentation et système de la parenté dans le Royaume mérovingien (481-751) d'après les sources hagiographiques (Hagiologia 2, Turnhout 2001)

Redgate, Anne E., The Armenians (Oxford 1998)

Rees, Roger, Diocletian and the Tetrarchy (Edinburgh 2004)

Reichert, Eckhard, Die Canones der Synode von Elvira. Einleitung und Kommentar (Diss. Hamburg 1990)

Reicke, Siegfried, Der Hammersteiner Ehehandel im Lichte der mittelalterlichen Herrschaftsordnung, in: RhVjbll 38 (1974) 203-224

Reinle, Christine, Das mittelalterliche Sodomiedelikt im Spannungsfeld von rechtlicher Norm, theologischer Deutung und gesellschaftlicher Praxis, in: Rechtsverständnis und Konfliktbewältigung. Gerichtliche und außergerichtliche Strategien im Mittelalter, hg. von Stefan Esders (Köln u.a. 2007) 165-209

Reuter, Timothy, The „imperial church system“ of the Ottonian and Salian rulers. A reconsideration, in: Journal of ecclesiastical history 33 (1982) 347-374

Reuter, Timothy, „Kirchenreform“ und „Kirchenpolitik“ im Zeitalter Karl Martells. Begriffe und Wirklichkeit, in: Karl Martell in seiner Zeit, hg. von Matthias Becher u. a. (Beihefte der Francia 37, Sigmaringen 1994) 35-59

Reuter, Timothy, „Filii matris nostrae pugnant adversum nos“: Bonds and Tensions between Prelates and their "milites“ in the German High Middle Ages, in: Chiesa e mondo feudale nei secoli X-XII (Miscellanea del Centro di studi medioevali 14, Mailand 1995) 247-276

Reuter, Timothy, The Medieval Nobility, in: Companion to Historiography, hg. von Michael Bentley (London - New York 1997) 177-202 
Reuter, Timothy, König, Adelige und Andere: „Basis“ und „Überbau“ in ottonischer Zeit, in: Ottonische Neuanfänge, hg. von Bernd Schneidmüller - Stefan Weinfurter (Mainz 2001) 127-150.

Reydellet, Marc, La royauté dans la littérature latine de Sidoine Apollinaire à Isidore de Séville (Bibliothèque des Écoles Françaises d'Athènes et de Rome 243, Rom 1981)

Reynolds, Philip Lyndon, Marriage in the Western Church. The Christianization of Marriage during the Patristic and Early Medieval Periods (Supplements to Vigiliae Christianae 24, Leiden - New York - Köln 1994)

Reynolds, Roger E., Unity and Diversity in Carolingian Canon Law Collections: The Case of the Collectio Hibernensis and Its Derivatives, in: Carolingian Essays. Andrew W. Mellon Lectures in Early Christian Studies, hg. von Uta-Renate Blumenthal (Washington 1983) 99-135

Rhijn, Carine van, Shepherds of the Lord. Priests and episcopal statutes in the Carolingian period (Cultural encounters in late antiquity and the middle ages 6, Turnhout 2007)

Richard, Jean, Le cartulaire de Marcigny-sur-Loire (1045-1144). Essai de reconstruction d'un manuscrit disparu (Dijon 1957)

Riché, Pierre, Gerbert et Hugues Capet, in: Annuaire - Bulletin de la Société de l'histoire de France (1989) 63-72

Riché, Pierre, Abbon de Fleury: Un moine savant et combatif (vers 950-1004) (Turnhout 2004)

Riezler, Sigmund, Die Vita Kiliani, in: NA 28 (1903) 232-234

Ritzer, Korbinian, Formen, Riten und religiöses Brauchtum der Eheschließung in den christlichen Kirchen des ersten Jahrtausends (Liturgiewissenschaftliche Quellen und Forschungen 38, Münster 1962)

Roda, Sergio, Il matrimonio fra cugini germani nella legislazione tardoimperiale, in: Studia et documenta historiae iuris 45 (1979) 289-309

Röckelein, Hedwig, Heiraten - ein Instrument hochmittelalterlicher Politik, in: Der Hoftag in Quedlinburg 973. Von den historischen Wurzeln zum Neuen Europa, hg. von Andreas Ranft (Berlin 2006) 99-135

Roll, Hans-Achim, Zur Geschichte der Lex-Salica-Forschung (Untersuchungen zur deutschen Staats- und Rechtsgeschichte N.F. 17, Aalen 1972)

Roth, Paul R., Ueber Entstehung der Lex Bajuvariorum (München 1848)

Rouche, Michel, L'Aquitaine des Wisigoths aux Arabes, 418-781. Naissance d'une région (Paris 1979)

Rouche, Michel, Des mariages païens au mariage chrétien. Sacré et sacrement, in: Segni et riti nella chiesa altomedievale occidentale (Settimane 33, Spoleto 1986) 835-873

Rouche, Michel, Clovis (Paris 1996)

Rüegger, Hans, Einflüsse des Römischen Rechts in der Lex Burgundionum (Diss. Bern 1949)

Rupp, Gabriele, Die Ekkehardiner, Markgrafen von Meißen, und ihre Beziehungen zum Reich und zu den Piasten (Europäische Hochschulschriften Reihe 3, 691, Frankfurt u.a. 1996)

Russell, Jeffrey B., St Boniface and the Eccentrics, in: Church History 33 (1964) 235247

Ryan, J. Joseph, Saint Peter Damiani and His Canonical Sources. A Preliminary Study in the Antecedents of the Gregorian Reform (Studies and Texts 2, Toronto 1956)

Sabean, David W., Inzestdiskurse vom Barock bis zur Romantik, in: L'homme 13 (2002) 7-28 
Sägmüller, Johann Baptist, Eine Dekretale des Papstes Paschalis II. vom 12. Mai (11011103) über das Verbot der Ehe innerhalb des 7. Grades und die Berechnung der Verwandtschaftsgrade, in: Theologische Quartalschrift 95 (1913) 56-70

Sahas, Daniel J., John of Damascus on Islam. The „Heresy of the Ishmaelites“ (Leiden 1972)

Saller, Richard P., European Family History and Roman Law, in: Continuity and Change 6/3 (1991) 335-346

Saller, Richard P. - Shaw, Brent D., Close-Kin Marriage in Roman Society?, in: Man 19 (1984) 432-444

Santifaller, Leo, Zur Geschichte des ottonisch-salischen Reichskirchensystems (SB Wien 229, 1964)

Schadt, Hermann, Vom Verwandtschaftsbild und der Weltalterlehre des Sachsenspiegels. Kunstgeschichte als Hilfswissenschaft der Rechtsgeschichte, in: FmSt 10 (1976) 406-436

Schadt, Hermann, Die Darstellungen der Arbores Consanguinitatis und der Arbores Affinitatis. Bildschemata in juristischen Handschriften (Tübingen 1982)

Schäferdiek, Knut, Die Kirche in den Reichen der Westgoten und Suewen bis zur Errichtung der westgotischen katholischen Staatskirche (Arbeiten zur Kirchengeschichte 39, Berlin 1967)

Schäferdiek, Knut, Die geschichtliche Stellung des sogenannten germanischen Arianismus, in: Kirchengeschichte als Missionsgeschichte 2,1: Die Kirche des früheren Mittelalters, hg. von Knut Schäferdiek (München 1978) 79-90

Schäferdiek, Knut, Das sogenannte zweite Konzil von Arles und die älteste Kanonessammlung der arelatenser Kirche, in: ZRG KA 71 (1985) 1-19

Schäferdiek, Knut, Kilian von Würzburg. Gestalt und Gestaltung eines Heiligen, in: Iconologia sacra. Mythos, Bildkunst und Dichtung in der Religions- und Sozialgeschichte Alteuropas. Festschrift Karl Hauck, hg. von Hagen Keller - Nikolaus Staubach (Arbeiten zur Frühmittelalterforschung 23, Berlin - New York 1994) $313-340$

Schäferdiek, Knut, Die Anfänge des Christentums bei den Goten und der sog. gotische Arianismus, in: ZKG 112 (2001) 295-310

Schäferdiek, Knut, Der vermeintliche Arianismus der Ulfila-Bibel. Zum Umgang mit einem Stereotyp, in: Zeitschrift für antikes Christentum 6 (2002) 320-329

Scheibelreiter, Georg, Der Bischof in merowingischer Zeit (Veröffentlichungen des Instituts für Österreichische Geschichtsforschung 27, Köln 1983)

Scherer, Rudolf Ritter von, Über das Eherecht bei Benedict Levita und Pseudo-Isidor (Graz 1879)

Scherer, Rudolf Ritter von, Handbuch des Kirchenrechts (Graz - Leipzig 1898) 2 Bde

Schieffer, Rudolf, Die Entstehung des päpstlichen Investiturverbots für den deutschen König (MGH Schriften 28, Stuttgart 1981)

Schieffer, Rudolf, „Priesterbild“, Reformpapsttum und Investiturstreit. Methodische Anmerkungen zu einer Neuerscheinung, in: AKG 68 (1986) 479-494

Schieffer, Rudolf, „Redeamus ad fontem“. Rom als Hort authentischer Überlieferung im frühen Mittelalter, in: Arnold Angenendt - Rudolf Schieffer, Roma - Caput et Fons. Zwei Vorträge über das päpstliche Rom zwischen Altertum und Mittelalter (Opladen 1989) 45-70

Schieffer, Rudolf, Das Familienbild der Karolinger, in: Bilder erzählen Geschichte, hg. von Helmut Altrichter (Freiburg 1995) 29-46

Schieffer, Rudolf, Die Beziehungen karolingischer Synoden zum Papsttum, in: AHC 27/28 (1995/96) $147-163$ 
Schieffer, Rudolf, „The Papal Revolution in Law“? Rückfragen an Harold J. Berman, in: Bulletin of medieval canon law 22 (1998) 19-30

Schieffer, Rudolf, Mediator cleri et plebis. Zum geistlichen Einfluss auf Verständnis und Darstellung des ottonischen Königtums, in: Herrschaftsrepräsentation im ottonischen Sachsen, hg. von Gerd Althoff - Ernst Schubert (VuF 46, Sigmaringen 1998) 345-361

Schieffer, Rudolf, Der geschichtliche Ort der ottonisch-salischen Reichskirchenpolitik (Nordrhein-Westfälische Akademie der Wissenschaften, Voträge G 352, Opladen/ Wiesbaden 1998)

Schieffer, Rudolf, Burchard von Worms. Ein Reichsbischof und das Königtum, in: Bischof Burchard von Worms 1000-1025, hg. von Wilfried Hartmann (Quellen und Abhandlungen zur mittelrheinischen Kirchengeschichte 100, Mainz 2000) 2949

Schieffer, Rudolf, Arn von Salzburg und die Kaiserkrönung Karls des Großen, in: Bayern und Italien. Politik, Kultur, Kommunikation (8. bis 15. Jahrhundert). Festschrift Kurt Reindel, hg. von Heinz Dopsch u. a. (ZBLG Beiheft 18, München 2001) $104-121$

Schieffer, Rudolf, Die Zeit des karolingischen Großreichs (714-887) (Handbuch der Deutschen Geschichte 2, Stuttgart 2005)

Schieffer, Rudolf, Die Karolinger (Stuttgart u.a. ${ }^{4} 2006$ )

Schieffer, Rudolf, Zur Entstehung des Sendgerichts im 9. Jahrhundert, in: Medieval Church Law and the Origins of the Western Legal Tradition. A Tribute to Kenneth Pennington, hg. von Wolfgang P. Müller - Mary E. Sommar (Washington 2006) $50-56$

Schieffer, Theodor, Ein deutscher Bischof des 11. Jahrhunderts: Gerhard I. von Cambrai (1012-1051), in: DA 1 (1937) 323-360

Schieffer, Theodor, Winfrid-Bonifatius und die christliche Grundlegung Europas (Freiburg 1954)

Schilling, Beate, Zur Datierung einer Synode Heinrichs II., in: Jahrbuch für westdeutsche Landesgeschichte 17 (1991) 67-73

Schipperges, Stefan, Bonifatius ac socii eius. Eine sozialgeschichtliche Untersuchung des Winfrid-Bonifatius und seines Umfeldes (Quellen und Abhandlungen zur mittelrheinischen Kirchengeschichte 79, Mainz 1996)

Schmale, Franz-Josef, Synoden Papst Alexanders II. (1061-1073). Anzahl, Termine, Entscheidungen, in: AHC 11 (1979) 307-338

Schmid, Karl, Zur Problematik von Familie, Sippe und Geschlecht, Haus und Dynastie beim mittelalterlichen Adel, in: ZGO 105 (1957) 1-62

Schmid, Karl, Ein verlorenes Stemma Regum Franciae. Zugleich ein Beitrag zur Entstehung und Funktion karolingischer (Bild-)Genealogien in salisch-staufischer Zeit, in: FmSt 28 (1994) 192-225

Schmidt, Hansgünther, Zum Geltungsumfang der älteren westgotischen Gesetzgebung, in: Gesammelte Aufsätze zur Kulturgeschichte Spaniens, hg. von Odilo Engels (Spanische Forschungen der Görresgesellschaft, 1. Reihe 29, Münster 1978) 1-84

Schmidt, Ludwig, Die Westgermanen (Geschichte der deutschen Stämme bis zum Ausgang der Völkerwanderung 2/2/1, München ${ }^{2} 1940$ )

Schmidt, Tilmann, Alexander II. (1061-1073) und die römische Reformgruppe seiner Zeit (Päpste und Papsttum 11, Stuttgart 1977)

Schmidt-Wiegand, Ruth, Die kritische Ausgabe der Lex Salica - noch immer ein Problem?, in: ZRG GA 76 (1959) 301-319 
Schmidt-Wiegand, Ruth, Spuren paganer Religiosität in den frühmittelalterlichen Leges, in: Iconologia sacra. Mythos, Bildkunst und Dichtung in der Religions- und Sozialgeschichte Alteuropas. Festschrift Karl Hauck, hg. von Hagen Keller - Nikolaus Staubach (Arbeiten zur Frühmittelalterforschung 23, Berlin - New York 1994) $249-262$

Schminck, Andreas, Kritik am Tomos des Sisinnios, in: Fontes minores 2, hg. von Dieter Simon (Forschungen zur byzantinischen Rechtsgeschichte 3, Frankfurt 1977) $215-254$

Schminck, Andreas, Livius als Kanonist, in: Rechtshistorisches Journal 1 (1982) 151 164

Schminck, Andreas, Bemerkungen zum sog. „Nomos mosaikos“, in: Fontes minores 11 (Forschungen zur byzantinischen Rechtsgeschichte 26, Frankfurt 2005) 249-268

Schmitt-Weigand, Adolf, Rechtspflegedelikte in der fränkischen Zeit (Münsterische Beiträge zur Rechts- und Staatswissenschaft 7, Berlin 1962)

Schmitz, Gerhard, Das Konzil von Trosly (909). Überlieferung und Quellen, in: DA 33 (1977) 341-434.

Schmitz, Gerhard, Zur Kapitulariengesetzgebung Ludwigs des Frommen, in: DA 42 (1986) $471-516$

Schmitz, Gerhard, Die Waffe der Fälschung zum Schutz der Bedrängten? Bemerkungen zu gefälschten Konzils- und Kapitularientexten, in: Fälschungen im Mittelalter, 2: Gefälschte Rechtstexte - Der bestrafte Fälscher (MGH Schriften 33, Hannover 1988) $79-110$

Schmitz, Gerhard, Die Vier-Bücher-Sammlung des Cod. Köln, Diözesan- und Dombibliothek 124. Zur kirchenrechtlichen Kenntnis im 10. Jahrhundert, in: Ex ipsis rerum documentis. Beiträge zur Mediävistik. Festschrift Harald Zimmermann, hg. von Klaus Herbers u.a. (Sigmaringen 1991) 233-255

Schmitz, Gerhard, Die Reformkonzilien von 813 und die Sammlung des Benedictus Levita, in: DA 56 (2000) 1-31

Schmitz, Gerhard, Die allmähliche Verfertigung der Gedanken beim Fälschen. Unausgegorenes und Widersprüchliches bei Benedictus Levita, in: Fortschritt durch Fälschungen? Ursprung, Gestalt und Wirkungen der pseudoisidorischen Fälschungen, hg. von Wilfried Hartmann - Gerhard Schmitz (MGH Studien und Texte 31, Hannover 2002) 29-60

Schmitz, Gerhard, Hinkmar von Reims, De presbyteris criminosis. Ein Memorandum Erzbischof Hinkmars von Reims über straffällige Kleriker (MGH Studien und Texte 34, Hannover 2004)

Schmitz, Gerhard, Echtes und Falsches. Karl der Große, Ludwig der Fromme und Benedictus Levita, in: Scientia veritatis. Festschrift für Hubert Mordek zum 65. Geburtstag, hg. von Oliver Münsch - Thomas Zotz (Ostfildern 2004) 153172

Schmitz, Gerhard, Die kirchenrechtliche Sammlung des Codex 124 der Kölner Domund Diözesanbibliothek, in: Mittelalterliche Handschriften der Kölner Dombibliothek, hg. von Heinz Finger (Libelli Rhenani 12, Köln 2005) 242-256

Schneider, Reinhard, Königswahl und Königserhebung im Frühmittelalter. Untersuchungen zur Herrschaftsnachfolge bei den Langobarden und Merowingern (Monographien zur Geschichte des Mittelalters 3, Stuttgart 1972)

Schneidmüller, Bernd, Otto III. - Heinrich II. Wende der Königsherrschaft oder Wende der Mediävistik?, in: Otto III. - Heinrich II. Eine Wende?, hg. von Bernd Schneidmüller - Stefan Weinfurter (Sigmaringen 1997) 9-46 
Schnith, Karl, Recht und Friede. Zum Königsgedanken im Umkreis Heinrichs III., in: HJb 81 (1961) 22-57

Scholz, Sebastian, Politik - Selbstverständnis - Selbstdarstellung. Die Päpste in karolingischer und ottonischer Zeit (Historische Forschungen 26, Stuttgart 2006)

Schott, Clausdieter, Traditionelle Formen der Konfliktlösung in der Lex Burgundionum, in: La giustizia nell'Alto Medioevo (secoli V-VIII) (Settimane 42, Spoleto 1995) 933-961

Schrader, Otto, Reallexikon der indogermanischen Altertumskunde. Grundzüge einer Kultur- und Völkergeschichte Alteuropas (Straßburg 1901)

Schramm, Percy Ernst, Karl der Große. Denkart und Grundauffassungen - Die von ihm bewirkte Correctio („Renaissance“), in: HZ 198 (1964) 306-345

Schreiner, Peter, Der byzantinische Bilderstreit. Kritische Analyse der zeitgenössischen Meinungen und das Urteil der Nachwelt bis heute, in: Bisanzio, Roma e l'Italia nell'alto Medioevo (Settimane 34, Spoleto 1988) 319-407

Schröder, Bianca-Jeanette, Bildung und Briefe im 6. Jahrhundert. Studien zum Mailänder Diakon Magnus Felix Ennodius (Millennium Studien 15, Berlin - New York 2007)

Schröder, Isolde, Die westfränkischen Synoden von 888 bis 987 und ihre Überlieferung (MGH Hilfsmittel 3, München 1980)

Schröder, Isolde, Zur Überlieferung von De institutione laicali des Jonas von Orléans, in: DA 44 (1988) 83-97

Schrörs, Heinrich, Hinkmar Erzbischof von Reims. Sein Leben und seine Schriften (Freiburg 1884)

Schubert, Ernst, Die Capitulatio de partibus Saxoniae, in: Geschichte in der Region. Zum 65. Geburtstag von Heinrich Schmidt, hg. von Dieter Brosius (Hannover 1993) 3-28

Schubert, Hans von, Staat und Kirche in den arianischen Königreichen und im Reiche Chlodwigs. Mit Exkursen über das älteste Eigenkirchenwesen (Historische Bibliothek 26, München 1912)

Schüssler, Heinz Joachim, Die fränkische Reichsteilung von Vieux-Poitiers (742) und die Reform der Kirche in den Teilreichen Karlmanns und Pippins. Zu den Grenzen der Wirksamkeit des Bonifatius, in: Francia 13/1 (1985) 47-112

Schütte, Bernd, Untersuchungen zu den Lebensbeschreibungen der Königin Mathilde (MGH Studien und Texte 9, Hannover 1994)

Schulze, Hans K., Die Grafschaftsverfassung der Karolingerzeit in den Gebieten östlich des Rheins (Schriften zur Verfassungsgeschichte 19, Berlin 1973)

Schwerhoff, Gerd, Blasphemie vor den Schranken der städtischen Justiz: Basel, Köln und Nürnberg im Verlgeich (14.-17. Jahrhundert), in: Ius commune 25 (1998) $39-120$

Schwerhoff, Gerd, Aktenkundig und gerichtsnotorisch. Einführung in die Historische Kriminalitätsforschung (Historische Einführungen 3, Tübingen 1999)

Sdralek, Max, Hinkmars von Rheims kanonistisches Gutachten über die Ehescheidung des Königs Lothar II. Ein Beitrag zur Kirchen-, Staats- und Rechtsgeschichte des IX. Jahrhunderts (Freiburg 1881)

Searle, John R., The Construction of Social Reality (London 1995)

Seckel, Emil, Studien zu Benedictus Levita I-VIII, in: NA 26 (1901) 39-72; 29 (1904) 275-331; 31 (1906) 59-139 (Nachtrag 238 f.); 34 (1909) 319-381; 35 (1910) $105-191$ u. 433-539; 39 (1915) 15-130; 41 (1919) 157-263, fortgesetzt von Josef Juncker: ZRG KA 23 (1934) 269-377 und 24 (1935) 1-112 
Seckel, Emil, Art. „Pseudoisidor“, in: Realencyklopädie für protestantische Theologie und Kirche $16\left({ }^{3} 1905\right)$ 265-307

Seckel, Emil, Die ältesten Canones von Rouen, in: Historische Aufsätze. Karl Zeumer zum sechzigsten Geburtstag als Festgabe dargebracht von Freunden und Schülern (Weimar 1910) 611-635

Seckel, Emil, Die Aachener Synode vom Januar 819, in: NA 44 (1922) 11-42

See, Klaus von, Altnordische Rechtswörter. Philologische Studien zur Rechtsauffassung und Rechtsgesinnung der Germanen (Tübingen 1964)

Seeck, Otto, Regesten der Kaiser und Päpste für die Jahre 311 bis 476 n. Chr. Vorarbeit zu einer Prosopographie der christlichen Kaiserzeit (Stuttgart 1919)

Seeliger, Gerhard, Die Kapitularien der Karolinger (München 1893)

Selb, Walter, Orientalisches Kirchenrecht 1-2 (Österreichische Akademie der Wissenschaften, Sitzungsberichte 543, Wien 1989)

Selb, Walter, Zur Christianisierung des Eherechts, in: Eherecht und Familiengut in Antike und Mittelalter, hg. von Dieter Simon (Schriften des Historischen Kollegs, Kolloquien 22, München 1992) 1-14

Seligman, Brenda Z., Studies in Semitic Kinship, in: Bulletin of the School of Oriental Studies 3 (1924) 51-68 u. 263-279

Seligman, Brenda Z., The Incest Taboo as a Social Regulation, in: The Sociological Review 27 (1935) 75-93

Semmler, Josef, $\mathrm{Zu}$ den bayerisch-westfränkischen Beziehungen in karolingischer Zeit, in: ZBLG 29 (1966) 344-424

Semmler, Josef, Episcopi potestas und karolingische Klosterpolitik, in: Mönchtum, Episkopat und Adel zur Gründungszeit des Klosters Reichenau, hg. von Arno Borst (VuF 20, Sigmaringen 1974) 305-396

Semmler, Josef, Bonifatius, die Karolinger und „die Franken“, in: Mönchtum - Kirche Herrschaft: $750-1000$, hg. von Dieter R. Bauer (Sigmaringen 1998) 3-49

Semmler, Josef, Der Dynastiewechsel von 751 und die fränkische Königssalbung (Studia humaniora 6, Düsseldorf 2003)

Settipani, Christian, La préhistoire des Capétiens, 481-987, 1: Mérovingiens, Carolingiens et Robertiens (Nouvelle histoire généalogique de l'auguste maison de France 1, Villeneuve d'Ascq 1993)

Settipani, Christian - Poly, Jean-Pierre, Les Conradiens: un débat toujours ouvert, in: Francia 23/1 (1996) 135-166

Shanzer, Danuta, History, Romance, Love, and Sex in Gregory of Tours, in: The World of Gregory of Tours, hg. von Kathleen A. Mitchell - Ian N. Wood (Cultures, beliefs and traditions 8, Leiden u.a. 2002) 295-418

Shanzer, Danuta - Wood, Ian N., Avitus of Vienne. Letters and Selected Prose (Translated Texts for Historians 38, Liverpool 2003)

Shaw, Brent D., Explaining Incest: Borther-Sister Marriage in Graeco-Roman Egypt, in: Man 27 (1992) 267-299

Siegmund, Frank, Pactus Legis Salicae $\$ 13$ : Über den Frauenraub in der Merowingerzeit, in: FmSt 32 (1998) 101-123

Siehr, Angelika, Objektivität in der Gesetzgebung. Symbolische Gesetzgebung zwischen Rationalitätsanspruch des Gesetzes und demokratischem Mehrheitsprinzip, in: Archiv für Rechts- und Sozialphilosophie 91 (2005) 535-557

Siems, Harald, Studien zur Lex Frisionum (Abhandlungen zur rechtswissenschaftlichen Grundlagenforschung 42, Ebelsbach 1980)

Siems, Harald, Zur Entwicklung des Kirchenasyls zwischen Spätantike und Mittelalter, in: Libertas. Grundrechtliche und rechtsstaatliche Gewährungen in Antike und 
Gegenwart. Festschrift Franz Wieacker, hg. von Okko Behrends - Malte Diesselhorst (Ebelsbach 1991) 139-186

Siems, Harald, Handel und Wucher im Spiegel frühmittelalterlicher Rechtsquellen (MGH Schriften 35, Hannover 1992)

Siems, Harald, Zum Weiterwirken römischen Rechts in der kulturellen Vielfalt des Frühmittelalters, in: Leges - Gentes - Regna. Zur Rolle von germanischen Rechtsgewohnheiten und lateinischer Schrifttradition bei der Ausbildung der frühmittelalterlichen Rechtskultur, hg. von Gerhard Dilcher - Eva-Marie Distler (Berlin 2006) 231-255

Siems, Harald, In ordine posuimus. Begrifflichkeit und Rechtsanwendung in Reginos Sendhandbuch, in: Recht und Gericht in Kirche und Welt um 900, hg. von Wilfried Hartmann (Schriften des Historischen Kollegs, Kolloquium 69, München 2007) 67-90

Simon, Dieter, Zur Ehegesetzgebung der Isaurier, in: Fontes minores 1, hg. von Dieter Simon (Forschungen zur byzantinischen Rechtsgeschichte 1, Frankfurt 1976) 1643

Simon, Dieter, Die Epochen der byzantinischen Gesetzgebung, in: Ius Commune 15 (1988) 73-106

Simon, Dieter, Legislation as both a world order and a legal order, in: Law and society in Byzantium (9th-12th Centuries), hg. von Angeliki E. Laiou - Dieter Simon (Washington 1994) $1-25$

Sirks, Adriaan J.B., From the Theodosian to the Justinian code, in: Attti dell'Accademia Romanistica Constantiniana: VI Convegno Internazionale (Neapel 1986) 265-302

Sivan, Hagith S., Why not marry a barbarian? Marital Frontiers in Late Antiquity (The Example of CTh 3.14.1), in: Shifting Frontiers in Late Antiquity, hg. von Ralph W. Mathisen - Hagith S. Sivan (Aldershot 1996) 136-145

Sivan, Hagith S., The invisible Jews of visigothic Spain, in: Revue des études juives 159 (2000) 369-385

Sjöholm, Elsa, Rechtsgeschichte als Wissenschaft und Politik. Studien zur germanistischen Theorie des 19. Jahrhunderts (Abhandlungen zur rechtswissenschaftlichen Grundlagenforschung 10, Berlin 1972)

Smith, Christopher J., The Roman Clan. The Gens from Ancient Ideology to Modern Anthropology (Cambridge 2006)

Smith, Julia M.H., Religion and lay society, in: The New Cambridge Medieval History 2: c. 700-c. 900, hg. von Rosamond McKitterick (Cambridge 1995) 654-678

Smith, Julia M.H., Europe after Rome. A New Cultural History, 500-1000 (Oxford 2005)

Smith, William Robertson, Kinship and Marriage in Early Arabia (Cambridge 1885)

Sonderegger, Stefan, Prinzipien germanischer Personennamengebung, in: Nomen et gens. Zur historischen Aussagekraft frühmittelalterlicher Personennamen, hg. von Dieter Geuenich u.a. (RGA Erg.-Bd. 16, Berlin - New York 1997) 1-29

Speck, Paul, Kaiser Leon III., die Geschichte des Nikephoros und des Theophanes und der Liber Pontificalis. Eine quellenkritische Untersuchung (Poikila Byzantina 19, Bonn 2002)

Spieß, Karl-Heinz, Familie und Verwandtschaft im deutschen Hochadel des Spätmittelalters (13. bis Anfang des 16. Jahrhunderts) (Vierteljahrschrift für Sozial- und Wirtschaftsgeschichte, Beihefte 111, Stuttgart 1993)

Springer, Matthias, Jährliche Wiederkehr oder ganz anderes: Märzfeld oder Marsfeld?, in: Rhythmus und Saisonalität, hg. von Peter Dilg u.a. (Sigmaringen 1995) $297-$ 324 
Springer, Matthias, Die Sachsen (Stuttgart 2004)

Sproemberg, Heinrich, Judith, Königin von England, Gräfin von Flandern, in: Revue belge de philologie et d'histoire 15 (1936) 397-428 u. 915-950

Stadelmaier, Michael, Collectio Sangermanensis XXI titulorum. Eine systematische Kanonessammlung der frühen Karolingerzeit. Studien und Edition (Freiburger Beiträge zur mittelalterlichen Geschichte 16, Frankfurt u.a. 2004)

Stafford, Pauline, Charles the Bald, Judith and England, in: Charles the Bald: Court and Kingdom, hg. von Margaret Gibson - Janet Nelson (Oxford 1981) 139-152

Stafford, Pauline, Queens, concubines, and dowagers. The king's wife in the early Middle Ages (Athens/Ga. 1983)

Stasser, Thierry, Adélaïde d'Anjou, sa famille, ses unions, sa descendance. État de la question, in: Le Moyen Age 103 (1997) 9-42

Staubach, Nikolaus, Das Herrscherbild Karls des Kahlen. Formen und Funktionen monarchischer Repräsentation im früheren Mittelalter (Diss. Münster 1981)

Stein, Dietrich, Der Beginn des byzantinischen Bilderstreites und seine Entwicklung bis in die 40er Jahre des 8. Jahrhunderts (Miscellanea Byzantina Monacensia 25, München 1980)

Stein, Ernest, Histoire du Bas-Empire 1-2 (Paris 1949-1956)

Steindorff, Ernst, Jahrbücher des Deutschen Reichs unter Heinrich III. (Leipzig 18741881) 2 Bde.

Steinen, Wolfram von den, Notkers des Dichters Formelband, in: Zeitschrift für Schweizerische Geschichte 25 (1945) 449-490

Stenton, F.M., Anglo-Saxon England (Oxford ${ }^{2} 1950$ )

Stiegler, Maria Albert, Dispensation. Dispensationswesen und Dispensationsrecht im Kirchenrecht 1 (Mainz 1901)

Stocking, Rachel L., Bishops, Councils, and Consensus in the Visigothic Kingdom, 589-633 (Ann Arbor 2000)

Stoclet, Alain J., Autour de Fulrad de Saint-Denis (v. 710-784) (Genf 1993)

Störmer, Wilhelm, Bayern und der bayerische Herzog im 11. Jahrhundert. Fragen der Herzogsgewalt und der königlichen Interessenpolitik, in: Die Salier und das Reich, hg. von Stefan Weinfurter (Sigmaringen 1991) 1, 503-547

Störmer, Wilhelm, Heinrichs II. Schenkungen an Bamberg: Zur Topographie und Typologie des Königs- und bayerischen Herzogsguts um die Jahrtausendwende in Franken und Bayern, in: Deutsche Königspfalzen. Beiträge zu ihrer historischen und archäologischen Erforschung, 4: Pfalzen - Reichsgut - Königshöfe, hg. von Lutz Fenske (Veröffentlichungen des Max-Planck-Instituts für Geschichte 11/4, Göttingen 1996) 377-408

Störmer, Wilhelm, Der junge Arn in Freising. Familienkreis und Weggenossen aus dem Freisinger Domstift, in: Erzbischof Arn von Salzburg, hg. von Meta NiederkornBruck - Anton Scharer (Veröffentlichungen des Instituts für Österreichische Geschichtsforschung 40, Wien - München 2004) 9-26

Story, Joanna, Carolingian Connections. Ango-Saxon England and Carolingian Francia, c. $750-870$ (Studies in Early Medieval Britain 2, Aldershot 2003)

Stratmann, Martina, Hinkmar von Reims als Verwalter von Bistum und Kirchenprovinz (Quellen und Forschungen zum Recht im Mittelalter 6, Sigmaringen 1991)

Stratmann, Martina, Zur Wirkungsgeschichte Hinkmars von Reims, in: Francia 22/1 (1995) $1-43$

Stroheker, Karl Friedrich, Leowigild, in: ders., Germanentum und Spätantike (Zürich Stuttgart 1965) 134-191 (erstmals 1939) 
Stroheker, Karl Friedrich, Der senatorische Adel im spätantiken Gallien (Tübingen 1948)

Stroheker, Karl Friedrich, Das spanische Westgotenreich und Byzanz, in: ders., Germanentum und Spätantike (Zürich - Stuttgart 1965) 207-245 (erstmals 1963)

Stutz, Ulrich, Erbenfolge und Verwandtschafts-Gliederung nach den alt-niederdeutschen Rechten (Untersuchungen zur Deutschen Staats- und Rechtsgeschichte 34, Breslau 1890)

Suntrup, Aloys, Studien zur politischen Theologie im frühmittelalterlichen Okzident. Die Aussage konziliarer Texte des gallischen und iberischen Raumes (Spanische Forschungen der Görresgesellschaft II 36, Münster 2001)

Tamassia, Giovanni, Le fonti dell'editto di Rotari (Pisa 1889)

Tangl, Georgine, Die Sendung des ehemaligen Hausmeiers Karlmann in das Frankenreich im Jahre 754 und der Konflikt der Brüder, in: Quellen und Forschungen aus italienischen Archiven und Bibliotheken 40 (1960) 1-42

Tangl, Michael, Studien zur Neuausgabe der Bonifatius-Briefe 1, in: NA 40 (1916) $639-790$

Tellenbach, Gerd, Königtum und Stämme in der Werdezeit des Deutschen Reiches (Quellen und Studien zur Verfassungsgeschichte des Deutschen Reiches in Mittelalter und Neuzeit 7/4, Weimar 1939)

Tellenbach, Gerd, Die westliche Kirche vom 10. bis zum frühen 12. Jahrhundert (Die Kirche in ihrer Geschichte 2/F 1, Göttingen 1988)

Tenbrock, Robert H., Eherecht und Ehepolitik bei Innozenz III. (Dortmund 1933)

Theis, Laurent, Robert le Pieux: le roi de l'an mil (Paris 1999)

Theuerkauf, Gerhard, Lex, Speculum, Compendium juris. Rechtsaufzeichnung und Rechtsbewusstsein in Norddeutschland vom 8. bis zum 16. Jahrhundert (Forschungen zur deutschen Rechtsgeschichte 6, Köln u.a. 1968)

Thier, Andreas, Dynamische Schriftlichkeit. Zur Normbildung in den vorgratianischen Kanonessammlungen, in: ZRG KA 93 (2007) 1-33

Thier, Andreas, Systemtheorie und kirchliche Rechtsgeschichte, in: Grundlagen des Rechts. Festschrift für Peter Landau, hg. von Richard H. Helmholz u. a. (Rechtsund Staatswissenschaftliche Veröffentlichungen der Görres-Gesellschaft, N.F. 91, Paderborn u.a. 1990) 1065-1102

Thierfelder, Helmut, Die Geschwisterehe im hellenistisch-römischen Aegypten (Fontes et commentationes 1, Münster 1960)

Thomas, Heinz, Zur Kritik an der Ehe Heinrichs III. mit Agnes von Poitou, in: Festschrift Helmut Beumann, hg. von Kurt-Ulrich Jäschke - Reinhard Wenskus (Sigmaringen 1977) 224-235

Thomas, Yan, Mariages endogamiques à Rome, in: Revue historique de droit français et étranger 58 (1980) 345-382

Thompson, Glen Louis, The earliest papal correspondence (Diss. Columbia University 1990)

Thraede, Klaus, Art. „Blutschande (Inzest)“, in: RAC Suppl. 2 (2002) 38-85

Thraede, Klaus, Inzest in der frühen Apologetik Tertullians, in: Hairesis. Festschrift Karl Hoheisel, hg. von Manfred Hutter u.a. (Jahrbuch für Antike und Christentum Erg.-Bd. 34, Münster 2002) 248-260

Tomeo, Paolo, Il segno di Edipo. Parricidio, incesto e 'materia tebana' nelle fonti agiografiche medioevali (con una Vita inedita di sant'Urso), in: Scribere sanctorum gesta. Recueil d'études d'hagiographie médiévale offert à Guy Philippart, hg. von Étienne Renard u.a. (Hagiologia 3, Turnhout 2005) 717-761

Timpe, Dieter, Arminius-Studien (Heidelberg 1970) 
Timpe, Dieter, Neue Gedanken zur Arminius-Geschichte, in: ders., Römisch-germanische Begegnung in der späten Republik und frühen Kaiserzeit. Voraussetzungen Konfrontationen - Wirkungen. Gesammelte Studien (Beiträge zur Altertumskunde 233, München - Leipzig 2006) 216-241 (erstmals 1973)

Timpe, Dieter, Die Söhne des Mannus, in: Chiron 21 (1991) 65-125

Todt, Klaus-Peter, Die letzte Papstreise nach Byzanz. Der Besuch Papst Konstantins I. in Konstantinopel im Jahre 711, in: Zeitschrift für Kirchengeschichte 113 (2002) 2450

Toubert, Pierre, La théorie du mariage chez les moralistes carolingiens, in: Il matrimonio nella società altomedievale (Settimane 24, Spoleto 1977) 233-282

Toubert, Pierre, L'institution du mariage chrétien, de l'Antiquité tardive à l'an Mil, in: Morfologie sociali e culturali in Europa fra tarda antichità e alto medioevo (Settimane 45, Spoleto 1998) 503-553

Treggiari, Susan, Roman Marriage. Iusti Coniuges from the time of Cicero to the time of Ulpian (Oxford 1991)

Troianos, Spyros N., Die Wirkungsgeschichte des Trullanum (Quinisextum) in der byzantinischen Gesetzgebung, in: AHC 24 (1992) 95-111

Tylor, Edward B., On a method of investigating the development of institution. Applied to the Laws of Marriage and Descent, in: Journal of the Royal Anthropological Institute 18 (1889) 245-269

Ubl, Karl, Doppelmoral im karolingischen Kirchenrecht? Ehe und Inzest bei Regino von Prüm, in: Recht und Gericht in Kirche und Welt um 900, hg. von Wilfried Hartmann (Schriften des Historischen Kollegs, Kolloquium 69, München 2007) $91-124$

Ubl, Karl, Der lange Schatten des Bonifatius. Die Responsa Stephans II. aus dem Jahr 754 und das fränkische Kirchenrecht, in: DA 63 (2007) 403-449

Udina Martorell, Federico, El Archivo Condal de Barcelona en los siglos IX-X. Estudio crítico de sus fondos (Barcelona 1951)

Uhlirz, Mathilde, Jahrbücher des Deutschen Reiches unter Otto II. und Otto III., 2: Otto III. 983-1002 (Berlin 1954)

Uytfanghe, Marc van, L'audience de l'hagiographie au VIe siècle en Gaule, in: „Scribere sanctorum gesta“. Recueil d'études d'hagiographie médiévale offert à Guy Philippart, hg. von Ėtienne Renard u. a. (Hagiologia 3, Turnhout 2005) 157-177

Van Dam, Raymond, Leadership and community in late antique Gaul (The transformation of the classical heritage 8, Berekeley 1985)

Van Dam, Raymond, Saints and their miracles in late antique Gaul (Princeton 1993)

Van Dam, Raymond, Becoming Christian. The Conversion of Roman Cappadocia (Philadelphia 2003)

Vanderkindere, Léon, La formation territoriale des principautés Belges au Moyen Age (Bruxelles 1902) 2 Bde.

Veyne, Paul, La famille et l'amour sous le Haut-Empire romain, in: Annales 33 (1978) $35-63$

Vismara, Giulio, Episcopalis audientia. L'attività giurisdizionale del vescovo per la risoluzione delle controversie private tra laici nel diritto romano e nella storia del diritto italiano fino al secolo nono (Pubblicazioni dell'Università cattolica del Sacro Cuore, Scienze giuridiche 54, Milano 1937)

Vismara, Giulio, Cristianesimo e legislazioni germaniche. Leggi longobarde, alamane e bavare, in: La conversione al cristianesimo nell'Europa dell'alto Medioevo (Settimane 14, Spoleto 1967) 397-467

Vogel, Cyrille, Le Pécheur et la Pénitence au Moyen Age (Paris ${ }^{2} 1982$ ). 
Vogel, Cyrille, La discipline pénitentielle en Gaule des origines à la fin du VIIe siècle (Paris 1952)

Vogel, Lothar, Vom Werden eines Heiligen. Eine Untersuchung der Vita Corbiniani des Bischofs Arbeo von Freising (Arbeiten zur Kirchengeschichte 77, Berlin 2000)

Vollmann, Benedikt, Studien zum Priszillianismus. Die Forschung, die Quellen, der fünfzehnte Brief Papst Leos des Großen (Kirchengeschichtliche Quellen und Studien 7, St. Ottilien 1965)

Vollrath, Hanna, Die deutschen königlichen Landfrieden und die Rechtsprechung, in: La giustizia nell'alto medioevo: secoli IX-XI (Settimane 43, Spoleto 1997) 591619

Volterra, Edoardo, La costituzione di Diocleziano e Massimiano contro i Manichei, in: La Persia e il mondo greco-romano (Accademia Nazionale dei Lincei 363, Rom 1966) $27-50$

Vones, Ludwig, Geschichte der Iberischen Halbinsel im Mittelalter (711-1480). Reiche - Kronen - Regionen (Sigmaringen 1993)

Vones-Liebenstein, Ursula, Katalonien zwischen Maurenherrschaft und Frankenreich. Probleme um die Ablösung westgotisch-mozarabischer Kirchenstrukturen, in: Das Frankfurter Konzil von 794. Kristallisationspunkt karolingischer Kultur, 1: Politik und Kirche, hg. von Rainer Berndt (Quellen und Abhandlungen zur mittelrheinischen Kirchengeschichte 80, Mainz 1997) 453-505

Voss, Monika, Symbolische Gesetzgebung. Fragen zur Rationalität von Strafgesetzgebungsakten (Abhandlungen zur rechtswissenschaftlichen Grundlagenforschung 72, Ebelsbach 1989)

Wagner, Anne, Gorze au XIe siècle. Contribution à l'histoire du monachisme bénédictin dans l'Empire (Turnhout 1996)

Waldmüller, Lothar, Die Synoden in Dalmatien, Kroatien und Ungarn. Von der Völkerwanderung bis zum Ende der Arpaden (1311) (Konziliengeschichte, Reihe A: Darstellungen, Paderborn u.a. 1987)

Wallace-Hadrill, John, Rome and the Early English Church: Some Questions of Transmission, in: Le chiese nei regni dell'Europa occidentale e i loro raporti con Roma sino all'800 (Settimane 7, Spoleto 1960) 519-548.

Wallace-Hadrill, John, Early Germanic Kingship in England and on the Continent (Oxford 1971)

Wallace-Hadrill, John, The Frankish Church (Oxford 1983)

Wallach, Luitpold, Alcuin and Charlemagne. Studies in Carolingian History and Literature (Cornell Studies in Classical Philology 32, Ithaca 1959)

Ward-Perkins, Bryan, The fall of Rome and the end of civilization (Oxford 2006)

Wasserschleben, Friedrich Wilhelm, Das Prinzip der Successionsordnung nach deutschem insbesondere saechsischem Rechte. Ein Beitrag zur deutschen Rechtsgeschichte (Gotha 1860)

Wasserschleben, Friedrich Wilhelm, Die pseudoisidorische Frage, in: Zeitschrift für Kirchenrecht 4 (1864) 273-303

Weidemann, Margarete, Kulturgeschichte der Merowingerzeit nach den Werken Gregors von Tours 1-2 (Römisch-Germanisches Zentralmuseum - Monographien 3, Mainz 1982)

Weigand, Rudolf, Die Naturrechtslehre der Legisten und Dekretisten von Irnerius bis Accursius und von Gratian bis Johannes Teutonicus (Münchener theologische Studien 3/26, München 1967)

Weigand, Rudolf, Kirchenrechtliche Verständnishintergründe des Kilianmartyriums, in: Würzburger Diözesangeschichtsblätter 51 (1989) 245-259 
Weigand, Rudolf, Die Ausdehnung der Ehehindernisse der Verwandtschaft, in: ZRG KA 80 (1994) $1-17$

Weinfurter, Stefan, Die Zentralisierung der Herrschaftsgewalt im Reich durch Kaiser Heinrich II., in: HJb 106 (1986) 241-297

Weinfurter, Stefan, Der Anspruch Heinrichs II. auf die Königsherrschaft 1002, in: Papstgeschichte und Landesgeschichte. Festschrift Hermann Jakobs, hg. von Joachim Dahlhaus - Armin Kohnle (AKG Beiheft 39, Köln u.a. 1995) 121-134

Weinfurter, Stefan, Heinrich II. Herrscher am Ende der Zeiten (Regensburg 1999)

Weinfurter, Stefan, Heinrich II. (1002-1024), in: Die deutschen Herrscher des Mittelalters. Historische Portraits von Heinrich I. bis Maximilian I. (919-1519), hg. von Bernd Schneidmüller - Stefan Weinfurter (München 2003) 97-118

Weinfurter, Stefan, Das Jahrhundert der Salier (1024-1125) (Ostfildern 2004)

Weinfurter, Stefan, Konfliktverhalten und Individualität des Herrschers am Beispiel Kaiser Heinrichs II. (1002-1024), in: Rechtsverständnis und Konfliktbewältigung. Gerichtliche und außergerichtliche Strategien im Mittelalter, hg. von Stefan Esders (Köln u. a. 2007) 291-311

Weiss, Egon, Endogamie und Exogamie im römischen Kaiserreich, in: ZRG RA 29 (1908) 340-369

Weitzel, Jürgen, Dinggenossenschaft und Recht. Untersuchungen zum Rechtsverständnis im fränkisch-deutschen Mittelalter (Quellen und Forschungen zur höchsten Gerichtsbarkeit im Alten Reich 15/1-2, Köln 1985)

Weitzel, Jürgen, Strafe und Strafverfahren in der Merowingerzeit, in: ZRG GA 111 (1994) 66-147

Weitzel, Jürgen, Versuch über Normstrukturen und Rechtsbewußtsein im mittelalterlichen Okzident (450-1100) in: Zur Entwicklung von Rechtsbewußtsein, hg. von Ernst-Joachim Lampe (Frankfurt am Main 1997) 371-402

Weitzel, Jürgen, „Relatives Recht“ und „unvollkomene Rechtsgeltung“ im westlichen Mittelalter. Versuch einer vergleichenden Synthese zum „mittelalterlichen Rechtsbegriff", in: Rechtsbegriffe im Mittelalter, hg. von Albrecht Cordes - Bernd Kannowski (Rechtshistorische Reihe 262, Frankfurt 2002) 43-62

Weitzel, Jürgen, Das Majestätsverbrechen zwischen römischer Spätantike und fränkischem Mittelalter, in: Hoheitliches Strafen in der Spätantike und im frühen Mittelalter, hg. von Jürgen Weitzel (Konflikt, Verbrechen und Sanktion in der Gesellschaft Alteuropas, Symposien und Synthesen 7, Köln u.a. 2002) 47-83

Weller, Tobias, Die Heiratspolitik des deutschen Hochadels im 12. Jahrhundert (Rheinisches Archiv 149, Köln u.a. 2004)

Wenskus, Reinhard, Sächsischer Stammesadel und fränkischer Reichsadel (Abhandlungen Göttingen 3/93, Göttingen 1976)

Wenskus, Reinhard, Stammesbildung und Verfassung. Das Werden der frühmittelalterlichen Gentes (Köln - Wien ${ }^{2} 1977$ )

Werner, Karl Ferdinand, Die literarischen Vorbilder des Aimon von Fleury und die Entstehung seiner „Gesta Francorum“, in: Medium Aevum vivum. Festschrift für Walther Bulst, hg. von Hans Robert Jauss - Dieter Schaller (Heidelberg 1960) 69103

Werner, Karl Ferdinand, Die Nachkommen Karls des Großen bis um das Jahr 1000 (1.-8. Generation), in: Karl der Große, 4: Lebenswerk und Nachleben, hg. von Helmut Beumann (Düsseldorf 1967) 403-482

Werner, Karl Ferdinand, Geschichte Frankreichs, 1: Die Ursprünge Frankreichs bis zum Jahr 1000 (Stuttgart 1989) 
Wickham, Chris, Framing Early Medieval Europe. Europe and the Mediterranean, 400-800 (Oxford 2005)

Wieruszowski, Helene, Die Zusammensetzung des gallischen und fränkischen Episkopats bis zum Vertrag von Verdun (843) mit besonderer Berücksichtigung der Nationalität und des Standes, in: Bonner Jahrbücher 127 (1922) 1-83

Wiesheu, Annette, Bischof und Gefängnis. Zur Interpretation der Kerkerbefreiungswunder in der merowingischen Hagiographie, in: HJb 121 (2001) 1-23

Wilhelmi, Hans-Albert, Die „Vita Gregorii Magni“ des Johannes Diaconus. Schwerpunkte ihrer Wirkungsgeschichte (Deutsche Hochschuledition, Neuried 1998)

Williams, Schafer, Codices Pseudo-Isidoriani. A palaeographico-historical study (Monumenta iuris canonici C: Subsidia 3, New York 1971)

Williams, Stephen - Friell, Gerard, Theodosius. The Empire at bay (London 1994)

Wilsdorf, Christian, Les Étichonides aux temps carolingiens et ottoniens, in: Bulletin philologique et historique du comité des travaux historiques et scientifiques 89 (1967) $1-33$

Winkelmann, Friedhelm, Quellenstudien zur herrschenden Klasse von Byzanz im 8. und 9. Jahrhundert (Berliner byzantinistische Arbeiten 54, Berlin 1987)

Winroth, Anders, The Making of Gratian's Decretum (Cambridge studies in medieval life and thought 4th ser. 49, Cambridge 2000)

Wipszycka, Ewa, Études sur le christianisme dans l'Égypte de l'antiquité tardive (Studia ephemeridis „Augustinianum“ 52, Rom 1996)

Wischermann, Else Maria, Marcigny-sur-Loire. Gründungs- und Frühgeschichte des ersten Cluniacenserinnenpriorates (1055-1150) (Münstersche Mittelalter-Schriften 42, München 1986)

Wolf, Armin, Königskandidatur und Königsverwandtschaft. Hermann von Schwaben als Prüfstein für das „Prinzip der freien Wahl“, in: DA 47 (1991) 45-117

Wolf, Armin, Quasi hereditatem inter filios. Zur Kontroverse über das Königswahlrecht im Jahre 1002 und die Genealogie der Konradiner, in: ZRG GA 112 (1995) 64157

Wolfram, Herwig, Die Goten. Von den Anfängen bis zur Mitte des sechsten Jahrhunderts. Entwurf einer historischen Ethnographie (München ${ }^{3} 1990$ )

Wolfram, Herwig, Salzburg, Bayern, Österreich. Die Conversio Bagoariorum et Carantanorum und die Quellen ihrer Zeit (Mitteilungen des Instituts für Österreichische Geschichtsforschung, Ergänzungsband 31, Wien 1995)

Wolfram, Herwig, Konrad II. 990-1039. Kaiser dreier Reiche (München 2000)

Woll, Carsten, Die Königinnen des hochmittelalterlichen Frankreich, 987-1237/38 (Historische Forschungen 24, Stuttgart 2002)

Woll, Ingrid, Untersuchungen zu Überlieferung und Eigenart der merowingischen Kapitularien (Freiburger Beiträge zur mittelalterlichen Geschichte 6, Frankfurt 1995)

Wollasch, Joachim, Eine adlige Familie des frühen Mittelalters. Ihr Selbstverständnis und ihre Wirklichkeit, in: Archiv für Kulturgeschichte 39 (1957) 150-188

Wolter, Heinz, Die Synoden im Reichsgebiet und in Reichsitalien von 916 bis 1056 (Konziliengeschichte, Reihe A: Darstellungen, Paderborn u.a. 1988)

Wood, Ian N., Kings, kingdom and consent, in: Early Medieval Kingship, hg. von Peter Sawyer -Ian N. Wood (Leeds 1977) 6-29

Wood, Ian N., Avitus of Vienne: religion and culture in the Auvergne and the Rhône Valley (470-530) (Diss. Oxford 1979)

Wood, Ian N., Gregory of Tours and Clovis, in: Revue belge de philologie et d'histoire 63 (1985) 249-272 
Wood, Ian N., Disputes in late fifth- and sixth-century Gaul: some problems, in: The Settlement of Disputes in Early Medieval Europe, hg. von Paul Fouracre - Wendy Davies (Cambridge 1986) 7-22

Wood, Ian N., Forgery in Merovingian Hagiography, in: Fälschungen im Mittelalter, 5: Fingierte Briefe, Frömmigkeit und Fälschung, Realienfälschungen (MGH Schriften 33/5, Hannover 1988) 369-384

Wood, Ian N., The Code in Merovingian Gaul, in: The Theodosian Code. Studies in the Late Imperial Law of Late Antiquity, hg. von Jill Harries - Ian Wood (London 1993) $161-177$

Wood, Ian N., The Mission of Augustine of Canterbury to the English, in: Speculum 69 (1994) $1-17$

Wood, Ian N. The Merovingian Kingdoms, 450-751 (London - New York 1994)

Wood, Ian N., Roman law in the barbarian kingdoms, in: Rome and the North, hg. von Alvar Ellegard - Gunilla Åkerström-Hougen (Studies in Mediterranean Archaeology and Literature 135, Jonsered 1996) 5-14

Wood, Ian N., Incest, law and the Bible in Sixth-Century Gaul, in: EME 7 (1998) $291-303$

Wood, Ian N., Family and Friendship in the Medieval West, in: The Cambridge Ancient History, 14: Late Antiquity. Empire and successors A.D. 425-600, hg. von Averil Cameron u.a. (Cambridge 2000) 416-436

Wood, Ian N., Avitus of Vienne, the Augustinian Poet, in: Society and Culture in Late Antique Gaul. Revisiting the Sources, hg. von Ralph W. Mathisen - Danuta Shanzer (Aldershot 2001) 263-277

Wood, Ian N., Gentes, Kings and Kingdoms - the emergence of states: the Kingdom of the Gibichungs, in: Regna and Gentes. The relationship between late antique and early medieval peoples and kingdoms in the transformation of the Roman world, hg. von Hans-Werner Goetz u.a. (The Transformation of the Roman World 13, Leiden 2003) 243-269

Wormald, Patrick, Lex Scripta and Verbum Regis: Legislation and Germanic Kingship from Euric to Cnut, in: Early Medieval Kingship, hg. von Peter H. Sawyer - Ian N. Wood (Leeds 1977) 105-138

Wormald, Patrick, The Making of English Law. King Alfred to the Twelfth Century, 1: Legislation and its Limits (Oxford 1999)

Wormald, Patrick, The Leges Barbarorum: law and ethnicity in the post-Roman West, in: Regna and gentes: the relationship between late antique and early medieval peoples and kingdoms in the transformation of the Roman world, hg. von HansWerner Goetz u.a. (The transformation of the Roman world 13, Leiden/Boston 2003) $21-53$

Wretschko, Alfred von, De usu Breviarii Alariciani forensi et scholastico per Hispaniam, Galiam, Italiam regionesque vicinas, in: Codex Theodosianus, hg. von Theodor Mommsen (Berlin 1905) CCCVII-CCCLXXVII

Wünsch, Thomas, Spiritalis intellegentia. Zur allegorischen Bibelinterpretation des Petrus Damiani (Regensburg 1992)

Zechiel-Eckes, Klaus, Auf Pseudoisidors Spur. Oder: Versuch, einen dichten Schleier zu lüften, in: Fortschritt durch Fälschungen? Ursprung, Gestalt und Wirkungen der pseudoisidorischen Fälschungen, hg. von Wilfried Hartmann - Gerhard Schmitz (MGH Studien und Texte 31, Hannover 2002) 1-28

Zechiel-Eckes, Klaus, Ein Blick in Pseudoisidors Werkstatt. Studien zum Entstehungsprozeß der falschen Dekretalen. Mit einem exemplarischen editorischen Anhang 
(Pseudo-Julius an die orientalischen Bischöfe, JK +196), in: Francia 28/1 (2002) $37-90$

Zechiel-Eckes, Klaus, Der „unbeugsame“ Exterminator? Isidorus Mercator und der Kampf gegen den Chorepiskopat, in: Scientia veritatis. Festschrift für Hubert Mordek zum 65. Geburtstag, hg. von Oliver Münsch - Thomas Zotz (Ostfildern 2004) 173-190

Zechiel-Eckes, Klaus, Historisch geordnetes und systematisches Kirchenrecht und seine frühmittelalterlichen Wechselbeziehungen. Beobachtungen zu den Codices 113, 114, 117 und 120 der Erzbischöflichen Diözesan- und Dombibliothek Köln, in: Mittelalterliche Handschriften der Kölner Dombibliothek, hg. von Heinz Finger (Libelli Rhenani 12, Köln 2005) 211-241

Zeddies, Nicole, Bonifatius und zwei nützliche Rebellen. Die Häretiker Clemens und Aldebert, in: Ordnung und Aufruhr im Mittelalter, hg. von Marie Theres Fögen (Ius Commune Sonderhefte 70, Frankfurt 1995) 217-263

Zeddies, Nicole, Religio et sacrilegium: Studien zur Inkriminierung von Magie, Häresie und Heidentum (4. - 7. Jahrhundert) (Europäische Hochschulschriften, Reihe 3, 964, Frankfurt u.a. 2003)

Zeumer, Karl, Geschichte der westgothischen Gesetzgebung 1-4, in: NA 23 (1898) $419-516$; 24 (1899) 39-122 und 571-630; 26 (1901) 90-149

Zhishman, Joseph, Das Eherecht der orientalischen Kirche (Wien 1864)

Zimmermann, Harald, Ottonische Studien, in: MIÖG Erg.-Bd. 20 (1962) 122-190

Zimmermann, Harald, Papstregesten 911-1024 (Regesta Imperii II/5, Wien - Köln Graz 1998)

Zöllner, Erich, Geschichte der Franken bis zur Mitte des 6. Jahrhunderts (München 1970)

Zotz, Thomas, Adelsherrschaften am Mittelrhein um 1000, in: Bischof Burchard von Worms 1000-1025, hg. von Wilfried Hartmann (Quellen und Abhandlungen zur mittelrheinischen Kirchengeschichte 100, Mainz 2000) 349-369

Zuckerman, Constantin, Learning from the Enemy and More: Studies in „Dark Centuries" Byzantium, in: Millennium 2 (2005) 79-135 


\section{Register}

Aachen 278, 283f., 286

d'Abadal, Ramón 380

Abbo 362f., 367, 369

Abbo von Fleury $399 f$.

Abel, Bf. von Reims 257

Abraham, Bf. von Freising 429, 435

Acta Andreae 86

Adalbero, Bf. von Laon $400 \mathrm{f}$.

- Rhythmus satiricus 400

Adalbero, Bf. von Metz 405-407, 417

Adalbero, Bf. von Reims $395 \mathrm{f}$.

Adalbold, Bf. von Utrecht 408, $415 \mathrm{f}$., 438

- Vita Heinrici II. 408, 438

Adalgar, Abt von Corvey $365 \mathrm{f}$.

Adalgisel, Hzg. 186

Adela von Blois 395, $464 f$.

Adelaida (Bonafilla) 380

Adelana 448

Adelheid, westfränk. Kg.in 379

Adelheid von Burgund, K.in 392

Adrianopel 56

Ägypten 7, 35, 43, 151

Aemilius Florus Paternus 60

Aemilius Lepidus, Marcus 38

Aethelbald, Kg. von Wessex 101, 226

Aethelbert I., Kg. von Kent 99, 205

Aethelwulf, Kg. von Wessex 101

Affinitas ex copula illicita 353, 471

Agathias

- Historiae 84

Agnes von Burgund 464

Agnes von Meran, franz. Kg.in 3

Agnes von Poitou, K.in 447f., 452, 467, 475

Agobard, Bf. von Lyon 292, 295, 297 , 361

- Brief 3292

Agrippina, Iulia $38 \mathrm{f}$.

Aistulf, langobard. Kg. 217, 264, 271

Akroinon 481

Alarich II., westgot. Kg. 123f., 192-195, 197-199, $211 \mathrm{f}$.
Albinus, Bf. von Angers 138, 152-156, 158, 172-174, 205, 213

Alethius 101

Alexander II., P. 16, 23, $441 \mathrm{f} ., 457$, 459f., 468-472, 475, 486f.

- JL 4477471

- JL $4500469 f$.

- JL 4506470

- JL 4523472

- JL 4524472

- JL 4582471

- JL 4617471

Alexander III., P. $472 \mathrm{f}$.

Alexios I. Komnenos, K. 437

Alfred der Große, ags. Kg. 101

Alkuin von York 277, 316

- Briefe 3316

- Brief 16316

Altfrid, Bf. von Münster

- Vita Liudgeri 287

Althoff, Gerd 403

Altmann 371

Amalarich, westgot. Kg. $199 \mathrm{f}$.

Amalrich I., Kg. von Jerusalem 2

Amboise 193

Ambrosius, Bf. von Mailand 12, 58, 60-65, 73, 146, 312, 320, 349, 410, 449

- Brief 58 58, 61, 63f., 71, 410

- Brief 5962

Ambrosius $85 \mathrm{f}$.

Amelrich von Ravenna 452

Amiens 1

Amphilochius, Bf. von Ikonium 54

Anastasius Bibliothecarius

- Brief 7341

Anathem 13, 143, 157, 235, 294, 371, 421

$\rightarrow$ Exkommunikation

Andreas, Hl. 86f., 92, 174

Anecdoton Livianum 38f., 69

Angelsachsen 20, 97, $101 \mathrm{f}$., 220, $225 \mathrm{f}$, 232, 249, 262, 287f., 338, 383, 415, 475,497 
Angers $161 \mathrm{f}$.

Annales

- Bertiniani 126, 355, 378

- Fuldenses 218

- Hildesheimenses 416, 435

- Laureshamenses 279, 284

- Magdeburgenses 392

- Nazariani 290

- Quedlinburgenses 392, 421

- regni Francorum 218, 267

Ansegis, Abt von Fontenelles 270

Anselm von Saint-Rémy

- Historia dedicationis 462

Ansgard, westfränk. Kg.in 379

Antiochia 49, $57 \mathrm{f}$.

Antonia Hybrida 37

Antonina 70

Apollinaris, Bf. von Valence 133f., 136

Aquitanien 144, 176, 178, 204, 239, 294, 304, 307, 342-344, 352, 355f., 447

Araber 238, 480, 483, 485

Arbeo, Bf. von Freising

- Vita Corbiniani 94

Arcadius, K. 29, 58, 65, 68, 223

Aregunde, fränk. Kg.in 95

Aremburgis 465

Arianismus 64, 103f., 110, 115, 118, 124f., 191, 194

Aribo, Bf. von Mainz 423-425, $444 \mathrm{f}$.

Aristokratie 38, 63f., 92, 104, 114-116, $131,174,213-215,257,290,385$, 402, 439, 488, 496, 498

- Reichsaristokratie 290, 380, $497 \mathrm{f}$.

Arles 148f., 154

Arminius 79

Arn, Bf. von Salzburg 281, 299, 301-303, 307

Arnebert, Hzg. 100

Arnulf, Bf. von Halberstadt 414

Arnulf, Bf. von Metz 169-171, 217f., 272 f., 438

Arnulf I., Gf. von Flandern 395

Arnulf II., Gf. von Flandern $395 \mathrm{f}$.

Asclepiodotus 177f., 182

Asser

- De rebus gestis Aelfredi $101 \mathrm{f}$.

Asylrecht 108, 128, 141, 166

Auctarium Havniense 193

Audentia 122
Augsburger Sendordnung 371

Augustinismus 9, 62

Augustinus, Bf. von Canterbury 17, 220, 223-226, 232, 241, 244, 305, 338, $342,415,429$

Augustinus, Bf. von Hippo 9, 31, 46, 61-63, 66, 73, 145, 164, 190, 304, 308f., 312f., 317, 455, 458, 479, $490 \mathrm{f}$.

- De civitate dei 61-63, 243, 490

- De octo quaestionibus ex veteri testamento 46

- Quaestiones in Heptateuchum 309, 317

Augustus, K. 45, 47

Aunacharius, Bf. von Auxerre 167

Aurell, Martin $380 \mathrm{f}$.

Austrasien 88f., 92f., 96, 150, 186f., 274,332

Auvergne 146, 159, 163

Avitus, Bf. von Vienne 95, 117-125, 127-133, 136f., 140, 148, 201-203, 212f., 215, 287, 320f., 478f., 493

- Brief 7140

- Brief 16 121, 123

- Brief 17121

- Brief $18122 \mathrm{f}$.

- Brief 44125

- De initio mundi 140

- De originali peccato 132

- De virginitate 122, 132

- Homiliae 140

d'Avray, David 455-457

Balduin V., Gf. von Flandern 462

Balduin VI., Gf. von Flandern 463

Balthild, fränk. Kg.in 89-91

Bamberg 403, 422

Barion, Hans 297

Basileios II., byzant. K. 488

Basilius, Bf. von Caesarea 12, 53-55, 57, 64, 72, 228, 260, 487

- Brief 160 53, 64

- Brief 19954

- Brief 21754

Bayern 93f., 156, 231, 234, 239, 267, 273, 281, 299, 403, 411

Beatrix von Hennegau 465

Beatrix von Tuszien $468 \mathrm{f}$. 
Beda Venerabilis 99, 102, 221, 225, 227f., 242, 244, 249, 295f., 305, $315,382 \mathrm{f}$.

- Historia ecclesiastica

- I 25225

- II 599

- II 699

- IV 2227

- IV $5227 \mathrm{f}$.

Belisar 70

Belló, Gf. von Carcasonne 380

Benedictus Levita 22, 26, 269f., 281, 323f., 327, 329-336, 339f., 360f., $375,378,389,428,430,486$

- Collectio capitularium

- Praefatio 324

- Versiculi 324, 336

- 1,3323

$-1,9323,331$

$-1,10323$

$-1,12323$

- 1,62 323

- 1,82 323, 331

$-1,91323$

- 1, 165-168 323

$-1,166331$

- 1, 226323

- 1, 241323

- 1, 274 323, 331

- 1,304323

$-1,310323$

$-2,31323$

$-2,37323$

- 2, 71 323, 331

- 2, 80 323, 339

$-2,87323$

- 2, 106323

- 2, 130 323, 331

- 2, 191323

- 2, 209 323, 331

- 2, 240323

- 2, 409-411 323

- 2, 419323

- 2, 421323,335

- 2, 424323

- 3, 143 323, 329f.

- 3, 179 323, 330, 389

- 3, 258 323, 331

- 3, 356 323, 331, 335

- 3, 377323
- 3, 381323

- 3, 432 323, 325, 331-335

$-3,433323$

$-3,434323$

- 3, 463 323, 327

- Additio 2, 23323

- Additio 3, 5323

- Additio 3, 92323

- Additio 4, 2 323, 331, 333

- Additio 4, 74323

- Additio 4, 75339

Benedikt III., P. 362

Benedikt VIII., P. 386, 417, 423f., 443, 451

Benedikt IX., P. $450 \mathrm{f}$.

Benedikt von Aniane 294

Benveniste, Émile 41

Berengar II., Kg. von Italien 394, 396

Berengar von Lomme 393

Bern, Abt von Reichenau $447 \mathrm{f}$.

- Brief 26448

Bernhard, Kg. von Italien 379

Bernward, Bf. von Hildesheim 416

Berta, franz. Kg.in 387, 394f., 397-402

Berthetrud, fränk. Kg.in 101

Bertrada von Montfort, franz. Kg.in 466

Besançon 447, 449

Beyerle, Franz 178, 186f., 189

Bibel

- Exod. 30, 12164

- Deut. 25, 5 51, 112

- Deut. 27, 2354

- Deut. 19, 20335

- Lev. 18 10, 72, 131, 245

- Lev. 18, 1-18 328

- Lev. 18, 6 64, 131, 201, 215, 239 , 306, 308f., 311

- Lev. 18, 1250

- Lev. 18, 12-13 10

- Lev. 18, 1351

- Lev. 18, 14 59, 96, 180, 229

- Lev. 18, 17161

- Lev. 18, 18 51, 53f.

- Lev. 18, 24328

- Lev. 18, 29 165, 201, 215

- Lev. 20, 11183

- Ezech. 3, 17245

- Luc. 18, 2910

- Act. 15, 2951

- 1. Cor. 5, 1 51, 102, 129, 143 
Bilichild, fränk. Kg.in 88f., 92

Biondi, Biondo 46

Blasphemie 5, 67

Böhringer, Letha 347

Boleslaw, Hzg. von Böhmen 402

Boleslaw Chrobry, Hzg. von Polen 402, 413, 416, 440

Bonifatius, Bf. von Mainz 20, 22, 26, 91f., 94, 96f., 112, 186, 218-221, 223, 230, 232-234, 236-255, 257-262, 264f., 268, 273-276, 284f., 287f., 296, 305, 310f., 315f., $323,339,354,363,376,430$

- Alloquutio sacerdotum 244f., 287

- Brief 16241

- Brief 32246

- Brief 33 220, 246-248

- Brief 50 22, 92, 97, 247-249

- Brief 58 247, 258

- Brief 60259

- Brief 78285

- Brief 93261

Bonifaz, Mkgf. von Tuszien 250, 452

Bordeaux 139, 163, 352

Boretius, Alfred 331

Boso, Kg. von Provence 379

Boso, Gf. von Arles 394

Boso, Gf. von Vitry 394

Bouchard, Constance 393, $395 \mathrm{f}$.

Bougard, François 282

Bourdieu, Pierre 492

Brechter, Heinrich 221

Bresslau, Harry $442 \mathrm{f}$.

Breviar 16, 85, 111, 126f., 168, 178, 180, 194-199, 201, 208

$\rightarrow$ Lex Romana Visigothorum

Britannien 98, 214, 227, 238, 252, 311, 497

Brooke, Christopher 457

Brown, Peter 47

Brun, Bf. von Augsburg 403, 424

Brunichilde, fränk. Kg.in 96

Bruning, Gf. $419 f$.

Brunner, Heinrich 18, 20, 76f., 79-81, 83,282

Bruno, Bf. von Toul

$\rightarrow$ Leo IX.

Brutus, M. Iunius 37

Bürgel 420
Burchard, Bf. von Worms 18, 23-25, 27, 32, 199, 359, 385f., 388, 408f., 424, 426-428, 430-435, 441f., 445-447, 450-457, 468, 470, 474f., 478, 486

- Decretum

- prol. 428

- II 80424

- VII 10 424, 430

- VII 18431

- VII 28 431, 433

- VII 29433

- VII 30431

- IX 4426

- XIX 5434

- XIX 51424

Burgund, Burgunder 75f., 89, 93, 95, 99f., 118, 125, 128-130, 133, 135f., 139, 143, 145, 150, 165, 188, 205, 211-213, 271, 436, 447 f., 469

Buße 30, 54f., 67, 87, 93, 100, 111, $121 \mathrm{f} ., 125,135,137,148 \mathrm{f} ., 152 \mathrm{f}$, 163, 167, 184, 258f., 266, 268, 273, 278f., 286, 298, 300, 303, 307, 309, 312, 316-321, 331, 333f., 345, $347 \mathrm{f}$, 350f., $357 \mathrm{f}$, $362 \mathrm{f} ., 370,381$, 387, 390, 399, 424, 434f., 445, 460, 468

- Bußbuch 227-231, 233, 298f., 301, $310,316,343,383,410$

- Kirchenbuße 169, 321 f., 332f., 339, 425

- Tarifbuße 30, 298, 317, 322, 494

Byzanz 9, 120, 214f., 233, 250, 303, 396, 437, 446, 480f., 487f., 493, 495

Caen 468

Caesar 79

Caesarius, Bf. von Arles 149, 151, 154, 164, 194, 200, 202f., 223

- Sermo 33164

- Sermo 44224

Calixt I., P. 327, 329, 340, 453

Canones apostolorum

- 1955

Canones synodi Romanorum 57, 59-61, $120,145,223$

$-1254$

- $1459 f$.

Canones Theodori

- Canones Basilienses 229 
- Canones Gregorii 229

- Discipulus Umbrensium

- II, 12, 26 228, 232

- II, 12, 27229

- II, 12, 28230

- II, 12, 29230

Capitula episcoporum

- Capitula Bavarica

- 12 281, 302

- Capitula Cameracensia

- 8306

- Capitula Frisingensia tertia

$-7358$

- 12358

- 21382

- Capitula Ottoboniana

- 13 281, 389

- Capitula Silvanectensia prima

- 5 357, 376

- Capitula Treverensia

- 4372

- Capitula Trosleiana

- 3389

Caracalla, K. 43

Cartagena 203

Cassian

- Collationes 190

Cassiodor 60, 74, 105-109, 119, 127

- Variae

- III 43105

- VI $8106 \mathrm{f}$.

- VII 46 60, 107

- VIII 20107

- edictum Athalarici 108

Chadwick, Henry 44f., 49

Champagne, Jean 138

Champeaux, Ernest $23 \mathrm{f}$.

Charibert I., fränk. Kg. 93, 95, 113, 156-162, 171

Charles-Edwards, Thomas $230 \mathrm{f}$.

Childebert I., fränk. Kg. 93, 113, 149, $151,154,156$

Childebert II., fränk. Kg. 93, 96, 114, $168,173,177,180,182-185,212$, $215,272 \mathrm{f}$.

Childebertus adoptivus 88

Childerich I., fränk. Kg. 113

Childerich II., fränk. Kg. 88-91

Childerich III. (von Bartenbruch) 84
Chilperich I., fränk. Kg. 96, 113, 160, 162, 176, 179-182, 190, 212f., 272

Chimnechilde, fränk. Kg.in 88

Chindasvinth, westgot. Kg. 208-211

Chlodomer, fränk. Kg. 93, 113

Chlodwig I., frank. Kg. 83, 113, 123, 140-143, 156, 174, 176-178, 181, 193

Chlothar I., fränk. Kg. 93, 95, 100, 113, $142 \mathrm{f} ., 150,160,171 \mathrm{f}$.

Chlothar II., fränk. Kg. 93, 160, 168, 180, 185, 187f., 272

Chlothar III., fränk. Kg. 89

Chrodechilde, fränk. Kg.in 93

Chrodegang, Bf. von Metz 27, $264 f$.

Chronica Caesaraugustana 193

Chronica monasterii Casinensis 468

Chronicae quae dicuntur Fredegarii

- IV 1597

- IV 47188

- IV 54100

- IV $58187 \mathrm{f}$.

- IV 66 215, 229

- IV 70105

- IV 75186

$\rightarrow$ Fredegar

Chronicon Moissiacense 286

Cicero

- Pro Cluentio 38

Cionta $170 \mathrm{f}$.

Claudius, K. 38, 40, 43, $49 \mathrm{f}$.

Clemens, Häretiker 94, 112, 250

Clemens II., P. 461

Clercq, Carlo de 127, 161, 166, 168, 267

Clermont 90, 92, 163, 355

Cloelius, Publius 37

Codex Euricianus 75, 84, 192f., 195

- 277192

- 305192

Codex Gregorianus 197

Codex Hermogenianus 194

Codex Theodosianus 16, 36, 47, 49-51, 55, 58f., 64-66, 68, 70, 75, 81, 108, 158, 177, 189, 192, 194-197, 199, $211 \mathrm{f}, 365$

$-3,7,181$

$-3,7,264$

- 3, 10, 1 16, 65, 108, 198, 365

$-3,12,149$ 
$-3,12,251$

- 3,12, 3 58f., 65, 68,108, 184, 196f., 328

$-3,12,458$

$-3,14,1108$

$-3,16,147$

$-8,16,147$

$-9,7,355$

$-9,7,564$

- 9, 15, 189

- 9, 38, 6-7 65

- 9, 38, 865

- 12, 1, 6108

Collatio legum Mosaicarum et Romanarum

$-5,364$

$-6,3197$

$-6,4$ 43-45, 50, 197

$-6,755$

$-15,345$

Collectio Bonnaevallensis prima 361

Collectio Dacheriana 32, 240, 297f., 360

- I 92298

Collectio Diessensis 168

Collectio Dionysiana 219, 259

Collectio Dionysio-Hadriana 32, 240, 291, 313, 346

Collectio Herovalliana

- 54, 5-7 360

- 54, 19360

- 71306,360

Collectio Hibernensis

- 32, 19232

- 46, 35 232, 360

Collectio Hispana 200, 202, 293, 298, 313, 328f., 350

Collectio Quesnelliana 161

Collectio Remensis 168

Collectio Sancti Amandi 306f., 354

Collectio Sancti Mauri 367

Collectio Sangermanensis 360

Collectio vetus Gallica 32, 911 167, 169, 227, 231, 240, 242, 360

- XIIX 4 169, 360

- XLIX 6-7 91, 360

- LXIII 20152

Collins, Roger 178

Compiègne 3

Conrat, Max 197
Constans I., K. 48

Constantin, K. 42, 45, 47-49, 51, 53, 72-74, 115, 206

Constantin II., K. 49

Constantin, Abt von St. Symphorian 405-409, 411, 413, 416

- Vita Adalberonis 405-411

Constantius II., K. 13, 46, 48-50, 55, 57f., 64, 72, 183, 490

Constitutiones Sirmondianae

$-865$

Corbet, Patrick 24, 310, 315f., 323, 366, 385f., 391, 402, 408, 431-433, 444, 468

Corbie 227, 230f., 240, 248, 270, 323, 336, 350, 354

Corbinian, Bf. von Freising 94, 241

Corcoran, Simon $49 f$.

Corpus Iuris Civilis

- Codex 36, 47, 57f., 65-67, 70, 108, 111,236

$-5,4,1965,70$

$-5,4,2670,236$

$-5,5,2108$

$-5,5,3108$

$-5,5,457$

$-5,5,557$

$-5,5,858$

$-5,5,958$

- 5, 17, 10-11 67

$-5,26,147$

- 6, 25, 2 42, 70

- 9, 9, 2947

- Digesta

- 23, 2, 342

- 28, 7, 23-24 42

- Institutiones

- 1, 10, 6111

- 1, 12, 470

- Novellae

- 12 68f., 109, 184, 208

$-7469$

$-7768$

$-8969$

- 11767,210

- 13467

- 13767

- 139109

- 14168

-154 69, 109 
Cresconius

- Concordia canonum 360

Cuneo, Paola 49f., 55

Cuthbert, Hl. 227

Cyprianus Gallus

- Heptateuchos 55, 132

Dagobert I., fränk. Kg. 215, 273

Dagobert II., fränk. Kg. 88

Dalmatien 471

Dalmatius, Gf. von Semur 465

Daly, William 178

Damaskusschrift 50

Damasus I., P. 54, 56, 60, 73

Damasus II. P., 461

Damiani, Petrus 21, 442, 451-460, $469 f ., 489$

Daudet, Pierre 15

David 395

Davidsohn, Robert 1

Decentius, Bf. von Gubbio 306

Declamationes minores 55

Decretales Pseudo-Isidorianae

- Ps.-Evarist c. 2327

- Ps.-Calixt c. 16 327f., 453

- Ps.-Julius c. 12338

- Ps.-Felix IV. 338

- Conc. Agath. c. 61329

- Decreta Gregorii iunioris 340

- Ps.-Felix v. Sizilien 338

- Ps.-Gregor 339, 353, 386, 409f., 428-430, $452 \mathrm{f}$.

$\rightarrow$ Pseudoisidor

Decretum Gratiani 2, 4, 199, 433, 486, 491

- C. 35 q. 1 c. $1-222$

- C. 35 q. 1. c. 1491

- C. 35 q. 2 c. $1-4486$

- C. 35 q. 2 c. 7486

- C. 35 q. 2 c. 10486

- C. 35 q. 2 c. 12486

- C. 35 q. 2 c. 16486

- C. 35 q. 2 c. 20486

- C. 35 q. 5 c. 6433

De ordinando pontifice 448

Dhuoda 437

Dietrich, Hzg. von Oberlothringen $405 \mathrm{f}$., 411

Digesten 42, 129

Dijon 163
Diocletian, K. 4, 42-45, 49f., 69, $71 \mathrm{f}$, $106,139,162,197,251,478$

Diodor, Bf. von Tarsus 53, 72

Dionysius Exiguus 52, 227, 240, 288

Doderer, Heimito von 84

Donatus

- Comm. in Hecyram 125

- Comm. in Andriam 125

Douglas, Mary 139f., 493

Duby, Georges 15, 374, 381, 387f., 393, $395,397,401,437,463-465$

Duda 344

Duddo, Abt 246

Dworkin, Ronald 484

Eadbald, Kg. von Kent 99, 113, 224, 226

Ebalus, Gf. von Roucy 465

Eberhard, Bf. von Bamberg 392, 424

Ebo, Bf. von Reims 306, 325

Ebroin, fränk. Hausmeier $89 \mathrm{f}$.

Eckhard, Gf. 416

Eckhardt, Karl August 81, 176-178, 180, 186

Ecloga 12, 256, 480-484

- prooimion $483 \mathrm{f}$.

- 2, 2 256, 482

$-2,9,1483$

- 17, 33482

$-17,34482$

- 17, 37480

Edgitha, ostfränk. Kg.in 392

Edictum Theoderici 107-109

$-36108$

$-54108$

$-70108$

$-108108$

$-125108$

- 154108

Egbert, Bf. von York 242, 315, 382, 416

Eherecht

- Ehebruch 47, 55, 70, 129, 169, 197, 210, 228, 253, 268, 282, 312, 320f., $330,350,357,366,369,382$

- Konkubinat 6f., 47, 54, 82, 209, 283, 392

- Scheidung 1, 3, 6, 33, 47f., 50, 57, $67,108,121,125,128,148,156$, 168f., 246, 257, 259, 265f., 311, 334, 347-349, 353-355, 358, 374, 
381, 397, 399, 437, 444, 446, 459-462, 472f., 476, 479, 482-484, $488 \mathrm{f}$.

- Unauflösbarkeit 2, 125, 228, 234, 241, 251, 267, 304, 346f., 349-351, 353, 359, 374, 388, 401f., 463, 473, 489

- Unzucht 51, 85, 99, 102, 130, 204, 209, 258, 277, 279, 284, 312, 319, 330, 344f., 351, 353, 366, 369, 382, 457, 471

Eichhorn, Karl Friedrich 14

Eike von Repgow 20f., $23 \mathrm{f}$.

Einhard 217

Eleonore von Aquitanien 466

Engersgau 419-421

England 3, 99, 113, 168, 220, 225, 227, 232f., 245, 316, 385, 462

Enguerrand von Ponthieu $462 \mathrm{f}$.

Ennodius, Bf. von Pavia 118-120, 127, 137

- Brief $5119 \mathrm{f}$.

- Vita Epifani 118, 120

Epiphanius - Cassiodor

- Historia ecclesiastica tripartita 74

Epistola de gradibus consanguinitatis $242-244,295,310,315,383$, $429 \mathrm{f}$.

Epistula episcoporum provinciae Turonensis 161-165

Epistulae Arelatenses

- 28200

$-34202$

- 38 148f.

Epistulae Austrasicae

- 11 147f., 155

Epistolae Moguntinae

- 23424

- 24425

- 25425

Epitome de Caesaribus $58 \mathrm{f}$.

Epitome Hispana 202

Erbschädigung 223, 330, 448

Erkanbald, Bf. von Mainz 420

Erkanbald, Bf. von Tours $398 \mathrm{f}$.

Ermengard von Anjou 465

Ermentrude, westfränk. Kg.in 378

Erminonen 79

Ermoldus Nigellus 383

Ernst, Hzg. von Schwaben $442 \mathrm{f}$.
Erpuin, Bf. von Senlis 376

Ervig, westgot. Kg. 210

Esmein, Adhémar 15

Etherius, Bf. von Lyon 169

Euchrotia 204

Eudoxia 74

Eufronius, Bf. von Tours 159-162, 165, 173

Eugenius 64

Eulalius, Gf. von Clermont 96

Eurich, westgot. Kg. 75, 192-194

Eustache von Boulogne $462 \mathrm{f}$.

Eustathios Rhomaios 491

Evans-Grubbs, Judith 47

Ewig, Eugen $186 f$.

Excarpsus Cummeani 230, $299 \mathrm{f}$.

Excerpta de libro Davidis 225

Exil 69, 88f., 96, 135, 172, 186, 189, 194, 207-209, 215, 260, 265, 325, 333

Exkommunikation 30, 121, 124, 134f., 148, 152f., 155f., 201, 203, 205, 264, 273, 286, 339, 357f., 368, 371, 373, 414, 420, 426, 433, 462f., 494

$\rightarrow$ Anathem

Felix, Bf. von Messina 337f., 341

Fergustus, Bf. 238

Fernan Gonzales, Gf. von Kastilien 464

Ficker, Julius von 15, 20-23, 437

Firmicus Maternus 48, 53, 55, 59

- Mathesis 48

Flandern 394-397

Flavianus Eutychianus 65

Fleury, Jean 15, 125-127, 223, 310

Flodoard von Reims 377, 391

- Annales 391

- Historia Remensis ecclesiae 341, 356, 358, 378, 383

Florenz $451 \mathrm{f} ., 469$

Fögen, Marie Theres 31, 71, $482 \mathrm{f}$.

Folz, Robert 408

Formulae

- Augienses 83, 373

- Collectio Sangallensis 370

- Salicae Lindenbrogianae 83

- Sangallenses 83

Foucault, Michel 46

Fouracre, Paul 28, 91, 289

Fournier, Paul 306 
Franciosi, Gennaro 41

Franken 75, 77, 79, 81-84, 88, 92, 97-99, 102f., 113f., 118, 123, 135, 138f., 147, 149, 151, 155, 171, 176f., $181 \mathrm{f} ., 186,193,212 \mathrm{f} ., 217$, 251, $270 \mathrm{f}$.

Frankreich 1, 3, 27, 30, 270, 385, 387, 393, 395-399, 402, 407, 429, 435, 447, 461, 463, 465f., 473, 475, 489

Frechulf, Bf. von Lisieux 308

Fredegar 186-188

Fredegunde, fränk. Kg.in 96, 236

Freisen, Joseph 15f., 310, 348

Freising 296, 299

Fried, Johannes 343, 374, 379, 403, 408, $437 \mathrm{f}$.

Friedrich I. Barbarossa, K. 1f., 14

Friesen 219, 274

Fulbert, Bf. von Chartres

- Brief 77464

Fulcher 358

Fulda 308, 354

Fulko II. der Gute, Gf. von Anjou 465

Fulrad, Abt von Saint-Denis 218, 264

Funktionalismus $492 \mathrm{f}$.

Fuscina 122, 132

Gainas 65

Gaius 43, 197

- Gai institutiones 43, 108

Galerius, K. 43, 45, 51

Gallien 54f., 63, 76, 86, 114-116, 118, $120,132,142,148,151,154,160$, 162, 172, 174, 191f., 194-197, 199, 202, 214, 246, 258, 264, 322, 497

Gallus, Bf. von Clermont 159

Ganshof, François-Louis $278 \mathrm{f}$.

Garibald, bayer. Hzg. 156

Gaudemet, Jean 137, 464, 466

Gauzlin, Bf. von Bourges 464

Gebhard, Gf. 418-420

Gelasius I., P. - JK 636190

Gerbald, Bf. von Lüttich 27, 302f., 307, 372, $375 \mathrm{f}$.

- Zweites Kapitular $302 \mathrm{f}$.

Gerbert von Aurillac 396, 398-400, 402

- Brief 111396

- Brief 181399
Gerhard, Bf. von Cambrai 415f., 435, 469

Gerhard, Gf. von Paris 379

Germanen 7, 9, 16, 18, 20, 25, 74f., 77-79, 82, 97, 104, 113, 129, 135, 138f., 149, 221, 227, 240f., 287, 494

$\rightarrow$ Sippenverbände

Germanus, Bf. von Paris 156, 158f., 213

Gerold, Gf. 378

Gertrude 416

Gesetze der Angelsachsen

- Aethelred 497

- Wihtraed 232

Gesetzgebung

- symbolische $31,33,64,101,181$, 190, 213, 274, 289, 475, 482, 484, 494, 496

Gesta episcoporum Cameracensium $416 f$.

Gesta Innocentii III 1

Giddens, Anthony 492

Gimmellus, Bf. von Vaison 128

Gisela, K.in 417, 432, 436-438, 440, 442-444

Giselbert von Mons

- Chronicon Hanoniense 24

Glatthaar, Michael 242, 244, 247

Godila 414, 433

Godinus, Hausmeier 100, 185f., 190, 272

Goericus, Bf. von Metz $169 \mathrm{f}$.

Goody, Jack 5-7, 9, 14, 27, 35, 42, 74, 477, 492, $496 \mathrm{f}$.

Gottesfrieden 30, 494

Gottfried II., Hzg. von Lothringen 415, 417,419

Gottfried III. „der Bärtige“, Hzg. von Lothringen $468 \mathrm{f}$.

Gottfried „der Gefangene“, Gf. von Verdun 417

Gottfried Martell, Gf. von Anjou 462, $464 f$.

Gottschalk von Orbais 314, 342

Gozbert, Hzg. 112

Grágás 84

Gratian, K. 56

Gregor I., P. 17, 26f., 120, 222, 226, $249,255,287,296,307,310-312$, 337, 359, 375, 386, 455f., 475, 487

- Dialogi 224, 323 
- Libellus responsionum (JE

1843) 17f., 27, 32, 113, 220,

223-227, 229-232, 242, 247-249,

255, 266, 269, 287f., 296, 301, 307, 309f., 313, 329f., 336, 338, 340, 342-344, 354, 359, 375, 386, 409f., 415, 426, 429, 451 f., 455, 471, 486

- Moralia in Iob 222, 224

Gregor II., P. 9, 13, 26, 219, 233-243, 247, 249f., 255f., 294, 307, 337, $354,363 f ., 374,468,475$

- JE 2153235

- JE 2174 (Ep. Bon. 26) 9, 236, 238, $240 \mathrm{f}$.

Gregor III., P. 9, 26, 236f., 244, $248 \mathrm{f}$, 268, 296, 306, 363

- JE 2239 (Ep. Bon. 28) 9, 237, 245

Gregor V., P. 387, 398f., 402, 407, 412, 429

Gregor VII., P. 4, 27, 374, 441 f., 472, 475

- Registrum 472

Gregor, Bf. von Tours 83, 85-88, 92f., $95 \mathrm{f}, 113 \mathrm{f} ., 116,118,141 \mathrm{f}, 146$, 151, 156f., 159, 161-163, 167, 172-174, 178f., 181f., 193, 389

- Decem libri historiarum

- praefatio prima 113

- II 983

- II 33118

- II 35193

- II 42141

- III 6142

- III 1893

- IV 3 95, 142

- IV 9 142, 156

- IV 26 93, 95, 156

- IV 31163

- IV 42167

- IV 45162

- IV 47162

- V 2 95f., 156

- V 14182

- V 17 173, 181

- V 18182

- V 3996

- V 44181

- VII 385

- VIII 36 93, 182

- IX 20173
- IX 21173

- IX 39161

- X 896

- De virtutibus Martini 224

- Liber de miraculis B. Andreae 87

- Vitae patrum

- 6146

- 17 146, 172-174

Gregor, Bf. von Langres 145,159

Gregor, Abt von Utrecht 274, 316

Grimald, Abt von St. Gallen 363

Grimm, Jacob 98

Grimoald, fränk. Hausmeier 88

Grimoald, bayer. Hzg. 94

Grönbech, Wilhelm 25

Gundobad, burgund. Kg. 118-120, 123-125, 128f., 195, 321

Gunhild von Dänemark 446

Gunthar, Bf. von Köln 345, 350

Guntheuca, fränk. Kg.in 93, 142

Gunthram, fränk. Kg. 93f., 113f., 137, $160,162,165-167,173,177,180$, 182,215

Guttenberg, Erich Freiherr von 422

Hadrian I., P. 291

Hadrian II., P. 341

Haimo, Bf. von Verdun $415 f$.

Haito, Bf. von Basel 303, 307, 318, 375

- Kapitular 303

- Visio Wettini 326

Halban, Alfred von 108

Haldon, John $481 \mathrm{f}$.

Halitgar, Bf. von Cambrai 298f., 306, 382

- Paenitentiale 298

Handschriften

- Bamberg, Staatsbibliothek - Can. 9296

- Berlin, Staatsbibliothek - Preußischer Kulturbesitz

- Phill. 1741 337, 354

- Cambridge, University Library

- Kk.V.16 296

- Den Haag, Museum Meermanno-Westreenianum

- 10.B.4 367

- Einsiedeln, Stiftsbibliothek - 254429 
- Frankfurt, Stadt- und Universitätsbibliothek

- Barth. 50432

- Gotha, Forschungs- und Landesbibliothek

- Mbr. I.84 428

- Heiligenkreuz, Stiftsbibliothek - 217409

- Köln, Erzbischöfliche Diözesan- und Dombibliothek

- 113410

- 114337,428

$-115296$

- 118 336, 409

- 120409

$-122298$

$-123298$

- Laon, Bibliothèque Municipale

- 201306

- $265268 f$.

- 468293

- Leiden, Bibliotheek der Rijksuniversiteit

- BPL 114 293, 367

- BPL 2005176

- Voss. Lat. Q. 199269

- München, Bayerische Staatsbibliothek

- Clm 3851371

- Clm 3852296

- Clm 3853 409, 428

- Clm 3860a 296

- Clm 6241296

- Clm 6242296

- Clm 6245296

- Clm 6255429

- Clm 14690 363, 410

- Clm 2817519

- Münster, Staatsarchiv

- msc. VII.5201 363, 410

- New Haven, Yale University, Beinecke Library

- 442329

- Paris, Bibliothèque Nationale

- Lat. 1451367

- Lat. 2796269

- Lat. 3858C 38

- Lat. 4403B 176

- Lat. 440480

- Lat. 5327217

- Lat. 9629329
- Lat. 9654269

- Lat. 17527429

- Lat. 18237176

- Saint-Omer, Bibliothèque Municipale - 194431

- Salzburg, St. Peter, Stiftsbibliothek - a.IX.32 369, 409

- St. Gallen, Stiftsbibliothek

- 23117

- 554429

- 578429

- 671 296, 363

- St. Petersburg, Rossiyskaya National'naya Biblioteka

- Q.v.II.5. 306

- Vatikan, Biblioteca Apostolica Vaticana

- Pal. Lat. 576342

- Pal. Lat. 577244

- Pal. Lat. 582269

- Pal. Lat. 583428

- Reg. Lat. 1127367

- Vat. Lat. 630329

- Vat. Lat. 1339296

- Vat. Lat. 3827269

- Wien, Österreichische Nationalbibliothek

- Lat. 694 429f., 432-434

- Lat. 2195301

- Lat. 2198296

- Lat. 2233301

- Wolfenbüttel, Herzog August Bibliothek

- Aug. 83.21 429-432

- Helmst. 454 409f.

Hardoisa 358

Hardrad, Gf. 290

Hart, H.L.A. 486

Hartbert, Bf. von Sens 257

Hatto, Bf. von Mainz 359

Hatto, Abt von Fulda 312f., 336

Hattuarien 187

Heather, Peter 214

Heiden 48, 51, 55, 58f., 62, 65, 71, 99, 101f., 253, 321, 406, 414

Heidentum 6, 48, 72, 94, 110, 114, 154, 206, 224, 276, 493

Heinrich I., franz. Kg. 446f. , 462f., 465, 467 
Heinrich I., ostfränk. Kg. 33, 390, 397, 406-408, 438-440, 442, 446-449, $465,467,489$

Heinrich II., K. 8, 13, 212, 383-387, 402-405, 407-413, 416-420, 422f., 425-427, 429-433, 435, 437-440, 442f., 463, 473-475, 478, 493, 495

- Diplomata

- 1428

$-20428$

- $34 \quad 405,411$

$-351419$

$-366419$

$-358420$

- 401422

- 417420

$-438422$

- 446420

- 454422

- 456-458 422

- 496422

- 506422

Heinrich III., K. 446-448, 450-452, $461 \mathrm{f} ., 467,475$

- Diplomata

- 294450

- 360450

Heinrich IV., K. 387, 441

Heinrich der Löwe 2

Heinrich „der Zänker“, Hzg. von Bayern 435

Heinrich von Schweinfurt, Mkgf. 403

Helgaud von Fleury 395, 399f.

- Vita Roberti regis 400

Helia von Semur 465

Helisachar 294

Herakleios, K. 215, 229

Herard, Bf. von Tours

- Kapitular 335

Heribald, Bf. von Auxerre 314, 317, 336, 381

Heribert, Bf. von Köln 410, 428

Heribert II., Graf von Vermandois $464 \mathrm{f}$.

Hermann, Bf. von Köln $449 \mathrm{f}$.

Hermann II., Hzg. von Schwaben 384, 405, 411f., 417, 427f., 436

Hermann, Gf. von Ename 415

Hermann von Werl 414

Hermegisclus, warn. Kg. 97-99

Herodes Antipas 50, 326
Herodias 326

Herold, Johannes 177

Herzogenaurach $422 \mathrm{f}$.

Hessen 219, $240 \mathrm{f}$.

Hesychius, Bf. von Vienne 122

Hieronymus 54, 73

Hieronymus, Sohn Karl Martells 217f., 264

Hildebald, Bf. von Köln 296

Himerius, Bf. von Tarragona 56

Hinkmar, Bf. von Reims 25f., 126, 269, 336f., 340-359, 369f., 372, 374-378, 382, 386, 391

- Brief 36358

- Brief 136 352-356, 378, 382

- Epistola synodalis 377

- De devortio 348f.

- De praedestinatione 375

- 3. Kapitular 357

Hinschius, Paul 324, 327, 331, 337

Historia Monasterii S. Florentii Salmurensis 465

Hlawitschka, Eduard 408

Höchst 425

Hoffmann, Hartmut 385, 396, 404, 418

Holtzmann, Robert 418, $422 \mathrm{f}$.

Homosexualität 55, 64, 67

Honoratus, Bf. von Bourges 145

Honorius, K. 16, 55, 74, 198, 365

Hrabanus Maurus, Bf. von Mainz 9, 237, 269, 308-323, 336f., 340, 342, 361-364, 367f., 369, 376f., 379, $381 \mathrm{f}$.

- Enarratio in Deuteronomium 309

- Expositiones in Leviticum 309

- Brief 29 309-312, 315, 337

- Brief 30312

- Brief 31 312-314, 337

- Brief 39314

- Brief 45314

- Brief 53 318f., 377

- Fragmenta 320-322, 377

- Paenitentiale ad Heribaldum 307, 314f., 317f., 323, 382

- Paenitentiale ad Otgarium 314

Hugbert, Hzg. 345, 348

Hugeburc von Heidenheim

- Vita Wynnebaldi 94

Hugo Capet, franz. Kg. 387, 395-398

Hugo Magnus, Hzg. 465 
Humbert, Bf. von Würzburg 309, 312f., Johannes Diaconus 337, 341, 429

$$
320,322,382
$$

Huntbert 344

Infamie $108,111,180 \mathrm{f}, 184,189$, 196f., 207, 209, 271, 305, 322, 328

Ingeborg von Dänemark 1, 3, 473

Ingelheim 447, 449

Ingunde, fränk. Kg.in 95

Ingwäonen 79,81

Innocenz I., P. 228

Innocenz III., P. 1, 3, 385, 437, 473, 476, 489

Irland 12, 30, 88, 220, 226, 230-232, 497

Irmingard von Hammerstein 379, 417-423, 425, 442

Isaak, Bf. von Langres

- Kapitular 281, 335

Isidor, Bf. von Sevilla 11, 16, 23-25, 31, 126, 190, 192, 242f., 293, 295f., 301, 305f., 309, 343, 367, 375, 424, $431 \mathrm{f} ., 454$

- Etymologiae

- 5, 26, 24190

- 9, 6, 2816

$-9,16,15126$

- 10,148190

- Historia Gothorum 192

Istwäonen 79

Italien 27f., 55, 63, 104f., 109, 112, $141,217 f ., 235,252,264,266,276$, 281f., 325, 369, 379, 396, 398, 412, 427, 450, 453, 456, 461, 466, 469f., 475

Ivo, Bf. von Chartres 464, 491

- Decretum 491

- Panormia 491

Ivois 447

Jackman, Donald 32, 392, 408

Johannes der Täufer 50, 133, 152, 172, 326

Johannes VIII., P. 341, 344

- JE 3025378

- JE 3125383

- JE 3263 344, 364

- JE 3265378

- JE 3325377

Johannes XII., P. 392
- Vita Gregorii Magni 341

Johannes Scholasticus

- Synagoga L titulorum 52

Johannes von Cesena 452

Johannes von Damaskus

- Liber de haeresibus 484

Johannes von Fécamp 462, 466f., 474

- Brief 462, 466f.

Jonas, Bf. von Orléans 304-307, 339, 342f., 350, 374, 409, 491

- De institutione laicali 304f., 343, 350

Jong, Mayke de 8, 139, 280, 354

Joyce, George H. 237

Juden 64f., $210 \mathrm{f}$, , 308, 406

Judith, K.in 308

Judith, Kg.in von Wessex 101

Julian, K. 48, 69

Juncker, Josef 327, $331 \mathrm{f}$.

Jussen, Bernhard 374

Justinian I., K. 48, 57, 66-71, 109, 199, 207, 211f., 215, 223, 236, 250, 451, 480-483, 491

Justinian II., K. 233f., 236, 480

Justinos II.

- Nov. 69, 123

Kamba 444

Kapitularien

- Edictum Chilperici (Nr. 4)

- 3180

$-6179 f$.

- Guntchramni regis edictum (Nr.

5) 173

- Childeberti II decretio (Nr.

7) 182-195, 188-191

- 2 183f., 273

- 4-5 183

$-7183$

- 14183

- Chlotharii II praeceptio (Nr. 8) 100, 160

- Karlmanni principis capitulare (Nr. 10) - 1257

- Pippini regis capitulare (Nr. 13)

- 1 261-263, 274, 293, 302, 333

$-2263$

- 3264

- Decretum Vermeriense (Nr. 16) 9, 22, 27, 264-269, 300, 303, 367 
$-1266$

$-8267$

- 10268

- 19267

- 20267

- 21267

- Decretum Compendiense (Nr. 15) 9 27, 264-269, 302f., 353

- 1-3 266

- 4266

$-10353$

- 14267

- 15 268, 302, 353

- 16267

- $17 \quad 268$

- 20267

- Capitulare primum Karoli Magni (Nr. 19)

$-7 \quad 285$

$-10275$

- Capitulare Haristallense (Nr. 20)

$-5276$

- 12269

- Admonitio generalis (Nr. 22) 251, 346 - 68315

- Capitulare missorum (Nr. 25) - 4 280, 334

- Capitulatio de partibus Saxoniae (Nr. 26)

- 20 276, 333

- Capitulare Francofurtense (Nr. 28) - 3126

- Capitulare missorum generale (Nr. 33)

$-2279$

$-3279$

$-33279$

$-35281$

- 37280

- Capitula de examinandis ecclesiasticis (Nr. 38)

$-15302$

- Capitulare missorum generale (Nr. 44) - 8334

- Divisio regnorum (Nr. 45) - 12290

- Capitula Karoli Magni (Nr. 56) - 4277

- Capitulare Aquisgranense (Nr. 77) - 1283

- Capitula ecclesiastica (Nr. 81)
$-20292$

- Capitula missorum (Nr. 83) - 6270

- Pippini Italiae regis capitulare (Nr. 91) $-8282$

- 9282

- Capitula cum Italiae episcopis deliberata $(\mathrm{Nr} .96)$

$-4283$

$-6283$

- Capitula e conciliorum canonibus collecta (Nr. 114)

$-2270$

- Capitula de Iudaeis (Nr. 131) - 3334

- Capitulare ecclesiasticum (Nr. 138) - 29295

- Capitula missorum (Nr. 148) - 6373

- Capitulare Olonnense ecclesiasticum primum (Nr. 163)

- 1334

- Capitulare pro lege habendum Wormatiense (Nr. 193)

$-3334$

- Episcoporum ad Hludowicum imperatorem relatio $(\mathrm{Nr} .196)$

- 54326

- Allocutio missi cuiusdam Divionensis (Nr. 267)

- 8357

- Capitulare Carisiacense (Nr. 278) $-1280$

- Capitulare generale Caroli Magni - 40286

- Capitulum de incestis 286

Karaïten 9

Karl der Einfältige, westfränk. Kg. 390

Karl der Große, K. 30, 32f., 102, 126, 212, 218, 249, 251, 260, 269-292, 295, 297, 299-307, 315-317, 319, 321, 326, 331, 333-335, 346, 356f., 360f., 367, 369, 372f., 377, 379, 381, 383, 397, 438f., 491, 497

Karl der Kahle, westfränk. Kg. u. K. 101, 126, 324, 340, 345, 347, 349-352, 355-357, 359, $378 \mathrm{f}$.

Karl, Kg. von Aquitanien $355 \mathrm{f}$.

Karl, Hzg. von Lothringen 396, 438

Karl Konstantin, Gf. von Vienne 394 
Karl Martell, Hausmeier 217, 241, 251-253, 265, 288, 378f.

Karlmann, Hausmeier 94, 97, 217f., 251-253, 255, 257f., 274-276, 288

Karlmann, westfränk. Kg. 379

Katalonien 380f., 497

Kelsen, Hans 486

Kent 99, 225, 232

Kilian, Hl. 94, 241

Kilikien 227, 311

King, Paul 195

Kirche

- armenische 9, 13

- byzantinische 12, 233f., 477, 480-484, 487f.

- irische 225f., 233, 245, 287

- koptische 12

- melkitische 12

- syrisch-orthodoxe 12

Knust, Friedrich Heinrich 331

Köln 139, 186-188, 369, 372, 388, 390, 405

Koeniger, Albert Michael 369

Königsbann 263, 276, 332f., 335

Konfiskation $58,65,108,111,184,186$, 189, 195, 263, 272, 274, 276, 280, 333f., 373, 418, 421, 423, 440

Konrad I., ostfränk. Kg. 384, 417

Konrad II., K. 384, 417, 421, 425, 432, 437, 440, 442-446, 450, 465, 467, 474

- Diplomata - 111421

Konrad III., Kg. von Burgund 397, 448

Konrad I., Hzg. von Kärnten 384, 403, 406-413, 417, 426, 430, 432, 437, 439f., 443, 474

Konrad II. d. Jüngere, Hzg. von Kärnten 407

Konradiner 33, 384, 392, 403, 419f., 423, 443

Konstantin, P. 234

Konstantin V., K. 481

Konstantinopel 12, 65, 124, 208, 221, 247, 256, 446, 478, 491

Konstanze, franz. Kg.in 387, 401

Konzile

- Aachen (818/819) - 1 294f., 306f., 318, 332, 376, 485

- Aachen (836)
$-36326$

- 38326

- Aachen (860)

- 18347

- 1. Gutachten $350 \mathrm{f}$.

- Aachen (862)

- 8350

- 10349

- Agde (506) 123, 140, 194, 200, 313, 350

$-33202$

- 48202

- $61328 \mathrm{f}$.

- Ankyra (314)

$-16300$

$-2555$

- Arles (524)

- 1202

- Arles (554) 137

- Arles (813)

- $11292 \mathrm{f}$.

- Aschheim (755/760) 274

- Auxerre (585/592)

- $31167 \mathrm{f}$.

- Bourges (1031)

- 17464

- Braga (572)

- 1284

- Chalkedon (451) 12, 124, 202

- Chalon (813)

$-18287$

- 28293

- 31378,381

- Cividale (796/7)

- 8278

- 12278

- Clermont (535) 148-151, 156, 158f., 169, 190, 215

- prol. 144

- 2144

- 4-5 144

- 12145

- Clichy (626/627) 137, 167-169, 190 - 10 169, 184f., 273

- Compiègne (757)

$\rightarrow$ Decretum Compendiense

- Compiègne (1193) 3

- Diedenhofen (1003) 23, 404-413, 416f., 425, 428, 430, 432, 435f., $439 f$. 
- Douzy (874)

- Ep. 342-344

- 2 26, 337, 344

- Eauze (551) 137

- Elvira (306) 72

- 6152

- Epaon (517) 121, 123-128, 130-134

139f., 144-146, 150-152, 154, 156,

$158,161,166-169,171,199$, 201-203, 211f., 268, 287, 292, 298-300, 306, 313, 315, 318, 328f., $331,340,343,348-350,354,358$, 479

- Epistola Aviti 124

- 1124

- 5202

- 12124

- 15124

- 19124

- 21124

- 23125

- 29125

- $30125,127,140,315$

- 33124

- 34125

- Frankfurt (1027) 445

- Freising (799/800)

$$
\text { - } 23302
$$

- Hertford (672) 227

- Ingelheim (826) 332

- Ingelheim (948)

- 10402

- 12 368, 391

- Koblenz (922)

- 1 368, 390

- Köln (887)

- 6 361, 371

- Konstantinopel (360) 103

- Konstantinopel (381) 56, 103

- Konstantinopel (680/681) 480

- Konstantinopel (691/692) 226, 233, 235f., 239, 259f., 480

- 54 226, 260

- Lérida (546)

- 3205

- 4205

- Les Estinnes (743)

- 1253

- 2253

- 3253,276
$-4253$

- Lyon (518/523)

- 1 133f., 205

- Lyon (567/570) 137

- Lyon (583) 165

- 4166

- Mâcon (581/3) 137

- Mâcon (585) 165, 173

- 1173

- 15167

- 18166

- Mainz (813) 270, 300, 302, 307, 315, 319,330

$-53287$

- 54293,367

- 55293

- 56 293, 315

- Mainz (847) 270, 363

$-24321$

- 28319

- 29315,317

- 30 315, 367

- Mainz (852)

$-8322$

- 10318

- 11321

$-12321$

- Mainz (861/863) 361-364, 377, 411

- Mainz (888) - 18 372, 378

- Mainz (1023) 423

- Meaux-Paris (845/846) 335, 369

- Metz (893) - $11361,371,378$

- Nicäa (324) 56f., 64, 337f., 485

- Neocaesarea $(314 / 315) 2$ 51f., 55, 72, 141, 149, 169, 219, 259, 292, 295, 298

- Nimwegen (1018) 418-420

- Orléans (511) 123f., 200

- Ep. 141

- 4141

- 18 141, 232

- Orléans (533)

- 1146

- 3145

- 4145

$-7 \quad 145$

- 10144,157

- 17146 
- Orléans (538)

- 11 150-152, 169, 215

- Orléans (541)

- prol. 155

- 2155

$-15154$

- 16154

- 27154

- Orléans (549)

- 10155

- 15157

- Paris (567) 173, 175, 182

- prol. 160

- 1160

-4161
-6

- 6160

- 8161

- Paris (614)

- 16 168, 190, 263

- Paris (829)

- 32298

- 34326

- Pavia (997)

- 1 387, 398, 429

- Quierzy (858)

- 7358

- Reims (1049)

- $10461 \mathrm{f}$.

- Rom (721) 32, 238f., 243, 245-247, 250, 254-256, 261, 269f., 292, 296, 298, 305-307, 311, 313, 328f., 340, $343,354,358,364,410,464$

- prol. 235

- 9236

- Rom (743) 9, 261, 296, 301, 306, 309f., 364

$-6254$

- 15 220, 255

- Rom (826)

- $38 \quad 365$

- Rom (853)

- 38365

- Rom (998/999)

- 1399

$-2399$

- Rom (1049) 461

- Rom (1059) 469f.

- Rom (1215) 385, 473, 489

- 50473

- 52473
- 66473

- Seligenstadt (1023) 23

- 3426

- 11424

- 18424

- Soissons (744)

- 4258

- 9257

- 10258

- Soissons (853)

- 11357

- Tarragona (516)

- 11200

- Toledo (400)

- 17392

- Toledo (526/531)

$-1202$

$-2202$

-4202
-

- 5 201, 208, 215, 238, 298, 313, 343,464

- ep. $1203 \mathrm{f}$.

- Toledo (589)

- 10 206f.

- 11206

$-12206$

- 14207

- 16206

$-17206$

- 18206

- Toulouges (1027) 464

- Tours (567)

- prol. 157

- 1157

- 22 127, 137, 158f., 199, 215, 268

- 25157

- Tours (813)

- 41286

- Trier (927)

- 24 390f.

- Tribur (895)

- 43-45 361, 378

- 47-48 361

- Tribur (1036) $445 \mathrm{f}$.

- Trosly (909)

$-8389$

- Ver (755)

- Prol. 264

-4267
-

$-5278$ 
- 6278

$-9265$

$-10278$

$-15265$

- Verberie (756)

$\rightarrow$ Decretum Vermeriense

- Worms (868) 362, 364-366

- 8362

$-14362$

$-15362$

- 19362

Korinth 51, 143, 145, 155, 158, 205, 245

Kottje, Raymund 164

Krusch, Bruno 91, 104f., 176, 193, 274

Kunibert, Bf. von Köln 186-188

Kunigunde, K.in 417, 425, $438 f$.

Laconius 118-120

Laieninvestitur 441

Laiou, Angeliki 437, 488

Lambert, Gf. von Löwen 415

Landau, Peter 297

Landricus, Gf. von Nevers 400

Langenzenn 422

Langobarden $21,76,103,110-112$, $217,235,261,264,271,288$

Lantbert 371

Laon 286, 367

Le Bras, Gabriel 297

Le Chaumontois $170 \mathrm{f}$.

Le Jan, Régine 374, 393

Le Mans $161 \mathrm{f} ., 166$

Leander, Bf. von Sevilla 208

Leges Langobardorum

- Edictus Rothari 18, 22, 181, 238

- 35110

$-15322,110$

$-154111$

$-185111$

$-169110$

$-272110$

$-359110$

$-367 \quad 112$

$-376110$

- Liutprand

- 33 238, 283, 333

$-44283$

$-81282$

- Aistulf $\begin{array}{ll}-8 & 271\end{array}$

Leidrad, Bf. von Lyon 297, 299, 303

- Brief 297

Leo I., P. 204, 353

- JK 412204

Leo III., P. 26, 237, 301, 339, 374

- JE 2503 237, 301, 364

Leo IV., P.

- JE 2599364

Leo IX., P. 441f., 449, 461-463, 466-468, 475

- JL 4307462

Leodegar, Bf. von Autun 89-92

Leon III., K. 8f., 12, 239, 478, 480-484, 495, 497

Leon VI., K. 488

Leovigild, westgot. Kg. 195, 199, 203, 206, 208

Lévi-Strauss, Claude 14, $30 \mathrm{f} ., 41,491 \mathrm{f}$, 495

Levison, Wilhelm 112, 230

Levy, Ernst 76

Lex Alamannorum 39 193, 274, 333

Lex Baiuvariorum

- prol. 178

- VII 2-3 193, 274, 333

Lex Burgundionum

- 14, 2130

- 34, 3-4 128

- 35, 3130

- 36129

$-85,2130$

- 86, 2130

- 102,3128

- extravag. 20128

- extravag. 21, 13128

Lex Ribuaria

- 40, 5-9 179

$-57,322$

$-59,3189$

- 61,2 187

- 72, 1189

- 72, 2 189, 333

- 91189

Lex Romana Visigothorum

- Auctoritas Alarici regis 195

- Cod. Theod. 3, 10, 1 127, 196

- Cod. Theod. 3, 10, 1 Int. 198

- Cod. Theod. 3, 12, 1197

- Cod. Theod. 3, 12, 2-4 196 
- Cod. Theod. 3, 12, 3 Int. 108, 126, 186, 196

- Cod. Theod. 3, 12, 4 Int. 208

- Cod. Theod. 3, 14, 1197

- Liber Gaii 4197

- Liber Gaii 4, 3-7 198

- Liber Gaii 4, 5-7 111

- Liber Gaii 4, 8198

- Pauli Sent. 4, 10 16, 201

- Pauli Sent. 4, 10, 4-6 126

$\rightarrow$ Breviar

Lex Salica 176-182

- prol. 178

- (C) 13, 683

- (C) 13, 11 180, 185

- (C) 35, 8179

- (A) 44 21, 79-84

- (A) $65 \mathrm{a} 83$

- (D) $78 \quad 180$

- (A) 100, 183

Lex Visigothorum

- 3, 5, 1 209f., 333

- 3, 5, 2 207-209, 272

$-3,5,5209$

- 4, 1, 1-7 201

- 12, 1, 2206

- 12, 2, 6210

- 12, 2, 11210

- 12, 2, 12207

- 12, 3, 8 211, 333

Libanios 58f., 62

- Oratio 162

- Oratio 3762

- Oratio 5058

Liber ex lege Moysi 225, 231, 483

Liber historiae Francorum

- 31236

$-4388$

$-4590$

Liber Papiensis

- Roth. 153 25, 453

- Liutp. 33450

Liber Pontificalis

- Vita Gregorii II. 234

Linke, Bernhard 41

Liudger

- Vita Gregorii 316

Liudolf, Gf. von Braunschweig 417

Liutchart $445 \mathrm{f}$.

Liuthar von Walbeck, Mkgf. 414
Liuthard, Bf. $225 \mathrm{f}$.

Liutprand, langobard. Kg. 111, 219, 237, 239, $282 \mathrm{f}$.

Liutprand von Cremona

- Antapodosis 394

- De Ottone rege 392

Livius 37-39, 41

- 42, 3437

$\rightarrow$ Anecdoton Livianum

Lothar I., K. 308, 324f., 334

Lothar II., fränk. Kg. 341, 345-353, $358,362,388,394$

Ludwig I. der Fromme, K. 270, 272, 284, 286, 294f., 304-308, 315, 325, 334f., 361, 373, 375-377, 379, 393, 485

Ludwig II., K. 394

Ludwig III. der Blinde, K. 126, 394

Ludwig der Deutsche, ostfränk. Kg. 308, $324,336,345,361$

Ludwig der Stammler, westfränk. Kg. 126, 379

Ludwig IV., westfränk. Kg. 391

Ludwig VII., franz. Kg. $1 \mathrm{f} ., 466$

Luhmann, Niklas 28f., 31

Lumpe, Adolf 52

Lupus, Bf. von Soissons 143

Lupus 85

Luxeuil 89f., 100

Lynch, Joseph 7, 70, 236

Lyon 117, 138, 150, 163, 297

Maastricht 188

Machielsen, Lambertus 242

Magnentius 55

Magnovaldus 93, 182, 190, 272

Magnus, Bf. von Sens 269

Mainz 139, $187 \mathrm{f} ., 354,372,375,389 f$, 404, 427, 429f., 434f., 444, 447, 449, 462, 474

Malinowski, Bronislaw 13f., 490

Manichäer 44f., 71, 204

Manichäismus 45, 203

Mannus 79

Mapinius, Bf. von Reims 147-149, 155

Marcoveifa, fränk. Kg.in 95, 156f., 159

Marcus Antonius 37

Marinus, Bf. von Bomarzo 391

Marseille 90f., 173

Martinianus, Bf. 234 
Maternus Cynegius 57

Matfrid, Gf. von Orléans 305

Mathilde, Tochter Balduins V. 462, 466, 468

Mathilde, Tochter Hermanns II. 384, 406f., 410, 413, 426, 432, 436f., 439, 443

Mathilde, Tochter Konrads II. 465, 467

Mathilde, Tochter Ludwigs IV. 448

Mathilde, Tochter Reginars V. $415 \mathrm{f}$.

Mathilde von Donzy 465

Mathilde von Polen 445

Matthews, John 57

Maximian, K. 45

McKitterick, Rosamond 373

Meens, Rob 225

Meginhard, Bf. von Würzburg 424

Meier, Mischa 68

Meigne, Maurice $52 \mathrm{f}$.

Merofledis, fränk. Kg.in 95, 156

Merovech, fränk. Kg. 96, 179, 182, 272

Metz 144, 169f., 186, 407

Meyvaert, Paul 221

Mikat, Paul 126f., 129, 135, 138f., 145, $150 \mathrm{f} ., 157,183,185$

Mitterauer, Michael 9-11, 13, 30, 50, 77, 477, 492, 496f.

Mommsen, Theodor 38, 197

Montanus, Bf. von Toledo 201-204

Moreau, Philippe 36, 41, 43, 48f., 52f., $55,59,61-63,65,71,73,86$

Morsberg 405

Moses 107, 403, 413

Mu'awiya, Kalif 480

Murray, Alexander $80 \mathrm{f},, 177$

Nantes $161 \mathrm{f}$.

Narbonne 381

Neapel $469 f$.

Nehlsen, Hermann 32f., 129, 177

Nelson, Janet 290, 355

Neustrien 89-91, 188, 274

Nicetius, Bf. von Trier 146-149, 152f., 155f., 158f., 169, 171f., 174, 205, 213

Nikephoros

- Breviarium 215

Nikolaus I., P. 26, 269, 341, 349f., 355, 361-364, 456

- JE 2706355
- JE 2787364

Nikolaus II., P. 442, $468 \mathrm{f}$.

- JL 4405469

Noddo, Hzg. 170, 273

Nothelm, Bf. von Canterbury 220, 242, 246-248

Notker von St. Gallen 27, 370, 429

Novempopulana 143

Odin 79

Odo, Bf. von Beauvais 350

Odo, Gf. von Blois 397

Odorannus von Sens

- Chronica 400

Offenbach 420

Oliba, Bf. von Vic 464

Ordericus Vitalis

- Gesta Normannorum ducum 468

Orléans 100, 123f., $304 f$.

Orosius 11

Ortegel, August 421-423

Ossius, Bf. von Córdoba 53

Otakar I., böhm. Kg. 2

Otgar, Bf. von Mainz 314, 324, 336

Otto I., K. 390-393

- Diplomata

- 331-333 392

Otto II., K. 392

Otto III., K. 387, 399, 402f., 408, 413, 427, $438 \mathrm{f}$.

Otto, Hzg. von Kärnten 384, 412

Otto von Hammerstein 384, 403, 417, 419-421, 440

Otto, Mkgf. von Schweinfurt 422, 445

Otto-Heinrich, Hzg. von Burgund 465

Otto-Wilhelm, Gf. von Burgund 393, 395

Paenitentiale Cummeani 225

Paenitentiale Martenianum 343, 382

Paenitentiale Oxoniense II 316

Paenitentiale Ps.-Bedae 315

Paenitentiale Ps.-Egberti 315

Paenitentiale additivum Ps.-Bedae-Egberti 242, 383

Paenitentiale mixtum Ps.-Bedae-Egberti 383

Paenitentiale Vindobonense B $299 f$.

Palencia $203 \mathrm{f}$.

Palladia 133-135 
Panegyrici Latini 47

Papinian 194

Pardessus, Jean-Marie 176

Paris 100, 181, 380

Parthenius 149

Paschalis II., P. 470

Paschasius Radbertus, Abt von Corbie 325f., 336, 379

- Expositio in Matheo 326

- Vita Adalhardi 379

Passio Leudegarii $90 \mathrm{f}$.

Passio Praeiecti $91 \mathrm{f}$.

Patrick, Hl. 230

Pauli Sententiae 16, 126, 194, 197, 199, 237, 431

Paulinus, Bf. von Aquileia 277f., $280 \mathrm{f}$, 318

- Brief 318

Paulus 51, 102, 143, 145, 155, 158, 205, 245,454

Pavia 25

Pehthelm, Bf. von Whithorn 246

Pertz, Georg Heinrich 176, 331

Pest 68, 163f., 173, 215, 347, 485

Petrus, Bf. von Alexandria 56

Petrus Damiani 21, 25, 442, 450-460, 462, 468, 470, 472, 475, 491

- Brief 19 451-456, 458f.

- Brief 36459

- Brief 48458

- Brief 51468

- Brief 96 457f., 460

- Brief 102462

- Brief 165 459f., 469

- Brief 172457

Philipp I., franz. Kg. 466

Philipp II. August, franz. Kg. 1, 3, 33, 473, 489

Phoenicia 49, 61

Piacenza 470

Pilgrim, Bf. von Köln 425, 446

Pippin I., fränk. Kg. 8, 22, 26, 180, 212, 217-219, 238, 251, 257-259, 261-265, 267-270, 274f., 288f., 293, 295, 300, 301-303, 307, 315, $331,333,346,353,366,367,375$, 383, 495-497

Pippin d.M., Hausmeier 219

Pippin, Kg. von Italien 281, 379

Pippin II., Kg. von Aquitanien 356, 359
Plinius

- Historia naturalis 81

Plutarch 39f., 61

- Aetia Romana 40, 61

Poitiers 85f., 91, 161-163, 194

Pokorny, Rudolf 281, 370, 376

Pollutio 139f., 144, 280, $354 \mathrm{f}$.

Poly, Jean-Pierre 8f., 62, 77-79, 81-83, $92,98,114,177,237,452$

Polybius $39 \mathrm{f}$.

- Historiae 39

Poppo, Bf. von Trier 443, 445

Poppo, Abt von Stablo 447-449

Porcia 37

Praetextatus, Bf. von Rouen 159, $181 \mathrm{f}$.

Priesterehe 441, 450, 458, 468, 486

Prieur, Jean-Marc 86

Priscillian von Ávila $203 \mathrm{f}$.

Procula 204

Prokop 70, 97-99, 102, 105, 112, 143, 163

- De bello gothico 97, 105

Pseudoisidor 26, 32, 250, 323-329, 336, 340, 348, 350, 353f., 358f., 374, 386, 429, 453, 486

Quadripartitus 298f., 382

Quierzy 262, 358

Radegunde, fränk. Kg.in 142, 161

Radigis, warn. Kg. 97-99, $143 \mathrm{f}$.

Ragnachar, fränk. Kg. 141

Raimund I., Graf von Toulouse 352, $355 \mathrm{f}$.

Ratold, Bf. von Straßburg 362

Ratramnus von Corbie 199, 350, 365, 374-376, 401

- Brief 350, 365, 401

- Contra Graecorum opposita 375

Ravenna 109, 118, $451 \mathrm{f}$.

Reccared, westgot. Kg. 105, 205-209, $211 \mathrm{f} ., 271 \mathrm{f}$.

Reccesvinth, westgot. Kg. $209 \mathrm{f}$.

Reginar IV., Gf. von Hennegau 415

Reginbald, Chorbf. von Mainz 312, 336

Regino von Prüm 32, 270, 341, 350, 359-361, 364, 366-369, 371-373, 375, 382, 388, 391f., 408-410, 427, 429f., 433f., 456, 464, 486

- Chronica 350 
- De synodalibus causis

- prol. 360, 375

- I 2-13 368

- I 427-429 392

- II $1368 \mathrm{f}$.

- II 2-3 368

- II 5366

- II 99392

- II 185366

- II 187366

- II 197382

- II 201367

- II 202367

- II 213367

- II 227367

- II 263366

- App. II 2429

Reims 139, 144, 147, 155, 299, 336, 342, 344, 348, 354, 389, 391, 396, 398, 402

Reindel, Kurt 458, 468

Remiremont 169

Rennes 161

Ribuarien 186f.

Riché, Pierre 396

Richer von Reims 396-398, 401

- Historiae

- IV 11396

- IV 87367

- IV 88367

- IV 108 397f.

- IV 109401

Richilde von Hennegau 463

Rietschel, Siegfried 77

Rimbert, Bf. von Hamburg-Bremen $365 \mathrm{f}$.

Robert II., franz. Kg. 387-389, 394-402, 407, 412, 429, 435, 462f., 465,473

Robert, Hzg. von Burgund 462, $465 \mathrm{f}$.

Rodulfus Glaber

- Historiae 444, $463 \mathrm{f}$.

Rothari, langobard. Kg. 105, 109-112, $114 \mathrm{f}$.

Rouche, Michel 78, 181

Rouen 96, 139, 150, 166, 369

Rozala/Susanna, franz. Kg.in 387, 395-397

Rudolf, westfränk. Kg. 394

Rudolf von Fulda
- Translatio S. Alexandri 436

Rüegger, Hans $129 \mathrm{f}$.

Rügeverfahren 281-283, 285, 289, 322, 369,373

Rufinus 65

Ruotger, Bf. von Trier 391

Rutilius, Marcus 37

Sachsen 27, 85, 232, 276, 290, 372, 414, $417,420,425,436$

Sachsenspiegel 18, 20f., 24

Saint-Amand 354

Saint-Denis 89, 262

Saint-Trond 265

Sakrileg 144, 148, 372

Salier 384, 403, 412, 425, 428, 437, $442-445,447,450,461,467,474$

Saller, Richard 42

Salomo I., Bf. von Konstanz 362

Salomo II., Bf. von Konstanz 370

Salzburg 299-301, 372

Sancho III., Kg. von Navarra 464

Schadt, Hermann 21

Schäferdiek, Knut 104, 200

Scherer, Rudolf von 353

Schieffer, Rudolf 441

Schieffer, Theodor 241

Schmidt, Ludwig 98

Schmidt-Wiegand, Ruth 177

Schminck, Andreas 39

Schrader, Otto $77 \mathrm{f}$.

Schramm, Percy Ernst 291

Scipio Aemilianus 37

Sdralek, Max 348

Seckel, Emil 243, 294f., 301, 306, 324f., 327, $331 \mathrm{f},, 335$

Sedulius, Bf. 238

Seeck, Otto 57

Sempronia 37

Sendgericht $30,285,319,322,359,366$, 368-373, 377, 494

Sens 139, 150, 165, 167, 180, 277

Sergius, Bf. von Tarragona 205

Sergius I., P. 234

Servilia 38

Sextus Pompeius Festus 126

Shaw, Brent 6f., 35, 39, 42

Sidonius Apollinaris 131

- Briefe 192 
Siegfried, Abt von Gorze 77, 408, 447-449, 467, 474

- Brief an Poppo von Stablo 447-449

- Brief an Bruno von Toul 449

Siems, Harald 177, 333

Sigibert I., fränk. Kg. 113, 160, 162

Sigibert III., fränk. Kg. 88f., 186

Sigismund, burg. Kg. 95, 105, $117 \mathrm{f}$, 120, 123f., 128, 134-136, 205, 212, 321

Simonie 89, 441, 450, 458, 461f., 486

Sinderedus, Bf. von Toledo 238

Sinodus Luci Victorie 225

Sippenverbände $8-10,25,85,114,181$, 213, 241, 404, $493 \mathrm{f}$.

Siricius, P. 54, 56

Sisinnios, Bf. von Konstantinopel 478, $487 f ., 491$

Socrates

- Historia ecclesiastica 74

Sodomie 5, 326, 330

Soissons 100, 181

Sonntagsruhe 173, 183

Spanien 21, 52, 60, 191f., $199 \mathrm{f}$, 203-205, 238, 497

Speyer $187 \mathrm{f}$.

Split 471

Spurius Ligustinus 37

Stephan II., P. 217f., 262, 288

- JE 2315 (Responsa) 262

Stephan V., P.

- JL 3439378

Stephan IX., P. 467

Stephan, Gf. 352-356, 358, 382

Stephanus, Burg. 95, 133-136, 138, 205

Straßburg 188, 318f., 321, 404

Stratmann, Martina 337

Sueton $39 f$.

Sulpicius Severus

- Chronicae 204

Sunifred II., Graf von Urgell 380

Sunyer I., Graf von Barcelona $380 \mathrm{f}$.

Symmachus, P. 65, 119, 200

Symmachus, Quintus Aurelius

- Briefe 65

Synodus II Sancti Patricii $231 \mathrm{f}$.

Syrisch-römisches Rechtsbuch 68

Szramkiewicz, Romuald 138f.

Tacitus 38-40, 43, 78f., 95, 131
- Annales 38-40

- Germania 78, 95

Tassilo III., bayer. Hzg. 126, 267

Tedbald, Gf. von Blois 462f., $466 \mathrm{f}$.

Tellenbach, Gerd 380, 460

Tetradia 96

Thegan

- Gesta Hludowici imperatoris 379

Theoderich d. Gr., ostgot. Kg. 85, 105-109, 112, 114f., 118, 135, 141, $181,198-200,212$

Theoderich, westgot. Kg. 192

Theoderich, Bf. von Cambrai 296, $306 f$.

Theoderid, westgot. Kg. $191 \mathrm{f}$.

Theodo, bayer. Hzg. 94, 234

Theodoald, bayer. Hzg. 94

Theodor, Bf. von Canterbury 227-233, 243, 268, 287, 299f., 310f., 354, 367,410

Theodor, Bf. von Pavia 255

Theodosius I., K. 46, 56-66, $71 \mathrm{f} ., 103$, 449

Theodosius II., K. 29, 36, 48, 58, $74 \mathrm{f}$.

Theodrada 379

Theodulf von Orléans (?)

- 2. Kapitular 370

Theophanu, K.in 392

Thessaloniki 56

Theudebald, fränk. Kg. 113, 142, 147

Theudebert I., fränk. Kg. $93 \mathrm{f} ., 97 \mathrm{f}$, $113,121,138,144,146,149,156$

Theudechilde, warn. Kg.in 98, $143 \mathrm{f}$.

Theuderich I., fränk. Kg. 98, 113, 143 f., $156,177 \mathrm{f}$.

Theuderich III., fränk. Kg. 89-91

Theutberga, fränk. Kg.in 5, 337, 345-352, 394

Thiefried, Vogt 445

Thietgaud, Bf. von Trier 345, 350

Thietmar von Merseburg 389, 405, 412, 414, 418f., 422, 436, 442, 463

- Chronica

- I 5392

- IV 14463

- IV 40436

- IV 54413

- IV 60436

- V 12412

- V 25412

- V 27405 
- V 35422

- VI 28414

- VI 86414

- VII 16443

- VII 46415

- VII 49419

- VII 62442

- VIII 7415

- VIII 18420

Thomas, Heinz 448

Thüringen 94, 97, 144, 186f., 219, 241, 320

Thusnelda 79

Timotheus, Gf. 195

Todesstrafe 13, 42f., 50, 55, 58, 64f., 69, 108, 182f., 185f., 188f., 195, $197,203,215,260,273,276,317$, 335,436

Tongern 144

Toul 169

Toulouse 191, 355

Tours 85f., 100, 139, 163, 165, 180, 269, 397

Translatio S. Pusinnae 27

Tribonian 69

Trier 139, 144, 359, 372, 377, 390, 403

Unigis 105

Urraca von Léon 464

Utrecht 219, 408, 415f., 438

Valentinian I., K. 81

Valentinian II., K. 56

Valentinian III., K. 48, 74, 196

Venantius Fortunatus 98, 145, 152-154, 171,174

- Carmina 98, 171

- Vita Albini 153f., 174

Venedig 471

Verdun 144, 170, 445

Verwandtenmord 189f., 280, 284, 320f., 369, 491

Veyne, Paul 46

Victorius, Bf. von Grenoble 121, 123, 125,136

Vidastis Avus 85

Vienne 121, 138f., 150, 165

Vigilius, P.

- JK 906 148f.
Vincomalus 95, 121-123, 125, 130, 132,135

Virgil, Bf. von Salzburg 299

Virus 96

Visitation 284f., 322, 368f., 377, 461

Vismara, Giulio 110

Vita Apollinaris 133f., 136

Vita sancti Arnulfi 170f., 217

Vita Austrigisili 215

Vita sanctae Balthildis 89

Vita Burchardi 427, 430

Vita Kiliani 94, 112

Vita Leonis IX papae 461, 467

Vita Mathildis antiquior 408

Vita Mathildis posterior 439

Vitalian, P. 227, 311

Vitellius, Lucius 39

Viventiolus, Bf. von Lyon 123f., 133

Volusianus 51

Vulgarrecht 76, 199

Waitz, Georg 176

Waldrada, fränk. Kg.in 142, 156, 345 f., 371

Ward-Perkins, Bryan 214

Warnachar, Hausmeier 99f., 185

Warnen 97-99, 102, 112, 143

Weinfurter, Stefan 403, 437

Werden $421 \mathrm{f}$.

Wergeld 110f., 130, 271, 283

Werner, Bf. von Straßburg 424

Westgoten 104, 123, 143, 176, $191 \mathrm{f}$., 195, 199, $211 \mathrm{f} ., 271$

Wetterau 419f.

Wickham, Chris 214

Widukind von Corvey

- Res gestae saxonicae 436

Wifred, Gf. von Katalonien 380

Wihtraed, Kg. von Kent 232

Wilfried, Bf. von York 227

Wilhelm, Bf. von Mainz 392

Wilhelm der Eroberer 462f., 465, $467 \mathrm{f}$.

Wilhelm V., Hzg. von Aquitanien 464

Wilhelm, Gf. 126, 378

Wilhelm II., Gf. von Montreuil 472

Wilhelm, Gf. von Provence 401

Willa, Kg.in von Italien 394

Willibald

- Vita Bonifatii 219

Willibrord, Bf. 219, 316 
Willigis, Bf. von Mainz 398, 412, 427, Wunnebald 94

Wipo 429, 435

- Gesta Chuonradi 438, $443 f$.

Wolfgang, Bf. von Regensburg 429, 435

Wolfram, Herwig 12, 227, $443 \mathrm{f}$.

Wolfhere

Würzburg 321, 371

- Vita Godehardi posterior 423

- Vita Godehardi prior 425

Wood, Ian 76, 84, 95, 136, 145, 159

Worms 187f., 427f., 432

Wulfila $103 \mathrm{f}$.

Wulfstan, Bf. von York

- Collectio canonum 497

- Predigt 497

Zacharias, P. 96, 220, 232, 247-249, 254-262, 288, 339, 363

- JE 2264 (Ep. Bon. 51) 92, 97, $248 \mathrm{f}$.

- JE 2277 (Cod. Carol. 3) $259 f$.

- JE 2278 (Ep. Bon. 77) 258

- JE 2306 220, 254-256

Zechiel-Eckes, Klaus 325, 340

Zehnten 164, 173, 274

Zeumer, Karl 192f., 207f., 210

Zölibat 8, 173, 175, 457

Zosimus

- Historia nova 55 
